\title{
WILHELM GENAZINOS ROMANFIGUREN
}



Nils Lehnert

WILHELM GENAZINOS ROMANFIGUREN 



\section{Inhalt}

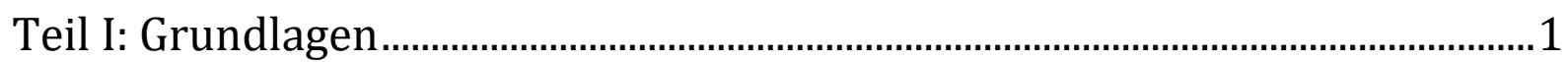

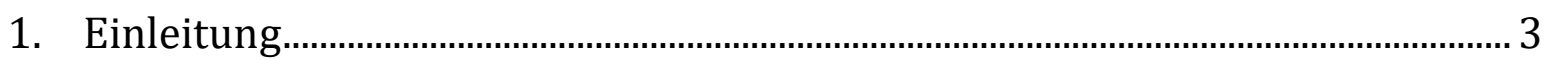

2. Wilhelm Genazinos Romanfiguren und ,Figurenromane' ...................................15

2.1 „Pendelbewegungen“: Grenzlinien, Schaffensphasen, Zäsuren ........................................... 21

2.2 Zwischen Induktion und Deduktion I: Musterhaftes Mischpult-Verfahren..................... 28

2.3 Romananalytische ,Vermessung der Erzählwelten` bei Genazino......................................33

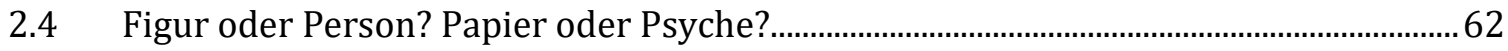

2.5 Von „Figurenbauplänen“ und dem ,familienähnlichen Genazino-Basistypus‘ ............... 81

3. Handlungsmotivation und Eindruckssteuerung..................................................91

3.1 Modelle motivationalen (Figuren-)Handelns..................................................................... 92

3.2 Literatur(wissenschaft) und Psychologie........................................................................... 104

3.3 Impression Management/Eindruckssteuerung/Selbstdarstellung ............................... 109

4. Das Selbst: multipel, (post-)modern, zersplittert.............................................132

5. Forschungsdesign und Modus Procedendi ..........................................................146

5.1 Zwischen Induktion und Deduktion II: Genese und Kontur der Schlaglichter............ 146

5.2 Plädoyer für einen moderaten Methodenpluralismus ...................................................... 152

5.3 Die Zu-kurz-Gekommenen: Anmerkungen zur (Auto-)Biografie, Sozialgeschichte und Scham

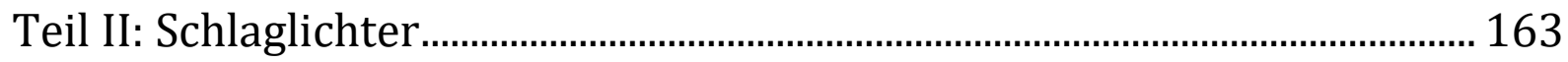

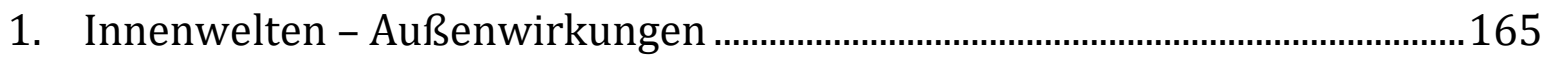

1.1 Individuum vs. Gesellschaft, Distinktion vs. Zugehörigkeit............................................... 166

1.2 Selbstdarstellung zwischen Authentizität, Verstellung und ,kleiner Lüge' ................. 175

1.3 Charaktereigenschaften oder: Makel, Marotten und andere Merkwürdigkeiten ..... 187

1.4 Nonverbale Kommunikation (sowie eine Randnotiz zur äußeren Erscheinung) ..... 207

1.5 Von Schichten, Milieus und den ,feinen Unterschieden' der Lebensstile ..................... 222

1.6 Einstellungen, Überzeugungen und (mangelnde) Weltanschauung .............................. 251 
2. Im Auge des Betrachters....................................................................................263

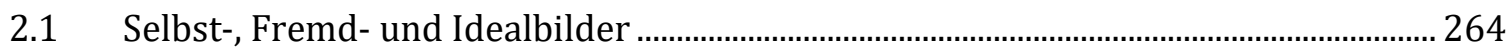

2.2 Beobachtungszwang und Besänftigungsstrategien ............................................................ 278

$2.3 \quad$ Konstruktion und Interpretation der ,Welt' ..................................................................... 291

2.4 Der (imaginierte) Blick auf sich: öffentliche vs. private Selbstaufmerksamkeit ....... 303

2.5 Strategien der Flucht, der Verborgenheit und des Verschwindens ................................ 319

2.6 Die innere Zensur......................................................................................................... 332

3. Strategien der Interessantheit bzw. Auffälligkeit................................................353

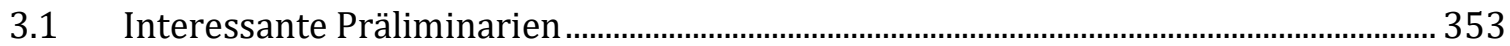

3.2 Auffälligkeit(en) im erzähltheoretischen Milieu................................................................. 366

3.3 Vorbereiten, Wappnen, inszenierte Spontaneität ............................................................... 370

3.4 Interessantheit ,im besten Sinne': Esprit sowie Extemporiergeschick ......................... 372

3.5 Über das Ziel hinausgeschossen ....................................................................................... 379

4. Das Ich, die anderen und das andere: Inszenierung - Beobachtung Evaluation

4.1 (Prä-)Figuration zwischen schwarzer und gelber Galle ..................................................... 392

4.2 Evaluative Inaugenscheinnahmen.................................................................................... 401

4.3 Brüchige Selbstentwürfe anderer und deren Entlarvung durch die Hauptfiguren.. 422

4.4 „[U]nter meiner schauenden Bestrafung“: Offensive Abwertung/Herabsetzung..... 428

4.5 (Anerkennendes und bewunderndes) Goutieren fremder Verhaltensweisen........... 438

5. Liebe und Sexualität............................................................................................. 444

5.1 Rekurs: von Liebeslügen und „dem Paarungsdrang eines Maikäfers“ ".......................... 445

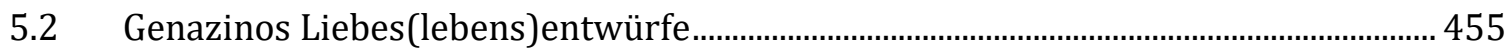

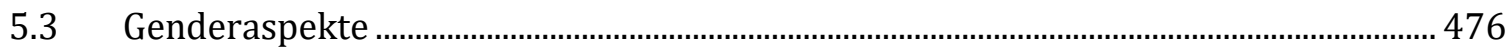

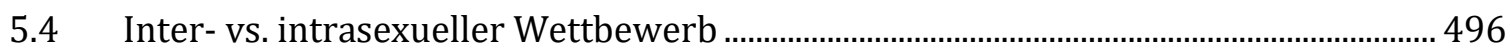

5.5 Sexuelle Wünsche, Vorlieben und Praktiken......................................................................... 502

5.6 Erotik vs. antiemotionales Erzählen (bis zum Ekel) ………………………………....... 512

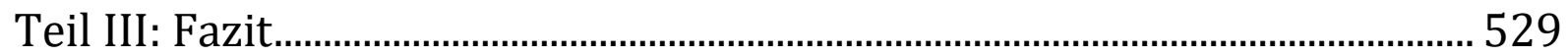

Teil IV: Literaturverzeichnis.................................................................................. 547

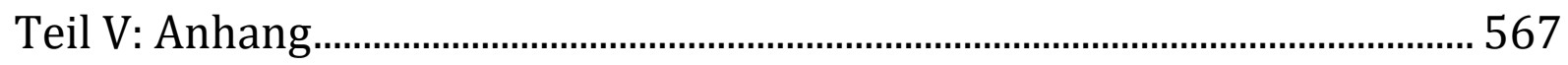


1. Kurzcharakterisierung der Hauptfiguren und Siglenliste 569

1.1 Laslinstraße. Roman (Köln: Middelhauve 1965) ……………………………………..... 569

1.2 Abschaffel. Roman (Reinbek bei Hamburg: Rowohlt 1977) ............................................. 569

1.3 Die Vernichtung der Sorgen. Roman (Reinbek bei Hamburg: Rowohlt 1978)........... 570

$1.4 \quad$ Falsche Jahre. Roman (Reinbek bei Hamburg: Rowohlt 1979) ……………………….... 570

1.5 Die Ausschweifung. Roman (Reinbek bei Hamburg: Rowohlt 1981) ............................. 571

1.6 Fremde Kämpfe. Roman (Reinbek bei Hamburg: Rowohlt 1984)................................... 572

1.7 Der Fleck, die Jacke, die Zimmer, der Schmerz. Roman (Reinbek bei Hamburg: Rowohlt 1989).................................................................................................................. 572

1.8 Die Liebe zur Einfalt. Roman (Reinbek bei Hamburg: Rowohlt 1990).......................... 573

1.9 Leise singende Frauen. Roman (Reinbek bei Hamburg: Rowohlt 1992)...................... 574

1.10 Die Obdachlosigkeit der Fische (Reinbek bei Hamburg: Rowohlt 1994) ..................... 574

1.11 Das Licht brennt ein Loch in den Tag (Reinbek bei Hamburg: Rowohlt 1996) ......... 575

1.12 Die Kassiererinnen. Roman (Reinbek bei Hamburg: Rowohlt 1998) ............................. 575

1.13 Ein Regenschirm für diesen Tag. Roman (München/Wien: Hanser 2001) ...................576

1.14 Eine Frau, eine Wohnung, ein Roman (München/Wien: Hanser 2003)........................ 577

1.15 Die Liebesblödigkeit. Roman (München/Wien: Hanser 2005) …………………………. 578

1.16 Mittelmäßiges Heimweh. Roman (München: Hanser 2007) …………………………..... 578

1.17 Das Glück in glücksfernen Zeiten. Roman (München: Hanser 2009) .............................. 579

1.18 Wenn wir Tiere wären. Roman (München: Hanser 2011) …………………………….... 579

1.19 Bei Regen im Saal. Roman (München: Hanser 2014)........................................................... 580

1.20 Außer uns spricht niemand über uns. Roman (München: Hanser 2016)...................... 581

1.21 Kein Geld, keine Uhr, keine Mütze. Roman (München: Hanser 2018) ............................. 582

2. Fragenpool für die Figurenanalyse …................................................................584

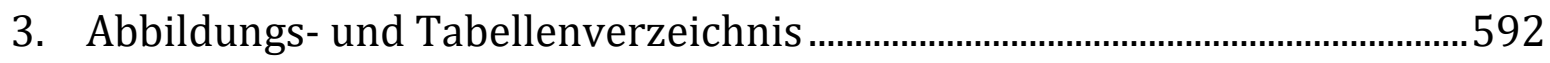

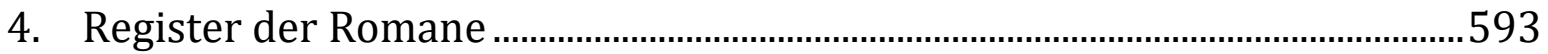

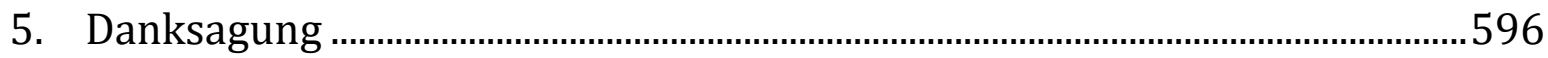



Teil I: Grundlagen 



\section{Einleitung}

„im Kern unverständlich, obwohl jedem Menschen sofort einleuchtend" (Glück, S. 41)

Um den zu skizzierenden drei Anliegen, die im Folgenden entfaltet werden, Genüge zu tun, ließe sich der Titel der vorliegenden Studie präzisierend wie folgt ergänzen: ,Abhandlung über Wilhelm Genazinos Romanfiguren ${ }^{1}$ nebst einer fundamentalen Kritik der figurenbezogenen Erzähltheorie jüngerer Provenienz, einigen Anmerkungen zur Erneuerung des Bündnisses von Psychologie und Literaturwissenschaft sowie den daraus resultierenden Effekten für handlungsmotivationale Fragestellungen'. Berechtigte Vorbehalte gegen diese an barocke Opulenz gemahnende Titelgebung verbieten eine solche freilich - es lässt sich jedoch nicht in Abrede stellen, dass sie Leserinnen und Leser ${ }^{2}$ schneller und sogar klarer hätte erahnen lassen, was sich vor ihnen auftun solle.

\section{BESTANDSAUFNAHME}

In etwa alle zwei Jahre wiederholt sich eine literaturbetriebliche ,Aufführung': Wilhelm Genazino liefert pünktlich einen neuen Roman, ${ }^{3}$ die Rezensenten und Experten sagen ihre ,Sprüchlein`

Vgl. für die Tatsache, dass manche Texte deswegen nicht, Roman' heißen, weil die Kritik jenen den mangelnden - für die Gattungszuordnung aber vermeintlich konstitutiven - Erzählzusammenhang vorgeworfen hat, Anja Hirsch/Wilhelm Genazino: Interview am 09. Februar 1998. In: Anja Hirsch: „Schwebeglück der Literatur“. Der Erzähler Wilhelm Genazino. Heidelberg 2006, S. 280 f., hier S. 281. An der Bezeichnung, Romanfiguren' wird dennoch festgehalten, zumal auch die ausgeklammerten Prosatexte letztlich durchaus als Romane verstanden werden können. Alle Romanfiguren werden im Anhang ( $\Rightarrow$ V.1) kurz und stellvertretend einmalig global charakterisiert. Dort finden sich auch die Siglenliste aller Romane sowie die jeweils verwendete Ausgabe der Primärtexte. Die erste Fußnote, die Genusfragen auf den Tisch legt, ist mittlerweile obligatorisch geworden was positiv gefasst einen Fortschritt der Gleichberechtigung bedeutet, negativ formuliert nur Ausdruck der Unsicherheit ist. Bis ein wissenschaftlich akzeptierter und hoffentlich nicht männlich dominierter pragmatischer Modus Operandi gefunden sein wird, bemühe ich mich schlicht um die Verwendung gendersensibler Sprache zumindest hinsichtlich der problematischen Bipolarität bzw. geschlechtsneutraler Formulierungen sowie kontextueller Disambiguierung. Ausgenommen davon sind Termini technici wie ,Rezipient', ,Protagonist' etc. - es sei denn etwa, die Ausnahme einer weiblichen Hauptfigur solle mit der Bezeichnung ,Protagonistin' markiert werden. Auch der Begriff ,Leser' wird dann in seiner generisch maskulinen Form verwendet, wenn er nicht allgemein die konkrete Leserschaft Genazinos, sondern Konstrukte wie den ,Ideal-Leser 'bzw. den zu vermutenden ,Standard-Leser' meint. Leserkonzepte und die Füllung von Leerstellen durch Leser bei Wilhelm Genazino sind flächig über die Arbeit verteilt von Belang $\Leftrightarrow$ I.2.3; $\Rightarrow$ I.2.4; $\Rightarrow$ I.3.1; $\Rightarrow$ I.3.3; $\Rightarrow$ I.5.6). Vgl. zu Rezipientenkonzepten bei Genazino auch Iris Hermann: Elemente einer Sehphilosophie in Wilhelm Genazinos Essay Der gedehnte Blick. In: Andrea Bartl/Friedhelm Marx (Hg.): Verstehensanfänge. Das literarische Werk Wilhelm Genazinos. Göttingen 2011, S. 165-178, hier S. 171 ff.; vgl. Annika Klinge: Poetische Collagen. Einflüsse der bildenden Kunst auf ausgewählte Texte Wilhelm Genazinos. In: Bartl/Marx (Hg.): Verstehensanfänge (2011), S. 199-224, hier S. 221 ff.; vgl. Alexandra Pontzen: Wilhelm Genazino: Poetik als romantische Psychopathographie des Alltagslebens. In: Alo Allkemper/Norbert O. Eke/Hartmut Steinecke (Hg.): Poetologischpoetische Interventionen: Gegenwartsliteratur schreiben. München 2012, S. 219-234.

3 Vgl. Thomas Reschke: [Wilhelm Genazino - Essay (letzte Aktualisierung 01.06.2008)]. In: Munziger Online/KLG - Kritisches Lexikon zur deutschsprachigen Gegenwartsliteratur. Online: $<$ http://www.munzinger.de/search/klg/Wilhelm+Genazino/176.html>. 
auf und die alten Ressentiments oder Lobhudeleien werden für einige Wochen aufgewärmt. Pause. Zwei Jahre später: wieder. Ein fester Akt dieser überlangen Tragikomödie - das Ende ist zwar versöhnlich, aber der Ablauf ist nicht frei von Pein - ist die Selbstvergewisserung: Kennen wir, können wir sortieren! Im immer gleichen Ton wird immer wieder das Gleiche gesagt - obwohl man doch eigentlich Genazino den Vorwurf des Immergleichen machen wollte: „[W]ieso folgt man einer Geschichte, deren Personal, Verlauf und Muster man kennt - wenn man Genazino kennt?“4 Eine Frage mit Berechtigung - wenn man sie das erste Mal hört -, die sich (und dem Rezipienten) der Rezensent Claus-Ulrich Bielefeld in der Welt anlässlich Genazinos 2014 erschienenem Roman Bei Regen im Saal gestellt hat. ${ }^{5}$ Selbstkritisch muss sich auch die wissenschaftliche Auseinandersetzung mit Wilhelm Genazino diese Frage abgewandelt gefallen lassen: Wieso analysiert und interpretiert man „Geschichte[n], deren Personal, Verlauf und Muster man [doch schon; N. L.] kennt"? Denn tatsächlich sind die Vergleichsparameter nachgerade aufdringlich: Mag dem ,Genazino-Gelegenheitsleser 'im 2018 erschienenen Roman Kein Geld, keine Uhr, keine Mütze der Selbstmord der Exfrau des namenlosen Ich-Erzählers überraschend oder außergewöhnlich vorkommen - den hat es schon in Außer uns spricht niemand über uns (2016) und letztlich bereits in Eine Frau, eine Wohnung, ein Roman (2003) gegeben. Das überraschende, große Geldgeschenk? Bekannt aus Ein Regenschirm für diesen Tag (2001). Der Brustkrebs mit anschließendem -verlust? Mittelmäßiges Heimweh (2007). Die Investigation der Eltern? Arbeitslosigkeit? Alles schon (häufiger) da gewesen. ${ }^{6}$

Genaugenommen muss Bielefelds rhetorische Frage allerdings selbst kritisch hinterfragt werden, präsupponiert sie doch, es gebe de facto nur einen ,Einheitsbrei ${ }^{\prime}(\Leftrightarrow I .2 .1$ u. $\Rightarrow I .2 .2) .{ }^{7}$ Denn bereits darüber lässt sich trefflich streiten und diese Sicht auf die Dinge - so eine allererste Hypothese - wird der Textweltrealität nicht gerecht. Davon zu unterscheiden ist die Frage nach dem ,Warum?' des engmaschigen Verweissystems innerhalb des Genazino'schen RomanOEuvres: Spekuliert er auf den spitzfindigen Leser (vgl. Kein Geld, S. 55 vs. S. 67)? Oder ,kann` er nicht anders? Eine qua Interviewsituation als epitextuell markierte ist die folgende Antwort Genazinos: ${ }^{8}$

Aber das ist sozusagen eine Monokultur, die der Autor aus seiner Ich-Substanz nimmt. Dort ist das vergraben oder jedenfalls irgendwie vorhanden, und das ist sein einziger Fundus, und mit dem muss er klarkommen. Das ist im Übrigen auch der Grund, warum mit der Zeit die Bücher eines Au-

4 [Bei Regen im Saal]: Rezensionsübersicht auf perlentaucher.de - Das Kulturmagazin. Online: <https://www.perlentaucher.de/buch/wilhelm-genazino/bei-regen-im-saal.html>.

5 Vgl. Claus-Ulrich Bielefeld: Der hessische Woody Allen im Finanzamt II. In: Welt.de vom 30. Juli 2014. Online: <https://www.welt.de/kultur/literarischewelt/article130705612/Der-hessischeWoody-Allen-im-Finanzamt-II.html>.

6 ,Neu' ist an den neueren Romanen Genazinos die Tendenz, dass diese Entsprechungen nicht mehr nur zwischen den Texten, sondern gar innerhalb eines Romans gefunden werden können $\Leftrightarrow$ I.2.1).

$7 \quad$ Die Machart dieser Arbeit legt ein internes ( $\Rightarrow$ Verweissystem) nahe. Aus den Fließtext entschlackenden Gründen wird auf die teils präzisere Nennung eines, vgl.' verzichtet.

8 Eine Antwort, die Genazino in seinen Romanen darauf findet, ist die „Panik der nie richtig erzählten Geschichte" (Einfalt, S. 103), doch dazu später mehr ( $\Rightarrow I .5 .3)$. 
tors einander ähneln. Die Leser können dann feststellen, aha, der hat wieder mal sein Äckerchen umgegraben. Und dann hat er dies gefunden. Und dann hat er jenes gefunden. So ist es in der Tat. Es gibt diese Gewalttouren, wo ein Autor sich entschließt, ich mache jetzt etwas, was ich bisher noch nie gemacht habe. Etwas völlig anderes. Und das ist das große Unglück. Ich will jetzt keine Namen nennen, aber es ist schrecklich, wenn das geschieht. Und es gehört deswegen eben auch zu den ,ethischen' Ansprüchen, die ein Autor an sich selbst hat, sozusagen das Blumenbeet, in dem er arbeitet, nicht ernsthaft zu verlassen, sondern die Selbsttreue zu riskieren, mit allem, was das bedeutet. Auch unter Einschluss einer sukzessive zunehmenden Verödnis dieses Blumenbeets oder der Langeweile. Mich juckt es, Namen von lebenden Autoren zu nennen, ich mache es nicht, weil ich die Autoren natürlich nicht verunglimpfen will. Wenn einem Autor das passiert, dass er sein langweilig gewordenes Gärtchen nicht verlassen kann, dann ist das ein großes Unglück. Wem es passiert, der hat damit Ärger genug, und er braucht nicht den Spott von Kollegen. ${ }^{9}$

Es handelt sich um einen schmalen Grat, den Wilhelm Genazino hier beschreibt, wenn nicht um einen offenen Widerspruch: Denn einerseits verteidigt er das wiederholte ,Umgraben des Beets“ und verwahrt sich gegen die „Gewalttouren“, die ein „Unglück“ darstellen - andererseits münde es ebenfalls im Desaster, wenn „Verödnis“ und „Langeweile“ den literarischen Garten ausgedörrt haben. Dass Genazino in das erste ,Fettnäpfchen' tritt, ist unwahrscheinlich; glaubt man dem Feuilleton, so ist die Gefahr, dass er „sein langweilig gewordenes Gärtchen nicht verlassen kann“, weitaus virulenter. ${ }^{10}$ Für das Roman-CEuvre Genazinos jedenfalls sind bereits flächendeckend wiedererkennbare Strukturen in beiden Bereichen des Erzählens: ${ }^{11}$ des ,Wie‘ und des ,Was' behauptet, gefunden und wenigstens mit Bleistift kartografiert worden:

$9 \quad$ Hubert Spiegel/Wilhelm Genazino: „Der Text ist sein eigenes Misstrauen“. Hubert Spiegel (F.A.Z.) im Gespräch mit Wilhelm Genazino (Transkription eines Podiumsgesprächs vom 17. Juli 2009). In: Bartl/Marx (Hg.): Verstehensanfänge (2011), S. 239-254, hier S. $242 \mathrm{f}$.

Eine Antwort über diejenige von Genazino hinaus, nach der ein Autor nur eine „Monokultur" zur Verfügung habe, könnte lauten: Weil der Wiedererkennungswert nun einmal eine kaum zu unterschätzende finanzielle Erwägung für Autoren geworden ist. Und sei es nur die relative Titelbildungsanalogie, die sowohl ihn als auch Bestsellerautoren kennzeichnet: Der Hundertjährige, der aus dem Fenster stieg und verschwand, wird da ganz schnell zur Analphabetin, die rechnen konnte. Dass der Twist vom zweiten zum dritten Bestseller von Jonas Jonasson über das Cover, das aus dem gleichen Strickmuster entwickelt wurde, läuft, und nicht mehr über den Titel, ist nur eine Verlagerung und Bestätigung der unique selling proposition, also des Alleinstellungsmerkmals. Auch Genazino erkennt in der „Verschiebung des Interesses vom Text auf den Event-Darsteller Autor möglicherweise eine Ressource [...], die dem Text doch wieder Interessenten zuführt. Das ist zwar ein umständlicher und mich persönlich abschreckender Vorgang, aber wenn es der Literatur nützt, dann bin auch ich bereit, ein Auge zuzudrücken." (Ulrich Rüdenauer/Wilhelm Genazino: Der Reiz des Scheiterns. Interview (erstveröffentlicht im Börsenblatt vom 21. Oktober 2004). In: Winfried Giesen (Hg.): Wilhelm Genazino. Begleitheft zur Ausstellung 11. Januar-25. Februar 2006 mit Beiträgen von Adolf Fink, Melanie Fischer, Anja Hirsch, Susanne Mittag und Ulrich Rüdenauer sowie einer Erzählung von Wilhelm Genazino. Frankfurt am Main 2006, S. 57-60, hier S. 59) Vgl. generell zum Autobiografische[n] in der Gegenwartskunst Kathleen Bühler (Hg.): Ego documents. Das Autobiographische in der Gegenwartskunst / The authobiographical in contemporary art. Anlässlich der Ausstellung Ego Documents. Das Autobiografische in der Gegenwartskunst, Kunstmuseum Bern, 14. November 2008-15. Februar 2009. Heidelberg 2008; sowie zu Autor(schafts)inszenierungen Christoph Jürgensen/Gerhard Kaiser: Schriftstellerische Inszenierungspraktiken - Heuristische Typologie und Genese. In: dies. (Hg.): Schriftstellerische Inszenierungspraktiken - Typologie und Geschichte. Heidelberg 2011, S. 9-30; vgl. dies: Abgrenzung, Re-Kombination, Neu-Positionierung. In: Sabine Kyora (Hg.): Subjektform Autor. Autorschaftsinszenierungen als Praktiken der Subjektivierung. Bielefeld 2014, S. 217-245.

11 Als Beschreibungskategorien werden für diese Arbeit,Wie', Erzähltechnik, Darstellung, Discours einerseits, ,Was', Erzählwelt, Diegese, Histoire, Plot, Sujet andererseits synonym verwendet. 
Wiederholungen sind im Romanschaffen Genazinos leicht auszumachen. Dies betrifft Motive und Themen, Erlebniswelten und Empfindungen, das Klima der Erzählung, die stets zu einer höheren Stufe von Kontemplation strebt, aber auch die Auflösung der Romankonvention in lediglich skizzierte Situationen und zu aphoristischer Pointierung neigende Reflexionen. ${ }^{12}$

Von der erzählerischen Machart - die (Unter-)Titel verraten es schon: Unterwegs im Monolog13; Der Erzähler Wilhelm Genazino ${ }^{14}$ - über zentrale Motive wie Scham oder Ekel ${ }^{15}$ hin zu „Figurenbaupläne[n] ${ }^{\text {"16 }}$ etwa des Flaneurs ${ }^{17}$ oder des Psychotikers hat die Forschung Wegmarken und erste kleine Meilensteine gesetzt $(\Leftrightarrow I .2)$, seit Genazino 2004 mit dem Büchnerpreis geadelt auch in literaturwissenschaftlichen Seminaren reüssiert. Sein Romanwerk ist dabei häufig,über einen Kamm geschoren' worden: Eine Gesellschaftsskizze der Nachkriegsgeneration respektive Adenauerära zeichneten seine Romane,18 ein Porträt des ,kleinen Angestellten' haben Interpreten darin zu entdecken geglaubt, ${ }^{19}$ auch Psychogramme ein und derselben Hauptfigur - im Extrem: derjenigen des Autors - oder eine selbstreflexive Poetologie, bei der alle wiederkehrenden Themen und Motive „grundsätzlich den Vorgang des Schreibens meinen können (und natürlich auch meinen)“.20 Da man jeder dieser pauschalisierenden Darstellungen begründet entgegnen kann, dem Gesamtwerk nicht und nicht dem Einzeltext gerecht zu werden, steht zunächst sowohl für die Romane im Allgemeinen $(\Rightarrow$ I.2.2) als auch für die Figuren im Speziellen $(\Leftrightarrow I .2 .5)$ eine genauere Überprüfung dieser ,Scheinhomogenisierung' an. Zwar stellt diese Arbeit ebenfalls nicht den Einzeltext in den Vordergrund, sondern strebt an, Figurenverhaltensfacetten innerhalb größerer

12 Reschke: [Wilhelm Genazino]. Wobei man so einfach weder für die Romane ( $\Rightarrow$ I.2.1 u. $\Rightarrow$ I.2.1) noch die Figuren $(\Rightarrow I .2 .5)$, aus dem Schneider' ist.

13 Vgl. Jonas Fansa: Unterwegs im Monolog. Poetologische Konzeptionen in der Prosa Wilhelm Genazinos. Würzburg 2008.

14 Vgl. Hirsch: „Schwebeglück der Literatur“.

15 Vgl. Anja Hirsch: Geheimgeschichten. Die (Ent)deckung der Scham. In: Giesen (Hg.): Wilhelm Genazino (2006), S. 61-69, hier S. $62 \mathrm{ff}$.

16 Fansa: Unterwegs im Monolog, S. 76 ff.

17 Weit über zwanzig Artikel und Rezensionen tragen ,F/flan*' im Titel. An dieser Stelle sei Herrn Dr. Winfried Giesen herzlich für seine Bibliografie (und die unkomplizierte und freundliche Korrespondenz) gedankt und seiner Bitte darum, diese in eigenen Arbeiten als Quelle publik zu machen, gerne entsprochen (vgl. Winfried Giesen: Wilhelm Genazino - Sekundärliteratur. Neu zusammengestellt und aktual. v. dems. 2014)! Vgl. für die zweite unerlässliche Auswahlbibliografie zu Genazino Hans-Joachim Jakob: Wilhelm Genazino - Auswahlbibliografie 1965-2004. In: Heinz L. Arnold (Hg.): Wilhelm Genazino. TEXT+KRITIK Heft 162. München 2004, S. 98-105. Vgl. als schlagendes Gegenbeispiel Axel Degen, der über sich ,Flaneur-kritisch“ festhält: „Spaziergang mit gemessenen Schritten, den Gaffer machen, den Trottoirputzer, Straßenlungerer, eingekeilt zwischen steifen Hemden und Schottenkrawatten" (Laslinstraße, S. 163) - das kommt dem insgesamt eher zielstrebigen Degen suspekt vor $(\Leftrightarrow \mathrm{V} .1)$.

18 Vgl. Anne Kraume: Den Dingen lauschen. Ein Leben aus Wörtern. Wilhelm Genazino begibt sich für seinen neuen Roman „Eine Frau, eine Wohnung, ein Roman“ zurück in die Adenauerzeit. In: taz vom 01. April 2003.

19 Vgl. Tanja van Hoorn: [Genazino, Wilhelm. Das erzählerische Werk (letzte Aktualisierung in 2010)]. In: Kindlers Literatur Lexikon online. Online: <http://kllaktuell.cedion.de/nxt/gateway.dll/kll/g/k0232700.xml/k0232700_020.xml?f=templates\$fn=index.htm $\$ \mathrm{q}=\% 5 \mathrm{Brank}, 500 \% 3 \mathrm{~A} \% 5 \mathrm{Bdomain} \% 3 \mathrm{~A} \% 5 \mathrm{Band} \% 3 \mathrm{~A} \% 5 \mathrm{Bfield}$,body\%3Agenazino\%5D\%5D\%5D\% 5Bsum\%3A\%5Bfield,lemmatitle\%3Agenazino\%5D\%5Bfield,body\%3Agenazino\%5D \%5D\%5D\$x=s erver\$3.0\#LPHit1>; vgl. Reschke: [Wilhelm Genazino]. 
Untersuchungsfelder musterhaft anhand des bisherigen Romanwerks von Genazino herauszuschälen ( $\Rightarrow I$ I.5.1) - aber erst, nachdem das Problem vorschneller Nivellierung genauestens besehen und beseitigt worden ist. Erst dann lassen sich - methodisch variabel ( $\Rightarrow$ I.5.2) - Aussagen treffen zu Wilhelm Genazinos Romanfiguren, die im Mittelpunkt dieser Untersuchung stehen und denen das erste der drei Anliegen gewidmet ist.

\section{DREI BEGEHREN}

Da Genazinos Romanfiguren bis dato noch nicht in toto hinsichtlich einer globalen Fragestellung einander gegenübergestellt worden sind, ${ }^{21}$ begreift sich diese Studie, welche narratologische, sozial- und persönlichkeitspsychologische sowie subjektphilosophische Zugänge im Rahmen einer literaturwissenschaftlichen Figurenanalyse verknüpft, sowohl als Pionierarbeit, um das weite Feld der Figuren Wilhelm Genazinos abzustecken, als auch als Vorarbeit insofern, als weitere Unternehmungen die schwungvollen Fluchtlinien romanspezifisch zu überprüfen hätten. Von vorrangigem Interesse ist es, herauszupräparieren, welche Strukturähnlichkeiten die Figuren in ihrem als intentional beschreibbaren Handeln verbindet, also: welche Muster sich ausmachen lassen, wenn es darum geht, was literarische Figuren Genazinos wie, wann, warum und mit welchem Erfolg tun, um andere oder sich selbst (bewusst oder unbewusst) zu einem bestimmten Verhalten bzw. einer bestimmten Sicht ihrer selbst zu veranlassen. Denn Genazinos Romanfiguren umkreisen nahezu manisch die Auswirkungen ihres eigenen Handelns auf andere $(\Leftrightarrow$ II.2.4) und betreiben - trotz der massiven Vorbehalte dagegen ( $\Rightarrow$ II.1.2) - permanent Selbstdarstellung. Wenn man überhaupt schon von einer etablierten Genazinofigurenforschung sprechen darf, dann steuert diese Studie mit ihrem ersten von drei Anliegen eine systematische Analyse des Figurenhandelns bei.

Sie forciert dabei - so die Paraphrase des zweiten Anliegens - den Zuschnitt auf die Handlungsmotivation des Figuren-Verhaltens. Fragt man sich, warum eine Person oder eine Figur auf eine bestimmte Weise handelt, kann man unterschiedlichste Erklärsysteme heranziehen: alltagspsychologische, soziologisch argumentierende, solche, die situative und strukturelle Aspekte, mithin das Rollenverhalten betonen, oder solche, die eher auf die Handlungsfreiheit des Einzelnen zielen. Hier ist die Wahl wohlerwogen auf ein Modell gefallen, das durch Einfachheit, begriffliche Präzision und einen immensen Radius hinsichtlich der erklärbaren Phänomene besticht: die Impression-Management-Theorie $(\Leftrightarrow I .3 .3)$. Es ist bisher unterblieben, Figuren - nicht nur bei Genazino - systematisch auf ihre eindruckssteuernden Handlungen hin zu untersuchen und das figurentheoretische Rüstzeug daran auszurichten. Eindruckssteuerung bzw. Impression Ma-

21 Dass es sich dabei um eine verspätete Notwendigkeit handelt, beglaubigt der Blick in die Forschungsliteratur zu Genazino: Die wenigen bisherigen Studien lassen sich eher als explorative Feldforschungen beschreiben, ohne größere Schnittmengen oder Bezüge untereinander. Man benötigt übrigens, um die Monografien und Sammelbände zu Genazino an den Fingern abzuzählen, nicht einmal zwei Hände $(\Rightarrow I .2)$. 
nagement (im Folgenden mit ,IM‘ abgekürzt) ist höchst unterschiedlich konzeptualisiert worden. Aus sozialpsychologischer Sicht eignet allen Definitionen als Definiens der „Versuch des Menschen, andere dazu zu bringen, ihn so zu sehen, wie er gesehen werden möchte“.22 Diesem Forschungszweig ist es - in der Folge Goffmans und Bourdieus - darum zu tun, die Einflussnahme auf das im Entstehen befindliche Fremdbild $(\Rightarrow$ II.2.1) einer Person in den Fokus zu rücken:

People have an ongoing interest in how others perceive and evaluate them. [...] Because the impressions people make on others have implications for how others perceive, evaluate, and treat them, as well as for their own views of themselves, people sometimes behave in ways that will create certain impressions in others' eyes. ${ }^{23}$

Um andere von einer bestimmten Sicht seiner selbst zu veranlassen und damit schließlich ein bestimmtes Verhalten wahrscheinlicher zu machen, existiert ein unerhört umfangreiches Repertoire. Dabei dienen unterschiedliche Techniken und Taktiken je bestimmten Zielen, was die Eindruckssteuerung als Kulturtechnik ausweist, die evolutionäre Vorteile ${ }^{24}$ versprochen hat und verspricht. Eindruckssteuerndes Verhalten erschöpft sich nicht in verbalen Aussagen. Non- und Paraverbales (Gestik, Mimik, Proxemik; $\Rightarrow$ II.1.4), Kleidung, symboltragende Gegenstände etc. $(\Leftrightarrow$ II.1.5) spielen eine ebenso gewichtige Rolle bei der Verfolgung bestimmter kommunikativer Absichten und können - sofern sie denn textlich gegeben oder begründet inferierbar sind $(\Rightarrow$ I.2.4 u. $\Rightarrow$ I.2.5) - auch für eine literarische Figurenanalyse wichtige Hebelpunkte darstellen.

Man könnte es nun für offenkundig halten, dass insbesondere diejenigen Figuren, die für große Worte und Taten bekannt sind, einer derartigen Untersuchung als Basis zugrunde gelegt werden sollten: Tasso zieht den Degen, um zu...; Faust möchte Grete (angestachelt durch Mephisto) verführen. Deshalb... Doch gerade die stilleren Figuren bedienen sich - zumal eingeprägt in die erzähltechnische Machart - subtilerer Mittel und Wege, ihren Eindruck zu steuern oder gar den Versuch zu unternehmen, möglichst wenig Eindruck zu machen $(\Leftrightarrow$ II.2.5). Ein Paradebeispiel der Gegenwartsliteratur sind Texte von Wilhelm Genazino. ${ }^{25}$ Seine Hauptfiguren sind häufig namenlos, zurückhaltend, pessimistisch bis melancholisch und prima facie alles andere als Menschen

22 Elliot Aronson/Timothy D. Wilson/Robin M. Akert: Sozialpsychologie. 6., akt. Aufl. Mit über 540 Abb. München 2008, S. 154.

23 Mark R. Leary/ Robin M. Kowalski: Impression Management: A Literature Review and TwoComponent Model. In: Psychological Bulletin 107 (1990), S. 34-47, hier S. 34.

24 Vgl. zur fiktionsinternen Thematisierung Liebesblödigkeit, S. 26 f.: „Ich interessiere mich für die Tauben, weil sie Ähnlichkeiten mit Menschen haben. Sie sind katastrophenresistent, das heißt, sie bilden (genau wie Menschen) Verhaltensweisen aus, die immer noch eine Spur härter und widerstandsfähiger sind als das, was ihnen von Natur oder Zivilisation zugefügt wird." Das ist eine häufiger geneidete Fähigkeit von Tieren, die den figürlichen Verhaltensstrategien ähneln, um das (meist) als zu hart empfundene Leben irgendwie praktikabel lebbar zu machen.

25 Dass an prominenter Stelle - mal erste Seite, mal vorletzer Satz - die Thematisierung von IM vorkommt, verdeutlicht die breite Verhandlung dieses Themenkomplexes bei Genazino: „Anstatt einen guten Eindruck zu machen, hörte ich bloß zu und schaute mich um.“ (Wohnung, S. 7) „Wahrscheinlich entschied er sein Verhalten erst am Montagmorgen an Ort und Stelle. Das paßte ihm zwar nicht, aber er konnte es nicht ändern." (Falsche Jahre, S. 572) Auch die bis ins Tierreich unterstellte Verstellungsvorstellung zeugt davon, dass IM bei Genazino bedeutsam ist: „Ein Affe saß auf dem Rücken des Pferdes und schaute gespielt verdutzt in die Zuschauerreihen." (Ausschweifung, S. 193) 
der Tat. Ausgerechnet deshalb sind sie darauf zurückgeworfen, die Kulturtechnik der Eindruckssteuerung auf anderen Kanälen zu realisieren: „Noch immer wußte er nicht, wie er sich am Montag verhalten sollte. Freundlich, aber gedämpft? Oder sollte er ein paar Geschichten aus Sattlach erzählen, sich dann aber vollkommen zurückziehen? Oder sollte er [...]?“ (Falsche Jahre, S. 571) Möglicherweise sind es mangelnde Sozialkompetenzen ( $\Rightarrow$ II.1.3), die es Abschaffel hier verunmöglichen, treffsicher aus einer paradigmatischen Liste alternativer Handlungsweisen die situationsadäquateste auszuwählen, eventuell liegt das Problem aber auch auf einer anderen Ebene: „Solche entscheidenden strategischen Fragen zeichnen sich im Werk Genazinos dadurch aus, dass ihre Lösung nicht in einer Antwort, sondern im Weiterwälzen der Frage liegt. “26 ( $\Rightarrow$ II.2.6) Damit ist eine ,Gretchenfrage' der Figurentheorie angesprochen: Was ,dürfen` Wissenschaftler mit literarischen Figuren eigentlich begründet ,tun', wie sie charakterisieren? Sie (oder den Autor) ,auf die Couch' zu legen, ist in der Vergangenheit wie der Gegenwart zumeist missglückt $(\Rightarrow$ I.3.2). Sollte man Figuren dann überhaupt ,intern' bspw. Motivation und Kalkül (oder wie eben: mangelnde Sozialkompetenzen), mithin eine ,menschliche' Psyche unterstellen, sind sie doch nur ,aus Text' gemacht? Oder ist man besser beraten, sich auf Aussagen zu beschränken, die Figuren ,extern' nur als funktionalen ,Baustein' im Textgebäude - à la: Genazino komponiert seine Texte nach dem Muster, dass „die entscheidenden strategischen Fragen“ unbeantwortet bleiben - werten $(\Leftrightarrow I .2 .4)$ ? Um dieses Problems Herr zu werden muss ein analytischer Rahmen geleimt werden, innerhalb dessen man Genazinos Romanfiguren charakterisieren und absichtsvolles Handeln attribuieren kann, womit das dritte Anliegen paraphrasiert ist: Die Forschung zur Figurenanalyse und -theorie wird - eingebettet in größere erzähltheoretische Kontexte $(\Leftrightarrow I .2 .3)$ - exemplarisch einer Kritik unterzogen. Wenn ein heuristisches Modell sich der Bewährungsprobe aussetzen möchte, ist es unerlässlich, es an das literaturwissenschaftliche Kerngeschäft: die Textexegese, weniger hochgegriffen: die Analyse, die Interpretation rückzubinden. Insbesondere in der aktuell boomenden Forschung zu Figuren - zu deren Ontologie, Analyse, Rezeption etc. ${ }^{27}$ sowie zur Emotionalisierung qua Figuren ${ }^{28}(\Rightarrow$ II.5.6) etc. - scheint es an der Zeit, an konkreten Texten die Reichweiten der ,galoppierenden` Modelle und Theorien zu überprüfen.

26 Alexander Honold: Doppelleben, halbbitter. Unentschiedenheit als erzählte Lebensform bei Wilhelm Genazino. In: Bartl/Marx (Hg.): Verstehensanfänge (2011), S. 33-56, hier S. 44.

27 Vgl. Jens Eder: Die Figur im Film. Grundlagen der Figurenanalyse. Marburg 2008, S. 61 ff.; vgl. Jens Eder/Fotis Jannidis/Ralf Schneider: Characters in Fictional Worlds. An Introduction. In: dies. (Hg.): Characters in Fictional Worlds. Understanding Imaginary Beings in Literature, Film, and Other Media. Berlin/New York 2010, S. 3-64, hier S. 6-10; vgl. Fotis Jannidis: [Character]. In: Peter Hühn/John Pier/Wolf Schmid/Jörg Schönert. (Hg.): the living handbook of narratology. Hamburg 2012/2018. Online: <http://www.lhn.uni-hamburg.de/article/character>.

Vgl. Thomas Anz: Kulturtechniken der Emotionalisierung. Beobachtungen, Reflexionen und Vorschläge zur literaturwissenschaftlichen Gefühlsforschung. In: Karl Eibl/Katja Mellmann/Rüdiger Zymner (Hg.): Im Rücken der Kulturen. Paderborn 2007, S. 207-239; vgl. Nadine van Holt/Norbert Groeben: Emotionales Erleben beim Lesen und die Rolle text- sowie leserseitiger Faktoren. In: Uta Klein/Katja Mellmann/Steffanie Metzger (Hg.): Heuristiken der Literaturwissenschaft. Disziplinexterne Perspektiven auf Literatur. Paderborn 2006, S. 111-130. 
In einem gewissen Maß wird zunächst niemand protestieren, wenn man literarischen Figuren Handlungsmotive zuschreibt, da dies der kognitionspsychologischen ,Binsenweisheit' der Theory of $\operatorname{Mind}^{29}(\Leftrightarrow I .3 .1)$ entspricht, derzufolge Menschen anderen Menschen genauso wie (literarischen) Figuren bzw. ,Menschendarstellungen' generell - also kultur- und epochenunspezifisch unterstellen, dass sie ein Inneres sowie Äußeres, überzeitlich stabile Eigenschaften und vor allem Motivationen haben $(\Rightarrow$ I.2.4):30 Baron von Instetten greift zur Ultima Ratio des Duells, weil er sich dem (vermeintlichen) gesellschaftlichen Zwang unterworfen sieht, seine Rehabilitation nicht anders bewerkstelligen zu können; Melanie van der Straaten schämt sich ihres Gemahls (nicht nur) in Gesellschaft anderer $o b$ seiner erotischen Anzüglichkeiten und Doppeldeutigkeiten, deshalb bemüht sie sich des Öfteren, den Gesprächen eine andere, unverfänglichere Wendung zu geben. Wenn sich Fräulein Else, um den Realismus zu überwinden, zu Beginn von Schnitzlers Monolog-Novelle fragt: „Sehe ich nun gnädig aus?“ ( $\Rightarrow$ I.3.3), ${ }^{31}$ dann handelt es sich nicht um eine wertneutrale Selbstbeobachtung aus Außenperspektive, sondern ganz offensichtlich um Kalkül, um den Wunsch, auf eine gelenkte Weise wahrgenommen zu werden bzw. worden zu sein, und ein bestimmtes Fremdbild in den Köpfen ihrer fiktiven Mitmenschen zu positionieren. Die Frage indes, wo nun diese Intentionalität angesiedelt werden sollte, ist ein die Geister scheidendes Kernproblem. Ist es der ,reale‘ Autor, der mittels Figur beim ,realen' Leser diesen Eindruck hervorrufen möchte oder hervorruft? ${ }^{32}$ Ist die Figur überhaupt nur Träger der Handlung, nur Mittel zum Zweck des fiktionalen Spiels? Oder liegt die Motivation im Innenleben der Figur, in ihrer geschilderten oder vermutbaren Psyche?33

$29 \quad$ Vgl. Lisa Zunshine: Why we read fiction - theory of mind and the novel. Columbus (OH) 2006.

30 Vgl. Silvia Reuvekamp: Hölzerne Bilder - mentale Modelle? Mittelalterliche Figuren als Gegenstand einer historischen Narratologie. In: DIEGESIS. Interdisziplinäres E-Journal für Erzählforschung 3 (2014). Online: $<$ https://www.diegesis.uniwuppertal.de/index.php/diegesis/article/view/168/221>. Arthur Schnitzler: Fräulein Else. In: ders.: Gesammelte Werke in drei Bänden. Band I: Erzählungen, hg. von Hartmut Scheible. Düsseldorf 1924/2002, S. 557-620, hier S. 557; vgl. dazu Nils Lehnert: „Sehe ich nun gnädig aus?" - Eindruckssteuerndes Verhalten, Selbst- und Fremdbilder literarischer Figuren als mögliche transepochale ,Universalien' der Literatur. In: Endre Hárs/Márta Horváth/Erzsébet Szabó (Hg.): Universalien? Über die Natur der Literatur. Trier 2014, S. 179-199, hier S. 192-195.

32 Vgl. Fotis Jannidis: Figur und Person. Beitrag zu einer historischen Narratologie. Berlin/New York 2004; vgl. Anz: Kulturtechniken der Emotionalisierung; vgl. Thomas Anz: Gefühl als Text? Möglichkeiten und Grenzen literaturwissenschaftlicher Emotionsforschung. Positionen der Neueren deutschen Literaturwissenschat. In: Miriam Langlotz/Nils Lehnert/Susanne Schul/Matthias Weßel (Hg.): SprachGefühl. Interdisziplinäre Perspektiven auf einen nur scheinbar altbekannten Begriff. Frankfurt am Main 2014, S. 253-264. Vgl. zu einer Diskussion von Leser- und Autorkonzepten grundlegend Wolf Schmid: Elemente der Narratologie. 3., erw. u. überarb. Aufl. Berlin/Boston 2014, S. 45-160.

33 Und selbst im letzteren Fall muss man sich fragen, ob man die Motivation aus anzunehmenden kindlichen Erlebnissen, traumatischen Erfahrungen etc. (psychoanalytisch; $\Rightarrow$ I.3.2) der fiktiven Vita, erzählgegenwärtigen Umständen oder per Figureninformationsvergabe qua indirekter bzw. direkter Charakterisierungen etc. $\Leftrightarrow \Rightarrow$ I.2.4) inferieren darf, soll oder kann. Vgl. dazu Harald Haferland: Psychologie und Psychologisierung: Thesen zur Konstitution und Rezeption von Figuren. Mit einem Blick auf ihre historische Differenz. In: Florian Kragl/Christian Schneider (Hg.): Erzähllogiken in der Literatur des Mittelalters und der Frühen Neuzeit. Akten der Heidelberger Tagung vom 17. bis 19. 
All dies kann nur dann adäquat untersucht und beantwortet werden, wenn man sich erstens unter Berücksichtigung des Untersuchungsgegenstands auf der Skala zwischen interner (Figur $=$ Person $)$ und externer $($ Figur $=$ Funktion $)$ Perspektive begründet positioniert hat $(\Rightarrow I .2 .4 u$. $\Rightarrow I .2 .5),{ }^{34}$ und zweitens die erzähltechnische Machart der Texte ernst nimmt $(\Leftrightarrow I .2 .3)$ - ist doch das ,Wie' das Fenster zur fiktionalen Welt und den in ihr sich befindenden Figuren. Ist das Glas, durch das der Erzähler ${ }^{35}$ den Leser zu blicken einlädt, etwa figurensubjektiv eingefärbt, plausibilisiert eine Textinstanz Einstellungen und Handlungen (nur) bestimmter Figuren etc., so führt diese ,sprachliche Verpackung‘ zu gänzlich anderen Bewertungen und Interpretationen der eindruckssteuernden Verhaltensweisen und Handlungsmotiven der Romanhauptfiguren Genazinos.

\section{ERKENNTNISLEITENDE FRAGESTELLUNGEN UND METHODOLOGIE}

Jedes dieser drei ,Begehren“ hat seine Forschungsrelevanz: Genazinos Romanwerk erhält erstens einen neuen Deutungszugang, indem die Forschungsliteratur um eine systematische Untersuchung der Romanfiguren erweitert wird; mittels des Zuschnitts auf intentional-eindruckssteuerndes Figurenverhalten werden zweitens sowohl bestehende literaturwissenschaftliche Motivations-Modelle in einen größeren Rahmen eingebettet als auch sinnvolle Konzepte der Sozial- und Persönlichkeitspsychologie als Analysetool für die Literaturwissenschaft fruchtbar gemacht; drittens wird die Forschung zur Figurentheorie und -analyse exemplarisch-kritisch auf ihre Tauglichkeit für ,die Arbeit an der Basis' geprüft. Diese drei Anliegen überschneiden sich in den folgenden vier übergeordneten Fragestellungen:

- Welche Muster lassen sich generell im (intentionalen) Figurenhandeln ausmachen?

- Was tun literarische Figuren Genazinos wie, wann, warum und mit welchem Erfolg, um andere oder sich selbst (bewusst oder unbewusst) zu einem bestimmten Verhalten bzw. einer bestimmten Sicht ihrer selbst zu veranlassen?36

Februar 2011. Heidelberg 2013, S. 91-117; vgl. Tilmann Köppe/Tom Kindt: Erzähltheorie. Eine Einführung. Stuttgart 2014, S. 115-160.

Am Rande: In der Filmwissenschaft gibt man sich zwar einerseits weniger zimperlich - Filmfiguren sieht und hört man und schreibt ihnen Attribute zu, die man intersubjektiv diskutieren kann -, unterscheidet andererseits aber auch die Trennung in interne und externe Analyseperspektive (vgl. Eder: Die Figur im Film).

35 Vgl. Köppe/Kindt: Erzähltheorie, S. 84-97, die in Frage stellen, dass es immer einen fiktiven Erzähler in fiktionalen Erzähltexten geben müsse.

36 Diese grundsätzlichen Fragestellungen sind hinsichtlich der Eindruckssteuerung und Handlungsmotivation näherhin zu untergliedern: Erstens lassen sich diejenigen Fragen zusammenfassen, welche die Einzelfigurenebene adressieren: Welcher (Sub-)Strategie (nach Astrid Schütz: Assertive, Offensive, Protective, and Defensive Styles of Self-Presentation: A Taxonomy. In: The Journal of Psychology 132 (1998), S. 611-628; $\Rightarrow$ I.3.3) bedient sich die Figur, warum tut sie dies, lässt sich ihre Selbstpräsentation einem der vier Quadranten zuordnen, wie sehen personale Einflüsse aus, wann verhält sich die Figur wie, wie erfolgreich werden bestimmte Strategien geschildert, welche Rückschlüsse für die Charakterisierung ergeben sich daraus, ändert die Figur ihre Taktik im Verlauf, wenn ja: zu ihrem Vorteil, kann die Figur generell soziale Interaktionen ihren Wünschen gemäß gestalten, welche Funktion für die Selbstvergewisserung übernimmt ihr Handeln? Zweitens die auf Interaktionsebene anzusiedelnden Fragen: Sind bestimmte Strategien bei bestimmten Interaktions- 
- Wie genau wird dies narratologisch ausgestaltet?

- Welche Selbstkonzepte stehen dabei zur Disposition?

Die letzte Frage, die aus den bisherigen Ausführungen höchstens mittelbar abgeleitet werden kann, erhellt vor dem Hintergrund, dass Genazinos Subjekte höchst fragile Selbstentwürfe verkörpern $(\Leftrightarrow I .4)$. Seine Romanfiguren werden gezeichnet als neurotische, von Depersonalisation und Dissoziation über existenzielle Ängste, Zwänge und Fixierungen bis hin zum (gefühlten?) Körperteilzerfall gebeutelte. Nicht zuletzt deswegen nutzen sie IM in der Absicht, damit auch ihr Selbstbild und -wertgefühl zu stabilisieren in einer unüberschaubaren Welt der (Post-)Moderne, von welcher sie nicht einmal wissen, ob sie ,dazugehören' wollen oder nicht ( $\Rightarrow$ II.1.1).

Diese übergeordneten Fragestellungen hängen auf das Engste zusammen und sind daher erstens nicht voneinander zu trennen und (deshalb) zweitens nicht so beschaffen, dass es Großkapitel gäbe, die jeweils eine ins Zentrum stellten. Vielmehr finden sich in jedem Unter(unter)kapitel Splitter aller. Die gemeinsame Verbindung präformiert dabei natürlich die Beschaffenheit des Aufbaus dieser Studie: Bspw. sind beim Modell zur Analyse von Figuren in fiktionalen Welten die Stellschrauben exakt eingestellt auf: Genazino, auf: realistische Figuren, auf: eine bestimmte Art von Erzählen und Erzähler usw. ( $\Rightarrow$ I.2.3). So werden auch nicht Genazinos Figuren untersucht, sondern nur deren mit bestimmten Handlungsmustern, Eindruckssteuerung und motivationalem Verhalten in Beziehung stehende Aspekte. Wie sind diese Leitplanken nun (methodologisch) zu operationalisieren?

Der zunächst nur dünne, aber dichte methodische Überbau besteht aus einer Verschmelzung von Figurentheorie bzw. -analysekategorien und ,allgemeiner' Erzähltheorie $(\Leftrightarrow I .2 .4 \quad$ u. $\Rightarrow$ I.2.3) sowie bereits vorliegenden Konzepten der Handlungsmotivation aus Literaturwissenschaft und Psychologie ( $\Rightarrow$ I.3.1), die auf die Ausprägung der Eindruckssteuerung zugespitzt, ergänzt und synthetisiert werden $(\Leftrightarrow I .3 .3)$. Diejenige/n zusätzliche Referenz-Theorie/n, die in den eigentlichen Analysekapiteln benötigt werden, sind mit dem Vorteil, dass nicht etliche Seiten Theorieballast aufgehäuft werden müssen, der späterhin nur punktuell relevant wird, direkt in die Unterkapitel ausgelagert worden $(\Rightarrow$ I.5.2). Da es um die Musterhaftigkeit von Verhaltensstrategien

partnern erfolgsversprechender, sind einzelne Figuren besser in der Lage, bestimmte Strategien zu fahren etc.? Drittens eine ,metatheoretische' Ebene: Wie lässt sich IM sinnvoll mit anderen sozialund persönlichkeitspsychologischen Referenztheorien für eine Figurenanalyse verknüpfen, bzw. gewinnt auch die angelegte Theorie durch die tentative Analysepraxis (vgl. Schütz: SelfPresentation, S. 620; vgl. Thomas Anz: Literatur und Psychologie. Eine Typologie möglicher Beziehungen. In: Peter Wiesinger unter Mitarbeit von Hans Derkits (Hg.): Akten des X. Internationalen Germanistenkongresses Wien 2000. Band 10: Geschlechterforschung und Literaturwissenschaft Literatur und Psychologie - Medien und Literatur. Bern 2003, S. 221-227, hier S. 223)? Gibt es Skripts als wiederkehrende Abläufe, Persönlichkeitsmerkmale (vgl. William H. Turnley/Mark C. Bolino: Achieving Desired Images While Avoiding Undesired Images: Exploring the Role of SelfMonitoring in Impression Management. Research Report. In: Journal of Applied Psychology 86 (2001), S. 351-360), die bestimmte Verläufe prädisponieren? Und können bestimmte soziale Normen als Niederschlag in Rollenvorgaben die Wahl der Strategie beeinflussen? 
gehen soll, wird nicht einzelfigurenbezogen vorzugehen sein, sondern werden die Strukturähnlichkeiten in fünf thematisch abgrenzbaren Themenfeldern, den Schlaglichtern, versammelt.

\section{AUFBAU UND SCHLAGLICHTER}

Nachdem in römisch I zunächst der Gegenstand umrissen, die Meta-Theorie eingeführt, die Textauswahl erläutert, die Forschungsstände der drei Anliegen vergegenwärtigt und schließlich das Theoriedesign der vorliegenden Studie begründet worden sein werden, gibt es einen Schwenk auf einzeln ausgeleuchtete Areale im musterhaften Figurenverhalten: Römisch II wirft - stets unter Berücksichtigung (potenziell) aller Genazino-(Anti-)Helden ${ }^{37}$ - einen Blick auf fünf Schlaglichter: ${ }^{38}$ Ein erstes fundiert unter dem Titel „Innenwelten - Außenwirkungen“ sowohl musterhafte Figurenmerkmale ( $\Rightarrow$ II.1.3) als auch deren Einstellungen $(\Rightarrow$ II.1.6), Lebensstilzugehörigkeiten $(\Leftrightarrow I I .1 .5)$ etc. Gefolgt vom zweiten Schlaglicht, das wechselseitiges, mitunter zwanghaftes Beobachten $(\Rightarrow$ II.2.2) und die dabei obwaltenden Probleme der Deutung und des Verständnisses von Zeichengebung generell ( $\Rightarrow$ II.2.3) usw. unter dem Titel „Im Auge des Betrachters" untersucht. Das dritte Schlaglicht thematisiert „Strategien der Interessantheit bzw. Auffälligkeit" und damit vergleichsweise seltene, aber höchst ergiebige Figurenfacetten zwischen inszenierter Spontaneität $(\Leftrightarrow$ II.3.3) und Extemporieren $(\Leftrightarrow$ II.3.4). Im vierten Schlaglicht werden vermehrt die ,Schattenseiten' der Romanfiguren im Vordergrund stehen, was sich besonders gut an den häufig abschätzigen Bewertungen anderer $(\Leftrightarrow$ II.4.3), mitunter auch in Form der ,Pöbellaune‘ ( $\Rightarrow$ II.4.4) zeigen lässt. Dieses vierte Schlaglicht ist überschrieben mit: „Das Ich, die anderen und das andere: Inszenierung - Beobachtung - Evaluation“. Ein weites Feld, innerhalb dessen Wilhelm Genazinos Romanfiguren einfallsreiche Eindruckssteuerungen an den Tag legen, gibt dem fünften Schlaglicht den Titel: „Liebe und Sexualität“ - von Liebesentwürfen ( $\Rightarrow$ II.5.2) über Genderaspekte $(\Leftrightarrow$ II.5.3) bis zu sexuellen Wünschen und Praktiken $(\Rightarrow$ II.5.5). Fazit dann unter römisch III.

37 Je nachdem, ob man von drei unterschiedlichen Abschaffel-Figuren ausgeht oder sie zu einer,Dreifaltigkeit' zusammenlegt, gibt es (Stand 2018) neunzehn bzw. einundzwanzig Figuren. Vgl. dazu Hannes Krauss: Menschen - Dinge - Situationen. Wilhelm Genazinos „Abschaffel“-Romane. In: Arnold (Hg.): Wilhelm Genazino (2004), S. 11-19, hier S. 11, der zudem den Fehler dekuvriert, es handele sich bei der 2002 erschienenen dtv-Ausgabe um die erste einbändige. Im Verlauf dieser Arbeit beziehe ich mich allerdings auf diejenige Ausgabe von 2002 und verwende ,AbschaffelTrilogie', wenn der Zusammenschluss aller drei Romane gemeint ist. Wenn sich eine bestimmte Verhaltensstrategie Abschaffels über die Romangrenzen hinweg stark verändert, wird etwa auf eine Formulierung wie: ,der Abschaffel des Romans Die Vernichtung der Sorgen', o. Ä. zurückzugreifen sein.

38 An Ort und Stelle findet sich lediglich ein kleiner,Vorgeschmack'; sowohl im Kapitel zu Genese und Struktur der Schlaglichter $(\Rightarrow$ I.5.1) als auch jeweils zu Beginn derselben sind systematischere Überblicke zu finden. 
Der eingangs gestellten ,Warum?'-Frage des Literaturkritikers Bielefeld ließe sich mit Andrea Bartl und Friedhelm Marx noch diese poetologische, ja beinahe poetische und für das hier angestrengte Unternehmen zielführendere Antwort geben: „Ästhetisch und ethisch bietet diese Wiederholungsstruktur einen weiteren Reiz: die Norm zu erkennen und die Abweichung zu goutieren, das Gängige zu reflektieren und die Variation als gleichberechtigte Möglichkeit gelten zu lassen.“39 Die Stichworte ,Wiederholung' und ,Variation', so viel sei vorab gesagt, sind zentrale Schlüsselbegriffe (vgl. Stockinger 2004; $\Rightarrow$ I.2.1; $\Rightarrow$ I.2.2; $\Rightarrow$ I.2.5; $\Rightarrow$ I.5.1), um etwas Licht ins Dunkel der Genazino-Figuren-Forschung zu bringen und den nur scheinbaren Widerspruch ${ }^{40}$ des Titels dieser Arbeit selbst wiederholt zu variieren: Genazinos Figuren sind „im Kern unverständlich, obwohl jedem Menschen sofort einleuchtend“, wie es in Das Glück in glücksfernen Zeiten heißt (Glück, S. 41). Am Ende dieser Arbeit wird eine leichte Verschiebung stehen: Der Figurenkern wird verständlicher geworden sein - ob die (Mit-)Sicht nach wie vor einleuchtend im Sinne von ,nachvollziehbar' oder gar ,überzeugend' geartet ist, darf indes angezweifelt werden.

39 Andrea Bartl/Friedhelm Marx: Wiederholte „Verstehensanfänge“. Das literarische Werk Wilhelm Genazinos. In: dies. (Hg.): Verstehensanfänge (2011), S. 7-20, hier S. 9.

40 Bei näherem Besehen - auch wenn die abendländische Denktradition nach dem Entweder-oder zu greifen strebt - handelt es sich um ein Sowohl-als-auch im Sinne zweier ,gleichberechtigter Möglichkeiten'. 


\section{Wilhelm Genazinos Romanfiguren und ,Figurenromane}

Es gibt Erzähltexte, die kommen gänzlich ohne Figuren im eigentlichen Sinn aus. Das ist allerdings gemessen an der Gesamtheit sehr selten - man denke etwa an manchen Nouveau Roman, die klassische Avantgarde oder an zeitgenössische, experimentellere Formen. ${ }^{1}$ Oder zumindest ohne eine Hauptfigur. Das gibt es schon häufiger - man denke etwa an den Russischen Realismus. Und dann existieren am anderen Ende des Spektrums diejenigen Erzähltexte, die ohne Hauptfiguren überhaupt nicht denkbar scheinen beziehungsweise in ihre Einzelteile zerfielen, wenn man diese subtrahierte - man denke etwa an den Bürgerlichen Realismus, zumal in der Ausprägung ,Titel $=$ Protagonist ${ }^{2}{ }^{2} \mathrm{Zu}$ letzteren gehören Genazinos Romane.

Da gemeinhin prinzipiell von einer engen Abhängigkeit zwischen Handlung und Figur für Erzähltexte ausgegangen wird $(\Leftrightarrow I .2 .3)$ und es bei Genazino für gesichert gelten kann, dass die Figuren die Romane ausmachen, tragen, gestalten - und sei es nur als Reflektorfigur, die die wahrgenommene Welt für den Leser spiegelt -, andererseits eine ,reine' Genazino-Figuren-Forschung, in die man sich medias in res einschreiben könnte, (noch) nicht existiert, steht neben einer Bestandsaufnahme der Forschung zu Genazinos Romanfiguren auch eine solche zu seinen ,Figurenromanen' allgemein an.

Die vom Grundton her melancholischen, ${ }^{3}$ sprachspielerischen wie sprachkritischen, von Ekel ${ }^{4}$ über Verrücktheit ${ }^{5}$ hin zu sozialer Exklusion, ${ }^{6}$ von Scham $^{7}$ und (Fremd-)Schämen ${ }^{8}$ über Humor und Komik ${ }^{9}$ hin zu Erinnern ${ }^{10}$ und Erinnerungen ${ }^{11}$ durchsetzten Romane, die mit Anleihen bei

1 Das sogenannte ,Suhrkamp-Pop'-Dreigestirn - Rainald Goetz, Thomas Meinecke, Andreas Neumeister - ist ein gutes Beispiel für die Autorschaft von Texten, die sich dagegen sperren.

2 Vgl. für die Auswirkungen auf literarische Figurencharakterisierungen sowie für den Befund, dass sich diese Einschätzung und Aufteilung nur in Relation zum Beobachtungszeitpunkt angeben lässt, Thomas Docherty: Reading (Absent) Character. Towards A Theory of Characterization in Fiction. Oxford 1983, S. xf.

3 Vgl. Svenja Frank: Melancholy in Wilhelm Genazino's Novels and Its Construction as Other. In: Mary Cosgrove/Anna Richards (Hg.): Edinburgh German Yearbook 6: Sadness and Melancholy in German-Language Literature and Culture. Rochester (NY) 2012, S. 151-172.

4 Vgl. Sven Hanuschek: „Das Sofa blieb und stank in abgeschwächter Form weiter“. Ekel und Erkennen im Werk Wilhelm Genazinos. In: Bartl/Marx (Hg.): Verstehensanfänge (2011), S. 131-147.

5 Vgl. Friedhelm Marx: Erzählfiguren der Verrückung im Werk Wilhelm Genazinos. In: Bartl/ders. (Hg.): Verstehensanfänge (2011), S. 57-68.

6 Vgl. Heinz Bude: Ein Mann verschwindet. Literarische und soziologische Evidenz an einem Fall sozialer Exklusion in Wilhelm Genazinos Roman Das Glück in glücksfernen Zeiten. In: Wiebke Amthor/Almut Hille/Susanne Scharnowski (Hg.): Wilde Lektüren. Literatur und Leidenschaft. Festschrift für Hans Richard Brittnacher zum 60. Geburtstag. Bielefeld 2012, S. 181-192.

7 Vgl. Melanie Ball: Das Phänomen Scham bei Wilhelm Genazino. Magisterarbeit Universität Münster 2008. Online: <https://d-nb.info/1049611209/34>; vgl. Hirsch: Geheimgeschichten. Die (Ent)deckung der Scham.

8 Vgl. Hans-Peter Ecker: Schiffbruch mit Zuschauer II: „Fremdschämen“ bei Wilhelm Genazino. In: Bartl/Marx (Hg.): Verstehensanfänge (2011), S. 115-129.

9 Vgl. Christian Krepold: „....als sei das Ende des Menschen die einzige ordentliche Verrichtung“. Altern, Melancholie und Komik bei Wilhelm Genazino und Italo Svevo. In: Andrea Bartl/Hanna V. Becker/Raoul Schrott (Hg.): Transitträume. Beiträge zur deutschsprachigen Gegenwartsliteratur: Interviews mit Raoul Schrott, Albert Ostermaier, Hanns-Josef Ortheil, Andrea Maria Schenkel, Kerstin 
einer Poetik der Entschleunigung ${ }^{12}$ Flaneure,13 Aussteiger, ${ }^{14}$ Tagediebe, Taugenichtse und Versager ${ }^{15}$ bei deren Wahrnehmungen, ${ }^{16}$ Beobachtung(en), ${ }^{17}$ (Selbst-)Reflexionen, ${ }^{18}$ Tagträumen ${ }^{19}$ und Epiphanien ${ }^{20}$ begleiten, suchen einerseits in der deutschsprachigen Gegenwartsliteratur Ihresgleichen, haben andererseits natürlich literarhistorische Vorbilder, was an wenigen und untereinander recht inkommensurablen Referenzautoren kurz verdeutlicht werden soll. ${ }^{21}$ Mit Jean Paul teilt sich Genazino erstens die Spaltung der Leserschaft in bekennende Anhänger und flammende Kritiker, zweitens die Eigenschaft, dass diesem wie jenem laut August Wilhelm

Specht, Nora-Eugenie Gomringer, Olaf neopan Schwanke und Franzobel. Augsburg 2009, S. 55-102; vgl. Philipp Petersen: Die Komik der Beiläufigkeit. Zur Verwendung von Komik und Humor bei Wilhelm Genazino. Magisterarbeit Universität Wien 2013. Online: <http://othes.univie.ac.at/25659/1/2013-01-30_0003406.pdf>; vgl. Silvia Henke: „Fluktuierende Uneindeutigkeit". Ironie, Witz und Komik bei und nach Wilhelm Genazino. In: Felix Christen/Thomas Forrer/Martin Stingelin/Hubert Thüring (Hg.): Der Witz der Philologie. Rhetorik - Poetik - Edition. Festschrift für Wolfram Groddeck zu 65. Geburtstag. Frankfurt am Main 2014, S. 7080.

10 Vgl. Susanne Mittag: Im INSTITUT FÜR MNEMOSYNE oder Grundkurs in der Kunst des Erinnerns. Aspekte der Erinnerung in den Romanen Wilhelm Genazinos. In: Giesen (Hg.): Wilhelm Genazino (2006), S. 47-56.

11 Vgl. Wolfram M. Fues: Erinnerung, Entinnerung. Fiktionalität und Hyperfiktionalität. In: Peter U. Hohendahl/Rüdiger Steinlein (Hg.): Kulturwissenschaften - Cultural Studies. Berlin 2001, S. 263271; vgl. Manuel Maldonado Alemán: „Das Bild schweigt. Aber es bringt mich zum Erzählen“. Intermediale Erinnerungen im Werk Wilhelm Genazinos. In: Bartl/Marx (Hg.): Verstehensanfänge (2011), S. 179-198; vgl. Manuel Maldonado Alemán: Intermedialität und Erinnerung. Zum Verhältnis von Bild und Text bei Wilhelm Genazino und Monika Maron. In: Olivia C. Pérez Díaz/Florian Gräfe/Rolf G. Renner (Hg.): Intermedialität und Alterität, Migration und Emigration. Tendenzen der deutschsprachigen Literatur. Tübingen 2014, S. 17-31.

12 Vgl. Hans-Peter Kunisch: Sätze in Bewegung. Preise für Genazino und Schamoni in der Bayerischen Akademie. In: Süddeutsche Zeitung vom 28. Mai 1998; vgl. Anne Fuchs: Poetiken der Entschleunigung in Prosatexten Wilhelm Genazinos, Julia Schochs und Judith Zanders. In: Silke Horstkotte/Leonhard Herrmann (Hg.): Poetiken der Gegenwart. Deutschsprachige Romane nach 2000. Berlin/Boston 2013, S. 213-227.

13 Vgl. Heiko Neumann: „Der letzte Strich des Flaneurs“. Schwierige Fußgänger in Wilhelm Genazinos Romanen Ein Regenschirm für diesen Tag und Die Liebesblödigkeit. In: Bartl/Marx (Hg.): Verstehensanfänge (2011), S. 149-164.

$14 \quad$ Vgl. Alexander Fischer: Wider das System. Der gesellschaftliche Aussteiger in Genazinos Ein Regenschirm für diesen Tag und literarische Verwandte bei Kleist und Kafka. Bamberg 2012.

15 Vgl. Katja Wallenhorst: Der Versager in der Literatur am Beispiel der Romane Wilhelm Genazinos. Magisterarbeit Universität Halle-Wittenberg 2012.

16 Vgl. Werner Jung: „Umhergehen und Zeitverschwenden“. Skizze zu einer literarischen Phänomenologie der Wahrnehmung. In: Arnold (Hg.): Wilhelm Genazino (2004), S. 65-69.

17 Vgl. Marit Hofmann: „Als könnte ich meinem eigenen Blick zuschauen“. Beobachtete Beobachter in Wilhelm Genazinos Romanen. In: Arnold (Hg.): Wilhelm Genazino (2004), S. 55-64.

18 Vgl. Susanne Krepold/Christian Krepold: Literarische Selbstreflexionen durch Lektüre. Wilhelm Genazino als Leser von Marguerite Duras. In: Steffen Buch/Álvaro Ceballos/Christian Gerth (Hg.): Selbstreflexivität. Beiträge zum 23. Nachwuchskolloquium der Romanistik (Göttingen, 30. Mai-02. Juni 2007). Bonn 2008, S. 107-124.

19 Vgl. Katrin Hillgruber: Beruf: Tagträumer. Genazino und Krechel im Literarischen Colloquium Berlin. In: Der Tagesspiegel vom 20. Februar 1999.

20 Vgl. Norbert O. Eke: Epiphanische Augen-Blicke. Inszenierungen der Alltagswahrnehmung in der Prosa Wilhelm Genazinos und Angela Krauß'. In: Heinz-Peter Preusser/Anthonya Visser (Hg.): Alltag als Genre. Heidelberg 2009, S. 177-190; vgl. Alexandra Koch: Das Bedeutungstheater des Epiphanikers. Zur Ver- und Entzauberung der Alltagswelt in der Prosa Wilhelm Genazinos. Hamburg 2012.

21 Für wichtige Hinweise sei an dieser Stelle vor allem Herrn Daniel Göske und Herrn Matthias Attig gedankt! 
Schlegel „,die Romane unter den Händen wie Pilze hervorschießen““ und schließlich, drittens, dass auch Genazino in mancherlei Hinsicht als „Abschweifungsvirtuose“22 Reflexionsreichtum bis zum Eindruck eines Selbstgesprächs zu stilisieren versteht. Damit haben Jean Paul wie Genazino hinsichtlich der Ab- und Ausschweifungen zumindest den auf Abwechslung, Kurzweil und Handlungsreichtum abonnierten Leser nur bedingt im Blick - „Noch kürzer zusammengefasst: Das Leben ist beschissen, und dann bist du tot. Das kann man Roman nennen, klar, warum nicht? Man könnte diese Nichtgeschichte aber auch auf 20 Seiten als nette Short Story erzählen“23 -, was als 250 Jahre überspringendes Vergleichsmoment zu Paul Ingendaays Roman Die romantischen Jahre (2011) dienen kann: Kristina Maidt-Zinke wirft jenem in ihrer Rezension vor,

dass nicht alle Menschen jedes Leben für so spannend halten, dass man einen Roman daraus machen muss. Und wenn sie 460 Seiten gelesen, in denen es um einen gescheiterte[n] Akademiker geht, der sein Dasein als Versicherungsvertreter fristet und in allen Details seine Familiensituation aufdröselt, wird sie ungehalten: Ein poetisches Konzept des ,Alles muss raus' nimmt doch sehr wenig Rücksicht auf Leser, beschwert sie sich. ${ }^{24}$

Aber auch inhaltlich liegen beide nicht so weit voneinander entfernt: „In gewisser Weise sind die Frauen, die er gekannt hat, wie große Versprechen, die das Leben nicht erfüllen wollte." ${ }^{25}$ Dieser Klappentext stünde eigentlich jedem Roman Genazinos gut zu Gesicht. Mit Graham Swift und Patrick Modiano verbindet Genazino hingegen die Vorliebe für die Erinnerung, mit ersterem zudem den Einsatz unzuverlässigen Erzählens, mit zweitem das Spiel mit der Autobiografie, der Bedeutung von Fotografie ${ }^{26}$ und den erstaunlich weit zurückreichenden Erinnerungen, die es den Hauptfiguren erlaubt, eigentlich an ihrer Eltern statt den Zweiten Weltkrieg zu reflektieren. Dutzende weitere Bezugslinien könnten diese Liste erweitern: Mit Kleist teilt sich Genazino die Vorliebe für schwierige bis unmögliche Weltwahrnehmungsreflexionen und die damit zusammenhängende problematische Deutbarkeit per se, mit Kafka teilen sich zumal die Angestellten einige Züge (nicht umsonst steht Abschaffel unter Kafkas Zitat des Freistunden fressenden Tie-

22 Sabine Eickenrodt: Ein Luftschiffer des Geistes. Eine Jubelrede auf Jean Paul, den größten Abschweifungsvirtuosen der deutschen Literatur - zum 250. Geburtstag des Dichters. Und ein Blick auf die Neuerscheinungen anlässlich des Jubiläums. In: Der Tagesspiegel vom 10. März 2013, S. 28. Online: <http://www.tagesspiegel.de/kultur/deutsche-literatur-ein-luftschiffer-desgeistes/7903438-all.html>.

23 Richard Kämmerlings: Genazino gilt als bedeutender Autor. Warum nur? In: Welt.de vom 26. Juli 2011. Online: <https://www.welt.de/kultur/literarischewelt/article13507983/Genazino-gilt-alsbedeutender-Autor-Warum-nur.html>.

24 [Die romantischen Jahre]. Rezensionsübersicht auf perlentaucher.de - Das Kulturmagazin. Online: <https://www.perlentaucher.de/buch/paul-ingendaay/die-romantischen-jahre.html>.

25 Klappentext; zit. n. [Die romantischen Jahre].

26 Vgl. Bernhard Oberreither: Mit einer Spur von Wirklichkeit. Fotografie und literarische Detektion bei Wilhelm Genazino. In: Konstanze Fliedl/ders./Katharina Serles (Hg.): Gemälderedereien. Zur literarischen Diskursivierung von Bildern. Berlin 2013, S. 129-150. 
res), mit Musil ${ }^{27}$ und mit Joyce nach Selbstaussage die „Epiphanie als literarische Technik“28 von den Theoretikern, die Genazino indirekt alludiert, gar nicht zu sprechen.

Obgleich Genazino also sicherlich nicht im ko- und kontextfreien Raum schreibt, so sind doch die markierten oder bisher ergiebig aufgespürten intertextuellen Bezüge im Romanwerk vergleichsweise überschaubar: Zwar hat sich Genazino selbst zur Bedeutung der Mottos, die er für die Abschaffel-Trilogie verwendet (vgl. Abschaffel, S. 7; vgl. Sorgen, S.159; vgl. Falsche Jahre, S. 401), und die dazugehörige Einbindung in die Literarhistorie geäußert, ${ }^{29}$ und haben Susanne und Christian Krepold 2008 „Wilhelm Genazino als Leser von Marguerite Duras“ portraitiert,30 doch insgesamt gilt mit Susanne Mittag, dass - gerade im Vergleich zur zeitgenössischen Literatur - bei Genazino eher wenig intertextuell gearbeitet werde:

Während in den Essays des überaus belesenen Wilhelm Genazino Vorbilder, bewunderte Autoren und ästhetische Programme benannt und analysiert werden, sind die intertextuellen Hinweise in den fiktionalen Texten von äußerster Diskretion. ${ }^{31}$

Recht ,diskret' nimmt sich auch die allgemeine Forschungssituation aus: Es gibt keine Gesellschaft, kein Jahrbuch, keine ,sekundären Regalmeter', aber etliche ,verstreute‘ Artikel; es gibt viel zu tun, aber ein eigentliches Forschungszentrum oder seit Jahren ausgewiesene Expertinnen bzw. regelmäßige Tagungen gibt es nun einmal nicht. Vergleichsweise dünn ist mithin die Trefferquote in den einschlägigen, datenbankengestützten Nachschlagewerken zu Genazino und seinen Romanfiguren, wenn man als Maßstab andere Büchner-Preisträgerinnen und -Preisträger anlegt. Im Wesentlichen liegen lediglich die ,üblichen` überblickenden Essays - Tanja van Hoorn zeichnet in Kindlers Literatur Lexikon,32 Thomas Reschke im Kritischen Lexikon zur deutschsprachigen Gegenwartsliteratur ${ }^{33}$ verantwortlich -, zwei Sammelbände und ein Ausstel-

Auch Anne Fuchs: Gendered Heimat discourse and the poetics of the ,gedehnter Blick' in Genazino's „Mittelmäßiges Heimweh“. In: German Life and Letters 64 (2011), S. 145-155, sieht Bezüge zu Kafka und Musil. Vgl. zur Verbindung mit Robert Musils Mann ohne Eigenschaften Honold: Doppelleben, halbbitter, S. $49 \mathrm{f}$. Wilhelm Genazino: Der gedehnte Blick. In: ders.: Der gedehnte Blick. München/Wien 2004, S. 3961, hier S. 52. Vgl. Koch: Das Bedeutungstheater, S. 36, die Hofmannsthal und Proust als Vergleichsmomente ergänzt; vgl. auch Eke: Epiphanische Augen-Blicke. Vgl. Wilhelm Genazino: Melancholische Renitenz. Bamberger Vorlesungen I. In: ders.: Idyllen in der Halbnatur. München 2009/2012, S. 31-44, hier S. 35 ff.

30 Krepold/Krepold: Literarische Selbstreflexionen.

31 Mittag: Im INSTITUT FÜR MNEMOSYNE, S. 55; vgl. Spiegel/Genazino: „Der Text ist sein eigenes Misstrauen“, S. 242. Genazino selbst setzt etwa seinen Roman Mittelmäßiges Heimweh mit Gogols Die Nase in Beziehung (vgl. Wilhelm Genazino: Der Roman als Delirium. In: Bartl/Marx (Hg.): Verstehensanfänge (2011), S. 21-31, hier S. 22 f.) - aber eben nur epitextuell. Vgl. für ein Gegenbeispiel ,indiskreter' Intertextualität etwa Einfalt, S. 134, oder Kein Geld, S. 23. Tatsächlich gehäuft finden sich im Roman Kein Geld, keine Uhr, keine Mütze auf zwei Druckseiten Verweise auf Prousts À la recherche du temps perdu sowie auf Rilkes fast zeitglich entstandenes Gedicht „Der Panther“ - beides mögliche Zustandsbeschreibungen für die desparate Lage; die Kindheitserinnerungen und Wiederholungsstrukturen doppeln die erzähltechnische Machart Genazinos (vgl. Kein Geld, S. 151 f.). Vgl. für intermediale Einflüsse und Anspielungen vor allem Maldonado Alemán: Intermediale Erinnerungen; vgl. ders.: Intermedialität und Erinnerung; sowie Klinge: Poetische Collagen. 
lungsbegleitheft mit ähnlichem Anspruch - neben dem die Forschung 2004 allererst konstituierenden TEXT+KRITIK-Band $162^{34}$ sind dies das Begleitheft zur Ausstellung Wilhelm Genazino von $2006^{35}$ sowie der qualitativ sehr hochwertige Beiträge versammelnde Band Verstehensanfänge. Das literarische Werk Wilhelm Genazinos von $2011^{36}$ - und wenige publizierte Monografien zumeist Dissertationen - vor (s.u.). ${ }^{37}$ Alle anderen Veröffentlichungen fokussieren (naturgemäß) Einzelaspekte, -texte und/oder -figuren, sind als Rezensionen nur bedingt überblicksgeeignet oder zu ,grau' - teilweise aber blendend gut! -, um an Einfluss oder Bekanntheit für ein größeres Publikum relevant zu sein. Für die hier zu verfolgenden Fragestellungen sind insbesondere drei Monografien als diskursive Fixpunkte wichtig.

Jonas Fansa analysiert 2008 in Unterwegs im Monolog. Poetologische Konzeptionen in der Prosa Wilhelm Genazinos in bemerkenswert genauem Close-Reading Sprache, Motive und Figuren bei Genazino, geht dabei erzähltheoretisch indes nicht sehr in die Tiefe und vermutet - an dieser Stelle zunächst in aller Brevität - in der Liebe zur Einfalt den ultimativen Schlüsselroman ( $\Rightarrow$ I.2.5). Das ist in zwiefacher Hinsicht zu verstehen: einerseits als Werk-Leben-Abgleich des realen Wilhelm Genazino mit seinem Romanwerk, andererseits als ,Schlüssel zum Romanwerk'. Auch und insbesondere für die Baupläne der Figuren postuliert er, hinter der Hauptfigur in Genazinos Roman Die Liebe zur Einfalt stecke schlechterdings der Prototyp der Genazino'schen Charaktere. Obwohl Fansa bei allen seinen Unterfangen stets erzähltheoretisch redlich das ,Was“ auf das ,Wie' wendet, kommt er zum möglicherweise zu monokausalen Schluss, dass die Romane Genazinos immer und ausschließlich das Schreiben und dessen Grundbedingungen poetologisch reflektierten. Fansa rückt mit seiner methodologischen Ausrichtung bisweilen Autor und Erzähler recht nahe aneinander, ${ }^{38}$ gibt es doch nahezu kein Zwischenfazit, das ohne Rekurs auf die Autorität des Autors auskäme. ${ }^{39}$

Anja Hirsch identifiziert in ihrer 2006 erschienenen Dissertation „Schwebeglück der Literatur“. Der Erzähler Wilhelm Genazino unter anderen die folgenden „Erzähltendenzen“:

Reflexion [...]; Dynamik von Scheitern und Aufbruch; die innenperspektivische Projektion dieser Bewegung auf einen Protagonisten; Sehen (und Gehen) als Ausgangspunkte der Reflexion; als Folge

34 Vgl. Arnold (Hg.): Wilhelm Genazino. Vgl. zu einer vergleichsweise harschen Kritik des Bandes sowohl hinsichtlich der Einseitigkeit der Zugriffe auf das Gesamtwerk als auch der im Vordergrund stehenden Kanonisierungsbemühungen Alexandra Pontzen: „Ziel der Scham ist das Verschwinden“. Wilhelm Genazino bei „Text und Kritik“. In: literaturkritik.de vom 11. November 2004. Online: $<$ http://literaturkritik.de/id/7590>.

35 Vgl. Giesen (Hg.): Wilhelm Genazino.

36 Vgl. Bartl/Marx (Hg.): Verstehensanfänge.

37 Mit den Nennungen ,s.u.' und ,s.o.' wird lediglich innerhalb eines Unterkapitels deiktisch Bezug genommen.

38 Vgl. Fansa: Unterwegs im Monolog, S. 45.

39 Nichtsdestotrotz handelt es sich um einen veritablen Meilenstein in der Genazinoforschung die Figuren anbelangend. 
dieses visuell ausgerichteten Erzählvorgangs: die Tendenz zur Verknappung und Verdichtung [...]; [...] die Tendenz zu insgesamt kompakten Werken [.... ${ }^{40}$

Wie Fansa verpflichtet auch Hirsch Genazinos Texte allerdings (ausschließlich) darauf, durch und durch selbstreflexiv-poetologisch geartet zu sein und lässt in ihren hellsichtigen Analysen häufiger den ,objektiven' Blick auf Texte vermissen. Freilich handelt es sich bei diesen um von Ko- und Kontexten abhängige Dichtung, aber sobald einem Romanwerk das Existenzrecht auf Deutung abgesprochen wird, sofern es nicht über die Autorenbiografie abgesichert wird, ist prinzipiell, und nicht nur aufgrund methodologischer Vorbehalte, Vorsicht angezeigt $(\Rightarrow I .5 .2){ }^{41}$ Matthias Hoffmann geht in seiner Dissertation mit dem Titel Gesellschaftskritik in Wilhelm Genazinos Roman Das Glück in glücksfernen Zeiten (2015) nicht nur der titelgebenden Gesellschaftskritik etwa im Rahmen der „Arbeits- und Konsumwelt“ auf den Grund, sondern denkt permanent auch „[d]as Subjekt und seine philosophische Verknüpfung“ von Adorno bis Žižek mit. ${ }^{22}$ Obwohl Hoffmann sich auf einen einzigen Roman Genazinos kapriziert, beanspruchen seine subjektphilosophischen Befunde durchaus auch Gültigkeit über diesen hinaus, sodass seine Ausführungen für das hier vorliegende Kapitel zum Selbst $(\Rightarrow I .4)$ als eine wichtige Grundlage dienen können.

Um - nach dieser freihändigen Schraffur der Genazino-Forschung und der Identifikation wichtiger Anknüpfungspunkte - zunächst einige Schneisen in das dichte Romanwerk Genazinos zu schlagen, müssen diejenigen größeren, seitens der Forschung behaupteten Schaffensphasen kritisch beleuchtet werden $(\Rightarrow$ I.2.1). Erst auf dieser Grundlage ist das poetische Verfahren Genazinos darzulegen, das sich etwa als ,Mischpult-Verfahren' metaphorisch ziemlich gut beschreiben lässt $(\Leftrightarrow I .2 .2)$, bevor die romananalytische und insbesondere erzähltheoretische Grundierung seines CEuvres vorgenommen wird $(\Leftrightarrow I .2 .3)$, um sodann auf die Figurenanalyse im engeren Sinn zu fokussieren ( $\Rightarrow$ I.2.4). Das letzte Unterkapitel $(\Rightarrow$ I.2.5) schließlich widmet sich Wesen und Machart von Genazinos Romanfiguren, indem die Volte von allgemeiner Figurenanalyse auf genazinotypische Figuren - gewissermaßen den ,Genazino’schen Basistypus` - geschlagen wird.

40 Hirsch: „Schwebeglück der Literatur“, S. 17 f. Was Hirsch veranlasst, gerade nach dieser Aufzählung weitgehend unbegründet „Reflexion und Distanz“ als künftige Analysekategorien ihrer Dissertation zu setzen, bleibt nebulös.

41 Bei aller Kritik kann die Pionierarbeit nicht genügend gewürdigt werden, die seitens der Autorin geleistet worden ist!

42 Matthias Hoffmann: Gesellschaftskritik in Wilhelm Genazinos Roman Das Glück in glücksfernen Zeiten. Frankfurt am Main 2015, S. 7. 


\section{1 „Pendelbewegungen“: Grenzlinien, Schaffensphasen, Zäsuren}

Kaum ein Genazino-Interpret hat sich bisher des offensichtlich reizvollen Vorhabens entzogen, das Romanwerk mit Grenzlinien zu durchziehen. ${ }^{1}$ Allerdings müssen dringend die jeweiligen Impetus offengelegt werden, die obwalten: Interpret A interessiert sich für die Erzählperspektive und kehrt - aus seiner Sicht völlig nachvollziehbar - den Wandel vom Ich- zum Er-Erzähler heraus. Mithin sieht er eine Grenze zwischen den Texten Fremde Kämpfe und Der Fleck, die Jacke, die Zimmer, der Schmerz. Interpret B bezieht sich mit seiner Grenzziehung zwar auf diejenige As, meint aber einen ganz anderen Wandel, sagen wir, denjenigen des Stils (von ernst zu heiter). Daher muss zunächst aufgearbeitet werden, welche Äpfel mit welchen Birnen verglichen worden sind, um in einem zweiten Schritt zu schauen, ob die - und wenn: welche der - vorliegenden Trennlinien für die vorliegende Untersuchung zu Genazinos Figuren erhellend scheinen. ${ }^{2}$

Dabei muss vergegenwärtigt werden, dass es eine damit auf das engste verquickte Debatte gibt, von der sich diese bereits elaborierten Grabenkämpfe um Zäsuren etc. abheben: diejenige bereits in der Einleitung angerissene darum, ob Genazino eigentlich überhaupt ,Neues' liefere. Jede Roman-Veröffentlichung des seit ca. 1990 recht präzise im Zweijahrestakt mit einem ,Hopsersprung' alle paar Schaltjahre liefernden Autors (1990, 1992, 1994, 1996, 1998, 2001, 2003, 2005, 2007, 2009, 2011, 2014, 2016, 2018) $)^{3}$ wird vom Literaturbetrieb mit sich selbst vergewisserndem Raunen begleitet: Selten geht es dann darum, den jüngst erschienenen Einzeltext, wie etwa Kein Geld, keine Uhr, keine Mütze, sondern darum, ,den neuen Genazino' auf den Prüfstand zu stellen, meist also um die implizite Debatte um Wiederholung und/oder Variation, wobei meist die ,Einheitsbrei'-Vorwürfe dominieren. ${ }^{4}$ So stellt Richard Kämmerlings unter der titelgebenden Frage, warum Genazino „als bedeutender Autor“ gelte, anlässlich des Erscheinens von Wenn wir Tiere wären (2011) in der Welt fest:

Das Erstaunlichste daran ist, dass Genazino in seinem Leben nur ein einziges Buch geschrieben hat - das freilich immer wieder unter anderem Titel. Sein Evergreen ist eine Geschichte aus dem deprimierenden Alltag eines mittelalten, mittelschlauen, mittelreichen Mannes, der meist zwischen zwei mittelscharfen Frauen und neben sich selbst steht. ${ }^{5}$

Prima facie wertneutral und wohlüberlegt legt Honold diese Debatte bei:

1 Selbst thematisch dessen eigentlich entbehrungsfähige Artikel frönen dem Unterfangen, Schaffensphasen und Zäsuren hinsichtlich ästhetischer, thematischer, erzähltechnischer etc. Aspekte zu postulieren. Diese Lockungen sind durchaus verständlich - ist es doch bei noch lebenden, noch schreibenden und, zumal bei Genazino, vielschreibenden Autoren ein wenig Deutungsmacht, die man sich erschreibt, wenn man ein schlüssiges Früher von späteren Manifestationen abgegrenzt hat.

2 Veritable Brüche die Figurenzeichnung betreffend bzw. die zu führende Diskussion, ob es sich immer wieder um ein und dieselbe Figur handele, sind weiter unten umrissen $(\Rightarrow$ I.2.5); hier geht es tatsächlich um Genazinos bisheriges Romanschaffen insgesamt.

3 Dem bisherigen Algorithmus folgend könnten die nächsten Romanveröffentlichungen 2020, 2022, 2024, 2026 und dann wieder 2029 erfolgen.

$4 \quad$ Vgl. ( $\Rightarrow$ I.2.2) für einen adäquateren Umgang mit wiederkehrenden Elementen.

$5 \quad$ Vgl. Kämmerlings: Genazino gilt als bedeutender Autor. Warum nur? 
Offenbar existieren Anhaltspunkte sowohl für die These der werkchronologischen Kontinuität wie für die Behauptung markanter stilistischer Differenzen innerhalb der Entwicklung dieses Autors. Nach vorherrschender Einschätzung der Literaturkritik gibt es im erzählerischen Werk Wilhelm Genazinos einen deutlichen Bruch zwischen dem in der Abschaffel-Trilogie kulminierenden sozialkritischen Frühwerk und den Prosawerken seit Beginn der neunziger Jahre, die, so der Eindruck, von einer Zurücknahme äußerer Handlungsdynamik und dem ,Weg nach innen' getragen wird. ${ }^{6}$

Und schleust gleichzeitig ein neues Problem mit ein, das vom Holzweg (Einheitsbrei) in eine Sackgasse führt: Ein Weg - wohin auch immer - ist stets deiktisch mit, von irgendwo bis irgendwo hin' konnotiert. Selbst Wanderungen mit Einkehr und Sprüngen über Felskluften oder Gebirgsbäche beginnen irgendwo und enden irgendwo. Hier ist es der Weg nach innen - geläufiger als Zuschreibung an Hermann Hesse -, den Honold im Rückgriff auf Bucheli beobachten zu können glaubt und damit eine wirkmächtige Kontinuität in Genazinos Romanwerk fortschreibt:

Seit gut zehn Jahren hat Genazino in seinem Werk den Weg nach Innen eingeschlagen. Einer entschiedenen Veräußerlichung folgte eine ebenso entschlossene Verinnerlichung. Es wäre dies gewissermaßen die kopernikanische Wende in Genazinos Werk. [...] Mag auch das Thema das gleiche geblieben sein, so hat sich doch die Perspektive gewandelt. ${ }^{7}$

Wenn man - wie Bucheli - mit der ,kosmologischen Kränkung' (Freud) ,die große Keule‘ hervorholt, tut man dies nicht aus Versehen. Allerdings in diesem Fall etwas leichtfertig, da die Umwälzungen eines Kopernikus noch immer Gültigkeit beanspruchen dürfen, wohingegen Genazinos Textproduktion ex post in einem ganz anderen Licht gesehen werden und die proklamierte Wende gar revidiert werden kann. ${ }^{8}$ Genazino selbst trägt daran eine Teilschuld, hat er selbst doch Fährten just in diese ,einseitige Entwicklungs-Richtung gelegt und etwa zwischen Abschaffel und spätere Romane das Auftauchen von Komik und Ironie gesetzt. ${ }^{9}$ Schaut man sich bei diesem, sein eigenes Werk üppig kommentierenden Autor allerdings etwas in seinen Para- und Metatexten um, dann finden sich auch Spuren, die aus der Sackgasse hinausführen.

Bartl und Marx stützen sich nämlich hinwiederum auf andere Selbstaussagen Genazinos und weichen die problematische Vorstellung von Kontinuität respektive einem teleologischen Entwicklungsmodell auf:

Die Tätigkeit des Schriftstellers erinnert an eine stetige „Pendelbewegung“, „eine kryptische Bewegung voller Anfänge, Wiederholungen, Versagungen“. Diese Schwankungen zwischen Gesellschaftskritik und individuell-privater Perspektive, Realität und phantastischen Einschüben, Moderne und Zeitlosigkeit sind niemals konstante Strukturen, vielmehr ein unvorhersehbares Oszillieren mit Stockungen, das auf die Texte abfärbt. ${ }^{10}$

6 Honold: Doppelleben, halbbitter, S. 39.

7 Roman Bucheli: Die Begierde des Rettens. Wilhelm Genazinos Poetik des genauen Blicks. In: Arnold (Hg.): Wilhelm Genazino (2004), S. 46-54, hier S. 48 f.

8 Vgl. für eine Bucheli stützende Einschätzung, die sich allerdings auch am Begriff stößt, Fansa: Unterwegs im Monolog, S. $145 \mathrm{f}$.

9 Vgl. Henke: „Fluktuierende Uneindeutigkeit, S. 70 f.; vgl. Genazino: Melancholische Renitenz.

10 Bartl/Marx: Wiederholte „Verstehensanfänge“, S. 9. Bartl/Marx paraphrasieren mit dem Zitat Genazinos eigenen Beitrag „Der Roman als Delirium“ (vgl. Genazino: Der Roman als Delirium). Genazino hat bereits 2001 in einem Interview von „wellenförmige[n] Bewegungen“ gesprochen: „Es stellt sich eine gewisse Übergeläufigkeit ein, und man wendet sich wieder anderen Formen zu." 
Diese Beobachtung liefert wichtige Impulse: Es gibt keine simple oder vorhersagbare Beständigkeit in Genazinos Romanwerk. Damit ist es auch zumindest höchst fraglich, ob es immer das gleiche Buch ist, das er schreibt. In jedem Fall aber bringen die Autoren den Gedanken auf den Punkt, es bei den Diskontinuitäten mit unterschiedlichen ,Wenden' zu tun zu haben! Das heißt, aus unterschiedlichen Perspektiven kann man clustern; chronologisch durchgängige Linien lassen sich höchstens bezogen auf bestimmte Attribute hin sinnvoll ziehen ( $\Rightarrow$ Tabelle 1). Dieser Komplexität eingedenk hält auch Hirsch fest, dass der „Versuch, die Werke nicht nur in solche vor bzw. nach 1989 einzuteilen, sondern neu zu gruppieren“, helfe, „Grundthemen und Tendenzen der Prosa Genazinos abzustecken."11 Ihr zufolge

stell[e] sich die [...] Gruppierung der Werke als ausgewogenes Dreierverhältnis dar, das die grundlegenden Themen der Prosa absteckt [...]: Die drei frühen Romane, in denen die Grenzen des arbeitenden und in unabänderbare Verhältnisse verstrickten Subjekts aufgezeigt werden und sich die Möglichkeit eines individuellen Weges abseits aller gesellschaftlichen Programme bereits vage andeutet; die eher autobiographisch orientierten Werke, in denen nicht nur Kindheit als Leidenszeit, sondern vor allem das Wunder des Entkommens aus diesen Leidensverhältnissen verhandelt und gleichzeitig dem Schreiben die vordringlich rettende Kraft zugestanden wird; schließlich die Werke, in denen die [...] Tendenz zur Verknappung auch als Schutz vor zudringlicher Wirklichkeitsaneignung auftritt und immer deutlicher hinter der Erzählung der Wunsch nach einem anderen, heimlichen Wissen auftritt, das in keiner Sprache ausdrückbar ist [...]. Erkennbar ist innerhalb dieses Dreierverhältnisses ein ausgesprochenes Gleichgewicht zwischen den beschriebenen Kräften, zwischen Weltvernichtung und Weltverzauberung, Scheitern und Aufbruch, Angst und Lust. ${ }^{12}$

Diese prinzipiell überzeugende Einteilung hat den Vorteil, dass sie induktiv bestimmte dominante Merkmale identifiziert und Gruppen bildet. Allerdings auch hier wieder auf gänzlich unterschiedlichen Ebenen, sodass andere Systematiken des Genazino-Textuniversums zu anderen Grenzziehungen kommen könnten (müssten).

Aufbauend auf der Debatte um Grenzlinien soll der Versuch unternommen werden, einerseits die bereits implizit angesprochenen Kategorien - privat vs. Gesellschaftskritik; Ich- vs. ErErzähler etc. -, andererseits weitere wichtige Merkmale der Romane auf unterschiedlichen Ebenen in den Blick zu nehmen. Und zwar, um einerseits die Vorstellung von allgemeingültigen Zäsuren wie auch Kontinuitäten zu verwerfen - nur bezogen auf einzelne Aspekte sind beide haltbar - und andererseits der Feststellung des Pendelns nachzukommen:13

Tabelle 1: Werkgruppen, Zäsuren und Besonderheiten

\begin{tabular}{|c|c|c|c|c|c|}
\hline Titel (Jahr) & $\begin{array}{c}\text { Form-Ex- } \\
\text { perimente }\end{array}$ & Tempus & $\begin{array}{c}\text { Erzähler- } \\
\text { spezifikati- } \\
\text { onen }\end{array}$ & Sozialkritik & $\begin{array}{c}\text { Stil, inhaltliche } \\
\text { Besonderheiten } \\
\text { etc. }\end{array}$ \\
\hline
\end{tabular}

(Anja Hirsch/Wilhelm Genazino: Die Lust an der komischen Empfindung - Interview am 3. Februar 2001. In: Giesen (Hg.): Wilhelm Genazino (2006), S. 19-27, hier S. 26)

11 Hirsch: „Schwebeglück der Literatur“, S. 15.

12 Hirsch: „Schwebeglück der Literatur“, S. $225 \mathrm{f}$.

13 Zur werkchronologischen Aufschlüsselung nach Figuren vgl. den Anhang ( $\Rightarrow$ V.1).

14 Freilich nur im ,Genazino-internen' Vergleich und also relational zu begreifen - im Vergleich zum Nouveau Roman oder zu Rainald Goetz etwa ist selbst der experimentellste Roman Genazinos konservativ erzählt. 


\begin{tabular}{|c|c|c|c|c|c|}
\hline $\begin{array}{l}\text { Laslinstraße. } \\
\text { Roman } \\
\text { (1965) }\end{array}$ & Hoch & Präteritum & $\begin{array}{l}\text { Ich, männ- } \\
\text { lich, Axel } \\
\text { Degen }\end{array}$ & $\begin{array}{l}\text { Hoch: Antizeit- } \\
\text { geist der ,golde- } \\
\text { nen Fünfziger; } \\
\text { Antikonsum }\end{array}$ & $\begin{array}{c}\text {,Poetischer' als } \\
\text { später; Bewusst- } \\
\text { seinsstrom; } \\
\text { Stimme des Ge- } \\
\text { wissens; Span- } \\
\text { nungsaufbau; } \\
\text { Zielstrebigkeit des } \\
\text { Protagonisten } \\
\end{array}$ \\
\hline \multicolumn{6}{|c|}{ Genaugenommen erste Zäsur: Ich zu Er; freie Form (auch in Satzstrukturen etc.) wird konservativ } \\
\hline $\begin{array}{l}\text { Abschaffel. } \\
\text { Roman } \\
\text { (1977) }\end{array}$ & Gering & Präteritum & $\begin{array}{l}\text { Er (intern, } \\
\text { selten extern } \\
\text { fokalisiert), } \\
\text { männlich, } \\
\text { Abschaffel } \\
\end{array}$ & $\begin{array}{l}\text { Durchschnitt: } \\
\text { Anti- } \\
\text { Angestellten- } \\
\text { milieu }\end{array}$ & $\begin{array}{l}\text { Langeweile; Bü- } \\
\text { rotristesse; Vor- } \\
\text { würfe an Eltern; } \\
\text { Pessimismus }\end{array}$ \\
\hline $\begin{array}{l}\text { Die Vernich- } \\
\text { tung der Sor- } \\
\text { gen. Roman } \\
(1978)\end{array}$ & Gering & Präteritum & $\begin{array}{l}\text { Er, männlich, } \\
\text { Abschaffel }\end{array}$ & $\begin{array}{l}\text { Mittel: Anti- } \\
\text { Erlebnisgesell- } \\
\text { schaft }\end{array}$ & $\begin{array}{l}\text { Vorausdeutung } \\
\text { auf späteren Kör- } \\
\text { perteilzerfall und } \\
\text {-verlust; Ver- } \\
\text { rücktheit nimmt } \\
\text { zu }\end{array}$ \\
\hline $\begin{array}{l}\text { Falsche Jahre. } \\
\text { Roman } \\
\text { (1979) }\end{array}$ & Gering & Präteritum & $\begin{array}{l}\text { Er (temporä- } \\
\text { rer Switch } \\
\text { zum Ich), } \\
\text { männlich, } \\
\text { Abschaffel }\end{array}$ & Gering & $\begin{array}{l}\text { Klinikaufenthalt; } \\
\text { Besänftigung } \\
\text { durch Sport; ver- } \\
\text { söhnliches Ende }\end{array}$ \\
\hline $\begin{array}{c}\text { Die Aus- } \\
\text { schweifung. } \\
\text { Roman } \\
(1981)\end{array}$ & $\begin{array}{l}\text { Gering: Strin- } \\
\text { gent und tradi- } \\
\text { tionell erzählt }\end{array}$ & Präteritum & $\begin{array}{l}\text { Er, männlich, } \\
\text { Eckhard } \\
\text { Fuchs }\end{array}$ & $\begin{array}{l}\text { Durchschnitt: } \\
\text { Leistungsgesell- } \\
\text { schaft in der } \\
\text { Kritik }\end{array}$ & $\begin{array}{l}\text { Frau und Kind; } \\
\text { relative Rundheit } \\
\text { der Nebenfiguren; } \\
\text { vergleichsweise } \\
\text { versöhnlicheres } \\
\text { Ende }\end{array}$ \\
\hline $\begin{array}{l}\text { Fremde } \\
\text { Kämpfe. Ro- } \\
\text { man (1984) }\end{array}$ & Gering & Präteritum & $\begin{array}{l}\text { Er, männlich, } \\
\text { Wolf Peschek }\end{array}$ & $\begin{array}{l}\text { Hoch: Harsche } \\
\text { Systemkritik, } \\
\text { Zukunftsangst }\end{array}$ & $\begin{array}{c}\text { Handlungs- und } \\
\text { temporeich, trost- } \\
\text { loses Ende; inne- } \\
\text { rer Mono- } \\
\text { log/mitunter Be- } \\
\text { wusstseinsstrom; } \\
\text { englischsprachige } \\
\text { Ausdrücke; sexu- } \\
\text { elle Überforde- } \\
\text { rung } \\
\end{array}$ \\
\hline \multicolumn{6}{|c|}{ „Kopernikanische Wende“15 vs. „Verschiebung“ ${ }^{\prime 16}$} \\
\hline $\begin{array}{l}\text { Der Fleck, die } \\
\text { Jacke, die } \\
\text { Zimmer, der } \\
\text { Schmerz. Ro- } \\
\text { man (1989) }\end{array}$ & $\begin{array}{l}\text { Hoch: Viel wei- } \\
\text { ßer Platz auf } \\
\text { Seite, fünf rö- } \\
\text { mische Ab- } \\
\text { schnitte, riesige } \\
\text { Absätze }\end{array}$ & Präsens & $\begin{array}{l}\text { Ich, männ- } \\
\text { lich, W. }\end{array}$ & $\begin{array}{l}\text { Gering: Durch } \\
\text { elitäre Kreise } \\
\text { Distanz von der } \\
\text { Gesellschaft }\end{array}$ & $\begin{array}{c}\text { Wenig gesproche- } \\
\text { ne Sprache; Text- } \\
\text { gattung ,Brief' } \\
\text { taucht erstmals } \\
\text { auf }\end{array}$ \\
\hline $\begin{array}{l}\text { Die Liebe zur } \\
\text { Einfalt. Ro- } \\
\text { man (1990) }\end{array}$ & $\begin{array}{l}\text { Hoch: Erinne- } \\
\text { rungsbilder } \\
\text { formal vom } \\
\text { Fließtext ge- } \\
\text { trennt, } \\
\text { manchmal nur } \\
\text { einzeilig }\end{array}$ & Präsens & $\begin{array}{l}\text { Ich, männ- } \\
\text { lich, ,William' } \\
\text { Genazino }\end{array}$ & $\begin{array}{l}\text { Durchschnitt: } \\
\text { Weniger System } \\
\text { als mangelnder } \\
\text { Aufstieg steht in } \\
\text { der Kritik }\end{array}$ & $\begin{array}{c}\text { Handlungsärms- } \\
\text { ter Roman; auto- } \\
\text { biografische Züge; } \\
\text { Elterninvestigati- } \\
\text { on; viel Selbstref- } \\
\text { lexivität }\end{array}$ \\
\hline
\end{tabular}




\begin{tabular}{|c|c|c|c|c|c|}
\hline $\begin{array}{l}\text { Leise singen- } \\
\text { de Frauen. } \\
\text { Roman } \\
(1992)\end{array}$ & $\begin{array}{c}\text { Hoch: } 26 \\
\text { Schnipsel, die } \\
\text { nur lose aufei- } \\
\text { nander aufbau- } \\
\text { en; sehr lang }\end{array}$ & $\begin{array}{l}\text { Wechsel } \\
\text { von Präteri- } \\
\text { tum und } \\
\text { Präsens }\end{array}$ & $\begin{array}{l}\text { Ich, männ- } \\
\text { lich, namen- } \\
\text { los }\end{array}$ & $\begin{array}{l}\text { Gering: Keine } \\
\text { finanziellen Sor- } \\
\text { gen }\end{array}$ & $\begin{array}{l}\text { Heiter und unbe- } \\
\text { schwert in Form } \\
\text { und Inhalt }\end{array}$ \\
\hline $\begin{array}{l}\text { Die Obdach- } \\
\text { losigkeit der } \\
\text { Fische (1994) }\end{array}$ & $\begin{array}{l}\text { Hoch: Flatter- } \\
\text { satz, Brücken- } \\
\text { schläge über } \\
\text { Absätze hin- } \\
\text { weg, drei Erin- } \\
\text { nerungsblöcke }\end{array}$ & Präsens & $\begin{array}{l}\text { Ich, weiblich, } \\
\text { namenlos }\end{array}$ & $\begin{array}{l}\text { Durchschnitt: } \\
\text { Schulsystem in } \\
\text { der Kritik }\end{array}$ & $\begin{array}{l}\text { Äußerst melan- } \\
\text { cholischer Ton bei } \\
\text { gleichzeitig über- } \\
\text { raschend positi- } \\
\text { vem Ende }\end{array}$ \\
\hline $\begin{array}{c}\text { Das Licht } \\
\text { brennt ein } \\
\text { Loch in den } \\
\text { Tag (1996) }\end{array}$ & $\begin{array}{l}\text { Hoch: Brief- } \\
\text { form als Neue- } \\
\text { rung; } 115 \mathrm{Ab}- \\
\text { schnitte (Brie- } \\
\text { fe, Notate, Er- } \\
\text { zählungen etc.) } \\
\text { auf } 125 \text { Seiten }\end{array}$ & Präsens & $\begin{array}{l}\text { Ich, männ- } \\
\text { lich, W. }\end{array}$ & Gering & $\begin{array}{c}\text { Erinnerungsver- } \\
\text { lust wird erstma- } \\
\text { lig thematisiert; } \\
\text { offenes Ende, } \\
\text { allerdings mit } \\
\text { versöhnlichem } \\
\text { Brief }\end{array}$ \\
\hline \multicolumn{6}{|c|}{$\begin{array}{c}\text {,Ptolemäische Wende': Experimentelle Form wird erneut zurückgefahren; die Ich-Erzähler werden } \\
\text { in der Tendenz namenlos! }{ }^{17}\end{array}$} \\
\hline $\begin{array}{l}\text { Die Kassiere- } \\
\text { rinnen. Ro- } \\
\text { man (1998) }\end{array}$ & $\begin{array}{c}\text { Durchschnitt: } \\
\text { Unnummeriert, } \\
\text { aber typogra- } \\
\text { fisch klar er- } \\
\text { kennbare } 15 \\
\text { „szenische' } \\
\text { Abschnitte }\end{array}$ & Präteritum & $\begin{array}{l}\text { Ich, männ- } \\
\text { lich, namen- } \\
\quad \text { los }\end{array}$ & Gering & $\begin{array}{c}\text { Versöhnlicher } \\
\text { Ton; expliziter als } \\
\text { vorher (Stil); Be- } \\
\text { obachtetwerden } \\
\text { ist ,neu'; erstmalig } \\
\text {,Therapeuten- } \\
\text { funktion' }\end{array}$ \\
\hline $\begin{array}{l}\text { Ein Regen- } \\
\text { schirm für } \\
\text { diesen Tag. } \\
\text { Roman } \\
\text { (2001) }\end{array}$ & $\begin{array}{l}\text { Gering: Elf } \\
\text { nummerierte } \\
\text { Abschnitte, } \\
\text { konventionell } \\
\text { erzählt }\end{array}$ & Präsens & $\begin{array}{l}\text { Ich, männ- } \\
\text { lich, namen- } \\
\text { los }\end{array}$ & $\begin{array}{l}\text { Mittel: Existenz- } \\
\text { probleme, Wirt- } \\
\text { schaftskrise, } \\
\text { Erlebnis- } \\
\text { gesellschafts- } \\
\text { kritik }\end{array}$ & $\begin{array}{l}\text { Gedehnter Blick } \\
\text { (Kindler); viel } \\
\text { Komik; weg von } \\
\text { Ausgeglichenheit; } \\
\text { Verrücktheit } \\
\text { nimmt zu; erst- } \\
\text { mals ,Leseran- } \\
\text { sprachen' }\end{array}$ \\
\hline $\begin{array}{c}\text { Eine Frau, } \\
\text { eine Woh- } \\
\text { nung, ein Ro- } \\
\text { man (2003) }\end{array}$ & $\begin{array}{l}\text { Gering: Form } \\
\text { ist gefunden: } \\
\text { Nummerierung } \\
\text { der acht } \mathrm{Ab}- \\
\text { schnitte }\end{array}$ & Präteritum & $\begin{array}{l}\text { Ich, männ- } \\
\text { lich, Weigand }\end{array}$ & $\begin{array}{l}\text { Mittel: Angestell- } \\
\text { te vs. Arbeiter; } \\
\text { Anti- } \\
\text { Spaßgesellschaft }\end{array}$ & $\begin{array}{c}\text { Gedehnter Blick } \\
\text { (Kindler); erwar- } \\
\text { tungsvolles Ende; } \\
\text {,Entwicklungs- } \\
\text { roman' } \\
\end{array}$ \\
\hline $\begin{array}{l}\text { Die Liebes- } \\
\text { blödigkeit. } \\
\text { Roman } \\
\text { (2005) }\end{array}$ & $\begin{array}{l}\text { Gering: } 11 \\
\text { Kapitel }\end{array}$ & Präsens & $\begin{array}{l}\text { Ich, männ- } \\
\text { lich, namen- } \\
\text { los }\end{array}$ & Gering & $\begin{array}{l}\text { Gedehnter Blick } \\
\text { (Kindler); ver- } \\
\text { söhnlicher Ab- } \\
\text { schluss; Hand- } \\
\text { lungsreichtum; } \\
\text { Akademiker }\end{array}$ \\
\hline
\end{tabular}

17 Melanie Fischer schlägt vor, die Namenlosigkeit auch darüber zu erklären, dass die Dinge „sprichwörtlich zu Titelhelden [...] avancieren“ (Fischer 2004, S. 122), wohingegen die Personen - wie im Nouveau Roman - verschwinden (vgl. Fischer 2006, S. 9). 


\begin{tabular}{|c|c|c|c|c|c|}
\hline $\begin{array}{l}\text { Mittelmäßi- } \\
\text { ges Heimweh. } \\
\text { Roman } \\
(2007)\end{array}$ & $\begin{array}{l}\text { Gering: } 11 \\
\text { Kapitel }\end{array}$ & Präsens & $\begin{array}{l}\text { Ich, männ- } \\
\text { lich, Dieter } \\
\text { Rotmund }\end{array}$ & $\begin{array}{l}\text { Gering: Probleme } \\
\text { im Privaten zu } \\
\quad \text { finden }\end{array}$ & $\begin{array}{l}\text { Gedehnter Blick } \\
\text { (Kindler); ,fantas- } \\
\text { tischer' Ohrver- } \\
\text { lust und Verlust } \\
\text { des kleinen Zehs; } \\
\text { Frau und Kind; } \\
\text { Akademiker; } \\
\text { erstmals Brust- } \\
\text { verlust; offenes } \\
\text { Ende mit Ausblick } \\
\text { auf Katastrophe }\end{array}$ \\
\hline $\begin{array}{l}\text { Das Glück in } \\
\text { glücksfernen } \\
\text { Zeiten. Ro- } \\
\text { man (2009) }\end{array}$ & $\begin{array}{l}\text { Gering: } 11 \\
\text { Kapitel (in } \\
\text { Buchstaben- } \\
\text { form) }\end{array}$ & Präsens & $\begin{array}{l}\text { Ich, männ- } \\
\text { lich, Gerhard } \\
\text { Warlich }\end{array}$ & $\begin{array}{l}\text { Durchschnitt: } \\
\text { Kritik der Leis- } \\
\text { tungsgesellschaft }\end{array}$ & $\begin{array}{c}\text { Figur stellt sich } \\
\text { selbst dem Leser } \\
\text { in Ich-Form vor; } \\
\text { Psychiatrie nach } \\
\text { lange währenden } \\
\text { kleinen Verrückt- } \\
\text { heiten; Ende in } \\
\text { Klinik }\end{array}$ \\
\hline \multicolumn{6}{|c|}{$\begin{array}{c}\text { Wegfall (bis auf Tiere und Außer uns) bzw. Unwichtigkeit des Titelbezugs; Tendenz zu auffälligen } \\
\text { Redundanzen; Anstrich der Unfertigkeit: Entweder beginnender Gedächtnisverlust der Figuren } \\
\text { oder schlecht redigiert? }{ }^{18} \text { Außerdem vermehrt Todesvorahnungen etc. }\end{array}$} \\
\hline $\begin{array}{c}\text { Wenn wir } \\
\text { Tiere wären. } \\
\text { Roman } \\
(2011)\end{array}$ & $\begin{array}{l}\text { Gering: } 10 \\
\text { Kapitel }\end{array}$ & $\begin{array}{l}\text { Präteritum } \\
\text { (durch } \\
\text { Präsens } \\
\text { unterbro- } \\
\text { chen) }\end{array}$ & $\begin{array}{l}\text { Ich, männ- } \\
\text { lich, namen- } \\
\quad \text { los }\end{array}$ & Gering & $\begin{array}{c}\text { Devianz (Aus- } \\
\text { weisbetrug) mit } \\
\text { Gefängnis; nicht } \\
\text { nur offenes Ende, } \\
\text { sondern auch } \\
\text { Verwirrung und } \\
\text { nicht ansatzweise } \\
\text { zu Ende erzählte } \\
\text { Narrationsfäden } \\
\end{array}$ \\
\hline $\begin{array}{l}\text { Bei Regen im } \\
\text { Saal. Roman } \\
\quad(2014)\end{array}$ & $\begin{array}{l}\text { Gering: } 12 \\
\text { Kapitel }\end{array}$ & Präteritum & $\begin{array}{l}\text { Ich, männ- } \\
\text { lich, Reinhard }\end{array}$ & $\begin{array}{l}\text { Durchschnitt: } \\
\text {,Warenverteufe- } \\
\quad \text { lung' }\end{array}$ & $\begin{array}{c}\text { Promovierter } \\
\text { Akademiker; } \\
\text { Dopplungen in } \\
\text { Formulierungen } \\
\text { etc. } \\
\end{array}$ \\
\hline $\begin{array}{c}\text { Außer uns } \\
\text { spricht nie- } \\
\text { mand über } \\
\text { uns. Roman } \\
(2016)\end{array}$ & $\begin{array}{l}\text { Gering: } 12 \\
\text { Kapitel fast } \\
\text { gleicher Länge }\end{array}$ & Präteritum & $\begin{array}{l}\text { Ich, männ- } \\
\text { lich, namen- } \\
\quad \text { los }\end{array}$ & $\begin{array}{l}\text { Gering: Ich inte- } \\
\text { ressiert sich } \\
\text { nicht (mehr) für } \\
\text { Umgebung }\end{array}$ & $\begin{array}{l}\text { Blasse Figur; } \\
\text { Selbstmord der } \\
\text { Freundin; Fehlge- } \\
\text { burt und Alkoho- } \\
\text { lismus; wechseln- } \\
\text { de Zeitebenen } \\
\text { bzw. keine klare } \\
\text { Erzählgegenwart; } \\
\text { Gedächtnisver- } \\
\text { lust; ,Leseran- } \\
\text { sprachen' errei- } \\
\text { chen neuen Höhe- } \\
\text { punkt; düsterer } \\
\text { Schluss }\end{array}$ \\
\hline
\end{tabular}




\begin{tabular}{|c|c|c|c|c|c|}
\hline $\begin{array}{c}\text { Kein Geld, } \\
\text { keine Uhr, } \\
\text { keine Mütze. } \\
\begin{array}{c}\text { Roman } \\
(\mathbf{2 0 1 8 )}\end{array}\end{array}$ & $\begin{array}{c}\text { Gering: } 12 \\
\text { Kapitel fast } \\
\text { gleicher Länge }\end{array}$ & Präteritum & $\begin{array}{c}\text { Störende Redun- } \\
\text { danzen und Kon- } \\
\text { struktionsfehler: } \\
\text { Vergesslichkeit } \\
\text { steigert sich zur } \\
\text { Demenz; doppel- } \\
\text { Ich, männ- } \\
\text { lichen- } \\
\text { los }\end{array}$ & $\begin{array}{c}\text { Gering: Ich inte- } \\
\text { ressiert sich } \\
\text { überhaupt nicht } \\
\text { mehr für irgend- } \\
\text { was }\end{array}$ & $\begin{array}{c}\text { Freundin; Todes- } \\
\text { vorbereitungen; } \\
\text { Bibelallusionen; } \\
\text { Selbstmord }\end{array}$ \\
\hline
\end{tabular}

Hirschs Gruppe 1: „autobiographisch orientierter Block“.19 Die Romane

sind geprägt von der Zeit der 50er und 60er Jahre und dem Ende der Adenauer-Ära. Sie zeigen die Sicht des Gymnasiasten (in „Laslinstraße"), die Sicht des endlich den kleinbürgerlichen Verhältnissen entronnenen Lehrlings und angehenden Schreibenden, der auf raffinierte Weise sein Doppelleben organisiert (in „Eine Frau, eine Wohnung, ein Roman“) und die Perspektive des reifen Erwachsenen in „Die Liebe zur Einfalt", das intime Zeugnis einer von Armut und Beschränkung geprägten Mannheimer Kindheit. ${ }^{20}$

Hirschs Gruppe 2: „die frühen, auch zeitlich zusammenhängend erscheinenden Angestelltenund Freiberuflerromane“.21 „Alle drei [Hirsch zählt die Abschaffel-Trilogie nur einfach; N. L.] sind spürbar motiviert vom soziologisch neugierigen Blick auf gesellschaftliche Missstände und deren Auswirkungen auf das in jeder Hinsicht scheiternde Subjekt“. ${ }^{22}$

Hirschs Gruppe 3: „Verdichtung, Verknappung“.23 „Wesentliche Details werden aus dem jeweils zur Verfügung stehenden visuellen Bild herausgebrochen, mit Bedeutung aufgeladen und in ein Gedankenspiel verwickelt."24

Kindler-Gruppierung: „In seiner reifen Prosa des ,gedehnten Blicks‘ knüpft Genazino in Duktus und Ton wieder stärker an die Abschaffel-Studie an und begleitet mit liebevoll-ironischer Genauigkeit Männer bei der Bewältigung ihres meist ziemlich banalen und von Enttäuschungen bestimmten Alltagslebens“. ${ }^{25}$

Das Hauptanliegen dieser Gegenüberstellung bisheriger Ordnungssysteme steht zugegebenermaßen nur bedingt im Dienst der besseren Übersichtlichkeit. Vielmehr möchte sie dafür sensibilisieren, skeptisch zu bleiben. So wird bereits am Widerspruch zwischen den Ordnungssystemen Hirschs und van Hoorns deutlich, dass es nicht die eine Lösung gibt; so müsste man der proklamierten kopernikanischen Wende mindestens eine ,ptolemäische' zur Seite stellen, wird doch die experimentelle Form zwischen 1996 und 1998 stark zurückgefahren. Das berücksichtigt auch die Kindler-Gruppierung nicht angemessen, zumal die erstmalige Namenlosigkeit der Ich-

\footnotetext{
19 Hirsch: „Schwebeglück der Literatur“, S. 15.

20 Hirsch: „Schwebeglück der Literatur“, S. 15.

21 Hirsch: „Schwebeglück der Literatur“, S. 16.

22 Hirsch: „Schwebeglück der Literatur“, S. 16.

23 Hirsch: „Schwebeglück der Literatur“, S. 17.

24 Hirsch: „Schwebeglück der Literatur“, S. 17.

25 Hoorn: [Genazino, Wilhelm].
} 
28 - Teil I: Grundlagen 2. Wilhelm Genazinos Romanfiguren und ,Figurenromane‘

Erzähler ein verbindendes Glied schafft. Apropos Ich-Erzähler: Diese sind für Genazino keineswegs erst seit der großen Verschiebung neu. Bereits sein nicht nur von der Forschung stiefmütterlich behandelter Erstling hatte einen Ich-Erzähler, sodass genaugenommen bereits zwischen diesem und Hirschs Gruppe 2 - die noch am ehesten eine konsensuelle Kleingruppe definiert eine Zäsur zu setzen wäre. Unbestreitbar bilden auch die mit deutlich blasseren Figuren arbeitenden Romane ab 2011 eine eigenständige Gruppe: der Wegfall bzw. die Unwichtigkeit des Titelbezugs, die Tendenz zu auffälligen Redundanzen und der Anstrich der Unfertigkeit sind hervorstechende Merkmale, die sie von früheren Romanen unterscheiden. Aber es ließen sich weitaus mehrere solche Pakete schnüren und (gut) begründen. So bleibt festzuhalten, dass all den bisher beschriebenen Entwicklungen, Kohärenzen und Zäsuren argumentativ entwaffnend entgegnet werden kann, sodass es letztlich vielleicht gar besser wäre, alle Wenden und Verlaufspläne zu Gunsten der Oszillation wieder im ,Argumentenschrank' zu verstauen. ${ }^{26}$

Ein zweiter Verstehens-Anlauf in dieselbe Richtung - die einer begehbaren Landkarte von Genazinos Romanwelten - scheint ergiebiger zu sein. Er führt über Genazinos poetisches Prinzip, das hier als ,Mischpult-Verfahren' bezeichnet werden soll.

\subsection{Zwischen Induktion und Deduktion I: Musterhaftes Mischpult-Verfahren}

Was hat ein Mischpult mit der Romankonzeption Genazinos zu tun? Freilich wäre es zu schlicht gedacht, Genazinos Romane - bzw. deren Haupthandelnde ( $\Rightarrow$ I.2.5) - aufgrund von ähnlicher Gestaltung bzw. wiederkehrenden Mustern etc. als Einerlei anzusehen und demgemäß en bloc abzuhandeln. Gerade die Spezifik der jeweils gegebenen sozioökonomischen und figurenkonstellativen Panoramen sträubt sich gegen einen solchen Zugriff. Gravierender noch muss die narratologische Inkommensurabilität genannt werden $(\Rightarrow$ I.2.1 u. $\Rightarrow$ I.2.3): Abschaffel, den Protagonisten derjenigen ,Trilogie' der 1970er Jahre, die Genazino bekannt machte, lernt der Leser als Er-, die neueren (und den ältesten) Romanhelden als Ich-Erzähler kennen. Eine die Regel bestätigende Ausnahme einer weiblichen Hauptfigur in Genazinos Die Obdachlosigkeit der Fische macht eine solche Einschätzung ebenso obsolet $(\Rightarrow$ I.2.5) wie mitunter auftretende Passagen unzuverlässigen Erzählens ( $\Rightarrow$ I.2.3).

Dennoch folgt Genazino faktisch und unbestreitbar einer Art transtextuellem Kompositionsprinzip, was seine Texte betrifft, und zwar in mindestens dreierlei Hinsicht: Seinen Erzähler lässt er erstens die Figuren in bis aufs I-Tüpfelchen ähnliche Situationen schicken und auch bestimmte Elemente, Motive, Situationen und Narrative ,transtextualisieren' durch alle einundzwanzig Ro- 
mane. Ein eigener Index der Querverweise und Wiederaufnahmen ließe sich gewinnbringend erstellen. ${ }^{27}$ Anhand des Beispiels ,Fernsehen' lässt sich dieses Prinzip illustrieren:

Als Abschaffel sie sah, wandelte sich seine Enttäuschung in Hohn um. Diese Fernsehkrüppel, diese elenden [...]. [P]lötzlich sehnte er sich danach, einen WUTSTEMPEL zu besitzen, ein klobiges, rundes Holzding [...], und mit diesem Wutstempel würde er alles abstempeln, was seine Wut hervorrief: zuallererst [...] die Fernsehsendungen [...]. Oder sollte er [...] einfach das Fernsehen verbieten? Aber vermutlich hätte sie nicht verstehen können, wenn er nun geschimpft hätte. [...] Bei Traudel halte ich es oft nur aus, weil ich (gegen meinen Willen) lange fernsehe. [...] Ich schaue mir fast alles an, was lange dauert, Boxkämpfe, Reitturniere, Diskussionen. [...] Das Fernsehen nützt die Not der Menschen skrupellos aus. Meine Zwiespältigkeit macht mir das Fernsehen besonders verhaßt. [...] Ich hoffte, Carola werde bald bemerken, dass ich auf sie wartete. Aber sie saß vor dem Fernsehapparat [...]. Meine Stimmung rutschte in einen nie gesehenen Keller. [...] Vielleicht bricht die allgemeine Zufriedenheit aus, wenn wir erst Bewohner von Fernsehstudios geworden sind. Im dritten Programm führt ein Moderator die ,Mitglieder einer Seniorengruppe'vor, unauffällige Menschen in Freizeitjacken und Sportkostümen, die nur eines wollen: Genugtuung herzeigen. Für eine halbe Stunde hat sich ihr Leben in eine Live-Übertragung verwandelt! Sie bewundern die Nettigkeit des Moderators, die draußen im Leben nicht vorkommt, sie nicken und schauen in ihre Orangensaftgläser, sie haben die Hände im Schoß und freuen sich still wie endlich ins Ziel eingelaufene Glückssucher. [...] Und immer gibt es jemanden, der den einzigen Fehler macht - und winkt. Für eine Sekunde kippt die Stummheit ins Bild und wird Programm. Schon ist die Kamera wieder auf den trainierten Gesichtern der Berufsdarsteller. Wer winkt, hat die Grunddifferenz nicht verstanden. Diesmal war es eine überschwenglich geschminkte Frau mit üppiger Frisur und großen Ohrringen. Es hat alles nichts genutzt. Die Kamera bestraft sie mit einer Totalen. Jetzt sehen wir sie wieder zurückversetzt ins große Publikum. Klein gemacht wie ein Spieltierchen sitzt sie da und tut, was sie gelernt hat: gucken. [...] Die Unterhaltungsmaschine des Fernsehens erinnert mich an meinen Friseur. Auch der Friseur kann die Leute, die in seinen Laden kommen, nicht unterhalten, obwohl er das gerne können möchte. Aber beide, der Friseur und das Fernsehen, hören nicht auf mit ihrem NichtKönnen. [...] Später, während des Philosophiestudiums, nannte ich das Lächeln der Mutter (mit Kant) das Naturschöne, das Fernsehen nannte ich (mit Hegel) den Schein des Wirklichen und das Gesäusel der Filmhelden nannte ich (mit Heidegger) das Gerede des Man. [...] In Wahrheit verwinde ich Schmerz, wenn ich abends vor dem Gerät sitze. Da ich immer weniger weiß, wonach ich mich sehnen soll (ist gar nicht wahr), verwandelt sich die zukunftslose Sehnsucht immer öfter in Wehmut. [...] Ich würde mich jetzt gerne zerstreuen, aber es gilt zwischen uns als unfein, nach einem Beischlaf den Fernsehapparat einzuschalten. [...] Es ist Spätnachmittag, ich schalte den Fernsehapparat ein. Auf dem Bildschirm erscheinen ein Interviewer und ein bekannter TV-Unterhalter [...]. [...] Ich gehe auf den Fernsehapparat zu und schaue höhnisch auf ihn herunter. [...] Vater hatte sich eine Angewohnheit zugelegt, die ihn zugleich lächerlich machte. Er hielt Menschen, die im Fernsehen auftraten, für so bedeutsam, daß er ihren Sätzen bekräftigend nachnickte. [...] Das laufende Gerät war das Eingeständnis, dass aus unserer Familie eine Art Notwehrverein geworden war, der mit sich allein nicht mehr weiterkam. Ich selbst war ein intimer Nutznießer des Fernsehens; da fast alle auf den Bildschirm starrten, blieb meine Scham unentdeckt.

Um dieses Zitat als montiertes zu erkennen, bedarf es - wenn man den Wandel vom Er- zum Ich-

Erzähler und die wechselnden Frauennamen großzügig ,überliest ${ }^{\prime}$ - profunder Textkenntnis: Elf

Besonders apart ist die Möglichkeit, anhand älterer Texte die Titelgebung neuerer vorskizziert finden zu können: „Tarzan am Main“ etwa findet sich bereits in der Vernichtung der Sorgen, wenn davon geträumt wird, „den Beruf Tarzan“ zu ergreifen (Sorgen, S. 185). Auch die vorausdeutende Nennung bestimmter Gegenstände, die später in einem Roman eine zentrale Rolle spielen sollen, ist damit zu verbinden: Teure Schuhe als symboltragende Gegenstände tauchen bereits in der Ausschweifung auf (vgl. Ausschweifung, S. 51 f.), bevor sie als italienische in Fremde Kämpfe wieder eine Rolle spielen, um im Roman Ein Regenschirm für diesen Tag dominant zu werden. Die extraordinären Berufe finden sich erstmals in den Kassiererinnen, S. 104 f. Vgl. für eine frappierende Häufung angespielter Titel auch: „Es gab kaum einen leeren Fleck in diesem Schaufenster. Auf eng stehenden Regalen waren die Schuhe neben- und übereinander angeordnet wie herabstürzende Fische" (Falsche Jahre, S. 443). 
30 - Teil I: Grundlagen 2. Wilhelm Genazinos Romanfiguren und ,Figurenromane‘

Romane Genazinos liefern hier einen Beitrag. ${ }^{28}$ Es ließe sich zu fast allen wiederkehrenden Elemente - hier: Fernsehen, Fernsehkonsum und Fernseh(konsum)kritik - eine solche Zusammenstellung anfertigen. In allen elf Romanen ist, um die Mischpult-Metapher aufzugreifen, folglich das Element ,Fernsehen' hochgeregelt worden. Zweitens: Auch die Figuren selbst gleichen sich zwar definitiv nicht wie ein Ei dem anderen ( $\Rightarrow I .2 .5)$, doch manche inneren Befindlichkeiten, Marotten und Charaktereigenschaften teilen sie sehr wohl $(\Leftrightarrow$ II.1.3). Als dritte Vergleichsgrundlage über die Romangrenzen hinweg lässt sich der Themenkomplex der figürlichen Verhaltensstrategien heranziehen, die in ähnlichen Situationen meist ähnliche sind, um bestimmten kommunikativen Herausforderungen zu begegnen.

Insofern muss die Einleitungs-eingangs gestellte Frage, wieso man einer Geschichte folge, deren Ingredienzien wohl bekannt seien, neu perspektiviert werden: Zwar gilt nicht die Einschätzung „Kennst du einen, kennst du alle - weder auf Histoire- noch auf Discours-Level, weder auf den Plot noch auf die Figuren bezogen -, wohl aber die Beobachtung, dass Bausteine von Figurenmerkmalen, Handlungsroutinen, Nebenfigurskizzen usw. usf. existieren, die - wiewohl kunstvoll und je neu apart - immer wieder neu arrangiert werden. ${ }^{29}$

Ausgehend von dieser abduktiven Mustererkennung ist das hier verfolgte Vorgehen (zunächst) induktiver Natur gewesen $(\Rightarrow$ I.5.1): Auf Basis der Genazino'schen Einzeltexte und unter Berücksichtigung der maßgeblichen Sekundärliteratur konnten häufig wiederkehrende Elemente, Motive und Situationen identifiziert werden, als da wären (in Auswahl): Jahrmarktbesuche, Frauenbekanntschaften, Überempfindlichkeit, Ekel, Kleidung (kaufen/testen), Dinge, Unentschlossenheit, Scham, Verrücktheit ${ }^{30}$, Tiere, Sex, Dünkel bzw. Überheblichkeit, Bescheidenheit bzw. Bedürfnislosigkeit, Besänftigung bzw. Beruhigung und Trost, Marotten, Merkwürdigkeiten und Eigenarten, Verwahrlosung usw. Dementsprechend hält auch Fansa fest, dass es - in summa -

eine starke Kontinuität der Themen- und Motivkomplexe in der Prosa Wilhelm Genazinos gibt, denn die Erzähltexte - und mit ihnen ihre Protagonisten - arbeiten sich immer wieder an denselben oder an zumindest einander stark verwandten Komplexen ab (das Chaos, der Staub, die Unordnung, die Scharlatanerie, das Erinnern an Eltern und eigene Kindheit, das Verstehen und Nichtverstehen, die Post, der Brief, die Schuhe, die Sing- und Stadtvögel usw.). ${ }^{31}$

$28 \quad$ Abschaffel, S. 216; Fremde Kämpfe, S. 57; Ausschweifung, S. 41; Glück, S. 112; Außer uns, S. 7; Frauen, S. 151 f.; Glück, S. 46; Glück, S. 82; Heimweh, S. 117; Glück, S. 31; Licht, S. 37; Liebesblödigkeit, S. 70; Einfalt, S. 39; Regen, S. 146.

Überzufällig häufig liefert bereits Die Vernichtung der Sorgen den Steinevorrat bspw. bezogen auf ,Körperzerfall' (vgl. Sorgen, S. 383 u. S. 387), Tierseinwollen (Sorgen, S. 356), Verrücktheit (Sorgen, S. 391) usw.

30 Verrücktheit wird immer wieder thematisiert (vgl. Marx: Erzählfiguren der Verrückung, S. 62 f.) und an einer Stelle sogar herbeigesehnt: „Ich stelle mir gern ein gespieltes Verrücktsein vor, das mir helfen soll, unangefochten zu leben. Zuweilen, für Minuten nur, sollte das gespielte Verrücktsein in ein echtes übergehen und meine Distanz zur Wirklichkeit vergrößern." (Regenschirm, S. 94 f.) Neben der Distanz zur Wirklichkeit ist es teils auch der Wunsch, sich der eigenen ,Normalität' zu vergewissern, die im direkten Vergleich mit den ,auffälligen Verrückten' möglich wird (vgl. Kein Geld, S. 68).

31 Fansa: Unterwegs im Monolog, S. 145. 
Hier wird deutlich, dass es eine riesige, offensichtlich zudem höchst subjektive Palette gibt auch die forcierteste Aufleitung ist immer bereits von vagen Erkenntnisinteressen durchsetzt.

Da man selbstredend einwenden kann, dass es auch abseits von Genazinos Romanwerk Konvolute anderer Autoren gibt, die wiederkehrende Motivreihen aufweisen, bei denen etwa Sex - und selbst die Verbindung von Sex und IM im weitesten Sinne - eine Rolle spielt, muss darauf hingewiesen werden, dass es nicht nur die Elemente, Situationen und Motive eo ipso sind, welche das Genazino-Spezifikum ausmachen. Vielmehr ist es die jeweilige Modulation bzw. die Verschränkung verschiedener Bausteine: Fernsehen kommt ohne die (Kultur-)Kritik nicht aus; Sex findet bei Genazino regelmäßig nur mit Ekelassoziationen oder in Verbindung mit der Poetik antiemotionalen Erzählens statt ( $\Rightarrow$ II.5.6); Kleidung wird permanent mit Verwahrlosung und dem gescheiterten Neukauf in Verbindung gebracht und Tiere sind selten einfach nur Tiere, sondern zumeist mit dem Wunsch danach, selbst eines zu sein, um dem permanenten Beobachtungszwang und den den Menschen eigenen Kommunikationsproblemen zu entkommen ( $\Rightarrow$ II.2.2),32 verquickt. Als zweite Besonderheit kann - um im Bild zu bleiben - Genazinos Mischpult ${ }^{33}$ das Alleinstellungsmerkmal bescheinigt werden, zumindest verhältnismäßig klein zu sein: 


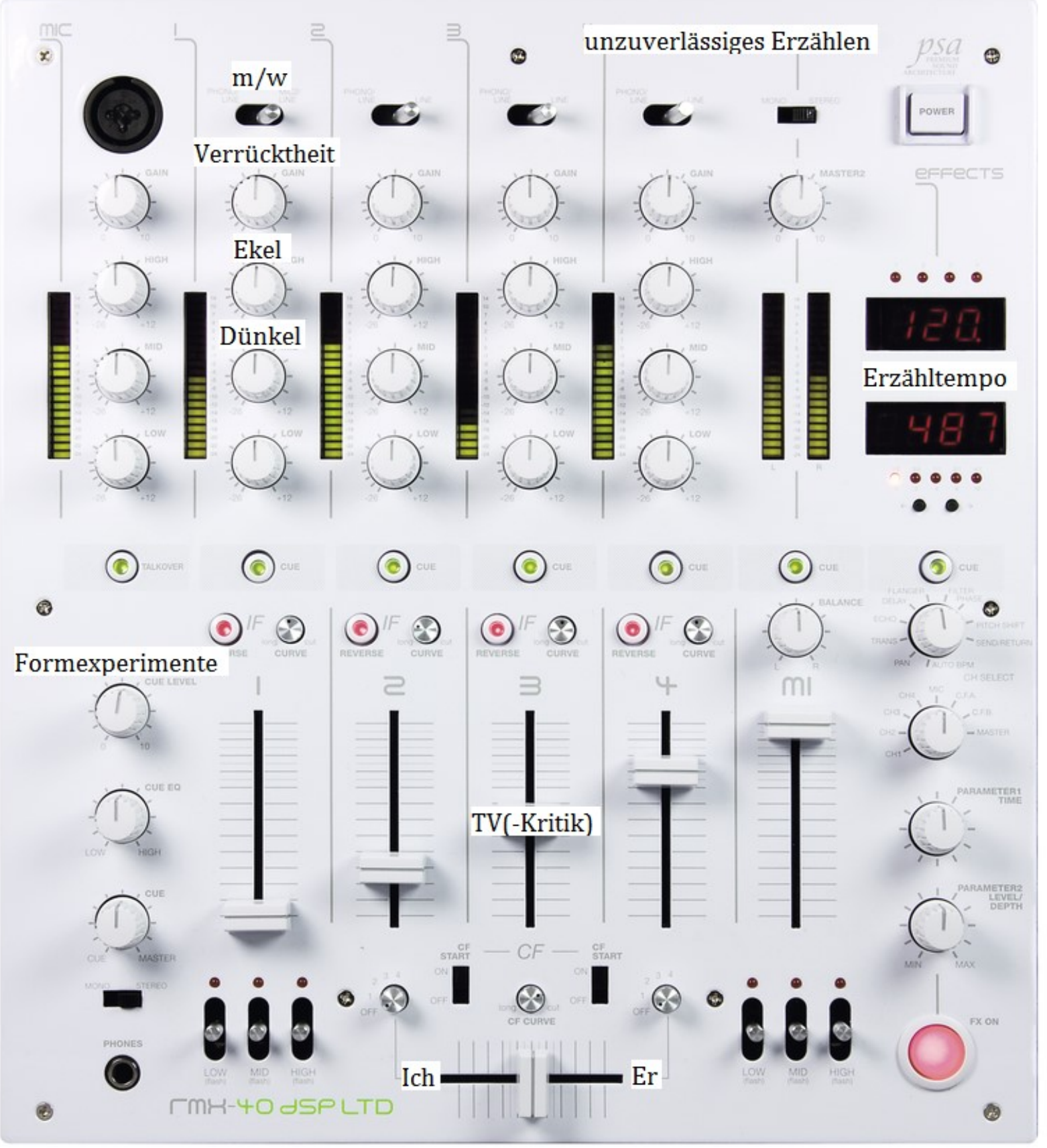

Abbildung 1: Genazinos Mischpult-Verfahren

Nochmal: Freilich bestehen die neueren Romane nicht lediglich aus der Rekombination der vorliegenden musikalischen Themen oder Hintergrundgeräusche, doch überzufällig häufig tauchen vorgefertigte Versatzstücke auf, die den Einzeltext transzendieren und - missverstanden - den Eindruck begünstigen können, Genazino habe „in seinem Leben nur ein einziges Buch geschrieben“ (s.o.). Hirsch bemerkt zur Verteilung von Themen in Genazinos Romanen, dass „jedes in allen immer enthalten ist" ${ }^{\prime 3}$ Zusammengenommen mit der Metapher des Mischpults ließe sich sagen, dass zwar alle Themen irgendwie immer anwesend sind, sie indes im Sinne der ,variier- 
ten Wiederholung' nur ,bei Bedarf' mehr oder weniger hochgeregelt werden, sodass jeder Roman eine spezifische Fader- bzw. Regler-Signatur erhält.

Nun lässt sich aus dieser Bestandsaufnahme entweder ableiten, dass jede Signatur Untersuchungsgegenstand einzelner Analysen sein sollte - weil ja jede doch hinreichend von den anderen abweicht; Stichwort: Variation -, oder aber, dass die Tatsache, dass bestimmte ,Melodien“ immer präsent sind, den flächigen Blick auf wiederkehrende Strukturen rechtfertigt (Stichwort: Wiederholung). Hier soll folgender Mittelweg gegangen werden: Die elementaren romananalytisch und erzähltechnisch gleichgestellten Regler werden - da sie den „Genazino-Sound“35 aller anderen Elemente nachhaltig beeinflussen - sofort einer generellen Analyse unterzogen $(\Leftrightarrow I$ I.2.3). Für die ,Figureneinstellungen' gibt es nicht nur ein eigenes Unterfangen $\Leftrightarrow$ I.2.4 u. $\Rightarrow$ I.2.5), sondern auch eine feingliedrige Analyse in den Schlaglichtern, und auf diejenigen Regler der Motive und Elemente wird etwas später erneut zurückgekommen $(\Leftrightarrow I .5 .1)$.

\subsection{Romananalytische ,Vermessung der Erzählwelten“ bei Genazino}

Auf die Frage, wie ein Roman zu analysieren sei, lassen sich viele Antworten finden. Vier immer wiederkehrende Hebelpunkte stellen allerdings die Kategorien ,Erzähltheorie/Narratologie‘, 36 ,Inhalt/Handlung', ,Stil' und ,Figuren' dar. ${ }^{37}$ In diesem Unterkapitel wird nun anhand der ersten drei Kategorien eine ,Vermessung' des Roman-Werks von Genazino vorgeschlagen, bevor die Figuren als eigentlicher Untersuchungsgegenstand in den Vordergrund rücken $(\Leftrightarrow I .2 .4 \mathrm{ff}$.); denn erst auf einem sicheren romananalytischen Fundament lassen sich generellere Aussagen zu diesen treffen. Dabei kann es nur um globale Fluchtlinien gehen, da die Romane nicht nur allgemeinen Pendelbewegungen unterliegen $(\Leftrightarrow$ I.2.1) und individuelle Fader-Stellungen ihre Besonderheiten markieren $(\Leftrightarrow I .2 .2)$, sondern natürlich auch - etwa was einzelne Aspekte der Inhaltsanalyse anbelangt - gar zu unterschiedlich geartet sind, um redlich zu verallgemeinern. ${ }^{38}$

35 Susanne Kunckel: „Ich bin ein humoristischer Leisetreter“. Besuch beim Büchner-Preisträger Wilhelm Genazino. In: Welt am Sonntag vom 17. Oktober 2004.

Abhängig davon, ob man lediglich den Discours als narratologisches Arbeitsgebiet versteht oder die ,Zuständigkeit' auf die Histoire ausdehnt, ließen sich nahezu alle romananalytischen Kategorien der Erzähltheorie unterordnen. Insbesondere die Kategorie ,Stil' wäre dann dem Discours zuzuschlagen und mithin ein potenzieller Unterpunkt der narratologischen Betrachtung.

Vgl. etwa Peter Wenzel (Hg.): Einführung in die Erzähltextanalyse. Kategorien, Modelle, Probleme. Trier 2004; vgl. Christoph Bode: Der Roman. Eine Einführung. Tübingen/Basel 2005; vgl. Silke Lahn/Jan C. Meister: Einführung in die Erzähltextanalyse. Mit Beiträgen von Matthias Aumüller, Benjamin Biebuyck, Anja Burghardt, Jens Eder, Per Krogh Hansen, Peter Hühn und Felix Sprang. 2., akt. Aufl. Mit Abbildungen und Grafiken. Stuttgart/Weimar 2013; vgl. Jost Schneider: Einführung in die Roman-Analyse. 3., aktual. Aufl. Darmstadt 2010. Die folgende erzähltheoretische Analysereihenfolge orientiert sich an Matías Martínez/Michael Scheffel: Einführung in die Erzähltheorie. 7. Aufl. München 2007, die romananalytische, die Kategorien ,Inhalt' und ,Stil' betreffende, an Schneider: Einführung in die Roman-Analyse. Herausgegriffen werden diejenigen für Genazinos RomanWerk sich als relevant erweisenden Kategorien, die eine Vergleichbarkeit der Romane ermöglichen. Über die Sinnhaftigkeit einer auf makrostruktureller Ebene für eine Vielzahl an Romanen Gültigkeit beanspruchender romananalytischen Herangehensweise lässt sich begründet streiten. Hier wird einer dadurch möglichen ersten Orientierung in Genazinos Roman-Welt der Vorzug gegeben ge- 
34 - Teil I: Grundlagen 2. Wilhelm Genazinos Romanfiguren und ,Figurenromane‘

\section{ERZÄHLTHEORETISCHE GRUNDIERUNG}

Müsste man ein Manko im Sinne eines Tertium comparationis der bis dato vorliegenden Forschungsliteratur zu Genazinos Romanen angeben, dann wäre es die mitunter verkürzende und vereinfachende erzähltheoretische Argumentation. So geht etwa Hirsch davon aus, dass die Figuren Genazinos mit dem Wandel vom Er- zum Ich-Erzähler (erstmals im Roman Der Fleck, die Jacke, die Zimmer, der Schmerz) „ihren Erzähler abgeschüttelt haben“. ${ }^{39}$ Das ist in (mindestens) ${ }^{40}$ dreierlei Hinsicht kritisch zu hinterfragen: Erstens sagt die Verwendung von Personalpronomen nichts über die Form der Fokalisierung - nach Gérard Genette neben der Distanz die zweite Kategorie des Modus - aus. Alfred Döblins Berlin Alexanderplatz ist kanonisierter, beliebter, eindrucksvoller Beleg für eine intern fokalisierte Er-Erzählung. ${ }^{41}$ Zweitens ist die Vorstellung einer von einem Erzähler ,befreiten` Figur narratologisch höchst umstritten. ${ }^{42}$ Drittens haben - um im Sinne eines konjekturalen ,Was-wäre-wenn' zu argumentieren - die Figuren ihren Erzähler auch in der Ich-Form mitnichten ,abgeschüttelt': Gerade weil man bei Genazino nicht davon ausgehen darf, dass eine variable interne Fokalisierung vorliegt, sind Passagen, in denen das Ich die Gedanken anderer kennt, deutliche Anzeichen in Richtung einer Nullfokalisierung!43 Auch in Techniken der Bewusstseinswiedergabe, wie man sie aus ,alten Zeiten' kennt, springt einen der Erzähler geradezu an (s.u.). Literaturkritiker Iljoma Mangold etwa erkennt ab Genazinos Roman Die Liebesblödigkeit (2005) die Tendenz, den Leser in das Spiel zu integrieren und unterschwellige Leseransprachen einzumontieren, die das Vorliegen einer Erzählinstanz akzentuieren:

In früheren Büchern von Genazino war Humor immer so etwas wie ein existentielles Begleitgeräusch der individuellen Art seiner Figuren, durch die Welt zu gehen. In „Liebesblödigkeit“ dagegen sehen wir einen Pointenkonstrukteur am Reißbrett arbeiten. „Ich hätte“, sagt der Held zum Beispiel, „nicht gedacht, dass die Apokalypse in diesem Jahr so gut läuft.“ Sagt er das extra so, weil man genau so einen komischen Satz baut? Manchmal hat man gar den Eindruck, dass der Ich-Erzähler nach besonders gelungenen Formulierungen wie der von der „Alterssicherung unserer Sexualität" oder der so genannten „Wackelerektion“ kurz innehält und aus den Seiten heraus dem Leser ins Gesicht guckt, ob sich auf dessen Gesichtszügen denn auch ein Schmunzeln breit gemacht habe. ${ }^{4}$

Diese Tendenz der Erzähler, ,dem Leser ins Gesicht zu gucken', setzt sich in den jüngeren und jüngsten Genazino-Romanen fort: Wie in ein Diktaphon gesprochen nehmen sich manche Passagen (genaugenommen bereits seit 2001 mit Regenschirm) aus und in Außer uns spricht niemand über uns ist dieses narrative Verfahren zur vorläufigen Blüte getrieben: „Tatsächlich hatte ich

genüber einer Position, die lediglich einzeltextbezogene Analysen gelten lässt - und zwar nicht zuletzt deshalb, weil das Spannungsfeld von Wiederholung und Variation nicht nur für das ,Was' der Romane gültig ist, sondern auch für das ,Wie'. Hirsch: „Schwebeglück der Literatur“, S. 78.

Ergänzen ließe sich die missverständliche Formulierung, dass es sich um den ersten großen und einzigen Perspektivwechsel handele, was bekanntlich nicht der Fall ist ( $\Rightarrow$ I.2.1).

Vgl. Martínez/Scheffel: Einführung in die Erzähltheorie, S. 65.

Vgl. Köppe/Kindt: Erzähltheorie, S. 84-97.

Vgl. etwa Fleck, S. 103, sowie zahlreiche weitere Beispiele (s.u.).

Iljoma Mangold: Du musst dein Frauenproblem lösen. In: Süddeutsche Zeitung vom 12./13. März 2005. 
immer Schauspieler werden wollen, nicht irgendeiner, sondern einer, der...ach, ich spreche es nicht aus." (Außer uns, S. 12; vgl. Außer uns, S. 16 u. S. 27) Allerspätestens damit ist es höchst fragwürdig geworden, anzunehmen, das erzählende Ich sei ohne eine wie auch immer geartete Erzählinstanz unterwegs. Nun legitimiert sich erzähltheoretische Pedanterie nicht durch sich selbst, sondern nur durch Funktionalisierung: Was lässt sich daraus ableiten? Für die Konzeption des Romans Außer uns spricht niemand über uns ließe sich neben der - von Mangold vorwurfsvoll vorgetragenen - verkaufsfördernden, reißbretthaften Machart auch die Autofiktion ins Spiel bringen: Seit langem weiß Genazino um den Reiz, seine Bücher-Ichs mit seinem echten Ich abzugleichen $(\Leftrightarrow I .1$ u. $\Rightarrow$ I.5.3). Festhalten kann man jedenfalls eine konzeptionell stilistisch mündlichere Anlage (s.u.), ${ }^{45}$ als dies in Romanen vor 2000 der Fall gewesen ist.

Der Beweis der Wichtigkeit, dass eine erzähltheoretisch profunde ${ }^{46}$ Einordnung von Genazinos Figurenromanen Conditio sine qua non ist, sei weiterhin anhand der folgenden Punkte geführt: unzuverlässiges Erzählen, Zeit, Modus und Stimme.

Ein basales Charakteristikum Genazino'scher Romane ist dieses: Nahezu jedes (literatur-)wissenschaftliche Analyseinstrument ist insofern zum graduellen Scheitern verurteilt, als die Texte ,metatheoretisch` dagegen ,imprägniert' sind. ${ }^{47}$ Am unzuverlässigen Erzählen ${ }^{48}$ lässt sich verdeutlichen, was damit gemeint ist. Köppe/Kindt trennen drei verschiedene Unterarten unzuverlässigen Erzählens: das „täuschende unzuverlässige Erzählen“,49 das „offen unzuverlässige Erzählen“50 und das „axiologisch unzuverlässige Erzählen“. ${ }^{51} \mathrm{Im}$,Normalfall” einer erzähltheoretischen Romananalyse würde man nun - bei genügend Indizien für das generelle Vorliegen unzuverlässigen Erzählens freilich - sondieren, welche Art überwiegt, die Definition mit den Fundstellen abgleichen und interpretatorische Schlüsse ziehen. Für Genazino scheinen die Zeichen zunächst auf offen unzuverlässiges Erzählen zu deuten. Nach der Definition von Köppe und Kindt ist ein „Erzähltext [...] genau dann offen unzuverlässig erzählt, wenn der Text in offensichtlicher Weise

Vgl. Schneider: Einführung in die Roman-Analyse, S. $45 \mathrm{f}$.

Es soll nicht überheblich klingen, aber durch eine andere Fokussetzung werden immer wieder ,Ungereimtheiten' sinnfällig, wenn man mit narratologischer Brille in die Forschungsliteratur zu Genazino blickt. Vgl. etwa Jung: „Umhergehen und Zeitverschwenden“, S. 65, der für Abschaffel eine „auktoriale Erzählerstimme“ behauptet, obwohl die zitierte Stelle eindeutig ein Gedankenzitat Abschaffels ist, der über Alleinstehende sinniert. Die Erzählerstimme der Abschaffel-Trilogie hingegen ist zweifelsfrei - global gesehen - von personalem Einschlag. (Obwohl Stanzel mit der personalen Erzählsituation eine Vielzahl von narrativen Charakteristika impliziert und sich diese Studie im Wesentlichen auf Genette beschränkt, wird insbesondere dann, wenn die besprochenen Sekundärtexte ihrerseits mit Stanzl arbeiten, dessen Instrumentarium verwendet.)

Kämmerlings hält dazu in seinem Verriss zu Wenn wir Tiere wären fest, es handle sich bei Genazino weniger um „Literatur“ als um „Literaturinterpretation“ (Kämmerlings: Genazino gilt als bedeutender Autor. Warum nur?). pe/Kindt: Erzähltheorie, S. 236-256. Vgl. für unzuverlässiges Erzählen bei Genazino Fansa: Unterwegs im Monolog, S. 13. 
falsche Angaben über fiktive Tatsachen enthält":52 "Nein, das war alles gar nicht wahr. Abschaffel [...] gestand sich ein, daß er dem Vater soeben etwas angedichtet hatte." (Falsche Jahre, S. 455) ${ }^{53}$ Allerdings deckt sich alles das, was Abschaffel zuvor seinem Vater ,angedichtet' hat, weitaus eher mit der Definition täuschenden unzuverlässigen Erzählens, die „besagt, dass Leser der Erzählung (vorübergehend) gute Gründe für falsche Annahmen über fiktive Tatsachen haben. ${ }^{54}$ Vorübergehend ist dies bei Genazino häufig der Fall und die nachträgliche Auflösung alleine reicht nicht, um grundsätzlich von offen unzuverlässigem Erzählen auszugehen. Denn es kommt nur selten vor, dass sich Genazinos Erzählfiguren „irren oder unzureichend informiert sind“; 55 stattdessen bedingen komplexere Motive die erzählerische Unzuverlässigkeit:

Zwischen vier weißen Kachelwänden stehend, gestand Abschaffel sich ein, daß er sich soeben belogen hatte wie schon lange nicht mehr. Er hatte sich als Kind nicht ein einziges Mal an einem Malwettbewerb beteiligt, nicht ein einziges Mal an einem Preisausschreiben oder einem Rätselturnier. Er hatte nie etwas gewonnen, weil er niemals an einem solchen Wettbewerb teilgenommen hatte. Er glaubte nur manchmal gern, an allem beteiligt gewesen zu sein. (Sorgen, S. 253)

Ist in diesem Beispiel einerseits der Grund für das zuvor täuschende unzuverlässige Erzählen angegeben, wird dieses andererseits selbst thematisiert und in der personalen Erzählsituation reflexiv gebrochen. Eine weitere Stufe vertrackter:

Als Zehnjähriger hatte er sich eine gewünscht und keine bekommen. Das war nicht wahr, und er wußte, daß es nicht wahr war. [...] [A] ber rätselhafterweise spielte ihm seine Erinnerung manchmal das Gegenteil vor. Aber weil es nur um eine Taschenlampe ging, erlaubte Abschaffel seiner Erinnerung ausnahmsweise das falsche Spiel, und er erlaubte sich selbst, daß er es bemerkte. (Falsche Jahre, S. 560)

Spätestens jetzt muss man eingestehen, dass mit der Klassifikation unzuverlässigen Erzählens in drei verschiedene Varianten kein passendes Analysewerkzeug gewählt wäre. Und selbst dann, wenn man mit Fludernik „biografisch-genetische Explikation“, „mimetische Explikation“ oder „metanarrative Explikation“ unterscheidet, um „die Diskrepanzen zwischen den Äußerungen der Erzählerfigur und der vom Leser konstatierten ,Weltsicht des Textes““ in Relation zu setzen, mithin vielleicht sogar eher von Diskordanz als von Unzuverlässigkeit sprechen müsste, ${ }^{56}$ gilt:

Der Nutzen von Taxonomien unzuverlässigen Erzählens, die alle diese Spielarten erfassen wollen, stößt jedoch recht bald an seine Grenzen: Nützlicher als eine Klassifikation dürfte in vielen Fällen

$52 \quad$ Köppe/Kindt: Erzähltheorie, S. 246.

53 Vgl. auch: „Wie man sieht, bin ich dabei ins Lügen verfallen.“ (Regenschirm, S. 9)

54 Köppe/Kindt: Erzähltheorie, S. 242.

55 Köppe/Kindt: Erzähltheorie, S. 246.

$56 \quad$ Monika Fludernik: Unreliability vs. Discordance. Kritische Betrachtungen zum literaturwissenschaftlichen Konzept der erzählerischen Unzuverlässigkeit. In: Fabienne Liptay/Yvonne Wolf (Hg.): Was stimmt denn jetzt? Unzuverlässiges Erzählen in Literatur und Film. München 2005, S. 39-59, hier S. 52 f. Vgl. zu dem kontrovers diskutierten Umstand, ob der weithin Verwendung findenden Kategorie ,Unzuverlässigkeit' sinnvollerweise diejenige der ,Unglaubwürdigkeit' zur Seite gestellt werden sollte, Ansgar Nünning, Ansgar unter Mitwirkung von Carola Surkamp und Bruno Zerweck (Hg.): Unreliable Narration. Studien zur Theorie und Praxis unglaubwürdigen Erzählens in der englischsprachigen Erzählliteratur. Trier 2013. 
eine differenziertere Beschreibung (und Interpretation) der fiktiven Unzuverlässigkeitsdimensionen der jeweils in Rede stehenden Figur sein. ${ }^{57}$

Das gilt für Genazino in besonderem Maße, da seine Romane immer suggerieren, mit Taxonomien, Typologien und anderen klassifizierenden Herangehensweisen auf der richtigen Fährte zu sein, sie letztlich aber alle Ordnungssysteme (teils: reflexiv) unterwandern. Die Frage, die sich stellt, lautet: Warum machen sowohl Figuren als auch - in den Fällen, in denen man von einem ,zusätzlichen' heterodiegetischen Erzähler ausgehen darf - Erzähler extensiv von unzuverlässigem Erzählen Gebrauch?

Warum fälsche ich zuweilen etwas ab, was ich doch richtig beobachtet habe? Ich frage mich, ob ich mir über meine Entstellungen Sorgen machen muß oder ob es normal ist, wenn man sich nach innen als Wirklichkeitsveränderer betätigt. Aber solange ich nur für mich entstelle, werden diese Vorgänge als gewöhnlich bezeichnet werden können, hoffe ich. Aufpassen muß ich nur, wenn ich anfange, anderen Menschen gegenüber meine Korrekturen als wahrhaftig darzustellen. (Liebesblödigkeit, S. 54)

Dass Genazinos Figuren nicht sehr gut aufgepasst haben, lässt sich am weit verbreiteten Gebrauch der ,kleinen' (und größeren) Lüge auch anderen Figuren gegenüber belegen ( $\Rightarrow$ II.1.2); hier interessiert vor allem, inwiefern erste Erklärungsansätze für die gestellte Frage fruchtbar gemacht werden können. Neben auf komische Pointen zielenden Antworten an anderer Stelle „Aber ich wollte nicht jeden Tag glauben, was ich wußte“ (Obdachlosigkeit, S. 54) -, lässt sich die Feststellung, es sei legitim, sich selbst mit ,alternativen Erinnerungsfakten' zu versorgen, als wichtiger Impuls aufgreifen. Das (unzuverlässige) Entsinnen bei Genazino ist relativ gut erforscht, ${ }^{58}$ die Figuren erinnern sich regelmäßig „auch gern an Vorgänge, die nie geschehen waren." (Außer uns, S. 41) Sich selbst eine andere Vita zur erinnern, ist möglicherweise Ausdruck einer aus Unzufriedenheit entstandenen Selbsttäuschung.59

Nicht prototypisch, der Sache nach aber zwischen offenem und täuschendem unzuverlässigen Erzählen changierend, lesen sich die Tagträume, die überraschenden bis absurden, mutmaßenden Alltags-Wahrnehmungs-Interpretationen ( $\Rightarrow$ II.2.3), Imaginationen und ,Was-wäre-wennÜberlegungen` der Protagonisten: „Nein, so war es natürlich nicht, aber das wiederholte Anhören der abgerissenen, stöhnenden Frauenstimme genügte, Herrn Fuchs auf diese Vorstellung zu bringen." (Ausschweifung, S. 63) An diesen Stellen ist es mitunter auch einfach „der gewöhnliche, einengende Unsinn, den sein Kopf manchmal zustande brachte und den er manchmal als solchen erkannte." (Falsche Jahre, S. 497) Allerdings ist hier die sonst üblichere Form der Selbsterkenntnis durch einen Erzählfilter ausgeblendet.

$57 \quad$ Köppe/Kindt: Erzähltheorie, S. 247.

58 Insbesondere Genazinos „Panik der nie richtig erzählten Geschichte“ wird dabei virulent (Einfalt, S. 103). Vgl. dazu Hirsch: „Schwebeglück der Literatur“, S. 32 ( $\Rightarrow$ I.5.3). Die alternative (fiktive) Wirklichkeit muss aber nicht in der Vergangenheit liegen, denn auch in der Erzählgegenwart begegnen dem Rezipienten unzuverlässiges und mitunter unentscheidbares Erzählen (vgl. Köppe/Kindt: Erzähltheorie, S. 241).

59 Vgl. dazu grundlegend die Kapitel zum Selbst $(\Rightarrow$ I.4) sowie zur Diskrepanz zwischen Selbst- und Idealbild ( $\Rightarrow$ II.2.1). 
38 - Teil I: Grundlagen 2. Wilhelm Genazinos Romanfiguren und ,Figurenromane‘

Eine Art der - vermeintlich allgemeingültigen - Blaupause für Genazino-Romane hinsichtlich der (Un-)Zuverlässigkeit des Erzählens ist nicht anzufertigen. Allerdings lässt sich festhalten, dass Genazinos Romane en gros „auf der Voraussetzung, daß hinter der Rede des Erzählers eine stabile und eindeutig bestimmbare erzählte Welt erkennbar wird, mit Bezug auf die sich manche der Erzählerbehauptungen als unzuverlässig abheben lassen“, beruhen.60 Davon setzt sich der Briefroman Das Licht brennt ein Loch in den Tag kunstvoll ab. Wohl fällt die Reflexion über unzuverlässiges Erzählen in diesem Fall mit derjenigen über unzuverlässiges Erinnern und damit mit einer in dieser Untersuchung weitgehend ausgeklammerten Thematik zusammen $(\Rightarrow$ I.5.3), doch bietet sie wertvolle Anhaltspunkte. In der progressiven Briefform ${ }^{61}$ werden dem (aufmerksamen) Leser zwei Berichte vorgelegt, die repetitiv ein und dasselbe Ereignis thematisieren (vgl. Licht, S. 43 vs. S. 60 f.): Einmal handelt es sich um den (vermeintlich) erzählten Selbstentwurf des Protagonisten als Provokateur, einmal um den als zögerlicher Zauderer in Form eines Briefes. Was macht der Leser mit diesen zwei, eindeutig kontradiktorischen ,Wahrheitsversionen'?62 Der Roman selbst schafft keine Klarheit, vielmehr sät er im Erzählverlauf weitere Zweifel: „Werner [der Briefpartner des Protagonisten; N. L.] hat übrigens bemerkt, daß meine Erinnerungen nicht immer ganz wahr sind, beziehungsweise, daß es von manchen mehrere Versionen gibt.“ (Licht, S. 70)63 Köppe/Kindt sprechen in diesem Zusammenhang vom „,unentscheidbaren (unzuverlässigen) Erzählen““.64 Letztlich „bleibt [es] unentscheidbar, welche dieser Varianten des Geschehens als die ,eigentliche‘ zu gelten hat. Die erzählte Welt löst sich auf in eine Serie alternativer Versionen“,65 und nimmt damit den Leser in die Pflicht:

Was der Erzähler, was die anderen Figuren und was die betreffende Figur selbst sagen, lässt sich u.U. nicht in Einklang bringen, so dass der Leser die verschiedenen Urteile bewerten und hierarchisieren muss, ein Vorgang, der für viele Leser einen hohen Reiz besitzt und einen beträchtlichen Teil des Lesevergnügens ausmacht. 66

Hier ließe sich nun der Genazino'sche Basistypus der Figur anbringen ( $\Rightarrow$ I.2.5), der im Leser vertraute Standardwerte für bestimmte Situationen aufruft und somit doch wieder Orientierung stiftet: Als ,Genazino-Figuren-Kenner' ist der Leser vermutlich eher geneigt, den provokanteren Selbstentwurf als für Genazinos Figuren unüblich zurückzuweisen. Selbst Das Licht brennt ein Loch in den Tag würde damit letztlich nicht zu den Romanen gehören, in denen „der Eindruck der Unzuverlässigkeit [...] nicht nur teilweise und vorübergehend entsteht, sondern unaufgelöst

60 Martínez/Scheffel: Einführung in die Erzähltheorie, S. 103.

61 Vgl. Hoorn: [Genazino, Wilhelm].

62 Vgl. Mittag: Im INSTITUT FÜR MNEMOSYNE, S. 50; vgl. Fansa: Unterwegs im Monolog, S. 67 f.

63 Vgl. dazu auch den Rückbrief an Werner mit Selbstreflexion zu unterschiedlichen Wahrheitsversionen (Licht, S. 73 u. S. 76 f.).

64 Köppe/Kindt: Erzähltheorie, S. 241.

65 Martínez/Scheffel: Einführung in die Erzähltheorie, S. 103.

66 Schneider: Einführung in die Roman-Analyse, S. 19. 
bestehen bleibt und sich in eine grundsätzliche Unentscheidbarkeit bezüglich dessen, was in der erzählten Welt der Fall ist, verwandelt."67

Da nun bei Genazino die mimetischen Sätze der Erzähler, welche „die konkrete Beschaffenheit der erzählten Welt" konstituieren, ${ }^{68}$ zumeist für wahr gelten können (Ausnahme: abgefallenes $\mathrm{Ohr}$ ), lassen sich die nun folgenden narratologischen Aspekte sowie diese Arbeit in dieser Form überhaupt (be-)schreiben - handelte es sich stets um in allen Hinsichten unzuverlässige Erzähler, wäre dieses Kapitel genauso vergeblich konzipiert wie die Studie schlechterdings. ${ }^{69}$

Neben der (Un-)Zuverlässigkeit des Erzählens steht die Analysekategorie ,Zeit'70 auf jeder narratologischen Agenda. Hinsichtlich dieser wird in der Forschung unterschieden zwischen Ordnung, Dauer und Frequenz, die in dieser Reihenfolge knapp und notwendigerweise verallgemeinernd für Genazinos Roman-Werk abgehandelt werden.

Im Regelfall wird bei Genazino bezogen auf die Ordnung chronologisch erzählt mit einigen kürzeren, unvollständigen Analepsen, die meist der Kindheits- und Jugenderfahrung/-erinnerung sowie den Frauenbekanntschaften geschuldet sind und die Erzählgegenwart mit zusätzlichen Informationen ,anreichern'.71 Ein prototypisches Beispiel aus Ein Regenschirm für diesen Tag für diese Rückblenden:

Es verwirrt mich, daß ich nach so vielen Jahren darüber nachdenke, ob ich mich Susanne nähern soll oder nicht und daß der Auslöser dieser Überlegung nur ein zufälliges Zusammentreffen in Susannes Mittagspause war. Ich kenne Susannes Busen sozusagen von Kindheit an, habe ihn aber viele Jahre nicht gesehen und nicht berührt und kann mir deswegen vielleicht nicht mehr einbilden, ihn zu kennen. (Regenschirm, S. 76)

Sehr häufig sind hingegen Prolepsen im Sinne eines ,foreshadowings', die sich zukunftsgewandt geben, dann aber nicht eintreten: „Das junge Paar links von mir saugt jetzt so heftig an seinen Trinkröhrchen, daß ich überlege, zu den beiden zu sagen: Ich gebe Ihnen fünf Euro, wenn Sie mit Ihrem Geröchel sofort aufhören.“ (Glück, S. 8) Der Leser wird darauf vorbereitet, dass späterhin etwas geschehen wird - das dann nicht eintritt: „Das Unangenehmste an meiner Ermüdung ist die Überempfindlichkeit. Ich bin noch nicht verrückt genug, dem jungen Paar das Angebot tatsächlich zu unterbreiten. Im Gegenteil, die Empfindung der öffentlichen Peinlichkeit macht mich noch schamhafter." (Glück, S. 8) Das Nicht-Eintreten kann - wie im Beispiel aus Das Glück in

67 Martínez/Scheffel: Einführung in die Erzähltheorie, S. 103.

68 Martínez/Scheffel: Einführung in die Erzähltheorie, S. 190; vgl. Martínez/Scheffel: Einführung in die Erzähltheorie, S. 100-103 u. S. 165.

69 Grenzfälle, in denen es zwar ,objektiv' unentscheidbar ist, ob eine Handlung vollzogen wird oder nicht, lassen sich über den angeführten Erzähl-Standard einfangen. Beispiele wie: „Unterwegs machte er seinen rechten Oberarm frei und stempelte sich selbst mit dem Wutstempel" (Fremde Kämpfe, S. 58 f.), sind nicht wirklich diskutabel, da es sich naheliegenderweise um im Indikativ formulierte Tagträume handelt. Bis auf wenige Ausnahmen werden diese Grenzfälle im Nachhinein auch wieder vereindeutigt (vgl. etwa Fremde Kämpfe, S. 66): „rief er aus: stellte er sich vor: daß er ausrief".

70 Vgl. in Bezug auf Genazino dazu grundlegend auch Hirsch: „Schwebeglück der Literatur“, S. 28, S. 102 ff. u. S. $232 \mathrm{ff}$.

71 Vgl. zu unvermittelten Sprüngen zwischen Erzählgegenwart und -vergangenheit Fansa: Unterwegs im Monolog, S. 80. Für Ausnahmen vgl. zusätzlich die Figurenliste im Anhang $(\Rightarrow$ V.1). 
40 - Teil I: Grundlagen 2. Wilhelm Genazinos Romanfiguren und ,Figurenromane

glücksfernen Zeiten - sofort und zukunftsgewiss thematisiert werden, es kann allerdings auch zukunftsungewiss bleiben, was als Indiz dafür gelesen werden kann, dass der Erzähler „auf einen übergeordneten Standpunkt verzichtet und sich auf den begrenzten Wahrnehmungshorizont der in das erzählte Geschehen verwickelten Figuren beschränkt."72 Zugleich wird diese Form bei Genazino insofern variiert, als der Rezipient schon nach der Lektüre nur weniger Genazino-Romane zum Skeptiker ,erzogen' wird und die Erwartungshaltung auf die Figur zurückgespiegelt wird: ,Das tut er/sie doch sowieso nicht' (s.u.).

Bezüglich der Dauer lässt sich testieren, dass das Erzähltempo schwankt: zwischen eher seltenen zeitdeckenden Szenen (Übergang zur Inhaltsanalyse: Dialogsequenzen), sehr häufigen Dehnungen (Reflexion) bis hin zu Pausen (eher häufig) und Ellipsen (insbesondere an Kapitelenden). Raffungen sind höchst selten, was dem Zeitempfinden eine mitunter zähe Langsamkeit verleiht und den typischen „Genazino-Sound“73 (s.u.) mit bedingt. Dadurch wird zudem aber eine ungeheure Präzision, die Suggestion der Eigenständigkeit des Augenblicks und eine Wichtigkeit unwichtig scheinender Momente ermöglicht. Innerhalb mitunter viele Druckseiten einnehmender Pausen in der erzählten Zeit - wenn also das Erzählen weitergeht, während die Handlung stillsteht ${ }^{74}$ - handelt es sich weniger darum, „eine signifikante Dehnung der Dauer von Vorgängen in der äußeren Welt in der Regel durch Einschübe" zu realisieren, ${ }^{75}$ wie es ein Definiens für zeitdehnendes Erzählen besagt, als vielmehr um die Grundfaktur vieler Romane. In Ein Regenschirm für diesen Tag etwa wird dem Fakt Rechnung getragen, dass es um die Figur und deren Innenleben geht, ,Tempo' mithin eine untergeordnete Rolle spielt:

Altmodisch gekonnt porträtiert Genazino diese skurrile Existenz. Leise ironisch, ohne Larmoyanz, ohne Angst, altmodische Gefühle wie Melancholie zu beschreiben, ohne Angst vor der Langsamkeit, vor der Langeweile. Mit Action, mit Tempo hat dieser brillante Erzähler nichts am Schuh. Dass sich dieses stille Buch viel verkauft, gehört zu den kleinen Wundern des lauten Marktes. ${ }^{76}$

„Bis zu einem Extremwert wird das Erzähltempo [...] verringert“,77 was man auch inhaltsanalytisch (Sequenzanalyse etc.; s.u.) untermauern kann, denn neben der Vorliebe für Dehnungen und Pausen sind bei Genazino weitere ,entschleunigende‘ Erzähltechniken zu beobachten: Viele Romane zeichnet eine fast extreme Handlungs- und Ortswechselarmut aus - für Falsche Jahre könnte man beinahe von einer ,Einheit des Ortes' sprechen -, und auch konkretisierende Deixis findet sich nur vereinzelt.78 Nichtsdestotrotz muss auch bezüglich der Kategorie ,Dauer die Ausnahme die Weichzeichnung konterkarieren: Es gibt mitunter Spannungsaufbau (kurze Sätze, Raffungen): „Guter Gott, wo wollten sie denn noch hin? Wenn Eckhard seine Zehn-Minuten-Frist

72 Martínez/Scheffel: Einführung in die Erzähltheorie, S. 37.

73 Kunckel: „Ich bin ein humoristischer Leisetreter“.

74 Vgl. Martínez/Scheffel: Einführung in die Erzähltheorie, S. 42-44.

75 Martínez/Scheffel: Einführung in die Erzähltheorie, S. 44; Herv. N. L.

76 Anita Pollak: Müßiggang ist aller Tugend Anfang. Besprechung des Romans Ein Regenschirm für diesen Tag. In: Wiener Kurier vom 28. September 2001.

77 Martínez/Scheffel: Einführung in die Erzähltheorie, S. 44.

78 Vgl. Schneider: Einführung in die Roman-Analyse, S. 36. 
ernst nahm, dann durfte er sie nur noch zwei oder drei Minuten verfolgen." (Ausschweifung, S. 182) 79 Und selbstredend kommt auch Genazino nicht ohne Raffungen aus (vgl. Fremde Kämpfe, S. 14). Global betrachtet allerdings sind Genazinos Romane nicht nur ,still', sondern eben auch ,langsam".

Zumeist handelt es sich, was die Frequenz anbelangt, einzeltextbezogen um singulatives Erzählen, das - zumal in den Romanen ab 2000 - allerdings von der unüblichen Form: „,wiederholt erzählen, was sich wiederholt ereignet hat" ${ }^{\prime \prime}, 80$ beerbt wird. So findet sich in Genazinos Außer uns spricht niemand über uns gleich drei Mal ein sexueller Übergriff von einer älteren Frau auf den an Jahren jungen Protagonisten ( $\Rightarrow$ II.5.3). Dabei sind die Grenzen - zumindest dann, wenn man die Lesart der Demenz derjenigen redundanten vorzieht - zum repetitiven Erzählen fließend: Wenn man davon ausgeht, dass die Gesetze der Wahrscheinlichkeit fiktionaler Lebensläufe in einer Standarddiegese gegen einen dreifachen Übergriff durch drei unterschiedliche Frauen arbeiten, könnte man mutmaßen, es mit drei Erzählungen ein und desselben Vorkommnisses zu tun zu haben.

Die Rubrik ,Modus' lässt sich weiter differenzieren in die Kategorien ,Distanz' und ,Fokalisierung' (s.o.).

In Genazinos Romanen liegt meist eine vergleichsweise geringe Distanz vor, ${ }^{81}$ sowohl wenn es um die Erzählung von Worten geht als auch um diejenige von Ereignissen, die in der häufigen Ich-Form ihren Sitz hat. Fast prototypisch liegt in vielen Momenten der ,gedehnten Blicke‘ bei Genazino

eine Art Selbstvergessenheit des Erzählers [vor], d.h. das Fehlen jeglicher Kommentare und Reflexionen auf der Ebene des Erzählens und damit die scheinbare Abwesenheit einer das Erzählte vermittelnden narrativen Instanz. [...] Der Detailreichtum der Erzählung in Kombination mit einem langsamen, scheinbar nahezu zeitdeckenden Erzähltempo trägt ebenfalls zum Eindruck der Gegenwart des Erzählten bei. Schließlich wird die Illusion einer unmittelbar greifbaren ,Wirklichkeit‘ auch dadurch unterstützt, daß hier zahlreiche Gegenstände genannt und detailreich beschrieben werden, die für die eigentliche Handlung im Rahmen der erzählten Geschichte offenbar funktionslos sind und die in einer Welt jenseits der Erzählung einfach ,da' zu sein scheinen. ${ }^{82}$

Was Martínez und Scheffel für Madame Bovary (1857) als Paradebeispiel für den dramatischen Modus einer Erzählung von Ereignissen beschreiben, ${ }^{83}$ liest sich wie ein Skript für die langsamen und präzisen Beobachtungseskapaden einer durchschnittlichen Genazino-Figur - bis hinein in

79 Für ein Beispiel, das Tempo und Unmittelbarkeit höchster Stufe in Form autonomer direkter Rede kombiniert, vgl. etwa Fremde Kämpfe, S. 72 f.

80 Martínez/Scheffel: Einführung in die Erzähltheorie, S. 45.

81 Vgl. dazu Martínez/Scheffel: Einführung in die Erzähltheorie, S. 47-62. Hingegen werden die Bewusstseinsinhalte mit einer größtmöglichen Distanz zur fiktiven Welt versehen. Vgl. zur Distanz bei Genazino auch Hirsch: „Schwebeglück der Literatur“, S. 21-23.

82 Martínez/Scheffel: Einführung in die Erzähltheorie, S. 50.

83 Ich danke Frau Caroline Frank herzlich (nicht nur) für den Hinweis, dass diese Beispielpassage insofern problematisch ist, als sie letztlich nur in Bezug auf das Erleben der Figur und nicht in Bezug auf die Ereignisschilderung des Treppenaufstiegs wirklich unmittelbar ist. 
die obsessive und detailreiche Reihung von Einzelbeobachtungen. Besonders zu Romanbeginn finden sich diese, selbstvergessenen' Parataxen:

In aller Gutmütigkeit rumpelte eine hell erleuchtete Straßenbahn um die Ecke. Elegant schwebte ein querschnittgelähmter Mann in einem chromblitzenden Rollstuhl vorüber. Eine junge Frau ritzte eine leere Plastiktüre auf einer Seite auf und zog sie sich als Kapuze über den Kopf. Am Nebentisch redete [...]. Feindlos schwamm [...]. Auf der Theke stand [...]. Wolf Peschek saß in einem Café und starrte durch die Scheibe hinaus auf die Straße. (Fremde Kämpfe, S. 7)

Doch auch weitere Indizien für geringe Distanz lassen sich anführen: Wenn gesprochene Rede oder Gedankenrede im Text präsentiert wird, nimmt in dem Maß, in dem sich die Waagschale zur Seite der zitierten - im Vergleich zur erzählten - Rede neigt, die Mittelbarkeit ab. ${ }^{84} \mathrm{Um}$ das Herein- und Herauszoomen deutlich zu machen, hier ein Beispiel aus Ein Regenschirm für diesen Tag, das vergleichsweise narrativ beginnt und endet, in der Mitte allerdings einen höchst unmittelbaren, dramatischen Kern umschließt:

Ich fühle, wie mich mein Tagtraum wieder verläßt, beziehungsweise wie er sich zuerst in eine Bedrohung und dann in eine Beschämung verwandelt. Ich werde kein Geld verdienen, jedenfalls nicht mit Kursen über Gedächtniskunst. [...] Ha! Erinnerungskunst für Angestellte! Damit können die gar nichts anfangen! Im Gegenteil, die fragen dreimal, wie man Mnemosyne denn schreibt, weil sie das Wort nie zuvor gehört haben. Die lachen dich aus! Gedächtniskunst! Was soll das denn sein! Mein Tagtraum flieht und verhöhnt mich während der Flucht. Das ist seine Art, ich kenne das seit langem. (Regenschirm, S. 48)

Obwohl gänzlich in der Ich-Form realisiert - mithin der inquit-Formeln ohnehin nicht bedürftig - und durch die Reflexionsebene bereits weit im Kopf der Ich-Erzähler-Figur verankert, hebt sich der am ehesten als autonomer innerer Monolog zu klassifizierende Passus ab „Ha!“ bis „sein!“ von der Klammerkonstruktion dadurch ab, dass es erstens keine Signale mehr für paralleles ,Bedenken der Gedanken' gibt - wie es vorher durch das ,Fühlen` etwa ins Bewusstsein gerückt wurde -, zweitens die ,Selbstvergessenheit' maximal ist und drittens die Emphase auch formal belegbar durch Ausrufungszeichen pointiert wird. Lediglich dadurch, dass es „letztlich offen bleibt, ob die entsprechenden Worte [...] gedacht oder gesprochen wurden“, 85 lässt sich ein Minimum an Distanzwahrung gewärtigen und auch das Moment des Wechsels ins selbstbezichtigende Du bzw. die in der Klammer angelegte Lesart, der personifizierte Tagtraum könne diese Anwürfe formuliert haben, lässt sich in diese Richtung interpretieren. Aber auch in solchen Passagen ist die Ansicht des ,abgeschüttelten Erzählers‘ keinesfalls rehabilitiert, obwohl sich tatsächlich Situationen ausmachen lassen, in denen das Bild eines den Erzähler (im Wortsinn) abschütteln wollenden Protagonisten evoziert wird:

In einem bestimmten Schaufenster von Sattlach lebte das Wort Trauringe noch, aber für die allermeisten Menschen war es schon lange gestorben. Er überlegte, ob er dem Uhrmacher Bescheid sagen sollte, daß in seinem Schaufenster ein sterbendes Wort lag, und während er ging, probte er schon die ersten Sätze aus: Wissen Sie eigentlich, daß in Ihrem Schaufenster ein Wort verwest, ein altes Wort, das für Sie vielleicht noch gilt, äh, ja, da vergaß er den ganzen Trauringkomplex, denn

84 Vgl. Martínez/Scheffel: Einführung in die Erzähltheorie, S. 62.

85 Martínez/Scheffel: Einführung in die Erzähltheorie, S. 59. 
inzwischen stand er vor dem Schaufenster eines kleinen Lebensmittelgeschäfts (Falsche Jahre, S. 441).

Unklar bleibt, ob das stammelnde „äh, ja“ der Nachzeichnung des Imaginierens der Worte, die die Figur (laut oder leise) zu sprechen plant, dient, oder ob der Erzähler - ob der Geschwindigkeit des Flaneurs - ins erzählerische Straucheln kommt und damit den Szenenwechsel abrupt zu vollführen gezwungen ist. Zwischen der Präsentation von Ereignissen und Worten, zwischen mimetischen und theoretischen Sätzen und mithin zwischen geringerer und größerer Distanz bewegen sich diese erzähltheoretisch interessanten Passagen, in denen der dramatische Modus zwar noch gegeben ist, im Oszillieren zwischen zitierter und erzählter Figurenrede aber der narrative Modus Einzug erhält:

In diesem Augenblick brachte Herr Fuchs den erbarmungswürdigen Anblick des Alkoholikers (Diese klebrigen Haare! Das lümmelnde Gehen! Diese hängenden, traurigen Schultern! Das labbrige Gesicht! O Gott!) in Zusammenhang mit den ordentlichen Gardinen, hinter denen sich eben doch nicht die Normalität verbarg (Ausschweifung, S. 13).

Wer hält den Anblick für erbarmungswürdig - Erzähler oder Figur? Oder handelt es sich schlicht um in Erzählerbericht eingebettete erlebte Rede à la Buddenbrooks?86 Welche Funktion übernehmen allerdings dann die distanzschaffenden Klammern im Fließtext, die das Potenzial der ,Doppelstimme ${ }^{\prime 87}$ mindern und den sonst im Roman höchst dramatischen Modus unterminieren? Diesen Fragen nachzugehen ist bei Genazino ein nicht nur lohnenswertes, sondern nachgerade unentbehrliches Unterfangen, da über Analysekategorien wie ,Handlung' etc. regelmäßig kein rechter Zugriff auf die Romane möglich und die Figurenanalyse ohne die Analyse der die Figur erzählenden Instanz schlichtweg unmöglich ist.

Die Erzählung von Worten bei Genazino ist freilich nicht so einfach unter einen Hut zu bringen, sind doch die Reflexionspassagen quasi ,Haupthandlung' und deswegen vielgestaltig. Beispiele für größere Distanz ( $\Rightarrow$ II.5.6) finden sich gehäuft in Form von Gesprächsberichten: „Er verkürzte ihr Reden, indem er in ihre Erklärungen hinein aufräumende und erledigende Sätze sagte, und er spürte, wie Frau Kaiser sich unsicher zu fühlen begann, weil sie den Eindruck hatte, es nicht richtig und ausführlich genug erklärt zu haben." (Abschaffel, S. 30) Abgesehen davon, dass Abschaffel eine IM-Strategie $(\Leftrightarrow I .3 .3)$ verfolgt, die sich mit ,Andere-sich-unwohl-fühlen-Lassen $(\Rightarrow$ II.1.4 u. $\Rightarrow$ II.3.5) bezeichnen lässt, liegt in der Grundstruktur eine eher unübliche Raffung vor, die das Tempo und in diesem Fall zugleich die Distanz immer dann erhöht, wenn Gesprächsberichte die Oberhand über direkte Rede gewinnen und der Erzähler eher Zusammenfassungen des Geschehens bzw. der Empfindungen gibt, ohne diese dem Leser im Sinne des ,showings‘ $(\Leftrightarrow I .2 .4)$ wirklich vorzuführen. Außerdem lässt sich konstatieren, dass die Perspektive der

86 Vgl. Martínez/Scheffel: Einführung in die Erzähltheorie, S. 59.

87 Vgl. Martínez/Scheffel: Einführung in die Erzähltheorie, S. 58; vgl. Jochen Vogt: Aspekte erzählender Prosa. Eine Erzähltechnik und Romantheorie. 10. Aufl. Paderborn 2008, S. 164-181. 
44 - Teil I: Grundlagen 2. Wilhelm Genazinos Romanfiguren und ,Figurenromane

Hauptfigur hier ganz deutlich verlassen wird und somit das zweite modale Feld, dasjenige der Fokalisierung, betreten wird.

Für viele Romane Genazinos lässt sich eindeutig die interne Fokalisierung als dominantes Gestaltungsmerkmal erkennen. Beim Regenschirm-Roman etwa wird die Definition dieser Erzählsituation - der ,Erzähler sagt nicht mehr, als die Figur wahrnehmen und wissen kann'- sogar ins Extrem getrieben, indem der Ich-Erzähler eine potenzielle Täuschung seinerseits einräumt (vgl. Regenschirm, S. 54; vgl. Fleck, S. 85; vgl. Regen, S. 9 u. S. 80). Damit ist der Leser zum Mitwisser88 und Mitfühlenden quasi abgestempelt: Alle Äußerungen und Handlungen müssen in der Folge aus einer verhältnismäßig unsicheren Figurenperspektive wahrgenommen werden. Bei Genazino taucht ferner das Wort ,wahrscheinlich' (vgl. Ausschweifung, S. 211) so unglaublich oft auf, um die Wiedergabe von Informationen auf den Wahrnehmungs- und Wissenshorizont des Haupthandelnden zu beschränken. Allerdings „stellt es eher die Ausnahme dar, daß eine Erzählung den gleichen Fokalisierungstyp durchgängig beibehält", 89 und so nimmt es nicht wunder, dass bei Genazino durchaus sowohl der Wechsel zwischen Mit- und Übersicht beobachtbar ist als auch variable Fokalisierungen - häufig in der Form, dass neben der internen Figurenperspektive auch momentweise interne Perspektiven der Mitfiguren anzutreffen sind -, wobei die externe Außensicht beidenfalls zu vernachlässigen ist. ${ }^{90}$ Für die Wechsel von interner und NullFokalisierung gibt es zwei verschiedene Grundmuster: klare Fälle und (spielerische) Unentscheidbarkeiten.

Eindeutigere nullfokalisierte Splitter finden sich expressis verbis etwa in Falsche Jahre, wenn der Erzähler über Abschaffel festhält: „[A]ber da begann er zu weinen. [...] In seinem Zimmer begann er, sich einen Daumenfingernagel abzukrubben, ohne es zu bemerken." (Falsche Jahre, S. 461) „Hier wird der Wahrnehmungshorizont der erlebenden Figur deutlich erkennbar überschritten“,91 hier werden den Figuren selbst nicht zugängliche Bewusstseinsinhalte ebenso erzählt wie die Vogelperspektive mitunter un- oder unterbewusste handlungsmotivationale Aussagen verstatten kann. ,Klassische‘ Marker dafür, die Nullfokalisierung anzunehmen, sind etwa verneinte verba credendi: „Bis zuletzt bemerkte er nicht, daß er lediglich einem Anfall von Heimweh zum Opfer gefallen war“ (Falsche Jahre, S. 450; Herv. N. L.); „Er kam nicht auf den Gedanken, daß es vielleicht zu früh am Tage war“ (Abschaffel, S. 76; Herv. N. L.); „aber diese Erklärung fiel ihm in diesen Augenblicken nicht ein, weil er viel zu sehr mit dem Gewinn seiner gelungenen Verheimlichung beschäftigt war" (Ausschweifung, S. 197; Herv. N. L.). In diesen Passagen, in denen die kommentierende Erzählinstanz mehr weiß als die Figur, werden immer wieder auch vertiefende

88 Vgl. für den Zusammenhang von Figurendarstellung und ,Wissen' auf Autoren- wie Rezipientenseite den anregenden Sammelband von Lilith Jappe/Olav Krämer/Fabian Lampart (Hg.): Figurenwissen. Funktionen von Wissen bei der narrativen Figurendarstellung. Berlin 2012. Martínez/Scheffel: Einführung in die Erzähltheorie, S. 67.

90 Vgl. dazu Martínez/Scheffel: Einführung in die Erzähltheorie, S. 64.

91 Martínez/Scheffel: Einführung in die Erzähltheorie, S. 65. 
Einblicke ins unterbewusste Traum- und Wunschleben ermöglicht: „Anstatt des Worts Betrieb dachte er einmal das Wort Betrüb, aber es fiel ihm nicht auf." (Falsche Jahre, S. 448)

An diese ,klaren Fälle' grenzen Zweifelsfälle, die auch spielerische Aspekte umfassen. Zur engagierten Arbeitsweise auch hinsichtlich des Non- und Paraverbalen $(\Leftrightarrow$ II.1.4) von Eckhard Fuchs etwa heißt es, er speise seine Kraft aus einer unbestimmten Hoffnung auf Besserung seiner Familiensituation, „und mit dieser Hoffnung (in der Wahl seiner Wörter, im Verhalten, in seiner Stimme!) redete er mit Kunden und verkaufte Reifen“ (Ausschweifung, S. 49). Nimmt man an, es handele sich um eine interne Fokalisierung, dann wäre die Klammerkonstruktion obsolet, nimmt man an, es handele sich um eine Nullfokalisierung, dann müsste man immerhin von einem für Genazino unüblich klar konturiertem Erzähler ausgehen, der nachgerade affektiv involviert ist (,!'). Ein Mittelweg in Form von erlebter Rede kommt auch nicht infrage, am ehesten ließe sich noch an Mangolds ,Stimme aus dem Off' (s.o.) denken oder über den Umweg eines unzuverlässigen Erzählers, der sich des Generalverdachts des Lesers ,bewusst' ist, argumentieren. Ein solcher Erzähler könnte stellenweise das Anliegen haben, seine mimetischen Sätze bekräftigen zu müssen - „Stöhnend (er stöhnte tatsächlich)“ (Falsche Jahre, S. 403) - - auf dass der Leser ihm bitte Glauben schenke. Erzähltheoretisch interessant und eigentlich ein auf den ersten Blick klares Signal für das Vorliegen eines wie auch immer gearteten Erzählers mit Übersicht findet sich in Wenn wir Tiere wären: Das erzählende Ich

fühlte kaum, wie mich der Schlaf überwältigte. In meinem schlafgetrübten Bewusstsein meinte ich einmal zu spüren, wie ein Hund an mir schnupperte, was mir gefiel. Fast eine Dreiviertelstunde lang hielt mich der Schlaf gefangen. Ich muss fest geschlafen haben, denn ich merkte nicht, wie ich von dem Baumstamm nach links wegkippte und dann auf der Seite liegend und gekrümmt weiterschlief. (Tiere, S. 30)

Dass es die Hauptfigur eigentlich nicht sein kann, die diese Gedanken sprachlich formuliert, ist insofern offensichtlich, als sie schlichtweg schlafend nicht dazu in der Lage ist, sich selbst zu beobachten und trotz des Kniffes, erzählendes und erzähltes Ich zu separieren (s.u.), ist der Sprecher dieses vorgeblichen Bewusstseinsberichts nicht ohne Weiteres dingfest zu machen. Deduktionen à la Sherlock Holmes zur Auffindposition - ,So und so bin ich aufgewacht, ich muss also so und so gefallen sein...' - oder der kaputten Uhr aus dem Krimi - ,Vor genau 45 Minuten bin ich eingeschlafen, beim Aufprall ist die Uhr stehengeblieben ...' - sind deshalb so absurd, weil es faktisch ein ,Ich' ist, dessen Bewusstseinsbericht der Erzähler ausführt, wohingegen für diese Form der Bewusstseinswiedergabe ein ,Er` erwartbar wäre. Im Kleinen wird bei Genazino mit erzähltechnischen Konventionen - hier: die Unentscheidbarkeit der genauen Fokalisierung gespielt.

Schwierig ist es ebenso, die (seltenen) Nebenfiguren-Mitsichten, die zumindest partiell variable Fokalisierungen in die Romane schleusen, exakt zu fassen. Wenige Beispiele mögen zur Illustration genügen. Natürlich ließe sich über elaborierte argumentative Umwege auch unterstellen, dass Elke Axel ihr Inneres in einem Gespräch, das der Erzähler der Erwähnung nicht für nötig 
46 - Teil I: Grundlagen 2. Wilhelm Genazinos Romanfiguren und ,Figurenromane

befindet, eröffnet habe, doch ungleich wahrscheinlicher ist es, im folgenden Beispiel aus Laslinstraße eine temporäre Innenperspektive anzunehmen: Es „schlich sich plötzlich die Erinnerung in ihren Kopf, weshalb wir eigentlich in die Stadt gegangen waren" (Laslinstraße, S. 145). Auch weitere Romane machen vom Perspektiven-Switch Gebrauch: „Wie weit von ihm saßen seine Frau und sein Sohn!“ (Ausschweifung, S. 122) Die ,erlebte Gedankenrede‘92 als solche ist nicht unüblich bei en gros intern fokalisierten Romanen, allerdings ist eine so zweifelsfreie Mitsicht (sogar mit sehr spärlich verwendetem Ausrufungszeichen) mit einer randständigen Nebenfigur durchaus bemerkenswert.

In Die Ausschweifung finden sich aber auch mehrere hinsichtlich der Fokalisierung strittigere Erzählkonstruktionen: „Möglicherweise hatte er als erster kapiert, daß der neue Mann [...] Löfflers Nachfolger war, der neue Prokurist.“ (Ausschweifung, S. 287) Ein Erzähler als autorisierte Instanz teilt den Fakt mit, dass „der neue Mann“ zugleich „der neue Prokurist“ sei, und gibt sich damit als nullfokalisierter aus. Postwendend ,tut er aber so“ („möglicherweise“), als ob er intern wäre. In diesen Widersprüchen der Festlegbarkeit selbst in den engen Grenzen einzelner Sätze entfaltet sich der Reiz der Konstruktion, der an dieser Stelle nur dann - und: mit Gewalt - Eindeutigkeit aufzuzwingen wäre, wenn man eine Nullfokalisierung annimmt, die zugleich die begrenzte Innensicht thematisieren möchte. Auch das folgende Beispiel verlangt einem dem genauen Blick verpflichteten Analysemodus einiges ab: „Ruth spürte, wie unbeholfen seine Unterhaltungsversuche waren, aber sie griff nicht ein." (Ausschweifung, S. 16) Meint die Hauptfigur, das zu wissen - wenn ja: auf welcher Grundlage -, oder weiß es ein von dieser loslösbarer Erzähler? Es hieße schon, den Leser zum Um-die-Ecke-Denken anzuhalten, diese Passage nicht zunächst als Innensicht Ruths zu rezipieren.

Gendertheoretisch $(\Leftrightarrow$ II.5.3) von Interesse sind insbesondere Beispiele, die insinuieren, dass die männlichen Protagonisten die Wünsche der Damenwelt zu erahnen imstande sind: „Er wußte, daß Dagmar es mochte, morgens im Halbschlaf und im Halbdunkel von ihm gesucht und genommen zu werden; dann hatte sie das Gefühl, für ihn zu einem Schicksal zu werden, und dieses Gefühl ließ sie die Macht spüren, die sie über ihn schon gewonnen hatte.“ (Fremde Kämpfe, S. 12) Ist das eine aus intimen Gesprächen resultierende Erkenntnis des Erzählers oder ein projizierter ,männlicher Blick ${ }^{\prime 93}$ auf Dagmars Sexualpräferenzen? Für erstere Perspektive mag die Gewöhnung in einer längeren und sexuell erfüllten und unverkrampften Beziehung sprechen (vgl. Fremde Kämpfe, S. 12 f., S. 53 f. u. S. 139); die nach dem Semikolon folgende Gefühlswelt in dieser Weise an den Protagonisten übermittelt zu haben, würde aber selbst Wolf Peschek - gleichsam Genazinos ,Kraft-Genie - in eine Vertrauensposition zu seiner Partnerin manövrieren, die - ge-

92 Vgl. Silke Lahn: Präsentation von Rede und mentalen Prozessen [Kap. IV.2.2]. In: dies./Meister: Einführung in die Erzähltextanalyse (2013), S. 116-133, hier S. 127.

93 Vgl. Stefanie Rinke: „...und beauftragte jemanden mit meiner Observation.“ Angestelltenhabitus und Blickökonomie bei Wilhelm Genazino zwischen Moderne und Gegenwart. In: Gisela Ecker/Claudia Lillge (Hg.): Kulturen der Arbeit. München 2011, S. 33-50. 
messen am Roman - unglaubwürdig anmutete. An der Grenze zu einer ,kollektiven Perspektivübernahme‘ mit fremden Passanten bewegt sich der Ich-Erzähler im Regenschirm:

Am Keifen zweier Männer kann ich dann doch erkennen, daß sie gar nichts sehen wollen, sondern etwas erwarten. Sie warten auf den Augenblick, in dem die Frau plötzlich das Geschlecht des Tieres entdeckt. Warum tritt sie nicht einen Schritt zurück und schaut wie zufällig unter den Leib des Tieres? [...] Jetzt! Ein kleiner Schritt zur Seite würde genügen, und der Zwischenfall wäre da. (Regenschirm, S. 10)

Der Ich-Erzähler gibt gewissermaßen den anderen eine Stimme, er schaut durch fremde Augen auf die (Ereignisse der) Welt. Damit ist allerdings die erzähltheoretische Sphäre bereits weit in Richtung,Reich der Interpretation' überschritten.

Unter der narratologischen Kategorie ,Stimme‘ werden die folgenden Aspekte zusammengefasst: ,Zeitpunkt', ,Ort', ,Stellung des Erzählers zum Geschehen' sowie ,Subjekt und Adressat'. ${ }^{94}$

Für die ,Präsensbücher ${ }^{\prime} \Leftrightarrow$ I.2.1/ $\Rightarrow$ Tabelle 1), wie etwa Ein Regenschirm für diesen Tag, lässt sich der Zeitpunkt mit gleichzeitigem Erzählen angeben, das - in den Analepsen - durch späteres unterbrochen wird. Ansonsten ist von späterem Erzählen auszugehen. Allerdings scheint die Tempus-Wahl tendenziell unabhängig von der Gleichzeitigkeit zu erfolgen: Viele im Präteritum verfassten Romane ,funktionieren' eins-zu-eins so wie die präsentischen. Am ehesten wird man Genazinos Komposition gerecht, wenn man die Zeitlosigkeit, ja die überzeitliche Gültigkeit in Anschlag bringt: Viele Erlebnisse und Reflexionen wären in den 1950ern ebenso zu erleben gewesen wie in den 2000ern $(\Rightarrow I .5 .3)$ :

Bekannt ist, dass Genazino keinen Computer besitzt, nicht einmal eine elektrische, sondern eine mechanische Schreibmaschine benutzt. Er hat, wie er gern in Interviews erzählt, kein Handy, keinen Fernseher und kein Auto. Man mag dies als liebenswürdige Marotten eines alternden Schriftstellers abtun, doch es hat Konsequenzen für die Literatur. Gegenwärtige Realität scheint in Genazinos Romanen seltsam ausgeblendet: Da kennt ein Zeitungsredakteur weder Internet noch Laptop, und den Flaneuren gerät nicht in den Blick, dass die Passanten auf der Straße mit Smartphones und Tablets beschäftigt sind..$^{95}$

Für den Ort des Erzählens lässt sich unisono konstatieren, dass extradiegetisch erzählt wird, mithin keinerlei Rahmung erkennbar ist. 96

Ergiebiger für die Kartografie von Genazinos Roman-Welt ist die Stellung des Erzählers zum Geschehen. Denn obwohl sich die Frage nach heterodiegetisch vs. homodiegetisch schnell damit beantworten lässt, dass die fünf Erzählungen in der dritten Person ( $\Rightarrow$ I.2.1) heterodiegetische Erzähler haben, ${ }^{97}$ es sich bei den sechzehn Ich-Erzählungen um prototypisch homodiegetische Erzählungen handelt, die genaugenommen sogar autodiegetische (Erzähler $=$ Hauptfigur) sind, ${ }^{98}$

94 Vgl. Martínez/Scheffel: Einführung in die Erzähltheorie, S. 67-89.

95 Reschke: [Wilhelm Genazino].

96 Ausnahme: Das Licht brennt ein Loch in den Tag mit Briefroman-Form ( $\Rightarrow$ I.2.1/Tab. 1).

97 Vgl. dazu kritisch Köppe/Kindt: Erzähltheorie, die Martínez'/Scheffels - und damit Genettes - Definition, nach der nur homodiegetische Erzähler „Teil der erzählten Welt“ (Köppe/Kindt: Erzähltheorie, S. 94) sind, hinterfragen. Vgl. für den bemerkenswerten, temporären Wechsel vom Ich- zum ErErzählen in Laslinstraße das Kapitel zum Selbst $(\Leftrightarrow I .4)$.

98 Vgl. dazu Martínez/Scheffel: Einführung in die Erzähltheorie, S. 81 f. 
fangen, gerade bezogen auf die Ich-Erzähler, damit erst die Fragen an. „In aufgeräumter Stimmung begebe ich mich eine halbe Stunde später nach unten und begrüße die Seminarteilnehmer mit einer kurzen launigen Rede. Hinterher plaudere ich mit den Leuten auf eine Art, die ich sogar selbst als charmant empfinden muß." (Liebesblödigkeit, S. 72) Ohne größere Redundanzen mit dem Kapitel zum Selbst $(\Leftrightarrow I .4)$ zu riskieren, lässt sich hier die prinzipielle Dopplung eines jeden Ich-Erzählers sowohl prinzipiell in Augenschein nehmen als auch erneut auf die metatheoretische Machart der Genazino'schen Textkompositionen verweisen: Das Ich-Erzähler-Selbst ist selbst in Kommunikationssituationen, in denen der Großteil der Aufmerksamkeit eigentlich auf das allmähliche Verfertigen der Gedanken beim Reden gerichtet sein sollte, ,nicht bei sich selbst', sondern in der Doppelperspektive, zusätzlich von außen auf sich zu sehen, befangen ( $\Rightarrow$ II.2.4).

Franziska Diller bestimmt in ihrer Dissertation Einheit in der Differenz - Die innere Struktur des Erzähler-Ichs „das grundlegende Verhältnis von erlebendem und erzählendem Ich genauer“, 99 als es gemeinhin getan wird. Am Ende ihrer Bestandsaufnahme - und bevor sie eigene Lösungsansätze vorstellt - bringt die Autorin das Kernproblem - im Rückgriff auf Constantinescus Selbstvermöglichungsstrategien des Erzählers im modernen Roman - mit den Worten auf den Punkt:

Auf der einen Seite existiert eine übermächtige Instanz, die die Erzählung kontrolliert und über ihr steht, auf der anderen Seite kann es diese Instanz nicht geben, wenn das erlebende Ich und das erzählende Ich eins sind und darin den Erzähler darstellen. [...] Auf der einen Seite ist das ErzählerIch eine ,Person', die eine normale Lebensgeschichte fingierend, sich an die Stadien seiner selbst zurückerinnert und diese niederschreibt. Diese sogenannte Erzählerillusion entsteht durch das Vermitteln der Einheitsaspekte. [...] Demgegenüber existiert aber eine weitere ,Persona' des Erzählers, nämlich der Erzähler als Schöpfer der Erzählung; das Ich, welches die Erzählung in seinem Schreiben erzeugt. Als Demiurg kann die Vorstellung eines anthropomorphen Erzählers nicht aufrecht erhalten werden [...]. Diese Position ist als Erzählerfunktion zu verstehen. [...] Gerade der Widerspruch aus Einheits- und Differenzmerkmalen, welcher die Opposition aus Authentifizierung und Fiktionalisierung, die unterschiedlichen Ebenen der Funktion, das besondere Subjekt-ObjektVerhältnis zwischen erlebendem und erzählendem Ich sowie das Performativ des Erzählers mit einschließt, erweist sich als konstitutiv für die Ich-Erzählung [...].100

Nachdem Diller im Folgenden ein Lösungsmodell für das als unlösbar geltende ,Problem` entwickelt hat, ${ }^{101}$ macht sie sich an die praktische Anwendung und wählt unter anderem den Roman Mittelmäßiges Heimweh von Genazino als Untersuchungsgegenstand. Sie kommt zu der Einschätzung,

die besondere Erzählsituation des präsentischen Erzählens weite[] [...] die Ebene, die dem erzählenden Ich zuzuordnen ist, in außergewöhnlichem Maße aus. Das erlebende Ich kann kaum noch ausfindig gemacht werden, da es in eine weit zurückliegende Vergangenheit verdrängt und in der Gegenwart des erzählenden Ichs kaum aufzufinden ist. Dem erzählenden Ich ist somit die Möglichkeit der Manifestation in der Diegesis genommen. Die Loslösung von der erzählten Welt, die sich aus der Entkoppelung vom erlebenden Ich [...] ergibt, führt dazu, dass sich dem Ich die Möglichkeit der Selbsterkenntnis entzieht. Es kann sich weder im ,Anderen' des erlebenden Ichs noch in der erzählten Welt wiederfinden und erkennen. Im Fehlen eines Gegenübers kann keine Kontrastierung S. 11.

100 Diller: Einheit in der Differenz, S. 105 f.

101 Vgl. Diller: Einheit in der Differenz, S. 107-185. 
der beiden Ich-Pole stattfinden, was oberflächlich ein fast einheitliches Identitätskonzept entwirft. Denn auch wenn die beiden Funktionen so weit voneinander getrennt sind wie dies selten in anderen Romanen zu beobachten ist, erscheint es doch so, als gäbe es kaum einen Konflikt zwischen erlebendem und erzählendem Ich. Eine ausgeprägte Erzählerillusion ist die Folge. ${ }^{102}$

Obwohl Dillers Genazino-Fazit sicherlich in einigen Punkten vollumfänglich zuzustimmen ist, und obwohl sie hinzusetzt, dass es selbst im Roman Mittelmäßiges Heimweh auch funktionale Aspekte des Ich-Erzählers gibt, ${ }^{103}$ kann es hinsichtlich des gesamten Romanwerks Genazinos nicht überzeugen, ${ }^{104}$ gibt es doch dort definitiv riesige „Konflikt[e] zwischen erlebendem und erzählendem Ich“, und wird doch das prinzipielle ,Doppel-Ich-Problem‘ in anderen Romanen durchaus selbstreflexiv thematisiert: „Und ich schaue umher, ob ich mich nicht als empörtes Kind irgendwo herumlungern sehe." (Regenschirm, S. 127)105

Für eine dezidierte Einzelfallanalyse, wie weit Ich und Ich jeweils auseinanderklaffen, ist in dieser Arbeit nicht nur kein Raum, sondern es besteht auch keine Notwendigkeit für das Vorhaben, globale Eigenarten der Roman-Welt Genazinos zu vermerken. Diesbezüglich bleibt vielmehr Hirsch zuzustimmen, dass die Wahl eines Ich-Erzählers nicht notwendigerweise mit einer Distanzabnahme im Vergleich zur intern fokalisierten Er-Erzählung zusammenfällt; ist doch die Dopplung von erzählendem und erlebendem Ich durchaus auch eine kleine oder eben größere Distanzquelle. ${ }^{106}$

Als letzte unter ,Stimme' firmierende narratologische Kategorie gilt es, das Verhältnis von Subjekt und Adressat des Erzählens genauer zu bestimmen: „Wer erzählt wem?“"107 Auch abseits von eindeutigen und literarhistorisch wohl bekannten Signalen wie „Lieber Leser“108 ist das extradiegetische Verhältnis von Erzähler und Rezipient von großem Interesse bei der Analyse.109 Welche Rolle weist die Textkomposition dem Adressaten zu? Einzelne Aspekte sind bereits überzeugend erklärt worden: Mangolds Einschätzung, dass der Erzähler „dem Leser ins Gesicht guckt“, das Spiel der Erzähler, die Erwartungshaltung des Lesers (etwa hinsichtlich der wahrscheinlich folgenden Figurentätigkeiten) zu berücksichtigen, sowie die Anmerkungen zum unzu-

102 Diller: Einheit in der Differenz, S. 304

103 Vgl. Diller: Einheit in der Differenz, S. 304.

104 Oftmals allerdings handelt es sich um eine - im Sinne Dillers - Überpointierung der ,Einheitsillusion', wie etwa im Roman Tiere: „Meine Verwandtschaft war (ist) nicht besonders wohlhabend.“ (Tiere, S. 11)

Für die - bezogen auf Mittelmäßiges Heimweh - eher untypische narratologische Konstellation lässt sich übrigens in Anschlag bringen, dass es der Roman der dezidierten Fremdbeobachtung ist $(\Leftrightarrow$ V.1) - ein verhältnismäßig konsistentes Ich muss also erzähltechnisch konstituiert werden, um dieses infrage stellen zu können.

106 Vgl. Hirsch: „Schwebeglück der Literatur“, S. 96 f.

107 Martínez/Scheffel: Einführung in die Erzähltheorie, S. 84-89; hier: S. 84. Wobei hier über Genette in der Taxonomie von Martínez/Scheffel insofern hinausgegangen wird, als auch Konzepte wie ,impliziter Autor/Leser' Verwendung finden.

108 Vgl. Martínez/Scheffel: Einführung in die Erzähltheorie, S. 87.

109 Dass es sich bei den meisten Untersuchungen, die sich theoretisch oder empirisch mit Lesen und Lesern auseinandersetzen, üblicherweise um solche handelt, die einen ,naiven' Leser annehmen und zugleich der Illusion erliegen, selbst auf einem höheren Ross zu sitzen, sei nur en passant kritisch angemerkt. 
50 - Teil I: Grundlagen 2. Wilhelm Genazinos Romanfiguren und ,Figurenromane‘

verlässigen Erzählen. Von der Rezeptionsästhetik über die Lesersoziologie bis zu den Kognitionswissenschaften beschäftigen sich verschiedene Forschungszweige mit der Rolle des Lesers im literarischen Kommunikationsprozess:110 Der Leser stiftet Sinn, Lebenswelt und Vita bestimmen seine Interpretation und die konkrete ,Füllung der Leerstellen` (Iser), erzählte Welten und auch Figuren entstehen letztlich erst in seinem Kopf. Zur Rolle der Leserinstanz bei Genazino formuliert Roman Bucheli:

Und was dem Leser die Romanfiguren vormachten, wurde nun auch ihm abverlangt. Die Geschichte hatte er sich schon selber zu erzählen, denn die Bücher sollten fortan nur noch Bruchstücke enthalten, den Bausatz sozusagen; die Bauanleitung musste sich der Leser selber besorgen, aus seinem eigenen Repertoire. Nun ließ ihm der Roman den Spielraum, in dem sich der ,Roman des Lesers' zutragen konnte. War er früher Zuschauer, gar ein wenig Voyeur, wenn er den Figuren bei ihrem Ungeschick über die Schultern schaute und ihnen ohne Scham ins Boudoir folgte, scheinen die Figuren in Genazinos neueren Romanen mit einer solchen Unverfrorenheit aus den Büchern heraus geradewegs zu den Lesern zu sprechen, dass sich dieser als Beobachter alsbald beim Beobachten ertappt fühlen muss. ${ }^{111}$

Es geht hier nicht darum, erneut nach Grenzziehungen in Genazinos Roman-Werk zu fragen, aber die Leserrolle und deren Verhältnis zur Diegese verdienen Beachtung. ${ }^{112}$ Ähnlich wie (und früher als) Mangold unterstellt Bucheli den Erzählern, ihre Adressaten nicht (nur) im intradiegetischen Bezirk zu suchen, sondern (auch) mit metaleptischem Beigeschmack im extradiegetischen. Aber wer genau erzählt wem, wenn der Ich-Erzähler des Romans Außer uns spricht niemand über uns ,sagt': „Kaum saß ich, erinnerte ich mich an Frau (der Name wird vom Erinnerer verschwiegen), die auf ihrem Schreibtisch im Sender ein kleines Radio stehen hatte" (Außer uns, S. 137)? Wilhelm Genazino dem konkreten Leser? Ein impliziter Autor kann es laut Definition dem impliziten Leser - seinem Gegenüber - nicht erzählen, da weder Normen noch Werte in Frage stehen. Aber typischerweise haben auch fiktionale Texte einen Empfänger ,im Sinn':

Die Rolle des Adressaten ist im hohen Maße kommunikationsrelevant [...], denn aus der Ausrichtung des Erzählers am Adressaten ist das Bild rekonstruierbar, das er von seinem fiktiven Leser hat. So nimmt zum Beispiel das vom Erzähler angenommene Vorwissen des Adressaten Einfluss auf die Quantität der Informationen, die er vergibt. Auch richtet sich der Erzähler nach den beim Adressaten vermuteten Normen moralischer und sozialer Art und passt seinen sprachlichen Duktus entsprechend an. Darüber hinaus kann der Erzähler mögliche Reaktionen des vorgestellten Adressaten antizipieren und in seinem Sinne regulierend gegensteuern. ${ }^{113}$

Ob der Erzähler den ,fiktiven Leser' mit der 'Schwärzung' des Namens nun insofern täuschen möchte, als dieser eben doch Erzähler und Autor - quasi als Authentizitätsbeglaubigung gleichsetzen soll, oder ob der Erzähler „mit einer solchen Unverfrorenheit aus den Büchern ge-

\footnotetext{
110 Eine wegweisende Untersuchung ist etwa Ralf Schneiders 2000 in Tübingen erschienener Grundri $\beta$ zur kognitiven Theorie der Figurenrezeption am Beispiel des viktorianischen Romans. Auch die vorliegende Studie bezieht Impulse der kognitionswissenschaftlichen Ausrichtung mit ein $(\Rightarrow I$ I.3.1).

111 Bucheli: Die Begierde des Rettens, S. 51.

112 Vgl. Alexandra Pontzen: Banalität und Empfindsamkeit. Wilhelm Genazinos Poetik alltäglicher Gefühle. In: Preusser/Visser (Hg.): Alltag als Genre (2009), S. 231-244.

113 Silke Lahn: Wer erzählt die Geschichte? Parameter des Erzählers [Kap. IV.1]. In: dies./Meister: Einführung in die Erzähltextanalyse (2013), S. 61-100, hier S. 97.
} 
radewegs zu den Lesern“ spricht, kann und muss nicht entschieden werden. Dass die Erzähler allerdings in einer wie auch immer gearteten Weise ,steuernd' die Größe ,Rezipient' mit denken,114 bestätigt neben Mangold und Bucheli auch die seit dem Frühwerk Genazinos musterhafte ,Angewohnheit' der Erzähler, sich selbst als solche zu erkennen zu geben:, Tatsächlich machte er sich frisch und zog sich an." (Falsche Jahre, S. 505) Der Leser hatte begründet erwarten können, dass Abschaffel sein Vorhaben - wie üblich - nicht in die Tat würde umsetzen ( $\Rightarrow$ II.2.6), und so ist das ,tatsächlich' einerseits der mögliche Ausdruck von Überraschung über sich selbst auf intradiegetischer Ebene, andererseits aber definitiv auch an den extradiegetischen (fiktiven) Leser gerichtet. Bei Genazino gibt sich diese Ambivalenz häufig durch die Verwendung von Klammern oder Schrägstrichen zu erkennen: „Er ist offenkundig (ähnlich wie Susanne) von meiner Wichtigkeit/Hintergründigkeit/Bedeutsamkeit überzeugt, mehr noch, er schreibt mir Einfluß in der Stadt zu." (Regenschirm, S. 107) Der Erzähler scheint nicht nur der Meinung zu sein, seinem Adressaten parenthetisch erneut ins Gedächtnis rufen zu müssen, dass Susanne den Protagonisten aus dessen Sicht überschätze, sondern er sieht sich auch bemüßigt, dem Adressaten - im Sinne von Buchelis „Bausatz“ - gleich drei Bedeutungskonzepte vorzulegen, aus denen sich der Leser ,seinen Roman` zusammenfügen kann/soll/muss. ${ }^{115}$

\section{INHALT}

Unterschieden werden thematische, stoffliche, motivische, raumkonzeptionelle sowie kompositionsstrukturelle Aspekte.116 Die Kategorie ,Thema' der Inhaltsanalyse, die sich etwa für den Roman Ein Regenschirm für diesen Tag mit ,Distanzierte Beobachtung und reflektierende Weltwahrnehmung eines Flaneurs (im ausgehenden zwanzigsten Jahrhundert)‘ angeben ließe, ist zu divers, um Aussagen für das Gesamt-Werk treffen zu können. ${ }^{117}$ Klarer, weil einheitlicher, verhält es sich mit der Kategorie des Stoffes: Kein Stoff der Weltliteratur wird in Reinform bei Genazino verhandelt und es erforderte größere Verbiegungen, einen feststellen zu wollen.

Ganz anders ist die Situation in Bezug auf die Motive zu bewerten: Neben den weiter oben verhandelten immer wiederkehrenden ( $\Rightarrow$ I.22) lässt sich ein Blick werfen auf die Motive der Weltliteratur, ${ }^{118}$ um die bereits angerissene Einordnung in die Literarhistorie $(\Rightarrow$ I.2) gewissermaßen

\footnotetext{
114 Vgl. zur vorsichtigen Kritik daran etwa Köppe/Kindt: Erzähltheorie, S. 235 f.

115 Vgl. sowohl zur Konzeption des ,Ideallesers' bei Genazino als auch zur externen Motivierung, bei der „eine Figur [...] in bestimmter Weise [handelt], weil Leser dieses Verhalten von einer entsprechenden Figur erwarten“, Köppe/Kindt: Erzähltheorie, S. $150(\Leftrightarrow$ I.3.1).

116 Entgegen der bei Schneider vorgeschlagenen Subsumierung der „Zeitkonzeptionsanalyse“ unter die Inhaltsanalyse (vgl. Schneider: Einführung in die Roman-Analyse, S. 34 ff.) ist die Kategorie bereits unter der Erzähltheorie verbucht worden.

117 Diejenigen Kategorien sowohl zum Inhalt als auch zum Stil, die sich nicht mustergültig, aber graduell verallgemeinern lassen, werden der Übersichtlichkeit halber im Sinne eines Pars-pro-toto etwa am Beispiel des Romans Ein Regenschirm für diesen Tag durchexerziert.

118 Elisabeth Frenzel: Motive der Weltliteratur. Ein Lexikon dichtungsgeschichtlicher Längsschnitte. 5., überarb. u. erg. Aufl. Stuttgart 1999. Vgl. auch Horst S. Daemmrich/Ingrid G. Daemmrich: Themen und Motive in der Literatur. Ein Handbuch. 2., überarb. u. erw. Aufl. Tübingen 1995.
} 
fortzuführen. Allein im Regenschirm-Roman kreuzen sich etliche Traditionslinien: „Die verletzte Gattenehre“; „Die heimliche Liebesbeziehung“; „Nebenbuhlerschaft“;119 „Hochstapler“; „Mann zwischen zwei Frauen“; „Der Mißvergnügte“; „Der Sonderling“. Es ist überraschend, wie vielfältige Motivketten ein einziger Genazino-Roman aufweist. Allerdings muss man aufpassen, dass die Motividentifikation nicht zum Selbstzweck gerät. Außerdem sind - gerade für die ,abgespeckten“ Nebenmotive (hier etwa: „Hochstapler“) - Kenntnisse ihrer Jahrhunderte alten literarischen Verarbeitungen für weiterführende Interpretationen unerheblich bis überflüssig. Allerdings gibt es auch hilfreiche Einsichten: Nicht nur für Ein Regenschirm für diesen Tag sind namentlich der „Mißvergnügte“ und der „Sonderling“ von einiger Relevanz. Denn Genazinos Figuren kennzeichnet eine „Unzufriedenheit nicht nur mit den Verhältnissen, sondern mit dem Leben überhaupt",120 Melancholie, ein

vom Durchschnittlichen abweichendes Verhalten, eine partielle Unangepaßtheit und ein Eigenbrötlertum [...], das ihnen ein hilflos-rührendes bis lächerliches Ansehen verleiht. Sonderlinge gehen bestimmten, nicht allgemein verbreiteten Neigungen nach [Blätterzimmer!; N. L.], leben nach Ideen, die nicht oder nicht mehr die der Allgemeinheit sind, fühlen sich von Abneigungen oder Ängsten ergriffen, die andere Menschen zu überwinden vermögen, setzen sich, ohne aggressiv zu werden, über die Gesellschaft und ihre Maßstäbe hinweg und sehen ihre Selbstverwirklichung in anderen Lebensformen [Schuhtester, Institut für Mnemosyne; N. L.] als den üblichen.121

Damit ist hinwiederum definitiv ein interpretativer Ansatz gegeben, unter welchem die Protagonisten sich näher betrachten lassen, „setzte sich [doch] das Sonderling-Motiv in einer Reihe von Gestalten durch, die ihren einzelgängerischen Neigungen und ziellosen Träumen nachgehen, um sich einer an Tüchtigkeit und Leistung orientierten Welt zu entziehen. "122 ( $\Rightarrow$ II.2.6)

Raumkonzeptionsanalytisch ( $\Rightarrow$ II.1.5 u. $\Rightarrow$ II.2.5) lässt sich - nicht nur für den Regenschirm festhalten, dass es sich um durchweg realistische Räume handelt, die in gleichem Maße auch als konkrete zu klassifizieren sind. Bei Genazino findet man immer wieder versteckte Hinweise darauf, dass es sich um ein fiktionalisiertes Frankfurt (alternativ: Mannheim) ${ }^{123}$ handelt, häufig sogar bestimmte Viertel beschrieben werden. ${ }^{124}$ Es sind - gerade bei einem krankhaft peniblen

119 „Da öffnet sich die Tür, und aus Margots Salon tritt Himmelsbach heraus. Das hätte nicht passieren dürfen. [...] Leider werde ich eifersüchtig, sogar auf der Straße" (Regenschirm, S. 90; vgl. Regenschirm, S. 130 f.).

$120 \quad$ Frenzel: Motive der Weltliteratur, S. 533.

121 Frenzel: Motive der Weltliteratur, S. 643.

122 Frenzel: Motive der Weltliteratur, S. 656.

123 In Laslinstraße, S. 64, ist von Groß Gerau-Dornberg die Rede; in Falsche Jahre, S. 550, von Frankfurt und auch Ausschweifung und Wohnung scheinen in Bornheim zu spielen.

124 Meistens fungiert die Stadt als merkwürdigerweise positiv und in ihrer undurchschaubaren Art tröstend empfundener locus amoenus (vgl. etwa Fremde Kämpfe, S. 62 f.) im Kontrast zum Land: „Das Nebeneinander von stillgelegten Bauernhöfen und billigen Sozialwohnungen machte sie gesichtslos und kränkelnd: das eine klappte nicht mehr und das andere klappte niemals." (Fremde Kämpfe, S. 81) Vgl. dementsprechend: „Er war Natur überhaupt nicht gewohnt. Er war in einer Stadt aufgewachsen" (Falsche Jahre, S. 414). Der absolute Kontrast einer nahezu rousseauistischen Landflucht als Besänftigungsstrategie erfährt der Protagonist aus Kein Geld, keine Uhr, keine Mütze auf einem Bauernmarkt (vgl. Kein Geld, S. 144). Vgl. zu einer Verbindung von raumtheoretischen, architektonischen und konsumkritischen Aspekten bei Genazino Neumann: „Der letzte Strich des Flaneurs", S. $150 \mathrm{ff}$. 
Beobachter - Schauplatzbeschreibungen von Detailreichtum, die auch „das gesellschaftliche Milieu und den Bildungshintergrund der (Haupt-)Figuren illustrieren sollen. "125 Sympathetische Hintergründe findet man im Text allerorts: Das Blätterzimmer bspw., das tief in die Psyche der Figur blicken lässt, wird stets als locus amoenus gezeichnet; Orte mit Insignien des ,modernen Lebens' - gerade dann, wenn es sich um Konsumgüter oder Technik handelt - und solche mit Menschenmassen konnotierte als locus terribilis (vgl. Regenschirm, S. 172 f.; $\Rightarrow$ II.1.4 u. $\Rightarrow$ II.1.6). Hinsichtlich der Kompositionsstrukturanalyse lassen sich vier verschiedene Ebenen unterscheiden. „Auf einer ersten Ebene geht es um die Verteilung von Aktions-, Deskriptions-, Dialog- und Reflexionssequenzen“.126 Bei Genazino im Allgemeinen, bei Ein Regenschirm für diesen Tag im Speziellen, überwiegen die Deskriptions- und Reflexionssequenzen massiv die Dialog- und Aktionssequenzen:

Zwei Schüler stehen von einer Litfaß-Säule und spucken auf ein Plakat. Dann lachen sie über die Spucke, die die Litfaß-Säule herunterrinnt. [Desk.; N. L.] Ich gehe ein wenig schneller; [Akt.; N. L.] früher war ich solchen Vorkommnissen gegenüber viel duldsamer. [Desk./Refl.; N. L.] Ich bedaure, daß ich neuerdings so schnell abgestoßen bin. [Refl.; N. L.] Wieder fliegen ein paar Schwalben durch die Fußgänger-Unterführung. Sie stürzen die U-Bahn-Station hinab und stoßen acht oder neun Sekunden später durch den gegenüberliegenden Ausgang wieder nach oben. [Desk.; N. L.] Ich würde gerne selber die Fußgänger-Unterführung durchqueren und mich dabei seitlich von den rasenden Schwalben überholen lassen. Aber diesen Fehler darf ich nicht noch einmal machen. Vor etwa zwei Wochen [Desk./Refl.; N. L.] (Regenschirm, S. 7).

Effektiv bewegt sich der Ich-Erzähler auf den zwei hier zusammengeschnittenen Druckseiten ca. 50 Meter - man merkt schnell: „es ist nicht so wichtig, was sich ereignet und was dann geschieht, aber wichtig ist, daß jemand durch die Welt geht wie ein Kind, mit den Techniken des Sehens, die ein Kind entwickelt, und sich mit diesen Techniken einen Reim auf die Welt machen möchte. ${ }^{127}$ Hier geht es darum, wie sich was im Bewusstsein der Figur spiegelt und weitaus weniger darum, was sich in der erzählten Welt ereignet. ${ }^{128}$

Auf der zweiten Ebene, derjenigen der „Positionierung und Proportionierung von Haupt- und Nebenhandlungen“,129 fällt eine globale Entscheidung schon für Genazinos Ein Regenschirm für diesen Tag derart schwer, dass man die diesbezügliche erzähltheoretische Fader-Signatur definitiv nicht als ,genazinoesk‘ klassifizieren kann. Für den konkreten Roman Ein Regenschirm für diesen Tag könnte man eine Ebene einziehen und sie ,Beziehung‘ nennen. Dann müsste man alle zielgerichteten Aktivitäten und Ereignisse, die mit geistigen oder körperlichen Verbindung zu vergangenen und gegenwärtigen Frauen zusammenhängen, auflisten und gewichten. Eine weitere Ebene könnte ,Erwerbsleben` heißen, eine dritte ,Selbstverwirklichung‘. Die Beliebigkeit de-

\footnotetext{
125 Schneider: Einführung in die Roman-Analyse, S. 34.

126 Schneider: Einführung in die Roman-Analyse, S. 36.

127 Christian Scholz/Wilhelm Genazino: „Ich bringe ja auch das Bild in Schwung“. Ein Gespräch mit dem Schriftsteller Wilhelm Genazino über Photographie. In: Neue Zürcher Zeitung vom 07 Mai 2001. Zit. n. Bucheli: Die Begierde des Rettens, S. 50 f.

128 Vgl. Hirsch: „Schwebeglück der Literatur“, S. 16 f.

129 Schneider: Einführung in die Roman-Analyse, S. $36 \mathrm{f}$.
} 
kuvriert sich selbst, wenn man die Haupthandlung gleichsetzte mit dem Bewusstseinsbericht des Erzählers.

„Auf einer dritten Ebene der Kompositionsanalyse beschäftigen wir uns mit der Struktur des Handlungsverlaufs, wobei in der Hauptsache zwischen dramatischer, episodischer und isotroper Handlungsstruktur zu unterscheiden ist." ${ }^{130}$ Da sich die Hauptfigur (aus dem RegenschirmRoman) definitiv nicht „nach erfolgter Exposition einem Problem, einer Aufgabe oder einem Konflikt gegenübergestellt" sieht und auch weder eine ,Lösung' noch eine ,Aussicht' am Ende stehen, ${ }^{131}$ scheidet die dramatische Struktur - bis auf wenige Ausnahmen - für Genazinos Roman(e) aus. Vielmehr handelt es sich um eine Mischung aus episodischer und isotroper Organisation, da es durchaus Passagen gibt, „die in sich dramatisch strukturiert sind [episodisch; N.L.]“,132 vielerorts die Handlung aber auch „gleichbleibend und gleichförmig vorausschreitet, ohne dass dramatische Höhen und Tiefen zu verzeichnen wären [isotrop; N. L.]“.133 Häufig sind auch die Episoden dem äußeren Handlungsgeschehen nach wie ein Mini-Drama mit Höhepunkt aufgebaut, werden aber im Bewusstsein eintönig gespiegelt und unaufgeregt bis antiemotional $\Leftrightarrow$ ( $\Rightarrow$ II.5.6) erzählt:

\begin{abstract}
Sie löst die Verschnürung des Umhangs und rasiert den Nacken aus. Die Katze reckt den Kopf, Margot schaltet das Kofferradio ab. An der Kasse küssen wir uns, genau wie beim letzten Mal vor etwa drei Wochen. Immer noch will ich keine neue Liebesgeschichte. Ich glaube, ich kann die Sätze nicht mehr sagen und nicht mehr hören, die im Verlauf einer Liebesaffäre ausgesprochen werden müssen. Dabei macht Margot es mir leicht. Sie spricht zwar relativ viel, aber das gewöhnliche Liebesgerede kommt nicht von ihr. Ich stecke meine Brieftasche wieder ein. Margot schließt die Ladentür ab, ich folge ihr nach hinten in das Zimmer, das sich seitlich an die Damenabteilung anschließt. Es ist nicht das erste Mal, daß Margot und ich im Anschluß an das Haareschneiden miteinander schlafen. Der Rolladen ist zur Hälfte herabgelassen. Durch eine dicht anliegende Gardine hindurch sehe ich auf einen leeren Innenhof, in dem beim vorigen Mal ein paar Kinder spielten. Heute entdecke ich nur einen kleinen Vogelkäfig im Fenster eines seitlich gelegenen Hauses. Erst jetzt fällt mir auf, daß meine Brille noch auf dem Rand des Waschbeckens liegen muß. Ohne Brille kann ich die beiden Vögel in dem Käfig nicht als Vögel erkennen, sondern nur als zwei bewegliche Flecke. Weil ich ohne Brille bin, kommt mir die Situation trotz ihrer Fremdheit auch intim vor. Nur zu Hause erlaube ich mir, die Brille über längere Zeit abzulegen. Das Umhergehen und Umhersehen ohne Brille ist für mich wie eine Erlaubnis zum zerbröckelnden Leben. Margot ist schon entkleidet. Ich komme nicht auf den Gedanken, daß sie es eilig haben könnte. Sie hilft mir beim Öffnen der Hemdenknöpfe und beim Aufknoten der Schnürsenkel. Wenn ich mich nicht täusche, schert sich Margot nicht viel darum, daß ich vielleicht nicht recht in Liebesstimmung bin. Sie erinnert mich an die Männer, von denen es immer heißt, sie schlafen auch dann mit ihren Frauen, wenn diese gar nicht wollen. Ich meine zu fühlen, daß es ihr Vergnügen macht, mir beim Ausziehen behilflich zu sein. Offenbar schätzt sie diese kleinen komischen Abenteuer während eines langen Arbeitstages. Wieder, wie schon voriges Mal, setzt sie sich auf die Couch, zieht mich zu sich heran und lutscht mir das Geschlecht. Ich sehe abwechselnd auf die beiden beweglichen Flecke am Fenster gegenüber und auf die drei Frisierhauben in der Damenabteilung. (Regenschirm, S. 53 f.)
\end{abstract}

Es ist eine unbestreitbare Tatsache, dass sich etwas ereignet, was sich auf einem Spannungsbogen abzeichnen ließe, und mithin zumindest episodisch genannt zu werden verdiente. Die Dar-

130 Schneider: Einführung in die Roman-Analyse, S. 37.

131 Schneider: Einführung in die Roman-Analyse, S. 37.

132 Schneider: Einführung in die Roman-Analyse, S. 37. Vgl. Regenschirm, S. 19 f., für den zumindest im Vergleich fulminanten Diebstahl von Rasierklingen.

133 Schneider: Einführung in die Roman-Analyse, S. 37. 
stellungsform hingegen überführt das Geschehen in erzähltechnische Isotropie. In einem Interview hat Genazino diesen Sachverhalt derart gefasst:

Es gibt bei aller Abwesenheit von Handlung und Action doch eine Verlaufskurve, auch mit Handlung, wenn sie auch noch so unscheinbar ist. [...]. Man kann nicht sagen, es geht um nichts, sondern es geht eigentlich um die letzten Dinge, es geht tatsächlich um Leben und Tod im Sinne von: Gelingt das Leben oder scheitert es? Es geht eigentlich um riesige Angelegenheiten, die da dauernd hinund herbewegt werden - unter Vortäuschung von geringfügigen Dingen. ${ }^{134}$

Auf der vierten Ebene der „Segmentierung“ können kompositionsstrukturell äußere - „optisch erkennbare Untergliederung des Textes durch Absätze, Leerzeilen und Buch- oder Kapitelüberschriften“ - von inneren - "thematisch-inhaltliche Sinnabschnitte“ - Strukturmerkmalen gesondert werden. ${ }^{135}$ Für den Regenschirm hieße das konkret: Der Roman besteht aus elf Kapiteln mit jeweils ca. 15 Druck-Seiten, es gibt keine größeren Sprünge (weder zeitlich noch mit viel dazwischenliegender Handlung, auf die Bezug genommen wird), durchschnittlich viele Schauplatzund nahezu keine Figurenwechsel. Indessen sind bei der inneren Segmentierung große Gedankensprünge möglich:

Ich schalte den Fernsehapparat ab. Ein Hemdknopf löst sich und rollt ein Stück auf dem Boden entlang. Ich schaue ihm nach, bis er umkippt und liegenbleibt. Durch die Mauern hindurch höre ich, wie die Kinder in der Nebenwohnung Arschloch und dumme Sau zueinander sagen. Das heißt, sie toben und rasen im Zimmer umher und schreien sich dabei die Worte Arschloch und dumme Sau entgegen. So ungefähr müssen die Kinder gewesen sein, die Lisa krank gemacht haben. Ich möchte Lisa anrufen und fragen, wie es ihr geht, aber ich möchte nicht, daß Renate an den Apparat geht und ich dann mit ihr reden muß. Reglos höre ich Arschloch, Arschloch rufen in der Nebenwohnung. Unter den neuen Schuhen, die mir Habedank mitgegeben hat, ist ein Paar kaum bezahlbarer, rahmengenähter Loafer aus echtem Chevreau. (Regenschirm, S. 88 f.)

Prinzipiell handelt es sich um sehr biederes, traditionelles ,Runtererzählen' der Geschichte, Kohärenzstörungen oder Irritationen bleiben weitgehend aus. Eine Ausnahme stellt der Roman Die Liebe zur Einfalt dar, indem etwa die Sentenzen - auch im Sinne der Kohärenzstörung (s.u.) den Fließtextfluss zerstören und den Leser ,rausreißen'.136

Die Inhaltsanalyse untermauert: Die Wirkabsicht des Textes/der Texte scheint auf das Ausloten der Bewusstseinsinhalte der Figur zu zielen. Weniger das aktive als das kontemplative Leben scheint thematisiert zu werden und die Identifikation des Lesers wird selten massiv gestört. Welche sprachliche Form Genazino für dieses Grundmuster seines Inhalts findet, ist Sache der stilistischen Analyse.

STIL

Eine für Genazinos Figurenromane relevante stilistische Analyse umfasst die Ebenen Laut-, Wort- (inklusive Neologismen, Sozio- und Dialekten), Satz- (inklusive syntaktischer Besonderheiten) und Textstilistik.

134 Hirsch/Genazino: Die Lust an der komischen Empfindung, S. 25.

135 Schneider: Einführung in die Roman-Analyse, S. $37 \mathrm{f}$.

136 Vgl. Fansa: Unterwegs im Monolog, S. 127. 
Ziemlich angenehm und zugleich unprätentiös wirken Genazinos Romane hinsichtlich ihrer lautstilistischen Machart: eher glatt und mitunter sogar sehr poetisch: „Still, weiß und langsam gleitet es dahin, große Kreise ziehend im Blau des Firmaments." (Regenschirm, S. 17) Hervorzuheben ist die hier wie sonst regelmäßig anzutreffende Passung von Form und Inhalt, von Gehalt und Gestalt: Ist es in diesem Beispiel so, dass flaneurhaftes Beobachten bestens mit einfacher und doch eingängiger Lautkomposition vereinbar ist, zeichnet das folgende Beispiel sprachbildnerisch den Rhythmus des Inhalts nach:

Sie ist eine Chilenin oder eine Argentinierin, sie ist jung und korpulent, sie singt und spielt zur Gitarre, und zwar so kräftig und lebendig, daß alle, die ihr zuhören, durch den Gesang hindurch ihren Lebensdrang bewundern müssen, diese bei uns seltene, ansteckend wogende Körperlichkeit, die in jeden ein wenig einströmt, der sich ihr aussetzt. (Frauen, S. 119)

Gegenteilig, wenngleich trotzdem Form und Inhalt verknüpfend, sind sowohl die Ekelassoziationen bzw. entemotionalisierenden Tendenzen im Bereich der Erotik ( $\Rightarrow$ II.5.6) als auch emotional negativ eingefärbte Sprechakte:

Ich bin so empört, daß ich kaum sprechen kann. Ich kann nicht einmal sagen, daß Edith nicht berechtigt ist, einen von uns beiden abgeschlossenen Mietvertrag ohne meine Zustimmung zu kündigen. Ich kann nur leise ins Telefon sagen: Du hast nicht das Recht, ich meine, wir haben unseren Mietvertrag als Paar unterschrieben, auch der Vermieter darf nicht ... dann bricht mein kümmerlicher Satz zusammen. (Heimweh, S. 109)

Das Vokabular, als eine erste Analysekategorie der Wortstilistik, dessen sich Erzähler und Figuren bedienen, lässt sich - mit Ausnahmen der Wortneuschöpfungen und dem Spaß am Wortspiel insgesamt - als ihren jeweiligen „Bildungsschichten“ und „Lebenssphären“ angemessen bezeichnen. ${ }^{137}$ En gros handelt es sich dabei zwar um "geläufiges Vokabular“, aber sowohl die Verwendung „seltene[r] Wörter (Rara)“ als auch die Vorliebe für Neologismen ( $\Rightarrow$ II.3.2), die man bei Genazino „teilweise als Produkte des lustvollen Spiels einer sich befreienden Phantasie, teilweise aber auch als Indiz für eine psychologisch oder philosophisch fundierte Sprachskepsis aufzufassen“ hat ( $\Rightarrow$ II.1.4), lassen „auf einen erweiterten Wortschatz und damit auf einen höheren Bildungsstand schließen“.138

Nur der Efeu ist winterhart, sagt die eine. Ja schon, sagt die andere, aber der Efeu wächst mir zu schnell. Ich will das Gespräch der beiden Frauen nicht mithören und gehe deswegen ein wenig umher. [...] Plötzlich kehrt das Wort winterhart in mein Bewußtsein zurück. Ich frage mich, ob ich selbst winterhart bin. Ich bin es nicht, im Gegenteil zur Winterhärte hat mir immer viel gefehlt, ich bin ja nicht einmal sommerhart! Mit einer Frau bin ich/wäre ich allerdings etwas winterhärter als

137 Schneider: Einführung in die Roman-Analyse, S. 40.

138 Schneider: Einführung in die Roman-Analyse, S. 40. Allerdings ist skeptisch festzuhalten, dass ein weiter Wortschatz noch lange nicht auf hohe Bildung schließen lässt. Vgl. für ein Beispiel, das eher auf Lebensstile abzielt, die Schilderung des Settings einer Einladung zum Abendessen: „Als Vorspeise gab es einen Artischockensalat mit Spinat und Pinienkernen, danach gegrillte Kammuscheln mit Prosciutto. Susanne kocht vorzüglich; ein wenig ungeduldig wurde ich nur, als sie gar zu lange über Herkunft und Eigenart der Pinienkerne und Kammuscheln redete. An der Wand links hängt ein Druck von Miró, an der Wand rechts ein Druck von Magritte, beide hinter Glas." (Regenschirm, S. 98) Obwohl es sich nicht um Rara handelt, werden wortstilistisch Distinktionssignale gesetzt $(\Rightarrow$ II.1.5). Vgl. für weitere Sprachreflexionen auf Wortebene auch Regenschirm, S. 89 f. 
ohne. Sollte es möglich sein, daß das zufällig gehörte Wort winterhart vielleicht den Ausschlag gibt, daß ich mich Susanne erneut zuwende? (Regenschirm, S. 77)

Die hier zwischen Spiel und Reflexion (und Komik) changierende Beschäftigung mit ,Winter-' respektive nur ,Sommerhärte' ist nur ein Beispiel für in jedem Roman auf diese oder jene Weise vorliegende Sprachreflexion. In Außer uns spricht niemand über uns reflektiert der Protagonist diese Reflexionen:

Aus Langeweile begann ich, ahnungslose Wörter zu verunstalten. Aus dem Wort Heimat macht [!] ich Schleimat, eine bösartige Entgleisung, die ich niemandem erzählen konnte. Mein zweiter Versuch war das Wort Entdeckung, aus dem bei mir Enteckung wurde. Wenn die Welt plötzlich ohne Ecken wäre, würde sich über das Wort Enteckung niemand wundern. (Außer uns, S. 37)

In anderen Romanen wächst sich dies mit der optischen Markierung durch Majuskelschrift zu seitenfüllenden Manien und ,Freud'schen Verlesern' aus. Bereits Laslinstraße hat die diesbezügliche Messlatte sehr hoch gelegt:

„'n Tag“, sagte sie, oben bei uns.

"'n Tag, gnä' Frau“, sagte der Uniformierte. Mit seinem Gnä Frau nahm er mir die Chance, zu meiner Mutter ein wahres Guten Tag zu sagen. So einer ist das also, dachte ich, so ein Gnä-Frau-Typ, so ein Noch-ein-Wunsch-Mensch, so ein Liebediener bei den Frauen, gleich, wie alt sie sind.

Meine Mutter kam in unseren Flur.

„Ich bringe die Gasrechnung, gnä' Frau“, welschte er zwischen seinen gelben Zähnen hervor, ich hätte ihn umbringen können, diesen schleimigen Kavalier, diesen blauen dienstmützenbeflissenen Treppenhauswandler. (Laslinstraße, S. 12 f.)

Auffällig ist neben den als Ad-hoc-Komposita intendierten Wortneuschöpfungen vor allem auch die Wichtigkeit der Soziolekte für die Charakterisierung (aus externer Perspektive; $\Rightarrow$ I.2.4): Im Unterschied zum Ich-Erzähler Axel Degen wählen sowohl Mutter als auch der uniformierte ,Gasmann', ein „verhungerter ausgemergelter häuserschluchtenschluckender dünner kribbliger Mann in Uniform“ (Laslinstraße, S. 12), die soziolektal gefärbte Kurzformel zur Begrüßung. Dadurch fühlt sich Degen in der ursprünglich gewünschten Äußerung, seiner „Mutter ein wahres Guten Tag zu sagen“, sogar gehemmt und sortiert den Beamten, der bereits zuvor aufgrund seines Äußeren und seiner Diktion stigmatisiert worden ist, in eine Typenschublade unter sich selbst. ${ }^{139}$ Die Charakterisierung über Dia- und Soziolekte ist allerdings nicht immer derart offensichtlich. So kann eine bloße Wortwiederholung für die Charakterisierung einer Figur über Wortwahl sehr subtil geschehen:

Er wollte, sagte Messerschmidt, aber es ist nie dazu gekommen; einmal hat er den Termin verschlafen, dann waren die Fotos, die er anbrachte, total mau, aber wirklich total mau, die konnte nicht einmal der Generalanzeiger drucken! rief Messerschmidt und lachte ein bißchen. (Regenschirm, S. 117)

Es ist weniger der ,verhinderte Fotograf', der hier seitens Messerschmidt erfolgreich herabgesetzt wird, sondern vielmehr dieser selbst, indem er mit der - zumindest aus Reflektorfigurensicht - peinlich anmutenden Dopplung „total mau“ einmal mehr karikiert wird. Auch Ge- 
58 - Teil I: Grundlagen 2. Wilhelm Genazinos Romanfiguren und ,Figurenromane‘

nazinos Figurenromane „ziehen [...] ihren Reiz zu einem Gutteil aus dem Aufeinanderprallen sehr unterschiedlicher Äußerungsstile“.140

Wenn man Genazinos Romane in puncto Satzstilistik näher betrachtet, ist zunächst das auf die Satzlänge bezogene Urteil schnell fällbar: Es handelt sich um für gewöhnlich kurze, einfache Sätze. „Bandwurmsätze, die weit, sehr weit über die für die geschriebene Sprache ermittelte durchschnittliche Satzlänge von 15 bis 20 Wörtern hinausreichen“,141 sind fast nicht existent. Der Protagonist wird dadurch allerdings nicht als einfältig charakterisiert, wie es eventuell zu erwarten wäre. Vielmehr besteht ein spannungsvoller Konflikt zwischen den einfach gehaltenen Satzbauplänen und den existentiellen Fragen, die darin verhandelt werden.

Insbesondere die häufigen und zunächst trivial scheinenden Alltagswahrnehmungen werden beständig parataktisch aneinandergereiht (s.o.): „Nach einer Weile drehte das Reh seine Ohren nach vorn, und Abschaffel ging weiter. In einiger Entfernung hörte er das Brummen eines Motorrads." (Falsche Jahre, S. 526) ${ }^{142}$

Die Komplexität der Satzgefüge erhöht sich signifikant, wenn ,überkomplexe' Szenarien des wechselseitigen Beobachtens und Mutmaßens abgebildet werden:143

Eckhard kam nicht auf den Gedanken, daß Ruth seine bloß phantasierte Annäherung an Martha bemerkt haben konnte und sich nun ihrerseits von ihm entfernte. Zwar wollte Eckhard immer noch den Eindruck erweckt sehen, daß Martha wie seine Freundin neben ihm oder vor ihm her lief, aber zugleich wollte er keine Entfernung von Ruth dulden (Ausschweifung, S. 98).

Dass der Eindruck von Komplexität entsteht, ist weder auf Laut-, Wort- oder Satzebene objektiv festzumachen. Vielmehr ist es die Umstandskrämerei der Hauptfiguren, die gelegentlich der Charakterisierung „als besonders gebildet und/oder als besonders umständlich und langweilig“ durchaus Vorschub leistet. ${ }^{144}$ Obwohl Genazinos Romane global unter dem Blickwinkel der Satzstilistik betrachtet „den im Durchschnitt relativ simplen, klaren Satzbau des modernen Romans“ befolgen, zeichnen sie sich nicht durchweg durch ,die Liebe zur Einfalt', also durch den „weitgehende[n] Verzicht auf Aposiopesen [...], Appositionen, Parenthesen, ungewöhnliche Satzgliedstellungen und Satzklammern, bei denen durch die im Deutschen mögliche Hintanstellung [...] äußerst unübersichtliche Sätze konstruiert werden können“, aus. ${ }^{145}$ Neben den genannten Indizien für Komplexität, von denen allzumal die Parenthese (vgl. Regenschirm, S. 24) als vergleichsweise häufiges Strukturmerkmal der Prosa Genazinos gelten kann, sind am Übergang zur Textstilistik auch optische Markierungen bzw. Strukturierungen, Schrägstriche, Großschreibung, Klammern etc. auffällig, die am Komplexitätsregler des Mischpults aufdrehen ( $\Rightarrow$ I.2.2):

\footnotetext{
140 Schneider: Einführung in die Roman-Analyse, S. 41.

141 Schneider: Einführung in die Roman-Analyse, S. 42.

142 Vgl. auch das weiter oben bereits zitierte Beispiel aus Fremde Kämpfe: „In aller Gutmütigkeit rumpelte [...]. Elegant schwebte [...]. Eine junge Frau ritzte [...].“ (Fremde Kämpfe, S. 7)

143 Vgl. Zunshine: Why we read fiction, S. $32 \mathrm{f}$.

144 Schneider: Einführung in die Roman-Analyse, S. 42.

145 Schneider: Einführung in die Roman-Analyse, S. 42.
} 
Endlich gelingt es mir, die Jugendlichen interessant zu finden. Gleich fünfmal müssen sie ausdrücken, daß sie jung sind: durch die Zappeligkeit ihrer Körper (1), durch die Gegenstände (Cola, Popcorn, Comics, CDs) in ihren Händen (2), durch ihre Bekleidung (3), durch ihre Musik, dargestellt durch Stöpsel in den Ohren und Drähten um den Hals (4), und durch ihren Slang (5). (Regenschirm, S. 112)

Freileich handelt es sich noch immer um einen verständlichen Satz, aber er wirkt ,sperriger':

Interessanterweise verfügt der Mensch, wie die Lesepsychologie [...] ermitteln konnte, über einen zweiten Verarbeitungsmodus [...]. Setzt die Syntax dem routinemäßigen ,Herunterlesen' Widerstände entgegen, so schaltet der Rezipient in diesen Reservemodus um, in dem eine genauere (vorbegrifflich-)grammatische Analyse durchgeführt wird. Die Syntax gewinnt dann an Bedeutung, wird also bewusster wahrgenommen. ${ }^{146}$

Mit der für literarische Texte (Genazinos) eher unüblichen, als Strukturierung gedachten, letztlich aber den Lesefluss irritierenden Klammerverwendung, nähert sich die Passage einem informationsdichten Sachtext an, was den Rezipienten in den ,Reservemodus' schalten lässt: Nicht nur die Nummerierung, sondern auch die in Klammern realisierte parenthetische Aufzählung suspendieren das „routinemäßige[] ,Herunterlesen“. Mit dieser Beobachtung sind in zweierlei Hinsicht bereits die Weichen gestellt, um auf die Textstilistik hinzusteuern: Einzelne Absätze können sich stilistisch nur vor dem Text-Gesamt abheben, zudem ist die Verständlichkeit bereits eine Dimension der Textstilistik.

Die sprachliche Einfachheit, die als erste von vier Dimensionen die Textverständlichkeit beeinflusst, ${ }^{147}$ ist genaugenommen bereits durch die Wort- und Satzstilistik vorweggenommen worden: Es handelt sich um leicht überdurchschnittlich gut verständliche Romane. Hinsichtlich der anderen drei textstilistischen Dimensionen allerdings sind Genazinos Romane nicht sonderlich verständlich.

Sie zeichnen sich nämlich zunehmend dadurch aus, dass „die relative Informationsdichte, die einen mittleren Wert nicht über-, aber auch nicht unterschreiten sollte",148 hin zur Redundanz abgleitet $(\Rightarrow$ I.2.1). Und da nicht nur „informationsüberladene, superkompakte Texte“, sondern auch „informationsarme, allzu weitschweifige Texte [...] die Verstehensleistung [reduzieren]“,149 sind zumal Romane wie Außer uns spricht niemand über uns, die sich iterativen Erzählens befleißigen (s.o.), durchaus, anstrengend' zu lesen.

Unterstützt wird dieser Leseeindruck durch die zwar kompositionsstrukturell eingängige (s.o.), aber genaugenommen fehlende „klare hierarchische Untergliederung“. 150 Und obwohl gerade die neuesten Genazino-Romane nicht nur in zehn bis zwölf Abschnitte unterteilt, sondern sogar auch in fast gleich dicke ,Scheiben' geschnitten sind - Außer uns: ein Kapitel von zwölf hat elf

\footnotetext{
146 Schneider: Einführung in die Roman-Analyse, S. 43.

147 Vgl. Schneider: Einführung in die Roman-Analyse, S. 45.

148 Schneider: Einführung in die Roman-Analyse, S. 45.

149 Schneider: Einführung in die Roman-Analyse, S. 45.

150 Schneider: Einführung in die Roman-Analyse, S. 45.
} 
60 - Teil I: Grundlagen 2. Wilhelm Genazinos Romanfiguren und ,Figurenromane‘

Seiten, fünf zwölf und sechs dreizehn -, stehen weder das Zusammenspiel aller Kapitel noch die kapitelinterne Struktur im Dienst der Textverständlichkeit.

Viertens und letztens ist noch die motivationale Stimulanz anzuführen. Zu den wichtigsten Ergebnissen der Lesepsychologie gehört die Feststellung, dass die Häufung interessanter Nebensächlichkeiten das Behalten der Hauptinhalte und -informationen beeinträchtigen kann. [...] Das erklärt, weshalb sich manche Leser nach einiger Zeit u. U. noch an einzelne Figuren und Episoden, aber nicht mehr an den Gesamtverlauf der Handlung erinnern können. ${ }^{151}$

Nicht-repräsentative (Flur-)Gespräche erhärten den Eindruck, dass das ,große Ganze' der Handlung bei Genazino nicht sauber erinnert wird. Es handelt sich textstilistisch, eigentlich: poetologisch, bei Genazino meist um aneinandergereihte (s.o.) Nebenhandlungen, die nur durch die Klammer der Hauptfigur zusammengehalten werden. Man erinnert sich - diese Einschätzung mag freilich noch dadurch verstärkt werden, dass sich die Romane hinsichtlich ihrer ,Ingredienzien' (stark) ähneln, - an eindrückliche Szenen (antiemotionaler Sex im Frisiersalon etwa), kaum jedoch auch nur einer einzigen Plotangabe eines Romans - das ist aber weniger Manko, als Mittel zum Zweck, um den Einzelbeobachtungen den Hautgout des Banalen abzustreifen und sie in den Rang von Offenbarungen zu erheben.

$\mathrm{Zu}$ guter Letzt ist hinsichtlich der stilistischen Analyse noch „die Unterscheidung zwischen Skripturalität und Kolloquialität, d. h. zwischen stilistisch schriftlicher und stilistisch mündlicher geschriebener Sprache“ vorzunehmen.152 Allerdings liegen bis auf wenige klar zu klassifizierende Beispiele häufig Zwischenfälle vor. Lässt sich von Laslinstraße noch guten Gewissens sagen, dass „Erzähler und Figuren [reden], ,wie ihnen der Schnabel gewachsen ist“" (= Kolloquialität),153 so lassen sich für die meisten anderen Romane zwar die „Verwendung kürzerer und einfacherer Sätze, das häufigere Vorkommen von [...] Abtönungspartikeln (doch, wohl usw.), [...] Satznachträgen und direkten Anreden“ vermerken; weitere Spezifika des stilistisch Mündlichen - „Ellipsen, Satzabbrüche[], fehlerhafte[] Satzkonstruktionen, [...] Deiktika“ etc. hingegen sind eher rar. 154

Nachdem nun einige größere relevante und grundlegende Einordnungen von Genazinos Romanen narratologisch und allgemein-romananalytisch vorgenommen worden sind, welche für alle Folgeschritte wichtig sind, muss noch eine letzte genazinospezifische Unterscheidung vorgenommen werden, die Monika Fludernik in Anlehnung an Harweg prominent macht, und welche bereits den Übergang zum Wesentlichen, den Romanfiguren, anbahnt: der Unterschied von emischen und etischen Textbeginnen: „Weil seine Lage unabänderlich war, mußte Abschaffel arbeiten. Er war schon mehrere Jahre in der gleichen Firma beschäftigt; er war Angestellter, und er

151 Schneider: Einführung in die Roman-Analyse, S. 45.

152 Schneider: Einführung in die Roman-Analyse, S. 45.

153 Schneider: Einführung in die Roman-Analyse, S. 45. Ein weiteres Mal gibt sich Das Licht brennt ein Loch in den Tag als Ausnahme zu erkennen, ist die Briefform doch der stilistischen Mündlichkeit nachempfunden.

154 Schneider: Einführung in die Roman-Analyse, S. 45. 
arbeitete in einem Großraumbüro, das die Firma vor zwei Jahren eingerichtet hatte." (Abschaffel, S. 8) Obwohl der Leser durch den Er-Erzähler bereits im ersten Satz den Namen des Protagonisten erfährt und mithin die „indefinite Bezeichnung“155 nicht erst späterhin präzisiert wird, handelt es sich bei den frühen Romanen Genazinos eindeutig um emische Textbeginne, also um solche, „die beim Texteingang alles ausladend für den Leser erklären und einführen“.156 Das „hilft dem Leser, sich zu orientieren“, und steht in einer Traditionslinie mit „traditionellen auktorialen Texten, also [...] Erzählungen, in denen ein Er-Erzähler eine ihn nicht betreffende Geschichte vorbringt“. ${ }^{157}$ Im Kontrast dazu steht der etische Textbeginn:

Moderne Erzählungen, insbesondere solche, die interne Fokalisierungen bevorzugen, also Reflektorfiguren dazu einsetzen, das Geschehen aus deren Wahrnehmung zu schildern, referieren auf Personen und Objekte der fiktionalen Welt als vorgegeben, bekannt, und daher nicht einführenswert. In solchen etischen Textbeginnpassagen herrschen unvermittelte Namensnennungen und der Gebrauch von Pronomina ohne Antezedens [...] sowie von Nominalphrasen mit definitem Artikel [...] vor. ${ }^{158}$

Ein Blick auf den Textbeginn von Außer uns spricht niemand über uns (2016): „Still ruhte der Sonntag in den Straßen der Stadt. Ich stand am Fenster und sah eine Frau [...]. Gestern Abend war ich bei Carola" (Außer uns, S. 7). Damit wird der emische durch den etischen Beginn abgelöst: Keine Figurennamen, die eingeführt werden - ab dem Roman Die Kassiererinnen von 1998 sogar häufig namenlose Ich-Erzähler $(\Leftrightarrow I .2 .1)$-, dafür sowohl „unvermittelte Namensnennungen“ und „Nominalphrasen mit definitem Artikel“.

Und doch berühren sich beide Romananfänge in einem ganz wesentlichen Punkt: Sie starten (haupt-)figurenkonzentriert. Christoph Bode merkt an: „In der europäischen Literaturtheorie hat es eine andauernde Debatte darüber gegeben, ob die Figuren der Handlung unterzuordnen seien oder ob die Handlung der sukzessiven Entfaltung und Entwicklung einer Figur (oder mehrerer) zu dienen habe“, 159 und nennt für erstere Überzeugung Aristoteles, für zweitere „alle Verfasser von Bildungs- und Entwicklungsromanen, von psychologischen Romanen sowieso“.160 Genazino reiht sich, wie unschwer zu erkennen ist, in die Ahnengalerie derjenigen Romane ein, bei denen, mit den Worten Schneiders, „[d]ie Handlung [...] oft nur ein zusätzliches Mittel der Figurenbeschreibung [ist], sie dient - wie Henry James in The Art of Fiction (1884) ausführte letzten Endes nur der Illustrierung des Charakters. " ${ }^{161}$ Damit ist also eine erste figurenrelevante Kategorie, die zwischen ,allgemeiner' und ,figurenbezogener' Romananalyse steht, für Genazino

Monika Fludernik: Erzähltheorie. Eine Einführung. 2., durchges. Aufl. Darmstadt 2008, S. 55.

Fludernik: Erzähltheorie, S. 170. Vgl. Genazino: Melancholische Renitenz, S. 38 f., für eine Selbsteinschätzung dieses Romanbeginns. Selbstironisch hält er unter anderem fest, es wirke, „als hätte der Autor in einer professionellen Schreibwerkstatt ,erste Sätze' schreiben gelernt" (Genazino: Melancholische Renitenz, S. 38).

Fludernik: Erzähltheorie, S. 55.

Fludernik: Erzähltheorie, S. 56.

Bode: Der Roman, S. 125.

Bode: Der Roman, S. 126.

Schneider: Einführung in die Roman-Analyse, S. 20. 
62 - Teil I: Grundlagen 2. Wilhelm Genazinos Romanfiguren und ,Figurenromane‘

entschieden: Wilhelm Genazinos Romane sind Romane der Figur, sind ,Figurenromane‘: ,novels of character'!162

\subsection{Figur oder Person? Papier oder Psyche?}

Bereits ,literaturtheoretisch unbefleckte‘ Kinder wissen: Weder Frau Holle noch Räuber Hotzenplotz, weder Urmel noch das Sams - ganz gleich, in welcher medialen Erscheinung - existieren in der ,wirklichen' Welt.163 Dennoch beharren manche (Erwachsene, Theoriegesättigte, figurentheoretisch Belesene) auf der Position: „Vom internen Standpunkt aus gesehen sind Figuren Lebewesen“,164 wohingegen andere (Erwachsene, Theoriegesättigte, figurentheoretisch Belesene) kontern: „Vom externen Standpunkt aus gesehen sind Figuren Artefakte, d.h., von Autoren geschaffene Aspekte von Erzähltexten."165

Bevor über die Stationen Forschungsabriss, Problemaufriss und pragmatische Lösung zu den Analysekategorien fortgeschritten werden wird, sei hier bereits als orientierende Vorwegnahme thesenartig die Position bestimmt, die dieser Arbeit zugrunde liegt:

1. Beide Standpunkte einzunehmen, ist vollkommen legitim.

2. Einen von beiden insofern zu verabsolutieren, als der jeweils andere damit diskreditiert wird, verfestigt die einander gegenüberstehenden Positionen hin zu einem Ausschlussdenken, das weder im Dienst der Sache steht (gelungene Figurenanalyse zu betreiben) noch einen ,königlichen' Mittelweg denkbar scheinen lässt, der skalar und nicht bipolar zu denken wäre.

3. An welchem Ende der Skala sich zu positionieren (eher) angemessen ist, bestimmt maßgeblich der Untersuchungsgegenstand.

4. Genazinos Romanfiguren fordern nachgerade ein, die in jüngster Vergangenheit von verschiedenen Seiten unter Beschuss geratene Perspektive, nach der Figuren Menschen ähneln - und sei es nur im Modus der Rezeption -, zu bevorzugen.

5. Trotz dieser Orientierung zur internen Perspektive auf der Skala muss auch für Genazinos Romanfiguren die externe immer in Betracht gezogen werden.

\section{META-FORSCHUNGSABRISS}

Erst seit der jüngeren Vergangenheit schlägt sich endlich auch in deutschsprachigen Einführungen zur Erzähltheorie nieder, was intuitiv und evident zugleich ist: dass der Blick auf Figuren ohne erzähltheoretische Brille nicht sinnvoll und schlechterdings nicht möglich ist. Was der Leser über die fiktive Welt erfährt und wie die Verpackung aussieht, ist erzähltheoretisches Terrain und gerade bei dem subtil und komplex angelegten Bild von Figuren ist das wichtig. ${ }^{166} \mathrm{Zu}-$ vor war das Interesse an der (Psychologie der) Figur - en passant: auch an der des Rezipienten seitens der Erzähltheorie (bei Martínez/Scheffel noch immer) eher gering. Dies ist sicherlich

\footnotetext{
162 Vgl. Schneider: Einführung in die Roman-Analyse, S. 20; vgl. Bode: Der Roman, S. 126 f.

163 Vgl. zur ontologischen Fundierung der nun folgenden Ausführungen insbesondere Eder: Die Figur im Film, S. 61 ff.; vgl. Eder/Jannidis/Schneider: Characters in Fictional Worlds, S. 6-10; vgl. Jannidis: [Character].

164 Köppe/Kindt: Erzähltheorie, S. 120.

165 Köppe/Kindt: Erzähltheorie, S. 128.

166 Vgl. Bode: Der Roman, S. 142.
} 
nicht zuletzt der strukturalistischen Lebensader der Narratologie anzulasten,167 obwohl auch hinsichtlich der Figuren etwa Barthes und Lotman Versuche unternommen haben, mit strukturellen Binaritäten vorzugehen. ${ }^{168}$

Wenn man sich die Forschungstradition zur Figur ansieht, ${ }^{169}$ lassen sich retrospektiv mit Eder/Jannidis/Schneider vier verschiedene, views' unterscheiden, mit denen sich auf Figuren schauen lässt. Alle vier

paradigms [...] reach across disciplines but have different tenets, emphases and methods:

1. Hermeneutic approaches view characters dominantly as representations of human beings and emphasise the necessity of taking into consideration the specific historical and cultural background of the characters and their creators.

2. Psychoanalytic approaches concentrate on the psyche of botch characters and recipients. They aim at explaining the inner life of characters, as well as the reactions of viewers, users, and readers with the help of psycho-dynamic models of personality (e.g., those developed by Freud and Lacan). 3. Structuralist and semiotic approaches in contrast highlight the very difference between characters and human beings, focusing on the construction of characters and the role of the (linguistic, visual, auditive or audio-visual) text. They frequently regard characters themselves as sets of signifiers and textual structures.

4. Cognitive approaches, which have been established since the 1980s, centre on modeling in detail the cognitive and affective operations of information processing. In these approaches, characters are regarded as text-based constructs of the human mind, whose analysis requires both models of understanding text and models of the human psyche.170

Die (bewussten?) Missverständnisse, die diese Seiten gegen die je andere(n) aufgebracht haben und aufbringen, sind, wie so oft, tatsächlich eine schlichte Frage des Blickwinkels. Selbst in dieser vermeintlich wertneutralen Liste werden dem aufmerksamen Leser bestimmte, bedeutende Signale nicht verborgen bleiben: Lediglich die kognitiv(istisch)e Betrachtung wird mit einer konkreten Jahresangabe als aktuellster Blickwinkel apostrophiert, lediglich sie wird mit werten-

167 Vgl. Matthias Bauer: Romantheorie und Erzählforschung. Eine Einführung. 2., akt. u. erw. Aufl. Stuttgart/Weimar 2005, S. $105 \mathrm{ff}$.

168 Vgl. Jannidis: [Character].

169 Der Mühe, eine möglichst vollständige Liste zur Figurenforschung aufzustellen, enthebt verdienstvollerweise die Bibliografie Jens Eders (vgl. Jens Eder: Figuren in Film, Fernsehen, Literatur und anderen Medien. Eine interdisziplinäre Arbeitsbibliographie. In: Medienwissenschaft / Hamburg: Berichte und Papiere 90 (2008/2010): Figuren im Film und in anderen Medien. Online: <https://publikationen.ub.uni-frankfurt.de/files/13799/Medienwissenschaft_90.08.pdf>). Dass die Figurenanalyse neben Handlung, Erzähltheorie, Stil etc. als einer der Königswege zur Analyse epischer Texte gilt, macht ein Blick in die Einführungsliteratur evident: Jost Schneider widmet der „Figurenanalyse“ innerhalb des „[a]nalytische[n] Instrumentarium[s]“ zehn Druckseiten (vgl. Schneider: Einführung in die Roman-Analyse, S. 17-26). Bei Christoph Bode sind es satte 20 Seiten zur Figur (vgl. Bode: Der Roman, S. 123-142). Der skeptischen Einschätzung Annemarie und Wolfgang van Rinsums, nach der das „Interesse an der literarischen Figur, ihrer psychologischen Anlage und ihrer Entwicklung [...] weniger, wissenschaftlich' sein [mag] als die Frage nach dem literaturtheoretischen Begriff oder nach der Kurzinterpretation des Werkganzen" (Annemarie van Rinsum/Wolfgang van Rinsum: Lexikon literarischer Gestalten. Deutschsprachige Literatur. Stuttgart 1988, S. VII), hält die neuere und basale Forschung zur Figurentheorie tatkräftig entgegen. Vgl. dazu bspw. Eder/Jannidis/Schneider (Hg.): Characters in Fictional Worlds; vgl. Jannidis: Figur und Person; vgl. Eder: Die Figur im Film. Einen kritischen Forschungsüberblick mit Fokus auf die antiken Vorläufer der Figurenforschung bietet Thomas Koch: Literarische Menschendarstellung. Studien zu ihrer Theorie und Praxis (Retz, La Bruyère, Balzac, Flaubert, Proust, Lainé). Tübingen 1991. 
64 - Teil I: Grundlagen 2. Wilhelm Genazinos Romanfiguren und ,Figurenromane‘

den Attributen hinsichtlich der Genauigkeit („,in detail“) bedacht. ${ }^{171}$ Um die teilweise mit harten Bandagen geführten Kämpfe zwischen den ,Schulen' zumindest im Ansatz nachvollziehen zu können, sei ein kurzer Parforceritt durch die - inzwischen prinzipiell in die Narratologie eingebettete $^{172}$ - Figurenforschung gestattet.

Ist ,die Hermeneutik ${ }^{\prime 173}$ prinzipiell geneigt gewesen, Figuren durchaus den Status der Menschenähnlichkeit zuzuerkennen, sofern bestimmte soziohistorische Überlegungen mit in die Analyse einbezogen werden (ein schönes Beispiel sind die Nachworte zu den Klassikern in den Reclam-Bänden), so hat dies auf die psychoanalytische Literaturinterpretation in besonderem und mitunter auch an Naivität grenzendem, unbedarften Maße $(\Rightarrow$ I.3.2) zugetroffen. Der Vorwurf, dem sich letztere (zu Recht) ausgesetzt gesehen hat, lässt sich in die Mahnung fassen: „Vergisst man, dass literarische Figuren keine realen Menschen sind, gelangt man zu einem falschen Verständnis des literarischen Werks - man wird der Literatur nicht gerecht. “174 Dieser seitens des Strukturalismus geäußerte Vorwurf ist andererseits gegen diesen selbst zu richten, da auch er gleichsam ,blind' ist - auf dem ,mimetischen' anderen Auge:175 Er reduziert Figuren auf bloße ,Handlungsträger', funktionalisiert und klassifiziert sie etwa nach Aktantenfunktionen etc. (s.u.). Von kognitiver Warte aus besehen werden empirische Leser und deren Psyche in das Spiel eingeführt: Figuren sind gleich Leserkonstrukte. Damit macht man sich nicht gemein mit den widerstreitenden Dualismen von Figur $=$ Person vs. Figur $=$ Funktion, sondern bezieht Position außerhalb des Schlachtfeldes.

Im Sinne der Gleichberechtigung sind alle vier Paradigmen der Kritik zu unterziehen und außerdem sind die Grenzen fließender, als es die Vierteilung glauben machen möchte: Eine 'Schwäche‘ der hermeneutischen Figureninterpretation ist - zumindest im Gewand der Sozialgeschichte eine starke Autorfixierung ( $\Rightarrow$ I.3.2), womit die Grenze zur psychoanalytischen Verfahrensweise

171 In ähnlich subkutaner Manier verfährt Jannidis, wenn er im living handbook of narratology schreibt, „[c] haracters have long been regarded as fictive people“ (Jannidis: [Character]; Herv. N. L.). Man ist geneigt, darin nicht nur einen vorläufigen Abschluss dieses seiner Meinung nach verkehrten Ansatzes zu erkennen, sondern auch die Aburteilung einer Denkschule als antiquiert.

172 Dass die Erzähltheorie sich schon lange nicht mehr auf ihr ,klassisches' Anwendungsgebiet, die Epik, beschränkt, sondern Film, Drama und Lyrik im Sinne einer trans- oder plurimedialen Narratologie in den Blick nimmt, bestätigen 2002 bereits Vera und Ansgar Nünning (vgl. Vera Nünning/Ansgar Nünning (Hg.): Erzähltheorie transgenerisch, intermedial, interdisziplinär. Trier 2002).

173 Wichtig sind an dieser Stelle zwei Anmerkungen. Erstens gibt es unterschiedliche Hermeneutiker: Schleiermacher ist nicht Dilthey. Zweitens ist es keineswegs das argumentative Anliegen, die Hermeneutik generell zu diskreditieren, sondern lediglich den in der Figurenforschung als, hermeneutischen Ansatz' bezeichneten Zugang - der selbst kein homogener ist, wie ein kontrastiver Blick etwa auf Horst Breuer (vgl. ders.: Historische Literaturpsychologie. Von Shakespeare bis Beckett. Tübingen 1989) und Thomas Leithäuser/Birgit Volmerg (vgl. ders./dies.: Anleitung zur empirischen Hermeneutik. Psychoanalytische Textinterpretation als sozialwissenschaftliches Verfahren. Frankfurt am Main 1979) beglaubigt - zu problematisieren. Letztlich ist auch diese Arbeit dezidiert einem hermeneutischen Verstehen-Wollen verpflichtet.

174 Per K. Hansen: Figuren [Kap. IV.3.3]. In: Lahn/Meister: Einführung in die Erzähltextanalyse (2013), S. 232-247, hier S. 233.

175 Vgl. Per K. Hansen: Figuren, S. 233. 
durchaus durchlässig wird. Ein Autor hat zweifelsfrei ungeheuren Einfluss auf das Druckerzeugnis, die Diegese und deren Bewohner; und spätestens nach der ,Wiederauferstehung' des Autors als Kategorie rund um das Jahr 2000,176 ist die theoretische Retourkutsche an Roland Barthes u. a. erfolgreich platziert worden. Aber eine auf die Autorenvita referierende Figurenanalyse ist mitnichten davor gefeit, entweder einer vermeintlichen Intention entsprungene Typisierung oder schlimmer: Schlüsselromanüberlegungen vorzunehmen (à la: ,Goethe verarbeitet in der Stella seine...') oder aber die erzähltechnische Machart, die objektive Beschreibung der Funktionsweise von Einzeltexten zu sehr zugunsten von Individualstilen und Gesamt-Werk-Aspekten à la ,Leben-Werk-Wirkung' zu bagatellisieren. Als Kardinalproblem der psychoanalytischen Literaturwissenschaft ist ja nicht zufällig die Unmöglichkeit beanstandet worden, den ,Autor auf die Couch`zu legen - leider hat dieser nicht immer überzeugende Versuch die Verbindung von Literaturwissenschaft und Psychologie insgesamt in Diskredit gebracht, obwohl durchaus auch nicht-freudianische Wege beschritten werden könn(t)en $(\Leftrightarrow I .3 .2)$. Neben der bereits erwähnten Verabsolutierung der Vermessungs- und Funktionalisierungsmanie lässt sich zudem anführen, dass der Strukturalismus sich in seinen Grundüberzeugungen durchaus einiges Gedankengut mit der psychoanalytischen Literaturinterpretation teilt (insbesondere mit Lacan), mithin nicht von der auf diese gerichteten Kritik freizusprechen ist. Der Kognitivismus hingegen, der sich mit der Psychoanalyse den Rückgriff auf Referenztheorien außerhalb des Textes, mit dem Strukturalismus die Skepsis gegen naive Figur = Person-Kurzschlüsse teilt, greift mit seinem Erklärungsansatz das Verstehensprimat der Hermeneutik an. Dadurch werden wiederum die Schulen, welche sich zumindest grob zur hermeneutisch arbeitenden Literaturwissenschaft bekennen, aber auch die nicht rein kognitivistisch arbeitende Narratologie zum Boykott auf den Plan gerufen: Köppe/Kindt wenden einen raffinierten rhetorischen Trick an, um Eder - immerhin qua Namen erstgenanntem Herausgeber des Characters-in-Fictional-Worlds-Bandes - seine eigene, $2008 \mathrm{im}$ Rahmen seiner Figur im Film eingenommene skeptische Position entgegenzuhalten ${ }^{177}$ und beschließen ihr nur zwei Seiten umfangreiches Kapitel zu „[m]entale[n] Figurenmodelle[n]“178 mit den Worten: „Letztlich gehört die Erforschung unserer mentalen Repräsentationen in den Bereich der Kognitionspsychologie, nicht in den Bereich der Narratologie“.179 Zack. Ob man es in dieser Schärfe tun sollte oder ob man nicht lieber die Positionen zusammenbringen und mithin die obige Viergliederung überwinden sollte, wird im Folgenden diskutiert werden.

\footnotetext{
176 Vgl. Fotis Jannidis/Gerhard Lauer/ Matías Martínez/Simone Winko: Texte zur Theorie der Autorschaft. Stuttgart 2000.

177 Vgl. Köppe/Kindt: Erzähltheorie, S. 154.

178 Köppe/Kindt: Erzähltheorie, S. $153 \mathrm{f}$.

179 Köppe/Kindt: Erzähltheorie, S. 154.
} 
66 - Teil I: Grundlagen 2. Wilhelm Genazinos Romanfiguren und ,Figurenromane‘

\section{PROBLEMAUFRISS}

Hat Sherlock Holmes ein Muttermal? Wie viele Kinder hat Lady Macbeth?180 Nichts ist ärgerlicher als unbegründete Mutmaßungen. Im Alltag wie in der Wissenschaft ist eine beobachtbare Faktenlage erforderlich, um den Bereich des nur Vermuteten hin zur Kenntnis zu transzendieren. Und doch lässt sich die deutungswütige Maschine Mensch nicht immer bändigen. Sogenannte Laterale (auch bekannt unter dem Namen ,Black Story') ziehen daraus ihren Reiz: Auf Basis einer kurzen Situationsbeschreibung ist vom ratenden Spieler die Vorgeschichte (im Krimiratespiel: der ,Tathergang') ans Tageslicht zu bringen. Ein kurzes Beispiel: „Ein Mann geht in ein Spezialitätenrestaurant, bestellt Albatros-Fleisch und isst davon. Plötzlich steht er auf, geht nach Hause und erhängt sich. Warum?" ${ }^{\prime 181}$ Die Spieler sind nachgerade angehalten, durch Mutmaßungen und Ja-/Nein-Fragen die richtige Antwort herauszufinden. Allerdings gibt es sie im Rahmen des Spiels ${ }^{182}$ - häufig im Gegensatz zu Literatur, Film und Fernsehen.

Denn die Frage nach dem Vorhandensein von Sherlock Holmes' Muttermal bspw. ist nicht nur nicht zu eruieren, sondern geradezu eine falsch gestellte insofern, ${ }^{183}$ als Figuren letztlich ,ontologisch“ nur „ein leserabhängiger Vorstellungskomplex“ sind. ${ }^{184}$ „Dass Figuren andersartige Entitäten als Personen sind, ist klar und so selbstverständlich, dass man nicht daran erinnert werden muss. “185 Daraus hingegen den Kurzschluss zu ziehen, Figuren rein auf eine Textfunktion zu reduzieren oder in den kognitionspsychologisch konzeptualisierten Kopf des Lesers zu verlagern, widerspricht nicht nur jedweder literaturwissenschaftlichen Tradition - beziehungsweise schreibt diejenigen strukturalistischen und formalistischen Ansätze weiter, welche die „anthropomorphen, auf den Menschen bezogenen Konnotationen literarischer Figuren"186 außer Acht lassen -, sondern insbesondere auch jedweder Intuition. Denn

\footnotetext{
180 Vgl. Jannidis: [Character].

181 [Lateral]. In: Wikipedia. Die freie Enzyklopädie. Online: <https://de.wikipedia.org/wiki/Lateral_(R\%C3\%A4tsel)>.

182 „Der Mann war vor Jahren gemeinsam mit seinem Freund zur See gefahren, schiffbrüchig geworden und auf einer Insel gestrandet. Sie waren die einzigen beiden Überlebenden, wobei er selbst krank und schwach in einer Höhle lag und von seinem Freund unter Verwendung des einzigen Nahrungsmittels gesund gepflegt wurde, das es auf der Insel gab: Das Fleisch der Albatrosse, wie ihm sein Freund sagte. Nach der Rettung gingen die Wege der beiden auseinander. Als der Mann am Restaurant vorbeikam und sah, dass es dort Albatros-Fleisch im Angebot gab, ging er in Erwartung an alte Erinnerungen hinein, um wieder etwas davon zu essen. Als er das Fleisch aß, wurde ihm plötzlich klar, dass er nie zuvor Albatrosfleisch gegessen hatte. Sein Freund hatte ihm in der Not das Fleisch der ertrunkenen und angeschwemmten Schiffskameraden zubereitet und ihm das mit einer Notlüge glaubhaft gemacht, um den geschwächten Kameraden nicht zusätzlich psychisch zu belasten. Mit der Vorstellung, Menschenfleisch gegessen zu haben, konnte der Mann nicht leben, woraufhin er sich erhängte." [Lateral] (Hg.): Fiktionalität. Ein interdisziplinäres Handbuch. Berlin/Boston 2014, S. 159-189, hier S. 177 f.

184 Hansen: Figuren, S. 236.

185 Haferland: Psychologie und Psychologisierung, S. 93.

186 Hansen: Figur, S. 233.
} 
auch Figuren haben z.B. einen Körper, den immerhin ihre Mitfiguren anfassen können. Sie haben ein Bewusstsein und ein Gedächtnis, die dafür sorgen, dass sie sich ihrer Absichten, Entscheidungen und Erinnerungen versichern können - so werden sie immerhin dargestellt. Sie fühlen etwas und haben Emotionen, die sich in ihren Gesichtszügen, Körperhaltungen und Verhaltensweisen ausdrücken (können), soweit dies denn erzählt wird. Sie handeln, kommunizieren miteinander und fügen anderen Figuren Glück oder Schaden zu. ${ }^{187}$

Somit muss die Frage gestattet sein, ob diejenige Figurenforschung, die die Unvereinbarkeit von Figuren und Personen verabsolutiert, sich nicht allzu weit von der textanalytischen Praxis entfernt hat. So scheint es - zumal für Genazinos Figuren - bisher jedenfalls interindividuell plausibel gelungen zu sein, sich im Großen und Ganzen mit etwa folgenden Einschätzungen gut verständigt zu haben: „Gerhard Warlich wird von seiner Lebensgefährtin Traudel zu einem gemeinsamen Theaterbesuch genötigt." 188 Beileibe möchte ich Bartl nicht widersprechen. Vermutlich findet sich sogar kein einziger empirischer Leser des Romans - der ideale ohnehin nicht -, der auch nur das geringste Problem damit hätte, dieser Aussage zuzustimmen. Und doch handelt es sich um im Hintergrund höchst komplexe Prozesse der Bedeutungszuweisung, des Abgleichs mit eigenen Normen und Vorurteilen, mit Alltagsüberzeugungen (Was ist eine Nötigung? Umfasst eine Nötigung Absicht?). Noch deutlicher tritt das Problem im folgenden Beispiel zutage: „Wie die Zukunft Pescheks aussieht, bleibt am Ende offen: vermutlich ein Leben ,ohne Netz und doppelten Boden', gekennzeichnet durch kurzsichtige und ungesicherte Beschäftigungen." 189 Hier wird endgültig derjenige leichtfüßige, plausible wie ontologisch problematische Schritt über die Text-Welt-Schwelle gegangen: Sich nach einem Bekannten zu erkundigen und zu fragen, was aus ihm geworden sei, ist Lebensweltrealität; dieselbe Frage an eine Figur zu richten, erweckt das begründete Misstrauen des Wissenschaftlers - es sei denn eine neue Staffel einer Serie erscheint demnächst. Und dennoch liest sich diese Prognose keineswegs unwahrscheinlich: Nimmt man etwa an, bei einer Figur eine vorher ausformulierte Vita in Ausschnitten zu Gesicht zu bekommen, dann ist diese Mutmaßung sogar eine vernünftige. ${ }^{190}$

Aber verlässt man damit nicht den Boden wissenschaftlicher Figurenbetrachtung? Schließlich sind jene doch faktisch nur aus Papier gemacht. ${ }^{191}$ Bereits vor über hundert Jahren mahnt Musil: „Personen eines Dichtwerks wie lebende Menschen behandeln ist die Naivität eines Affen, der in

\footnotetext{
187 Haferland: Psychologie und Psychologisierung, S. 93.

188 Andrea Bartl: „The kindness of strangers“. Das Motiv der Fremdheit in ausgewählten Romanen Wilhelm Genazinos. In: dies./Marx (Hg.): Verstehensanfänge (2011), S. 69-84, hier S. 69.

189 Oliver Sill: Moderne Zeiten. Wolf Peschek als Held der achtziger Jahre. In: Arnold (Hg.): Wilhelm Genazino (2004), S. 29-35, hier S. 35.

190 Vgl. zu einer Kritik an dieser Vorstellung Bode: Der Roman, S. 124. Wobei gerade die Schreibratgeberliteratur tatsächlich häufiger insinuiert - und auch bei Genazino zumindest die Möglichkeit in Betracht gezogen werden sollte -, dass es um im Vorfeld komplett ausgestaltete Figuren mit Vergangenheit, Gegenwart und Zukunft, mithin vollständiger Biografie geht (s.u.; $\Rightarrow$ I.3.1).Vgl. für eine gründliche schreibdidaktische Reflektion dieses Problems Felix Woitkowski: Figurenwürfel. 36 mal 6 Seiten kreatives Schreiben. Norderstedt 2015.

191 Dass es sich um einen Fehlschluss handelt, legt Haferland in „Psychologie und Psychologisierung“, S. 108 f., überzeugend dar.
} 
68 - Teil I: Grundlagen 2. Wilhelm Genazinos Romanfiguren und ,Figurenromane‘

den Spiegel greift.“192 Bezogen auf Holmes' Muttermal und diejenigen Interpreten, die keinerlei Unterschied zwischen Buch und barer Münze haben gelten lassen, nicht in den Wind gesprochen. Und trotzdem würde sich die Suche nach einem - damaligen wie heutigen - Romanleser, der nicht hin und wieder mit diesem naiven - über die faktische (Nicht-)Einfältigkeit der Primaten soll hier nicht gesprochen werden; Musil hat es noch nicht wissen können - Griff wenigstens geliebäugelt hätte, schwierig gestalten. Und das mit gutem Recht: „Als Figuren werden sie in dem Augenblick, in dem sie als solche identifiziert werden, auch schon interpretiert. Figur und Psychologie sind hier im Akt der Interpretation gleichursprünglich. "193 Harald Haferland, der sich auf die Heider-Simmel-Demonstration beruft, die bereits 1944 den Beweis antritt, dass sich das menschliche Hirn nicht einmal entblödet, geometrischen Figuren „ein Geschlecht und menschliche Eigenschaften“ zuzuschreiben, leitet daraus seine siebte von sechzehn mit ,Figur und Person“ in Verbindung stehenden Thesen ab: „7. Es gibt keine Figuren ohne Psychologie.“194 Je nachdem, welche Literatur zur Figurenanalyse konsultiert wird, gibt man sich mehr oder weniger zimperlich, was die prinzipielle Vergleichbarkeit von Figuren und Menschen anbelangt.195 Dies schlägt sich etwa auch in terminologischen Nuancen nieder: Ist ,die Psyche‘ bspw. in ,kognitiven` Texten ausschließlich für den Leser reserviert, trifft man den Begriff in literaturwissenschaftlicheren Bereichen auch für Figuren an. Jost Schneider etwa arbeitet explizit mit der Vorstellung einer Figurenpsyche, was er mit der Ähnlichkeitsbeziehung von fiktiver und realer Welt begründet:

\begin{abstract}
Die Figuren eines Romans bilden im Prinzip einen eigenen sozialen Raum, d.h. eine erfundene kleine Gesellschaft mit ihren eigenen Normen und Konventionen des Zusammenlebens. In den allermeisten Fällen ist der fiktive soziale Raum des Romans jedoch ganz ähnlich strukturiert wie der reale soziale Raum, in dem sich Autor und Leser bewegen. Das dürfte damit zusammenhängen, dass es neben der individuellen Psyche der Figuren häufig ihr Sozialverhalten ist, für das sich die Leser in besonders starkem Maße interessieren. Würden in einem Roman keine wirklichkeitsähnlichen Liebesbeziehungen, Freundschaften, Rivalitäten etc. dargestellt, sondern völlig fremdartige, frei erfundene Formen von Sozialbeziehungen, so würde das offenbar aus der Sicht vieler Rezipienten den Lektüreanreiz stark vermindern. Jedenfalls ist es sehr auffällig, dass selbst in Urwelt-, Sciencefiction- oder phantastischen Romanen so gut wie immer Gesellschaftsstrukturen auftauchen, die ein Pendant in den eigenen Erfahrungen oder in den historischen Kenntnissen des Lesers finden: Unter Tieren gibt es dann einen Staat, unter Vorzeitmenschen Familien, unter Außerirdischen ganz menschlich wirkende Rivalitäten oder Freundschaftsbeziehungen usw. ${ }^{196}$
\end{abstract}

Bei Leschke, der nicht per se gegen eine Vergleichbarkeit von Figur und Person optiert, jedoch eher den menschlichen Wahrnehmungsmodus als Vergleichsmoment stark macht, kommt ein

192 „Aus dem Entwurf für eine Rezension von Theodor Reiks Arthur Schnitzler als Psycholog.“ Zit. n. Jannidis: Figur und Person, S. 170, Fußnote 48.

193 Haferland: Psychologie und Psychologisierung, S. 103.

194 Haferland: Psychologie und Psychologisierung, S. 103.

195 Alle tatsächlich mit intentionalem Handeln in Verbindung stehenden Ausführungen sind dem dritten Kapitel des Grundlagensegments vorbehalten.

196 Schneider: Einführung in die Roman-Analyse, S. 21; Herv. N. L. 
Mittelweg in Betracht. ${ }^{197}$ In ein ähnliches Horn stößt Nicolas Pethes. Sein Artikel „Helden, Hunde, Eigenschaften. Figurenkonzepte in der literarischen Narration“

entfaltet die lange Tradition der Konstruktion literarischer Figuren und versteht sie als textintern generierte Instanzen, denen Handlungen und Aussagen zugeordnet werden. Während hierbei bis ins 18. Jahrhundert statische Charaktertypen dominieren, treten vor dem Hintergrund der neuen Semantik von Individualität Figuren in den Vordergrund, die dynamischen und nicht immer zielgerichteten Entwicklungsprozessen unterworfen sind. Die damit einhergehende Entfaltung der innerpsychischen Dimension von Charakteren ermöglicht den in der älteren Forschung so genannten Übergang von ,flachen' zu ,runden' Charakteren. Dieser Übergang betrifft aber nicht nur anthropologische Aspekte, sondern verweist auf die Relevanz verschiedener Erzählperspektiven bei der Gestaltung literarischer Figuren: Neben auktorialen Beschreibungen sowie Aussagen literarischer Figuren übereinander betrifft das in der modernen Literatur zunehmend implizite Selbstcharakterisierungen von Figuren durch Techniken der internen Fokalisierung. Für alle diese Fälle lässt sich zeigen, dass das Bild einer literarischen Figur, indem es sich aus Fremd- und Selbstaussagen strukturiert, auf die gleiche Weise entsteht, wie Vorstellungen über reale Personen, so dass die vieldiskutierte (ggfs. auch historische) ,Realität' literarischer Figuren eher in dieser strukturellen Analogie ihrer jeweiligen Konstitution als in mimetischen Referenzen auf die außertextuelle Wirklichkeit zu sehen ist. [...] Auch in der sozialen Interaktion konstruieren wir anhand von Aussagen und Handlungen unseres Gegenübers ein bestimmtes Figurenmodell, das in der Folge affirmiert oder modifiziert wird. [...] Ein literarischer Text evoziert aufgrund seiner Struktur ein Wahrnehmungsmuster, das demjenigen der Wirklichkeit entspricht. [...] Entscheidend ist, dass literarische Figuren weniger reale Personen nachahmen, als sie die Präsentations- und Wahrnehmungsweise von Personen aufgreifen und inszenieren. Darin liegt die Realität einer Figur. ${ }^{198}$

Diese Mittelwege, die Jens Eder 2008 in seinem Forschungsstand des Standardwerks zur Figur im Film höchst optimistisch mit „Koexistenz und Integrationsmöglichkeiten“ apostrophiert und beobachten zu können glaubt, dass sich die „in ihren theoretischen Grundannahmen kaum vereinbar[en]“ Strömungen „Strukturalismus, Psychoanalyse und Kognitivismus“ hinsichtlich ihrer „Forschungsergebnisse ergänzen, und in der letzten Zeit [...] vielfach eine Annäherung der Positionen festzustellen" sei, ${ }^{199}$ werden indessen immer noch sowohl durch gängige Tagungspraxis als auch in der Literatur konterkariert durch Positionen, die deutlich eher auf deren Unterschiede abzielen als auf deren wie auch immer geartete Ähnlichkeit:

Wie eine reale Person kann man sie [Figur; N. L.] aber auch nicht behandeln, da es sich um ein sprachlich erzeugtes Gebilde handelt, das multifunktionaler Teil einer narrativen Kommunikation ist. Aufgrund dessen ist sie stets intentional strukturiert, und das Wissen über sie ist so begrenzt wie die in der Darstellung vergebenen Informationen. Nur mit sehr starken Zusatzannahmen kann man bei diesen Gegebenheiten so etwas wie ein realistisches Substrat unterstellen. Alle Autoren bzw. alle ,großen' Autoren müßten dann unabhängig von den verschiedenen historischen Konzepten, die ihre Figurenbeschreibung offensichtlich prägen, eine historisch invariable Schicht des Menschen dargestellt haben. ${ }^{200}$

197 Vgl. Rainer Leschke: Einleitung: Zur transmedialen Logik der Figur. In: ders./Henriette Heidbrink (Hg.): Formen der Figur. Figurenkonzepte in Künsten und Medien. Konstanz 2010, S. 11-26, hier S. 14. Leschke/Heidbrink (Hg.): Formen der Figur (2010), S. 87-107, hier S. 87 u. S. 105.

199 Eder: Die Figur im Film, S. 56 f.

200 Jannidis: Figur und Person, S. 170. 
Es nimmt nicht wunder, dass Jannidis im gleichen Atemzug die Psychoanalyse in Sippenhaft nimmt für diese „Tiefenschicht“.201 Mit Haferland könnte man dagegen das kognitions- und evolutionärpsychologisch unumstößliche Faktum der Theory of Mind $(\Leftrightarrow I .3 .1)$ anführen und mit der präzisierten 7. These entgegnen: „Es gibt keine Figuren ohne Psychologie. Figuren teilen als ausgedachte Wesen immer ein anthropologisches Minimum mit lebendigen Menschen."202 - Damit wäre die hermeneutische Spirale einmal erkenntnisfördernd umrundet, treffen sich doch hier Schneiders Annahme der ,Wirklichkeitsähnlichkeit', der ,menschliche Wahrnehmungsmodus‘ bei Leschke und Pethes, Jannidis „historisch invariable Schicht“ und die kognitionspsychologische Überzeugung, dass Menschen, die papierne Menschen erdenken, und Menschen, die papierne Menschen als Menschen erlesen, en gros gar nicht aus ihrer Haut und daher nicht anders können - bzw., um den Markt zu bedienen: wollen, - als Figuren zu entwerfen, die ein Innen und Außen etc. haben. ${ }^{203}$

Wichtig mit Bezug auf Genazino ist hinzuzufügen, dass zwar durchaus nur die gegebenen Informationen dort stehen, wie Haferland und Jannidis gleichermaßen anmerken, diese bei Genazino jedoch so reichhaltig sind, wie sie schwerlich im echten Leben aufgefunden werden können.204 Was sich abzeichnet, sind eigentlich nur zwei sich - leider immer noch - gegenüberstehende Lager: dasjenige, welches die Menschenähnlichkeit von Figuren hervorkehrt auf der einen, dasjenige, welches die Funktionalität derselben herausstreicht, auf der anderen Seite. ${ }^{205}$ Für die vorliegende Arbeit wird wertneutral mit dieser allgemein anerkannten prinzipiellen Reduktion auf zwei Sichtweisen gearbeitet. 206 Es lohnt sich, beide noch einmal zu kontrastieren, um eine für diese Studie pragmatische Lösung zu formulieren:

Vom internen Standpunkt aus gesehen sind Figuren Lebewesen. Meist handelt es sich um Menschen, häufig - wenn der Erzähltext realistischen Darstellungskonventionen folgt [...] - handelt es sich um Personen, denen im großen und ganzen Eigenschaften zugesprochen werden können, wie wir sie auch uns selbst und unseren Mitmenschen zuerkennen. Dazu gehören insbesondere ein breites Spektrum innerer (geistiger) und äußerlicher Charakteristika, wie etwa die Fähigkeit zu

201 Jannidis: Figur und Person, S. 170.

202 Haferland: Psychologie und Psychologisierung, S. 106.

203 Erneut geht es nicht darum, so zu tun, als gäbe es keine experimentelle Prosa $(\Leftrightarrow I .2)$.

204 Für die legitime Inferenz von, nicht da stehenden' Informationen, die aber qua soziokulturell historischen Weltwissensbeständen durchaus ergänzt werden dürfen, vgl. Haferland 2013, S. 109, sowie unten $(\Rightarrow I .3 .2)$.

205 Bezeichnenderweise sprüht Eder einerseits vor Optimismus und zählt eine ganze Heerschaar von Forschern und Forscherinnen auf, die diese Bipolarität überwinden wollen oder gar überwunden haben, schreibt aber - genau wie diese Studie - letztlich die Trennung in „Figuren als fiktive Wesen“ und „Figuren als Artefakte“ fort (vgl. Eder: Die Figur im Film, „Teil III“ u. „Teil IV“).

206 Die oben aufgerufene Vierteilung lässt sich zwar relativ gesichert zuordnen - Hermeneutiker und Psychoanalytiker ins interne Töpfchen, Strukturalisten und Kognitivisten ins externe -, aber zwei Faktoren geben der Zweiteilung den Vorzug Erstens: Die ,Kognitiven' sind von beiden Lagern vereinnahmt worden. Zweitens: Ein interner Blick muss sich nicht auf Hermeneutik und Psychoanalyse verpflichten, sondern ist auch aus anderer Perspektive einnehmbar, wie es auch der externe aus anderer als strukturalistischer Warte aus ist. 
denken und zu empfinden, bestimmte Bedürfnisse und Absichten, intentionales Handeln, soziale Beziehungen usw. ${ }^{207}$

Hingegen sind „[v]om externen Standpunkt aus gesehen [...] Figuren Artefakte, d.h., von Autoren geschaffene Aspekte von Erzähltexten. Die auf den Artefakt-Charakter abzielende übergreifende Frage der Figurenanalyse lautet ,Wie ist die Figur gemacht bzw. gestaltet?'“"208 Trotz dieser erfreulich teilnahmslosen Gleichberechtigung ließe sich das perpetuierte ,Entweder-oder` als Kapitulation der Autoren vor den möglicherweise sich auftuenden Abgründen, an denen entlang ein Mittelweg führen würde, werten:

Whereas in mimetic theories (i.e. theories which consider literature as, in some sense, an imitation of reality) characters are equated with people, in semiotic theories they dissolve into textuality. What remains? If both approaches end up cancelling the specificity of fictional characters, though from different standpoints, should the study of character be abandoned, or should both approaches be rejected and a different perspective sought? Can such a perspective reconcile the two opposed positions without ,destroying' character between them? Is it possible to see characters ,at once as persons and as parts of a design'?209

\section{PRAgMATISCHE LÖSUNG}

Drei für die vorliegende Arbeit relevante Punkte lassen sich bislang vor der Folie der bisherigen Ausführungen aus dieser Doppelperspektive ableiten:

1. Beide Standpunkte einzunehmen, ist vollkommen legitim.

2. Einen von beiden insofern zu verabsolutieren, als der jeweils andere damit diskreditiert wird, verfestigt die einander gegenüberstehenden Positionen hin zu einem Ausschlussdenken, das weder im Dienst der Sache steht (gelungene Figurenanalyse zu betreiben) noch einen ,königlichen' Mittelweg denkbar scheinen lässt, der skalar und nicht bipolar zu denken wäre.

3. An welchem Ende der Skala sich zu positionieren (eher) angemessen ist, bestimmt maßgeblich der Untersuchungsgegenstand.

Ergänzend ist nun anzumerken, dass man sich nicht notwendigerweise begründet auf eine Seite schlagen muss, wie es etwa Jannidis oder Haferland tun, - man kann auch „zwischen dem internen und dem externen Standpunkt hin- und herwechseln“,210 wie es Köppe/Kindt - zumindest für die Handlungsmotivationsanalyse $(\Leftrightarrow I .3)$ explizit - anempfehlen und wie es auch Bachorz die Wogen der Ufer zu glätten vorschwebt. ${ }^{211}$ Im Falle einer Positionierung allerdings müssen bei der Wahl einer der beiden Seiten die „Darstellungskonventionen“ berücksichtigt werden; kurz: Figur und methodischer Blick müssen eine bestmögliche Passung gewährleisten.212

Global betrachtet wird hier die argumentative Doppelstrategie gefahren, dass das Hin-undHerwechseln als Kardinallösung zu begrüßen und zu verfolgen ist, wobei eher von einer Skala

Köppe/Kindt: Erzähltheorie, S. 120.

Köppe/Kindt: Erzähltheorie, S. 128.

Shlomith Rimmon-Kenan: Narrative Fiction. Contemporary Poetics. 2. Aufl. London/New York 1983/2002, S. 33; zit. n. Stephanie Bachorz: Zur Analyse der Figuren. In: Wenzel (Hg.): Einführung in die Erzähltextanalyse (2004), S. 51-67, hier S. 61 f.

Köppe/Kindt: Erzähltheorie, S. 151.

Vgl. Bachorz: Zur Analyse der Figuren, S. $51 \mathrm{f}$.

Vgl. Bachorz: Zur Analyse der Figuren, S. 52. 
72 - Teil I: Grundlagen 2. Wilhelm Genazinos Romanfiguren und ,Figurenromane‘

denn einer Dichotomie ausgegangen wird: extern und intern lassen sich abstufen. Hier wird mit leichtem Übergewicht intern gearbeitet. Wenn man es negativ auslegt, wird also doch einer Seite der Vorzug gegeben. Dann muss dafür Sorge getragen werden, dass Figur und Analysewerkzeug zusammenpassen, was für die interne Perspektive laut Köppe/Kindt genau dann der Fall ist, „wenn der Erzähltext realistischen Darstellungskonventionen folgt“.213 Auch Bode sieht prinzipiell eine „Verrechnung des Verhaltens fiktionaler Figuren mit real life-Wahrscheinlichkeitsannahmen (die selbstverständlich selbst wieder historisch und kulturell variabel sind)“ am Werk, die erst dann problematisch wird, sobald „der Roman sein ästhetisches Programm ändert und sich nicht mehr als verpflichtet auf die Abbildung und Darstellung von ,Realität' betrachtet."214 Der Punkt ist: Bei Genazino begegnen dem Leser nicht nur menschenähnliche, sondern Menschen möglichst ähnliche Figuren!215 Obwohl man häufig nicht gut beraten ist, Autoren zu ernst zu nehmen, wenn sie über (zumal: eigene) Bücher und deren ,Aussagen' sprechen,216 sind Genazinos flächendeckend auffindbare Hinweise zum Pinselstrich der Figurenzeichnung eine Fundierung für die Annahme einer realistischen, ,runden` und psychologisch ausgestalteten Figur. So steht etwa hinsichtlich der Hauptfigur aus Das Glück in glücksfernen Zeiten zu lesen, dass „sich der Erzähler in ein Erlebnis, das für ihn typisch ist“, verstrickt.217 Genazino spricht hier und im Folgenden wie über einen Vertrauten, jedenfalls nicht wie über eine Textfunktion. Er spricht über seine Reflektor-Figur, wie man nur über etwas sprechen kann, das aus-gedacht in dem Sinne ist, dass es nicht nur an-gedacht ist: ${ }^{218}$ Genazinos Figuren sind also auch in der produktionsästhetischen Sicht solche, die es in besonderem Maße nahelegen, sie personenähnlich zu erlesen.

Nun kann man, wie bereits angedeutet, die Forschung zur kognitiven Narratologie fruchtbar machen, um für einen internen Blick zu optieren: Wo bspw. Jannidis - trotz gleicher Grundannahmen - häufig deutlich gegen die Gleichsetzung von Figur und Person schreibt, ${ }^{219}$ ließe sich

213 Köppe/Kindt: Erzähltheorie, S. 120.

214 Bode: Der Roman, S. 131.

215 Vgl. zum Realismus Köppe/Kindt: Erzähltheorie, S. 140 ff.; vgl. für eine Auslotung des Raums zwischen realistischem und fantastischem Erzählen in der Gegenwartsliteratur generell Moritz Baßler: Realismus - Serialität - Fantastik. Eine Standortbestimmung gegenwärtiger Epik. In: Horstkotte/Herrmann (Hg.): Poetiken der Gegenwart (2013), S. 31-46; vgl. Leonhard Herrmann: Andere Welten - fragliche Welten. Fantastisches Erzählen in der Gegenwartsliteratur. In: Horstkotte/ders. (Hg.): Poetiken der Gegenwart (2013), S. 47-65; vgl. Nathan Taylor: Am Nullpunkt des Realismus. Terézia Moras Poetik des hic et nunc. In: Horstkotte/Herrmann (Hg.): Poetiken der Gegenwart (2013), S. 13-30. Vgl. Pontzen: Banalität und Empfindsamkeit, für eine Position, die Genazinos Romane insgesamt als nicht sehr realistisch einstuft.

216 Unter anderem Michael Ende schreibt man das Diktum zu, dass sich Autoren besser nicht zu ihren Texten äußern sollen.

217 Genazino: Der Roman als Delirium, S. 21.

218 Vgl. Matthias Bauer: Romantheorie. Stuttgart/Weimar 1997, S. 216.

219 Man könnte einwenden, dass auch er, von hinten durch die Brust ins Auge' die Möglichkeit einräumt, dass Figuren menschenähnlich sind - dann aber immer stark relativiert und verklausuliert wie etwa in der Formulierung: „Außerdem scheint die Differenz zwischen vorübergehenden Innenzuständen und mehr oder weniger stabilen Merkmalen des Inneren - wie immer das bezeichnet und konzeptualisiert wird - interkulturell relativ stabil zu sein. Es gibt sicherlich überhaupt keine 
von der Basis des kognitiv(istisch)en Betrachterstandpunkts genau gegenteilig argumentieren, dass ,von alten Zeiten her' die menschliche Psyche so beschaffen sei, dass Figuren als Menschen behandelt werden $\Leftrightarrow$ I.3.1 $)^{220}$ - mit allen Gefahren bei der Attribution, die es auch im echten Leben gibt:

Die postklassische kognitive Narratologie befasst sich mit dem Leseprozess des naiven Lesers und behauptet, dass der Leser die literarische Figur so und nur so versteht, dass er ihr eine komplexe Psyche zuschreibt. Sogar solche Instanzen, die nicht als Figur dargestellt werden, wie der heterodiegetische Erzähler, werden vom Leser als eine menschliche Psyche wahrgenommen. Grund: Das menschliche Gehirn ist evolutionär so gestaltet, dass es auch dort mentale Inhalte wahrnimmt, wo eventuell keine sind. Zuschreibungen von mentalen Zuständen (ToM) ist nämlich evolutionäres Produkt, ohne das der Mensch als gesellschaftliches Wesen nicht hätte überleben können. ${ }^{221}$

Zwar muss dringend ergänzt werden, dass der Mensch als kulturelles Wesen auch deshalb erfolgreich ,überlebt' hat, weil er zwischen fact und fiction (meist) zu unterscheiden wusste, aber glaubt man den kognitionspsychologischen Erkenntnissen, gelten diese Annahmen transepochal und transkulturell:

So gibt es keine bisher bekannte Kultur, in der Menschen ihrem Gegenüber keinen mentalen Innenraum unterstellen oder die Persönlichkeit eines anderen nicht aus situationsübergreifenden, also langfristigen Merkmalen und Eigenschaften konstruieren. Und auch die Tatsache, dass Menschen Informationen, die sie über andere Menschen erhalten, verarbeiten, indem sie sie an Merkmalen wie Glaubwürdigkeit, Offensichtlichkeit und Status messen, scheint eine anthropologische Konstante zu sein (vgl. Jannidis 2004, 185-195). Das hieße aber, dass auch elementare Mechanismen in der Rezeption literarischer Figuren weitgehend stabil sein müssten. ${ }^{222}$

Und zwar: sowohl in Bezug auf den ,naiven“ wie den wissenschaftlichen Leser:223 „Geschichten lesend, sind wir nicht damit beschäftigt, Informationen über intentionale Konstrukte zusammenzutragen, sondern imaginieren wir Personen“.224 Und das, obwohl es Texte gibt, denen diese Lesart Gewalt antut. Man denke an Watson, dessen Charakterisierung bzw. Figuren-Analyse wohl oder übel mit den Zuschreibungen ,naiv', ,besorgt', ,dümmlich' hantieren müsste, würde sie die interne Perspektive verabsolutieren. Erst durch die externe, die Watson als das nimmt, was er ist: ein Figurant/Charaktant ${ }^{225}$ Holmes', ein nur dazu eingeführter Charakter, um ,den Großartigen' ins rechte Licht zu setzen, wird dem Text und der Figur genüge getan. Diese literarisch-

logische Notwendigkeit, aber [...]." (Jannidis: Figur und Person, S. 126f.) Die bloße Anzahl der den Kern der Aussage abschwächenden Mutmaßlichkeits-Markern spricht Bände.

Vgl. Robert Vellusig: Die Sinnenhaftigkeit der Poesie. Eine Literaturpsychologie ohne Freud. In: Wiesinger (Hg.): Akten des X. Internationalen Germanistenkongresses (2003), S. 245-250, hier S. 245 ff.; vgl. Zunshine: Why we read fiction; vgl. Haferland: Psychologie und Psychologisierung, S. 102.

Márta Horváth: Unveröffentlichtes, unpaginiertes Manuskript zum Vortrag: „Arthur Schnitzlers Der Tote Gabriel aus Sicht der kognitionspsychologischen Figurenanalyse" am 16. Juni 2016 im Rahmen meines Seminars „Figur oder Person? Papier oder Psyche? Einführung in die Figurenanalyse“ an der Universität Kassel im SoSe 2016. Vgl. für eine ähnliche Position auch Mark Currie: Postmodern Narrative Theory. 2. Aufl. Oxford 2010. Reuvekamp: Hölzerne Bilder - mentale Modelle?

223 Vgl. Haferland: Psychologie und Psychologisierung, S. 96.

224 Vellusig: Die Sinnenhaftigkeit der Poesie, S. 245.

225 Vgl. Hansen: Figuren, S. $243 \mathrm{f}$. 
74 - Teil I: Grundlagen 2. Wilhelm Genazinos Romanfiguren und ,Figurenromane‘

rhetorische Technik ist zurückzuverfolgen bis in die Antike, wo die Sokratischen Dialoge mit der ,Sokratischen Methode' hantieren, um einen randläufigen Stichwortgeber zur Hand zu haben. ${ }^{226}$ Aber eine derart den externen Blick einfordernde Gemengelage liegt bei Genazino schlicht nicht vor. Es ist mithin nicht bloßes Wohlgefallen, sondern die Passung von Figur und Perspektive, die die Wahl auf einen primär internen Blick nahelegt, wohingegen immer dann, wenn es der Text gebietet, die externe eingenommen wird. Anhand eines in der figurentheoretischen Literatur häufiger anzutreffenden Beispiels soll gezeigt werden, was einerseits eine Figurentheorie, die Allgemeingültigkeit beansprucht, von der hier vorliegenden sondert, und andererseits, was Genazinos Prosa von experimentellerer scheidet:

Es war einmal ein Rotschopf, der hatte weder Augen noch Ohren. Er hatte auch keine Haare, so daß man ihn an sich grundlos einen Rotschopf nannte. Sprechen konnte er nicht, denn er hatte keinen Mund. Eine Nase hatte er auch nicht.

Er hatte sogar weder Arme noch Beine. Er hatte auch keinen Bauch, keinen Rücken, er hatte keine Wirbelsäule, und er hatte auch keine Eingeweide. Nichts hatte er. So daß unklar ist, um wen es hier eigentlich geht.

Reden wir lieber nicht weiter darüber. ${ }^{227}$

Was Jannidis dazu verwendet, sein Modell vor demjenigen Margolins auszuzeichnen, und veranschaulichen möchte, dass eine universelle Figurenerzähltheorie auch mit derartigen Texten zurande kommen muss, ist für die Figurenanalyse bei Genazino - und des Gros' der Romanliteratur schlechthin - theoretisch verstiegen. Wirklichkeitsfern, weil die übliche Prosa so nicht funktioniert. Abwegig, weil auch dann, wenn man mit Jannidis argumentiert, diese Figur nun mal lediglich mit externem Blick analysiert werden kann und, auch wenn vier von fünf Merkmalen gegeben sein mögen, viel kontraintuitiver Aufwand betrieben werden muss, um den Ex-negativoRotschopf als vollgültige Figur anzuerkennen.228 Perfiderweise - und das ist der eigentliche Vorwurf - haben strukturalistisch orientierte Figurentheorien den Fokus auf den externen Blick, der für einige Figuren definitiv (allein-)gültig ist, illegitim verallgemeinert und in der figurenanalytischen Erzähltheorie die interne Perspektive insofern massiv in den Schmutz gezogen, als deren Apologeten als naiv gebrandmarkt worden sind. Etwas reißerisch lässt sich mit einem Beispiel von Genazino zeigen, was erzähltheoretische Figurenforschung, die sich dem externen Blick verpflichtet hat, und der eigentliche Analysegegenstand gemeinsam haben: nur oberflächliche Bezüge (hier: die Farbe und das Vorhandensein von Ohren):

Ein Mann mit sehr roten Ohren geht vorüber. Ich könnte sagen: Seine Ohren sind so rot wie brennende Fackeln. Nein, das wäre übertrieben. Seine Ohren sind so rot wie Herbstblätter. Ja, Herbstblätter! Das ist das Wort. (Frauen, S. 19)

\footnotetext{
226 Auch Sidekicks in Shows sind letztlich dafür da, die „Hauptfigur' (hier: Showmaster) zu profilieren, zu figurieren, zu charakterisieren.

227 Daniil Charms: Das blaue Heft Nr. 10. In: ders.: Fälle. Szenen, Gedichte, Prosa, hg. u. übers. von Peter Urban. Zürich 1988, S. 207; zit. n. Jannidis: Figur und Person, S. 174 f. 
Genazino - und viele weitere Schriftsteller - schreiben keine experimentelle oder wie im Charms-Beispiel absurde Prosa. Das ,höchste der Gefühle' ist der in der Schwebe bleibende Ohrverlust in Mittelmäßiges Heimweh, wo man nach realistischen Darstellungskonventionen oder der Symbolhaftigkeit fragen kann. ${ }^{229}$ Genazinos Romane sind zur Imagination gedachte, detailreich charakterisierende und hochgradig von ausgestalteten Figuren lebende, also: ,realistische', die die interne Perspektive nicht nur ermöglichen, sondern nahelegen. ${ }^{230}$ Daraus ergibt sich:

4. Genazinos Romanfiguren fordern nachgerade ein, die in jüngster Vergangenheit von verschiedenen Seiten unter Beschuss geratene Perspektive, nach der Figuren Menschen ähneln - und sei es nur im Modus der Rezeption -, zu bevorzugen.

Diese Untersuchung geht weiterhin pragmatisch davon aus, dass Genazinos Texte einen Leser anvisieren, der eine ausbuchstabierte ,Person' hinter der Figurenoberfläche vermutet, ${ }^{231}$ die in Grundzügen lesend - selbstredend rezeptionsästhetisch gedacht und nicht naiv auf die Black Stories bezogen - ,rekonstruiert' bzw. vervollständigt werden kann $(\Rightarrow$ I.3.1). Auch Bode zufolge könne sich jeder Autor generell „bei der Evozierung ,seiner Figuren recht weitgehend darauf verlassen, dass seine Vorgaben vom Leser (in der Regel: automatisch und unbewusst) ,komplettiert' werden."232 $(\Rightarrow$ I.3.3)

Ein eindrucksvolles Beispiel, das abschließend neben der ,Rundheit' und realistischen ,Psychizität' der Figuren aus Genazinos Romanen auch gleich ein Indiz dafür liefert, dass die Blaupause dieser Untersuchung, Genazino und motivationales Figurenhandeln zusammenzudenken, höchst ertragreich ist, findet sich in Kein Geld, keine Uhr, keine Mütze:

Ich stand eine Weile herum und fragte mich, ob ich auf Sibylle noch einmal neugierig werden könnte. Das war nicht der Fall. Wahrscheinlich unter dem Einfluss einer traurigen Anmutung (kein Verlangen mehr nach Sibylle) ging ich rasch nach Hause und putzte meine Wohnung. Ich fragte mich, was muss weggeräumt, weggeworfen, verhüllt, verbrämt, verborgen werden? Gerade entdeckte ich, dass sich auf der Marmelade, die im Glas auf dem Tisch stand, ein wenig Schimmel gebildet hatte. Es war unwahrscheinlich, dass meine gewesene Ehefrau je ein Marmeladenbrot essen wollte, aber ich wollte kein Risiko eingehen und entfernte das Glas. Mein Blick fiel auf einen verschlissenen Pulli, den ich nur am späten Abend trug und in dem ich manchmal auch schlief, wenn ich zum Ausziehen zu müde war. Auch ihn räumte ich weg. Ich musste innerlich lachen über meine weit vorausschauende Fürsorge. [...] Ich wollte Sibylle nicht wieder treffen, aber ich wollte nicht, dass sie das merkte. [...] Vorerst musste ich verhindern, dass sie in meine Wohnung kam. Ich fühlte, dass sie ausgehungert war und gegen einen Sexualimbiss mit ihrem Ex-Mann nichts einzuwenden hatte. (Kein Geld, S. 10 u. S 12)

Ohne externen Blick, der in der „weit vorausschauende[n] Fürsorge“ zugleich auch eine literarische Vorausdeutung erkennt, in der paradigmatischen Reihung - „weggeräumt, weggeworfen,

229 Vgl. Dana Pfeiferová: „Ich frage mich, ob aus dem simulierten ein wirklicher Tod werden kann, wenn er zu lange anhält“. Metaphern des sozialen Todes in Wilhelm Genazinos Roman Mittelmäßiges Heimweh. In: Bartl/Marx (Hg.): Verstehensanfänge (2011), S. 85-97, hier S. 89 f. Vgl. zur einschränkenden Tendenz, in den Romanen nach 2010 sowohl Kohärenz als auch Rundheit zurückzufahren, die Figurenliste im Anhang ( $\Rightarrow$ V.1). Vgl. zur Problematisierung dieses Sachverhalts Bode: Der Roman, S. 124, der in Kritik von E.M. Forster Isers Leerstellen nicht als bewusste Auslassung, sondern notwendigem Datenmangel geschuldet gelesen wissen will. 
verhüllt, verbrämt, verborgen“ - die Sprachspiellust nicht nur der Figuren selbst, sondern auch diejenige Genazinos zu entdecket und der nicht übersieht, dass es eine genderproblematische genazinotypische Fassade ist ( $\Rightarrow$ II.5.3), sich vor Sexualofferten seitens der Frauen nicht retten zu können, kann keine Analyse funktionieren. Allerdings sind auch intern in dieser kurzen Passage einige Beobachtungen anzustellen: Der namenlose männliche Ich-Erzähler reflektiert unmittelbar nach einem zufälligen Treffen mit seiner Exfrau - er hat eine Vergangenheit - seine Gefühle ihr gegenüber. Er kommt zu dem Schluss, dass ein Wiederanknüpfen der Beziehung für ihn nicht in Frage kommt, auch nicht für einen One-night-Stand, er möchte sie nicht einmal in seine Wohnung lassen. Allerdings ist er darum bemüht, diesen Eindruck bei ihr nicht entstehen zu lassen, was ihn in einen Widerspruch zwingt: Sollte Sibylle ihn doch besuchen, dann würde sie seine wenig einladend geschilderte Wohnung und sein wohl leicht ramponiertes eigenes Äußeres nicht goutieren, sodass er vorausschauend und vorsorglich den Ist-Zustand überarbeitet. Neben einer Gegenwart hat diese Figur auch ein zukünftiges Ziel, eine Motivation: Sibylle fernzuhalten. Diesem namenlosen, männlichen ,Menschen aus Papier', der vermutlich Schriftsteller ist, dürfen Handlungsziele, Motivationen, Befindlichkeiten attribuiert werden, sofern der Text die erforderlichen Indizien liefert, was er fraglos tut. Die (teilweise) begründeten Einwände gegen ein solches Vorgehen entspringen dabei zumeist einer Forschungsposition, die sich vom ,Alltagsgeschäft' der Figurenanalyse weit entfernt hat. Und obwohl in dieser Untersuchung - entgegen des Optimums der Mischung - der Blick eher auf die interne Seite verschoben wird, geschieht dies nach der vorherigen Trennung und der Anwendung der Doppelperspektive. Und das ist etwas anderes. Damit gilt:

5. Trotz dieser Orientierung zur internen Perspektive auf der Skala muss auch für Genazinos Romanfiguren die externe immer in Betracht gezogen werden.

\section{ANALYSEKATEGORIEN UND -MODELLE}

Nach dieser ontologisch-theoretischen pragmatischen Lösung heißt es abschließend, geeignete Kategorien für die konkrete Figurenanalyse zusammenzustellen, wobei sowohl die interne als auch die externe Perspektive vertreten sein müssen. ${ }^{233}$ Fast alle in der Figuren(analyse)forschung virulent gewordenen Beschreibungskategorien und Fragen aus Analysepools lassen sich distinkt einer der beiden skizzierten Perspektiven zuordnen $\left(\Leftrightarrow\right.$ V.2). ${ }^{234}$

233 Hier eine Reproduktion aller prinzipiell vorliegenden Kategorien zu liefern, verbietet sich aus naheliegenden Gründen. Allerdings findet sich im Anhang $(\Leftrightarrow$ V.2) ein Kategorienpool für die Figurenanalyse, von denen hier nur kursorisch im Fließtext diejenigen herausgegriffen werden, die eine besondere Relevanz haben - sei es für Genazinos Romanfiguren oder die Figurenforschung insgesamt. Schaut man genau hin, so trennen viele Theoretiker diese Sphären, allerdings manchmal implizit: Bode etwa spricht von einer Analogie zu story und discourse sowie von Figurenzeichnung vs. -konzeption (Bode: Der Roman, S. 125); Culpeper (vgl. Jonathan Culpeper: Language and characterisation. People in plays and other texts. Harlow 2001), Bachorz (vgl. dies.: Zur Analyse der Figuren) und Eder (vgl. ders.: Die Figur im Film) hingegen werden explizit. 
Auf der Suche nach geeigneten externen Kategorien für (Genazinos) Figuren ${ }^{235}$ fallen schnell ,alte Bekannte' auf: Culpeper,,236 Jannidis, ${ }^{237}$ Bode,,238 Eder, ${ }^{239}$ Schneider, ${ }^{240}$ Lahn/Meister, ${ }^{241}$ Köppe/Kindt ${ }^{242}$ etwa beziehen sich allesamt auf die bereits - qua Zitat (s.o.) - eingeführten Kategorien ,round' vs. ,flat' und kommentieren diese basale Unterscheidung mehr oder weniger ausführlich. ${ }^{243}$ Es handelt sich um eine ,klassische` auf Edward Morgan Forster zurückgehende Einteilung aus externer Perspektive. ,Flache‘ Figuren sind „auf Basis einer einzigen Idee oder Eigenschaft konzipiert“, können „vom Leser auf Anhieb eingestuft werden“ und bleiben „im Verlauf der Erzählung stets gleich“. ${ }^{244}$,Runde', also

mehrdimensionale Figuren überraschen uns mit einem Verhalten, das wir nachträglich aber als kohärent erkennen [...], d.h. sie zwingen uns zu einer Modifikation ihrer Konzeption, zu einer prozessualen Ausdifferenzierung unserer Vorstellung von ihnen. Mehrdimensionale Figuren halten den Leser auf Trab. 245

Genazinos Figuren erfüllen allerdings ,nur' eine der Forster'schen Kategorien wirklich mustergültig: Zwar sind sie zweifelsfrei „durch mehrere Eigenschaften oder Ideen charakterisiert", vermögen es allerdings nicht in jeder Hinsicht, „die Lesenden immer wieder [zu] überraschen“, jedenfalls dann nicht, wenn man den Basistypus bereits kennt ( $\Rightarrow$ I.2.3 u. $\Rightarrow$ I.2.5) - und vor allen Dingen ist es nicht immer so, dass sie „sich im Verlauf der Erzählung verändern“.246 Obwohl mit Pethes durchaus davon gesprochen werden kann, dass es sich um runde Figuren handelt, ${ }^{247}$ passen sie nicht in Forsters Schema, was dem Modell anzulasten ist: „Diese Unterscheidung, so einleuchtend sie im ersten Moment auch sein mag, scheitert an Figuren, bei denen die drei Kriterien nicht zusammengehen, die also z.B. durch mehrere Eigenschaften charakterisiert werden, sich aber im Verlauf der Handlung nicht ändern. “248 Dieses Manko führt dazu, dass in der Folge bspw. Pfister eine differenziertere Auffächerung vorgenommen hat: ${ }^{249}$ Er stellt die vier Merkmalspaare statisch-dynamisch; eindimensional-mehrdimensional; völlig definiert-offen, mysteriös; trans-

235 Vgl. für eine dezidiert extern verfahrende Figurenanalyse bei Genazino etwa Fansa 2008, S. 140 f., sowie Wilhelm Amann: „Doppelleben“. Begründung von Autorschaft in Wilhelm Genazinos „Eine Frau, eine Wohnung, ein Roman“. In: Arnold (Hg.): Wilhelm Genazino (2004), S. 87-97, hier S. 91 f. Vgl. Culpeper: Language and characterisation.

237 Vgl. Jannidis: Figur und Person.

238 Vgl. Bode: Der Roman.

239 Vgl. Eder: Die Figur im Film.

240 Vgl. Schneider: Einführung in die Roman-Analyse.

241 Vgl. Lahn/Meister: Einführung in die Erzähltextanalyse.

242 Vgl. Köppe/Kindt: Erzähltheorie.

243 Andererseits setzen die jeweiligen Autoren - in Abhängigkeit von ihrer fachlichen Ausrichtung Akzente: So ist bspw. Culpeper vorwiegend an externen Faktoren interessiert, Köppe/Kindt sowie Bachorz sind um ein ausgewogenes Verhältnis und sogar um eine Synthese bemüht etc. Bachorz: Zur Analyse der Figuren, S. 57.

Bode: Der Roman, S. $130 \mathrm{f}$.

Bachorz: Zur Analyse der Figuren, S. 57 f.

Vgl. Pethes: Helden, Hunde, Eigenschaften, S. 94-97. Allerdings variiert das Maß der Reflektiertheit und des Einblicks in die eigene Psyche massiv. Vgl. für ein Paradebeispiel ,sehr rund und Einblick': Kassiererinnen, S. 151.

248 Bachorz: Zur Analyse der Figuren, S. 58.

249 Vgl. Bachorz: Zur Analyse der Figuren, S. 58. 
psychologisch-psychologisch einander gegenüber und ermöglicht somit eine weitaus genauere Einordnung von Figuren, die sich in Bezug zu Forsters Schema als ,sperrig' erweisen. Letztlich lässt sich diese - immer noch die externe Perspektive bespielende - Liste natürlich weiter ausdifferenzieren. Das von Culpeper in Rückgriff auf Hochmans Character in Literature (1985) favorisierte Modell nutzt acht Dimensionen:

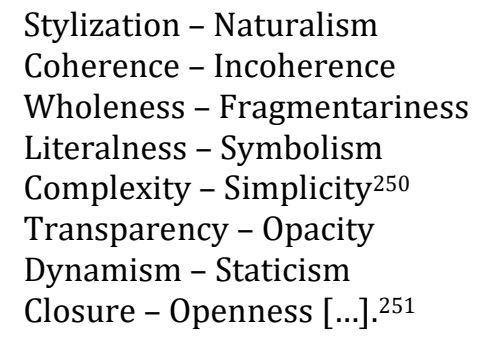

Geht man der Vereinfachung halber von einem, durchschnittlichen' Protagonisten Genazinos aus $(\Leftrightarrow I .2 .5)$, dann lässt sich dieser wie folgt auf den Skalen verorten: Er ist tendenziell eher ,naturalistisch“ ( nicht gezeichnet als „larger than life“,252 eher ,inkohärent” ( überraschend), eher ,ganz' (obwohl das Äußere bspw. nur inferiert werden kann), deutlich eher ,literal' (verkörpert keinen Typus 253), definitiv ,komplex' (Reflexionen etc.), ,transparent' (hohes Maß an Einblick in das Figureninnere), rangiert ziemlich genau in der Mitte zwischen ,Dynamik' und ,Statik' und ist ,offen' angelegt (Probleme und Fragen sind nicht gelöst am Ende).

Eine weitere Unterscheidung, die sich bei nahezu allen Autoren findet, ist diejenige zwischen direkter und indirekter Beschreibung bzw. Charakterisierung: „Wird die Figur in erster Linie von einem allwissenden Erzähler explizit beschrieben oder müssen wir als Leser die Persönlichkeit der Figur aus ihrem Handeln und ihren Äußerungen erschließen?“254

Während die direkten Charakterisierungstechniken auf expliziten verbalen Äußerungen basieren, die alle konstitutiven Merkmale des Sprechaktes Personenvorstellung oder Personenbeschreibung aufweisen, handelt es sich bei den Techniken der indirekten Charakterisierung um en passant mitgelieferte Zusatzinformationen über eine Figur, die vom Erzähler und von den Romanfiguren nicht explizit als solche thematisiert werden. Neben der Kleidung ist es häufig z.B. die Physiognomie oder die Wohnung einer Figur, die ihrer näheren Charakterisierung dient [...].255

Bei Genazino liegt fast ausnahmslos ein hohes Übergewicht auf der indirekten Charakterisierung. Erklärlich wird dies unter anderem aus der Tatsache, der überwiegend internen Fokalisierung in Verbindung mit dem häufig anzutreffenden defensiven Verhalten, möglichst wenig über sich selbst preisgeben zu wollen $(\Rightarrow I .3 .3)$.

\footnotetext{
250 Vgl. Bode: Der Roman, S. 127 ff., der die Grade an Komplexität in der Figurenkonzeption feingliedriger auffächert und Personifikation, Typ, Individuum unterscheidet.

251 Culpeper: Language and characterisation, S. $54 \mathrm{f}$.

252 Culpeper: Language and characterisation, S. 54.

253 Vgl. für die Klassifikation einer Genazino-Nebenfigur als Typus (des Außenseiters) Fansa: Unterwegs im Monolog, S. $61 \mathrm{ff}$.

254 Hansen: Figuren, S. 246.

255 Schneider: Einführung in die Roman-Analyse, S. 19.
} 
Daran anknüpfend ist erneut Manfred Pfister einflussreich geworden, der diese Opposition mit einer zweiten gekreuzt hat: derjenigen der figürlichen und auktorialen Charakterisierung:256

Ausgehend von der Überlegung, dass eine ,charakterisierende Information' entweder von einer Figur (figural) oder vom Autor (auktorial) ausgehe und dass sie ferner entweder explizit oder implizit erfolgen könne, kam er zu vier Klassen von Techniken der Figurencharakterisierung: explizitfigurale, implizit-figurale, explizit-auktoriale und implizit-auktoriale. ${ }^{257}$

Da es sich bei Genazinos Romanfiguren ausschließlich um Hauptfiguren handelt - Nebenfiguren dienen meist nur zur Konturierung der Hauptfigur, selten leisten sie einen Beitrag zur Introspektion der Haupthandelnden, ${ }^{258}$ - die im Extrem sogar autodiegetische Ich-Erzähler sind, werden zumal die figural-expliziten Charakterisierungen aufgrund gradueller Unzuverlässigkeit, die figural-impliziten aufgrund der Reflektoreigenschaft zu wahren Charakterisierungsherausforderungen, da immer eine Privilegierung von Aussagen und eine Gewichtung der Relevanz mitschwingt.259

Ebenso relevant ist es, „ob man aufgrund einer Reihe von gezeigten Handlungen selbst zu dem Schluss kommt, dass es sich bei Mr. Scrooge um einen rechten Geizkragen handelt, oder ob man ,dieselbe‘ Einschätzung dieser Figur vorgesetzt bekommt.“260 Handelt es sich im ersten Fall um ,showing', das im Ruf steht, die „literarästhetisch wirkungsvollste Weise“ und zudem „nachhaltiger und eindrücklicher“ zu sein, so ist das ,telling „zwar effizienter“, aber nicht notwendigerweise überzeugender als „etwas, was man sich selbst ,erarbeiten“ muss“. ${ }^{261}$ Das ist aus externer Perspektive, ergänzt man die bereits getroffenen figurenrelevanten Einschätzungen hinsichtlich der (Un-)Zuverlässigkeit, des Stils, der (Un-)Mittelbarkeit, der Erzählperspektive, der Klassifizierung als ,Figurenromane' etc. ( $\Rightarrow I .2 .3)$, eine gute Basis, um (Genazinos) Figuren zu begegnen. ${ }^{262}$

256 Vgl. zur (berechtigten) Kritik an der Übertragung eines für die Dramatik entworfenen Modells auf erzählende Literatur Bode: Der Roman, S. $136 \mathrm{f}$.

257 Bode: Der Roman, S. 136; vgl. auch Rüdiger Zymner/Harald Fricke: Einübung in die Literaturwissenschaft. Parodieren geht über Studieren. 5., überab. u. erw. Aufl. Paderborn 2007, S. 159-163.

258 Vgl. Bode: Der Roman, S. 127. Ein Gegenbeispiel findet sich im Roman Die Liebe zur Einfalt: „Theo sagt, daß die Luft heute so weich ist und das Licht so sanft. Das ist wahr! Wie kommt es nur, daß mich an manchen Tagen ein anderer Mensch auf das aufmerksam machen muß, was mir selber gefällt?“" (Einfalt, S. 151)

259 Vgl. Bode: Der Roman, S. 137 f.; vgl. Schneider: Einführung in die Roman-Analyse, S. 19. Das reizvolle Spannungsverhältnis von Selbst- und Fremdcharakterisierungen spiegelt sich auch in der Verhandlung von Selbst- und Fremdbildern im ersten Schlaglicht ( $\Rightarrow$ II.2.1).

260 Bode: Der Roman, S. 132.

261 Bode: Der Roman, S. 132 f.

262 Allerdings haben etwa Eder (vgl. ders.: Die Figur im Film) und Köppe/Kindt die Forschung zur Figur zu langen Aspekt-Listen synthetisiert, aus denen etliche weitere Punkte, sofern sie über die bereits aufgeführten Quellen hinausgehen, herausgegriffen werden könnten (vgl. Köppe/Kindt: Erzähltheorie, S. 131 ff.). Für Genazino von vordringlicher Relevanz sind sie zwar nicht, werden aber in Auszügen im Anhang präsentiert ( $\Leftrightarrow V .2$ ). Und selbst diese sind notwendigerweise nicht vollständig: So ist etwa Christian Friedrich Delius' Dissertation von 1970, Der Held und sein Wetter, eindeutig als Bereicherung der externen Perspektive zu werten (vgl. Friedrich C. Delius: Der Held und sein Wetter. Ein Kunstmittel und sein ideologischer Gebrauch im Roman des bürgerlichen Realismus. Dissertation T.U. Berlin 1970). 
80 - Teil I: Grundlagen 2. Wilhelm Genazinos Romanfiguren und ,Figurenromane‘

Seitens der diegetischen Figurenanalyse, also derjenigen vom internen Standpunkt aus, lassen sich die folgenden Kategorien und Fragen an Figuren herantragen:263

- Psychische Konstitution, Charakter: Über welche Persönlichkeitsstruktur verfügt die Person? Was sind ihre Bedürfnisse, Prinzipien, Verhaltensdispositionen? [...] usw.

- Äußeres, Verhalten: Wie sieht die Person aus? Über welche physischen Merkmale, welche Kleidung usw. verfügt sie? Wie agiert sie habituell und situativ? usw.

- Mentales: Was glaubt, denkt, fühlt, wünscht, plant, fürchtet usw. die Person in Bezug auf sich selbst und die Welt? Warum verfügt sie über diese Einstellungen? Was hält sie für wichtig, richtig, normal, geboten usw.? Wie ist das Verhältnis von bewussten und unbewussten Anteilen im Mentalen der Person? usw.

- Soziale Beziehungen: In welchen sozialen Beziehungen steht die Person? Wie verhält sie sich zu anderen? usw.

- Sozialer Status, Habitus, Rollenproblematiken: In welchen Umfeldern bewegt sich die Person? Welchen sozialen Status hat sie innerhalb eines Umfelds? Welche Rollen füllt sie aus, und wie verhält sie sich zu Rollenangeboten oder Rollenzwängen? usw.

- Kultureller, gesellschaftlicher, historischer Hintergrund: In welchen gesellschaftlichen, kulturellen und historischen Umfeldern bewegt sich die Person? In welcher Weise prägen oder beeinflussen diese Umfelder ihr Leben?

- Lebensgeschichtlicher Hintergrund: Welche Selbst- und Fremdzuschreibungen gibt es in Bezug auf die Vergangenheit, Gegenwart und Zukunft der Person? Gibt es Entwicklungen?264

Es handelt sich um eine offene Liste, worauf die Autoren auch dezidiert hinweisen. ${ }^{265}$ In Abhängigkeit vom zu untersuchenden Text und der jeweiligen erkenntnisleitenden Fragestellung lassen sich einzelne Aspekte zu neuen Fragen verdichten und konkret anwenden, etwa in Form der Kapitalstrukturanalyse $(\Leftrightarrow$ II.1.5) und etlichen weiteren Konstellationen.

Anders als heuristisch ist die Unterteilung in externe und interne Analysekategorien nicht zu nennen: Um eine Figur etwa als Typus oder als Verkörperung einer Idee klassifizieren zu können, bedarf es in einem ersten Schritt natürlich des intern operierenden, grundlegenden $\mathrm{Zu}$ sammentragens von Attributen, Wertvorstellungen, Habitusformen etc.; genauso wie die Charakterisierung einer Figur als melancholisch nur dann auf einer soliden Basis steht, wenn Aspekte der (Un-)Zuverlässigkeit des Erzählens, der Privilegierung von Aussagen, der Auftauchenshäufigkeit etc. $(\Rightarrow$ V.1) dieser Einschätzung vorangegangen sind. Die Empfehlung, bei der Analyse beide Aspekte auf dem Schirm zu haben, ist also in jedem Fall zu beherzigen, um Rimmon-Kenan

263 Es ist stets die Aufgabe der Nachgeborenen, zu entscheiden, ob bei den Quellen der Forschung begonnen oder eine möglichst aktuelle Zusammenschau für einführende Kapitel der eigenen Arbeit verwendet werden soll. Da nahezu alle Aspekte einer intern perspektivierten Figurenanalyse in den Schlaglichtern vorkommen, wird hier lediglich im Schnelldurchgang eine ziemlich vollständige Liste präsentiert. Für eine vollständigere Übersicht vgl. den Anhang ( $\Rightarrow$ V.2). Außerdem wird die Füllung der Kategorien durch Aussagen zu Genazinos Romanfiguren an dieser Stelle bewusst unterbunden, um keine Redundanzen zu befördern.

264 Köppe/Kindt: Erzähltheorie, S. $121 \mathrm{f}$. Die Autoren verweisen in diesem Zusammenhang per Fußnote auf „Eder 2008, S. 144 u.ö.; Kunda 1999“ (Köppe/Kindt: Erzähltheorie, S. 121; Fn 175). Es grenzt an eine herkulische Aufgabe, jedwede Liste gegen andere zu legen, da jede Veröffentlichung mehr oder weniger bei älteren abschreibt. 
die Antwort zu geben: „It is possible to see characters ,at once as persons and as parts of a design“.'266

Mit diesem Fächer an für Genazino-Figuren potenziell bedeutenden Fragestellungen in der Hinterhand, wird nun endlich mit Genazinos Figuren auf Tuchfühlung gegangen.

\subsection{Von „Figurenbauplänen“ und dem ,familienähnlichen Genazino-Basistypus“}

In Analogie zu den Vorwürfen des immer gleichen Buchs ( $\Rightarrow$ I.2.1) wird die Forschung nicht müde, Genazinos Figuren einerseits als Wiedergänger früherer anzusehen, andererseits Brüche und klare Grenzlinien zu behaupten. In Analogie muss aber auch dezidiert auf die Figuren bezogen differenzierter geschaut werden, um beide Positionen schließlich in einem Verstehens-Modell aufgehen zu lassen:

Von den Anfängen mit der Abschaffel-Trilogie aus gesehen, sind [...] die Unterschiede zu den in der Ich-Form vorgestellten Hauptfiguren späterer Texte [...] gar nicht so eklatant. Wie Abschaffel sind auch die folgenden, durchweg männlichen Protagonisten [!] eher schwach in ,ihre' Berufs- und Familienbindungen integriert und vor allem von einer existentiellen Rastlosigkeit und Unzugehörigkeit angetrieben, die sie einsame, ziellose Streifzüge durch die Stadt unternehmen lässt, vorzugsweise in deren tristeren Regionen. Auf solchen Flaneurswegen erleben die Helden obstinate Tagträume und flüchtige Sexualkontakte, sie sammeln randständige Beobachtungen zu einigen sichtbar vom Leben beschädigten Personen und unterziehen sich denkbar unenthusiastisch den immer gleichen Arbeitsabläufen und Verkehrsformen. Sie leben ihr Leben, ohne es im betonten Sinne zu führen. Eine gewisse Änderung in Richtung eines aktiven, planerischen beruflichen Verhaltens tritt erst insofern ein, als Genazino in den jüngsten Romanen dazu tendiert, seine Protagonisten als freischaffende und selbstständige Dienstleister oder als höhergestellte Verkaufs- oder Beratungsexperten anzulegen. ${ }^{267}$

Honold bemüht sich, neben der Anerkenntnis einer "gewisse[n] Änderung“, darum, gleichmachende Konstanten aufzuzeigen, die die Figuren betreffen. Dass es sich mindestens in einem Punkt um eine krasse Fehleinschätzung handelt, zeigt der Blick auf Wilhelm Genazinos Die Obdachlosigkeit der Fische (1994), in welchem eine weibliche Protagonistin vertreten ist. ${ }^{268}$ Hirsch sieht es grundlegend anders:

Während die Schilderung Abschaffels als Figur durchaus auch beißend-satirische Züge trägt, erweist sich der Wechsel zur Ich-Erzählsituation, die seit 1989 beibehalten bleibt, als tragfähig für ei-

266 Versuche einer integrativen Synthese liefern etwa Per K. Hansen: Karakterens rolle. Aspekter af en litterær karakterologi [Die Rolle des Charakters. Aspekte einer literarischen Charakterologie]. Holte 2000, S. 117-155; zit. n. Hansen: Figuren, S. 237 ff., sowie Culpeper: Language and characterisation, S. 35; zit. n. Bachorz: Zur Analyse der Figuren, S. 62 ff., wobei es sich zwar um beide Seiten der Medaille berücksichtigende, letztlich aber nicht zur konkreten Anwendung gedachte Modelle handelt. Vielmehr zeigen sie auf - wie auch diese Studie -, dass Verständnismodelle, die kognitionspsychologische Konzepte integrieren, verhärtete Forschungs-Fronten überwinden können. Die Rückschlüsse für ,echte' Charakterisierungsarbeit sind dann immer noch ,händisch' zu bewerkstelligen. Honold: Doppelleben, halbbitter, S. 44 f.

268 Dass man zunächst der, Unschuldsvermutung' (Susan Lanser) folgend davon ausgeht, es mit einem männlichen Protagonisten zu tun zu haben, und dezidierte Selbstbeschreibungen wie: ,Ich bin eine Frau', tatsächlich nicht im Text vorkommen, mag zur Entschuldigung zumindest angeführt werden - obwohl bereits auf der zweiten Druckseite von Brüsten (vgl. Obdachlosigkeit, S. 8) die Rede ist und spätestens auf Seite zehn der Wink mit dem Zaunpfahl erfolgt (vgl. Obdachlosigkeit, S. 10). 
82 - Teil I: Grundlagen 2. Wilhelm Genazinos Romanfiguren und ,Figurenromane

ne neue Form der (Selbst-)beobachtung. Deren Nebenprodukt ist der (vergleichsweise sanftere) komische Effekt. Führte Abschaffels gleichfalls gekonnter Blick auf sich selbst zu einem Mehrwissen, dem er aufgrund seiner neurotischen Disposition und mangelnder Distanzierung nicht gewachsen war, erweisen sich die insgesamt viel reflektierteren Ich-Figuren als fähiger, mit diesem Mehrwissen umzugehen. ${ }^{269}$

Möchte man nun nicht etwas wohlfeil beide Positionen zusammenbringen, indem man Hirschs Argumente in Honolds "gar nicht so eklatant" unterbringt, muss man feiner sondern: Bereits in der Ausschweifung (1981!) ist ein Wechsel angelegt, ist die Hauptfigur durchaus befähigt, „mit diesem Mehrwissen umzugehen“ (Hirsch), ist der Protagonist in der Lage, im Sinne „eines aktiven, planerischen beruflichen Verhaltens“ (Honold), zu reüssieren. Mit der Ich-Perspektive hat das zunächst nichts zu tun $(\Rightarrow I .2 .3)$. Allerdings ist Hirschs Befund beizupflichten, dass die IchErzähler diese Fähigkeit weiter ausgebaut haben; und Hirsch ist auch einige der wenigen, die sich des ,Kennst-du-einen-kennst-du-alle' entzieht. Auch die von Honold gezogene Abstammungslinie mit der Zäsur erst ab den Selbständigen ist zutreffend und revisionsbedürftig zugleich: Bereits nach der Abschaffel-Trilogie wäre eine zweite Zäsur zu setzen.

Im Folgenden sollen qua Forschungsreferat die bestehenden Klassifikationen der Figuren dargestellt und problematisiert werden, um danach ein Modell anzubieten, das beide Positionen (Konstanten und Unvergleichbares) integriert.

\section{,EINHEITSBREI': STATISCHE KONSTANTEN}

Jonas Fansa, dem das Verdienst zukommt, einige Grundlagen in der Figurengestaltung bei Genazino entdeckt zu haben, geht davon aus, in Die Liebe zur Einfalt den Grundtypus der GenazinoFiguren gefunden zu haben. Im Sinne eines „reverse engineering“ stelle der Roman „eine Art Bauplankatalog für Genazinofiguren inklusive dazugehörigem Stammbaum“ dar. ${ }^{270}$ Mithin nimmt er sich diesen einen Roman stellvertretend vor und analysiert ihn mit dem Ziel, „dem Ursprung dieser Ängste und Leidenschaften und der Genese dieser Figuren im allgemeinen auf die Spur zu kommen“.271 Fansa nutzt Die Liebe zur Einfalt dazu, „Figurenbaupläne“272 - etwa der Mutter etc. - zu zeichnen, die allesamt auf Wilhelm Genazino und dessen autobiografischen ,Schlüsselroman` zurückgeführt werden könnten $(\Leftrightarrow I .2)$. Diesen (Kurz-)Schluss halte ich aus den Gründen A (reverse engineering nur sinnvoll, wenn nicht auf Roman vor dem Bauplanprotagonisten angewendet), B (wenn die Geschichte nie richtig erzählt werden kann, die Figur aber komprimiert der Prototyp sein soll; warum dann nicht bei diesem Typ bleiben?) und C (autobiografisch; $\Rightarrow$ I.5.3) für überaus problematisch. Indessen möchte ich nicht darauf verzichten, die Idee von Konstruktionsskizzen und Figurenbauplänen, die allen Genazino-Figuren Pinselstriche geben, weiterzuverfolgen, ist sie doch mit einer Prämisse der vorliegenden Studie bestens ver-

\footnotetext{
269 Hirsch: „Schwebeglück der Literatur“, S. 114.

270 Fansa: Unterwegs im Monolog, S. 143.

271 Fansa: Unterwegs im Monolog, S. 76.

272 Überschrift des dritten Kapitels von Fansa: Unterwegs im Monolog, S. 76-144.
} 
einbar: der Anerkenntnis der Wiederholung bei gleichzeitiger, hinreichender Abweichung an Genazinos Mischpult ( $\Rightarrow I \cdot 2 \cdot 2)$.

Bei aller gebotenen Vorsicht, was die hermeneutischen Höhenflüge Fansas anbetrifft: „allein und rastlos durch die Welt der Großstadt" zu streunen, ist zweifelsfrei eine Signatur ,des‘ Genazino'schen Figurenbauplans. Aber warum? Zumindest bezogen auf Die Liebe zur Einfalt liest sich Fansas Votum überzeugend:

Diese abstrakte Sehnsucht nach den Eltern, das heißt: einer familiären Heimat, ist vielmehr ein Fundament für die Figurenpoetologie Genazinos. Der heimatlose Grenzgang der monologisierenden Eigenbrötler, der Intellektuellen Penner in den Prosatexten, wird hier beispielhaft, also anhand der biografischen Genese eines prototypischen Helden demonstriert. Dieser Held ist - wie alle seine Verwandten aus anderen Texten - auf der ständigen Suche nach dem Eigentlichen: dem eigentlichen Wort, dem eigentlichen Bild oder auch dem eigentlichen Ort zu verweilen. ${ }^{273}$

Mit dem Ansinnen, ,den' Genazino-Protagonisten zu entwerfen, steht Fansa nicht allein da. Etliche Bemühungen existieren, ein festes Gerippe aller Genazino(anti)helden zu behaupten, mit (fast) jeder Veröffentlichung tritt eine neue hinzu. Eine kurze Auswahl allein derer, die $2004 \mathrm{im}$ TEXT+KRITIK-Band aufgeworfen worden sind, möge dies - zunächst vollkommen unkommentiert - exemplifizieren:

Genazinos ,Helden' sind Sonderlinge, monologisierende Flaneure mit einem neurotischen Reflexionszwang. [...] Genazinos ,Helden' sind ,-lose': Rastlose, Heimatlose, Biografielose, Gewichtslose, Beziehungslose, die es weder bei sich noch anderswo aushalten. Sie sind auch Schicksalslose, denn das, was sie sind, sind sie nicht durch einen Schicksalsschlag geworden. Sie sind wie vom Himmel gefallen. Genazino gibt ihnen kaum je einen Hintergrund. Sie stammen aus einfachen, vor allem aber unbedeutenden Verhältnissen, die nicht wirklich ins Gewicht fallen, weder positiv noch negativ. $^{274}$

Genazinos Figuren sind hoch kultivierte, ebenso zurückhaltende wie bescheidene Menschen mit einem vielleicht etwas zu ausgeprägten Vermögen zur Selbstreflexion; denn immer schämen sie sich ein wenig ihrer intellektuellen Überlegenheit und nichts fürchten sie mehr als eine daraus entstehende Überheblichkeit. ${ }^{275}$

Und es handelt sich grosso modo auch immer wieder um denselben Protagonisten, jenen auf unauffällige Weise auffällig-unangepassten Verweigerer, der sich quer stellt zur Wohlstandsideologie mit entsprechenden Zweckrationalitäten und dabei das „Nebendraußen“ (Hermann Lenz) kultiviert. 276

Wollte man ein implizites Programm benennen, dem die meisten Protagonisten aus Genazinos Romanwerk zustimmen könnten, so trüge es ungefähr diese Konturen [...] [:] Die Mischung aus dezidiertem Unbehagen an der Integration in die traditionelle Arbeitswelt, lustvoller Planlosigkeit im Tagesablauf und der Beobachtung der eigenen Person im Zufälligen findet sich in beeindruckender Häufung in zahlreichen fiktionalen Texten des Autors beschrieben. ${ }^{277}$

Es existieren aber nicht nur unterschiedliche Versuche, ,denselben' Protagonisten per se zu beschreiben, sondern gar um die Einheitlichkeit aller Protagonisten postulierende Widersprüche

\footnotetext{
273 Fansa: Unterwegs im Monolog, S. $142 \mathrm{f}$.

274 Samuel Moser: Isola Insula. Aspekte der Individuation bei Wilhelm Genazino. In: Arnold (Hg.): Wilhelm Genazino (2004), S. 36-45, hier S. 40.

275 Bucheli: Die Begierde des Rettens, S. 48.

276 Jung: „Umhergehen und Zeitverschwenden“, S. 65.

277 Tilman Spreckelsen: Manche möchten lieber nicht. Gesellschaftliche Teilhabe und Initiation in den Romanen Wilhelm Genazinos. In: Arnold (Hg.): Wilhelm Genazino (2004), S. 79-86, hier S. 81.
} 
innerhalb des Diskurses zu einem einzigen Roman. Das lässt sich besonders eindrücklich am Rezensions-Zusammenschnitt des Kulturmagazins perlentaucher.de anlässlich des 2014 erschienenen Romans Bei Regen im Saal illustrieren:

Rezensent Ulrich Rüdenauer begrüßt nach der Lektüre von „Bei Regen im Saal“ einen neuen Protagonisten im „Genazino-Mikrokosmos“, der, wie seine Vorgänger, ebenfalls trostlos und weltverloren durch die eigene Biografie mäandert, dabei aber doch den Alltagsanforderungen und urbanen Belanglosigkeiten trotzt und still und traumverloren durch Fluchtwelten flanierend, Individualität bewahrt.278

Reinhard, der Protagonist des neuen Romans „Bei Regen im Saal“, ist ein antriebsloser Tropf, der sein problembeladenes Leben beinahe widerstandslos hinnimmt und dabei - trotz Soßenflecken auf dem Hemd - ziemlichen Erfolg bei den Frauen hat, weil er ihnen seltene Komplimente macht und sich nicht vom „Schönheitsideal der Gegenwart“ beschränken lässt, fasst der Rezensent zusammen. ${ }^{279}$

Moment: Bereits Rüdenauer macht ja die Diskrepanz zwischen weltverlorenem Mäandern und Alltagsanforderungen trotzenden Verhaltensweisen auf - und beansprucht damit Allgemeingültigkeit für Genazinos Kosmos. Nun lesen wir bei Burkhard Müller von Antriebslosigkeit und Widerstandslosigkeit, zugleich aber auch von seinem ,Schlag bei den Frauen', was sich nicht nur auf den ersten Blick nicht zur vorherigen Einschätzung fügt, zumal auch Müller annimmt, dass „der Typus von Wilhelm Genazinos Romanhelden konstant bleibt“.280 Man hole eine dritte Meinung ein:

Judith von Sternburg kennt es schon, das „passiv-lebenszugewandte Romanpersonal“ Wilhelm Genazinos. Auch Reinhard, der Erzähler und Protagonist seines neuen Romans „Bei Regen im Saal“ fällt also in diese Kategorie, verrät die Rezensentin. Reinhard ist promovierter Philosoph, hält sich aber nur mit Gelegenheitsjobs über Wasser [...]. Permanent schwankt er zwischen Desinteresse, Elegie und Existenzkrise, betont selbst sein „lockeres Verhältnis zur Selbstverschrottung der Welt“, hilft Freunden beim Überwinden ihrer jeweiligen Neurosen, an sein eigenes, anscheinend ziemlich belastetes Verhältnis zu seiner verstorbenen Mutter will er aber nicht rühren, fasst die Rezensentin zusammen. 281

Das klingt vertraut und beansprucht erneut eine Allgemeingültigkeit - Promotion und Gelegenheitsjobs sind aber sicher nicht universell ( $\Rightarrow$ II.1.5). Seltener sind die Abweichungen vom Gesamtpaket - um es dann doch wieder zu buchen:

Der Protagonist in Wilhelm Genazinos neuem Roman „Bei Regen im Saal“ heißt Reinhard, Roman Bucheli jedoch identifiziert den ehemaligen Philosophiestudenten unschwer als Wiedergänger Gerhard Warlichs - einer anderen Romanfigur Genazinos -, mit dem er nicht nur die „Schwindsucht der Seele" teilt, wie der Rezensent verrät. Überhaupt sind eigentlich alle (Anti-)Helden des Autors wahre „Feinschmecker des Weltschmerzes und der Melancholie“, so Bucheli.282

Reschke argumentiert ganz ähnlich:

\footnotetext{
$278 \quad$ [Bei Regen im Saal].

279 [Bei Regen im Saal].

280 Burkhard Müller: Mut zum zarten Trost. „Bei Regen im Saal“: Wilhelm Genazino schreibt mal wieder den Roman eines versonnenen Außenseiters. In: ZEIT ONLINE vom 21. August 2014. Online: <http://www.zeit.de/2014/33/wilhelm-genazino-roman-bei-regen-im-saal>. [Bei Regen im Saal].

282 [Bei Regen im Saal]; Herv. N. L.
} 
Eigentlich ist er aber mit seinem Leben zufrieden und stellt wie alle Genazino-Helden sich die Diagnose: „Meine Krankheit bestand aus einer eingebildeten Benachteiligung, aus der schöne innere Bereicherungen hervorgingen, auf die ich auch in Zukunft nicht verzichten wollte." 283

Die bislang referierten Versuche eint - bei gleichzeitiger unterschiedlicher Akzentsetzung - die Leugnung, es mit Figuren ohne Gleichen zu tun haben zu können: Flanierende Sonderlinge mit neurotischem Reflexionszwang, ${ }^{284}$ Kultivierte mit intellektueller Überlegen- und Überheblichkeit, ${ }^{285}$ auffällig-unangepasste Verweigerer, ${ }^{286}$ trostlose und weltverlorene Trotzige, ${ }^{287}$ Antriebslose mit Erfolg bei Frauen,288 Passiv-Lebenszugewandte mit problematischem Verhältnis zur eigenen Mutter ${ }^{289}$ und zu guter Letzt, so befindet Bielefeld, ${ }^{290}$ sei Reinhard „ein schrulliger Protagonist - gescheitert natürlich - taumelt versehen mit allerlei Neurosen, Komplexen und Marotten durch eine sich im Verfall befindliche Welt.“291 Zusammengenommen ist das Beliebigkeit im Anstrich der Universalität, die mehr oder weniger prominent gemacht wird (im letzten Beispiel durch das „natürlich“ vermeintlich ironisch gebrochen).

\section{(AUCH DYNAMISCH GEDACHTE) UNVERGLEICHBARKEITEN}

Doch es gibt auch Versuche, klare Grenzlinien zu ziehen oder wenigstens Entwicklungen zu skizzieren. Neben Hirsch (s.o.) fällt besonders Genazinos Selbstaussage ins Gewicht, der „zwischen den ,Abschaffel'-Romanen und dem viel später hinzugekommenen Roman ,Eine Frau, eine Wohnung, ein Roman““ „einen wichtigen Unterschied“, also eine Trennlinie, sieht:

Es ist der Humor (oder, ersatzweise: die Ironie, die Komik). Abschaffel ist (war) ein vollkommen humorloser Mensch. Die einzige Möglichkeit, die ihm ein Lachen ermöglichte, war (zuweilen) die Schadenfreude, der Zynismus, das kaum versteckte Vergnügen an den Fehlschlägen des Lebens: weil sich in der Beobachtung der Fehlschläge die eigene pessimistische Konstitution wiedererkennen lässt. Eine Möglichkeit, die Gleichschaltung zwischen Ich und Wirklichkeit aufzuheben, ist der Humor. Der Humor deswegen, weil im Humor ein Abstand zwischen Ich und Welt aufscheint. ${ }^{292}$

Reschke: [Wilhelm Genazino]; Herv. N. L. Spätestens hier wird evident, dass die auf KLG.de hinterlegte letzte Änderung des Essays nicht korrekt datiert sein kann.

284 Vgl. Moser: Isola Insula.

285 Vgl. Bucheli: Die Begierde des Rettens.

286 Vgl. Jung: „Umhergehen und Zeitverschwenden“.

287 Vgl. Ulrich Rüdenauer: Weltekel mit Grundsicherung. „Bei Regen im Saal“ heißt die neueste Ausfaltung des Genazino-Mikrokosmos. In: Süddeutsche Zeitung vom 30. Juli 2014.

288 Vgl. Müller: Mut zum zarten Trost.

289 Vgl. Judith von Sternburg: Elegie eines Provinz-Redakteurs. Wilhelm Genazino erzählt auch in seinem neuen Roman „Bei Regen im Saal“ fast von einer Existenzkrise. In: Frankfurter Rundschau vom 30. Juli 2014.

290 Vgl. Bielefeld: Der hessische Woody Allen im Finanzamt II.

291 [Bei Regen im Saal].

292 Genazino: Melancholische Renitenz, S. 43 f. In seinem Vorlesungstext geht Genazino akribisch wie sonst kaum der Frage nach, ob tendenziell überdauernde Konstanten oder Inkonsistenzen seine Romanproduktion prägen und optiert hinsichtlich der Komik für eine neue Phase ab Wohnung (vgl. Henke: „Fluktuierende Uneindeutigkeit“, S. 70 f.). Vgl. zum literarischen Topos, demzufolge im Humor die Lösung scheinbar auswegloser Situationen liege, Sabrina Skrzypczak: Psychologie in Prosa. Die Einflüsse der Analytischen Psychologie C.G. Jungs auf Hermann Hesses Erzählung Der Steppenwolf. Masterarbeit Universität Kassel 2016, S. 31 f. 
86 - Teil I: Grundlagen 2. Wilhelm Genazinos Romanfiguren und ,Figurenromane

Das impliziert zugleich, dass Genazinos Figuren nicht notwendigerweise statisch angelegt sind, wovon Feuilleton wie Forschung stillschweigend auszugehen scheinen. Statik vs. Dynamik $(\Leftrightarrow$ I.2.4) sind dabei doppelt zu fassen: als Entwicklung einer Figur - Abschaffel und andere Texte lassen sich durchaus als Entwicklungsromane, andere auch als Adoleszenzromane lesen -, oder als Entwicklungen bezogen auf das Gesamtwerk, wie es Genazino im Kopf hat. Honold plädiert zudem für die erstgenannte Ausformung der Entwicklung, wenn er konstatiert: „Dieses Personal mittlerer Hauptfiguren entfaltet sich in einigen Segmenten oder Momentaufnahmen, die lang genug sind, um bestimmte Linien und Entwicklungstendenzen im Sinne eines Lebenslaufes erkennen zu können“.293 Das ist korrekt und innovativ, aber noch immer keine ultimative Annäherung an die Struktur des Wesens von Genazinos Roman-Hauptfiguren. Genazinos Mischpultverfahren ( $\Rightarrow$ I.2.2) weist erneut den Weg.

\section{SYNTHESE: „VARIIERTE[] WIEDERHOLUNG“}

Denn auch im Hinblick auf die Figuren gilt das Darstellungsprinzip der variierten Wiederholung, verfügen doch im Grunde alle Helden über ein ähnliches Persönlichkeitsprofil: Genazinos Hauptfiguren sind Streuner, die allein und rastlos durch die Welt der Großstadt flanieren. [...] Mit der räumlichen Unbehaustheit geht eine innere einher. Statt sich in Partnerschaft, Familie, Freundeskreis oder Bürogemeinschaft aufgehoben zu fühlen, taumeln die Figuren zwischen Nähe und Distanz, wobei beide Empfindungen umgepolt werden: Gängige Begegnungsweisen der Nähe (Partnerschaft, Sexualität) werden zur Erfahrungswelt der Isolation [...], wohingegen Nähe und Zugehörigkeit gerade im Kontakt mit Fremden (und dort auch nur momenthaft) erfahren werden.

Versagensängste, Hypochondrie ${ }^{294}$ und eine fast zwanghafte Beobachtung des eigenen Ichs und der Umwelt charakterisieren diese Figuren ebenso wie Melancholie und Langeweile. Beides kann erneut gesellschaftskritisch (als Entfremdungserscheinung einer irrwitzigen, ökonomisch grundierten Leistungsgesellschaft) wie als Ausdruck individueller Krisen gewertet werden: als Spätfolgen einer problematischen Kindheit, Krise der Lebensmitte, Alterungsprozesse oder Vorbote des Todes. $^{295}$

Auf den ersten Blick wähnt man vielleicht, das Modell ,Einheitsbrei` vor sich zu haben, aber der Schein trügt. Ohne es zu explizieren, geben Bartl und Marx nämlich einer Idee Kontur, die als synthetisierende Lösung der Standpunkte herhalten kann: die Variation muss auf einem anderen Level des ,Figuren-Bauplans‘ angesiedelt werden als die Wiederholung.

Nachdem einige Positionen referiert worden sind, die Genazinos Figuren einen gemeinsamen und ab den frühesten Romanen gültigen Figurenbauplan zu bescheinigen suchen und sich dabei in ,Einheitsbrei'-Vorwürfe versteigen, nachdem auch die Brüche und Inkonsistenzen in der Figurenzeichnung zur Sprache gekommen sind, bleibt vorerst nur noch eines zu tun: synthetisieren.

Ludwig Wittgenstein vertritt in seinem zweiten Hauptwerk, den Philosophischen Untersuchungen (posthum veröffentlicht 1953), unter anderen die These, dass es zwischen artverwandten Kon-

Honold: Doppelleben, halbbitter, S. 35.

Vgl. zur ,nabelschauenden' Selbstbeobachtung, die sich manchmal ins Hypochondrische auswächst - „Ich bin ein einschlägig gebildeter Amateurmediziner (Tausend Zeitungsartikel! Tausend Fernsehsendungen!)“ (Liebesblödigkeit, S. 83) -, Susanne Kunckel: Liebeswirrwarr eines Hypochonders. In: Welt am Sonntag vom 06. Februar 2005. 
zepten zwar Ähnlichkeiten gebe, sich diese aber nicht notwendigerweise streng logisch im Sinne einer hierarchischen - strukturalistischen - Systematik erklären lassen können müssen, ohne dass sich „der Verstand Beulen holt“. ${ }^{296}$ Als Behelf vergleicht er zu diesem Behuf

begriffliche Strukturen mit den Ähnlichkeiten zwischen den Mitgliedern einer Familie. Zwar gleichen sich je einige Familienmitglieder hinsichtlich ihres Wuchses, ihrer Gesichtszüge, ihrer Augenfarbe, ihres Gangs, ihres Temperaments etc., aber es gibt kein Merkmal, das allen Familienangehörigen zukäme. ${ }^{297}$

Mit Wittgenstein als Gewährsmann ${ }^{298}$ wird hier die These vertreten, dass Genazinos Roman(haupt)figuren mit dem Konzept der Familienähnlichkeit bestmöglich begegnet werden kann. Das prinzipiell Antithetische bei Genazino - Wiederholung vs. Variation $(\Longrightarrow I .2 .2)$ - lässt sich damit auf einer höheren Ebene in Gestalt eines Drei-Schichten-Modells der GenazinoFiguren aufheben:

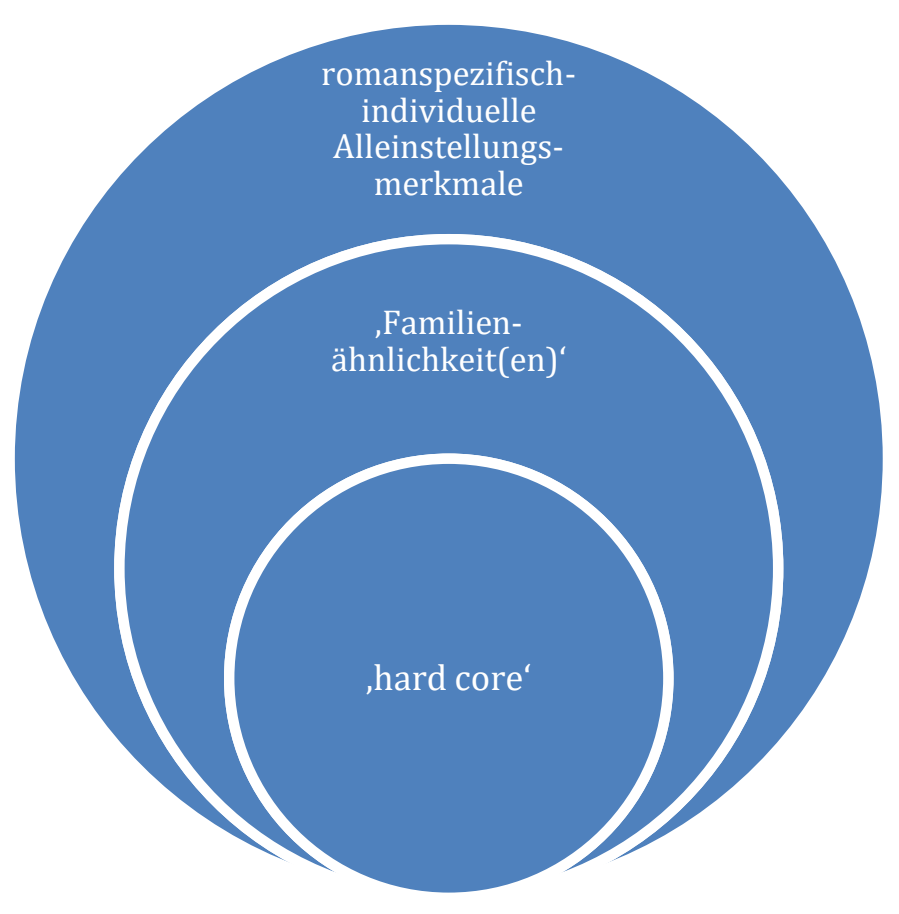

Abbildung 2: Drei-Schichten-Modell der Romanhauptfiguren bei Genazino

\footnotetext{
296 Ludwig Wittgenstein: Philosophische Untersuchungen. (Philosophical Investigations). DeutschEnglische Ausgabe. 3. Aufl. Übersetzt von G.E.M. Anscombe. Oxford/New York 1953/1967, S. 119; $\S \S 65-67 \mathrm{ff}$.

297 Ralf Goeres: [Familienähnlichkeit]. In: Online-Wörterbuch Philosophie: Das Philosophielexikon im Internet. Online: <http://www.philosophie-woerterbuch.de/onlinewoerterbuch/?tx_gbwbphilosophie_main\%5Bentry\%5D=334\&tx_gbwbphilosophie_main\%5Baction\%5D=s how\&tx_gbwbphilosophie_main\%5Bcontroller\%5D=Lexicon\&cHash=6323674fdb181fc888f14ce9 $118 \mathrm{c} 86 \mathrm{c} 4>$.

298 Für den sich seinerseits als „Inspirationsquellen für die Entwicklung der Familienähnlichkeitsidee [...] Mill, Whewell, Stewart, Mauthner, Spengler und [...] insbesondere die ,Sammelbegriffe' von James und die Konzeption synchytischer Begriffe des Logikers Johannes von Kries [...] ausmachen“ lassen (Goeres: [Familienähnlichkeit]).
} 
88 - Teil I: Grundlagen 2. Wilhelm Genazinos Romanfiguren und ,Figurenromane

Einen ,harten Kern' teilen sich alle Figuren (reine Wiederholung), bestimmte Akzidenzien zeichnen das Individuelle aus und werden nur - bisher: Stand 2018 - einmalig vergeben (reine Variation). Dazwischen gibt es einen recht breiten Gürtel, in dem das Familienähnliche schwirrt: Es finden sich immer mindestens zwei, maximal neunzehn (bzw. 21; $\Rightarrow$ I.1) Figuren bei Genazino, die sich diese Merkmale teilen!299

Einige Forscherinnen und Forscher hat die implizite Antizipation dieses breiten Gürtels dazu veranlasst, den äußeren Kreis nicht einmal wahrzunehmen, wenige betonen nur letztgenannten. Auch hier scheint die Mitte der Argumentation bestmögliche Orientierung zu schaffen, denn beide extremen Positionen sind nicht haltbar: Genazinos Figuren sind mitnichten Ausformungen nur einer Figurenblaupause (und schon gar nicht derjenigen aus der Liebe zur Einfalt)! Dagegen spricht der äußere Kreis der Abbildung, der auf Romanspezifisch-Individuelles abhebt: „Ekelreferent" ist nur eine Hauptfigur, es gibt nur eine Protagonistin, auch Axel Degen heißt nur eine Figur. Genauso wenig sind es gänzlich voneinander abtrennbare Einzelfiguren: Im ,Hardcore‘ teilen sie sich (alle!) etwa aus externer Perspektive die Konzeption als runde, komplexe, transparente, offene Figuren $(\Leftrightarrow I .2 .4)$ und die graduelle Unzuverlässigkeit $(\Leftrightarrow I .2 .3)$, aus interner Perspektive feststehende Persönlichkeitsmerkmale ( $\Rightarrow$ II.1.3 u. $\Rightarrow$ II.1.4) und wiederkehrende Handlungsstrategien $(\Rightarrow I I)$. Vermeintlich für diese Kategorie des inneren Zirkels angefertigte Verallgemeinerungen, die eigentlich in den mittleren Kreis gehören, bereiten aber ,dem Verstand Beulen'. Denn einerseits teilen sich zwar mehrere Figuren die von der Forschung postulierten Sets, andererseits ist es zu kurz gedacht, den „monologisierenden Eigenbrötler“ ${ }^{\text {300 }}$ oder den ,Arbeitsweltintegrationsverweigerer " mit dem Hang zu „lustvoller Planlosigkeit im Tagesablauf“ ${ }^{\prime 301}$ als Prototypen herauszupräparieren, weil es stets die Verallgemeinerung Lügen strafende Ausnahmen gibt. Obwohl Burkhard Müller genaugenommen mitten ins Schwarze der, variierten Wiederholung' trifft, besteht er doch wieder darauf, absolute Konstanten zu postulieren:

Obschon der Typus von Wilhelm Genazinos Romanhelden konstant bleibt (Akademiker mit dauerhaft provisorischem Beruf und Hang zur distanzierten Beobachtung seiner Mitmenschen), der Autor variiert ihre jeweiligen Marotten aber immer ausreichend, um ein „tatsächlich neues Buch“ entstehen zu lassen, findet Burkhard Müller. ${ }^{302}$

Indes: Zwischen den Polen Hardcore und Romanspezifisch-Individuellem tummelt sich der „Akademiker mit dauerhaft provisorischem Beruf und Hang zur distanzierten Beobachtung seiner Mitmenschen“ (und auch alle eben genannten Verallgemeinerungen) - aber eben nicht im

299 Es handelt sich um eine dem Modell der Familienähnlichkeit entlehnte Setzung, die insofern problematisch ist, als Eigenschaften, Verhaltensstrategien, Aussehen etc. $(\Rightarrow$ I.2.4), die auf fünfzehn Protagonisten zutreffen, natürlich ,Basistypus'-relevanter sind als solche, die nur zwei Hauptfiguren verkörpern (s.u.). Ein weiteres, doch fast wieder Beulen bereitendes Problem betrifft den Sonderfall, dass es durchaus auch jeweils (mindestens) zwei Figuren gibt, die gegensätzliche Strukturen ausbilden ( $\Rightarrow$ II.4.4 vs. $\Rightarrow$ II.4.5); in diesem Fall muss zwischen der Annahme zweier Seiten einer Familienähnlichkeit und zwei unterschiedlichen Lagern unterschieden werden. 
harten Kern, weil längst nicht alle Helden ein Studium hinter sich gebracht haben und bspw. der Hang zu „lustvoller Planlosigkeit im Tagesablauf“ - zugegeben: Spreckelsen grenzt klug mit „die meisten“ ein, wie es auch Jung (s.o.) mit der Floskel "grosso modo“ tut - nur im Familienähnlichkeitsbereich anzutreffen ist; Eckhard Fuchs, der Protagonist aus dem Roman Die Ausschweifung, damit aber sicherlich nicht mitgemeint sein kann (er also - in dieser Hinsicht - zu den romanspezifisch-individuellen Ausreißern gehört).

Erst jetzt lässt sich das Figurenbauplan-Unterfangen sinnvoll und wohlbegründet weitertreiben: Im Bereich der Familienähnlichkeit lassen sich den Versuchen der Forschung weitere Aspekte hinzufügen, die für die folgende Untersuchung von Belang sind und hier als ,Basistypus des Genazino-Helden ${ }^{303}$ eingeführt werden soll - immer mit dem Versuch, die ,Ausreißer` zu identifizieren und Ausnahmen von der Regel zu benennen; vor allem aber: nicht vorzugaukeln, es gäbe schlicht und ergreifend die erforderliche Trennung in die drei Bezirke nicht. ${ }^{304}$ Das macht das Unterfangen allerdings erst interessant: Wären nämlich alle Figuren rein individuell und unvergleichbar, müsste man nach Romanen ,aufdröseln‘ bzw. die Schlaglichter in Einzeltextuntersuchungen splitten; wären alle gleich, müssten sich die bisherigen Verallgemeinerungen den Vorwurf gefallen lassen, nicht interindividueller den ,Kern` beschrieben zu haben.

Der Genazino'sche Basistypus, der in den Schlaglichtern $(\Leftrightarrow$ I.5.1) im Fokus stehen wird, ist in gewisser Weise also doch der über einen Kamm geschorene Durchschnittsprotagonist: „mittelalt[], mittelschlau[], mittelreich[]“305 - in dieser Hinsicht durchaus vergleichbar mit ,weichgezeichneten', also aus für schön empfundenen, dutzendfach übereinandergelegten, Frauen/Männergesichtern, die man Probanden zur Beurteilung vorlegt: langweilig, aber schön. Hier findet sich eine zweite bemerkenswerte Fluchtlinie zu Wittgenstein:

Weiterhin veranschaulicht die composite portraiture von Francis Galton, mit der Wittgenstein experimentierte, die vorgestellten Verhältnisse. Bei dieser Technik des Photographierens werden verschiedene Porträts übereinander projiziert, sodass man durch Verstärkung der gemeinsamen und Verschwinden der vereinzelten Merkmale ein Kollektivphoto erhält, das ein charakteristisches oder typisches Gesicht darstellt. Ein solcher ,Idealtypus' (dieser Begriff Webers ist ebenfalls in der genannten Tradition zu sehen) hat dabei keine Existenzweise, es wird keine tatsächlich lebende Person abgebildet. ${ }^{306}$

Was Weber als Idealtypus modellbildend meint, wird hier - in Anlehnung an und Abgrenzung von Jannidis ,Basistypus‘ - verstanden als Figurenähnlichkeit: Sie teilen sich Merkmale mit ,ih-

303 Es handelt sich um eine produktive Anverwandlung des von Jannidis als „Minimaltypus der Figur“ konzeptualisierten Begriffs (Jannidis: Figur und Person, S. 126; vgl. Jannidis: Figur und Person, S. 185-195). Jannidis' Basistypus ist im Vergleich zur hier vorliegenden Begriffsverwendung allerdings - aus guten Gründen! - sehr rudimentär und umfasst die Annahmen, dass Menschen Figuren und Menschen mit folgenden drei Grundfähig- bzw. -fertigkeiten auszustatten tendieren: „Fähigkeit zum intentionalen Handeln, die Innen/Außen-Differenz und die Unterscheidung zwischen transitorischen und stabilen Merkmalen" (Jannidis: Figur und Person, S. 127). Hier wird der Begriff als ,Standard-Set' sowohl äußerlicher wie innerlicher Grunddispositionen verstanden. Gewissermaßen scheinen manche Interpreten das Konzept der Familienähnlichkeit zwar anzuwenden, aber nicht zu reflektieren.

305 Kämmerlings: Genazino gilt als bedeutender Autor. Warum nur?

306 Goeres: [Familienähnlichkeit]. 
90 - Teil I: Grundlagen 2. Wilhelm Genazinos Romanfiguren und ,Figurenromane‘

rer' Protagonistenfamilie, wobei für diese,spezielle Familie' im Gegensatz zu Wittgensteins Überzeugung durchaus ein taxonomischer Kern existiert, der allerdings auf einer anderen Ebene anzusiedeln ist. Die Dreiteilung der Figuren wird über diese Arbeit hinweg stets mit reflektiert und am Ende der jeweiligen Schlaglichter immer in eine Einteilung der Ergebnisse in die drei Bezirke überführt. 307

Damit kann die bis dato differenzierteste Untersuchung von Genazinos Romanfiguren und Figurenromanen ihren Ausgangspunkt in Richtung der prinzipiellen Untersuchung der Handlungsmotivationen und (eindruckssteuernden) Verhaltensweisen verlassen. spezifischen Elemente werden - bis auf die Figurenliste im Anhang $(\Leftrightarrow V .1)$ bzw. an der jeweiligen Stelle zentrale Ausnahmen - im Fließtext eher ausgeklammert und geraten bei den abschließenden, jeweils ausgefüllten Schemata in den Blick, der skizzierte Hardcore wird weiter unten $(\Rightarrow$ II.1.3 u. $\Rightarrow$ II.1.4) genauer untersucht, bleibt aber auch an jedem Schlaglichtende in Form der Aufschlüsselung entnehmbar. 


\section{Handlungsmotivation und Eindruckssteuerung}

Ist es bisher vorwiegend darum gegangen, zu sondieren, ob Figuren ,menschlich` seien oder ,nur aus Papier, wird die prinzipielle Zweigliedrigkeit und Gleichberechtigung der Perspektiven nunmehr vorausgesetzt und (mit leichtem Übergewicht: intern, diegetisch) ausgelotet, welche Konsequenzen daraus für motivationales Figurenverhalten abgeleitet werden können und wie die diesbezügliche Theoriebildung beschaffen ist.

Weswegen eine Figur handelt oder Handlungen unterlässt, ihr damit zusammenhängendes „Bewusstsein, ihr Denken, ihre Reflektionen, ihr Fühlen und Wünschen“,1 und zwar just in der Weise, wie es geschrieben steht, macht offenkundig einen Schlüsselreiz für Leser aus. ${ }^{2}$ Die potenzielle Menschenähnlichkeit im Handeln von literarischen und filmischen Figuren ist häufig ein markanter Ausgangspunkt für Charakterisierungen, aber auch Quell der Sympathie- und Empathielenkung des Lesers bzw. Zuschauers, allzumal dann, wenn die eigenen Handlungsnormen und Überzeugungen mit denen der Figuren abgeglichen werden. Die begriffliche Nähe von ,Motivation' und ,Motiv' ist freilich kein Zufall und die Tatsache, dass sowohl in der Kriminologie als auch vor Gericht die Suche nach den letzten Gründen für deviantes Verhalten großen Raum einnimmt, lässt sich auch auf die Literatur übertragen: Möglicherweise empfundenes Mitleid für Kleists Kohlhaas ${ }^{3}$ etwa kann sich nicht aus dessen Taten speisen, sondern nur aus deren Rechtfertigung, aus den Motiven dafür. ${ }^{4}$

Zur Untersuchung der Motive, der Handlungsmotivation, bedarf es einerseits der expliziten Positionierung hinsichtlich des Untersuchungsstandpunkts $(\Rightarrow I .2 .4)$, andererseits der Einbettung in Modelle, die Handlungsmotive zu erklären suchen. Alle anderen Erwägungen würden in etwa auf der Ebene rangieren, Mutmaßungen und Allgemeinplätze anzuführen oder dem suizidalen Protagonisten zuzurufen, er möge doch bitte nicht springen.

Bevor in diesem Kapitel - nach einem Exkurs, der die ,Hassliebe‘ von Literatur(wissenschaft) und Psychologie verhandelt ( $\Rightarrow$ I.3.2), - ein sozialpsychologisches Modell zur Motivierung von Verhalten vorgestellt und für die Figurenanalyse fruchtbar gemacht werden wird ( $\Rightarrow$ I.3.3), ist ein Blick auf die bis dato vorliegende Forschung zu motivationalem (Figuren-)Verhalten angezeigt.

$1 \quad$ Fludernik: Erzähltheorie, S. 93.

2 Vgl. Bernard J. Paris: Imagined human beings. A psychological approach to character and conflict in literature. New York 1997, S. xi.

3 Vgl. für Michael Kohlhaas als literarischen Verwandten des Protagonisten aus Ein Regenschirm für diesen Tag Fischer: Wider das System, S. 36 ff.

$4 \quad$ Zu diesem komplexen Sachverhalt vgl. etwa Katharina Bruch: Sympathische Verbrecher und Mörder. Analytische und empirische Untersuchungen zu emotionalen Wirkungen von ausgewählten Erzähltexten. Marburg 2015. ( $\Rightarrow$ II.3.5) 
92 - Teil I: Grundlagen 3. Handlungsmotivation und Eindruckssteuerung

\subsection{Modelle motivationalen (Figuren-)Handelns}

Als prominentester Zweig der literaturwissenschaftlichen Forschung, der sich mit der Motivation auseinandergesetzt hat, ist erneut die Erzähltheorie zu nennen. Allerdings ist das Theoriedesign dieser Arbeit so angelegt, dass in einem zweiten Schritt disziplinübergreifend auch nach tauglichen Modellen in der Psychologie geschaut werden muss.

\section{LITERATURWISSENSCHAFTLICHE ANNÄHERUNGEN}

Man kann vom internen Standpunkt aus fragen, welche Gründe oder Motive die fiktive Person hatte, wie sich die Handlung in das Gesamtbild ihres motivationalen Haushalts einfügt, welche Wünsche oder auch Zwänge sie veranlasst haben, usw. [...] Auch vom externen Standpunkt aus können wir Handlungen von Figuren erklären, indem wir sie als motiviert auffassen; entscheidend sind hier aber nicht die Motive fiktiver Personen, sondern vielmehr die Motive der Autoren der Texte, die die Handlungen der Figuren in bestimmter Weise gestaltet haben, um bestimmte Zwecke zu erfüllen. ${ }^{5}$

In grundsätzlicher Analogie zu den zwei Perspektiven, mit denen man prinzipiell auf Figuren schauen kann, lässt sich also auch deren Motivationslage von zwei Seiten beleuchten. ${ }^{6}$

Wenn man intern orientiert vorgeht, drängen sich verschiedene erprobte Konzepte zur Handlungsmotivation auf. Etwa: Lubomír Doležels Typologie, nach der rationales - „der Handelnde ist durch Motive bestimmt, die einer rationalen Überprüfung standhalten“, impulsives - „der Handelnde ist durch Reflexe, Triebe o.ä. motiviert" -, akratisches - „der Handelnde tut etwas wider besseres Wissen“ - und irrationales Handeln - „der Handelnde ist nur minimal - oder im Extremfall des Wahnsinns gar nicht mehr - durch rationales Überlegen bestimmt" - voneinander unterschieden werden kann, und die für diese Arbeit nicht unwichtig ist.7 Für Genazinos Figuren kommen in der Tat alle angeführten Varianten in Betracht, wenngleich diese Arbeit - zumal aus der theoretischen Einschränkung des IM $(\Leftrightarrow I .3 .3)$ heraus - die ersten beiden Sorten fokussiert. „Weiterhin kann man fragen, ob das Handeln habituell oder eher situativ bestimmt ist, ob die Motive dem Handelnden vollständig klar sind, wie er selbst zu seinen Motiven steht [...] usw.“ Hier ist das Gewicht schwieriger auf der Waage zu verteilen, da nahezu keine Situation denkbar ist, in der das Handeln nicht irgendwie habituell verankert zu nennen wäre, genauso wenig wie sich Handeln ohne passenden situativen Rahmen ereignen würde. Damit ist die Unterscheidung von Inhalts- und Prozessmodellen, wie sie in der Motivationstheorie üblich ist, angeschnitten (s.u.). ${ }^{9}$

$5 \quad$ Köppe/Kindt: Erzähltheorie, S. $149 \mathrm{f}$.

6 Vgl. Eder 2008, S. 461-463, für eine Liste analyseleitender Fragestellungen zur Handlungsmotivation, die versuchsweise beide Sichtweisen integriert.

7 Köppe/Kindt: Erzähltheorie, S. $149 \mathrm{f}$.

8 Köppe/Kindt: Erzähltheorie, S. 150.

9 Ob die Motive dem Handelnden vollständig klar sind, kann mit der Erzähltheorie untersucht werden, da sich bei der hohen Reflexionsdichte vermutlich nicht gänzlich klare Motivationslagen über einen tendenziell nullfokalisierten Erzähler zu erkennen geben sollten. 
Ziemlich genau zwischen interner und externer Motivierung liegt Thomas Pavels Ansatz einer an der Spieltheorie angelehnten „move-Grammatik“:10

Seine move grammar analysiert die Gesamthandlung als ein komplexes Gewebe von einzelnen moves, also (Spiel-)Zügen, die die Figuren ausführen. Jede Figur verfolgt nach Pavel ein eigenes, übergeordnetes Handlungsziel; sie reagiert aber zugleich mit jedem ihrer moves auf die sich kontinuierlich ändernde dynamische Gesamtkonstellation. Denn der ,Spielzug' der einen Figur durchkreuzt oder unterstützt immer zugleich die Strategie einer anderen.

Einen einzelnen move kann man damit als eine Transformation von einer Ausgangssituation (problem) in eine Folgesituation (solution, Lösung) beschreiben; jede Folgesituation wird ihrerseits zur Ausgangssituation eines übergeordneten move - und so weiter, bis schließlich eine Gesamtkonstellation hergestellt ist, in der den handlungstragenden Figuren keine Handlungsoptionen mehr verbleiben. Das heißt nicht unbedingt, dass ihre ursprünglichen individuellen Absichten zu ihrer Zufriedenheit realisiert worden wären - es bedeutet vielmehr, dass das Spiel ihrer Handlungen sich erschöpft hat und an sein Ende gekommen ist. ${ }^{11}$

Pavel berücksichtigt beiderlei: In Form der figurenbezogenen Motivation die interne Seite, in Form des Geflechts die externe: Neben der Figurenkonstellation als solche hat er auch HelferFunktionen im Sinn, wie sie der doch eher rein extern verfahrenden Propp'schen Aktantenfunktionsanalyse (s.u.) nahe stehen.

Wenn man die externe Motivation in den Blick nimmt, wird man vor allem bei Eder ${ }^{12}$ und Jannidis ${ }^{13}$ fündig. Köppe/Kindt fassen deren Formen externer Motivierungen wie folgt zusammen:

Jens Eder unterscheidet dramaturgische Funktionen oder Genre-Vorgaben (eine Figur handelt in bestimmter Weise, um einem Plot-Muster oder Genre-Vorgaben gerecht zu werden; soziale oder mediale (Stereo-)Typen (eine Figur handelt in bestimmter Weise, weil Leser dieses Verhalten von einer entsprechenden Person oder Figur erwarten; kognitive oder affektive Wirkungen (eine Figur handelt in bestimmter Weise, etwa um die Erzählung für Leser interessanter oder spannender zu machen); ${ }^{14}$ Anspielung auf reale oder intertextuelle Vorbilder (das Verhalten der Figur ist an das Verhalten anderer Figuren oder realer Personen angelehnt). Diese Liste ist offen. ${ }^{15}$

Da die Liste offen ist, wird sie prompt erweitert: um Propps formalistische Morphologie ${ }^{16}$ und Greimas' Aktantenfunktionsmodell.17

10 Thomas G. Pavel: The Poetics of plot. The case of English renaissance drama. Minneapolis 1985; zit. n. Jan C. Meister: Handlung [Kap. IV.3.2]. In: Lahn/ders.: Einführung in die Erzähltextanalyse (2013), S. 210-231, hier S. 227.

11 Meister: Handlung, S. $227 \mathrm{f}$.

12 Vgl. Eder: Die Figur im Film.

13 Vgl. Jannidis: Figur und Person.

14 Vgl. dazu etwa Anz: Kulturtechniken der Emotionalisierung; vgl. ders.: Gefühl als Text?

15 Köppe/Kindt: Erzähltheorie, S. 150. Die Autoren verweisen in einer Fußnote auf Eder: Die Figur im Film, S. 430 f., und Jannidis' Kapitel 6.3 (vgl. Jannidis: Figur und Person).

16 Vgl. Wladimir J. Propp: Morphologie des Märchens. München 1928/1972; vgl. Meister: Handlung, S. 222-227; vgl. Schneider: Einführung in die Roman-Analyse, S. 20; vgl. Köppe/Kindt: Erzähltheorie, S. $18 \mathrm{f}$.

17 Vgl. Bachorz: Zur Analyse der Figuren, S. 54 ff.; vgl. Meister: Handlung, S. 226 f.; vgl. Schneider: Einführung in die Roman-Analyse, S. $20 \mathrm{f}$. Vgl. Michael Neumann sowohl für eine Erweiterung von Propp als auch für eine das Erzählen als anthropologische Konstante nehmende Studie, die daraus bestimmte, immer wiedererkennbare ,Erzählströme‘ ableitet (vgl. ders.: Die fünf Ströme des Erzählens. Eine Anthropologie der Narration. Berlin/Boston 2013). Vgl. dazu auch Michael Neecke: Literarische Strategien narrativer Identitätsbildung. Eine Untersuchung der frühen Chroniken des Deutschen Ordens. Frankfurt am Main 2008. 
94 - Teil I: Grundlagen 3. Handlungsmotivation und Eindruckssteuerung

Dass Genazinos Romane mit Propps Untersuchungsgegenstand der russischen Zaubermärchen keine größere Überschneidung haben, muss nicht eigens erwähnt werden. Dass ihm und seinem Modell hingegen ein Platz in der Ahnengalerie der formalistischen, zugleich die Figuren berücksichtigenden Erzähltextanalyse gebührt, ist indes Grund genug, sein Unterfangen zumindest kurz zu skizzieren. Propp arbeitet in seiner Morphologie des Märchens (1928/1972) durch die Reduktion der in den Zaubermärchen auftauchenden „handlungsbestimmenden Geschehensmomente und Ereignisse auf abstrakte Funktionsbegriffe wie ,Auszug des Helden“"18 31 auf- und auseinanderfolgende Funktionen heraus. Diese sind wie Perlen auf eine eindimensionale Handlungsverkettung der Märchen gereiht, können also nicht bezogen auf ihre Position verschoben werden, sehr wohl können aber einzelne Perlen entfernt werden: Ein Königssohn, der ohne schwierige Aufgabe, Widersacher und Hexenwerk die Prinzessin freit, ist zwar nicht sehr zauberhaft, aber eben doch ein prototypische Märchen-Königssohn. „Tatsächlich lassen sich, wenn man sie sehr abstrakt auffasst, in vielen Erzähltexten abstrakte Grundkonstellationen identifizieren, die dem Handlungsverlauf als Grundidee unterliegen - oder die man ihm selber interpretierend unterlegend kann. ${ }^{19}$ Allerdings müsste man selbst das Konzept von ,Interpretation' noch sehr weit auslegen, um aus den Propp'schen Funktionen einen Genazino-Roman zu basteln: Mit gutem Willen finden sich Mangelsituationen, Abreise und Rückkehr in dieser Reihenfolge - sie haben aber nicht wirklich etwas miteinander zu tun. „Wie aber kommt man von einer derartigen abstrakten Strukturbeschreibung zurück zum konkret erzählten Geschehen, zu den Ereignissen und zum Figurenhandeln?"20

„Das am weitesten verbreitete Modell der Figurenanalyse im Zusammenhang mit Handlungsmodellen ist das von Algirdas J. Greimas [...]. Greimas teilt Figuren anhand ihrer Funktionen in der Handlung ein. Er differenziert dabei zwischen der Figur selbst, dem Akteur, und der Funktion des Akteurs in der Handlung, dem Aktanten.“21 „Danach kann eine Figur in einem konkreten Handlungsgeschehen als Subjekt oder Objekt, als Adressat oder Adressant sowie als Adjuvant oder Opponent fungieren." 22

Beide strukturalistisch verfahrenden Zugänge zur Handlungsmotivierung sind „- so interessant sie in theoretischer Hinsicht sein mögen - nur unter hohem Aufwand konkret anwendbar." ${ }^{23}$ Und, was schwerer wiegt: für Genazinos Figuren nur bedingt erkenntnisfördernd. Propps Standardstationen einer Geschichte werden von Genazinos Handlungsarmut und den nicht gelösten Konflikten am Ende unterlaufen und obwohl man den Protagonisten die Aktantenfunktion ,Sub-

18 Meister: Handlung, S. 223.

19 Meister: Handlung, S. 226.

20 Meister: Handlung, S. 226.

21 Bachorz: Zur Analyse der Figuren, S. 54.

22 Schneider: Einführung in die Roman-Analyse, S. 20. Bachorz (vgl. dies.: Zur Analyse der Figuren, S. 54 f.) weicht von der Benennung bei Schneider und Meister (vgl. ders.: Handlung, S. 226) hinsichtlich der Angabe der Aktantenfunktionen zumindest begrifflich ab. 
jekt/Held' zuweisen kann, das ,begehrte Objekt' - versteht man es „als abstraktes Gut Macht, Glück etc." ${ }^{24}$ - mit dem ,richtigen', bedeutungsvollen Leben angegeben werden kann und sich in vielen Romanen Genazinos unterschiedliche Nebenfiguren die Opponentenrolle teilen (Vorgesetzte, Ehefrau), wirkt die Anwendung auf Genazinos Figurenromane ,unmotiviert': „Die Grenzen [...] sind [...] schnell erreicht, wenn man die Rahmen formelhafter Literatur [...] verläßt und komplexere, vor allem moderne Prosa untersuchen will." ${ }^{25}$

Hilfreicher ist das Unterkapitel zur Motivierung bei Martínez/Scheffel, die kausale, finale und kompositorische bzw. ästhetische Motivierung unterscheiden. Obgleich die Autoren der Figur wenig Platz in ihrer Einführung einräumen und die Motivierung tendenziell nicht an die Figurenhandlungen knüpfen, lohnt ein Blick:

Die (1) kausale Motivierung erklärt ein Ereignis, indem sie es als Wirkung in einen UrsacheWirkungs-Zusammenhang einbettet, der als empirisch wahrscheinlich oder zumindest möglich gilt. Kausale Motivierung umfaßt nach dieser Bestimmung nicht nur Figurenhandlungen, sondern auch Geschehnisse [...]. [...] Vor allem bei älteren Erzähltexten ist die Handlung außer durch kausale Motivierung häufig durch eine (2) finale Motivierung bestimmt. Die Handlung final motivierter Texte findet vor dem mythischen Sinnhorizont einer Welt statt, die von einer numinosen Instanz beherrscht wird. Der Handlungsverlauf ist hier von Beginn an festgelegt, selbst scheinbare Zufälle enthüllen sich als Fügungen göttlicher Allmacht. [...] Eine ganz andere Dimension narrativer Texte wird mit dem Begriff der (3) kompositorischen oder ästhetischen Motivierung bezeichnet. Diese umfaßt die Funktion der Ereignisse und Details im Rahmen der durch das Handlungsschema gegebenen Gesamtkomposition und folgt nicht empirischen, sondern künstlerischen Kriterien. ${ }^{26}$

Von hinten aufgezäumt bieten sich ästhetische Motivierungen für all die bei Genazino eher frei fluktuierenden und nicht, verknüpften' Motive an, ${ }^{27}$ die ästhetische Funktionen übernehmen, finale Motivierung kann ein Beschreibungsansatz für die mannigfaltigen Deus-ex-MachinaMomente $\Leftrightarrow$ II.2.2) ${ }^{28}$ der Romane herhalten und die kausale Motivierung harrt noch ihrer Zuspitzung auf motivationales Figurenverhalten und die Einbettung in ein taugliches Modell.

Aber bedarf es überhaupt dieser mehrdimensionalen Theoriediskussion, um für Genazinos Figuren zu einer plausiblen Antwort auf das ,Warum' ihrer Handlungen zu kommen? Schließlich sind die - zumindest internen - Angebote an den Leser bisweilen recht konkret, wie auch Hofmann festhält: „Und wir würden uns nicht in einem Genazino-Buch befinden, hätte der Erzähler nicht auch sogleich eine Erklärung parat". ${ }^{29}$ Man kann sogar noch weitergehen: Bei Genazino muss man sich mitunter nicht einmal die Mühe machen, die Erklärungen flächig über den Text verstreut zu suchen - man muss lediglich die Romane nach Kausalitätsmarkern durchforsten: So-

Bachorz: Zur Analyse der Figuren, S. 54.

Thorsten Pflugmacher: [Vladimir Propp]. In: Einladung zur Literaturwissenschaft. Ein Internetvertiefungsprogramm zum Selbststudium. Online: <http://www.einladung-zurliteraturwissenschaft.de/index.php?option=com_content\&view=article\&id=245:personenpropp\&catid $=40$ : kapitel $-5>$. Martínez/Scheffel: Einführung in die Erzähltheorie, S. 111 u. S. 114. Vgl. Martínez/Scheffel: Einführung in die Erzähltheorie, S. 109, S. 111 u. S. 114.

Vgl. Anja Hirsch: Zwischen Lust und Angst. Erzählen im Zeichen des Verschwindens. In: Arnold (Hg.): Wilhelm Genazino (2004), S. 70-78, hier S. 70.

Hofmann: Beobachtete Beobachter in Wilhelm Genazinos Romanen, S. 60. 
96 - Teil I: Grundlagen 3. Handlungsmotivation und Eindruckssteuerung

bald ein ,weil' auftaucht, ist eine Antwort auf die Motivationsausgangslage nicht weit: Auf Druckseite 120 des Romans Die Ausschweifung finden sich allein zwei weil-Konstruktionen! Erstens: „Weil er Ruth auf sich und seinen Krankenhausbesuch aufmerksam machen wollte, gab er sich Mühe, die Vorgänge des Ankleidens künstlich zu verlängern." (Ausschweifung, S. 120) Zweitens: „Weil sich Eckhard fürchtete, beherrschte er sich und lief Ruth nicht hinterher." (Ausschweifung, S. 120 f.) Da ist es wohl nicht weit hergeholt für die proximat-kausale Handlungsmotivation auf die angeführten Gründe zu verweisen. Bode rollt diesbezüglich klug und unter Zitataufbietung auf, was bezüglich der Handlungsmotivation der Unterschied von echten Menschen und Figuren in Texten ist, etwa qua Zitat aus „Julian Barnes' Flaubert's Parrot: ,Books say: she did this because. Life says: she did this. Books are where things are explained to you; life is where things aren't. [...] “30 Dieser Auffassung, obwohl freilich nicht für die Geschichte des deutschsprachigen Romans per se, so doch für Genazino höchst zutreffend, lässt sich mit Ter-Nedden kontrastierend entgegenhalten: „Der prinzipielle methodologische Mangel aller ,realistischen“ [nach der Realität, der Lebenswirklichkeit erfolgenden; N. L.] Interpretationen: sie leiden immer unter Daten-Mangel.“31 Prinzipiell: ja! Im konkret vorliegenden Fall: nein! Denn die Dichte der Motive ist bei Genazino tendenziell höher als ,im echten Leben', sodass gilt: „3. Über Figuren kann man weitaus mehr als über Personen sagen/erzählen“.32 Diese dritte These Haferlands bringt auf den Punkt, dass das Repertoire dessen, was Figuren in der Diegese zugeschrieben werden kann, „ungleich größer und vielfältiger als das der Personen" ist. ${ }^{33}$

In der Tat lässt sich auch über Genazinos Figuren und deren Handlungsmotivation einiges berichten, aber ohne einen theoretischen Rahmen würde man schnell in diejenige Falle tappen, die Haferland mit dem Slash implizit andeutet: Es kann nicht darum gehen, über die Handlungsmotivation von Figuren im Sinne von „sagen/erzählen“ zu spekulieren, sondern fundierte - das heißt in der textwissenschaftlichen Analysepraxis: einerseits primärstellenbelegte, zweitens in sinnvolle und explizierte Theorie eingebettete - überprüfbare Aussagen zu treffen.

\section{MODELLE AUS DER (VOLKS-)PSYCHOLOGIE}

Die Motivationspsychologie, die sich in einer weiten Definition an der Antwort auf die Frage, warum sich Lebewesen so verhalten, wie sie es tun, ${ }^{34}$ abarbeitet, unterscheidet psychoanalytische, behavioristische, feldtheoretische, leistungsmotivationale, entscheidungstheoretische, at-

$30 \quad$ Bode: Der Roman, S. 140.

31 Gisbert Ter-Nedden: Psychologie und Literatur. Unpaginiertes Manuskript, Hagen 1989 (Grundlage für eine Vorlesung: 1995 Die Seele und die Formen. Graz Sommersemester). Zit. n. Hans H. Hiebel: Zur Kritik der Literaturpsychologie. In: John K. Noyes/Gunther Pakendorf/Wolfgang Pasche (Hg.): Kultur - Sprache - Macht. Festschrift für Peter Horn. Frankfurt am Main 2000, S. 41-67, hier S. 59.

32 Haferland: Psychologie und Psychologisierung, S. 97.

33 Haferland: Psychologie und Psychologisierung, S. 97. Vgl. dazu auch Fludernik: Erzähltheorie, S. $93 \mathrm{f}$.

34 Vgl. Udo Rudolph unter Mitarbeit von Andreé Körner: Motivationspsychologie kompakt. 2., vollst. überarb. Aufl. Weinheim/Basel 2009, S. 1. 
tributionstheoretische, humanistische und evolutionäre Ansätze. ${ }^{35}$ Je nachdem, welchen Ansatz man favorisiert, gelangt man zu ganz anderen Modellen, Erklärungsansätzen und Ergebnissen $(\Leftrightarrow I .5 .2):$ Wenn man etwa Epikurs Lust-Unlust-Prinzip, das als Vorgänger neuerer Modelle angesehen werden kann, anlegt, findet man bei Genazinos Romanfiguren durchaus Hinweise auf diese hedonistische Ader - ,Lustprinzip', Treibenlassen (vgl. Frauen, S. 102) -; wenn man die psychoanalytische Herangehensweise an Figurenmotivation wählt, rückt die Interpretation von Wünschen und Träumen (vgl. Frauen, S. 113; vgl. Kassiererinnen, S. 54 f.) in den Fokus, die sich zumindest insofern gut bewerkstelligen ließen, als zumeist zusätzlich ein Selbstdeutungsversuch vorliegt (vgl. Heimweh, S. 178); wenn man hingegen Attributionstheorien zurate zieht, wird der Hedonismus, der beiden vorigen Ansätzen eignet, zugunsten eines komplexeren Menschenbilds verworfen: dem „eines ,naiven Wissenschaftlers', der seine Umwelt verstehen, vorhersagen und kontrollieren möchte.“"36 Damit ist man Genazinos Figuren deutlich näher gekommen, denn „Ursachenzuschreibungen spielen im menschlichen Erleben und Verhalten eine große Rolle.“"37 Um die Vielschichtigkeit der motivationalen Gemengelage auch nur einer Genazino-Figur in einer Situation zu veranschaulichen, eignet sich ein Beispiel, bei dem „in die Gedanken und Gefühle von Figuren ,hineingesehen' werden kann - ganz im Gegensatz zum wirklichen Leben, wo wir über das Denken und die wahren Motive unserer Mitbürger nur spekulieren können“: 38

Es ist mir nicht recht, daß Lisa bei ihr wohnt. Renate ist neugierig, und Lisa wird, schon aus Dankbarkeit für die Bleibe, dann und wann Intimitäten preisgeben. Lisa wird das selbst nicht wollen, aber sie wird meinen, daß sie keine Wahl hat. Durch Lisas Schilderungen wird Renate den Eindruck gewinnen, daß nicht nur Lisas, sondern auch mein Leben gescheitert ist. Diese Vorstellung wird dazu führen, daß ich mit Renate überhaupt nicht mehr sprechen will. Und in der Art, wie ich ihr aus dem Weg gehen werde, wird Renate eine Bestätigung sehen, daß ich gescheitert bin. Ich wiederum werde nicht wollen, daß sich in Renate diese Vorstellung festsetzt. Also werde ich auch weiterhin Renate nicht aus dem Weg gehen, obwohl ich gerade dies sehr gern möchte. (Regenschirm, S. 38 f.)

Wenn das nicht menschenähnlich ist, dann nur deswegen, weil man es mit mehr Daten (ungleich Ter-Nedden, gleich Haferland) und einer höheren Reflexionsfähigkeit als bei durchschnittlichen, ,normalsterblichen' Personen zu tun hat; nicht weil man fälschlicherweise die Handlungsmotivation alltagsähnlich vornimmt. Es findet sich die Thematisierung von Selbst- und Fremdbildern ( $\Rightarrow$ II.2.1), die ,innere Zensur' ( $\Rightarrow$ II.2.6), die Neigung zur öffentlichen Selbstaufmerksamkeit $(\Leftrightarrow$ II.2.4), das Persönlichkeitsmerkmal ,Minderwertigkeitsgefühl' $\Leftrightarrow \Rightarrow$ II.1.3) und viele weitere, in den Schlaglichtern akribisch zu untersuchende und auf Handlungsmotivationsmustern beruhende Ansatzpunkte. Auch wenn die bisher referierte Theoriebildung eine Einordnung vorgibt hauptsächlich anerbietet sich der interne Blick, Doležels Kategorie des rationalen Handelns befindet sich im Widerspruch mit dem akratischen (expressis verbis wird dem Leser mit „obwohl“ die Konzession auf dem Silbertablett der Deutung serviert) -, braucht es, zumindest um allge-

35 Vgl. Rudolph: Motivationspsychologie, S. 12.

36 Rudolph: Motivationspsychologie, S. 113.

37 Rudolph: Motivationspsychologie, S. 129.

38 Fludernik: Erzähltheorie, S. 93. 
98 - Teil I: Grundlagen 3. Handlungsmotivation und Eindruckssteuerung

meingültigere Aussagen zu figuralen Motivationsverflechtungen bei Genazino treffen zu können, eine grobkörnigere Schematisierung, die abzubilden sucht, wie es vom ersten Gedanken zu einer Handlung kommt. Sonst ist es vorprogrammiert, sich im Klein-Klein der Theorien und des Closereadings zu verlieren. 39

Eine Möglichkeit zu einer ersten Annäherung liefert die (unter anderem durch Jannidis bekannt gewordene) Referenz auf Bertram F. Malles aus der folk psychology bzw. ,Populärpsychologie‘ entlehntes Konzept zur Erklärung von Verhalten, das durch schematische Einfachheit besticht und für die vorliegende Untersuchung wichtige Anreize geben kann:

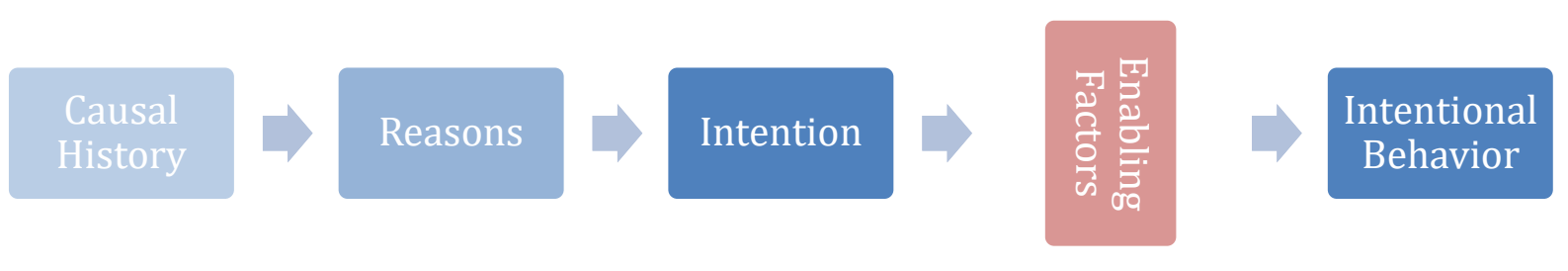

Abbildung 3: Alltagspsychologisches Modell zur Erklärung intentionalen Verhaltens (nach Malle) ${ }^{40}$

Für den 46-jährigen Protagonisten aus Genazinos Regenschirm-Roman ließe sich das Schema anhand des eben zitierten Ausschnitts beispielhaft wie folgt füllen: Sein bisheriges Leben lässt sich zumindest von außen betrachtet und mit der Richtschnur von Erfolg etc. als gescheitert ansehen. Wie genau sich dieses bis zum Zeitpunkt des Zitats ausgenommen hat, wäre im Kästchen Causal History einzutragen. Diese ,Vorgeschichte‘ beeinflusst die Gründe (Reasons): Auch das Ich ist unzufrieden und anerkennt das Faktum, dass sein Leben vor dem Richterstuhl der Communis Opinio keinen Bestand hat. Seine Intention lässt sich in etwa damit angeben, sein Fremdbild vor Beschädigungen zu schützen und also als Spiegel seines Idealbildes aufrecht zu erhalten, damit „sich in Renate diese Vorstellung“ erst gar nicht etabliert. Das bis dato lediglich imaginierte und auf höchstem Reflexionsniveau eindruckssteuernde Verhalten, „auch weiterhin Renate nicht aus dem Weg [zu] gehen, obwohl ich gerade dies sehr gern möchte“, wäre dem Intentional Behavior zuzuschlagen. Dafür allerdings mangelt es noch an denjenigen handlungsermöglichenden Faktoren (Enabling Factors), die zwischen einer Absicht und absichtsvollem Handeln stehen. In der Abbildung absichtlich quergestellt, da sie bei Nicht-Vorliegen handlungsverhindernd wirksam werden, handelt es sich bei den Enabling Factors um eine Art Schranke: Sofern Menschen/Figuren dazu ertüchtigt sind, diese zu überwinden - das ist wertfrei gemeint: immer nur von einem Banküberfall zu erzählen, ist allemal ehrenhafter als diesen letztlich

39 Alternativ müsste sonst eine Einzeltextuntersuchung an die Stelle der Untersuchung des Musterhaften treten, was aus den benannten Gründen ausscheidet.

$40 \quad$ Vgl. Bertram F. Malle: How People Explain Behavior: A New Theoretical Framework. In: Personality and Social Psychology Review 3 (1999), S. 23-48, hier S.36; zit. n. Jannidis: Figur und Person, S. 191; eigene Darstellung. 
durchzuführen -, werden Vorhaben in die Tat umgesetzt. Für das Regenschirm-Beispiel lassen sich diese Faktoren etwa mit ,Ich ist (nicht) mutig genug' oder ,Ich hat (nicht) die Gelegenheit‘ angeben.

Die Enabling Factors sind im Sonderfall Literatur zweiseitig: Es sind einerseits diejenigen figurenbezogenen gemeint, die auch Malle für echte Menschen im Blick hat, und die für die vorliegende Arbeit mit dem Etikett ,intern' bzw. „interne Motivierung“41 gelabelt werden können. Die Zuordnung, nach der das Zitat in das Schema eingeordnet worden ist, ist bspw. hauptsächlich intern erfolgt. Es sind andererseits kompositionsbezogene Erwägungen mit einzubeziehen:42 Für das obige Zitat hieße das etwa, dass Genazino seinen Erzähler plausibilisieren/nicht plausibilisieren lässt, dass die Gründe aus der Lebensgeschichte erklärbar sind, oder dass die handlungsermöglichenden Faktoren für eine so geartete Situation wohl mit,überraschender Mut, der zum Treffen ermächtigt', ,zufällige Begegnung' o. Ä. typischerweise auch extern gelesen werden könnten. Die Frage, die sich extern stellen würde, lautete, wie Genazino „die Handlungen der Figuren in bestimmter Weise gestaltet habe[], um bestimmte Zwecke zu erfüllen." ${ }^{43}$ Eine denkbare Antwort, auf die später noch rekurriert werden wird, wäre: Leserüberraschung. Wo es bspw. üblich ist (s.o.), die Figuren als zögerlich zu zeichnen, wäre ein benennbares Motiv für einen externen Enabling Factor: Lesererwartungsenttäuschung.

Dass diese handlungsermöglichenden Faktoren für die Analyse und Mustererkennung der Handlungsmotivation eine immens wichtige Rolle spielen, hebt auch Genazino selbst - hier bezogen auf den Protagonisten aus Das Glück in glücksfernen Zeiten - in einem Interview hervor:

Sie müssen natürlich berücksichtigen, dass dieser Gerhard Warlich eine schwierige gesellschaftliche Erfahrung hinter sich hat. Nämlich hat er einen Beruf gelernt, eine akademische Bildung genossen und diese sogar mit einer Promotion abgeschlossen und muss nun schon seit vielen Jahren damit zurechtkommen, dass er keine Umgebung hat finden können, in der er seine Bildung sozusagen ausleben kann. [...] Aber bei ihm ist die Sache mit dem scheiternden Beruf eine Art biographisches Senkblei, was ein tiefes Zerwürfnis dieses Mannes mit seinem eigenen Lebensentwurf hervorbringt. Es gibt keine Möglichkeit der Korrektur für ihn. Das ist ein endgültiges biographisches Faktum. Und er wird von seinem Job als Wäschereigeschäftsführer nicht mehr wegkommen. Das ist ihm bewusst. Und das ist sozusagen der entscheidende Faktor. Dann kommt noch hinzu - und das ist, meiner Meinung nach, psychologisch das letzte Stück, was das Fass zum Überlaufen bringt -, dass er seinen Job verliert. Er will sich am Nachmittag einmal eine halbe Stunde oder eine Stunde lang ausruhen, setzt sich irgendwo an den Rand einer Demonstration und wird prompt von einem Firmenkollegen beobachtet, anschließend verpfiffen und sofort entlassen. Das ist genau das, was nicht passieren

$41 \quad$ Köppe/Kindt: Erzähltheorie, S. 151.

42 Jannidis bringt in Figur und Person, S. 191, das folgende Beispiel: Jemand „,wollte [...] den Baumstamm, der die Straße versperrte, zur Seite räumen, und weil er körperlich sehr stark war, konnte er das auch tun." Diese das Schaubild füllende Inferenz bezieht sich bei Jannidis auf Menschen und ist daher notwendigerweise intern perspektiviert. Textkompositionsbezogen ließe sich das Diktum transformieren in: ,Weil der Autor/Erzähler dem Leser Figur X als körperlich starken Menschen vorgestellt hat, der in diesem Moment erzähllogisch an Ort Y gelangen muss, um Z zu tun, wird X textintern befähigt, den Baum von der Straße zu räumen.'

43 Köppe/Kindt: Erzähltheorie, S. 150. Thomas Anz hat sich in einer Reihe von Artikeln (vgl. ders.: Kulturtechniken der Emotionalisierung; vgl. ders.: Gefühl als Text?) dieser externen Perspektive aus text- und emotionsanalytischer Sicht zugewandt und unterschiedliche Regeln postuliert, nach denen literarische Texte beim Leser bestimmte emotionale Reaktionen hervorrufen ( $\Rightarrow$ II.5.6). 
100 - Teil I: Grundlagen 3. Handlungsmotivation und Eindruckssteuerung

darf, nämlich wenn Angestellte sozusagen ihre Zeit, für die sie bezahlt werden, als Freizeit verbringen. Und das ist das, was, aus meiner Sicht, sozusagen das Fass zum Überlaufen bringt. Das hätte nicht passieren dürfen. Er wäre sonst mit knapper Not in dieser Existenzkonstruktion weitergesegelt. ${ }^{44}$

Einerseits ist hier die Kreuzung von interner und externer Perspektive erneut sinnfällig überblickbar: Gerhard Warlich, der im Roman Das Glück in glücksfernen Zeiten nach einem Zusammenbruch in eine Klinik eingeliefert wird, ist seit längerer Zeit am Limit und überlegt häufiger, ob er - als Hilferuf? also in Form einer symbolischen Ersatzhandlung? - anderen Personen bspw. eine Scheibe Brot in die Hand drücken sollte, was dann letztlich auch passiert. Soweit zur innerpsychischen, also internen Handlungsmotivation. Die externe hingegen muss konsequent mitgedacht werden: Wenn Genazino sagt, „Das hätte nicht passieren dürfen“, ist natürlich die externe Motivierung am Werk: Genazino konzipiert es so, damit es zum Überlaufen des Fasses kommt.

Zudem kann das Schema ( $\Rightarrow$ Abb. 3) hier erhellend nochmal mit Inhalt gefüllt werden, nicht zuletzt um unter Beweis zu stellen, dass auch Genazinos Äußerung die Handlung aus den genannten Stufen erklärt: Die Kausalgeschichte entspricht - intern besehen - dem „biographische[n] Senkblei“; ein gewichtiger Grund lässt sich in der Unzufriedenheit hinsichtlich des „Zerwürfnis[ses] [...] mit seinem eigenen Lebensentwurf" sehen; die mögliche Intention lautet: Hilferuf; die intentionale Handlung: Brotscheibe in die Hand drücken; der ermöglichende Faktor ist, wie Genazino sagt, der Jobverlust, durch welchen das „Fass zum Überlaufen“ gebracht wird. Extern besehen bereitet Genazino den Leser peu à peu darauf vor, in der Diegese die Handlung ,Brot überreichen' als Eklat zu werten, dem man gar nicht anders begegnen kann, als Warlich mehr oder minder postwendend, einzuliefern:

Was in dieser Arbeit untersucht wird, sind Figurenhandlungen und -reflexionen, die sich darauf beschränken, intentional (bzw. volitional; $\Rightarrow$ Abb. 4) zu sein und im Bannkreis eindruckssteuernden Verhaltens - die kürzest denkbare Formel der Fragestellung - zu stehen. Gründe und Kausalgeschichte hingegen werden zwar partiell mitgedacht und eingebunden, doch gerade die besser beobachtbare Faktenlage der Informationsvergabe an der Textoberfläche sowie die - je weiter zurückliegend, je blasser - unzuverlässigere Verknüpfung von weiter in der Erzählvergangenheit liegenden Befunden mit tatsächlichen Motivationen und Handlungen verschiebt den analytischen Blick der Arbeit auf die rechte Hälfte des Schaubilds. Zwar ließen sich viele Einschätzungen der Genazinoforschung nur dann einholen, wenn man auch diese linke Seite berücksichtigte, wie es etwa Michaela Krützen vorschwebt, wenn sie von einer ,Backstory Wound ${ }^{` 45}$ als einem in der Vergangenheit liegenden Ereignis/Erlebnis spricht, das die Handlung in der Erzählgegenwart motiviert. Aber die bessere Faktenlage dessen, was die Figuren in den

44 Spiegel/Genazino: „Der Text ist sein eigenes Misstrauen“, S. 253.

45 Vgl. Michaela Krützen: Dramaturgie des Films. Wie Hollywood erzählt. Frankfurt am Main 2004, S. 25-62 u. S. 265. 
Texten tatsächlich tun, und die selten auf eine konkrete Wunde festzulegenden Lebensläufe der Figuren Genazinos, entbinden von stark auf psychoanalytische Momente zurückgreifen müssenden Inferenzen à la ,Traumatisierung' oder ,Wie-die-Eltern-so-die-Kinder', wie es etwa Fansa versucht: „Erzählen ist demnach zu einem großen Teil Erinnern; Kindheitsthemen spielen in der Prosa Genazinos eine Schlüsselrolle, und auch die biografischen Rückblenden sind stets ein integraler Bestandteil der Figurengenese in den Romanen." ${ }^{46}$

Die Fokussierung auf die rechte Seite des Schaubilds (also auf die auch grafisch abgehobenen dunkelblauen und roten Aspekte) reduziert indes nicht die Komplexität. Denn wie Heckhausen und Gollwitzer 1987 in ihrem Modell der Handlungsphasen festgehalten haben, ist der ,Sprung' über die Enabling Factors durchaus genauer aufzuschlüsseln. Die Autoren verwenden den Fluss „Rubikon in dem nach ihm benannten Modell als Metapher für das Überschreiten der Grenze vom Abwägen und Planen zum konkreten Handeln. "47 Wie bei Caesar, der - nachdem die Würfel gefallen waren - mit seinen Truppen unumkehrbar über den besagten Fluss geschritten ist, ist Warlichs Entscheidung, die symbolische Brotscheibe in die Hand zu nehmen, der erste entscheidende Schritt von der Vor-Entscheidungs- zur Vor-Handlungsphase:

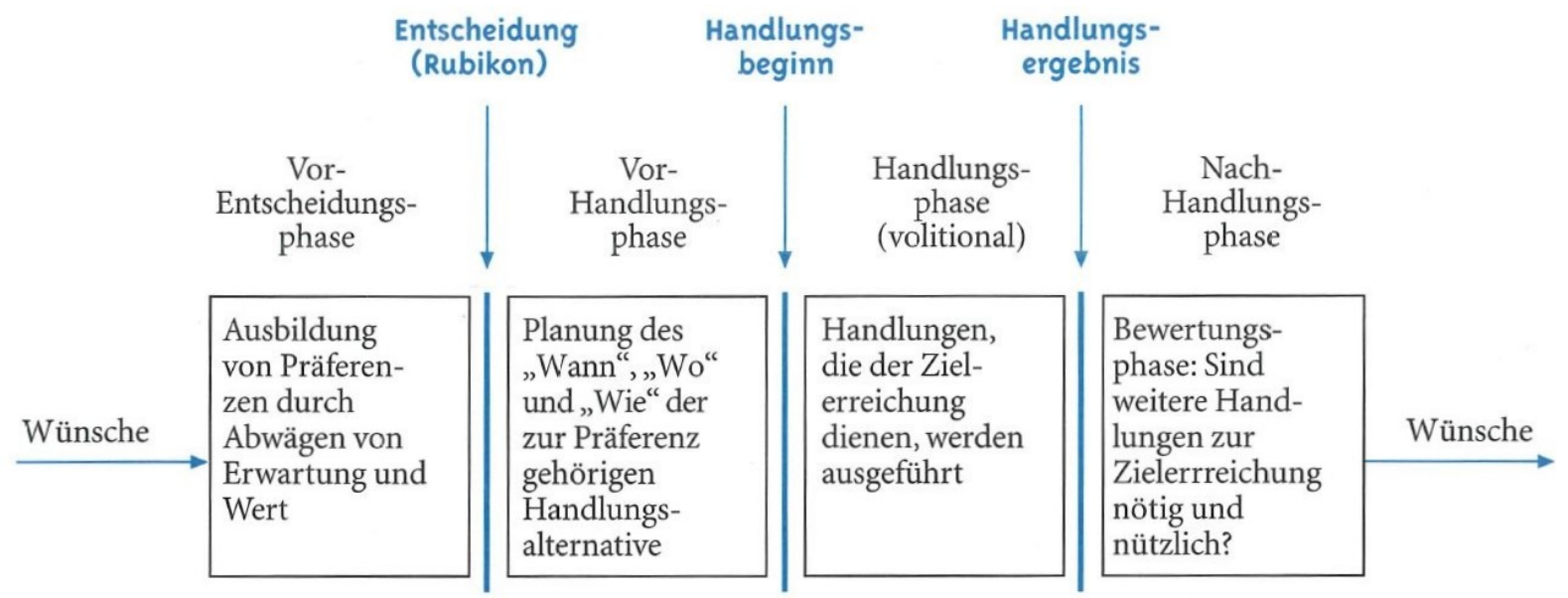

Abbildung 4: Rubikonmodell der Handlungsphasen (nach Heckhausen/Gollwitzer) ${ }^{48}$

Allerdings muss für Genazino eingewendet werden, dass dieser Schritt ein verhältnismäßig kleiner für seine Figuren ist im Vergleich zur „Fiat-Tendenz“",49 die das Ende der VorHandlungsphase in Form einer „Realisierungsintention[]“ bildet und notwendige Bedingung für

46 Fansa: Unterwegs im Monolog, S. 67. Fansa misst den Elternfiguren aus Die Liebe zur Einfalt eine immense Rolle für alle Protagonisten bei. Zumal die Mutter-Figur wertet er als maßgebliche Einflussgröße auf Genazinos Hauptfiguren, wenn er von „poetischen Kindern dieser Mutter“ spricht, wobei die fiktionale Vita der Mutter bis „in die Biografien genazinoscher Helden“ ausstrahle (ders.: Unterwegs im Monolog, S. 86).

47 Rudolph: Motivationspsychologie, S. 160.

48 Vgl. Heinz Heckhausen/Peter M. Gollwitzer: Thought Contents and Cognitive Functioning in Motivational versus Volitional States of Mind. In: Motivation and Emotion 11 (1987), S. 101-120; zit. n. Rudolph: Motivationspsychologie, S. 160. Rudolph: Motivationspsychologie, S. 161. 
102 - Teil I: Grundlagen 3. Handlungsmotivation und Eindruckssteuerung

die tatsächliche Ausführung der Handlung bildet. Denn Genazinos Figuren zögern und zaudern und nicht selten brechen Handlungspläne erst in der Vor-Handlungsphase ab ( $\Rightarrow$ II.2.6). Für diese Fälle ist das Modell von Malle also auf den ersten Blick ausreichend, wenn nicht gar überzeugender geeignet, weil genaugenommen gar keine erste Grenze überschritten wird. Bei genauerem Besehen - und für alle anderen motivierten Handlungen ohnehin - hingegen, ist dieses differenziertere Modell angebrachter. Nicht nur geht es über Malles Modell ,nach rechts' auf dem Zeitstrahl hinaus und umfasst mit der Nach-Handlungsphase das Moment der Evaluation, sondern ermöglicht auch die Unterscheidung in motivationale und volitionale Aspekte und also eine Erklärung der Zögerlichkeiten. Da mit dem Übertritt in die Vor-Handlungsphase die volitionale Bewusstseinslage die motivationale ablöst, tritt üblicherweise (beim Menschen) Folgendes ein: „Der Person ist daran gelegen, optimistisch an eine Sache heranzugehen, etwaige negative Rückmeldungen über den Fortgang der Umsetzung auszublenden und sich nicht entmutigen zu lassen.“50 Das sieht Genazinos Pinselstrich bei der Zeichnung seiner Figuren (externe Perspektive) allerdings nicht vor: Genazinos Figurenbasistypus neigt zwar volitional - wie im Modell beschrieben - zur hohen „Selektivität der Aufmerksamkeit“ und zugleich zur „Offenheit für wenige Informationen" - aber diejenigen Informationen, die zu ihm durchdringen, sind just im Bereich der „mögliche[n] Hindernisse“ und der „etwaige[n] negative[n] Rückmeldungen“ zu finden.51

Genazinos Figuren fühlen sich in der motivationalen Bewusstseinslage wohler: „Sie ist vor allem dadurch gekennzeichnet, dass verschiedene Handlungsalternativen miteinander verglichen werden, und zwar insbesondere hinsichtlich der jeweiligen subjektiven Werte und der subjektiven Wahrscheinlichkeiten, dieses Ziel auch tatsächlich zu erreichen. “52 Das kann bei Genazino so weit gehen, dass die Figuren beim lustvollen Nebeneinander von etlichen Varianten verharren und erst gar nicht in die nächste Handlungsphase eintreten, was im Umkehrschluss natürlich zur Offenheit der Figurenkomposition $(\Rightarrow$ I.2.4) wie des Romanschlusses führt: Probleme und zu treffende Entscheidungen bleiben bestehen, was sich sinnfällig in Honolds Beitragstitel spiegelt: „Unentschiedenheit als erzählte Lebensform“. 53

Beide in diesem Unterkapitel skizzierten Modelle eint, dass sie zu modellieren versuchen, wie der Mensch denkt, dass der Mensch denkt. Im ersten Fall handelt es sich um ein volkspsychologisches, im zweiten um ein elaborierteres Verständnis. Unter Rückgriff auf kognitionswissenschaftlichen Input kann man daraus Kapital für literaturwissenschaftliche Belange schlagen: Der Bezug zum Leser, die „Grundausstattung des menschlichen Geistes“, die „von Erzähltexten als leserseitiges Kohäsionsmittel vorausgesetzt" wird, ${ }^{54}$ sowie die Vorstellung, dass auch literari-

Rudolph: Motivationspsychologie, S. 163.

Rudolph: Motivationspsychologie, S. 163.

Rudolph: Motivationspsychologie, S. 162.

Vgl. Honold: Doppelleben, halbbitter.

Márta Horváth/Katja Mellmann: Ankündigungstext zur interdisziplinären Tagung „Die biologischkognitiven Grundlagen narrativer Motivierung" vom 3.-5. September 2014 in Göttingen. Online: 
sche Figuren als ,Mind-Reader entworfen werden, sind Grundannahmen eines letzten hier zu diskutierenden Ansatzes, der unter dem Namen

\section{THEORY OF MIND (TOM)}

bekannt geworden ist. Lisa Zunshine, die in ihrer einflussreichen Untersuchung Why we read fiction - theory of mind and the novel (2006) neuere kognitions- und evolutionspsychologische sowie anthropologische Forschungsergebnisse mit literaturwissenschaftlichen gekreuzt hat, definiert das Konstrukt, Theory of Mind' wie folgt:

In spite of the way it sounds, mind-reading has nothing to do with plain old telepathy. Instead, it is a term used by cognitive psychologists, interchangeably with ,Theory of Mind', to describe our ability to explain people's behavior in terms of their thoughts, feelings, beliefs, and desires. Thus we engage in mind-reading when we ascribe to a person a certain mental state on the basis of her observable action [...]; when we interpret our own feelings based on our proprioceptive awareness [...]; when we intuit a complex state of mind based on a limited verbal description [...]; when we compose an essay, a lecture, a movie [...] and try to imagine how [...] our target audience will respond to it; when we negotiate a multilayered social situation [...]; and so forth. ${ }^{55}$

Menschen schreiben anderen Menschen als Erklärung ihres Verhaltens Gedankeninhalte zu - im Alltag wie bei der Lektüre von literarischen Texten (was für manche Menschen ja auch alltäglich ist). Das geschieht auf Basis kleinster Indizien, nichtsprachlicher Handlungen und umfasst die Selbstbeobachtung ebenso wie das Abwägen von Publikumsreaktionen und Kalkül bei eigenen Handlungen. In zweierlei Hinsicht kann diese Setzung für die Figurenanalyse bei Genazino nutzbar gemacht werden: Einerseits ist die dem Leser eigene ToM relevant, die er den Figuren unterstellt - also die Überzeugung, dass auch die Figuren dem Malle-Schema gemäß denken und agieren -, andererseits diejenige, die Genazino dem Leser unterschiebt:

Ich wollte das alles nicht. Ich wollte keinen 400-Seiten-Roman schreiben, wo sozusagen die gesamte Struktur der Motive erst geschürzt wird, dann gibt es den Lauf auf die Spitze der Konflikte, dann knallt es, und dann werden in einer nachträglichen Aufarbeitung wie bei einem Feuerwerk, wenn die Sterne wieder heruntersinken, die Ursachen für kurze Zeit angestaunt, ehe sie sich wieder auflösen. Das ist auch der Moment der Analyse, wenn, im Augenblick der Mitteilung eines Konflikts, der Analytiker, sofern er fachlich kompetent ist, diesen Moment erkennt und sagt, so, aha, also das hat Sie damals geschockt. Und der betroffenen Person ist das gar nicht bewusst, dieser ganze Ursachenzusammenhang. Wie gesagt, ich habe lange überlegt, es bietet sich natürlich die Möglichkeit, einen riesigen Wälzer zu schreiben und das alles auseinanderzuklamüsern, aber dann dachte ich, nein, ein Roman ist nicht die Volkshochschule. Ein kluger Leser muss das erkennen können, er muss so viel an Apparatwissen mitbringen, dass er natürlich irgendwann selbst, wie ein Analysant, diesen Einfall hat. Irgendwann wird er darauf kommen. So wie Warlich darauf kommt, so wird auch der Leser darauf kommen. Jedenfalls der Leser, auf den ich spekuliere. ${ }^{56}$

Damit stellt Genazino höchstpersönlich und dezidiert in Rechnung, dass er auf einen bestimmten Idealleser abzielt $(\Rightarrow$ I.2.3), dass dieser mit internem Blick nach Beweggründen der Handlung fragt, und dass er (Genazino) und der Leser ein und dieselbe Theory of Mind teilen. Weiterhin

<https://www.uni-goettingen.de/de/die-biologisch-kognitiven-grundlagen-narrativermotivierung/489234.html>.

55 Zunshine: Why we read fiction, S. 6.

56 Spiegel/Genazino: „Der Text ist sein eigenes Misstrauen“, S. $253 \mathrm{f}$. 
verbalisiert das Statement, dass aus externer Perspektive das Füllen der Kategorie ,Intention“ nicht plakativ-einfach leserseitig leistbar sein soll. Außerdem steckt in den schönen Worten „Apparatwissen“ und „Analysant" bereits die Vorstellung davon, dass man, um das unterkapiteleinführende Zitat zu vervollkommnen, bei einer intern operierenden Figurenanalyse „[u]nter den Bedingungen einer realistischen Darstellungskonvention [...] alle Erklärungen und Erklärungsmuster anführen [kann], die wir auch auf das Handeln realer Personen anwenden. ${ }^{\text {57 Aber }}$ hat es das nicht schon einmal gegeben?

\title{
3.2 Literatur(wissenschaft) und Psychologie
}

Ja, hat es. Grundsätzlich wird hier die Position vertreten, dass eine (Neu-)Verquickung von psychologischer mit literatur-/kulturwissenschaftlicher Forschung nützlich und wechselseitig anregend ist.

\begin{abstract}
Literatur hat viele Bezüge zur Psychologie. Schon im 18. Jahrhundert verhandelten Schriftsteller wie Publikum in literarischen Texten Entwürfe eine psychologischen Figurenkonstruktion und deutung. [...] Im 19. Jahrhundert nahm die Psychologisierung der Literatur weiter zu [...]. In der hermeneutischen Tradition wird Literatur als Lebensäußerung (Dilthey) aufgefaßt, die die inneren Zustände der Verfasser ausdrückt. Eigentlich ist es nur konsequent, daß von einem bestimmten Grad von Spezialisierung an ihre Erforschung schließlich als Aufgabe einer eigenständigen Psychologie angesehen wurde [...]. Erst mit der Herausbildung einer Disziplin Psychologie (erste Institutionalisierungen um 1875) konnte diese Übertragung im akademischen Bereich geschehen. [...] Die Trennung von psychischer gegenüber formal-ästhetischer Modellierung von Literatur schien nun geboten; manche Kritik an der Hermeneutik - beispielsweise bei den Formalisten und frühen Strukturalisten - richtete sich ja gerade gegen deren implizierten Psychologismus, der ästhetische wie soziale Entstehungs- und Wirkungsbedingungen weitgehend außer acht ließ [...].58
\end{abstract}

Leider ist der Blick für ein derartiges Bündnis getrübt durch manchen Holzweg, den die prominenteste Verbindung literaturpsychologischer Couleur, die daraus erwachsen ist, die ,psychoanalytische Literaturwissenschaft', eingeschlagen hat. ${ }^{59}$ Häufig ist es dort (leider) darum gegangen, ,den Autor auf die Couch zu legen' und (teils) illegitime Rückschlüsse von vermeintlich autobiografischen Texten auf Autorenpersönlichkeiten zu ziehen (etwa Kafka-Brief-Vater) bzw. Texte in stumpfsinniger Fleißarbeit nach Phallussymbolen (etwa Kafka-Brücke-Spazierstock)

57 Köppe/Kindt: Erzähltheorie, S. 149. Köppe/Kindt verweisen zur Begründung in diesem Zusammenhang qua Fußnote auf Holmer Steinfath: Orientierung am Guten. Praktisches Überlegen und die Konstitution von Personen. Frankfurt am Main 2001.

58 Rainer Baasner: Literaturpsychologie/Psychoanalytische Literaturwissenschaft. In: ders./Maria Zens: Methoden und Modelle der Literaturwissenschaft. Eine Einführung. 3., überarb. u. erw. Aufl. Berlin 2005, S. 147-158, hier S. 147. Vgl. für einen sehr positiven Blick auf die Verbindung Ilka Quindeau: Psychoanalyse. Paderborn 2008, S. 61-64.

59 Vgl. für eine kenntnisreiche Darstellung sowie eine Auswahlbibliografie grundlegend Joachim Pfeiffer: Literaturpsychologie/Psychoanalytische Literaturwissenschaft. In: Jost Schneider unter redaktioneller Mitarbeit von Regina Grundmann (Hg.): Methodengeschichte der Germanistik. Berlin/New York 2009, S. 355-384. 
oder sprachlichen Repräsentationen der Vulva zu durchforsten. ${ }^{60}$ Eine einzige exemplarische, wie Baasner sie nennt (s.u.): ,küchenpsychologische ${ }^{\prime 61}$ Aussage möge dazu genügen:

Als Grundregel mag fungieren: alles Längliche, Schmale, Aufrichtbare ist Symbol für männliche Sexualorgane, Weites, Breites, Höhlenartiges für weibliche. Einige Beispiele: In der Lyrik hat man bei Ebenen und Wiesen Vulva zu verstehen, Hügel sind der Mons veneris, Sonnenaufgang repräsentiert Erektion etc. ${ }^{62}$

Was Groeben ganz ernst im Rahmen literaturwissenschaftlich-psychoanalytischer Traumdeutung - unter Berufung etwa auf Barron 1947 - als ,Grundregel' der Symbolerkennung beschreibt, erhält in ,objektiveren' Darstellungen eine ironische Note: „Vasen, Flaschen und Höhlen als weibliche, Schwerter, Stangen, Würstchen und Zeppeline als männliche Geschlechtskennzeichen gehören zu den Deutungen, die in Zeiten breitenwirksamer ,Küchenpsychoanalyse' allen sogleich auffallen.“63 Das kann man machen - auch bei epischen Texten und auch bei Genazino: Fansa etwa findet dort die Worte „Puffreis“ und „Spritzgebäck“ in unmittelbarer Nachbarschaft, worin er eine „obszöne Note“ der „Sexualthematik“ sieht.64 Es wäre aber wohl eher zu diskutieren, ob Genazino sich dieser ,anstößigen', anspielungsreichen Wortverwendung nicht durchaus bewusst ist und den Hobby-Psychoanalytikern ein paar Brocken zum Fraß vorgeworfen hat - die Textdeutung ernsthaft nach vorne bringen solche Identifizierungen wohl nicht. ${ }^{65}$ Daher soll diese Arbeit keinesfalls in einer Aufwärmung der Phallussymbolsuche und der Entlarvung (ver-

60 Vgl. Ralph Köhnen: Psychoanalytische Literaturwissenschaft. In: Benedikt Jeßing/ders.: Einführung in die Neuere deutsche Literaturwissenschaft. 2., aktual. u. erw. Aufl. Stuttgart/Weimar 2007, S. 302-306, hier S. 303; vgl. Gisbert Ter-Nedden: Charakterprobleme. Philologische Psychologismus-Kritik der Jahrhundertwende - eine wissenschaftsgeschichtliche Erinnerung in systematischer Absicht. In: Wiesinger (Hg.): Akten des X. Internationalen Germanistenkongresses (2003), S. 235243.

61 Psychoanalytische Literaturanalysen sind allerdings auf keinen Fall in Bausch und Bogen zu verdammen: Arthur Schnitzlers Texte etwa sind ,ohne überhaupt nicht angemessen zu interpretieren. Psychoanalyse und deren Anwendung auf Literatur haben durchaus ihre Berechtigung. Insonderheit die Kategorie des Unbewussten auf Figurenebene in den literaturwissenschaftlichen Diskurs eingeführt zu haben, bleibt verdienstvoll. Auch der generelle Vorwurf, Texte, die vor ,Erfindung' der Psychoanalyse entstanden sind, mit ebendieser zu analysieren, sei unredlich, lässt sich nicht halten (vgl. Köppe/Kindt: Erzähltheorie, S. 123). Vgl. für ,gelungene' psychoanalytische Literaturinterpretationen auch Thomas Anz in Zusammenarbeit mit Christine Kanz (Hg.): Psychoanalyse in der modernen Literatur. Kooperation und Konkurrenz. Würzburg 1999. Vgl. für einen reflektierten, wenngleich älteren Einführungsband Ralph Langner (Hg.): Psychologie der Literatur. Theorien, Methoden, Ergebnisse. Weinheim/München 1986. Für das künftige Studium und wissenschaftliche Denken sind allerdings bei vielen Studierenden, wenn sie lediglich mit der ,küchenpsychoanalytischen Theorieauslegung in Verbindung kommen, damit häufig Literaturwissenschaft und Psychologie zu wenn nicht Antipoden so doch zumindest - unvereinbaren Einzeldisziplinen verdammt.

62 Norbert Groeben: Literaturpsychologie. Literaturwissenschaft zwischen Hermeneutik und Empirie. Stuttgart 1972, S. 129. Dass Genazinos Romane demgemäß als „,anal ausgerichtete literarische Werke“, die "die Beschreibung von Schmutz, ekelerregenden Gerüchen [bevorzugen]“, beschrieben werden können, sei nur der Information halber angeführt (Groeben: Literaturpsychologie, S. 129).

63 Baasner: Literaturpsychologie/Psychoanalytische Literaturwissenschaft, S. 156.

64 Fansa: Unterwegs im Monolog, S. 46.

65 Graduell anders sieht es hinsichtlich der inzestuös eingefärbten Mutter-Erinnerungen und der Überblendungen von Mutter und Geliebter bzw. Frau aus: „Aus der einstigen Geliebten und Ehefrau wurde jetzt eine Art Mannmutter, die erkannt hatte, dass sie heute andere Aufgaben hatte als früher." (Kein Geld, S. 28; $\Rightarrow$ II.5.2) 
106 - Teil I: Grundlagen 3. Handlungsmotivation und Eindruckssteuerung

meintlich) psychisch kranker Autorenpersönlichkeiten gipfeln, wird doch allzu schnell dabei der Punkt erreicht, die Erkenntnisse als spekulativ und monokausal, mitunter gar als wissenschaftlich banal zurückweisen zu müssen.

Dass es jenseits der Psychoanalyse Freud'scher Provenienz ${ }^{66}$ - und neben den äußerst komplexen Reflexionen à la Lacan etc. - und der etablierten Literaturpsychologie ${ }^{67}$ handfeste Konzepte aus anderen Psychologiezweigen gibt, die auf einen verhältnismäßig einfachen Nenner gebracht den ,methodischen Handwerkskoffer' des Literaturwissenschaftlers veritabel bereichern können, wird zumeist ausgeblendet. Dabei bedienen sich viele Forscher bereits implizit der populärwissenschaftlich diffundierten Ergebnisse: ,Ich-Dissoziation', ,Identitätskonstruktion', ,Doppelbindung' etc. sind Schlagworte, mit welchen in der philologischen Interpretationspraxis behände hantiert wird. Schaut man sich diese und weitere Konzepte im Ursprungskontext der Psychologie an, wird schnell klar, dass dort Potenziale schlummern, die einen zentralen Beitrag zur Deutung literarischer Texte leisten können - und zwar auch im Rahmen einer „Literaturpsychologie ohne Freud“.68

Das daraus folgernde Desiderat, das Duo Literaturwissenschaft und Psychologie neu zusammenzudenken und dabei methodologisch-allgemeine wie methodisch-konkrete Fragen aufzuwerfen, wird zunehmend offenkundig. Und so werden ungefähr seit der Jahrtausendwende diesbezüglich neue Wege auf der Forschungslandkarte kartografiert, skizziert, erprobt und gegangen, die hoffen lassen auf eine interdisziplinäre Neuauflage. Thomas Anz wirft symptomatisch den bisherigen ,Literaturpsychologen' 2003 folgendes Defizit vor:

Wer literarische Texte psychologisch interpretiert, weiß oft nicht, was er tut. Oder er tut etwas anderes, als er zu tun behauptet. Das hat in der literaturpsychologischen Praxis zu erheblichen Konfusionen geführt und einen konstruktiven Dialog vielfach verhindert. ${ }^{69}$

Da der Verfasser dieser Untersuchung nicht nur nicht glaubt, es nicht zu wissen, sondern ganz im Gegenteil massiv auch von der prinzipiellen Fruchtbarkeit dieses Unterfangens überzeugt ist, soll die vorliegende Arbeit somit zunächst in der darauf zielenden Typologie von Anz verortet werden, die mit der Absicht, „einige Implikationen literatur-psychologischer Praxis explizit zu machen und damit die Verständigung zu verbessern“,70 seit langem wieder ein begehbares Fundament bereitet, auf welchem neue Theoriegebäude aus der Wahlverwandtschaft von Literaturwissenschaft und Psychologie entstehen können. Die vorliegende Studie ist grundsätzlich am ehesten in folgender Kategorie anzusiedeln: „III Intuitive Psychologie des Autors und wissen-

66 Vgl. als Vertreter bspw. Peter von Matt: Literaturwissenschaft und Psychoanalyse. Stuttgart 2001.

67 Vgl. Baasner: Literaturpsychologie/Psychoanalytische Literaturwissenschaft, S. $147 \mathrm{ff}$.

68 So der Untertitel von Vellussig: Die Sinnenhaftigkeit der Poesie.

69 Anz: Literatur und Psychologie, S. 221; vgl. Hans H. Hiebel/Astrid Lange-Kirchheim: Einleitung zu „Literatur und Psychologie“. In: Wiesinger (Hg.): Akten des X. Internationalen Germanistenkongresses (2003), S. 213-220.

70 Anz: Literatur und Psychologie, S. 221. 
schaftliche Psychologie des Interpreten“. ${ }^{11}$ „Hat der Interpret Kenntnisse wissenschaftlicher Psychologie, so kann er diese mit der intuitiven Psychologie des Autors“, der „in seine literarischen Texte zum Beispiel Vorstellungen darüber eingeschrieben [hat], nach welchen psychischen Gesetzmäßigkeiten Personen sich in der Regel verhalten“, „[...] vergleichen. In der interpretatorischen Praxis führt dies zumeist zu einer Übersetzung literarischer Psychologie in die Konzeption und Begrifflichkeit wissenschaftlicher Psychologie, die der Interpret sich angeeignet hat und an deren Wahrheit er zumeist auch glaubt.“72 In dieser Hinsicht, so Anz weiter, suche die „wissenschaftliche Psychologie des Interpreten [...] in der intuitiven Textpsychologie [erstens] Bestätigungen oder Anschauungsmaterial für [...] psychologische Theorien“, zweitens „Anregungen zur partiellen Weiterentwicklung der eigenen Theorien“ und beanspruche drittens, „die oft nur implizite Textpsychologie zu explizieren und zu präzisieren“.73 In jedem Fall gilt: „Wissenschaftliche Psychologie erhält damit eine heuristische Funktion zur Verdeutlichung literarischer Psychologie." 74

Hinzuzusetzen ist, dass Genazino, wie nun bereits klar sein sollte, „nicht unbedingt nur intuitives psychologisches Wissen, sondern potentiell das der wissenschaftlichen Psychologie, soweit es ihm bis zum Zeitpunkt der Niederschrift seines Textes zugänglich war und er es sich angeeignet hat“, hat einfließen lassen. Die Grenzen zu Anz' Typologie-Kategorie: „IV Literatur und wissenschaftliche Psychologie ihrer Zeit", sind also fließend.75

Ein Exkurs muss diese Einschätzung auf ein solideres Fundament stellen. Auf die Frage Hubert Spiegels, ob Genazino auch die Forschungsliteratur zu zentralen Themen seiner Prosa zur Kenntnis nehme, antwortet dieser:

Doch, unbedingt. Allerdings ist das strikt getrennt. Ich lese natürlich gern solche theoretischen Sachen, insbesondere zu Themen, die mich selbst interessieren. [...] Aber das ist sozusagen eine Abteilung für sich. Und mein Glück ist, und ich hoffe, das wird noch lange andauern, dass ich das trennen kann. Wenn es nämlich so wäre, dass ich mich in der theoretischen Literatur munitionieren müsste, dann, glaube ich, könnte ich den Laden dichtmachen. Das geht überhaupt nicht. Im Gegenteil, der Schriftsteller ist jemand, der fast wie ein Analphabet anfängt, das heißt, ein Unwissender darüber ist, was er tun könnte. ${ }^{76}$

In der vorliegenden Arbeit wird massiv bezweifelt, dass diese Trennung erstens im Allgemeinen möglich sei, dass zweitens Genazino sie im Speziellen aufrecht zu erhalten vermag ( $\Rightarrow$ I.2). Weitaus eher wird hier einem idealisierten Schriftstellertypus das Wort geredet.77 Exkursende.

Anz: Literatur und Psychologie, S. 222.

Anz: Literatur und Psychologie, S. 222.

Anz: Literatur und Psychologie, S. 223.

Anz: Literatur und Psychologie, S. 223.

Anz: Literatur und Psychologie, S. 223.

Spiegel/Genazino: „Der Text ist sein eigenes Misstrauen“, S. $242 \mathrm{f}$.

Vgl. dazu Nils Lehnert: Refus aus Kalkül?! Zu Christian Krachts Fernsehauftritten. In: Stefan Greif/ders./Anna-Carina Meywirth (Hg.): Popkultur und Fernsehen. Historische und ästhetische Berührungspunkte. Bielefeld 2015, S. 133-166, hier, S. 136; vgl. Gunter E. Grimm/Christian Schärf (Hg.): Schriftsteller-Inszenierungen. Bielefeld 2008. 
Auf drei Ebenen ist Genazino etwa mit Psychoanalyse und Psychologie in Bezug zu setzen: In seiner Funktion als ,Beiträger' zur psychologischen Fachpublikation Faszination Psychologie. Glanzlichter aus drei Jahrzehnten ${ }^{78}$ manifestiert sich die eben angerissene kategorische Grenzüberschreitung; in der bevorzugten Behandlung seiner Romane aus psychologischer und psychoanalytischer Interpretationsrichtung auch in namhaften Publikationsorganen - Psyche. Zeitschrift für Psychoanalyse und ihre Anwendungen; ${ }^{79}$ Die Wissenschaft des Unbewussten; 80 Psychosozial-Verlag ${ }^{81}$ - lässt sich zumindest legitimerweise ein Rückschluss auf die psychologisch gut interpretierbare ${ }^{82}$ Prosa sehen; und schließlich ist drittens - als Addition aus den vorgenannten Gründen - den Texten und Figuren selbst ohne größere Anstrengung abzulesen, dass kein psychologischer Laie die mechanische Schreibmaschine bedient und seinen Figuren zudem eine Psychologie zugedacht hat. Genazino ist nämlich nicht nur psychologisch interessierter Psychogrammautor, er thematisiert dies auch in seinen Romanen auf Figuren- und Erzählerlevel: „In einem meiner Nebenberufe bin ich auch Laienpsychologe" (Liebesblödigkeit, S. 88), sagt der namenlose Ich-Erzähler über sich selbst. Eine andere Figur weiß ebenso kenntnisreich, genaugenommen bereits über das Laien-Level hinausweisend: „Ein Psychiater wird von starken desintegrativen Ich-Störungen reden, von einer depressiven Irritation mit psychotischer Symptomatik, von einem wahnhaften paranoiden Verfolgungserleben." (Regenschirm, S. 56) Gerhard Warlich schließlich fährt weitere Geschütze auf, die seine ,Vorbildung' in Sachen Psychologie offensiv beglaubigen:

Es ist gleichgültig, ob wir unser Problem eine unipolare Depression, eine mittelschwere Melancholie, eine bipolare Störung, ein autistisches Syndrom, eine akute Angstneurose oder sonstwie nennen. Dr. Adrian nimmt Remergil, Serotonin, Noradrenalin und, wie ich, Cipralex. Er klagt über Hemmungen, Antriebsschwäche und Weinerlichkeit. (Glück, S. 153 f.)

Bartl schlussfolgert demgemäß:

In das Werk Genazinos sind sicherlich an mehreren Stellen psychologische Theorien eingeschrieben, was die detailliert geschilderten psychiatrischen und psychosomatischen Therapien der Figuren Abschaffel und Warlich [...] oder die spürbare Auseinandersetzung mit Freud und der Methode der Psychoanalyse in manchen Essays andeuten. Es lohnt sich daher, versuchsweise Ergebnisse und Debatten der aktuellen Persönlichkeitspsychologie an das Thema des Fremderlebens in Genazinos

Vgl. Wilhelm Genazino: Gott ja, die Angestellten! In: Faszination Psychologie. Glanzlichter aus drei Jahrzenten, hg. von der Redaktion Psychologie Heute. Weinheim/Basel 1981/2004, S. 70 f.

Vgl. Christa Hoffmann: Die Bedeutung einer Romanfigur als unsichtbarer Begleiter einer psychoanalytischen Behandlung. In: Psyche. Zeitschrift für Psychoanalyse und ihre Anwendungen 63 (2009), S. 429-454; vgl. Esther Grundmann: Zur Konstruktion von Mikrowelten: Genazino und die Kunst des bedeutungsvollen Sehens. In: Psyche. Zeitschrift für Psychoanalyse und ihre Anwendungen 70 (2016), S. 337-350.

Vgl. Kathy Zarnegin: Wilhelm Meisters Trauerjahre. Die Melancholie der Glückssuche in W. Genazinos Roman „Das Glück in glücksfernen Zeiten“. In: dies. (Hg.): Die Wissenschaft des Unbewussten. Würzburg 2010, S. 235-253.

81 Vgl. Tilmann Moser: Tödliche Leere und schmerzliche Einsamkeit. Über zwei Romane von Wilhelm Genazino. In: ders.: Lektüren eines Psychoanalytikers. Romane als Krankengeschichten. Gießen 2013, S. 25-43.

82 Und in den meisten der vorliegenden Fälle: tatsächlich auch einfach handwerklich gut interpretierten! 
Werk heranzuführen, ja gar eine Art vorsichtiger Anamnese beispielsweise Dieter Rotmunds [...] zu unternehmen. ${ }^{83}$

Aber nicht nur solche: Auch motivations- und sozialpsychologische Überlegungen zum Selbst und zur Selbstdarstellung können interessante Aspekte auf Figurencharakterisierung, Handlungsmotivation und inner- wie interpersonelle Konflikte innerhalb literarischer Texte (Genazinos) richten helfen. Prinzipiell sind nahezu alle psychologischen Forschungsergebnisse, die sich nutzbringend für die Charakterisierung und Handlungsmotivation anbieten, in Betracht zu ziehen und in die Konstruktkiste zu packen. ${ }^{84}$

Und so schließt sich der Kreis: Literatur(wissenschaft) und Psychologie sind - bestenfalls ,mit nur wenig Freud' und ohne vereinfachende Psychologisierung - wieder gesellschaftsfähig zu verbinden, um nicht von manchen Fehltritten abgeschreckt die Analysewege zu vergessen. Just dies soll nun qua Rekurs auf ein vielversprechendes sozialpsychologisches Handlungserklärungsmustersystem von der Vorhandlungsphase in die Tat umgesetzt werden. ${ }^{85}$

\subsection{Impression Management/Eindruckssteuerung/Selbstdarstellung}

Spätestens seit Goffmans hellsichtiger Feldforschung weiß man soziologisch fundiert, dass Personen anderen gegenüber bestimmte Verhaltensweisen nicht als reiner Spielball der Situation an den Tag legen, sondern für gewöhnlich Absichten hegen, auf eine bestimmte Weise wahrgenommen werden und schließlich andere zu bestimmten Verhaltensweisen veranlassen möchten. ${ }^{86}$ Die Psychologie hat diese Erkenntnis intensiv aufgegriffen und von der Rollenbasierung (Betonung der sozialen und gruppendynamischen Aspekte) zur Eindruckssteuerung (Fokus auf rollenübergreifendes, persönlich-individuelles und evolutiv-adaptives Verhalten) weiterentwickelt. ${ }^{87}$ Das in Rede stehende Forschungsgebiet der Psychologie nennt seinen Gegenstand ,Impression-Management', was hier mit ,Eindruckssteuerung' übersetzt, in der mitunter disparaten Forschungslandschaft auch als größten Teils synonym zu ,Selbstdarstellung' und ,Selbstinszenierung' verwendet wird. ${ }^{88}$

83 Bartl: „The kindness of strangers“, S. $71 \mathrm{f}$. Ganz so einfach macht es Genazino dem Leser dann doch nicht und legt qua Erzähler immerhin einer Figur mal einen Kontrapunkt in den Mund: „Dr. Wolters sprach jetzt [...] über die ebenso große Unmöglichkeit der psychoanalytischen Literaturanalyse. Er nannte die Namen anderer Privatdozenten und Professoren, die von diesen Unmöglichkeiten nicht so überzeugt waren wie er und die von ihm deswegen verwerfungsgehemmte Textbürokraten genannt wurden." (Kassiererinnen, S. 13) Vgl. Köppe/Kindt: Erzähltheorie, S. 149. Vgl. Haferland für das immer virulente „Problem der Psychologisierung" (Haferland: Psychologie und Psychologisierung, S. 106-114, hier S. 106). Vgl. generell zur Verbindung von Handlungsmotivation und IM auf Figurenebene Lehnert: „Sehe ich nun gnädig aus"? Teile des folgenden Unterkapitels $(\Leftrightarrow I .3 .3)$ sind unausgewiesene Selbstzitate daraus.

86 Vgl. Erving Goffman: Wir alle spielen Theater. Die Selbstdarstellung im Alltag. 9. Aufl. München 2011, S. 7 f.

87 Vgl. Leary/Kowalski: Impression Management, S. 35.

88 Vgl. zu terminologischen ,Spitzfindigkeiten' Leary/Kowalski: Impression Management, S. 34; vgl. Hans D. Mummendey: Psychologie der Selbstdarstellung. Göttingen 1990, S. 128 f. Hier wird an der 


\section{ZUM KONZEPT}

Individuen sind in der Lage, sich selbst wahrzunehmen, zu beurteilen und zu bewerten, also Selbstkonzepte zu bilden. Sie können sich bemühen, ihr Bild von der eigenen Person zu beeinflussen, aufrechtzuerhalten oder zu verbessern, ihren Selbstwert zu verteidigen oder zu erhöhen. Dazu sind sie gewöhnlich auf ihre Interaktionspartner angewiesen, denen gegenüber sie sich und ihre Selbstkonzepte präsentieren. ${ }^{89}$

Bekannt sind einzelne Facetten ,eindruckssteuernden' Verhaltens fraglos aus dem Alltag: Der „Strategie, sich selbst Hindernisse zu schaffen und Ausreden zurechtzulegen, um sich bei schlechter Ausführung einer Aufgabe nicht selbst die Schuld geben zu müssen“, ${ }^{90}$ bediente sich wohl jeder bereits einmal (,Self-Handicapping'). ${ }^{91}$ Auch dem Vorgesetzten ,Honig um den Bart zu schmieren",92 sich ergo "durch Einschmeicheln und Lob beliebt zu machen“,93 ist ein so bekanntes wie erprobtes und probates Mittel des Menschen, Einfluss darauf zu nehmen, welches Fremdbild seiner selbst erweckt wird (,Ingratiation').

Was veranlasst Menschen, andere auf eine bestimmte Weise wahrzunehmen, anderen bestimmte Attribute - ambitioniert, apart, aufdringlich, anmaßend, Abscheu erregend etc. pp. - zuzuschreiben? Wie entstehen Selbst-, Ideal- und Fremdbilder, wie entstehen Charakterisierungen anderer? Wie werden einmal bestehende Images korrigiert? „Einfach` verhält es sich bei Einschätzungen und Zuweisungen, die sich quasi-objektiv beobachten lassen: Ein ,Langweiler' vermag es etwa selten oder nicht, überraschend oder kurzweilig zu agieren, ein ,Wendehals' lässt in seinen Handlungen und Aussagen keine übergeordneten Handlungsmaximen oder Einstellungen erkennen. Persönlichkeitsmerkmale wie soziale Verträglichkeit o. Ä. ( $\Rightarrow$ II.1.3) lassen sich qua

verbreiteten Handhabe, IM und Selbstdarstellung bzw. -inszenierung gleichzusetzen, festgehalten, obwohl die Schlagworte ,Inszenierung' und ,Selbstdarstellung' in letzter Zeit inflationär an medialen Darstellungsstrategien von Autoren u. a. abgeschliffen worden sind. Zur Verwandtschaft der Konzepte mit Goffmans Theatermetapher vgl. Noortje Goethals: A dramaturgical perspective on Impression Management. The influence of audience characteristics. Masterarbeit Universität Maastricht 2008. Anz formuliert für die Emotionsforschung Parallelen zum IM-Konzept: „Emotionen sind jedoch, hält man sich an die kognitionswissenschaftliche Terminologie, nicht nur Programme der Informationsverarbeitung, sondern auch Programme der Informationsvergabe an andere. Man lächelt nicht nur als Reaktion auf ein erfreuliches Umweltereignis, sondern auch, um andere zum Lächeln zu veranlassen, man hat und zeigt Angst nicht nur als Reaktion auf ein als gefährlich eingeschätztes Objekt der Wahrnehmung, sondern auch, um anderen eine Gefahr zu signalisieren oder sie zu helfenden Reaktionen zu veranlassen. [...] Emotionen und Signale der Emotionalisiertheit werden mehr oder weniger kontrolliert eingesetzt, um andere zu emotionalisieren und zu motivieren, sich in gewünschter Weise zu verhalten. Emotionalisierung anderer kann zugleich Motivationalisierung anderer sein." (Thomas Anz: Emotional Turn? Beobachtungen zur Gefühlsforschung. In: literaturkritik.de $\quad$ vom $12 . \quad$ Dezember 2006.2 Online: <http://literaturkritik.de/public/rezension.php?rez_id=10267>.) Hans D. Mummendey: Selbstdarstellung: Die Präsentation der eigenen Person. In: Hans-Werner Bierhoff/Dieter Frey (Hg.): Handbuch der Sozialpsychologie und Kommunikationspsychologie. Göttingen 2006, S. 49-56, hier S. 49.

90 Aronson/Wilson/Akert: Sozialpsychologie, S. 154.

91 „Wieder (wie in letzter Zeit öfter) habe ich das Gefühl, daß ich mich ohne Not unwürdig darstelle.“ (Liebesblödigkeit, S. 11)

92 Die Redewendung scheint übrigens bereits im Mittelalter verbürgt zu sein und spiegelt damit einmal mehr die Tiefe der Verwurzelung im Handlungsrepertoire menschlicher Aktionen wider.

93 Aronson/Wilson/Akert: Sozialpsychologie, S. 154. 
standardisierter Fragebögen ermitteln, notfalls unter Zuhilfenahme von Verhaltensbeobachtungen, Selbst- und Fremdeinschätzungen etc. Komplex und forschungswürdig wird es dann, wenn man die Strategien und Verhaltensweisen in den Blick nimmt, mit denen eine wie auch immer geartete Einflussnahme der in Frage stehenden Person ins Spiel kommt. Wenn die zu charakterisierende Person das evozierte Fremdbild mitgestaltet, steuert, ja auch: schönt:

Die Darstellung der eigenen Person und ihrer Eigenschaften geschieht in aller Regel auf recht selbstdienliche Weise, selbstschädigende Selbstpräsentation ist eher selten. Man stellt sich also in allen möglichen Hinsichten eher günstig dar, und zwar je nach den Erfordernissen der Situation und der Personen, an die sich die Selbstdarstellung richtet. ${ }^{94}$

Der dazugehörige Fragenkatalog: Wie möchte die Person von anderen wahrgenommen bzw. behandelt werden? Wie wird sie tatsächlich wahrgenommen bzw. behandelt? Was kann sie tun, um das Bild, das andere von ihr haben, zu steuern? Welche Techniken und Taktiken der Einflussnahme gibt es dabei? Kein Mensch handelt aus Spaß. Es gibt stets Gründe, Überzeugungen, natürlich ggf. unbewusst oder unbemerkt (s.u.), für Handlungen. Üblicherweise liegt eine Intention zugrunde (s.o.), die sich aus der methodischen Perspektive der Eindruckssteuerung etwa damit angeben lässt, einen bestimmten Eindruck zu vermitteln oder andere zu etwas zu motivieren. Verschiedene Wege stehen stets zur Verfügung: Um bspw. andere davon zu überzeugen, als verständiger und sachkundiger Mensch wahrgenommen zu werden - eine Kategorie, bei der es nicht gar so einfach ist wie bei den ebengenannten -, kann man in der Diskussion permanent ,ja‘ sagen (Interesse bekunden), kann sich aber auch über seine Veröffentlichungen zu diesem Bereich indirekt als Experten ausweisen, kann auch die Expertise der Mitdiskutanten zu erschüttern suchen usf. Welcher Spielraum besteht, innerhalb dessen jemand seinen Eindruck auf andere steuern kann? Wie erfolgt dies, wie erfolgreich erfolgt dies? Das sind einige Eckpfeiler der IMForschung.

Ob man möchte oder nicht: IM ist ubiquitär. Da (nahezu) alle Handlungen in einem sozialen Kontext stattfinden, präsentiert man sich fortwährend selbst - sogar gegenüber der eigenen Person in Form von Spiegelbetrachtungen oder dem Verfassen eines Tagebuchs ( $\Rightarrow$ II.1.2). Ein Redner auf einer x-beliebigen Tagung befleißigt sich eines wissenschaftlich-angemessenen Rededuktus, trägt wohlweislich ausgewählte Kleidung, kontrolliert seine non- und paraverbalen Handlungen; die Zuhörerschaft legt Verhaltensweisen an den Tag, die sich mit höflicher Aufmerksamkeit etc. paraphrasieren lassen. Ein rein verbales Beispiel: ,Der heutige Vortrag ist nichts weiter als ein Einblick in mein aktuelles Forschungsprojekt - genauere Zielsetzungen etc. sind derzeit noch im Entstehen befindlich.... Diese Aussage und also soziale Handlung arbeitet mit den eindruckssteuernden Mitteln der ,Untertreibung' (understatement und accounting; vgl. Fremde Kämpfe, S. 51) und der ,vorsorglichen Entschuldigung; sie setzt - im günstigsten Fall - die Erwartungshaltung der Hörerschaft herab und baut zugleich einen Schutzwall gegen mögliche Einwände 
oder Nachfragen usw. auf. Allerdings kann dies auch ,nach hinten losgehen': Nicht nur positive Eindrücke werden durch die Anwendung bestimmter Strategien ,gemanaged', sondern jedes intendiert-positive Bild kann genauso gut negativ rezipiert werden! ${ }^{95}$ Ein Angestellter, der seinen Vorgesetzten bauchpinselt (ingratiation), kann tendenziell liebenswürdig (likable) oder schleimerisch (sycophant) wahrgenommen werden, derjenige, der die soeben fingierte Äußerung realiter anbrächte, auch für schlecht vorbereitet und/oder um Ausreden bemüht.

Abschaffel, um erstmals die Grenze von Person und Figur auch in diesem Kapitel permeabel werden zu lassen, reflektiert diesen Umstand treffend:

Am besten wäre, dachte er, wenn ich den Eindruck einer leicht kränklichen Empfindlichkeit aufrechterhalten könnte. Davon versprach er sich am meisten Schutz. Aber dann erinnerte er sich an einen früheren Kollegen, [...] der [...] versucht hatte, mit der Zur-Schau-Stellung von Dünnhäutigkeit in Ruhe gelassen zu werden. Aber diese Rechnung ging leider nicht auf. Zeißbergs Zurückhaltung wurde von den Kollegen als Verachtung und Überheblichkeit aufgenommen (Falsche Jahre, S. 570).

Doch nicht nur Abschaffel, sondern alle Hauptfiguren Genazinos sind in diesem Punkt beschlagen: „Peschek bemühte sich, abweisend und unnahbar zu erscheinen. [...] Die ganz jungen Kontaktassistenten hielten Pescheks Zurückhaltung für Stil. Die älteren, zum Beispiel Moratz und Kösterbier, wußten, daß es Überheblichkeit und Einsamkeit war." (Fremde Kämpfe, S. 131) ${ }^{96}$ Unerlässlich ist es, bereits jetzt anzuerkennen, dass jedwede Aussage bzw. soziale Handlung - ob (so) intendiert oder nicht - für gewöhnlich auf IM-Faktoren hin gedeutet wird. Ob es gewünscht ist oder nicht: Der Rezipient wertet es so, als ob es so gewünscht gewesen wäre! Deutungswütige Mindreading-Maschine Mensch. Selbst wenn sich ein in Frage stehendes Individuum bei seiner Wort-, Kleidungs-, Habituswahl keinerlei kalkulierte Gedanken gemacht hätte, gilt das Folgende unumschränkt:

Insofern die anderen stets so handeln, als ob das Individuum einen bestimmten Eindruck übermittelt habe, läßt sich in jedem Falle konstatieren, das Individuum habe ,effektiv' eine Situation definiert - sei dies nun tatsächlich absichtlich oder ohne besondere Absicht erfolgt. ${ }^{97}$

Dass daraus ein munteres Spiel von Beobachtungen x. Ordnung entstehen kann, das notwendige Mutmaßungen ( $\Rightarrow$ II.4.2) mit einschließt, wenn man beginnt, „zu denken, was andere denken, daß wir denken usw.",98 zeigt einmal mehr ein Blick in Genazinos Romane:

Isolde spricht über einen Satz, den ich ihr von der Küste geschrieben habe: Je aufgewühlter das Meer ist, desto ruhiger fühle ich mich. Eine Weile glaubte ich, sagt sie, du willst genau das Gegenteil mitteilen: Je ruhiger das Meer ist, desto mehr fühle ich meine Aufgewühltheit. Dann hielt ich den Satz für eine allgemeine Beschuldigung. Eigentlich wolltest du sagen: Je aufgewühlter ich bin, desto weniger komme ich mit der Ruhe der anderen zurecht. Jetzt denke ich, sagt sie, der Satz ist nichts

Vgl. Edward E. Jones/Thane S. Pittman: Toward a General Theory of Strategic Self-Presentation. In: Jerry Suls (Hg.): Psychological perspectives on the self. Hillsdale (NJ) 1982, S. 231-262. Vgl. beispielhaft für ,gescheitertes“ IM: „Es sollte überheblich und arrogant klingen, aber es klang nur rechthaberisch und kleinlich." (Regen, S. 123)

98 Vellusig: Die Sinnenhaftigkeit der Poesie, S. 245; vgl. Zunshine: Why we read fiction, S. 6. 
weiter als ein Ausdruck deiner Selbstgewißheit, daß niemand die Geduld mit dir verlieren wird. Ich antworte, daß ich mir nichts dabei gedacht habe. Isolde lacht und glaubt mir kein Wort. (Licht, S. 100 f. $)^{99}$

Doch der Reihe nach: Wie lässt sich IM konkret definieren? Warum investieren Menschen Zeit, Geld und Mühe in das Beeindruckungsgebaren? Welche Wege hat die Forschung genommen?

\section{DEFINITION UND FORSCHUNGSSTAND}

IM umfasst kurz gesagt „alle Versuche des Menschen, andere dazu zu bringen, ihn so zu sehen, wie er gesehen werden möchte“.100 Diese Minimaldefinition ist aber in mehrerlei Hinsicht ergänzungsbedürftig. Dabei geht die Impression-Management-Theorie wie gesagt zwar auf die Beobachtungen Goffmans zurück, aber auch darüber hinaus, insofern, als

Individuen in der sozialen Interaktion bei ihren Interaktionspartnern den Eindruck, den sie auf diese machen, kontrollieren, daß sie also nicht nur passiv sozialem Eindruck ausgesetzt sind, sondern den Einfluß, der auf sie ausgeübt wird, durch die Vermittlung eines bestimmten Eindrucks von sich selbst auf die anderen mit steuern [...].101

Mit dieser Definition ergänzt Mummendey, dass IM nicht nur auf Rollenvorgaben reagiert, sondern die Selbstwirksamkeit, die Selbstbestimmung, die Selbstorganisation oder anders: der Gestaltungsspielraum, das Autonome in das Scheinwerferlicht gerückt wird.

Eingebettet in die Selbstkonzeptforschung stellt die Selbstdarstellung die Präsentation des Selbstbildes nach außen für andere dar. Unter IM wird ein größeres Bündel an Taktiken und Techniken der Selbstinszenierung zusammengefasst. Dieses ,Bündel ${ }^{‘}$ lässt sich beschreiben als ein mit der Absicht einer Eindruckssteuerung zusammengestelltes Ensemble von symboltragenden Dingen und Handlungen, das - zumindest in Teilen absichtlich inszeniert - als Botschaft interpretierbar ist. ${ }^{102}$ Das gesamte Portfolio an mit IM in Verbindung stehenden Kommunikationsformen, das im Folgenden zu diskutieren sein wird, lässt sich auf unterschiedlichen ,Manifestationsebenen' beobachten: Analoge Kommunikation, Gestik, Mimik, Blick und Haltung ( $\Rightarrow$ II.1.4), symbolische Selbstergänzung, Hobbies, Lebensstile, Habitus $(\Leftrightarrow I I .1 .5)$ uvm. spielen - zumal für Genazino - eine ebenso wichtige Rolle, wie es verbalsprachliche Formen tun.

Die Begriffe ,Selbstpräsentation/-inszenierung‘ bzw. ,Eindruckssteuerung‘ legen zwar die Vorstellung nahe, es ausschließlich mit bewusstem Taktieren zu tun zu haben, IM läuft indes großenteils auch permanent, unkontrolliert, automatisch ab:

99 Vgl. für einen ähnlich gelagerten Fall auch Sorgen, S. 250, sowie für komplexe und indizienreiche, letztlich aber klar gemutmaßte IM-Reflexionen Kassiererinnen, S. 64 f.

100 Aronson/Wilson/Akert: Sozialpsychologie, S. 154.

101 Mummendey: Psychologie der Selbstdarstellung, S. 128. Vgl. auch ders.: Selbstdarstellung, S. 50, für eine leicht modifizierte Definition.

102 Vgl. Ernst-Dieter Lantermann: Selbstbehauptung in unübersichtlichen Zeiten. Unveröffentlichtes, unpaginiertes Skript zur Vorlesung am 07. Dezember 2009 im Rahmen der Vorlesung „Psychologie der Selbstinszenierung“ im WiSe 2009/2010 an der Universität Kassel. 
Impression management, or image control, is a central aspect of interpersonal relations. Consciously or unconsciously, people attempt to control images in real or imagined social interactions. By doing so, they define the nature of the interaction, the identities they and others possess, and the meanings of their interpersonal actions. What people believe they ,are' and the outcomes they receive from social life are both predicated in large part on impression management. ${ }^{103}$

Der Widerspruch zwischen Steuerung und Unbewusstheit ist dabei nur ein scheinbarer:

Although concerns about how one is perceived and evaluated by others are prevalent in everyday life, people are not always attuned to what others might be thinking about them, and do not direct all of their behaviors toward creating an impression. Situational and dispositional factors interact to determine how attentive people are to information how they are coming across to others. [...] In general, people appear to process others' impression-relevant reactions at a preattentive or nonconscious level. Without consciously considering how others might be perceiving them, people nonetheless scan the social environment for information regarding how others regard them. [...] Furthermore, because many patterns of self-presentation are overlearned, habitual, and unconscious (Hogan, 1982; Hogan et al., 1985; Schlenker, 1980), people sometimes engage in impressionrelevant behavior with little attention to what they are doing. ${ }^{104}$

So gibt es nicht nur individuelle Faktoren, die die diesbezügliche Selbstüberwachung (impression monitoring) beeinflussen - etwa die Neigung zur öffentlichen oder privaten Selbstaufmerksamkeit ${ }^{105}(\Leftrightarrow I I .2 .4)$-, sondern auch bestimmte Situationen - man denke an Flow-Erlebnisse während des Sports, Ekstase ${ }^{106}$ u. a. -, die die Motivation, überhaupt IM zu betreiben (impression motivation), minimieren. 107

Damit ist die Grenze zur zweiten Frage überschritten: Wozu das Ganze? „Because the impressions people make on others have implications for how others perceive, evaluate, and treat them, as well as for their own views of themselves, people sometimes behave in ways that will create certain impressions in others' eyes."108 Leary/Kowalski, die zwischen der Motivation, überhaupt IM zu betreiben (impression motivation), und der konkreten Ausgestaltung (impression construction) unterscheiden, führen folgende Motivationsgründe an ( $\Rightarrow$ I.3.1): „Social and material outcomes“, „Self-esteem maintenance“ und "Development of identity“.109 Zwar sei es die Grundmotivation allen menschlichen Verhaltens, Belohnungen zu maximieren und Bestrafungen zu minimieren, sodass diese Grundannahme auch für die erste von drei Motivationen für IMVerhalten anwendbar sei:

103 Barry R. Schlenker: Impression management. The self-concept, social identity, and interpersonal relations. Monterey (CA) 1980, S. V; Herv. N. L.

104 Leary/Kowalski: Impression Management, S. $36 \mathrm{f}$. Wie in psychologischer Fachkonvention üblich, weisen die hier zitierten Texte eine hohe Dichte an wiederum zitierten Studien auf. Da allerdings nicht fremde Federn für das Literaturverzeichnis gesammelt werden sollen, tauchen die nicht weiter im Fließtext thematisierten Forscher und Forscherinnen nicht dort auf. Vgl. Leary/Kowalski: Impression Management, S. 36.

Vgl. Leary/Kowalski: Impression Management, S. 36.

Vgl. auch Jones/Pittman: Toward a General Theory of Strategic Self-Presentation, S. 234. Vgl. für ein diesbezügliches Genazino-Pendant etwa Falsche Jahre, S. 480.

Leary/Kowalski: Impression Management, S. 34.

Leary/Kowalski: Impression Management, S. 37. Vgl. für eine alternative Erklärung der Motivation Lorenz Fischer/Günter Wiswede: Grundlagen der Sozialpsychologie. 3. Aufl. München 2009, S. 416418. 
The use of impression management in the acquisition of desired social and material outcomes has been widely studied and well documented (Schlenker, 1980; Tedeschi, 1981). However, the fact that people often are concerned with how others perceive them even when no immediate or future outcomes depend on the impressions they make suggests that other factors may motivate impression management. 110

Der erste von diesen zwei ,anderen Faktoren', der nach Leary/Kowalski für impression motivation verantwortlich sein kann, ist die Aufrechterhaltung bzw. Verbesserung des Selbstwertgefühls („maintain and enhance [...] self-esteem“), ${ }^{111}$ also der Beurteilung des eigenen Selbstkonzepts. Dieser Faktor kann hinsichtlich der Motivation, IM anzuwenden, auf zwei Weisen wirksam werden:

First, others' reactions to the individual may raise or deflate self-esteem. Compliments, praise, and indications of liking serve to enhance self-esteem, whereas criticism and rejection deflate it. As a result, people often try to make impressions that will elicit esteem-enhancing reactions, particularly when they expect feedback from others (D. J. Schneider, 1969).

Second, self-esteem is affected by people's self-evaluations of their performances and others' imagined reactions to them. People may perceive they have made a good or bad impression and experience resulting changes in self-esteem in the absence of explicit or implicit feedback from others (Darley \& Goethals, 1980; Filter \& Gross, 1975; Reis \& Gruzen, 1976).112

Insbesondere der zweite Punkt ist mit dafür verantwortlich, dem Kapiteltitel zum Blick der anderen auf das eigene Selbst ein eingeklammertes ,imaginiert' zur Seite zu stellen $(\Rightarrow$ I.2.4). Dass die Selbstbewertung der eigenen Darstellung ex post in der Nach-Handlungsphase $(\Rightarrow$ I.3.1) nicht nur für Fräulein Else $(\Rightarrow$ I.1), sondern auch für Genazinos Basistypus eine wichtige Rolle spielt, wird zum Ende dieses Unterkapitels diskutiert.

Als dritte Meta-Motivation benennen die Autoren die Identitätsentwicklung, die eng mit dem Konstrukt der symbolischen Selbstergänzung („symbolic self-completion“) einhergeht ( $\Rightarrow$ II.1.5).113 Um der Gesellschaft zu zeigen, dass man bestimmte Rollenidentitäten auch tatsächlich hat,

people sometimes ,self-symbolize', that is, engage in public behaviors that indicate the possession of identity-relevant characteristics. For example, a new assistant professor can solidify his or her identity as an academician by behaving like a faculty member ,should' behave. ${ }^{114}$

Es handele sich zwar um abgrenzbare, aber prinzipiell sich auch überlappen könnende Motivationslagen. ${ }^{115}$ Dass es sich in jedem Fall um höchst abstrahierte und zugleich um eine unvollständige Liste handelt, wird evident, wenn man sich in die neuere und neueste IM-Forschung vertieft: Solga etwa identifiziert allein für defensives IM (s.u.) fünf „soziale[] Funktionen [...], die als Zwecke höherer Ordnung nicht mit den bewussten oder gar taktischen Zielsetzungen des Ak-

110 Leary/Kowalski: Impression Management, S. 37.

111 Leary/Kowalski: Impression Management, S. 37.

112 Leary/Kowalski: Impression Management, S. 37.

113 Dass symbolische Selbstergänzung und Selbstdarstellung mitunter einander entgegengesetzt werden, diskutieren Leary/Kowalski: Impression Management, S. 38, und liefern auch prompt ein Argument, es nicht zu tun - wie auch hier verfahren wird.

114 Leary/Kowalski: Impression Management, S. 38.

115 Vgl. Leary/Kowalski: Impression Management, S. 38. 
teurs zu verwechseln sind“, von denen vier nicht ohne weiteres unter Learys und Kowalskis drei subsumiert werden können:

Aufrechterhaltung kognizierter Kontrolle, also der generellen Überzeugung, bedeutsame Ereignisse beeinflussen und kontrollieren zu können [...] [,] Aufrechterhaltung von joint action (d. h. eines reibungslosen Ablaufs der Dinge) in kurzfristigen Interaktionsprozessen [...] [,] Vermeidung sozialer Konflikte bzw. einer Eskalation derselben [...] [,] Stabilisierung langfristiger Interaktionsbeziehungen und Stabilisierung der sozialen Ordnung $[\ldots] . .^{116}$

Solch eine Spezifizierung, wie sie Solga im Rahmen seiner 2007 veröffentlichten Dissertation Defensives Impression Management in Einstellungsinterviews: Effekte verantwortlichkeitsbasierter Rechenschaftskommunikation auf Urteilsprozesse des Interviewers vornehmen kann, ist freilich ohne einen soliden Forschungsstand zu einzelnen Aspekten von IM nicht möglich, der teilweise erst deutlich nach 1990 konstituiert worden ist, weswegen hier zumindest ein kurzer, unvollständiger und selektiver Überblick gegeben werden soll. Dieser Blick zurück kann für die künftigen Schritte nach vorne nur bereichernd sein.

Zu Beginn der 1980er Jahre, also erst mit ca. zwanzigjähriger Verspätung bezogen auf Goffmans Wir alle spielen Theater (ersterschienen 1959), erlebt die IM-Forschung einen ersten Höhepunkt, nachdem in den 1960er Jahren „[e]in motivationaler Ansatz wie der des Impression Management [...] umstritten [war] und [...] als Manipulation interpretiert" worden ist:117 Barry R. Schlenker legt 1980 mit der Monografie Impression Management. The Self-Concept, Social Identity, and Interpersonal Relations eine erste systematische und umfassende Studie vor, die sich, wie der Titel nahelegt, zwar bereits darauf hat verlassen können, dass der Ansatz eine ,kritische Masse an Befürwortern oder zumindest Kennern gefunden hatte, sich allerdings noch nicht von der Bühnenmetaphorik Goffmans hatte lösen können. ${ }^{118}$ Wenig später unternehmen Jones/Pittman (1982) den vollmundigen Versuch, mit „Toward a General Theory of Specific SelfPresentation“ einerseits in Aufsatzlänge Allgemeines zu postulieren, andererseits auch konkrete Techniken und Taktiken zu untersuchen, womit neben der Veröffentlichung von Tedeschi

116 Marc Solga: Defensives Impression Management in Einstellungsinterviews: Effekte verantwortlichkeitsbasierter Rechenschaftskommunikation auf Urteilsprozesse des Interviewers. Dissertation Universität Bonn 2007, S. 27. Online: <https://d-nb.info/98646709X/34>.

117 Christian B. Brunner: Portfolio-Werbung als Technik des Impression Management. Eine Untersuchung zur gegenseitigen Stärkung von Dachmarke und Produktmarken in komplexen Markenarchitekturen. Dissertation Universität Gießen 2010, S. 33; vgl. Leary/Kowalski: Impression Management, S. 35. Die Impression-Management-Forschung kennt zwei unterschiedliche Perspektiven auf eindruckssteuerndes Verhalten: Der "restriktive Ansatz beschreibt selbstdarstellendes Verhalten als taktisch und manipulativ", die „expansive Perspektive hebt den universellen und alltäglichen Charakter selbstdarstellenden Verhaltens hervor" (Solga: Defensives Impression Management in Einstellungsinterviews, S. 22). Diese Arbeit wird einer wertneutralen Sicht verhaftet sein, wobei einzelne Figuren durchaus wohlweislich kalkuliert handeln und das nicht immer moralisch einwandfrei. Impression Management als Konstrukt jedenfalls ist zunächst weder gut noch böse, sondern ein beschreibbares und allgegenwärtiges Phänomen in Gesellschaft und Literatur. Vgl. Brunner: PortfolioWerbung als Technik des Impression Management, S. 32 ff., für einen umfassenden Forschungsüberblick.

118 Mit Kapitelüberschriften wie „Setting the Stage“, „The Actor“ und „The Curtain“ wird explizit auf die Theatrum-Mundi-Vorstellung referiert. 
$1981^{119}$ der Versuch im Vordergrund steht, spezifische Verhaltensweisen als Unterkategorien der Theorie abzuleiten.

Die 1990er Jahre bringen dann bereits erste Überblicksstudien hervor, um die rege Forschung zu ordnen. Leary und Kowalski fügen der bisherigen Forschung die elementar wichtige Unterscheidung von Warum („impression motivation“) und Wie („impression construction“) hinzu. Ihre Publikation „Impression Management: A Literature Review and Two-Component Model“ (1990) ist also mittlerweile bereits im wissenschaftsgeschichtlichen Stadium angekommen, die vorliegende Forschung hinsichtlich Übereinstimmungen und Widersprüchen zu systematisieren. Sie problematisieren die widerstreitenden Begriffsverwendungen und fassen IM mehrdimensional: von verbalen Äußerungen bis hin zu bevorzugtem Essen und bringen damit die Lebensstilverknüpfung mit rein ( $\Rightarrow$ II.1.5). Außerdem reagiert in den Neunzigern auch die deutschsprachige Forschung: Mummendey, der vorab bereits gut vernetzt in der IM-Forschung gewesen ist, veröffentlicht 1990 die Monografie: Psychologie der Selbstdarstellung - ein Standardwerk. Gegen Ende des Jahrzehnts (1998) formuliert Schütz in ihrem Artikel „Assertive, Offensive, Protective and Defensive Styles of Self-Presentation: A Taxonomy" eine der überzeugendsten Taxonomien von IM-Techniken und -Taktiken (s.u.). Schütz bekräftigt nicht nur Leary/Kowalski hinsichtlich der unterschiedlichen kognitiven Aufmerksamkeit hinsichtlich der Selbstdarstellung und das Wechselspiel von Persönlichkeitsmerkmalen und bevorzugter IM-Dimension in Abhängigkeit vom Erlernen; sie diskutiert außerdem sehr aufschlussreich die Wechselwirkungen zwischen personalen und situativen Aspekten. Negatives IM (self-handicapping, intimidation etc.) wird nur am Rande betont; das wird die Forschung erst ein Jahrzehnt später für sich entdecken.

Seit den Nullerjahren des dritten Jahrtausends lassen sich hinsichtlich der IM-Forschung nur noch Tendenzen ausmachen: Neben einer zunehmenden Ausdifferenzierung und einer Empirisierung im Sinne der Anwendung 120 fällt besonders der Impetus einer In-Bezug-Setzung von IM mit anderen Theorien ins Auge: Turnley/Bolino 2001 gehen in ihrem Beitrag: „Research Report. Achieving Desired Images While Avoiding Undesired Images: Exploring the Role of SelfMonitoring in Impression Management", der Hypothese nach, ob Menschen, die eher zum selfmonitoring neigen auch effektiver IM betreiben als Menschen mit niedriger self-monitoringAusprägung. Kurz: Ja: ,Selbstüberwacher' greifen nicht nur häufiger auf IM zurück, sondern sind auch erfolgreicher in der Evokation bestimmter Fremdbilder. Außerdem schauen Turnley/Bolino im Vergleich zu anderen Studien auch auf möglicherweise negativ wahrgenommenes IM.

Seitdem IM - spätestens seit Mitte der Nullerjahre - einen festen Platz in den Handbüchern und Standardeinführungen der Psychologie hat, tröpfeln die aktuellsten Forschungsergebnisse peu à peu auch in die Seminare sowie die anderen Fachbereiche. Erwähnenswert für diese Arbeit sind

119 Vgl. James T. Tedeschi: Impression management theory and social psychological research. New York 1981.

120 Das ist eine mögliche Erklärung für die Schwemme an Ratgeberliteratur (s.u.). 
118 - Teil I: Grundlagen 3. Handlungsmotivation und Eindruckssteuerung

schließlich Mummendey (2006) für den wiederaufgegriffenen Forschungsfaden, wie unterschiedliche Taktiken in Kombination zu IM-Sequenzen weitergedacht werden können; Solga (2007), der neben einer ,Rehabilitierung' des zwischenzeitlich wieder in die Manipulationsecke gerückten IM auch eine akribische Untersuchung des häufig unbelichteten Sektors des defensiven IM leistet (s.u.); Fischer/Wiswede 2009,121 die relativieren, dass IM die einzige Theorie ist, sich selbst positiv darzustellen (auch: symbolische Selbstergänzung etc.), und den wichtigen Zusammenhang von IM und Selbstüberwachung kanonisieren.

\section{ZWEI (MAL ZWEI) TYPOLOGIEN IM WIDERSTREIT}

Konsens besteht in der Literatur dahingehend, dass „man einerseits zwischen langfristigen ,Strategien' und kurzfristigen ,Taktiken' der Selbstdarstellung unterscheiden“ kann. ${ }^{122}$ Als Beispiel für eine Strategie nennt Mummendey in diesem Zusammenhang eine Schönheits-OP, für eine Taktik das Schminken. ${ }^{123}$

Andererseits lässt sich eine Unterscheidung zwischen ,assertiven' und ,defensiven' ImpressionManagement-Techniken treffen: Assertive Techniken zielen darauf ab, von anderen Personen Vorteile zu erhalten, bei einer defensiven Impression-Management-Technik geht es jemandem vorrangig darum, seine Identität zu schützen und zu bewahren. ${ }^{124}$

Da laut Mummendey „[d]ie Kombination von Impression-Management-Techniken, die sich aus den Dimensionen ,strategisch - taktisch“ und ,assertiv - defensiv' bilden ließe, also die Einteilung in vier Impression-Management-,Typen', [...] sich nicht als widerspruchsfrei erwiesen“ habe, empfiehlt er die Unterteilung in ,positive` und ,negative` Techniken: „Mit einer positiven Darstellung der eigenen Person versucht man, ganz direkt Eindruck zu machen“, hingegen könne man

[v]on negativen Formen des Impression-Management [...] sprechen, wenn jemand sich selbst (zunächst) herabsetzt oder ungünstig präsentiert; dabei kann impliziert sein, dass er (letztlich) einen Vorteil erwartet - es handelt sich also um eine indirekte Form positiver Selbstdarstellung [...]. ${ }^{125}$

Astrid Schütz, die 1998 dennoch eine sinnige 2x2-Systematisierung vorgeschlagen hat, obwohl sie sich der Kritik Mummendeys, die dieser erstmals 1990 geäußert hatte, durchaus bewusst gewesen sein muss, umgeht insofern die Kritik, als sie ihre Typologie nicht auf der Skala von strategisch - taktisch aufbaut, sondern die bei Mummendey (in Rückgriff auf Tedeschi und andere) bereits angelegte von assertiv vs. defensiv in die Quadranten II und IV legt und für die Quadranten I und III neue Füllungen vorschlägt. ${ }^{126}$ Sie gründet ihre Taxonomie also einerseits auf den zwei unterschiedlichen Arten der Intentionalität (verbessern vs. schützen), kombiniert diese

\footnotetext{
121 Vgl. Fischer/Wiswede: Grundlagen der Sozialpsychologie, S. 407-418 u. S. 470-473.

122 Mummendey: Selbstdarstellung, S. 52.

123 Vgl. Mummendey: Selbstdarstellung, S. 52.

124 Mummendey: Selbstdarstellung, S. 52.

125 Mummendey: Selbstdarstellung, S. 53.

126 Nota bene: Die Quadrantennummer bezieht sich auf ,übliche' Koordinatensysteme, die gleich folgende Nummerierung auf die Reihenfolge bei Schütz: Self-Presentation.
} 
dann aber mit den - ebenfalls bei Mummendey teilweise angelegten - zwei Stufen der Aktivität (positiv vs. negativ/direkt vs. indirekt/aktiv vs. passiv).127 Die Frage, warum Mummendey diese Verknüpfung nicht selbst vorgenommen hat, kann nicht beantwortet werden; möglicherweise ist mit der Forschungskritik an den eben beschriebenen IM-,Typen` für ihn jedwede Zwei-mal-zweiTeilung zum Scheitern verurteilt. Nichtsdestotrotz erfreut sich das Modell von Schütz weitgehender Akzeptanz und wird im Praxisteil dieser Arbeit als Referenzsystem für IM-Techniken und -Taktiken dienen.

\section{(ERWEITERTES) MODELL NACH SCHÜTZ}

Als planvoll rezipiertes und somit vermeintlich intendiertes Handeln lassen sich so mit Schütz vier distinkte Stile des IM taxieren:
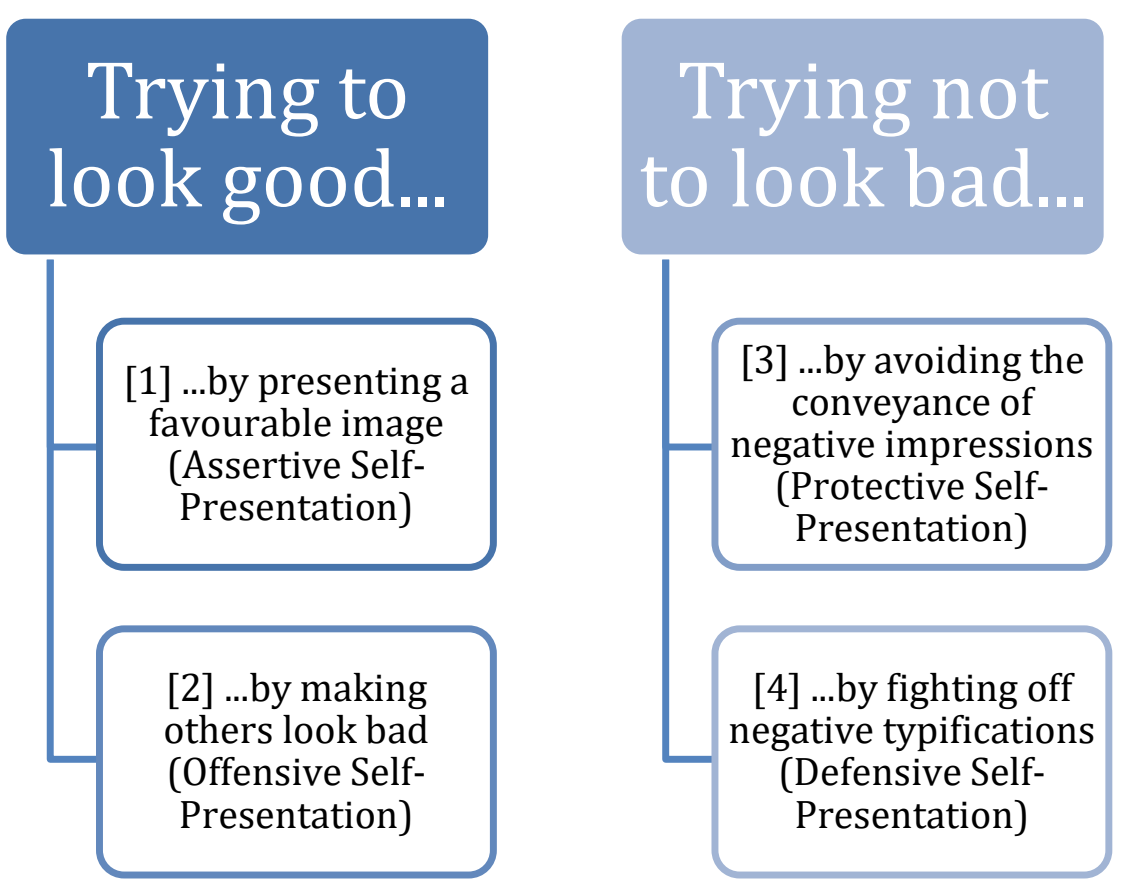

Abbildung 5: Zwei-mal-zwei-Taxonomie des Impression Managements (nach Schütz) ${ }^{128}$

Die Dimensionen [1] und [2] entsprechen sich also darin, das Bild verbessern zu wollen, wohingegen im Vergleich bei [3] und [4] die Intentionalität im Bewahren bzw. in der Restitution des Status quo liegt. Beides kann dabei aktiver ([2] und [4]) oder passiver ([1] und [3]) vonstattengehen. Wichtig ist, dass Schütz mit ,aktiv‘ eher ein „outgoing, aggressive behavior“, mit ,passiv‘

127 Vgl. für in Schütz’ Schema nicht explizit berücksichtigte, teils aber implizit verarbeitete „Beschreibungskriterien und Klassifikationsansätze“ Solga: Defensives Impression Management in Einstellungsinterviews, S. 26.

128 Eigene Visualisierung von Schütz: Self-Presentation, welchselbe ohne Veranschaulichung auskommt. 
120 - Teil I: Grundlagen 3. Handlungsmotivation und Eindruckssteuerung

ein „conservative“ Verhalten umschrieben wissen will129 - Aktivität und Passivität also den alltagssprachlichen Konnotationen des Wertgefüges von extraversiv vs. introvertiert entgegenstehen. Konkret lassen sich diese IM-Typen wie folgt beschreiben:

[1] „Bei der assertiven Technik ist ein Individuum aktiv darum bemüht, ein positives Fremdbild aufzubauen“, „versucht, den Einfluss auf andere Personen zu erhöhen und möchte, dass man ihm bestimmte Attribute zuschreibt".130 Die Person/die Figur möchte sympathisch wirken durch Komplimente, konforme Ansichten etc., sie stilisiert sich selbst als Vorbild, indem sie anderen hilft oder zu helfen vorgibt und Aufgaben erledigt; kurz: Die in Frage stehende Figur weist auf eigene Vorzüge hin und betreibt ,Eigenwerbung'.

[2] Offensiv nennt Schütz ein Verhalten, bei dem andere direkt abgewertet werden, um selbst positiver - in Relation - wahrgenommen zu werden. Andere werden dementsprechend ironisch bloßgestellt, harsch kritisiert etc.

[3] Protektiv verhält man sich, wenn man das Fremdbild, das ohnehin besteht, bewahren will, respektive nicht verschlechtern möchte. Passivität ist das Schlagwort: Man bzw. Figur kann, um nicht negativ aufzufallen, in einer Diskussion den Mund oder sich selbst im Hintergrund halten (vgl. Kassiererinnen, S. 63).

[4] Defensives IM liegt dann vor, wenn das ,Image‘ bereits aufgrund eines negativen Ereignisses beschädigt ist: Man kann letzteres zunächst einmal anerkennen oder nicht, kann, sofern man es dementiert, einen anderen Hergang konstruieren (,So war das ja gar nicht!'), oder komplett ableugnen (,Das ist nie passiert!'). Wenn das Ereignis als real akzeptiert wird, kann man hinwiederum sagen, man sei es schlichtweg nicht gewesen (Ja, das war so, ich war es jedoch nicht.'), bzw. die Eigenverantwortung in Zweifel ziehen (Ja, so war das, ich handelte zwar, bin aber gar nicht verantwortlich.'). Graduell grundverschieden kann man natürlich auch eine ,Strategie‘ verfolgen, die in etwa lautet: ,Ja, das war so, ich war das, ich bin auch verantwortlich, aber: ich habe das getan, weil...', und dergestalt eine Rechtfertigung einleiten. Und schließlich gibt es die defensiv(st)e Variante, bei der jemand sagt: ,Ja, so war das, ich war das, ich bin verantwortlich, es tut mir leid!' Über ein derart reumütiges und selbstattribuiertes Schuldzugeständnis lässt sich auf ,Entschuld(ig)ung' hoffen. ${ }^{131}$

Um dieses Modell für die künftige Arbeit fruchtbar zu machen, ist dafür zusätzlich eine Auflistung genauer, identifizierbarer Techniken und Taktiken der jeweiligen Strategie vonnöten: Andernfalls bliebe die Aussage, ,Protagonist A verhält sich protektiv', doch ein wenig holzschnittartig.

\footnotetext{
129 Schütz: Self-Presentation, S. 613.

130 Brunner: Portfolio-Werbung als Technik des Impression Management, S. 38.

131 Letzteres Verhalten wird üblicherweise in westlich-christlich-demokratischen Kulturkreisen als sympathischste defensive Möglichkeit gewertet.
} 
Aufgrund des angesprochenen Dissenses zwischen einer Zweiteilung vs. einer Zwei-mal-zweiTeilung, existieren in der Literatur unterschiedliche Aufzählungen, die in der folgenden synthetisiert werden. ${ }^{132}$ Zur übersichtlicheren Darstellung zunächst eine Kurzfassung als Abbildung:

132 Zwar wird im Rahmen dieser Arbeit prinzipiell der Rekurs auf die Vierteilung forciert und auch davon ausgegangen, dass in den Schlaglichtern zwei bis vier einzelne dieser Taktiken überwiegen, aber die aus der Systematisierung entstandene Unvollständigkeit der Listen bei Schütz nur der Bevorzugung ihres Modells halber in Kauf zu nehmen, hieße, sich selbst hinsichtlich der Beschreibungskategorien zu beschneiden. Deshalb werden - nach Tilgung der Dopplungen - etwa Mummendeys positive vs. negative Formen dieser Liste einverleibt sowie diejenigen zusätzlichen Kategorien von Brunner (vgl. ders.: Portfolio-Werbung als Technik des Impression Management) übernommen. Diese hat er bereits auf die vier Schütz'schen Ausprägungen zugeschnitten. Brunner geht den Weg, jede bei Schütz vorfindliche Klammer der genuinen Forscher in Primärnennungen zu übersetzen. Dies mag auf den ersten Blick wissenschaftlich redlicher erscheinen, als in dieser Studie verfahren wird. Allerdings muss erstens hinzugesetzt werden, dass Brunner jeweils verschweigt, diese Primärnennungen fast eins-zu-eins bei Schütz vorgefunden zu haben - so wie hier mit zitiert -, und zweitens, dass die Psychologie - bis auf Ausnahmen - keine wörtlichen von indirekten Zitaten trennt. Die Klammern hinter eigenen Aussagen wären also in jedem Fall daraufhin zu überprüfen, ob es sich um wörtliche oder sinngemäße Entlehnungen handeln würde. Die Psychologie kümmert das nicht - ist sie doch ihrem Selbstverständnis nach rein objektiv -, Brunner hingegen kümmert nicht wirklich, ob die jeweiligen Formulierungen von Schütz oder den primär Forschenden stammen, verändert die Reihenfolge der Listungen von Schütz und Mummendey und setzt zu $100 \%$ ein ,vgl.' davor. Was nun redlicher ist, entscheide der Leser. 


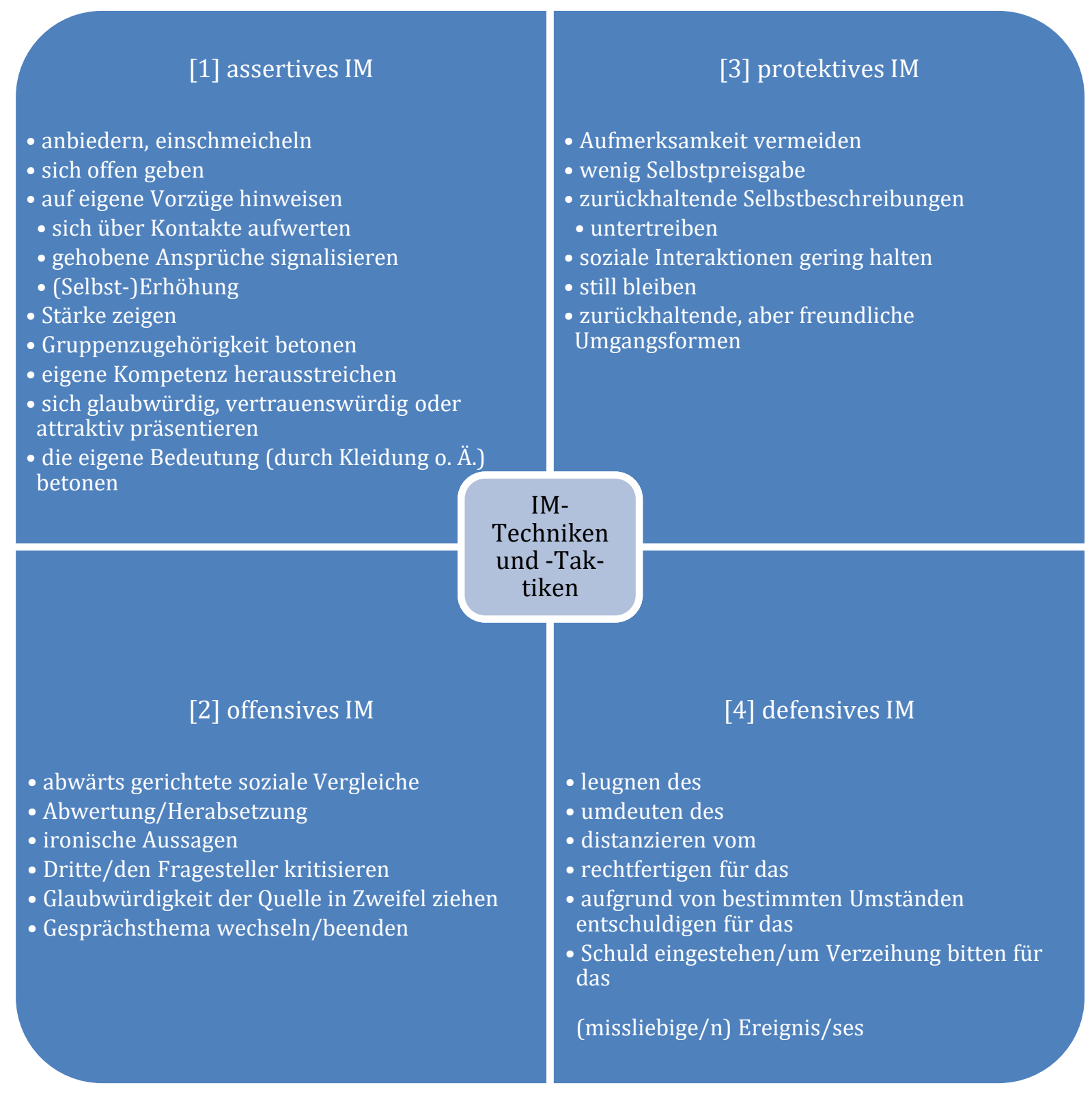

Abbildung 6: IM-Techniken und -Taktiken133

[1] Unter assertives IM lassen sich fassen:

- „Ingratiation [ anbiedern, einschmeicheln $\left.{ }^{134}\right]$. The ingratiator wants to appear likable by doing favors, complementing others, ${ }^{135}$ describing himself or herself favorably, or showing opinion conformity (Jones, 1964).“136

Vgl. Schütz: Self-Presentation, S. 614-619; vgl. Mummendey: Selbstdarstellung, S. 53 f.; vgl. Brunner: Portfolio-Werbung als Technik des Impression Management, S. 38-56.

134 Alle folgenden, näherungsweisen Übersetzungen verdanken sich unausgewiesen - sofern dort gelistet - Mummendey: Selbstdarstellung, S. 53 f.; Brunner: Portfolio-Werbung als Technik des Impression Management, S. 38-56, bzw. meiner Übersetzung. Die mitunter spannungsreichen Diskrepanzen zwischen den Begriffsverwendungen werden bewusst in Kauf genommen, um die unterschiedliche Akzentsetzung und die überlappenden Kategorisierungen, mithin: die wenig kanonisierte Forschung insgesamt augenfällig zu machen.

Mummendey: Selbstdarstellung, S. 53, spricht zudem von „other-enhancement“ [ anbiedern, einschmeicheln].

136 Schütz: Self-Presentation, S. 614. 
○ „[Man] gibt sich offen (self-disclosure)“.137

- „Exemplification [ als vorbildlich präsentieren]. Helping others, neglecting one’s own interests, or engaging in similar behavior represents a desire to appear morally worthy (Jones \& Pittman, 1982)."138

- $\quad$ „Self-promotion [ auf eigene Vorzüge hinweisen]. Showing successful performances or claiming such performances in the past are means of conveying the impression of competency to observers (Jones \& Pittman, 1982).“"139

$\circ \ldots$, ,B]asking in reflected glory“ [ sich über Kontakte mit wichtigen Personen, Gruppen und Ereignissen aufwerten] (Cialdini et al., 1976; Cialdini \& Richardson, 1980) refers to attempts to ,look good' by associating oneself with others who are evaluated positively". 140

○ „Using entitlements [ durch Selbstzuschreibung von Leistungen und Titeln gehobene Ansprüche signalisieren], people associate themselves with positive events (AbeleBrehm, 1989)“.141

○ „[W]ith enhancements [ (Selbst-)Erhöhung], they try to convince others that events with which they are already associated are more positive than they appear at first." 142

- Showing strength or ,power display“ [ Stärke/Macht zeigen/demonstrieren, um auf eigenes Potenzial zu verweisen] is an assertive tactic observed in studies on campaigning politicians' selfpresentation (Schütz, 1986, 1992). Politicians were found to present themselves as strong and powerful; unlike the tactic of ,intimidation' (Jones \& Pittman, 1982), a power display was not used to create fear in others but to assure potential voters that the candidate was in charge and able to achieve rewards for people. Showing strength thus appears to be the positive sibling of intimidation, in that the display of power is used to reassure observers of one's potential to create positive outcomes." 143

- „Identification [ (die selbst für positiv erachtete) Gruppenzugehörigkeit betonen] aims at emphasizing membership in a specific group that is evaluated positively by the actor. The technique includes verbal claims of membership and the use of ,symbolic self-completion' (Wicklund \& Gollwitzer, 1982; [ $\Rightarrow$ II.1.5]), such as references to one's tatoos and features of one's motorbike." 144

- $\quad$ „[Man] streicht eigene Kompetenz und Expertentum heraus (competence, expertise)“,145

- „präsentiert sich als [...] glaubwürdig (credibility), vertrauenswürdig (trustworthiness) oder attraktiv (attractiveness)“, 146

- „betont die eigene Bedeutung durch Kleidung und andere Symbole (status, prestige)“.147

An der Grenze zum offensiven IM findet sich bei Mummendey noch die Übertreibung „(overstatement)“. ${ }^{148}$

\section{[2] Offensives IM umfasst folgende Performanzen:}

- „As observers usually judge by comparison, one means of achieving a more positive evaluation is to make others with whom one is compared look less positive (Heider, 1958). ${ }^{149}$ Wills (1981) has termed such behavior ,downward comparison [ abwärts gerichteter sozialer Vergleich].' Cialdini

137 Mummendey: Selbstdarstellung, S. 53.

138 Schütz: Self-Presentation, S. 614.

139 Schütz: Self-Presentation, S. 614.

140 Schütz: Self-Presentation, S. 614.

141 Schütz: Self-Presentation, S. 614.

142 Schütz: Self-Presentation, S. 614 f.

143 Schütz: Self-Presentation, S. 615.

144 Schütz: Self-Presentation, S. 615.

145 Mummendey: Selbstdarstellung, S. 53; vgl. Brunner: Portfolio-Werbung als Technik des Impression Management, S. 47.

146 Mummendey: Selbstdarstellung, S. 53; vgl. Brunner: Portfolio-Werbung als Technik des Impression Management, S. $45 \mathrm{f}$.

147 Mummendey: Selbstdarstellung, S. 53; vgl. Brunner: Portfolio-Werbung als Technik des Impression Management, S. 53.

148 Mummendey: Selbstdarstellung, S. 53.

149 Mummendey spricht in diesem Zusammenhang davon, dass man „andere so [beurteilt], dass man selbst positiv abschneidet (boosting)“ (ders.: Selbstdarstellung, S. 53). 
and Richardson (1980) have shown that students rated the quality of their university's rival school less positively after they were given negative feedback of their own performance. This strategy, which the researchers have termed ,blasting the opposition [ direkte Abwertung anderer/der Opposition]', obviously serves self-enhancement purposes in the context of a failure experience. Buss and Dedden (1990) have called such behavior ,derogating competitors [ Herabsetzen von Wettbewerbern]." ${ }^{\prime 150}$

○ „[Man] bedroht andere oder schüchtert sie ein (intimidation)“.151

- „In the eyes of observers, ironic statements [ ironische Aussagen treffen, um als scharfsinnig zu gelten] create the impression of a sharp mind that sets tough standards of evaluation." 152

- $\quad$ „C]ritical evaluation of a third party [ Dritte kritisieren, um sich selbst als kompetent darzustellen] [...] [:] When people criticize the government for political errors or criticize the abilities of a football player, they make themselves appear competent in the relevant sphere because they seem to be able to make judgments or to know the proper solution." 153

- $\quad$ „In this offensive form of self-presentation [= criticizing the questioner] [ den Fragesteller kritisieren/an dessen Kompetenz zweifeln, um die Kritik zu minimieren], the actor criticizes a person who has posed a critical question. [...] Franz-Josef Strauss [...] once asked a journalist who posed a critical question whether he had finished high school."154

- „By attacking the source's competency or credibility [ die Kompetenz/Glaubwürdigkeit der (nicht notwendigerweise menschlichen) Quelle (Zeitung, Studie...) kritisieren, um vor anderen überlegen zu wirken], its criticism can be weakened and actors can manage to look superior to observers. This technique includes charges of incompetence and bias." 155

- „Another offensive technique has been named ,determining the topic of discussion [ (offensichtlich oder weniger offensichtlich) das Gesprächsthema zu wechseln/beenden suchen]' (Schütz, 1992). This form of self-presentation includes both attempts to change the topic of discussion and attempts to prevent others from changing the topic." 156

\section{[3] Protektives IM speist sich aus:}

- „Avoiding public attention [ die (öffentliche) Aufmerksamkeit anderer vermeiden]. Not being looked at prevents critical evaluation, so avoiding attention can be a means of trying to avoid criticism (Schlenker, 1987)."157 ( $\Rightarrow$ II.2.5)

- $\quad$ „Minimal self-disclosure [ möglichst wenig Selbstpreisgabe, um keine Angriffsfläche für Kritik zu bieten]. If one has to say something about oneself, the cautious approach is to say as little as possible (Schlenker \& Leary 1985), giving others little opportunity for criticizing." 158

- „Cautious self-description [ durch zurückhaltende Selbstbeschreibungen die Aufmerksamkeit nicht auf eigene Fähigkeiten lenken, um bei künftigem Misserfolg nicht am eigenen prinzipiellen Vermögen gemessen werden zu können]. People engaging in protective self-presentation try not to draw attention to their abilities and avoid the risks of positive self-presentation (Baumeister et al., 1989), which would expose them to the possibility of negative evaluation in the case of future failure. They rather reduce standards, use self-handicapping strategies (Baumgardner \& Arkin, 1987), describe themselves modestly, or even engage in self-depreciation (Arkin, 1981; Schlenker, 1987; Schlenker \& Leary, 1985). “159 ( $\Rightarrow$ II.1.3)

○ „[Man] untertreibt verbal (understatement)“, „stellt sich als hilfsbedürftig dar (supplication)“, ,zeigt oder betont Krankheitssymptome“. 160

- „Minimizing social interaction [ soziale Interaktionen aufgrund möglichen Fehlverhaltens und der damit einhergehenden negativen Beurteilung durch andere vorab gering halten]. The fear of misbehaving and consequently being evaluated negatively may result in avoidance of social inter-

150 Schütz: Self-Presentation, S. $615 \mathrm{f}$.

151 Mummendey: Selbstdarstellung, S. 53.

152 Schütz: Self-Presentation, S. 616.

153 Schütz: Self-Presentation, S. 616.

154 Schütz: Self-Presentation, S. 616.

155 Schütz: Self-Presentation, S. 616.

156 Schütz: Self-Presentation, S. $616 \mathrm{f}$.

157 Schütz: Self-Presentation, S. 617.

158 Schütz: Self-Presentation, S. 617.

159 Schütz: Self-Presentation, S. 617.

160 Mummendey: Selbstdarstellung, S. 53. Vgl. zum Understatement in der Liebesblödigkeit Dante A. Franzetti: Die große Kunst des Understatements. In: Der Standard vom 12. Februar 2005. 
actions (Arkin, 1981). Not interacting with others reduces the risk of leaving negative impressions, just as it reduces the chances of conveying favorable ones." 161

- „Remaining silent [ negative Zuschreibungen durch Still-Bleiben reduzieren]. When one says little or nothing in social interactions, there is little probability of saying something wrong - the risk of negative evaluation is reduced (Schlenker \& Leary, 1985)."162

- „Passive but friendly interaction [ zurückhaltende, aber freundliche Umgangsformen an den Tag legen, um andere zu gewogenen Einschätzung zu veranlassen]. Self-presentation in pleasant, friendly terms, including agreeing frequently with one's interaction partners may limit others to uncritical responses. (Schlenker \& Leary, 1985; Schütz, Schiepek, Richter, \& Köhler, 1997)."163

\section{[4] Defensives IM umfasst die Ausprägungen:}

- „Denial [ leugnen des (missliebigen) Ereignisses]. The main statement of this tactic is ,It did not happen.' Schönbach (1980) has called similar behavior ,refusals.' Maintaining one's position, one could then also question the trustworthiness of those who claim that a negative event occurred (which would be offensive self-presentation)." 164

- „Reframing [ umdeuten des (missliebigen) Ereignisses]. The person admits that a certain event has happened but argues that it should not be seen in a negative way. The main statement is ,It was different!' C. R. Snyder et al. (1983) framed this tactic as ,It was not so bad!'“165

- „Dissociation [ distanzieren vom/abstreiten der Beteiligung am (missliebigen) Ereignis]. The main statement is ,It was not me.' People using disassociation accept that a negative event has taken place, but affirm that they have not caused it. Tedeschi and Riess (1981) called this behavior ,denial of agency.' To strengthen the claim of not having caused a certain event, a person may name a scapegoat. He or she might even claim not to be associated with the event in question." 166 „Justification [ sich für das Ereignis rechtfertigen, ohne dieses und ohne die eigene Verursachung per se zu leugnen]. The main statement is ,It was legitimate' (Schönbach, 1980; Scott \& Lyman, 1968; Tedeschi \& Riess, 1981). Actors using justifications accept that they caused a negative event but claim that it was inevitable or justified and that they should not be blamed. They may even expect people to be grateful rather than angry, in view of the "fact' that they caused short-term inconvenience for the sake of long-term improvement."167

- Excuses [ sich aufgrund der Umstände für ein selbst verursachtes Ereignis entschuldigen]. The main statement of this tactic is ,I could not help it' (Schönbach, 1980; Scott \& Lyman, 1968; Tedeschi \& Riess, 1981). Actors using excuses accept responsibility for a negative event, but they put forward extenuating circumstances. They may claim that they could not control the event or did not foresee the consequences. Tedeschi and Riess (1981) listed lack of volition and lack of intention as major excuses. By using excuses, actors try to minimize negative inferences that might be drawn about their personality."168

- „Concessions, apologies, and remediation [ durch Eingeständnis, Entschuldigung und/oder in Aussicht gestellte Wiedergutmachung um Verzeihung bitten]. A final possibility is to take full responsibility for a negative event (Schönbach, 1980), show remorse, and ask for forgiveness (Tedeschi \& Riess, 1981), perhaps promising that it will not happen again. If remediation is offered in addition to apology, the effect is usually stronger than the effect of apology alone (Darby \& Schlenker, 1989). Apologies and remediation may save a person's image as honest and responsible, even though he or she may have to bear the consequences of being responsible for a negative event."169

Mummendey gliedert das defensive Verhaltensspektrum minimal anders und fasst

Schütz: Self-Presentation, S. $617 \mathrm{f}$. Schütz: Self-Presentation, S. 618. Schütz: Self-Presentation, S. 618. Schütz: Self-Presentation, S. 618. Schütz: Self-Presentation, S. 619. Schütz: Self-Presentation, S. 619. Schütz: Self-Presentation, S. 619. Schütz: Self-Presentation, S. 619. Schütz: Self-Presentation, S. 619. 
Taktiken, die sich auf Reaktionen auf negativ bewertetes eigenes Verhalten, meist in misslichen Lagen beziehen (predicaments), [...] unter dem Begriff des accounting zusammen[]. Man:

- entschuldigt sich für einen Fehler, drückt Bedauern aus (apology),

- streitet die Sache ab (defense of innocence),

- leugnet die Verantwortung (excuse),

- rechtfertigt sich (justification) oder

- spricht anderen das Recht ab, negativ zu urteilen (refusal).

Man kann sich auch, bevor eine missliche oder peinliche Situation eintritt, durch Widerrufen, Ableugnen, Dementieren, vorsorgliches Abschwächen (disclaimers) seiner Verantwortung entledigen $[\ldots] \cdot{ }^{170}$

Was nun ist mit diesem Wust an fein säuberlich auseinanderklamüserten Einzeltechniken anzufangen?

\section{ÜBERTRAGUNG AUF FIGUREN}

Überall wimmelt es von Untersuchungen der Selbstdarstellung/-inszenierung: Historische Persönlichkeiten, Stars, soziale Netzwerke im Internet, Homepageauftritte, Poetry Slams, Science Slams, Selbstkonturierungen einzelner Studiengänge, ganzer Nationen und auch der deutschen Jugendfeuerwehr usw. werden unter diesem Gesichtspunkt beleuchtet, die Ratgeberliteratur für den angehenden Medienprofi quillt aus den Regalen, ${ }^{171}$ autobiografische Zeugnisse oder dafür gehaltene namhafter Autoren - Kleist, Hölderlin, George, Franz Werfel, Sophie von La Roche, Wieland, Thomas Bernhard, Karl-Phillip Moritz, Varnhagen, Brecht, Jelinek, natürlich Goethe, Kästner, Waiblinger, Martin Walser, Walther von der Vogelweide; wer bliebe verschont? - werden auseinandergenommen.

Literarische Figuren davon abseits in den derart eingefärbten methodischen Blick zu nehmen, ist bisher weitgehend unterblieben, obwohl bereits Goffman seine Beobachtungen mit literarischen Beispielen illustriert hat, ${ }^{172}$ wie dies bekanntlich Freud bereits getan hatte. Und obwohl die Verquickung dieses ergiebigen Forschungsfelds mit literarischen Texten ertragreich zu sein verspricht, ist die Applizierung auf literarische Figuren bisher eher tentativ auf wenigen Druckseiten erfolgt. ${ }^{173}$ Roger H. Stephenson bspw. untersucht in seinem Aufsatz „The presentation of self

170 Mummendey: Selbstdarstellung, S. $53 \mathrm{f}$.

171 Schreckliche Blüten treibt diese gedankliche Saat in manchen Sparten der (Forschungs-)Literatur; alles und jeder wird auf seine ,Selbstdarstellung' und ,Inszenierungstaktik' hin untersucht: Sind es in der kulturwissenschaftlichen Literaturwissenschaft die medialen Inszenierungen von Schriftstellern usw., denen ein gesteigertes Interesse zuteilwird, so dürfen sich angehende Selbstmarketingexperten über Berge von vermeintlich ,ratgebender' Literatur freuen. Der Aspekt der strategischen Planung und selbstwirksamen Inszenesetzung wird dabei prononciert und überschattet jegliche analytisch-wertneutrale Beschreibung, da die Forschungsdiskussion zwischen expansiv und restriktiv (s.o.) geflissentlich, überlesen' wird (vgl. Gary Yukl: Leadership in Organizations. 7. Aufl. Upper Saddle River (NJ) 2010; vgl. Thomas Jendrosch: Impression Management. Professionelles Marketing in eigener Sache. Wiesbaden 2010): „Was früher nur für Unternehmen, Marken, Produkte und Stars wichtig war, nämlich gezielt ein positives und markantes Image aufzubauen, das verspricht heute auch im privaten Bereich einen wachsenden Nutzen." (Jendrosch: Impression Management, S. 7)

172 Vgl. Goffman: Wir alle spielen Theater, S. $8 \mathrm{f}$.

173 Eingrenzend muss gesagt werden, dass unter anderen Bezeichnungen zumindest Ähnliches unternommen worden ist. Kaja Papke etwa nimmt sich Mentalitäten, Habitusformen und ihre narrative 
in Goethe's Die Wahlverwandtschaften" 174 das Bestreben Ottilies, eine selbstbestimmte Persönlichkeit auszubilden, was indes wenig Schnittmenge mit der vorliegenden Arbeit aufweist. Dirk Windemuths Aufsatz „Selbstdarstellung in Alltagserzählungen als Technik des ImpressionManagements" ${ }^{175}$ bietet interessante Ansätze, insbesondere, wenn es darum geht, durch elaborierte Erzählungen über das eigene Selbst die Differenz von Selbst-, Ideal- und Fremdbild zu minimieren. Allerdings argumentiert der Autor eher, linguistisch“ und anhand eines Korpus, das aus ,faktualen' Alltagserzählungen besteht und daher die literarische Komponente von Texten außer Acht lässt. Jaakko Lehtonen legt schließlich überzeugend dar, dass IM - beeinflusst durch Werbung und Wirtschaft - stets unter Berücksichtigung der negativen Aspekte und des Hautgouts des potenziellen Missbrauchs zur Manipulation zu betrachten sei (s.o.). Sich einer moralischen Argumentation bedienend referiert er auf Kosten und Nutzen des verbalen und nonverbalen IM und skizziert psycholinguistische Gefahren von IM-Workshops etc. ${ }^{176}$

Systematische Überlegungen zur Verschränkung von Literatur(wissenschaft) und Impression Management liegen derzeit nicht vor, weswegen diese Arbeit einen ersten Schritt in diese Richtung wagen möchte, um das Konzept im Sinne eines Theorientransfers fruchtbar zu machen und zugleich Genazinos Texten eine zusätzliche Deutungsfacette bzw. alternative Lesart angedeihen zu lassen. Ohne es banalisieren zu wollen: Integraler Bestandteil einer jeden Interpretation literarischer Texte mit psychologisch hinlänglich ausgefeilten Figuren besteht in der Antwortsuche auf die Fragen nach den proximaten und ultimaten Handlungsursachen: Wozu handelt Instetten so und nicht anders? Warum überhaupt, welche kurzfristigen, welches langfristigen Ziele stehen damit in Verbindung? Was folgt daraus? Was sagt das Figurenverhalten für die Charakterisierung aus? Es sind Fragen, die sich allesamt darauf zurückführen lassen, wie, womit, wozu sich Figuren anderen gegenüber just auf diese Weise darstellen und ihnen gegenüber verhalten. Man kann sich nicht nicht verhalten; ${ }^{177}$ auch literarische Figuren werden von Watzlawick eingeholt: „Ich komme nur nicht damit zurecht, daß ich mich fortlaufend zu ihr verhalten muß.“ (Glück, S. 19) Verbal, durch Kleidung, Lebensstil, selbstergänzende Symbole etc. pp. Antworten auf diese

Gestaltung bei Heinrich Mann vor, was zumindest Schnittflächen mit dem hier angestrengten Vorhaben aufweist (vgl. dies.: Heinrich Manns Romane Die Jagd nach Liebe und Zwischen den Rassen. Mentalitäten, Habitusformen und ihre narrative Gestaltung. München 2007). Auch Gerhart von Graevenitz ist mit seiner veröffentlichten Vorlesung: Das Ich am Rande. Zur Topik der Selbstdarstellung bei Dürer, Montaigne und Goethe (1989) sicherlich zu nennen, wobei er zwar eindeutig mit dem Begriff ,Selbstdarstellung' arbeitet, aber etwas Grundlegend anderes als die vorliegende Arbeit im Blick hat, wie auch Rudolf Käsers Rhetorik der Selbstdarstellung in Texten des ,Sturm und Drang: Herder - Goethe - Lenz (1987) kaum Berührungspunkte aufweist.

174 Vgl. Roger H. Stephenson: ,Man nimmt in der Welt jeden, wofür er sich gibt': The Presentation of Self in Goethe's Die Wahlverwandtschaften. In: German Life and Letters 47 (1994), S. 400-406.

175 Vgl. Dirk Windemuth: Die Selbstdarstellung in Alltagserzählungen als Technik des ImpressionManagements. In: Zeitschrift für Germanistik 2 (1992), S. 128-137.

176 Vgl. Jaakko Lehtonen: Imagepflege und ,Impression-Management'. Verfall der Sprecherziehung oder eine Neuorientierung? In: Siegrun Lemke/Susanne Thiel (Hg.): Sprechen - Reden - Mitteilen. Prozesse allgemeiner und spezifischer Sprechkultur. München 1996, S. 50-56.

177 Vgl. Paul Watzlawick/Janet H. Beavin/Don D. Jackson: Menschliche Kommunikation. Formen, Störungen, Paradoxien. 11., unv. Aufl. Bern 2007, S. 50 ff. 
Fragen lassen sich extern - weil der Autor es so wollte, weil es die Rollenvorgabe diktiert etc. sowie intern formulieren $(\Rightarrow I .3 .1)$.

Wenn sich Fräulein Else zu Beginn von Schnitzlers gleichnamiger Monolog-Novelle fragt: „Sehe ich nun gnädig aus?", dann handelt es sich jedenfalls nicht um eine wertneutrale Selbstbeobachtung, sondern ganz offensichtlich um Kalkül, um den Wunsch, auf eine gelenkte Weise wahrgenommen zu werden:

Das war ein ganz guter Abgang. Hoffentlich glauben die zwei nicht, daß ich eifersüchtig bin. - Daß sie was miteinander haben, Cousin Paul und Cissy Mohr, darauf schwör' ich. Nichts auf der Welt ist mir gleichgültiger. - Nun wende ich mich noch einmal um und winke ihnen zu. Winke und lächle. Sehe ich nun gnädig aus? ${ }^{278}$

Derartiges motivationales Handeln - im Falle Elses lässt sich leider nur das Scheitern ihrer, als Selbstsicherung zu begreifenden, Handlungsstrategien ins Auge fassen - ist in der Realität wie in der Fiktion ubiquitär: Es eint literarische Genres, nivelliert epochale und sprachliche Demarkationslinien der Literatur. Das Genazino-Pendant zu Else, das neben der Nach-Handlungsphase $(\Leftrightarrow$ I.3.1) auch die zweite Meta-Motivation von Leary/Kowalski betrifft (s.o.), lautet etwa:

Ach Gott, denke ich, so einer ist Himmelsbach geworden. Er parfümiert sich kostenlos in Kaufhäusern und kommt sich wahrscheinlich noch raffiniert dabei vor. Ich sehe, es ist ein ältliches Gespenst aus ihm geworden, ein Pfft-Mann, der niemals seine Schulden bezahlen wird. Trotzdem gelingt es mir, meinem Blick die Schärfe zu nehmen, jedenfalls sekundenweise. Wenn Himmelsbach mich jetzt anschaut, muß er mich für milde halten. (Regenschirm, S. 22) ${ }^{179}$

Trotz der vollkommen unterschiedlichen Ausgangssituationen, literarischen Genres, Figurenzeichnungen etc. ist das Vergleichsmoment evident: Die Figuren bemühen sich darum, durch ihr habituelles Gebaren eine bestimmte Wirkung zu erzielen, die sich nach außen mit der Motivation, „gnädig“ bzw. „milde“ erscheinen zu wollen, nach innen mit der Wahrung des Selbstwertgefühls angeben lässt.

Im Sinne einer kurzen Zusammenfassung lässt sich konstatieren: Es gibt zahlreiche Begründungen für die Wahlverwandtschaft von Psychologie und Literatur(wissenschaft) $(\Leftrightarrow I .3 .2)$. Verbindende Glieder sind Handlungsmotivation und Figuren-Charakterisierung. IM-Forschung kann den Werkzeugkoffer des Textwissenschaftlers bereichern und an literarischen Texten als intern wie extern perspektiviertes Analysewerkzeug ( $\Rightarrow$ I.2.4) ${ }^{180}$ bei der Untersuchung literarischer Figuren zum Einsatz kommen. Auf Basis einzelner Ebenen - Sprache, non- und paraverbales Verhalten, Kleidung, Hobbies, symboltragende Gegenstände etc. - sind Einzelbeobachtungen in einen Gesamteindruck zu integrieren, welcher dann als Basis für eine Charakterisierung/Deu-

178 Schnitzler: Fräulein Else, S. 557; vgl. Lehnert: „Sehe ich nun gnädig aus?“, S. 192-195.

179 Vgl. auch: „Ich muß mich soweit bringen, sagte er, bis mein Kopf wieder wirklich mir gehört, und das gelingt mir am besten dadurch, wenn ich mich zerstreue. Er fand, das hatte er gut gesagt." (Sorgen, S. 264; Herv. N. L.)

180 Eine ,unmotivierte' Beleidigung, die eine Figur an eine andere richtet, kann extern als vom Autor an dieser Stelle aus kompositorischen Erwägungen erforderlicher Bruch einer Freundschaft gewertet werden, intern motiviert als Ausdruck von Unbeherrschtheit oder,Cholerik' $(\Rightarrow$ II.4.1). 
tung fungiert. 181 „Da Figuren im literarischen Text jedoch gegenüber der Wirklichkeit in ihrer Komplexität stark reduziert sind“, so die berechtigte Kritik, können sich Deutungen höchstens auf „alle dargestellten oder deutlich erschließbaren Figurencharakteristika“182 berufen ( $\Rightarrow$ I.2.4). Allein: Im IM-Fall insonderheit greift die Theorie diese Reduktion, diesen „prinzipielle[n] methodologische[n] Mangel aller ,realistischen' [nach der Realität, der Lebenswirklichkeit erfolgenden; N. L.] Interpretationen“, diesen „Daten-Mangel“ expressis verbis auf:183 Mittels einzelner Indizien wird eine kognitive Repräsentation des Images erzeugt werden: pars pro toto! Auch wenn man einen Menschen, auch wenn eine Figur eine andere nicht kennt; auf Basis der geringsten Information werden Typen-Schubladen geöffnet, wird man ein Bild, einen (ersten) Eindruck entwerfen (s.o.). ${ }^{184}$ Dies spiegelt sich selbstredend in der erzähltheoretisch-rezeptionsästhetischen Reflexion einer jeden figurenbezogenen Lektüre wider: „Der Autor kann sich bei der Evozierung ,seiner' Figuren recht weitgehend darauf verlassen, dass seine Vorgaben vom Leser (in der Regel: automatisch und unbewusst) ,komplettiert' werden. “185 Das liegt an der Neigung von Autoren, Lesern; an der Neigung von Lesern, Figuren; an der Neigung von Figuren, ihren ,Mitfiguren' - laut der postklassischen, kognitiven Narratologie - als ,Mind-Reader' eine ToM zuzuschreiben $(\Rightarrow I .3 .1)$.

Eingedenk dieser Begleitumstände lautet die hier vertretene These: Auch literarische Figuren verwenden verschiedene Strategien, Techniken und Taktiken des Impression Managements, vermittels derer sie sich - bewusst oder unbewusst - bemühen, auf andere und damit - direkt oder indirekt - auch auf sich selbst (vgl. Frauen, S. 139) einen ganz bestimmten Eindruck zu machen und gleichzeitig sich selbst oder andere zu einem bestimmten Verhalten zu veranlassen. Abschaffel etwa bedient sich mannigfacher eindruckssteuernder Verhaltensweisen, als er und eine Kollegin sich in einer auf einen dramatischen wie späterhin sexuellen Höhepunkt zusteuernden Szene annähern:

181 Es gibt eine ganze Palette an Beschreibungsformen für eindruckssteuerndes Verhalten: Licht unter den Scheffel stellen, schüchtern sein, prahlen und einige tausend mehr. Alle lassen sich in die Schütz-Taxonomie einordnen. Und sicherlich könnte man einwenden, dass die IM-Forschung lediglich systematisiere und in Worte fasse, was vorbewusst zur naiv-intuitiven Alltagsvorstellung gehört: Dass bestimmte Menschen/Figuren bestimmte Verhaltensstrategien haben, um bestimmte Ziele zu erreichen. Aber: Diese unzähligen Nuancen des Verhaltensspektrums literarischer Figuren lassen sich erst über ein methodisch tragfähiges Gerüst in größere Sinnzusammenhänge einordnen, in Strategien und Taktiken des Impression Managements überführen, mit dazugehörigen Stilaccessoires, Freizeitbeschäftigungen usw. garnieren, und schließlich auf Basis des Konstrukts in eine handlungsmotivationale Charakterisierung, in eine Text-Teilinterpretation überführen. Baasner: Literaturpsychologie/Psychoanalytische Literaturwissenschaft, S. 155 f.

Ter-Nedden: Psychologie und Literatur; zit. n. Hiebel: Zur Kritik der Literaturpsychologie, S. 59.

Vgl. Baasner: Literaturpsychologie/Psychoanalytische Literaturwissenschaft, S. 155 f.

185 Bode: Der Roman, S. 124. Dass dies nicht nur für Figuren, sondern auch für die übrigen „weißen Flecken in seiner Darstellung“ gilt, fasst Matthias Bauer wie folgt zusammen: „Wie schon die Phänomenologen bemerkt hatten, kann sich der Autor eines Romans bei seiner kartographischen Tätigkeit jederzeit auf das stumme Wissen der Leser verlassen, mit dem sie die weißen Flecken in seiner Darstellung überbrücken werden." (Bauer: Romantheorie, S. 216) 
Und jetzt stellen Sie sich mal vor, sagte er, da kommt so ein neunzehnjähriger Balkanlümmel hier an. [...] Er hatte Spaß daran, mit einer diskriminierenden Rede ihr Vergnügen hervorzurufen. Der weiß doch gar nicht, wo er zuerst hinsehen soll, sagte er. Frau Schönböck kicherte in ihr Erdbeertellerchen hinein und hörte überhaupt nicht mehr auf. Abschaffel wußte in jedem Augenblick, daß er nicht so war, wie er jetzt redete. Hätte er je eine Unterhaltung gehört wie die, die er nun selber führte, er hätte sich empört abgewendet. Und alle, die an solchen Unterhaltungen teilnehmen, hätte er zu den niederen Menschen gerechnet. Zum Glück konnte er im Augenblick nicht mehr nachdenken. Er wurde nur wütend auf Frau Schönböck [...]. Aus Wut empfand er Lust, Frau Schönböck für alles zu bestrafen, und als Strafe fiel ihm ein, sie in gemeiner Schnelligkeit zu vögeln und dann sofort nach Hause zu gehen. [...] Wenigstens schreien konnte er kurz, als es ihm kam, aber er fürchtete vielleicht doch heulen zu müssen. Ich befinde mich dauernd in Panik, weil ich nicht herausfinden kann, was ich will und was ich nicht will, dachte er hastig. [...] Er trug Frau Schönböck in ihr Bett, und sie wachte nicht auf. Dann löschte er das Licht und verließ die Wohnung. [...] Am folgenden Morgen war leider nicht Samstag oder Sonntag, sondern Donnerstag. Abschaffel mußte arbeiten. Er hätte einen Tag zu Hause bleiben können, um Frau Schönböck zu zeigen, daß er ihr aus dem Weg gehen wollte. Aber eine Störung dieser Art war ihm zu deutlich, obwohl er sich zugab, daß er nichts anderes wollte als die sofortige Distanzierung von Frau Schönböck. Als er um Viertel vor sieben im Bus saß, suchte er angestrengt nach einem Verhalten. Eine Weile spielte er sogar mit der Möglichkeit, Frau Schönböck als eine Art Betriebskonkubine zu behalten. [...] Erst im Büro bemerkte er, daß alles ganz anders geworden war. Frau Schönböck flirtete offen über mehrere Schreibtische zu ihm herüber. [...] Die Mattigkeit, mit der er ihre Signale erwiderte, richtete bei ihr nichts aus. Er wartete schon darauf, daß Ronselt oder Schobert die erste Bemerkung über diese neue Firmenliebe machten. [...] Wahrscheinlich glaubte Frau Schönböck lediglich, daß sie inmitten hektischer Liebkosungen eingeschlafen war, und dann war er auch noch so lieb gewesen und hatte sie in ihr Bett getragen und auch noch das Licht gelöscht. Wie vornehm, anständig und rücksichtsvoll von ihm. [...] Er wollte ohne Erklärung verschwinden. [...] Punkt halb zwölf verließ Abschaffel das Büro. Es kostete ihn Kraft, den Blick starr auf die Doppelglastür zu halten, als er den Weg durch den Großraum zurücklegte. [...] Schon kurz danach war klar, daß es ihm gelungen war, Frau Schönböcks Verhalten zu dämpfen. Sie war verwirrt und wahrscheinlich beleidigt. Abschaffel fühlte sich schlecht. Unvorhergesehen empfand er Mitleid. (Sorgen, S. 295-300)

Neben der negativen Evaluation des eigenen Verhaltens in der Nach-Handlungsphase $(\Rightarrow I .3 .1)^{186}$ und der als untypisch zu bewertenden Tendenz, trotz volitionaler Phasenzuordnung eine verhältnismäßig geringe selektive Aufmerksamkeit an den Tag zu legen, fächert sich diese Passage in viele Bereiche auf, die die bisherigen Ausführungen bebildern: Abschaffel malt sich Frau Schönböcks - aus externer Perspektive der Figurenanalyse sind die sprechenden Namen ${ }^{187}$ beider Figuren untersuchenswert - Gedankenwelt im Sinne einer ToM aus, es findet sowohl die Dichotomie ,bewusstes vs. unbewusstes‘ IM - „Zum Glück konnte er im Augenblick nicht mehr nachdenken“ - als auch diejenige, vor sich selbst vs. vor anderen' Verwendung, das faden zwischen Er- und Ich-Perspektive sowie die Entschleunigung des Erzähltempos lassen sich gut beobachten, akratisches Handeln (wider besseres Wissen) und rationales überblenden sich, direkte und indirekte Charakterisierungstechniken haben Anteil und schließlich kann die Szene sogar die Funktion eines Teasers für alle fünf Schlaglichter übernehmen. Mit der Thematisierung von Authentizität und Verstellung ( $\Rightarrow$ II.1.2) ist nämlich das erste, mit dem Widerstreit von Selbstund Idealbild $(\Leftrightarrow$ II.2.1), der gewünschten Unsichtbarkeit $(\Leftrightarrow$ II.2.5) und der kalkulierten Außenwirkung $(\Rightarrow$ II.2.4) das zweite, mit dem Bemühen, sich für jemanden interessant zu machen ( $\Rightarrow$ II.3), das dritte, mit der Herabsetzung und dem abwärtsgerichteten Vergleich qua negativen

186 Vgl. Rudolph: Motivationspsychologie, S. $160 \mathrm{ff}$.

187 Vgl. dazu Adolf Fink: Der Name als Schreib- und Verstehensprogramm. Onomastische Beobachtungen zu Wilhelm Genazinos Abschaffel-Trilogie. In: Giesen (Hg.): Wilhelm Genazino (2006), S. 28-36. 
bzw. offensiven IMs das vierte $(\Leftrightarrow$ II.4.4) und schließlich mit unterschiedlichen Aspekten zur Sexualität - Gender $(\Rightarrow$ II.5.3) etc. - das fünfte Schlaglicht vertreten. IM kann dabei eine zentrale Schaltstelle sein, um Figurencharakterisierung, Handlungsmotivation und Narratologie zu integrieren und zu dirigieren - im diskutierten Beispiel etwa in der Funktion ,Selbstwerterhalt' (s.o.). Es ist bereits gesagt worden, dass IM große Schnittflächen mit Selbstinszenierung/-darstellung aufweist. Wenn das so ist, dann müsste selbst bei einem kopulativ verstandenen Kompositum neben den Mechanismen der Darstellung und Inszenierung natürlich auch das erste Wort untersucht werden: das Selbst. Umso wichtiger, da es sich um ein Determinativkompositum handelt und mithin die Darstellung in der Wichtigkeit dem Selbst gar unterzuordnen ist! 


\section{Das Selbst: multipel, (post-)modern, zersplittert}

Dieses Kapitel schickt sich an, zweierlei Funktion für die vorliegende Arbeit zu übernehmen: Erstens versteht es sich als unabkömmlichen Rahmen, innerhalb dessen die für Genazino eminent wichtigen Fragen nach dem (post-)modernen Selbst und der Subjektivität generell zu diskutieren sind, ${ }^{1}$ zweitens knüpft es die bisherigen Fäden (Erzähltheorie, Figuren-Basistypus, IM) just an diese Verhandlung von Selbstkonzepten, Individualitätsreflexionen usw. und weist das Selbst als wichtiges Scharnier für die gesamte Arbeit aus.

\section{INDIVIDUUM? SUBJEKT? SELBST?}

Es gibt wenige schwieriger zu fassende Konzepte als dasjenige mit ,Selbst', ,Individuum', ,Ich', ,Subjekt', ,Persönlichkeit' oder anderen Signifikanten bezeichnete. ${ }^{2}$ Es ist wesentlich entweder nur intradisziplinär in Abhängigkeit vom Fach - Philosophie (besonders: Subjektphilosophie, Existenzialismus), Psychologie (Psychoanalyse aber auch Persönlichkeitspsychologie), Soziologie (Goffman, Elias, Weber) etc. - näherungsweise eingrenzbar oder aber - so Peter V. Zima „,nur im interdisziplinären Kontext, in dem Philosophie, Soziologie, Semiotik, Psychologie und Literaturwissenschaft zusammenwirken, konkret zu erfassen “. ${ }^{3}$ Diese Problematik soll nicht leichtfertig übergangen werden, doch der Zuschnitt auf Genazino, also wie das Selbst als Schnittstelle von Erzähltheorie, Figurenanalyse, Handlungsmotivation und IM konzeptualisierbar ist, muss pragmatisch über der Diskussion stehen, welche disziplinäre Begriffsverwendung und -definition jeweils zugrunde liegt. Vorzugsweise wird hier - sofern möglich - vom ,Selbst' als der ,internsten' Möglichkeit zu sprechen sein, wohingegen ,Individuum' und ,Subjekt' in dieser Reihenfolge abstraktere Stufen bezeichnen. Dass es in der Genazino-Forschung keine diesbezügliche Einheitlichkeit gibt, sollte nicht weiter verwundern. So spricht der Paratext auf der Buchrückseite des TEXT+KRITIK-Bands zu Genazino vom ,Individuum - „Wilhelm Genazinos Romane [...] zeichnen

Vgl. Hoffmann: Gesellschaftskritik; vgl. Fischer/Wiswede: Grundlagen der Sozialpsychologie; vgl. Efrat Tseëlon: Is the Presented Self Sincere? Goffman, Impression Management and the Postmodern Self. In: Theory, Culture \& Society 9 (1992), S. 115-128.

Peter V. Zima, auf dessen jüngst (2017) in vierter Auflage erschienene Theorie des Subjekts hier mehrfach Bezug genommen werden wird, geht den Weg, egal, welchem Begriff in den von ihm gebrachten Zitaten der Vorzug gegeben wird, ausschließlich vom ,Subjekt' zu sprechen. Eine pragmatische Leitplanke gibt den Ausschlag, weswegen hier - in Umdrehung des Verfahrens von Zima vorzugsweise vom Selbst und nicht vom Subjekt, Individuum etc. die Rede ist: Selbstcharakterisierungen, Selbstbilder, Selbstzweifel, Selbstaufmerksamkeit, Selbstreflexion, Selbstwirksamkeit, Selbstgespräche, Selbstkonzepte und schließlich Selbstdarstellungsstrategien sind immer wiederkehrende Schlagworte sowohl thematisch als auch methodisch in dieser Arbeit und auch für Genazinos Romanfiguren und Figurenromane sind Aushandlungsprozesse des Selbst ein Schmelztiegel und auch thematisch Kulminationspunkt. Vgl. grundlegend zu diesem Kapitel auch Genazinos Aussagen in Bezug auf seine eigene Poetologie im Allgemeinen und auf Abschaffel im Besonderen (vgl. ders.: Melancholische Renitenz).

3 Peter V. Zima: Theorie des Subjekts. Subjektivität und Identität zwischen Moderne und Postmoderne. 4., durchges. u. erw. Aufl. Tübingen 2017, S. 3. 
sich durch minutiöse Analysen des [...] vereinsamten, neurotischen Individuums [...] aus" ${ }^{4}-$, wohingegen etwa Bartl/Marx den Terminus bzw. das Konzept ,Subjekt' favorisieren:

Genazinos Texte variieren immer wieder die Frage nach dem Subjekt und skizzieren dessen „Zerbröckelung“, „Zerfaserung oder Ausfransung“. Hier verbinden sich philosophische Reflexionen über das Subjekt mit dem Interesse am Randständigen, Abseitigen und mit psychologischen Fragen: Genazinos Figuren sind Grenzgänger; sie leben beständig im Interim von Normalität und Abweichung und suchen und finden damit ihre spezifische Lebensform erneut in der „Unentschiedenheit“. 5

Dass es nicht möglich ist, die Kulturgeschichte des Selbst, selbst nicht diejenige seit 1945, ,herzubeten', versteht sich von selbst: Zu vielfältig und buntscheckig sind die Annäherungen und Akzentsetzungen. Daher wird hier primärzitatgestützt und durch die Eingrenzung auf Genazino, IM und die Erzähl-/Figurentheorie eine subjektive Auswahl an vielversprechenden Konzepten diskutiert. Nach einer disziplinübergreifenden Annäherung aus historischer Perspektive wird das zwischen den Polen von ,Fragmentierung‘ und ,Kohärenz' aufgespannte Geflecht von Selbstentwürfen bei Genazino verhandelt. Diese Pole berufen sich in gewisser Weise auf die im Begriff der Subjektivität enthaltene Dopplung von Bedeutung: „Subjekt ist, etymologisch betrachtet, ein zweideutiges Wort, das sowohl Zugrundeliegendes (hypokeímenon, subiectum) als auch Unterworfenes (subiectus = untergeben) bedeutet" ${ }^{\prime \prime}$

\section{ZWEI MODERNEN, DREI KRÄNKUNGEN, VIER,SELBSTBEHAUPTUNGSRÄUME}

Das Individuum als individuelles Subjekt, das eigene Meinungen äußert, Verantwortung trägt, Dissens anmeldet und autonom handelt, hat es nicht immer gegeben. In archaischen Gesellschaften ging und geht der Einzelne im kollektiv praktizierten Mythos, in der von Durkheim beschriebenen mechanischen Solidarität auf, die von der Ähnlichkeit der Stammesmitglieder lebt. Auch im Feudalismus denkt, spricht und handelt er im kollektiven Kontext der religiösen Gemeinschaft, der Gilde, der Sippe. ${ }^{7}$

Der Schwund an wichtigen Fixpunkten des gesellschaftlichen Lebens markiert eine erste Trendwende hin zur Subjektivität, die zugleich als erste Krise des Selbst verstanden werden kann: Wurde ehedem der Sohn eines Handwerkers idealiter Handwerker, war für andere aufgrund äußerlicher Erkennungsmerkmale (Habitus, Kleidung, Diktion etc.) leicht und zweifelsfrei als solcher zu identifizieren und konnte seine Stellung in der Gesellschaft mit (wenigen) Rechten und (vielen) Pflichten klar angeben, macht - in diesem Beispiel - erst der Wegfall der ständischen Ordnung das permanente Sich-selbst-Behaupten und mithin IM in seiner Gänze nötig: sobald das Individuum überhaupt sichtbar aus der Gruppe heraustritt.

$4 \quad$ Vgl. Arnold (Hg.): Wilhelm Genazino.

5 Bartl/Marx: Wiederholte „Verstehensanfänge“, S. 12 f. Die Zitate stammen aus Regenschirm, S. 39, was die Autoren im Original mit einer Fußnote nach „Ausfransung“ kenntlich machen.

6 Zima: Theorie des Subjekts, S. 3.

7 Zima: Theorie des Subjekts, S. $4 \mathrm{f}$. 
Auf Basis dieser ,Vorgeschichte' bietet es sich aus vielerlei Gründen an, die Wende zum zwanzigsten Jahrhundert als Ausgangspunkt im engeren Sinne zu wählen, ${ }^{8}$ ruft doch Freud nach der kopernikanischen und der nicht einmal ansatzweise verdauten biologischen Kränkung durch Darwin die psychologische aus und degradiert damit das zuvor als Hausherr empfundene Ich zum ,Mitbewohner' im psychodynamischen Gebäude. ${ }^{9}$

Das Fin de Siècle kennt eben nicht nur Individualitätsexzesse, sondern bereits eine (zweite) Krise des Selbst, die etwa Lukács 1920 (1914/15 verfasst) in seiner Theorie des Romans ${ }^{10}$ in die griffige Formel der ,transzendentalen Obdachlosigkeit' kleiden sollte; die Kunst der Moderne hält Einzug und weicht die Vorstellung eines kohärenten Selbst in Folge zunehmender Psychologisierung und welterschütternder Forschungsergebnisse (Einstein, Planck uvw.) weiter auf. Es gibt objektiv keine ,Wahrheit' mehr, das autonome Subjekt verliert als Konzept an Glaubwürdigkeit. Ein neues Denken wird erforderlich. Die Literatur reagiert um 1900 mit interner Fokalisierung, Ich-Perspektive, stream of consciousness (Joyce, Proust, Schnitzler) - der allwissende Erzähler stirbt dieserhalb so langsam aus: Wenn das Subjekt die Welt nicht mehr fassen kann, misstraut man auch einer diese Fähigkeit suggerierenden Erzählinstanz.

Aber nicht nur die ,klassische Moderne', auch die ,zweite' (Beck) bzw. Postmoderne stellt die Vorstellung vom Selbst als unverbrüchliche Einheit „radikal in Frage“. Laut Zima „zeigten uns“ „die Junghegelianer[] und Nietzsche, [...] Surrealisten und Modernisten, schließlich [...] nachmoderne[] Denker[] wie Foucault, Deleuze, Derrida und Vattimo“:

die Kehrseite der idealistischen Medaille und faßten das subiectum nicht als Zugrundeliegendes (fundamentum), sondern als Unterworfenes oder Zerfallendes auf: als Produkt von Machtkonstellationen oder Ideologien, als Spielball von unbewußten, libidinösen Impulsen, als Opfer von Diskontinuität und Kontingenz. ${ }^{11}$

Es scheint, als seien Genazinos Figuren weder über die erste (,transzendentale Obdachlosigkeit‘ etc.) noch die zweite (Multioptionalität etc.) moderne Selbst-Krise hinweggekommen: In keinem der Romane wird gebetet oder ein gläubiger - ganz gleich, welcher Religion - Protagonist gezeigt, ${ }^{12}$ und Genazino zeigt sich unter dem Eindruck der Nachkriegsgeneration noch mit Blick auf

8 Dann kommen auch bürgerliche Selbstinszenierungen gehäuft auf (vgl. Peter W. Marx: Ein theatralisches Zeitalter. Bürgerliche Selbstinszenierungen um 1900. Tübingen/Basel 2008). Vgl. für den Versuch, bereits ab 1800 Ich-Identität zu behaupten, Ralph Köhnen (Hg.): Selbstpoetik 1800-2000. Ich-Identität als literarisches Zeichenrecycling. Frankfurt am Main/New York 2001.

9 Vgl. Zima: Theorie des Subjekts, S. 53-70, für die die Subjektivität tangierenden Implikationen sowie insgesamt die Entwicklung von „der Psychoanalyse und der Persönlichkeitstheorie zur Sozialpsychologie: das Unbehagen in Kultur und Gesellschaft" (Unterkapiteltitel Zimas).

10 Vgl. Georg Lukács: Die Theorie des Romans. Ein geschichtsphilosophischer Versuch über die Formen der großen Epik. Berlin 1916/1920.

11 Zima: Theorie des Subjekts, S. 3 f.

12 Geschweige denn, dass Religion überhaupt ,im großen Stil' thematisiert werden würde. Vgl. dazu Ursula Homann: Zerbrechliches Glück und transzendentale Obdachlose. In: Der Literat. Fachzeitschrift für Literatur und Kunst 2 (2002), S. 11-15; vgl. für eine mögliche biografische Erklärung Wilhelm Genazino: Der Untrost und die Untröstlichkeit der Literatur. Dankesrede anlässlich der Verleihung des Georg-Büchner-Preises $2004 . \quad$ Online: <https://www.deutscheakademie.de/de/auszeichnungen/georg-buechner-preis/wilhelm- 
die Milleniumswende davon überzeugt, dass „das Subjekt am Ende des Jahrhunderts einfach ein durch und durch neurotisches Subjekt" sei. ${ }^{13}$ Verschiedene Versuche liegen vor, postmodernen westeuropäischen Gesellschaften mit einem Schlagwort beizukommen, um diesen unterschiedlichen Bedrohungen des Selbst gerecht zu werden: Risikogesellschaft (Beck 1986), ${ }^{14}$ Erlebnisgesellschaft (Schulze 1992), ${ }^{15}$ Inszenierungsgesellschaft (Willems/Jurga 1998). ${ }^{16}$ Alle17 teilen sich bei unterschiedlicher Akzentsetzung, unterschiedlichen Graden an Opti-/Pessimismus, unterschiedlich ausgeprägten Schuldzuweisungen und Handlungsanregungen etc. - die Beobachtung, dass mit Individualitätszwang, Überkomplexität, Globalisierung etc., das stabile Selbst der Individuen einer schweren Prüfung unterzogen werde. Ernst-Dieter Lantermann formuliert vier „eng miteinander verwobene Komponenten gesellschaftlicher Dynamik zur Beantwortung der Frage":

Wie gelingt es Menschen in einer keinerlei Gewissheiten mehr liefernden modernen Gesellschaft, ihr Selbstwertgefühl aufrecht zu erhalten, die Kontinuität ihres Selbstkonzeptes, ihres Bildes von sich selbst, zu wahren und gegen alle vorgeblichen Zwänge zur ,Selbstauflösung' zu behaupten?18

Diese einer Auflösung des Selbst möglicherweise entgegenstehenden Dimensionen lauten: Kommerzialisierung des Alltags, Ästhetisierung des Alltags, Vergegenwärtigung der Lebensführung, und - als Quintessenz -: Zwang bzw. Drang zur (Selbst-)Inszenierung. ${ }^{19}$ Sie sind insofern wertneutral zu verstehen, als ihnen allesamt eine durchaus negative Note anhaftet - eine Kommerzialisierung ist nie per se gut -, alle aber auch dazu genutzt werden können, um für das Selbst stabilisierende Funktion zu übernehmen. ${ }^{20}$ Hinsichtlich der Kommerzialisierung des All-

genazino/dankrede>. Eine romanspezifische Ausnahme bildet Kein Geld insofern, als derart häufig thematisiert wird, dass der Protagonist nicht religiös sei, dass die Religion durch die Hintertür in den Roman tritt. Zumal Bibelallusionen treten gehäuft auf (vgl. Kein Geld, S. 13 u. S. 67; $\Rightarrow$ V.1). Hirsch/Genazino: Interview am 09. Februar 1998, S. 280.

Vgl. Ulrich Beck: Risikogesellschaft. Auf dem Weg in eine andere Moderne. Berlin 1986/2016.

Vgl. Gerhard Schulze: Erlebnisgesellschaft: Kultursoziologie der Gegenwart. Frankfurt am Main 1992.

Vgl. Herbert Willems/Martin Jurga (Hg.): Inszenierungsgesellschaft. Ein einführendes Handbuch. Opladen 1998.

Freilich ist zu ergänzen, dass andere Philosophen - etwa Plessner - ganz andere Subjektentwürfe favorisieren.

Lantermann: Selbstbehauptung in unübersichtlichen Zeiten.

Vgl. Lantermann: Selbstbehauptung in unübersichtlichen Zeiten. Vgl. zur literarischen Bearbeitung insbesondere die beiden hervorragenden Sammelbände: Vincent Kaufmann/Ulrich Schmid/Dieter Thomä (Hg.): Das öffentliche Ich. Selbstdarstellungen im literarischen und medialen Kontext. Bielefeld 2014; sowie Ulrich Fülleborn/Manfred Engel (Hg.): Das neuzeitliche Ich in der Literatur des 18. und 20. Jahrhunderts. Zur Dialektik der Moderne - Ein internationales Symposion. München 1988. Vgl. grundlegend auch Josef Früchtl/Jörg Zimmermann: Ästhetik der Inszenierung. Dimensionen eines gesellschaftlichen, individuellen und kulturellen Phänomens. In: dies. (Hg.): Ästhetik der Inszenierung. Dimensionen eines künstlerischen, kulturellen und gesellschaftlichen Phänomens. Frankfurt am Main 2001, S. 9-47.

In diesem Punkt lassen sich Lantermann und Zima engführen: Beide testieren, in unterschiedlichem Maß, die ,Angriffe' auf das Selbst bzw. das Subjekt, beide formulieren jedoch eine vorsichtig optimistische Perspektive auf deren Fortbestand und vor allem die Entbindung von damit einhergehenden Freiheiten (vgl. Lantermann: Selbstbehauptung in unübersichtlichen Zeiten; vgl. Zima: Theorie des Subjekts). Genazino vertritt demgegenüber eine eher pessimistische Sicht und weist derartige ,Utopien` von sich (vgl. Hirsch/Genazino: Interview am 09. Februar 1998, S. 280). 
tags hat Lantermann den „unendlich vielfältigen Markt der käuflich erwerbbaren Symbole“ im Sinn, der dem Einzelnen helfen könne,

seine unverwechselbare Einzigartigkeit zur Geltung zu bringen und wegen der den Dingen inhärenten Trägheit auch für eine längere Zeit aufrechtzuerhalten. Die mit der Käuflichkeit einhergehende und aus Produktionsgründen notwendige Standardisierung der Symbolobjekte kommt dabei dem wachsenden Bedürfnis nach sozialer Zugehörigkeit und Abgrenzung entgegen [...]. ${ }^{21}$

Unter die Ästhetisierung des Alltags fasst er die

Tendenz [...], das ,Ästhetische' über das ,Instrumentelle‘ zu stellen, die Erscheinungsweise eines Objekts höher zu bewerten als das, wozu es taugt, die Einkleidung eines Arguments in eine ,schöne‘ Gestalt für überzeugender zu halten als dessen Stichhaltigkeit, einer Person, die ,überzeugend' auftritt, eher zu folgen als jemandem, dessen Handlungen überzeugen, der aber in seinem Erscheinen wenig ,Stil' zeigt. ${ }^{22}$

Der dritte Punkt der Vergegenwärtigung der Lebensführung ist eng an Schulze angelehnt und besagt, dass „die Unsicherheit und Fragmentarisierung von individuellen Zukunftsentwürfen“ in einer psychologischen Konsequenz zur „verstärkte[n] Zuwendung zum Nahbereich der Gegenwart, zu der momentanen Lebenslage, die man noch einigermaßen zu überschauen meint", führe. ${ }^{23}$ Daher seien „,Ideen', ,Überzeugungen“ oder langfristig angelegte Lebensplanungen“ immer weniger in der Lage, „als handlungsleitende Prinzipien“ zu fungieren ( $\Rightarrow$ II.1.6), weswegen sie „durch solche Ziele, die sich in der Situation anbieten und schnelles Glück und angenehme Erlebnisse versprechen“, abgelöst werden würden. ${ }^{24}$ Schließlich gibt es viertens den Drang zur Selbstinszenierung, „der als wichtiges Beschreibungsmerkmal des modernen Individuums gilt“ und Situationen wie Teamarbeit, Bewerbungsgespräche, aber auch alltägliche Kommunikationssituationen durchdringt. Als Resümee hält Lantermann fest:

Im Trainingscamp unserer radikalisierten Moderne lernen wir, dass die geschickte Selbstdarstellung, ein kluges Impression Management, eine geschmeidige Selbstinszenierung wichtiger für den Erfolg und für das schöne Leben sind als alle anderen Fähigkeiten und Kompetenzen. Zur Selbstinszenierung als Mittel und Medium der Selbstbehauptung gibt es keine Alternative. Stilbildung und Stilpräsentation gehören damit zu den wichtigsten Ingredienzien des modernen Menschen. ${ }^{25}$

Fraglich ist nur, in welchem Maß das Individuum dazu bereit ist, und zu welchem Grad es dem Individuum tatsächlich gelingt, „sich seine eigene Balance von Verschließung und Öffnung, von Sicherung und Wagnis [zu] schaff[en] und auf diesem Wege seine Selbstwertschätzung, sein Selbstbild und seine Identität im Fluss der Ereignisse aus[zu]bilde[n] und [zu] behaupte[n]“.26 Genazinos Figuren scheinen jedenfalls nicht recht in dieses Setting zu passen: Sie scheinen das ,Trainingscamp‘ zu negieren, scheinen - zum Teil ,frühvergreist' - aus der Zeit gefallen ( $\Rightarrow$ II.1.3) und bei der Anerkenntnis der Zersplitterung stehengeblieben zu sein.

21 Lantermann: Selbstbehauptung in unübersichtlichen Zeiten.

22 Lantermann: Selbstbehauptung in unübersichtlichen Zeiten.

23 Lantermann: Selbstbehauptung in unübersichtlichen Zeiten.

24 Lantermann: Selbstbehauptung in unübersichtlichen Zeiten.

25 Lantermann: Selbstbehauptung in unübersichtlichen Zeiten.

26 Lantermann: Selbstbehauptung in unübersichtlichen Zeiten. 
Nichtsdestotrotz ist es aufgrund der hohen Reflexivität der Romanfiguren nicht verwunderlich, dass diese vielgestaltige Worte finden für das Gefühl, in der (Post-)Moderne verloren zu sein und die Selbstidentität nicht ohne Weiteres als gegeben annehmen zu können. Auf dem Rücken verschiedener Protagonisten und der Protagonistin wird diese

\section{„ZERBRÖCKELUNG“, „ZERFASERUNG“, „AUSFRANSUNG“: DEPERSONALISATION UND DISSOZIATION BEI GE- NAZINO}

an- und ausdiskutiert. Exemplarisch lassen sich die Manifestationen im mehr oder weniger metaphorischen Umkreis des ,Auseinanderfallens' ( Dissoziation) ansiedeln. ${ }^{27}$

Laut DSM-5 (2013), einem der beiden Standardwerke, wenn es um die Diagnose bzw. Klassifikation von psychischen Störungen geht, charakterisieren „Erfahrungen von [...] Loslösung, oder wie die eines außenstehenden Beobachters der eigenen Gedanken, Gefühle, des Körpers" eine Depersonalisation, ${ }^{28}$ was bei Genazino etwa im Roman Außer uns spricht niemand über uns nahezu idealtypisch in die Worte des Ich-Erzählers gegossen lesbar ist: „[D]ann stand ich plötzlich wieder neben mir und schaute auf die rätselvollen Splitter einer sich nicht zusammenfügenden Existenz." (Außer uns, S. 39) Diese Bestandteile sind nicht diejenigen eines ,multiplen Ichs', die sich aus Rollenbestandteilen o. Ä. zusammensetzen ließen, sondern solche, die sich eben nicht mehr - zumindest subjektiv - als Bestandteile eines Individuums erfahren lassen. Mehr noch: Sie sind „rätselvoll[]“, also nach ICD-10, dem zweiten maßgeblichen Klassifikationssystem, wahrgenommen als „,fremd, nicht ihr eigen, unangenehm verloren“29 und nähern sich damit dem Befund der Autoskopie, der „Sicht (ohne Spiegel oder Kamera) auf den eigenen Körper wie von außen“ an. ${ }^{30}$ Im Sinne der Meta-Reflexivität der Figuren bzw. Erzähler lässt sich auch für den Bereich der Depersonalisation und Dissoziation Kenntnisreichtum konstatieren. In Außer uns spricht niemand über uns werden nicht nur Aussagen, die man dem Krankheitsbild zuordnen könnte, geliefert, sondern ein cleveres Spiel mit diesem inauguriert:

Ich würde in der Stadt umhergehen und ganz langsam, verteilt über die Zeit, Stück für Stück, Teile meines Lebens und meiner Erinnerung verlieren, bis sie in dem großen Container des Vergessens verschwunden waren und von niemandem mehr gesucht wurden, auch von mir nicht. Wenn ich im ICE unterwegs war, würde ich mir einen Fensterplatz suchen und die Erinnerungsreste auf vorübereilende Felder [...] verteilen. (Außer uns, S. 139)

Dieser Selbstzerfall, namentlich in Bezug auf die Erinnerungen, spielt hier virtuos mit der als desiderabel vorgestellten Dissoziativen Amnesie: Bei einer solchen

27 Obwohl ,Depersonalisation' sowohl im ICD-11-Entwurf als auch im DSM-5 unter Dissoziation gefasst wird, ist die heuristische Trennung sinnvoll.

28 [Depersonalisation]. In: Wikipedia. Die freie Enzyklopädie. Online: <https://de.wikipedia.org/wiki/Depersonalisation\#Diagnostische_Kriterien_nach_DSM5_.282013.29>.

29 [Depersonalisation].

30 [Dissoziation]. In: Wikipedia. Die freie Enzyklopädie. Online: <https://de.wikipedia.org/wiki/Dissoziation_(Psychologie)>. 
fehlen der betreffenden Person ganz oder teilweise Erinnerungen an ihre Vergangenheit, v. a. an belastende oder traumatische Ereignisse. [...] Die Amnesie geht weit über das Maß der normalen Vergesslichkeit hinaus [...]. Der Betroffene kann dann nicht unterscheiden[,] ob Erinnerungen wahr sind oder nicht. ${ }^{31}$

Neben der eklatanten Übereinstimmung des fiktionalen Wunsches mit der lebensweltlichen Diagnose, rückt hier auch die Erinnerungsproblematik in Form der verschiedenen Wahrheitsversionen und Erinnerungswidersprüche, wie sie etwa in Kein Geld sowie in Licht auf die Spitze getrieben wird, ins Zentrum ( $\Rightarrow$ I.2.3).

An das Vergessen anknüpfend liefert der Protagonist aus Ein Regenschirm für diesen Tag den Beweis dafür, dass eine gestörte Ich-Identität bei Genazino durchaus auch im Dienst weiterer metaphorischer Defizite stehen kann:

Nachmittags findet eine Art Zerbröckelung meiner Person statt, gegen die ich wehrlos bin, eine Zerfaserung oder Ausfransung. Ich vergesse dann, daß es im Leben Hauptsachen und Nebensachen gibt, weil irgendeine Nebensache in mich eindringt und mich nicht mehr freigibt. (Regenschirm, S. 39)

Hierbei an ,Entbettung' (Giddens) oder ,Entfremdung' (nicht nur Marx) aufgrund äußerlicher Einflüsse, die in Verkleidung „irgendeine[r] Nebensache in“ die Figurenpsyche „eindringt“, zu denken, ist nicht nur möglich, sondern sicherlich sogar plausibel. Einerseits metaphorisch wie die bisherigen Beispiele, andererseits konkreter im Sinne eines visuell-sinnlich wahrnehmbaren Zerfalls, lesen sich Passagen, in denen die Hauptfiguren sinnbildlich, ,unentscheidbar' oder fiktional tatsächlich ihrer physischen Bestandteile verlustig gehen: „Obwohl ich gehe, zerfalle ich. Körperteile fallen von mir ab, ich sehe sie zurückbleiben, während ich gehe." (Glück, S. 85) ${ }^{32} \mathrm{Ob}$ wohl klarer metaphorisch als in Mittelmäßiges Heimweh konzipiert, wo der Ohrverlust eben nicht entscheidbar (un-)zuverlässig erzählt ist $(\Rightarrow I .2 .3)$, wirkt die Vorstellung doch sehr plastisch-realistisch. Für letztgenannten Roman konstatieren Bartl/Marx: In „der seltsamen Krankheit des Körperteilverlustes [...] manifestiert sich zudem die allgegenwärtige Auflösung des Ichs.“33 Auf die Gefahr hin, den Sprachverlust im Sinne einer Dissoziativen/Psychogenen Bewegungsstörung ${ }^{34}$ fehlzuinterpretieren bzw. Genazinos Kenntnis des psychologischen Konzepts überzustrapazieren, lässt sich eine Passage aus Genazinos Glücks-Roman anführen, bei der die Sprachlosigkeit mit der gefühlten Diskrepanz zwischen ,den Ichs' einhergeht:

Im Grunde war schon der innere Vandalismus meiner Kindheit eine Selbstaussetzung. Als ich neun Jahre alt war, habe ich fast den Verstand verloren, weil ich zu lange von mir selbst getrennt war. Damals lief ich völlig verstummt und verlassen ganze Nachmittage in der Stadt umher, um den Abstand zwischen mir und mir zu verkleinern. (Glück, S. 142 f.)

Bezeichnenderweise bestätigt diese Selbstdiagnose diejenige des Therapeuten, sodass eben doch mit Anz' Kategorie IV ( $\Rightarrow$ I.3.2) geliebäugelt werden darf, zumal die Nähe zur ,Dissoziativen

$31 \quad$ [Dissoziation].

32 Vgl. für ein ähnlich gelagertes Beispiel Fremde Kämpfe, S. 225.

33 Bartl/Marx: Wiederholte „Verstehensanfänge“, S. 12.

34 Vgl. [Dissoziation]. 
Fugue', dem „unerwartete[n] Weggehen“,35 frappierend ist. Das Abhandenkommen bzw. Abhandengekommensein der Ich-Identität jedenfalls erscheinen wie eine psychische Signatur des Protagonisten: „In einem Meer ichfremder Augenblicke drohe ich unterzugehen. Ich schäme mich und warte darauf, daß ich sofort sterbe." (Glück, S. 85)

Wie gelingt es Genazinos Figurenbasistypus damit umzugehen? Überraschenderweise findet an dieser Stelle Lantermanns Kategorie der für Genazinos Figuren sonst so verhassten Dingwelt (,Kommerzialisierung des Alltags'; s.o.) als Selbst-Klammer Erwähnung: „Die Hose beginnt in diesen Augenblicken, mir meine eigenartig zusammengewürfelte/zusammengehauene/zusammengeklumpte Lebensgeschichte zu erzählen." (Liebesblödigkeit, S. 22) Nur ein Gegenstand ( $\Rightarrow$ II.1.5), der die nötige „Trägheit“ (Lantermann), damit aber auch die Konstanz hat, ein Leben ,miterlebt' zu haben, kann alle wandelbaren Stufen eines Subjekts (von außen) überblicken.

Metatheoretisch liest sich im Kontext von Dissoziation und Depersonalisation auch der Versuch des Ich-Erzählers aus dem Regenschirm-Roman:

Ich versuche, mich vorübergehend in zwei Personen aufzuspalten, in einen trockenen Streuner, der an diesem Tag Arbeit und Frau verloren hat, und in einen tätigen Phantasten, der davon nichts wissen will. Die Spaltung gelingt, jedenfalls für eine Weile. [...] Ich versuche, die Erinnerung an den Spruch dem von mir abgespaltenen Doppelgänger unterzuschieben, leider ohne Erfolg. Ich bin es, der unter dem Spruch aufseufzt, sonst niemand. (Regenschirm, S. 91-93)

Es ist abstrus, aber hier liegt der motivationale, gar volitionale ( $\Rightarrow$ I.3.1), Versuch vor, eine dissoziative Persönlichkeitsstörung als Lösung proaktiv herbeizuführen. Natürlich geht das nicht, wie auch der Protagonist schließlich einsehen muss, aber die reflektierte Heranziehung der potenziellen Möglichkeit lässt einmal mehr tief blicken in die psychologisch elaborierte Innenwelt der Genazino-Figuren $(\Leftrightarrow I .3 .2)$. Genazino schreibt seine Figuren damit in eine moderne Tradition ein. Diese ist

von einem Dissoziationsprozess geprägt. Dieser greift die Identität, die autonome Selbstbegründung des Subjekts, im Innersten an, setzt sie heteronormen Bestimmungen aus und erklärt schließlich das Ich zur ,unrettbaren' Kategorie, wie es Ernst Mach [...] ausgeführt und sein Verehrer Hermann Bahr [...] auf die griffige Formel gebracht hat. [...] ,Unrettbar' ist die transzendentale Ich-Einheit, weil sie sich im Zuge der Säkularisierung und der Ausdifferenzierung des Wissens zu mannigfaltigen Funktionen gewandelt hat. ${ }^{36}$

Obschon zweifelsfrei festgehalten werden kann, dass das (post-)moderne Selbst - sowohl in der Theorie ${ }^{37}$ als auch bezogen auf Genazinos Figuren-Basistypus - ein zerstückeltes, fragmentiertes, ja geradezu ,unrettbares“ ist, mithin „das Ich ziemlich viel von seiner dank Descartes, Kant und Fichte erworbenen Selbständigkeit [hat] einbüßen müssen“,38 gibt es nun einmal in aktuel-

$35 \quad$ [Dissoziation].

36 Heribert Tommek/Christian Steltz: Vom Ich erzählen. Identitätsnarrative in der Literatur des 20. Jahrhunderts. Einleitung. In: dies. (Hg.): Vom Ich erzählen. Identitätsnarrative in der Literatur des 20. Jahrhunderts. Frankfurt am Main 2016, S. 7-25, hier S. 7.

37 Aus der hier gewählten Theorieperspektive. Andere nehmen eine stärkere Wahlfreiheit an.

38 Vincent Kaufmann/Ulrich Schmid/Dieter Thomä: Einleitung. In: dies. (Hg.): Das öffentliche Ich (2014), S. 7-9, hier S. 7. 
len westeuropäischen gesellschaftlichen Entwicklungen einen immer stärkeren Druck und Zwang, dem Selbst nach außen eine intakte Hülle zu geben und diese möglichst selbstwertdienlich zu vermarkten (s.o.). ${ }^{39}$ In der Inszenierungsgesellschaft, in der wir leben, ist es einerseits bekannt, dass wir verschiedene Rollen und Facetten haben, diese sind aber andererseits auch erst performativ zwingend durch die Simulation eines größeren Rahmens einer Selbstinszenierung nach außen doch wieder kohärent zu machen. ${ }^{40}$

\section{KOHÄRENZ(BESTREBEN)}

Einerseits durch äußere Zwänge, andererseits aber auch aus dem Bedürfnis, wider besseres Wissen die ,Zerfaserung' für das eigene Selbst nicht anzuerkennen, loten Genazinos Romane auch immer wieder das Kohärenzbestreben, die Ich-Identität aus: 41

Wieder habe ich ein bißchen Angst vor Morgenthalers Party. Ich werde viel zuviel reden und auch noch voller Eifer. Schon nach einer Stunde werde ich mir total unauthentisch vorkommen. Ich lese und höre immer wieder, daß die Menschen heute ein multiples Ich haben und daß es völlig normal ist, wenn wir heute ein anderes Ich haben als gestern und vorgestern. Insofern müßte ich mich über meine Nichtauthentizität nicht beunruhigen. Das Problem ist nur, daß ich die vielen Ichs gar nicht haben möchte, im Gegenteil. Ich beharre darauf, daß ich heute genau derjenige bin, der ich schon gestern war und der ich übermorgen wieder sein werde. Ich strenge mich manchmal sogar an, mir selbst möglichst geschlossen und widerspruchsfrei zu erscheinen. (Liebesblödigkeit, S. 130 f.)

Die hier nicht näher ausgeführten, aber offenbar unternommenen ,Anstrengungen', um als zeitlich stabiles Ich aufzutreten, bringen Hahn/Willems in ihrem Artikel mit dem Untertitel „Identität und Identitätsdarstellung“ (1998) auf den theoretischen und allgemeinmenschlichen Punkt:

Immer wieder beanspruchen wir im Alltag, nicht nur für einen Moment das zu sein, als was wir implizit erscheinen. Vielmehr lassen wir oft durchblicken, daß wir den Augenblick als charakteristisch oder untypisch für unser Ich ansehen. Situationale Selbstthematisierungen könnte man diese Vorgänge nennen. Wenn auch mit knappen Zeichen, durch einige handlungsbegleitende Worte, Gesten oder Arrangements verweist der Handelnde absichtlich auf situationsübergreifende Selbstbezüge.

Vgl. Lantermann: Selbstbehauptung in unübersichtlichen Zeiten.

Vgl. Lothar Laux/Karl-Heinz Renner: Theater als Modell für die Persönlichkeitspsychologie. In: Erika Fischer-Lichte (Hg.): Theatralität als Modell in den Kulturwissenschaften. Tübingen 2004, S. 83-110. Der Widerspruch, der zwischen dem ,inkohärenten' Selbst und der sozialpsychologischen Modellbildung, nach der transsituative und zeitlich stabile Faktoren eine Person charakterisieren, aufklafft, lässt sich auf zwei Weisen flicken. Erstens sind auf der Darstellungsebene von Genazino häufig einerseits Figuren entworfen worden, die sich über den Roman hinweg Eigenschaften und Verhaltensmustern treu bleiben, obwohl sie andererseits den Zerfall ihres Selbst wahrnehmen, reflektieren usw. Zweitens ist die Grenzziehung von Hardcore und Familienähnlichkeit bei den Figurenbauplänen von Relevanz ( $\Rightarrow$ I.2.5): Wohingegen sich Persönlichkeitsmerkmale wie ,Offenheit für Erlebnisse' ( $\Rightarrow$ II.1.3), eine Eigenschaft, die die „Wahrscheinlichkeit dissoziativer Symptome [erhöht]" ([Dissoziation]), auf der Ebene des harten Kerns befinden (überzeitlich), sind Selbstzweifel oder empfundene Depersonalisation feingliedrigere Konzepte, die auf einer anderen Ebene rangieren und Figuren auch jenseits ihres harten Kerns tangieren können.

Vgl. sowohl zum Streben danach, kohärente Selbstentwürfe als Erzählung zu konzipieren, als auch dazu, dabei widersprüchliche Informationen einzuflechten, den wegweisenden Sammelband: Claudia Holler/Martin Klepper (Hg.): Rethinking Narrative Identity. Persona and perspective. Amsterdam/Philadelphia (PA) 2013. 
Er macht ein Ich geltend, das über das Hier und Jetzt, sei es als dessen Fortsetzung, sei es als dessen Gegensatz, Bestand hat. ${ }^{42}$

Genazino hat diese Problematik, die man auch als ,ideationale Prädikatenzuweisung' bezeichnen kann (s.u.), an anderem Ort ,faktualer' wie folgt gefasst: „Wir müssen mit einem Ich zurechtkommen, das uns dreist unsere Bruchbudenhaftigkeit zeigt - die wir dann auch noch als Vorteil erleben sollen.“43 Die Absage an Goffman, Lantermann und Zima könnte deutlicher nicht ausfallen. Andererseits hilft es nichts, die Augen vor den Tatsachen zu verschließen:

Zeitlich gesehen, ist das Ich keineswegs starr. Schon körperlich sind Menschen einem Wandel unterworfen. Forscher betrachten es daher als Meisterleistung des Gehirns, einem das Gefühl zu vermitteln, stets dasselbe Ich zu sein. Tatsächlich sind wir sogar blind für Veränderungen. Wandeln sich die eigenen Lebensumstände, meint man oft, die Welt habe sich verändert, schreibt der USPsychologe Thomas Gilovich in einer Studie. Stellen Menschen Veränderungen fest, tendierten sie dazu, ,auf der falschen Seite der Haut' nach einer Erklärung zu suchen. Manchmal ist es leicht zu durchschauen, etwa wenn ein Erwachsener nach vielen Jahren wieder das Haus seiner Kindheit betritt und ihm alles klein vorkommt. ${ }^{44}$

Aber wie gehen die Figuren Genazinos mit diesem Zwiespalt um? Offensichtlich lässt die eigene Arbeit am Selbstentwurf, lässt die „Meisterleistung des Gehirns“ zu, die Differenzen zu glätten, um handlungsfähig zu bleiben:

Am stärksten beeindruckte mich das Wort Romanhaftigkeit. Es bedeutete nicht, dass das Leben wie ein Roman niedergeschrieben werden musste. Die Betonung lag auf der inneren Gestalt, die ein Mensch von sich selber erfand, indem die Zustände der Romanhaftigkeit wie ein schöpferischer Anhauch durch ihn hindurchzogen. (Regen, S. 115)

Erneut muss der im Roman verhandelten Debatte um die Vergleichbarkeit der retrospektiven Selbstbeschreibung als Roman mit einem Roman vermittels der außerfiktionalen Forschung begegnet werden, sind doch die Gedanken allzu deckungsgleich:

Mit zunehmender gesellschaftlicher Differenzierung wächst die Schwierigkeit, die Phasen der Biographie als Momente eines einheitlichen Prozesses unmittelbar zu erfahren. Es sind nicht mehr gesellschaftlich ,vorgesehene', institutionelle Altersstufen, deren Abfolge sinnhaft koordiniert ist, welche von allen Mitgliedern der Gesellschaft mehr oder minder in ähnlicher Folge durchlaufen werden. Biographie wird ein zunehmend von Individuum zu Individuum verschiedener und in seiner Folge von Status schwer zu prognostizierender einzigartiger Wechsel von Teilidentitäten. Ein großer Teil der Dichtung bis in unser Jahrhundert hinein scheint gleichsam kontrapunktisch funktional auf diese Situation bezogen zu sein. Insbesondere im Entwicklungsroman wird die Identität des Helden trotz sehr mannigfaltiger phasenmäßig heterogener Realisierungen doch als eine in sich verständliche Entwicklung erfahren. Der alte Mensch ist zwar anders als der junge. Aber zwischen diesen Polen lassen sich sinnvolle Beziehungslinien zeichnen. Zwar mag es unmöglich sein, ex ante den werdenden Charakter des Helden aus der Kenntnis seiner Jugend zu prognostizieren, doch zu-

42 Alois Hahn/Herbert Willems: Zivilisation, Modernität, Theatralität: Identität und Identitätsdarstellung. In: Willems/Jurga (Hg.): Inszenierungsgesellschaft (1998), S. 193-213, hier S. 202.

43 Wilhelm Genazino: Ein Auftrittstreppchen fürs Ich. In: ders.: Idyllen in der Halbnatur. München 2009/2012, S. 185-189, hier S. 189. Vgl. dazu auch Hoffmann: Gesellschaftskritik, S. 105-145. Hoffmann verdanke ich auch den Fund dieses Zitats. In ganz ähnlicher Absicht äußert sich der Schuhtester aus Genazinos Ein Regenschirm für diesen Tag: „Dahinter steht vermutlich der mich bis heute erstaunende Mechanismus, daß sich neue Identität dann bildet, wenn einem jemand zu nahe tritt" (Regenschirm, S. 123), was als forcierte Wandlung im Inneren höchst unwillkommen ist.

$44 \quad$ Claudia Wüstenhagen: Ich-Bewusstsein. Die Ich-Perspektive. In: ZEIT Wissen vom 10. April 2012. Online: <http://www.zeit.de/zeit-wissen/2012/03/Das-Ich-Serie-Teil-2/komplettansicht>. 
mindest ex post fügen sich die dem Handelnden vielleicht zunächst inkompatiblen Fragmente seines Daseins zum Roman, zur bei allem Wandel doch nachvollziehbaren Einheit einer Biographie. Nicht nur die Dichtung selbst, sondern auch die interpretierenden Disziplinen legen immer wieder dieses Muster frei.

Erst sehr spät, eigentlich erst mit dem Ende des 19. Jahrhunderts, scheint hier ein fundamentaler Wandel einzutreten. Die Phasenfolge, in die sich die Biographie zerlegt, erscheint als zufällige Sukzession, der auch ex post kein Sinn abzugewinnen ist. Die diachrone Einheit der Persönlichkeit löst sich auf. Auch die literarische Darstellung spiegelt diesen Tatbestand. Teils läßt sie die Zeiträume, in denen sie Biographien darstellt, so zusammenschrumpfen, daß nur noch ein Ausschnitt thematisiert wird, teils dramatisiert sie gerade die absurde Zufälligkeit der nur zeitlich aufeinander aufbauenden Phasen der Biographie, die sich keinem darstellbaren Entwicklungsgesetz mehr fügt. Bisweilen wird ein Zusammenhang der Biographie zwar noch angenommen, aber deutlich bereits als Konstruktion ausgewiesen: Kunst bildet dann keine einheitliche Biographie mehr ab, sondern stellt diese her. Diachronische Identität erscheint dann als immer neue und jeweils unterschiedliche mehr oder minder willkürliche Komposition. Der Zerfall diachronischer Identität führt dazu, daß in der jeweils späteren biographischen Phase die jeweils früheren Phasen für den Handelnden uninteressant werden, daß er sich nicht mehr auf sie als integrale Bestandteile seiner eigenen jetzigen Identität bezieht. 45

Genazino liebäugelt just mit dem Gedanken, ein Mensch könne „die dem Handelnden vielleicht zunächst inkompatiblen Fragmente seines Daseins zum Roman“ „fügen“ - dadurch dass er „romanhaft“ eine „innere[] Gestalt“ erfindet. Selbsterzählungen übernehmen damit eine kohärenzstiftende Funktion, die allerdings auch bis ins Romanhafte im Sinne des nicht unbedingt ,Wahren' gehen kann: „Er hatte überhaupt nur mit erfundenen Geschichten eine Person sein können.“ (Falsche Jahre, S. 461; vgl. Falsche Jahre, S. 478; $\Rightarrow I I .1 .2)^{46}$

In diesem Sinn hat Sprache bei Genazino Bestand: Als Selbsterzählung eines unüberschaubar komplexen, auseinander gefallenen Ichs, an dessen Fassbarkeit auch Genazino längst nicht mehr glaubt - wohl aber treibt er die Annäherung an diesen ,Nullpunkt Ich`voran und hält das Gespräch über sich selbst, über das Selbst seiner Figuren, in Gang. Beständig prüft er, was denn Wert hat für die Identität - ein viel zu großes Wort schon. Die Erinnerung? Wahrheit? Die verlässliche Wiederholung des Alltäglichen - wenn schon nichts anderes das Ich im Innersten zusammenhält? ${ }^{47}$

\section{VERSTRICKUNG DER FÄDEN}

Es gibt unterschiedliche Antworten auf die Frage, wer man ist, beziehungsweise darauf, „was denn Wert hat für die Identität“, was „das Ich im Innersten zusammenhält“: Die Psychologie antwortet darauf in der ihr eigentümlichen Pragmatik in der Form: Wie kann ich Wissen über mich sammeln? Damit sind ganz konkret Antworten auf Fragen angerissen, die Hirsch aufwirft:

Für den Aufbau und die Entwicklung des Selbstkonzepts stehen nach Filipp (1979) fünf Quellen selbstbezogenen Wissens zur Verfügung (s. auch Markus \& Cross, 1990).

Dabei ist eine erste wesentliche Quelle selbstbezogener Informationen die Beobachtung des eigenen Verhaltens, wobei die Rückschlüsse einer solchen Selbstbeobachtung auch auf die eigene Person als „reflexive Prädikatenzuweisung“ bezeichnet werden können („Ich komme zu Verabredungen immer pünktlich, also bin ich zuverlässig").

Eine weitere wichtige Quelle selbstbezogener Informationen ist die Interaktion mit anderen. Dabei werden bei einer "direkten Prädikatenzuweisung" bestimmte Attribute von anderen Personen explizit formuliert und dann in das eigene Selbstkonzept übernommen („Mein [!] Freunde sagen immer wieder, dass ich geizig sei; also bin ich wohl ein sparsamer Mensch").

45 Hahn/Willems: Zivilisation, Modernität, Theatralität, S. 208; Herv. N. L.

46 Vgl. dazu auch Windemuth: Die Selbstdarstellung in Alltagserzählungen.

47 Hirsch: „Schwebeglück der Literatur“, S. 257. 
Im Gegensatz dazu erfolgt bei der „indirekten Prädikatenzuweisung“ eine Eigenschaftszuweisung aufgrund der Verhaltensbeobachtung von sozialen Interaktionspartnern („Meine Kommilitonen fragen mich immer wieder um Rat bei Herzensangelegenheiten, also bin ich wohl ein einfühlsamer Gesprächspartner").

Eine weitere wichtige Quelle für selbstbezogene Informationen ist der Vergleich mit anderen Personen, wobei eine „komparative Prädikatenzuweisung“ erfolgt („Im Vergleich mit meinen Geschwistern habe ich mehr Freunde, also bin ich wohl beliebter").

Eine letzte Quelle selbstbezogenen Wissens ist das Nachdenken über vergangenes oder zukünftiges Handeln, wobei eine „ideationale Prädikatenzuweisung“ resultieren kann („Wenn ich über meine Schulzeit nachdenke, dann komme ich zu dem Schluss, dass ich ein leistungsorientierter Mensch bin"). ${ }^{48}$

Mannigfaltig sind die Anknüpfungspunkte zu bereits getätigten Überlegungen: Die Spiegelung bis in die Terminologie der Figurenanalyse hinein ( $\Rightarrow I$ I.2.4) lässt die Kategorien ,direkt/indirekt ${ }^{`}$ als äußerst treffend erscheinen; die ideationale Prädikatenzuweisung übernimmt in Form der analeptischen Rückwendung bei Genazino insbesondere für die Erzählgegenwart eine wichtige Funktion; die komparative weist eine hohe Passung mit Schütz' „making others look bad“ auf ( $\Rightarrow$ I.3.3), wenn der (soziale) Vergleich als Quelle der ,Selbst-Bestimmung' im Netz der verfügbaren Referenzsubjekte wirksam wird: „Rastlos beobachte ich, was andere Menschen um mich herum tun und was ich nicht tue. Es beruhigt mich, Details zu entdecken, die zwischen mir und den anderen liegen. In der Wahrnehmung dieser Differenz lebt mein Ich.“ (Glück, S. 152 f.; $\Rightarrow$ II.1.1) Dass die (selbst-)reflexive Prädikatenzuweisung eine höchst wichtige Rolle für Genazinos Romanfiguren spielt, muss nicht erneut betont werden, aber Passagen wie: „Es war, als müßte Abschaffel eine fremde, zweite Person in sich beruhigen. [...] Aber diese zweite Person schien ein äußerst scheues Wesen zu sein“ (Falsche Jahre, S. 551 f.), lässt sich in ihrer SelbstInkongruenz, den Fehlattributionen der Erzähler und dem nicht immer gegebenen Zugriff auf das Wissen darum mit der Feststellung einer fehlerhaften reflexiven Zuweisung begegnen.

Auch hinsichtlich der Erzähltheorie sind dissoziative Betrachtungen untersuchenswert, die sich bspw. im Switch vom ,Ich'- zum ,Er'- Erzähler niederschlagen, wobei es sich nicht um die bereits erschöpfend abgehandelte ,kopernikanische Wende handelt' ( $\Rightarrow$ I.2.1), sondern um punktuell auftretende Phänomene innerhalb eines Romans ( $\Rightarrow$ I.2.3): „[A] us Elkes Gesicht sprach der Samstag, der mich aufforderte, ihn nicht verstreichen zu lassen, ihn anzuhäufen mit Erlebnissen, also: Axel rutschte von seinem Barhocker herunter" (Laslinstraße, S. 189). Hier liegt laut Schneider der Fall vor,

dass [...] die Unterschiedlichkeit der Sichtweisen auf ein Phänomen selbst zum Gegenstand und zum zentralen Inhalt der Darstellung erhoben wird. Ich-/Er-Wechsel können dann gehäuft auftreten und zudem in ihrer Wirkung verschärft werden, wenn ihre Motivation rätselhaft bleibt, weil sich auf der Erzähler- und/oder Figurenebene keine klar konturierte Bewusstseinsinstanz identifizieren lässt, der die alternative Perspektive auf die mal in der ersten und mal in der dritten Person erscheinende Figur zuzuordnen wäre. Am Rande sei erwähnt, dass ein solcher ,verschärfter' Ich-

$48 \quad$ Gerhard Stemmler/Dirk Hagemann/Manfred Amelang/Dieter Bartussek: Differentielle Psychologie und Persönlichkeitsforschung. 7., vollst. überarb. Aufl. Stuttgart 2011, S. $427 \mathrm{f}$. Online: $<$ https://content-select.com/media/moz_viewer/517a52ea-10e4-413f-853c-

1b855dbbeaba/language:de>. 
/Er-Wechsel nicht nur als gestalterisches Äquivalent eines modernen bewusstseinsphilosophischen, identitätspsychologischen oder rollensoziologischen Problembewusstseins, sondern auch als hochwirksames Instrument der Rezeptionssteuerung gelten kann. Jedenfalls dürfte es kaum ein effizienteres Mittel zur Identifikationsvereitelung geben als die permanente Entkonturierung jener Figuren, mit denen sich der Leser potentiell identifizieren könnte. ${ }^{49}$

Zugegeben handelt es sich bei Genazino um seltene Effekte, aber die auch erzähltheoretisch nachweisbare Dopplung und Spaltung der Selbstentwürfe beglaubigt die Relevanz „eines modernen bewusstseinsphilosophischen, identitätspsychologischen oder rollensoziologischen Problembewusstseins" von Genazinos Figurenromanen und Romanfiguren.

Genazinos Figuren wissen - innerer Blick - um die Dopplung von Zersplitterung des Selbst einerseits und der Notwendigkeit andererseits, diese irgendwie graduell ,überspielen` zu müssen, um handlungsfähig zu bleiben. Der Abneigung zum Trotz sind sie (meist) in der Lage, über Selbst(v)erklärungen und/oder IM die inneren Unsicherheiten vor der Welt zu verbergen: „Wie froh bin ich, daß niemand etwas von meiner inneren Zersplitterung erfahren muß.“ (Liebesblödigkeit, S. 87) Sie sind allerdings so konzipiert, dass sie - äußerer Blick - in der Dopplung von Ich und Ich für den Leser die Unvereinbarkeit transportieren. Das wird insbesondere dann überdeutlich, wenn die Protagonisten ex post Überlegungen qua ,ideationaler Prädikatenzuweisung' anstellen, die schwerlich glaubhaft sind: „Tatsächlich fühlte ich mich als Achtjähriger alt, erschöpft und von der Welt angewidert.“ (Tiere, S. 87 f.) Da hilft auch die Tatsachenbeglaubigung („tatsächlich“) nichts: „[D]ie diachrone Einheit der Persönlichkeit löst sich auf“50 - alles Dagegen-Anschreiben und das Postulieren einer Junge-Mann-Identität prononciert lediglich die Konstruktion von kausaler Biografieschreibung:

Goffmans Verständnis der modernen Multiplizität des Selbstes und der entsprechenden Zwänge und Freiheiten der ,Selbst-Verwaltung' und Selbst-Gestaltung deckt sich in wesentlichen Punkten mit Prousts ,Theorie' der Selbstdarstellung. Proust und Goffman beschreiben das Selbst als Fiktion von Strategen und von zum Glauben gezwungenen und gewillten Beobachtern. [...] Im Gegenteil zu zahlreichen Literaten, Soziologen und Sozialphilosophen sieht Goffman in der systematischen Fragmentarisierung, Selbstfalsifikation und Fiktivisierung des modernen Selbstes weniger ein Identitäts- oder Sinnproblem als eine Kombination von Freiheitsgewinnen mit den Notwendigkeiten eines strategisch-dramaturgischen Informationsmanagements, das sich an den jeweils relevanten Beobachtern und Adressaten zu orientieren hat. ${ }^{51}$

Wiewohl Genazinos Figuren die „Freiheitsgewinne“ als linke Seite der aus der „Multiplizität des Selbstes“ folgenden Addition nicht goutieren können, bzw. sie damit hoffnungslos überfordert sind, erkennen sie die „Zwänge“ und „Notwendigkeiten eines strategisch-dramaturgischen Informationsmanagements, das sich an den jeweils relevanten Beobachtern und Adressaten zu orientieren hat", in aller Deutlichkeit. Genazinos Figurenbasistypus hat mithin IM als Lösungsstrategie für das Problem erkannt, trotz gefühlter und ungewollter Zersplitterung ein kohärentes Selbst hervorbringen zu müssen. Damit fügen sie den Zwecken der impression motivation

49 Schneider: Einführung in die Roman-Analyse, S. 57.

50 Hahn/Willems: Zivilisation, Modernität, Theatralität, S. 208.

51 Hahn/Willems: Zivilisation, Modernität, Theatralität, S. 209; vgl. Laux/Renner: Theater als Modell für die Persönlichkeitspsychologie. 
4. Das Selbst: multipel, (post-)modern, zersplittert - 145

einen neuen hinzu: Zusätzlich zu dem formulierten Ziel: „establishing particular identities (Tedeschi \& Norman, 1985)“ ( $\Rightarrow$ I.3.3),52 übernimmt IM die ,Defragmentierung' des multiplen, (post)modernen, zersplitterten Selbst. 


\section{Forschungsdesign und Modus Procedendi}

Bevor mit der Analyse der fünf großen Schlaglichter das Herzstück der Studie angegangen werden kann, sind nolens volens einige Ausführungen zu Entstehung, Konzept und Gerippe der Arbeit notwendig.

Dass Genazinos Figurenromane ihrem poetischen Prinzip nach zwischen den Polen Variation und Wiederholung aufgespannt sind ( $\Rightarrow$ I.2.1-I.2.3 u. $\Rightarrow$ I.2.5), und welche unterschiedlichen Bausteine, Elemente, Motive und Situationen dabei repetitiv auftauchen $(\Rightarrow I .2 .2)$, ist bereits dargelegt worden. Wie sich diese nun zu Analysefeldern über die einundzwanzig Romane (Stand 2018) hinweg und bezogen auf die hier verfolgten interesseleitenden Fragestellungen modellieren lassen $(\Rightarrow I .5 .1)$, sind richtungsweisende Vorüberlegungen. Wie diese Schlaglichter methodisch ,funktionieren' und weswegen sie selbst zusätzliche Theoriesplitter, die über die bislang vorgestellte Theoriebildung ( $\Rightarrow$ I.2-I.4) hinausgehen, enthalten (müssen), diskutiert ein zweites Unterkapitel ( $\Rightarrow$ I.5.2). Eine selbstkritische Bestandsaufnahme, was alles weiterhin hätte analysiert werden können, soll abschließend erörtert werden $(\Leftrightarrow I .5 .3)$, um etwa darzulegen, warum ausladende biografische Text-Autor-Bezüge so klein gehalten sind und warum der Fokus ,lediglich' die Romanfiguren scharfstellt.

\subsection{Zwischen Induktion und Deduktion II: Genese und Kontur der Schlaglichter}

Um eine möglichst breite Palette an ,variiert wiederholten' Elementen, Motiven und eindruckssteuernden Figurenverhaltensweisen bei Genazino berücksichtigen zu können, modelliert diese Arbeit fünf Analysefelder, gleichsam Schlaglichter, unter denen sich verschiedene der bereits beschriebenen Bausteine und Versatzstücke aus Wilhelm Genazinos Baukastensystem/Mischpult $\Leftrightarrow \Rightarrow$ I.2.2) verdichten und flächig ausleuchten lassen. ${ }^{1}$

Not und Tugend dieses Vorgehens zugleich ist: Nicht etwa die Einzelfigur Gerhard Warlich aus dem Roman Das Glück in glücksfernen Zeiten ist Untersuchungssubjekt oder -objekt und nicht primär eine für einen Einzeltext herauspräparierte Figurencharakterisierung dieser, sondern die Strukturähnlichkeiten aller Genazinoromanhauptfiguren mit den Scheuklappen der Schlaglichtcluster. Zwar werden ab und an einzelne Figuren gegen andere abgegrenzt werden - wenn bspw. die namenlose Figur aus den Kassiererinnen in einer bestimmten Situation anders handelt als die namenlose Figur aus der Ausschweifung in derselben Situation, oder wenn der idiosynkratische fiktionale Lebenslauf (Causal History) besondere Bedeutung für die gewählte Strategie hat -, doch genaugenommen geht es darum, des genazinotypischen, des ,genazinoesken`

1 In Anlehnung an die empirische Wissenschaft ließe sich hier behelfsweise von einer hermeneutischen Faktoranalyse sprechen. 
Figurenverhaltens im Bereich der Familienähnlichkeiten $(\Rightarrow I .2 .5)$ habhaft zu werden. ${ }^{2}$ Im Vorfeld des hier lesbaren Substrats sind dazu

- qua mehrmaliger Lektüre aller vorliegenden Romane wiederkehrende Motive etc. in den 21 Texten induktiv identifiziert - und zugleich das tatsächlich flächige Vorliegen der seitens der Forschung behaupteten ( $\Rightarrow$ I.2.2) überprüft - worden,

- diese zu größeren Komplexen von beteiligten Verhaltensstrategien zusammengefasst, also - unter Berücksichtigung der vorgegebenen Stoßrichtung der Eindruckssteuerung zu Schlaglichtern gebündelt aufgeleitet worden,

- $\quad$ welche in der Folge die Maßgabe für eine weitere komplette Sichtung des Roman-Werks in deduktiver Manier gebildet haben, aus der eine mehrere hundert Seiten umfassende Synopse hervorgegangen ist.

- Auf dieser breiten Materialbasis sind die Schlaglichter zunächst auf fünf reduziert, ${ }^{3}$ ferner kulturwissenschaftlich und unter Berücksichtigung auch der Genazino-Sekundärliteratur beschrieben und aufbereitet worden,

- bevor die jeweiligen Analysewerkzeuge qua Synthese aus literatur- und kulturwissenschaftlicher, subjektphilosophischer sowie persönlichkeits- und sozialpsychologischer Forschung zusammengestellt worden sind,

- um schließlich methodengeleitet und - dank Synopse - eng am Text durch Zitatkonglomerate Schlaglicht für Schlaglicht analysieren und Figurenfacetten charakterisieren zu können.

Folgende fünf Schlaglichter also, die nicht nur hinsichtlich der absoluten Häufigkeit die meisten Treffer/Textstellen auf sich vereinen, sondern auch in der Breite ,jedes in (fast) allen` $(\Rightarrow I .2 .2)$ Romanen auftaucht und mithin jedes einzelne für Genazino Repräsentativität beanspruchen darf, wirken strukturbildend:

2 Genauer werden die Ähnlichkeiten in der Darstellung von Figurenverhalten in der Diegese und die erzähltechnische Verpackung derselben aufgezeigt. Möchte man Aussagen über bestimmte Facetten des Figurenhandelns und des Figurenbewusstseins insgesamt tätigen, so muss man eine gewisse Kohärenz annehmen, was bereits fundiert worden ist ( $\Rightarrow$ I.2.5): Genazinos Hauptfiguren sind Einzelgänger usw. Prinzipiell werden wie gesagt alle (geeigneten) Genazinofiguren in einem Schlaglicht herangezogen, doch die Synopse hat freilich alle ,Schnipsel' textsensibel gesammelt, sodass als ,Kollateralschaden' immer auch eine Einzeltextfigurenanalyse möglich ist $(\Rightarrow$ V.1).

3 Es handelt sich um eine Reduktion aus insgesamt 12 distinkten Schlaglichtern, die sich hätten formen lassen. Herausgenommen worden sind bspw. ,Macht/Einfluss' ,Unaufrichtigkeit/Lügen' sowie ,Der erste Eindruck', die ihrerseits allerdings häufig in Unter(unter)kapiteln ihre Spuren hinterlassen haben. Der Grund für die Reduktion ist neben dem Umfang die relative Seltenheit des Auftretens gewesen. 
[1] Innenwelten -

Außenwirkungen

[2] Im Auge des Betrachters

[3] Strategien der

Interessantheit bzw. Auffälligkeit

[4] Das Ich, die anderen und das andere: Inszenierung Beobachtung - Evaluation

[5] Liebe und Sexualität
- Individuum vs. Gesellschaft; Authentizität vs. Lügen; Charaktereigenschaften; analoge Kommunikation; Lebensstile; Einstellungen etc.

- Selbstaufmerksamkeit; Selbst-, Fremd- und Idealbilder; Beobachtungszwang; innere Zensur etc.

- Inszenierte Spontaneität; Originalität, Esprit,

Extemporiergeschick; Auffälligkeiten im Erzählen etc.

- Evaluationsprozesse; brüchige Selbstentwürfe anderer; Abwertung, Herabsetzung; Anerkennung, Bewunderung etc.

- Liebes(lebens)entwürfe; Genderaspekte; Inter- vs. intrasexueller Wettbewerb; Erotik vs. antiemotionales Erzählen etc.

Abbildung 7: Schlaglichter

Die drei Cluster [2], [3] und [4], die sich neben der thematischen Kontur auch durch die vorherrschende Verwendung besonders eines Typs von IM charakterisieren lassen und also nicht nur auf-, sondern auch auseinander folgen - von der protektiven Zurückhaltung4 in [2] geht es über die assertiven Eigenwerbungsstrategien in [3] hin zur strategisch eingesetzten Abwertung anderer in [4] -, werden von zwei Schlaglichtern gerahmt, die verschiedene Strategien mischen. Insbesondere in den ,umarmenden' Kapiteln wird dabei das IM-Kerngeschäft gelegentlich verlassen, obwohl die erkenntnisleitenden Fragestellungen $(\Leftrightarrow I$.1) stets erkennbar bleiben.

Das erste Schlaglicht setzt die Leitplanken für die folgenden und verortet Genazinos Individuen in ihrem Verhältnis zur jeweiligen Gesellschaft inklusive der virulenten Distinktions- vs. Zugehörigkeitsbestrebungen ( $\Rightarrow$ II.1.1). Dass Selbstdarstellung immer zwischen Verstellung und Authentizität schillert, ist theoretisch bereits diskutiert worden $(\Rightarrow$ I.3.3); unter anderem anhand der ,kleinen Lüge‘ lässt sich dies aber primärtextlich genauer untersuchen ( $\Rightarrow$ II.1.2). Um die in Aussicht gestellte Dreiteilung der Genazino-Figuren $(\Rightarrow I .2 .5)$ mit Leben zu füllen, werden zunächst diejenigen musterhaften Makel, Marotten und Merkwürdigkeiten des Figurenensembles besprochen ( $\Rightarrow$ II.1.3), bevor die nicht-verbalen Kommunikationsmittel der Hauptfiguren in den Blick genommen ( $\Rightarrow$ II.1.4), Schichten- vs. Milieuzugehörigkeiten des Genazino'schen Basistypus diskutiert $(\Rightarrow$ II.1.5) und letztlich wiederkehrende Überzeugungen herauspräpariert werden $(\Rightarrow$ II.1.6). 
Die dabei jeweils vorherrschenden Referenztheorien finden sich hauptsächlich im Bereich der Soziologie, Kommunikationstheorie und Persönlichkeitspsychologie.

Das zweite Schlaglicht versammelt unter dem Titel „Im Auge des Betrachters“ unter Zuhilfenahme unterschiedlicher methodischer Zugänge zunächst die Faktoren Selbst-, Fremd- und Idealbild der Figuren $(\Rightarrow$ II.2.1). Neben psychoanalytischen Impulsen werden dabei weitere psychologische Forschungsergebnisse berücksichtigt. Einem Zwang nicht unähnlich beobachten Genazinos Figuren unentwegt. Wie es sich genau damit verhält und auch, welche besänftigenden Ablenkungsmöglichkeiten denkbar sind ( $\Rightarrow$ II.2.2), stehen genauso auf der Agenda wie die konstruktivistische Interpretation von Welt per se ( $\Rightarrow$ II.2.3). Genazinos Figurenbasistypus beobachtet aber nicht nur, sondern wird seinerseits mitunter selbst (vermeintlich) zum Beobachteten ( $\Rightarrow$ II.2.4), was ihn nicht selten zu Strategien der Flucht, der Verborgenheit und des Verschwindens greifen lässt $(\Leftrightarrow$ II.2.5). Schließlich wird das immer wieder erzählte angedachte/imaginierte oder erwünschte Figurenverhalten, das sich die Figur selbst letztlich versagt, verhandelt ( $\Rightarrow$ II.2.6). Allen Unterkapiteln eignet die Tendenz zum protektiven IM, was dem zweiten Schlaglicht eine auch methodisch hohe Kohärenz verleiht.

Im Gegensatz dazu arbeitet das Gros der Verhaltensstrategien der Interessantheit/Auffälligkeit des dritten Schlaglichts mit assertiven Techniken und Taktiken. Nachdem einige Vorbemerkungen dieses Schlaglicht konturiert haben $(\Rightarrow$ II.3.1), stellt der Fokus den narratologischen Blick auf interessante, also eigenartige, Phänomene scharf ( $\Rightarrow$ II.3.2). ( $\Rightarrow$ II.3.3) zeigt eine Figurenfacette, die dem Basistypus zunächst zu widersprechen scheint: Die Figuren sind nämlich durchaus nicht immer ,soziophob‘ - im Gegenteil, sie suchen mitunter gar die Bühne bzw. neigen zur Selbstpräsentation. Allerdings müssen sie dazu einigen planerischen Aufwand betreiben. Seltener werden die Figuren als mit großem Extemporiergeschick begabte gezeichnet. Diesem Befund wird unter ( $\Rightarrow$ II.3.4) nachgegangen, ehe das Kapitel mit Verhaltensstrategien abschließt, die vielleicht noch auffällig, aber nicht mehr ,im besseren Sinne` interessant zu nennen sind ( $\Rightarrow$ II.3.5). Methodisch werden dazu insbesondere in der Sprachwissenschaft Anleihen gemacht: Facework - ein Konzept ursprünglich aus der Soziologie -, Gesprächspläne etc.

Gewissermaßen als Steigerung der Radikalität im aktiven Handeln lassen sich Muster beschreiben, in denen sich die Figuren anderen gegenüber überheblich zeigen, andere abwerten, sie verhöhnen oder bloßstellen ( $\Rightarrow$ II.4.4). Dabei handelt es sich um Mechanismen offensiver Eindruckssteuerung, die für das vierte Schlaglicht von großer Bedeutung sind und zunächst unter Rückgriff auf die Denkfigur der Humoralpathologie als dem Figurenhardcore zugehörig klassifiziert werden $(\Rightarrow$ II.4.1). Ferner geht es um die Spezifikation der evaluativen Situationen - wer wird eigentlich wie genau bewertet? - $(\Leftrightarrow I I .4 .2)$, sowie um das häufige Muster, dass ein Selbstentwurf einer Nebenfigur als brüchig entlarvt und der Lächerlichkeit preisgegeben wird ( $\Rightarrow$ II.4.3). Ultimativ im Kontrast dazu stehen Anerkennung und Bewunderung gegenüber anderen Verhaltensweisen ( $\Rightarrow$ II.4.5). 
150 - Teil I: Grundlagen 5. Forschungsdesign und Modus Procedendi

Den Abschluss bildet mit dem fünften Schlaglicht das für Genazinos Figuren hauptmotivationale Feld der Liebe und Sexualität. Es ist hinsichtlich der Verhaltensstrategien und Handlungsmotivationen verhältnismäßig ,abhängig` von den vorigen Schlaglichtern, weswegen ein Rekurs vorangeschickt wird ( $\Rightarrow$ II.5.1), dem die Analyse der immer wieder verhandelten Liebes(lebens)entwürfe bei Genazino folgt $(\Rightarrow$ II.5.2). Eine gendertheoretische Untersuchung der Romanhauptfiguren zu unterlassen, wäre sträflich, sind doch bei Genazino durchaus problematische Konstellationen zu beobachten ( $\Rightarrow$ II.5.3). Das konkrete Liebeswerben im intra- wie intersexuellen Bereich ( $\Rightarrow$ II.5.4) leitet über zu den präferierten Sexualpraktiken, Wünschen und Vorlieben ( $\Rightarrow$ II.5.5), die Konfliktpotenziale bergen. Abschließend wird der Blick noch einmal dezidiert dem Discours zugewendet, indem die erzähltechnischen Besonderheiten bei Genazinos Wahl des ,Sprachgewands der Liebe' zentriert werden: Erotik wird ent-emotionalisiert, mithin antiemotional erzählt ( $\Rightarrow$ II.5.6).

Nun stehen die Scheinwerfer, die bestimmte Areale der Genazinofiguren ausleuchten. Für sich selbst können diese Spots Ergebnisse generieren, aber sobald eine Figur an einer bestimmten Stelle der paginalen Bühne auftaucht, überblenden sich auch die Lichtkegel. An dieser Stelle muss daher abschließend ein nicht zu unterschätzendes Entscheidungs-Problem thematisiert werden: Nimmt man einen prominenten Roman pro Unterkapitel? Oder zwei? Oder gibt man einen Überblick und vertieft anhand eines Textes? Oder anhand von zweien? Man hätte ja auch diesen Weg einschlagen können: Jedes Schlaglicht eröffnet mit einem Essay, der knapp in die Kontur einführt sowie über den Seitenrand des die jeweilige Textpatenschaft übernehmenden Romans und seiner Hauptfigur hinausblickt. Anschließend wird auf einen Text je Unterkapitel fokussiert.

Obgleich - oder gerade: weil - es gängige Forschungspraxis ist, Wilhelm Genazinos (Roman-)Figuren einen vermeintlich ,harten Kern' an basistypischen Eigenschaften zuzuerkennen $(\Rightarrow I .2 .5)$ und diese per arrangierten und drapierten Fundstellen verifizieren zu suchen, sei das Redlichkeits-Argument Hans-Peter Eckers zitiert, dem es darauf ankommt, dass ,jeglicher Verdacht, dass hier nur Zufallsfunde aus einem großen Textkorpus arrangiert würden, um eine mehr oder willkürlich [sic!] formulierte These suggestiv mit Plausibilität auszustatten",5 ausgeräumt werden solle. Er tut dies recht redlich in seinem Artikel über das Motiv der Fremdscham bei Genazino und beschränkt sich mit ebenjener Formulierung just auf einen Text: Genazinos Eine Frau, eine Wohnung, ein Roman. Die vorliegende Studie weiß um die Problematik, argumentiert jedoch anders: Sobald gezielt ermittelte Fundstellen aus einem großen Textkorpus eine plausible These zum Gesamtwerk stützen - ist das nicht ohnehin die Paraphrase von Textwissenschaft? -, ist deren mögliche Suggestionskraft nicht wissenschaftliches Manko, sondern rhetorisches Verdienst dieser und jeder argumentativen und also geisteswissenschaftlichen Arbeit. 
Warum eine Verfahrensweise, die Einzeltext-zentriert gearbeitet hätte, - abgesehen davon, dass ein Pars pro toto nicht gut mit der Familienähnlichkeitsannahme $(\Leftrightarrow I .2 .5)$ zu vereinbaren gewesen wäre - nicht zielführend hätte sein können, mag das folgende Beispiel vorführen, in dem viele Schlaglichter und einige Unterkapitel kunstvoll verflochten sind:

Ich bewundere ihre schimmernde, weiße Seidenbluse, ihren gutsitzenden schwarzen Rock und ihre Lackschuhe. Die Verkäuferin überreicht mir den kleinen Gegenstand und errötet dabei, vielleicht, weil sie mir einen Wunsch hat erfüllen können. Ich reiche einen Geldschein über die Theke und frage mich, ob die Verkäuferin ihr Erröten als auszeichnend oder belastend empfindet. Doch im Augenblick, als sie meinen Schein in der Hand hat, hält sie diesen gegen das Licht. Kurz darauf ruft sie einen Namen in den hinteren Teil des Raumes. Es erscheint ein ebenfalls gutgekleideter Herr, der meinen Schein an sich nimmt und mit ihm verschwindet. Gleich wird es still im Geschäft, die Verkäuferin bittet mich um ein wenig Geduld. Ich warte und spüre dabei, für die Dauer der Überprüfung gilt nicht nur mein Geld, sondern auch meine Person als unecht. Schon zögern zwei Kunden ihren Aufenthalt auf versteckte Weise hinaus, weil sie damit begonnen haben, sich eine überraschende Enthüllung vorzustellen. Mein Bewußtsein bringt jetzt so stille wie haltlose Beschimpfungen der Verkäuferin hervor. Ihre Seidenbluse, die mir eben noch gefallen hat, kommt mir jetzt herrisch, böse und glatt vor. [...] Er gibt ein befreiendes Zeichen, und es ist allen Anwesenden klar, daß ich nicht mit Falschgeld habe bezahlen wollen. Im stillen erwarte ich, daß die Verkäuferin auch jetzt errötet, aber sie errötet nicht. Sie bemerkt auch nicht, daß ich mir nicht mit derselben Geschwindigkeit, in der mir die Echtheit aberkannt worden ist, mir diese wieder zuschreiben kann. Mein einziger Trost ist, die Scham, die mich jetzt heimsucht, bleibt ebenfalls unentdeckt. (Frauen, S. 121 f.)

Zitatchronologisch tauchen auf: das Goutieren fremder Inszenierungspraktiken $(\Rightarrow$ II.4.5), die Wichtigkeit von Kleidung für die Analyse der ,feinen Unterschiede‘ ( $\Rightarrow$ II.1.5), der Beobachtungszwang generell $(\Rightarrow$ II.2.2), das als Pein empfundene Beobachtetwerden sowie die darein involvierte öffentliche Selbstaufmerksamkeit ( $\Rightarrow$ II.2.4), die Tendenz, (haltlose) Mutmaßungen zur Grundlage der Interpretation von ,Welt' anzuwenden ( $\Rightarrow$ II.2.3), (still realisierte) Beschimpfungen und Herabsetzungen anderer ( $\Rightarrow$ II.4.4), spontane Stimmungsschwankungen $(\Rightarrow$ II.1.3), welche die Messlatte der Beobachtungsobjekte beeinflussen ( $\Leftrightarrow$ II.4.2), sowie der Wunsch nach Verborgenheit ( $\Rightarrow$ II.2.5). Das Zitat ist ein Kulminationspunkt etlicher weiterer, sich über die Schlaglichter und Unterkapitel verteilender Aspekte: Schwellenmomente, Unsicherheit, Selbstreflexion. Wohlüberlegt schneidet diese Arbeit also - basierend auf der vorab erstellten Synopse (s.o.) - dieses Zitat in ,Scheiben', und sortiert das jeweilige Verhalten respektive die jeweilige Gedankenführung an die jeweilige Stelle der Schlaglichter, um dort das Material neu zusammenzufügen. Für den an sinnzusammenhängende Interpretationen gewöhnten Leser muss dieses Verfahren einer Verstümmelung gleichkommen, allein es befördert das hier angestrebte Ziel. Unter welchen methodologischen Gesichtspunkten die einzelnen Schlaglichter dieses neuarrangierte Material dann diskutieren, ist hier angerissen worden und findet sich an Ort und Stelle der Schlaglichter expliziert. 


\subsection{Plädoyer für einen moderaten Methodenpluralismus}

„Niemand will Literaturtheorie, sagte Linda, glauben Sie mir; es gibt sie nur, weil wir so große Hoffnungen in die Literatur gesetzt haben und die Literatur diese Hoffnungen enttäuscht. Die Literaturtheorie ist ein ein [!] einziger riesiger Kompensationsakt.“ (Wohnung, S. 49)

Viele Theoretiker wurden bereits auf Genazino und seine Texte ,gehetzt': Lacan und Freud, Merleau-Ponty, Benjamin, Kracauer, Scham- und Ekeltheoretiker, Sartre, Foucault, Heidegger und viele, viele mehr. Meist gewinnbringend, manchmal gar erhellend, immer legitim. Aber: nie kategorisch besser, als es geworden wäre, hätte man andere bemüht.

Mit der Konstruktion einzelner Schlaglichter und dem ,Outsourcing' der spezifischen Methodik in diese, lässt sich ein vielschichtiges Theoriedesign ermöglichen, das wirklich mal im Dienst der Literaturwissenschaft steht. Bei der aktuellen ,Desideratahuberei' und vor allem dem Zelebrieren bestimmter Methoden - häufig mutet es an, als würde die ein oder andere etwa korpuslinguistische oder intersektionelle Arbeit nur deshalb geschrieben, weil die Korpuslinguistik bzw. Intersektionalität so en vogue sei -, ist die methodenpluralistische Relativierung ein gutes Korrektiv, um zu zeigen, dass eine Frage an die Literatur - und als nicht mehr aber auch nicht weniger lässt sich die Aufgabe der Literaturwissenschaft zunächst bezeichnen - Hand in Hand gehender, letztlich subjektiv dem Erkenntnisinteresse geschuldeter Methoden bedarf, um beantwortet werden zu können.

Der Wust an konkurrierenden Methoden, die sich bei einer Figurenanalyse anwenden lassen, und die vielfältigen Möglichkeiten, die Eindruckssteuerung literarischer Figuren zu konzeptualisieren, ließe sich nur um den Preis eines gewaltigen und trägen Theoriekonglomerats zusammenfügen. Ein derart vorab geschönt zusammengestelltes Theoriegebäude bliebe überdies recht allgemein. Hier soll jedoch den Figuren Genazinos ein Maximum an Relevanz eingeräumt werden. Deshalb wird methodologisch einer etwas unkonventionellen Verfahrensweise der Vorzug gegeben. Die kondensierten Untersuchungsfelder $(\Leftrightarrow$ I.5.1) selbst sind es, die den methodischen Zugriff präformieren. ${ }^{6}$ In altbewährter Rhetorikmanier müsste man nun konzessiv auseinandersetzen, welche Gefahren ein derartiger Methodenpluralismus birgt. Doch zäumt man den Gaul von hinten auf, lässt sich auf die Vorzüge verweisen: Den Figuren Genazinos und ihrem eindruckssteuernden Handeln im Rahmen einer Figurentheorie soll auf die Schliche gekommen werden. Alles andere muss sich unterordnen und als Werkzeug fungieren, als zielführender Weg zur Erkenntnis hinsichtlich bestimmter Forschungsfragen. Dass dabei Methoden, die üblicher-

6 Fußnotiger Exkurs: Das Rahmensetting von motivationalem, eindruckssteuerndem Figurenverhalten, dessen Analyse erzähltheoretisch grundiert ist, ist fix. Allerdings wird das methodische Feintuning in die Schlaglichter bzw. Unterkapitel ausgelagert. Die innere Zensur lässt sich dabei etwa anders erklären als die Inszenierungen anderer Figuren und deren abschätzige Aburteilung durch den Protagonisten. Das Schlaglicht der Außenwirkung erfordert grundverschieden andere analytische Instrumente, sozusagen ,Plugins', die in die Metatheorie eingebaut werden müssen, als das Unterkapitel zu Strategien der Unsichtbarkeit. 
weise in anderen Disziplinen Anwendung finden, in eine literaturwissenschaftliche Arbeit mit eingebunden werden können und sollen, wenn sie einen Erkenntnismehrwert generieren, setzt diese Arbeit als Grundannahme $(\Leftrightarrow I .3) .^{7}$ So ist bspw. das Facework mit großem Gewinn anzuwenden $(\Leftrightarrow I I .3 .1$ u. $\Rightarrow$ II.4.2), genauso wie sich für die innere Zensur die Toposanalyse gut anbietet ( $\Rightarrow$ II.2.6). Allerdings wird damit nur dasjenige Feld bestellt, das dieses Werkzeug erfordert. Kein Bauer würde mit dem Pflug weiterarbeiten, wenn es die Egge braucht. ${ }^{8}$ Somit wird das Werkzeug häufiger gewechselt. Mit der methodischen Vielfalt und dem Abduktions-InduktionsDeduktions-Mix ${ }^{9}$ potenziert sich der Aussagenertrag der Untersuchung und perspektiviert Genazinos Figuren und deren Verhaltensfacetten mehrfach.

Abschließend ist die hier in Anspruch genommene Position natürlich auch gegen die vorliegende Studie selbst zu wenden: Die hier beschrittenen Wege der kreativen Aneignung der Romanfiguren Genazinos sind mögliche, sind plausible, aber sind keine Königswege..$^{10}$

\subsection{Die Zu-kurz-Gekommenen: Anmerkungen zur (Auto-)Biografie, Sozialgeschichte und Scham}

In diesem ,Quasi-Defizitkapitel' ist darzulegen, weswegen bestimmte Bereiche der Forschung obwohl sie auf den ersten Blick mindestens mittelbar etwas mit Wilhelm Genazinos Romanfiguren zu tun gehabt hätten - für diese Arbeit begründet ausgeschlossen worden sind.

Generell lässt sich zunächst ein methodischer Grund dafür anführen, etwa die „Text-BildBücher"11 und Essay-Bände Genazinos kategorisch auszuklammern (s.u.), obwohl auch dort Figuren, die mitunter dem Basistypus recht nahe kommen können, auftauchen:12 Erstens lässt sich die oben getroffene Einordnung der Romanfiguren etwa hinsichtlich der Hochman/CulpeperDimensionen ( $\Rightarrow$ I.2.4) schlicht nicht auf nur skizzierte Figuren übertragen. Zweitens ist die oh-

$7 \quad$ Als Zielpublikum avisiert diese Studie den (wissenschaftlichen) Genazinoleser. Weder der Toposanalytiker noch der Soziologe kommt ergo auf seine vollen Kosten. Methoden sind und bleiben Hilfestellungen für Erkenntnisinteressen. In Anlehnung an Neuhaus' Werkzeugkoffermetapher (vgl. Stefan Neuhaus: Grundriss der Literaturwissenschaft. 2., überarb. Aufl. Tübingen/Basel 2005, S. 191) ließe sich polemisch fragen, warum - gleichsam - in einem Baumarkt die Funktionsweise einer Kettensäge erläutert werden muss, wo der Kunde doch unmissverständlich eine Hecke schneiden möchte. Andererseits kann eine Gardinenstange mit Dübeln, mit Kleber oder notfalls auch mit einem Hammer und mit abgebrochenen Streichhölzern in/an der Wand befestigt werden. Der Weg zum Ziel ist für eine passabel sitzende Gardinenstange zwar nicht unwichtig, aber unwichtiger, als eine passabel sitzende Gardinenstange an der Wand.

9 Der abduktiven Erkenntnis, IM-relevante Verhaltensmuster bei Wilhelm Genazinos Romanfiguren annehmen zu können, folgt die induktive Stoßrichtung vom Einzeltext zur Schlaglichtgewinnung und jeweiligen Methodenwahl. Schließlich ist auch der umgekehrte Prozess - vom Konzept zum bebildernden Textkorpus - deduktiv wirksam gewesen.

10 Insbesondere der Psychologie, die mitunter ,Banalitäten' im Gewand der Empirie als Weltweisheit verkauft, kann man skeptisch gegenüberstehen.

11 Hoorn: [Genazino, Wilhelm].

12 Die genannten Gründe sprechen auch gegen eine Thematisierung von Genazinos Theatertextfiguren, obwohl es dort bspw. auch randläufig um die Unmöglichkeit des Kaufs neuer Kleidung geht, wie in Genazinos 2006 erschienenem Stück Der Hausschrat. 
154 - Teil I: Grundlagen 5. Forschungsdesign und Modus Procedendi

nehin problematische Grenzziehung zwischen Autor und Erzähler (s.u.) in diesen Texten - in Ermangelung der paratextuellen Gattungsbezeichnung - allzumal nicht dazu angetan, nicht systematisch konfundierte Aussagen über literarische Figuren zu treffen. Die weiteren ,Ausschlusskriterien' lassen sich entweder dadurch rechtfertigen, dass es sich um für die Genazinoforschung ,überdüngte' Forschungsbereiche gehandelt hätte (Erinnern, Eltern etc.), denen bewusst ein Korrektiv entgegengesetzt werden soll, um neue Blickwinkel zu eröffnen, oder um solche ,peripheren', die einem Artikel gut zu Gesicht stünden, aber nicht in das Konzept einer größeren, systematischen Studie passen, teilweise hier aber am Wegesrand berücksichtigt werden - etwa Alterität $(\Leftrightarrow$ II.4.2) oder die Verbindung von Partner-/Mutterliebe $(\Rightarrow$ II.5.5) etc. Im folgenden Argumentationsgang insbesondere erwähnenswert und deshalb einzeln kurz anzusprechen ist der kategorische Ausschluss der Bereiche (Auto-)Biografie, Sozialgeschichte und Scham.

\section{(AUTO-)BIOGRAFIE}

Durch die namentliche Identität des Erzählers mit dem Autor ist die schriftstellerische Karriere eine Tatsache der referenziellen Textwirklichkeit. Mit anderen Worten: Es liegt uns Lesern nah, die familiäre Sozialisation und die Elternkonflikte als Hintergrundinformationen zur literarischen Genese der Protagonisten aufzunehmen. ${ }^{13}$

Mit diesen Worten schließt Fansa - hier bezogen auf Die Liebe zur Einfalt - sein letztes Untersuchungskapitel zur Figur. Sei es auch so, dass es manchem Leser nahe läge, von einer Figur mit gleichen Initialen oder gar dem gleichen Namen des Autors biografi(sti)sche Verbindungen zu ziehen - es ist damit um keinen Deut, ungefährlicher' oder zu Missverständnissen und Fehldeutungen weniger einladend, als es bei Franz Kafkas ,K's oder Christian Krachts namenlosen IchErzählern der Fall ist. Selbst Genazino ist da tendenziell kritischer: „Autobiographisch ist daran nur, dass ich alles oder Teile davon irgendwann einmal selbst erlebt habe. Aber manchmal werden diese Erlebnisse so umgearbeitet, dass nichts mehr übrig bleibt von der Erstfassung." ${ }^{14}$ Allerdings ist die Nähe der Romanfigur zum real existierenden Autor insbesondere in der Liebe zur Einfalt freilich nicht von der Hand zu weisen:

Ein paar Jahre später, als mein erster, jugendlicher Roman erschienen war und in der örtlichen Tageszeitung rezensiert wurde, fragte mich Vater, die Zeitung mit dem Artikel über mein Buch in der Hand haltend: Was hast du dafür bezahlt? Ich war ratlos und bestürzt; Vater glaubte tatsächlich, ich hätte die Redakteure der Zeitung bestochen, mein Buch zu besprechen. (Einfalt, S. 158)

Aber Genazino ,arbeitet' an diesen Erinnerungen, die sich mühelos mit Interviewaussagen zu seinem Erstling Laslinstraße parallelisieren ließen, und entfremdet sie etwa selbstkritisch: „Auch jetzt kommt es mir nicht rätselhaft vor, daß ich Lust habe, EDEN CINEMA zu kaufen, obwohl ich ahne, daß darin erneut und abermals die Familientragödie der Autorin ausgebreitet sein wird.“ (Laslinstraße, S. 18) Das ist metaleptisch umgebogen just derjenige ,Vorbehalt' des Genazino-

13 Fansa: Unterwegs im Monolog, S. 144.

14 Anja Hirsch/Wilhelm Genazino: Interview am 19. Januar 1998. In: Hirsch: „Schwebeglück der Literatur" (2006), S. 293-295, hier S. 294; vgl. Rüdenauer/Genazino: Der Reiz des Scheiterns, S. 59. 
Lesers vor dem jeweils neuen Roman. Eine weitere ,Umarbeitung' lässt sich etwa hinsichtlich der tatsächlichen Vita Wilhelm Genazinos ausmachen: Sein spätes Abitur mit Ende 30 sowie sein daran sich erst anknüpfendes Studium (und seine nie erfolgte Promotion) sind nicht eins-zueins mit den Bildungsbiografien und Kapitalstrukturen des Basistypus vereinbar $(\Leftrightarrow$ II.1.5). Allerdings legen etliche Interviews zumindest die Vermutung nahe, dass Genazino sehr wohl versucht, seine ,wahre' Biografie literarisch aufzuarbeiten. ${ }^{15}$ Auch Hinweise auf seine eigene Flaneurtätigkeit, seine Text-Bild-Bände vom Flohmarkt - etwa: Aus der Ferne. Auf der Kippe. Bilder und Texte (2012) - und Essay- sowie Vorlesungssammlungen - etwa: Idyllen in der Halbnatur (2012) - loten das Verhältnis von Fakt und Fiktion immer wieder neu aus. Die wohl meistzitierte Passage, die in den Augen der meisten Interpreten einen unmittelbaren Bezug von (Auto-)Biografie des Schriftstellers Wilhelm Genazino und dessen Poetik suggeriert, ist indessen die folgende, welche sich auf den Zwang bezieht,

daß wir unsere eigene Geschichte immer wieder erzählen müssen und nach jedem Erzählen glauben, wir hätten sie noch nicht richtig erzählt. So fangen wir immer wieder von neuem an, unsere Geschichte zu erzählen, ohne je der noch viel fürchterlichen Gewißheit zu entgehen, daß wir sterben werden, ohne unsere Geschichte wenigstens einmal vollständig und vollständig richtig erzählt zu haben. Ich stecke das Buch in die Tasche und spüre die Panik der nie richtig erzählten Geschichte. (Einfalt, S. 103)

Freilich lässt sich diese Reflexion - nota bene: Es handelt sich noch immer um eine fiktionale, die im Nachhinein als Beglaubigung für eine Poetik Verwendung findet! - als Argument für die Vermutung, immer wieder eine Hauptfigur zu haben, ebenso leicht(fertig) verwenden wie für die ,unterschiedlichen Wahrheitsversionen' und letztlich auch für das unzuverlässige Erzählen in toto (vgl. Licht, S. 17; vgl. Regenschirm, S. 36). Zu fragen ist jedoch: Auch wenn es so ist, dass Genazino seiner Figur wortwörtlich in den Mund gelegt hat, dass es im Leben darum geht, „unsere Geschichte wenigstens einmal vollständig und vollständig richtig [zu] erzähl[en]“; welchen Mehrwert hat derjenige an einer sachlichen Textanalyse Interessierte dadurch, dass er die in der Einleitung gestellten Frage nach dem Immergleichen damit beantworten kann: ,Weil Wilhelm Genazino es seiner Ansicht nach noch nicht geschafft hat, seine eigene „Geschichte wenigstens einmal vollständig und vollständig richtig erzählt zu haben“"? Was sich ja auch vehement in Konflikt mit Genazinos gebetsmühlenartig vorgebrachter Äußerung befindet, dass er nach der Veröffentlichung von Laslinstraße (1965) „nicht wusste, was ich nun noch schreiben sollte“16 - wenn man einer Schlüsselromanvorstellung das Wort redet, ist der einzig zulässige Schluss daraus, dass der Roman zwar möglicherweise die Lebensgeschichte nicht „vollständig richtig“, aber doch bereits „vollständig [...] erzählt" hatte.

Vgl. Wilhelm Genazino/Jochen Kölsch: Wilhelm Genazino im Gespräch mit Jochen Kölsch im Rahmen der Sendung alpha-forum vom 22. Oktober 2007. Online: <https://www.br.de/fernsehen/ardalpha/sendungen/alpha-forum/wilhelm-genazino-gespraech100.pdf>. 
In jedem Fall kann es bei aller In-eins-Setzungen hier nicht darum gehen, das als überholt bekannte Problem, Autoren auf die Couch legen bzw. über deren Figuren Rückschlüsse auf deren Person ziehen zu wollen $(\Rightarrow I .3 .2)$, ernsthaft zu verfolgen. Sobald man nämlich eine allzu große Nähe von Autor und Erzähler bzw. Figur annimmt, läuft man Gefahr, Aussagen zu treffen, wie die von Kämmerlings:

Und damit zum schlimmsten Makel dieses skandalös schlecht lektorierten Buchs: Wann spielt das alles eigentlich? In welcher Welt? Es wird mit Euro bezahlt, der Erzähler ist Anfang vierzig, angeblich ein Akademiker, der es aber „außerordentlich“ findet, „dass es jetzt eine Zeitung für Obdachlose gab“. Und als er sich an die Rummelplätze seiner Kindheit erinnert, denkt er an „kleine Holzgatter“ mit Esel oder Ponys: „Mehr gab es damals nicht zu sehen. Jetzt ging ich an lärmenden Fahrgeschäften und halb verlassenen Losbuden vorbei“. Tatsächlich schiebt der 68-jährige Genazino hier seinem 25 Jahre jüngeren Alter Ego die eigenen Kindheitserinnerungen unter. ${ }^{17}$

Was hilft es, vermittelt über eine Figur ein möglicherweise ,unbearbeitetes` Lebensereignis (s.o.) des Autors kennenzulernen? Ja, Rummelplätze tauchen häufiger auf ( $\Rightarrow$ I.2.2), vielleicht hat oder hatte Genazino auch privat ein Faible für sie. So what? Obwohl es so kurzsichtig wie ergebnislos ist, die Figur als „Alter Ego“ Genazinos anzusehen, ist Kämmerlings Kritik ansonsten fruchtbar zu verfolgen. Genazino sind wiederholt Schnitzer bei der Textkomposition vorgeworfen worden und weitere zu identifizieren fällt nicht schwer: In Wilhelm Genazinos Roman Ein Regenschirm für diesen Tag passt das Spielen in Nachkriegsbaustellen nicht in die erzählte Zeit (vgl. Regenschirm, S. 113); es besteht eine Inkohärenz zwischen der als lebhaft draußen zugebrachten Kindheit in Die Obdachlosigkeit der Fische und der Einschätzung, nach der die Protagonisten „so verstört über die Langeweile der Wohnung und der Welt und der Kindheit" seien (Obdachlosigkeit, S. 107). Auch in Die Liebesblödigkeit konterkariert die vermeintliche Kindheitserinnerung, der Ich-Erzähler habe aus Hunger „an den Endstücken der Lederriemen meiner Hosenträger gekaut" (Liebesblödigkeit, S. 195), die zuvor getroffene Aussage, er habe sein Lebtag nicht Hunger leiden müssen (vgl. Liebesblödigkeit, S. 127; vgl. Heimweh, S. 127 vs. S. 163). Diese Inkonsistenzen lassen sich aber besser im Sinne eines ,Störreglers‘ auf dem Mischpult $(\Leftrightarrow I .2 .2)$ begreifen oder als Vorbote nicht wirklich vollumfänglich zufriedenstellend lektorierter Romane insgesamt $\Leftrightarrow$ I.2.1) verbuchen als für eine Parallelisierung von Kindheitserinnerungen im Verständnis geteilter Erfahrung von Genazino und Erzähler bzw. Figur - selbst dann nicht, wenn man die Absicht wiederholter richtiger Geschichten als Argument ins Feld führt. Vielmehr ist von mehreren Zeitebenen auszugehen: Die erzählte Gegenwart, so sie denn markiert ist, und diejenigen unzähligen Analepsen, in denen hauptsächlich die Adenauer-Ära der Bundesrepublik Deutschland das Bezugssystem bildet. 


\section{SOZIALGESCHICHTE}

Zunächst exemplarisch zu zwei klar markierten sozioökonomischen und sozialgeschichtlichen Anspielungen, die zeitlich eindeutig nach der unmittelbaren Nachkriegszeit angesiedelt sind und zudem eine große Nähe zur Erzählgegenwart beanspruchen. Die lakonische Feststellung Abschaffels, es habe „[i]n den letzten Wochen [...] wieder mehrere kleine Sprengstoffanschläge im Bahnhof gegeben“ (Sorgen, S. 318), lässt sich zeitlich zunächst - nicht nur aufgrund des Erstveröffentlichungsdatums im Jahr 1978 - mit dem Deutschen Herbst in Verbindung bringen. Allerdings ,nutzt' Genazino die folgenden Szenen nicht dazu, um in irgendeiner Weise die Debatte um die RAF, um Verständnis oder Sympathieverlust aufzugreifen, sondern er schildert genazinotypisch eine Einzelbeobachtung. Zwar ist die sozialgeschichtliche Rahmenbildung erzähllogisch erforderlich, um die beobachtete Kontrolle eines ,junge[n] Mann[s] mit einem großen schweren Koffer" (Sorgen, S. 318) zu plausibilisieren, aber es hätte genauso gut eine zu passierende Grenze sein können, die diese Funktion hätte übernehmen können. Das Augenmerk gilt nämlich der Tatsache, dass besagter Mann nur leere Flaschen in seinem Koffer hat sowie dessen Reaktion in der Interaktion mit den Beamten. Ähnlich verhält es sich mit der Bedeutung der Sozialgeschichte im Roman Fremde Kämpfe:

Dahinter die vergitterten Kampffahrzeuge mit Kommandokabinen obendrauf, aus denen vorne drehbare Wasserrohre herausragten. [...] Im Augenblick fehlten nur noch die Menschen, gegen die sich das alles richtete. Wer bloß eine Siedewurst in der Hand hielt, war noch kein Feind. Peschek hatte keine Lust, in fremde Kämpfe hineinzugeraten. (Fremde Kämpfe, S. 67)

Obwohl Peschek in der Folge einen von der Polizei eskortierten „geordneten Demonstrationszug“ (Fremde Kämpfe, S. 67) beobachtet, dessen Teilnehmer er „für anständige, aber hoffnungslos konservative Menschen“ (Fremde Kämpfe, S. 68) hält, und obwohl er daraus den durchaus als Gesellschafts- und/oder Systemkritik interpretierbaren Schluss zieht: „Das Ziel der Geschichte war, aus allen Menschen Einzelkämpfer zu machen: die Polizei hatte es schon begriffen“ (Fremde Kämpfe, S. 68), verlaufen sich unmittelbar danach Demonstration, Zuschauer und also auch Peschek - ohne bleibende Wirkung für die Handlung in der Erzählgegenwart Anfang der 1980er Jahre oder Pescheks Einstellungen generell.

Zwar kann der Leser in den genannten Beispielen Kämmerlings Frage nach dem ,Wann` beantworten, ${ }^{18}$ aber ,hilft' dieses Wissen ihm bei der Interpretation zumal handlungsmotivationaler Aspekte? Diesen konkreten zeitgeschichtlichen Fixpunkten, die zwar für die jeweilige situative

18 Es gibt diesbezüglich immer wieder eingestreute Hinweise. So ist in Laslinstraße, S. 154, von Farah Diba zu lesen; in Abschaffel, S. 62, von einer bestimmten Kafka-Ausgabe - „billige[] Taschenbuchausgabe (Fischer Bücherei Nr. 1078)“ -, die als frühestmögliche Erzählgegenwart 1970 fixiert; in Ausschweifung, S. 5 u. S. 220, lässt sich aus den gegebenen Informationen schließen, dass Fuchs in den 1950er Jahren halbwüchsig gewesen sein muss - wie auch in Licht - und die Erzählgegenwart Anfang der 1980er Jahre liegt. Tagesaktuelle Bezüge etwa zur Flüchtlingskrise in Kein Geld werden immer wieder durch vermeintlich konkrete, sich aber als ,Fakenews' entpuppende Informationen konterkariert (vgl. Kein Geld, S. 78 f.). 
'Stimmung' eine gewisse Relevanz haben, immer wieder aber darauf befragt werden müssen, ob die einmalige Nennung ausreicht, um einen ganzen Roman psychosozial in diese Zeit zu versetzen, entgegen stehen flächendeckend ,die neuen schlechten Zeiten', die sich sowohl retrospektiv auf Wirtschaftskrisen als auch auf neuere Aspekte beziehen können: „Zum erstenmal sah Peschek das kleinliche Gesicht der schlechten Zeiten." (Fremde Kämpfe, S. 104) Dass damit die zweite Ölkrise und die damit in Zusammenhang stehende Rezession literarisch aufgegriffen werden, ist naheliegend (vgl. Fremde Kämpfe, S. 17 u. S. 182), die Allgegenwart der Armutsbeobachtung in Genazinos Romanschaffen indes abstrahiert von dieser konkreten Verortung: „Die höchste vorstellbare Einsamkeit, die Irritation des inmitten des Reichtums erklärungslos Verelendeten, hat den Mann längst unansprechbar gemacht.“ (Frauen, S. 38) Oder:

Es gab in der Stadt immer mehr Leute, die plötzlich ohne Arbeit waren und nach einer Weile die Miete nicht mehr zahlen konnten. Jetzt waren die Mieter verschwunden, vertrieben, verstoßen oder vielleicht sogar verstorben, und die Sachen, mit denen sie gelebt hatten, verwandelten sich in diesen Minuten in Sperrmüll. (Kassiererinnen, S. 113)

Dieses und ähnliche Phänomene werden bei Genazino immer wieder mit einem „plötzlich“ oder mit der Markierung der Neuartigkeit bedacht, wobei es sehr fragwürdig scheint, ob diese Unvermitteltheit je sozialgeschichtlich durch gesellschaftlichen Wandel verbürgt ist, eher der erstmaligen Aufmerksamkeit des Protagonisten geschuldet ist oder es sich eventuell gar um eine Floskel handelt, um sozialen Problemen in der Diegese mehr Gewicht zu verleihen. Unverkennbar werden im folgenden Beispiel die sozial Marginalisierten der Erzählgegenwart als unfreiwillige Teilnehmer eines ,Kriegs', eines mehr oder minder metaphorischen ,Überlebenskampfs“ dargestellt:

Aber wer wie Theo in einem heutigen Krieg kämpft, trägt keinen Verband, sondern ein paar schmutzige, ineinandergeschobene Plastiktüten. Die heute Kämpfenden wissen nicht recht, wer oder was sie angreift und gegen wen oder was sie sich wehren müssen. Sie wissen nicht einmal genau, wann und warum ihnen der Krieg erklärt wurde. Sie gehen nur immer wieder auf ein sonderbar ruhiges Schlachtfeld, von dem sie jeden Tag ein wenig elender zurückkehren. (Einfalt, S. 153)

Das hat wiederum durchaus Auswirkungen auf das Selbstkonzept, welches Genazino in seinen Romanen verhandelt. Allerdings tritt hier auch ein Problem zutage: Kämmerlings nennt Genazinos Diegese eine „als Gegenwart kostümierte Retro-Welt“,19 der es eigen ist, konkrete Erzählgegenwart und frühere bundesrepublikanische Ist-Zustände ineinanderzuschieben. Würde Genazino (Figur) im zitierten Beispiel jetzt noch eine Kindheitserinnerung in den Sinn kommen, die Armut im Rahmen der unmittelbaren Nachkriegszeit situiert, würde es mitunter nahezu unmöglich, die Zeitebenen klar voneinander zu trennen. Einfach gelingt dies freilich, wenn die Referenz nicht nur deutlich gemacht, sondern auch mit der Nennung von ,Nachkriegszeit' klar wird:

Augenblicksweise ging mir auf, warum mir die Nachkriegszeit damals gefiel: Die Gesichter der Menschen waren voller eingestandenem Entsetzen. Es gab weit und breit niemanden, der von ihnen 
verlangte, daß sie fröhlich, erfolgreich, lustig, optimistisch oder sonstwie sein sollten. (Wohnung, S. 88)

Das Kolorit, mit dem die Nachkriegszeit gemalt wird, ist nicht nur metaphorisch hauptsächlich farb- und mithin trostlos - „[d]enn damals gab es noch kein Farbfernsehen“ (Falsche Jahre, S. 446) -: „[E]s war eines der schwarzen unscheinbaren Räder der Nachkriegszeit, mit dem gewöhnlich die stummen Väter zur Arbeit fuhren." (Sorgen, S. 186) Diese aus der Trümmerliteratur bestens bekannten Vaterfiguren und ihre massiven Probleme bevölkern viele Romane Genazinos:

Vater hatte nicht bemerkt, daß es jetzt nicht mehr ehrverletzend für einen verheirateten Mann war, wenn die Ehefrau ebenfalls arbeitete, um das Ziel eines möglichst großzügigen Konsums zu erreichen. [...] Wie vor dem Weltkrieg fürchtete Vater, als Versager zu gelten, wenn offenbar würde, daß das von ihm nach Hause gebrachte Geld nicht genügte. (Einfalt, S. 28)

Im Kontrast werden die als abenteuerreich im Gedächtnis fixierten Momente erinnert: „In der Nachkriegszeit war Herr Fuchs als kleiner Junge fast jeden Tag auf irgendeinem Schrottplatz der Stadt zu finden gewesen. Mit anderen Kindern war er tagelang in den Ruinen der Häuser herumgeklettert und hatte alles abgeschraubt" (Ausschweifung, S. 45).

Auch einzelne Verhaltensweisen der literarischen Hauptfiguren in der jeweiligen Erzählgegenwart resultieren aus dieser, anderen Zeit' $(\Rightarrow$ II.1.6), illuminieren sie und verschieben sie zugleich anachron (vgl. Sorgen; vgl. Laslinstraße, S. 157 u. S. 178 ff.). An zwei Stellen des bis dato vorliegenden Gesamtwerks wird unüblich deutlich Bezug nicht nur auf die Nachkriegszeit, sondern auch auf die Kriegszeit genommen: Einmal geht es um die Aburteilung des NS-Regimes, die allerdings über die fiktionalisierte Lebensgeschichte von Paul Celans Mutter realisiert wird (vgl. Frauen, S. 82 ff.), einmal wird um Verständnis für die aufgrund des Zweiten Weltkriegs ,zerstörten' Eltern geworben (vgl. Kein Geld, S. 73 f.).

Wichtig ist: Bei diesen kurzen Passagen bleibt es dann aber auch. In rund 150 Seiten Roman wie en passant kleine sozialgeschichtliche, in seltenen Fällen auch dezidiert sozialkritische Blöcke einzumontieren, reicht nicht für eine interpretatorische Schwerpunktsetzung. Zumal ein einziger kleiner Schritt ins ,Meta' der Abstraktion klarer sehen lässt: Warum und wie genau Genazinos Figurenbasistypus ,dies und jenes' tut, bestimmte Verhaltensmuster an den Tag legt und zu Handlungsstrategien aufgrund benennbarer Motivationslagen greift, lässt sich nahezu ,sozialgeschichtslos‘ adäquat beschreiben und strukturieren. ${ }^{20}$ In den deutenden Passagen indes muss selbstredend Sozialgeschichtliches Einzug halten: Sich heutzutage einer Frau derart massiv zu nähern, wie es die Protagonisten allenthalben - insbesondere in den frühen Romanen - tun, wäre heute nicht nur aufgrund der unlängst neu aufgekeimten Sexismusdebatte um \#MeToo (glücklicherweise) auch literarisch undenkbar ( $\Rightarrow$ II.5.3), wohingegen in der Erzählvergangenheit allenthalben auch kritiklos von übergriffigem Verhalten seitens Frauen und Männern gespro-

20 Dass es sich mehrfach um zeitlose Schilderungen handelt, versprachlicht auch der Romantext bisweilen: „Es herrschte die normale Langeweile zwischen den Generationen.“ (Ausschweifung, S. 279) 
chen wird, die aus den kindlichen Erinnerungsbildern ihre Schatten in die Erzählgegenwart werfen. Doch nicht nur der Genderdiskurs hat bei Genazino seine Wurzeln in die (Erzähl-)Vergangenheit getrieben: „Auch [...] Schamerlebnisse speisen sich vielfach aus Kindheitserinnerungen der Protagonisten an die 1950er Jahre und werden im Laufe der Texte mehrfach reflektiert, umformuliert und analysiert." 21

\section{SCHAM}

Scham, als letzte hier abzuhandelnde Kategorie, ist zwar ,offiziell' keine der sieben Basisemotionen - Freude, Wut, Furcht, Ekel, Traurigkeit, Überraschung und Verachtung -, liest man Genazino, kann sie aber als eine höchst basale Emotion des Basistypus gelten. Sie kann bei Genazino eine sein über mangelnden Erfolg oder Erfolg, über Beobachtetwerden oder Beobachten (oder beim Beobachten beobachtet werden). Das auch expressis verbis unglaublich häufige Auftauchen von Scham hat nicht nur die Forschung inspiriert, ${ }^{22}$ sondern auch dazu geführt, dass unter den Begriff in der sich noch etablierenden Genazino-Forschung ( $\Rightarrow$ I.1 u. $\Rightarrow$ I.1.2) höchst Diverses subsumiert worden ist, was sich durch die bereits von Genazino groß angelegte Begriffsintension noch potenziert hat. Anhand weniger Beispiele kann dies demonstriert werden:

Nach dem Abendbrot räume ich die Lebensmittel zurück in den Kühlschrank, ich spüle Geschirr, ich putze Lauras und meine Schuhe, ich reinige die Badewanne und bringe die Mülltüten in den Hof. Ich möchte herausfinden, warum ich während des Ablaufs dieser Vorgänge neuerdings Scham empfinde. Unklar ist schon, ob ich die Tätigkeiten selber als beschämend einschätze oder nur ihre Ausführung durch meine Person. Ich spekuliere, der Grund der Scham werde sich von selber preisgeben, je genauer ich die Arbeiten und meine Reaktion auf sie beobachte. Eine solche Selbstenthüllung ist im Augenblick nicht in Sicht. Die Scham wird durch Wiederholungen nur undeutlicher, aber nicht einsichtiger. (Licht, S. 110 f.)

Das Unterfangen, die Notwendigkeit aufzuzeigen, weshalb Scham generell zwar eine für Genazino ergiebig zu untersuchende Größe darstellt, in der vorliegenden Untersuchung allerdings detaillierter untergliedert werden muss, lässt sich beginnen, indem man bereits im zitierten Beispiel mit der (begrifflichen) ,Unklarheit' konfrontiert wird: Handelt es sich um Selbst- oder Fremdscham? ${ }^{23}$ Aus welchen Gründen ließe sich ,objektiv‘ oder ,subjektiv‘ das Aufkommen von Scham erklären? Möglicherweise ließen sich gendertheoriesensibel die „Tätigkeiten“ als weiblich codierte und mithin einem Mann nicht wohl anstehende begreifen ( $\Rightarrow$ II.5.3) - aber das ist bereits eine die textliche Vorgabe weit dehnende Interpretation. Das folgende Beispiel fügt eine Begriffsfacette hinzu, die dem hier verwendeten Konzept der öffentlichen bzw. privaten Selbstaufmerksamkeit $(\Rightarrow$ II.2.4) nahe kommt:

21 Ball: Das Phänomen Scham bei Wilhelm Genazino, S. 25.

22 Vgl. Ball: Das Phänomen Scham bei Wilhelm Genazino; vgl. Hirsch: Geheimgeschichten. Die (Ent)deckung der Scham.

23 Vgl. dazu Peter Ecker, der sich der Fremdscham bei Genazino annimmt (vgl. Ecker: Schiffbruch mit Zuschauer II). 
Ich empfinde Glück über die vielen mich streifenden Blicke. Das Bedürfnis der Menschen nach etwas, das sie nicht angeben können, bestärkt mich darin, mein Gesicht schamlos und kindisch in die vorübergleitenden Blicke der anderen hineinzuhalten. Ich strenge mich an, den Passanten zu zeigen, daß ich ihr Bedürfnis kenne und es teile. (Einfalt, S. 138) ${ }^{24}$

Das Wort „schamlos“ suspendiert hier die übliche Neigung des Basistypus, nicht von anderen beobachtet werden und mithin unsichtbar sein zu wollen sowie den (imaginierten) öffentlichen Blick auf sich selbst, fraglos. Damit nähert es sich den hier vertretenen Hypothesen an und ähnelt den Konzepten. Aber nicht jede Handlung aus Maximen der öffentlichen Selbstaufmerksamkeit/Neigung zur Unsichtbarkeit ist auch ein Schamphänomen, sodass ,Scham' ein Sammelbecken ist, das analytisch nichts hergibt. Vielmehr sind, wäre elektronisch verfahren worden, alle Stellen, an denen Scham auftaucht, genau auf die jeweils vorliegende Begriffsverwendung zu untersuchen gewesen, um sie an die ,passende' Stelle in dieser Arbeit zu sortieren - was sich nicht zuletzt aus dem Grund verboten hat, dass ,Scham' tausendfach vorkommt:

Bezugspunkt beinahe aller Prosawerke des Autors ist die Enge der kleinbürgerlichen Verhältnisse der 1950er Jahre, die dort sorgfältig gepflegten Neurosen und tief verinnerlichten Schuldgefühle. Beherrschend für das Befinden der in diesem Klima aufgewachsenen, meist männlichen Hauptfiguren ist ein undefinierbares, an Kafka erinnerndes Gefühl der Scham, aus dem es kein Entkommen gibt und das den weiteren Lebensweg, insbesondere die persönlichen Beziehungen der Figuren entscheidend prägt. ${ }^{25}$

Reschke bringt es auf den Punkt: Erstens sträubt sich das Schamgefühl bei Genazino dem konzeptualisierenden Zugriff, zweitens ist es als Grundgefühl immer schon vorab da - es befindet sich also am linkesten Ende der Handlungserklärungschematik ( $\Rightarrow$ I.3.1/Abb. 3), welche hier indessen begründet ausgeschlossen worden ist - nicht zuletzt aus dem gewichtigen Grund, dass alles im Bereich der Causal History zwar weiterhin wirkt, aber niemals alleine als Erklärungsmuster für Handlungsstrategien befriedigen kann: Das Kind armer Eltern ist nicht aufgrund dieser Tatsache per se Neureichen und Emporkömmlingen gegenüber skeptisch, ${ }^{26}$ denn viele andere Kinder armer Eltern sind es nicht. Hirsch spricht in diesem Zusammenhang von einer „Scham zweiter Ordnung“, die „das Ursprungsgefühl, welches die Scham überhaupt auslöste, mehr und mehr in den Hintergrund“ treten lässt. ${ }^{27}$ Damit beglaubigt sie indirekt beide Einwände gegen die Scham-Untersuchungen der Genazino-Prosa: Erstens ist die „Scham zweiter Ordnung" nur noch ein Platzhalter, ein Sammelbegriff, der andere Affekte überdeckt, weshalb keinerlei Trennschärfe und also auch keine Einheitlichkeit im Sinne der hier verfolgten romanübergreifenden Untersuchungs-Anlage zu gewinnen ist. Zweitens wäre die Suche nach der ursprünglichen ,Scham erster Ordnung' nur psychoanalytisch und hinsichtlich der Causal History möglich.

24 Es handelt sich um eine höchst seltene Ausnahme wie auch im folgenden Beispiel für eine positiv empfundene (Fremd-)Scham: „Nach ungefähr fünfzehn Minuten empfand ich plötzlich Scham über die alt gewordenen Sänger. Gleichzeitig gefiel mir meine Scham, was für mich etwas Neues war. Gewöhnlich rief Scham mein Missfallen hervor. Aber jetzt betrachtete ich sie mit Wohlgefallen und war froh, dass es sie gab." (Tiere, S. 129) 
Mögen auch Genazino selbst oder seinen Figuren durch ihre Sozialisation während der Adenauerära, die Konstellation und die Wesensart ihrer Eltern oder durch sonst welche Faktoren Schuld und Scham ${ }^{28}$,in die Wiege' gelegt worden sein - für eine Untersuchung der Handlungsund Motivationsmuster der Figuren, bei der feingliedrige Einzelhandlungen analysiert werden müssen, und die nicht rein psychoanalytisch verfährt $(\Leftrightarrow I .3 .2)$, besitzt die Untersuchungskategorie ,Scham' aufgrund ihrer begrifflichen Unschärfe und situativen Beliebigkeit bei Genazino keine große Relevanz.

Genug des Solls, hin zum Haben.

28 Vgl. zur systematischen, affekttheoretischen Verknüpfung von Scham und Schuld Claudia Benthien: Tribunal der Blicke. Kulturtheorien von Scham und Schuld und die Tragödie um 1800. Köln 2011. Vgl. zu den Schuldgefühlen des Genazino'schen Basistypus, seinen Ängsten und Unsicherheiten Florian Öchsner: Subjekte der Arbeit in der Gegenwartsliteratur. Enno Stahls Diese Seelen und Wilhelm Genazinos Das Glück in glücksfernen Zeiten. In: Susanna Brogi/Carolin Freier/Ulf Freier-Otten/Katja Hartosch (Hg.): Repräsentationen von Arbeit. Transdisziplinäre Analysen und künstlerische Produktionen. Bielefeld 2013, S. 347-364. 
Teil II: Schlaglichter 



\section{Innenwelten - Außenwirkungen}

„Wie sonderbar unser Innenleben organisiert ist, denke ich und seufze ein bißchen." (Heimweh, S. 40)

Alle in diesem Schlaglicht getroffenen Aussagen grundieren gewissermaßen den Genazino'schen Basistypus und tauchen - mal mehr, mal weniger prominent - in den folgenden Schlaglichtern immer wieder auf. Die angerissenen Themenbereiche rund um innere Einstellungen des Basistypus und um dessen äußere Wirkung lassen sich insofern als Meta-Kategorien verstehen, als etwa die Reflexionen zu Individuum vs. Gesellschaft $(\Leftrightarrow I$ I.1.1) in alle übrigen Schlaglichter strahlen und hier nicht eigentlich konkrete Verhaltensstrategien verhandelt werden, sondern vielmehr eine (Theory-of-),Mind-Map', die sich in allen Folgekapiteln als Wegweiser gebrauchen lässt, skizziert wird.

Damit versteht sich dieses Schlaglicht einerseits als Fortsetzung und Ausarbeitung derjenigen unter $\Leftrightarrow(I .2 .5)$ in Aussicht gestellten Charakteristika von Genazinos Figuren, andererseits als darüber hinausgehender Fundus von Untersuchungskategorien und basalen Präliminarien, die in den folgenden Schlaglichtern in variabler Kombination den Einzeluntersuchungen Leitplanken geben.

Nach einer für Genazino schon vergleichsweise gut untersuchten Auseinandersetzung mit Aspekten von Vergesellschaftung und Individualität, ohne die kein einziger Roman Genazinos auch nur in Ansätzen adäquat zu lesen ist $(\Leftrightarrow$ II.1.1), wird auf die grundlegende und auf den ersten Blick ambivalente Haltung zur Eindruckssteuerung von Genazinos Figuren selbst abgehoben $(\Leftrightarrow$ II.1.2). Inbegriffen sind die für die Erzähltheorie bereits angeklungenen $(\Rightarrow I .2 .3)$ Kategorien des Täuschens, der unterschiedlichen Wahrheitsversionen und der Lüge.

Als kleinster gemeinsamer Nenner der Familienähnlichkeiten führt das dritte Unterkapitel ( $\Rightarrow$ II.1.3) dezidiert das Unterfangen fort, die immer wieder auftauchenden Persönlichkeitseigenarten des Basistypus einzufangen. Dabei wird neben der neutralen Bestandsaufnahme vor allem auch von den gesellschaftlich sanktionierten oder beargwöhnten Marotten, Merkwürdigkeiten, psychischen Problemen wie Zwängen und Neurosen zu sprechen sein, die Genazinos Figuren erst zu solchen machen und einen beträchtlichen Leserreiz wie Analyseansatzpunkt gleichermaßen darstellen.

Was weiter unten in den anderen Schlaglichtern, sofern nötig, erneut auf das jeweilige Untersuchungsobjekt zugeschnitten wird, nämlich die unterschiedlichen Manifestationsformen der interessierenden Verhaltens- und Eindruckssteuerungsstrategien, wird darauf folgend $(\Leftrightarrow$ II.1.4) bereits einmal global besehen eruiert werden: Welche figurenanalytisch relevanten Ausdrucksformen neben der Verbalsprache stehen einem Roman zu Gebote? Körpersprache ist solch ein 
Ansatzpunkt, der Verstehen und Nicht-Verstehen genauso maßgeblich tangiert, wie es die Blickregie oder das (Ver-)Schweigen ihrerseits tun.

Abschließend malen die beiden letzten Kapitel des ersten Schlaglichts ein kleines Sittengemälde des Genazino’schen Basistypus: Zunächst wird der Lebensstil samt Diskussion des Milieubegriffs unter die Lupe genommen ( $\Rightarrow$ II.1.5), um Aussagen etwa zur Kapitalstruktur(analyse) oder symboltragenden, selbstergänzenden Gegenständen und deren Relevanz für Genazinos Romanfiguren treffen zu können. Das letzte Unterkapitel $(\Rightarrow$ II.1.6) hingegen zoomt noch weiter hinaus und abstrahiert einige wenige über die Romangrenzen hinweg gültige Weltanschauungen, Überzeugungen und Einstellungen der Figurenwelt, wie sie sich bspw. in der Grundüberzeugung, es mit einer maroden konsumkapitalistischen Welt zu tun zu haben, widerspiegelt. ${ }^{1}$

\subsection{Individuum vs. Gesellschaft, Distinktion vs. Zugehörigkeit}

Genazinos Romanfiguren sind erstens stets unsicher, ob es sich überhaupt lohne, die eigene Stellung im gesellschaftlichen Gefüge suchen zu sollen, oder ob lieber direkt ein möglichst weiter Bogen um potenzielle Vergesellschaftungsmechanismen erste Wahl sei.2 Zweitens und in Affirmation der ersten Erwägung sind sie entweder noch auf der Suche nach ihrer Position und dann wiederum unschlüssig, wo sie ihren Platz am liebsten fänden, oder, haben sie eine solche bereits gefunden, sind sie damit unzufrieden. Aber zurück zur ersten Unterscheidung: ,Die Gesellschaft ${ }^{3}$ kommt bei Genazinos Figurenbasistypus in aller Regel nicht gut weg ( $\Rightarrow$ II.1.6). Dennoch ist selbst den angeekeltsten Protagonisten die Tendenz eingeschrieben, eine wie auch immer geartete Bezugnahme zum Referenzsystem ,Gesellschaft' aufrechtzuerhalten: „[S]tarr halte ich die Mitte zwischen Neugier und Abscheu.“ (Frauen, S. 35) ,Zugehörigkeit versus Distinktion“ ist ein implizit permanent mitzulesender Trigger des Figurenhandelns und wenn ein Protagonist einmal wissend geworden sein sollte, hält er lakonisch und präzise zugleich Sentenzen wie die folgende in Richtung der Nachgeborenen parat: „Sie sind noch so jung, daß sie ihren wichtigsten Konflikt noch gar nicht erkannt haben: ob sie aus der Gesellschaft heraus- oder erst richtig in sie hineinwollen." (Fleck, S. 15) Die Wichtigkeit dieses Komplexes hat freilich die Forschung klar erkannt:

In Genazinos Werk berühren sich [...] individuelle wie gesellschaftliche Faktoren, werden hier doch [...] anthropologisch-psychologische Diagnosen des Einzelnen und seines vergesellschafteten $\mathrm{Zu}$ -

1 Für alle folgenden Ausführungen muss die prinzipielle Unterscheidbarkeit in Selbst- vs. Fremdcharakterisierung vergegenwärtigt werden, die bereits im Figurenkapitel $(\Leftrightarrow I .2 .4)$ angeklungen ist und im zweiten Schlaglicht ( $\Rightarrow$ II.2.1) noch einmal aufgerollt wird. Eng dazu gehören auch die unterschiedlichen Möglichkeiten, sich Wissen über sich selbst anzueignen ( $\Rightarrow I$ I.4).

2 Vgl. das Walser-Motto, das der Vernichtung der Sorgen vorangestellt ist: „Ich bin einer der Vielen, und das gerade finde ich so seltsam." (Sorgen, S. 159)

3 Vgl. zur Terminologie und dem Verhältnis von Genazinos Figuren und soziologischer Betrachtung insbesondere Fischer: Wider das System. 
sammenlebens mit wahrnehmungsphilosophischen und nicht zuletzt kunsttheoretischen Reflexionen verbunden. ${ }^{4}$

Die Reflexe in den Romanen sind so vielfältig, dass es fast beliebig anmutet, wo man hineinzoomt, wenn man eine erste Übersicht geben möchte. Dabei sind die entsprechenden Aussagen manchmal glasklar, wie die eben genannten Beispiele, manchmal aber auch eher verklausuliert: „Die Biografie macht immer zwei Personen aus uns: einen einzelnen Bestimmten und einen einzelnen Irgendjemand." (Einfalt, S. 149) Um sich in diesen Gewässern zwischen den Polen von Individualität und Gesellschaft zurechtzufinden, diene laut Honold „[a]ls Leitkompass des Helden [...] eine navigatorische Vernunft, welche die Sozialtauglichkeit eines tendenziell idiosynkratischen Individuums in der richtigen Dosierung von Abstand und Zugehörigkeit stets wieder aufs Neue auszutarieren versucht. ${ }^{\text {" }}$ Das in Rede stehende Geflecht scheint sich entwirren zu lassen, wenn man fürs Erste strukturalistische Raster bildet.

\section{DIE STRUKTURALISTISCHE ANNÄHERUNG...}

Dabei bietet sich folgender Dreischritt an: In der Nähe welches Pols (Individuum vs. Gesellschaft) wähnen sich die Protagonisten? Inwieweit sind sie damit zufrieden? Welcher Leidensdruck, welche Navigationsbereitschaft zwischen Distinktion(swunsch) und Zugehörigkeit(swunsch) geht damit einher?

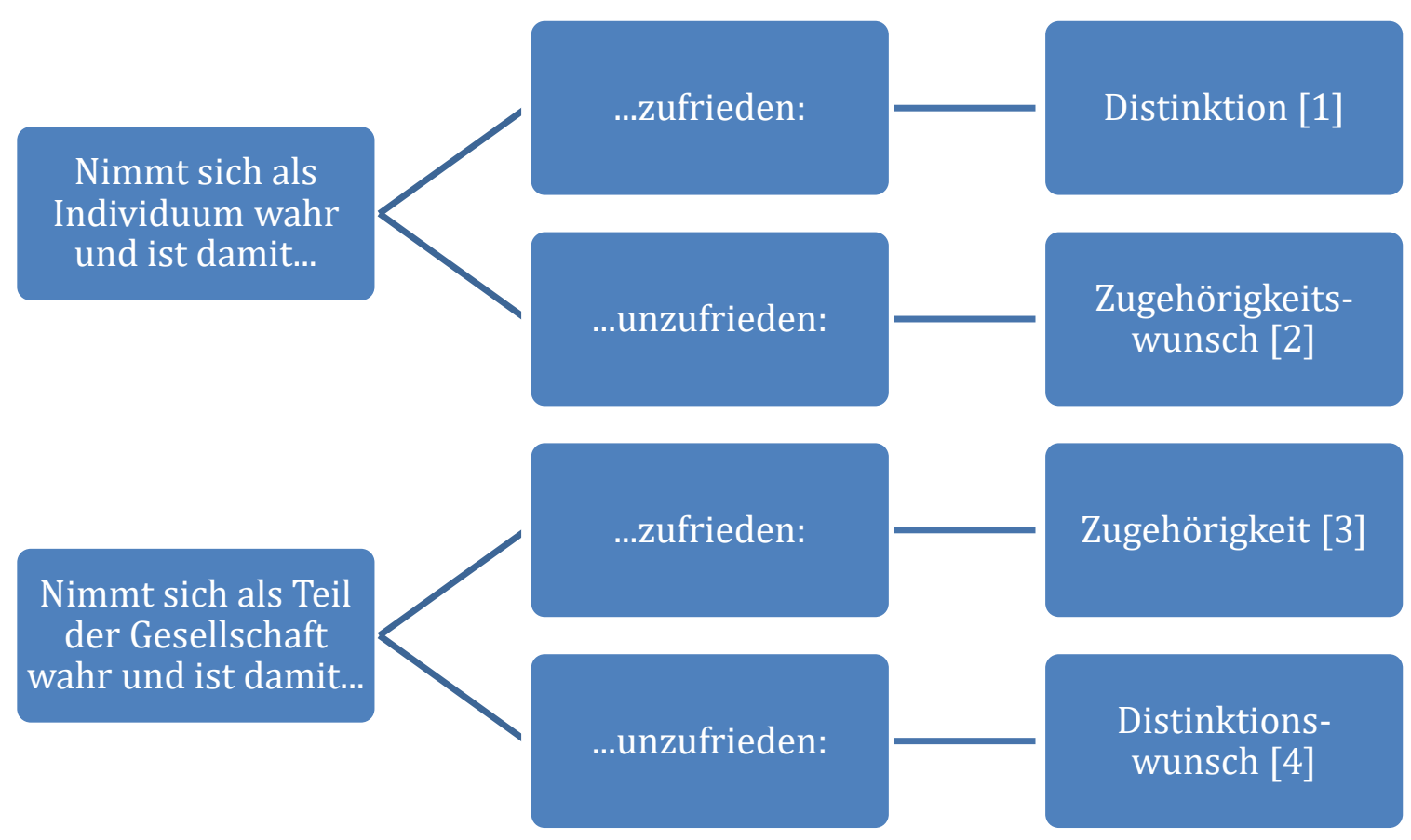

Abbildung 8: Pfaddiagramm Individuum vs. Gesellschaft

4 Bartl/Marx: Wiederholte „Verstehensanfänge“, S. 10; vgl. Fansa: Unterwegs im Monolog, S. 141.

5 Honold: Doppelleben, halbbitter, S. 43. Honold bezieht sich an dieser Stelle auf Abschaffel. 
Anders als in hochkomplexen Schemata strukturalistischer Provenienz, ${ }^{6}$ sind alle Optionen reichhaltig mit Belegstellen unterfütterbar. Allerdings handelt es sich hier ,nur' um eine Hinleitung zu einem grundsätzlicheren Problem und mithin sollen einige wenige kommentierte Beispiele genügen.

„Sie schienen ihre Dumpfheit nicht zu bekämpfen. Sie erlaubte ihnen, als Halbtote durch das Leben zu kommen." (Wohnung, S. 22 f.) Im Duktus des altbekannten Unterschieds von ,Wir haben gewonnen' vs. ,Die haben verloren' geht mit der offensiven Herabwürdigung der ,third party' $\Leftrightarrow$ I.3.3) auch die 3. Person Plural einher, womit zwischen zwei unterscheidbaren Positionen eine Demarkationslinie gezogen wird: „Er glaubte, daß zwischen ihm und den anderen ein grundsätzlicher Unterschied war." (Sorgen, S. 160) Mit den abweichenden Überzeugungen $\Leftrightarrow$ II.1.6) und Lebensstilen ( $\Rightarrow$ II.1.5) und also dem Status Quo der Distinktion bei gleichzeitiger Wahrnehmung als Individuum sind die Protagonisten durchaus zufrieden, da mit der Geringschätzung der anderen immer eine gleichzeitige Hochstufung des eigenen Selbst verbunden ist.

„Gleichzeitig belastete mich die Unzufriedenheit mit meiner derzeitigen Lage. Ich sehnte mich nach mehr Normalität. Wie die meisten anderen Menschen wollte ich tagsüber arbeiten und nachts schlafen und am Wochenende ins Kino gehen." (Regen, S. 20) Was unter der Chiffre der ,Normalität' verborgen wird, ist die implizite Setzung von ,Viele machen das, also ist es wohl normal'. Die empfundene Abweichung wird als unangenehm wahrgenommen, sodass ein unzufrieden gelabeltes Einzelschicksal in den Zugehörigkeitswunsch mündet:

Plötzlich verstand ich die vielen Menschen, die sich immerzu die allerneueste Kleidung, die allerneuesten Schuhe und Taschen, die allerneuesten Brillen und die allerneuesten Autos anschaffen mussten. Auch sie fürchteten offenkundig die Selbstverfremdung, die öffentliche und doch geheime Zurückweisung durch die anderen, die in einem versteckten und doch mitgeteilten Hohn nistete. (Kassiererinnen, S. 125)

Zwar darf die Ironie nicht überlesen werden, aber der Wunsch ,dazuzugehören', ist nichtsdestotrotz sinnfällig.7 $(\Rightarrow$ I.4 u. $\Rightarrow$ II.1.5) Den Übergang zur nächsten Kategorie bilden Aussagen, die im Grenzbereich der Wahrnehmung zwischen Individuum und Gesellschaft anzusiedeln sind: „Ich betrachte die an mir vorbeigehenden Leute und rede mir ein, daß ich so bin wie sie. Ich zähle auf, was ich mit ihnen gemeinsam habe. Eine Weile geht es ganz gut." (Regenschirm, S. 109) Auch hier handelt es sich um den Wunsch, ,normal' zu sein; dass es des Einredens, des Bruders des Selbstbetrugs, bedarf, um sich als Teil der Gesellschaft wahrnehmen zu können, spricht noch für den Zugehörigkeitswunsch. Dass das Herzählen von Gemeinsamkeiten - wenngleich auch nur „eine Weile“ - „ganz gut“ funktioniert, bereits für die tendenziell zufriedene Zugehörigkeit.

\footnotetext{
6 Vgl. etwa Martínez/Scheffel: Einführung in die Erzähltheorie, S. 95.

7 Vgl. für einen dezidierten Zugehörigkeitswunsch: „Immerhin habe ich jetzt das Bedürfnis, zu den anderen Menschen gehören zu wollen." (Fleck, S. 20) Vgl. auch Regenschirm, S. 9 f.
} 
[3]

Erzählpraktisch interessant ist - in der eben bereits angesprochenen Unterscheidung der Personalpronomen - das folgende Beispiel für ungetrübtes Einverständnis mit der Zugehörigkeit zur Gesellschaft: „Wir sind alle nur sommerlich bekleidet.“ (Frauen, S. 8) Zwar handelt es sich eher um Einschätzungen, die am äußeren Kreis der Familienähnlichkeit ihren Platz haben, aber sie sind nichtsdestoweniger überindividuell zu belegen: Sei es während eines öffentlichen Essens (vgl. Frauen, S. 61 f.), währenddessen sich der Protagonist mit der Zugehörigkeit zur Gesellschaft durchaus einverstanden und zufrieden erklärt, sei es während einer getätigten Beobachtung anderer Menschen: „Aus der Entdeckung eines Details ging immer nur die innere Gewißheit hervor, irgendwo dazuzugehören“ (Ausschweifung, S. 26; vgl. Ausschweifung, S. 45).

Bereits mit einem Fragezeichen zu versehen ist die Zufriedenheit des Protagonisten aus Genazinos Roman Wenn wir Tiere wären: Seine Aussagen, er würde sich „einzelne Individuen suchen, mit denen ich mich an versteckten Orten verabreden würde“ (Tiere, S. 28), sowie: „Du täuschst dich. Ich achte sehr darauf, dass ich Menschen, die nicht zu mir passen, aus dem Weg gehe (Tiere, S. 67), relativieren das Einverständnis, dazuzugehören und verengen den Begriff ,Gesellschaft ${ }^{\prime}$ auf eine als solche empfundene ,In-Group’ Gleichgesinnter.

[4]

Diejenigen Menschen, denen der namenlose Ich-Erzähler lieber ausweicht, kennen alle Figuren Genazinos und nicht selten spielt dabei die Verknüpfung mit dem Komplex ,Dünkel als Strategie der Distinktion“ eine wichtige Rolle ( $\Rightarrow$ II.1.3 u. $\Rightarrow$ II.1.5): „Der Anblick der Touristen machte ihm Lust, sich von allen Menschen zu distanzieren." (Ausschweifung, S. 154) Hier im negativen Fall der Pars pro toto, wünscht sich Eckhard Fuchs nichts sehnlicher, als eine Mauer zwischen sich und anderen zu errichten, wie auch Abschaffel „davon überzeugt [war], daß es eine Schande war, mit sinnlosen Kollegen einen sinnlosen Abend in einer sinnlosen Wirtschaft zu verbringen.“ (Sorgen, S. 353) Dieses Grundgefühl des Andersseins, aus dem sich die Unzufriedenheit speist, wird mitunter auch expressis verbis mit ,Vergesellschaftung' in Konnex gebracht: „Andere grillen auf ihren Balkonen, man muß die Fenster schließen, wenn man nicht in Bratwurstgeruch eingehüllt werden möchte. Im Sommer wird man viel stärker vergesellschaftet als im Winter.“ (Liebesblödigkeit, S. 126)

Nahezu tragische Dimensionen nimmt der Distinktionswunsch an, sobald die Unmöglichkeit hervorgekehrt wird, gesellschaftliche Gefüge nicht sanktionslos verlassen zu können: „Und doch machte ich mit, ich schlug den anderen auf die Eier, wie mir auf die Eier geschlagen wurde. Zum erstenmal empfand ich, daß ich nicht in einer solchen, vielleicht in überhaupt keiner Gemeinschaft leben wollte." (Einfalt, S. 122)

Wäre es allerdings so einfach, wäre es allerdings langweilig: Wie so oft verstatten Genazinos Erzähler prima vista die Sortierwut, um sie immer wieder selbst zu thematisieren und zu problematisieren und sie somit ad absurdum zu führen. In bester Genazino-Manier wird dieser 
Schritt ins ,Meta' allerdings sofort unglaublich bodenständig an basale Alltagserfahrungen gebunden, um nicht hochtrabend zu erscheinen: „Kaum hatte ich ihn erhalten, schämte ich mich seiner. Ausgerechnet ich, der sich auf seine Individualität so viel zugute hielt, ging wie ein $x-$ beliebiger Massenmensch mit einem Fertigsalat nach Hause." (Tiere, S. 18) Die FertigsalatSentenz passt nicht mehr in nur eine der vier Schubladen.

\section{... WIRD SUBVERSIV ÜBER DEN HAUFEN GEWORFEN}

Samuel Moser erhebt die „Aspekte der Individuation bei Genazino“ zu seinem Beitragsuntertitel in dem die Forschung allererst wirklich konstituierenden 162. Band der TEXT+KRITIK-Reihe. Hauptsächlich in einer mit „Ja zum Nein“8 überschriebenen Passage bricht er mit der Vorstellung, bei Genazino Gesellschaft und Individualität kontrastiv gegenüberstellen zu können:

Genazinos Philosophie des „Abstands“, wie er sie in der Bremer Preisrede skizziert, besagt, dass sich das Subjekt nur in der Differenz zum Andern bilden kann: „Individualität gewinnen wir nur in der Abweichung." (AB, S. 166) Mit Vehemenz wehrt er sich gegen Habermas' Forderung, Anderssein bedürfe der Akzeptanz durch die andern (AB, S. 42). Darin sieht die Lehrerin in der „Obdachlosigkeit der Fische“ den Horror der „Vergesellschaftung“ (O, S. 121). Genazino ist gar noch provokativer: Er meint mit Differenz nicht einmal Konfrontation. Seine Figuren sind keine Kämpfer des Entweder-Oder: Gesellschaft oder Individuum (AB, S. 48 f.). Es geht ihnen um die „Erfindung“ ihres Lebens in der Mitte der Gesellschaft, die sie entweder zu zerdrücken oder an den Rand zu schleudern droht. Hier „spielen“ sie Selbstbestimmung. Die Menschen können erst dann glücklich sein, wenn sie „zwischen gespielter und echter Verrücktheit jederzeit wählen können“, meint der Schuhtester vertrackt und selbstironisch (R, S. 95). Dafür brauchen sie Fluchträume, Ausweichstellen, Täuschungsmöglichkeiten und Tricks wie die „Nebenbeschäftigungen“ (0, S. 124), zu denen die Lehrerin greift. Genazino nennt sie die „interessanten Manöver“, mit denen sich das Ich konstituiert „unterhalb“ der Verluste ans „kollektive Schicksal der Anonymität und Auswechselbarkeit“ (AB, S. 33). Die Lehrerin ist gefangen in ihrer inneren „Zitadelle“ (O, S. 60), die es ihr nicht erlaubt „ohne Vorbehalte“ (ebd.) zu leben. Aber nur unter diesem Vorbehalt ist Individuation möglich (vgl. AB, S. 167). Mit Erstaunen entdeckt der Schuhtester im „Regenschirm“-Roman, „daß sich neue Identität dann bildet, wenn einem jemand zu nahe tritt“ (R, S. 123), und man sich verbirgt. Während alle „an der Erfindung des Gefühls“ arbeiten, „zur Welt zu gehören“ (R, S. 170), arbeitet er deshalb in die Gegenrichtung: an seiner Nichtzugehörigkeit. Nicht die „innere Genehmigung auf der Welt (zu sein)“ (R, S. 14) erteilt er sich schließlich, sondern die Genehmigung, auch ohne Genehmigung zu leben. ${ }^{9}$

Obwohl diese Beobachtungen im Großen und Ganzen zutreffen mögen, stellt sich Genazinos Textweltrealität noch ein wenig ambivalenter dar. Moser zieht hier bspw. ein Zitat heran, dass es nahelegt, die Wiege der Individualität quasi als Automatismus zu begreifen, der einsetzt, wenn die Differenz „zum Andern“ auf den Plan tritt. Diese nicht zuletzt auf komparativer Prädikatenzuweisung ( $\Rightarrow I .4$ ) fußende Binsenweisheit der Soziologie wie der Sozial- und Persönlichkeitspsychologie muss aber zumeist teuer erkauft werden: „Allzu dichte Nähe wird von allen Lebewesen, Menschen eingeschlossen, als feindlich empfunden.“ (Frauen, S. 163) Mit dieser evolutionär ausgerichteten Einschätzung wird die notwendige ,Austreibung aus dem Paradies der Ein- 
heit', der irgendwann einmal notwendigerweise zerfallenden Zugehörigkeit zu allem und zu allen, als schmerzhafte Erfahrung konnotiert.

Hauptsächlich bezüglich der Punkte ,Zugehörigkeitswunsch', ,Überforderung als Einzelner` und ,Ausloten des Raums zwischen den Polen Individualität und Gesellschaft' soll diese Komplexität unter Heranziehung weiterer Primärtextstellen, die auf Moser bezogen werden können, eruiert werden. Denn Genazino selbst hat zwar paratextuell Position bezogen (prinzipielles Votum für die Individualität, allerdings durch „interessante[] Manöver“ verborgen irgendwo in der Gesellschaft lebend), seine Figuren sind hingegen häufig noch auf der Suche nach ihrer Stellung zwischen Individualität und Gesellschaft und teilen dabei durchaus nicht immer die Frontstellung gegen Habermas: „Ich beobachtete mich in ein paar Schaufensterscheiben und hatte das Gefühl, dass ich genauso undeutlich und verwischt wirkte wie die anderen. Ich wollte anders aussehen als sie und war doch froh, dass ich ihnen glich." (Kassiererinnen, S. 60) Ist es hier noch die Unentschlossenheit, die den Ich-Erzähler im Sowohl-als-auch festhält, bezieht er im Romanverlauf (etwas) deutlicher Position:

Lächerlichkeit war nichts weiter als der Zeitpunkt, an dem eine Zurückweisung öffentlich einsetzte, dachte ich. Seit ich denken konnte, hatte ich immer geglaubt, dass ich irgendwo dazugehörte, und das ,irgendwo' waren in meiner Vorstellung die anderen, die mich nicht kannten, mich aber fraglos akzeptierten. Und doch merkte ich jetzt wieder, dass ich nur vorübergehend zu ihnen gehört hatte oder dass mein Dazugehören immer nur eingebildet war. (Kassiererinnen, S. 124)

Freilich bildet sich Identität erst im Kontrast; die prinzipielle Anerkennung durch die anderen im eigenen Anderssein ist aber auch eine hier noch in Rechnung gestellte Grundbedingung. Zwar beginnt diese Überzeugung zu bröckeln, aber die Konsequenz daraus, gänzlich aus dem Raster zu fallen, gelänge nur, wie Moser zitiert, dann, wenn man switchen könnte: jetzt verrückt, gleich nicht mehr. Da dies sich aber aus naheliegenden Gründen verbietet, erträumt sich der Protagonist aus Ein Regenschirm für diesen Tag vielmehr den radikalen Ausstieg aus der Gesellschaft und den (dauerhaften) Eintritt in die Welt der „Verwirrten, Halbverrückten und Durchgedrehten“:

Ich stelle mir dann vor, daß ich bald zu ihnen gehören werde. Dann werde ich davon befreit sein, mir einen endgültigen und sicheren Beruf suchen und mein Leben so gestalten zu müssen, daß es zu diesem endgültigen und sicheren Beruf paßt. Und ich werde, wenn ich erst selber verwirrt bin, endlich die Kraft haben, alles niederzuhauen und totzumachen, was nicht in dieses endlich gefundene Leben paßt. (Regenschirm, S. 62 f.)

Im Rahmen dieser ,alternativen Peergroup', die mit den Anforderungen des ,normalen', bürgerlichen Lebens nichts zu tun hat und deshalb als desiderable Alternative für den Ich-Erzähler glänzt ( $\Rightarrow$ II.1.6), wird mit einem anderen Maß gemessen. Aber trotzdem oder gerade deswegen wird den gesellschaftlich Stigmatisierten wie ehedem dem Narren ${ }^{10}$ einiges verziehen, was Mo-

10 Zwar in anderer Absicht, aber dennoch den Vergleich von Genazinos Liebesblödigkeit und der karnevalesken Romantradition hinsichtlich des „,Narrenkostüm[s]““ ziehend, bringt Kathrin Tittel Michail Bachtin und Genazino zusammen (vgl. Kathrin Tittel: „Die postmoderne Welt im Narrenkostüm“ - Genazinos Roman „Die Liebesblödigkeit" in der karnevalesken Romantradition. In: Tina 
sers Einschätzung, die Protagonisten würden nicht in ihrem (gewünschten) Anderssein akzeptiert werden wollen, wenn nicht widerspricht, so doch problematisiert, da auch Genazinos Figurenbasistypus ohne soziale Erwünschtheit nicht auskommt.11 Die Doppelbödigkeit oder auch Gefahr der nur temporären Akzeptanz ist diesem Problemkreis schließlich hinzuzufügen, um rund zu werden:

Denken Sie an die vielen Behinderten, Homosexuellen, Ausländer und sonstigen Fremdem, die sich im Schein der Toleranz outen; sie überschätzen einen kurzen Anerkennungseffekt, den ihnen die Selbstkennzeichnung einbringt, und sie unterschätzen beziehungsweise verkennen die Bedrohung, die langfristig auf sie zukommt. In den Augenblicken der Selbstkennzeichnung, sage ich, weiß niemand, ob sie dem Gekennzeichneten nutzen oder schaden wird. Erst nach der Kennzeichnung schlagen die Normen wieder zurück. Denn nur in der großen Menge, sage ich, die sich der Ähnlichkeit mit sich selbst immer sicher ist, entsteht das Bedürfnis nach Diskriminierung derer, die dieser Ähnlichkeit nicht oder nicht ausreichend nachkommen. Jeder neue Faschismus, sage ich, ist die Folge eines Systems gelungener Kennzeichnungen, die nicht mehr zurückgenommen werden können. (Liebesblödigkeit, S. 74)

Verschiedene Intentionen sind dieser schwarzmalerischen Rede des freischaffenden Apokalyptikers beizumessen: Sowohl kann man das Outing als ,anders' zur Eintrittskarte in die Gesellschaft verstehen und mit Habermas als Wunsch nach Akzeptanz begreifen, was laut Protagonist der Liebesblödigkeit zu teuer erkauft wird, sodass als implizite Handlungsanweisung zu entnehmen wäre: ,Verstecke deine Makel, Individuum!' Man kann den Spieß aber auch umdrehen und die Homogenität der Masse als Problem identifizieren, das es aufzubrechen gilt, um in einer maximal pluralisierten Welt gar nicht mehr die faschistischen Züge, die sich im „Bedürfnis nach Diskriminierung“ äußern, annehmen zu müssen. Die Größe allein der stigmatisierten bzw. kennzeichenbaren Gruppe spricht dafür, dass es in der fiktionalen Gesellschaft einen (insgeheimen) Zugehörigkeitswunsch (s.o.) gibt, den auch der Basistypus hegt, der sich allerdings nicht selten aus der Überforderung des (angehenden) Individuums speist: „Es ist nicht einfach, ein einzelner zu sein." (Heimweh, S. 7) ${ }^{12}$ Der Nichtzugehörigkeit zur Gesellschaft sind die meisten Protagonisten nicht fähig. Häufig sind die Distinktionsbemühungen nämlich deutlich erkennbar (s.o.), aber für den Einzelnen eine zu große Zumutung, um vor sich selbst Bestand zu haben: „Obwohl ich die Leute nicht ansehen wollte, beobachtete ich sie, distanzierte mich von ihnen und dann auch von mir, weil ich mich von niemandem distanzieren wollte." (Regen, S. 97)

Einerseits ist der Wunsch nach Distanz, nach Distinktion unverkennbar, andererseits ist die Aufgabe, sich von der „Akzeptanz durch die andern“ (s.o.) zu befreien, eine herkulische für die qua öffentlicher Selbstaufmerksamkeit zur Abhängigkeit von der öffentlichen Einschätzung ver-

Hoffmann/Marie-Christin Lercher/Annegret Middeke/dies. (Hg.): Humor. Grenzüberschreitende Spielarten eines kulturellen Phänomens. Göttingen 2008, S. 157-170).

11 Jedenfalls sind diejenigen Vorstellungen oder Tagträume, in denen sich Figuren als Individuum gegen die ganze Gesellschaft stellen und die Konsequenzen (nüchtern und klar bei Verstand) ertragen wollen, bei Genazino faktisch nicht existent.

12 Vgl. für eine ausführliche Diskussion dieses Sachverhalts, die just an diesem Satz ansetzt, Christian Steltz: „Es ist nicht einfach, ein einzelner zu sein“ - Denormalisierungsangst und Normalisierungslust in Thomas Manns Tonio Kröger und Wilhelm Genazinos Mittelmäßiges Heimweh. In: Tommek/ders. (Hg.): Vom Ich erzählen (2016), S. 49-66. 
dammten Figuren Genazinos ( $\Rightarrow$ II.2.4). Das Distanzwahren ist, wie Moser unter Rückgriff auf Genazino treffend schreibt, Conditio sine qua non für die eigene Kontur, außerhalb der Gesellschaft kann dieses Glück aber nicht gefunden werden:13 „Er fühlte sich zu stolz dazu, mit irgendwelchen Personen an irgendwelchen Stränden zu liegen, aber er wurde seiner Distanz nicht froh." (Sorgen, S. 160) Diese gebrochenen, ambivalenten Positionen dominieren die Texte bis in die neueren und neuesten Romane hinein:

Es erstaunte mich, dass ich mit vielen Menschen und Dingen, die ich eigentlich unerträglich fand, im großen und ganzen einvernehmlich zusammenlebte. Im Augenblick wusste ich nicht, ob ich schon ein Individuum war oder erst noch eines werden musste, was ich mir immer noch wünschte. (Tiere, S. 79)

Aber wie gesagt: ein Individuum in den Grenzen der bestehenden Gesellschaft, denn abgesehen davon, dass es soziologisch argumentierend kaum außerhalb einer solchen einen Platz gibt, ist die Nähe zu dieser Voraussetzung, um sich distanzieren zu können: „Trotz einer äußerlichen Angleichung sah ich deutlich, dass ich mich immer mehr von den Formen des allgemeinen Alltags löste." (Regen, S. 122) Aber nur bis zu einem gewissen Grad, was Genazinos Figuren von gelegentlich auftauchenden Nebenfiguren, die ihre Individualität fruchtlos ins Absolute steigern, unterscheidet:

Hirrlinger war ein Mitschüler des Protagonisten Wolf Peschek auf der Zeichenakademie, aber anders als Peschek, der seither freiberuflich für Werbeagenturen arbeitet, versuchte Hirrlinger - offenbar völlig erfolglos - von seinen Bildern zu leben. Er betont sein Außenseiterdasein, Peschek seinerseits bewahrt eine innerliche Distanz gegenüber den sozialen Strukturen, die er im Umgang mit seinen Arbeitgebern wie auch bei seinen ausufernden Spaziergängen vorfindet, und nicht zuletzt gegenüber seiner lebenstüchtigen Freundin Dagmar. Gleichzeitig hat er ein waches Empfinden für die Notwendigkeit, seinen Lebensunterhalt zu bestreiten und sich dem Arbeitsmarkt gegenüber konform zu verhalten. ${ }^{14}$

In ein ähnliches Horn stößt auch die bereits von Moser kurz erwähnte Lehrerin aus Genazinos Text Die Obdachlosigkeit der Fische in ihrem erinnerten und zugleich weitergesponnenen Gespräch mit einer Kollegin in der Vergangenheit:

Frau Aumann hatte mich vor einem halben Jahr eingeladen, an ihrem Klassenausflug teilzunehmen, und ich hatte abgelehnt, indem ich wahrheitsgemäß eingestand, daß ich kein Vergnügen daran habe, meine Nächte in einem Vier-Bett-Zimmer des Landschulheims zuzubringen. Darüber war Frau Aumann pikiert. Denn sie ist nicht nur eine heftige Lehrerin, sondern eine ebenso deutliche Verfechterin der Idee der Vergesellschaftung durch das Instrument Schule. Was mehrere Menschen miteinander machen, ist für Frau Aumann pädagogisch wertvoller als das, was ein einzelner für sich allein tut. Daß jeder Mensch, der in eine Gemeinschaft eintritt [...], auch genötigt wird, deren Verwicklungen entweder zu ertragen oder mitzumachen, ist für Frau Aumann kein Problem. Seither bin ich für sie eine nicht ganz saubere Individualistin, der sie auch noch anzusehen meint, daß sie sich feige vorkommt. Ich müßte Frau Aumann klarmachen können, daß ich nicht das mindeste gegen andere Menschen habe; ich möchte nur nicht, daß einzelne, wie so oft, Ordnungsopfer der anderen werden müssen, sobald sie sich auf deren Konfliktregulierungen einlassen. (Obdachlosigkeit, S. 121)

13 Das ist auch ein gewichtiger (externer) Grund dafür, warum Genazinos Figuren nicht in der Einsiedelei enden dürfen ( $\Rightarrow$ II.2.5).

14 Spreckelsen: Manche möchten lieber nicht, S. 84. 
Auch hier ist es ein Mosers und Spreckelsens Argumentation gemäßes Sowohl-als-auch mit der Tendenz zur individuellen Seite der Medaille - allein schon aufgrund der Charakterisierung von Frau Aumann als „heftige[r] Lehrerin“, die nachgerade „pikiert“ darüber ist, dass man anderer Meinung sein könne als ,Nötigungen“ bereitwillig zu „ertragen oder mitzumachen“, ist die Sympathie klar zugunsten der „nicht ganz sauberen Individualistin“ verteilt -, wobei das prinzipielle Wohlwollen der Gesellschaft gegenüber nie in Frage gestellt wird („daß ich nicht das mindeste gegen andere Menschen habe"). Allerdings blenden sowohl Spreckelsen als auch Moser darüber zweierlei aus: die nicht nur auf zweckdienliche Konformität zurückzuführenden Anbiederungen bzw. Angliederung an die Gesellschaft (s.o.) ${ }^{15}$ sowie die nicht immer nur nach Modell ,ContraHabermas' funktionierenden Individuationsbestrebungen ( $\Rightarrow$ II.2.4).

Am ehesten ließe sich das Verhältnis von Individuum und Gesellschaft für Wilhelm Genazinos Figurenbasistypus wie folgt präzisieren: A) Er braucht die Gesellschaft (gleich Moser und Spreckelsen), B) lehnt sie in der vorliegenden Form allerdings mehrheitlich ab ( $\Rightarrow$ II.1.6), weshalb er mitunter auf die „interessanten Manöver“ zurückgreift (ungefähr Moser und Spreckelsen) und positioniert sich damit C) am Rand der Individualität (ungefähr Moser und Spreckelsen). Allerdings nicht immer in der Bereitschaft, AC1) dafür die Anerkennung der anderen nicht zum Maßstab seines Handelns zu machen (ungleich Moser) und schon gar nicht, ohne die Gesellschaft und hier schließt sich der argumentative Kreis - AC2) nicht auch fernab des auf den Arbeitsmarkt gerichteten eigenen Vorteils zu suchen, da Alleinsein AC3) selbst dem schwierigsten Menschen auf Dauer schwer und zur Belastung wird:

Die Stadt ist fast leer. Die meisten Leute sind in Urlaub oder sitzen in Gartenlokalen. Die Hitze drückt auf die Dächer. Ich könnte in mein Apartment gehen [C], aber dort ist es genauso warm wie draußen. Gestern abend bin ich so lange in der Stadt umhergelaufen, bis ich durch die Müdigkeit ganz leicht geworden war. Schließlich habe ich mich auf eine Bank gesetzt und bin dort sogar eingeschlafen. Grölende Jugendliche haben mich zwanzig Minuten später geweckt, das war unangenehm. [B] Es ist nicht einfach, ein einzelner zu sein. [AC3] [...] Ich ekle mich ein bißchen über die tief nach unten hängenden Unterlippen einiger vorüberkeuchender Jogger. [B] Die Türen vieler Lokale sind weit offen. In manches Lokal trete ich kurz ein und kehre rasch wieder um. [B] [...] Ich biege in die Wormser Straße ein und sehe in einiger Entfernung das Sportlereck. In diesem Lokal bin ich in der vorigen Woche zweimal gewesen. [A] Der Wirt hob schon beim zweiten Mal wohlwollend die Hand, als er mich wiedererkannte. [...] Seit etwa einer Woche werden im Fernsehen die Spiele der Fußball-Europameisterschaft übertragen. [...] Meine Schritte führen mich halbautomatisch in die offene Tür des Sportlerecks hinein, obwohl ich mich nicht für Fußball interessiere. Ich suche sogar den Blick des Wirts, damit er in mir wieder den halbwegs bekannter werdenden Fremden erkennt. [AC3] [...] Ein Mann beugt sich über meinen Tisch und sagt: Das sieht aus wie 74, jetzt kommt ein Konter, dann fällt ein Tor, und dann ist es aus, Sparwasser damals! Ich nicke, als wüßte ich, wovon er redet. [AC1] Das Zittern nimmt zu, sagt der Reporter. Ein Mann bietet mir fünf Euro für meinen Platz vor der Wand, ich lehne ab. [AC2] [...] Plötzlich ein schreckliches Schreien und Kreischen. [B] [...] Plötzlich sehe ich unter einem der vorderen Tische ein Ohr von mir liegen. Es muß mir im Gebrüll unbemerkt abgefallen sein. Offenbar hat es niemand bemerkt. Ich will nicht mit

15 Vgl. dazu auch die stillen, heimlichen Übereinstimmungen in Form der liminalen Momente von Verbrüderung im Geiste, Situationen, in denen (unausgesprochen?) Gesellschaft im Kleinen entsteht: „Plötzlich fällt mir auf, daß wir nur deswegen, weil der Hund seine Verletztheit zeigt, den Gedanken an seine Gesundung hegen, und zwar, vermutlich, gleichzeitig. Wir schauen uns kurz an, die Pflasterer und ich, dann erklingen wieder die Schläge über dem Platz." (Frauen, S. 170) 
unüberlegten Handlungen auffallen [AC1], ich gehe auf die Toilette und schaue in den Spiegel. (Heimweh, S. 7-10)

Als figurenanalytisch externer Faktor lässt sich die geschilderte Hitze dafür anführen, nicht den eigentlich gewünschten Rückzugs- und Schutzraum betreten zu können, was der Unmöglichkeit der totalitären Gesellschaftsflucht eine Chiffre gibt. Dass die Gesellschaft indes in Form grölender Halbstarker und Fußballfans für den Basistypus keinen Reiz ausstrahlt, dazugehören zu wollen, ist evident. Dennoch geht es ohne Gesellschaft genauso wenig wie mit: Es kostet ihn Überwindung, den Kontakt zur Gesellschaft nicht abreißen zu lassen - erzähltheoretisch interessant: mit dem ,sogar' wird die Ambivalenz markiert -, die letzte Konsequenz, das gesellschaftliche Wohlwollen zu verspielen, kommt jedoch nie in Frage, da das Auffallen - man darf durchaus an eine milde Form der „Selbstkennzeichnung“ (s.o.) denken - einer Selbstentblößung gleichkäme und Konsequenzen zeitigen würde. Die Brüchigkeit und Vielschichtigkeit der Empfindungen wird im Roman mit dem Ohrverlust quittiert - einem starken Symbol, das sowohl die Suche nach Ruhe im Sinne von Lautstärke als auch von Übernähe der Gesellschaft verkörpert, zudem aber auch als ,Desensibilisierungsmaßnahme‘ interpretierbar ist, die es dem Protagonisten als Stellvertreter des Basistypus erlaubt, sich weiterhin in der Gesellschaft bewegen zu können.

Neben den auf Individualität und Gesellschaft bezogenen Erwägungen wird an dieser Passage deutlich, dass auch in diesem Bereich der Figurenfacetten die kalkulierte Wirkung des eigenen Handelns eine exzeptionell wichtige Rolle spielt: Der Protagonist täuscht seinen Tischnachbarn, sucht aktiv den Blick des Wirtes und verheimlicht nach Möglichkeit das abgefallene Ohr - allesamt Aspekte der Selbstdarstellung.

\subsection{Selbstdarstellung zwischen Authentizität, Verstellung und ,kleiner Lüge‘}

Verständlicherweise ist hier nicht der Ort, um erneut über Notwendigkeit vs. Manipulation von IM prinzipiell zu theoretisieren ( $\Rightarrow$ I.3.3). Vielmehr geht es um die Einstellungen von Genazinos Figuren ihrerseits, was Selbstdarstellung in den Ausprägungen von überbetonter Authentizität über Täuschungen bis zur ,kleinen' oder auch mal größeren Lüge anbelangt. ${ }^{16}$ Wie in nahezu

16 Vgl. zum Themenkomplex von „Lüge und Wahrhaftigkeit“ generell etwa Jörn Müller, der differenziert und in der fruchtbaren Verbindung von Antike und moderner Sprechakttheorie mehrdimensional die „Unwahrheit der Aussage (enuntiatio falsa)“ von der „Unwahrhaftigkeit des Sprechers (locutio contra mentem)“, dessen „Täuschungsabsicht [...] (intentio fallendi)“ und die „[i]ntendierte Folge bzw. [den] beabsichtigte[n] Zweck (finis intentus)“ unterscheidet (Jörn Müller: Lüge und Wahrhaftigkeit. Eine philosophische Besichtigung vor dem Hintergrund der Sprechakttheorie. In: ders./Hanns-Gregor Nissing (Hg.): Die Lüge. Ein Alltagsphänomen aus wissenschaftlicher Sicht. Darmstadt 2007, S. 27-55, hier S. 28). Vgl. allgemein zur Lüge auch Angelika Ebrecht-Laermann: Lügen als Passion. Über einige Möglichkeiten, die Wahrheit $\mathrm{zu}$ verwirren. In: Amthor/Hille/Scharnowski (Hg.): Wilde Lektüren (2009), S. 65-81; sowie Gunther Klosinski (Hg.): Tarnen, Täuschen, Lügen. Zwischen Lust und Last. Tübingen 2011. Vgl. zur Lüge intratextuell auf, horizontaler Kommunikationsachse' - also auf Figurenlevel - auch $(\Rightarrow$ II.2.5 u. $\Rightarrow$ II.3.5) sowie auf vertikaler (Erzähler-Leser-)Achse $(\Leftrightarrow$ I.2.2) für unzuverlässiges Erzählen. Zum Sonderfall der Lüge als „Etwas-nicht-Sagen“ vgl. Reika Hane: Gewalt des Schweigens. Verletzendes Nichtsprechen bei 
allen untersuchten Schlaglichtern und deren Unterkapiteln sind die Verhaltensstrategien und muster dabei im Figurenbewusstsein gespiegelt, sodass die Gefahr einer rein psychoanalysierenden Lektüre gebannt scheint, die ,lediglich` Inferenzen ziehen würde. Wenige aussagekräftige Selbstreflexionen zu IM generell können illustrieren, wie kenntnisreich und sensibel Genazino seine Figuren diesbezüglich ausgestaltet hat.

Eine erste Station in der Schnelldurchsicht bietet sich bei Abschaffel an, der sich allenthalben damit auseinandersetzt, ob er sich verstellen, ob er einen bestimmten Eindruck forcieren, ob er lügen solle: Abschaffel „wollte nicht, daß seine Eltern dachten, er hätte ihnen nicht mehr mitzuteilen als die Ankündigung seines Besuchs. Um diesen Eindruck nicht entstehen zu lassen" ( $A b$ schaffel, S. 23). Dass das Zitat hier abbricht, hat den schlichten Grund, lediglich den Mechanismus aufzeigen zu wollen, der nahezu keine Handlung und auch keine Handlungsplanung unkommentiert lässt und Abschaffel bis in seinen dritten Roman dauerhaft begleitet: „Das Allerschlimmste war, daß ich zum dauernden Taktieren gezwungen war, aus dem ich eigentlich bis heute nicht herausgekommen bin." (Falsche Jahre, S. 423) Teilweise wächst sich diese Selbstbeobachtung durch (imaginierte) fremde Augen ( $\Rightarrow$ II.2.4) bis zur Selbstversagung des gewünschten Handelns aus ( $\Rightarrow$ II.2.6): „Eine Weile hatte er geschwankt, ob er nicht schon heute die Arbeit wiederaufnehmen sollte, aber er fand dann doch, daß eine solche Überkorrektheit bei den Kollegen vielleicht nicht gut ankam." (Falsche Jahre, S. 553) Die Wichtigkeit der Selbstdarstellung für Abschaffel auch in Ausprägung der Täuschung bricht sich in der in vorauseilendem Gehorsam der Gesellschaft folgenden Formulierung Bahn: „Ein Angestellter durfte sich keinerlei Blößen geben, und er mußte jeden Tag den Eindruck erwecken können, der Herr seines Geschicks zu sein.“ (Falsche Jahre, S. 571) Erzähltechnisch besonders interessant sind Beispiele, die auf DiscoursEbene nachzeichnen, was sich ,im Protagonisten' Histoire-seitig abspielt:

Schon oft war ich in Versuchung gewesen, Carolas Eltern anzurufen und sie zu fragen, ob sie ... vielleicht ... in zwangloser Atmosphäre ... aber schon an diesem Punkt begann meine Unsicherheit: Was könnte ich sie fragen, was würden sie gerne von mir hören, wie sollte ich mich darstellen? (Außer uns, S. 145)

Eine weitere Dimension kunstvoller lässt Genazino seine Figuren diese Mechanismen auch auf theoretischem Level diskutieren: „Von Ruth wußte er, daß es nicht genügte, die Treppen geputzt zu haben; man mußte den anderen Hausbewohnern auch ein Signal geben, aus dem sie schließen konnten, daß es wirklich geschehen war." (Ausschweifung, S. 244) Wenn man mit dem Goffman'schen Prätext Wir alle spielen Theater. Die Selbstdarstellung im Alltag (1959/2011) vertraut ist, fühlt man sich notgedrungen an dessen Ausführungen im Unterkapitel „Dramatische Gestaltung" erinnert: 
Vor anderen durchsetzt der Einzelne gewöhnlich seine Tätigkeit mit Hinweisen, die bühnenwirksam ihn bestätigende Tatsachen illustrieren und beleuchten, welche sonst unbemerkt oder undeutlich bleiben könnten. Denn wenn die Tätigkeit des Einzelnen Bedeutung für andere gewinnen soll, muß er sie so gestalten, daß sie während der Interaktion das ausdrückt, was er mitteilen will. ${ }^{17}$

Obwohl der Vergleich zwischen Treppe putzen und den im Folgenden von Goffman herbeizitierten Tätigkeiten etwa einer Krankenschwester, die, um ihre wichtigen, aber für andere nicht notwendigerweise in ihrer Wichtigkeit erkennbaren, Handlungen zu unterstreichen, zusätzlich bestimmte ,Signale‘ an ihr Publikum senden muss, ${ }^{18}$ hinkt, ist das Element der forcierten Bühnenhaftigkeit bei Genazino bis ins Detail nachzuvollziehen.

Den Höhepunkt der reflexiven Auseinandersetzung mit selbstdarstellendem Verhalten bildet wohl eine Passage im Roman Die Liebe zur Einfalt. Nicht nur aufgrund der Verlagerung in die 1920er Jahre und der auf eine andere Person bezogenen analeptischen Beobachtung, sondern auch durch die klar auf ,Sein vs. Schein` zielende Dimension verdient sie es, näher betrachtet zu werden:

In meinem Arbeitszimmer hängt ein Foto, das ich oft anschaue. Es entstand Ende der zwanziger Jahre und zeigt meinen damals eindrucksvollen jungen Vater. Er steht vor einem kleinen lichten Wäldchen und ist elegant gekleidet. Er trägt einen Paletot und schmale, gestreifte Hosen. Das linke Bein ist ein wenig nach vorne gestellt. Mit der rechten Hand stützt er sich auf einen Stock, den er leicht von sich abgestellt hält. Seine Erscheinung entspricht dem damals verbreiteten Klischee vom jungen Mann. So wie er waren die besseren Herren gekleidet. Nur war Vater kein besserer Herr, sondern ein von Arbeitslosigkeit umhergetriebener Mechaniker, der auswärtige Montage-Aufträge annehmen mußte, um seinen Lebensunterhalt verdienen zu können. Während eines auswärtigen Arbeitsaufenthaltes ist ein weiteres Foto entstanden, eine betörende Studioaufnahme, die gleich mehrere Verwechslungen zuläßt. Der makellose Ernst und die kommende Bedeutsamkeit dieses jungen Mannes sind nicht in Zweifel zu ziehen. Vater trägt einen dunklen, vorne leicht geöffneten Anzug. Darunter ist eine dunkle, zweireihige Weste sichtbar. Auf der rechten Seite der Weste hängt aus einer Brusttasche die Schmuckkette einer goldenen Taschenuhr heraus. Aus der Anzugtasche ragt ein helles seidenes Tuch. Das Bild ist in angenehmen Rot- und Brauntönen gehalten. Vaters Gesichtsausdruck ist sanft und energisch. Auf diesem Bild kann Vater alles sein oder werden, ein Philosoph oder ein Stahlmagnat, ein Lyriker oder ein Textilfabrikant, ein Filmschauspieler oder ein Erbe, ein Liebhaber oder ein Hausbesitzer. Beide Fotos, das Wäldchenbild und die Studioaufnahme, hat Vater sehr geliebt. Sie lagen in seiner Schreibtischschublade; wann immer er sich als aufstrebenden jungen Mann zu sehen wünschte, zog er die Schublade auf und betrachtete die alten Bilder. Erst viel später entdeckte ich, daß solche makellosen Selbstbilder in den zwanziger und dreißiger Jahren unter jungen Menschen sehr verbreitet waren. Besonders Arbeiter, kleine Angestellte und Ladenmädchen drängten in die Fotoateliers, um einen Schein von sich herstellen zu lassen und diesen Schein ein Leben lang als inneres Monument aufzubewahren. Die einfacheren unter ihnen sind auf ihre eigene Bildwirkung hereingefallen. Die von den Fotos ausgehende Verführung, in der äußeren Makellosigkeit das die Zukunft bestimmende Zeichen zu sehen, ist fast unwiderstehlich. Die Wirkung ist auf den Dargestellten so beflügelnd, daß er zwischen Erfolg und Erfolgsdarstellung immer weniger unterscheiden mag. So täuschte sich der Abgebildete darüber hinweg, daß Schwierigkeiten auf ihn zukommen würden, die mit tadelloser Kleidung nicht zu bestehen waren, die mit Kleidung nicht einmal etwas zu tun hatten. Zwischen dem diskret lächelnden Mann im Paletot, der mein Vater war, und dem erheblich ausdrucks- und sprachgehemmten Kleinbürger, der ebenfalls mein Vater war, gibt es keine Verbindung. Und weil Vater mit Umständen, in die er gemäß seines Selbstbildes niemals hätte geraten dürfen, nicht zurechtkam, betrat er niemals die Bank, in der Onkel Albert öfter gute Worte für ihn eingelegt hatte. Vater wollte nicht jemand sein, der öffentlich eingestand, daß er Hilfe brauchte. Er war der Mann im Paletot! Er haßte Situationen, in denen er sein sprachliches Ungeschick, seine Unkenntnis in kaufmännischen Angelegenheiten und seine 
leicht bäuerlich-proletarischen Verhaltensweisen hätte zeigen müssen. Wenn er sich sehr angestrengt hätte, hätte er alles, was ihm fehlte, für die Dauer einer Kreditverhandlung kaschieren können. Schon diese Überwindung setzt voraus, daß er mit sich selbst einig hätte werden können, daß die Gewährung eines Kredits eine solche Verstellung lohnte. Aber es gab etwas, was er durch keine Camouflage hat verbergen können, etwas niederschmetternd Einfaches und zugleich unüberwindbar Schweres. Ich glaube, Vater hat nicht gewußt, wie er die Halle einer Bank betreten sollte, ohne sich zu schämen. Sein Leben lang hat Vater jede Handlung vermieden, für die auch nur ein Mindestmaß an Selbstdarstellung und also Repräsentation nötig war. (Einfalt, S. 80-82)

Anlass der Beobachtung, Reflexion und (Über-)Interpretation Genazinos (Figur) sind zwei Fotografien des Vaters, ${ }^{19}$ dessen Wirkung auf den Betrachter - Vater wie Sohn - den Anschein erweckt, gesellschaftlich höher bewertet zu werden als es faktisch zur Zeit der Aufnahmen gewesen ist. Dass sich die Außenwirkung hauptsächlich über die Körpersprache ( $\Rightarrow$ II.1.4), symboltragende Gegenstände und Kleidung $(\Rightarrow$ II.1.5) konstituiert, liegt freilich einerseits in der Natur von Fotos, ist andererseits aber bezeichnend, sind diese doch für die Selbstdarstellung immens wichtige Kategorien $(\Rightarrow$ I.3.3). Der Schein kann gelingen, da es nicht hart auf hart zum Abgleich des imaginierten Selbst und des faktischen kommen kann, das Sein (des Vaters) hingegen unterliegt bereits der äußerst kritischen Messlatte des betrachtenden Sohnes. Dass es schließlich in der Deutungsoffenheit zur (potenziellen) Überinterpretation ggfs. unbedeutender Details kommt und die Wichtigkeit des IM vor sich selbst thematisiert wird, spricht für die Dichte an Selbstdarstellungs-relevanten Aspekten dieses Zitats.20

Bereits im Grundlagensegment konnte gezeigt werden, dass es erstens unmöglich ist, sich nicht in irgendeiner Weise selbstdarstellend zu verhalten $(\Leftrightarrow I .3 .3)$. Zweitens und eng damit verbunden ist es Forschungskonsens, dass eine ,Verteufelung' der Position von ,Notwendigkeit' von IM gegenübersteht. Drittens existiert eine auch in der Theoriebildung bestehende Trennung zwischen Positionen wie: ,Er/sie ist so, seine/ihre (übertriebene) Darstellung dessen ist ok', und: ,So ist er/sie ja eigentlich gar nicht, warum tut er/sie dann so', existiert, die dem zutiefst verständlichen Grund entspringt, sein Gegenüber ,korrekt' einschätzen zu wollen. Für Genazinos Romanfiguren scheint es angezeigt, zunächst die beiden Pole von Authentizität und Verstellung ins Vorfeld der Analyse zu setzen.

\section{AUTHENTIZITÄT IST GUT, VERSTELLUNG BÖSE? ZUM BEFINDEN DER FIGUREN}

Von weit weg besehen ist es bereits an den bisherigen Primärzitaten ablesbar, dass es Genazinos Figuren (nicht ihren Vätern) häufig unwohl dabei ist, insbesondere selbstwertdienliches (assertives) IM überhaupt zu betreiben und allzumal dann, wenn die erforderliche Darstellung nicht ihren vermeintlichen Wesenskern trifft. In diesen Fällen lässt sich von einer subjektiv negativen Einstellung zum IM sprechen, die zunächst unabhängig davon ist, ob es ,objektiv', besser: an den

Vgl. zur Funktion von Fotografien für IM Helmut Ebert/Manfred Piwinger: Impression Management: Die Notwendigkeit der Selbstdarstellung. In: Manfred Piwinger/Ansgar Zerfaß (Hg.): Handbuch Unternehmenskommunikation. Wiesbaden 2007, S. 205-225, hier S. 207. 
fiktionsintern gesellschaftlichen Normen und Werten gemessen, moralisch vertretbar (authentisch) oder problematisch (verstellend) wäre: „Heute setzte die Verlogenheit Abschaffels schon darin ein, wenn er anderen Personen heiter begegnete. Immerzu hatte er das Gefühl, nicht wahrhaftig zu sein. Immer fehlte ihm etwas, damit er sagen konnte: So bin ich wirklich." (Abschaffel, S. 40) Abschaffel nimmt die restriktive Sicht ( $\Rightarrow$ I.3.3) auf Eindruckssteuerung ein und wünscht sich absolute Kongruenz zwischen Selbst- und Fremdbild $(\Rightarrow$ II.2.1), wie sie verhältnismäßig selten in einem Figurenroman Genazinos zu finden ist. ${ }^{21}$ Dabei unterstellt Abschaffel die prinzipielle Möglichkeit, auch vor Publikum ,einfach so‘ er selbst sein zu können, was erwiesenermaßen bereits mit einem Spiegel im Raum ausgeschlossen ist. ${ }^{22}$

Nichtsdestoweniger finden die Protagonisten immer wieder verstellende und täuschende Mittel und Wege, um Wirkungen zu evozieren, brandmarken diese aber reumütig nahezu noch in actu als Fehler: „Überheblich ging er an den Mädchen vorbei und wußte in jedem Augenblick, wie sehr er sich selbst spielte, wie künstlich sein Gesichtsausdruck war, wie falsch seine spähende, abschätzende Haltung." (Sorgen, S. 232) Wie bei sich selbst missfällt dem Genazino'schen Basistypus auch bei anderen ( $\Rightarrow$ II.4.3 u. $\Rightarrow$ II.4.4) ,zu dickes Auftragen': „Die Art, wie Schube sich als abseits stehender Künstler darstellte, machte mir Beklemmungen. Ohnehin hegte ich Mißtrauen gegen alle, die irgendetwas beteuerten oder betonten." (Wohnung, S. 58) Dieser Vorbehalt lässt sich verallgemeinern: „Jede Art des Auftrumpfens (Klamottengehabe, Autogehabe, Geldgehabe) war widerlich und doch in jedem besseren Haushalt anzutreffen." (Kein Geld, S. 54 f.) In Das Glück in glücksfernen Zeiten transzendiert der Protagonist diesen Vorbehalt, indem die situative Notwendigkeit assertiven IMs akzeptiert und zugleich kategorisch für den Ich-Erzähler stigmatisiert wird: „[U]nd wer etwas anpreisen will, muß auf eine Weise reden, die mir das Fremdeste ist, was es auf der Welt überhaupt gibt." (Glück, S. 50) Dieser Vorbehalt gegenüber der Täuschung kommt gelinder daher, geht sie doch zumindest teilweise auf das Konto gesellschaftlicher Erfordernisse und spiegelt also extrinsische, fremdbestimmte Anteile an der Motivation zur Täuschung, wie sie andere Figuren Genazinos auch von sich selbst kennen: Später „gestanden wir uns, dass wir überhaupt nicht melancholisch und nicht depressiv und so weiter waren, wir hatten nur so getan als ob, weil es damals Mode war, wenigstens niedergeschlagen und hoffnungslos und von der Gesellschaft kaltgestellt zu sein." (Außer uns, S. 19) Ob man nun in der Attribuierung einer Fremdbestimmung eher eine wahrhaftig extrinsische Motivation der Täuschung oder erneut IM mit Kalkül zu veranschlagen habe, muss unentschieden bleiben.23

21 Jedenfalls nimmt es wunder, dass Axel Degen ausdrücklich erwähnen muss: „Mein Lächeln dabei war keine Lüge." (Laslinstraße, S. 153)

22 Vgl. Aronson/Wilson/Akert: Sozialpsychologie, S. $134 \mathrm{f}$.

23 Vgl. auch Axel Degens glaubwürdige Konfession: „[E]s war schwierig, zwanzig Zeilen über neunzehn Jahre zusammenzubringen, geboren als Sohn des, Besuch der Volksschule von bis, Besuch des Gymnasiums von bis, die eigentliche und wirkliche Axelgeschichte durfte in den Lebenslauf nicht hinein, die Geschichte von dem Jungen, der eigentlich Eisverkäufer werden wollte, darüber würde jeder nur lachen, dachte ich“ (Laslinstraße, S. 145 f.). 
180 - Teil II: Schlaglichter 1. Innenwelten - Außenwirkungen

Sind die letzten Beispiele solche, die bereits in die Ambivalenz zwischen unmöglicher Authentizität und gebotener Verstellung (s.u.) abgleiten, die Figuren dabei aber immer noch subjektiv gegen (täuschendes) selbstdarstellendes Verhalten eingenommen sind, gibt es durchaus auch Darstellungen von goutiertem IM-Gebrauch, wobei erneut die ,moralische Komponente' in den Hintergrund treten möge.

Zu Beginn ein Exempel aus dem Bereich des eher Romanspezifisch-Individuellen: „Fuchs hatte Lust, sich ab sofort wieder als überaus bescheiden darzustellen“ (Ausschweifung, S. 288). Geradezu den Wunsch nicht nur überhaupt nach einer Darstellung, sondern gar nach einer kalkulierten zu haben, ist zumindest in Verbindung mit dem Wort ,Lust' ein Einzelfall. ${ }^{24}$ Das heißt jedoch mitnichten, es gäbe keine dem IM gegenüber wohlgesonnenen Situationen, in denen die Protagonisten wohlüberlegt und verhältnismäßig zwanglos eine subjektiv positive Einstellung dazu hätten. Denn auch Abschaffel, „als er in die Straßenbahn stieg, gefiel [...] sich bereits darin, alt zu sein und alles nicht mehr richtig zu können. Übertrieben kniff er hinter den Brillengläsern die Augen zusammen“ (Abschaffel, S. 65). Hier kommt über die positive Färbung eines unverfänglichen Rollenspiels ( $\Rightarrow$ II.3.4) eine durchaus wohlwollende Einstellung dem Verstellen gegenüber zum Vorschein, die in den folgenden Beispielen derart dezidiert zwar nicht zu beobachten ist, aber auch weit entfernt vom Gegenteil sich bewegt: „Ich halte mich an meinem Glas und erwecke den Eindruck von jemand, der in erhebliche Reflexionen versunken ist, um einer geistigen Herausforderung standzuhalten. Es ist meine alte Intellektuellennummer, mit der ich so gut wie alles verdecken kann." (Liebesblödigkeit, S. 110) Diese wohl seit längerem im Repertoire befindliche ,Nummer', also ein Handlungsmuster, das sich bereits unter dem Einfluss regelmäßigen Erfolgs verfestigen konnte, wird ebenso mit keinem Wort negativ eingefärbt wie der ,Trick' Degens, um sich die heißbegehrten Zigaretten zu erschleichen: „Dann hätte ich sicher wieder Geld bekommen. Geld für Axels Lunge, wenn ich dazu noch schön Danke gesagt hätte, denn ich wußte, das Tante Elsbeth mich gerne beobachtete, wenn ich Danke sagte." (Laslinstraße, S. 26)

Moralische Wertungen sind zugunsten der erfolgreichen Vorteilnahme suspendiert. Diese zu beobachtende Tendenz steigert sich erneut, sobald das Feld der Selbstrechtfertigungen $(\Rightarrow$ II.2.1) betreten wird. Dann, wenn die Protagonisten für und vor sich selbst entschieden haben, dass höhere und wichtigere Zwecke die kommunikativen Mittel heiligen, dann ähneln auch verstellende und täuschende Maßnahmen Notwendigkeiten, die über jeden Zweifel erhaben sind: „Die Arbeit eines Büroangestellten hat den Vorteil, daß sie vorübergehend gespielt werden kann.“ (Abschaffel, S. 143) Das scheint Goffman zu widersprechen: Wo üblicherweise viel Aufhebens gemacht werden muss, um das eigene Tun als nichtig darstellen zu können (eben so, dass es ,leicht' aussieht), scheint ein Büroangestellter mit wenig Aufwand den Anschein des Gewichtigen

$24 \quad$ Jedenfalls, wenn es nicht um der inneren Zensur zum Opfer fallende Handlungen geht $(\Rightarrow$ II.2.6). 
hervorrufen zu können. ${ }^{25}$ Ebenfalls eine glückende Verstellung führt Abschaffel dann vor, wenn er seinen Therapeuten paraverbal glauben lässt, in einer sorgenfreien Stimmung zu sein, indem „er versuchte, seiner Zustimmung einen leichten, lockeren Ton zu geben. Dr. Haak war dankbar und griff diesen Ton sofort auf." (Falsche Jahre, S. 407)

Aufschlussreich sind spannungsreiche Mischformen, die eine subjektiv positive bis neutrale Position erkennen lassen, zugleich aber phraseologisch mit negativ konnotierten Bildern arbeiten: „Das Bemühen, Alltäglichkeit von sich zu geben, Beiläufigkeit auszustrahlen, setzte sich mit mir auf meinen angestammten Platz [...] mein Teller ahnte an der Art, wie ich ihn behandelte, was ich im Schilde führte“ (Laslinstraße, S. 130). Die arglistige Täuschung einer Person, die - obgleich diese negative Lesart des Erkennungszeichens der Ritter erst später auftrat - im heutigen Sprachgebrauch nicht etwas Gutes, sondern nichts Gutes im Schilde führt, steht hier der neutralen Schilderung sowie der positiven Einstellung zu dieser ,Camouflage' entgegen.

Wichtig ist also festzuhalten, dass Genazinos Romanfiguren ein ambivalentes Verhältnis zur Selbstdarstellung generell haben. Sowohl im subjektiv positiven als auch im subjektiv negativen Bereich tauchen Verhaltensstrategien sowohl aus der Trickkiste leicht überpointierter Authentizität als auch aus derjenigen mit Täuschungen und Verstellungen bestückten auf. Das lässt den Schluss zu, dass die Einstellung zu IM allgemein nichts damit zu tun hat, ob das Verhalten ,objektiv' positiv oder negativ markiert ist. Besonders deutlich wird dies in einem Bereich, der sich mit der ,kleinen Lüge' befasst.

VON DER , KLEINEN LÜGE' ALS GESELLSCHAFTLICHEM SCHMIERMITTEL ÜBER DEFINITIONS- UND RECHTFERTIGUNGSMUSTER BIS HIN ZUR MYTHOMANIE

Sozusagen als Vorstufe zur Lüge lässt sich das Verschweigen von ,Wahrheit’ ansehen $(\Rightarrow$ II.1.4), was in Genazinos Romanen musterhaft in IM-Reflexionen gekleidet wird:

Jetzt schon mußte ich meine Antworten sortieren, konnte nicht mehr wahllos von Elke sprechen, vorsichtig mußte ich sein, die Phantasie meiner Eltern einkalkulieren, ich durfte keine Sätze sagen, die Unausgesprochenes enthielten, die Schlüsse zuließen, Folgerungen, ich fühlte eine Klemme: die Schwierigkeit, Antworten zu geben, die sinnvoll waren und doch nicht verrieten - (Laslinstraße, S. 48).

Im weiteren Romanverlauf wird das gefälschte Erzählen über Degens Freundin Elke zum Ausdruck für seine sich immer mehr der kalkulierten Lüge anverwandelnde Absicht, seine Eltern aus der kommunikativen Isolation zu locken: „[I]n Zukunft wollte ich mehr erzählen von Elke, immer mehr, ausholen, gewaltig, sie durften nicht merken, daß es meine Absicht war, nein, sie durften nicht erfahren, was ich mit ihnen machen wollte" (Laslinstraße, S. 69). Nicht nur verschleiert er die Intention hinter der geplanten Erzählung, er zieht auch ,gewaltiges Ausholen` und also Überzeichnen der Realität ernsthaft in Erwägung. Damit ist der Leser gefragt: Wie viel

25 Vgl. Goffman: Wir alle spielen Theater, S. 31-34. Die Kernbeobachtung, dass zwischen der tatsächlichen Arbeit und deren Dramatisierung Welten liegen, bleibt unbenommen bestehen. 
Kontextualisierung und Sympathie für die Vorhaben der Figuren sind erforderlich, um von lässlicher Sünde sprechen zu können? Und hängt diese Einschätzung davon ab, ob sich bei den Figuren Skrupel regen?

Insbesondere Laslinstraße fällt einerseits durch die flächig sich konstituierende Lügenlandschaft, andererseits durch deren - trotz meist hundertprozentigen Wissens darum - NichtProblematisierung auf. Axel Degen „machte ein lächelndes Personalausweisgesicht, wartete ein paar Sekunden, ein Lächler mit Absichten“ (Laslinstraße, S. 141; $\Rightarrow$ II.1.4). Und warum? „Freude kauft man nur einem Lächelnden ab“ (Laslinstraße, S. 142). Keine Gewissensbisse, lediglich selbstreflexive Kosten-Nutzen-Erwägungen:26 Wenn andere etwa „[k]eine Möglichkeit, meine Mitwisserschaft zu erkennen“ (Laslinstraße, S. 96), haben, dann lohnt sich die Täuschung, sofern am Ende ein erfolgreich kontrollierter Eindruck das Unterfangen adelt:

Elke gab mit ihren Augen mein Gesicht nicht frei, so daß sich mein Lächeln nicht normal legen konnte, so wie sich der Wind wieder legt, erst als wir mitten auf der Brücke waren und ich mir mit der Hand durch die Haare fuhr und sie wieder nach hinten packte, sah Elke auf ihren Weg, so daß ich mein Lächeln wegnehmen konnte von meinen Lippen, wie man einen Blumentopf von einem Fenstersims wegnimmt. (Laslinstraße, S. 147)

Mit Lakonie und der Überzeugung der Notwendigkeit agiert Axel Degen, dessen bislang hier geschilderte Verhaltensweisen noch nicht einmal erzählerseitig als ,Lügen' klassifiziert worden sind, obwohl sie sich bereits im Grenzbereich bewegt haben. Nimmt man diese markierten Textpassagen hinzu, ergibt sich eine interessante Neuperspektivierung des von Genazino selbst ungeliebten Erstlings. Denn so, wie etwa Stewardessen in langen Verhaltenstrainings lernen, ein den Kunden überzeugendes Grinsen nicht nur aufzusetzen, sondern auch selbst zu mögen, lernt Axel Degen in Laslinstraße, kleine Lügen als gesellschaftliches Schmiermittel zu verwenden: „[D]a war sie schon wieder, die kleine Lüge, pünktlich zum rechten Augenblick: ,Das macht doch nichts, Frau Gabold, das macht nichts...' Ich lachte sogar mit Phil“ (Laslinstraße, S. 196). Laslinstraße lässt sich einerseits als positiver Entwicklungsroman lesen, der Degen mehr und mehr Eigenständigkeit und Mündigkeit zukommen lässt, allerdings wird diese andererseits durch die (von Degen wie gesagt ambivalent, prinzipiell mit Blick auf sich positiv wahrgenommene) Fähigkeit, die kleinen Lügen und Verstellungen zu erlernen, erkauft: „Die kleine Lüge würde so etwas werden wie mein Tisch, mit dem ich auch täglich lebte." (Laslinstraße, S. 195) Der Protagonist akzeptiert die Lüge um des, lieben Friedens‘ willen. Die Allgegenwärtigkeit des Lügens ist frappierend:

Die kleine Lüge ließ sich gebrauchen. Einen Augenblick lang, aber nicht länger bewunderte ich mich, wie ich lügen konnte, wie gut ich meine Lügen verpackte in Redensarten, ohne rot und unsicher zu werden, jede Lüge gelang mir, als hätte ich schon jahrelang gelogen, Kontrolle von außen war unmöglich, nur von innen, also von mir, nur von mir. (Laslinstraße, S. 197)

26 Einschränkend muss angemerkt werden, dass Verstellung und Lüge bei anderen von Degen durchaus negativ bemerkt werden: „Es können doch nicht so viele Gesichter jeden Tag die große unbestechliche Lüge lügen“ (Laslinstraße, S. 11). 
Doch Laslinstraße ist bei weitem nicht der einzige Roman, der die (kleine) Lüge als IM-Mittel unterschiedlichster Couleur - gute Miene zum bösen Spiel usw. - gestaltet. Sogar in der Wortverbindung mit ,klein' findet sie sich in Romanen der 2010er Jahre:

Nach dieser Eröffnung betrat ich das Gebiet meiner zärtlichen kleinen Lügen. Sie waren klein und zärtlich, weil sie unerheblich und sinnlos waren, aber trotz ihrer Dümmlichkeit nicht verschwanden. Ich sagte, ich war drei Tage in München, um an neue Aufträge heranzukommen. (Tiere, S. 69 f.)

Und nicht nur diese Übereinstimmung sichert die fast 50-jährige Genealogie der Musterhaftigkeit von 1965 bis (in diesem Fall) 2011, sondern auch die subjektiv positive Evaluierung. In Wenn wir Tiere wären wird der Diminutiv durch das ,zärtlich' noch ein bisschen niedlicher und auch in einem Beispiel aus dem Roman Bei Regen im Saal ist die Verharmlosung lesbar: „Neulich hatte ich sogar ein bisschen übertrieben beziehungsweise geschwindelt und Erfolg damit gehabt." (Regen, S. 49) Jedenfalls scheint den Figuren häufiger das Bewusstsein dafür abhanden gekommen zu sein, dass Lügen gesellschaftlich und religiös verbürgte ,Untugenden' sind:

Seine wichtigsten Bauteile (platte Dramaturgie, dümmliche Dialoge, albernde Handlung, absehbarer Plot) waren von bedrückender Einfalt. Besonders peinigend waren die so zahlreichen wie unmotivierten Gesangseinlagen von Peter Alexander. Nichts davon erschien in der Filmkritik, die ich am folgenden Morgen schrieb. Sie fing mit diesen Sätzen an: ,Einen Strauß bunter Melodien präsentiert Peter Alexander in seinem neuesten Musikfilm [... [ [...]. Daß mein Empfinden im Kino und meine Filmkritik zwei völlig verschiedene Dinge waren, störte mich nicht, jedenfalls nicht während des Schreibens. (Wohnung, S. 75 f.)

Immerhin, so könnte der Moralapostel argumentieren, ist die mikrogesellschaftliche Akzeptanz dieser Diskrepanz derart eingeschliffen, dass das Individuum gar nicht anders kann, als zu lügen, um den reibungslosen Ablauf nicht zu gefährden: „Offenbar mußte ich hinnehmen, daß alle, die hier arbeiteten, mal mehr, mal weniger an eingestandener Infamie litten und daß Herrdegen ein Argument gefunden hatte, daß ihm ein Wohlbehagen inmitten dieser Infamie erlaubte." (Wohnung, S. 109) Da die Lüge mit überraschender Omnipräsenz das Figurenhandeln des Basistypus kennzeichnet, scheint es nur konsequent, dass die Figuren auch selbst zu Definitionsversuchen anheben:

Von den Lügen des Arbeitslebens waren mir die kleinen, kindischen, unnützen am liebsten. Ich log mit, weil die sinnlosen Lügen schon nach kurzer Zeit ihre Dummheit und Leere einräumten. Geständnisse waren nicht nötig, weil die Alltagslügen so geläufig waren, dass sich für sie eine Begründung von selbst erübrigte. Die besseren Lügen hießen wenigstens Notlügen, weil ihre Unausweichlichkeit eine gewisse heimliche Verbitterung zurückließ. Die kleinen Lügen, die ich meinte, hatten nicht einmal einen Namen. Sie waren eine Folge der Lächerlichkeit des Lebens selbst, aber Lächerlichkeitslügen konnte man sie nicht nennen, weil niemand, der von Zeit zu Zeit log, lächerlich erscheinen wollte, auch vor sich selbst nicht. (Außer uns, S. 64 f.)

An der Notwendigkeit des Versuchs einer Typologie ${ }^{27}$ kleiner und kleinster Lügen lässt sich erkennen, dass der Stellenwert in der alltäglichen Kommunikation der Figuren ein hoher ist und

27 Vgl. Nissing für eine ,echte‘ Typologie der Lüge. Er unterscheidet „(1) Eine grundlegende Skepsis gegenüber allen kategorischen und prinzipiellen Moralvorstellungen, seien sie nun religiös, weltanschaulich oder ethisch begründet", von (2) Eine umfassende Erfahrung von Unwahrhaftigkeit und Lü- 
mithin auch die Gesamthäufigkeit immens ist. Dies ist auch der Grund dafür, dass das gesamte Ausmaß an Lügeninhalt den Figuren über den Kopf zu wachsen droht. Für den Apokalypsereferenten aus Die Liebesblödigkeit etwa „ist klar, daß ich mit meinen Auskünften äußerst vorsichtig sein muß. Wie jeder Lügner überblicke ich meine Lügen nicht ganz." (Liebesblödigkeit, S. 188) Abschaffel fasst es seinerseits in ein Straßenbild: „An einigen Stellen [...] kreuzten sich die Lügen aber doch, und man wünschte sich an den Kreuzstellen ordnende Ampeln, die die Lügen gut aneinander vorbeiließen." (Abschaffel, S. 39) Und bei Eckhard Fuchs findet sich die Formel des Irrgartens:

Und ehe das Spiel von vorne losging, schaute sie zu Eckhard hin, weil er einen Vater spielte, der nicht merkte, daß alles nur gespielt war. Die verschiedenen Ebenen ihrer beider Täuschungsversuche waren wie ein schlecht erdachtes Labyrinth, das zugleich schöner war als ein wirkliches, weil es an jeder Stelle des Spiels Auswege in authentisches Verhalten gab. (Ausschweifung, S. 216)

Aber wozu das Ganze, wenn - wie Abschaffel in anderem Kontext konstatiert - „nach einer Weile [...] keiner von beiden mehr [wußte], warum sie sich so sehr verstellen mußten"? (Sorgen, S. 395) Vielerorts finden sich nahezu apodiktische Aussagen zum Themenkomplex Lüge: „In der Regel mußte ein Angestellter seiner Familie zu Hause mehr vorspielen als seinem Betrieb, und die beiden Sorten dieser Täuschungen durften weder durcheinandergebracht noch überhaupt gestört werden." (Sorgen, S. 177) Aus dieser Aussage lässt sich bereits ein erstes Erklärungsmuster für die Figuren-Lügen ableiten: Sie lügen, ,weil das eben so ist', ,weil das alle machen'!

Eine nicht nennbare Instanz insinuiert Abschaffel, es sei zwar „immerhin weitgehend möglich, sie [andere Personen; N. L.] einmal nicht mehr zu belügen, nur bei den Eltern nicht. Bis zum Tode muß man seine Eltern anlügen." (Abschaffel, S. 23) Eine Antwort auf die Frage des Warum ist dies freilich nicht und die Erzähler werden nicht müde, dem Leser lediglich Tatsachen zu servieren, dadurch dass sie frei bekennen, sie seien schlichtweg „voll von diesen kleinen Unaufrichtigkeiten, die das fortgeschrittene Leben mit sich bringt wie Hornhaut an den Fersen oder ein überzogenes Konto.“ (Tiere, S. 12) Natürlich lassen sich im Einzelnen einfache Begründungen finden wie eine plumpe Ausrede, um sich schnell zu verabschieden (vgl. Kassiererinnen, S. 14), die Minderung von sozialem Druck durch fremde Blicke, die eine Erklärung des eigenen Verhaltens erpressen (vgl. Kassiererinnen, S. 86 f.) oder auch eine Unzufriedenheit hinsichtlich der Passung von Selbst- und Idealbild ( $\Rightarrow$ II.2.1):

Sie hätte sich nach meinem Leben erkundigt, von dem ich nicht gerne redete. Sie kannte mich aus der Zeit, als ich promovierte, und sie hätte (genau wie ich) nur mit Staunen hingenommen, dass ich jetzt als Barkeeper arbeitete. Manchmal, wenn mir dieses Geständnis zu peinlich war, erfand ich einen Beruf oder eine Stellung, und die Sache war vergessen. (Regen, S. 19)

ge in unseren sozialen Bezügen und Institutionen“ und „(3) Eine Neubewertung des Wahrheits- und Wirklichkeitsverhältnisses des Menschen und ein [!] Ästhetisierung des Scheins" (Hanns-Gregor Nissing: Die Lüge. Ein Alltagsphänomen aus wissenschaftlicher Sicht. Zur Einleitung. In: Müller/ders. (Hg.): Die Lüge (2007), S. 7-25, hier S. 9-16). 
Abseits dieser als regelhaft-notwendig erachteten Einstellung dem Lügen gegenüber, gibt es aber auch komplexere Sachgründe, die als Erklärungsangebot in Anschlag gebracht werden, wie etwa die schmerzliche Einsicht Abschaffels, er habe „überhaupt nur mit erfundenen Geschichten eine Person sein können“ (Falsche Jahre, S. 461; $\Rightarrow$ I.4), die er später mit der Mutmaßung anreichert: „Vielleicht war es auch nur eine Auswirkung seines ewigen Gefühls von Unvollständigkeit, das ihn manchmal dazu trieb, sich die Komplettheit teuer erlügen zu müssen." (Falsche Jahre, S. 478) Dieser Erklärungsansatz ist gegenüber anderen - zumindest für Abschaffel - insofern vorzuziehen, als er bereits dem ,Ur-Abschaffel' gewissermaßen in die Wiege gelegt zu sein scheint:

Er hatte das Gefühl, daß für ihn, wenn er ganz und gar aufrichtig wäre, nichts mehr übrigbleibe. Das Lügen hatte er in seiner Familie gelernt. Zwischen der Mutter, dem Vater, ihm und seinen Geschwistern gab es ganze Lügengespinste, eigenartige Gebilde aus Vertuschung und Heimlichkeit (Abschaffel, S. 39).

Auch andere Figuren räumen unumwunden in der Ich-Perspektive ein,

„daß ich seit der Kindheit lüge. Als Kind log ich bedenkenlos, weil ich sicher war, das Lügen hört auf, wenn man erwachsen geworden ist. Verschwunden ist nur das Gefühl des moralischen Vergehens. Vermutlich ist das Lügen nichts weiter als eine Begleitform des Sprechens; wer spricht, muß auch lügen, das ist alles." (Licht, S. 54)

Erneut lässt sich in der Knappheit, ja beinahe Patzigkeit („das ist alles“) zur Verteidigung die Unumstößlichkeit ausmachen, mit der Genazinos Romanfiguren das Lügen als Teil des Lebens betrachten. Der Gefahr, als Lügner abgestempelt zu werden, sind sie sich dabei häufig bewusst: „Wenn du willst, kannst Du mich deswegen Manipulateur oder Lügner nennen. [...] Ich denke, eine umgebaute Erinnerung ist nichts weiter als ein Versteck, vielleicht das Beste, was es für uns gibt, weil sich ein Ort im Bewußtsein verbirgt, unauffindbar." (Licht, S. 104) ${ }^{28}$

Ein weiterer Erklärungsansatz in diese Richtung findet sich in Genazinos Bei Regen im Saal: „Zum Beispiel sagte mein Vater oft zu mir: Du sollst nicht dauernd lügen, hörst du?! Dabei wusste ich nicht einmal, dass ich log. Ich sprach doch nur aus, was mir durch den Kopf zog. Das wiederum verstand aber mein Vater nicht.“ (Regen, S. 103 f.) Die verbalisierten Tagträume eines Kindes als Lüge zu werten, ist vermutlich pädagogisch eher fragwürdig. Anscheinend konnte Reinhard jedenfalls trotz der damals nicht verstandenen Mahnungen nicht davon lassen:

Peinlich war nur, dass ich diese Erinnerungen während der Fahrt in der S-Bahn erfand und sie später in der Redaktion als Wahrheit erzählte. Zur Erklärung sagte ich mir, dass ich zu lange mit mir allein war, obwohl mir die Schönheit meiner erfundenen Erinnerungen selber gefiel. Ich überlegte sogar, ob ich in der Redaktion nicht einfach sagen sollte: Ich erzähle euch jetzt wieder ein paar einsa-erfundene Erinnerungen! Ich war überzeugt, dass niemand Einspruch erhoben hätte. (Regen, S. 106) 
Trotz der spielerischen Leichtigkeit, mit der diese Überlegung vorgetragen wird, lässt sich die subjektiv-negative Sicht auf die (nicht einmal waschechte) Lüge nicht verhehlen, die in der Empfindung der Peinlichkeit bereits anklingt. Und auch mit Blick auf andere Romane ist - zwar selten, aber nicht nur romanspezifisch-individuell - eine Abneigung gegen sie zu beobachten. So „bedrückte es Peschek, daß sich die Menschen in wichtigen Angelegenheiten nur über den Weg von Verheimlichungen verständigen konnten." (Fremde Kämpfe, S. 85) Auch Axel Degens sonst ziemlich ungebrochen positive Einstellung zur kleinen Lüge schlägt punktuell ins Gegenteil um:

Schnell eine kleine Lüge vorbereiten: „Ach...nichts, ich dachte an meine Eltern.“ Ich lachte dazu, die Antwort mit dem Lachen dürfte glaubhaft erschienen sein [...]. Aber ich ärgerte mich, daß ich meine Eltern als Ausweg benutzen mußte, um die Situation und die Zukunft, soweit sie vorstellbar war, nicht zu versauen, es bedrückte mich, daß ich lügen mußte, die Lüge als augenblicklich wirkendes Beruhigungsmittel (Laslinstraße, S. 165).

Die Bedrückung wird hier von ihm als Zwang verkauft, als Alternativlosigkeit, und dieses fragwürdige Erklärgebaren schließt wieder an die bereits behauptete Nähe von Verschweigen und Lüge an, wie sie sich in etlichen Selbstaussagen findet: „Ihre Fragen tyrannisierten mich, ich mußte wieder lügen, nein, das sollte sie nicht wissen, das nicht, jedenfalls noch nicht, später, dachte ich, später" (Laslinstraße, S. 72). ${ }^{29}$ Insbesondere im Zusammenhang mit den eigenen Eltern wird die tragische Dimension deutlich. Wolf Peschek erinnert sich an die permanente Verbrüderung mit der Mutter gegen den Vater mit den Worten: „Später hatte sie ihm gesagt, wenn er damals schon wie sie heimlich zu leben verstanden hätte, dann hätte er auch den Zeichenkurs besuchen dürfen." (Fremde Kämpfe, S. 177) Heimlichkeit als Grundbedingung ließe sich unter diese Szene schreiben, die darstellt - und das ist die Tragik -, wie einerseits Peschek in seiner Kindheit der Zeichenkurs verwehrt bleibt, weil er (noch) nicht nach den ungeschriebenen Gesetzen der kleinen Lüge bzw. des Verschweigens im Kleinen zu leben versteht (hamartia), andererseits gerade die moralische Unschuld des Nicht-Verstellens in der Kindheit ja einwandfrei erwiesen ist. Diese negativen Auswirkungen (gefühlte Dissoziation, Unaufrichtigkeitszwang etc.) lappen noch weit in die Erzählgegenwart hinein. ${ }^{30}$ Mit einer so gearteten Sozialisation (Lügen sind nötig, auch wenn sie wehtun) ist es eventuell zumindest erklärbar, dass Genazinos Figurenbasistypus nicht nur mit dem Hang, sondern mitunter auch mit dem Zwang zum Lügen begabt/verdammt ist.

Lässt sich die Lüge lange Zeit entweder über einen der drei Umwege der Nichtigkeit als ,zärtliche' oder ,kleine', der Notwendigkeit als Notlüge oder die Reue der Protagonisten legitimieren oder entkräften, verspielt sie sich des Lesers Gunst allerdings spätestens dann, wenn sie sich als der Mythomanie geschuldete zu erkennen gibt:

29 Für die Spielart des temporären Verschweigens mit taktischem Vorteil vgl. auch Ausschweifung, S. 267.

30 Dieses Motiv findet sich auch in Einfalt, S. 30, wenn die aus der Nebentätigkeit der Mutter finanzierten Kaffeerunden vor dem geizigen Vater (vgl. Kein Geld, S. 32) versteckt werden müssen, was das Kind schwer belastet. 
Eben noch wollte Abschaffel wahrheitsgemäß mitteilen, daß er die Studie vom Schreibtisch des Verkaufsreferenten mitgenommen hatte, um sie heimlich mit Hornung zu lesen. Aber dann log er eine Geschichte zusammen, von der er selbst vor fünf Minuten noch nichts gewußt hatte. [...] In jedem Augenblick wußte er, daß er log, und in keinem Augenblick wußte er, warum er log, auch noch so sinnlos und peinigend. (Sorgen, S. 214 f.)

Wiewohl mit Reue kokettierend, ist das nach gängigem Verständnis nicht ohne weiteres hinzunehmen. Allerdings beißt sich hier die Katze in den Schwanz: Wie soll das Subjekt eine gesunde Position zwischen Selbstdarstellung als notwendiger Täuschung und Ehrlichkeitsgebot beziehen, wenn neben den Eltern selbst der Psychologe dem Protagonisten aus Mittelmäßiges Heimweh den IM-verschleiernden Ratschlag erteilt: „Sie müssen den Eindruck vermeiden, daß Sie die Mitarbeiter beobachten und einschätzen, obwohl Sie natürlich genau das tun, sagt der Trainer schon bei unserer ersten Begegnung." (Heimweh, S. 82) Kalkül im kommunikativen Handeln hat immer zur Grundlage, dass mit Wissensungleichgewicht $(\Leftrightarrow$ II.2.2) und Manipulation operiert wird. Wie verstörend diese Notwendigkeit, zum „Taktieren gezwungen“ zu sein (Falsche Jahre, S. 423), sich für den Einzelnen darstellen kann, setzt Genazino in Außer uns spricht niemand über uns mit einem Augenzwinkern in Szene. „Man kann eben nicht zu anderen Menschen aufrichtig sein und gleichzeitig zu sich selbst" (Außer uns, S. 106), heißt es da. Das ist bereits philosophisch wie psychologisch frag- und denkwürdig - oder auch einfach: widersinnig - genug, könnte man leichtfertig denken. Aber 40 Druckseiten später zeigt sich die Tragikomik darin, dass nicht einmal für diese eine Figur in Ansätzen Klarheit herrscht: „Man kann nicht zu einem anderen Menschen aufrichtig sein und gleichzeitig zu sich selbst nicht. Allerdings war auch das Gegenteil richtig: Man kann nicht zu sich selbst aufrichtig sein und zu den anderen nicht. Stimmte das wirklich?“ (Außer uns, S. 146; $\Rightarrow$ I.4) Anhand des Beispiels ,Bedingungen der Möglichkeit von Authentizität' kristallisiert sich somit heraus, dass die vorgebliche Einfachheit der Figuren-Innenwelten ( $\Rightarrow$ II.2.1) selbst eine kalkulierte Täuschung ist.

\subsection{Charaktereigenschaften oder: Makel, Marotten und andere Merkwürdigkeiten}

Genazinos Figuren sind nämlich alles andere als einfach gestrickte. Als thematischer Anschluss zum vorigen Unterkapitel eignet sich beispielhaft die folgende Selbstaussage aus Ein Regenschirm für diesen Tag:

Es kann nicht mehr lange dauern, denke ich, dann wirst du in eine Lügenheilanstalt eingeliefert. Denn die Wahrheit hinter der Wahrheit ist, daß ich natürlich hundertprozentig zu wissen meine, was sich tatsächlich ereignet hat und was nicht. Ich habe ein Interesse an verschiedenen Wahrheitsversionen, weil ich es schätze, vor mir selber ein wenig verwirrt zu erscheinen. (Regenschirm, S. 37)

Ohne an dieser Stelle auf die zahlreichen zu verfolgenden inter- (Blechtrommel) wie intratextuellen (unzuverlässiges Erzählen) Spuren eingehen zu können, ließe sich dem Protagonisten mit Abschaffel zur Seite springen: „Wie entsetzlich wäre es, wenn ich diese Verhaltensweisen jemand erklären müßte.“ (Sorgen, S. 167) Dieser Jemand ist dabei als Platzhalter zu verstehen, 
der sowohl für andere Figuren als auch für die Protagonisten selbst einstehen kann, sind doch auch Letztere beständig damit beschäftigt, ihre Macken, Marotten und anderen Merkwürdigkeiten allererst zu erkennen, in einem Folgeschritt zu durchschauen oder sie letztlich zu verbalisieren und mit mehr oder weniger plausiblen Gründen zu fundieren. Häufig ist dabei bereits beim Durchschauen der Erkenntnis ein Ende gesetzt:

Ich habe keinen Krieg miterleben müssen, ich habe nie gehungert, ich habe nie Gewalt kennengelernt, ich habe einen von mir geschätzten Beruf, ich liebe zwei Frauen [...], aber warum leide ich fast immer an inneren idiosynkratischen Hysterien, das heißt, warum brauche ich gar keine wirkliche Not, um mich fast immer in Not zu befinden? Mir fehlt eigentlich nur...ja, was eigentlich? (Liebesblödigkeit, S. 127)

Auch hier könnte man mit den Worten eines anderen Protagonisten antworten: „fehlende Selbstfürsorge [...] und meine nach wie vor mangelhafte Verwurzelung in der Welt.“ (Regen, S. 104) Aber es handelt sich nur um momentweise aufblitzende, selten derart fixierte Antworten auf die immer wieder in Variation gestellten Fragen nach der Ursache der eigenen ,Kompliziertheit‘ (s.u.): „Tatsächlich hatte ich und habe ich in meinem Leben nicht mehr Unglück und nicht mehr Glück als die meisten anderen Menschen auch. Wie es trotzdem dazu gekommen ist, daß ich von Jugend an tragisch empfinde, ist mir schleierhaft. Wie mir diese nicht beendbare Unglückseitelkeit auf die Nerven geht!“ (Liebesblödigkeit, S. 137; vgl. Kein Geld, S. 13 u. S. 18 f.) Den Figuren selbst sind ihre Innenwelten gelegentlich „im Kern unverständlich, obwohl jedem Menschen sofort einleuchtend“, wie es in Das Glück in glücksfernen Zeiten heißt (Glück, S. 41).

Obwohl es sich anböte und hinreichend Belegstellen für ernstzunehmende psychische Probleme - in diesem Fall bspw. einer depressiven Verstimmung - zu finden sind, soll nicht sofort im Schnellsch(l)ussverfahren mit Krankheitsbildern aufgewartet werden, die sich nämlich häufig eher an der Peripherie der Familienähnlichkeit ansiedeln lassen ( $\Rightarrow$ I.2.5). Das Unterkapitel entfaltet sich vielmehr vom Zentrum des Hardcores, des Figurenkerns, aus und schweift dann langsam nach außen weg in Richtung romanspezifisch-individueller Alleinstellungsmerkmale, die ja erklärtermaßen nicht mehr im engeren Kegel der Schlaglichter stehen. Im Verlauf dieser Betrachtungen wird das dreilagige Zwiebelmodell des Genazino'schen Basistypus beschriftet werden, was als Grundlage für alle weiteren Schlaglichter von hoher Relevanz ist.

\section{DIE ,BIG FIVE' ZWISCHEN HARDCORE UND FAMILIENÄHNLICHKEIT}

Es hat sich in der psychologischen Forschung weitgehend durchgesetzt, von fünf Eigenschaftsdimensionen auszugehen, mittels derer sich eine Person in ihrem Wesen zumindest grobmaschig einfangen lässt. ${ }^{31}$ Es handelt sich dabei um einen unter dem Namen ,Big Five‘ bekannten

31 Dies ist interkulturell der Fall (vgl. Howard S. Friedman/Miriam W. Schustack: Persönlichkeitspsychologie und Differentielle Psychologie ergänzt um ein Kapitel zur Intelligenz von Heiner Rindermann. 2., akt. Aufl. München 2004, S. 348). Vgl. zur berechtigten Kritik am Modell selbst bspw. dies., S. 347 ff. Vgl. für eine alternative Vierteilung nach Eysenck $(\Rightarrow$ II.4.1). 
Erklärungsansatz menschlichen Verhaltens aus der Persönlichkeit heraus, der seit den $1960 \mathrm{er}$ Jahren an Einfluss gewinnt und letztlich auf einer lexikalischen Annäherung fußt: Qua Induktion sind personenbeschreibende Attribute gesammelt und immer wieder eine Ebene höher synthetisiert worden. Am Schluss dieses Reduktionsprozesses, um gewissermaßen Struktur in die lange Liste von Persönlichkeitseigenschaften bringen zu wollen, zeigen sich fünf Faktoren als bestmöglich geeignet, um der Kriterienliste für das Vorliegen ,tatsächlicher' Persönlichkeitsmerkmale zu genügen. Denn um mit Fug und Recht von einem Personenmerkmal - und in Folge dessen auch von einer Figureneigenschaft - sprechen zu können, muss die Tendenz erkennbar sein, sich immer wieder ähnlich zu verhalten, um rein situative Aspekte als Störvariablen zu eliminieren. Üblicherweise geht man insgesamt von drei Kriterien aus, die angelegt werden können müssen:

1. Zeitliche Stabilität: Eigenschaft taucht immer wieder bei der Person auf.

2. Transsituative Konsistenz: Person zeigt Eigenschaft in verschiedenen Situationen.

3. Alleinstellungsmerkmal: ermöglicht, relative‘ Aussagen (bspw. Abschaffel ist schüchterner als Axel Degen).

Die fünf Dimensionen, die Big Five, lauten:

- Extraversion (auch als Aufgeschlossenheit bezeichnet): Extravertierte Menschen sind tendenziell energisch, enthusiastisch, dominierend, gesellig und gesprächig. Introvertierte Menschen sind tendenziell schüchtern, zurückhaltend, unterwürfig und ruhig.

- Soziale Verträglichkeit: Sozial verträgliche Menschen sind freundlich, kooperativ, vertrauensvoll und warmherzig. Menschen, die über diese Dimension nur in einem geringen Ausmaß verfügen, sind kalt, streitsüchtig und unfreundlich.

- Gewissenhaftigkeit (auch als Mangel an Impulsivität bezeichnet): Gewissenhafte Menschen sind im Allgemeinen vorsichtig, zuverlässig, gut organisiert und verantwortungsvoll. Impulsive Menschen sind tendenziell unvorsichtig, unordentlich und unzuverlässig. Die frühe Persönlichkeitsforschung bezeichnete diese Dimension als „Willen“.

- Neurotizismus (auch als emotionale Instabilität bezeichnet): Neurotische Menschen sind tendenziell nervös, unruhig, angespannt und besorgt. Emotional stabile Menschen sind ruhig und zufrieden.

- Offenheit (auch als Kultur oder Intellekt bezeichnet): Offene Menschen erscheinen im Allgemeinen als fantasievoll, geistreich, originell und kreativ. Menschen, die über diese Dimension nur in einem geringen Ausmaß verfügen, sind oberflächlich, einfach und schlicht. 32

Wenn es nun so ist, dass sich die Einordnung einer Person auf diesen fünf Skalen sowohl über die Zeit hinweg als auch in unterschiedlichen Situationen nicht nennenswert verschiebt - und vieles spricht für diese Annahme -, dann liegt die Schnittmenge dieses Persönlichkeitsmodellparadigmas zum angenommenen harten Kern der Romanfiguren Genazinos nicht nur auf der Hand, sondern zudem im Nahbereich der Deckungsgleichheit. Allerdings betrifft eine solche Engführung auch den schmalen Figurenrand des Romanspezifisch-Individuellen und das 3. Kriterium: Es ist also durchaus möglich, dass es jeweils einzelne Figuren gibt, die als Ausreißer nicht im Figurendurchschnitt liegen. Häufiger ist allerdings der Fall, dass zwar unterschiedliche Schattierungen etwa von Neurotizismus bei Genazinos Einzelfiguren wahrzunehmen sind, alle (oder im Extrem: alle, bis auf eine) jedoch einem der beiden Pole zustreben. Konkret heißt das für den 
Genazino'schen Basistypus, dass er sich eindeutig auf den fünf Skalen einsortieren lassen müsste und beim Lesen selten der Eindruck entstehen dürfte, gravierende Abweichungen festzustellen. ${ }^{33}$ Es scheint dabei nicht geboten, die in der psychologischen Wirklichkeit zu Rate gezogenen Messinstrumente wie den NEO-PI oder den NEO-FFI ausführlicher vorzustellen, sondern Pars pro toto und in Bezug auf Genazinos Figuren ein Item zu präsentieren, das die Skala der Offenheit in den einschlägigen Fragebögen misst, um die Verortung plastischer werden zu lassen: „Ich verbringe nicht viel Zeit damit, über Dinge nachzudenken (umgekehrt).“34 Genazinos Figurenbasistypus wäre also daraufhin zu befragen, ob er zeitlich stabil und transsituativ tendenziell viel (= Offenheit) oder wenig (= Gegenpol) Zeit mit Nachdenken zubringe. Freilich handelt es sich um ein plakatives Beispiel, aber man findet vermutlich vom Genazino-Leser über den -Rezensenten bis zum -Forscher niemanden, der nicht d'accord wäre, Genazinos Basistypus zumindest hinsichtlich dieser vorgestellten Aussage näher am Pol der Offenheit, also in der Nähe von Fantasie und Neugierde, aber auch Nachdenklichkeit und dem Hang zu Reflexionen einzuordnen.

Die folgende Übersicht verortet Genazinos Basistypus auf den fünf Skalen der Big Five: Neben den verschlagworteten Itemaussagen findet sich die vorgeschlagene Ausprägung, die wiederum mit Belegstellen nicht einzelner Aussagen der Protagonisten arbeitet, ${ }^{35}$ sondern mit ganzen Unterkapiteln dieser Arbeit. ${ }^{36}$

33 Die Ausnahmen sind: starke situative Einflüsse auf die Rahmung der Kommunikation; romanspezifisch-individuelle Ausreißer; bewusste Kompositionsabweichungen hinsichtlich der Konsistenz die dann als Trigger für die externe Figurenanalysesicht $(\Leftrightarrow I .2 .4)$ zu veranschlagen sind -; psychische Probleme im Bereich etwa manischer Phasen o. Ä.

$34 \quad$ Friedman/Schustack: Persönlichkeitspsychologie und Differentielle Psychologie, S. 359.

35 Was nicht als Unredlichkeit, sondern als Dienst am Leser verstanden werden möge. Jedes der 35 Items aus dem NEO-FFI in Kurzform ließe sich nämlich mühelos mit (Selbst-)Charakterisierungen der Protagonisten im Sinne der Einordnung in der Tabelle unterfüttern. Das Item 17 bspw., das positive Offenheit misst: „Wenn ich Literatur lese oder ein Kunstwerk betrachte, empfinde ich manchmal ein Frösteln oder eine Welle der Begeisterung“, wird mustergültig in Liebesblödigkeit, S. 102, bedient. Vgl. dazu auch Wohnung, S. 42, sowie flächendeckend Fleck.

36 Zwar nicht repräsentativ, aber immerhin ein diese Grafik aufwertendes Mosaiksteinchen ist die Tatsache, dass in verschiedenen meiner Seminare die Kreuze (zumindest hinsichtlich der Bipolarität) exakt so gesetzt worden sind - und dies immerhin in Bezug auf sechs unterschiedliche Romane. 

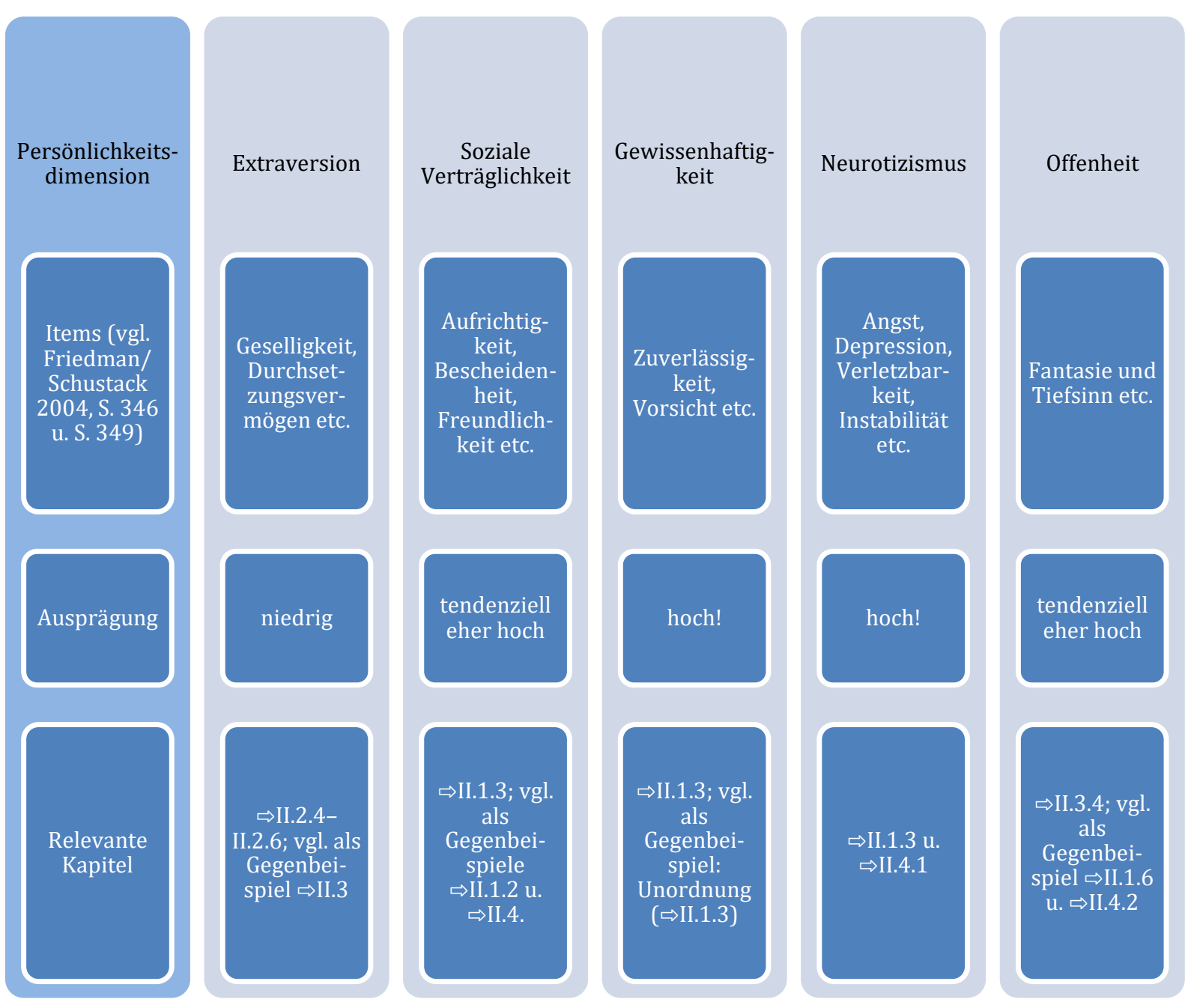

Abbildung 9: Genazinos Figurenbasistypus und die Big Five

Im Innenkreis des Schichtenmodells der Persönlichkeit von Wilhelm Genazinos Romanfiguren ließen sich also - zunächst mit Bleistift - eintragen: introvertiert, sozial verträglich, gewissenhaft, neurotisch und offen ( $\Rightarrow$ II.1.6). Das sind die kleinsten gemeinsamen Nenner der Tiefendimension. Warum der Bleistift den Vorzug vor der Feder erhält, erklärt sich aus einer Ausnahmeregelung: Genazino stattet seine Figuren, die in der Kategorie ,Offenheit' über alle Romane hin hoch punkten, eben doch auch - gewissermaßen als Schattenseite ihrer selbst - mit dem Hang zu Intoleranz und Frühvergreisung $(\Leftrightarrow$ II.1.5 u. $\Rightarrow$ II.1.6) aus, sodass die Einordnung ,nur' bei ,tendenziell hoch` erfolgen kann, wiewohl etliche hundert Aussagen für ,hoch` oder ,sehr hoch` gesprochen hätten.

Hier begegnet das bereits unter $(\Leftrightarrow I .3 .2)$ angerissene Problem (positiv formuliert: das metapsychologische Potenzial von Genazinos Figurendarstellung), dass Genazino keine ,Germanistenköderei' ungebrochen stehen lässt. Das Auffinden (tiefen-)psychologischer Besonderheiten oder ,Vermessungen' wird sogleich verkompliziert, da die Kenntnis (auch zeitgenössischer) psycholo- 
gischer Forschungsergebnisse den ,Heureka!'-Ruf insofern torpediert, als Genazinos Figuren zu keiner Zeit nach ,Schema F' (etwa: nur depressiv) gestaltet sind. So kann der Leser eindrucksvoll nachlesen, dass auch eine ,Verschlossenheit für neue Erfahrungen' einen Teil der BasistypusFamilienähnlichkeit beansprucht: „In der Langsamkeit verarbeite ich, daß ich wenig verstehe und nicht viel Neues kennenlernen möchte." (Glück, S. 73) Verstreut finden sich diese Häppchen, aber eben doch zu regelmäßig, um sie zu ignorieren. ${ }^{37}$ Ein mindestens in zwei Romanen wiederfindliches Motiv, das als negative Offenheit gewertet werden kann, betrifft die Eigenschaft, alles im Vorfeld kennen und können zu wollen. Die Hauptfigur des Romans Das Glück in glücksfernen Zeiten sagt über sich: „Ich möchte die Ereignisse, bevor sie eintreten, sozusagen vorab erleben“ (Glück, S. 75), und auch der Protagonist der Fremden Kämpfe wünscht sich „fast täglich [...], alle Schwierigkeiten wenigstens einmal vorher gespielt zu haben, bevor sie wirklich eintraten." (Fremde Kämpfe, S. 7) Dieses an Lebensangst grenzende (und damit zumindest das Ausrufezeichen auf der Neurotizismus-Skala stützende) Moment darf nicht zugunsten einer plakativen Darstellung übersehen werden. Immerhin ließe sich über Umwege argumentieren, dass - wenn diese Metalepse im übertragenen Sinne erlaubt ist - die Figuren vermutlich, wenn Sie einen NEO-FFI-Bogen vor sich liegen hätten, aufgrund sozialer Erwünschtheit, ihr Kreuz bei den positive Offenheit messenden Items mit ,trifft zu' setzen würden, denn: „Er wollte nicht jemand sein, der Veränderungen nicht hinnehmen konnte." (Fremde Kämpfe, S. 59)

Mit diesem Einwand gegen die Gleichsetzung von Big Five und Hardcore sei die Zwischenüberschrift thematisiert: Zum einen existieren Figurenfacetten, die sich der Skaleneinordnung sträuben und mithin eher der Familienähnlichkeit zugeordnet werden müssen (obwohl, wie gesagt, diese Fälle bereits in die Ausprägung eingegangen sind), zum anderen lassen sich zweifelsfrei weitere (Beobachtungszwang; öffentliche Selbstaufmerksamkeit etc.) zum Hardcore hinzufügen - doch aus Redundanzminimierung erst zu gegebener Zeit $(\Rightarrow$ II.1.6, $\Rightarrow$ II.2.6, $\Rightarrow$ II.3.5, $\Rightarrow$ II.4.5 u. $\Rightarrow$ II.5.6). Jetzt verlagert sich der Fokus auf den ,Speckgürtel' der Familienähnlichkeiten.

\section{FAMILIENÄHNLICHE FIGURENMERKMALE (INKL. MAROTTEN UND MERKWÜRDIGKEITEN)}

So naheliegend es wäre, die getroffenen Big-Five-Kreuze als Richtschnur zu nehmen, um die jeweils skalenbeschreibenden Schmelztiegel an den jeweiligen Polen - etwa vermutbare Sozialphobie als Ausdruck negativer Extraversion usw. - als deduktive Setzung mit Beispielen zu beglaubigen, wird weiterhin der ,zitatübersäte' induktive Weg über die zahlreichen Primärtextstellenfunde gegangen. Zwar birgt auch dieser die Gefahr, in die geschilderte Sackgasse der Beliebigkeit einzubiegen ( $\Rightarrow$ I.2.5). Allerdings konnte über das Zwiebelmodell die absolute Allgemeingültigkeit relativiert werden und dies in der vollen Überzeugung, da wirklich alle bis dato (2018)

37 Vgl. Sorgen, S. 312, oder Ausschweifung, S. 269, wo „Lebenserschrockenheit“ als Erklärungsansatz angeführt wird. 
vorliegenden Genazino-Romane unter genau dieser Fragestellung untersucht und verschlagwortet worden sind, nicht pauschalisierend zu verfahren.

Genazinos Figurenbasistypus zeichnet sich unter anderem aus durch folgende Attribute - wobei für bestimmte Unter(unter)kapitel nur bestimmte Sets von Bedeutung sein werden -:

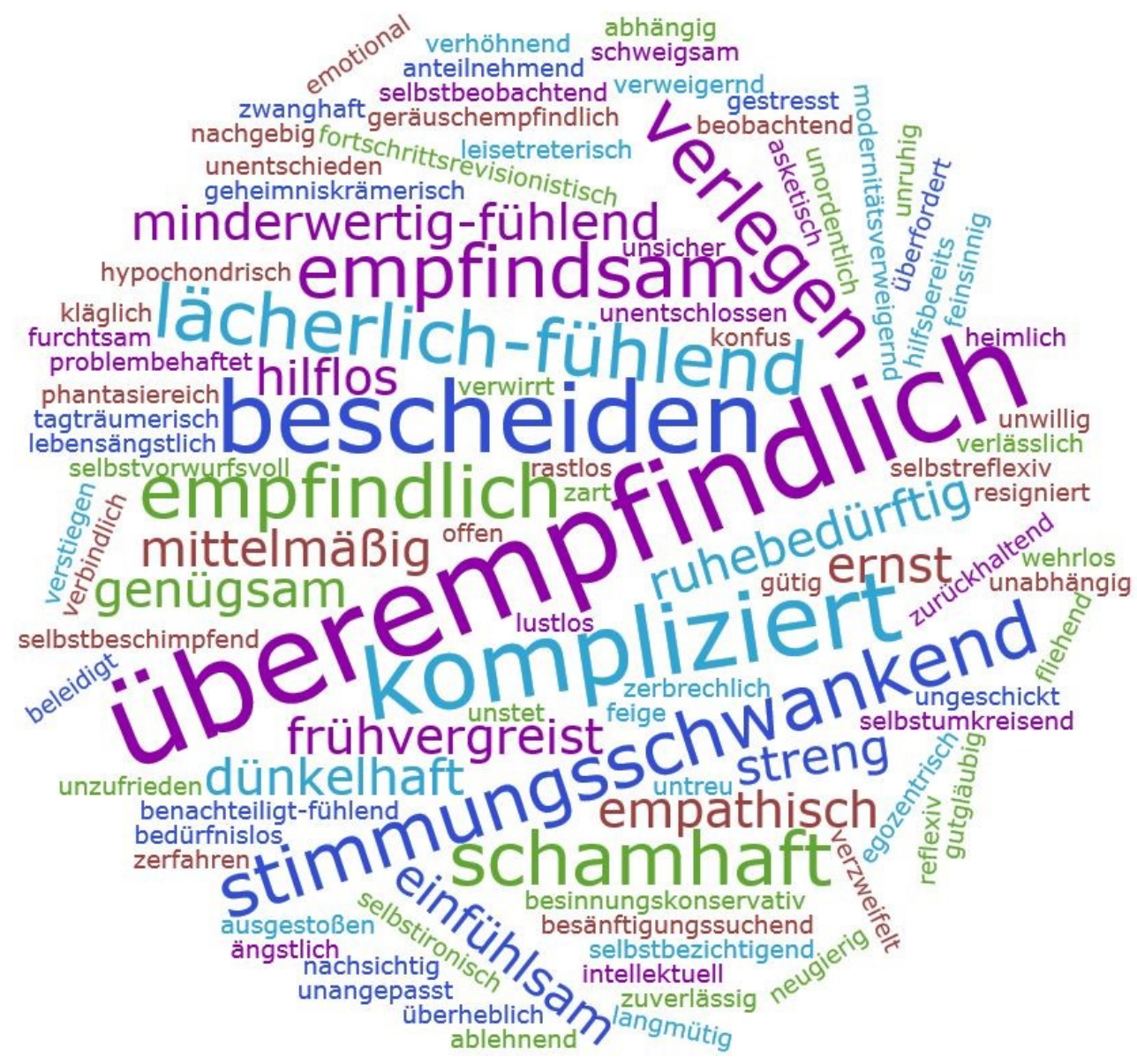

Abbildung 10: Wortwolke familienähnlicher Figurenmerkmale

Es handelt sich um eine Auswahl ${ }^{38}$ an figural-expliziten und auktorial-expliziten Selbst- und Fremdzuschreibungen $(\Leftrightarrow I .2 .4)$, die häufiger vorgenommen werden und sowohl zeitlich stabil als auch transsituativ konstant zu werten sind. ${ }^{39}$

38 Zumal aus dem Grund, Wiederholungen gering zu halten, ist etwa der Beobachtungszwang nicht in die Grafik aufgenommen worden, obwohl er zu einem immens großen Adjektiv geworden wäre.

39 Als Grundfiguration werden Genazinos Figuren eher statisch ( $\Rightarrow$ I.2.4) gezeichnet - nicht zuletzt auch aus dem Wunsch heraus, ein überdauerndes Selbst zu haben $(\Rightarrow I .4)$. Dennoch gibt es auch Ambivalenzen, Prozesse und Entwicklungen in den Figuren $\Leftrightarrow \Rightarrow$ I.2.5). Eine Manifestation bezieht sich zurück auf die Stimmungsschwankungen: „dann stieg ein fassungsloser Unglaube in ihm hoch, der alles verhöhnte, was er an den übrigen Tagen des Jahres doch so gutgläubig annahm; dann flüchtete er zu Vorstellungen der Untreue und des Abenteuers, und es kränkte ihn, daß es ihm wieder und wieder nicht gelang, immer ein und dasselbe für gut und richtig zu halten." (Ausschweifung, S. 178) Aber auch über die Romane hinweg gibt es Entwicklungen: Die sexuelle ,Verklemmtheit', wie sie bspw. in Ausschweifung, S. 59, noch gilt, wird später zunehmend aufgebrochen; die Figuren werden (spätestens mit den Kassiererinnen) ausgestattet mit die öffentliche Selbstaufmerksamkeit dämpfenden Verhaltensmechanismen, die sich später im Roman-CEuvre sogar auswachsen zu Seel- 
Wie grafisch bereits ersichtlich ist, spielt die Empfindsamkeit bzw. Überempfindlichkeit, der sich auch Attribuierungen wie ,zart', ,zerbrechlich' etc. zuordnen lassen, eine wichtige Rolle. ${ }^{40}$ Der Ich-Erzähler aus dem Roman Ein Regenschirm für diesen Tag etwa fragt sich diesbezüglich, „ob ich selbst winterhart bin. Ich bin es nicht, im Gegenteil, zur Winterhärte hat mir immer viel gefehlt, ich bin ja nicht einmal sommerhart!" (Regenschirm, S. 77) ${ }^{41}$ Andere Figuren teilen diese Sicht: „Jedesmal, wenn ich Bach höre, sage ich, bin ich den Tränen nahe. Du bist eben ein empfindsamer Mensch, sagt Judith." (Liebesblödigkeit, S. 102) Allerdings wird die Grenze von der Empfindsamkeit zum (neurotischen) Überempfindlichen regelmäßig überschritten: „Wie so oft leide ich unter zu starken Empfindungsströmen." (Liebesblödigkeit, S. 145) Diese drohen die Protagonisten mitunter zu überwältigen, sodass die Überempfindlichkeit ${ }^{42}$ auch die Dimension des Leidensdrucks annehmen kann: „Als Todesursache würde er in den Totenschein eintragen: Überempfindlichkeit." (Glück, S. 95)

In diesen Sekunden war ich so überempfindlich, dass ich fürchtete, bei der nächsten Berührung mit der sogenannten Realität in meine Einzelteile auseinanderzufallen. Ich überlegte, dass es das Beste sei, mich in meiner Wohnung zu verschanzen und diese nur noch in Härtefällen (arbeiten und einkaufen) zu verlassen. (Tiere, S. 155)

Ist es hier der an den Zerfall des Selbst $(\Rightarrow I .4)$ gemahnende Tenor, sind einige Figuren diesbezüglich anders gestrickt und können sogar anderen ihre erlernten Besänftigungsstrategien weitergeben:

Es ist nirgendwo festgelegt, wie empfindlich ein Mensch sein darf, sagte ich. [...] Ich empfehle Ihnen kleine zärtliche sinnlose Tätigkeiten, die Ihnen helfen, über den Tag zu kommen. [...] Beobachten Sie die Flugzeuge über der Stadt. Sie sehen aus, als würden sie gleich vom Himmel fallen. Aber sie fliegen nur langsam über die Dächer und landen ordentlich auf dem Flughafen, sagte ich. (Regen, S. 94)

Die hohe Frequenz, mit der (über-)empfindliche Wahrnehmungs- und Verhaltensweisen thematisiert werden, lässt die Erwägung zu, diese sogar in den Figuren-Hardcore zu verschieben. ${ }^{43}$ Eng mit der Überempfindlichkeit verwandt sind Überforderung und Stress, insbesondere im Kleid der Geräuschempfindlichkeit und der dazugehörigen Ruhebedürftigkeit. ,Lärm‘ vs. ,Stille‘ werden bei Genazino immer wieder durchdekliniert (vgl. Frauen, S. 39). Dabei sind die Grenzen zur allgemeinen Ablehnung bestimmter Facetten der Außenwelt, Modernitätsverweigerung und

sorgern, sprich: Therapeuten (auch schon in Kassiererinnen, S. 101; dann in Regenschirm, S. 140), wohingegen etwa Abschaffel selbst noch einen gebraucht hatte $(\Leftrightarrow \mathrm{V} .1)$. Vgl. Jan Wiele: Der Überempfindliche hat keine Wahl. Der Künstler als empfindsamer Vorturner des Scheiterns. In Frankfurter Allgemeine Zeitung vom 12. Juni 2014.

41 Die anklingende Selbstironie, die mitunter Selbstcharakterisierungen relativiert, findet sich häufiger: „Eines meiner inneren Probleme ist, daß ich immer gern etwas voraussagen möchte. Jetzt sage ich voraus, daß die Verhunzung der Welt durch kaputte Geräte in kurzer Zeit dramatische Formen annehmen wird. Zu meinem Prophetie-Zwang gehört, daß ich mich fast immer inmitten von Menschen befinde, die mir sofort recht geben." (Liebesblödigkeit, S. 75) Vgl. auch Regenschirm, S. 144.

$42 \quad$ Vgl. auch Wohnung, S. 16; vgl. Glück, S. 8; vgl. Liebesblödigkeit, S. 64.

43 Ähnlich verhält es sich mit einer weiteren Eigenschaft, die im Beispiel aus Wilhelm Genazinos Roman Bei Regen im Saal schon angesprochen worden ist: Genazinos Figuren neigen zum Beobachten; das kann bis ins Manische, Zwanghafte gehen ( $\Rightarrow$ II.2.2). 
,Frühvergreisung' als „Fortschrittsrevisionist und Besinnungskonservativer“ (Liebesblödigkeit, S. 25; $\Rightarrow$ II.1.6), fließend: „Es gibt zuviel Lärm, sogar hier. Die Hotelbar ist bis in die Morgenstunden geöffnet. Immer wieder fahren Taxis vor und laden Betrunkene aus. Schrille Frauen kommen zurück und reden so laut" (Licht, S. 52). Diese Überzeugung ist familienähnlich konsensfähig: „Wieder habe ich das Gefühl, daß sich fast alle Menschen leicht an neue Geräusche gewöhnen, nur ich bleibe mit meinen Anpassungsleistungen zurück." (Liebesblödigkeit, S. 61) Auch Rotmund bekräftigt:

Durch meine Geräuschempfindlichkeit lebe ich in einer Art Dauerlärmangst. Früher waren Samstage und Sonntage ruhige Tage. Die Autos blieben zwei Tage am Straßenrand stehen, umhergrölende Fußballfans gab es noch nicht, offene Fenster mit dröhnender Popmusik auch nicht. [...] Mann + Motor = Lärm. (Heimweh, S. 119)

Aber nicht nur Un-Ruhe des Geräuschpegels, sondern auch Unruhe selbst ist ein für die Figuren wichtiger Punkt: „Ich bin derartige innere Tumulte nicht gewöhnt. Am liebsten möchte ich irgendwo sein, wo es extrem bedeutungslos zugeht." (Liebesblödigkeit, S. 202; vgl. Regen, S. 58)

Dass Unruhe in verschiedenen Ausprägungen eine wichtige Facette der Familienähnlichkeit von Genazinos Figuren ist, lässt sich auch am Eigenschaftskomplex von ,Unentschlossenheit', ,Unstetigkeit', ,Rastlosigkeit' und ,Stimmungsschwankungen' festmachen:44 „Ich verhülle, oft mit erheblicher Anstrengung, daß ich es nirgendwo lange aushalte. Kaum bin ich im Büro, will ich wieder nach draußen. Bin ich endlich draußen, will ich zurück in einen geschlossenen Raum." (Glück, S. 112) Dieses Getriebensein und die parallele Unzufriedenheit darüber lässt sich dem Basistypus flächendeckend testieren: „Auf der Fahrt zu ihr würde ich möglicherweise anderen Sinnes werden, ich kenne das von mir. Dann würde ich an Frau Grünewalds Tür klingeln und wollte gar nicht mehr mit ihr zusammensein, unaussprechlich scheußlich.“ (Heimweh, S. 87) Warlich erkennt: „(Dieser überraschende Wechsel der Stimmungen ist ein wichtiger Teil der Fremdkompliziertheit.)“ (Glück, S. 156)

Mit Kompliziertheit ist genaugenommen ein weiterer über die Familienähnlichkeit hinausgehender Figurenkern angesprochen: „Eines meiner innerlichsten Probleme ist, daß ich nicht mehr mit der Kompliziertheit des Lebens in Berührung kommen will. Erst vor ein paar Tagen habe ich mir vorgenommen, meinen Alltag so einzurichten, daß ich nur einfache Verhältnisse mit einfa-

44 Vgl. Hirsch: Geheimgeschichten. Die (Ent)deckung der Scham, S. 66. Vgl. zur Unentschlossenheit und Stimmungsschwankungen auch: „Ich bin unentschieden, weigere mich aber nicht, das heißt ich passe mich an wie so oft und ärgere mich darüber lautlos.“ (Glück, S. 154) Analog: „Ein Grundzug meiner Lächerlichkeit bestand sicher darin, dass ich vieles, was ich lange und vehement ablehnte, irgendwann dann doch annahm. Lächerlich wurde ich durch die beiden Enthüllungen, dass mein inneres Verweigerungstheater nie gestimmt hatte, dass ich ohne dieses Verweigerungstheater aber nicht hätte leben können." (Kassiererinnen, S. 151) Der Stimmungsschwankung positive Seiten abzugewinnen, ist romanspezifisch-individuell: „Ich begreife den Stimmungsumschwung nicht, nehme ihn aber dankbar hin. Schließlich sind es solche emotionalen Verstrickungen, sage ich mir, die den Menschen individuieren und seinem armseligen Dasein doch noch eine unverwechselbare Gestalt geben." (Liebesblödigkeit, S. 72) 
chen Personen darin vorfinde." (Heimweh, S. 10) ${ }^{45}$ Aus Scheu vor der (Fremd-)Kompliziertheit resultieren vermeidende und verweigernde Verhaltensmuster:

Ich habe keine Lust mehr, an dieser immer noch zunehmenden Kompliziertheit teilzunehmen. Das Leben wird derart unaufklärbar, daß ich immer öfter Generalverzicht üben möchte. Aber dann verzichte ich auch auf den Generalverzicht und rutsche in das mir vertraute Gefühl der Kläglichkeit hinein, von dem ich auch nichts mehr wissen will. Dabei habe ich schon länger den Eindruck, daß die Kompliziertheit, obwohl ich ihr Austragungsort bin, gar nicht von mir stammt. Ich muß sie von einem Unbekannten übernommen haben. Es handelt sich um eine Fremdkompliziertheit, wenn es so etwas gibt. (Glück, S. 156)

Kompliziert sind die Figuren nicht nur für andere und den Leser, sondern auch für sich selbst (s.o.):

Wie so oft ist mein Gefühlsleben grenzwertig anteilnehmend und grenzwertig fliehend. Mal interessiere ich mich für andere Menschen, dann wieder überhaupt nicht, leider auch nicht für solche, für die ich mich früher schon einmal interessiert habe. Ich würde diese unseriösen Gefühle gerne ersäufen (hier im Becken), aber sie sind fest in mich verkrallt und lassen nicht mit sich handeln. (Heimweh, S. 90)

Dieses Beispiel lässt sich grob noch mit der Stimmungsschwankung in Verbindung bringen, wohingegen das nächste in Reinform die Undurchschaubarkeit der eigenen Psyche zur Sprache bringt: „Ich begreife diesen Zusammenhang nicht. Es scheint so zu sein, daß das Erscheinen einer Person, der es noch schlechter geht als mir, in mir das Verhalten eines guten Menschen hervorruft. Der Satz klingt plausibel, in Wahrheit klärt er nichts und läßt mich ratlos zurück." (Regenschirm, S. 20) Wie später noch genauer auseinandergesetzt werden wird ( $\Rightarrow$ II.3.1), ist es eine einschneidende Erfahrung, sich selbst nicht zu kennen oder eigenes Verhalten vorhersagen zu können. Das macht nicht nur „ratlos“, sondern verzweifelt: „Meine Umständlichkeit und meine Zerfahrenheit werden mich umbringen. Dabei darf ich mich bei niemandem über diese Eigenschaften beschweren.“ (Regenschirm, S. 66) Warlich fasst zusammen: „Ich werde dadurch daran erinnert, daß ich leider ein komplizierter Mensch bin." (Glück, S. 19) ${ }^{46}$ Es bleibt wohl nur zu fixieren, dass weder Menschen noch literarische Figuren - so sie denn ein höheres Maß an Komplexität aufweisen - widerspruchsfrei oder in den Worten von Culpeper: „coherent“ ( $\Rightarrow$ I.2.4) zu sein haben oder überhaupt sein können.

Zwei Metakategorien sollen diese Zusammenschau beenden: erstens ausgewählte ,traditionelle‘ Charakteristika - etwa: der Basistypus ist unordentlich (vgl. Außer uns, S. 9), feinsinnig (vgl. Heimweh, S. 117) und schätzt die Unabhängigkeit (Heimweh, S. 175), die verhältnismäßig klar zuschreibbar sind, in der Wortwolke eher klein dargestellt, da schlecht verallgemeinerbar, sind, und zweitens ein Komplex, der die psychischen Problembezirke anschneidet: Minderwertigkeitsgefühle und Selbstvorhaltungen.

45 Vgl. auch: „Eines Tages werde ich mir selbst die Brust öffnen und mir meine überflüssige Kompliziertheit herausreißen und sie für immer an die Wand werfen." (Liebesblödigkeit, S. 95) 
Genazinos Basistypus ist in zweifacher Hinsicht ,medioker': zum einen bezogen auf die immer wieder genannten Mittelmäßigkeiten, zum anderen auf die Methodik: Familienähnlichkeiten suchen ja dezidiert nach dem ,Kollektivfoto‘ $(\Rightarrow$ I.2.5). Auch die Selbstcharakterisierung geht häufig in Richtung Mittelmaß: „Dabei führte ich ein normales Leben. Ich trank nur mäßig Alkohol, ich ging früh zu Bett, ich war schuldenfrei, litt nicht unter Abartigkeiten, zeugte keine unehelichen Kinder" (Außer uns, S. 46 f.). Dieser protektiven Eindruckssteuerung korrespondieren die der sozialen Verträglichkeit (s.o.) zuzuordnenden Eigenschaften von ,Bescheidenheit‘ bzw. ,Genügsamkeit', die die Protagonisten nicht nur selbst verkörpern - manchmal auch an sich selbst mögen: „Er hatte oft das Gefühl, daß sein bescheidenes Auftreten am Telefon viele unschlüssige Kunden in letzter Minute dazu brachte, ihre Reifen eben doch bei Norris zu kaufen" (Ausschweifung, S. 44) -, sondern sie auch als positive Eigenschaft an anderen lobend hervorheben: „Ihre Art, nichts Besonderes zu erwarten, gefiel mir." (Licht, S. 49) Als Genügsamkeit (vgl. Regenschirm, S. 41) lässt sich diese Charaktereigenschaft des Basistypus bis hin zur materiellen Askese (vgl. Falsche Jahre, S. 560) beobachten:

Im Supermarkt kaufte ich Zahnpasta, Schnürsenkel, Toilettenpapier, Seife, Shampoo, Rasierklingen, Filterpapier. Als ich in die Wohnung zurückkehrte, rief ich aus: Ich brauche keine Zahnpasta, keine Schnürsenkel, kein Toilettenpapier, keine Seife, kein Shampoo, keine Rasierklingen, kein Filterpapier. (Kein Geld, S. 40)

Als artverwandte Spielform dieser Anspruchslosigkeit lassen sich auch Zurückhaltung, Diskretion und Vorsicht nennen ( $\Rightarrow$ II.2.6): „Ich war nicht jemand, der Erlenbach auf seine mangelnde Pietät hinwies.“ (Tiere, S. 29; $\Rightarrow$ II.2.1 u. $\Rightarrow$ II.2.6) Auch in Form von Verlässlichkeit und Zuverlässigkeit ist die Gewissenhaftigkeit (s.o.) ein hohes Gut für den Basistypus: ein Versprechen oder selbst eine Zusage sind von unumstößlicher Verbindlichkeit: „Ich bin jemand, der einmal gegebene Zusicherungen nicht gerne relativiert, auch vor mir selber nicht.“ (Heimweh, S. 27)

Es handelt sich ferner zwar um humorbegabte Figuren, ${ }^{47}$ aber letztlich sind es „ernste Männer“ (Außer uns, S. 111) bzw. Frauen, „bedacht und sehr selbstkritisch“,48 die auch einer gewissen Strenge im Anspruch an eigenes Denken und Handeln nicht entbehren: „Dabei war ich im Umgang mit anderen Menschen nicht streng, im Gegenteil, ich war offen und nachsichtig. Allerdings dachte ich streng, und strenges Denken ist die heimlichste und deswegen härteste Form der Strenge.“ (Wohnung, S. 37) Die Selbsteinschätzung als „offen“ überschneidet sich mit der BigFive-Zuordnung, zu der auch die Neugierde - verfolgt andere, will immer alles lesen, was andere dabeihaben oder liegenlassen $(\Rightarrow$ II.2.2) - und Fantasie 49 - auch in Form von Tagträumen realisiert - passen.

\footnotetext{
47 Vgl. Tittel: „Die postmoderne Welt im Narrenkostüm“, S. 157.

48 Tittel: „Die postmoderne Welt im Narrenkostüm“, S. 157.

49 Vgl. für eine gegenteilige Selbsteinschätzung Liebesblödigkeit, S. 188.
} 
Eine ganz andere, sozial verträgliche Eigenschaft betrifft die Empathiefähigkeit ${ }^{50}$ der Protagonisten: „Abschaffel konnte das Leiden dieser Frau so gut begreifen, daß er sich am liebsten ihre Tränen auf das Hemd geschmiert hätte“ (Falsche Jahre, S. 510); „und es tat ihm gut, daß er sich eine Weile in Personen einfühlte, die er nicht kannte." (Falsche Jahre, S. 521; vgl. Frauen, S. 33) Durch die Perspektivübernahme - so sie denn glückt - kommt es gelegentlich zu guten Taten altruistischer Provenienz. Der Protagonist aus Leise singende Frauen nimmt sich etwa der Obdachlosen an, indem er beginnt, „die aus den Papierkörben rund um die Berufsschule eingesammelten Brote, das Obst und die Trinkpäckchen in den Abfallkörben auf der Zeil unterzubringen." (Frauen, S. 57)

Ganz anders als bei der immer wieder thematisierten Nähe zu den Ausgestoßenen und Verrückten, rührt sich familienähnlich bei subjektiv nicht bemitleidenswerten Nebenfiguren ein Charakterzug, der sowohl gesellschaftlich beargwöhnt wird als auch die Figuren selbst enerviert: Dünkel und Überheblichkeit haben für den Basistypus hohen Wiedererkennungswert ( $\Rightarrow$ II.4.1): „Für Augenblicke erkannte ich meinen innersten Feind, meine lächerliche Verstiegenheit." (Tiere, S. 139) ${ }^{51}$ Das ist für die Figuren ein bereits verhältnismäßig ,problematischer ' Wesenszug, der neben der Selbstüberschätzung bzw. -überhebung auch ins andere Extrem kippen kann: der nicht immer erklärlichen - Selbsteinschätzung als Benachteiligter, Minderwertiger. Der Aufstieg in die ,neurotische Oberliga' ist damit vollzogen. Genazinos Figuren zeigen sich nicht nur häufig beleidigt, sie fühlen sich auch allgemein benachteiligt, wobei ihre massive Reflexionsbegabung diese Tatsache zu durchdringen weiß: „Noch dazu litt ich unter mehreren heimlichen Grundgefühlen, von denen mich einige sogar versteckt leiteten. Eines davon war die Überzeugung, dass ich vom Leben ein wenig zu schlecht behandelt wurde." (Tiere, S. 9 f.) Auch über Abschaffel heißt es, dass er „stets das Gefühl hatte, nicht eigentlich zu leben, sondern sein Leben immerzu zu überbrücken mit der zweit- und drittbesten Möglichkeit, weil die erste Wahl auch für ihn nicht zu haben war." (Abschaffel, S. 10) ${ }^{52}$ Familienähnlich verwandt sind Gefühle der Minderwertigkeit:

Diese hocharschigen, fein lachenden Männer, die in Gruppen über die Straßen gingen und auf ihre sandelholzbraunen Schuhkappen sahen, machten ihn ganz klein. [...] Er dagegen, Wolf Peschek, war nichts als ein umherschweifender Schattenunternehmer, der an einem verborgenen Fernraumdelikt verdiente (Fremde Kämpfe, S. 191).

50 Die Egozentrik, die als diametraler Gegenpol wirksam ist, lässt sich in der Ausprägung, alles auf sich zu beziehen, gut beobachten in Regenschirm, S. 160, sowie Heimweh, S. 139 u. S. 153.

51 Auch für solche, gar als „Feind“, als ,innere Dämonen' erkannte, unliebsame Eigenschaften sind die allheilsamen Besänftigungsstrategien anwendbar: „Ich durfte mich zu meinem Leben als ein Lauschender verhalten. Ich durfte so lange in die Wirklichkeit hineinhören und hineinsehen, wie ich nur wollte. Beim Belauschen der Dinge und Ereignisse wurde ich nicht hochmütig." (Wohnung, S. 146)

52 Nur gelegentlich geht den Figuren auf, dass es sich zumeist um Hirngespinste handelt: „Zum Glück legte sich das Armutsgetue in meinem Inneren. Meine Krankheit bestand aus einer eingebildeten Benachteiligung, aus der schöne innere Bereicherungen hervorgingen“ (Regen, S. 84). 
Obwohl zumindest hier ein gehöriges Maß an Verachtung mitschwingt, ist die eigene (gefühlte) Subalternität dominierend, ${ }^{53}$ die auch den Ich-Erzähler aus dem Roman Bei Regen im Saal umtreibt: „Die einzige Angst, die mich zuweilen überfiel, war die Angst vor meiner Verstoßung durch die anderen. Immer mal wieder dachte ich, dass gleich jemand das Zimmer betreten und zu mir sagen würde: Du gehörst nicht mehr zu uns, geh weg.“ (Regen, S. 60; $\Rightarrow$ II.1.1) ${ }^{54}$ Wie Kinder suchen auch ,neurotische' Erwachsene im Normalfall die Schuld zunächst bei sich selbst berechtigt oder unberechtigt $(\Leftrightarrow I I .2 .4)$. Die Romanfiguren Genazinos jedenfalls ergehen sich in Selbstvorhaltungen und Selbstbeschimpfungen: „Du redest zuviel, halte ich mir vor, du hörst zuviel zu, du trinkst zuviel Kaffee, du sitzt zu lange in fremden Zimmern, du schläfst zu schlecht, du bist zu lange wach, du denkst zuviel flaches Zeug, du hoffst zuviel, du tröstest dich zu oft.“ (Glück, S. 93) Wenig später wird Warlich sich selbst gegenüber sogar sarkastisch: „Ich bin mal wieder enorm schlau. Sogar ein Hundescheißhaufen genügt mir, um mir selbst meinen jederzeit losbeißenden Intellekt vorzuführen." (Glück, S. 118) ${ }^{55}$

Als prototypisch kann auch Reinhard aus Wilhelm Genazinos Regen-Roman gelten. Er geht zunächst davon aus, dass die nicht anwesende Sonja ihm - wie üblich - „wahrscheinlich stille Vorwürfe [mache]: Du versäumst dein Leben, du drückst dich von Tag zu Tag, du musst endlich etwas aus dir machen, du ... du ... und so fort.“ (Regen, S. 44) Just diese Vorwürfe sind eine mögliche Begründung für die gefühlte Gesamtschuld der Figur, sodass sich aus einer gemutmaßten Kritik Selbstkritik entspinnt:

Plötzlich nahm ich mir übel, dass ich selbst nie geflohen war. Ich hatte alles ausgehalten: die Schule, die Eltern, die Armut, die kleine Wohnung, das Schweigen, die Ratlosigkeit, den Überdruss, den Ekel, sogar eine kurze Ehe. Eine Erklärung dafür war nur schwer zu finden. Vermutlich hatte ich zu große Angst. Ich wäre nur geflohen, wenn ich auch vor der Angst hätte fliehen können, aber das war nicht möglich. (Regen, S. 45)

Erzähltechnisch interessant ist die zunächst imaginierte, erahnte Tirade, der er aber selbst Worte verleiht, die späterhin in ähnlicher Form auch vom Gegenüber geäußert werden und erneut die Schuldgefühlspirale weiterdrehen: „Mein Innenleben war nicht so großartig, dass ich vor ihm keine Angst hätte haben müssen. Sonjas Vorwürfe klangen immer noch in mir nach. Du hast keine Zukunft, du hast keinen Halt, du hast nicht einmal eine Gegenwart.“ (Regen, S. 71 f.)

53 Man könnte zwar die vermeintlich selbstbewusste Aussage: „Ich habe das Gefühl, ich könnte Wahrheiten sagen, die von allgemeinem Nutzen sind (wären), wenn mich jemand fragen würde“ (Heimweh, S. 174), als Gegenbeispiel wahrnehmen, aber es ließe sich auch ein gedachter Gedankenstrich statt des Kommas vor das „wenn“ setzen - und schon hätte man eher eine Beglaubigung des Gefühls der Zurücksetzung.

54 Eindrückliche Auswüchse dieses Minderwertigkeitskomplexes finden sich insbesondere in Obdachlosigkeit, S. 34 f., S. 35 u. S. 38.

55 Vgl. auch den Protagonisten aus Ein Regenschirm für diesen Tag, der sich erst in Ich-, dann in DuForm selbst herabsetzt (vgl. Regenschirm, S. 48 f.), oder Rotmund, der mit sich selbst unzufrieden ist und Selbstbeschimpfungen vornimmt (vgl. Heimweh, S. 21). 
Wenn der Basistypus sich als benachteiligt, als minderwertig und schließlich als schuldig ansieht, ist die Konsequenz aus Unsicherheit, Lächerlichkeit und Furcht nicht sehr verwunderlich und der Griff zum protektiven Impression Management naheliegend:

Auf keinen Fall wollte ich den Kellner bitten, mir meine Zeitung zu bringen. Lächerlich und hilflos durfte ich nicht erscheinen. Zum Glück kümmerte sich niemand um mich. [...] Es sah vermutlich ein wenig ungeschickt aus, aber es ging. [...] Offenbar niemand, dachte ich, hat bemerkt, dass ich ungefähr drei Minuten lang lächerlich gewesen war. (Kassiererinnen, S. 40)

Die ,Exit-Strategie‘ ist erneut eine ähnliche: „Lächerlichkeit entsteht durch zu langes Hinsehen, dachte ich, durch die törichte Dehnung der Blicke. Ich muss mich zur Flüchtigkeit erziehen, zur umherschweifenden Undeutlichkeit, die keine präzisen Wahrnehmungen hervorbringt." (Kassiererinnen, S. 96)

Als Quintessenz dieser Aufzählung, die sich weitaus eher wie ein Fass voller Makel, Marotten und anderer Merkwürdigkeiten liest, als dem zu entsprechen, was eine ,klassische‘ Figurencharakterisierung im Normalfall auftut, soll ein wiederkehrendes Element in verschiedenen Ausprägungen in die Tiefe dieser psychischen Vertracktheiten und zugleich langsam aus den Familienähnlichkeiten führen.

\section{PSYCHISCHE PROBLEMBEZIRKE ZWISCHEN FAMILIENÄHNLICHEM UND ROMANSPEZIFISCH-INDIVIDUELLEM:} MANGELNDE SOZIALKOMPETENZEN

Bezeichnenderweise speisen sich die hier subsumierten Verhaltensweisen aus der Kombination neurotischer (labiler) und zugleich introvertierter Grundbedingungen und widerspiegeln damit den Melancholiker aus Eysencks Typenkreis $(\Leftrightarrow I I .4 .1 / \Rightarrow$ Abb. 13) mit den Etiketten ,launisch', ,ängstlich', ,rigide', ,bedrückt', ,pessimistisch', ,zurückhaltend', ,ungesellig' und ,schweigsam'.56 Diese ,positive' Liste kann man ins Negativ übertragen und mangelnde Sozialkompetenzen als Ursache für Situationen angeben, in denen sich die Figuren inadäquat verhalten, (objektiv unbegründet) unwohl fühlen, sich unsicher zeigen oder (vermeintlich) lächerlich machen.

Soziale Kompetenzen ${ }^{57}$ lassen sich in drei Bereiche unterteilen: den perzeptiv-kognitiven, der neben der Selbstaufmerksamkeit die Personenwahrnehmung beinhaltet, weiterhin Perspektivübernahme, Kontrollüberzeugung, Entscheidungsfreudigkeit und Wissen; den motivationalemotionalen, der emotionale Stabilität, Prosozialität und Wertepluralismus umfasst; und den

56 Zu ergänzen wäre: schwermütig: „Sie tänzelt vor mir her und will mit mir anbändeln. Ich gebe ihr den Namen Gertrud, damit ich sie wirkungsvoller verhöhnen kann. Gertrud Schwermut, hau ab. Prompt stellt sie sich vor: Gestatten, Gertrud Schwermut, darf ich Sie ein bißchen herunterziehen?" (Regenschirm, S. 125)

57 Vgl. grundlegend für eine Verbindung von IM und sozialer Kompetenz Miriam Epple: Soziale Kompetenz und Impression Management. Eine multimodale Validierung des Social Skills Inventory. Diplomarbeit Universität Bielefeld 2007. 
behavioralen Bereich, der Extraversion, Durchsetzungsfähigkeit, Handlungsflexibilität, Kommunikation, Konfliktverhalten und Selbststeuerung einschließt. ${ }^{58}$

In Bezug auf den perzeptiv-kognitiven Bereich übererfüllen Genazinos Figuren die Grundvoraussetzungen der Selbstaufmerksamkeit zwar auf den ersten Blick, indem sie nahezu permanent die Aufmerksamkeit darauf richten, wie andere Interaktionspartner auf sie reagieren ( $\Rightarrow$ II.2.4); ein sozialkompetentes Verhalten resultiert letztlich jedoch nicht daraus:

Welches Auge soll man anschauen? Das schielende oder das nicht schielende? Welches Auge ist das schielende, welches das nicht schielende? Und ist es für die Frau eine Kränkung, wenn ich aus Versehen in das falsche Auge schaue? Darf man überhaupt von einem falschen Auge sprechen? Ich nehme an, die Frau kennt die Dummheit solcher Gedanken. Vermutlich hat sie schon vor langer Zeit allen verziehen, die beim Vorübergehen ihre Einfalt eingestehen, weil sie ohne eine solche Generalverzeihung nicht einen Tag durchleben könnte. In raschem Wechsel blicke ich auf die Straße und dann wieder in das Gesicht der Frau. Dabei sehe ich mich zugleich auch noch selber und muß hinnehmen, wie traumartig bedürftig und entblößt ich an der schuldlosen Frau vorübergehe, es ist nicht zu sagen, nur zu gestehen. (Frauen, S. 118)

Andere Personen korrekt einschätzen zu können, fällt dem Basistypus prinzipiell schon schwer. Zum kompletten Scheitern verurteilt sind diese Aspekte der Personenwahrnehmung, wenn die Überinterpretationsmaschine $(\Leftrightarrow I I .2 .3)$ angeworfen wird: „Ich bin jetzt sicher, daß die Japanerin auch von mir errettet werden möchte. In der Art, wie sie ihre kleinen Füße bewegt, als wären sie bittende Hände, habe ich den Rettungsauftrag erblicken können.“ (Frauen, S. 10) Das ist zweifelsfrei nicht der Fall. Es wurde bereits gesagt (s.o.), dass die Figuren Empathiefähigkeit besitzen und sich in andere im Sinne einer Perspektivübernahme einfühlen können. Dass sie aber auch fehlgehen (vgl. Ausschweifung, S. 21) oder graduell unterbleiben kann (vgl. Obdachlosigkeit, S. 116), muss ergänzt werden. Was in der Forschung zu Sozialkompetenzen Kontrollüberzeugung genannt wird, ist in dieser Arbeit als ,Selbstwirksamkeit' benannt, wobei es sich tatsächlich lediglich um eine terminologische Unterscheidung handelt. Beide Konzepte meinen die „[s]ubjektive Einschätzung einer Person, Ereignisse beeinflussen und ihren Ausgang verändern zu können“,59 die dem Basistypus häufig abgeht:

Ich, Axel, tat erst so, als hätte ich nicht kapiert, ich tat so, als hätte ich eine Wahl gehabt, als hätte ich wirklich entscheiden können, als hätte nicht schon die Kenntnis von Elkes Wunsch, den ihr Blick verraten hatte, eine Vorentscheidung getroffen, als sei ich noch in der Lage gewesen, ein Nein zu sagen (Laslinstraße, S. 181 f.).

Degen fühlt sich genötigt, fühlt sich überrumpelt und fühlt sich letztlich nicht Herr der Lage. Diese mangelnde Kontrollüberzeugung respektive Selbstwirksamkeit verbalisiert auch der Ich-

$58 \quad$ Vgl. Susanne Jurkowski: Soziale Kompetenzen und Lernerfolg beim kooperativen Lernen. Kassel 2011, S. 14. Die vermeintlich distinkte Trennung in fünfzehn Facetten sollte nicht darüber hinwegtäuschen, dass viele Passagen aus Genazinos Romanen Mischformen abbilden, also Kreuzungen mehrerer sozial inkompetenter Verhaltensweisen darstellen: „Natürlich wurde er sich nicht klar darüber, wie er sich heute abend verhalten sollte." (Ausschweifung, S. 291) Einerseits handelt es sich um mangelnde Entscheidungsfreudigkeit, andererseits auch um mangelndes Rollen- und Regelwissen in kommunikativen Situationen. 
Erzähler aus Eine Frau, eine Wohnung, ein Roman: „Obwohl er mich de facto wie seinen Diener behandelte, sagte er gerne: Herr Weigand, würden Sie bitte so freundlich sein..." (Wohnung, S. 36). Er thematisiert damit das verlogene Gebaren eines eigentlich die Selbstwirksamkeit untergrabenden Abhängigkeitsverhältnisses, das dem Individuum schlicht keine Kontrollüberzeugung angedeihen lässt. 60 Ganz klar ist es Genazinos Figuren von externer Seite der Konzeption wie von interner Seite der Persönlichkeit zudem nicht vergönnt, Entscheidungsfreudigkeit an den Tag zu legen $\left(\Rightarrow\right.$ II.2.6). ${ }^{61}$ Zögern und Zaudern sind eher ihre Sache:

Soll ich zu ihr hingehen und sagen: Sie haben ein Kaugummi verloren? Vielleicht würde es genügen, wenn ich sagte: Ihnen ist etwas heruntergefallen. Oder einfach: Sie haben etwas verloren. Zur Verdeutlichung (und weil ich das Wort Kaugummi nicht aussprechen mag) könnte ich mit dem Zeigefinger auf den am Boden liegenden Gegenstand deuten. Allerdings wäre (ist) mir das Deuten mit dem Finger peinlich. Es ist schrecklich, ich ähnele Gunhild, ich kann niemanden auf nichts aufmerksam machen. Vermutlich will die Frau gar nicht auf den Verlust hingewiesen werden. (Regenschirm, S. 13)

Wird hier der Konflikt zwar durch Komik beigelegt bzw. durch eine Selbstrechtfertigung umgedeutet $(\Leftrightarrow I$ I.2.1), so ist die ,Entscheidungsfeindlichkeit' des Basistypus immer wieder Gegenstand der Reflexion: „[F]alls ich mich je über meinen ärgerlichen Wankelmut beklagen sollte, erinnere mich bitte an meine prinzipielle Verlegenheit vor dem Leben. Sie beherrscht mich oft ganze Tage.“ (Licht, S. 60; s.o.) Mit der „Kenntnis“ der „Normen und Regeln interpersonellen Verhaltens“ ist die letzte perzeptiv-kognitive Kompetenzfacette Wissen aufgerufen: „Peschek lachte dünn und unentschlossen und wußte nicht, wie er eine Absage formulieren sollte." (Fremde Kämpfe, S. 112) Zum Teil durch andere Facetten sozial inkompetenten Verhaltens beeinflusst, stehen die Protagonisten allenthalben kenntnislos da: „Mir fällt nichts ein. Die Verdutztheit ist im Prinzip nichts Neues für mich. Ich weiß oft nicht, was ich sagen soll.“ (Liebesblödigkeit, S. 108) Und selbst, wenn die eigentlich geläufigen Regeln bekannt sind, überfordern sie die Figuren: „Er genierte sich, als er von Dr. Buddenberg vorgestellt wurde" (Falsche Jahre, S. 407 f.).

Im motivational-emotionalen Sektor wurde bezüglich der emotionalen Stabilität bereits für die Big-Five konstatiert, dass es mit dieser beim Basistypus nicht weit her ist. Diese mangelnde Kompetenzfacette, die bspw. „die Kontrolle der eigenen Emotionen auch in Belastungssituatio-

60 Vgl. auch: „Leider kann ich nicht sichtbar machen, wie ich mich fühle. [...] Wenn es mir möglich wäre, wirklich meinen Gefühlen gemäß zu handeln, müßte ich Ihnen antworten: Suchen Sie sich einen anderen! Aber Sie meinen, Sie können mich einfach herbeirufen wie einen Hund, und Sie haben sich nicht geirrt! Ich komme!" (Fremde Kämpfe, S. 126) Der Protagonist verabscheut das System, dennoch ist er folgsam. Als ,Rache' entwerfen die Figuren immer wieder Wunschfantasien der Selbstwirksamkeit, wie die, später einmal mit spitzer Feder über den unliebsamen Vorgesetzten schreiben zu können: „Wieder beruhigte mich die Überlegung, daß ich über den Prokuristen früher oder später schreiben würde. [...] Es fiel ihm nicht auf, daß die lachhafte Strickweste und die Hornbrille nicht zusammenpaßten." (Wohnung, S. 63)

61 Für eine eher individuelle Ausnahmesituation eines beherzten Eingreifens vgl.: „Ich habe die große weiße Papierserviette vom Mittagessen fast unbenutzt in der Hosentasche und eile auf den jungen Mann zu. [...] Ich fasse den jungen Mann an der Hand und führe ihn zu einer Bank." (Heimweh, S. $150 \mathrm{f.})$ 
nen“ einschließt,62 lässt sich auch aus dem beobachtbaren Verhalten der Figuren stützen: „Vermutlich nahm Herrdegen an, daß ich gleich zusagen würde. Stattdessen erlitt ich einen Schweißausbruch. [...] Denken Sie nicht, sagte ich (und suchte nach einer Förmlichkeit), daß ich Ihr Angebot nicht zu schätzen weiß. Ich bin nur so sehr verblüfft, daß ich im Moment nichts sagen kann.“ (Wohnung, S. 125 f.) Drastischer wird die körperliche Komponente, die begründet auf eine emotionale Instabilität schließen lässt, etwa in Genazinos Roman Die Liebesblödigkeit vorgeführt. Aus der Sicht des namenlosen, 52-jährigen Ich-Erzählers wird die folgende Szene in einem Schnellrestaurant geschildert:

Der Mann kommt zu mir, ich zittere ein bißchen, weil ich nicht weiß, was ich machen soll. [...] Plötzlich frage ich den Mann, ob er meine so gut wie unberührten Spaghetti zu Ende essen möchte. Der Mann ist sprachlos, ich auch, etwa vier Sekunden lang. [...] Die Spaghetti sind sehr gut, sage ich dann, ich meine es nicht im geringsten herablassend [...]. Ich spüre den Druck zwischen meinen Gesten und meinen Sätzen, ich halte es für möglich, daß der Mann gleich ausholt und mir ins Gesicht schlägt. Ich bin ein wenig erregt beziehungsweise eingeschüchtert beziehungsweise von mir selber überfordert. (Liebesblödigkeit, S. 200)

Der Protagonist zeigt nicht nur die bereits benannten ,Schwächen' des Basistypus, bei Personenwahrnehmung, Perspektivübernahme und Verhaltenswissen Probleme zu haben, sondern er lässt auch eine rundum ungefährliche Situation in der Wahrnehmung in eine ,Belastungssituation' kippen. Erzähltheoretisch bemerkenswert ist die ungewöhnliche Spannungserzeugung, die die (empfundene) Bedrohung apostrophiert. Nichtsdestotrotz unterstreicht diese Passage erneut den prinzipiell vorhandenen Impetus der Prosozialität. Gerade dann, wenn es um dyadische Bezugspersonen - etwa in einer Beziehung oder im nächsten Freundeskreis - geht, kommt Hilfsbereitschaft durchaus zustande. Mit einem großen ,aber' ist hinzuzusetzen, dass andere mangelnde Kompetenzen prosoziales Verhalten eindämmen können: So hätte der Protagonist der Leise singenden Frauen die Obdachlosenpapierkorbbestückung (s.o.) ja auch zugunsten eines prosoziale(re)n Verhaltens verwerfen können, bei dem Essen und Trinken direkt an die betreffenden Personen ausgehändigt worden wären. Toleranz bzw. Wertepluralismus ist die dritte und letzte Facette des motivational-emotionalen Kompetenzverhaltens. Um es kurz zu machen: Der Basistypus versagt auf ganzer Linie ( $\Rightarrow$ II.1.6 u. $\Rightarrow$ II.5.3).

Was man von diesen inneren Voraussetzungen tatsächlich auch im performativen Verhalten beobachten kann, ist dem behavioralen Bereich zugeschlagen. Der Basistypus ist zunächst am entgegengesetzten Pol von Extraversion einzuordnen (s.o.). Anderen gegenüber aufgeschlossen und zugewandt zu sein, bedarf etlicher, höchst selten in dieser Verschränkung vorkommender Begleitumstände, sodass die Romanfiguren weitaus eher sozialscheu zu nennen sind: „Besonders fürchte ich mich vor dem sogenannten gegenseitigen Kennenlernen!“ (Liebesblödigkeit, S. 62) Schon Abschaffel ist lieber für sich: „Bei jedem Halt hoffte er, daß sich niemand zu ihm in 
das Abteil setzte." (Falsche Jahre, S. 403) ${ }^{63}$ Extraversiven Menschen schreibt man häufig auch Durchsetzungsfähigkeit zu. Die poetische Selbstbeschreibung des Regenschirm-Protagonisten markiert die Distanz auch zu dieser Kategorie: „Genau wie eine Staubfluse bin auch ich halb durchsichtig, im Kern weich, äußerlich nachgiebig und übertrieben anhänglich und außerdem schweigsam.“ (Regenschirm, S. 44) Sich „auch gegen Widerstände anderer Personen“ nicht am „Verfolgen und Realisieren eigener Interessen“ abbringen zu lassen, ${ }^{64}$ liegt der Familienähnlichkeit fern. Im Gegenteil: „So einfach ist es, mich in wackligen Stunden fremdzubestimmen.“ (Liebesblödigkeit, S. 31) ${ }^{65}$ Ferner misslingt es dem Basistypus beständig, situationsadäquate Handlungsflexibilität zu zeigen:

Als es soweit war, ging Abschaffel mit festen Schritten über die Straße, und aus Ängstlichkeit und Überraschung ließ das Kind tatsächlich den Schlauch nach unten sinken und sah auf Abschaffel. Er tat dem Kind nichts, sondern zog nur eine Schachtel Zigaretten und ging nach Hause. (Sorgen, S. 171)

Ignoriert man die Komik, die dieser Szene die Schärfe nimmt, finden sich hier auch motorische Ursachen sozial inkompetenten Verhaltens. ${ }^{66}$ Hier lässt sich eindeutig die „Umsetzung von Verhaltensoptionen, die in der Situation nicht angebracht sind“, anführen.67 Mit der Kompetenzfacette Kommunikation ist neben der prinzipiellen „Teilnahme an Interaktionen“ auch die „Gesprächs- und Ausdrucksfähigkeit" angeschnitten. ${ }^{68}$ Beiderlei bildet für den Basistypus zumindest in actu hohe Hürden: „Frau Balkhausen lacht, ich schweige, beziehungsweise ich bringe einen knappen Satz hervor, der verunglückt, indem ich ihn ausspreche." (Regenschirm, S. 147) Erstens überrascht die erzähltechnische Verpackung, die das Essenzielle,wegrafft' und zugleich die Kommunikationsfähigkeit retrospektiv als defizitär, als erzählendes Ich aber wortgewandt ausdrückt, zweitens zeigt das Beispiel, dass es nicht immer die protektive Vermeidung von Kommunikation per se sein muss, ${ }^{69}$ sondern sich ereignende Kommunikationen von Peinlichkeiten und Unsicherheiten dominiert werden: „Peschek war bemüht, auf Elisabeth einzugehen, aber es gelang ihm nur, sich eine Zigarette anzuzünden." (Fremde Kämpfe, S. 114)70 Macht man dafür zumindest teilweise den ersten behavioralen Punkt der geringen Extraversion geltend, lohnt ein Blick auf eine der zahlreichen Schilderungen von Vorstellungsgesprächen, in denen es immer an

Vgl. auch: „Ich weiß nicht, ob ich zu Morgenthalers Fest gehen soll. Menschenansammlungen, selbst kleine, bekommen mir nicht mehr." (Liebesblödigkeit, S. 123) Jurkowski: Soziale Kompetenzen, S. 14.

Schilderungen in gegenteiliger Tendenz gibt es, allein sind sie meist gebrochen und verraten das Kooperationsprinzip: „[U]nd aus lauter Verlegenheit sagte er die Wahrheit: Ich habe keine Lust, mir die Geschichten anderer Patienten anzuhören. Und weil in dieser Antwort eine gewisse Überheblichkeit lag, fühlten sich gleich zwei andere Patienten herausgefordert." (Falsche Jahre, S. 476; vgl. Licht, S. 60).

Vgl. Jurkowski: Soziale Kompetenzen, S. 19.

Jurkowski: Soziale Kompetenzen, S. 19.

Jurkowski: Soziale Kompetenzen, S. 14.

Vgl. etwa: „Er hatte ihren Wohnungsschlüssel, und er wollte ihn zurückgeben, ohne mit Frau Kaiser selbst in Kontakt zu kommen." (Abschaffel, S. 122)

Vgl. auch: „Er glaubte, vor der Aufgabe zu stehen, glaubwürdig über seine Arbeitsunfähigkeit zu sprechen. Und wahrscheinlich mußte er dabei übertreiben, aber wie?" (Sorgen, S. 388) 
allen Ecken und Enden an Soft-Skills hapert: „Anstatt einen guten Eindruck zu machen, hörte ich bloß zu und schaute mich um. [...] Ich blieb verstockt, ich brachte die Lippen nicht auseinander.“ (Wohnung, S. 7 f.; $\Rightarrow$ II.1.4) Die vorletzte Kategorie im behavioralen Kompetenzbereich ist das Konfliktverhalten. Genazinos Romanfiguren sind (mindestens) im Bereich der Familienähnlichkeit weder konflikt- noch kritikfähig. Vielmehr ist Beleidigtsein ein Grundmotiv, das sich der Kompromissbereitschaft in den Weg stellt: „Zum Zeichen, daß Abschaffel böse mit ihr war und so nicht mit sich reden lassen wollte, ging er ein wenig schneller als sie“" (Falsche Jahre, S. 500). Auch immer dann, wenn eine Nebenfigur den Basistypus erkennt, enttarnt oder ihm zu nahe kommt, zieht er sich qua Flucht in die Maske des Schmollens in sich selbst zurück. Die „[b]ewusste Steuerung des eigenen Verhaltens"71 bildet in Form der Selbststeuerung die letzte der fünfzehn Kompetenzfacetten:

Weil mich das in mich einstürzende Gefühlsgemisch aus Scham, Lust, Neugier, Begehren zu sehr bedrängte, machte ich genau das Gegenteil dessen, was ich eigentlich wollte. Ich erhob mich, stopfte mein Hemd in meinen Hosenbund, kontrollierte den Inhalt meiner Hosentaschen und suchte mit Blicken den Ausgang. Das war ein dümmlicher Fehler, den ich wenig später bereute. Warum bleibst du nicht in der Nähe deiner Lust und ergibst dich ihr wie ein Kind? (Regen, S. 142)

Fraglos handelt es sich hier um eine gefühlschaotische Ausnahmesituation, aber auch häufiger lassen sich derartige Übersprungs- bzw. Zwangshandlungen beschrieben finden:72 „Er sah kurz hinter geparkte Autos und in halbdunkle Hauseingänge hinein, aber er entdeckte keine Brieftasche. Er bohrte in der Nase“ (Fremde Kämpfe, S. 131). Diese direkte Abfolge von Zwangs- und Übersprungshandlung ist zwar ungewöhnlich massiert, doch gerade dadurch Ausdruck der Omnipräsenz: „Nach einer Weile der Stummheit habe ich das Gefühl, als würden Hunderte von Ameisen über meine geschlossenen Augen laufen. Ich reibe mir die Augen, aber davon lassen sich die Ameisen nicht vertreiben. Gewohnheitsmäßig gehe ich auf die Toilette, etwas anderes fällt mir nicht ein." (Heimweh, S. 62) Es handelt sich erneut um die Figuren überfordernde Anforderungen, denen sie aufgrund der nicht zu Gebote stehenden Kompetenzfacetten nur desperat begegnen können, sie gewissermaßen keine ,Handhabe' für die interpersonellen kommunikativen Probleme haben. In Form des Tiervergleichs gesteht sich Dieter Rotmund denn auch ein, dass er „in diesen Augenblicken einem überforderten und deswegen verirrten Stallhasen [ähnle], der unter den unverständlichen Bedingungen von Menschen leben muß.“ (Heimweh, S. 64)73

71 Jurkowski: Soziale Kompetenzen, S. 14.

72 Vgl. für Übersprungshandlungen in Form des ,Freud'schen Versprechers' (auch ablesbar in der Wortspiellust) etwa Kassiererinnen, S. $114 \mathrm{f}$.

73 Bezogen auf das Anliegen, Genazinos Figurenbasistypus charakterisieren zu wollen, sind einige Attribute nicht ohne Weiteres auf die Kompetenzfacetten abbildbar, die dennoch im weiteren Sinne hierher gehören: So sind die Grundzüge einer resignativen Lebensangst, die aus Verlegenheit und Scham erwächst, zu beobachten: „Es erfasste mich die Furcht, dass dem Blinden ein Missgeschick zustoßen könnte und dass ich ihm dann helfen müsste - und dass ich dabei nur ein neues Missgeschick zustande bringen würde. Mein Ausweg war, dass ich rasch die Straßenseite wechselte und ebenfalls das Familienlokal aufsuchte." (Regen, S. 144) Vgl. etwa auch Sorgen, S. 388, u. Falsche Jah$r e$, S. 452. Diese ungelenke Art ist den Figuren dabei regelmäßig reflexiv bewusst: „Immer noch 
Man könnte resümieren, dass Genazinos Romanfiguren-Basistypus aufgrund seiner (auch) melancholischen Art ein durchweg sozial inkompetenter sei. Tatsächlich liest sich die Verneinungstendenz der Kompetenzliste wie ein Figurenbauplan ganz anderer Art: Wenn es an fast allen sozialkompetenten Fähig- und Fertigkeiten mangelt, ist es kein Wunder, wenn Kommunikationssituationen unbefriedigend verlaufen und mitunter sogar zur Qual für die unbeholfenen Akteure werden. Aber auch die (Selbst-)Erkenntnis dieses Umstands hilft nichts: „Leider hatte er das Pech, sich andere Verhaltensweisen zwar vorstellen und wünschen, sie aber nicht für sich persönlich erfinden zu können." (Ausschweifung, S. 255)74

Die ultimaten Ursachen (Vererbung, soziales Umfeld, Sozialisation) für sozial inkompetentes Verhalten sind in diesem Rahmen (es geht eben dann doch nur um literarische Figuren) nicht sinnvoll zu diskutieren, die proximaten hingegen durchaus: Hinsch/Pfingsten und Kanning identifizieren Probleme hinsichtlich der „[s]ituative[n] Bedingungen“, der „Situationsanalyse",75 der „Analyse von Verhaltensoptionen“,76 der „[e]motionale[n] Verarbeitung“, des „[m]otorische[n] Verhalten[s]" und der fehlerhaften "Verhaltensevaluation“.77 Neben den bereits kurz angesprochenen Defiziten sind für diese Arbeit und auch die folgenden Schlaglichter insbesondere die „[v]erzerrte Wahrnehmung von Konsequenzen“ sowie die „[i]nadäquate Einschätzung von Bedürfnissen und Interessen des Interaktionspartners" von großer Wirkmächtigkeit.78

Nicht unberücksichtigt sollten ,sozialkompetente‘ Ausnahmeerscheinungen bleiben. So entwickelt sich etwa in Genazinos Die Kassiererinnen eine Symbiose zwischen Ich-Erzähler und der Figur Wischinski; beide haben ob ihrer jeweiligen Kompetenzdefizite Probleme und helfen sich gegenseitig: Wischinski kauft für den Protagonisten ein, dieser erledigt einen unliebsamen Anruf beim Finanzamt für jenen (vgl. Kassiererinnen, S. 102). Stimmt die Chemie, so ließe sich argumentieren, sind in passenden Dyaden durchaus nicht alle angelegten Defizite bemerkbar. Aber an diesem Punkt verlässt man auch schon wieder die Familienähnlichkeiten und landet im Alleinstellungsbereich: „Ruth ist (außer Laura) der einzige Mensch, mit dem mir gemeinsame Ver-

hoffte ich, im Schaukeln des Busses werde sich meine Unbeholfenheit als Schüchternheit darstellen und die Schüchternheit werde mich liebenswert erscheinen lassen." (Wohnung, S. 69)

74 Davon zu unterscheiden sind Situationen, in denen man sich nur, falsch' verhalten kann; notwendige Überforderungen sozusagen: „Was soll ich tun? [...] Aber ich bin kein Fachmann, ich weiß nicht, wie man einen Vogelring entfernt. Ich kann noch nicht einmal den Vogel anfassen, ohne zugleich das Gefühl zu haben, ihn falsch zu behandeln. Tatenlos stehe ich vor dem Tier. Wenn der Ring weg wäre, könnte der Vogel seine Route auf der Stelle vergessen. Ein Gefühl der Scham steigt in mir hoch. Ich zucke mit den Schultern wie vor einem Menschen." (Frauen, S. 40) Das Scheitern an derartigen Situationen lässt sich nicht auf das Konto mangelnder Sozialkompetenzen verbuchen. Vgl. etwa: „Mir fiel nicht einmal auf, dass ich das Arrangement zu lange anstarrte. Plötzlich erhob sich Maria und verabschiedete sich." (Tiere, S. 68)

76 Vgl. etwa: „Auf dem Weg hierher habe ich mir schon überlegt, ob ich bedeutungsvoll reden soll oder nicht. Im Augenblick bin ich unruhig und gleichzeitig verlegen, eine unangenehme Mischung, die ich gut kenne. Sie führt oft zu etwas Drittem, nämlich zu einer stummen, inneren Trockenheit, aus der ich nicht leicht herausfinde." (Regenschirm, S. 100) 
legenheit möglich und erträglich ist. Immer noch reden wir nichts, ohne Scham zu empfinden, Ruth stöhnt, ich frage nicht warum, ich schaue irgendwohin, wo nichts passiert." (Licht, S. 33) Gerade die Kommunikation, die über nicht verbale Kanäle erfolgt, ${ }^{79}$ ist für Genazinos Romanfiguren bezeichnend und von eminenter Wichtigkeit. Nicht ohne Grund findet sich im zitierten Beispiel die Ausnahme eines schamlosen Miteinanders im Schweigen - im Schauen und im paraverbal wahrnehmbaren Stöhnen. Viele Charaktereigenschaften und Verhaltensstrategien lassen sich sogar besser im analogen Bereich entdecken und beschreiben, zumal sie sich - wenn nicht durch unzuverlässiges Erzählen ,kontaminiert’ - vorurteilsfreier ,beobachten‘ lassen.

\subsection{Nonverbale Kommunikation (sowie eine Randnotiz zur äußeren Erscheinung)}

Gleich mehrere theoretische Rahmen anerbieten sich, sobald man die Grenze des Verbalsprachlichen (in der Literatur) hinter sich lässt. Hier soll von der allgemeinen menschlichen Kommunikation Watzlawicks ${ }^{80}$ der Weg über Barbara Kortes nach wie vor aktuelle Körpersprache in der Literatur ${ }^{81}$ gegangen werden, um, nach einem Exkurs zum Unsagbarkeitstopos und der Sonderform des Schweigens, ${ }^{82}$ schließlich zu den fragmentarischen Untersuchungssplittern der genuinen Genazino-Forschung zu gelangen, ${ }^{83}$ und so einem außerordentlich wichtigen Teilaspekt der Figuren(-Kommunikation) angemessen zu begegnen. ${ }^{84}$

Watzlawick entwickelt ein Kommunikationsmodell, das in seiner Ausrichtung flexibel ist (jede kommunikative Situation kann erfasst werden) und zugleich pragmatisch. Es baut auf fünf Axiomen auf, von denen hier (zunächst und vordergründig) vor allem das vierte, dasjenige, welches sich mit dem Unterschied von digitaler und analoger Kommunikation beschäftigt, interessiert:

Menschliche Kommunikation bedient sich analoger und digitaler Modalitäten.

In der Kommunikation gibt es zwei Möglichkeiten Objekte darzustellen. Zum einen kann man sie durch die Analogie (z.B. eine Zeichnung) ausdrücken oder dem Objekt einen Namen geben. Nicht nur das gesprochene Wort (in der Regel digitale Kommunikation), sondern auch die nonverbalen Äußerungen (z.B. Lächeln, Wegblicken,...) teilen etwas mit. [...]

Die digitale Kommunikation verfügt über eine komplexe und logische Syntax, entbehrt aber auf dem Gebiet der Beziehungen einer Semantik. Die analoge Kommunikation verfügt über ein solches semantisches Potenzial auf dem Gebiet der Beziehungen, entbehrt aber einer Syntax, die eine eindeutige Definition der Natur von Beziehungen leisten könnte. Mit analogen Elementen wird häufig die Beziehungsebene vermittelt, mit digitalen die Inhaltsebene.

Es gibt Tränen des Schmerzes und der Freude und ein Lächeln kann Sympathie oder Verachtung ausdrücken. Analoge Kommunikation ist mehrdeutig und kann unterschiedlich entschlüsselt wer-

79 Vgl. Miriam Langlotz/Nils Lehnert/Susanne Schul: SprachGefühl - eine Einleitung. In: Langlotz/Lehnert/Schul/Weßel (Hg.): SprachGefühl (2014), S. 9-25.

80 Vgl. Watzlawick/Beavin/Jackson: Menschliche Kommunikation.

81 Vgl. Barbara Korte: Körpersprache in der Literatur. Theorie und Geschichte am Beispiel englischer Erzählprosa. Tübingen/Basel 1993.

82 Vgl. Aleida Assmann: Formen des Schweigens. In: dies./Jan Assmann (Hg.): Schweigen. Paderborn 2013, S. 51-68; vgl. Hane: Gewalt des Schweigens; vgl. Beatrice Michaelis: (Dis-)Artikulationen von Begehren. Schweigeeffekte in wissenschaftlichen und literarischen Werken. Berlin/New York 2011.

83 Vgl. etwa Bucheli: Die Begierde des Rettens.

84 Vgl. für die systematische Untersuchung des Zusammenhangs von nonverbaler Kommunikation und IM Schlenker: Impression management, S. 234 ff. 
den. Durch mögliche Fehlinterpretationen können Konflikte zwischen den Kommunikationspartnern entstehen. ${ }^{85}$

Obwohl also die analoge Kommunikation weitaus eher geeignet scheint, die Beziehung zwischen Sender und Empfänger auszudrücken, stößt sie an eine andere Grenze - die der Eindeutigkeit: „Der weitere Ablauf war schwieriger, weil es fast nicht zu schaffen war, nur auf Grund von Zeichengebung sich zu einigen, daß man nun in eine Wohnung wollte, noch schwieriger die Klärung der Frage, in welche Wohnung" (Abschaffel, S. 85). Gleichwohl wird aber der analogen Kommunikation ein hohes Maß an zwischenmenschlichem Verständigungspotenzial zugemessen und im direkten Vergleich mit der arbiträren Verbalsprache wird sie mitunter bevorzugt:

Wenn sie seine Einladung annahm, dann könnte er auch leichter zugeben, daß er ihr gefolgt war. Ja, die Verfolgung würde eine gewisse Begehrlichkeit ausdrücken, vielleicht sogar eine Art von Unausweichlichkeit andeuten. Und er war dankbar für alles, was sich aus Handlungen und Gesten ablesen ließ und nicht mehr extra ausgedrückt werden mußte. (Ausschweifung, S. 182)

Im gleichen Roman sind für Eckhard „Handlungen und Gesten“ auch in puncto Sex mehr als Surrogat für digitale Sprachverwendung: „Du sagst gar nichts mehr. Eckhard kam aus einer unerhörten Weite zurück und sagte: Das Geschehen ist auch vollkommen ausreichend." (Ausschweifung, S. 206) ${ }^{86}$

Regalmeter an Ratgeberliteratur werden nicht müde zu betonen, dass nur wenige Prozent des Eindrucks, der beim Gegenüber ankommt (Überzeugungskraft beim Verkaufs- oder Kompetenzdemonstration im Fachgespräch, Attraktivität beim Flirten etc.), über den digitalen Inhalt vermittelt werden. Weitaus wichtiger sind para- (Stimmfarbe, Lautstärke etc.) und nonverbale Parameter. Doch auch die analoge Körpersprache lässt sich - das insinuiert bereits der Begriff - als Zeichensystem verstehen und mithin ,lesen' und deuten (und missverstehen). ${ }^{87}$ Wie jedes menschliche - und in diesem besonderen Fall eigentlich allen Lebewesen eignende - Verhalten findet es permanent sein Abbild in der Literatur. Und nur weil es sich um fiktive Figuren handelt, heißt es nicht, dass es nicht ergiebig wäre, die Körpersprache in der Literatur zu untersuchen, ist sie doch gerade im „Gegensatz zum nonverbalen Alltagsverhalten [...] in einem künstlerischen Kontext stets ,signifikant' insofern, als sie zumindest potentiell am Aufbau der Sinngestalt und an der ästhetischen Wirkung Anteil hat." 88 Während Korte damit zugleich die in diesem Untersuchungsfeld äußerst wichtige externe Perspektive der Figurenanalyse hervorkehrt - in diesem Kontext ließe sich etwa an Kafkas puffende und schubsende Gehilfen aus dem Proce $\beta$ denken,89

85 [Axiome Watzlawick]: Die Axiome von Paul Watzlawick. Online: <http://www.paulwatzlawick.de/axiome.html>. Vgl. Watzlawick/Beavin/Jackson: Menschliche Kommunikation, S. 61-68.

86 Lesbar auch als Parallele zum Sport: Denken und Reden werden überflüssig.

87 Vgl. Korte: Körpersprache in der Literatur, S. 3. Vgl. etwa Außer uns, S. 13 f., für eine explizite Analogie von Verbalsprache und anderen Ausdrucksmitteln. Vgl. für eine grundsätzlichere Diskussion von Zeichengeben und -(miss)verstehen ( $\Rightarrow$ II.2.3).

88 Korte: Körpersprache in der Literatur, S. 3.

89 Vgl. Matthias Ott: „Er hob die Hände und spreizte alle Finger“. Nonverbale Kommunikation in Franz Kafkas „Der Proceß“. Bachelorarbeit Universität Kassel 2013. 
die wohl eher als Slapstick-Element des kommunikativen Gesamtkonstrukts zu werten sind, als deren absonderliche Körpersprache mit deren Persönlichkeit kurzschließen zu wollen -, ist für Genazinos Figuren weiterhin auch die interne Perspektive lohnenswert. Korte unterscheidet drei Modi nonverbaler Kommunikation:

\section{KINESIK, HAPTIK, PROXEMIK}

Während die Kinesik „Körperbewegungen [Gesten [...] und Aktionen], Körperhaltungen, Gesichtsausdruck, Blickverhalten, automatische physiologische und physiochemische Reaktionen (Zittern, Farbwechsel, Perspiration etc.)“ umfasst, kann Haptik mit „Berührungsverhalten“ gleichgesetzt werden..${ }^{90}$ Proxemik schließlich erfasst die Bewegung der Körper im Raum, worunter Entfernung und weitere Kategorien fallen. ${ }^{91}$ Naheliegenderweise finden sich bei Genazino etliche Beispiele für alle drei, und eine beispielreiche ,Füllung der Kategoriegefäße' scheint nicht zielführend. Aufschlussreicher ist die Inbezugsetzung mit den „Funktionsklassen der nonverbalen Kommunikation und deren Ausdruckspotential“, innerhalb derer Korte „Emotions-Darstellung und Externalisatoren“ als wichtigste Kategorie identifiziert, zusätzlich aber auch „Illustratoren und Regulatoren" sowie „Embleme“ untersucht.92

Prinzipiell ist jeder Modus mit jeder Funktionsklasse kombinierbar, bestimmte Wahlverwandtschaften zeichnen sich dennoch ab. An wenigen Beispielen lässt sich dies gewinnbringend demonstrieren. Nach eingängiger Überlegung entscheidet sich Eckhard Fuchs dagegen, demonstrativ nonverbal das Büro zu verlassen, um seinem ,Konkurrenten“ eins auszuwischen, denn: „Diese halbdramatischen Gesten gelangen ihm einfach nicht, weder zu Hause noch im Büro." (Ausschweifung, S. 88) Es handelt sich um eine Unterkategorie der Kinesik, um Körperbewegungen genauer, und präzise um eine Aktion. In jedem Fall hätte diese kommunikative Handlung - sofern realisiert - die Funktion eines Externalisators inne, worunter

solche Formen der NVK [nonverbalen Kommunikation; N. L.] verstanden [werden], die Informationen über eine Figur außer deren temporären Gemütszustand indizieren: relativ stabile mentale Gegebenheiten (dauerhafte Gemütszustände wie eine psychische Krankheit, Einstellungen, Meinungen, Werthaltungen, Persönlichkeitsmerkmale) sowie geistige Aktivitäten und Zustände. ${ }^{93}$

Als Beispiel für einen der Haptik zuzuordnenden - und in der Analepse tatsächlich realisierten Externalisator, als Exempel für die emotionale Wirkmacht von Körpersprache allzumal, kann die folgende Kindheitserinnerung aus Das Glück in glücksfernen Zeiten dienen:

Korte: Körpersprache in der Literatur, S. 38 f. Dezidiert paraverbales Verhalten klammert Korte aus; auch dort wären Beobachtungen anzustellen: „Abschaffel fürchtete, das Reden des Arztes sei so laut, daß es in allen anderen Räumen gehört werden könnte; er setzte ein ganz leises Sprechen dagegen, um den Arzt auf die Idee zu bringen, selbst auch leiser zu sprechen." (Abschaffel, S. 124; $\Rightarrow$ II.2.5).

91 Vgl. Korte: Körpersprache in der Literatur, S. 39.

92 Korte: Körpersprache in der Literatur, S. 39-58.

93 Korte: Körpersprache in der Literatur, S. 43. 
Um mich wieder schuldfrei freuen zu können, faßte ich meine Mutter an der Hand und streichelte sie. [...] Durch das Anfassen ihrer Hand war meine Bereitschaft, ihre Scham, ihre Melancholie und sogar ihren Ärger zu teilen, plötzlich öffentlich geworden. Meine Mutter war so stark gerührt, daß sie wieder freundlich wurde. Erst dadurch schien meine Freude genehmigt zu sein und ließ mein Kinderglück zwischen ihr und mir hin- und herströmen. (Glück, S. 115)

Obwohl das folgende Beispiel Spielraum lässt, ob es sich genaugenommen um kinetisches Blickverhalten, kinetische Gestik oder Aktionen handelt, ist die funktionale Bestimmung als Externalisator ziemlich eindeutig:

Von den vielen Personen in meiner Nachbarschaft, die ich nicht kenne, die mir aber immer wieder begegnen, möchte ich keine missen. Manche grüße ich, manche nicht, andere schaue ich nur an. Ihre Unverzichtbarkeit gründet auf Blickprogrammen, die sich zwischen ihnen und mir über Jahre hin eingespielt haben. Das heißt, es mußte mit jedem einzelnen lange und fast immer nur mit Blicken geklärt werden, ob ein Sich-Anschauen möglich und genehmigt und vielleicht sogar angenehm sei. (Frauen, S. 111)

Im Kontrast dazu wird unter Emotions-Darstellung diejenige Körpersprache „verstanden, die momentane psychische Befindlichkeiten einer Figur anzeigt, also Affekte, Stimmungen und andere vorübergehende Gemütsverfassungen." ${ }^{94}$ Im folgenden Beispiel wird zwar iterativ erzählt nichtsdestotrotz handelt es sich jeweils um (die gleiche) momentane Gemütsverfassung und also um Emotions-Darstellungen, wenn Dieter Rotmund analeptisch festhält: „Er hat mir schon öfter in kameradschaftlicher Manier vom Scheitern seiner eigenen Ehe erzählt. Ich habe schon mehrfach versucht, mit mimischen Mitteln meinen Unwillen vor solchen Erzählungen auszudrücken, bis jetzt ohne Erfolg." (Heimweh, S. 55) Dass es sich um eine kinetische und auf den Gesichtsausdruck bezogene Emotions-Darstellung einerseits, um fehlgehendes, da unwirksames IM mit Kalkül andererseits handelt, ist evident. Dass zu unterschiedlichen Zwecken unübliche mimische Mittel aufgefahren werden, bestätigt auch ein Blick auf Abschaffels Verhaltensstrategien: „Das Kino hatte sich rasch gefüllt, und Abschaffel versuchte, durch Beibehaltung eines finsteren Gesichts zu erreichen, daß sich niemand neben ihn setzte." (Abschaffel, S. 100) Um für sich zu bleiben, wird intentional der Gesichtsausdruck, „als die prominenteste Partie des Körpers“,95 offensiv eindruckssteuernd instrumentalisiert. Etwas komplizierter wird es, wenn die Funktion nicht einwandfrei zu bestimmen ist, wie zwei zusammengehörende Passagen des dritten AbschaffelBandes zeigen: „Vor lauter Anstrengung und Widerstand verliere ich dann sogar die Mimik, sagte er, und ich habe das Gefühl, ein Stück Holz geworden zu sein.“ (Falsche Jahre, S. 493) „Morgens [...] war sein Gesicht meistens angenehm und weich und freundlich [...]. Aber [...] am Abend sah es oft nur noch eng und schmerzlich aus." (Falsche Jahre, S. 501) Der eindeutig bestimmbare Gesichtsausdruck changiert hier zwischen zeitlicher Stabilität ( $\Leftrightarrow$ II.1.3) und also Externalisator und kurzfristiger Emotions-Darstellung.

Ein weiteres Zitatenpaar verkompliziert die Lage: Der Werbegrafiker Peschek muss einsehen, dass „er nicht mehr mit ein paar geschmeidig-powervollen Gesten in den Vorzimmern erschei-

$94 \quad$ Korte: Körpersprache in der Literatur, S. 41.

95 Korte: Körpersprache in der Literatur, S. 59. 
nen und wie ein achtungsgebietendes Neutalent seine Mappe öffnen" konnte (Fremde Kämpfe, S. 23). Seine damalige Selbstsicherheit ist nicht mehr , authentisch' möglich, seine potente Jugend passé: „Ein paarmal hatte er versucht sich neu zu verkaufen. Es war unmöglich und beschämend." (Fremde Kämpfe, S. 23) Ob es sich um Gesten oder Aktionen im Bereich der Kinesik handelt, ist ebenso fraglich bzw. der Leerstelle anheimgestellt, wie es die Funktionsbestimmung als Externalisator oder Emotions-Ausdruck ist. Auch das folgende, Körpersprache und Unsicherheit ( $\Rightarrow$ II.1.3) verknüpfende Beispiel ist doppelt unterdeterminiert: „Eckhard entfernte sich mit viel zu großen Schritten. Das kannte er schon; in diesem Krankenhaus mißlangen ihm manchmal sogar die einfachen Bewegungen." (Ausschweifung, S. 66) Erneut werden die Funktionen Emotions-Darstellung und Externalisator nicht ausgeschlossen, sodass in der Kombination mit der Vagheit von Kinesik und Proxemik gleich mehrfache Kreuzverbindungen im Bereich des Möglichen liegen.

Mit diesem Unbestimmtheitschisma sind die Grenzen der Korte'schen Kategorienbildung in puncto Handhabbarkeit eigentlich schon ausgelotet. Genazino hingegen dreht die Schraube auch in diesem Bereich ein Stück weiter und nimmt als subversives Moment die Reflexion mit in das Deutungsspiel. Obwohl die Protagonistin in den Vierzigern eindeutig eine kinetische Körperbewegung, genauer: eine Geste im Blick hat, wird die Eindeutigkeit der nonverbalen Kommunikation reflektiert, wie auch die Bedingung der Möglichkeit von Zeichengeben und -verstehen $(\mapsto$ II.2.3) generell:

Das größere der beiden Mädchen winkt mir. Ich bin gerührt und traue mich nicht zurückzuwinken. An der Geste des Winkens gefällt mir ihre Undeutlichkeit. Es ist nicht klar, was das Winken mitteilen will. Heißt es einfach: Ich sehe dich? Oder meint es: Gleich sehe ich dich nicht mehr? (Obdachlosigkeit, S. 78 f.)

Auch die an Abschaffel gerichtete Empfehlung, seinen Gesichtsausdruck bezüglich einer intrafiktionalen Emotions-Darstellung kalkuliert zu beherrschen, geht weit über eine körpersprachliche Beschreibung hinaus und anverwandelt sich der Sentenz: „Mache dein Angesicht hart wie Kieselstein, wiederholte sie; das soll man tun, wenn man inmitten seiner Feinde ist und nichts tun kann als warten." (Abschaffel, S. 155) Spielerische Formen nimmt die Unbestimmtheit der Funktionalität an, wenn mit dem kulturellen Wissen gespielt wird, dass ein „intensiver Blickkontakt [...] vor allem ein wichtiges Anzeichen für Sympathie, Liebe und erotische Anziehung“ sei, ${ }^{96}$ diese (unterlassene) Blickfunktion aber im Grenzbereich von Kinesik und Proxemik ins Gegenteil und tendenziell ad absurdum geführt wird:

Wir mögen uns nicht, und wir wissen es. [...] Unser Meisterstück haben wir einmal in einer Buchhandlung abgeliefert. Wir wußten, daß wir uns gleichzeitig in ein- und demselben Laden aufhielten, wir nahmen Bücher in die Hand und blätterten darin, wir schauten zwischendurch auf, ohne unseren Blicken zu begegnen, wir lasen uns fest, wir wechselten die Standplätze und begegneten uns dennoch nicht. Obgleich wir uns nicht ansahen und nicht miteinander redeten, brachten wir unser 
gemeinsames Entkommen hervor. Hinterher war ich erschöpft. Wo hatte ich nur die Taktik des dauernden Ausweichens bei gleichzeitiger Nähe gelernt? (Obdachlosigkeit, S. 40) ${ }^{97}$

Dieser nonverbale Tanz zwischen Nähe und Distanz ist kunstvoll - erzähltechnisch wie reflexiv. Obwohl das Ausmaß an Komplexität in den beiden folgenden Beispielen wieder zurückgefahren wird, ist eine Funktionsklassenzuordnung nun gänzlich zugunsten der Reflexion von Blickverhalten generell aufgegeben worden:

Sekunden später ergab sich eine Blickkette. Das Kind entdeckte seine Betrachter und sah sie kurz nacheinander an. Erst die beiden Frauen, dann mich, dann die Amerikaner. In der Blickkette stießen das heimliche und das öffentliche Leben sanft aneinander. Das Kind sonnte sich in der Huldigung seiner Betrachter und hob das Brot kurz in die Höhe, dann verschwand es. (Wohnung, S. 159 f.)

Der an Korte orientierte Interpret muss feststellen, dass die Grenzen „zwischen Blickkontakt (dem gegenseitigen In-die-Augen-Sehen zweier Personen), Anblicken (eine Person sieht eine andere an) und Wegblicken (Vermeiden von Blickkontakt)“98 überschritten worden sind und genaugenommen eine vierte Funktionsklasse, die der Reflexion, hinzugefügt werden müsste: „Früher habe ich angenommen, Menschen schauen einander an, weil sie sich immerzu vor dem Eintreffen schlimmer Nachrichten fürchten. Dann glaubte ich, indem sie sich anschauen, suchen sie nach Worten für die Merkwürdigkeit des Lebens." (Regenschirm, S. 9) Es geht längst nicht mehr darum, bestimmten ,Augenblicken` im Sinne einer nonverbalen literarischen Kommunikation eine Funktion zuzuweisen, sondern um die in Laienperspektive gekleidete ästhetiktheoretische Frage nach der Zweckhaftigkeit und der evolutiv-pragmatischen Erklärung für Augenkommunikation überhaupt. ${ }^{99}$ Genazinos Romanfigurenreflexionen lässt sich also erneut nicht mit der klassifikatorischen Methode beikommen, sondern höchstens durch die Ergänzung weiterer Funktionsweisen der menschlichen Blickregie:

Der Blick ist von herausragender Bedeutung in der Face-to-Face-Interaktion. Ein Großteil der Information über den Mitmenschen wird über das Auge eingeholt; der Blick kann Kontakt stiften und aufrechterhalten, Gespräche regulieren und fungiert als Träger vielfältiger Informationen über die Interaktanten und die Natur ihrer interpersonalen Beziehung [...].100

Es geht nicht zuletzt darum, den Leser auf die gelegten Fährten anzusetzen, um die gleichberechtigten Mutmaßungen zu ergänzen, zu verwerfen oder zu bestätigen - gerade weil Genazino von nonverbalen Emblemen, „für deren Signifikat im Lexikon einer Sprache eine verbindliche verbale Übersetzung vorhanden ist und die wie Sprache intentional zur Kommunikation eingesetzt" werden, ${ }^{101}$ nur spärlich Gebrauch macht, um das In-der-Schwebe-Halten von Bedeutung nicht durch Fixierungen zu gefährden. Es geht um Grenzen und Potenziale analoger Kommunikation,

97 Vgl. für eine ausführliche Schilderung eines,Versteck- und Verfolgungsspiels' zwischen W. und einer unbekannten Frau auch Licht, S. $30 \mathrm{f}$.

98 Korte: Körpersprache in der Literatur, S. $61 \mathrm{f}$.

99 Vgl. auch: „Abschaffel überlegte, ob er sie grüßen sollte oder nicht, und weil er zur Entscheidung einen Anhaltspunkt brauchte, wollte er den Gruß davon abhängig machen, ob sie ihn vorher anblickte oder nicht." (Falsche Jahre, S. 519)

100 Korte: Körpersprache in der Literatur, S. 61.

101 Korte: Körpersprache in der Literatur, S. 51. 
um Ausdrucksmittel und die Ausdrückbarkeit von Innerem, um Sprachskepsis und Unsagbarkeit.

\section{ANALOGE KOMMUNIKATION ALS ANTWORT AUF DEN SPRACHKRITISCHEN UNSAGBARKEITSTOPOS}

Obwohl digitale Kommunikation (vulgo: Sprache) mit einer vermeintlich eindeutigen Syntax ausgestattet ist, sind in der Literarhistorie verschiedentlich Zweifel daran geäußert worden, ob Sprache als Medium Bedeutung transportieren könne. Nicht nur die Romantiker haben diese Bedenken geäußert; populär wurde der Unsagbarkeitstopos vor allem auch um 1900 (s.u.). Auch für Genazinos Figurenbasistypus ist das reflexive Umkreisen von Sprache und Schrift allgegenwärtig. Die positiven Aspekte gelangen dabei nur ausgesprochen selten in den Blick und so lässt sich die Aussage W.s, er "lebe gern in der Unklarheit nicht genau verstandener Wörter“, als unüblich klassifizieren: „Das ungenaue Verstehen ruft eine Fülle des Fühlens und Erinnerns hervor, die der Eindeutigkeit des genauen Verstehens niemals möglich ist." (Fleck, S. 207) Für gewöhnlich wird jedoch genau diese Eindeutigkeit herbeigesehnt: „Ich hatte immer den Wunsch, daß das Gefühl von der Undurchschaubarkeit des Lebens endlich zurückgehen möge. Statt dessen nimmt dieses Gefühl noch zu. Ich kann meine Erfahrung nicht ausdrücken, ich lebe im unaussprechlichen Bereich." (Liebesblödigkeit, S. 193) Der (häufig enttäuschte) Wunsch, sein Innenleben nach außen mitteilbar zu machen $\left(\Leftrightarrow\right.$ II.2.3), ${ }^{102}$ findet sich in Genazinos Figurenromanen sowohl auf der digitalen als auch der analogen Ebene von Kommunikationsprozessen. Dabei ist bemerkenswert, in welchem Ausmaß sich die Figuren auf eindruckssteuernde Aspekte versteifen:

Er hatte begonnen, Kafka zu lesen, und er blickte nur noch selten und dann kurz aus dem Fenster hinaus. Eine ganze Zeit lang, bevor er mit dem Lesen angefangen hatte, hatte ihm ein älterer Arbeiter gegenübergesessen, die Bild-Zeitung lesend. Abschaffel hatte sich nicht getraut, in Gegenwart des Zeitung lesenden Arbeiters sein Buch herauszuholen, weil er fürchtete, der Mann könnte sich gedemütigt fühlen, wenn er sah daß er nur eine Zeitung, sein Gegenüber aber ein Buch las. Abschaffel hatte sich nicht hervorheben wollen und so getan, als sei er noch weniger als dieser Arbeiter, weil er noch nicht einmal eine Zeitung, sondern gar nichts zu lesen hatte. (Abschaffel, S. 64)

In der Erwartung, es handele sich beim Lesen eines Buches um eine ostentative Demonstration von Herrschaftswissen oder einen Affront in Lebensstilfragen ( $\Rightarrow$ II.1.5), wird mit der fragwürdigen Einschätzung der Situation, seines Gegenübers und den Handlungskonsequenzen erneut der Hang zu defizitär ausgeprägten Sozialkompetenzen lesbar ( $\Rightarrow$ II.1.3). Ebenso lässt sich protektive Selbstherabsetzung als IM-Technik am Werk beobachten.

102 Vgl. für wortlos psychosomatisch ausgedrückte, übersprungsartige Handlungen etwa Sorgen, S. 262, u. Falsche Jahre, S. 461; für Beispiele mühelos gelingender analoger Kommunikation Licht, S. 33, u. Ausschweifung, S. 49; für nonverbale Unmutsbekundungen Fremde Kämpfe, S. 149, u. Kassiererinnen, S. 132 f.; für die Wahl ungewöhnlicher nonverbaler Mittel, um Sachverhalte und Inneres überhaupt darstellen zu können, Fremde Kämpfe, S. 113, u. Glück, S. 100. 
Der Glaube an die Wirksamkeit analoger, kinetischer Aktionen ist jedenfalls in diesem und etlichen anderen Beispielen ${ }^{103}$ unerschütterlicher als der an die verbalsprachliche Vermittlung, ${ }^{104}$ wenngleich auch dort Missverständnisse ob der ,syntaktischen Vagheit' resultieren können (s.o.): „Wir suchen nach einer Floskel für die Beendigung des Telefonats, aber wir finden keine und lachen statt dessen über die Plötzlichkeit unserer Verabredung." (Einfalt, S. 139) Die Suche nach der sprachlichen Floskel misslingt, das Lachen vermag zu verbinden, obwohl es nicht wirklich definiert ist. 105

Wie groß hinsichtlich der Mitteilbarkeit der Vertrauensvorschuss gegenüber der nonverbalen Kommunikation ist, zeigt auch ein eindrucksvolles Beispiel aus Genazinos Text Eine Frau, eine Wohnung, ein Roman. Um Weigands unaussprechliche Innenwelt anzuzeigen, lässt Genazino den Ich-Erzähler zu einem unüblichen Mittel greifen. In der Rolle als Lokalredakteur ist es seine Aufgabe, einer Autogrammstunde mit Rex Gildo beizuwohnen, um darüber zu berichten:106

Plötzlich war ich überzeugt, daß jedes Zeichen und jede Bewegung in diesem Raum eine Fälschung war. [...] Ich fühlte mich erniedrigt. Unklar war nur, ob mich das Geschehen direkt erniedrigte oder ob ich mich selbst erniedrigte, weil ich an diesem Geschehen teilnahm. [...] Aus Langeweile betrachtete ich in einem kleinen Spiegel meine Zähne. Sie wurden schon gelb, so fremd fühlte ich mich hier. Ich mußte verschwinden, solange der Trubel mich noch deckte. (Wohnung, S. 79-81)

In der Funktion einer Emotions-Darstellung wird hier mit einer Poetik des Hässlichen eine Metapher geschaffen: Um unsägliche Gefühle (Distinktion, Ekel, Scham) auszudrücken, müssen ,psychosomatisch' die Zähne gelb werden, was der kinetischen Kategorie „physiologische und physiochemische Reaktionen ([...] Farbwechsel [...])“ zuzuordnen ist. ${ }^{107}$ Diese

Automatismen [...] indizieren ausschließlich Gemütszustände [...]. Hierfür bilden sie allerdings einen sehr verläßlichen Indikator, da sie in der Regel nicht der Kontrolle des Bewußtseins unterliegen und somit als aufrichtiger Ausdruck gelten. In allen Epochen der Erzählliteratur sind Automatismen als Emotions-Darstellung reichlich vertreten. ${ }^{108}$

Offensichtlich vertraut Genazino bzw. der Erzähler zur Darstellung erneut nicht auf eine verlässliche Mimesis-Wirkung der Worte und präferiert eine (eingebildete) körpersprachliche Regung in extremer Form, um einwandfrei zu markieren, wie deplatziert sich Weigand in diesem Setting fühlt. Das geht soweit, dass sich der Unsagbarkeitstopos ins Philosophische versteigt: „[Z]ugleich war er wütend darüber, daß niemand die Echtheit seines Unwohlseins sehen konnte. Aber so

103 „Er lief nicht allzu langsam, weil er nicht als Tourist mißverstanden werden wollte.“ (Sorgen, S. 309)

104 Vgl. auch: „Wir können uns nicht sagen, was wir empfinden, so wirr und eigenartig geht alles durcheinander." (Fleck, S. 67)

105 Vgl. für eine amibivalentere Funktionalisierung des Lachens aus Verlegenheit, als Schutz vor anderen Emotionen, etwa: „Ich verstehe es auch nicht, ich spüre nur, daß mein Lachen mich nicht richtig ausdrückt. Es ist, als schütze es eine wahrere Empfindung." (Einfalt, S. 162)

106 Vgl. Gerhard Zeillinger: Rex Gildo oder: Vom Glück der kleinen Bürger. In: Die Presse vom 26. April 2003.

107 Korte: Körpersprache in der Literatur, S. 38. Vgl. dazu: „[I]ch tupfe mir den Schweiß der Verlegenheit von der Stirn. Frau Balkhausen beobachtet mich, aber sie hält, glaube ich, meine Transpiration für ein Zeichen von Seriosität und Vertiefung." (Regenschirm, S. 153) 
war es immer: das wirklich Wirkliche war nicht teilbar, es blieb auf der Person sitzen, die damit herumlief." (Fremde Kämpfe, S. 144) Die Unzulänglichkeit auch der schriftlichen Verbalsprache gerät in diesem Zusammenhang expressis verbis ins Visier. Der eigenbrötlerische Schriftsteller aus dem Roman Leise singende Frauen hegt einen „tiefen Unwillen gegen die weitere und immer neue Vertextung der Welt. Am liebsten möchte ich rufen: Aufhören! Es gibt genug Schrift auf der Welt! Sofort aufhören!“ (Frauen, S. 35) Damit ist dem Wunsch danach, sich aus der verbalen Unaussprechlichkeit gänzlich protektiv zurückzuziehen, Gestalt gegeben: „Daß man mich im Fernsehen dann ebenfalls Tölpel nennen würde, wäre mir egal, denn als Blaufußtölpel wüßte ich endlich nichts mehr von Worten und ihren Bedeutungen." (Regenschirm, S. 88) Als Tier stünde der Protagonist final außerhalb der digitalen - und störanfälligen - Kommunikation. Gespiegelt wird diese radikale Sprachskepsis auch im Roman Wenn wir Tiere wären:

Anfangs hatte ich kein gutes Gefühl. Üblicherweise konnte ich auch dann normal sprechen, wenn ich zum ersten Mal auf fremde Menschen traf. Aber es gab Tage, an denen mir vollständige Sätze kaum gelingen wollten, wenn ich mich in einer neuen Umgebung bewegte. Die paar Mitteilungen, die ich über mein Leben zu machen bereit war, lagen mir dann wie teigige Klümpchen aufder Zunge und regten sich kaum. (Tiere, S. 69; Herv. N. L.)

Von Genazinos „teigige[n] Klümpchen“ zu Hugo von Hofmannsthals „modrige[n] Pilze[n]“, die in seinem „Chandos-Brief“ (1902) die Metapher für Sprachkritik bilden, ist es nicht weit:109

Es gibt einen utopischen Glücksmoment, von dem die Figuren in Genazinos Büchern seit langem schon und immer wieder träumen: dass die Dinge mit ihren Namen in Übereinstimmung sein möchten und dass mit dem Nennen ihrer Namen auch die Dinge ganz gegenwärtig würden. Die Sprache wäre dann nicht mehr das Zeichensystem, das die Welt nach ganz eigenen und von den Bedürfnissen ihrer Benutzer bestimmten Regeln ordnet; vielmehr stünde jedes Wort zugleich ein für die Sache, der es den Namen gibt. Ausgeräumt wäre aus dieser Welt jede Zweideutigkeit, unmöglich ein Missverständnis und Überheblichkeit ausgeschlossen. Auch gäbe es dann keine Zonen des Schweigens mehr: Alles hätte einen Namen, und nichts könnte sich dann noch ins Dämonische auswachsen, nur weil die Sprache dafür fehlt. Die Sprache wäre wieder im Zustand der Unschuld. ${ }^{110}$

Solange indes dieser „utopische[] Glücksmoment"111 auf sich warten lässt, müssen die unzähligen Schattierungen von analoger, nonverbaler Kommunikation diese Versprechen kompensieren. Oder wäre es besser ,darüber zu schweigen, wovon man nicht sprechen kann` (Wittgenstein)? ${ }^{112}$

109 Vgl. Melanie Fischer: „Schläft ein Lied in allen Dingen“ - Wilhelm Genazinos Prosa im Kontext des literarischen Ding-Diskurses. In: Giesen (Hg.): Wilhelm Genazino (2006), S. 9-18, hier S. 12.

110 Bucheli: Die Begierde des Rettens, S. 53.

111 Das eigentliche ,Nonplusultra' bei Genazino liegt in der für den Basistypus unerreichbaren, harmonischen Verknüpfung von analoger und digitaler Kommunikation, also im Bereich der Illustratoren und Regulatoren, die bei Genazino zumeist störanfällig sind. Diesen Wunsch formuliert etwa der Protagonist aus Leise singende Frauen: „[0] Gott, was wäre das ein Abend und ein Kuß und eine Liebe geworden, wenn es ihm möglich gewesen wäre, über das wirklich Geschehene zu sprechen, einzigartig und unvergeßlich!" (Frauen, S. 79)

112 Die Genazino-Fassung dieses Gedankens lautet in etwa: „Es war sowieso alles immer komplizierter, als sich denken oder sagen ließ. Deswegen war es gar nicht schlimm, wenn man den Mund hielt." (Ausschweifung, S. 255) 


\section{(VER-)SCHWEIGEN UND STUMMHEIT}

Reika Hane unterscheidet in ihrer Studie Gewalt des Schweigens vier verschiedene Arten von Schweigen, die sie letztlich noch von der "Stille, die niemandem zugeschrieben wird“, abgrenzt, welche solange nicht mit dem Schweigen in Verbindung gebracht wird, bis „mir eine Stille unangenehm wird, ich darin also die Möglichkeit eines Schweigens vernehme." ${ }^{113}$ Die vier Ausprägungen, deren Unterscheidung diesen Exkurs gut säumt, lauten:

(1) Nichtssagen als Unterlassung oder Nichtvollziehen [...] der Rede überhaupt. (2) Etwas-nichtSagen als Unterlassung oder Nichtvollziehen einer bestimmten Rede. Schweigen in diesem Sinne kann man sowohl durch Reden als auch durch dessen Unterlassung bzw. Nichtvollziehen. [...] (3) ,Anschweigen' als Unterlassung der Anrede, d.h. der Adressierung der Rede an eine bestimmte andere Person. Nicht nur Rede überhaupt unterlassend (also nichts sagend), sondern auch redend kann man dem anderen gegenüber schweigen, indem man unterlässt, die eigene Rede an ihn zu richten, wie im Fall der Rede in der dritten Person. Beim Nichtvollziehen der Anrede, d.h. bei ungerichtetem Nichtansprechen, ignoriert der Schweigende keinen bestimmten anderen, sondern es bleibt eine Adressierung insgesamt aus. Dies kann jedoch auf bestimmte Anwesende wie ein Anschweigen wirken. (4) Verstummen als Zustand eines alternativlosen Schweigens, in das man etwa durch physische oder sprachliche Gewalt, den Monolog des anderen oder das Überhören durch den anderen gedrängt wird, oder aber wegen eines Schocks, einer Krankheit, innerer Hemmungen oder eines Mangels an Sprachkenntnissen gerät. Neben dem lautlosen Verstummen gibt es Äußerungen wie etwa den wortlosen Schrei, das unverständliche Lallen oder die erzwungene Rede, die sich als etwas dem Verstummen oder Stummsein Nahes betrachten lassen. ${ }^{114}$

Nicht zufällig ist eine von Genazinos Basistypus bevorzugte Technik des protektiven IM $(\Rightarrow I .3 .3)$ das Stillbleiben im Sinne der „Unterlassung [...] der Rede überhaupt“ - allerdings eher mit dem Ziel, negative Zuschreibungen zu minimieren als in irgendeiner Art und Weise Gewalt auszuüben. Diese Form des Schweigens wird ausführlicher unter der Sigle der ,inneren Zensur $\Leftrightarrow$ ( $I$ II.2.6) behandelt. Eine Sonderform soll aufgrund der thematischen Nähe zur analogen Kommunikation dennoch bereits hier diskutiert werden:

Beim Einkaufen deute ich wie ein Ausländer mit den Fingern auf die Sachen, die ich haben will; es klappt ausgezeichnet, man kommt mir entgegen. Die Leute in den Geschäften halten mich für eine maulfaule Hysterikerin, denke ich, und solche Frauen soll man bevorzugt behandeln, dann ist man sie schnell wieder los. Natürlich können die Leute nicht wissen, wie es ist, wenn man sich von der eigenen Stimme verhöhnt fühlt. (Obdachlosigkeit, S. 111)

Aufgrund eines nur geringen Selbstwertgefühls und der Unzufriedenheit mit der eigenen Stimme, verzichtet die Protagonistin darauf, zu sprechen - und greift dabei einmal mehr auf die (funktionierende) Körpersprache zurück. Auf einer darunterliegenden Ebene bricht sich aber auch der doppelte Wunsch Bahn, „alles zu sehen und alles zu kriegen ohne den Zwang, es durch Äußerungen von Worten der Außenwelt abbetteln zu müssen." (Abschaffel, S. 27) In den subtilen Wunsch nach Wortlosigkeit mischt sich das Begehren, die (soziale Um-)Welt solle das Wunschablesen von den Augen bzw. Lippen üben. 
Etwas nicht zu sagen taucht bei Genazino in vielen Schattierungen auf: etwa als stummes Verschweigen $^{115}$ ( $\Rightarrow$ II.1.2 u. $\Rightarrow$ II.3.5), als durch analoge Kommunikation abgewehrtes Nichtssagenmüssen ${ }^{116}$ oder als Effekt von kalkulierter Kommunikationsverweigerung zu Selbstschutzzwecken: 117

Leider bedrückte mich die Gefängniszeit erheblich. Ich vermied inzwischen sogar das Zusammentreffen mit anderen Menschen, weil ich nicht über das Gefängnis reden wollte. Es war mir klar, dass dies keine Lösung des Problems war. An manchen Tagen konnte ich mir dabei zusehen, wie ich bei lebendigem Leib vereinsamte. (Tiere, S. 146 f.)

In der Vermeidung des sozialen Umgangs, um nicht über seine Zeit im Gefängnis reden zu müssen, spiegelt sich eine Fülle an miteinander verwobenen IM-Techniken $(\Rightarrow$ I.3.3): protektives ,minimizing social interactions' aus Gründen der gewünschten ,minimal self-disclosure', zugleich aber auch eine defensive Mischung aus ,denial' und ,dissociation'. Im Roman Außer uns spricht niemand über uns hebt der Protagonist die Triebfeder dafür, ,etwas' nicht zu sagen bzw. sagen zu können, auf eine theoretische Ebene: „Wie unaussprechlich merkwürdig das wieder war: Jeder trug ein Leiden und ein dazu passendes Redeverbot mit sich herum - wegen sonst entstehender Peinlichkeit, Indiskretion, Wichtigtuerei und so weiter." (Außer uns, S. 118)

Hinsichtlich des Gewaltlevels ist das Anschweigen nach Hane sicherlich die relevanteste Kategorie. Genazinos Romanfiguren schwelgen bspw. gedankenspielerisch darin, wenn sie die mangelnde Selbstwirksamkeit durch Anschweigen zu kompensieren trachten: „Er stellte sich sein Schweigen als große Bestrafung vor, der niemand entkam. Er wünschte es sich so sehr, daß er sich schon die Auswirkungen vorstellte: ein paar Tage lang den Mund halten: das würde alle zur Vernunft bringen.“ (Fremde Kämpfe, S. 31)118 Ähnliches, allerdings weiter in der Erzählvergangenheit Liegendes, hält Abschaffel fest: „Die, die ihn schamlos geboren hatten, sollten verzweifeln über die Mitteilungslosigkeit, in die das Kind flüchtete." (Abschaffel, S. 24) ${ }^{119}$ In diesem Zusammenhang nennt Hane den Sonderfall „Momente[] des Schweigens“, „wo jemand eine Erwartung, ein Verlangen oder Begehren nach Entsprechung mitkommuniziert und die Reaktion des

115 Etwa: „Ich konnte überhaupt nichts sagen, ich wollte mich zwar entschuldigen, ich wollte sagen, daß ich ab sofort freundlicher zu ihr sein wolle, aber jetzt konnte ich nicht, weil sie so untertänig fragte" (Laslinstraße, S. 152).

116 „Wenn die Möglichkeit drohte, daß sich Isolde nach meiner Familie erkundigte, blieb ich auf der Straße stehen und verschloß ihr mit einem langen Kuß den Mund." (Einfalt, S. 110)

$117 \quad$ Vgl. Lehnert: Refus aus Kalkül?!

118 Vgl. für weitere Beispiele etwa Abschaffel, S. 29, u. Sorgen, S. 162. Vgl. dazu auch Spreckelsen 2004, S. 81. Vgl. für ein Beispiel, in dem die Figur ,am eigenen Leib' die Gewalt der mangelnden Adressierung in Form des Nicht-angeblickt-Werdens erfährt: „Ich behielt für mich, daß ich diesen aufgespaltenen Blick (nicht angeschaut werden, aber doch gemeint sein) noch weniger verstand als mein Lachen." (Wohnung, S. 9) Hier handelt es sich zudem um eine Double-bind-Aktion, die bekanntlich Menschen massiv verunsichert (vgl. Watzlawick/Beavin/Jackson 2007, S. 194 ff.). Vgl. für eine ebenfalls die Doppelbindung thematisierende Analyse bei Genazino Honold: Doppelleben, halbbitter, S. $51 \mathrm{f}$.

119 Diese Grundhaltung findet sich in Genazinos CEuvre als wiederkehrendes Motiv ( $\Rightarrow$ I.2.2) häufiger: „Aus Bosheit gegenüber Gunhild behalte ich die Frage für mich.“ (Regenschirm, S. 12) 
anderen diese Entsprechung verweigert."120 Unter Berufung auf Roland Barthes lässt sich laut Hane von ,schiefen Erwiderungen' sprechen: „Indem schiefe Antworten dieser Forderung [nach einem gelungenen Gespräch] ${ }^{121}$ nicht entsprächen, widerständen sie der normativen Macht hinter der gesellschaftlichen Normalform des guten Dialogs",122 was der Einschätzung Abschaffels entspricht: „Es gab viel zuwenig Gelegenheiten, wo es einem erlaubt war, keine Antwort zu geben." (Abschaffel, S. 121) Im weiteren Verlauf zitiert Hane Judith Butlers The Psychic Life of Power, um das „machtkritische Potential von Momenten des Schweigens in der Antwort“ zu eruieren. ${ }^{123}$ Genazinos Figurenbasistypus versteht sich darauf auf das Eloquenteste: „Ronselt erzählte statt dessen halblaut Witze und sah immer wieder auf Abschaffel, ob er nicht einmal mitlachte. Abschaffel verzog keine Miene." (Abschaffel, S. 143) Auf den Gipfel treibt es der Schuhtester, indem er Selbstwirksamkeit, Schweigelust und Strafe verflicht:

Neulich hatte ich die Idee, [...] einen Schweigestundenplan zu verschicken. Auf diesem Plan steht genau, wann ich reden will und wann nicht. Wer sich nicht an den Schweigestundenplan hält, wird überhaupt nicht mehr mit mir sprechen können. Für Montag und Dienstag ist/wäre DURCHGEHENDES SCHWEIGEN angeordnet. [...] Nur freitags und samstags bin ich/wäre ich zu haltlosem Gerede bereit, allerdings erst ab elf Uhr. An Sonntagen besteht TOTALES SCHWEIGEN. (Regenschirm, S. 44)

Ein solchermaßen strategisch eingesetztes „[s]trafendes Schweigen“124 verortet Assmann

in der martialischen Pädagogik des Zweiten Kaiserreichs bis in die Zeit des NS-Staates hinein [...]. Gemeint ist der Entzug von Kommunikation innerhalb der Familien. Dieses Schweigen ging vom Vater aus, der dieses Mittel der Züchtigung nicht selten gegenüber seinen Kindern einsetzte. Was diese Form der Strafe besonders grausam machte, war die Tatsache, dass die davon betroffenen Kinder dieses stark moralisierende Verhalten oft nicht einordnen konnten und von allen Möglichkeiten einer adäquaten Reaktion von vornherein abgeschnitten waren. Stattdessen wurden ihnen tiefe Schuldgefühle anerzogen, die sie oft lebenslang plagten und ihnen den Zugang zu einem positiven Selbstbild versperrten. ${ }^{125}$

Wiewohl viel Wahrheit, insbesondere für Genazinos Romanfiguren, in dieser Einschätzung liegt - Schuldgefühle, Vaterinvestigation, biografisch besehen: nachträgliche Aussprache im Medium der Literatur etc. ${ }^{126}$-, lässt der Erzähler den Stundenplan ins Komische und unzuverlässig Anmutende kippen, sodass der Ich-Erzähler hinzuzusetzen sich bemüßigt fühlt: „Die Wahrheit ist, daß der Schweigestundenplan schon weitgehend ausgearbeitet war und daß ich ihn um ein Haar verschickt hätte." (Regenschirm, S. 44) Das hieße indessen, die tyrannische Pädagogik reproduzieren.

Sinnverwandt ist das Machtspiel um Sagen und Schweigen, Hören und Gehörtwerden in Form des Nicht-Zuhörens: „Zur Strafe höre ich fünf Minuten lang niemandem zu“ (Fleck, S. 15). Auch

120 Hane: Gewalt des Schweigens, S. $23 \mathrm{f}$.

121 Erstaunlicherweise verzichtet Hane darauf, die Grice'schen Konversationsmaximen des Kooperationsprinzips als Stützargument aufzugreifen, gegen die qua Schweigen als Antwort verstoßen wird.

122 Hane: Gewalt des Schweigens, S. 24.

123 Hane: Gewalt des Schweigens, S. 25.

124 Assmann: Formen des Schweigens, S. 60.

125 Assmann: Formen des Schweigens, S. 60.

126 Vgl. Assmann: Formen des Schweigens, S. 61. 
„Abschaffel hörte nicht mehr hin. Er setzte sich bereits ab.“ (Sorgen, S. 350) Dieser gerichteten ,Bestrafung' korrespondieren Fassungen des Weghörens aus psychischen Ursachen: „Das Wort Venenklappen flößt mir eine so starke Unlust ein, daß ich dem Arzt nicht mehr zuhöre. Ich schaue aus dem Fenster und beobachte" (Liebesblödigkeit, S. 135). Die Strategie erinnert an die von Kindern, sich bei unliebsamem Feedback jedweder Art die eigenen Ohren zu verschließen, um die Welt auszublenden. Diese Form konzeptualisiert Assmann mit der Chiffre: „Die Augen verschließen - opportunistisches Aus der Welt Schaffen“.127 Just einer solchen ,Vogel-StraußTaktik‘ befleißigt sich Eckhard Fuchs - unwillkürlich:

Wenn Eckhards Kopf zu lange in verschiedenen Problemen verfangen war, bemächtigte sich seiner ein Gefühl, das er sonst nur vom Duschen her kannte: Die Ohren fielen ihm zu und mit ihnen der ganze Kopf, und er lief eine Weile herum, als könnte er die Welt nicht mehr hören. (Ausschweifung, S. 244)

Mit diesem einseitigen Kappen der Schnittstelle zwischen Individuum und Welt rückt die Definition von ,Verstummen' in greifbare Nähe: Die Eckpfeiler jener - Alternativlosigkeit, Fremdbestimmtheit, Schockhaftigkeit (s.o.) - entsprechen den Selbstreflexionen des Basistypus, wenn er über Schweigen und Verstummen räsoniert: „Ich kann trotzdem nicht verhindern, daß ich jetzt stiller und stiller werde, bis ich vollständig in meinem Innenraum angekommen bin. Dort bedauert mich niemand so kenntnisreich wie ich selbst." (Glück, S. 23) Den Figuren bleibt - so die externe Absicht - nichts anderes übrig: Weniger selbstmitleidig als fatalistisch ist somit auch Abschaffels Diktum zu werten: „Mein Ausweg ist das Stillwerden.“ (Abschaffel, S. 155) ${ }^{128}$

In Wahrheit überfällt mich immer öfter eine Schweigelust, die mir ein bißchen angst macht, weil ich nicht weiß, ob soviel Schweigen, wie ich es zum Leben brauche, noch normal ist oder vielleicht der Beginn meiner inneren Krankheit, die mit Zerbröckelung oder Zerfaserung oder Ausfransung nur mangelhaft bezeichnet ist. (Regenschirm, S. 44)

Bündig lässt sich sagen: Wofern - etwa durch mangelnde Sozialkompetenzen oder Sprachskepsis per se - die Verbalsprache suspendiert wird und analoge Kommunikation nicht zielführend zum Zug kommen kann, ist für Genazinos Basistypus ,der Rest Schweigen` - deshalb stirbt er nicht.

Zum Unterkapitelabschluss sei noch auf etwas Kurioses aufmerksam gemacht: Es besteht ein großer Unterschied zwischen der Detailfülle analoger Kommunikation und Körpersprache und der ,Körperlosigkeit', auf der sie beruht.

\section{ÄUßERE ERSCHEINUNG}

Denn wie Genazinos Figuren tatsächlich aussehen, erfährt der Leser - wenn überhaupt - nur andeutungshaft:

127 Assmann: Formen des Schweigens, S. 59.

128 Neben den Varianten eher resignativen oder strafenden Schweigens existiert eine seltenere: „Mindestens darin war ich ihm ähnlich: Wir hielten das Schweigen für ehrenvoll, weil wir es mit Würde gleichsetzten." (Einfalt, S. 36) 
Während die Äußerlichkeiten der im Mittelpunkt stehenden männlichen Person nur am Rande oder gar nicht beschrieben werden, wird bei jenen der Frauen etwas mehr ins Detail gegangen. Die Frauen erfüllen die gesellschaftlichen Anforderungen an Attraktivität, ohne besonders hervorzustechen. Aus den Texten erschließt sich, dass das auch auf die männlichen Protagonisten zutrifft, die demnach weder besonders schön noch hässlich, groß noch klein, dünn noch dick sind. ${ }^{129}$

In der Tat sind diejenigen auf das „körperliche[] Erscheinungsbild“ bezogenen Angaben zur „natura“, die in der langen Tradition der literarischen Figurenzeichnung etwa bei Cicero von höchster Wichtigkeit gewesen sind,130 frappierend spärlich und nur - wenn überhaupt - im Außenbezirk der Romanfiguralleinstellungsmerkmale auffindbar: „Er war ein stattlicher, gutgebauter Mann, und er konnte es sich leisten, sein Interesse für Ruth zu zeigen." (Ausschweifung, S. 6; vgl. Fremde Kämpfe, S. 12) Graduell häufiger sind indirekte, verklausulierte Anmerkungen zum Aussehen der Hauptfiguren. Mit der Beobachtung: „[S]ie hatte ein rundes Gesicht, genau wie ich“ (Laslinstraße, S. 107), ist ein externer Anlass gegeben, über das eigene Erscheinungsbild zu sprechen, so wie es etwa die Beschreibung der Passfotos seiner selbst sind, „auf denen Axel oder Herr Degen blond, blaß und mit langen Haaren zu sehen war" (Laslinstraße, S. 141), die Axel Degen zur sonst unüblichen - da protektives IM überschreitenden - Selbstaussage verführen. Ein wirkliches Bild kann man sich kaum von den Figuren machen - sie scheinen auch in der externen ,Gemachtheit' das Risiko bereitwillig einzugehen, „only a faint impression“ zu hinterlassen; „being considered uninteresting or unimportant, or even being totally overlooked.“131 Aus externer Perspektive und bezogen auf die Charakterisierungstechnik ist dies mit der Neigung zum showing im Vergleich zum weniger wichtigen telling engzuführen: „Abschaffel war dreißig Jahre alt und lebte allein. Oben rechts gingen ihm die Haare aus“ (Abschaffel, S. 13). Punkt. Alles Weitere ist entweder implizit-figural oder implizit-auktorial zu inferieren.

Allerdings nicht vollends idiosynkratisch, sondern auch in diesem Metier musterhaft: (drohende) Verwahrlosung, (unterschwellige) Ungepflegtheit und mangelnde Selbstsorge ${ }^{132}$ sind sowohl hinsichtlich des eigenen Körpers als auch der ihn umhüllenden Kleidung rekurrent ( $\Rightarrow$ II.1.5): „So ließ er den Schweiß unabgewaschen und ertrug, daß sein Hemd zur Windel wurde, an einigen Stellen schon klebrig und formlos.“ (Abschaffel, S. 37) Dieses ist allerdings auf die eigenen vier Wände beschränkt, wohingegen auch die Außenwelt davon Kenntnis nehmen kann: „Ein Problem war, dass ich heute Morgen mein Haar nicht gewaschen hatte. Das bedeutete, ich musste ein Lokal finden, in dem ich meine Mütze nicht abnehmen musste." (Regen, S. 66) Kontrastiv zu diesen eher auf mangelnde Selbstsorge zurückführbaren Ausweisen an - zumindest in den Augen der Hauptfiguren von der Gesellschaft so gewerteten - unzureichend gepflegten Äußerlichkeiten, werden diese auch instrumentalisiert; etwa in Form offensiven IM: „[E]r beschloß, mit die-

\footnotetext{
129 [Wilhelm Genazino]. In: Wikipedia. Die freie Enzyklopädie. Online: <https://de.wikipedia.org/wiki/Wilhelm_Genazino>.

130 Schneider: Einführung in die Roman-Analyse, S. 18.

131 Schütz: Self-Presentation, S. 621.

132 Vgl. Ernst-Dieter Lantermann/Elke Döring-Seipel/Frank Eierdanz/Lars Gerhold: Selbstsorge in unsicheren Zeiten. Resignieren oder Gestalten. Weinheim 2007.
} 
sen schmutzigen Fingernägeln später zu Dr. Buddenberg zu gehen. Er wollte ihm zeigen, daß er sich darüber ärgerte, noch einmal bei ihm erscheinen zu müssen." (Falsche Jahre, S. 530)

Damit ist die Grenze zwischen äußerem Erscheinungsbild und Auftreten bzw. Habitus übertreten $(\Rightarrow$ II.1.5) und, um bei Abschaffel zu bleiben, muss auch in diesem Bereich die später noch zu diskutierende Ästhetik des Hässlichen ( $\Rightarrow$ II.5.6) als gängiges Gestaltungsmerkmal herausgehoben werden:

Abschaffel rauchte im Büro und drehte dabei zwischen Daumen und Zeigefinger die Haare seiner Augenbrauen. Er zwirbelte kleine Bündel zusammen und sah dann auf seine Fingerkuppen. Häufig lösten sich einzelne Haare, und Abschaffel legte sie vorsichtig nebeneinander auf den Aschenbecherrand. Manchmal steckte er sich ein einzelnes Augenbrauenhaar in den Mund, spielte eine Weile damit und zerkaute es. Abschaffel wußte, daß diese Art des Zeitvertreibs keinen guten Eindruck auf den ihm gegenübersitzenden Angestellten machte. (Abschaffel, S. 9)

Geraucht wird bspw. (zu) viel (vgl. Abschaffel, S. 9), getrunken regelmäßig, aber eher maßvoll,133 und andere Drogen spielen seltener eine Rolle: „Vermutlich war es die Stärke meines inneren Widerstands, die einen Rausch ausschloß.“ (Wohnung, S. 60; $\Rightarrow$ II.1.6) „Habituell performative[] Inszenierungspraktiken“ umfassen freilich nicht nur „Genuss- und Rauschmittel“, sondern allzumal auch „Lebensführung“, „Kleidung“ ( $\Rightarrow$ II.1.5) sowie „signifikante körperliche Selbstdarstellungsformen (etwa in Mimik und/oder Gestik)“,134 wie sie im folgenden Beispiel zusammengedacht verdichtet auftreten:

Obwohl beide dunkle Anzüge trugen, obwohl beide in aufgeräumter Stimmung miteinander rauchten und plauderten, obwohl beide Ringe an den Fingern hatten und obwohl beide groß und stattlich waren, gab es doch Unterschiede zwischen ihnen. Onkel Albert rauchte kurze, flache Orientzigaretten, die er aus einer schmalen Schachtel holte, die sich nach oben öffnen ließ wie ein kleines Schmuckkästchen. Vater dagegen rauchte prallgestopfte Billigzigaretten, die er mit einer kräftigen Bewegung aus der kleinen Fünfer-Packung herausstoßen mußte. Dem Anzug des Vaters war anzusehen, daß er nicht oft getragen wurde. Er war steif und schränkte Vaters Bewegungsfreiheit ein. Wenn Vater sich erhob, strich er sich mit den Händen an der Anzugjacke entlang. Und wenn von einem Gebäckstück ein wenig Puderzucker auf seinen Ärmel geraten war, wischte er es unverzüglich herunter. Der Anzug von Onkel Albert war weich und nicht neu. Es war sofort zu sehen, daß Onkel Albert an Anzüge gewöhnt war. Es gefiel mir, daß er nicht immerzu sein Aussehen kontrollierte. Gegen ihn war Vater ein altes Kind, das nicht vergessen konnte, was man es einst gelehrt hatte: daß man auf seine Kleidung aufpassen muß. Ich stellte fest, daß mir Onkel Albert besser gefiel als Vater. Es war schrecklich; am liebsten wäre ich in der Wohnung des Onkels geblieben. Weil das nicht ging, versuchte ich, das Verhalten des Onkels nachzuahmen. Ich wollte genauso souverän und sicher sein wie er. Deswegen ging ich bald dazu über, meine Sonntagshose und meine Sonntagsschuhe auch werktags zu tragen. Ich rechnete mit einer Rüge, aber sie blieb aus. Vater sah mich nur an und schwieg. Vielleicht wußte er, daß meine Rechnung nicht aufging. Denn wer, wie Onkel Albert, an bessere Kleidung gewöhnt sein wollte, mußte viele Anzüge und viele Hosen und viele Hemden besitzen. Ich aber hatte nur zwei Hosen, eine für werktags, eine für sonntags. (Einfalt, S. 50 f.)

Das sind im wahrsten Wortsinne feine Unterschiede - handelt es sich doch um andersartige ,Geschmacksklassen' (Bourdieu) -, die der Protagonist Genazino - so heißt die Figur - hier zwischen den Stühlen sitzend seismografisch und auf den verschiedensten Selbstdarstellungsebe-

133 Die Romane Außer uns und Kein Geld räumen Alkohol etwas mehr Bedeutung ein.

134 Jürgensen/Kaiser: Schriftstellerische Inszenierungspraktiken, S. 13 f., u. dies: Abgrenzung, ReKombination, Neu-Positionierung, S. 219 ff. 
nen zwischen seinem Vater und seinem Onkel wahrnimmt. Das nächste Unterkapitel nimmt mithin dezidiert Aspekte des Lebensstils der Romanfiguren Genazinos unter die Lupe.

\subsection{Von Schichten, Milieus und den ,feinen Unterschieden' der Lebensstile}

Dass der omnipräsente Zwang zur Selbstdarstellung ,für jedermann` allererst aus dem Wegfall eines ständisch organisierten Gesellschaftssystems geboren worden ist, ist bereits dargelegt worden $(\Leftrightarrow I$.4). Aber auch die es ablösenden Entwicklungen zeichnen sich noch Jahrhunderte lang durch starres Klassendenken, geringe soziale Mobilität und klare Rollen-, Verhaltens-, Kleidungsregeln für den Einzelnen aus, der als Angehöriger einer deutlich umrissenen Bezugsgruppe daraus Sicherheit für sein Selbstkonzept hat ziehen können - oder daran zerbrechen. Soziologische Vermessungen der zweiten Hälfte des neunzehnten und der ersten des zwanzigsten Jahrhunderts haben soziale Ungleichheiten dann im Lichte des Positivismus mehr oder weniger erfolgreich durch ,harte Fakten' wie Einkommen, Beruf, Bildungsniveau, Elternhaus, also durch Ererbtes, Erlebtes und Erlerntes, zu beschreiben versucht. Später hat diese Überzeugung ihre Darstellung in eindimensionalen Schichten-Modellen in der Folge des Soziologen Theodor Geigers gefunden, die eine Hierarchie zwischen oben und unten als alleingültige Messlatte für soziale Sortierung anlegt. Noch heute ist die Unterteilung in Ober-, Mittel-135 und Unterschicht erstaunlich geläufig, obwohl sich die Forschung diesbezüglich meilenweit davon entfernt hat, eine Person lediglich in drei Sammelbecken stecken zu wollen, weil sich soziale Ungleichheiten schlichtweg in einer pluralisierten Gesellschaft nicht mehr an den wenigen genannten Parametern festmachen lassen. Auf Basis dieser Ausgangsüberzeugung greifen neuere Herangehensweisen, die soziale Milieus als Bezugsgröße wählen, diese vertikale Achse weiterhin auf, ergänzen sie aber dadurch um eine zweite Dimension, dass sie zusätzliche Kategorien wie Werthaltungen, ästhetische Präferenzen, Konsum- und Freizeitgewohnheiten heranziehen. Damit reagiert das Milieu- (oder auch: Lebensstil-)Konzept auf gesamtgesellschaftliche Veränderungen: Nicht nur, was einer ist, definiert seine relative Stellung und Positionierung in der Gesellschaft, sondern auch - und vielleicht sogar: in erster Linie -, wie er sich darstellt, welchen Geschmack, welchen Lebensstil er pflegt.

Mit diesem Paradigmenwechsel gehen nicht nur Selbstdarstellungsschwierigkeiten für den Darsteller einher - der sich neben einer nahezu erdrückenden Wahlfreiheit dennoch in ungeschriebenen Gesetzen und symbolischem Sendungszwang gefangen sieht -, sondern auch für den Lebensstilentschlüsselnden: Lange Jahre funktionierendes, kognitiv-ökonomisches Schubladendenken funktioniert nicht mehr. Freilich haben beide Brenzligkeiten auch eine positive Rücksei-

135 Wes Zeitgeistes Kind diese Taxonomie ist, erhellt aus der parallel gebräuchlichen Wendung ,Mittelstand'. Vgl. dazu auch den Protagonisten aus Ein Regenschirm für diesen Tag, der von seiner Freundin verlassen wird, weil er sich nicht um einen „,, besseren Hintergrund““ kümmert (Regenschirm, S. 35). 
te: Im Sinne einer Maslow'schen Bedürfnishierarchie ist der Mensch im westlichdemokratischen Kapitalismus weitgehend an der Spitze der Selbstverwirklichung angekommen; und man darf darauf vertrauen, dass sich auch bei der Einschätzung nicht mehr auf eine Schicht festlegbarer Individuen neue feine Beobachtungsunterschiede entwickeln werden. ${ }^{136}$ Genazinos Figuren jedenfalls scheinen bis in den Roman Kein Geld, keine Uhr, keine Mütze jedenfalls einige Jahre ,hinter dem Mond' gelebt zu haben - bzw. extern: die Funktion, es sich mit einem Leserpublikum auch jenseits der 50 nicht zu verscherzen und auf eine ToM zu vertrauen, die ,Neumodisches' kritisch betrachtet -: „Ich wollte noch immer nicht hinnehmen, dass es eine Unterhaltungsunterschicht gab, die auf anderen Gebieten durchaus nicht der Unterschicht angehörte.“ (Außer uns, S. 11)

Diese Weigerung ist nur die ,Spitze des Eisbergs', was die Wichtigkeit der Lebensstil-Analyse anbetrifft (und damit sind sowohl Analysen der Hauptfiguren gemeint als auch deren diegeseinterne Analysetätigkeit). Daher stehen allgemeine Untersuchungen dazu im folgenden Vierschritt an erster Stelle, bevor eine Übertragung auf eine konkrete literarische Kapitalstrukturanalyse aufgezeigt wird (s.u.). Zwei aus dem Lebensstil-Gesamtkomplex herausgelöste Elemente werden unterkapitelabschließend unter die Lupe genommen: (selbstergänzende und symboltragende) Gegenstände und Kleidung - beides für Genazino ertragreiche Kategorien.

\section{FIGURENSOZIOLOGISCHE BETRACHTUNGEN}

Wie die Hauptfigur aus Genazinos Außer uns spricht niemand über uns Bedenken anmeldet, dass zwei Personenmerkmale („Unterhaltungsunterschicht“ vs. „andere[] Gebiete[] [...] der Unterschicht") nicht (mehr) der grobschlächtigen Einordnung in die erlebten und erlernten Klassifikationsschablonen folgend harmonieren, rechnen auch andere Figuren noch mit dem SchichtKonzept, um sich zu orientieren:

Es sind gut verdienende, vermutlich kinderlose Paare, gehobener Mittelstand. Die Woche über arbeiten sie hart, trinken wenig, rauchen nicht und gehen früh zu Bett, damit sie am nächsten Morgen wieder fit sind. Es behagt mir nicht, daß wir dieser Schicht angehören. Ich möchte nicht Teil einer empirisch festgestellten Gruppe sein. (Glück, S. 70)

Einerseits bricht sich darin der Wunsch Bahn, nicht zum messbaren Objekt degradiert werden zu wollen, andererseits präsupponiert die Aussage gleichzeitig, dass es so etwas wie einen „gehobene[n] Mittelstand" und damit auch eine empirisch feststellbare, aus der Gesamtgesellschaft herauspräparierbare Gruppe gebe. Noch im Bannkreis dieser Überzeugung, der Sache nach aber deutlich weiter und längst inmitten dessen, was als ,feine Unterschiede ${ }^{`} 137$ dem kollektiven Be-

\footnotetext{
136 Utopisch ließe sich davon schwärmen, dass ,Schein` eines Tages nicht mehr so viel zählt, wie das Kennenlernen der dahinter befindlichen Person; pessimistisch ließe sich argwöhnen, dass der Schein das gesamte Wesen sein wird.

137 Vgl. Pierre Bourdieu: Die feinen Unterschiede. Kritik der gesellschaftlichen Urteilskraft. 30. Aufl. Frankfurt am Main 2003.
} 
wusstsein seit Jahren eingeschrieben ist, denkt die Figur: dass das gesamte Ensemble an nach außen wahrnehmbaren Habitusformen einerseits nicht von Generation an Generation weitergegeben wird (werden muss), dass man trotz höchster Bestrebungen, individuell sein zu wollen, immer noch in ein Milieu pressbar ist und daraus auch die absurdesten Distinktionsbestrebungen resultieren können. Jedenfalls ist auch der Protagonist aus Fremde Kämpfe nominell noch der Schichten-Vorstellung verhaftet, bezieht aber mit der Wohnungseinrichtung eine traditionell ,moderne' Kategorie der Lebensstilanalyse mit ein:

Vor der Badewanne lag eine flauschige, hellgrüne Matte. Über dem Toilettendeckel spannte sich ein rosa Toilettenvorleger. Das kleine Fenster war eingerahmt von hellgelben, mit weißen Blumenmustern durchmischten Gardinen. Das helle Gardinengelb wiederholte sich in der Färbung des Vorhangs an der Dusche. Die Handtücher am Waschbecken waren wieder hellrosa, und der Frotteestreifen auf dem Badebord erstrahlte hellgrün. Aus Abscheu und Unlust erfand Peschek eine kleine UNTERSCHICHT-FARBENTHEORIE. Je armseliger der Geist, desto farbiger die Zimmer. Je dunkler das Leben, desto heller seine Farben. (Fremde Kämpfe, S. 90 f.)

Eine der großen Stärken Genazinos ist bekanntlich die Alltagsbeobachtung. Und so überrascht es nicht wirklich, dass man - reales Vorbild hin oder her - dieses Badezimmer schon einmal gesehen zu haben glaubt. Interessant nimmt sich der Wunsch nach Distinktion aus, der bereits in Richtung ,Klassismus', also der Benachteiligung einer als inferior wahrgenommenen sozialen Stellung, abzudriften droht. Nicht nur setzt Peschek die in seinen Augen geschmacklose Innenausstattung „aus Abscheu“ mit dem „armselige[n] Geist“ seines Besitzers gleich; er wertet sich damit auch selbst auf und setzt sich von einer postulierten Unterschicht ab, der er sich in puncto Stil und in Folge der besagten Gleichsetzung auch Geistreichtum (weit) überlegen fühlt.

Als wohl breitenwirksamste Lebensstilforschung dürfen die sogenannten ,Sinus-Milieus' gelten, die nicht nur „Von formalen demografischen Kriterien wie Schulbildung, Beruf oder Einkommen“ ausgehen, sondern „[g]rundlegende Wertorientierungen“ und „Alltagseinstellungen (zur Arbeit, zur Familie, zur Freizeit, zum Konsum)“, also neben der sozialen Lage auch die Lebenswelt und ,Wohnwelten' als Kriterien für die Zuordnung zu einem Milieu (Stand 2017: zehn) mit einbeziehen. ${ }^{138}$ Laut Selbstaussage folge man einem „[e]thnologische[n] Ansatz: Verstehen!“,139 mit dem Ziel, Einzelpersonen, „die sich in Lebensauffassung und Lebensweise ähneln“ zu „,Gruppen Gleichgesinnter“" zusammenzufassen, ohne dass dabei „lebendige[] Menschen [...] auf den künstlichen Status von ,Merkmalsträgern' reduziert werden sollten. “140

Welches Milieu der sogenannten Unterschicht könnte Peschek mit seiner Farbentheorie im Blick gehabt haben? Was in den 1980er Jahren zwischen kleinbürgerlichem und traditionellem Arbei-

\footnotetext{
138 [Sinus-Milieus 2017]: Informationen zu den Sinus-Milieus 2017, S. 6. Online: <http://www.sinusinstitut.de/fileadmin/user_data/sinus-institut/Dokumente/downloadcenter/Sinus_Milieus/201701-01_Informationen_zu_den_Sinus-Milieus.pdf>.

139 [Sinus-Milieus 2017], S. 4.

140 [Sinus-Milieus 2017], S. 6. Zur Forschungsethik eines eindeutig auf finanzielle Weiterverwertung zielenden Unterfangens - man fühlt sich unfreiwillig an facebook erinnert - soll hier nicht die Sprache gerichtet werden; allein scheint das Institut seine Sache ganz gut zu machen, sonst wäre der Umsatz nicht gegeben.
} 
termilieu angesiedelt gewesen ist $(\Leftrightarrow$ Abb. 11), heißt heute „traditionelles Milieu“ ( $\Rightarrow$ Abb. 12), das sich hauptsächlich aus der „Sicherheit und Ordnung liebende[n] ältere[n] Generation“ zusammensetzt, und „Bescheidenheit, Sparsamkeit“, „Bodenständigkeit“ etc. als Kennzeichen aufgeklebt bekommt. Unter dem „Leitmotiv: Keine Experimente“ 141 sind die dort einsortierten Menschen aber - und das ist das Interessante - seit den 1980er Jahren zwischen Unterschicht und unterer Mittelschicht mit einer „[t]raditionelle[n] Grundorientierung“ bzw. mittlerweile dem „,Festhalten“" und „,Bewahren““ verknüpft.

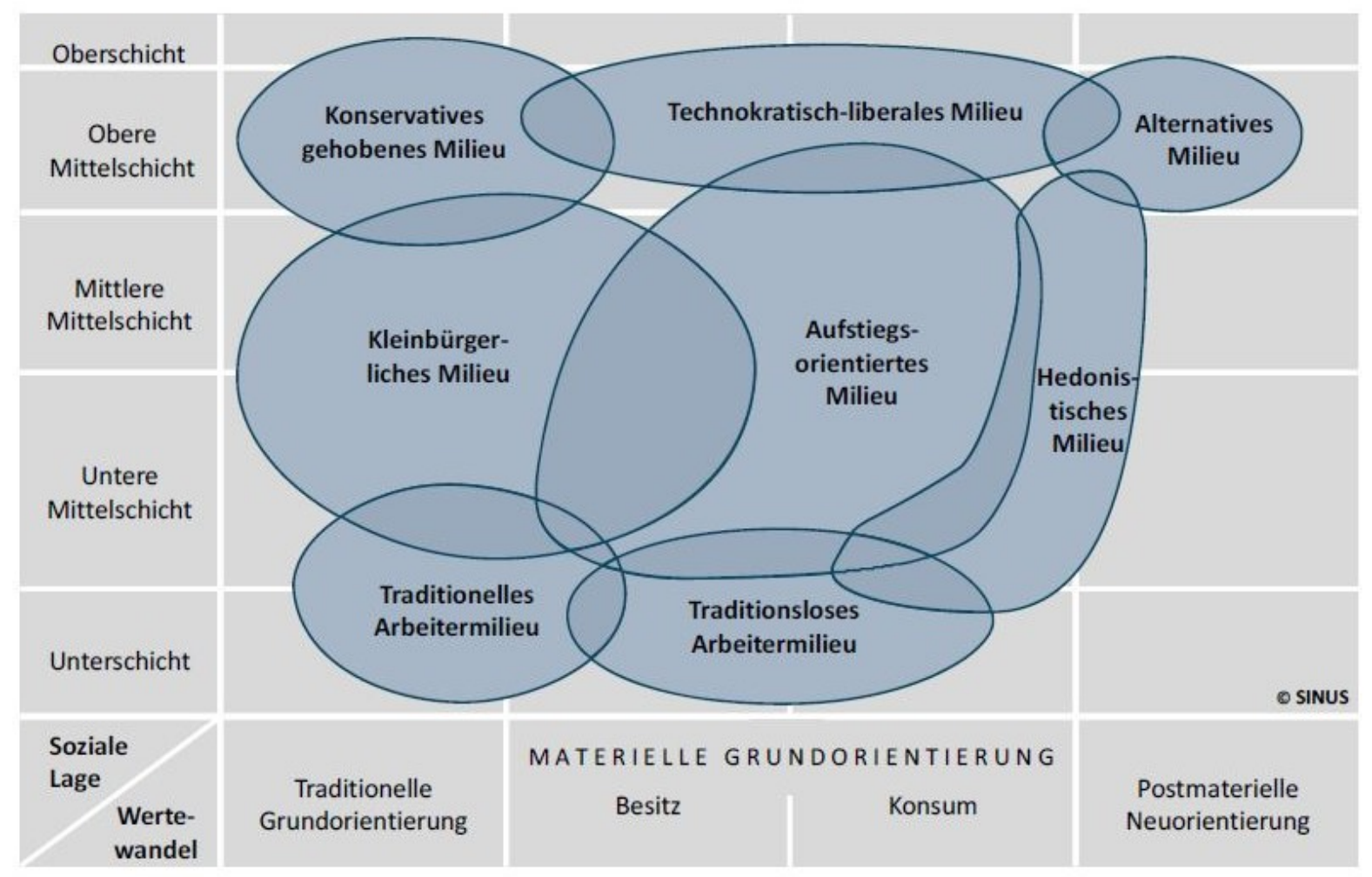

Abbildung 11: Sinus-Milieus der 1980er Jahre'142

\footnotetext{
141 [Sinus-Milieus]: Die Sinus Milieus, S. $13 . \quad$ Online: <https://www.sinusinstitut.de/fileadmin/user_data/sinus-institut/Bilder/sinus-mileus-2015/2015-09-23_SinusBeitrag_b4p2015_slide.pdf>. 


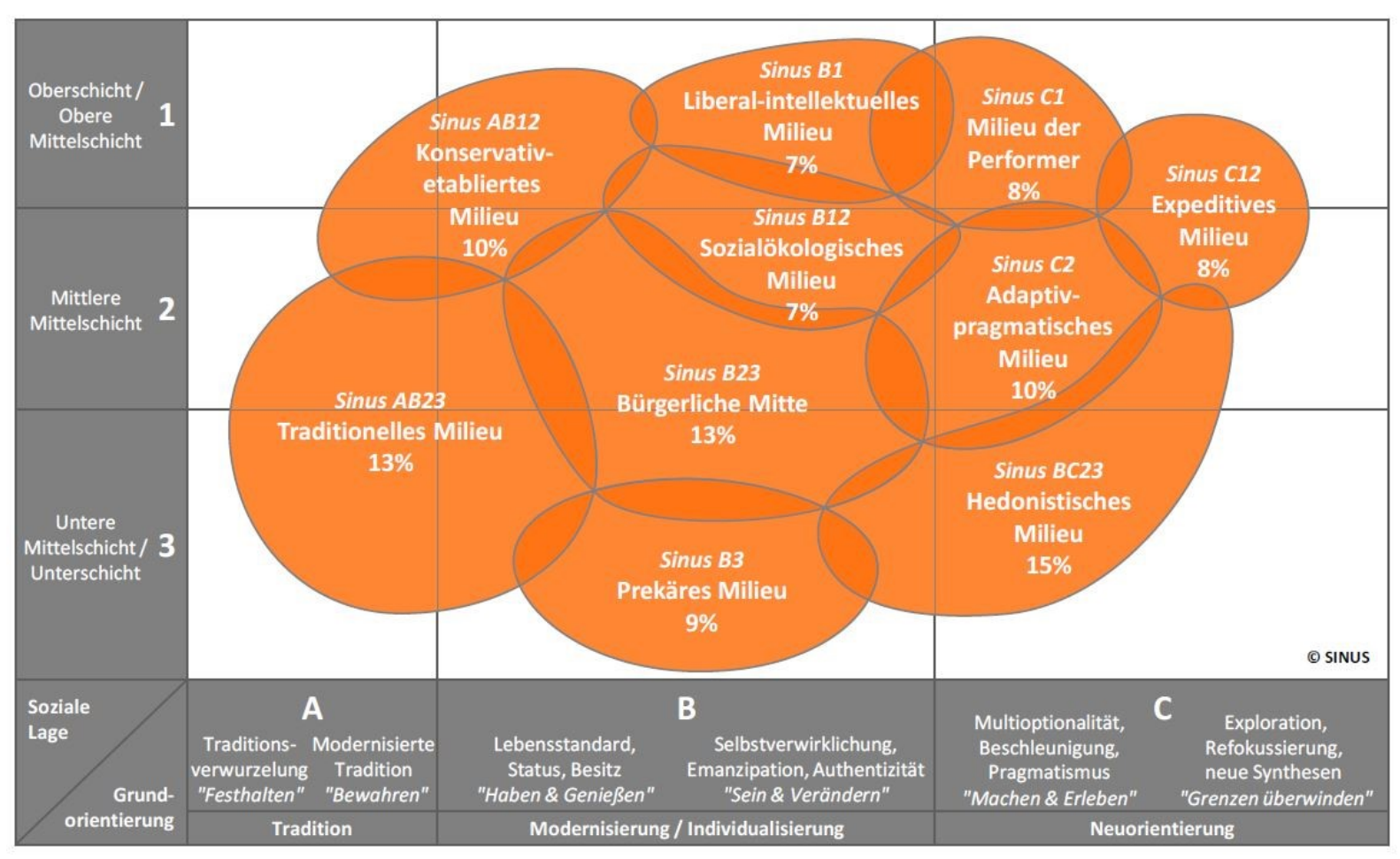

Abbildung 12: Sinus-Milieus in Deutschland 2017143

Gegen diese Spießigkeit opponiert Peschek, und tut damit etwas Bemerkenswertes: Er verunglimpft als „kräftig[er] und großgewachsen[er]“ (Fremde Kämpfe, S. 12) Ausreißer aus dem Figurenensemble Genazinos just ein häufig gewähltes Milieu des sonstigen Basistypus! Als freischaffender Werbegrafiker in Frankfurt wähnt er sich von der Milieuecke, links unten' meilenweit entfernt, obwohl er - vermutlich im Bereich der großen Schnittmenge in der Mitte ( $\Rightarrow$ Abb. 11) nicht sehr weit entfernt ist. Mit Werten wie ,Sparsamkeit' (vgl. Fremde Kämpfe, S. 39 u. S. 176) durchaus vertraut und bemüht, sich aus dem Milieu zu lösen, muss eine starke Entwertung gegen naheliegend Bekanntes und Verhasstes einhergehen.

Der Lehrling Weigand muss dieser Logik zufolge den Arbeiter noch weiter auf Distanz halten als die Elite den Parvenü:

Die Flaschen waren längst, von den Arbeitern unbemerkt, zu einem Eingeständnis geworden. Jedesmal, wenn ein Arbeiter trank, sagte die Flasche in seiner Hand: Wir beide, du und ich, fürchten uns vor den Labyrinthen der Verfeinerung, wir bleiben bei den Vorteilen der Einfachheit. (Wohnung, S. 64)

Die „Verfeinerung“, die Weigand damit in der Abgrenzung für sich selbst in Anspruch nimmt, wird bezeichnenderweise nicht im Einkommensunterschied, sondern im Konsumhabitus ausgewiesen. Mitunter sind es just die Aufgestiegenen, denen ihre Vorstellungen von ,denen da oben' zu kleinen Verhängnissen gereichen: 
Ihm, meinem Vater, war es in den siebziger Jahren gelungen, ein Angestellter zu werden. Es war der große Traum vieler Arbeiter in diesen Jahren, die Drehbank und den Schraubstock gegen einen Schreibtisch zu tauschen. Einmal, als er Hunger hatte, öffnete er seine Arbeiteraktentasche und holte ein Wurstbrot heraus, das ihm seine Frau wie jeden Tag in die Tasche geschoben hatte. Er verspeiste das Brot am Schreibtisch sitzend; er weigerte sich, den Telefonhörer in die Hand zu nehmen, weil ein Angestellter beim Kauen nichts anderes tun sollte als essen. Zwei jüngere Angestellte (erzählte er damals zu Hause) verließen das Büro, weil sie lachen mussten und einen Arbeiter beim Essen nicht kränken wollten. (Kein Geld, S. 89 f.)

Wie wichtig diese gepflegten kleinen, aber feinen Unterschiede - hier: zwischen Arbeiter- und Angestelltenhabitus ${ }^{144}$ - für die Romanfiguren sind, verdeutlicht neben der hohen Frequenz auch die ,Reflexionsumwittertheit' der Passagen:

Sie aßen tatsächlich Austern und schlürften hörbar. Es sind aufgestiegene Kleinbürger, die können sich am besten freuen, sagte Maria. Obwohl mir die Bemerkung gefiel, konnte ich mich meiner Distanz nicht erfreuen. Zum Zeichen meines Abstands bestellte ich keine Austern, sondern einen gewöhnlichen Salatteller mit Röstkartoffeln. (Tiere, S. 32)

Der „[p]ostmaterielle“, studierte, namenlose Ich-Erzähler ist freier Architekt, der sich einiges auf seine Individualität zugutehält. Er lässt sich treffend über die Sinus-Merkmale fassen:

Höchster Wert ist die Lebensqualität des einzelnen. [...] Sie schätzen subtile Genüsse, die durchaus einen hohen Preis haben dürfen. [ursprünglicher Plan, Austern zu bestellen] Überflüssigen Konsum lehnen sie aber ab. Nach dem Motto ,weniger ist mehr' kaufen sie selektiv und mit hoher Kennerschaft. [...] Ihre postmateriellen Ansprüche richten sich auf die Entfaltung ihrer individuellen Bedürfnisse und Neigungen, auf das Schaffen von Freiräumen für sich und auf mehr Zeitsouveränität. Sie wollen Erfolg im Beruf - aber nicht um jeden Preis [...] [Gedanken zur Festanstellung; N. L.], [...] weil sie sich mehr über Intellekt und Kreativität definieren als über Besitz und Konsum. ${ }^{145}$

Wird nun ein diesem Milieu Zugehöriger mit ostentativ schlürfenden „aufgestiegene[n] Kleinbürger[n]" konfrontiert, ${ }^{146}$ setzt der Distanz- und Distinktionsinstinkt ein und führt in diesem überzeichneten Beispiel ironischerweise dazu, die eigenen, höheren Ansprüche - wiederum gut sichtbar nach außen - zurückzufahren, und dem Austernessen um des Austernessenwillens („[ü]berflüssige[r] Konsum“) dennoch mit einem „Zeichen meines Abstands“ zu begegnen - im Rückgriff auf einen „gewöhnlichen Salatteller mit Röstkartoffeln“. Was als Understatement dem protektiven IM $(\Leftrightarrow I .3 .3)$ zuzuschlagen ist, bestätigt der Protagonist im weiteren Verlauf als postmateriell-typisch: „Ich selbst hatte leider kein Talent für einen auffälligen Lebensstil.“ (Tiere, S. 47)

W. aus Der Fleck, die Jacke, die Zimmer, der Schmerz, der wiederum finanziell völlig gesichert scheint, gerne reist und kunstbeflissen ist, formuliert es seiner diplomatischen und IM gekonnt nutzenden Eigenschaft gemäß in einer Mischung aus Euphemismus und Herablassung:

144 Vgl. Rinke: Angestelltenhabitus und Blickökonomie bei Wilhelm Genazino.

145 Marc Kirschbaum/Kai Schuster: Architektur und Lebensstil. Individuum, Gesellschaft und Raumpraxis. Dissertation Universität Kassel 2008, S. 128 f. Online: <https://kobra.bibliothek.unikassel.de/bitstream/urn:nbn:de:hebis:342009021626305/3/DissertationKirschbaum\%2BSchuster.pdf>.

146 Vgl. dazu auch: „Mit heftiger Missbilligung betrachtete ich die sogenannten Neureichen, die sich neue Autos, neue Fernsehapparate, neue Kleidung, neue Armbanduhren, neue Möbel kauften." (Kein Geld, S. 33) 
In den Theatern und Museen gibt es die ernsteste und höchste Kunst, die zu verstehen wir unsere ganze Bildung brauchen. Weniger komplizierte Menschen treffen sich unter freiem Himmel, in Gärten und Lauben; sie scherzen und zeigen sich ihre neuesten Kinder und vertrauen auf die Haltbarkeit ihres Glücks. (Fleck, S. 35)

Erneut ist das Ziel der Kritik nicht mangelnde formale Bildung o. Ä., sondern ein sich im Lebensstil manifestierendes - hier: aus konservativer Ecke - vorgetragenes Unverständnis für die Bildungsferne derjenigen, die Museen meiden und Glück und Harmonie ,im Freien‘ finden wollen.

Das konservativ etablierte Milieu, aus dessen Sicht häufiger argumentiert wird, existierte schon in den 1980er-Sinus-Studien und hält sich mit rund 10 \% der Bevölkerung Deutschlands relativ konstant. Mittlerweile ist es minimal von ganz oben links nach unten und nach rechts gewandert, aber die Beschreibung des Milieus trifft nach wie vor:

Sie interessieren sich für klassische Kunst und Kultur (Theater, Oper, Museen) [...], repräsentieren das alte deutsche Bildungsbürgertum [und pflegen] gehobene Umgangsformen. Entsprechend leiden sie unter dem ,Verfall der Werte und guten Sitten'. Sie legen großen Wert auf Abgrenzung durch die Betonung ihrer gehobenen Stellung in der Gesellschaft. ${ }^{147}$

In Der Fleck, die Jacke, die Zimmer, der Schmerz wird insbesondere die „konservative Kulturkritik“148 ausgestellt: „Es läuft eine futuristische Oper [...]. Ich öffne das Fenster, der Autolärm dringt ins Zimmer und paßt sofort zur Oper." (Fleck, S. 50) Der Protagonist kokettiert häufiger mit seiner Musikkennerschaft (vgl. Fleck, S. 7) und auch die jüngste Genazinohauptfigur gefällt sich als Connaisseur der Klassik, was er mit dem ,flotten', die Popkultur alludierenden und möglicherweise gleichzeitig verspottenden, ${ }^{149}$ Spruch zum Ausruck bringt, er höre „immer nur die alten Hits, von denen ich kaum genug kriegen konnte, also das Beste von Bach, Mozart, Haydn, Mendelssohn und so weiter." (Außer uns, S. 28 f.) Durch diese Wortwahl mischt der Protagonist die sonst fein säuberlich getrennten ,Geschmäcker: ${ }^{\prime} 150$ Ist die Komponistenkenntnis zweifelsfrei Ausdruck des ,legitimen', so lässt die saloppe Rede von ihren Werken eher an den ,mittleren“ Geschmack denken - interpretiert man nicht genau jene Vermischung als intendierten Herrschaftsgestus.

Die Kulturkritik umfasst bei Genazino zwar über die Romangrenzen hinweg alle Kunstgattungen, ${ }^{151}$ hauptsächlich wird sie aber auf dem Rücken von Musik und bildender Kunst ausgetragen: „Die hier ausgestellten Bilder waren nicht aufregend, es handelte sich um Collagen mit gemisch-

147 Kirschbaum/Schuster: Architektur und Lebensstil, S. 131.

148 Kirschbaum/Schuster: Architektur und Lebensstil, S. 131.

149 Vgl. Pontzen: Banalität und Empfindsamkeit, für eine beiläufige Kontrastierung von Genazino und ,Pop'.

150 Vgl. etwa: „Allmählich rutschte ich in eine angenehmere Stimmung. Aus dem Radio kam Klaviermusik von Chopin. Ich überlegte, warum es mir nicht möglich war, Maria gegenüber den Fertigsalat zu erwähnen. Ich wollte nicht der Mensch sein, der ich war. Am Abend allein einen Fertigsalat essen, das war unmöglich." (Tiere, S. 22; $\Rightarrow$ II.2.1)

151 Sie tritt darüber hinaus auch im Gewand des beanstandeten Sittenverfalls in Erscheinung: „Es gab schon genug Kinder auf der Straße, die ein solches Ding immerzu mit sich führten und es sich sogar an das Ohr hielten, wenn ihnen die Umwelt entweder zu langweilig oder zu anspruchsvoll war." (Ausschweifung, S. 75; $\Rightarrow$ II.1.6) 
ten Materialien, geschmackvoll, tauglich für jedes moderne Wohnzimmer, das war schon fast das Problem." (Außer uns, S. 20 f.) Das ,Problem' ist ein doppeltes: Auf der einen Seite ist der Geschmack des Mainstreams für ihn die verkommene Fratze ,echter', ernster Kultur per se, auf der anderen Seite tritt die konservative Abgrenzung auch in der Formulierung des negativ behafteten ,Modernen' in Erscheinung. Dass der Protagonist im Übrigen ein Problem darin sieht, dass sein Geschmacksurteil über Artefakte des ,mittleren` Geschmacks gewogen ausfällt, veranschaulicht erneut sinnfällig, wie elementar die Reflexionen von Lebensstil- und Schichtenzugehörigkeiten für Genazinos Figurenbasistypus sind.

Neben der nun detailliert dargelegten Abgrenzung nach unten findet sich auch die ,klassische‘ Orientierung am ,Oben', die seit Laslinstraße den Basistypus ebenso charakterisiert. Axel Degen etwa muss für sich selbst konstatieren, dass er im Gegensatz zum Bonvivant nicht einmal alle dargebotenen Alkoholika wenigstens des Namens nach kennt: „Verlegenheit der Wahl: Alles Fremdworte für mich, Bestandteile einer anderen Welt, ich mußte beginnen, mir diese Worte einzuverleiben, anzuvertrauen“ (Laslinstraße, S. 183).152 Ohne das habituelle Repertoire wird das Überspielen, ganz abgesehen vom tatsächlichen Übertreten, einer Geschmacksklasse zur anderen zum Scheitern verurteilt bleiben. Das vage Kokettieren mit sozialem Aufstieg kennt auch W. aus Genazinos Roman Das Licht brennt ein Loch in den Tag allzu gut. Einer seiner Erinnerungsaufträge, die er per Brief erteilt, beginnt imperativisch wie folgt:

[E]rinnere mich, daß ich mit dreizehn einige Wochen lang die Angewohnheit hatte, mich am Spätnachmittag in die Empfangshalle eines großen Luxushotels zu setzen. In einem prunkvollen Ledersessel wartete ich darauf, von einem reichen Mann angesprochen und mitgenommen zu werden. Ich hatte keine Vorstellung, wie die Verhältnisse sein sollten, in die ich hineinverpflanzt werden wollte, ich war nur sicher, irgendwo würde es eine Welt geben, die auf mich wartete und die mir gefiel. (Licht, S. 88 f.)

Vertikale soziale Mobilität als Lebenswunsch? Jedenfalls doppeln sich hier die Distinktionsperspektiven: Abgrenzung nach unten (Elternhaus) und naive Orientierung nach oben: Luxus, Prunk, Reichtum sind die verheißungsvollen Hochwertworte, die das erzählte Ich damals gelockt haben. Genazinos Romanfiguren haben überwiegend eine unscharfe Vorstellung davon, wie das Leben der Reichen und Schönen beschaffen sei: „Schon immer hatte er den Wohlstand für ein schönes buntes Zirkuszelt gehalten, in dem alle ein wenig umhergehen durften, aber nach einer Weile trieb jeder unausweichlich auf den Ausgang zu." (Fremde Kämpfe, S. 80 f.) Dort, wo die Figuren realiter in der fiktionalen Gesellschaft verortet sind, ist zumeist ,draußen', sodass die sowohl für das Großbürgertum als auch für andere besser situierte Milieu-Zugehörigen Selbstverständlichkeiten der Upperclass zu unsicheren IM-Erwägungen führen:

Zwanzig Mark waren als Geschenk für einen Vierzehnjährigen zwar mehr als genug, aber immer noch zu wenig. Fünfzig Mark waren mit Sicherheit zuviel, aber gerade eben ausreichend. Wenn Christian von seinem Vater gefragt wurde, was sein Kollege Fuchs geschenkt hatte, dann wollte sich

152 Vgl. dazu auch Abschaffels Not: „Er wollte Wein dazu trinken, kannte aber die Weinsorten nicht.“ (Sorgen, S. 305) 
Herr Fuchs vorstellen, daß Christian sagte: Fünfzig Mark. Und Herr Wohlleben sollte daraufhin anerkennend schlucken, und Herr Fuchs wollte sich dieses Schlucken schon jetzt vorstellen. (Ausschweifung, S. 112)

Kalkuliert, aber schwank sucht Fuchs denjenigen Schwellenbetrag zu taxieren, der seinen gut betuchten Kollegen mit dem - externer Blick - sprechenden Namen ,Wohlleben' - man könnte im Umkehrschluss an dieser Stelle mit ,Spar-Fuchs' kalauern - hinreichend beeindrucken könnte. Es handelt sich um selbstwertdienliches IM, das auf Basis einer Theory of Mind von Wohlleben neben dem assertiven Selbstbildschönen auch die Generosität nach außen im Blick hat.

Diese grundsätzliche soziologische Einführung lässt sich konkret als Methode für die figurensoziologische Analyse zuspitzen.

\section{KAPITALSTRUKTUR(ANALYSE)}

Jost Schneider unterscheidet mit Bourdieu fünf Formen des Kapitals, „die über die gesellschaftliche Stellung des Einzelnen entscheide[n]“, und definiert „Kapitalstruktur" als „die Summe seines materiellen, kulturellen, sozialen, symbolischen und körperlichen Kapitals“:153

Individuen werden mit einer spezifischen Kapitalstruktur geboren, entwickeln aber im Laufe ihres Lebens persönliche Kapitalstrukturideale, die in aller Regel auf die zusätzliche Akkumulation einer oder mehrerer Kapitalsorten sowie auf die Konvertierung überschüssiger Kapitalien der einen Form in fehlende Kapitalien einer anderen Form hinauslaufen. ${ }^{154}$

Der Autor erhebt in der Folge „das Ringen der (Haupt-)Figuren um die Realisierung ihres zugleich individuellen und epochen- bzw. schichtenspezifischen Kapitalstrukturideals“ gar zu einem der „beherrschenden Themen der gesamten Romanliteratur“ und macht die Kapitalstrukturanalyse als figurenanalytische Disziplin prominent. ${ }^{155}$ Für Genazinos Figurenbasistypus soll dies tentativ - zunächst global hinsichtlich der Kapitalformen, ferner en détail an den Beispielen von symboltragenden, selbstergänzenden Gegenständen und Kleidung - probiert werden. Dazu ist ein kurzer klassifikatorischer Blick auf die Unterformen und den jeweiligen Begriffsumfang vonnöten:

Dabei gehören zum materiellen Kapital Besitztümer wie z.B. Geld, Immobilien, Wertpapiere und ähnliche Objekte, die sich unmittelbar zu Geld machen und verschenken oder vererben lassen. Das kulturelle Kapital existiert in drei Erscheinungsformen. In objektivierter Form umfasst es die vorzeigbaren, anfassbaren Requisiten und Insignien der Kultur wie etwa Bücher, Musikinstrumente oder Gemälde. In institutionalisierter Form besteht es aus staatlich anerkannten Bildungspatenten und -zertifikaten [...]. Und in inkorporierter Form enthält es das, was man als die eigentliche Bildung bezeichnen könnte, also Einsichten und Erfahrungen, Kenntnisse und Kompetenzen, die man sich im Verlauf seines Lebens, sei es innerhalb oder außerhalb von Ausbildungseinrichtungen, angeeignet hat. Zum sozialen Kapital einer Person zählen ihre sämtlichen Beziehungen zu anderen Menschen, also z.B. Freundschaften, Liebesbeziehungen, nützliche Kontakte, Familienbande oder kollegiale Beziehungen. Viertens ist dann das symbolische Kapital zu nennen, das Ehre, Ansehen, Autorität und gesellschaftliche Geltung umfaßt. Und an fünfter Stelle ist schließlich noch das kör- 
perliche Kapital zu erwähnen, zu dem die Schönheit, die Gesundheit, die Geschicklichkeit oder auch z.B. die Kampfes- und Körperkraft einer Person gehören. ${ }^{156}$

Genazinos Basistypus zeichnet sich hinsichtlich des materiellen Kapitals üblicherweise durch Bedürftigkeit aus: ${ }^{157}$ Wertpapiere, Wohlstand und Wohneigentum sind keine Variablen, mit denen gerechnet wird, und auch hinsichtlich der Liquidität ist es regelmäßig familienähnlich nicht auf das Beste bestellt: „Es war Samstagnachmittag, wir wollten ausgehen, ich hatte kein Geld. Oder nur wenig. Elke wußte, daß ich kein Geld hatte, obgleich wir nie darüber sprachen. Sie gab mir Geld, wenn wir weggehen wollten wie heute." (Laslinstraße, S. 37 f.) Die genderanalytischen Implikationen ( $\Rightarrow$ II.5.3) interessieren hier nicht, aber Axel Degens Mangelerfahrungen sind darüber hinaus ein den Roman durchziehendes Leitmotiv: „[I]ch blieb zu Hause, ich, Axel, hatte noch keinen schwarzen Anzug, denn mein Vater hatte gesagt, einmal, früher: In meiner Jugendzeit bekam man erst mit einundzwanzig Jahren einen schwarzen Anzug" (Laslinstraße, S. 90) Nicht anders ergeht es späteren Figuren: „[D]er Monat erreichte in diesen Tagen sein Ende, und Abschaffel mußte überlegen, ob er zehn Mark für ein Mittagessen mit Bier so einfach ausgeben konnte. Er konnte es nicht." (Abschaffel, S. 116 f.) An diesem festinstallierten Fader des Mischpults ( $\Rightarrow$ I.2.2) wird häufiger gerührt: „Ich muß sparen und möchte auf den Besuch teurer Lokale verzichten. Freilich habe ich auch die Nase voll von Bistros und Imbiß-Theken." (Regenschirm, S. 65$)^{158}$

Denn nicht selten ist ,mehr erwünscht' und implizit der Wunsch nach einer Korrektur der realexistierenden Kapitalstruktur erkennbar. Das kann sich erstens im Spott für materiell Unterprivilegierte (häufig: Angehörige) Bahn brechen - „Diese Art von Mangelleben hielt der Vater für DAS LEBEN überhaupt“ (Abschaffel, S. 61); „da saß sie wieder, verlangte portofreie Kataloge, mit den fein gemalten Buchstaben täuschte sie die Adressaten, als wollte sie tatsächlich kaufen, fliegen, fahren oder ein Haus bauen“ (Laslinstraße, S. 16) -; zweitens im Blick nach oben, der nicht immer frei von Neid sein muss, oder im Begriff, tatsächlich vertikal-materiell nach oben sich zu bewegen. Alle Formen sind gerahmt von der Vorstellung der Wichtigkeit materiellen Kapitals: „Seinerzeit habe ich versucht, Bettina darüber zu belehren, daß Geld nicht banal ist, ganz im Gegenteil.“ (Liebesblödigkeit, S. 117) Die zumeist aus einer als finanziell mangelhaft erinnerten Kindheit stammende Vorstellung der Benachteiligung führt zu einer Mischung aus Wunsch und Neid mit Blick auf andere: „Jedes Familienmitglied, auch die Kinder, hatten das Recht, die Haushälterin in Anspruch zu nehmen." (Einfalt, S. 50) Die Orientierung nach oben geht zugleich mit Scham einher: „Plötzlich hatte er den Wunsch nach sehr viel Geld, und gleich schämte er sich dafür." (Abschaffel, S. 147) Ein gewisses Aufstiegsstreben ist zumal den erinnerten, erzählten

\footnotetext{
156 Schneider: Einführung in die Roman-Analyse, S. $21 \mathrm{f}$.

157 Vgl. Fischer: „Schläft ein Lied in allen Dingen“, S. 15 f.

158 Eine diese Grundform umspielende Variante: „Zur Zeit verdiente ich nicht allzu üppig und hatte seit längerer Zeit endlich wieder einmal das Gefühl, dass ich mitten im Leben stand und von mir beeindruckt war." (Außer uns, S. 23; $\Rightarrow$ II.2.1)
} 
Figuren eigen. So erinnert sich Axel Degen an die Situation seines Bewerbungsgesprächs mit den Worten: „[I]ch weiß nicht, ob ich aufgeregt war, ich dachte plötzlich an das Wort verdienen, Geld verdienen, das in der Anzeige nicht genannt war" (Laslinstraße, S. 117). Damit wird ein erster Schritt tatsächlicher sozial-materieller Mobilität gegangen, der schließlich dazu führt, dass Degen der Almosen nicht mehr bedürftig ist: „Obwohl ich mich daran gewöhnt hatte, diese Zigaretten gerne anzunehmen, war ich froh, daß ich jetzt Geld hatte, eigenes Geld, und es würde sicher reichen, daß ich manchmal Elke etwas bringen konnte." (Laslinstraße, S. 151) Insgesamt walzt Laslinstraße das Thema Haben oder Nichthaben ungewöhnlich breit aus und verhandelt en passant den Aufstiegswunsch im Wirtschaftswunder: „Wenn man Silber-Schmiera kaufte, das sagte dem Kaufmann, daß man nun bald zu Gold-Schmiera überwechseln würde, und Gold-Schmiera war die letzte Station vor der Butter." (Laslinstraße, S. 154) Natürlich wird mit Komik abgeschmeckt, wenn Degen im Gemischtwarenladen ein Päckchen Gold-Schmiera erwirbt: „[U]nd, so schien es mir, es waren einige Frauen da, die noch bei der Silber-Schmiera waren und mich neidvoll ansahen." (Laslinstraße, S. 156)

Damit ist der Neid auf die andere Blickseite gewechselt, was aber nicht per se negativ zu werten ist, da die Protagonisten prinzipiell - sofern die materiellen Mittel vorhanden sind - gönnerisch agieren: „Ich lege hundertfünfzig Mark auf die Theke und halte Margot mit einer Geste davon ab, mir Wechselgeld zurückzugeben. Margot leistet keinen Widerstand." (Regenschirm, S. 58; vgl. Kein Geld, S. 48) Außerdem sind sie durch zwei unterschiedliche, in moralischer Hinsicht gegensätzliche, aber in der Stoßrichtung vergleichbare Grundhaltungen gefeit gegen Prahlerei. Einerseits durch (unliebsamen) Geiz: „Ich fürchtete schon, dass ich bei diesen Gelegenheiten meinen momentweise sichtbar gewordenen Geiz nicht verbergen konnte. [...] Danach beschimpfte ich mich: Es kann doch nicht sein, dass dein Privatkonto deine einzige Freude geworden ist." (Außer uns, S. 36; $\Rightarrow$ II.2.1) Andererseits durch die Beargwöhnung von Luxus (vgl. Laslinstraße, S. 191; vgl. Ausschweifung, S. 10)

Bevor man nun vorschnell festhält, dass eine moderate Mehrung des materiellen Kapitals basistypisch sei, müssen zwei weitere Einschränkungen angebracht werden: Zum einen gibt es eine nicht unerhebliche Zahl an Protagonisten, die anscheinend keinerlei finanzielle Sorgen haben, ja, deren finanzielle Situation nicht einmal eigens im Text erwähnt wird, sondern nur über ausschweifende Reisen oder einen kostenintensiven Lebensstil vorgeführt wird (vgl. Fleck; vgl. Frauen; vgl. Licht). Zum anderen stellt sich das Kapitalstrukturideal in Betreff der Wohnungen bzw. Elternhäuser beinahe umgekehrt dar: Obwohl diese mit Regelmäßigkeit als klein (vgl. Heimweh, S. 11), dunkel (vgl. Laslinstraße, S. 8), mitunter heruntergekommen (vgl. Laslinstraße, S. 67), in jedem Fall aber ärmlich (möbliert) (vgl. Heimweh, S. 120) und unordentlich bis stark verschmutzt (vgl. Sorgen, S. 343; vgl. Liebesblödigkeit, S. 20 f.; vgl. Kein Geld, S. 28) dargestellt 
werden, werden seitens der Hauptfiguren nicht nur keine Anstrengungen unternommen, ${ }^{159}$ diesen Zustand zu ändern, ${ }^{160}$ sondern eine Änderung des Zustands ruft gar deren Unbehagen hervor: „Bisher war es immer so gewesen, daß er, sobald er mit Putzen fertig war, in eine Art Panik vor der Sauberkeit geriet und die Wohnung sofort danach verließ, weil er glaubte, hier könne er nicht mehr wohnen" (Abschaffel, S. 43) Auch die Wahl einer größeren Wohnung führt im Nachhinein zur kritischen Evaluation des Umzugs. Der Ich-Erzähler aus Wilhelm Genazinos Roman Außer uns spricht niemand über uns bemerkt, „dass meine Drei-Zimmer-Wohnung mit Küche und Bad für mich allein zu groß war. Damals, als ich die Wohnung anmietete, hatte ich gedacht, es müsse ein Ende haben mit diesen Ein-Zimmer-Appartements, in denen ich zuvor gelebt hatte. Jetzt, in drei Zimmern, stöhnte ich immer mal wieder über die zu wenig genutzten Räume“ ( $\mathrm{Au}$ ßer uns, S. 9; vgl. Regen, S. 59 f.).

Korrespondierend zur Wohnsituation, ist in den Romanen Wilhelm Genazinos das objektivierte kulturelle Kapital des Basistypus spärlich geraten: Bis auf vereinzelt vorkommende Gitarren (vgl. Sorgen, S. 187; vgl. Einfalt, S. 129) und ein solitäres Klavier (vgl. Fleck, S. 19) sind weder Musikinstrumente noch Gemälde in nennenswertem Umfang akkumuliert. Bücher hingegen sind omnipräsent, selten wird allerdings deren Privatbesitz thematisiert. Eine größere Rolle nimmt das institutionalisierte kulturelle Kapital des Basistypus ein:

Gemessen an Sonjas Verankerung in der realen Welt gehörte ich eher zu den Problemfällen. Ich hatte ein überlanges Philosophiestudium hinter mir und hatte dann über Kants Apodiktizität promoviert. Von Anfang an hatte ich gewusst, dass meine Promotion (Kant hätte gesagt) nur sittlichen Wert hatte oder, bösartiger formuliert, nichts weiter war als ein biografischer Zierrat. Ein bisschen niederschmetternd war, dass ich mich auch darin noch irrte. Die Zeiten, in denen ein Doktortitel die Menschheit beeindruckte, waren lange vorbei. Ich hatte mir tatsächlich vorgestellt, dass ich in der akademischen Welt Karriere machen würde. Über diese Illusion konnte ich heute kaum sprechen, ohne mich zu genieren. (Regen, S. 10)

Wie Gerhard Warlich, der Protagonist aus Das Glück in glücksfernen Zeiten (s.u.), ist auch Reinhard promovierter Philosoph, der seinen Lebensunterhalt in einem für diese Vorgeschichte unüblichen Rahmen verdient: als Barkeeper und Lokalredakteur. Obwohl er rational glasklar erkennt, dass institutionalisiertes kulturelles Kapital in Form des Doktortitels nicht gleichbedeutend ist mit materiellem oder symbolischem Kapital, ist dieser Sachverhalt emotional nach wie vor belastend für ihn:

159 Vgl. für ein Gegenbeispiel den Roman Kein Geld, keine Uhr, keine Mütze, wobei die Angst des Protagonisten, „verrückt geworden zu sein“, von der in unmittelbarer Nähe zur ,Putzstelle' erzählt wird, eine Ausnahmesituation insinuiert (Kein Geld, S. 25).

160 Allerdings ist den Figuren durchaus bewusst, dass andere ihre Wohnverhältnisse kritisch beäugen. Das führt dann aber ebenfalls nicht zwangsläufig zur Motivation, Änderungen herbeizuführen, sondern zu IM mit Kalkül der Rechtfertigung: „Ich frage mich, ob mein Apartment ärmlich aussieht. Notfalls werde ich darauf hinweisen, daß ich nur der Arbeit wegen in dieser Stadt lebe. Die Stadt gefällt mir nicht, sage ich probehalber zu mir selber, sie ist wie alle Städte. [...] Sie wissen, die Bilderflut draußen ... Das klingt plausibel und modern und noch nicht abgenutzt. Durch diesen Satz wird Frau Schweitzer in mir einen kritischen Menschen erkennen können." (Heimweh, S. 120) 
Die Scham rührte sonderbarerweise von meiner Bildung her. Ich konnte nur schwer fassen, dass ein Mann meines Wissens dann und wann gezwungen war, in einem Schnellbuffet eine Nudelsuppe zu sich zu nehmen. Ich konnte mir hundertmal zusichern, dass meine Bildung und eine Nudelsuppe aus seinslogischen Gründen absolut nichts miteinander zu tun hatten und dass ich mir meine künstlichen Konflikte endlich abgewöhnen müsste. (Regen, S. 59)

Klarer überpointiert und auf Überheblichkeit angelegt ist der philosophische Rededuktus in der folgenden Szene: „Später, während des Philosophiestudiums, nannte ich das Lächeln der Mutter (mit Kant) das Naturschöne, das Fernsehen nannte ich (mit Hegel) den Schein des Wirklichen und das Gesäusel der Filmhelden nannte ich (mit Heidegger) das Gerede des Man." (Glück, S. 82) Allerdings sind bei weitem nicht alle Figuren Akademiker, wie Burkhard Müller meint $(\Leftrightarrow I .2 .5): 161$ „Abschaffel war zwar ein abgebrochener Gymnasiast und hatte ansehnliche Englischkenntnisse, aber dennoch arbeitete er nicht in den favorisierten Abteilungen. Er wußte selbst nicht warum, und er überlegte auch nicht." (Sorgen, S. 182) Abgebrochene Bildungsbiografien lassen sich nicht mehr dem institutionalisierten, sondern dem inkorporierten kulturellen Kapital zuordnen, also dem, „was man als die eigentlichen Bildung bezeichnen könnte“. ${ }^{162}$ So gibt es im harten Kern der Figur keinen Protagonisten, der nicht zumindest entfernt an dieser Form der Kapitalakkumulation sich interessiert zeigen würde: „Er hatte begonnen, Kafka zu lesen“ (Abschaffel, S. 63). Abschaffel, der Schulabgänger, ist Literatur und Film durchaus aufgeschlossen, wobei die externe Analyseperspektive dabei nicht übersehen werden darf: Die intertextuelle Nähe der Kafka-Protagonisten zu Abschaffels Angestelltenvita ist bereits erwähnt worden ( $\Rightarrow$ II.5.4) und auch sein Interesse für Luis Buñuel (vgl. Abschaffel, S. 152) ist zumindest nicht nur diegetisch, sondern mindestens auch metafiktional und auf den Artefaktcharakter von Figuren bezogen zu verstehen, gilt jener doch als gegen bürgerliche Erstarrung aufbegehrender Regisseur, was Abschaffels Situation konterkariert. Die ,Kulturlosigkeit' der Kapitalstruktur wird immer wieder zum Gegenstand der Beobachtung erhoben:

Ich wußte damals nicht, daß sich in unserem Wohnzimmer zwei Exemplare eines Jahrhunderttypus ausbildeten: Menschen, die mit Hilfe des Fernsehens die Fatalität ihres Lebens aushielten. Als Kind glaubte ich, das Fernsehen sei schuld an der Zerstörung unserer Familie. Erst später war zu erkennen, daß die Reihenfolge umgekehrt war: Zuerst erloschen die Menschen, dann kam das Fernsehen und unterhielt die Erloschenen. (Einfalt, S. 87)

Gerade in Bezug auf die Eltern ist die Vorstellung des Erlöschens in der Lesart von Geistlosigkeit verstanden als Bildungsferne allgegenwärtig: „Diese undeutliche Kritik erinnerte mich an meinen Vater, der sich ebenfalls über seine kulturlosen Verwandten beklagte. Er hatte vollständig vergessen, dass auch sein Leben kulturlos war." (Außer uns, S. 66; vgl. Kein Geld, S. 24) Die Protagonisten streichen demgegenüber ihr inkorporiertes Kapital heraus: „Die Wahrheit ist, daß ich seit meinem fünfzehnten Lebensjahr fast täglich mit Literatur beschäftigt war. Ich las und schrieb und schrieb und las." (Wohnung, S. 8; vgl. Wohnung, S. 15) Als Resultat eines vereinfach-

161 Vgl. [Bei Regen im Saal].

162 Schneider: Einführung in die Roman-Analyse, S. 21. 
ten Lernprozesses steht am Ende: „Ich bin vergleichsweise gebildet“ (Heimweh, S. 12). Lesen (und schreiben) bildet zumindest insofern, als es zu Gesprächen über Literatur befähigt: Genazino (Figur) und sein Bekannter Theo „sprechen über Becketts Satz. Theo glaubt, daß es die harte und doch sanfte Gegenüberstellung ist, die die Wirkung des Satzes ausmacht" (Einfalt, S. 134). Wenn man unter inkorporiertes kulturelles Kapital tatsächlich alle „Einsichten und Erfahrungen, Kenntnisse und Kompetenzen, die man sich im Verlauf seines Lebens [...] angeeignet hat",163 fasst, dann fallen bspw. auch die lebensstilspezifischen (Un-)Kenntnisse der Restaurantlandkarte der eigenen Stadt darunter:

Natürlich habe ich nicht gesagt, daß ich mich in der Lokal-Szene nicht auskenne, sie hätte es mir wahrscheinlich sowieso nicht geglaubt. Ich habe mich frühzeitig auf den Weg gemacht, habe aber immer noch kein geeignetes Restaurant gefunden, das ich Susanne später wie selbstverständlich vorschlagen werde. (Regenschirm, S. 129)

Interessanterweise klaffen hier Selbst- und Fremdwahrnehmung auseinander $(\Rightarrow$ II.2.1): Obwohl es dem Ich-Erzähler größte Mühe bereitet, sich in der "Lokal-Szene“ zurechtzufinden, scheint sein Ansehen bei Susanne diesbezüglich ein anderes zu sein; würde sie doch der eigenen Aussage des Protagonisten nicht einmal glauben, wenn er ihr die Wahrheit sagte und seine Unkenntnis eingestünde. So ist auch hinsichtlich des kulturellen Kapitals nicht nur das faktisch vorhandene, sondern auch das qua assertiver Eindruckssteuerung übermittelte („wie selbstverständlich“) zu unterscheiden. Sich wider besseres Wissen als Kenner eines Sachverhalts auszugeben und sich, um sich nicht die Blöße geben zu müssen, tatsächlich Wissen anzueignen, sind also zwei Seiten einer Medaille, obwohl das Resultat das gleiche bleibt: „Nur als Kind wußte ich ein bißchen Bescheid, aber auch nur, weil ich vor den anderen Kindern nicht ahnungslos sein wollte." (Heimweh, S. 9) Dieter Rotmunds erinnertes kindliches Alter Ego ist also gewissermaßen ein Fußballkenner aus IM mit Kalkül gewesen.

Zynisch und die Grenze der distanzierten Figurenanalyse passierend könnte man sagen: Das ist in gewisser Weise auch nötig, da die sozialen Kontakte zu anderen nicht nur sein, sondern das Manko mannigfacher Hauptfiguren ist: Bereits das Spiel mit Gleichaltrigen im Kindergarten ist ihnen suspekt (vgl. Regenschirm, S.67), was sich mit der Einschulung sogar intensiviert (vgl. Kein Geld, S. 52), und so hart es klingt, so platt klingt es: ,Besitz' in Form von „Freundschaften, [...] nützliche Kontakte, Familienbande oder kollegiale Beziehungen“, also soziales Kapital, kann der Basistypus für sich nicht geltend machen - „Liebesbeziehungen“, die zumindest gelegentlich Elemente jener beinhalten hingegen zur Genüge. Bis auf wenige Ausnahmen, von denen der ,Briefroman' Das Licht brennt ein Loch in den Tag allein schon aufgrund der Fülle von Personen, an die intime Gedanken adressiert werden, als romanspezifisches Alleinstellungsmerkmal gelten kann, kann der Genazino'sche Basistypus wenige oder keine Freunde sein eigen nennen (vgl. Kein Geld, S. 69), auch ,nützliche Kontakte' sind rar, die Familie immer ein rotes Tuch und die 
Kollegen werden üblicherweise in Bausch und Bogen verurteilt. Wie sieht es mit der symbolischen Kapitalform aus?

Genaugenommen sind die Schnittflächen von „Ehre, Ansehen, Autorität und gesellschaftliche[r] Geltung"164 und Genazinos Figuren wenn überhaupt am äußeren Rand der Familienähnlichkeiten anzusiedeln ( $\Rightarrow$ I.2.5): „Nur ich, Finanzchef, kann mir nach dem Mittagessen noch zwei Garnelen leisten und mich zum Nachtisch von zwei Maschinenpistolen beschwichtigen lassen." (Heimweh, S. 115) Unschwer ist die ironische Brechung dieses nur scheinbaren Privilegs zu erkennen, die auch den seltenen Führungspositionen (vgl. Ausschweifung, S. 43 f.) der Figuren den Glanz nimmt. In der Regel handelt es sich um Angestellte (vgl. Abschaffel, S. 8; vgl. Ausschweifung, S. 265 f.), deren Ansehen im jeweiligen Mikrokosmos tadellos sein mag - und meist auch ist -, indessen wenig Strahlkraft darüber hinaus entwickelt. Der Regenschirm-Ich-Erzähler problematisiert den Zusammenhang von inkorporiertem kulturellem und symbolischem Kapital drastisch:

Meiner Bildung nach könnte ich bedeutend sein, meiner Stellung nach nicht. Wirklich bedeutend sind nur Personen, die ihr individuelles Wissen und ihre Position im Leben haben miteinander verschmelzen können. Außenstehende Leute wie ich, die nur gebildet sind, sind nichts weiter als moderne Bettler, denen niemand sagt, wo sie sich verstecken sollen. (Regenschirm, S. 76)

In der Tat wird er bekanntlich im Textverlauf arbeitslos werden. ${ }^{165}$ Dieses Schicksal teilt er mit der Hauptfigur des Romans Außer uns spricht niemand über uns:

Ich war schon öfter arbeitslos, aber ich nannte mich nicht arbeitslos. Meine Sprachregelung lautete: Ich bin gerade ohne Engagement. Wenn ich diesen Satz gesagt hatte, musste niemand über meine Lage erschrecken, auch ich selbst nicht. Der Kontakt zur Behörde musste deswegen vermieden werden, weil das Arbeitsamt dann mit einer Umschulung drohen würde. (Außer uns, S. 90; vgl. Außer uns, S. 46)

Einerseits vermeiden die Figuren, sich aus Scham, Stolz oder anderen impulsiven, akratischen oder irrationalen Motivationsgründen $(\Leftrightarrow I .3 .1)$ arbeitslos zu melden, andererseits schaffen sie es in der Regel nicht, sich ,am eigenen Schopf' aus dieser Misere herauszuziehen.

Demgegenüber ist der Wunsch, symbolisches Kapital in Form von beruflichem Aufstieg anzuhäufen, gerade bei den jüngeren Figuren-Alter-Egos zu bemerken:

Ich betrachtete mich in Schaufensterscheiben und dachte: Schau schau, der als Lagerarbeiter mißbrauchte Lehrling geht zu einer Pressekonferenz. [...] Es gefiel mir, immer mehr Aufträge zu bekommen, auch von anderen Zeitungen. Es gefiel mir, die Welt der Wichtigtuer und Vereinsmeier kennenzulernen, die ihren Namen in der Zeitung wiederfinden wollten. Das heißt, ich hatte Anteil an der Überheblichkeit des Schreibens und der Schreibenden. [...] Ebenso anregend war das Eintauchen in eine andere Welt, das Herumsitzen in Foyers und Nebenzimmern, das Studium eines nachlässigeren Lebensstils. (Wohnung, S. 24)

164 Schneider: Einführung in die Roman-Analyse, S. 21.

165 Vgl. zum Komplex von Erwerbslosigkeit, Kapitalismus(kritik) und Individualität Fischer: „Schläft ein Lied in allen Dingen“, S. 14-17. 
Es lässt sich also vereinfachend festhalten, dass der Basistypus verhältnismäßig wenig symbolisches Kapital vorzuweisen, gegen eine Vermehrung - so denn die eigene Kraft ausreicht - hingegen nichts einzuwenden hat. Beim körperlichen Kapital sieht dies anders aus:

Diese fünfte Kapitalform wird übrigens in manchen Schriften Bourdieus stiefmütterlich behandelt und nicht zu den eigentlichen Kapitalformen gezählt. Im Hinblick auf die Analyse der Romangattung, in deren populärsten Spielarten strahlende Schönheiten und athletische Muskelhelden bekanntlich stark überrepräsentiert sind, wäre ein Verzicht auf diese Kategorie jedoch unverzeihlich. 166

Mit Blick auf Genazino kann man getrost bei Bourdieu bleiben: Die spärlichen Aussagen zur Körperlichkeit sind bereits erläutert worden ( $\Rightarrow$ II.1.4), bezogen auf die Gesundheit und das Alter(n) ( $\Rightarrow$ II.5.6) ist es ebenfalls nicht auf das Beste bestellt. Im Gegensatz etwa zum materiellen oder symbolischen Kapital sind diesbezüglich jedoch, trotz der eklatanten Unzufriedenheit etwa mit dem eigenen Aussehen und/oder Erscheinungsbild ( $\Rightarrow$ II.2.1), keinerlei Ambitionen erkennbar, andere Kapitalien in diese Form zu überführen.

Zum Abschluss dieser kapitalstrukturellen Zusammenschau des Basistypus sei kurz anhand von Wilhelm Genazinos Roman Das Glück in glücksfernen Zeiten eine Interpretation skizziert, die sich auf diese methodische Herangehensweise stützt:

Gerhard Warlich, der „Held“, hat, wie er anfangs glaubt, beste soziale Voraussetzungen, um in unserer komplexen Wirklichkeit eine gute Figur zu machen. Er ist akademisch gebildeter Philosoph (mit einer Promotion über Heidegger) und insofern hervorragend geeignet, unserer Gesellschaft das zu vermitteln, woran es dieser am meisten mangelt, nämlich Selbsttransparenz, kritische Distanz, philosophische Erleuchtung. Um sein Studium zu finanzieren, hat sich Warlich von Anfang an als Ausfahrer einer Großwäscherei betätigt. Im Verlauf von Warlichs Jugend verschiebt sich das Parallelogramm der Kräfte immer mehr. Seine Vorstellung, als Philosoph an einer Universität Karriere zu machen, verflüchtigt sich zunehmend und löst sich bald ganz auf. Auch ein anderes Arbeitsfeld, auf dem ein Philosoph gebraucht werden könnte, läßt sich nicht finden. Es stellt sich heraus, daß ein Philosophiestudium in unserer Gesellschaft genau das ist, was Warlichs Doktorvater prophezeit hatte: „Bildungslametta“ - ein Glitzerzeug, das niemand wirklich braucht. Im Gegenzug zeigt sich, daß Warlich immer tiefer in das unternehmerische Profil eines Wäscherei-Managers einsteigt. In dem Bereich, in dem er als Student als Ausfahrer angefangen hatte, wird er schließlich Geschäftsführer [...]. Noch immer, auch im 21. Jahrhundert, zeigt das bürgerliche oder das kleinbürgerliche Leben seine Krallen: es versagt sich den Wünschen seiner Liebhaber. [...] Er kann nicht ablassen von seinem Wunsch, als Philosoph durchs Leben zu gehen und als Philosoph sein Geld zu verdienen. Immer mal wieder schleicht er sich aus seinem Berufsleben heraus und sucht das alte Philosophische Seminar der Universität auf, wo er sich vor vielen Jahren einmal wohl gefühlt hatte. Von seiner Lebensgefährtin Traudel wird er deswegen gerügt. Sie hält ihm vor, daß ein „so gebildeter“ und realitätstüchtiger Mensch wie er die Welten besser trennen können müßte. Was Traudel hervorbringt, sind Erwartungsprofile des „vernünftigen“ Menschen, der Warlichs Scheitern an der Wirklichkeit nicht versteht und deswegen auch nicht hinnehmen kann. De facto gibt es Zeichen genug, die darauf hindeuten, daß Warlich mit zunehmendem Realitätsverlust fertig werden muß und eben nicht fertig wird. Der Realitätsverlust bildet sich in phantastischen Projekten ab, die den Wirklichkeitsverlust schon vollzogen haben. So besucht Warlich eines schönen Nachmittags das Büro des Kulturamtsleiters der Stadt und unterbreitet ihm sein Projekt einer „Schule der Besänftigung". 167 
Warlichs Realitätsverlust lässt sich durchaus an einer von der Gesellschaft als Ideal vorgegebenen Kapitalstruktur und der eklatanten Abweichung von seiner eigenen aufzeigen $(\Rightarrow I .3 .1) .168$ Allerdings weniger in dem Sinne, dass es Warlich schlechterdings unmöglich wäre, vorhandene Kapitalformen zu konvertieren oder es ihm generell an „Chancen zur Realisierung dieses Ideals“ mangelte, 169 sondern hinsichtlich der „Krallen“ des Lebens auch im einundzwanzigsten Jahrhundert: Die Gesellschaft begünstigt das Streben nach anderen Kapitalstrukturkonstellationen, als es Warlich wünscht. Besonders perfide daran ist die Tatsache, dass es vereinzelte Signale aus Warlichs Umfeld gibt, die ihn von der Loslösung seines alten Traums abhalten:

Traudel überschätzt meine Bildung. Sie läßt sich von meinem Doktortitel blenden, ohne zu ahnen, [...] daß es Abertausende solcher überflüssiger Spezialisten gibt wie mich, die sich am Ende eines überlangen Studiums auch noch entschlossen haben, sich auf ein paar abwegige Bildungssplitter zu stürzen und über sie zu promovieren. [...] In Wahrheit gehöre ich zu den vielen Menschen, die sich von ihrem Studium haben blenden lassen. Weil ich (zum Beispiel) Gadamers „Wahrheit und Methode“ und Wittgensteins „Philosophische Untersuchungen“ gelesen hatte, glaubte ich auch schon, ebenfalls auf dem Niveau dieser Bücher denken zu können. Mein Besonderheitsgefühl wuchs ins geradezu Unermeßliche. Ich brauchte Jahre, bis ich vom Berg meines Dünkels wieder herabgestiegen war. (Glück, S. 45; $\Rightarrow$ II.1.3 u. $\Rightarrow$ II.2.1)

Dieser Abstieg führt allerdings in

Warlichs um sich greifende Bodenlosigkeit. Sie [Traudel; N. L.] kann ihm nicht nur nicht helfen, sondern erkennt nicht einmal die für ihn neue, die psychische Ebene seines Leidens. Es kommt zu einer schmerzlichen Abspaltung Warlichs von der Wirklichkeit. Traudel selbst ist es, die ihn in der ihnen gemeinsamen Ratlosigkeit in eine psychiatrische Klinik fährt. ${ }^{170}$

Institutionalisiertes und inkorporiertes kulturelles Kapital ist letztlich - in der Gesellschaft der Diegese wie in der Wirklichkeit - selbst dann, wenn es im Überfluss vorhanden ist, nicht ohne Weiteres umzumünzen in materielles oder symbolisches - und daran zerbricht Warlich, obwohl er es selbst weiß.171 „Am Fall dieses von der Welt Erschreckten ist das Schicksal einer Generation zu studieren, die sich im Übergang von der Bildung in den Beruf vom Aufstiegsversprechen getäuscht und mit der Exklusionsdrohung konfrontiert sah“,172 resümiert der Soziologe Heinz Bude und weitet damit die individuelle ,Fallgeschichte‘ auf die Generation der Babyboomer aus:

Man kann Genazinos Roman soziologisch als Beispiel für das Schicksal eines ,Unzugehörigen` nehmen, der aus relativ privilegierter Lage, was Bildungsabschluss, Partnerschaft und Beschäftigungsverhältnis betrifft, in einem ,schwarzen Loch' der Sozialstruktur verschwindet. Exklusion meint hier [...] die Form [...] eines unerklärlichen Verlustiggehens aus einer mittleren, leidlich abgesicherten und halbwegs auskömmlichen Soziallage. ${ }^{173}$

\footnotetext{
168 Vgl. Spiegel/Genazino: „Der Text ist sein eigenes Misstrauen“, S. $253 \mathrm{f}$.

169 Schneider: Einführung in die Roman-Analyse, S. 22.

170 Genazino: Der Roman als Delirium, S. 31.

171 Dieses Wissen wird in Genazinos Romanen regelmäßig in die Ecke gelacht, um es zu bannen: „Dr. Wolters nannte die Universität ein Arbeitslosenzwischenlager, was großes Gelächter hervorrief." (Kassiererinnen, S. 81; vgl. Skrzypczak: Psychologie in Prosa, S. 31 f.)

172 Bude: Ein Mann verschwindet, S. 191.

173 Bude: Ein Mann verschwindet, S. 188.
} 
Strenggenommen gehören die folgenden zwei Aspekte (Dinge und Kleidung) in eine vollständige Kapitalstrukturanalyse hinein, aber deren Wichtigkeit für Genazinos Figurenbasistypus legitimiert eine gesonderte Thematisierung.

\section{(SYMBOLTRAGENDE UND SELBSTERGÄNZENDE) GEGENSTÄNDE}

Vor allen anderen,174 die sich mit Dingen bzw. Gegenständen bei Genazino beschäftigt haben, ist Melanie Fischer zu nennen, deren Masterarbeit systematisch die Darstellung der Dingwelt bei Wilhelm Genazino anhand der Romane Ein Regenschirm für diesen Tag und Eine Frau, eine Wohnung, ein Roman angeht, ${ }^{175}$ bevor ihr Beitrag „,Schläft ein Lied in allen Dingen“ - Wilhelm Genazinos Prosa im Kontext des literarischen Ding-Diskurses"176 einerseits thematisch zuspitzt, andererseits bezogen auf die Referenzromane ausdehnt. Sie unterscheidet eine doppelte Funktion: Einerseits „dienen Dinge als Repräsentationsflächen für die Romanfiguren. Gegenstände inkorporieren folglich, was der Betrachter in ihnen sehen möchte. So werden sie zu Auslösern jener komplexen Reflexionsketten, welche für die Protagonisten insbesondere der jüngeren Bücher so charakteristisch sind.“177 ( $\Rightarrow$ II.2.2 u. $\Rightarrow$ II.2.3) „Demgegenüber finden sich zahlreiche Beispiele, bei denen die Objekte des Alltags zu semiotisch aufgeladenen Repräsentanten der ganzen Kultur oder gar zum scheinbar intentionalisierten Agens, zu ,Quasi-Subjekten' [Latour; N. L.] werden. “178 Der Binnendifferenzierung Fischers folgend, die für die Untersuchung der ,QuasiSubjekte‘ neben der ,Vermenschlichung der Gegenstände‘ auch eine „,Verdinglichung des Menschen“'179 im Blick hat, sollen hier hauptsächlich erstere im Fokus stehen, zumal sie sich mit der sozialpsychologischen Theorie zur Symbolischen Selbstergänzung (s.u.) gut verbinden lassen.

Welche Anziehungskraft die kleinen und kleinsten Dinge für Genazino haben, verrät ein Blick in seine erste Frankfurter Poetikvorlesung, „Batterien des Poetischen“:

174 Vgl. etwa Karl-Heinz Jakobs: Tiefsitzendes Mißtrauen gegenüber den Dingen des Lebens. Interview. In: Neues Deutschland vom 04. November 1994; vgl. Wilfried F. Schoeller: Die Dinge blicken zurück. In: Frankfurter Rundschau vom 07. Oktober 1998; vgl. Helmut Böttiger: Anwalt kleinster Dinge. Eine Laudatio auf den Erzähler Wilhelm Genazino, der in Berlin mit dem Fontane-Preis 2003 ausgezeichnet wurde. In: Die Welt vom 26. April 2003. Online: <https://www.welt.de/printwelt/article690748/Anwalt-kleinster-Dinge.html>; vgl. Kraume: Den Dingen lauschen; vgl. Krauss: Menschen - Dinge - Situationen; vgl. Annette Wollenhaupt: Ein Streuner, dessen Blick den kleinen Dingen gilt. In: Frankfurter Rundschau vom 20. September 2004; vgl. Katharina Deschka-Hoeck: Die Magie der Dinge: Wilhelm Genazinos erste Poetik-Vorlesung. In: Frankfurter Allgemeine Zeitung vom 12. Januar 2006; vgl. Dierk Wolters: Die Dinge zum Leuchten bringen. In: Frankfurter Neue Presse vom 09. Februar 2006.

Vgl. Melanie Fischer: Ding-Diskurs - die Darstellung der Dingwelt bei Wilhelm Genazino, beispielhaft an „Ein Regenschirm für diesen Tag“ und „Eine Frau, eine Wohnung, ein Roman“. Magisterarbeit University of Waterloo 2004.20 Online: <https://uwspace.uwaterloo.ca/bitstream/handle/10012/752/m4fische2004.pdf?sequence=1\&is Allowed=y>. Vgl. Fischer: „Schläft ein Lied in allen Dingen“.

177 Fischer: „Schläft ein Lied in allen Dingen“, S. 9.

178 Fischer: „Schläft ein Lied in allen Dingen“, S. 9 f.

179 Fischer: „Schläft ein Lied in allen Dingen“, S. 10. 
Ich werde mich also mit nichtswürdigen, bedeutungsvollen Kleinteilen beschäftigen, das heißt mit alten Fotos (mit eigenen und fremden), mit Koffern und ähnlichen Behältnissen (also mit Taschen, Schachteln, Dosen, Etuis), dann mit Schubladen und Kleidung, ferner mit einer Großgruppe nicht rubrizierbarer Einzeldinge, deren gemeinsames Merkmal ist, daß sie im Alltagsgebrauch auftauchen und dort gewöhnlich auch untergehen und weggeworfen oder eben (und das ist der interessantere Fall) nicht weggeworfen werden; also zum Beispiel mit Brillen, Rabattmarkenheftchen, Knöpfen, Orden, Schlüsseln, Münzen, Nadeln, Scheren - und so weiter. ${ }^{180}$

Nichts davon ist zu unscheinbar, um diese ,Kleinteile“ nicht entweder als „Repräsentationsflächen für die Romanfiguren“ (s.o.), die „bei ihren Betrachtern zu poetischen Epiphanien“ führen,181 zu funktionalisieren oder deren Symbolgehalt literarisch zu poetisieren. ${ }^{182}$ Zwar können prinzipiell alle Gegenstände für beide Verfahrensweisen genutzt werden, aber ein wichtiger Unterschied besteht in der Nähe des Dings zum Besitzer: Während etwa ein einzelner, auf der Straße liegender Schuh eher Gegenstand der Reflexion sein wird, ist ein wie, wo und wann auch immer gefundener Gegenstand, mit dem die jeweilige Figur bereits eine ,Beziehung' aufgebaut hat, eher dazu angetan, in die Kategorie ,symboltragend, vermenschlicht' zu fallen:

Die egozentrische Voreingenommenheit wirkt sich auch auf die Wahrnehmung von Personen und sogar Gegenständen aus, denen man sich verbunden fühlt. Harvard-Forscher fanden heraus, dass Menschen Möbel, die sie selbst aufgebaut haben, und sogar Papierfrösche, die sie selbst gefaltet haben, für wertvoller halten als die Möbel und Origamiwerke anderer Personen. ${ }^{183}$

Im Gefühl der Verbundenheit werden diese Gegenstände nicht selten zu Quasi-Subjekten für die Figuren, deren Vermenschlichung so weit gehen kann, dass sie das Wort an sie richten respektive in der Vergangenheit gerichtet haben:

[E]rinnere mich, daß ich als Kind mit den Dingen redete. Insbesondere mit Häusern, Fenstern, Mützen und Käfern. Ich habe zwischen den Dingen und den Wörtern, die es für sie gab, nicht unterschieden. [...] Offenbar entnahm ich dem Schweigen der Dinge die Erlaubnis, alles über sie erfinden zu dürfen. (Licht, S. 123)

Damit ist en passant eine kleine Vorschau auf die späterhin noch zu diskutierenden ,Überinterpretationen“ bzw. übertriebenen Mutmaßungen gegeben ( $\Rightarrow$ II.2.3): „Heute kommt es mir so vor, als liege in der Gewißheit unseres Sterbens die Nötigung, ein Phantast werden zu müssen.“

180 Wilhelm Genazino: Batterien des Poetischen. Erste Vorlesung. In: ders.: Die Belebung der toten Winkel. Frankfurter Poetikvorlesungen. München/Wien 2006, S. 5-23, hier S. 10. Genazino: Batterien des Poetischen, S. 10; vgl. Eke: Epiphanische Augen-Blicke; vgl. Koch: Das Bedeutungstheater des Epiphanikers.

182 Bei Genazino findet sich eine bemerkenswerte Ambivalenz: Im Roman Falsche Jahre distanziert sich Abschaffel durch den Kauf eines Gegenstandes von der Geizigkeit des Vaters (vgl. Falsche Jahre, S. 568-570). Andererseits der Abschaffel der Sorgen: „Er verstand die Geste des Sammelns nicht, die Verankerung des Lebens in einer Anhäufung gleicher oder ähnlicher Objekte, von denen eine Art Zuversicht auszugehen schien." (Sorgen, S. 273) Dazu passt sowohl die weitgehende ,Hobbyfreiheit' der Genazino-Protagonisten als auch die negativ besetzten "Materialkulte“ (Regenschirm, S. 140): Genazino (Figur) etwa ist genügsam, bis ultimo' und „empfinde[t] plötzlich Lust, alle meine Sachen zu verschenken, meine Hosen, meine Schuhe, meine Hemden, auch Bücher, Geschirr, Möbel. Ich muß froh sein, daß im Augenblick niemand bei mir ist, der die Sachen wirklich gebrauchen kann." (Einfalt, S. 120) 
(Licht, S. 123) In der lebhaften Imagination der Figuren kann durchaus auch ein Gegenstand das Wort ergreifen:

Nicht weit von den Grasbüscheln liegt ein ebenfalls feuchtes Telefonbuch. Ich bleibe stehen und betrachte das ein bißchen aufgequollene Ding, und plötzlich bemerke ich, daß mich das Telefonbuch an das Meer erinnert. Nur in seiner Nähe bin ich davon erlöst, immerzu um mich besorgt sein zu müssen. Ich bücke mich und nehme das Telefonbuch mit. Kurz bevor ich meine Wohnung erreiche, lege ich es so auf den Bürgersteig, daß ich es von meinem Fenster aus gut sehen kann. Kaum bin ich oben im Zimmer, blicke ich auf das Ufer herunter. Grau und schwer wie ein kleines Stück Meer liegt das Telefonbuch an einer Hauswand. [...] Ich wundere mich, daß ich mich freue, das zerfledderte Ding wiederzusehen. [...] Später, beim Einkaufen, bücke ich mich und nehme das Telefonbuch erneut an mich und trage es mit nach Hause. [...] Ich beschließe, das Telefonbuch in der Küche liegenzulassen und jeden Tag nachzuschauen, wie schnell oder wie langsam die Nässe verschwindet. Aber schon am Frühabend habe ich das Gefühl, daß mich das Telefonbuch nur tröstet. [...] Das halbnasse Telefonbuch! Es liegt vor mir auf dem Küchentisch und sagt: Kleine Frau, in diesem Augenblick hast du die Grenze zum Nichts, zur Schwärze, zum Tod überschritten. Wer nimmt schon ein halbnasses Telefonbuch mit nach Hause? Alle werden denken müssen, die Frau ist übergeschnappt. Die Frau schnappt nicht über. [...] Nach drei Tagen ist das Telefonbuch trocken. [...] Wenig später lasse ich das Telefonbuch in einem Papierkorb nahe der Bushaltestelle verschwinden. (Obdachlosigkeit, S. 82-85)

Das Telefonbuch fungiert nicht nur als Projektionsfläche („Meer“), sondern wird zugleich darüber mit symbolischer Bedeutung (Trost) aufgeladen und stellt die veräußerte Form innerer Befindlichkeiten dar. Zugleich nimmt es parasoziale Funktionen an, wovor die Protagonistin derart erschrickt, dass sie sich seiner letztlich - einem angst- oder ekelbesetzten Fetisch nicht unähnlich (vgl. Abschaffel, S. 29 f.) - entledigt. Aber auch ohne diese ,bedrohliche‘ Komponente können Gegenstände im Romanverlauf kurz- oder längerfristige, wichtige Bedeutung für die Protagonisten entwickeln: So evoziert etwa ein Stein im Schuh für Abschaffel Kindheitserinnerungen, weshalb er ihn lange Zeit nicht entfernt (vgl. Falsche Jahre, S. 542), so bleibt „es [...] nicht aus, daß er gegenüber den Schachteln Gefühle bekam“ (Abschaffel, S. 32), so freut er sich über den Fund eines halben Tennisballs derart, dass er ihn mitnimmt und über einige Druckseiten nicht mehr hergibt:

Er erinnerte sich, daß er sich als Kind oft gefragt hatte, wie ein Tennisball von innen aussieht. Er erinnerte sich mit merkwürdiger Genauigkeit an dieses kindliche Rätsel, und nun endlich war es gelöst. Dieser behaarte, pralle, harte und doch nachgiebige Ball hatte innen eine fünf bis sechs Millimeter starke Gummiwand, auf deren Außenseite die pelzig behaarte Hülle aufgeklebt war. Er wischte den gröbsten Dreck von der Ballschale herunter und steckte sie in die Manteltasche. Er wollte sie am Abend in seinem Zimmer waschen und trocknen, so daß die Behaarung wieder frisch und hell werden mußte [...] Den halben, für die Kinder unbrauchbaren, wollte er für sich behalten, weil er seiner Bedeutung noch eine Weile nachhängen wollte. (Falsche Jahre, S. 440 u. S. 443)

Insbesondere bei Kindern ist umgangssprachlich nicht selten die Rede von ,heißgeliebten' Gegenständen - und auch die erwachsenen Romanfiguren Genazinos vermenschlichen - affiziert zumeist von Kindheitserfahrungen ${ }^{184}$ - Dinge allenthalben. Ist diese Tatsache bei der Bezeichnung „Behaarung“ für einen Tennisball selbst bereits nur eine mögliche Zuschreibung, wird dies etwa an einem Beispiel aus Genazinos Roman Mittelmäßiges Heimweh offensichtlich:

184 Vgl. dazu: „Ich nehme an, daß die Erinnerungskraft von Gegenständen weniger manipulierbar ist.“ (Licht, S. 99) 
Dieser Tage ist mein kleiner blauer Reisewecker endgültig zu Bruch gegangen. Der Wecker gehörte einmal meiner Mutter, ich habe ihn seit ihrem Tod aufbewahrt, zusammen mit zwei oder drei anderen, ebenso lächerlichen Erbstücken. Ich habe schon oft darüber nachgegrübelt, warum ich zu den Menschen gehöre, denen die Eltern nur ein paar peinliche, fast schon idiotische Dinge hinterlassen. Trotz seiner Lächerlichkeit habe ich den Reisewecker all die Jahre aufbewahrt. Ich habe ihn sogar in seiner Funktion als Wecker hin und wieder benutzt, weil mir die modernen Digitaluhren nicht gefallen, beziehungsweise, weil ich mit ihrer Technik nicht zurande komme. Mit der Zeit habe ich bemerkt, daß der Wecker eine magische Eigenschaft hatte, die ihn mir besonders liebenswert machte. Die Uhr blieb manchmal etwa eine Stunde lang stehen und fing dann wieder an zu ticken. Das heißt, die Uhr verhielt sich zuweilen wie ein alter Mensch, der etwa eine Stunde lang keine Lust für nichts hat, dann aber wieder weitermacht. Wunderbar! Als er endgültig aufgehört hatte zu ticken, steckte ich ihn in meine Hosentasche und warf ihn beim Spazierengehen in einer kleinen Parkanlage in einen Abfallkorb. Das hätte ich nicht tun sollen. Denn nach ungefähr einer Stunde tat mir der kaputte Wecker so leid, daß ich zu dem Abfallkorb zurückging und darin herumwühlte wie ein nach Nahrung suchender Obdachloser. Zum Glück fand ich den Wecker und nahm ihn wieder an mich, jedenfalls eine Weile. (Heimweh, S. $130 \mathrm{f}$.)

Erstens sind die Signale für eine Anthropomorphisierung nicht zu überlesen: „peinliche“ und „idiotische“ Eigenschaftszuschreibungen, insbesondere aber dessen Fähigkeit, für Rotmund „liebenswert" zu sein und dessen Mitleid zu erregen, zeugen davon, dass es sich nicht nur um einen Wecker handelt. Zweitens ist die Diskrepanz zwischen erkannter „Lächerlichkeit“ und ,symbolischem Wert' bemerkenswert: Der Wecker steht für etwas anderes, erlangt darüber Zeichenstatus und übernimmt Repräsentationsfunktion (s.o.). Diese Funktion muss nicht auf einen einzelnen Gegenstand beschränkt bleiben, auch ganze Ensemble werden ,befähigt', Repräsentanten komplexer Sachverhalte zu sein:

Überhaupt übernahmen die Dinge die Darstellung der Situation. Am besten wurde sie ausgedrückt von einem kleinen Tisch, der in der hinteren linken Ecke stand. Ein rosa Deckchen lag auf der Tischplatte, auf der Decke war ein Teller abgestellt und auf dem Teller lagen eine halbe Scheibe Brot und zwei oder drei Salatblätter. Die Reste sahen aus wie die Mahlzeit von jemand, der buchstäblich während des Essens weggestorben war. (Kassiererinnen, S. 88)

Dass Genazino in Bildern denkt und schreibt, ist nichts Neues und das vermutlich prominenteste Beispiel für einen symboltragenden Ort gibt vermutlich das Blätterzimmer aus Ein Regenschirm für diesen Tag ab $\Leftrightarrow$ I.2.3 u. $\Rightarrow$ II.2.5). Dass einzelne Gegenstände dabei die Funktion von „Repräsentanten der ganzen Kultur“ (s.o.) übernehmen können, und dabei „die schwer zugängliche Sonderbarkeit von verflossener Zeit aus[drücken], die sich wunderlich in Gegenständen staut“ (Frauen, S. 54),185 mag exemplarisch die Beschreibung eines Fahrplanautomaten aus Abschaffel illustrieren:

Es fiel ihm ein großer Automat auf, vor dem einige Männer standen. Abschaffel stellte sich hinzu. Es war ein Computer, der vollautomatisch Fahrplanauskünfte gab. Der Automat hatte die Größe eines Türrahmens und war rot angestrichen; vorn blinkten verschiedene Lämpchen auf einer Schautafel. Der Automat erregte die Bewunderung der Männer; sie sprachen über ihn, und was sie sagten, war voller Begeisterung. „Er arbeitet, er arbeitet“, sagte einer der Männer mit vergnügter Stimme. [...] Ungläubig hielten die Männer die Papierbogen in der Hand und zeigten sie herum. Aus ihren Bemerkungen war zu sehen, daß viele eine Zugverbindung zu erfahren wünschten, die sie vorher schon an einem Auskunftsschalter erfragt hatten. Die Männer wollten nur die Maschine kontrollie- 
ren, und weil die Maschine dieser Kontrolle standhielt, wurde sie als prächtige Maschine eingestuft. Die Männer lachten. (Abschaffel, S. 117 f.)

Die Technik der elektronischen Fahrzeitermittlung ist zum Entstehungszeitpunkt von Abschaffel brandaktuell und dem Duktus nach spiegeln sich Technik- und Fortschrittsgläubigkeit in der Prüfung der Maschine wider, wodurch ein merkwürdiger Kontrast zum RAF-Deutschland einerseits, zur Technophobie bzw. zur Skepsis dem Neuen per se gegenüber der Hauptfiguren geschaffen wird.

Sie behielten das alte Gerät, weil es ein Gegenstand ihrer persönlichen Geschichte geworden war; damals, Ende der sechziger Jahre, hörten sie an eben diesem Radio gemeinsam die Frankfurter Hitparade, die jeden Donnerstag- oder Freitagabend gesendet wurde. Das einstündige Beieinandersitzen am Radio war so kitschig und doch so wirklich gewesen, so träumerisch und in seinen Folgen unausweichlich, daß das gemeinsame Hören und Sich-Anschauen wahrscheinlich einer der Gründe dafür wurde, warum sie später einander geheiratet hatten. (Ausschweifung, S. 10)

Bei Genazino „werden Dinge häufig zu Substituten menschlicher Probleme. In der Beschreibung des Alltäglichen wird so nicht nur die Kultur durch ihre Objekte thematisiert, sonder sie stehen als Stellvertreter für existentielle menschliche Fragen und kulturelle Hintergründe.“186 Der symboltragende Gegenstand ,Radio‘ bildet dabei als vergleichsweise kommunikatives Medium (Gemeinsamkeit; „Sich-Anschauen“) zunächst also einen Kontrapunkt zum häufiger als verdummendes und zum Schweigen bringendes akzentuiertes Massenmedium ,Fernsehen'. Damit einhergehend schafft es „das alte Gerät“, nicht nur irgendein Teil „ihrer persönlichen Geschichte“ etwa aus Gewöhnung - geworden zu sein, sondern gleichsam als Heiratsvermittler aufgrund geteilter Lebenszeit und ähnlich gelagerter Interessen. Dass sich ein derart symbolisch aufgeladener Gegenstand nicht ohne Weiteres durch ein neues Radio ersetzen lässt - geschweige denn gegen ein Digitalradio (vgl. Kein Geld, S. 72 f.) -, ohne mit dem Material- und Gebrauchswert auch den symbolischen wegzuwerfen (vgl. Fischer 2006, S. 12), ist nachvollziehbar.187 Wie deutlich einzelne Gegenstände ein Surplus an Bedeutung transportieren können, verdeutlicht eine an einen Werbeslogan erinnernde Selbstaussage Degens: „Als ich meinen Schlüsselbund in den Fingern hatte, spürte ich, daß diese Schlüssel mir etwas sagten, warm lagen sie auf meiner Handfläche“ (Laslinstraße, S. 130). Der Schlüssel öffnet nicht nur faktisch, sondern auch im übertragenen Sinne Türen - er verweist auf die damit verbundene Freiheit und den Abnabelungsprozess.

Dadurch übernimmt er bereits Anteile der Funktion der Symbolischen Selbstergänzung. In einem engeren Verständnis ist damit die durch Gegenstände (auch: kulturelles Kapital etc.) kompensierte Diskrepanz zwischen Selbst- und Idealbild ( $\Rightarrow$ II.2.1) gemeint. In dieser Definition wirksam werden etwa die Visitenkarten und der Siegelring von Abschaffels Vater, der an einem

186 Fischer: „Schläft ein Lied in allen Dingen“, S. 12.

187 Genazino spricht in seiner vierten Frankfurter Poetikvorlesung, „Von der Spielbarkeit der Angst“, bezogen auf Fremde Kämpfe und dem darin wiederfindlichen ,Kofferexperiment' von ,symbolischer Entsorgung' (vgl. Wilhelm Genazino: Von der Spielbarkeit der Angst. Vierte Vorlesung. In: ders.: Die Belebung der toten Winkel. Frankfurter Poetikvorlesungen. München/Wien: 2006, S. 65-86, hier S. 84; vgl. Krepold: Altern, Melancholie und Komik bei Wilhelm Genazino, S. 88). 
bestimmten Punkt seiner Vita mittels dieser die Kluft zwischen (faktischer) Bedeutungslosigkeit (mangelndes symbolisches Kapital) und gefühlter bzw. gewünschter gesellschaftlicher Stellung zu neutralisieren sich bemüht hat (vgl. Falsche Jahre, S. 432 f.). Fasst man Selbstergänzung etwas weiter und nimmt diejenigen Gegenstände hinzu, die als Verkörperung von Teilen des Selbstkonzepts gelten können, treten leitmotivisch eingesetzte Dinge wie ein verlorener Kreisel in Genazinos Leise singenden Frauen auf den Plan. Mit diesem verbindet der Ich-Erzähler erneut mannigfache Erinnerungen, ${ }^{188}$ zugleich reizt er ihn immer wieder zum Nachdenken:

Leider habe ich meinen Kreisel verloren oder irgendwo liegenlassen. Es ist mir unerklärlich, wie das geschehen konnte. Der Kreisel hatte eine vergleichsweise lange Mittelachse und eine breiten hölzernen Körper. Aufgrund dieser Konstruktion hatte er eine überproportionale Schwerkraft und beschrieb, wenn ich ihn auf einem Tisch kreiseln ließ, knappe enge Ellipsen. (Frauen, S. 12)

Mit dieser Einführung werden dem Kreisel in einem ersten Schritt die Standardwerte des Prototypen abgesprochen („vergleichsweise lange“; „überproportional[]“), sodass er sich vom technisch reproduzierbaren Massenprodukt zum Quasi-Unikat wandelt. Hinweise auf den emotionalen Bezug zum Kauf, erste Erinnerungen an die Außenwirkung auf andere Menschen sowie Mutmaßungen zum Verlust (vgl. Frauen, S. 12 f.) laden ihn peu à peu mit Bedeutung auf und kennzeichnen die Wichtigkeit dieses nur scheinbar banalen Gegenstands für den Erzähler. Der Kreisel übernimmt darüber hinaus gliedernde Funktion für den nur aus eher lose miteinander verknüpften Kleinteilen bestehenden Text, indem jener die Motivation stiftet, die Wohnung zur Suche zu verlassen: „Natürlich möchte ich meinen Kreisel wiederhaben. [...] Aber in welchen Straßen bin ich gelaufen, in welchen nicht?!“ (Frauen, S. 13) Allerdings handelt es sich zum Teil auch nur um eine dankbare Gelegenheit, weitere Beobachtungen auf seinen Streifzügen anzustellen, denn erst viele Erlebnisse, etwa eine Stunde erzählter Zeit und gute zehn Druckseiten später spielt der Kreisel wieder eine Rolle: „Zum erstenmal streift mich die Idee, es sei nicht wichtig, ihn wiederzufinden. Viel angenehmer ist, in der Stadt etwas verloren zu wissen, nach dem ich trotzdem immer wieder suchen kann." (Frauen, S. 25) Spätestens diese Formulierung legt es nahe, den Kreisel als Selbstergänzung zu begreifen: als symbolischen Teil des Protagonisten, der immer wieder neue Suchen rechtfertigt. Die beruhigende Kraft, die der Kreisel auf ihn ausgeübt hat, veranlasst ihn wenig später auch dazu, festzustellen: „Nein, ich will ihn doch wiederhaben!“ (Frauen, S. 28) Ein ähnlich selbstergänzendes und auch in Bezug auf die engere Definition passenderes Leitmotiv, das genaugenommen funktional einem Dingsymbol gleicht, stellt der Roman aus Eine Frau, eine Wohnung, ein Roman dar: Titelgeber, Lebenstraum, Verheißung versinnbildlicht er; Menschen, die an einem schreiben, werden verklärt: „Zum zweiten Mal an diesem Abend traf ich auf einen Menschen, der an einem Roman arbeitete. Es entstand dadurch das Gefühl, an einer beträchtlichen Bedeutsamkeit teilzuhaben." (Wohnung, S. 42) Wenn Wei-

188 Vgl. für die Möglichkeit, sich über Gegenstände verloren geglaubter Erlebnisse zu entsinnen, etwa Obdachlosigkeit, S. 115. 
gand im weiteren Textverlauf eine Parallelisierung von Ekstatisch-Rauschhaftem und Literatur bis hin zur Bevorzugung eines Kultur-Radiogesprächs im Vergleich zum Beischlaf heraufbeschwört, nimmt es nicht wunder, dass die beiden letzten Sätze des Romans metaleptisch mit dem geplanten genialischen Abfassen von Literatur in Literatur - und romanspezifisch positiv enden: „Ich zweifelte nicht, daß ich mich in einem ungeschriebenen Roman bewegte. Ich sah auf mein Frühstück herunter und wartete auf das Aufzucken des ersten Wortes.“ (Wohnung, S. 160) Was für die Gegenstände gezeigt werden konnte, nämlich, dass sie neben Fischers Kategorien von Projektionsfläche und Repräsentantenfunktion zusätzlich das Selbst ergänzende und erweiternde Bedeutungsanteile ,verkörpern' können, gilt in besonderem Maße auch für Kleidung. Mehr noch: An diesem Zeichensystem lässt sich wiederkehrend die Theoriesättigung der Genazino'schen Romane demonstrieren.

\section{KLEIDUNG}

Dass Genazinos Figuren ein ambivalentes Verhältnis zu Kleidung generell haben und Genazinos Romane nicht ohne die Thematisierung von Kleidung auskommen, ist weithin spätestens durch den Schuhtester aus dem Regenschirm der Allgemeinheit bekannt. Acht Rezensenten wählen für ihre Besprechungen zu diesem Roman dezidiert den Terminus ,Schuhtester' oder naheliegende Derivate im Titel. ${ }^{189}$ Allerdings beschränken sich die literarischen Reflexe von Kleidung nicht nur auf Schuhe, wie es insbesondere Christian Krepold 2009190 und Anne Schmuck $2011^{191}$ überzeugend herausgearbeitet haben, doch dazu erst nach einer kurzen Verweilpause beim Schuh. Mitnichten hätte Genazino diesen Mischpultregler erst im Roman Ein Regenschirm für diesen Tag entdeckt; bereits Fuchs fachsimpelt: „Es waren seine Lieblingsschuhe, teure, weiche, italienische Stadtschuhe" (Ausschweifung, S. 51). Eine gewisse Vorliebe für Schuhwerk ist Flaneuren und Streunern ja ohnehin in die Wiege gelegt und so schwärmt auch Genazino im Interview: „Schuhe sind ja einfach großartig, ein Symbol wie überhaupt alles, was man am Leibe trägt." ${ }^{192}$ Bevor

189 Vgl. Heinz L. Arnold: Der Schuhtester. In: Schweizer Monatshefte 6 (2002), S. 46; vgl. Matthias Bischoff: Der Lauf des Schuhtesters. Wilhelm Genazino im Pariser Hoftheater zu Wiesbaden. In: Frankfurter Allgemeine Zeitung vom 24. April 2002; vgl. Katrin Hillgruber: Das Quietschen des Kunstleders. Wilhelm Genazino erzählt von Geld- und Liebesproblemen eines freiberuflichen Schuhtesters. In: Literaturen 11 (2001), S. 79 f.; vgl. Kristina Maidt-Zinke: Die Schuhwurzel. Wilhelm Genazino spannt den Regenschirm auf. In Süddeutsche Zeitung vom 04./05. August 2001; vgl. Iljoma Mangold: Probelauf in neuen Schuhen. Wer genehmigt dem Helden das Leben? Wilhelm Genazinos Roman „Ein Regenschirm für diesen Tag“. In: Berliner Zeitung vom 08. September 2001; vgl. Peter Mohr: Flaneur mit Luxusschuhen. Wilhelm Genazinos Roman „Ein Regenschirm für diesen Tag“. In: literaturkritik.de vom 09. September 2001. Online: <http://literaturkritik.de/id/4127>; vgl. Andreas Wirthensohn: Ein beschuhter Sisyphos oder die Wiederentdeckung des Flaneurs. „Ein Regenschirm für diesen Tag“ und die von Wilhelm Genazino zur Perfektion getriebene Wahrnehmung des Unbeachteten. In: Aargauer Zeitung vom 22. August 2001. Vgl. Krepold: Altern, Melancholie und Komik bei Wilhelm Genazino.

191 Vgl. Anne Schmuck: Poetische Doppelgänger. Bedeutung und Funktion von Kleidung in ausgewählten Romanen Wilhelm Genazinos. In: Bartl/Marx (Hg.): Verstehensanfänge (2011), S. 225-238. Hirsch/Genazino: Interview am 09. Februar 1998, S. 281. 
diese dann späterhin im Regenschirm-Roman ausgebaut werden zum Broterwerb qua Luxusschuhtesten (vgl. Regenschirm, S. 60 f.), haben sie einige prominente Auftritte auch im Roman Der Fleck, die Jacke, die Zimmer, der Schmerz, dem bezeichnenderweise einzigen Roman - neben dem jüngst erschienenen Roman Kein Geld, keine Uhr, keine Mütze (2018) -, der Kleidung im Titel trägt. In einer Szene, welche die Skepsis gegen Selbstdarstellung überhaupt $(\Leftrightarrow I I .1 .2)$ mit der abschätzigen Evaluation anderer $(\Leftrightarrow I I .4 .3$ u. $\Rightarrow$ II.4.4) und den bisherigen Ausführungen zur Kapitalstruktur (s.o.) in Berührung bringt, beobachtet, klassifiziert, verhöhnt der ca. 40-jährige W. einen jungen Mann, wobei ein Schuh und ein daran befindlicher weiterer symboltragender und in gewisser Weise selbstverräterischer Gegenstand einen nicht unerheblichen Anteil haben:

Die Hose des jungen Mannes ist makellos gebügelt, das Hemd ebenso, der Schal im Halsausschnitt sitzt wie modelliert. Weiße Manschetten schauen aus seinen Jackenärmeln heraus und geben den vorsichtigen Bewegungen seiner Hände eine dekorative Einrahmung. Die Jacke ist wie für seine Figur erfunden; nirgendwo eine Rutschfalte, nicht unter den Armen, nicht auf dem Rücken. Zum zweitenmal zieht er aus seiner linken Hosentasche ein weißes, unbenutztes Taschentuch heraus und betupft sich Stirn und Lippen. Vorsichtig schiebt er das Taschentuch in die Hosentasche zurück, damit in der Hose keine Ausbuchtung entsteht. Von Zeit zu Zeit blickt der junge Mann an sich herunter und freut sich an seiner einwandfreien Erscheinung. Auf den Mittelstücken der Sohlen seiner ebenfalls neuen Schuhe prangen noch die Preisschilder. Es sind kleine signalrote Aufkleberchen, die unverschämt aufdringlich unter den Schuhen hervorleuchten, sobald der junge Mann die Füße hochstellt oder die Beine übereinanderlegt. Die ersehnte Seriosität stellt sich nicht ein, man starrt auf den rot schreienden Sensationspreis der Schuhe. Zur Strafe dafür, daß er sich zu sehr mit den Waren gemein gemacht hat, wird er heimlich von ihnen verraten. Seine ganze Erscheinung: ein Sonderangebot. (Fleck, S. 45)

Der unverhohlene Spott für diese in den Augen des Betrachters zu glatte Erscheinung ${ }^{193}$ lässt sich nur vor dem Hintergrund verstehen, dass Genazinos Figuren eine fast zwanghafte Abneigung gegen die „neueste[] Mode“ einerseits, gegen Menschen, die sich „zu sehr mit den Waren gemein“ machen, andererseits hegen: „Nun gut, ich war nicht nach der neuesten Mode gekleidet, aber ich hatte es immer abgelehnt, zu den Männern zu gehören, die man früher Fatzkes und heute Fuzzys nannte." (Kassiererinnen, S. 19 f.) ${ }^{194}$ Dieser vorgeblichen Makellosigkeitsinszenierung gebricht es bei näherem Besehen nämlich an Herz und Seele der Kleidung, was besonders gut im Kontrast erhellt:

Plötzlich löst sich von meinem linken Schuh die Sohle; am Innenrand steht sie bis in eine Tiefe von drei Zentimetern leicht ab. Der gute Schuh! Ich schaue ihn an wie einen alten Bekannten und rede nur deshalb nicht mit ihm, weil zuviel fremde Menschen um mich herum sind. [...] Ich werde ihn schonen; ich werde ihn nicht zum Schuhmacher bringen. Lieber will ich beobachten, was aus ihm wird. [...] dann hätte ich einen Schuh, der mir zeigt, wie ich lebe und gelebt habe, einen Schuh, der erzählt, während ich gehe. (Fleck, S. 200)

Und damit lässt sich medias in res in die Diskussion der vorliegenden Sekundärliteratur einsteigen. Krepold verknüpft die Kleidung pointiert mit seinen eigentlichen Untersuchungsgegenstän-

193 Vgl. dazu: „Auch die anderen Besucher sahen ihm entschieden zu glatt und geputzt aus.“ (Ausschweifung, S. 121)

194 In diesem Zusammenhang ist auch auf die prinzipielle Abneigung gegen den Neukauf von Kleidung per se betreffend hinzuweisen: Abschaffel „war froh, sich keinen neuen Anzug gekauft zu haben; sonst hätte er diesen Herren vielleicht allzu ähnlich gesehen." (Sorgen, S. 310) 
den, „Altern, Melancholie und Komik bei Wilhelm Genazino und Italo Svevo“, fördert insbesondere hinsichtlich des Alterns von Mensch und Kleidung dabei aber auch generell Bedeutsames zutage. ${ }^{195}$ Wie auch Schmuck ${ }^{196}$ bezieht sich Krepold in großen Teilen auf eine zentrale Stelle aus Genazinos zweiter Frankfurter Vorlesung, „Metaphysische Westentaschen“, ohne die auch hier nicht gearbeitet werden kann:

Kleider bilden die Gestalt des Menschen nach. Ihre Menschenähnlichkeit flößt uns Vertrauen ein. Selbst alt gewordene Kleider sind, obwohl fadenscheinig und vernutzt, kein Müll. Sie drücken auch dann noch ihre Menschenähnlichkeit aus, sie sind Gestalt gewordene Repräsentanten und Stellvertreter derer, die sie einmal getragen haben oder immer noch tragen. Ältere Leute, die in alt gewordenen Kleidern umhergehen, gewinnen dadurch oft ein heroisches Moment, einen Impuls, der gegen ihren Untergang gerichtet ist, mithin gegen ihren Tod. Man merkt deutlich: Zwischen dem Träger und seinen Kleidern besteht ein affektiver Pakt, eine Art Beistandsabkommen. Es ist dann offenkundig, daß sich jemand von seiner Jacke oder von seiner Hose dabei helfen läßt, sein Leben immer wieder neu aufzubereiten oder diesem eine Form zu geben. Der Mensch altert in seinen Kleidern, die Kleider altern mit - und doch bleiben die Kleider hinter der Alterung des Menschen zurück. Mensch und Kleidung altern nicht im gleichen Rhythmus, nicht im gleichen Zeittakt. Viele Menschen ziehen aus der Empfindung, daß sie (sozusagen) stabiler altern als ihre Kleidung, einen beträchtlichen narzißtischen Gewinn: Zu ihrer Hose sagen sie dann: Meine gute alte Hose, und zu ihrem Mantel sagen sie: Ja, wenn ich dich nicht hätte! Wenn sie diesen Mantel nicht hätten, hätten sie einen anderen, aber das ist nicht gemeint. Gemeint ist: Wir haben eine gemeinsame Strecke des Alterns hinter uns, ich aber bin widerständiger als mein Mantel, ich bin altersresistenter. ${ }^{197}$

Krepold interpretiert diese Passage wie folgt:

Der Mantel mag der schneller alternde Doppelgänger seines Trägers sein, er ist jedoch auch [...] „Zeichen der Unsterblichkeit“. In Genazinos Buch Das Licht brennt ein Loch in den Tag gibt der Protagonist einen alten, inzwischen schäbig gewordenen Mantel, an dem er , wie an etwas Lebendigem hängt, in die Reinigung, holt ihn aber von dort nicht mehr ab. Doch geht er regelmäßig dorthin, um seinen Mantel durch das Schaufenster beobachten zu können: „Die Reinigung ist ein Museum, von dem niemand etwas weiß." Zu einem ähnlichen Kult artet bei Laura, der Lebensgefährtin des Erzählers, die Behandlung alter, abgelegter Kleidung aus: Meist zu Anfang des Sommers zieht sie diese an einem Tag für eine gewisse Zeit an, um eine „Art Verschmelzung mit früheren Identitäten“ zu vollziehen, was nach Genazinos Selbstinterpretation in seinen Frankfurter Vorlesungen „eine Art Einverleibung der Tragegefühle von Kleidungsstücken in die inneren Körpertatsachen eines Menschen“ bedeuten soll. Das ist dann [...] - gerade als „Aspekt der Ich-Erweiterung“ - der Versuch, die vergangene Zeit einzuholen und wieder lebendig zu machen, mithin das Altern zu überwinden, wobei die alte, abgetragene Kleidung sich als treuer Weggefährte des Menschen erweist. ${ }^{198}$

Anne Schmuck knüpft in ihrem Beitrag „Poetische Doppelgänger. Bedeutung und Funktion von Kleidung in ausgewählten Romanen Wilhelm Genazinos“ an diesen Gedanken an:

Wilhelm Genazinos Prosawerk ist vielfältig geprägt von Körper-Metaphern und deren enger Kopplung an die menschliche Kleidung. Immer wieder beobachten seine Protagonisten Menschen, deren Körperlichkeit offensichtliche Mängel aufweist und die in der Kleidung ihr Spiegelbild finden. [...] Die schadhafte Kleidung [...] verweist ebenso wie die sich in Selbstauflösung befindenden Unter-

\footnotetext{
195 Vgl. Krepold: Altern, Melancholie und Komik bei Wilhelm Genazino.

196 Vgl. Schmuck: Poetische Doppelgänger.

197 Wilhelm Genazino: Metaphysische Westentaschen. Zweite Vorlesung. In: ders.: Die Belebung der toten Winkel. Frankfurter Poetikvorlesungen. München/Wien 2006, S. 25-43, hier S. 27 f.

198 Krepold: Altern, Melancholie und Komik bei Wilhelm Genazino, S. 89.
} 
hemden des Protagonisten auf die Sterblichkeit des Menschen, gleichzeitig aber auch auf dessen beschädigte Identität.199

Insbesondere dieser andere Aspekt Schmucks, derjenige, der die „Relevanz menschlicher Kleidung für die Herausbildung personaler Identität“ betrifft, ${ }^{200}$ kann den (Un-)Sterblichkeitsgedanken veritabel anreichern:

Wie eng das Kleidungsmotiv mit der Identitätssuche der Genszino'schen Figuren verknüpft ist, zeigt sich schon in den frühen Texten des Autors. Abschaffel [...] findet wiederholt im Betrachten seiner Kleidung Trost und Stabilität; analog dazu bedeutet ihm die Trennung von seinen Kleidern den Verlust seiner Selbstsicherheit. 201

Anhand zweier Protagonisten fasst Schmuck ihre Ergebnisse zusammen:

Während der Erzähler in Ein Regenschirm für diesen Tag wiederholt das Bild seiner in ein Gebüsch geworfenen Jacke phantasiert, hat Gerhard Warlich in Das Glück in glücksfernen Zeiten das ihn rettende Bild bereits inszeniert, seine Hose schaukelt auf dem Balkon und verwittert dort als sein Gestalt gewordener Doppelgänger. Gemeinsam ist beiden Figuren nicht nur die Übertragung eigener Identitätsanteile in ihre Kleidungsstücke - und damit die Etablierung einer Doppelgänger-Existenz -, sondern vielmehr noch das Medium, mit dessen Hilfe sie diese Ich-Aufspaltung erfahrbar machen. [...] Der ,gedehnte Blick' schließlich, mit dem die Protagonisten die von ihnen inszenierten Bilder betrachten, ermöglicht den Ausweg aus der drohenden Identitätskrise und generiert gleichzeitig aus der bloßen Anschauung ihres Ichs heraus letztlich einen Akt der Kunst, der Rettung verspricht. ${ }^{202}$

Letztlich ist es eine Anspielung auf Oscar Wildes Dorian Gray unter umgedrehtem Vorzeichen: Genazinos Protagonisten werden mit der Zeit nicht rücksichtsloser und fallen der Dekadenz anheim bei gleichzeitiger Jugend, sondern sie altern selbst sichtbar und merklich, werden mut- und kraftloser und wollen sich dabei wenigstens zusehen können, um es zu begreifen. Die von Schmuck in Aussicht gestellte Rettung ist stets temporäre, nicht aber auf die Dauer mögliche.

Schmuck (und Krepold zum Ende des Zitats) verlässt sich allzu sehr auf die epitextuelle Einschätzung Genazinos: Es mag auf einzelne Kleidungsstücke und idiosynkratische, romanspezifische Lebensläufe der Protagonisten zutreffen - „Denn in Wahrheit ist aus der alten Jacke längst ein Trick gegen die Überfälle des Todesgefühls geworden. Ich brauche nur auf die beschädigten Ärmel zu sehen, und schon habe ich die mich besänftigende Gewißheit: Diese Jacke wirst du auf jeden Fall überleben“ (Einfalt, S. 141) -, (auf den Basistypus) verallgemeinern lässt sich diese Sicht indessen nicht. Man könnte viel eher dazu tendieren, den von Krepold nicht mehr zitierten Zusatz der Vorlesung auszudeuten:

Viele Menschen werfen auch schäbig gewordene Kleidung nicht weg. Sie kommen mit ihrer Kleidung überein, sie nur noch nicht-öffentlich zu tragen, das heißt zu Hause oder allenfalls bei Besuchen in Bierkneipen oder auf Friedhöfen, wo niemand auf Kleidung achtet. Den Toten ist es gleichgültig, wie wir angezogen sind. Ich behaupte: Wir bemerken diese Gleichgültigkeit der Toten und

Schmuck: Poetische Doppelgänger, S. 238. Vgl. für Ausführungen zu zerfallenden Unterhemden und deren Zeichenhaftigkeit Glück, S. 18.

201 Schmuck: Poetische Doppelgänger, S. 227. Vgl. für eine lieb und teuer gewordene Mütze auch Fleck, S. $90 \mathrm{f}$.

202 Schmuck: Poetische Doppelgänger, S. 238. 
sind über sie erleichtert. Endlich müssen wir niemanden mehr beeindrucken, nicht einmal uns selbst. ${ }^{203}$

Was bleibt, ist das Kleidungsstück, nicht der Mensch; der Mantel ist das „Zeichen der Unsterblichkeit". Wenn es hart auf hart kommt, man von der Schäbigkeit, Fadenscheinigkeit und Abgetragenheit der Kleidung einmal absieht und ,nicht-öffentliches Tragen' in Betracht zieht, so überdauert die Hose auf dem Balkon genauso wie die ins Gebüsch imaginierte Jacke mehr als nur eine Generation von basistypischen Protagonisten. Kurz: Obwohl Genazino und mit ihm seine Interpreten und in Teilen auch der Basistypus die Auffassung teilen, dass alternde Kleidungsstücke in irgendeiner Weise den eigenen Tod hinauszögern, abmildern oder in weite Ferne rücken lassen (Dorian Gray), handelt es sich lediglich um eine trostspendende Vorstellung - vielmehr ist die symbolische Handlung, den Mantel in die Reinigung zu geben, nicht nur mit einem Museum, sondern mit einem ,Altersheim ‘ür Kleidung verwandt, das sehr lange Belegzeiten hat. Wichtiger ist die kalkulierte Funktion von (alter) Kleidung als ,Veräußerlichung von Innerem', in der sie häufiger anzutreffen ist, und auch auf Schmucks Funktion der ,beschädigten Identität‘ verweist.

Sonja hatte mich schon oft aufgefordert, das Hemd (die Hemden) wegzuwerfen und neue zu kaufen, ich lehnte meistens ab und zog die vernutzten Hemden weiter an. Denn sie waren für mich die stummen Zeugen meines vielfachen und dennoch geheim bleibenden Scheiterns, die ich nur momentweise zu zeigen bereit war. (Regen, S. 111)

Das hat nichts mit Sterblichkeit zu tun, viel aber mit der ,Ich-Erweiterung: Vermittels der Kleidung sind nicht anders kommunizierbare innere Zustände veräußerbar. Nicht in der Funktion eines Memento mori, ${ }^{204}$ sondern als Ausdruck verdrängter Anteile des Selbstkonzepts kommen sie ,zum Tragen؛. Auch weitaus weniger weitreichende Erwägungen können qua Kleidung ihr Spiegelbild finden: „Das schwarze Hemd brauchte er zum besseren Ausdruck seines Totalargwohns." (Fremde Kämpfe, S. 212) Die kalkulierte Kleidungswahl205 in schwarzer Farbe soll die Grundstimmung nach außen explizieren. Vergleichbar ,Düsteres' hat der Protagonist aus Genazinos Wenn wir Tiere wären im Sinn: „Aber ich konnte ihr nicht deutlich machen, dass ich mich schon seit langer Zeit von der Welt abwandte und dass sich diese Abwendung (unter anderem) durch karge Kleidung darstellen und ausdrücken konnte." (Tiere, S. 149)

\footnotetext{
203 Genazino: Metaphysische Westentaschen, S. 28.

204 Vgl. Schmuck: Poetische Doppelgänger.

205 Vgl. als Gegenbeispiel des Kalküls: „Wie immer hieß, daß er irgendeine Jacke und irgendeine Hose trug, darunter irgendein Hemd." (Sorgen, S. 306) Dahinter lässt sich die wenig modebewusste Ausrichtung des Basistypus vermuten, die selbst wieder mit Gegenbeispielen konfrontiert werden kann: „Er hatte seine Schuhe geputzt und trug ein frisches Hemd und hatte ein Gefühl, als werde er von allen erwartet.“ (Falsche Jahre, S. 556 f.) Oder: „Obwohl mich meine verdreckte Kleidung geniert, merke ich doch, daß ich als kommender Finanzdirektor eine Spur gemessener nach Hause gehe als zuvor. Ich beschließe, mir in den nächsten Tagen einen neuen Anzug anzuschaffen." (Heimweh, S. 88)
} 
Wie bereits geläufig zeichnet sich Genazinos Mischpult nicht (nur) durch die Regler aus, sondern durch die Kopplung; und so ist auch derjenige für ,Kleidung' mit weiteren gekoppelt ${ }^{206}$ - etwa demjenigen für Unsichtbarkeit ( $\Rightarrow$ II.2.2 u. $\Rightarrow$ II.2.5):

Auch dann, wenn Gesa das Hotel verläßt, will sie das Gefühl der Behausung, und das ist die Gewißheit des Verstecks, mitnehmen dürfen. Ihr Motiv ist die Scham, ihr Interesse (deswegen) die Verhüllung. Der verbergende Sinn von Kleidung ist uns seit zweitausend Jahren ausgetrieben. Der sich den Kopf ganz und gar abdeckende Sokrates (im „Phaidros“) ist uns heute unverständlich. Wir übertragen der Kleidung nicht mehr die Aufgabe öffentlicher Selbstverheimlichung. (Fleck, S. 80 f.)

Nicht nur die Selbstdarstellung mittels Kleidung in aktiv-assertiven, sondern auch diejenige in passiv-protektiven Gefilden der Eindruckssteuerung sind folglich denkbar und wurzeln in einer langen Tradition, welche Genazinos Basistypus bereitwillig wiederaufleben lässt.

Zum Übergang werden drei Zitate, die das zur Kleidung Gesagte bündeln, in einer Weise arrangiert, die das Spannungsfeld von unscheinbar-alt und scheinbar-neu ausmessen und den Weg der Ich-Erweiterung umdrehen: Es muss nicht die Kleidung sein, die als zusätzliche Hülle und eigentlich zunächst sichtbare ,Haut' dem Betrachter etwas über das darunter befindliche Individuum vermittelt, sondern die (Wahl der) Kleidung kann in entgegengesetzter Richtung auch nach innen wirken. Die erste Station der verknappten Argumentation bildet eine Aussage, die der bereits referierten Skepsis gegenüber Neuem das Wort redet: „Ich zog den dritten Anzug an, der noch fast neu war und den ich deswegen nicht besonders mochte. In diesem tollen Ding kann ich mich glatt verloben, spottete ich und ärgerte mich darüber." (Außer uns, S. 26) Neues ist suspekt; gebietet nun aber die Situation, dass die zwei verbleibenden, nicht mehr ganz so neuen Anzüge inadäquat wären respektive erscheinen könnten, so wirkt sich die Selbst-Wahrnehmung als overdressed aus, als würde man die als Desiderat formulierte „Selbstverheimlichung“ Sokrates' nicht mehr kennen. Abschaffel hingegen ,trägt neu' und ,wirkt alt', wodurch einer aparten Contradictio in adiecto Vorschub geleistet wird: „Aber er sah auf seine Schuhe und seine frisch gereinigte Hose, er wollte weder das eine noch das andere beschmutzen und ließ den Ball liegen. Wie ein sturer alter Mann trottete er weiter und schämte sich und sah nicht mehr zurück." (Sorgen, S. 270) Just die gepflegte Erscheinung entpuppt sich als Hinderungsgrund, eine in Erwägung gezogene ,Jugendlichkeit' in die Tat zu setzen - im fadenscheinig gewordenen Sakko hätte es wohl was werden können. Als Quintessenz des CEuvres allzumal in puncto Selbstbild spricht das folgende Zitat Bände, für sich und den Basistypus generell: „Ich gefiel mir in meinen nicht mehr ganz frischen Kleidungsstücken. Ich sah aus wie ein aus früherer Zeit übriggebliebener Herr.“ (Tiere, S. 14) Ob immer wünschenswert oder nicht - es handelt sich um eine für das folgende Unterkapitel richtungsweisende und vor allem bezüglich des Figurenbasistypus exakte Einschätzung. 


\subsection{Einstellungen, Überzeugungen und (mangelnde) Weltanschauung}

Trotz der ambivalenten Positionen, die Genazinos Figuren zu Geld und Gegenständen, zu Lebensstilen und Luxus beziehen, zieht sich die tiefe Überzeugung, es mit einer maroden Kulturund Konsumindustrie ( $\Rightarrow$ II.1.3) zu tun zu haben, wie ein Ariadnefaden durch die Wirren der Figurenpsychen. Für eine vollgültige ,Figurenethik' reicht es zwar nicht - „Ich kam auf den Gedanken, dass man sich für das sogenannte normale Leben niemals eine Ethik zurechtlegen sollte“ (Außer uns, S. 96) -, aber von einer kritischen Weltanschauung, von bestimmten unumstößlichen Überzeugungen und Einstellungen lässt sich mit Fug und Recht sprechen.

Allerdings muss vorher eine diese Kritik trübende Filterfolie eingeschoben werden, die sich mit (euphemistisch formuliert) Fremderfahrung bzw. (drastisch gefasst) diskriminierenden und rassistischen Tendenzen befasst. ${ }^{207}$

\section{POLITISCH INKORREKTE RESSENTIMENTS}

Sind doch die Haupthandelnden nicht selten politisch inkorrekte oder bestenfalls ziemlich ,unpolitische' Figuren ( $\Rightarrow$ I.2.1 u. $\Rightarrow$ II.4.2): „Ach so, wieder ein Film über den Hunger. Einen solchen Film wollte Abschaffel heute abend nicht sehen." (Falsche Jahre, S. 506) Ohne 1979 von extensivem Zapping ausgehen zu dürfen, ist die Abwendung von zeitgenössisch-sozialkritischer TVLektüre zumindest zur Kenntnis zu nehmen. Unpolitisch par excellence ist die folgende Aussage: „Ich selbst schalte gegen 19.00 Uhr die Fernsehnachrichten ein. Die Informationen interessieren mich kaum, ich will nur das öffentliche Altern der Nachrichtensprecherinnen beobachten." (Liebesblödigkeit, S. 112) Wohingegen unsensibles Desinteresse - bis in die höchst problematische Wortwahl - an veritablen Problemen, die indes diejenigen des Protagonisten nicht sind, augenscheinlich wird an Beispielen wie dem folgenden: „Tatsächlich schaue ich mir den Film über Mischehen an, obwohl mich das Problem sowenig interessiert wie die Eifersucht schwuler Männer." (Liebesblödigkeit, S. 12) Auch die mehrfache Nennung von "Neger' (Falsche Jahre, S. 550 u. Fremde Kämpfe, S. 93) ist freilich zunächst durch den Zeitgeist versuchsweise zu entschuldigen späterhin finden sich vermehrt auch die Bezeichnungen ,Schwarzer' und ,Farbiger' (Kassiererinnen, S. 153) -, - dass das betreffende Individuum dann allerdings ein klischierter Drogenkurier sein muss (vgl. Kassiererinnen, S. 154), frappiert. Menschen mit Behinderung (vgl. Obdachlosigkeit, S. 115) und (vermeintliche) Ausländer bzw. Menschen mit Migrationshintergrund werden als Minorität ebenso pauschal ,abgewatscht': „[S]ofort schlägt mir süßliche Klingel-KlangelMusik entgegen. Guter Gott! Die tiefstehende Abendsonne macht allen Menschen gelbe Gesichter.“ (Regenschirm, S. 130) ,Positiv' hervorgehoben werden muss in diesem Ko- und Kontext allerdings auch, dass auf nicht-außergewöhnliche, da auf den ersten Blick in puncto Nationalität,

207 Vgl. für weitere Ressentiments, die auch zum Figurenbasistypus gehören, insbesondere ( $\Rightarrow$ II.4.2) für gemischte und $(\Rightarrow$ II.5.3) für frauenverachtende. 
Ethnie, Hautfarbe, sexuelle Orientierung etc. ,ähnliche‘ Mitmenschen, manchmal völlig fühllose Aussagen zielen: „Wahrscheinlich schlägt ein Mann eine Frau oder eine Frau ein Kind, und das an- und ausgehende Licht ist ein Hilferuf. Dennoch halte ich mich an das milde Kehrgeräusch und denke sonderbar ruhig: Schlagt euch! Meinetwegen! Macht immer so weiter!" (Obdachlosigkeit, S. 105) ${ }^{208}$ Diejenigen ,prosozialen` Ausnahmen, die sich finden lassen, sind derweil hauptsächlich auf Menschen getrimmt, die nicht offensichtlich vom ,Default-Wert' - aus der Sicht des Basistypus: weiß, deutsch und männlich - abweichen:

Als Kind schon hatte sich Wolf, wenn er arme Leute sah, ein perfektes Notprogramm ausgedacht, mit dem es jederzeit möglich war, aus schlechten Zeiten wieder gute zu machen. Alles, was offenkundig und in jedermanns Sinn überflüssig war und nur Geld verschlang, würde ersatzlos gestrichen (Fremde Kämpfe, S. 105). ${ }^{209}$

Vergleichbar hilfsbereit agiert der Protagonist aus den Kassiererinnen oder derjenige aus dem Roman Die Liebe zur Einfalt: „Dann werde ich sagen, daß ich die Hose, die Jacke und die Schuhe nicht mehr benötige und daß ich die Stücke wahrscheinlich wegwerfen werde, früher oder später. Dann soll Theo auf die Idee kommen, daß die Sachen gerettet werden müssen. Das ist mein Plan." (Einfalt, S. 153) Genazino (Figur) geht hier planvoll vor, um den durchaus bedürftigen Theo ,zu seinem Glück zu zwingen' - allerdings ist er ein alter Bekannter (und zudem deutsch und weiß und männlich), der auf die Sympathie des Protagonisten bauen und vertrauen darf. Die ,private‘ politische Inkorrektheit stellt aber nur bedingt einen Widerspruch dar zur ,linksgrünen', antikapitalistischen Sozialkritik.

\section{SOZIALKRITIK IN FORM DES ,ANTI-' ODER: KONSERVATIVE AUSSTEIGER...}

Gemäß der Metapher des Pendels ( $\Rightarrow$ I.2.1), derzufolge Genazino immer wieder zwischen unpolitischen und politischen Büchern oszilliere, existieren Figurendarstellung beider Seiten ebenso wie Zwischenpositionen: „Jetzt habe ich doch wieder die Gesellschaft kritisiert! Immer will ich mich zurückhalten, aber dann verliere ich die Beherrschung und falle zurück." (Regenschirm, S. 18) Dem Ich-Erzähler lässt sich also durchaus ein politisches Interesse testieren, das er sich jedoch selbst verbietet. Ganz anders der Ich-Erzähler aus Die Liebesblödigkeit: „Ich ermahne mich, mich mehr für Wirtschaft und Globalisierung zu interessieren.“ (Liebesblödigkeit, S. 16) Er ist nicht unreflektiert a-politisch, aber glaubt für sich die Notwendigkeit erkannt zu haben, dass Nachbesserungsbedarf bestehe. Da politische Bildung nicht zwangsläufig in Agitation gipfeln muss - und vice versa - und auch politisches (Des-)Interesse per se keinesfalls mit der (Un-)Zufriedenheit die Gesellschaftsordnung betreffend zusammenhängt, wundert es um desto mehr, dass Genazinos Figuren - ob politische oder unpolitische; kapitalstrukturell mehr oder weniger

\footnotetext{
208 Allerdings wird dieser Gedanke später aber aufgegriffen und entkräftet (vgl. Obdachlosigkeit, S. 112); vielleicht weil es die Identifikation von Leserinnen und Lesern mit der Figur zu sehr erschwert hätte ( $\Rightarrow I .2 .3)$. 
,bessergestellte‘ $\Leftrightarrow$ II.2.5) - in der Breite sozialkritische Ansichten hinsichtlich Konsum, Kapitalismus und Bürgerlichkeit vertreten:

Die Motivik der Konsumkritik ist bei Genazino in praktisch jedem Text zu finden. Sie findet Ausdruck in der Solidarität mit Armen und Ausgestoßenen, in der Verhöhnung des marktwirtschaftlichen Apparates und seiner Teilnehmer und in Form der Außenperspektive, die stets Teil der IchErzählernaturen ist. Sie sind entweder momentweise gar nicht Teilnehmer des Konsums oder aber sie thematisieren ihre Teilnahme am Konsum mit Distanz und Skepsis. ${ }^{210}$

Dem ersten Teil der Zusammenfassung („entweder“) scheint ein Problem innezuwohnen, da die Nicht-Eingebundenheit in Konsumzusammenhänge noch nicht letztgültig etwas zur Einstellung der Figuren zu dieser beiträgt. Der zweite Teil der Zusammenfassung („oder aber“) ist in der Tat von Laslinstraße an gegenwärtig und belegt als Baustein/Element am Mischpult $(\Rightarrow$ I.2.2) einen festen Regler. Für Axel Degen schon ist

die Idee, daß man sich einen Schirm kaufen konnte, der einem gefiel, [...] neu, für mich hatte ein Schirm nur einen Zweck, er brauchte nichts und niemanden zu repräsentieren. Aber wir waren schon beim nächsten Schaufenster, Glasrechtecke, spiegelnde und blankgeputzte für Sonntagsmenschen, Anstalten für die Bestätigung des eigenen guten Aussehens, Wunschfabriken, hier Schirme, dort Pelzmäntel, Illusionsinstitute, Geschmackslenker, Kanäle der Eigentumsbildung. (Laslinstraße, S. 164)

Für Flaneure bzw. Streuner sind Schaufenster unabwendbare Bekannte im Stadtbild und das Feilgebotene dokumentiert und repräsentiert den Zeitgeschmack - mindestens lange Jahre lang. Als Gegenbeispiel fungieren bei Genazino die ,veralteten' Auslagen in im Sterben befindlichen Kleinstadt- oder Dorf-Läden, die ein Bild der Vergangenheit ausstellen. Degen verweigert sich nicht einzelnen Produkten, sondern der Maschinerie des Konsumkapitalismus generell, „die jedes Problem mit einem Neukauf aus der Welt zu schaffen gewohnt ist" (Regen, S. 107), wie es der Protagonist aus Bei Regen im Saal auf den Punkt bringt. Auch die Hauptfigur aus Die Liebesblödigkeit steht dem Konsum höchst kritisch gegenüber, was bei folgendem Selbstzweifel angesichts der „Illusionsinstitute, Geschmackslenker, Kanäle der Eigentumsbildung“ nicht vergessen werden darf:

Ich betrachte im Schaufenster der Badeboutique die goldglänzenden Wasserhähne, die Blumenmuster auf den zierlichen Porzellanbecken, die zitronengelben Naturschwämme und empfinde die Fremdheit zwischen den Dingen und mir. Du wünschst dir nicht genug, du kaufst nicht schnell genug und du wirfst nicht schnell genug weg! Immer wieder brechen lange Konsumstockungen in dein Leben ein und trennen dich vom Denken der Mehrheit! (Liebesblödigkeit, S. 152 f.)

Der Bogen zum Schlaglichtbeginn ( $\Rightarrow$ II.1.1) wird hier geschlagen: Zwar ist das „Denken der Mehrheit" eigentlich genauso verhasst, wie es die Gesellschaft insgesamt ist, aber: „Es ist nicht einfach, ein einzelner zu sein." (Heimweh, S. 7) Die Selbstvorhaltungen sind dabei allerdings unverkennbar solche, die er sich selbst anstelle ,des Systems zuruft, denn „die Fremdheit zwischen den Dingen und mir" spricht eine ganz andere Sprache. Einen immer wieder angeführten Erklärungsansatz, der hinsichtlich der fast verschwörerisch anmutenden Fremdbestimmung durch- 
254 - Teil II: Schlaglichter 1. Innenwelten - Außenwirkungen

aus sogar über Adorno hinausgeht, führt der Protagonist aus Mittelmäßiges Heimweh auf den Lippen: „Unsere Gegenwart ist die Wiederholung der Nachkriegssituation. Jetzt sollen wir nicht merken, daß wir uns durch unsere sinnlosen Konsum-Exzesse ein zweites Mal ruinieren." (Heimweh, S. 73) Zwar hat es etwas Apartes, den Konsumzwang als einer fremden Macht entspringenden anzusehen, aber es ähnelt dann doch einer etwas wohlfeilen Schwarz-weißMalerei.

Nicht nur die „Konsum-Exzesse“ werden mit dem Zweiten Weltkrieg enggeführt, auch die als Bedrohung empfundene Erlebnisgesellschaft wird mit an eine Machtergreifung erinnernder Rhetorik als Unvermeidbarkeit dargestellt: „Der neue Faschismus kommt in der Maske der permanenten Massenunterhaltung auf uns zu." (Liebesblödigkeit, S. 47) Genazinos Figuren misstrauen Konsumkultur und Unterhaltungsindustrie gleichermaßen und sehen dabei die Schuld an der kulturellen Dekadenz - wie es Horkheimer und Adorno in der Dialektik der Aufklärung ebenfalls getan haben - zunächst als von oben kommende. Mit „,sollen“, „Konsum-Exzesse“, „Faschismus" und „Massenunterhaltung" durchschauen die Protagonisten aus den Romanen Mittelmäßiges Heimweh und Die Liebesblödigkeit allerdings den Mechanismus und werden selbst nicht, wie von der Frankfurter Schule befürchtet, für kritisches Denken blind. Die Verzweiflung und der Kulturpessimismus sind ihnen nichtsdestoweniger eingeschrieben: „Damals glaubten wir noch, uns gegen Fremdsteuerung, Medienübermacht und so weiter wehren zu können, guter Gott!“ (Heimweh, S. 102) In der Erzählgegenwart der Diegese also sind - so die naheliegendste Lesart Fremdsteuerung, Medienübermacht etc. nicht nur real, sondern gewissermaßen alternativlos geworden und auch wenn Wilhelm Genazinos Romanfiguren als Kritiker dieser Missstände auftreten, sind die anderen akut in Gefahr, von Konsum- und Erlebnisindustrie übermannt und willenlos gemacht zu werden, wobei die empfundene Glücksverheißung des Einzelnen genauso in die Kritik genommen wird wie die Akteure der Kulturindustrie selbst: „Ein Organisator ergreift ein Mikrophon und nennt das ganze Gelände die PARTYMEILE. [...] Es sind vermutlich die Leute, die Frau Balkhausen das Erlebnisproletariat genannt hat. Ich schaue mir die Menschen an und schaue sie nicht an. Ich kenne sie und kenne sie nicht.“ (Regenschirm, S. 169) Das „Erlebnisproletariat“ entspricht im ,Sinus-Milieu-Sprech“ der „spaß- und erlebnisorientierte[n] moderne[n] Unterschicht“, die seit einigen Jahren weiter (auch in die ,Mitte der Gesellschaft') wächst, und unter den Koordinaten BC23 als „Hedonistisches Milieu“ bezeichnet wird ( $\Rightarrow$ II.1.5/ $\Rightarrow$ Abb. 12). Angehörige dieses Milieus werden genauso geringgeschätzt, wie der Organisator einer „PARTYMEILE“: „Weshalb waren denn so viele Personen unterwegs? Änderte sich dadurch etwas in ihrem Leben?" (Falsche Jahre, S. 403) Kommt Abschaffel diese Frage bereits rhetorisch in den Sinn und ist bereits entschieden, so wandelt sich häufig die Form der Aussage in Feststellungen: „Er konnte Personen nicht leiden, die aus ihrem Leben ein Unterhaltungsprogramm machen mußten, damit immer irgend etwas passierte." (Ausschweifung, S. 178) Denn der Glaube der Hedonisten, „an diesem Tag werde sich der Alltag endlich mit jener Lebendigkeit anfühlen, die sie 
das ganze Jahr über erwarteten" (Außer uns, S. 8), wird im harten Kern der Einstellungen und Ansichten des Basistypus ein Irrglaube gescholten. Als Systemimmanenz und als Milieuspezifikum - und das scheint die einzig taugliche Sicht der Dinge zu sein - erkennt es der Protagonist aus Genazinos Eine Frau, eine Wohnung, ein Roman:

Es gab offenbar so etwas wie ein Kartell der Einfalt; dümmliche Leute lasen dümmliche Kritiken und sahen sich dann dümmliche Filme an. Seit einigen Tagen hatte ich in diesem Kartell eine leitende Stelle inne. Aber vielleicht waren viele Teilnehmer des Kartells nicht wirklich, sondern nur gespielt einfältig, weil sie nur so am riesigen Ertrag der Volksschlichtheit teilhaben konnten. Oder war überhaupt niemand dumm? Gab es ein allgemeines Vergnügen an der humoristischen Versimpelung des Lebens, das mir aufgrund meiner inneren Strenge nicht zugänglich war? (Wohnung, S. 83)

An der Grenze zur Tragik geht mit dieser eindeutigen Absage an die Kulturindustrie die Schuldhaftigkeit an dieser zugleich einher. Solipsistisch im übertragenen Sinne schließlich darf die fixe Idee genannt werden, ganz alleine, sozusagen radikalindividualistisch einer gesamten Gesellschaft gegenüberzustehen, die insgeheim großen Gefallen an der ,Dümmlichkeit' hat; und der fromme Wunsch, alles könne „nur gespielt einfältig“ sein, erinnert doch stark an Selbstrechtfertigungsbestrebungen, um das eigene Idealbild nicht gänzlich fahren lassen zu müssen $(\Rightarrow$ II.2.1). Teil und Kritiker dieses Systems zugleich zu sein, ist auch Degen genauso peinlich wie unvermeidbar, wenn er seiner Liebe Elke nicht abschlagen möchte, einige Erlebnisse an einem Samstag - dem Inbegriff des „Erlebnisproletariat[s]“ - anzusammeln, denn „aus Elkes Gesicht sprach der Samstag, der mich aufforderte, ihn nicht verstreichen zu lassen, ihn anzuhäufen mit Erlebnissen, also: Axel rutschte von seinem Barhocker herunter" (Laslinstraße, S. 189). Was in Laslinstraße 1965 vorgezeichnet wird, liest sich in Zeiten von Werbeslogans wie ,Du bist, was du erlebst', mit dem der ,Erlebnispapst' Jochen Schweizer ein erfolgreiches Leben an die Aneinanderreihung möglichst vieler Freizeiterfahrungen zu knüpfen sucht, nahezu visionär.

Es hängt nun bei Genazinos Figuren aber einiges davon ab, von welcher Warte aus, von welchem Milieu kritisch ,die Masse` beäugt wird. So ist die distinguierende Geringschätzung nicht notwendigerweise an ein ,Hedonistenbashing' gebunden. Auch ,höherwertige‘ Zweige der Kulturindustrie werden mit Kritik bedacht: „Die Kulturinstitute veranstalteten jetzt wieder Kammerkonzerte, Streitgespräche, Liederabende, Lesungen, Podiumsdiskussionen.“ (Außer uns, S. 114 f.) Zwar ist es ein Freud'scher Verleser des Verfassers dieser Arbeit, aber damit ist er mit Genazinos Figuren ja in guter Gesellschaft: An die Stelle der „Kulturinstitute“ lässt sich auch ohne größerer Aufwand die ,Kulturindustrie' setzen.

Neben der offenkundigen Absage an turbokapitalistischen Kaufrausch auf der einen, erlebnisgesellschaftliche Glücksverheißungen auf der anderen Seite, richten sich die Hauptfiguren auch hinsichtlich der Antibürgerlichkeit gegen das System. ${ }^{211}$ Alexander Fischer widmet sich 2012 in seiner Monografie Wider das System. Der gesellschaftliche Aussteiger in Genazinos Ein Regen-

211 Aber eben fast immer in Form des „stillen Protests“. Vgl. Roman Bucheli: Partisanen des stillen Protests. In: Neue Zürcher Zeitung vom 29. Juli 2014. 
schirm für diesen Tag und literarische Verwandte bei Kleist und Kafka der Fragestellung, „inwieweit die (Haupt)Figuren als Aussteiger gelesen werden können, wie sich deren Aussteigertum gestaltet und verändert und was ihre Beweggründe für den gesellschaftlichen Ausstieg sind." Mit den zwei hinteren Aspekten seiner Forschungsfrage beantwortet er bereits graduell den ersten dahingehend, dass man en gros - hier interessieren freilich nur Genazinos Figuren - von Aussteigern, die Fischer zwischen „mündige[n] Wesen par excellence“ und „Wirklichkeitsverweigerer[n]“ situiert, ${ }^{213}$ sprechen könne. Und demzufolge resümiert er schließlich auch, dass auf der Basis einer Minimaldefinition - „Ablehnung der Gesellschaft, ihrer Anforderungen und Grundanschauungen, speziell bezogen auf Gewinnstreben, Karrieredenken, Leistungsdruck, Konformitätszwang und Menschenfeindlichkeit"214 - auch Genazinos Ich-Erzähler als Aussteiger $\mathrm{zu}$ verstehen sei. Insbesondere folgende Zuschreibungen haben laut Fischer als Causal-HistoryElemente $(\Longrightarrow$ I.3.1) Gültigkeit für Genazino: „das Gefühl einer paradoxen Lebenslage“ sowie das „Grundgefühl der Entfremdung“. ${ }^{215}$ Als Rettung vor einer „informationsüberfluteten, konsumorientierten und sinnentleerten Umgebung“,216 so Fischer im Rückgriff auf Sartre, Luhmann und andere, flüchte der Protagonist durch Flanerie und Ironie vor den Verhältnissen, um sich schließlich existentialistisch gedacht „,,alternativ` einzurichten“:217

Der Protagonist verweigert sich der allgemeinen sinnentleerten Geschäftigkeit, gibt sich dem von der Gesellschaft geringgeschätztem Müßiggang und der genauen Beobachtung hin und wird so zum gesellschaftlichen Aussteiger [...]. [...] Der Aussteiger schafft sich so etwas wie seine eigene Blase, einen dritten Raum - die leidfreie Zwiespältigkeit - in dem er insofern zwiegespalten ist, als dass er einerseits mit einem Bewusstsein für eine gesellschaftliche Verankerung lebt, aber sich andererseits in seiner individuellen Aussteigerposition einrichtet. Mit einem buchstäblichen Durchschauen der Mechanismen findet er seinen Notausgang, so durchbricht er das System, aber verändert es nicht - es ist im Prinzip gegenteilig, er lebt auch davon. ${ }^{218}$

Was für den Regenschirm-Protagonisten zutreffen mag, ist vor dem Hintergrund des Ansinnens einer basistypischen Weichzeichnung $(\Rightarrow I .2 .5)$ und im Hinblick auf bereits Eruiertes $(\Leftrightarrow I I .1 .1) \mathrm{zu}$ relativieren. Denn in letzter Konsequenz wirkt der Basistypus Genazinos nicht nur deshalb systemstabilisierend, weil er nicht aktiv verändernd eingreift, sondern in Teilen auch aufgrund seiner eigenen ,Bürgerlichkeit':

Meine kleinbürgerliche Angst und die Überkontrolliertheit, die aus dieser Angst hervorgeht, hat niemals zugelassen, daß mein Leben in derartige Fahrwasser geriet, wofür ich plötzlich dankbar war. Ich fragte mich sogar, ob mein Leben es verdient, daß ich es immerzu mit dem Wort kleinbürgerlich verunglimpfe. Immerhin hat mich die sogenannte Kleinbürgerlichkeit bis heute vor derartigen Strudeln bewahrt. (Heimweh, S. 142 f.)

212 Fischer: Wider das System, S. 13.

213 Fischer: Wider das System, S. 11.

214 Fischer: Wider das System, S. 90.

215 Fischer: Wider das System, S. 91 u. S. 92; vgl. Cora Rok: „Wir spüren nämlich nichts mehr, werte Dame“ - (Selbst-)Entfremdung bei Melle, Genazino, und Von Steinaecker. In: La prose allemande contemporaine: voix et voices de la generation postmoderne 55 (2014), S. 111-126.

216 Fischer: Wider das System, S. 93.

217 Fischer: Wider das System, S. 95.

218 Fischer: Wider das System, S. 95 f. 
Es ist die auch von Fischer beobachtete Ambivalenz ${ }^{219}$ gegenüber der ,Leitkultur', nach der sich das Außenseiter- und Aussteigerpotenzial bei Genazino bemisst: momentweise ,verunglimpfend - „Der Kleinbürger möchte in seiner Bedürftigkeit wenigstens vor sich selber einen passablen Eindruck machen“ (Außer uns, S. 73) -, dann wieder „plötzlich dankbar“ und den bürgerlichen Milieus auf das Wärmste verbunden. Denn, wie bereits gezeigt werden konnte $\Leftrightarrow$ II.1.1 u. $\Rightarrow$ II.1.5), sind deutlich bestimmte Distinktionsbestrebungen erkennbar, welche durchaus bürgerlichen Sphären zugeordnet werden können, gerade dann, wenn Kunst und Kultur betroffen sind:

Für Menschen wie mich, die das Leben als bedeutsam empfinden wollten, gab es nicht viele Orte, wo sich diese Bedeutsamkeit ohne störende Nebengeräusche einlöste. Früher war ich öfter ins $\mathrm{Mu}$ seum gegangen, aber dort stieß ich mich an diesem den Leuten ins Gesicht geschriebenen Verlangen nach einem Kunsterlebnis, das sie sich als außeralltäglich zurechtmodelten. Aber im Vorraum sahen sie (und ich) den Andrang der Massen, mit denen sie (und ich) nichts zu tun haben wollten, weil das Museum inzwischen einem Kaufhaus ähnelte, worauf sich niemand einen Reim machen konnte. (Außer uns, S. 65)

In Hinblick auf den sich abzeichnenden Kontrast: Bürgerlichkeit vs. Aussteigertum ist es unvermeidlich, kurz auf Genazinos Dankesrede anlässlich des Erhalts des Büchner-Preises 2004, „Der Untrost und die Untröstlichkeit der Literatur“,220 einzugehen, wird doch in dieser eine Lanze gebrochen für die Langeweile, die einer künstlichen Ersatzbefriedigung gegenübergestellt wird:

Wir Heutigen kennen Langeweile als verscheuchte Langeweile. Unsere Erlebnisplaner haben sie zu unserem Feind erklärt. Als Ersatz bieten sie uns hochdosierte Fremdunterhaltung an: die permanente Fernsehshow, die Massenparty, der Urlaub, die Promiskuität, der Konsum - und so weiter. ${ }^{221}$

Bis auf die Promiskuität ( $\Rightarrow$ II.5.2) finden sich alle Ingredienzien der Kulturindustrie auch in Genazinos Romanen verteufelt. Bezeichnenderweise sucht Genazino in seiner Rede das Heil in der (Hoch-)Kultur:

Leonce und Lena hätten nicht verstanden, warum wir uns für die gute Laune von Thomas Gottschalk immer mehr interessieren als für die eigene Melancholie, obwohl diese mit uns auf dem Sofa sitzt. Sie hätten nicht verstanden, daß man eine afterworkparty aufsucht, wenn einem der IchZerfall zu nahe tritt.222

Damit ist der nur scheinbare Widerspruch bestmöglich beigelegt: Nicht die Gesellschaft ist der Feind, sondern die $U$-Kultur, die Spaß- und Erlebnisgesellschaft, repräsentiert durch „Chefredakteure, Programmdirektoren, Eventdenker, Kaufhauschefs“, „Planer von Freizeitparks, Loveparades, Expo's und all dem anderen Nonsens!"223 Daraus gilt es ,auszusteigen‘:

Sie genießt es, in der Kirche zwei Stunden lang Menschen um sich zu haben, die gerade nicht reden und nicht einkaufen, die keine Pommes frites kauen, kein Eis lecken, kein Auto waschen und nicht

Vgl. Fischer: Wider das System, S. 96 f.

Vgl. Fischer: Wider das System, S. 96 f.

Genazino: Der Untrost und die Untröstlichkeit der Literatur.

Genazino: Der Untrost und die Untröstlichkeit der Literatur.

Genazino: Der Untrost und die Untröstlichkeit der Literatur. 
258 - Teil II: Schlaglichter 1. Innenwelten - Außenwirkungen

telefonieren, keine Bierdose öffnen und nicht fernsehen, sondern still in einem hohen Raum sitzen und wie wirkliche Menschen aussehen. (Liebesblödigkeit, S. 99 f.)

,Wirkliche', nicht konsumexzessive Dumme, nicht erlebnishungrige Nimmersatte - das ist dann doch wieder ziemlich elitär und konservativ. Es kann sich selbstredend lediglich um einen möglichen Erklärungsansatz handeln, doch das prinzipielle ,Unbehagen an der (Post-)Moderne` ist nicht zuletzt dem mediokren und gleichzeitig ambivalenten Figurenbasistypus mit seinem Hang zur ,Frühvergreisung ${ }^{224}$ selbst anzulasten - es handelt sich immerhin um ,gemischte Charaktere'.

\section{...UND EIN ERKLÄRUNGSANSATZ DURCH (ELITÄRE) ,FRÜHVERGREISUNG"}

„Wir Heutigen gewöhnen uns lieber an die gequälten Gesichter der Massen, die aus der für sie erfundenen Billigkonditionierung nicht mehr herausfinden." 225 In der ersten Person Plural drückt sich just nicht aus, was gemeinschaftsstiftend üblicherweise damit gemeint ist, sondern es versteckt sich darunter genau Gegenteiliges: Sowohl Genazino als auch das Gros seiner Romanfiguren gehören dem ,Wir' gerade nicht an, sondern opponieren scharf gegen die kulturindustrielle „Billigkonditionierung“ der Unterhaltungsmaschinerie und diejenigen Menschen, die daran Gefallen finden können: „Susanne und ich plaudern über unsere Verwunderung, daß die zeitgenössischen Vergnügungen und die zeitgenössischen Menschen immer so gut zusammenpassen." (Regenschirm, S. 170) Böswillig ließe sich die Nähe zu C/Kalau ins Spiel bringen, aber die Sachaussage vermag dem ungeachtet und vor allem selbstironisch zu verdeutlichen, dass die Hauptfiguren häufig aus einer anderen Generation stammen oder zu stammen meinen - aus einer anderen Zeit. Sie kennen - unabhängig ihres fiktiven Alters - die Produkte und Gepflogenheiten der neuen noch nicht oder nicht mehr: „Es beschlich mich ein seit Kindertagen vertrautes Gefühl: dass ich vielleicht aus der Zeit herausgefallen war.“ (Tiere, S. 157) Diese viele Protagonisten einende Empfindung zeitigt diffus-emotionale - „Er konnte dann nur schwer fassen, daß inzwischen Menschen nachgewachsen waren, deren Entscheidungen und Lebenshaltungen er nicht mehr so recht einschätzen konnte" (Ausschweifung, S. 9 f.) - wie konkret-lebenspraktische - „In der Zeitung stieß ich auf Worte, die mir nicht bekannt (vertraut) waren“ (Außer uns, S. 113) - Folgen. Innerhalb dieser Anachronismen ist der Basistypus zu leben gezwungen: „Ein Plastikflugzeug hielt er für ausgeschlossen und unmöglich, aber für die Kinder war es eine sichere Sache." (Falsche Jahre, S. 413)

Allerdings sind Wilhelm Genazinos Romanfiguren nicht selten auch ganz einverstanden damit: „Ich fand es (heimlich) schön, hinter meiner Zeit zurückzubleiben (Urlaubsverweigerung).“ (Tiere, S. 42) Der Stolz, gegen die „hochdosierte Fremdunterhaltung“ (s.o.) vorzurücken, ist unüberhörbar und gipfelt in der bewussten

224 Vgl. Neumann: „Der letzte Strich des Flaneurs“, S. 161 ff.

225 Genazino: Der Untrost und die Untröstlichkeit der Literatur. 
Aufrichtung einer Verstehensgrenze; alles, was davor lag, verstand er, weil es ihn lebensgeschichtlich begleitet hatte, und alles, was jenseits der Grenze lag, wies er von seinem Verständnis ab, weil es ihm aus anderen Welten zu kommen schien, die er nicht kannte und nicht kennen wollte. (Ausschweifung, S. 216)

Es ist also nicht zwangsläufig ein Nicht-verstehen-Können, sondern mitunter auch ein Nichtverstehen-Wollen, das die Zeit in zwei Teilstücke schneidet: ,frühere' und ,heutige - dazwischen: Verstehensbarrieren. In etlichen Einzelbeispielen deklinieren Genazinos Romane diese Grundfigur durch, wobei sich überwiegend sozialkritische von überwiegend komischen Impetus sondern lassen. Als exemplarisch für erstere Prägung kann etwa gelten: „Und das erste, was er nicht verstand, war die Zeit, in der er lebte: es gab zwei Millionen Arbeitslose, aber es wurden keine Volksküchen eröffnet, sondern rätselhafte Schwulenläden, die keinen einzigen Arbeitslosen satt machten." (Fremde Kämpfe, S. 59) Eine gesinnungsunverfänglicher formulierte Probe der sozialkritischen ,Frühvergreisung“: „Er war gefühlsmäßig eingestellt gegen die Verlagerung so vieler Ereignisse des Alltags in die Kaufhäuser, das war alles." (Ausschweifung, S. 52) Als Unterkategorie findet sich das Aufwiegen von E- und U-Kultur: „Eckhard hatte Lust, die Erlebnisse seiner Kindheit zu verteidigen gegen die hochnäsige Geringschätzung der heutigen Fernsehkinder." (Ausschweifung, S. 212) Vorwiegend auf Komik aus sind Beispiele, die sich allzumal an alltäglichen Bedeutungswandel andocken:

Natürlich habe ich mir eingebildet, daß ich den kleinen lächerlichen Wortkrieg, den ich in einer Bäckerei [...] gegen eine dort arbeitende Verkäuferin führe, am Ende auch gewinnen werde. Ausgebrochen ist die Auseinandersetzung, als die Verkäuferin plötzlich dazu überging, anstelle des Wortes Brötchen das Kunstwort Krusti zu verwenden. Jedesmal, wenn sie Krusti sagte, setzte ich das alte Wort Brötchen dagegen und sah sie dabei unerträglich belehrend an. [...] Etwa eine Viertelminute lang war ich innerlich sprachlos und gestand mir ein, es war vergeblich, gegen die beiden Monster Zeit und Gegenwart anzusprechen. [...] Jetzt stapfe ich die dröhnende Friedberger Landstraße hinunter und suche nach einem anderen Laden, in dem das frühere Wort noch gilt. (Frauen, S. 146 f.)

Ganz ähnlich hatte schon der Abschaffel aus Falsche Jahre bemerkt: „Aber vielleicht gab es heutzutage schon jüngere Menschen, die Sahneleberwurst essen konnten. Er jedenfalls zählte nicht zu ihnen." (Falsche Jahre, S. 554) Die Abgrenzung von einem verderbten Ist-Zustand und die Hinwendung zu einem (wenn nicht unbedingt) besseren (, so doch erfassbareren) Früher wird durch Alltags-Komik abgemildert, wie am Beispiel der Artenvielfalt von Pfirsichen: „Ja, sage ich, seit Ihrer weißfleischigen Jugend! In meiner schon leicht angegilbten Jugend hat man diesen Unterschied noch nicht gekannt.“ (Liebesblödigkeit, S. 11) 226

Im krassen Gegensatz dazu steht die tiefe Resignation der Protagonisten, die desperat und hilflos - mitunter auch vom Alter - gezeichnet einer undurchschaubar gewordenen Welt gegenüberstehen: „Manchmal erschienen sie mit Jacken, die mit Nieten, Nägeln und Broschen beschlagen waren, und Abschaffel gestand sich ein, daß es jemanden geben müßte, der ihm diese Jacken

226 Als Ausnahme hat der Protagonist aus Kein Geld, keine Uhr, keine Mütze zu gelten, der „die vielen neuen Wörter, die ich in der Zeitung las, ebenfalls“ zu verwenden beginnt (Kein Geld, S. 38). 
erklärte." (Sorgen, S. 342) Gehäuft in der Öffentlichkeit auftretende Punks sind zur Entstehungszeit des Romans ähnlich überfordernd wie das „Kunstwort Krusti“ - eine zeitgenössisch ,frühvergreiste‘ Figur mit skeptischer Haltung gegen Neues muss sich überfordert fühlen: „Man hätte das Gespräch wie einen Zug anhalten und ihn bitten müssen, an einer für ihn passenden Stelle einzusteigen.“ (Sorgen, S. 263) Und so bleibt „ihm nichts anderes übrig, als sich halbherzig und verstockt irgendwie in den Lauf der Ereignisse einzufügen." (Sorgen, S. 349)227 Gemildert wird diese absolute Hilflosigkeit Abschaffels durch reflektiertere Positionen späterer Figuren:

Vielleicht ahnten Ruth und Eckhard auch, daß sie sich im Grunde nur gegen etwas wehrten, was es in ihrer eigenen Jugend nicht gegeben hatte und deshalb zu einem Markierungszeichen ihres eigenen Alters wurde: Es hatte keinen Sinn, rückwärtsgewandte Kämpfe auszutragen, für die es schon längst keine Schauplätze mehr gab. (Ausschweifung, S. 75 f.)

Was hier metaphorisch als ,Frühvergreisung' konzeptualisiert worden ist, wird in den Romanen Genazinos ab und zu gar als Wunsch ausgestellt:

Ich hatte schon längst bemerkt, dass ich selbst alt sein wollte, weil mir die Lust an jeder Art von Arbeit abhanden gekommen war. Ich sehnte mich nach Ruhe und Untätigkeit. Ich musste diese Sehnsüchte verheimlichen, weil sie mir altersmäßig noch lange nicht zustanden. Ein Mann, der nicht Tag für Tag arbeiten will, gilt als unmännlich. Angeblich sollte ich mich jetzt in den besten Mannesjahren befinden. (Tiere, S. 44)

Als Absage an den Jugendlichkeitswahn des Alter(n)s wird der verfrühte Starrsinn als Desiderat gesetzt: „Denn genaugenommen ist Altern ein Zustand, der zu mir paßt. Altern ist nur ein anderes Wort für Unwilligkeit, und unwillig war ich schon als Kind.“ (Liebesblödigkeit, S. 144) Selten gehen dann auch tatsächliches Figurenalter und ,Vergreisung' gedacht als „Unwilligkeit“ Hand in Hand: „Jedenfalls war mir unklar, was ich inmitten der schnellverderblichen Welt noch anfangen sollte." (Regen, S. 24) In Genazinos Kein Geld, keine Uhr, keine Mütze ist der ,Abschied' von der Welt am weitesten vorangeschritten, insofern der Protagonist sich zunehmend desinteressiert daran zeigt, „ob es draußen Frühling oder Herbst oder sonst was war.“ (Kein Geld, S. 64; $\Rightarrow$ II.5.6) Der Opposition gegen Konsum-, Erlebnis- und Warenwelt, die als beständiges Merkmal des Genazino'schen Figurenkosmos festgehalten werden kann, gesellt sich eine im Vehikel der Frühvergreisung reisende, durchaus elitär-konservativ zu nennende Attitüde bei, die sich als ,Aus-der-Zeit-gefallen-Sein' und vielleicht auch mit dem ,In-die-(Waren-)Welt-Geworfensein` bezeichnen lässt. Zudem ist zu konstatieren, dass Bürgerlichkeit zwar bspw. in Form der Fantasie-Berufe $(\Rightarrow$ II.3.4) subversiv unterlaufen wird, die Liebäugelei mit derselben aber nie ganz abbricht und nur ein Konglomerat bestimmter ,U'-Lebensstile ( $\Rightarrow$ II.1.5) den Wunsch nach einem Bruch mit der Gesellschaft erzwingt. Fischer bleibt insofern beizupflichten, als der Genazino'sche Basistypus das System nicht gutheißt, in seiner ,Früher-war-alles-irgendwie-doch-schonbesser'-Lebenseinstellung aber auch an durch und durch noch kapitalistischeren, bürgerlicheren

227 Vgl. für eine Form des nonverbalen Anachronismus: „daß Abschaffel sich die Ohren zuhalten mußte. Niemand hielt sich die Ohren zu, und Abschaffel spürte, daß er sich unpassend verhielt." (Falsche Jahre, S. 503) 
etc. Gesellschaftskonzepten festhalten möchte, obwohl diese Zeit nun einmal unwiederbringlich vergangen ist. In der Kritik der Verhältnisse allerdings lässt sich ein Aufbegehren feststellen, das es Genazinos Figuren jedenfalls im Falschen ${ }^{228}$ gefühlt richtiger zu leben erlaubt.

Zum Abschluss des ersten Schlaglichts lässt sich der Schichtenkreis der Figuren $(\Rightarrow I .2 .5)$ mittels der Ergebnisse ausfüllen:229 Im ,harten' Hardcore finden sich strenggenommen höchstens die ,Big Five': introvertiert, sozial verträglich, gewissenhaft, neurotisch und offen $(\Rightarrow I I .1 .3)$, wobei die Zugehörigkeit zum innersten Zirkel nicht für alle in Stein gemeißelt ist ( $\Rightarrow$ II.1.3).

Die Wichtigkeit analoger, nonverbaler Kommunikation und die vielfache Funktion von ,Schweigen' ist derart breit im CEuvre Genazinos verstreut, dass man geneigt sein könnte, von einer dem Figureninnenkreis angehörigen Dimension zu sprechen ( $\Rightarrow$ II.1.4). Allerdings gibt es zu gravierende Unterschiede in der jeweiligen literarischen Verarbeitung etwa hinsichtlich des Unsagbarkeitstopos (hier: literaturwissenschaftliche Begriffsverwendung), als dass dies nicht einer voreiligen Verallgemeinerung gleichkäme. Weiterhin braucht der Basistypus die Gesellschaft, kritisiert sie aber zugleich, ohne dass er dabei wirklich aktiv tätig werden würde und ohne dass er sich klar positionieren ließe ( $\Rightarrow$ II.1.1). Gerade der letzte Aspekt spiegelt sich in der ,Anti-'Haltung der Protagonisten wider, die chronisch unzufrieden sind, sich jedoch selten bis nie wirklich wahrnehmbar ,gegen das System‘ stellen $(\Leftrightarrow$ II.1.6). Vielmehr wählen sie den Standpunkt einer eingebildeten Frühvergreisung, der nicht zuletzt einen Schutzraum, einen - in Analogie zum ,Welpenschutz' vielleicht: - ,Greisenschutz‘ ermöglicht ( $\Rightarrow$ II.1.6). Generell sind Genazinos Figuren familienähnlich dadurch gekennzeichnet, dass sie eine ambivalente Einstellung zur Selbstdarstellung per se und zur ,kleinen Lüge' im Besonderen haben ( $\Rightarrow$ II.1.2), was sich an uneinheitlichen moralischen Richtschnüren und unterschiedlich ausgeprägten Vorlieben für Mythomanie etc. zeigen lässt. Auch die Einzelbestandteile der Merkmalslisten sind eindeutig immer mindestens zwei Figuren zuzuweisen, in den seltensten Fällen aber diskutabel für den Hardcore, da sich immer wieder Ausreißer finden, die der Unordentlichkeit, der Bescheidenheit etc. als universellem Label das Recht entziehen -bis auf Überempfindlichkeit, Kompliziertheit und wenige weitere $(\Rightarrow$ II.1.3). Die mangelnden Sozialkompetenzen hingegen ließen sich dann in den Figurenkern verschieben, wenn nicht die Ausprägungen und die jeweiligen Kompetenzfacetten, an denen es mangelt, höchstens familienähnlich, teils sogar idiosynkratisch genannt werden müssten

228 Vgl. Claudia Stockinger: Das Leben ein (Angestellten-)Roman. Wilhelm Genazinos Ästhetik der Wiederholung. In: Arnold (Hg.): Wilhelm Genazino (2004), S. 20-28.

229 Hier wie an allen anderen Kapitelenden wird keine vollgültige Zusammenfassung des Bisherigen geliefert, sondern es werden ,lediglich' die Ergebnisse bündig hinsichtlich der Figurenschichten sortiert. Erzähltechnische Besonderheiten bleiben dabei ebenso unterbelichtet wie der dezidierte Bezug zu den weiteren erkenntnisleitenden Fragestellungen hinsichtlich IM etc. ( $\Rightarrow$ I.1). Auch auf die erneute Nennung der maßgebenden Sekundärliteratur wird jeweils verzichtet. Außerdem hat die Einordnung jeweils nur Gültigkeit für das untersuchte Schlaglicht. 
262 - Teil II: Schlaglichter 1. Innenwelten - Außenwirkungen

( $\Rightarrow$ II.1.3). Als immens wichtige Analysekategorie hat sich die Kapitalstrukturanalyse herausgestellt: Viele Ansatzpunkte sind im Bereich der feinen Unterschiede anzutreffen; die Lebensstile und ungleichen Kapitalakkumulationen sowohl der Figuren untereinander als auch zwischen tatsächlichem Kapital und gewünschtem Ideal klaffen auseinander und auch hinsichtlich der symboltragenden und/oder selbstergänzenden Gegenstände sowie der Kleidung lassen sich Verstehensfortsetzungen behaupten $(\Leftrightarrow$ II.1.5).

Im romanspezifisch-individuellen Distrikt hingegen sind Namen, Alter und Berufe einzusortieren; dort finden sich auch die ,Ausreißer' hinsichtlich herausragender körperlicher Merkmale ( $\Rightarrow$ II.1.4). Die Ausnahme einer einzigen Protagonistin codiert den familienähnlichen Bereich nachträglich männlich. 


\section{Im Auge des Betrachters}

„die Schande des Besichtigtwerdens“ (Fremde Kämpfe, S. 251)

Hat das erste Schlaglicht recht besehen das figurencharakterliche Fundament für die weitere Arbeit erhellt, verhandelt das zweite die idiosynkratische (Welt-)Wahrnehmung und -Verarbeitung des Basistypus-Protagonisten und konzentriert sich dabei hauptsächlich auf die Ästhetik des Sehens. Nicht zufällig hat sich Genazino breit dazu geäußert, ${ }^{1}$ nicht zufällig die Sekundärliteratur in diesem Feld einen Anker gesetzt und Aspekte wie ,Beobachten und Beobachtetwerden', ,Voyeurismus' uvm. hervorgekehrt - die Figuren Genazinos sind ausgeprägte ,Augentiere'.2

Üblicherweise versucht die titelgebende idiomatische Wendung in wenige Worte zu fassen, dass der Betrachter (durchaus rezeptionsästhetisch gedacht) an der Schönheit o. Ä. einer Person oder einer Sache einen mindestens ebenso großen Anteil hat wie diese selbst. Für das vorliegende zweite Schlaglicht umfasst diese Bedeutungsvariante allerdings nur eine Facette; es handelt sich vielmehr um einen ganzen Fächer an Blicken, den aufzuschieben und einzeln abzuhandeln der Mühe lohnt.

Zunächst geht es um den Blick der Protagonisten auf sich selbst, auf ihr Selbst, allerdings auch um die bei anderen existierenden Bilder und Vorstellungen von ihnen, wenn der Komplex von Selbst-, Fremd- und Idealbildern bei Genazino untersucht wird ( $\Rightarrow$ II.2.1). Darüber hinaus wird die manische Beobachtung qua ,gedehntem Blick‘ auf die Außenwelt ( $\Rightarrow$ II.2.2) näher analysiert: Genazinos Protagonisten können nicht anders: Sie sind „Blick-Künstler[]“.3 Drittens findet sich die eingangs erwähnte, naheliegendste Bedeutungsdimension: Zumal im Unterkapitel, das die Konstruktion und Interpretation von ,Welt' in den Blick nimmt ( $\Rightarrow$ II.2.3), ist es der nach außen gerichtete Blick des Beobachters und also der Hauptfiguren, der allerdings im übertragenen Sinn verdeutlicht, dass es im Auge der Hauptfigur liegt, wie die Welt gedeutet wird. Viertens ist der (imaginierte) öffentliche Blick auf das Selbst gemeint ( $\Rightarrow$ II.2.4), der auf das Tun der Protagonisten einen nicht unerheblichen Einfluss hat. Spielarten des tatsächlichen und/oder eingebildeten Beobachtetwerdens, aber auch die psychologische Unterfütterung dieser Grundtendenz des Genazino'schen Basistypus müssen hier verhandelt werden. Frei nach dem Motto: ,Ich will schauen, aber nicht geschaut werden', bemühen sich die Figuren fünftens regelrecht um den Status der ,Un-Sichtbarkeit', insofern der Elaborationsgrad von Strategien zur Vermeidung/Unsichtbarkeit etc. beachtlich ist $(\Leftrightarrow I I .2 .5)$. Zu guter Letzt führen die daraus ableitbaren

$1 \quad$ Vgl. Genazino: Der gedehnte Blick.

2 Vgl. grundlegend zu diesem Schlaglicht vor allem Hirsch: Zwischen Lust und Angst; vgl. Bucheli: Die Begierde des Rettens; vgl. Jung: „Umhergehen und Zeitverschwenden“; vgl. Hirsch: Geheimgeschichten. Die (Ent)deckung der Scham, S. 63, sowie Wilhelm Genazino: Aus dem Tagebuch der Verborgenheit. In: Arnold (Hg.): Wilhelm Genazino (2004), S. 3-10. 
Folgen, die sich häufig als ,innere Zensur' ( $\Rightarrow$ II.2.6) bezeichnen lassen, die Strategien der Unsichtbarkeit konsequent weiter und schließen den Bogen zum Kapitelbeginn, sind doch die psychischen Triebfedern etwa für unterlassene Handlungen nicht zuletzt auch in der Minimierung der kognitiven Dissonanz $(\Rightarrow$ II.2.1) zu suchen.

Wenn man diese Blickvielfalt systematisieren möchte, bietet es sich an, die Blicke ,nach außen“ $(\Leftrightarrow I I .2 .2$ u. $\Rightarrow$ II.2.3) von denen ,nach innen' ( $\Rightarrow$ II.2.4 u. $\Rightarrow$ II.2.5) zu unterscheiden, wobei die Hauptfigur immer das Koordinatensystem bildet: Blicke ,nach innen' sind also zunächst eine Kategorie eigenen Rechts, ob sie nun von anderen oder vom Ich selbst stammen $\Leftrightarrow$ II.2.1, $\Rightarrow$ II.2.4 u. $\Rightarrow$ II.2.5). Auch Fansa sieht in dieser Dopplung „eine Grundtendenz aller späten GenazinoHelden“ begründet, „denn sie blicken stets durch ihre eigenen Augen nach außen und vergessen dabei dennoch nie den Blick von außen auf sich selbst."4

\subsection{Selbst-, Fremd- und Idealbilder}

Genazinos Figuren blicken nicht nur sackgassenartig mit dem Blick der anderen auf sich selbst bzw. mit ihrem eigenen in die Umwelt. Vielmehr handelt es sich um dynamische Feedbackschleifen, denen verschiedene Facetten korrespondieren, die mit der Selbst-, Fremd- und Idealsicht der Protagonisten zu tun haben.

Um an das Kapitel zum Selbst $(\Leftrightarrow I .4)$ anzuknüpfen, lässt sich zunächst festhalten, dass das Selbstbild die reflexive, komparative und ideationale Prädikatenzuweisung umfasst. Alle diese Zuweisungstypen lassen sich nämlich unter ,Selbstwahrnehmung' subsumieren: Ob sich ein Individuum dabei beim eigenen Handeln selbst beobachtet (reflexiv), sein Tun und Handeln mit anderen vergleicht und also ex negativo zu einer Bestandsaufnahme des eigenen Selbst kommt (komparativ) oder aber früheres und künftiges Handeln in seinen Selbstentwurf integriert (ideational), ist zwar hinsichtlich der ,Zuverlässigkeit' sowie der Vorgehensweise von einander strikt zu trennen, indessen homogen im Sinne der Formel: ,Ich blickt auf sich' (s.o.). Die Vorstellung eines Individuums, wie es selbst sei (Selbstbild), ist dabei untrennbar mit demjenigen Bild verknüpft, das andere von ihm haben (Fremdbild). In dieser Hinsicht kommen die direkte und die indirekte Prädikatenzuweisung zum tragen: Was andere über das Individuum sagen (direkt), beziehungsweise, was das Individuum (indirekt) aus dem Habitus seiner Kommunikationspartner ableitet $(\Leftrightarrow$ II.2.3 u. $\Rightarrow$ II.2.4), steht in einer Beziehung zum Selbstbild: Menschen wägen beide Bilder ab und sind gemeinhin nicht nur daran interessiert, ein positives Selbstbild zu haben respektive ein solches zu erlangen, sondern auch an einer möglichst geringen Diskrepanz

$4 \quad$ Fansa: Unterwegs im Monolog, S. 93; vgl. Bucheli: Die Begierde des Rettens, S. 50 f. Hier soll demgegenüber die These vertreten werden, dass es sich durchaus um eine Konstante - nicht einmal eine besonders großen Wellenbewegungen $(\Leftrightarrow I$ I.2.1) unterworfene - handelt: Bereits in Laslinstraße sind beide Blicke ausgeprägt. 
zwischen Selbst- und Fremdbild. ${ }^{5}$ Salopp gesagt: Was hilft der bezauberndste Entwurf vom eigenen Selbst - der auch faktisch gestützt sein kann -, wenn ,die anderen` einen gänzlich anderen, negativen, ,falschen' Eindruck haben? Neben den möglichen Abweichungen zwischen beiden Bildern und den daraus resultierenden psychischen Problemen muss festgehalten werden, dass beide: Selbst- und Fremdbild letztlich stark aufeinander bezogen bleiben: Eigenes Verhalten wirkt auf das Publikum, das sich seinerseits ein Fremdbild konstruiert ${ }^{6}$ und direkt wie indirekt Feedback gibt, was wiederum die Basis für das eigene Selbstbild bildet.7

Allerdings gibt es eine weitere potenzielle Abweichung, sobald die dritte hier diskutierte Kategorie ins Spiel kommt: die Inkongruenz von Selbst- und Idealbild. Dieses Problem wird in der Literatur als Theorie der kognitiven Dissonanz diskutiert: ${ }^{8}$ Es geht um das „Unbehagen, das [...] durch eine Handlung verursacht [wird], die dem üblichen, typischerweise positiven Selbstbild zuwiderläuft.“9 Als mehr oder weniger selbstbestimmtes Individuum könnte man davon ausgehen, dass es ein Leichtes sei, das eigene Verhalten am Idealbild auszutarieren, doch damit ist die menschliche Psyche und in der Folge deren literarische Nachzeichnung weit unterschätzt. Weitaus eher wahrscheinlich sind nämlich die Strategien a) „Änderung der dissonanten Kognition, um unser Verhalten zu rechtfertigen“, und b) „Hinzufügen weiterer Kognitionen, um unser Verhalten zu rechtfertigen “.10 Der empirisch überprüften Kognitiven-Dissonanz-Theorie soll hier ergänzend die psychoanalytische Auffassung von Abwehrmechanismen zur Seite gestellt werden, die an den (permeablen) Grenzen des Ichs zum Über-Ich und zum Es verortet sind, und etwa die bekannten Mechanismen ,Verschiebung', ,Projektion', ,Sublimierung' und ,Regression“ umspannen. Hier interessiert allerdings vornehmlich die ,Rationalisierung', also der „Versuch zu beweisen, dass das eigene Verhalten ,rational' und zu rechtfertigen und insofern wert ist, von einem selbst und von anderen Zustimmung zu erfahren“.11

Wie wichtig diesbezügliche Überlegungen und Probleme für Genazinos Figuren sind, soll im Folgenden dargelegt werden, sind sie doch nachgerade vom gedanklichen Umkreisen von Selbst-, Fremd- und Idealbild Getriebene. An einem Beispiel aus Leise singende Frauen lässt sich die Verflechtung der angesprochenen Kategorien gut zeigen: „Ich spüre, daß man mich beobachtet, und natürlich möchte ich nicht als jemand gelten, der sich nach dem lächerlichen Eigentum abtrans-

$5 \quad$ Alternativ gibt es die Möglichkeit, Selbst- und Fremdbild quasi zu splitten, um die Kollision zu vermeiden, sprich: ein Fremdbild aufzubauen, das zwar nichts mit Selbst- und Idealbild zu tun hat, aber einen Schutz vor der Konfrontation mit der Nicht-Passung aufbaut: „Dass ich in der Provinz arbeitete, war mir angenehm, denn dort kannte mich niemand, und ich musste auch nicht sagen, dass ich eigentlich Schauspieler war und als solcher gelten wollte." (Außer uns, S. 39) Lässt man Nullbekanntheit außer Acht, strahlt allein das durch Hören-Sagen diffundierte ,Wissen“ immer auf die Einschätzung der Person aus.

7 Vgl. Mummendey: Psychologie der Selbstdarstellung, S. $128 \mathrm{f}$.

8 Vgl. Aronson/Wilson/Akert: Sozialpsychologie, S. $163 \mathrm{ff}$.

9 Aronson/Wilson/Akert: Sozialpsychologie, S. 163.

10 Aronson/Wilson/Akert: Sozialpsychologie, S. 164.

11 Richard J. Gerrig/Philip G. Zimbardo: Psychologie. 18., aktual. Aufl. Aus dem Amerikanischen von Ralf Graf, Dagmar Mallett, Markus Nagler und Brigitte Ricker. Deutsche Bearbeitung von Ralf Graf. Mit über 430 Abb. München 2008, S. 519. 
portierter Personen bückt. Deswegen gehe ich langsam weiter“ (Frauen, S. 65 f.; $\Rightarrow$ II.2.4 u. $\Rightarrow$ II.2.6).12 Zum einen besteht eine Diskrepanz zwischen Selbst- und gewünschtem Fremdbild: Während das Selbstbild - und ein guter Prüfstein für dieses könnte lauten: Der eigenbrötlerische Protagonist würde ohne Zuschauer im Einklang mit sich selbst handeln - es durchaus zuließe, die dem kurz zuvor aus der Tasche geglittene Mundharmonika eines stadtbekannten trinkenden Sängers einzustecken, ist das möglicherweise entstehende Fremdbild, das aus dem Aufsammeln resultieren könnte, für den Protagonisten ein Hemmschuh. Zum zweiten tangiert dieses unliebsame Feedback einen anderen Teil des Idealbildes: Nicht in eine bestimmte Kategorie einsortiert zu werden, ist dabei wichtiger als der Wunsch, das „Schmuckstück des Stadtsängers“ (Frauen, S. 65) aufzuheben. Die Freud'schen Kategorien in dieses Abwägen einzubeziehen, gelingt ohne weiteres: Das Es - „Ich habe Lust, die Mundharmonika aufzuheben“ (Frauen, S. 65) - will den Gegenstand, das Über-Ich, repräsentiert durch die „Zuschauer“ (Frauen, S. 65), obsiegt, da das Ich als vermittelnde Instanz „natürlich“ nicht so wirken möchte, als ob es sich um das „lächerliche[] Eigentum abtransportierter Personen" schere. Das Resultat kommt in Gestalt des unauffälligen Weitergehens daher ( $\Rightarrow$ II.2.4 u. $\Rightarrow$ II.2.5), das letztlich einer inneren, Über-Ich gesteuerten Zensur entspringt ( $\Rightarrow$ II.2.6). Zugleich lässt sich sagen, dass Selbst- und Idealbild zumindest in dieser Hinsicht von einer geringen Dissonanz geprägt sind - allerdings zum Preis des sofort einsetzenden Rationalisierungsprozesses durch „Hinzufügen weiterer Kognitionen, um unser Verhalten zu rechtfertigen“" (s.o.). So wird nicht nur der eigene Wunsch der Lächerlichkeit preisgegeben („natürlich“ „lächerlich[]“), sondern auch stehenden Fußes die Erklärung mitliefernd benannt: „[d]eswegen“! „Books say: she did this because“ ( $\Rightarrow$ I.3.1) - Genazinos Figurenromane auch. In den Schritten Selbst- vs. Idealbild und Selbst- vs. Fremdbild wird dieses Feld nun bestellt - immer mit Blick auf die erzähltechnische Formung.

\section{SELBST- VS. IDEALBILD: KoGNITIVE DISSONANZ UND BEARBEITUNGSMECHANISMEN}

Genazinos Figurenbasistypus leidet regelmäßig darunter, dass die eigenen selbstentworfenen Idealbilder das den Protagonisten Mögliche übersteigen. In einem ganz schlichten Sinn handelt es sich dabei bereits auf der Ebene der äußeren Erscheinung ( $\Rightarrow$ II.1.4) um eine nicht mögliche Passung von Selbst- und Idealbild: „Aber leider gefalle ich mir auch heute nicht. Mein feuchtes Haar klebt eng am Schädel und gibt mir das Aussehen eines Bademeisters oder Pförtners." (Liebesblödigkeit, S. 195 f.) Eine Stufe härter geht Abschaffel mit sich selbst ins Gericht: „Es war ihm möglich, sich widerwärtig zu finden.“ (Sorgen, S. 325) Aber auch hinsichtlich eigener Charakterzüge und den daraus entspringenden problematischen Auswüchsen - für die folgenden Beispiele: die Hybris ( $\Rightarrow$ II.4.1) - ist ein Missverhältnis zu konstatieren:

12 Natürlich gilt auch für dieses Kapitel, dass es nicht nur um sprachliche Äußerungen, sondern stets auch um non-, paraverbale etc. Kommunikation geht. Vgl. dazu auch: „Als Ersatz für den Rückzug, der ihm nicht gelang, senkte er den Kopf." (Abschaffel, S. 118) 
Vor allem wollte ich wissen, ob der Hochmut schon immer ein Teil meiner Substanz war, der nur auf seine Entbindung (durch den Journalismus) gewartet hatte. [...] Möglicherweise war ich nur ein kleiner Stadtaffe, der unauffällig seine Ressentiments ausleben wollte. Schon fürchtete ich das langsame Anwachsen der Arroganz in mir. (Wohnung, S. 94 f.)

Und diese Furcht Weigands ist nicht ganz unbegründet, wenn man sich etwa seine um Distinktion bemühte $(\Leftrightarrow$ II.1.5) und die offensiven IM-Spielarten der Abwertung und Herabsetzung $(\Leftrightarrow$ I.3.3) mischende Reaktion auf Gudruns Vorschlag, einen Tanzkurs zu belegen, ansieht:

Der Abendreporter, dem gerade die Urlaubsvertretung eines Redakteurs angeboten worden war, sollte sich mit pickligen Jugendlichen zusammentun, um das allgemeine Herumhopsen zu lernen. Unaussprechlich lächerlich! Ich mußte mir Mühe geben, meinen Unmut zu zügeln. (Wohnung, S. 55)

Anspruchsvolle Idealbilder finden sich bei Genazinos Figuren häufig, eine Näherung an diese ist eher die Ausnahme: „Meine Schlichtlösungen passten nicht zu meinem Verlangen nach Bedeutsamkeit." (Außer uns, S. 21) ${ }^{13}$ Allerdings belässt es Genazino nicht beim schnöden Sammeln von Charaktereigenschaften, die er mit einem für die Figuren selbst nicht einlösbaren Idealbild kontrastiert - wiewohl ,Unzufriedenheit' sicherlich eine eher sich in den Hardcore als den Familienähnlichkeitsgürtel eingliedernde universelle Genazino-Charaktereigenschaft ist ${ }^{14}-$, sondern er problematisiert, ironisiert und vor allem: subvertiert einmal mehr die platte ,Anwendbarkeit‘ psychologischer Theorie:

Noch schöner wäre, wenn Abschaffel selbst ein Motorrad hätte und mitrasen könnte. Nein, das war zu schnell gewünscht. Richtig gewünscht mußte es heißen: Noch schöner wäre, wenn Abschaffel ein Mensch sein könnte, der am Lärmen und Rasen von Motorrädern manchmal Freude haben könnte. Abschaffel und ein Motorrad! (Falsche Jahre, S. 527)

Das Motorrad, das hier gleichsam ,vorschnell gewünscht wird' - man denke intertextuell an Paul Maars sechs Jahre zuvor erschienene Sams -, ist eben nicht leichtfertig mit dem Idealbild zu verwechseln. Es genügt nicht, ein Motorrad in der Garage stehen zu haben, wenn das Selbstbild nicht dazu passt. Hier wird in der Tendenz die Grenze zum Wunschdenken überschritten, wird genaugenommen ein Idealbild gewünscht! Die Unerfüllbarkeit letztlich beider Wünsche ist in Form der erlebten Rede zunächst einer Reflektorfigur in den Mund gelegt, bevor die Erzählerstimme stärker die Oberhand gewinnt und den Leser dadurch an den Genazino'schen Basistypus gemahnt: „Abschaffel und ein Motorrad!“ Das ist ja nun weitgehend abwegig, lieber Leser.

Dass in anderen Ko- und Kontexten durchaus die Arbeit aufgenommen wird, die Dissonanz zwischen Selbst- und Idealbild zu minimieren bzw. dieser Prozess nicht nur beobachtet werden kann, sondern sowohl thematisiert als auch gar theorisiert wird, lässt sich stufenweise belegen. Zunächst einmal sind die Bestandsaufnahmen zu erwähnen - nicht immer dringt das offensichtliche Missverhältnis von Selbst- und Idealbild bis zur der Figur bewussten Ebene, wofür sich interne wie externe Faktoren in der Erklärung ergänzen. Jedenfalls kann Abschaffel „es nicht

13 Konträr: „Ich möchte auch gerne schlicht sein, von Schlichtheit verspreche ich mir Glück.“ (Heimweh, S. 29)

14 Vgl. Tilman Krause: Er wollte nicht der Mensch sein, der er war. In: Die Welt vom 23. Juli 2011. 
ertragen, vor sich selber den Eindruck zu erwecken, sein Leben bestünde in diesen zwanzig Minuten lediglich aus dem Warten auf das Garwerden von Spaghettis." (Abschaffel, S. 102) Das lässt sich einerseits mit dem oben angerissenen „Verlangen nach Bedeutsamkeit“ rückkoppeln, führt zugleich aber auch die Bewusstwerdung vor Augen. Denn es sagt nicht eine reflexionsarme Figur in direkter Rede: ,Ich schäme mich der Unbedeutsamkeit des Wartens auf Spaghetti', sondern die erzähltechnisch elaborierte Form steht geschrieben. ${ }^{15}$

Wie wendig Genazinos Figuren in Fällen zumindest teilweise bewusst gewordener kognitiver Dissonanz zu agieren verstehen, lässt sich in der Wahl der Bearbeitungsmechanismen sehen: „Außerdem wollte ich nicht gerne vor mir selber zugeben müssen, dass mein einziges Motiv nicht irgendwelche zerfetzten Unterhemden waren, sondern meine Eifersucht auf vorgestellte andere Männer." (Außer uns, S. 106) Zwar kann keine Rede mehr von einer ,echten Verdrängung‘ sein, wenn sie bereits in der Figurenpsyche reflektiert wird, aber es ließe sich mit gutem Grund doch immer noch zumindest eine ,Sublimierung', also eine „Befriedigung oder Abarbeitung frustrierter sexueller Begierden in nicht sexuellen Ersatzhandlungen, die in der eigenen Kultur sozial akzeptiert sind“,16 denken. Der Aberwitz, dass zerfetzte Unterhemden die Stelle etwa einer Thomas Mann'schen ,Schreibbesessenheit', die immer wieder als seiner Homosexualität entspringende Sublimierung (v)erklärt worden ist, einzunehmen genötigt werden, darf dabei gerne der Genazino'schen Komik einerseits, der bereits bemerkten ,Metapsychologie‘ andererseits zugeschrieben werden. Häufig finden sich nämlich Beispiele, welche die Arbeit des mit psychologischem Handwerkszeug Analysierenden untergraben, indem sie bspw. eine Verdrängung, eine Sublimierung oder eine Rationalisierung bereits selbst ansprechen und gelegentlich sogar ausdeuten, wohingegen es bei anderen Autoren typisch ist, solche ,unterbewussten“ psychischen Mechanismen unterschwellig im Text zu verstecken und den Interpreten implizit dazu auffordern, jene in ,Fleißarbeit' aufzufinden.

Demgemäß wird die Selbstrechtfertigung des Protagonisten, warum es besser sei, „(vermutlich) dann doch nicht“ mit der „Linie 11“ nach Hause zu fahren, dem Leser dezidiert aufgetischt: „Ich sammle jetzt doch Gründe dafür, warum es für mich sinnvoller ist, auf die Straßenbahn zu verzichten." (Regenschirm, S. 25) Und im Sinne eines kleinen Spannungsbogens werden diese nacheinander sogar mit „Enge“ und ,Platzeroberungsangst” (Regenschirm, S. 25; vgl. Regenschirm, S. 26) angegeben. Auch der Protagonist aus Die Ausschweifung, welcher sich während einer Zirkusvorstellung, die er mit seiner Tochter besucht, langsam selbst bewusst wird, dass „ihn nicht die Zirkusdarbietungen erregten, sondern die Unmöglichkeit, schon jetzt etwas über den Verlauf

15 Wenn sie auch häufig überzeitlich stabil sind, kann es doch vorkommen, dass die situativen Selbstbilder bzw. die Situationsinterpretationen der Tagesform unterworfen sind: „Dennoch geben mir die Filmreste das Gefühl, daß ich modern und zeitgenössisch bin, was mir tagsüber kaum gelingt.“ (Liebesblödigkeit, S. 62; $\Rightarrow$ II.1.6 u. $\Rightarrow$ II.4.2) Auch dieser Tatsache sind sich die Figuren bewusst: „So habe ich mir die Dinge gestern zurechtgelegt. Nächste Woche sehe ich sie wahrscheinlich schon wieder anders. Bewahre, bitte, die heutige Version auf." (Licht, S. 65) 
des morgigen Abends zu wissen“ (Ausschweifung, S. 193), in dessen Rahmen eine wichtige private Entscheidung bevorstehen wird, nämlich die, ob „Christine [...] ihn schnell wieder loszuwerden“ (Ausschweifung, S. 193) gedenke, entäußerst in einer vom Erzählerbericht in erlebte Rede wechselnden - und also damit erzähltechnisch den Inhalt der Bewusstwerdung durch den Switch von Erzähler- in Figurenrede ${ }^{17}$ nachzeichnenden - Passage: „Er konnte diese Idee so rasch nicht zurückweisen, wie er gehofft hatte. Deswegen tat er nun wieder so, als hätte seine Aufregung etwas mit diesem Zirkus zu tun." (Ausschweifung, S. 193) Das ist Rationalisierungsarbeit par excellence, die Eckhard Fuchs hier betreibt, um seinem Ich, seinem idealisierten Selbstbild nicht zumuten zu müssen, sich die Zurückweisung einer Frau unter einem perfiden Vorwand als reale Angst eingestehen zu müssen ( $\Rightarrow$ II.5.2 u. $\Rightarrow$ II.5.3). Später im Romangeschehen ist die Befürchtung fiktionale Realität geworden und man darf erneut am Innenleben Eckhard Fuchs' anteilnehmen, der seinerseits nicht vollumfänglich darauf zugreifen kann:

Natürlich, die Geschichte mit Christine war ohne Gegenwart und deswegen auch ohne jede Zukunft, redete er sich ein, und dies war eine der typischen, halbbetäubenden Beruhigungen, die immer nur minutenlang galten, weil sie kurz danach an ihrer eigenen Unwahrhaftigkeit zugrunde gingen. Er war neidisch auf jeden Menschen, der in Zukunft die Möglichkeit hatte, Christine kennenzulernen. Er merkte nicht, daß er dadurch auch neidisch auf sich selbst war, und er konnte es nicht merken, weil er in diesen Minuten seine Gefühle für Christine aufgespalten hatte: Eine Hälfte machte ihm Christine streitig und nahm sie ihm wieder weg, und die andere Hälfte wandelte sich in ein ewiges Bedauern über diesen Selbstdiebstahl um. So hatte er sich die Möglichkeit geschaffen, sich in $\mathrm{Zu}$ kunft nach Christine zu sehnen und zugleich zu verstehen, daß er sie verloren hatte. Seinen Neid, den er noch immer spürte, löschte er auf die einfachste Weise aus; er hielt ihn für eine bloße Überheblichkeit seiner törichten Gefühle. Er hatte doch Ruth, und es gab keinen Grund, neidisch zu sein. (Ausschweifung, S. 224)

Um angemessen darlegen zu können, dass es sich sowohl auf Discours- als auch auf HistoireEbene um eine Passage höchst reflektierter Psychologie handelt, ist ein Exkurs über die ,echte Psychologie‘ nötig: In der Kognitiven-Dissonanz-Theorie wird das Entstehen von Kognitiver Dissonanz durch die Koinzidenz (mindestens) zweier Kognitionen beschrieben, die einander widersprechen. Diese Aufspaltung der Gefühle wird in dieser Passage treffend beschrieben und durch die Tatsache, dass Fuchs darauf keinen reflektierten Zugriff besitzt, wie der Erzähler qua temporärer Nullfokalisierung vermittelt, umso überzeugender.

Nicht immer sind die widerstreitenden Kognitionen als solche aber überhaupt benannt. Genazinos Fabulierkunst ist beileibe nicht so begrenzt. Abschaffel etwa, nach dem Kuraufenthalt in Falsche Jahre wieder in seine alte Heimat zurückgekehrt, ist mit zwei Sichtweisen konfrontiert:

Es hatte sich überhaupt nichts verändert. [...] Alles war vertraut. Seine Erfahrung, die die Dinge rasch wieder annahm, arbeitete schneller als sein Bewußtsein, das sich abzuquälen versuchte. Mühsam machte er sich klar, daß er eigentlich erwartet hatte, sein Wohnviertel nicht mehr wiederzuerkennen. Während er planlos umherging, tröstete er eigentlich seine falsche Erwartung und wies sie sanft darauf hin, daß ihr fremdes Getue nicht angebracht war. Es war, als müßte Abschaffel eine fremde, zweite Person in sich beruhigen. Er verspürte Lust, diesen inneren Vorgängen, die er nur unklar wahrnehmen konnte, weiter nachzuhängen. So lief er länger umher, als er beabsichtigt 
hatte, weil er es darauf ankommen lassen wollte, den fremden Herrn in sich noch ein wenig näher kennenzulernen. Aber diese zweite Person schien ein äußerst scheues Wesen zu sein. (Falsche Jahre, S. 551 ff.)

Nach den psychoanalytischen Sitzungen im Kuraufenthalt ließe sich von einer geläuterten Verfassung sprechen, die Abschaffel nun mit einem veränderten Selbstbild beigebracht hat, sich in seiner alten und teilweise verabscheuenswürdig wahrgenommenen Welt neu zurechtzufinden. Die als „fremde, zweite Person“ beschriebene Facette seines Selbstkonzepts darf hier als Metapher für den Widerstreit der Kognitionen und also als Manifestation der Dissonanz verstanden werden: Eigentlich gelingt dem ,erneuerten' Selbst(bild) die Reintegration in die alten Verhältnisse, doch das Alte schimmert durch. Als Abschaffel die „Ansichtskarten aus Sattlach, die er nicht verschickt hatte“, findet, überkommt ihn „das Gefühl, nie dort gewesen zu sein. Oder war das wieder der zweite Herr in ihm, sein Neben-Ich, das ihm mächtig seine Erlebnisse streitig machte?“ (Falsche Jahre, S. 552) Lässt man die neuerlich bis ins Terminologische reichende, präzise Subebene der psychoanalytischen Lesart außer Acht, bleibt erneut eine Dissonanz zweier Kognitionen übrig: Weitermachen wie gehabt? Oder den Erfolg der Therapiesitzungen, den neuen Schwung des Selbstkonzepts als Ausweg aus der Misere nutzen? „Abschaffel setzte sich auf das Bett, hielt die Ansichtskarten in der Hand und wartete ab. Und es dauerte nicht lange, dann war sein Distanzgefühl wieder verschwunden." (Falsche Jahre, S. 552) Der nächste Tag bringt mit einer geballten Schilderung von Aktionen, die für den Genazino'schen Basistypus tendenziell nahezu unüberwindbare Hindernisse darstellen, wie den Entschluss, „erst am folgenden Montag wieder zu arbeiten“ (Falsche Jahre, S. 553), viel (bzw. überhaupt) einzukaufen, Aktionen prompt auszuführen - etwa die Wäsche in die Wäscherei zu bringen - und Situationen, die ihn üblicherweise in Rage oder Verzweiflung gestürzt hätten, auszuhalten und zu meistern. Das geht über nahezu zwanzig Druckseiten lang und ist romanspezifisch-individuelles Milieu (vgl. Falsche Jahre, S. 552-571). Erst, als Abschaffel wieder im Büro antritt, dräut das psychische Unheil, aber es wird milde formuliert.

Dieser Höhenflug inklusive der Aussöhnung von Selbst- und Idealbild, diese Momente unglaublich geringer Dissonanz und die Abwesenheit aller Rationalisierungsbestrebungen gehen auf die - zwar in Ansätzen selbsttäuschenden, in letzter Konsequenz aber eben ent-täuschenden selbstvergewissernden Momente seiner Therapie zurück:

Abschaffels erste Schwimmstunde am Nachmittag wäre beinahe gescheitert. Er fand sich in Bade-
hose und Badekappe unerträglich [ungleich Idealbild; N. L.]. Die Badehose hatte er sich von zu Hau-
se mitgebracht, aber die Badekappe hatte er sich vom Bademeister ausleihen müssen. Als er sich,
die Badekappe auf dem Kopf, zum erstenmal im Spiegel sah, wollte er schreiend wegrennen. Er sah
aus wie ein verrückter Gefangener oder wie ein groteskes Tier. Nur weil der Rückzug [ $\Rightarrow$ II.2.5] aus
der schon betretenen Schwimmhalle zu umständlich war, mußte er die Schwimmstunde irgendwie
überstehen. [...] Erst der Anblick des Schwimmbeckens verschaffte ihm überraschend angenehme
Empfindungen. Die Halle war an einer Längsseite und an einer Schmalseite von Glaswänden einge-
faßt. Mehr als einmal, bevor er in das Wasser stieg, lief er langsam um das Becken herum, nicht weil
er sich vor dem Wasser fürchtete, sondern weil er es schön fand, aus der gläsernen Halle nach
draußen sehen zu können. Er fühlte sich wie in einem Aquarium. [...] Es war schön, den Winter 
draußen zwar zu sehen, aber nicht zu spüren, und dies nur durch die Trennung einer Glasscheibe, die selbst wiederum nicht gesehen werden konnte, wenn das Glas nicht gerade spiegelte [Reflexionsmomente der Figurenpsyche; N. L.]. Wieder und wieder sah er hinaus [ $\Rightarrow$ II.2.2], und bald hatte er herausgefunden, warum ihm das Hinausschauen ein solches Vergnügen bereitete: Die Arbeit der Unterscheidung zwischen Innenwelt und Außenwelt [Selbst- vs. Fremdbild; N. L.] war aufgehoben, wenn auch nur für Augenblicke und um den Preis einer sentimentalen Täuschung. [‥] Endlich hatte er es geschafft, immerzu in sich selbst umhergehen zu können [ $\Leftrightarrow$ II.2.4] und nie mehr nach außen gehen zu müssen [ $\Rightarrow$ II.2.5]. Es kam darauf an, die Täuschungen glaubhaft zu machen [psychoanalytische Abwehrmechanismen bzw. Rationalisierungen zur Dissonanz-Reduktion; N. L.]. Er wurde fast verrückt über diesen Gedanken. Sollte er damit begonnen haben, nicht mehr ganz so streng und unerbittlich mit sich selbst zu sein? (Falsche Jahre, S. 510 f.)

Diese überaus dichte Stelle bietet mannigfaltige Hebelpunkte für alle in diesem Unterkapitel genannten und zusätzlich auch für nahezu alle in diesem zweiten Schlaglicht noch anstehenden Unterkapitel verhandelten Sachverhalte. Über die Referenzen, die direkt im Zitat angebracht worden sind, sei nur so viel im Fließtext gesagt: Eine simple unsichtbare Schwimmbad-Glasscheibe - ganz zu schweigen davon, was mit der temporären Sichtbarkeit dieser einen Scheibe für weitere Deutungsangebote gemacht werden - kann bei Genazino qua nahezu allegorischem Mehrfachvergleich sowohl als unsichtbare und überwindbare Trennwand zwischen Ich-Konzept, Es und Über-Ich gelesen und somit als Sitz der Abwehrmechanismen interpretiert werden, als auch als unsichtbare und überwind- bzw. verschiebbare Trennwand zwischen Selbst- und Ideal- bzw. als zwar unsichtbare, aber schützende von Innensicht und Außenwahrnehmung, vulgo: von Selbst- und Fremdbild. ${ }^{18}$

\section{SELBST- VS. (VERMUTETES) FREMDBILD}

Es ist hinsichtlich des Idealbildes anhand des Beispiels vom Nicht-banal-sein-Wollen aus Dünkelgründen bereits die Rede gewesen (s.o.). Hier verschieben sich nun die Vorzeichen: Weniger steht der eigene Anspruch, der eigene Blick auf sein ideales Selbst, sondern derjenige durch die Augen der anderen im Vordergrund: „Das hätte ja ausgesehen, als wäre er ein Mann, der an seinem Feierabend einen leeren Karton in einen Mülleimer wirft." (Sorgen, S. 168) Welches Bild in den Köpfen der fiktiven Mitmenschen existiert, und ob es demjenigen von sich selbst widerspricht oder mit ihm in Einklang steht, ist nicht nur IM-Metier durch und durch, sondern auch figurenanalytisch von eminenter Wichtigkeit, da es erstens für das Selbstkonzept der Figuren Konsequenzen zeitigt, zweitens die Schnittstelle von reflexiver und ideationaler vs. direkter und indirekter Prädikatenzuweisung bespielt und drittens in Form von Selbst- und Fremdcharakterisierungen - sofern sie nicht durch eine klar identifizierbare Erzählinstanz hierarchisiert werden - narratologisch als Leserherausforderung bzw. abzuwägende, mitunter unauflöslich widerstreitende Erzählfakten vorliegen.

Im Folgenden werden hauptsächlich Fallbeispiele ausgewählt, die das Inbezugsetzen der soeben genannten Kategorien illustrieren und problematisieren sollen; sprich: Es geht weniger darum, was das tatsächliche Selbst- respektive Fremdbild ausmacht, als vielmehr um das prinzipielle Zustandekommen derselben. Vgl. für weiterführende Analysen und Inhaltsfüllungen der Konzepte ( $\Rightarrow$ II.2.4). 
Erstens geht es also um die problembehaftete Verortung des Status Quo zwischen Selbst- und Fremdbild, sobald die Wahrnehmung als nicht zuverlässig aufgefasst wird, sich die Protagonisten nicht auf ihre Einschätzungsgabe hinsichtlich des fremden Blicks verlassen können bzw. direkt die Relation beider Kategorien auszuloten suchen. Diese Form findet sich gewöhnlich mit Möglichkeitsmarkern versehen: „Vielleicht hatte er schon den Ruf eines schwächlichen, weibischen Angestellten, und er wußte gar nichts davon“ (Sorgen, S. 256), fragt sich etwa Abschaffel und sucht so das Fremdbild zu eruieren, das seine Bürokolleginnen und -kollegen von ihm haben könnten. Zwar geht dieser Mutmaßung immerhin ein Scherz zu seinen Lasten voraus, in dessen Rahmen er mit einer „Tippse“ verglichen worden war, doch der Beigeschmack des Graswachsen-Hörens $\left(\Leftrightarrow\right.$ II.2.4) ist nicht von der Hand zu weisen. ${ }^{19}$ Die Einschätzung des eigenen Leumunds in Form des existierenden Fremdbilds scheint bei Dieter Rotmund hingegen von deutlich mehr Selbstsicherheit getragen zu sein, wiewohl auch er ein letztes Quäntchen Unwägbarkeit nicht auszuräumen vermag, wenn er sagt, „ich glaube, ich habe einen guten bis sehr guten Ruf." (Liebesblödigkeit, S. 49) Allerdings spielt hier bereits die IM-Technik des protektiven Understatements mit hinein. Die Verwunderung über gespiegelte Diskrepanzen zwischen dem selbst vermuteten Fremdbild und dem direkt bzw. indirekt rückgemeldeten treibt auch den 41jährigen Protagonisten aus Die Kassiererinnen um: „Ich wunderte mich, dass er sich ausgerechnet an mich wandte. Ich hatte von mir das Bild eines zurückhaltenden, an der Grenze zur Scheu lebenden Einzelgängers, der zu anderen Personen kaum mehr als Bedenken äußerte." (Kassiererinnen, S. 24) Diesem Fremdbild nun wird widersprochen, indem man ihn um Rat ersucht. ${ }^{20}$ Indessen ist der in Rede stehende Protagonist wohl Genazinos elaboriertester Selbst- und Fremdbildexperte, der auch mit IM-Mitteln Fremdbilder bewusst gestaltet: „Ich war der Kunst seit Jahren entfremdet und lebte entsprechend kunstabgewandt, aber das wusste von meinen Bekannten kaum jemand, weil ich nicht darüber redete." (Kassiererinnen, S. 27) Wie es die Signatur dieses Schlaglichtes verlangt, erreicht er die Etablierung dieses Fremdbildes just durch eine protektive Strategie: minimal self-disclosure und remaining silent. Eine ganz ähnliche, nominell dem protektiven IM zuzurechnende Technik nutzt auch Dieter Rotmund kalkuliert, um das Fremdbild zu beeinflussen: „Vielleicht deswegen erwecke ich den Eindruck eines etwas linkischen Strebers, von dem nicht klar ist, was er eigentlich erreichen will." (Heimweh, S. 56) Der Grund ist schlicht und tiefsinnig wie Genazinos Prosa: „weil ich weder mit Zuckschwert noch mit anderen Kollegen zusammen sein möchte" (Heimweh, S. 55 f.) - minimizing social interactions. Dabei wird auch die externe Analyseperspektive im bedrohlich klingenden sprechenden Namen virulent: Wer möchte ernsthaft gerne mit einem Herrn zusammenarbeiten, der das Schwert zu zücken wohl nicht zögern würde?

19 Dieses Motiv des Nicht-über-sich-selbst-lachen-Könnens findet sich immer wieder bei Abschaffel: „Hornung lachte still, und Abschaffel lachte mit und verachtete sich dafür.“ (Sorgen, S. 214)

20 Ganz ähnlich die Situation im Roman Ein Regenschirm für diesen Tag: „Immer wieder wundere ich mich darüber, warum mir Fremde ein solches Vertrauen entgegenbringen." (Regenschirm, S. 9) 
Weiterhin muss die erzähltechnische Unterscheidung mit der Prädikatenzuweisung in Konnex gesetzt werden. Wenn hauptsächlich aus von sich selbst umkreisender Ego-Perspektive erzählt wird, dann sind diejenigen verstreuten Passagen, die andere ,ungebrochen` zu Wort kommen lassen, unüberschätzbare Korrektive für die sonst so unzuverlässig arbeitenden Erzähler. Zugleich ist der Interpret freilich abhängig vom skizzierten Selbstbild, wie es lange und breit vor ihm ausgefaltet wird. Für die direkte Prädikatenzuweisung von anderen existieren bei Genazino unterschiedliche Grade an Direktheit, die sich an der Unmittelbarkeit des Erzählens festmachen lassen. So wird der Protagonist Fuchs aus Die Ausschweifung folgendermaßen fremdcharakterisiert: „Ihm war die Arglosigkeit beinahe ins Gesicht geschrieben. [...] Fuchs war Wohlleben menschlich überlegen: Das war jedenfalls die Meinung der Mehrheit der Angestellten, die ihm gegenüber auch ausgesprochen wurde." (Ausschweifung, S. 50 f.) Zweifelsohne liegen hier gehäuft Indizien für den narrativen Modus vor, da die Unmittelbarkeit doppelt gebrochen wird: einerseits durch die Einschränkung, dass es lediglich Mehrheitsmeinung sei - was an dieser Stelle auch als produktionsästhetischer erzählerischer Trick aufgefasst werden kann, um nicht in die Sphäre der Allwissenheit abzudriften -, andererseits durch die lediglich iterativ-geraffte Fassung der Fremdbild-Feedbackschleife („die ihm gegenüber auch ausgesprochen wurde“). ${ }^{21}$ In Genazinos Roman Ein Regenschirm für diesen Tag hingegen, in welchem häufiger mit Fremdcharakterisierungsverklausulierungen experimentiert wird, gibt es eine der direktesten, da im unmittelbareren Modus gehaltenen, Fremdcharakterisierungen:

Und was steht in dem Brief? Ist er peinlich?

Nein, sagt Susanne, dir ist die Liebe peinlich, mir nicht.

Die Antwort verblüfft mich, ich schweige. (Regenschirm, S. 96)

Bis auf die autonome direkte Rede, ${ }^{22}$ die neben der Inquit-Formel vermutlich noch die Anführungszeichen und den ,stychomythischen Zeilenstil' über Bord geworfen hätte, müssen die Worte Susannes durch keinen Reflektor- oder anders gelagerten Erzählerfilter und dürfen präsentisch, wie sie geäußert werden, demgemäß getrost für bare Charakterisierungsmünze gelten.23 Hier interessiert allerdings das Fremdbild, das offenkundig - zumindest für die Dyade SusanneProtagonist in dieser Szene - durch Peinlichkeit in Liebesdingen $(\Leftrightarrow I I .5)$ geprägt ist. Interessanterweise bleibt die Replik ob Verblüffung aus, woraus sich beide Extreme hinsichtlich des Verhältnisses von Selbst- und Fremdbild mitlesen lassen: Entweder trifft Susanne den Nagel auf den Kopf (keine/geringe Diskrepanz zwischen Selbst- und Fremdbild) oder sie liegt verhältnismäßig

21 Vgl. Martínez/Scheffel: Einführung in die Erzähltheorie, S. 39-47.

22 Vgl. Martínez/Scheffel: Einführung in die Erzähltheorie, S. 47-63.

23 Obwohl auf den ersten Blick noch unmittelbarer muss im Beispiel: „ich dachte an meinen Lehrer, Degen, Sie waren nie ein Licht, sagte er jetzt öfter“ (Laslinstraße, S. 99), berücksichtigt werden, dass es sich um eine Verquickung von ideationaler - Axel Degen erinnert sich zurück - und direkter Lehrer trifft Aussage - Zuweisung handelt, was den Zugriff auf den Aussagegehalt zumal bei Genazinos Figuren, die als Erinnerungs(be)arbeiter bekannt sind, mittelbarer gestaltet. Auch das Präteritum per se muss in die Gleichung aufgenommen werden. 
weit entfernt, sodass das Schweigen als Reflexionspause ausgedeutet werden kann, innerhalb derer sich die Hauptfigur fragt, wie ein solches Fremdbild hat entstehen können. Gerade an solchen Stellen muss eine redliche Figurenanalyse Ko- und Kontexte berücksichtigen. Denn die durch Hohn relativierte (imaginierte, aber aufgrund des bisherigen Vorkommens dennoch relevante) Fremdcharakterisierung: „Susanne würde das Schild nicht begreifen und ausrufen, jetzt bist du endgültig übergeschnappt. Das hat sie schon öfter gesagt, sie sagt es eigentlich immer, wenn sie etwas nicht sofort begreift oder nicht hinnehmen möchte“ (Regenschirm, S. 18), färbt freilich auf den folgenden Erzählverlauf ab. Ein Beispiel (zu)treffender Fremdcharakterisierung findet sich auch in Wilhelm Genazinos Roman Wenn wir Tiere wären:

Bei ihrem letzten Besuch ließ sie durchblicken, dass sie nicht mehr unbedingt heiraten wolle. Es genüge ihr, sagte sie, einen Mann zu kennen. Als Grund für ihre Zurückhaltung nannte sie mein Eigenbrötlertum. [...] Obwohl du noch jung bist, hast du schon das Verhalten eines älteren Mannes. Diese Bemerkung traf mich im Innersten. Gleichzeitig bewunderte ich Maria für ihre treffsichere Beobachtung. (Tiere, S. 132)

Maria bekommt in der erzählerischen Konzeption den Part zugeschustert, dem Protagonisten nicht luzide Eigenschaften zu entdecken. Vergleichbare figural-explizite Treffsicherheit stellt Sonja für Reinhard unter Beweis: „Deine Rückzugsgefechte führen nicht zu einem eigenen Leben, sondern höchstens zu einer Eigenbrötlerei. [...] Und aus deiner Abkapselung tritt die Einsamkeit hervor und aus dieser ein vorzeitiges Altern." (Regen, S. 153) Dieser über mehrere Seiten hinweg ausgetragene Disput zeitigt auf Seiten Reinhards zwar auch Rechtfertigungsversuche, die das Fremdbild stützen sollen, hauptsächlich ist er aber „verblüfft“ (Regen, S. 153), „empört[]“ (Regen, S. 154), „verdutzt“ (Regen, S. 155) ob der fremdinduzierten Anagnorisis.

Tatsächlich entpuppen sich auch die weniger ,gesichtsbedrohenden' ( $\Rightarrow$ II.3.1), Ausdruck über bestehende Fremdbilder gebenden Sprechakte ähnlich: Der Basistypus reagiert auf Lobhudelei „Den ganzen Tag liest er und schreibt Gedichte und spielt Klavier!“ (Fleck, S. 19) - entweder beschämt oder er wird sich erneut der Inkongruenz von Fremd- und Selbstbild (allerdings weniger schmerzhaft) bewusst. Wenn er mit sein eigenes Selbstwertgefühl überschreitenden Zuschreibungen konfrontiert, wenn er gar bewundert wird - „sie bewunderte ihn, weil sein Leben durch feine Ziele herausgehoben war“ (Fremde Kämpfe, S. 201); „Angelika staunte und war mir eine Weile zugetan. Du wirst Schauspieler! Angelika war voller Bewunderung und erzählte anderen von den großen Ereignissen, die mit mir geschahen" (Einfalt, S. 127) - meldet sich postwendend die Skepsis, was zur protektiven Grundgestimmtheit der Figuren passt. „Er ist offenkundig (ähnlich wie Susanne) von meiner Wichtigkeit/Hintergründigkeit/Bedeutsamkeit überzeugt, mehr noch, er schreibt mir Einfluß in der Stadt zu." (Regenschirm, S. 107) - Der Solidus markiert die Beliebigkeit der Zuschreibungen und mithin die dem Selbstbild widersprechende Beschaffenheit all jener. Ganz anders sind die ambivalenteren, tiefsinnig-treffenden Fremdcharakterisierungen gestaltet, die auf einer partiellen Deckung von Selbst- und Fremdbild beruhen: 
Wenn ich mich nicht täuschte, war ich bei den Sekretärinnen beliebt, obwohl ich nicht mehr jung war, nicht unbedingt gut aussah, keinen sportlichen Eindruck machte und meine Kleidung zuweilen ungepflegt war. Ich könnte sagen: Ich stand in gewisser Weise unter Naturschutz. [...] Schmidbauer nannte mich einen Modernitätsverweigerer, und das war ich wohl auch. Ich hatte keinen Computer, kein Laptop, kein Handy, kein Ipad. (Regen, S. 80 f.)

Allerdings sind unschwer auch hier die im Hintergrund wirksamen Techniken und Taktiken der Bescheidenheit und Zurücknahme transparent; alleine schon durch die einschränkende Verbalisierung der potenziellen Unzuverlässigkeit („Wenn ich mich nicht täuschte“). Verschiedene Möglichkeitsformen finden sich auch im folgenden Beispiel, das damit gleichzeitig die Problematik einer charakterlichen Fixierung vor Augen führt: „Nach Gesa könnte ich ein Pilger, ein Mönch, ein Hirte, ein Abwesender oder ein Suchender sein. Die Beschreibung als Abwesender gefällt mir am besten. Gesa lacht. Unter dem Deckmantel der Abwesenheit willst du extrem anwesend sein, sagt sie." (Fleck, S. 121) Dass sich die Hauptfigur W. gewissermaßen die Wunschkategorie herauspicken darf, ist figurenanalysetheoretisch höchst ambitioniert: Das Augenmerk wird auf die Grundbedingungen von Zuschreibungen überhaupt gerichtet; ob die Selbsteinschätzung als Typus ,Abwesender` zutreffender ist als eine der anderen Optionen, ist genauso irrelevant wie die Liste eo ipso.

Dieser kurzen Bestandsaufnahme der mitunter schockant-,heilsamen` Fremdeinschätzungen, die man en gros als dem jeweiligen Protagonistenkalkül entzogene und als externer Figurenfaktor den Leser adressierende klassifizieren kann, stehen etliche Selbstbeschreibungen, -enthüllungen, -erkenntnisse, -reflexionen, -charakterisierungen und teilweise auch die unübliche Fähigkeit, sich der eigenen Kritik zu stellen, entgegen. Komplexer und schwieriger, als es die Psychologie, derzufolge qua reflexiver bzw. ideationaler Prädikatenzuweisung jeder in seines eigenen Lebens Buch lesen bzw. blättern könne, glauben machen möchte, stellt es sich für Genazinos Basistypus dar, selbstbezogene Informationen zu sortieren und zu formulieren. In den allerseltensten Fällen sind es prima vista ,objektive' Selbstbeschreibungen bzw. -charakterisierungen, zumeist schamhaft geäußerte -enthüllungen, fragliche -erkenntnisse, umgearbeitete -erinnerungen, tiefgreifende, aber durchaus fehlbare -reflexionen, melancholische -zweifel oder die unübliche, dem Basistypus widerstrebende Fähigkeit, sich der eigenen Kritik zu stellen. ${ }^{24}$

Für einen ersten Befund sei erneut (s.o.) die immense Schwierigkeit herausgestellt, die es Genazinos Figuren abverlangt, das eigene Aussehen, das nun einmal zwangsläufig zum Selbstkonzept gehört, ,neutral' in Worte zu fassen. In Wortwahl und Satzbau besonders krass - und das ist eine der Stellen, an denen man Genazinos Verleugnung seines Erstlings in Ansätzen nachvollziehen zu können meint - manifestiert sich dies in Laslinstraße:

Ich, Axel, ein blasser anderslispelnder ausbrechenwollender fensterstehender milchgesichtiger Jüngling, lattenlang, schuppenblond und kragenhaarumwachsen, ich stand am Fenster unseres

24 Im Folgenden werden von diesen allerdings wieder nur diejenigen untersucht, die auch einen zumindest mittelbaren Bezug zum (vermuteten) Fremdbild aufweisen. 
Wohnzimmers. [...] Pracht aus dem Dunkel für den blassen weichsüchtigen Jüngling namens Axel. (Laslinstraße, S. 10)

Es handelt sich nicht nur um eine ungewöhnliche Selbstcharakterisierung und eine ungewöhnlich negative, durch geringes Selbstwertgefühl ausgekleidete Sicht auf das Selbstkonzept, sondern auch auf Discours-Ebene der sprachlichen ,Verpackung' um eine Radikalität, die im Genazinokosmos $(\Rightarrow I .2 .1$ u. $\Rightarrow$ I.2.2) Ihresgleichen sucht. Kommaarm ist die Selbstbeschau geraten, dem Text eignet eine „disziplinlos taumelnde Syntax, eine mit Adjektivreihungen und Neologismen auftrumpfende Beschreibungswut“. ${ }^{25}$ Vor allem aber ist er Ausdruck von massiver Unzufriedenheit - welche „als Reaktion auf die emotionale Totenstarre der Eltern“26 verstanden werden kann - und einer implizit hohen Differenz zwischen Selbst- und Idealbild wie auch Selbstund Fremdbild, wenn man begründet annehmen darf, dass eine andere Figur die Wortwahl „schuppenblond“ oder „,anderslispelnder“ vermutlich nicht freiwillig gewählt hätte, sondern nur der externe Faktor des wertenden Erzählers verantwortlich zeichnet. Diese Vehemenz weicht über die Jahre, aber das Kernproblem, das eigene Selbst nicht durch ungefärbte Brillengläser betrachten zu können, bleibt bestehen:

Es ist ein weißliches, rundliches, fast mondförmiges Gesicht mit hellem Haar an den Rändern. Die Augen sind blau und wäßrig, die Lippen kleben trocken aufeinander, die Haut ist ein wenig aufgerauht, im Mund verharrt ein fader Geschmack, der nicht verschwindet, die Kopfhaut juckt immerfort, die Zunge bewegt sich nicht, nur die kleinen Mondaugen irren umher und fragen immerzu: Wann tritt die Qual ins Leben? Und wodurch? Wird mich jemand verspotten? Wird ein anderes Kind bald du kleines Mondkalb zu mir sagen? Und dann meinen lächerlichen Pullover anfassen und mich auch endlich meiner Kleidung wegen verhöhnen? (Regenschirm, S. 150)

Diese Beschreibung des äußeren Erscheinungsbildes erfolgt als Analepse und verwandelt das erzählende in ein 11-jähriges erzähltes Ich, das sich an peinliche Gefühle und Gedanken rund um das eigene Äußere erinnert. Zwei Genazino-Romane später bietet sich die gleiche Sicht: „Ich kann deutlich erkennen, wie sie sich überlegen: Wie kommt dieser nervöse, im Gesicht grünlichgelbe, im Nacken zu starke und im ganzen zu unelegante Mensch zu so einer schönen Frau?“ (Liebesblödigkeit, S. 113) Hier wird am deutlichsten, dass es sich nicht um einen lupenreinen Versuch handelt, sich selbst zu charakterisieren, sondern der Blick nach innen und der Blick nach außen interagieren: Beginnend mit dem Versuch, das Fremdbild in den Augen anderer abzulesen, wird erzähltechnisch komplex insinuiert, es handle sich notwendigerweise und faktisch-objektiv um eine „nervöse“ und „unelegante“ Erscheinung mit merkwürdiger Gesichtsfarbe und Stiernacken. Allein sind es lediglich vermutete Kognitionen anderer; sprachwissenschaftlich-narratologisch gefasst: Präsuppositionen - einmal ausgesprochen konstruieren sie (Erzählwelt-)Realität. ${ }^{27}$ Alle diese Beispiele flirren dementsprechend zwischen den Polen von Fremd-, Ideal- und Selbstbild hin und her: Ohne jemals Feedback von außen erhalten zu haben, müsste

\footnotetext{
25 Reschke: [Wilhelm Genazino].

26 Reschke: [Wilhelm Genazino].

27 Obwohl der Leser natürlich direkt ,kaputte‘ Selbstzuschreibungen darin sehen kann.
} 
die Pubertät allen diesen Jungen doch sehr zugesetzt haben, um diese Sicht auf sich so drastisch wahrzunehmen; ohne Unzufriedenheit mit der eigenen Konstitution wäre das Idealbild nicht so weit entfernt und ohne Anhaltspunkte für bestimmte Fremdbilder oder die Beobachtung seiner Selbst per se wäre die gefühlte Minderwertigkeit nicht Teil des Selbstkonzepts und die chronische Unzufriedenheit nicht ein Merkmal im Hardcore des Basistypus.

Obzwar als gesichert gelten kann, dass die Innenwelt des Protagonisten im Glücks-Roman höchst vielfältig ist, entscheiden sie sich bezüglich der protektiven Einfärbung der eigenen Sicht auf sich selbst und deren Transport nach außen, begünstigt durch eine weite Entfernung vom Idealbild, für die Techniken der Untertreibung und der Selbstverkleinerung: „Ich glaube nicht, sagte ich daß Sie es schwer mit mir haben werden. Meine Innenwelt ist nicht sehr geräumig. Man kann mich schnell durcheilen und dann feststellen: Außer ein paar Schuldgefühlen und ein bißchen Scham ist nicht viel da." (Glück, S. 132) Veritable Selbstzweifel scheinen die Figurenzeichnung zu durchziehen. Der Baustein ,Selbstzweifel' ist bereits in Falsche Jahre verhältnismäßig hochgeregelt ( $\Rightarrow$ I.2.2) gewesen: „War seine stille Sprödigkeit so umgreifend, daß eine andere Person, die mit ihm zu tun hatte, ebenfalls still und spröde sein mußte?" (Falsche Jahre, S. 516) Warum, muss man sich fragen, fragt sich jemand diese Frage? Ursachen für Schuld jedenfalls vermuten Genazinos Figuren romanübergreifend und Hardcore-beständig bei sich selbst $\Leftrightarrow \Leftrightarrow I I .1 .3 \mathrm{u}$. $\Rightarrow$ II.2.4).

Es geht bei Genazino im Zeichen der Selbst-, Fremd- und Idealbilder aber auch eine Nummer leichter, humoristischer oder tragikomischer zu, obwohl der mit Schuld zusammenhängende Rechtfertigungsdrang durchaus aufscheint $(\Rightarrow$ II.2.4):

Herr Fuchs, geboren im Zeichen der Fische, las [auf einem Würfelzuckerpapier; N. L.], seine schlechten Eigenschaften seien Zorn und Phantasie. Frau Wohllebens Schwester beugte sich zu ihm herüber und sagte ihm lachend, ihre schlechten Eigenschaften seien Vergeßlichkeit und fehlende Ausdauer. Das stimmt, rief sie aus, das stimmt ganz genau! Und was sind Ihre schlechten Eigenschaften? Zorn und Phantasie, sagte Herr Fuchs freundlich. Oh, rief sie, sind Sie so oft zornig? Dann muß ich mich ja in acht nehmen vor Ihnen! Sie lachten, und während des Lachens spürte Herr Fuchs, daß er etwas erklären wollte. Er war weder zornig noch phantasievoll, wollte er erklären, im Gegenteil, er war duldsam und hielt sich an das, was er sah und was er hörte. Nein, das stimmte auch nicht ganz, und weil er herausfinden wollte, was wirklich stimmte, lehnte er sich ebenfalls zurück und überlegte. Er hatte durchaus Phantasie, dachte er, nur war er mit der Art dieser Phantasie nicht sehr zufrieden. Er wünschte sich eine Phantasie, die alle anderen Menschen auch als solche akzeptieren konnten, eine Phantasie, die das Leben verschönte, weil sie etwas aus ihm herausschlug, was auf den ersten Blick nicht in ihm drin war. Seine Art der Phantasie hingegen, unter der er gelegentlich sogar litt, führte ihn bloß zu abgelegenen Einfällen und Vorstellungen, die er meistens für sich behalten mußte, wollte er nicht riskieren, jemanden durch deren Mitteilung zu erschrecken oder zu peinigen." (Ausschweifung, S. 135 f.)

Es kulminieren, eingebettet in die Situationskomik einer Konfirmandenfeier, alle drei in diesem Unterkapitel diskutierten, relevanten Einflussgrößen: Fuchs' Selbstbild setzt sich zusammen aus den Attributen ,duldsam', ,faktengläubig' und ,eigenartig fantasievoll'; ergänzt werden muss es um die externe, zumindest situative, auktorial-explizite Zuschreibung ,freundlich'. Sein Idealbild weicht insofern von jenem ab, als er sich eine einnehmendere, ,aufregendere` und massenkom- 
patiblere Fantasie wünscht $(\Rightarrow$ II.3). Zusammengehalten wird die Trias durch das (vermutete) Fremdbild ( $\Rightarrow$ II.2.4) und die Sorge, als ,eschreckend' oder ,peinigend' zu gelten, was zur Folge hat, dass er seinen „Einfällen und Vorstellungen“ „meistens“ keinen freien Lauf lässt ( $\Rightarrow$ II.2.6). Dies lässt sich mit dem Ansinnen des ,trying not to look bad' paraphrasieren. Zugleich werden die Schwierigkeiten einer reflexiven Prädikatenzuweisung verdeutlicht: „[W]as wirklich stimmte" ist eben einerseits nicht in Echtzeit abrufbar, andererseits durch die Definition von ,Fantasie‘ sprachskeptisch $(\Rightarrow$ II.1.4) erschwert.

Korrespondierend zum nahezu zwanghaften Umkreisen des eigenen Selbst(-Bildes) sowie den zwei denkbaren Bezugsgrößen Ideal- und Fremdbild ist auch der Blick ,nach draußen' mehr Arbeit denn Selbstverständlichkeit oder gar Vergnügen für den Genazino’schen Basistypus.

\subsection{Beobachtungszwang und Besänftigungsstrategien}

Genazinos Essay aus seinem gleichnamigen Band Der gedehnte Blick (2004) kann in vielerlei Hinsicht poetologischer Schlüssel (auch) zu seinem Roman-CEuvre sein. ${ }^{28}$ In Momenten, in denen etwa Reinhard verdutzt und verblüfft zurückbleibt $(\Rightarrow$ II.2.1), kann man die überfordernde Selbsteinsicht stark machen, kann auch das Schweigen ( $\Rightarrow$ II.1.4) als Symptom des Unausdrücklichen ansprechen - ganzheitlicher verfährt man allerdings, wenn man sich die epitextuelle Mühe macht, Genazinos Ästhetik-Grundkurse zu rezipieren:

Perplex ist ein Wort aus dem Lateinischen, es meint: verdutzt sein, überrumpelt sein, sprachlos sein - aus Verdutztheit. Diese drei Eigenschaften (verdutzt, überrumpelt, sprachlos) sind es, die im gedehnten Blick einen Unterschlupf finden. Wir sehen etwas, was wir nicht mit der gewünschten Klarheit und Eindeutigkeit verstehen, das heißt einordnen, hinnehmen und gelten lassen können, und sind deswegen perplex [...]. Die Perplexion ist das Gefäß für die Mannigfaltigkeit der Erfahrung, die wir mit dem gedehnten Blick machen und machen müssen. Die Perplexion ist das allmähliche Vertrautwerden mit der uns melancholisch stimmenden Zumutung, daß wir immer nur Splitter und Bruchstücke von etwas verstehen. ${ }^{29}$

Genazinos Romanfiguren, die von diesen Exkursen zwar gesäumt werden, auf sie aber freilich höchstens verquer gedacht metaleptisch Zugriff haben, hindert diese autoritäre Haltung nicht daran, den gedehnten Blick schweifen zu lassen:

Wir wissen nicht, warum unser Blick immerzu unterwegs ist, warum das Auge nicht still sein kann. Wir können nicht einmal sagen, warum es oft nicht entscheiden kann, wer oder was sein wahres Schauobjekt ist. Wir sind nur staunende Zeugen, wie es rastlos umherwandert von Bild zu Bild, von Detail zu Detail. Das Auge ist offenbar in einer sprachlosen Aufholjagd befangen, es lebt in der Regsamkeit eines dauernden Ungenügens, die wir das Spiel eines immerzu fliehenden Sinns nennen können. ${ }^{30}$

28 Vgl. Hermann: Elemente einer Sehphilosophie; vgl. Hubert Winkels: Schauen, langsam. In: Die Zeit vom 13. Januar 2005. Vgl. Bartl: „The kindness of strangers“, S. 76-80, für eine grundlegende Verankerung von Genazinos Konzept in Sartres Philosophie. 
Zwar weiß Genazino im Plural nicht, warum die Beobachtung niemals schläft, immerhin geht aber sein poetologischer Kommentar wie seine Romanprosa davon aus, dass das Auge zwanghaft schauen muss - obwohl es nicht klar sehen kann. Dieser Metaphorik verpflichtet ist auch das folgende Zitat, das als gutes Motto für das manische Bobachten und Verstehen-Wollen ( $\Rightarrow$ II.2.3) gelten kann: „Ich lebe wie ein Blinder in einem fahrenden Bus. Er sah auf die Straße hinunter und hatte Lust, jedem Passanten kurz die Schädeldecke aufzuklappen, um endlich Gewißheit darüber zu haben, was in aller Leute Kopf vor sich ging." (Fremde Kämpfe, S. 213)

\section{BEOBACHTUNGSZWANG UND LEIDENSDRUCK}

Aber andererseits will der Basistypus nicht zwanghaft beobachten und wahrnehmen und reflektieren müssen: ${ }^{31}$ „Ich will auf keinen Fall die ganze Zeit über nachdenken.“ (Regenschirm, S. 133) Vielmehr noch fühlt er sich nachgerade gepeinigt: „Und er wollte endlich davon befreit sein, daß ihm immerzu irgend etwas auffiel. Er wollte eine belanglose Wahrnehmung haben, weil er sich davon Ruhe versprach. [...] [E]r achtete darauf, nichts zu bemerken. [...] Das gefiel ihm gut" (Abschaffel, S. 130). Der namenlose (Anti-)Held aus Außer uns spricht niemand über uns bekommt ganz ähnliche Worte in den Mund gelegt: „Tatsächlich fühlte ich mich frei, wenn mir belanglose Dinge auffielen.“ (Außer uns, S. 62) Auch Genazino (Figur) merkt an: „Dabei spüre ich nur meine Sehnsucht danach, auch einmal auf nichts ,aufpassen' zu müssen." (Einfalt, S. 112) ${ }^{32}$ Momentweise scheint die Hauptfigur des Romans Kein Geld, keine Uhr, keine Mütze das „Glück, dass ich nichts lernen und nichts denken musste“ insofern gefunden zu haben, als er beim Laufen sogar vergisst, „ob heute Dienstag oder Donnerstag war“ (Kein Geld, S. 64).

Zumeist aber ist dieser unschuldige Zustand nicht zu haben - „Ich möchte einmal aufhören dürfen, über mein Leben nachzudenken. Aber offenbar ist das niemandem erlaubt“ (Licht, S. 11) und weicht dem Eingeständnis, „daß wir überforderte Bildmaschinen sind, die von ihrer eigenen Produktion paralysiert werden.“"33 „Er war wieder in die Fragentortur eingetaucht, die die meisten Menschen ihr Leben nennen müssen. Kurz zuvor, im Grüneburgpark, war er zufrieden gewesen, weil er sich mit nichts beschäftigt hatte." (Fremde Kämpfe, S. 196) Seit Genazinos Erstling hat dieses Prinzip bestand: Axel Degen „sah wieder ein Fräulein mit schwarzer Brille und roten langen Fingernägeln, sie trug eine hochwichtige Bluse und einen bedeutenden Rock und noch bedeutendere Schuhe: Ich ärgerte mich, weil mir das alles gleich auffiel“ (Laslinstraße, S. 122).34 Auch „Abschaffel ärgerte sich, weil er immerzu etwas beobachten mußte. Es war, als müßte er die Welt durch Beobachtung zerkleinern, weil sonst alles zuviel für ihn war." (Falsche Jahre,

31 Vgl. Genazino: Der gedehnte Blick, S. $42 \mathrm{f}$.

32 Vgl. für weitere Beispiele der Suche nach Ruhe vor den Eindrücken etwa Abschaffel, S. 130 f., Falsche Jahre, S. 495, u. Ausschweifung, S. 226.

33 Genazino: Der gedehnte Blick, S. 50.

34 Den Sachgrund dafür, beobachten zu müssen, delegieren die Figuren teils auch an die Beobachteten selbst: „Es war ihm nicht recht, daß er sofort begann, sie zu beobachten. [...] Es ärgerte Abschaffel, daß sich alte Leute so gut beobachten ließen“ (Abschaffel, S. 67). 
S. 495) Der Schuhtester aus Ein Regenschirm für diesen Tag ärgert sich nicht nur, er ist richtiggehend enerviert: „Guter Gott, wie mir dieser Zwang zum bedeutungsvollen Sehen auf die Nerven geht." (Regenschirm, S. 158) ${ }^{35}$ Eine Grundvoraussetzung des gedehnten Blicks sowohl als auch des mit ihm eng verbundenen Leidensdrucks ist das Vorhandensein von viel Zeit. Dieter Rotmund erkennt diesen Zusammenhang: „[U]nd ich habe wieder viel zuviel Gelegenheit, mich in die Vorgänge um mich herum zu vertiefen." (Heimweh, S. 20) Genazino bemüht den Vergleich mit einem Kleinkind, ${ }^{36}$ das die Unverständlichkeit der Welt qua Auge zwar vorbewusst schon ahnt, dabei aber nicht die Resignation des Erwachsenen an den Tag legt, keine standardisierte und ökonomisierte Zeit für seine Beobachtungen veranschlagt und mithin den gedehnten Blick, der erst beginnt, nachdem es vermeintlich nichts mehr zu sehen gibt, perfektioniert hat. In der Wiederentdeckung des gedehnten Blicks liegt damit bereits ein erstes Korrektiv vor, um dem Beobachtungszwang eine Besänftigungsstrategie gegenüberzusetzen.

\section{LÖSUNG DURCH BESÄNFTIGUNG}

Sich mit nichts zu beschäftigen ist/wäre dem Genazino'schen Basistypus Quell der Freude, kognitive Erholung und Entspannung. Aus der inneren Notwendigkeit aufgrund des Leidensdrucks der Protagonisten heraus sind vielfältige Besänftigungsstrategien bzw. Lösungsansätze entwickelt worden, mittels derer sich Genazinos Figuren aus den Fängen des manischen Beobachtens zu befreien suchen. Diese liegen hauptsächlich auf figureninterner Achse, aber auch externe Faktoren kommen diesbezüglich zum Tragen. So sind die kompositorisch motivierten Deus-exMachina-Strategien ( $\Rightarrow$ II.2.2) als tendenziell der externen Perspektive zugehörig näher zu untersuchen, wofür sich ein ganz bestimmtes Muster aus Genazinos Außer uns spricht niemand über uns als erkenntnisfördernd anzubieten scheint.

Wieder einmal ist ein Protagonist in seinen beobachtenden Reflexionen gefangen, bevor - aus Figurenperspektive - unversehens eine unmotivierte Lösung des Geschehens eintritt: „Endlich sah ich auf den Stufen einer U-Bahn-Haltestelle die Scherben einer Bierflasche und beendete mit diesem Bild meine mir selbst zu schöngeistigen Ausschweifungen." (Außer uns, S. 77) Zwei Dinge machen diese Szene, aber auch die Deus-ex-Machina-Situationen bei Genazino insgesamt, doppelbödig: Erstens ist es ungewöhnlich, dass kein ,Gott' bzw. keine Figur diese Aufgabe übernimmt, sondern bei Genazino in Rekurs auf die Theatermaschine Gegenstände - zumal in dieser Szene: tatsächlich im Gegensatz zum Schöngeistigen stehende - den Bildwechsel, den Szenenumbau begünstigen. Zweitens ist es außergewöhnlich, dass mit dem ,endlich` ein Signal aufscheint, das zunächst nur die Figurenmitsicht in interner Fokalisierung zu beglaubigen scheint, letztlich aber eine doppelte Lesart forciert. Während die eine einer Wunscherfüllung gleichkommt - etwa: ,Was ein Glück, das Bild erlöst mich endlich!' -, kann man das ,endlich` auch al-

35 Vgl. Grundmann: Genazino und die Kunst des bedeutungsvollen Sehens.

36 Vgl. Genazino: Der gedehnte Blick, S. 42-52. 
ternativ als ,schließlich' und somit als schlichten Marker auffassen, der eine Szene von einer nächsten sondert, der im Präteritum Schnittfolgefunktion übernimmt. Allerdings nähmen dann die mehrfach in diesem Bedeutungsumfeld auftauchenden Erlösungssignale wunder, die nicht immer mit einem endlich markiert sein müssen, ${ }^{37}$ sondern auch in Abwandlung vorliegen können: „Ich war dankbar, als ich zwei Kinder bemerkte, die weitere Überlegungen überflüssig machten." (Außer uns, S. 97)

Deus-ex-Machina-Momente tauchen mit großer Zuverlässigkeit immer dann auf, wenn ein Stimmungswechsel (vgl. Liebesblödigkeit, S. 143) hervorgerufen werden und/oder die Handlung wieder in Gang kommen soll: „Wie mir diese nicht beendbare Unglückseitelkeit auf die Nerven geht! In diesen Augenblicken kommt Herr Bausback, der Postfeind“ (Liebesblödigkeit, S. 137). Her Bausback, der Postfeind, ist ein Vehikel für den Szenenwechsel, den Stimmungsumschwung und die nahende Besänftigung, die auch immer wieder als solche benannt wird: „Zu meiner Besänftigung trägt ein Junge bei [...]. Zum Glück gehe ich gerade unterhalb eines Balkons vorbei, auf dem eine Frau steht und laut in ein Handy hineinredet." (Heimweh, S. 92 f.) Stets ist es erzählerisch ähnlich gestrickt: „Zum Glück muß ich nicht anfangen, sie nacheinander aufzuzählen, weil ich in diesen Augenblicken auf einen Obststand zugehe“ (Heimweh, S. 150). Oder: „Zum Glück entdeckte ich [...] einen Grashüpfer." (Tiere, S. 42)

,Zum Glück‘ finden die Protagonisten in den Momenten denjenigen äußeren Impuls, der - wie auch immer er konkret geartet ist - als Tertium comparationis die ,inneren Tumulte' lösen kann. ${ }^{38}$ Diese externe Besänftigungsstrategie gegen Beobachtungszwang allgemein, gegen den darin schlummernden ,Schmerz' im Speziellen, findet sich etliche Male in Genazinos Romanen und führt regelmäßig dazu, dass die innere Befindlichkeit an ein äußeres Bild bzw. eine äußere Betrachtung weitergereicht wird (vgl. Licht, S. 65; vgl. Glück, S. 85 f.). Gewissermaßen wird hier der Teufel mit dem Beelzebub ausgetrieben, indem Beobachtungen mit Beobachtungen begegnet wird. Allerdings liegen die heilsamen, besänftigenden Beobachtungen eben hauptsächlich im Bereich der Belanglosigkeiten - wenn man das bei Genazino überhaupt so trennen kann oder nennen darf -: „Die Operation gefällt mir so gut, daß ich dem Mädchen auf der Stelle ein weiteres Brötchen spendieren möchte. Natürlich halte ich mich zurück; ich schaue nur hin, weil mich die Bilder beruhigen“ (Einfalt, S. 109); „bis mich die Stille der angeschauten Dinge langsam ergreift und mich ebenfalls ruhig macht“ (Heimweh, S. 150); „Guter Gott, jetzt gehen diese Fragen schon wieder los. Da kommt mir der Anblick eines etwa zehnjährigen Jungen zu Hilfe. [...] Er ist nur das Zeichen, daß ich mich habe beruhigen können. Ich glaube jetzt sogar, daß Teile der Ausgeglichenheit der Bürste auf mich selber übergehen." (Regenschirm, S. 134)

37 Aber durchaus immer wieder sein können: „Ich stöhnte über die Überflüssigkeit meiner Reflektionen. Endlich roch ich den Schweiß in meinem Hemd. Der Geruch half mir, mit Denken sofort aufhören zu können.“ (Außer uns, S. 120) Auch: „Da sehe ich einen älteren Mann in einem dünnen grauen Regenmantel, der mich endlich ablenkt." (Einfalt, S. 117) 
Wie Dei ex Machina tauchen Personen, Erlebnisse und mithin Beobachtungen aus dem Nichts auf, um dem Protagonisten kleine Inseln des Nicht-nachdenken-Müssens zuzuschustern oder zu starke/bedeutsame/unerträgliche Gedanken und Beobachtungen zu ,erden'. So wird es dem Schuhtester aus Genazinos Ein Regenschirm für diesen Tag durch die Beobachtung eines Jungen, der sich eine Höhle baut, ermöglicht, sich vom spaßgesellschaftlichen Sommerfest abzukehren (vgl. Regenschirm, S. 172 f.; $\Rightarrow$ II.1.6), und auch Weigand wird durch einen „Blick nach draußen“ (Wohnung, S. 80) aus der Tristesse gerettet. In Eine Frau, eine Wohnung, ein Roman tritt auch zutage, wie sich innere angestaute Probleme tatsächlich kanalisieren lassen, wenn sie auf plötzliche äußere Erscheinungen abfließen können: „Gierig stürzte sich meine Trauer auf das Aufund Abblitzen der Perlen und löste sich dabei langsam auf." (Wohnung, S. 110) Die personifizierte Emotion kann sich entladen, wenn ablenkende Bilder als Rettungsanker fungieren.

Nicht weniger plötzlich ,aus der Maschine', indes weniger ,extern vorgesetzt' als intern perspektiviert und gewollt gewählt kristallisiert sich die ,aktive Besänftigung' „Von den Bildern gehen eigenartige Verstummungseffekte aus, die jetzt sogar in mein Innenleben eindringen. Ich wehre sie ab, indem ich zwei hellen Kinderstimmen folge." (Liebesblödigkeit, S. 16 f.) Diese proaktive, interne Spielart findet sich auch im Roman Außer uns spricht niemand über uns:

Ich geriet in eine sonderbare Schleuderstimmung, die mir aus meinem Leben vertraut war. Es würde jetzt nicht lange dauern, dann würde mich eine mittlere Hysterie erfassen und mir einflüstern, dass alles um mich herum heimlich abstarb; ich würde allein übrig bleiben und genau diese Verlassenheit dann nicht begreifen. Um aus diesen Stimmungen herauszufinden, betrat ich einen Obstladen (Außer uns, S. 50).

Das ist das Gegenteil von Deus-ex-Machina-Plötzlichkeit! Der namenlose Ich-Erzähler zieht sich selbstinitiativ am Schopf aus der anschleichenden depressiven Stimmung heraus und stellt seine psychische Widerstandsfähigkeit in der Bekämpfung individueller Krisensituationen (Resilienz) eindrücklich unter Beweis. Der Protagonist kennt seine inneren Mechanismen so gut, dass er aktiv Schauplatz/Blickrichtung ändert, 39 um auf andere Gedanken zu kommen. Aber natürlich hat dieser Abwehrmechanismus auch seine Grenzen: „Ich will nichts Bestimmtes sehen, ich will mich durch sehen beruhigen, aber es klappt nicht.“ (Liebesblödigkeit, S. 112)

Genaugenommen möchten die Protagonisten sich nicht durch Sehen beruhigen, sondern durch Schauen besänftigen: „Beobachten ist dann nicht nötig; an seine Stelle tritt das Schauen, das nichts herausfinden muß." (Fleck, S. 227) ${ }^{40}$ Die Betrachtungen leicht zu nehmen, sie auch wieder schnell vergessen zu können, sie der Bedeutungsschwere zu entkleiden, sind die Stoßrichtungen: „Vielleicht ließ sich überhaupt nur dort richtig leben, wo bedeutungslose Beobachtungen möglich waren." (Ausschweifung, S. 26) Diese gewünschte Gleichgültigkeit findet sich z.B. in den Kassiererinnen: „Es freute mich, inmitten von bedeutungslosen Augenblicken zu leben, die rück-

$39 \quad$ Als Variation dieses Themas kann das kalkulierte betreten oder verlassen von Geschäften aller Art gewertet werden und auch das (Nicht-)Kaufen bestimmter Gegenstände sowie Lebensmittel.

40 Vgl. dazu auch Jung: „Umhergehen und Zeitverschwenden“, S. 66 f., sowie für Beispiele, die in der gleichschwebenden Aufmerksamkeit das Heil finden, Einfalt, S. 20, und Kein Geld, S. 81. 
standsfrei von mir durcheilt wurden." (Kassiererinnen, S. 10) In diesen Momenten fühlt der Basistypus sich „als würden gewisse Teile der Welt vor mir in ein Flüstern verfallen, für das ich mich nicht mehr interessiere. Ja, es ist sogar so, als dürfte ich mir jetzt endlich eingestehen, daß mich dieses Flüstern nie interessiert hat." (Liebesblödigkeit, S. 185) ${ }^{41}$ Als Topos der Schau des Ewigen im Kontrast zu kurzlebigen (Deutungs-)Arbeitshypothesen ist diese Form der ungezwungenen ästhetischen Wahrnehmung via Auge bei Genazino nur selten zu haben und wenn, dann in Begleitung eines der vier Signalkonzepte: Tiere, Flanieren, Meer, (Sport).

Im Bereich des Romanspezifischen findet etwa Abschaffel die Lösung einmal kurz beim Sport:

Erleichternd empfand er, daß er während des Laufens nichts dachte, nichts erinnerte und, außer den unmittelbaren Reaktionen des Laufens selbst, nichts fühlte. [...] War der Sport deshalb bei den Menschen so beliebt, weil der Kopf leergeschüttelt wurde wie ein altes Kissen? In keiner anderen Situation seines Lebens war Abschaffel eine derartig unmittelbare Erleichterung vergönnt. (Falsche Jahre, S. 480; vgl. Falsche Jahre, S. 435)

Als Modell macht diese Form aber keine Schule. Weitaus eher sind die omnipräsenten Flanerien das Mittel der Wahl bzw. gar ein „Allheilmittel[]“ (Kein Geld, S. 25):

So gehen wir eine Stunde lang im Schweigen des Meeres umher. Bei der Rückkehr in das Dorf [...] setzt das andere Leben wieder ein, das Registrieren, das Aufmerken, das Beobachten, die unablässig tätige Zurechtfindungsmaschine, die beim Anblick des Meeres einmal ausfallen durfte. (Fleck, S. 177) 42

Der Flaneur flaniert, um die „Zurechtfindungsmaschine“ ruhen zu lassen, Ruhe vor Gedanken und Sorgen allgemein zu finden (vgl. Fremde Kämpfe, S. 63) oder auch, um sich nicht erinnern zu müssen (vgl. Regenschirm, S. 17 f.). Es sollte dabei nicht vergessen werden, dass sich Besänftigungsstrategien auch abnutzen und überleben können. So ist es für Wilhelm Genazinos Romanfiguren familienähnlich typisch, am Nicht-/Transit-Ort ,Bahnhof ${ }^{\prime}$ zur fast meditativen Übereinstimmung mit sich selbst zu gelangen; der Protagonist aus dem Roman Außer uns spricht niemand über uns hingegen hält wehmütig fest: „In früheren Jahren war ich in solchen Stimmungen zum Bahnhof gegangen, aber dieser Fluchtweg war verschlissen und reizlos geworden." (Außer uns, S. 65) ${ }^{43}$

Quasi als Quintessenz fassen Genazinos Erzähler den Wunsch nach Ruhe, Gleichgültigkeit und Besänftigung immer wieder gerne in Tiervergleiche, die noch immer ein probates Besänftigungsmedikament darstellen. Für diese Formation mag Sokrates Pate gestanden haben oder nicht, jedenfalls ist es kein Zufall, dass sich Sokrates einem glücklichen Schwein und keinem

41 Vgl. für ein Beispiel mit Schnittmengen zur Sprachskepsis ( $\Rightarrow$ II.1.4) auch: „So möchte ich immer leben können: als glücklich Enttäuschter, der die Augen schließt und wieder öffnet, der die Dinge sieht und arglos die ihnen zugehörenden Wörter denkt: Motorrad, Zeitung, Abfall, Frau, Schuhe, Baum, Balkon, Bus, Licht." (Fleck, S. 118)

42 Zum Meer als besänftigendem Trostspender vgl. auch Obdachlosigkeit, S. 82.

43 Besondere Verzweiflung entsteht dann, wenn selbst das Schauen nicht mehr zu helfen scheint: „Er hatte nicht bemerkt, daß er selber schon seit einiger Zeit bemüht war, sich selber aus dem Weg zu gehen. Dies gelang immer eine Weile mit allerlei Beobachtungen und Unterhaltungen aus Beobachtungen, bis der Punkt erreicht war, da ihm schon die Arbeit des Beobachtens und Bemerkens zuviel wurde." (Abschaffel, S. 55) 
glücklichen Toren gegenübergesehen hatte. Die Wichtigkeit dieser Denkfigur bei Genazino beglaubigt bereits die Titelwahl von Wenn wir Tiere wären (2011), den man als Konditionalsatz weiterführen kann: dann stünde die „Zurechtfindungsmaschine“ zeitweilig still, dann wären die Protagonisten vom Beobachtungszwang befreit, dann wären „bedeutungslose Beobachtungen möglich“. Der Bezug zu Peter Lichts Songtext „Safarinachmittag“ (2003) mag von Genazino nicht intendiert sein, aber auch dort führen das lyrische Ich und sein Gegenüber „Gespräche / über unsre Fragen / welche Tiere wir gerne wären / wenn wir mal wieder Tiere wärn“, dieweil „die Hirne ruhn“. Licht und Genazino tradieren damit die bukolische Vorstellung einer Verklärung der vermeintlichen Einheit von Tier und Mensch inklusive Sorgenfreiheit im Idyll.

Der das interesselose Schauen teilweise gelernt zu haben scheinende männliche Protagonist aus dem Roman Leise singende Frauen jedenfalls nimmt „Teil an der poetischen Angstlosigkeit der Tiere, die mich mehr und mehr ausfüllt mit der unerhörten Entdeckung, daß wir vielleicht nur dann zufrieden sein können, wenn wir nichts bedenken müssen." (Frauen, S. 106) Bezüglich der Artenvielfalt sind keine Grenzen gesetzt: Sei es zu Luft, zu Wasser oder zu Land - Tiere in ihrer nicht IM-bestimmten Art zu leben bzw. ihren Wesensmerkmalen (Flucht, Unsichtbarkeit) bilden häufiger den Bezugspunkt (Kulmination im Roman Wenn wir Tiere wären) für erstrebenswertes Handeln: „Schafe können es sich leisten, sich für nichts zu interessieren, und darum habe ich sie damals beneidet" (Obdachlosigkeit, S. 48), gesteht sich die Lehrerin ein und setzt später hinzu: „Dann erst fiel mir ein, daß es Tränen des Verlangens waren, des Verlangens nach der Gleichgültigkeit der Schafe." (Obdachlosigkeit, S. 77) Aber auch Vögel vereinen auf sich diejenigen Merkmale, die Genazinos Figurenbasistypus so unerreichbar sind: „Ich wollte doch naturnah leben, wie eine Amsel von Baum zu Baum hüpfen und das menschliche Verlangen nach Größe und Eindrücklichkeit vergessen." (Außer uns, S. 33) All diese Wünsche, die aus Gründen der weitgehenden Nicht-Erfüllbarkeit ins arkadische Tierreich verschoben werden, gipfeln in dem Bekenntnis: „Ich will [...] ein zarteres Leben als das, was ich bisher hatte, und ich glaube, daß die meisten Menschen das ebenfalls wollen, aber nicht wissen, wo sie nach einem zarteren Leben suchen sollen. Ebendiese Suche ist das Thema der Schule der Besänftigung." (Glück, S. 147; $\Rightarrow$ II.2.5)44 Letztlich gibt es aber auch bestimmte Beobachtungszwänge, denen die Figuren überhaupt nicht entgegentreten möchten, da sie als lustvoll wahrgenommen werden. Dies ist immer dann der Fall, wenn es etwas intellektuell zu durchschauen gibt.

$44 \quad$ Ein anderes Bild für ,innere Mitte und einen Standpunkt über den Dingen findet sich in Ein Regenschirm für diesen Tag, wo es heißt, man benötige bestenfalls „die Unangefochtenheit eines Mönchs. [...] Schon nach ein paar Schritten merke ich, daß es kaum etwas gibt, was ich mehr vermisse als die Unangefochtenheit eines Mönchs." (Regenschirm, S. 66) 


\section{DURCHSCHAUEN UND (NICHT-)DURCHSCHAUTWERDEN ${ }^{45}$}

,Sich nicht gerne in die Karten schauen lassen', ,jemandem auf die Schliche kommen', ,Wissen ist Macht' etc. sind Redewendungen, die sich in einem zentralen Punkt überschneiden: Das eigene Wissen wird dem der anderen im Sinne eines hierarchischen Machtverhältnisses entgegengesetzt, wobei es die Spielregeln erfordern, dieses Ungleichgewicht im Wissensvorsprung um jeden Preis aufrecht zu erhalten. Bei Genazino findet sich ein Reichtum an Variationen dieser Denkfigur, die mitunter die Grenze des psychologisch Unbedenklichen überschreiten. Bereits vor ca. 70 Jahren konstatiert Adorno in seinen Studien zum autoritären Charakter (1947/1950) etwa „pathologische Überlegenheitsfantasien“46 als Signum der charakterlichen Struktur autoritärer Persönlichkeiten. Und tatsächlich punkten Genazinos Figuren nicht nur in dieser Hinsicht in ableitbaren Aussagen auf der sogenannten F(aschismus)-Skala, die „implizite antidemokratische Tendenzen und Faschismuspotential“ misst, sondern auch etwa in der „Überbetonung der gesellschaftlich befürworteten Eigenschaften des Ich“ ( $\Rightarrow$ II.2.4), ${ }^{47}$ der autoritären Aggression „Tendenz, nach Menschen Ausschau zu halten, die konventionelle Werte missachten, um sie verurteilen, ablehnen und bestrafen zu können“48 ( $\Rightarrow$ II.4.1 u. $\Rightarrow$ II.4.4) - oder der Subskala „Aberglaube und Stereotypie“49 $(\Leftrightarrow$ II.1.6, $\Rightarrow$ II.2.3 u. $\Rightarrow$ II.4.2). Von besonderem Interesse ist an dieser Stelle allerdings die Neigung, dem Narzissmus zu huldigen, um der eigenen mangelnden Selbstwirksamkeit $(\Leftrightarrow I I .1 .3$ ) qua Allmachtsfantasie bzw. pathologischer Überlegenheitsfantasie zu begegnen: „Nur ich, Axel, wußte das alles und sagte es niemandem“ (Laslinstraße, S. 16). In anderen wie in offenen Büchern zu lesen, diese Fähigkeit aber unter Verschluss zu halten, wirkt auf den ersten Blick wie ein Widerspruch zur defizitären Personenwahrnehmung $(\Leftrightarrow$ II.1.3). Allerdings handelt es sich im Gegensatz zur generellen (In-)Kompetenz bei den hier im Vordergrund stehenden Zügen um solche aus intimen Vertrauensverhältnissen (Eltern, Partnerinnen) oder um erzähltechnisch ausgewiesene Unzuverlässigkeiten, sodass der Widerspruch sich als lediglich scheinbarer auflöst. In Axel Degen, der - positiv formuliert - Freude an der Geheimniskrämerei wie kaum eine andere Figur hat, sind die Überlegenheitsfantasien dementsprechend stark ausgeprägt. Über seine Freundin Elke erhebt er sich, denn „sie ahnte nicht, daß ich mehr wußte als sie, viel mehr, wahrscheinlich dachte sie schon jetzt nur noch an Brautschleier" (Laslinstraße,

45 Vgl. auch ,Beobachtet- und Durchschautwerden' $\Leftrightarrow$ II.2.4) sowie ,Flucht', ,Versteck(n) und Verborgenheit' $\Rightarrow$ II.2.5).

46 Gero von Randow: Theodor W. Adorno. Der Trick mit der Gefühlsbefreiung. In: ZEIT ONLINE vom 01. Dezember 2016. Online: <http://www.zeit.de/2016/48/theodor-w-adorno-faschismusautoritarismus/komplettansicht>.

47 [Autoritäre Persönlichkeit]. In: Wikipedia. Die freie Enzyklopädie. Online: <https://de.wikipedia.org/wiki/Autorit\%C3\%A4re_Pers\%C3\%B6nlichkeit>. [F-Skala]. In: Wikipedia. Die freie Enzyklopädie. Online: <https://de.wikipedia.org/wiki/FSkala_(Autorit\%C3\%A4re_Pers\%C3\%B6nlichkeit)>.

49 Johannes Schwarte: Der werdende Mensch. Persönlichkeitsentwicklung und Gesellschaft heute. Wiesbaden 2002, S. 255 f. 
S. 196). ${ }^{50}$ Auf diesem Mehrwissen findet seine Überheblichkeit ihren Nährboden, wie auch Abschaffel aus seinem (vermeintlichen) Wissensvorsprung Allmachtsfantasien zieht: „Als er in der Stadt war, glaubte er, weit und breit der einzige zu sein, der auf allen Gebieten Bescheid wußte." (Sorgen, S. 270) Handelt es sich dabei um den bloßen Glauben, ist er sich an anderer Stelle sicher, „daß außer ihm niemand in diesem Zelt war, der seine Selbsttäuschung überhaupt hätte begreifen können." (Sorgen, S. 261) Wie diese erfolgreiche Verheimlichung51 nehmen sich etliche Beispiele aus, am idealtypischsten auch hinsichtlich des Durchschauens ist wohl dieses: „Herrn Fuchs gefiel es, diese unsichtbaren Gegebenheiten durchschauen und begreifen zu können." (Ausschweifung, S. 132)

Weniger durch autoritäres Herrschaftswissen als durch die Genugtuung ob seiner eigenen Verstehensleistung zeichnet sich eine Reflexionspassage Fuchs' aus:

Er entdeckte, daß er in diesen Augenblicken insgesamt vier Personen verstand: seinen eigenen singenden Vater von damals, sich selbst als damals gegen den Vater protestierendes Kind, sein eigenes, heute gegen ihn protestierendes Kind und am Ende sich selbst als heute singender und Laute hervorstoßender Vater, der sich von seinem Kind nicht einschüchtern ließ. (Ausschweifung, S. 192)

Fuchs genießt es schlicht, sich den intellektuellen Kitzel vorzugaukeln, er allein wäre derjenige, der unsichtbare,Weltformeln' erkennen und verstehen kann, wie es auch W. blasiert beseelt, er „sei der einzige, der von der Himmelsbahn des Mondes wüßte.“ (Licht, S. 17) Einmal auf dieser ,metaphysischen' Spur ist auch die namenlose Figur aus Die Kassiererinnen mit der hellseherischen - und damit wieder näher an der pathologischen Form - Vorstellung zu zitieren: „Die ganze Zeit wurde ich das Gefühl nicht los, dass ich jederzeit wusste, was im nächsten Augenblick passieren würde." (Kassiererinnen, S. 81) Lediglich der Nachtrag, dass dieser Eindruck an der „Übervertrautheit mit Gesichtern, Gesten und Redeweisen“ (Kassiererinnen, S. 81) liege, führt zurück in die Wohlbegründetheit einer realistisch angelegten Erzählwelt.

Da sich Realismus im Discours und Fantasiebegabtheit in der Histoire mitnichten ausschließen, leitet ein alter „Wunschtraum“ Wolf Pescheks über vom Durchschauen zum NichtDurchschautwerden: Er

wollte einmal in einem Schaufenster eines Kaufhauses übernachten dürfen. Er hatte es sich wunderbar vorgestellt, ruhig im Bett zu liegen, während es draußen langsam Nacht wurde und immer mehr Menschen auf den hell erleuchteten Straßen erschienen und ihren Absichten nachgingen: und

$50 \quad$ Gerade in Gleichberechtigungsbelangen finden sich viele asymmetrische Kommunikationen (vgl. Watzlawick/Beavin/Jackson: Menschliche Kommunikation, S. 68 ff. u. S. 103 ff.; $\Rightarrow$ II.5.3): „Frau Schönböck, Sie trauen sich nicht, mir zu sagen, daß Sie mich nicht verstehen; Sie hängen so sehr an all den Dingen, die Sie sich leisten, an jedem Urlaub, an jeder Schallplatte [...], daß Sie gar nicht begreifen können, wie sich zwei Dutzend Schallplatten in Wohnzimmermüll verwandeln. Das ist unfaßlich für Sie, sagte er." (Sorgen, S. 377 f.)

51 Vgl. für ein aus Rücksichtnahme motiviertes Verschweigen auch Sorgen, S. 176 f. 
er, Wolf, hätte das Geschehen beobachten können und wäre heimlich wissend geworden. (Fremde Kämpfe, S. 250 $)^{52}$

Es handelt sich um einen verhältnismäßig naiven Wunsch, ist doch die offenkundige Gefahr, selbst zum Objekt der Beobachtung zu werden - im Schaufenster! - nicht mit einem Wort erwähnt. Dabei ist Genazinos Basistypus höchst vorsichtig in dieser Richtung: „[I]ch konnte meine Richtungsänderung begründen mit Zigarettenbedarf, und kein Mensch, weder Niemand noch Jemand, weder die Bedienung noch Elke, niemand wußte davon." (Laslinstraße, S. 190) Als Bildspender dieser Familienähnlichkeit möge die Tarnkappe dienen, die zwar das Erkennen erlaubt, das Erkannt-Werden aber unterbindet: „Nur mit dem einen, allerdings grandiosen Unterschied, daß es von Jürgen Grabowski alle Zuschauer wußten, von ihm aber, Eckhard Fuchs, nur er selber." (Ausschweifung, S. 237) Dafür arbeitet der Basistypus hart an sich: Abschaffel etwa „behielt es für sich, weil er nicht mochte, daß in diesem Büro über ihn nachgedacht wurde.“ (Abschaffel, S. 8) Das Verbergen des eigenen Selbst beherrscht auch der Protagonist aus Außer uns spricht niemand über uns kalkuliert und protektiv geschult mit assertiver Wirkung:

Ich erkannte, dass Carola eine Spur einfältig war; ich kam häufig zu dieser Einsicht, weil ich auch einfältig war, wenn auch auf anderen Gebieten und außerdem meine Einfalt verbarg. Oft dachte ich: Du bist der geheime Einfältige und wirst deswegen von allen gehemmt Einfältigen bewundert. ( $\mathrm{Au}$ ßer uns, S. 72)

Undurchschaubar sein zu wollen, äußert sich weiterhin in Abschaffels „Wunsch, ganz und gar unansehnlich zu sein. Er wollte wie ein häßlicher Klumpen dasitzen und von niemandem eingeschätzt werden können.“ (Abschaffel, S. 19) Allzumal nicht von seinen Eltern, die „alles in der Welt von ihm glaubten, aber nur nicht, daß er am Abend des gleichen Tages in ein Bordell ginge.“ (Abschaffel, S. 20) Dass es nicht wirklich dazu kommt, ist den zukunftsungewissen Vorausdeutungen unzuverlässigen Erzählens geschuldet $(\Rightarrow I .2 .3)$, trotzdem ist Genazinos Figurenbasistypus in diversen Situationen „froh, daß dies niemand von ihm wußte." (Ausschweifung, S. 68) Es bedarf nicht der Rumpelstilzchen-Allusion, um der Macht des Wissens über andere als Herrschaftsinstrument Ausdruck zu verleihen, es genügt, die Überzeugung Pescheks anzuführen, nach der es wünschenswert sei, „ein undurchschaubarer, das heißt sein eigener Mensch geblieben zu sein." (Fremde Kämpfe, S. 124) In der Gleichung: ,Selbstbestimmung = Undurchschaubarkeit’ drückt sich genaugenommen ein Merkmal des harten Kerns der Figuren aus, was Grund genug ist, mehrere ,Firewalls‘ des Selbstschutzes wertzuschätzen: „Er fühlte sich von den anderen Menschen falsch eingeschätzt und deshalb doppelt geschützt: wahrscheinlich hielten sie ihn für einen Arbeitslosen, der seine Unterstützung verplemperte." (Fremde Kämpfe, S. 151) ${ }^{53}$ Mitun-

52 Die Mehrheit der Beispiele widerspricht der oben zitierten Überzeugung Genazinos, Sehen und Verstehen seien ein und dasselbe: „Abschaffel hatte immer noch die lächerliche Idee, durch Beobachtung herauszufinden, ob sie es von Anfang an nur auf ihn abgesehen hatte." (Sorgen, S. 294) Vgl. dazu auch: „[D]as Zusammensein mit einer Frau, die mich von morgens bis abends durchschaute, wäre für mich eine extreme Belastung gewesen." (Kein Geld, S. 31) 
ter ereignet es sich aber nichtsdestotrotz, dass die Tarnkappe ihre Wirkung verliert und das aufwendig verdeckte Figurenselbst enthüllt:

Leider gab es nicht viel, was ich mit den anderen Lehrlingen besprechen konnte. Sie waren bloß jung und hatten keine geheimen Pläne. Mit einer Ausnahme: Anselm Marquard. Er war schon fast zwanzig Jahre alt und fiel mir durch seine nervösen, fliehenden Bewegungen auf. Er war der einzige, der die Idee meines Selbstschutzes in der Kantine (das Sitzen an unaufgeräumten Tischen) zuerst durchschaute und dann ignorierte. (Wohnung, S. 18 f.)

Eine Möglichkeit, diese Durchschaubarkeit der Protagonisten auf ein Minimum zu beschränken, besteht in der Wahl unbeobachteter bzw. mitunter unbeobachtbarer Beobachterpositionen.

\section{UNBEOBACHTETE BEOBACHTER}

Andrea Bartl hält hellsichtig fest, dass Genazinos

Figuren das Erblickt-Werden mitunter als Zudringlichkeit [erleben]. Der Blick von anderen, der auf sie fällt, verortet sie wider Willen in alternativen Bedeutungszuschreibungen, die nicht die ihren sind. [...] Der an Sartre orientierten Erfahrung, der Blick des Anderen degradiere den Betrachteten, wird in Genazinos Texten immer wieder ein utopisches Gegenkonzept an die Seite gestellt: das Ideal der Verborgenheit, genauer: sehen zu können, ohne selbst gesehen zu werden. ${ }^{54}$

Für ein solches „Ideal der Verborgenheit“ benennt Bartl die gebaute Höhle des Jungen (s.o.): „Die Szene setzt das Ideal des Beobachtens, ohne selbst beobachtet zu werden, als Ideal des SichVerbergens und damit des Sich-des-sozialen-Zugriffs-Entziehens ins Bild." $\left(\Rightarrow\right.$ II.2.4) ${ }^{55}$ Das ist bestmöglich in die Blick-Tat überführbar, wenn die ,Tarnkappe“ noch sitzt: „Der Blick aus gut geschützten Passagen, der Blick aus Fensterscheiben oder von perspektivisch erhöhten Standpunkten, die Übersicht bieten, aber den Beobachter von den Blicken der anderen schützen, ist ja bereits der vielfach erprobte Blick des Ich-Erzählers.“56 In der Tat sind Genazinos Figuren Virtuosen im unbeobachteten Beobachten: „Die drei konnten die Masse der Angestellten beobachten, von ihnen aber nicht beobachtet werden, das war ihr Privileg." (Abschaffel, S. 51 f.) Hirsch ist zudem beizupflichten, dass in Genazinos Figurenromanen sogar expressis verbis von „erhöhten Standpunkten“ aus geschaut wird: „Die Lehrlinge küßten sich und rauchten dabei und merkten nicht, daß ich ihnen aus einiger Entfernung (und von oben) zusah." (Wohnung, S. 23) Genauso verhält es sich mit den Blicken „aus gut geschützten Passagen“:57

Ich versteckte mich hinter einem Stapel Matratzen und verfolgte Thea mit leider immer noch erregten Blicken. Ich wollte nicht, dass sie mich entdeckte, ich wollte nicht mit ihr reden. Schon gar nicht wollte ich ihr zeigen, dass ich mich immer noch zu ihr hingezogen fühlte, sogar in einem Möbelhaus. (Tiere, S. 142)

Zu Hirschs „Blick aus Fensterscheiben“ gesellt sich ferner derjenige ,in Fensterscheiben“:

54 Bartl: „The kindness of strangers“, S. 79.

55 Bartl: „The kindness of strangers“, S. 80. Vgl. auch: „Aber um eine Aktentasche aus dem Verborgenen zu betrachten, ist das Café geeignet." (Frauen, S. 16) Vgl. auch Regenschirm, S. 10.

56 Hirsch: „Schwebeglück der Literatur“, S. 108.

57 Vgl.: „Dennoch wollte ich Elisa aus einiger Entfernung eine Weile betrachten. Ich versteckte mich in einer Passage" (Licht, S. 12). 
Dort, im Erdgeschoß, gut verborgen hinter einem Lamellen-Sichtschutz, sitzt mein ehemaliger Freund Henschel, der sich vor vielen Jahren aus verletzter Scham von mir abgewandt hat. [...] Die Lamellen hinter der Scheibe seines Zimmers stehen günstig. [...] Er blättert eine Akte durch und kommt niemals auf die Idee, daß ihn von draußen jemand anschaut (Liebesblödigkeit, S. 154).

Erzähltheoretisch frappant ist in dieser Schilderung die überpointierte Verborgenheit: Der alte Bekannte seinerseits ist versteckt, dennoch gelingt es dem sich selbst verbergenden Beobachter, diese Tarnung zu durchschauen und zugleich noch ,einen draufzusetzen', indem er sich dessen und des Mind-Readings, dass jener davon nichts weiß - erfreut. Derart mannigfaltig ist diese Grundkonstellation, dass es nicht möglich ist, sie hier systematisch zu durchdringen. Unbeobachtete und unbeobachtbare Beobachtungen sind schlicht und ergreifend im Hardcore anzusiedeln und wenige Beispiele müssen als Teil für die Gänze stehen: Degen freut sich darüber, dass „sie wieder nicht bemerkte, daß ich am anderen Ende unseres langen Flurs stand und sie beobachtete“ (Laslinstraße, S. 17); Abschaffel „beobachtete sie heimlich, und wenn er sie lange genug beobachtet hatte, wußte er nicht mehr genau, ob er nicht auf dem Boden seiner tiefen Verachtung, die er für die Campingleute hegte, zu niemandem sonst gehören wollte" (Sorgen, S. 160; vgl. Sorgen, S. 273; vgl. Falsche Jahre, S. 427; $\Rightarrow$ II.1.1); Rotmund ist es wichtig, „daß ich mein gutes Versteck (immer noch hinter den Holunderbüschen) halte“ (Glück, S. 43) - die Lehrerin aus Die Obdachlosigkeit der Fische bricht insofern die Regeln, als eine Patt-Situation die Szenerie der versteckten Standpunkte bestimmt: „Die Katze verharrte in ihrem geschützten Winkel, ich verharrte in meinem geschützten Ausguck.“ (Obdachlosigkeit, S. 76)

Nuancen mit Mehrdimensionalität und Interpretationsspielraum im gesteckten Rahmen gibt es natürlich auch. So überschreitet Degen sowohl die unbeobachtete Beobachtung in Form des ,unbeobachteten Belauschens - „[I]ch hörte das Gekreisch der Juttamutter und lief an unsere Wohnungstür, stellte mich dahinter auf und lauschte durch die verschlossene Tür" (Laslinstraße, S. 39) - als auch die Maßnahme mit zweierlei Einheit: „[A]uf der anderen Straßenseite hatten sich ein paar Frauen angesammelt, vereinigt zum Glotzen und Gaffen“ (Laslinstraße, S. 40). Er tut prinzipiell nichts anderes, aber eben unsichtbar - den Vorwurf an die anderen als selbstbezüglichen zu erkennen, fehlt allerdings die Sensibilität.58 Ein gänzlich anderes, nichtsdestoweniger interpretationswürdiges Beispiel gibt W. ab, der einen Gegenstand zur heimlichen Beobachtung kürt:

Ich lege das Album auf eine Bank, an der viele Menschen vorübergehen, und beobachte aus einiger Entfernung, was mit ihm geschieht. Viele Personen bemerken das Album, aber sie interessieren sich nicht und gehen weiter. Erst ein ungefähr zwölfjähriges Mädchen setzt sich auf die Bank, legt sich das Album in den Schoß und schlägt sorgfältig Seite um Seite um. Offenbar betrachtet sie jedes einzelne Foto. Ich spüre, daß ich auf seine ruhige Art des Schauens neidisch werde. Ich hätte nicht so schnell aufgeben sollen! Ich hätte mir einen Platz suchen, ich hätte mir eine Menge Zeit lassen und mich den Bildern hingeben sollen. (Fleck, S. 46)

58 Vgl. für eine Situationsbeschreibung, in der Abschaffel dezidiert zu den skizzierten ,Gaffern' gehört: „Abschaffel gehörte zu den Zuschauern, die sich draußen an der Schaufensterscheibe aufstellten und noch immer nicht von der Beobachtung des alten Mannes ablassen wollten.“ (Sorgen, S. 193) 
Als Schnittfläche vom neidvoll anerkannten gedehnten Blick aus Kinderaugen (s.o.) mit der Vorliebe dafür, andere(s) unbeobachtet beobachten zu können, fungiert die Neugier: „Mein erster Impuls, zu ihr zu gehen und mich an ihren Tisch zu setzen, verschwindet in der Beobachtung, daß auch Sonja angespannt ist, genau wie ich. Außerdem bin ich neugierig, ich möchte sehen, was sie allein macht." (Heimweh, S. 153)

Dagegen ist es vom heimlichen Betrachten zum Voyeurismus und somit zur Störung der Sexualpräferenz (vgl. ICD-10 F65.3) nicht sonderlich weit.

\section{VOYEURISMUS UND STALKING}

„Tatsächlich linste ich, so versteckt ich konnte, auf die Brust der stillenden Frau. Wenn ich Brüste (oder Teile davon) im Ausschnitt einer Frau sehe, kämpfe ich sofort gegen eine übermäßige Anziehung, auch bei schwangeren Frauen." (Tiere, S. 16; vgl. Kein Geld, S. 44) Nicht nur von der Brustfixierung wird später noch die Rede sein ( $\Rightarrow$ II.5.5); dem sexuell ausgerichteten Voyeurismus korrespondiert zudem die in einer weiteren Begriffsverwendung anzutreffende Lust am geheim(nisvoll)en Beobachten intimer Details generell: „Aber er hatte bemerkt, welche Lust es ihm machte, unbeobachtet und allein in einer fremden Wohnung zu sein und alles ansehen zu können.“ (Abschaffel, S. 35) Desgleichen ist dies Degens Vergnügen, sich ins elterliche „Schlafzimmer geschlichen [zu haben], gerade so, als hätte ich beobachtende Augen zu fürchten“ (Laslinstraße, S. 90).

Um diese Lust zu befriedigen, sind auch die Mittel des Stalkings geheiligt: Die Verfolgung fremder Personen - bevorzugt: Frauen - ist gang und gäbe, ein Problembewusstsein für diese Form der Indiskretion Mangelware: „Er hatte kurz zuvor den Plan gefaßt, die Frau ein wenig zu verfolgen, weil er sehen wollte, was sie mit dem Brief machte." (Falsche Jahre, S. 562) Während der Basistypus andere Personen ,ein wenig verfolgt', darf der Leser natürlich dabei zusehen, wie sich diese (unbewusst und/oder unfreiwillig) vor den Verfolgern ,entblößen` (vgl. Frauen, S. 18 f.) Ein Movens wird immer wieder genannt: „Wieder bemerkte Herr Fuchs, daß sich seine eigene Unruhe legte, wenn er die Unruhe einer fremden Person betrachtete." (Ausschweifung, S. 19) ${ }^{59}$ Eigene Probleme werden überdeckt, der Basistypus besänftigt sich durch die heimliche Beobachtung anderer, sie söhnt ihn mit der Welt aus. Der namenlose Ich-Erzähler im Text Leise singende Frauen etwa beobachtet eine Frau dabei, wie sie in einem Geschäft eine Schreibmaschine testet. Während sie eine Probeseite beschreibt, wächst in ihm der starke Wunsch, diese Seite zu lesen, um über die Gedankenwelt seines Beobachtungsobjektes etwas in Erfahrung zu bringen, was ihm schließlich auch gelingt und die Seite mit den Sätzen: „Wir wollen übers Land fahren, über die Grenzen hinaus“, und: „Banane Rattegiggl Friedrich der Strumpf we.“ wie ein Kleinod zunächst „mit nach Hause nehmen und dort den Satz und die Worte noch öfter lesen“ möchte (Frauen, 
S. 26 f.). Freilich wird die Frau dadurch nicht im strengen Stalking-Sinne psychisch oder physisch belästigt, aber das Nach- und Ausspionieren ist bemerkenswert familienähnlich.

Genazinos Romanfiguren neigen bekanntlich dazu, Situationen nicht immer korrekt einzuschätzen ( $\Rightarrow$ II.1.3), und so ist es auch mehr als fraglich, ob Degens Freundin, „wenn sie gewußt hätte, daß ich hier unten stand, drei Stockwerke von ihr entfernt, vielleicht [...] das Fenster geöffnet [hätte]“ (Laslinstraße, S. 65). Die angelegentliche Arglosigkeit hinter dem „Hinterherlaufen hinter Fremden“ (Außer uns, S. 141) verbürgt etwa die entwaffnende Offenheit eines Eckhard Fuchs, der angibt, „der Grund dafür, daß ihm sein Beobachten nicht verletzend erschien, war die Tatsache, daß er alles Beobachtete sofort wieder vergaß und nichts davon auf irgendeine Weise weiterverwendete." (Ausschweifung, S. 26) Mit zweierlei Maß misst Eckhard Fuchs die Blicke: Neben den unerwünschten, ,bösen' der anderen gibt es seine eigenen ,harmlosen'. Die Hauptfiguren fühlen sich dabei also keineswegs schlecht (vgl. Ausschweifung, S. 26; vgl. Fleck, S. 172; vgl. Einfalt, S. 10 f.; vgl. Obdachlosigkeit, S. 92), sind sich in den häufigen Bekundungen ihrer Arglosigkeit allerdings des potenziell negativen Fremdbildes bewusst, das ,impertinentes Beobachten und/oder Verfolgen' geringschätzt.

Nach einem ähnlich dualen System denkt ,William‘ Genazino in Die Liebe zur Einfalt: „Ohne Herabsetzung betrachte ich das Leben der anderen, und ich bin sicher, daß nichts von dem, was ich sehe, Nachteile davon hat, daß ich es bin, der es gesehen hat. Es kommt eine verzeihende Stimmung über mich.“ (Einfalt, S. 119) Der Mann, den Genazino (Figur) zuvor im Blick hatte, war Anlass zu verschiedenen Interpretationen bzw. Konstruktionen der banalen Realität:

Und während der Mann langsam kaut und mit gesenktem Blick auf die Wurst blickt, bemerkt er nicht, daß andere Menschen ihren kleinen Glücksmüll in den gleichen Abfalleimer werfen und daß dadurch der Mann selber den Schatten eines Müllmannes auf sich zieht. [...] Der Mann steht, genau wie ich, nur deshalb hier herum, weil es immer etwas gibt, was wir nicht fassen können. Oder er weiß nicht einmal, daß er eine Rindswurst ißt. Ein skandalöser Schmerz hat ihn so irritiert, daß er in die Stadt gelaufen ist und sich an einer Losbude angelehnt hat. (Einfalt, S. 117 f.)

Wie Marit Hofmann für Genazinos Roman Die Kassiererinnen völlig zu Recht anmerkt, weiß der Erzähler indes darum,

dass sich seine Wahrnehmung der Dinge je nach Stimmung ändern kann und, man denke an Prousts Madeleines, von persönlichen Erinnerungen und Assoziationen abhängig ist. Als er in einem Tapetenriss „sofort ein Symbol für das Mißlingen“ einer Beziehung sieht, ärgert er sich, „daß ich mich von einer aufgepumpten Assoziation so einschüchtern ließ." Durch dieses Wissen gibt sich der Protagonist nicht nur als Selbstbeobachter zu erkennen, sondern auch als Anhänger des Konstruktivismus, der sich der endlos autobiographischen Tätigkeit der Wahrnehmung, der Konstruiertheit seiner Weltsicht bewusst ist. ${ }^{60}$

\subsection{Konstruktion und Interpretation der ,Welt}

Tatsächlich ist auch in der Realität 
das Bild der Welt, das in unserem Kopf entsteht, kein originalgetreues Abbild. Es ist weit mehr als die Summe der sensorischen Reize. Es ist das Ergebnis einer höchst subjektiven Konstruktion. Ob simple räumliche Maße oder komplexe soziale Eindrücke, etwa vom Wesen unserer Mitmenschen oder dem Ablauf einer Situation - was wir wahrnehmen und wie wir es interpretieren, beeinflussen individuelle Faktoren: die Persönlichkeit, der eigene Körper, sogar Wünsche, Gefühle und Lebensumstände. Was immer das Ich ausmacht, prägt auch seinen Blick. Zu einem gewissen Grad ist die Welt, in der wir leben, für jeden eine andere. ${ }^{61}$

Erinnert sei in diesem Zusammenhang an die im Rahmen der Bearbeitungsmechanismen $(\Leftrightarrow I I .2 .1)$ bereits andiskutierte Bereitschaft, die Wirklichkeitswahrnehmung (selbstdienlich) zu verzerren. ${ }^{62}$ Die damit angesprochene Deutung und Deutbarkeit der Welt berührt sich in einem Punkt auch mit einem Axiom der IM-Forschung: Jedes Verhalten kann auf verschiedene Art interpretiert werden $(\Leftrightarrow I .3 .3)$. Welche „individuelle[n] Faktoren“63 die Wahrnehmung und die Interpretation beeinflussen, aber auch, welche Schwierigkeiten die Interpretation für Genazinos Figuren generell bedeutet, wird nun verhandelt, wobei auch hier die Referenz auf den ,gedehnten Blick' ( $\Rightarrow$ II.2.2) lohnt:

In seinem programmatischen Essay Der gedehnte Blick beschreibt Genazino das Auge als Vermittlerinstanz von Ich und Welt und entwirft, im Gegensatz zum nutzenorientierten Besehen, das Konzept des "gedehnten Blicks" als andere, reichere Wahrnehmungsform. [...] [Diese ermöglicht] eine weitere Erkenntnisform als ,nur' eine reflektierende, rationale: Sie kombiniert das Wahrgenommene assoziativ-kreativ und setzt in einem gleichsam künstlerischen Akt Bedeutung. ${ }^{64}$

Bartl greift in ihrem eigenen Beitrag zum Sammelband später diese Einschätzung auf und ergänzt: „Als dezidiert künstlerischer Akt [...] vermittelt das Sehen den Protagonisten die Möglichkeit, momenthaft Bedeutungsgehalte zu konstruieren und das Wahrgenommene mit Reflexionen darüber zu verbinden."65 Das trifft die genazinospezifische Weltwahrnehmung - zumindest in ihrer positiven Form ${ }^{66}$ - präzise. Als Resultat muss allzumal in Interpretationskontexten der Figuren die letztlich auf das Engste mit unzuverlässigen Erzählern zusammenhängende Beobachtung Sills in das Problembewusstsein eigeschrieben werden: „Pescheks Wirklichkeit gelangt zur Darstellung, nicht die Wirklichkeit.“67 Gültig ist diese für Genazinos Basistypus schlechthin.

\section{ZEICHENGEBUNG UND -VERSTEHEN IN THEORIE UND PRAXIS}

Dass die Mitteilbarkeit von Innerem in Genazinos Erzählkosmos problembehaftet bis unmöglich ist und dass die analoge, nonverbale Kommunikation bei Genazino eine besondere Rolle einnimmt, obwohl sie zugleich für ein unmissverständliches Zeichengeben nicht geeignet scheint, steht bereits geschrieben $(\Rightarrow$ II.1.4). Wie genau die Verständigungsformen, deren Grenzen, aber

61 Wüstenhagen: Ich-Bewusstsein.

62 Vgl. Aronson/Wilson/Akert: Sozialpsychologie, S. $16 \mathrm{f}$.

63 Vgl. für die Abhängigkeit der Konstruktion von Stimmungsschwankungen $\Leftrightarrow$ II.4.2).

64 Bartl/Marx: Wiederholte „Verstehensanfänge“, S. 15 f.

65 Bartl: „The kindness of strangers“, S. 79.

66 Vgl. zum Beobachtungszwang $\Leftrightarrow$ II.2.2) sowie Bartl/Marx: Wiederholte „Verstehensanfänge“, S. 16.

67 Sill: Moderne Zeiten, S. 30. 
auch zeichentheoretische Grundlagen gestaltet sind, lässt sich nur in concreto zeigen und dann induktiv als Familienähnlichkeit begreifen.

In Analogie zu deren bewunderter Gleichgültigkeit $(\Leftrightarrow$ I.2.2) sind Tiere auch bezüglich ihrer vermeintlich unmissverständlichen Kommunikation ,Vorbild': „Wenn wir flugfähige Tiere gewesen wären, hätten wir dann und wann mit den Flügeln schlagen können. Aber wir waren Menschen und verhielten uns, trotz aller Offenheit, verhüllend." (Tiere, S. 74) Selbst in vielfach durchlebten und vergleichsweise einfachen Zeichengebungsprozessen stößt der Basistypus an seine Verstehensgrenzen: „Sonja suchte nach einer Wolldecke, woraus ich weiter schließen durfte, dass sie richtig schlafen wollte, aber sicher war auch das nicht." (Regen, S. 11) Gewissermaßen als Widerpart zum ,überheblichen Durchschauen'( $\Rightarrow$ II.2.2) können ausgesendete Zeichen jenseits der Sprache, etwa in Form von Blicken ( $\Rightarrow$ II.1.4), die Ungewissheit befördern, da es nun einmal „fast nicht zu schaffen war, nur auf Grund von Zeichengebung sich zu einigen“ (Abschaffel, S. 85): „[S]ein Blick siedelte in mir Zweifel an, ob ich mich vielleicht doch nicht glaubwürdig ausgedrückt hatte" (Laslinstraße, S. 133). Allerdings ist es nur fast nicht zu schaffen und, so es glückt, für den Basistypus höchst befriedigend - sowohl hinsichtlich der damit wieder auf den Plan gerufenen Überlegenheitsfantasie als auch der glückenden Übermittlung einer Botschaft per se:

Elke gab mir ein Zeichen, niemand verstand es außer mir, ich kannte Elke und sonst kannte sie niemand. Ein Zeichen mit den Augen, klitzeklein, flohwinzig schnell, unverkennbar deutlich für mich, brutal auffordernd, unwiderruflich. Ich stand auf, Elke stand sofort auch auf. „Ja...", sagte ich. „Ich muß nämlich früh schlafen gehen heute“, lachte Elke dazwischen, und das war gut, einmalig gut, wunderbar, mein Ja war unbefriedigend, nur scheinbar, vielleicht vorgetäuscht, unehrlich, umstößlich, unecht, aber Elkes Lachen dazwischen war gut (Laslinstraße, S. 174).

Elke springt Axel bei, um den Abbruch des Besuchs bei dessen Eltern glaubhaft zu machen. Mit einer gelungenen Verstellung im Sinne der kleinen Lüge $(\Leftrightarrow$ II.1.2) ermöglicht sie ihm seinen Wunsch, die Distanz zu seinen Eltern zu wahren. Allerdings wird dem Rezipienten eine doppelte Lesart offeriert: Entweder er schlägt sich auf die Seite des Figurenbewusstseins, auf ,dessen Wirklichkeit', und anerkennt im momentweisen Schweigen, das der Abschieds-Inszenierung vorangegangen ist, die Bestätigung von Degens Vorwurf, seine Eltern seien wahrer Kommunikation nicht fähig. In diesem Fall wäre Elkes Verhalten tatsächlich als Verbrüderung bzw. Verschwisterung im Geiste gegen eine dritte Partei und Axels Interpretation als korrekt zu werten. Genaugenommen legt aber die Situationsanalyse nahe, dass Elke seine Unbeholfenheit (korrekt) wahrnimmt, die möglicherweise einer selffulfilling prophecy entspringt, und die situativen Zeichen insofern richtig deutet, als sie ihn aus der inkommoden Szene erlösen möchte. Die Eltern Degens haben sich nämlich im Vorfeld minutenlang gelöst und durchaus kommunikativ gezeigt, 
was jedoch als bedeutsame Zeichenfolge von Axels emotionaler Verfasstheit nicht registriert wird. 68

An anderer Stelle wird die Vermutung genährt, dass es nicht immer an der Ambiguität der Zeichen selbst liegt, dass diese nicht verstanden werden können, sondern die Figuren gravierenden Anteil an gestörter Kommunikation haben:

Es war die Haltung eines Kindes, das Nichtverstehen bloß spielt. Für einige Augenblicke glaubte er es sich sogar selbst, daß er nichts verstand. Das war ganz herrlich. Er hatte für sich selbst schon lange ein System des abgestuften Verstehens erfunden, das er jetzt wieder anwandte. Es bestand darin, immer nur so viel zu verstehen, daß er vor sich selbst die Idee der Verletztheit nicht aufgeben mußte. (Sorgen, S. 247) 69

Unmissverständlich ist Abschaffels Handlungsmotivaton mit dem Kalkül anzugeben, bestimmte, seinem Selbstkonzept widersprechende ,Fakten` oder - weniger hart: - Zeichen gezielt auszublenden, um sein Selbstbild im Allgemeinen, hier seine gefühlte Benachteiligung ( $\Rightarrow$ II.1.3) im Speziellen, nicht modifizieren zu müssen. Insbesondere gegenüber Frauen existiert der Topos von fremder Beschwerde mit eigener Zeichenentschlüsselungsforderung über die Romane hinweg:

Alles, was mich an unsere Ehe erinnerte, waren Elisas Handbewegungen. An ihnen konnte ich erkennen, welche Vorwürfe sie dem Mann gerade machte. Und an der verstockten, schuldhaft aufmerksamen Art des Mannes sah ich, daß ihn die Vorwürfe beeindruckten, genau wie mich damals (Licht, S. 12 f.).

Während in diesem Beispiel eine sich gegenseitig unterstützende Verbindung von nonverbaler und verbaler Kommunikation besteht $\left(\Rightarrow\right.$ II.1.4), ${ }^{70}$ existiert auch für die reine Verbalsprache die genazinotypische ToM, derzufolge es in der Kommunikation eigentlich um das Codieren und Decodieren von Botschaften gehe. So schreibt W.:

Liebe Anna,

erinnere mich an einen Lieblingsspruch meines Vaters. Er lautet: An einem schönen Tag kommt ein schöner Tag. Ich weiß bis heute nicht, was der Spruch ausdrücken soll. Vermutlich ist er ein Trost dafür, daß es nie einen schönen Tag gab. Oder soll er aussprechen, daß jeder Tag ein schöner Tag ist? Oder gar: Es gibt keine schönen Tage, aber es ist immer gut, auf einen zu warten? Es kam vor, daß Mutter auf den Spruch ihrerseits mit einem Spruch antwortete. Der unvergeßlichste lautet: Das Licht brennt ein Loch in den Tag. Auch von diesem Satz weiß ich nicht, was er meint. Es war, als wollten die Eltern einander etwas mitteilen, was sie in entschlüsselter Rede nicht zu sagen wagten. (Licht, S. 79 f.)

Man könnte davon ausgehend auch fragen, ob nicht Degen selbst an der gestörten Kommunikation zwischen sich und seinen Eltern eine Teilschuld trage und etwa die Interpunktion der Ereignisfolge: ,Eltern schweigen - Kind schweigt - Eltern schweigen' gegen diejenige ,Kind schweigt - Eltern schweigen - Kind schweigt' zu ersetzen wäre (vgl. Watzlawick/Beavin/Jackson: Menschliche Kommunikation, S. 57 ff. u. S. 92 ff.).

69 Vgl. für ein Beispiel, in dem die Figur ,den Spieß umdreht'„„,Ein paar Augenblicke später fühlt die Kassiererin, daß sie mit ihrer Bemerkung zu weit gegangen ist. Sie hat nicht den Mut, sich zu entschuldigen, aber ihr Gesicht bittet deutlich um Vergebung. Ich tue so, als würde ich ihren Gesichtsausdruck nicht verstehen." (Heimweh, S. 177) 
Ein kleiner Exkurs kann helfen, um die Gefahr des Wagnisses besser verstehen zu können: „Setzt ein Partner eine bestimmte Sinnvorgabe, so hat der andere Partner die Möglichkeit, diese zu akzeptieren und sie in ihrer kommunikativen Validität sich selbst wie dem anderen zu bestätigen." 71 So hilft die Mutter qua „retrospektiven Definierens“72 dem Vater, dessen - zumindest für den außenstehenden Sohn - kryptische Aussage in den Rang von Sinnhaftigkeit zu erheben, indem sie selbst eine nahezu ritualisierte Antwort gibt und als Rückmeldeverhalten eben nicht signalisiert, nicht(s) verstanden zu haben, sondern den Beziehungsaspekt betonend damit das ,Gespräch' einhellig beschließt. Auch wenn man annimmt, es handele sich um einen ,Insider zwischen Mutter und Vater und also um ein inhaltliches Verständnis, so tritt der Sachaspekt im Vergleich zum Beziehungsaspekt zurück, wie auch im folgenden Beispiel die Beziehungsgrundlage die ausbleibende Kommunikation bestimmt: „Seine Vermutung, daß ihr England-Aufenthalt nur ein verdeckter Trennungswunsch war, konnte er wiederum nicht aussprechen, weil sie das offiziell geltende Vertrauen zwischen ihnen grob verletzt hätte." (Falsche Jahre, S. 482) Denn er denkt, dass sie denkt, dass er nicht denkt, dass sie sich möglicherweise von ihm trennen will ${ }^{73}$ ob sie dies möchte, ist dabei zweitrangig, die kommunikative Heraufbeschwörung dieser seiner Sicht würde „das offiziell geltende Vertrauen“ wenn nicht verletzen, so doch nachhaltig verändern.

Um sich erst gar nicht in solche Fahrwasser begeben zu müssen, ist der menschliche Wunsch, die Welt wortfrei verstehen zu können, durchaus verständlich. Genazinos Romanfiguren wälzen ihre eigenen Unzulänglichkeiten im Zeichengeben und -verstehen dabei häufiger auch auf andere Figuren ab: „Im Augenblick, als er mich sieht, zögert sein Schritt ein wenig. Ich habe das Gefühl, daß Theo niemandem begegnen möchte, auch mir nicht. Aber was soll ich tun? Ich habe schon zu verstehen gegeben, daß ich ihn erkannt habe." (Einfalt, S. 151) Der eigene Handlungsspielraum in diesem als unangenehm apostrophierten Schwellenmoment wird künstlich minimiert, die Verursachung dem Gegenüber zugewiesen. Ähnlich ,tickt' auch Abschaffel, wenn er denkt: „Gern wäre er einfach gegangen, aber Abschaffel haßte solche betonten Situationen. Eigentlich erwartete er daß Frau Schönböck bemerkte, was er wollte, und sich ihrerseits verabschiedete." ( $A b$ schaffel, S. 84)

Man kann diesen Gestus der Fremdattribution aus der Unsicherheit ob der immer wieder nicht verstandenen Zeichen deuten, die Genazinos Figuren zusetzt:

71 Klaus Brinker/Sven F. Sager: Linguistische Gesprächsanalyse. Eine Einführung. 4., durchges. u. erg. Aufl. Berlin 2006, S. 158.

72 Brinker/Sager: Linguistische Gesprächsanalyse, S. 158.

73 Vgl. dazu Zunshines Diskussion der problematischen Bewusstseinszuschreibungen im Feld des mind-readings (ToM; $\Rightarrow I .3 .1$ ), bei der aberwitzige Situationen denkbar sind: „,X doesn't know that $Y$ knows that $X$ knows that $Y$ knows that $X$ knows that $Y$ knows what $X$ does“'; oder: „,A wants B to believe that $C$ thinks that D wanted E to consider F's feelings about G." (Zunshine: Why we read fiction, S. 31 u. S. 29). 
Seit ein paar Wochen plagte mich der Verdacht, dass Sonja mich loswerden wollte. Sie sagte es mir nicht direkt, ich sollte es selbst bemerken. Wenn ich sie küsste, öffnete sie den Mund oft nur unwillig und auf jeden Fall nicht ausreichend. War das nur Müdigkeit oder ein Zeichen? Dann ging sie dazu über, ihr Gesicht wegzudrehen. Das war eindeutig und auch wieder nicht. [...] Vor etwa drei Wochen lagen wir im Bett und plauderten, dann umarmte ich sie und zog sie an mich heran. Sie schob meinen Arm weg und vergrub sich in ihren Bettsachen. Ich war gekränkt, verließ das Ehebett [...]. [...] Ich dachte dann sogar, dass Sonja diesen Eindruck absichtlich hervorrufen wollte, um mich auf die Dauer so unsicher zu machen, dass ich mich eines Tages überhaupt nichts mehr trauen würde. (Regen, S. 22 f.) ${ }^{74}$

Die Vagheit der Zeichen wird hier der gestörten Partnerkommunikation untergeschoben als Erklärung für Missverständnisse, dem Verstehenstrieb des Protagonisten somit das NichtVerstehenkönnen entgegengesetzt. Familienähnlich sind jener wie dieses insofern, als es zahlreiche Anzeichen dafür gibt, dass der Basistypus generell mit der Einschätzung von Personen und Situationen überfordert ist ( $\Rightarrow$ II.1.3): „Was sollte ich denn von einem Leben halten, das sich nicht in die Karten schauen ließ, obwohl ich die Karten selbst in der Hand hielt und sie fast unablässig anschaute, umdrehte und mischte." (Kein Geld, S. 72)

\section{PLATONS HÖHLE: VERSTEHENWOLLEN UND NICHT-VERSTEHENKÖNNEN}

Dementsprechend kommt der Haupt-Titel des Sammelbands Verstehensanfänge $e^{75}$ nicht von ungefähr, sondern bezieht sich auf eine figurale Selbstcharakterisierung durch ideationale Prädikatenzuweisung $(\Rightarrow I .4)$ :

Ich hätte wie als Kind wieder das Gefühl, daß ich von fast allem, was sich ereignet, immer nur den Anfang verstehe. Nach dem verstandenen Anfang würde ich vielleicht fliehen, weil ich mich zu sehr daran erinnern würde, wie sehr mich die Kompliziertheit allen Lebens immer geängstigt hat. (Regenschirm, S. 57)

Für den Ich-Erzähler des Romans Wenn wir Tiere wären gleicht ein ähnliches Eingeständnis sogar einer erlösenden Einsicht, die lange Zeit verdrängtes Vorbewusstes endlich in Erkenntnis überführt: „Ich traute mich endlich zu denken, dass ich die anderen nicht verstand. Das hatte ich schon im normalen Leben oft empfunden, aber ich hatte mich nicht getraut, es auch zu denken." (Tiere, S. 130) Was ist es, das eine so große Scheu beim Basistypus auslöst, das Nicht-Verstehen als Teil seiner Selbst zuzulassen? Neben der Kränkung eines positiven Selbstbildes scheint eine weitere Komponente Anteil daran zu haben:

Ich wollte jetzt gerne wie ein kleines Tier beide Ohren gleichzeitig nach vorne aufstellen und jedes mich störende Moment sofort erkennen. Gegenüber der verbreiteten Vorstellung, dass unsere Welt verständlich sei, fühlte ich in mir einen harten Kern, der auf Unverstandensein beharrte. Ich kam

Vgl. für die andere - kleinere - Seite der Medaille: die ostentative Deutungshoheit im sexuellen Milieu etwa: „Abschaffel bemerkte, daß sie ihm in diesen Augenblicken die Führung des Abends übergab. Er mußte ein Zeichen geben, aus dem klar wurde, daß er verstanden hatte" (Abschaffel, S. 85); oder: „Was er am meisten verabscheute, war ihr Veröffentlichungsverhalten. Ständig gab sie Zeichen ihrer neuen Intimität mit Abschaffel von sich." (Sorgen, S. 298) Abschaffel möchte die Affäre geheim halten und vermutet die Offensichtlichkeit der Zeichengebung, die jedoch angezweifelt werden darf $(\Rightarrow$ II.5.3).

75 Vgl. Bartl/Marx (Hg.): Verstehensanfänge. 
mir verstoßen vor wie ein kleines Tier, das sich in einer Ecke versteckt und darauf wartet, dass alle fixen Versteher endlich und für immer den Mund den Mund [!] halten. (Außer uns, S. 154)

Außer der wiederkehrenden herben Einsicht, dass die Welt weder innerhalb noch außerhalb der platonischen Höhle verständlich sei, geht die Hauptfigur zum Angriff über und verspottet „alle fixen Versteher" - um im Höhlengleichnis zu bleiben also eine Umkehrung der Perspektive. Ein Angeketteter wertet just diejenigen ab, die die Schatten für die Wahrheit halten, obwohl ihnen nichts anderes übrig bleibt. Er selbst, kurz Richtung Höhleneingang gewandert, kehrt zurück als Verstoßener und ist ihnen entfremdet; allerdings nicht erleuchtet und schon gar nicht in der Lage, den anderen ihren Irrtum weiszumachen, sondern resigniert, verzweifelt und vorwurfsvoll ohne Lösungsstrategie.

Eine solche hat allerdings eine andere Figur aufgetan: „Dabei hatte ich mir erst dieser Tage vorgenommen: Um leben zu können, musst du kaltblütig am Unverstandenen vorbeigehen und dich nicht nach ihm umdrehen. Wieder entstand der Wunsch nach einer Flucht ohne Wiederkehr." (Regen, S. 29) Dem Verstehenszwang bei gleichzeitiger Unmöglichkeit des Verstehens zu entkommen, scheint ein ernstzunehmendes Dilemma, nicht nur weil der Genazino'sche Basistypus doch - ähnlich dem Beobachtungszwang ( $\Rightarrow$ II.2.2) - meist seit Kindesbeinen an beseelt ist vom „Drang, jede Situation jederzeit restlos zu durchschauen“ (Glück, S. 133).76 Da nun dem Durchschauen außerhalb der pathologischen Überlegenheitsfantasie ( $\Rightarrow$ II.2.2) wie auch dem Verstehen aber prinzipiell Grenzen gesetzt sind und Genazinos Figuren zusätzlich nicht davon lassen können, verstehen zu wollen, ist als logische Konsequenz das wahrnehmungstheoretische Glück nur in zwei ähnlich liegenden Richtungen zu finden: im Bereich der Mutmaßungen, die notwendigerweise mit Fehlinterpretationen einhergehen können/müssen, einerseits - für Platons Höhle hieße dies: weiterhin (meist missmutig) Schatten zu deuten im gleichzeitigen Bewusstsein der Fehlbarkeit -; andererseits im Bezirk bewusst selbstmanipulierender Kontraintuition, die bspw. aus übertriebenem Kohärenzbestreben resultieren kann und nicht selten Züge einer ,Wiederverzauberung der Welt' trägt - im Gleichnis: nicht die realitätsnächsten Interpretationen und Prognosen zu prämieren, sondern (mitunter freudig) die einfallsreichsten oder abwegigsten.

\section{(FEHLBARE) MUTMAßUNGEN}

Die (geringe) Probabilität der (fehlbaren) Mutmaßungen ${ }^{77}$ wird meist auch herausgestellt: „Vermutlich waren die Zettel entweder eine zusammenhängende Bestrafung (Herrdegen demütigte Fräulein Weber wegen irgendetwas) oder eine Maßnahme des Selbstschutzes (Herrdegen will nicht reden)“ (Wohnung, S. 77; Herv. N. L.); „[S]ie schämte sich wohl wegen gestern, mich heute zu sehen in Kleidern und gut frisiert, ich rätselte und war nicht ganz sicher." (Laslinstraße,

76 Vgl. für eine lange diesbezügliche Reflexionspassage auch Regenschirm, S. 66 f.

77 Hier werden eher auf allgemeine Sachverhalte gemünzt untersucht, personenbezogene finden sich im vierten Schlaglicht ( $\Rightarrow$ II.4.2). 
S. 98; Herv. N. L.) Die Mutmaßungen, die sich auf Personen beziehen, werden im vierten Schlaglicht zur Inszenierung anderer noch genauer unter die Lupe genommen $(\Leftrightarrow$ II.4.2), hier zählen eher die allgemeinen Prinzipien: Unsicherheit im Gefühlelesen (s.o.) und fragliche Personenwahrnehmung $\Leftrightarrow$ II.1.3) dominieren, was den Figuren im Sinne der Fehlbarkeit auch bewusst ist. Abschaffel etwa, gerade in der volitionalen Handlungsphase $(\Leftrightarrow I .3 .1)$ eines Diebstahls und im Modus selektiver Aufmerksamkeit, beobachtet an sich „[d]ieses nervöse Umherflackern des Blicks, die Neigung, in allen Leuten geheime Mitwisser zu vermuten, die nur den richtigen Augenblick zum Verrat abwarteten, und die reuige Lust, den gestohlenen Gegenstand wieder in das Regal zurückzustellen." (Sorgen, S. 165; Herv. N. L.) Bereits die Formulierung legt dem Leser nahe, die Entdeckung als fehlgehende Vermutung abzutun. Das disjunktive Entweder-Oder der bisherigen Beispiele wird mitunter auch in eine Polyvalenz überführt:

Eckhard überlegte, ob der Mann mit dieser Haltung der übrigen Welt zeigen wollte, daß er sie nicht mehr benötigte. Wahrscheinlich war es aber umgekehrt: Ohne den Anblick seiner Wohnung und seiner Möbel konnte er gar nicht mehr leben. Allerdings konnte es auch möglich sein, daß er alle anderen Menschen durch seinen Anblick beschämen wollte. (Ausschweifung, S. 196; vgl. Regenschirm, S. 132 f.)

In der Sonderform der Frage wird die Unsicherheit der Einschätzung weiter erhöht: „Warum grüßte sie ihn plötzlich wieder? Er fühlte sich beunruhigt." (Sorgen, S. 249) Nicht mehr zwei, drei oder mehrere bestimmte Optionen sind es, sodass sich Abschaffel für eine von ihnen entscheiden müsste, sondern ein komplexes Spektrum:

Es bedeutete etwas, wenn man plötzlich wieder gegrüßt wurde, ebenso wie es etwas bedeutete, wenn man plötzlich nicht mehr gegrüßt wurde. Das heißt, manchmal bedeuteten beide Vorgänge auch nichts, wenn sie nur Launen und unbestimmten Haltungen von Kollegen entsprangen. Aber wie sollte man beurteilen, ob man nur einmal aus Launenhaftigkeit nicht gegrüßt wurde oder ob man aus bestimmten, das heißt feindlichen Absichten heraus gegrüßt wurde? (Sorgen, S. 250 f.)

Genaugenommen hinterfragt der Protagonist damit einmal mehr die Grundannahme, wann von kalkuliertem IM auszugehen sei und wann nicht. ${ }^{78}$ Die Attribution, dass Wieder-Grüßen negativ - da aus „feindlichen Absichten“-, potenzielles Nicht-mehr-gegrüßt-Werden lediglich „aus Launenhaftigkeit" geschehe, verdeutlicht das familienähnliche Merkmal, selbstbezogene Interpretationen zu bevorzugen. Der Abschaffel der Vernichtung der Sorgen ist eine der fragendsten, verstehenwollendsten Ausformungen des Basistypus, der tatsächlich das bereits angesprochene stufenweise Verstehen (s.o.) in seine Frageform einbaut: „Aber, wenn es so war, warum wollte er die Flaschen dann in einem Schließfach unterbringen?“ (Sorgen, S. 319) Und: „Aber was sollte der Text sonst bedeuten, wenn er schon weder eine Drohung noch eine Entschuldigung war?“ (Sorgen, S. 397) Diese und ähnliche Fragen erregen auf Dauer beim fragenstellenden Basistypus

78 Vgl. dazu auch: „[V]ielleicht hatte er den anderen zeigen wollen, daß [...]. Vielleicht hatte er aber auch gar nichts zeigen wollen und nur sein unseliges Hineinragen in die Welt vorführen müssen." (Sorgen, S. 179) 
Ärger: „Weil mir das Herumspintisieren selbst auf die Nerven ging, freute ich mich auf das Nachtkonzert der ARD“ (Außer uns, S. 55).

Zwei Instanzen - zuzüglich der Deus-ex-Machina-Strategien ( $\Rightarrow$ II.2.2), die auch im Schwenk „auf das Nachtkonzert der ARD“ angelegt sind, - können dem „Herumspintisieren“ Einhalt gebieten: die auktorial-explizite Dekuvrierung sowie die Selbsterkenntnis - und beide sind verhältnismäßig marginale, zwar nicht romanspezifische, aber seltene Erscheinungen. Namentlich der $A b$ schaffel-Roman Vernichtung der Sorgen weist beide auf: „Es gab gar kein Getue. Nur Abschaffel machte aus seiner Einladung eine innere Bewegung, weil er nicht fassen konnte, daß er eingeladen worden war." (Sorgen, S. 341) Die vorangehende Überinterpretation wird durch den Erzählerkommentar, der hier mit Übersicht ausgestattet ist, überstimmt. Ebenso selten stellen Protagonisten selbst fest, dass ein tieferes Verstehen der Realität nicht nur deswegen nicht möglich ist, weil sie komplex und unverständlich, sondern weil sie gelegentlich auch einfach so banal und unterkomplex ist: „Vielleicht ist er an einem Punkt angelangt, wo er... aber nein, ich vermute nichts mehr. Herr Magnapane fährt in einem der Anzüge spazieren, die er gern verkaufen möchte; weiter ist nichts." (Fleck, S. 52)

Dem überbordenden Wunsch, an einmal getätigten Beobachtungen immer neue Vermutungen aufzuhängen, wird abgeschworen, was gleichbedeutend ist mit der Rückbesinnung auf das Phänomen als nicht notwendigerweise zeichengebendes, erst sekundär mit fakultativer Bedeutung aufzuladendes: „und schaue auf das Gestrüpp neben der Bank. Es gefällt mir sehr gut, weil es nichts als sein eigenes Ausharren ausdrückt." (Regenschirm, S. 93) ${ }^{79}$ Mutmaßungen werden also mitunter schnell in die tatsächlich beobachtbare Faktenlage umgemünzt, sodass die IM-Anteile der Handlungen reflektiert werden. „Er hatte sich geirrt, sogar zweimal, und in beiden Fällen war die Wahrheit viel harmloser gewesen als seine Ängste!“ (Sorgen, S. 212) Abschaffels Revision wird mit „!“ als erlösend markiert, die Mutmaßung relativiert, der Verstehenszwang entdramatisiert. 80

Damit sind die Figuren am möglichen, aber seltenen, selbstbefreienden ,Ende der Interpretationsfahnenstange' angelangt. Weitaus eher im Bereich der Familienähnlichkeit findet sich die Antwort auf die Fragen nicht im Ausrufungszeichen, sondern in einer Art „kindische[n] Alltagsmystik“ (Tiere, S. 57).

79 Vgl. zur diesbezüglichen Zeichentheorie Nils Lehnert: Oberfläche - Hallraum - Referenzhölle. Postdramatische Diskurse um Text, Theater und zeitgenössische Ästhetik am Beispiel von Rainald Goetz' Jeff Koons. Hamburg 2012.

80 Vgl. für eine ähnlich befriedigende Situation: „Der Alte überquert die Straße und trifft auf einen anderen alten Mann, und jetzt erst erkenne ich, daß das Stockschwenken eine Begrüßung war. Wunderbar legt sich in mir der Tumult der falschen Auslegung." (Fleck, S. 122) 


\title{
,ÜBER'INTERPRETATIONEN: KONTRAINTUITION, KOHÄRENZBESTREBEN, WIEDERVERZAUBERUNG
}

\begin{abstract}
Das Gehirn ist ein Genie
Immer wieder unglaublich faszinierend, zu erleben, wie alles zusammenhängt: Ein Gitarrist, den ich seit Jahrzehnten kenne, schenkte mir eine CD mit einer Aufnahme von ihm und seiner Band live in Fresno. Fresno ist spanisch und heißt Esche - ich wohne im Eschenweg. Fresno liegt in Kalifornien. Das ist einer von 50 US-Staaten. Ich wohne im Haus Nummer 50. In Fresno ist Sam Peckinpah geboren und der hat meinen Lieblingsfilm gedreht. In dem Film spielt einer mit, bei dem ich immer an einen Bekannten denken muß, der mal was mit der Schwester des Gitarristen hatte, deren Name die weibliche Form des Namens einer meiner Freunde ist, der am 19. März Geburtstag hat. Und siehe: Die maximale Durchschnittstemperatur in Fresno beträgt im März fast genau 19 Grad. Bei solchen Verknüpfungen kann einem doch einfach nur schwindlig werden, oder nicht? ${ }^{81}$
\end{abstract}

Mit der ironischen Überschrift, die dem Veröffentlichungskontext in der Titanic Rechnung trägt und zugleich die „Verknüpfungen“ als lediglich im interpretierenden Gehirn existierende verortet, ist der Grenzübertritt von der Mutmaßung zur (bewussten) Überinterpretation getan. In den Leise singenden Frauen liest sich dies bezogen auf den Beruf und das Verfahren des Schriftstellers wie folgt: „Und sie weiß nicht und kann es nicht wissen, daß durch die Wahrnehmung dieser Schöpfungsverknüpftheit für ein paar Momente eine diesmal sogar sichtbare Poesie in die Welt tritt, die ich Gott sei Dank weit und breit niemandem erklären muß.“ (Frauen, S. 166)

Das menschliche Gehirn scheint tatsächlich dazu angetan, Wahrnehmungssplitter, kleinste Zeichenstückchen und jedwede Information allererst als selbstrelevant behandeln zu wollen. Freilich lernt der Mensch im Laufe seiner Sozialisation durch unterschiedliche Mechanismen diesen Informationsstrom zu unterteilen: tatsächlich relevant oder nicht? ist die Frage, die ganz automatisch jeden Tag tausendfach beantwortet wird. Allerdings ist die Literatur ein Möglichkeitsraum und bereits beim gedehnten Blick ist der Regress auf eine (vermeintliche, von Genazino so postulierte) Wahrnehmungsstufe des Kindes gewagt worden. Auch für die Überinterpretationen - die in Form von ,Verschwörungstheorien' medial realiter geläufig sind - ist also die Entsprechung von Fakt und Fiktion zugunsten der ,kindlich'-,,kindische[n] Alltagsmystik“, der „Schöpfungsverknüpftheit“ verworfen. Drei Impetus scheinen bei den fantastischen, ,poetischen' Welterklärungsversuchen des Basistypus wirksam zu sein: Erstens die - mit Paul Feyerabend vielleicht gut so zu benennende - Kontraintuition, also eine der Erfahrungswirklichkeit wie der Intuition widersprechende Interpretation, die sich allerdings durchaus in (ferner) Zukunft als völlig einwandfreies Erklärmodell auszeichnen könnte, gegenwärtig aber hanebüchen zu sein scheint; zweitens das Kohärenzbestreben, das sich evolutionärpsychologisch als Komplexitätsreduktion verstehen und als das allgemeinmenschliche Unbehagen gegenüber einer als undurchschaubar wahrgenommenen Welt begreifen lässt; und drittens der Wunsch nach einer Hans Jonas'schen ,Wiederverzauberung der Welt' 82 - also nach einer nicht durchrationalisierten,

81 Karsten Wollny: Das Gehirn ist ein Genie. In: Titanic. Das endgültige Satiremagazin (01/2016). Online: <https://www.titanic-magazin.de/fachmann/2016/januar/\#c25148>.

82 Vgl. Meike Fessmann: Vom stillen Zauber des Alltäglichen. In: Financial Times Deutschland vom 05. Oktober 2001; vgl. Hans M. Hennig: Zwischen den Stühlen. Poetisierung des Alltags. Wilhelm Ge- 
auf Zwecke und Ökonomie basierenden Einrichtung von Natur und Gesellschaft, die auch die Dimension eines Schöpfers nicht ausschließt. Dementsprechend benennt auch Alexandra Koch ihre Untersuchung mit dem Titel Das Bedeutungstheater des Epiphanikers. Zur Ver- und Entzauberung der Alltagswelt in der Prosa Wilhelm Genazinos, führt aber aus, dass bei Genazino im Gegensatz zu christlich tradierten „Epiphanie-Erlebnissen“ „das Erkenntnismoment zeitlich vom auslösenden Moment deutlich getrennt sein kann“, zudem teilweise auch von Gegenständen ausgehen, „die auch als vollkommen wertlos gelten könnten“, und schließlich auch „negative Beobachtungen[...] das Potential [haben], eine Epiphanie auszulösen“.83

Eine Erscheinungsform sind Sinnfragen, die - zwischen Auspizien und Wahrsagerei - Beobachtungen auf eine mögliche Bedeutsamkeit oder gar Handlungsanweisung für die Erzähler abklopfen: „Zum Beispiel treffe ich an einem Tag wie heute am Theaterplatz auf eine schielende Frau. Das kommt nicht oft vor; warum gerade heute und gerade jetzt?" (Frauen, S. 118) Ent-täuschend müsste die stochastische Antwort heißen: Zufall! Aber der Basistypus ist deutlich zu egozentrisch, was für diese Figurenfacette völlig wertneutral zu verstehen ist, und überlegt, „ob das heruntergerutschte Plakat ein Hinweis für mein Leben sein soll, eine Erklärung, ein Fingerzeig oder eine Warnung, dieses oder jenes zu tun oder nicht zu tun. Wieso habe ich genau in den Augenblicken in das Schaufenster geschaut, als sich das Plakat löste?“ (Liebesblödigkeit, S. 152)

Doch nicht nur die ,moralische' Ebene, denkt man an den vierfachen Schriftsinn der Auslegung, interessiert Genazinos Romanfiguren. Kontraintuitiv und ,verzaubernd' geht es bereits im literalen und allegorischen Verständnis des Buchs der Welt zu. Bei der Beobachtung einer Passantin legt sich der Protagonist aus Leise singende Frauen etwa die folgende Erklärung zurecht: „Heute endlich wird sich die Frau ein Paar neue Strümpfe kaufen! Das hat sie schon seit ein paar Tagen tun wollen, aber sie glaubte, nicht genügend Geld zu haben." (Frauen, S. 19) Genaugenommen hat der Ich-Erzähler nicht die leiseste Ahnung, was in der Frau vorgeht, und konstruiert aus deren Beobachtung von Damenstrümpfen seine Geschichte. Die beliebten Figuren aus der KinderTV-Serie Jan \& Henry, ihres Zeichens Erdmännchen, rätseln immer wieder ausgehend von einem Geräusch, was dessen Ursache sei. Ein Quietschen (einer Tür) wird dabei zur unterhaltsamen Vorstellung umgedeutet, eine Oma in Ritterrüstung koche Pudding, ein Dinosaurier beim Zahnarzt wird imaginiert, wo das Geräusch eines ins Wasser springenden Schwimmers ursächlich für das Platschen ist. Komik wird dadurch evoziert, dass bereits die kindlichen Rezipienten in dieser Mystifizierung eine von ihrem Erfahrungsschatz massiv abweichende, kontraintuitive Erklärung sehen - ein Tropfgeräusch werten auch Kinder als Index eines Wassertropfens, der sich vom Hahn löst, und eben nicht als Geräuschkulisse von Tieren, die ein Kirschkernweitspucken veranstalten. Im Sinne der platonischen Höhle liegt also der zweite Ausweg vor: freudig die Imaginati-

nazinos Roman „Ein Regenschirm für diesen Tag“. In: Freitag vom 16. November 2001; vgl. Koch: Das Bedeutungstheater des Epiphanikers, S. $27 \mathrm{ff}$. 
onskräfte auszureizen. Ganz genau so gehen Genazinos Figuren vor; etwa Fuchs, der „zwischen ihr und den Fotos eine familiäre Geschichte zusammenphantasieren wollte" (Ausschweifung, S. 55) oder fantasiereich mutmaßt, die Stadttauben seien eventuell „inzwischen in den Abgasen blind geworden“, da sie erst "gefährlich knapp vor den Autos auf[flogen]“ (Ausschweifung, S. 214). Die Hauptfiguren wollen die Welt wieder verzaubern - auch wenn Norbert Otto Eke schreibt, „Genazinos Figuren“ seien über die „Verzauberung der Alltagswirklichkeit [...] längst hinweg" ${ }^{\prime 84}$-, wollen sie mit Sinnhaftigkeit und Kohärenz aufladen, wo Koinzidenz und Kontingenz ihre strengen Königreiche errichtet haben:85

Wieder einmal bin ich fast sicher, daß es zwischen den Wespen und den Verkäuferinnen ein Abkommen gibt. [...] Nur auf der Basis einer solchen Vereinbarung kann ich mir das hundertprozentig problemlose Zusammenleben von Wespen und Verkäuferinnen erklären. [...] Der einzige Weg, die Möglichkeit eines Vertrags zu beweisen, wäre seine plötzliche und unbeabsichtigte Verletzung. [...] Ein solcher Zwischenfall müßte die Wespen insgesamt alarmieren und zu einer Reaktion zwingen und die Existenz eines geheimen Vertrags wäre erwiesen. (Frauen, S. 155 f.; vgl. Falsche Jahre, S. 414)

Unmöglich ist dieses auf Anthropomorphisierung beruhende und auf einer tieferen Ebene letztlich Erkenntnistheorie durchexerzierende Staunen nicht - unwahrscheinlich (und komisch) allemal. Mit Regelhaftigkeit setzt sich die Hauptfigur in das Zentrum dieser Fantasterei, ${ }^{86}$ sodass alle äußeren Geschehnisse in Bezug auf jene lesbar werden (vgl. Frauen, S. 108-110). Zufälle und andere Wahrscheinlichkeiten geraten dann als nicht deutbare Zeichen in den Blick des Figurenbewusstseins und setzen die Interpretationsmaschine in Gang (vgl. Frauen, S. 118):

Die Koinzidenz der Ereignisse erregt mich auf gewisse Weise. Ich beobachte einen Kuchendieb und werde selbst des geplanten Obstdiebstahls beargwöhnt, das heißt ich kann mich in diesen Sekunden als Erfinder einer Blickkette fühlen, die unbekannte Ereignisse miteinander verbindet und mich selber auf unaussprechliche Weise auszeichnet beziehungsweise erhöht beziehungsweise in eine andere Wirklichkeit hineinhebt. (Glück, S. 13)

Genazinos Figuren sind sich ihrer häufig weit von der beobachtbaren Indizienlage abschweifenden Interpretationen durchaus bewusst. Als elaborierte Form der Besänftigungsstrategie $\Leftrightarrow$ ( $\Rightarrow$ II.2.2) resümiert die Protagonistin aus dem Text Die Obdachlosigkeit der Fische im Sinne des Wollny-Zitats (s.o.): „Auch jetzt kehrte meine Fassung zurück, indem ich drei Vorgänge wahrnahm, die nicht miteinander zu tun hatten: außer in meinem Kopf, wo sie sich miteinander verknüpften, um mich zu besänftigen." (Obdachlosigkeit, S. 76)

Auf der anderen Seite gibt es, wie bei den handfesteren Mutmaßungen (s.o.) auch, die gegenläufige Tendenz, sich selbst zur Räson zu rufen: „Ich muß meine Überempfänglichkeit für solche Details zurückdrängen. Aber wie?“" (Liebesblödigkeit, S. 152) Oder:

$84 \quad$ Eke: Epiphanische Augen-Blicke, S. 190.

85 Vgl. Rok: „Wir spüren nämlich nichts mehr, werte Dame“.

86 Vgl. für weitere diesbezügliche Beispiele etwa Wohnung, S. 146; vgl. Regen, S. 126 f.; vgl. Ausschweifung, S. $44 \mathrm{f}$. 
Ich versuchte, mich mit einer simplen Rekonstruktion der Ereignisse zu beruhigen. Genau genommen haben sich zwei unbekannte junge Frauen ein paar Augenblicke über dich lustig gemacht, mehr war nicht. Nein, das stimmte nicht. Denn du hast dir dieses Erlebnis zu Herzen genommen und hast es dadurch zu etwas ganz und gar Eigenem gemacht. Du hast etwas eindeutig Äußerliches in etwas ebenso eindeutig Innerliches verwandelt. Das war der Fehler! (Kassiererinnen, S. 56)

Genau an diesem Punkt werden aber auch dezidiert öffentliche vs. private Selbstaufmerksamkeit und die damit einhergehenden Eigenschaften der Person thematisiert! Man kann auf sich selbst als Subjekt (private Selbstaufmerksamkeit) oder als Objekt (öffentliche Selbstaufmerksamkeit) blicken - bewusst steuern, sodass man in der evaluativen Phase von einem „Fehler“ sprechen könnte, lässt sich der eingenommene Blick indessen nicht.

\subsection{Der (imaginierte) Blick auf sich: öffentliche vs. private Selbstaufmerksamkeit}

Schlenker, der IM und Selbstaufmerksamkeit zusammendenkt, betont die unbewusste Dimension:

[W]e do not always consciously attend to ourselves as objects, social or otherwise. Sometimes we just act, and we can truthfully assert later that we weren't even thinking about how we looked at the time. We weren't consciously playing a role, protecting our identity, or trying to please an audience. At these moments, caught up in the flow of our activity, we lose personal awareness. Selfpresentation in its deliberate, tactical form is the last thing on our minds; we are in an I state. At other times, the $M e$ gains ascendence. We contemplate what we are like, how we look to real or imagined audiences, and how information in the environment reflects on our status as social objects. These different states have different implications for impression management. ${ }^{87}$

In Der Fleck, die Jacke, die Zimmer, der Schmerz wird diese Unterscheidung (und IM insgesamt) in selbstreflexiver Form für das Segment „how we look“ durchgespielt:

Der Sahnefleck auf meinem Jackenärmel, den ich der vergeßlichen Bedienung aus dem Café Heimatland verdanke, ist nicht groß. Er verblaßt, aber er verschwindet nicht. Fast immer genügt ein Blick von Fremden auf den Fleck: und ich bin als nicht recht zugehörig eingestuft. Ein Blick ist das schnellste Urteil; es braucht nicht mehr als eine Sekunde Herstellungszeit. Ich trage den Fleck erst seit kurzer Zeit, und seither habe ich erfahren: es sind eine große Anzahl Schnellrichter unterwegs. Sobald sie den in der Wolle festgesaugten Punkt erblicken, packt sie eine kleine Reserviertheit, die wie ein Ruck durch sie hindurchgeht. Sie zucken deutlich sichtbar ein paar Millimeter zurück. Ich rede nicht über den Fleck, ich erkläre ihn nicht, ich entschuldige ihn nicht, ich beseitige ihn nicht, ich verberge ihn nicht. Es entsteht der Eindruck, daß ich in voller Übereinstimmung mit ihm lebe, und eben das scheint das Unannehmbare zu sein. An manchen Nachmittagen werde ich von flüchtigen Passanten so oft abgelehnt, daß mir ein wenig schwindlig wird. Dann denke ich fast schon über den Fleck nach. Dabei soll mich der Fleck nur an die große Aufgabe erinnern, daß ich ohne die Urteile der anderen Leben will. Man muß durch die Welt gehen wie durch einen einsamen Wald. (Fleck, S. 48)

Reschke schreibt in seinem Essay für das $K L G$ bezogen auf eine Passage dieses Zitats:

Hubert Winkels' polemischer Vorwurf, Genazino habe sich vom „poetischen Soziologen“ zum „Schönschreiber“ gewandelt, der alle sozialen Wahrnehmungen und Gefühle ausblendet, trifft jedoch nur zum Teil. An einigen Stellen scheint elitärer Hochmut auf - es gibt im Buch pathetische Sentenzen wie: „Man muß durch die Welt gehen wie durch einen einsamen Wald“ -, doch in der 
weitaus überwiegenden Mehrzahl erinnern die Prosaminiaturen eher an Robert Walser denn an Peter Handke. ${ }^{88}$

Reschkes Einwand trifft: Weit weniger als um elitistisches Ihr-seid-mir-egal-Gebaren, geht es hier darum, die „große Aufgabe“, an der Genazinos Romanfiguren sich immer wieder abmühen, ein Stück weit voranzutreiben: jenseits der Kategorisierung und Einordnung der anderen ein Leben führen zu können, dessen Handlungsmaximen sich nicht nach ,Gefällt-mir-Angaben' der sie umgebenden Akteure ausrichten. Großer Mut wird hier beschrieben, weil die öffentliche Selbstaufmerksamkeit üblicherweise nur in der Form präsent ist, Handlungen von vornherein auszutarieren an Bewertungsskalen der anderen. Wenn nun bewusst in Kauf genommen wird, sich absichtlich den (abschätzigen) Blicken anderer auszusetzen, um dem Selbst den sonst wirksamen Opportunismus abzuerziehen, dann handelt es sich um die Erziehung zum Selbstbewusstsein, was keineswegs mit Hochmut zu verwechseln ist (vgl. Fleck, S. 94).

Denn vorwiegend eines ist es, was dem Genazino'schen Basistypus zu „seinem Glück einzig fehlt: die Souveränität der vollkommenen Lösung vom Beifall.“ (Fleck, S. 57) In nuce findet sich hier die Absage an die öffentliche Selbstaufmerksamkeit in einem einzigen Satz - üblicherweise Lebensaufgabe für viele Figuren Genazinos.

\section{ÖFFENTLICHE VS.PPRIVATE SELBSTAUFMERKSAMKEIT}

Wie so oft ist dieser Problemkomplex bei Genazino selbst zum Thema erhoben worden, ist es also mitnichten Theorieballast als vielmehr gebotene Redlichkeit der Analyse das Konzept von privater vs. öffentlicher Selbstaufmerksamkeit an die Texte anzulegen:

Sandra hat es gern, wenn ich den Eindruck erwecke, ich sei tief in Gedanken versunken. Sie möchte mich in abwesend versonnenen Stimmungen vorfinden, aus denen sie mich dann, wie sie es nennt, mit einem Schlag ins Leben zurückholt, nämlich mit ihrer quirligen, redseligen Aufgedrehtheit. [...] Ich tue so, als hätte ich sie nicht sofort gesehen (bemerkt), das gehört zu unserem Spiel. Sondern ich blicke ein wenig betröppelt, fast somnambul auf dem Boden herum, damit mich Sandra mit gehörigem Effekt aufschrecken kann. Das Problem meines momentweise aufgeteilten Daseins (Anwesenheit/Abwesenheit: changierend) könnte ich das Problem des introspektiven Selbstbewußtseins nennen, über das ich vielleicht gleich reden werde. (Liebesblödigkeit, S. 103 f.)

Der Ich-Erzähler greift zwar auf einen anderen Terminus zurück, ${ }^{89}$ aber es ist unverkennbar, auf welchen Sachverhalt der Signifikant „introspektive[s] Selbstbewußtsein[]“ zielt: Auf den Forschungskonsens,

dass man prinzipiell zwischen öffentlicher Selbstaufmerksamkeit und privater Selbstaufmerksamkeit unterscheiden kann. Bei [p]rivater Selbstaufmerksamkeit richtet sich der Fokus auf persönlichinterne Aspekte wie z.B. Gefühle, Fantasien, Motive oder Stimmungen. Dagegen steht bei der öffentlichen Selbstaufmerksamkeit die Art der Aufmerksamkeit, die auf das Selbst als soziales Objekt gerichtet ist[,] im Vordergrund. Vorrangig sind hier Aspekte wie z.B. das Aussehen, die Bewertung anderer, und die Selbstdarstellung in öffentlichen Situationen (vgl. Schiefele, 1990, S. 116f).

$88 \quad$ Reschke: [Wilhelm Genazino].

89 Vgl. für eine weitere alternative Terminologie: [Selbstaufmerksamkeit]. In: Lexikon der Psychologie. Online: <http://www.spektrum.de/lexikon/psychologie/selbstaufmerksamkeit/13858>. 
Bei der dispositionalen Selbstaufmerksamkeit geht man davon aus, dass die Selbstaufmerksamkeit als Merkmal eines Individuums zeitlich und situativ relativ stabil ist. Individuen mit dispositionaler Selbstaufmerksamkeit zeigen eine erhöhte Sensibilität für selbstbezogene Informationen bzw. neigen dazu Informationen als selbstbezogen zu interpretieren (vgl. Hintze, 1997, S. 11). ${ }^{90}$

Alltagspsychologisch gesprochen und zugleich operationalisiert in die kürzest mögliche Formel aus dem Inventar sozialer Kompetenzen (ISK) gepresst, versteht man unter öffentlicher Selbstaufmerksamkeit das „Ausmaß, in welchem eine Person bewusst wahrnimmt und reflektiert, wie sie auf andere Menschen wirkt.“" ${ }^{11}$ Das findet sich im Fragebogen zur Messung allgemeiner sozialer Kompetenzen (FASK) etwa in folgenden Items präzisiert:

- Ich mache mir Gedanken darüber, wie ich auf meine Mitmenschen wirke.

- Ich mache mir Gedanken darüber, was meine Mitmenschen über mich denken.

- Ich achte darauf, wie meine Mitmenschen auf mein Verhalten reagieren. ${ }^{92}$

- Ich achte darauf, welche Körperhaltung ich gegenüber meinen Mitmenschen zeige.

- Je nachdem, wie meine Mitmenschen auf mein Verhalten reagieren, ändere ich es sofort.

Obwohl bereits en gros gezeigt werden konnte, wie fixiert Genazinos Figuren mit dem öffentlichen Blick auf sich selbst sehen bzw. zwischen beiden Blickrichtungen gefangen sind, erübrigt es sich nicht, den Blick auf das Detail zu richten und anhand der Primärtexte das Potenzial des Selbstaufmerksamkeitskonzepts für die Figurenanalyse zu diskutieren. ${ }^{93}$

Genazinos Figuren sind seit seinem Erstling geradezu Inbegriffe öffentlicher Selbstaufmerksamkeit. Sowohl die Neigung, das eigene Verhalten in actu bzw. ex post am Verhalten der anderen auszurichten, als auch das Bestreben, bereits vorab das Feedback der anderen erahnen zu wollen ( $\Rightarrow$ II.2.6), sind den Figuren im Hardcore eingeschrieben: Axel Degen „schaute auf Mutter und Vater, wie sie reagieren würden, schlecht oder gut oder mittelmäßig oder träge, aber: Sie reagierten überhaupt nicht.“ (Laslinstraße, S. 43) Oder: „Für heute hatte ich es mir fest vorgenommen, heute mußte ich von Elke erzählen. [...] Aber meine Mutter würde mir keine Ruhe lassen [...] Würde sie lachen, wenn ich davon begann?“ (Laslinstraße, S. 42)

Allerdings sollen nicht nach Items aufgeschlüsselt weitschweifig Belegstellen angeführt werden, sondern demgegenüber exemplarische Passagen in den Blick geraten, die einerseits den Basistypus als öffentlich-selbstaufmerksamen ausweisen, andererseits diese Bestandsaufnahme reflektieren und problematisieren. Abschaffel etwa ordnet sich klar der öffentlichen Selbstaufmerksamkeit zu; er „betrachtete seine Gefühle immer von außen, immer so, als würden sie ihm nicht wirklich gehören. Merken konnte er das daran, daß er in Ereignissen, die mit ihm zu tun

90 Werner Stangl: [Selbstaufmerksamkeit]. In: Lexikon für Psychologie und Pädagogik. Online: $<$ http://lexikon.stangl.eu/5150/selbstaufmerksamkeit/>.

91 Vgl. Aronson/Wilson/Akert: Sozialpsychologie, S. 134-136. Vgl. zum eng damit verwandten Konzept des ,Self-monitoring', das ebenso zu beschreiben versucht, wie stark Menschen das Fremdbild in ihre eigenen Handlungen mit einbeziehen, sowie zur Verbindung zu IM Turnley/Bolino: Exploring the Role of Self-Monitoring in Impression Management ( $\Rightarrow$ I.3.3).

92 Die negative Fassung als Kontroll-Item: ,Mich interessieren die Reaktionen meiner Mitmenschen auf mein Verhalten nicht'.

93 Vgl. Wolfram Schütte: Im Gespinst verschiedener Aufmerksamkeiten. Wilhelm Genazinos ProsaMosaik „Leise singende Frauen“. In: Frankfurter Rundschau vom 18. Juli 1992. 
hatten, nie ganz drin war; immer war er ein Stückchen daneben, damit er auf sich selbst sehen konnte." (Abschaffel, S. 90) Eine Konsequenz daraus ist Abschaffels soziale Ängstlichkeit bereits bei Bagatellen: „Alles, was er sich traute, war das Fallenlassen von Bonbonpapierchen in dunklen Kinos, und sogar dann drehte er sich noch im Dunkeln um, ob ihn niemand beobachtet hatte." (Sorgen, S. 324) In der Straßenbahn geht es dem Ich-Erzähler aus Das Licht brennt ein Loch in den Tag ganz ähnlich: Während der Fahrt

fiel oft das Licht aus. Ich nutzte die Gelegenheit, um schnell auf den Boden zu spucken. Nach ein paar Sekunden flammten die Glühbirnen wieder auf, und ich glaubte, alle Fahrgäste hatten wie ich etwas Verbotenes getan. Ich sah ringsum in die Gesichter, aber ich sah keine Anzeichen dafür, daß die anderen etwas verbrochen haben könnten. Ich nahm an, sie waren nur geschickter als ich. (Licht, S. 29 f.)

Es geht nicht eigentlich um Gehorsam oder Ungehorsam, nicht um Mut(proben) oder dergleichen $^{94}$ - wichtig ist das figurenbasistypische Merkmal, die Evaluation des Verhaltens nach außen zu delegieren und mithin die öffentliche Selbstaufmerksamkeit als wesentlich anzuerkennen. Für Genazinos Romanfiguren ist diese Unterscheidung aber nicht möglich; sie schließen die öffentliche Selbstaufmerksamkeit kurz mit dem für sie als negativ konnotierten ,Leisetreten': „Wie ein Spießer sorgte ich mich darum, Nachbarn könnten das Schluchzen gehört haben." (Tiere, S. 108) Mit dem Vergleich zum Philister, der „wichtigsten Sozialfigur[] der deutschen Literaturund Kulturgeschichte",95 ist die reflektierte Wahrnehmung sowohl als auch die Problematisierung als öffentlich Selbstaufmerksamer bereits in Kraft getreten. Mehr oder weniger unmerklich bzw. unkommentiert, dafür aber auf einem höheren Beobachtungslevel angesiedelt, zerbricht sich Axel Degen auf zweiter Stufe den Kopf seiner Zimmerwirtin: „[S]o leise wie möglich ging ich die Stufen hinunter, um die Wirtin vor dem Gerede ihrer Nachbarinnen zu bewahren" (Laslinstraße, S. 57).

Im gleichen Maß, wie der Basistypus, sofern es zur Reflexion kommt, die eigene Tendenz zur öffentlichen Selbstaufmerksamkeit kritisiert, erscheint die private Selbstaufmerksamkeit in einem günstigeren Licht. Insofern ließe sich die zwanghafte Wahrnehmung aus Außenperspektive mit dem Beobachtungszwang engführen; auch dort werden ja bekanntlich Momente gemocht, in denen der Blick und in einem zweiten Schritt die Interpretation der Außenwelt ruhen darf. Abschaffel etwa „achtete darauf, nichts zu bemerken. [...] Das gefiel ihm gut [...]. Plötzlich war er ganz bei sich angekommen. Die Außenwelt war ausgeschlossen." (Abschaffel, S. 130) Mitnichten wird diese andere Aufmerksamkeitsseite nur als Negativfolie mitgedacht, sondern ausdrücklich

94 Auch zur öffentlichen Selbstaufmerksamkeit neigende Individuen können etwa ,mutig` oder ,provokant' handeln - gefallen sich vielleicht sogar vermehrt darin.

95 Remigius Bunia/Till Dembeck/Georg Stanitzek: Elemente einer Literatur- und Kulturgeschichte des Philisters. Einleitung. In: dies. (Hg.): Philister. Problemgeschichte einer Sozialfigur der neueren deutschen Literatur. Berlin 2011, S. 13-51, hier S. 13; vgl. auch Nils Lehnert: „So ermahnte man ihn, in Zukunft besser beim Niesen aufzupassen, und schickte ihn nach Hause." Paul Maars Pixi-Buch Vorsicht, Niesgefahr! zwischen Exklusion und (Re-JIntegration, Über-Ich und Es, Philistertum und Selbstbestimmung, Sams und Sturmniesen. In: Andreas Wicke/Nikola Roßbach (Hg.): Paul Maar. Studien zum kinder- und jugendliterarischen Werk. Würzburg 2017, S. 139-158, hier S. 140. 
sogar als (an anderen) bewundernswert herausgestellt $(\Leftrightarrow$ II.4.5): „[W]egen ihrer Freiheit, in aller Öffentlichkeit zu seufzen, wurde sie von Herrn Fuchs allerdings beneidet." (Ausschweifung, S. 53 f. $)^{96}$ Im gleichen Zug erfolgt der wehmütige Abgleich mit dem eigenen Handeln: „Niemals würde er in der Lage sein, so offen wie der Mann vor ihm seine Mangelhaftigkeit zu zeigen. Abschaffel hätte ruhelos gewartet, bis das Wasser abgelaufen war" (Abschaffel, S. 109). ${ }^{97}$

$\mathrm{Zu}$ grenzenlos subjektiv sollten sich andere Figuren dann allerdings doch nicht mit sich selbst befassen. Denn dem Basistypus ist es etwa „unbegreiflich, wie jemand einen Gegenstand umwerfen konnte, ohne es zu bemerken." (Sorgen, S. 278) Eine ähnliche Beobachtung und Bewertung trifft Weigand: „Am eindrucksvollsten war vermutlich, daß keiner der aufbrechenden Gäste das von ihm verursachte Mißgeschick bemerkte." (Wohnung, S. 34) Weigand wie Abschaffel uvw. stellen - sich selbst als Messlatte begreifend - ein ,Mindestmaß’ an öffentlicher Selbstaufmerksamkeit auch bei anderen in Rechnung, was aber nicht heißt, dass bspw. Weigand nicht fasziniert davon wäre, wenn jemand rein privat selbstaufmerksam ist:

Hörte die Frau schlecht? Oder war ihr das Geräusch gleichgültig? War ihr vielleicht alles egal? Der Einfall weckte mein Interesse an der Frau. Schon immer wollte ich einen Menschen kennenlernen, dem alles egal war. Die Leute, die ich kannte, sagten immer nur, ihnen sei alles egal. Aber es genügte, sie ein wenig zu beobachten, und schon wurde deutlich, daß ihnen nichts egal war. (Wohnung, S. $158 \mathrm{f}$.)

So sehr Genazinos Figuren private Selbstaufmerksamkeit (in Maßen) bei ihren Gegenüber schätzen oder doch zumindest interessiert zur Kenntnis nehmen, so schwer fällt es ihnen, sie sich selbst ,anzutrainieren': „Sie lobte mich, weil ich mir im 1. Klasse-Abteil erlaubt hatte, ein Butterbrot auszupacken und es ohne „sichtbare Hemmungen“ verzehrte.“ (Außer uns, S. 71) Dass der Protagonist sein gängiges Verhaltensmuster des protektiven IM - möglichst wenig Aufmerksamkeit erregen - durchbricht und der öffentlichen Selbstaufmerksamkeit zum Trotz ein Brot in Anwesenheit anderer isst, wird von seiner Freundin gelobt und er nimmt dieses Lob auch an. Allerdings nur, wie sich herausstellt, weil „Carola [...] sich wieder viel Mühe gegeben [hatte]. Das Brot war kleinformatig, damit es nicht aussah wie ein Bauarbeiterbrot, sondern wie ein Karrierebrot für die 1. Klasse." (Außer uns, S. 71; $\Rightarrow$ II.1.5) ${ }^{98}$

Immerhin gibt es also vereinzelte Momente, in denen Genazinos Figuren den Blick nur auf sich selbst zustandebringen, wobei dies gelegentlich mit in der Schwebe gehaltener Position zwi-

96 Vgl. für eine Szene, in der sich eine Hauptfigur romanspezifisch selbst das Seufzen erlaubt und dadurch „auf stumme Weise frech“ wird, Kein Geld, S. 36.

97 Vgl. für weitere Bewunderungen der privaten Selbstaufmerksamkeit Licht, S. 78, sowie den Text Die Obdachlosigkeit der Fische, wo sich in die Bewunderung allerdings auch rassistische Verachtung mischt ( $\Rightarrow$ II.1.6 u. $\Rightarrow$ II.4.2).

98 Vgl. für die genderproblemtaische Frage, warum die Frau dem Mann das Brot schmieren muss, $(\Leftrightarrow$ II.5.3). 
schen öffentlicher und privater Selbstaufmerksamkeit ${ }^{99}$ einhergeht und alles andere als problemfrei verlaufen muss.

NABELSCHAU UND RECHTFERTIGUNGSDRANG: SELBSTBEOBACHTUNGEN ZWISCHEN PRIVATER UND ÖFFENTLICHER SELBSTAUFMERKSAMKEIT

„[R]ichtet sich der Fokus auf persönlich-interne Aspekte wie z.B. Gefühle, Fantasien, Motive oder Stimmungen", wie es die Definition privater Selbstaufmerksamkeit besagt (s.o.), so kommen entweder noch ganz anders geartete Probleme ans Licht oder bereits als problematisch erlebte Situationen werden erneut ins Bewusstsein gerufen: „Später, nach dem Frühstück, fragte ich mich, was ich eigentlich nicht verstanden hatte: mein Zittern vor einem etwa fünfzehnjährigen Bäckermädchen, meine idiotische Hast oder mein Ausharren in dieser vorstädtischen Umgebung." (Regen, S. 46) Eine Verkettung ungünstiger Zufälle in Kombination mit mangelnden Sozialkompetenzen $(\Leftrightarrow$ II.1.3) führt dem Protagonisten in der Introspektion einige seiner impulsivirrationalen Handlungsweisen $(\Leftrightarrow I .3 .1)$ vor Augen. Diese zweifelsfrei subjektive Sicht kann sich bis zur quälenden Nabelschau auswachsen: ${ }^{100}$ „Abschaffel überlegte und überlegte, und seine Augen wuchsen langsam nach innen in seinen Kopf." (Sorgen, S. 186) Zu Tage treten z.B. Minderwertigkeitsgefühle ( $\Rightarrow$ II.1.3): „Ich arbeite, ich ruhe mich aus, ich denke, ich wohne, ich liebe, ich hoffe, ich reise, aber manchmal fürchte ich, nichts davon wirklich zu können. Es ist leicht, eine solche Ahnung hervorzulocken“ (Licht, S. 10). Man ist geneigt, zu ergänzen: wenn man zu lange in sich hineinhorcht:

Ich höre jetzt nur noch das Wehklagen meiner ratlosen Seele. Sie möchte gern etwas erleben, was ihrer Zartheit entspricht, und nicht immerzu dem Zwangsabonnement der Wirklichkeit ausgeliefert sein. Ich beschwichtige meine Seele und schaue mich nach geeigneten Ersatzerlebnissen um. (Glück, S. 9 f.)

Das Bei-sich-selbst-Sein ist also oft negativ besetzt, obwohl es zunächst - freilich in anderer Form ${ }^{101}$ - herbeigesehnt wird. Damit wird die private Selbstaufmerksamkeit zum zweiten Gefängnis: „Aber leider steckte ich gerade wieder in meinem eigenen inneren Oratorium, aus dem ich nur noch selten hervortrat. Im Gegenteil, ich geriet allmählich an den Rand einer weitreichenden Untätigkeit, die sogar das Sprechen einschloss." (Tiere, S. 63)

99 In der Forschung wird davon ausgegangen, dass man sich zwar immer nur in einem Zustand befinden, aber schnell zwischen beiden hin-und-her-wechseln könne (vgl. Schlenker: Impression management, S. 73); die Formulierung sei hier eher metaphorisch verstanden. Vgl. Christoph Kuhn: Kein Plädoyer für Nabelschau. Aus der Solothurner Laudatio auf Wilhelm Genazino. In: Tages-Anzeiger vom 15. Juli 1995.

101 Vgl. für neutrale private Selbstaufmerksamkeit etwa: „Ich, Axel, konnte keinen Unterschied feststellen in meiner Gangart, als ich unser großes dunkles Haus verließ, ich ging, wie ich immer ging, ich blieb stehen, wo ich immer stehenblieb“ (Laslinstraße, S. 118); für eine trotzige Ausformung: „Kurz darauf weine auch ich. [...] Sonderbarerweise ist es mir gleichgültig, daß andere Leute meine Tränen bemerken und mich schamlos anglotzen. Sollen sie doch sehen, daß ich über das Ufer trete“ (Heimweh, S. 169); für positiv erlebte: „Liegend finde ich, daß der, der hier lebt, wohl lebt, und ich beneide ihn ein wenig um seine Gelassenheit und um sein Verstecktsein." (Einfalt, S. 76) 
Daraus lassen sich zwei Folgerungen ableiten: entweder die Abkehr vom eigenen Inneren oder die soziale, protektives IM nutzende Abkehr von der Gesellschaft. Für den ersten Fall kann der Protagonist der Liebesblödigkeit einstehen: „Genaugenommen will ich mit meinem Innenleben nichts mehr zu tun haben. Beziehungsweise, wenn ich könnte, würde ich mein Innenleben nur noch bei besonderen Gelegenheiten an mich heranlassen." (Liebesblödigkeit, S. 96) Mit der Abkehr von der Überempfindlichkeit soll zugleich auch die Distanz zum eigenen Bewusstsein eintreten. Die zweite Variante wählt der Architekt aus Wenn wir Tiere wären:

Ich hatte natürlich keine Defekte beziehungsweise nur eingebildete, die allerdings heftiger waren als wirkliche. Ich war zum Beispiel überzeugt, dass ich langweilig war und auch nicht sprechen konnte, ohne Langeweile bei anderen Menschen hervorzurufen. Deswegen redete ich, soweit möglich, nur wenig und galt als schüchtern. Als Schüchterner war ich allerdings beliebt bei vielen anderen, die wirklich schüchtern waren und in mir einen verständigen Menschen vermuteten. (Tiere, S. 25 f.)

Ob er nicht selbst ,tatsächlich`als schüchtern zu gelten habe, sei hintangestellt; in jedem Fall existiert eine Diskrepanz zwischen Selbst- und Fremdbild ( $\Rightarrow$ II.2.1), die dazu führt, dass er sich falsch eingeschätzt, letztlich missverstanden fühlt. Diese Grundempfindung ist basistypisch und ein beständig angeschlagenes Motiv ( $\Rightarrow$ I.2.2): „Das wird wie gewöhnlich niemand verstehen. Außer Lisa natürlich, aber Lisa ist nicht da und wird nie wieder dasein." (Regenschirm, S. 55) Aufgrund des vermuteten Sich-missverstanden-Fühlens, wird mitunter auch gar nicht erst der Versuch unternommen, dieses Verständnis einzuwerben. Abschaffel lebt etwa in der „tiefen Überzeugung: daß er Margot nicht sagen konnte, wer er sei.“ (Sorgen, S. 196) Eine Reaktion des Basistypus ist es in der Folge, ostentativ ,verständlich“ wirken zu wollen: „Zeitweilig verhielt ich mich besonders brav, weil ich wollte, daß sie wenigstens mich von morgens bis abends vollständig verstehen könnten." (Einfalt, S. 35) Zu dieser Form des Gefallen-Wollens wird noch die Rede sein (s.u.), die Frage, die sich den Rezipienten auf Dauer stellt, lautet: Verstehen die Nebenfiguren die Hauptfiguren wirklich nicht? Abschaffel ist eine der wenigen Figuren, die dies zu reflektieren scheinen (aber nur in Klammern): „Aber weil das niemand verstand (oder verstand es jeder?), mußte er so tun, als wollte er Briefmarken kaufen." (Falsche Jahre, S. 561) ${ }^{102}$

Als habitueller Ausdruck des Gedankens, andere könnten sie nicht verstehen, finden bei Genazinos Figuren (empfundene) Schuld und (realer) Rechtfertigungsdrang kompositorische Anwendung:

Auf dieser zweiten Ebene ist die Schuldempfindung weniger an konkrete Ereignisse gebunden denn als allgemein menschliches Grundgefühl verankert, das sich aus der individualpsychologischen Entwicklung notwendig ergibt [...]. Eben diese Art von Schuld steht meines Erachtens im Mittelpunkt dieser Prosa, die zahlreiche Szenen enthält, in denen es vor allem um übersteigertes oder in jedem Falle rein subjektives Schuldempfinden geht, deren Ursache nicht immer erkennbare äußere

102 Für Formen des zweifelsfreien Missverstehens vgl. etwa: „Das Wort Pop-Akademie läßt mich kurz erstarren. Eine Pop-Akademie ist das krasse Gegenteil dessen, was mir vorschwebt." (Glück, S. 77) 
Ereignisse sind. Dieser Schwerpunkt ließe sich mit einer über viele Werke sich allmählich positiv entwickelnden Individuation parallel setzen $[. ..] .^{103}$

Da sich die IM-Forschung hauptsächlich mit faktisch vorliegenden Fällen von wie auch immer gearteten Schuldsituationen beschäftigt, ${ }^{104}$ sind diejenigen defensiven Techniken und Taktiken, mittels derer sonst Entschuldigungen und Entschuldungen erfolgen $(\Leftrightarrow I .3 .3)$, zwar nur bedingt in Anschlag zu bringen, ,passen' aber erstaunlich gut: „Für den Fall, daß es jemand beobachtet hatte, hatte er ein enttäuschtes und überraschtes Gesicht bereit, das die Schuld an diesem Zwischenfall auf das brüchige Plastikbesteck schob.“ (Abschaffel, S. 119) Abschaffel benennt „das brüchige Plastikbesteck" gewissermaßen als ,Sündenbock':

Dissociation [ distanzieren vom/abstreiten der Beteiligung am (missliebigen) Ereignis; N. L.]. The main statement is ,It was not me.' People using disassociation accept that a negative event has taken place, but affirm that they have not caused it. Tedeschi and Riess (1981) called this behavior ,denial of agency.' To strengthen the claim of not having caused a certain event, a person may name a scapegoat. He or she might even claim not to be associated with the event in question. ${ }^{105}$

Bei den hier in Rede stehenden Rechtfertigungen handelt es sich im Gegensatz zu den Selbstrechtfertigungen $\Leftrightarrow$ II.2.1) ${ }^{106}$ um solche im Modus öffentlicher Selbstaufmerksamkeit: „Zwischendurch empfand er das Bedürfnis, seine Schuldlosigkeit zu beteuern, aber wie immer war niemand da, der sich für derartig bedeutsame Beteuerungen interessierte." (Fremde Kämpfe, S. 209) Das muss nicht immer so sein: Teils sind es „imagined audiences“ (s.o.) - „Abschaffel sah in der Küche umher, weil er einige Augenblicke lang dachte, jemand hätte seine Verfehlung gehört und würde ihn nun verurteilen“ (Sorgen, S. 248); „Einen Augenblick lang dachte er, es handle sich um einen Artikel über die Gesamtschuld seines bisherigen Lebens, die einem Reporter endlich aufgefallen war" (Sorgen, S. 275 f.) -, teils aber auch konkrete Personen oder Personengruppen, denen der Basistypus Rechtfertigung zu schulden meint:107 „Ich habe Lust, einen einzigen Satz den Balkon hochzurufen, der uns alles erträglich macht, aber ich kann den Satz in der Eile nicht finden. Die Frau sieht mich an wie einen Ertappten, dessen Vergehen noch erfunden werden muß." (Einfalt, S. 92) Darf man dieses Beispiel vielleicht als futuristisches Schuldemp-

\footnotetext{
103 Hirsch: „Schwebeglück der Literatur“, S. $91 \mathrm{f}$.

104 Die es bei Genazino natürlich auch gibt! Vgl. etwa: „Und obwohl ich sofort weiß, daß das Lachen unangebracht war, ist es für eine Rücknahme zu spät. Der Kellner erschrickt leicht, wendet mir den Rücken zu und verschwindet im Inneren des Restaurants. Ich bedaure die unbeabsichtigte Beschämung des Kellners." (Frauen, S. 117) Schütz: Self-Presentation, S. 619.

106 Vgl. für eine Ausnahme: „[A]ber wie immer suchte er in seinem Kopf irgendeine Instanz, wo er sich dafür entschuldigen konnte [...]. Er glaubte, er müsse unentwegt sprechen und immerzu alles erklären" (Abschaffel, S. 105).

Für einen gar nicht so seltenen Sonderfall, dass auch Tiere als potenzielle Kommunikationspartner angesehen werden, vgl. etwa: „Das Mißverständnis, daß der Hund vielleicht glaubte, er, Abschaffel, wolle etwas gegen ihn unternehmen, indem er auf den Automaten zuging, wollte er nicht riskieren." (Sorgen, S. 170)
} 
finden mit vorauseilendem Rechtfertigungswunsch bezeichnen, ${ }^{108}$ ist die Grundkonstellation naheliegenderweise die Nachträglichkeit. Auch ohne sich das Rubikon-Modell $(\Leftrightarrow I .3 .1)$ zu vergegenwärtigen, können dem gesunden Menschenverstand nach weder Schuldgefühle noch Rechtfertigungsstrategien oder Entschuldigungen vor der Handlungs-, sondern frühestens in der evaluativen Bewertungsphase ihren Ort haben: „Jetzt wollte er ihnen nachträglich erklären, daß er gar nicht so sei, wie er sich eben benommen hatte, daß er so ein Mensch ganz und gar nicht sei.“ (Abschaffel, S. 99) Auch: „Er wollte das Mißverständnis unbedingt sofort aufklären und ihnen sagen, daß er sie nicht bloß anglotzen wollte“ (Sorgen, S. 233). Die, wenn überhaupt existierende, Schuld lastet zumeist schwer auf dem Figurengewissen: „Ich mache mir Vorwürfe, daß ich weder die Brille noch die Tasche aufgehoben habe. Diese ins Leere gehende Fürsorge ist ganz typisch für mich. Deswegen komme ich mir jetzt oberflächlich, halb zerfleddert und nichtswürdig vor." (Glück, S. 109)

Etwas verspielter gibt sich die folgende Situation, weil die Frage, ob man dazu neige, eine bereits vorher beschmutzte Toilette zu reinigen, um sich selbst des Verdachts zu entziehen, Verursacher dieser Verschmutzung zu sein, mittlerweile als klassischer Gag in zahlreichen TV-Serien und Spielfilmen verhandelt worden ist: „Ich muß jetzt dulden, daß die Leute ringsum annehmen, ich hätte den Boden beschmutzt oder mitbeschmutzt." (Liebesblödigkeit, S. 34) Denn eigentlich will der Basistypus - wenn es sich nicht protektiv vermeiden lässt, überhaupt evaluiert zu werden nur eines: schuldlose Anerkennung.

\section{(AUCH ASSERTIVE) GEFALLSUCHT}

Es nimmt nicht wunder, dass Genazinos Figurenbasistypus - von externer wie interner Figurenperspektive aus besehen - ein Korrektiv braucht, um dem Bedürfnis nach einem positiven Selbstbild gerecht zu werden. Flapsig formuliert: Bei derart vielen psychischen Problemen (Minderwertigkeitskomplexe, Schuldgefühle etc.) muss ja irgendein Mechanismus die Bestätigung ermöglichen.

Allerdings formieren sich die Fundstellen, in denen die Gefallsucht durchschlägt, alarmierend um die eigene Kindheit: „Die ganze Familie lobte mich, und ich fühlte mich gut.“ (Abschaffel, S. 151) In dieser Reminiszenz mag das noch völlig unproblematisch genannt werden, aber spätestens dann, wenn Abschaffel aufgeht, dass er auch lange nach seiner räumlichen und geistigen Distanzierung von seinen Eltern „noch immer nicht aufgehört hatte, seinen Eltern mehr als allen anderen Personen gefallen zu wollen“ (Abschaffel, S. 60), droht die öffentliche Selbstaufmerksamkeit als ,Strippenzieherin“ bedrohlich zu wirken. Diese Feststellung scheint der Erzähler mit nullfokalisiertem Einschlag auch zu bemerken, wenn er das Alter der Figur hervorhebt und in

108 Vgl. dazu auch Abschaffels im Gedankenspiel ausgemalte künftige Schuld, wenn er sich fragt, „wie er eines Tages den Eltern und Arbeitskollegen sein neues Leben als Zuhälter erklären konnte." (Sorgen, S. 226) 
Kontrast zur Reichweite der Analepse setzt, um den noch immer wirksamen Anerkennungswunsch durch den eigenen Vater zu akzentuieren: „[U]nd der dreißigjährige Abschaffel erinnerte sich, wie er vor mehr als zwanzig Jahren an Sonntagmorgenden seine Schuhe putzte, um ihn, den Vater, für sich einzunehmen." (Abschaffel, S. 68) Gänzlich ins Düstere wird dieses Setting bereits qua Satzstilistik $(\Leftrightarrow I .2 .3)$ in Die Liebe zur Einfalt verlagert: „Und obwohl ich vor Schreck erstarrt war, lächelte ich vom Bett aus Vater zu und spürte das Glück, seinem Willen gefolgt zu sein.“ (Einfalt, S. 77) Per Anbiederung und dem Verweis auf eigene Vorzüge $(\Leftrightarrow I .3 .3)$ gefallen sich die Figuren im assertiven IM.

Erlernte Mechanismen perpetuieren sich in der echten Welt wie in dieser nachempfundenen Vitae, sodass einer der wenigen Familienväter in Genazinos Romanwerk unumwunden die Bewunderung durch seine eigene Kleinfamilie als Motivation benennt: „Genau dieses Angeblicktwerden hatte ihm gefehlt, damit er sich selbst wieder ein wenig großartiger vorkam." (Ausschweifung, S. 74) Fast ins Groteske übersteigert wünscht sich Fuchs von Frau und Tochter: „Wenn es irgend möglich wäre, sollten sie beide vor Glück heulen, vielleicht sogar schreien.“ (Ausschweifung, S. 127) Prima vista handelt es sich um den Wunsch nach Anerkennung im Verbund mit dem Bedürfnis, seine Familie glücklich zu machen. Aber was ist das für ein hellhörig werden lassender Widerspruch in der wortstilistischen Semantik? Ohne das „Glück“ handelte es sich um das Zufügen von Qual - wie auch im Beispiel des am Bett sitzenden Ich-Erzählers verliert die Valeur des Wortes ,Glück' unmerklich ihre Denotation.

Nicht nur bezogen auf die eigenen Eltern oder die eigen gegründete Familie ist das GefallenWollen immer frei von Brechung. Während die Beispiele des Vaters einer Freundin - „Denn ich hatte begonnen, Carolas Vater gefallen zu wollen“ (Außer uns, S. 26) -, eines Arbeitskollegen „Es war Abschaffel angenehm, sich von Mörst vorübergehend geachtet zu wissen“ (Sorgen, S. 281) - sowie einer fremden Thekenkraft - „Ich fange an, die einzeln auf der Theke herumliegenden Mohnkörner [...] aufzuklauben [...]. Die Wirtin ist von meinem Sauberkeitssinn beeindruckt und lächelt mich jetzt an" (Liebesblödigkeit, S. 92) - neutral bist klar positiv vermerkt werden, lauert auch hier die Eintrübung. Denn die aufgrund unterschiedlicher Rollenerwartungen parallel existierenden Selbstentwürfe geraten nicht selten in Widerstreit: „Plötzlich ärgerte ich mich, daß ich mich so schnell und freundlich bereit gefunden hatte, Phil diesen Gefallen zu erweisen, als hätte ich keinen anderen Axel in mir, der störrisch war, der das nicht gutfand“ (Laslinstraße, S. 194). Degen wird sich hier, um mit Friedemann Schulz von Thun zu sprechen, seiner „innere[n] Pluralität“, seines „Inneren Team[s]“ bewusst:

Wenn wir in uns hineinhören, finden wir dort selten nur eine einzige ,Stimme', die sich zu einer bestimmten Situation oder einem Thema zu Wort meldet. In der Regel stoßen wir vielmehr auf ver- 
schiedene innere Anteile, die sich selten einig sind und die alles daran setzen, auf unsere Kommunikation und unser Handeln Einfluss zu nehmen. ${ }^{109}$

Obwohl von Thun hervorhebt, dass es sich dabei generell „um einen ganz normalen menschlichen Zustand“ handele, ${ }^{110}$ lässt sich für Genazinos Figuren durchaus auch hier von einem eher neurotisch-zwanghaften Verhalten sprechen: Zwar zeigen viele Figuren dann Genugtuung, wenn sie Wertschätzung erfahren, aber der Preis ist für sie hoch: „Ich war hier befreit davon, die Leute um mich herum beeindrucken zu müssen. Für jemand wie mich, der mit innerer Geltungssucht geschlagen war, war die Zelle eine Erleichterung." (Tiere, S. 128) Just im Gefängnis findet der namenlose Ich-Erzähler ,Freiheit' - viel plakativer ist es nicht zu schildern.

Insgesamt sind alle Spielarten des zuvor geschilderten, gewünschten „Angeblicktwerden[s]“ (s.o.) solche, bei denen eine wie auch immer geartete Belohnung in Aussicht steht. Ganz anders verhält es sich, wenn das erwartbare oder mutmaßliche Feedback ein negatives sein könnte: „Aber ich genierte mich, mit einer Plastiktüte und einem Thermobehälter darin durch die Straßen zu gehen. Ich wollte nicht, dass jemand über mich denkt, schau, da geht ein Mann und trägt einen Teller Suppe nach Hause." (Kassiererinnen, S. 7) Dann schwindet der Wunsch, dass die Blicke der anderen auf das eigene Verhalten, das eigene Selbst, treffen.

\section{BEOBACHTET- UND DURCHSCHAUTWERDEN}

Schon in der das Unterkapitel einleitenden Überschrift ist ein eingeklammertes, imaginiert' zu lesen. Die Erklärung sei hiermit ausdrücklich nachgeholt: Es gibt eine Spielart des öffentlichen Blicks, der als lediglich gemutmaßter aufzufassen ist (das sind diejenigen Momente, in denen der Leser sich fragt: Warum muss der Protagonist das alles so unerträglich aufbauschen?). Zwar ließe sich bereits für diesen Bereich der psychologische Holzhammer mit der Aufschrift ,Gefühlte-Realität-ist-Realität' herausholen, allein lässt sich jenseits eines die Grenzen verwischenden Graubereichs auch von tatsächlichen Beobachtungssituationen sprechen, in welchen vermutlich selbst der privat-selbstaufmerksamste Mensch zur Perspektivübernahme genötigt wäre.111 Der Probierstein ist erneut narratologischer Machart: Nur die genaue erzähltechnische Umsetzung der Aussagen vermag die Einteilung zu gewährleisten. In der Umkehrung der Vorzeichen ist im Gegensatz zum Durchschauen und Nicht-Durchschautwerden $(\Rightarrow$ II.2.2) daher das Beobachtetund Durchschautwerden zu eruieren.

Um mit den eher unverifizierbaren Mutmaßungen zu beginnen und die Wichtigkeit des Discours ins Spiel zu bringen, soll am Beispiel von Laslinstraße gezeigt werden, dass nicht jeder registrierte Blick der anderen auch das eigene Selbst trifft, geschweige denn gefährdet: „[A]lle liefen sie an mir vorbei und dachten sicher, als sie mich sahen: Der hat's gut, der ist noch jung“" (Laslinstraße,

\footnotetext{
109 [Inneres Team]: Schulz von Thun Institut: das Innere Team. Online: <https://www.schulz-vonthun.de/die-modelle/das-innere-team>.

110 [Inneres Team].

111 Ein prominentes Roman-Beispiel dafür sind Die Kassiererinnen.
} 
S. 28). Die doppelte Apodiktik („alle“; „sicher“) stellt die Glaubwürdigkeit der Wahrnehmung eher infrage als sie zu unterfüttern, wie auch im folgenden Beispiel ein dem aufmerksamen Leser nicht verborgen bleibendes, zur Skepsis gemahnendes narratologisches Detail sich versteckt: „Ich spürte, daß er mir nachblickte, als ich auf dem weichen roten dicken Teppich einen Gang entlangging, und als ich an dem seitlichen Aufgang war, vermied ich es, zurückzublicken“ (Laslinstraße, S. 121). Die Skepsis in Bezug auf den ,fünften Sinn' (,spüren') alleine würde schon ausreichen, um der Schilderung den Beigeschmack der Fragwürdigkeit hinzuzufügen, doch - im Gegensatz zu den zitierten Schnitzler- und Genazino-Beispielen, die im Gesichtumdrehen Gewissheit suchen ( $\Rightarrow$ I.3.3), - unterlässt es Degen, „zurückzublicken“. Im gleichen Metier der Augen-Blicke $(\Leftrightarrow$ II.1.4) scheint sich Degen an anderer Stelle genauso sicher in seiner Einschätzung, beobachtet und durchschaut zu werden: „An den Blicken, mit denen mich der Ladeninhaber musterte, sah ich, daß er mich vielleicht anders behandeln wollte als seine übrigen Kunden, ich war neu für ihn [...] und deshalb sagte er sehr freundlich“ (Laslinstraße, S. 156). Als unverkennbares Indiz hat sich ein „vielleicht“ eingeschleust - zwar nicht in der eigentlichen Aussage, aber im davon abhängigen Kausalzusammenhang. Schwieriger einzuschätzen ist das folgende Beispiel: „Ein Mann im himmelblauen Anzug tauchte zwischen den Lippen auf, sah uns an, schätzte nach dem Gesicht, das ich machte, den Barbetrag in meinem Geldbeutel, für ihn offenbar ein zwiespältiger Eindruck, er wünschte uns aber trotzdem viel Vergnügen“ (Laslinstraße, S. 182). In Ermangelung alternativer Sichtweisen oder eines, allwissenden` Erzählerkommentars muss der skeptische Interpret die Mosaiksteine, die gegen ein Durchschauen sprechen, zusammenklaubend inferieren: Wenn der Mann den Barbetrag anhand eines Gesichtsausdrucks zu schätzen vermag, dann schafft er es auch; wenn ihm ein Gesichtsausdruck „zwiespältig[]“ vorkäme, würde er vermutlich den Eintritt verwehren; wenn er hingegen „viel Vergnügen“ wünscht, scheint er das Bargeld hoch genug taxiert zu haben - ganz abgesehen davon, ob er jemals dieses zu taxieren gesucht hat. Wieder deutlicher sind die Marker im folgenden Beispiel:

[E]inmal kam mir der Verdacht, sie hätte sich nur deshalb einen Untermieter zugelegt, damit sie ein anderes Leben genau registrieren konnte [...] der Feldzug der Neugierde, den Phil führte, war noch nicht zu Ende, sie drang immer weiter vor, nahm mir jeden Tag etwas weg, Stückchen für Stückchen. (Laslinstraße, S. 195)

Der bloße „Verdacht“, der zudem nur singulativ „einmal“ aufkommt, rahmt alles Folgende; zumal nicht die Rede davon sein kann, dass Phil Axel bewusst „Stückchen für Stückchen“ seiner Privatsphäre wegnähme.

Im Schnelldurchlauf verhält es sich ähnlich bei Abschaffel (vgl. Abschaffel, S. 77; vgl. Sorgen, S. 332; vgl. Falsche Jahre, S. 402 u. S. 528), ${ }^{112}$ Eckhard Fuchs (vgl. Ausschweifung, S. 126), Wolf

112 Vgl. ausnahmsweise: „[E]r fühlte sich nicht beobachtet“ (Sorgen, S. 307), sowie: „[U]nd Abschaffel sah, während er sich dem Mann näherte, unablässig auf dessen Lippen. Der Mann bemerkte, daß ihm auf die Lippen gesehen wurde, und Abschaffel fand es selbst gemein“ (Sorgen, S. 336 f.). 
Peschek (vgl. Fremde Kämpfe, S. 30 u. S. 77), ${ }^{113}$ dem Protagonisten aus Genazinos Leise singenden Frauen (vgl. Frauen, S. 162), demjenigen aus Ein Regenschirm für diesen Tag (vgl. Regenschirm, S. 9 u. S. 111) sowie dem namenlosen Ich-Erzähler aus Die Kassiererinnen (vgl. Kassiererinnen, S. 41 f., S. 42 u. S. 66).

Zwei Szenen verdienen eine genauere Analyse - eine aus dem in diesem Zusammenhang noch nicht erwähnten Roman Mittelmäßiges Heimweh, eine aus den Kassiererinnen, die überleitet zum ,expliziten' Beobachtet- und Durchschautwerden. Zunächst: „Es ist angenehm, von niemand beobachtet zu werden und nur leise Geräusche zu hören. [...] Es sieht ganz schön verwegen aus, wenn man so aus der Flasche trinkt." (Heimweh, S. 86) Nichts spricht dafür, dem Erzähler Unzuverlässigkeit zu testieren, nichts dagegen, davon auszugehen, dass er unbeobachtet ist. Daher ist es erzähltheoretisch höchst bemerkenswert, dass der Indikativ Präsens auch in der öffentlichen Selbstaufmerksamkeit Bestand hat: Die Schilderung des ,verwegenen' Aus-der-Flasche-Trinkens ist der Außensicht zuzuordnen, was sich nur sinnergebend einfassen lässt, wenn man eingebildete Publika (s.o.) ernst nimmt oder einen temporären Fokalisierungswechsel $(\Leftrightarrow I .2 .3)$ annimmt. Das zweite Beispiel strotzt geradezu vor IM- und Selbstaufmerksamkeitsaspekten:

Ich sah, wie ich mir einbildete: auffällig, an meiner Jacke herab und stellte fest, dass die beiden losen Knöpfe noch nicht erkennbar lose waren. Wieder fragte ich mich, ob und wann ich auch für andere lächerlich sein würde und ob ich mich dann vor Beschimpfungen und vielleicht sogar vor Schlägen zu fürchten hätte. (Kassiererinnen, S. 94 f.) ${ }^{114}$

Genazinos Figurenroman Die Kassiererinnen ist der geheime Kronzeuge sowohl was IM insgesamt angeht als auch hinsichtlich des expliziten Beobachtet- und Durchschautwerdens. Hier allerdings ist die Hauptfigur eindeutig noch im Modus der Mutmaßungen befangen: Nicht nur die eigens verbalisierte Einbildung, sondern auch die Einschätzung, „dass die beiden losen Knöpfe noch nicht erkennbar lose waren“, verleitet zu der Auffassung, dass jedenfalls in näherer Zukunft wohl kaum „Beschimpfungen“ oder „Schläge[]“ ob der zur Schau getragenen Ungepflegtheit zu erwarten sind.

Zunehmend mehren sich allerdings die Indizien, dass es sich wirklich um einen Roman des Beobachtetwerdens handelt: 115

113 Wobei die gemutmaßte Beobachtung bereits Züge von Verfolgungswahn annimmt: „Es hörte sich an, als sei es gar kein Läuten, sondern ein klingelndes Sehen: als habe ihn jemand die ganze Zeit heimlich beobachtet." (Fremde Kämpfe, S. 213 f.)

114 Vgl. dazu die im Vorfeld immer wieder aufgeworfene Frage des Protagonisten: „Ich fragte mich, ob ich im Augenblick ansehnlich war oder nicht, ob gegen irgendein Detail meiner Erscheinung Einwände erhoben werden konnten und welche." (Kassiererinnen, S. 19)

115 Vgl. für zwei Momente, in denen der Graubereich zwischen Einbildung und faktischem Beobachtetund Durchschautwerden vorliegt: „Das Schließen und Wiederöffnen der Augen ließ mich jedoch affektiert erscheinen. Nach ein paar Minuten zwang mich die Affektiertheit zum Abbruch des Essens. Ich tat so, als sei das Menü zu schlecht für mich. Ich schob den Teller wie ein schlechter Schauspieler in die Mitte des kleinen Tisches und wandte mich ab. Im Wegdrehen merkte ich, daß mindestens zwei der Essenden mein Gehabe nicht ernst nahmen. Sie hatten heimlich erkannt, daß ich, ach, ich weiß nicht, was sie erkannt hatten." (Regenschirm, S. 65 f.); „Er hatte nicht recht bedacht, daß er so viele Zuschauer haben würde, und er wollte schon einen Schritt zurücktreten, damit er selbst in der 
Zwischen der Kunsthalle, dem Dom und dem Rathaus gab es ein paar tote Winkel mit wenig Publikumsverkehr. Ich stellte mich dicht vor eine halb hohe Mauer und öffnete den Hosenladen. Ich pinkelte nur kurz, und plötzlich hörte ich ein Lachen hinter mir. Ich drehte mich um und sah, dass es von zwei Männern kam. Einer von ihnen hob sich eine Kamera vor das Gesicht. Ich hörte mehrmals das Klicken des Fotoapparats und kurz darauf, ein wenig weiter entfernt, erneut das Lachen der Männer. Ich überlegte, worüber sie lachten. Pinkelnde Männer waren, als Motiv, schon lange nicht mehr originell. [...] Gab es an meiner äußeren Erscheinung ein Detail, das andere zum Lachen reizte? (Kassiererinnen, S. 14 f.)

In der Verarbeitung dieses Erlebnisses wird dem beobachtenden Flaneur „mit einem Mal bewusst [...], dass auch er selbst Gegenstand der Beobachtung ist." ${ }^{116}$ Mutmaßungen in diese Richtung gab es immer schon, nicht jedoch in diesem explizit-bewussten, reflektierten und zu IM mit Kalkül verleitenden Ausmaß. Das hat zunächst eine starke Beunruhigung zur Folge und veranlasst den Protagonisten zu mannigfachen Reflexionen rund um seinen eigenen Eindruck auf andere (vgl. Kassiererinnen, S. 14-20):

Sofort spürte ich den Blick der Leute und sogar ihre Gedanken. Natürlich, in meinem Alter geht man nicht mehr kauend durch die Straßen. Da hatte ich eine Idee: Lächerlichkeit entsteht, wenn jemand ohne erkennbare Not eine Form aufgibt (auf der Straße essen) und im Habitus eingesteht (Verlegenheit beim Kauen), dass er dem Formverlust nachtrauert; und außerdem durch sichtbares Erschauern einräumt, dass er nicht weiß, womit die eben entstandene Lücke künftig ausgefüllt werden soll. (Kassiererinnen, S. 40 f.)

An kaum einer anderen Stelle des Roman(werk)s tauchen derart gedrängt IM-Erwägungen auf dass diese am Beispiel der Lächerlichkeit durchgespielt werden, liegt mit Blick auf den schamhaften und protektiv-aufmerksamkeitsscheuenden Basistypus nahe.

Am ärgerlichsten war die Unklarheit darüber, ob meine Lächerlichkeit, sofern es sie gab, nach außen gedrungen und also für andere sichtbar geworden oder ob sie nichts als ein subjektives Gefühl war. Ich glaubte, es war mir bis jetzt gelungen, als weitgehend diskreter Mensch durch das Leben zu kommen. Aber auf einmal war ich durch eine aufdringliche Befindlichkeit zu sehr mit den anderen Menschen verbunden und empfand ihren Urteilseifer und ihre heimliche Lust auf Verachtung und Hohn. Wenn es die Lächerlichkeit gab, musste ich von ihr eine Entwicklung erwarten, die mir am Ende gefährlich werden konnte. Zum Beispiel könnte sie sich mit meiner Schau verbinden und mich in eine immer stärker werdende Isolation hineintreiben. In ihrem Kern wirkte so etwas wie eine Selbstverfemung, die mich dazu verleitete, Lächerlichkeit schon vor ihrem Eintritt zu empfinden oder sie gar, ohne äußere Anlässe, nur für mich selbst hervorzubringen. (Kassiererinnen, S. 45 f.)

Er hat sich, der Vorfall ist banal, für einen Moment der Lächerlichkeit ausgesetzt und registriert fortan, dass er sich zu einer lächerlichen Figur entwickelt: in den Augen der Mitmenschen, aber auch vor sich selbst. Versucht er anfangs, dies zu verbergen, was ihm nicht gelingen will, hat er es am Schluss akzeptiert und versteht es nicht als individuelles Versagen, sondern ist überzeugt, „daß alle Menschen offen oder verdeckt am Projekt ihrer Lächerlichkeit arbeiteten, und das war nicht schlimm, im Gegenteil“ [...]. Die Umkehr der Blickrichtung - der durch die Stadt streifende Voyeur wird selbst Objekt der Beobachtung, ist fremden Blicken ausgesetzt - gibt dem Buch eine selbstiro-

ersten Zuschauerreihe stehen konnte. Damit hätte er aber zugegeben, daß er mit der Beachtung, die er für seine Person selbst hervorgerufen hatte, nicht zurechtkam." (Abschaffel, S. 118)

116 Der Klappentext, dem das Zitat entnommen ist, ist insofern mit Vorsicht zu genießen, als die Angabe, es mit Kassiererinnen aus dem ,Prezzoprezzo'-Supermarkt zu tun zu haben, schlicht falsch ist (vgl. Kassiererinnen, S. 54 f.). Vgl. dazu auch Gerrit Bartels: Das Glück des Sisyphos. Vom beobachtenden Subjekt zum Objekt der Beobachtung. Eine Begegnung mit dem Schriftsteller Wilhelm Genazino. In: die tageszeitung vom 23./24. Oktober 2004. 
nische Gelöstheit, die den „Reflexionszwang“ des Erzählers und damit auch die eigene Haltung zur Welt sanft karikiert. 117

Bis zu dieser romanspezifischen Einsicht ist für den Protagonisten jedoch noch ein weiter und steiniger Weg zu gehen. Während eines Supermarktbesuchs „begannen zwei junge Verkäuferinnen über mich zu lachen. Sie blickten in die vergitterte Leere meines Einkaufswagens, in dem sich nichts als eine kleine Tafel Schokolade befand, und kicherten." (Kassiererinnen, S. 55) Hat sich der Protagonist bislang immer noch gefragt, ob es seine Lächerlichkeit überhaupt gebe und wenn, ob diese nach außen für andere sichtbar sei, so steht beides nun - zumindest situativ außerfrage. Lediglich das Ausmaß ist noch fraglich: „Draußen, auf der Straße, fragte ich mich, ob ich nur vor den beiden Verkäuferinnen lächerlich geworden war oder auch vor mir selbst - oder gar vor allen, die die Szene beobachtet hatten." (Kassiererinnen, S. 56) Spätestens mit der Begegnung mit zwei Jugendlichen, die die Hauptfigur „zuerst zwiespältig, dann höhnisch und herablassend“ angrinsen, was diesen sogar somatisch („,stieß schubweise wie ein Frösteln in mich hinein“) affiziert und er sich in der Folge von allen anderen, „die auch nicht besonders gut aussahen“, für immer distanziert und sich der Gesellschaft insgesamt entfremdet fühlt $(\Leftrightarrow I I .1 .1)$, ist die „Umkehr der Blickrichtung“ Fakt in der Diegese (Kassiererinnen, S. 123).118

Dieses Schicksal teilen auch andere Figuren: „Das unablässige Beobachtetwerden trifft mich im Innersten." (Tiere, S. 91) So ergeht es auch der Protagonistin aus Genazinos Die Obdachlosigkeit der Fische:

Prüfend mustert sie, was von mir noch brauchbar ist und wie lange. Die Beine? Auf keinen Fall. Mein Kopf, die Frisur? Nein. Das Gesicht? Nein. Die Figur? Schon lange nicht mehr. Als sie ihren Ungültigkeitsbescheid zu Ende geblickt hat, lacht mich die Zwölfjährige an. Oder lacht sie mich aus? Meine kleine Gutachterin bemerkt, daß die Prüfung in mir ein Gefühl der Auflösung hervorruft. Aber sie hört deswegen nicht auf. Frech wie ein Mann schaut sie mir auf die Brust. (Obdachlosigkeit, S. 24) 119

Immer wieder ist es der ,böse Blick', der nicht nur beobachtet, sondern durchschaut, der in die Intimsphäre dringt, und dem Basistypus psychisch und - wie im folgenden Beispiel - auch physisch schwer zusetzt:

Der Straßenbahnführer und der Schaffner blieben in der Nähe der Bahn und rauchten und beobachteten mich. Um sie zu beschwichtigen, tat ich so, als suchte ich ein bestimmtes Haus. Ich las die Namen auf vielen Klingelschildern und schüttelte von Zeit zu Zeit den Kopf. Der Straßenbahnführer

117 Reschke: [Wilhelm Genazino].

118 Vgl. für weniger drastische Beispiele expliziten Beobachtetwerdens: „Meine umherflackernde Raublust ist von der Schwangeren offenbar bemerkt worden. Sie schaut mich ein bißchen höhnisch an, sie schließt die Beine und schiebt den Rock nach vorne“ (Obdachlosigkeit, S. 8); „Dabei weiß ich, daß ich seit kurzem, seit mir ein Ohr fehlt, selber zu den Menschen mit einem Seltsamkeitszeichen gehöre, das von anderen nur versteckt angeschaut wird. Allein die Kinder beobachten offen und direkt. Die beiden [...] starren jetzt auf meine Ohrenklappe und kichern unverhohlen." (Heimweh, S. 19)

119 Für ein weiteres Beispiel, in dem der Beobachter auch dann nicht aufhört, die Hauptfigur zu taxieren, wenn diese sich sichtlich unwohl fühlt, vgl.: „, $[$ A]n der Grobheit, mit der er Abschaffel und Margot betrachtete, war zu sehen, daß es ihm nichts ausmachte, wenn die anderen zeigten, daß sie nicht beobachtet werden wollten." (Sorgen, S. 237) 
und der Schaffner glaubten mir nicht, daß ich jemanden suchte. Sie merkten, daß ich Theater spielte, und sie merkten, daß ich schlecht Theater spielte. Sich lachten und amüsierten sich über mich und sahen dabei in den Himmel. Nach ein paar Minuten verlor ich den Mut und setzte mich in die leere Bahn. Ich hatte soeben erfahren, daß ich nicht frei war. Aus Schmerz über diese Entdeckung biß ich mir einen Fingernagel ab. (Licht, S. 41)

W. weiß seinen Schmerz nicht anders zu kanalisieren als durch eine übersprunghafte Autoaggression ( $\Rightarrow$ II.1.3). Er selbst muss sich qua öffentlicher Selbstaufmerksamkeit dabei zusehen, wie sein kalkuliertes Theater mit der Intention, nicht beobachtet zu werden, eskaliert und dazu führt, sogar durchschaut zu werden. Dieses Gefühl setzt ungewöhnlich starke Emotionen bei Genazinos Romanfiguren frei:

Es überschwemmt mich der Eindruck, in den Augenblicken meiner größten Ratlosigkeit restlos durchschaut worden zu sein. Deswegen rutsche ich jetzt in eine Art inneren Vandalismus hinein, der mir seit meiner Kindheit vertraut ist. Ich möchte jetzt etwas stehlen, etwas zerstören oder jemanden beschimpfen. (Glück, S. 142)

Zwar ist er nicht selbst das abzuwertende Objekt, die zerstörerische Kraft hingegen bleibt die gleiche. ${ }^{120}$

Umso verwunderlicher ist es auf den ersten Blick, dass es Ausnahmen gibt, in denen der Basistypus die Erlaubnis erteilt, beobachtet zu werden: „Auch ich erlaube, daß gegenüber wohnende Personen in mein Zimmer schauen können, und mache das Licht an." (Heimweh, S. 14) Allerdings handelt es sich erstens um eine Rarität und zweitens wie gesagt um eine Entscheidung aus freien Stücken: mit einem Handstreich könnte das Licht wieder ausgeschaltet werden. Eine überaus ähnliche Begebenheit trägt sich im Regenschirm-Roman zu: „Dann und wann unterbreche ich die Arbeit, gehe ein bißchen durch die Wohnung und betrachte die Leute in den Häusern von gegenüber. Auch sie betrachten mich, wir fliehen nicht voreinander, manchmal lächeln wir uns kurz an, vielleicht hat uns der Regen milde gemacht." (Regenschirm, S. 146) Auch im Rahmen einer Partnerschaft, die auf großer Zuneigung basiert, sind solche Momente tolerierten Zuschauens möglich: „Es störte ihn nicht, daß sie ihm beim Ausziehen zuschaute.“ (Abschaffel, S. 152) Bis hierhin handelt es sich um seltene Fundstellen des Einverständnisses mit erlaubtem Beobachtetwerden; ${ }^{121}$ einverstanden mit Durchschautwerden ist eher romanspezifisches Alleinstellungsmerkmal:

Schon nach wenigen Minuten durchschaute sie meine Verlegenheit und zog aus ihrer Handtasche eine zusammengefaltete Plastiktüte hervor. Ich faltete sie auseinander und versenkte darin den

120 Dementsprechend verwundert es nicht, dass diejenigen seltenen Momente, in denen die Hauptfiguren das Gefühl haben, befreit von fremden Blicken leben und existieren zu dürfen, ähnlich positiv bewegend verfasst sind: „Schon nach ein paar Schritten habe ich das Gefühl, niemand schätzt mich ab, niemand denkt über mich nach, niemand beobachtet mich. Zum Damm hin steigt die Stadt leicht an. Kurz danach sehe ich das Meer und zittere ein wenig" (Licht, S. 46). Auch die Nähe zu den Besänftigungsstrategien bezogen auf den eigenen Beobachtungszwang ( $\Rightarrow$ II.2.2; hier: Meer) ist bemerkenswert.

121 Fälle, in denen das Beobachtetwerden sogar zu gefallen weiß, sind ebenso selten und werden tendenziell unter das dritte Schlaglicht gefasst: „Es gefiel mir, dass ich von anderen Gästen beobachtet wurde." (Außer uns, S. 95) 
Präsentkorb. Etwas zu heftig bedankte ich mich bei Frau Clemens und verabschiedete mich von ihr. (Wohnung, S. 94)

Weigand freut sich geradezu, durchschaut worden zu sein, - allerdings, um vom Anlass der potenziellen öffentlichen Aufmerksamkeit befreit zu werden (durchschaut zu werden ist schlimm, aber Präsentkorb ist schlimmer; Plastiktüten sind schlimm, aber Präsentkorb ist schlimmer). In der überwiegenden Mehrzahl zeitigt drohendes Durchschautwerden entweder Flucht oder strategisches Handeln in Gestalt der Täuschung bzw. Lüge: „Carola sorgte sich, weil ich, wie sie sich ausdrückte, zu oft der Wirklichkeit auswich, um so unauffällig wie möglich leben zu können. [...] Ich musste vertuschen, dass ich etwas anderes als ein umherschweifender Mensch nie hatte werden wollen." (Außer uns, S. 48 f.) Der Ich-Erzähler und mit ihm der Basistypus, als dessen Stellvertreter jener hier getrost verstanden werden kann, wird in seinem Wesenskern erkannt, was einerseits die Fremdcharakterisierung als eine selten präzise herausstellt $(\Leftrightarrow I I .2 .1)$, andererseits ein weiteres wichtiges Untersuchungsfeld in den Blick rückt.

\subsection{Strategien der Flucht, der Verborgenheit und des Verschwindens}

Im gleichen Maße, in dem viele Protagonisten ihr Gegenüber taxieren, verfolgen, beobachten, belauern usw., in just diesem Maße ist es ihnen verhasst, selbst in den Kegel des Lichts der Aufmerksamkeit zu geraten, wie bereits in Ansätzen gezeigt werden konnte ( $\Rightarrow$ II.2.4). ${ }^{122}$ Bei Genazino ist dieser Sachverhalt bspw. unter „Verborgenheit",123 „Sehen, ohne gesehen zu werden“,124 „Unsichtbar sein“125 und „Kleine Fluchten“126 gefasst worden. Gemeinsam ist den meisten Forschungsbeiträgen, dass sie die in Der Fleck, die Jacke, die Zimmer, der Schmerz zum Zentrum der Überlegungen erhobene „Theorie der Verborgenheit“ als Bezugspunkt wählen:

Was wir brauchen, ist eine Theorie der Verborgenheit. Der Grundgedanke könnte sein, daß das Subjekt die Gesellschaft beobachten darf, diese aber nicht das Subjekt. Die Beteuerung, der beobachtete Bewohner sei auch der behütete Bewohner, darf als verwirkt angesehen werden. Solange es die Theorie nicht gibt, muß ich auf meine verschlissene Hose zurückgreifen. Sie hält immerhin Prospektverteiler [...] fern. (Fleck, S. 189)

Gefordert wird hier ein ,latebraischer Imperativ', welcher zwei Funktionen hätte: Einerseits würde er die prinzipiell intern verortete Problematik - der Genazino'sche Basistypus leidet an der öffentlichen Selbstaufmerksamkeit - als externes Gebot bekämpfbar machen, andererseits

122 Vgl. dazu auch Frauen, S. 44 f., wo der Protagonist gegen seinen Willen in den Mittelpunkt gestellt wird. Nebenfiguren, denen es ähnlich geht, ist das Mitleid des Basistypus sicher: „Ich schaue dem Bäcker zu und bedaure ihn, weil er sich den ganzen Tag von fremden Menschen betrachten lassen muß." (Einfalt, S. 112) Helmut Böttiger: Wilhelm Genazino und die Verborgenheit der Verkäuferinnen. In: ders. (Hg.): Nach den Utopien. Eine Geschichte der deutschsprachigen Gegenwartsliteratur. Wien 2004, S. 55-67. Michael Bauer: Sehen, ohne gesehen zu werden. In: Süddeutsche Zeitung vom 08./09. April 1989. Hermann Wallmann: Ein lesender Flaneur im Biotop Großstadt. Unsichtbar sein, um ganz Auge sein zu können: Wilhelm Genazinos Roman „Der Fleck, die Jacke, die Zimmer, der Schmerz“. In: Basler Zeitung vom 14. Juli 1989. 
zugleich den unstillbaren Drang zum Beobachten straffrei halten und mithin denjenigen Schutzraum schaffen, den die Protagonisten stets verzweifelt suchen. Hirsch führt dazu aus:

Der Ich-Erzähler drückt damit nachträglich aus, was parallel auf der ästhetischen, erzähltechnischen Ebene längst stattgefunden hat: Das heimliche Verschwinden-Wollen des Subjekts hinter einer allzu aufdringlich (fingierten) Wirklichkeit [...]. [...] Ironisch gebrochen klingt in dieser hochtrabend betitelten „Theorie der Verborgenheit" ein vertrautes Repertoire tatsächlicher „Theorien“ und außerliterarisch konkret vorhandener Konzepte an [...]: Walter Benjamins an Franz Hessel sich orientierende Definition des Flaneurs beruht ja auf eben dieser Einbahnstraßen-Blickrichtung; Sartre entfaltete bekanntlich in „Das Sein und das Nichts“ das gesamte Dilemma des Sehens und Gesehenwerdens [...]. Auch an Foucaults Lektüre des „zwingenden Blicks“ wäre hier zu denken - tatsächlich mit allen Konsequenzen, denn auch die Prosa Genazinos schreibt sich vehement, wenn auch verdeckt, in einen allgemeinen, ohne Zweifel vorausgesetzten Schuld- und Machtdiskurs ein, dem sich die Ich-Erzähler permanent zu entziehen trachten. [...] Die gewünschte Abwehr der fremden Blicke sichert ja erst den angestrebten individuellen Blick und könnte den Einzelnen vor dem Zugriff der Gesellschaft noch am besten bewahren. ${ }^{127}$

Hirsch referiert hier die wichtigsten Theorien, die blicktheoretisch für Genazino von Belang sind. Und obwohl dieser für sein Schreiben die strikte Trennung von ,Forschungsliteratur' und eigener Textproduktion behauptet ( $\Rightarrow$ I.3.2), ist es nahezu ausgeschlossen, dass sich Benjamin/Hessel, Sartre oder Foucault nicht in irgendeiner Weise eingebracht haben. Dennoch soll für dieses Unterkapitel ein zunächst theoriefernerer Ausgangspunkt unmittelbar beim Material, sprich: bei Genazinos Romanfiguren gewählt werden, da die Absolutsetzung der anzitierten Theoretiker den Blick auf Flucht, Verborgenheit und Verschwinden zum Teil zu versperren drohen würde, indem etwa Sartres Opposition zu Freud für Genazino problematisch ist $(\Rightarrow I .3 .2)$ und nicht alle Fundstücke der Primärliteratur in die diskursiven Kategorien von ,Schuld' und ,Macht gepresst werden können. Späterhin geraten vielmehr andere Referenztheorien in den Blick.

Die verborgenen Lebensläufe bei Genazino sind prima vista nicht als Manko entworfen. Vielmehr sind die Stille, die Zurückgezogenheit, die Flucht in die Unsichtbarkeit Wunsch und Ziel der Protagonisten. Genau in diesen ephemeren Momenten des äußerlichen Verschmelzens mit der Umgebung, die den Figuren möglichst wenig Kontur verleiht und damit möglichst wenig Format abverlangt, sind sie bei sich:128 „Ich wollte [...] ein weißer Schneehase sein, der am Rand eines riesigen Schneefeldes sitzt und von niemandem bemerkt wird.“ (Regen, S. 147)129

Drei unterschiedlich weit entfernte ,Fluchtpunkte‘ lassen sich in diesem Gemälde unterscheiden: Erstens: tatsächliche Fluchtbemühungen, die als konkrete Reaktion auf unzumutbare Zustände und Gefahr gewertet werden können und Fight-or-flight-Mechanismen ebenso umfassen wie die mehr oder minder deutliche Thematisierung der ,Fluchtursachen'; zweitens: Verstecke(n) und

127 Hirsch: „Schwebeglück der Literatur“, S. 89 f.

128 Nur auf den ersten Blick ist übrigens die Auffälligkeit paradox zu nennen, dass es Handlungsroutinen - auch bei gleichbleibender Hauptfigur - gibt, die diametral entgegenlaufen, und die hier als Interessantheit bzw. Provokation verbucht werden ( $\Rightarrow$ II.3.4). Es handelt sich um zwei Seiten einer Merkmals-Medaille.

129 Vgl. für eine ähnlich gelagerte Hasenmetapher Glück, S. 62 f., sowie für einen Käfervergleich: „Er war ein Vorbild für meinen tiefsten Wunsch: er wollte spurlos und unentdeckt verschwinden." (Kein Geld, S. 24) 
Verborgenheit, die nicht mehr unmittelbar mit einer Flucht in Verbindung stehen (müssen), sondern als allgemeines Figurendesiderat - im Sinne der Theorie der Verborgenheit - gelten dürfen; und schließlich drittens: das „Verschwinden-Wollen“130 auf höherer Ebene, das das Nichtsichtbar-Sein-Wollen für andere in eine Selbstauflösungssphäre transzendiert und eigentlich nur noch metaphorisch-psychologisch dingfest gemacht werden kann.

Alle drei, die im Folgenden in dieser Reihenfolge diskutiert werden sollen, sind in der Forschung en bloc abgehandelt worden, was vermutlich daran liegt, dass die im Hintergrund wirksamen Mechanismen zum Selbstschutz bei allen dreien ähnliche sind. In einem letzten Schritt werden diese Gemeinsamkeiten tentativ diskutiert.

\section{FLUCHT}

Es ist allgemein bekannt, dass sich nahezu alle Tiere in Gefahren- und also: Stresssituationen auf ihren Organismus verlassen können, der sie automatisch mit einer extra Portion Neurotransmittern und in der Folge mit ,Kraft' versorgt. Auch was mit dieser zusätzlichen Energie anzufangen sei, ist dem (menschlichen) Willen nicht unterworfen, sondern wird aufgrund unterschiedlicher Parameter in Sekundenschnelle ,berechnet' - das Ergebnis ist im Normalfall ein evolutionär bestmöglich adaptatives Verhalten, um das Überleben der Art sicherzustellen. Die bekanntesten Reaktionen, mit denen Lebewesen auf, Gefahr' reagieren sind ,fight or flight'.131

Obwohl Genazino sowohl in einem Romantitel die Kämpfe ausstellt und seine Figuren gleichsam das Leben wie einen Kampf erleben, ist dieser - etwa in der Form: gegen die Verhältnisse vorgehen, die offene Auseinandersetzung mit Personen suchen etc. - offensichtlich keine reelle Handlungsoption. ${ }^{132}$ Weitaus eher neigt der Basistypus zur Flucht (womit im Möglichkeitsraum der literarischen Verhandlung freilich auch willentliche Fluchten mit gemeint sind):

Ich erinnerte mich an den Satz des Haftrichters, dass Fluchtgefahr bei mir nicht bestehe. Es ärgerte mich, dass mich der Haftrichter verkannt hatte, und es freute mich, dass ich einen meiner Hauptlebenstriebe hatte verhüllen können. Der Wunsch nach Flucht war vermutlich der beständigste Impuls meines Lebens. Es gab so gut wie nichts, wovor ich nicht hatte fliehen wollen: vor meinen Eltern, vor dem Kindergarten, vor der Schule, vor Thea, vor Wohnungen, vor der Kultur, vor dem Militär, vor der Festanstellung, vor Maria. Viele Fluchten waren gelungen, einige nicht, wieder andere standen immerzu auf der Kippe. (Tiere, S. 126)

Tatsächlich zieht sich die „Fluchtgefahr“ als „Hauptlebenstrieb[]“ und als „beständigste[r] Impuls“ wie ein roter Faden durch den harten Kern des Figurenmodells wie durch alle möglichen Lebenssituationen. Dass darüber hinaus der Fluchtimpuls „verhüll[t]“ wird und die Reihung der

130 Hirsch: „Schwebeglück der Literatur“, S. 97 f.

131 Zu ergänzen sind der Vollständigkeit halber: ,freeze and fright', was für Genazinos Figuren ebenfalls eine Option darstellt: „[J]a, ich könnte sogar behaupten, daß das Sich-tot-Stellen eine meiner Hauptlebenstechniken ist." (Glück, S. 60)

Vgl. dazu eine zentrale Überlegung: „Unangenehm ist, sage ich, daß ich als Überwinder oft scheitere. Wenn ich merke, ich habe beim Überwinden keinen Erfolg, fliehe ich. Ich will dem zu überwindenden Gegner nicht unterliegen. Deswegen breche ich das überwindende Denken oft ab. In Wahrheit müßte ich mich eigentlich Zerstreuer nennen." (Heimweh, S. 159) 
inkommensurablen Fluchtursachen schier endlos wirkt, kann als ironische Überspitzung - wie die Tatsache, dass Haftrichter und Hauptfigur von zwei unterschiedlichen Fluchten sprechen per se - interpretiert werden, um einerseits die Relevanz zu betonen, andererseits mit einem Augenzwinkern die Gravität zu mindern.

Bei Genazinos Romanfiguren kann zwischen dem Vorliegen einer mehr oder weniger konkreten Fluchtursache und der ,sachgrundlosen' Flucht unterschieden werden. Das zuletzt zitierte Beispiel verdeutlicht bereits das Spektrum, am häufigsten jedoch handelt es sich um situative Beweggründe, die zudem mit einer bestimmten Person in Zusammenhang stehen: „Er löste sich von Frau Schönböck und überlegte, wie er sein Verschwinden einleiten könnte.“ (Abschaffel, S. 91) Diese Grundkonstellation findet sich auch in den Romanen Die Vernichtung der Sorgen „Es fiel im auf, daß er heute [...] zweimal vor etwas geflüchtet war [...] und daß er soeben dabei war, zum drittenmal vor etwas zu flüchten, was noch gar nicht angefangen hatte: vor dem Abend mit Margot“ (Sorgen, S. 164) -, Ein Regenschirm für diesen Tag - „Für Augenblicke überlege ich, ob ich wegen Himmelsbach die Stadt verlassen soll. Die Lächerlichkeit dieser Überlegung mach mich noch schwächer“ (Regenschirm, S. 133) - sowie Die Liebesblödigkeit: „Ich erhöhe mein Tempo, obwohl ich auch nicht möchte, daß Dr. Ostwald meinen Fluchtimpuls bemerkt" (Liebesblödigkeit, S. 19). Auf ihre je eigene Weise ist es den Protagonisten ,zu viel': zu viel Überheblichkeit, zu viel Nähe, zu viel Abneigung und Neid zugleich, zu viel Smalltalk.

Derart konkret geht es indessen selten zu: „Ich wollte fliehen, weil mir der Tag zu kompliziert geworden war. Doch dann hob ich die Tasse [...], damit die Frau die Platte besser säubern konnte." (Kassiererinnen, S. 97) Trotz der Angabe eines Grundes bleibt dieser unterbestimmt und lässt sich weiter in die Unbestimmtheit skalieren: „Ich fühlte, dass mein Innenleben auf Flucht angelegt war. Einen besonderen Grund zur Flucht brauchte ich schon lange nicht mehr. Ich bedurfte einer Besänftigung und ging deshalb in Richtung Opernplatz." (Außer uns, S. 54) Außer der losen Verquickung zu den allgemeinen Besänftigungsstrategien ( $\Rightarrow$ II.2.2) räumt die Figur ein, nicht nur keinen Grund zu haben, sondern auch gar keinen zu brauchen, um die Handlungsmöglichkeit ,Flucht' in Betracht zu ziehen. ,Ohne erkennbaren Grund' flieht auch Warlich immer wieder:

Zuerst bin ich lange lustlos, dann lange angeödet, dann stark abgestoßen und fluchtbereit. [...] Flüchtig-Sein ist ein guter Zustand, weil sich während des Fliehens die Gründe der Flucht unmerklich auflösen. Schon oft war ich sonderbar berührt, daß ich, an einem Ziel angekommen, leicht einsehen konnte, daß die Flucht überflüssig war. (Glück, S. 39)

Iterativ wird hier die für Warlich, dessen sprechender Name durchaus mit seiner Fähigkeit zur messerscharfen Selbstanalyse in Verbindung gebracht werden darf, eine typische Empfindungsund Handlungssequenz vorgeführt. Interessanterweise wird aber nicht dem Ziel die ,therapeutische“ Wirkung beigemessen, sondern der Flucht: Bereits „während des Fliehens“ verschwinden die nicht näher benannten Gründe für dieses. Dementsprechend ist die Äußerung auch logisch 
bedenklich, weil die Flucht als solche zwar nachträglich rational, aber aus der Situation heraus nicht impulsiv ( $\Rightarrow$ I.3.1) für „überflüssig“ erklärt werden kann. Vielmehr scheint der Basistypus ein verfeinertes Sensorium dafür entwickelt zu haben, beim kleinsten Trigger das Fluchtprogramm zu aktivieren. So ist für die Genazino'schen Eigenbrötler und Einzelgänger (vgl. Falsche Jahre, S. 505 f.) „das Recht auf Flucht [...] ganz und gar unantastbar.“ (Frauen, S. 168) Der Wunsch oder der Entschluss zur Flucht muss nicht der Vernunft standhalten, sondern folgt dem Bauchgefühl: „Früher oder später, denke ich, lasse ich alles zurück und gehe weg. Die Reizung wird so unwiderstehlich, daß ich an der nächsten Haltestelle die U-Bahn verlassen muß. Es beunruhigt mich, daß ich wegen solcher Kleinigkeiten neuerdings fliehe." (Licht, S. 40) Es sind Kleinigkeiten - viele kleine Aspekte, die sich zum Bild der Unzufriedenheit zusammensetzen, der basistypisch wie gesagt nicht mit Kampf, sondern nur mit Flucht begegnet wird: „[I]ch kann immer nur denken, daß alles unzureichend ist und daß ich mich von allem, was es gibt, entfernen möchte, und zwar sofort und ohne Umkehr." (Heimweh, S. 150) Individuationsbestrebungen $(\Leftrightarrow$ II.1.1), Dünkel $(\Leftrightarrow$ II.1.3) und Distinktion $(\Leftrightarrow$ II.1.5) gehen hier eine Verbindung ein, die sich in dieser Trias auch in denjenigen reflexiven Passagen finden, die um Flucht und Fluchtursachen kreisen: 133

[I]n früheren Jahren, wenn ich für ein paar Tage verschwand, gebrauchte ich pompöse Worte wie Erschöpfung, Flucht, Überdruß, Ekel. Heute ist klar, und Laura weiß es auch, daß ich immer nur der Beklommenheit vor dem eingerichteten Leben entkommen will, jedenfalls für eine Weile. Es ist nichts weiter als ein Übergriff der Gegenstände auf das Bewußtsein, eine Überreizung durch das Allzuvertraute. (Licht, S. 44)

Als viertes wichtiges Element der ,Meta'-Gründe tritt die Unzufriedenheit mit „dem eingerichteten Leben“ hinzu, das sich einerseits als antibürgerlicher Reflex ( $\Rightarrow$ II.1.6), andererseits, aber nichtsdestotrotz damit verknüpft, als Midlifecrisis deuten lässt. Auf dem Weg vom Konkreten zu Vagen findet sich eine weitere Selbstdeutung:

Für etwa zehn Minuten verwandelte ich mich in dieses Tier, das in eifriger Bedrängnis nach einem Schlupfwinkel suchte. Wenn ich tatsächlich ein solches Tier wäre, würde ich an vielen Tagen ganz andere Wege gehen, damit ich nicht immerzu den großen Tieren begegnen müsste. Meine Schuld würde darin bestehen, dass ich von allen Unglücken wüsste. Ziel meines Lebens wäre, allen möglichen Zusammenstößen aus dem Weg zu gehen, auch wenn ich (wieder) plötzlich fliehen müsste, außer Atem wäre und meine Kleidung an mir herunterhing, als würde ich gerade (wieder) mein Fell wechseln. (Außer uns, S. 154 f.)

,Flucht' wird somit zur kalkulierten Vorab-Vermeidung von ,Kampf ${ }^{\prime}$ - und zur Paraphrase protektiven Impression Managements schlechterdings. Lieber ein Leben auf der Flucht als ein einziger Kampf im Sinne von „Zusammenstößen“ mit „den großen Tieren“ ist das Credo. Schwieriger zu interpretieren ist in dieser Allegorie die Schuld: Ist es eine aufgrund der Tatsache, sich selbst in dieser Vermeidungshaltung durchschaut zu haben? Eine Art schlechtes Gewissen, immerzu fliehen zu wollen? Das mag eine Teilschuld erklären, aber der Konnex von Flucht und Schuld

133 Vgl. auch: „Es überflutet mich ein Widerwille gegen die Wirklichkeit, vermischt mit der inneren Überzeugung der Minderwertigkeit alles dessen, was sich hier ereignet." (Glück, S. 51) 
umfasst auch eine ganz andere Dimension: „Weil ich nicht flüchten konnte, entstand aus dieser Fixierung eine Art Zwang und aus diesem Zwang eine Schuld." (Außer uns, S. 98) Wenn der Basistypus nicht fliehen kann, wenn das „unantastbar[e]“ „Recht auf Flucht“ beschnitten wird, resultieren daraus Zwang und Schuld.

Reelle und zugleich geglückte Fluchtversuche sind in Genazinos Figurenromanen eher die Ausnahme: „Ich kann nicht fliehen und ich werde nicht fliehen, aber die Sicherheit einer jederzeit möglichen Flucht ist trotzdem sehr gut." (Heimweh, S. 155) Entweder handelt es sich um imaginierte, aus inneren - „Nur aus Furcht, dass die Flucht nicht gelingen könnte, fand sie nicht statt“ (Kein Geld, S. 95) - oder äußeren Zwängen verhinderte oder um nur für den Moment verwirklichte; zwar Besänftigung stiftende, aber letztlich folgen- und lösungslose.

\section{VERSTECKE(N) UND VERBORGENHEIT}

„Es gibt keine Flucht, keine Rettung und kein Heil, es gibt nur das Versteck und auch dieses nur vorübergehend." (Licht, S. 35 f.) Dieses wird allerdings sehr positiv konnotiert wahrgenommen, sodass es sich somatisch Bahn bricht und Unbeschwertheit ermöglicht:

Daß ich in einem Versteck angekommen bin, merke ich daran, daß ich laufend in kleine Euphorien ausbreche. [...] Eigentlich müßte ich mich bei der Hotelleitung beschweren. Aber dann hebe ich den Blick, sehe schräg gegenüber ein hinter Häuserkanten verschwindendes Schiff, und der Gedanke an eine Beschwerde verliert sich von selber. (Licht, S. 47 f.)

Die Heimlichkeit heimelt den Basistypus an, die „Euphorien“ sind so stark, dass sie leicht über die negativen Empfindungsanteile dominieren. Sich dem Zugriff durch andere entzogen zu wissen, nimmt einen hohen Stellenwert für Genazinos Figuren ein: „Schon nach zwei Minuten spüre ich, wie immer kurz nach Abfahrten, das Glück der Unauffindbarkeit." (Fleck, S. 151) Doch geht es weniger um extraordinäre Aufbrüche zu fernen Ufern ${ }^{134}$ als vielmehr um das Verstecktsein an sich:

Wenn er unter dem Tisch saß, wußte die Mutter, daß er nicht entdeckt werden wollte. [...] Aber warum war ausgerechnet das gegenseitige Sich-nicht-Sehen ein Glück? [...] Am Ende wünschte er sich eine schöne, kleine und leere Wohnung, die ihm nur als Versteck dienen sollte. [...] [D]ie er nur aufsuchte, wenn ihm daran lag, daß niemand, auch Dagmar nicht, seinen Aufenthaltsort wußte. (Fremde Kämpfe, S. 216 f.)

Bereits als Kind, so erinnert sich Peschek, ähneln in seiner Empfindung Geborgenheit und Verborgenheit einander. „Und wer sich, wie Peschek in diesen Augenblicken, seiner Verborgenheit inne wurde, spürte die Freiheit wie ein schönes kleines Ding, das ihm angenehm durch den Körper rann." (Fremde Kämpfe, S. 174) ${ }^{135}$ Der Erzähler greift hier über den Einzelfall des Wolf Pe-

134 Obwohl es mitunter als Wunschvorstellung angerissen wird, etwa "für eine Weile nach Amerika [zu] verschwinden“ (Außer uns, S. 138). Vgl. auch: „Am liebsten hätte er sich drei Monate vom Leben zurückgezogen und sich im September zurückgemeldet. Aber wer einmal lebte, mußte es ununterbrochen tun." (Sorgen, S. 161) Vgl. auch Abschaffel, S. 27. 
schek deutlich hinaus, indem er nullfokalisiert eine Aussage trifft, die in dieser Form für alle Gültigkeit beansprucht.

Genazino findet für dieses Grundgefühl immer neue Worte und Präsentationsmodi: Die Form des kindlichen Triebs, sich eine Höhle zu bauen, wie es Peschek tut, beobachtet der Basistypus immer wieder anerkennend und sich zurücksehnend auch bei anderen (vgl. Regenschirm, S. 172-174), W. wird wehmütig, wenn er im Radio ( $\Rightarrow$ II.1.5) hört: „Die Waschbären, sagt der Kommentator, sind KAUM BEOBACHTBAR, weil VERBORGEN LEBEND und NACHTAKTIV.“ (Fleck, S. 76) Die nicht ganz ungewöhnliche, aber nur dosiert eingesetzte Majuskelschrift hebt bereits optisch die Vorzüge hervor, die ihm die Waschbären voraus haben. Allerdings sehen sich die Protagonisten vor die Herausforderung gestellt, in der Großstadt Verstecke zu finden, was nicht ganz einfach ist (vgl. Außer uns, S. 137): „Natürlich war es meine Aufgabe, Herrn Schimmelpfennig aus dem Weg zu gehen. Dazu bot sich im Augenblick nur eine Fußgängerunterführung an, in die ich abtauchen wollte." (Kassiererinnen, S. 48) Mit der doppelten Wortbedeutung, nach der tatsächlich doppelbödig unter den Asphalt der Großstadt in das temporäre Versteck abgetaucht werden kann, ist zudem eine Traditionslinie bei Genazinos Figuren angesprochen, nach der - gerade aufgrund der häufig misslingenden, ,echten' Fluchten - das Versteck ganz in der Nähe gesucht werden muss: „Das war meine Mutter, Tritte auf den Treppen, im ersten Augenblick war mir nicht klar, in welcher Situation ich mich befand, daß mich meine Mutter nicht erwischen durfte" (Laslinstraße, S. 95). Die situative "Gefahr' erlaubt gar keine andere Handlungsalternative als die, sich schnellstmöglich in einem Nebenraum zu verstecken. So sieht sich auch Abschaffel genötigt, den naheliegendsten Fluchtweg zu nehmen: „Er fuhr mit dem Fahrstuhl hinunter in das Kellergeschoß, lief dann unter dem Foyer hindurch und kam über eine Treppe direkt zum Hauptausgang." (Falsche Jahre, S. 436) Dass Verborgenheit Mühe macht, weiß auch W.: „Zurückgezogensein ist Arbeit.“ (Fleck, S. 189)136 Und die nimmt der Basistypus gerne in Kauf, wenn er sich damit vor Zusammenkünften oder auch nur Blicken der anderen ( $\Rightarrow$ II.2.4) verbergen kann: „Ich möchte nicht, daß mich jemand dabei beobachtet, wie ich Blätter aus Plastiktüten herauskippe. Ich suche mir eine abgelegene kleine Grünanlage und gehe zwischen zwei mannshohen Gebüschen hindurch." (Regenschirm, S. 167) Da es die ,Theorie der Verborgenheit' in der Diegese nicht gibt, sind die Figuren immer wieder eigeninitiativ zur Blickschutzsuche gezwungen: „Ich wollte schnell zum Buffet, ein Glas Wein verlangen und mich dann in eine stille Ecke des Foyers verdrücken. Sogar hier, im Theater, fühlte ich meine Unruhe. Mein derzeit größter Wunsch war: Ich wollte einmal einen einfältigen Tag durchleben." (Regen, S. 5)

136 Damit ist auch ,Beziehungsarbeit' in der Weise gemeint, dass etwa das Zusammenziehen mit der Partnerin als bedrohlich wahrgenommen wird: „Ich wusste genau, was mich erschreckte: Sibylle zog in mein Versteck ein und hob es damit auf." (Kein Geld, S. 65) Bahnwärter Thiel lässt grüßen. 
Unterführungen, Treppen, Fahrstühle, Gebüsche, Theaterfoyers: Es handelt sich um Nicht-Orte, die zwar die gesuchte Einsamkeit bestmöglich in Szene setzen, zugleich aber auch schmerzlich die Nicht-Identität bzw. Beschränkung in der Kommunikationssituation vor Augen führen. ${ }^{137}$

\section{VERSCHWINDEN, AUFLÖSUNG, UNSICHTBARKEIT}

Manche Nicht-Orte weisen einen weiteren ,Vorzug' auf: Sie ermöglichen das Verschwinden in der Menge, was die Überleitung vom Versteck zum ebenso doppeldeutigen Verschwinden markiert. Axel Degen bemerkt hinsichtlich der Stellung eines Individuums in einer Menschenansammlung: „[A]lle Männer blieben, auch ich, niemand wußte, weshalb ich hier zu den Zuschauern zählte“ (Laslinstraße, S. 119). Die Menge wahrt die Anonymität und deshalb „versuchte er um so rascher, im unübersehbaren Gewimmel der Menschen, die über den Goetheplatz liefen, zuverlässig und unauffindbar zu verschwinden." (Ausschweifung, S. 108)

Bezeichnenderweise sind es erneut Bahnhöfe, die dem Basistypus das ambivalente Gefühl ermöglichen, sich im Grundgesamt der Anwesenden aufzulösen: „In der Bahnhofshalle wurde ihm gleich leichter. Erstaunlich viele Menschen liefen hier umher, und das große Dach, das über sie alle gespannt war, war etwas Gutes." (Abschaffel, S. 116) Mit dem Sprachbild des alle Anwesenden überspannenden Dachs - die Anspielung auf die christliche Ikonografie ist möglich, aber nicht nötig - wird zudem ein Zugehörigkeitsgefühl aufgerufen, das den Einzelnen nicht nur verbirgt, sondern zugleich aufhebt. Bahnhöfe befreien also nicht nur vom Beobachtungszwang ( $\Rightarrow$ II.2.2), sie sind auch ein Nicht-Ort der absoluten Selbstwerdung durch die Unbeobachtbarkeit wie zugleich der Ent-Individualisierung. Außerdem sind sie die schnöde Eintrittshalle zu den Zügen, die ihrerseits als Transitorte begriffen werden können und Nähe wie Distanz, Intimität wie Anonymität in sich beherbergen:

Wie immer treffe ich so frühzeitig im Hauptbahnhof ein, daß ich mich von meiner Nervosität wieder erholen kann. [...] Es wird mir nichts ausmachen, still in einer Ecke einer Plattform auszuharren und aus dem schmalen Türfenster auf die vorüberhuschenden Landschaften zu sehen und, zum Beispiel, den Hasen bei der Flucht zuzuschauen. Ich erhole mich von der Scham, wenn ich in überfüllten Zügen beinahe unsichtbar werde und längere Zeit nicht sprechen muss. (Heimweh, S. 23)

Genazino packt immer noch eine Schippe oben drauf: Es ist nicht nur der Zug, ${ }^{138}$ sondern der überfüllte; es ist nicht damit getan, an Bord zu sein, sondern Rotmunds Standpunkt ist der (eigentlich unwirtliche) Ort zwischen den Wagons; die Landschaften ,huschen' wie sonst die Hasen, die hier tatsächlich noch bei der Flucht, die seine eigene doppelt, beobachtbar sind, wohingegen Rotmund seinerseits durch die „schmalen Türfenster" wie hinter einer Schießscharte nicht selbst von außen in den Blick genommen werden kann. Nun muss vergegenwärtigt werden, dass

137 Vgl. Marc Augé: Orte und Nicht-Orte. Vorüberlegungen zu einer Ethnologie der Einsamkeit. Frankfurt am Main 1994.

138 Der seinerseits schon „das erste faßbare Symbol für meine Sehnsucht nach dem Verschwinden war[]." (Einfalt, S. 130) 
der (metaphorische) Ohrverlust Rotmunds - deutbar als externer Grund für die Beobachtungen durch andere wie als Identitäts- und Selbstzerfall - freilich besondere Vorsichtsmaßnahmen erfordert und Wünsche freisetzt: „Am besten wäre, wenn es demnächst mehr Einohrige geben würde. Dann würde ich nicht mehr so stark auffallen wie in diesen Augenblicken vor mir selber.“ (Heimweh, S. 11) Hinzuzusetzen ist aufgrund des „vor mir selber" erneut ein ,imaginiert", denn faktisch „kann man nicht mehr auffallen in einer von Schrillheiten überfüllten Welt. Ich hätte nicht für möglich gehalten, daß ich von dieser überdrehten Gegenwart einmal profitieren würde." (Heimweh, S. 113 f.) Ein vorgestellter Einohriger ist diesbezüglich genauso (un)auffällig, wie ein ungetarnter Einzelner ohnehin:

Besonders unangenehm war es ihm, wenn er als einziger Kunde im Schalterraum stand; dann war er noch mehr davon überzeugt, den Verdruß der vier oder fünf Filialangestellten hervorzurufen. Es war deswegen sogar schon vorgekommen, daß er draußen vor der Bank gewartet hatte [...]. Dann erst war er nachgefolgt und fühlte sich im Strom des Allgemeinen gut untergebracht. (Sorgen, S. 230)

Maritime Metaphorik ist bereits durch das Untertauchen (in der Menge) heraufbeschworen worden, jetzt kommt das ,Schwimmen im/mit dem Strom' hinzu, welches ambivalent antiindividuell wirksam wird: Ist es vordergründig das gleichmachende Mitlaufen, so kann man auch umformulieren und die These aufstellen, dass nur im Rahmen einer gleichförmigen Bewegung ein Maximum an Individualität verborgen verpackt transportiert werden kann; die Ecken und Kanten des Basistypus schliffen sich sonst zu schnell ab. Hat im Bereich des Verstecks noch die Beobachtung eines Schiffes genügt, um sich im Verborgenen besonders heimelig zu fühlen, lässt sich das Bild auch in den Dienst des Verschwindens stellen: „Jetzt bin ich selbst ein Schiff und sehe mich, ganz klein, am Horizont verschwinden." (Obdachlosigkeit, S. 11)

Viele Hauptfiguren teilen die Familienähnlichkeit, sich „nach der Totalität eines solchen Verschwindens zu sehnen." (Einfalt, S. 86) Ist weiter oben hinsichtlich der Beobachtungen die Tarnkappe als Bild installiert worden ( $\Rightarrow$ II.2.2), findet W. selbst ein mediales Vorbild in „Beckmanns Tagebüchern“, das den mythischen Wunsch, unsichtbar zu sein, materialisiert: „,Nun, invisible man, Du wirst unangenehm sichtbar und es ist höchste Zeit, ein neues Pulver des Verschwindens zu erfinden' (9. Juli 1946). Ein Pulver des Verschwindens!“ (Fleck, S. 126) ${ }^{139}$

Man kann dem Nachhall gewissermaßen zuhören: W. ist tief beeindruckt, er spricht den Satz (innerlich?) langsamer nach als er ihn gelesen hat, das desiderable Pulver nimmt momentweise Gestalt vor seinem inneren Auge an, der Wunsch, dieses zu besitzen, ergreift seinerseits von ihm Besitz - genug der Mutmaßungen. Ohne es banalisieren zu wollen kann man jedenfalls festhalten, dass mit dem Fluchtpunkt ,Max Beckmann` Sichtbarkeits- und Unsichtbarkeitsdimensionen hochreflexiven Ausmaßes in einen Satz getaucht werden, der auf den ersten Blick nur dazu 
dient, das eigene Bedürfnis, unsichtbar zu sein oder zu werden, untermauert. ${ }^{140}$ Es ist als Alleinstellungsmerkmal zu werten, dass die Hauptfigur aus Wilhelm Genazinos Roman Bei Regen im Saal in den Besitz der Tarnkappe, des Pulvers oder wie auch immer gelangt zu sein scheint: „Jetzt war ich dankbar, dass es mir gelungen war, unauffindbar zu werden. Ich hatte es tatsächlich geschafft, mein Leben zu verstecken." (Regen, S. 104) Hinsichtlich einzelner Lebensäußerungen, situativer Aspekte etc. gelingt es dem Basistypus zwar immer wieder, das Verschwinden zu streifen, aber in dieser Totalität gibt es das sonst nicht: „Wenn es ihm zuviel wurde, ließ er sich nicht mehr sehen, rief nicht mehr an, und rasch war alles vergessen." (Abschaffel, S. 40; vgl. Obdachlosigkeit, S. 23; vgl. Wohnung, S. 61) Erstens ist es nur Abschaffels Vermutung, dass sein Bild damit bei der jeweiligen Partnerin ausgelöscht sei, zweitens ist sie nur auf Sexualität gerichtet. Um das Auslöschen von Bildern und damit von Erinnerungen dreht es sich auch in einer Szene aus Wilhelm Genazinos Text Eine Frau, eine Wohnung, ein Roman: „Auf einem der Fotos war ich selber im Hintergrund zu sehen. Ich nutzte meine Stellung aus und kaufte auch dieses Foto, freilich nur, um es wenig später zu vernichten. [...] und das Dokument meines Zusammentreffens mit Rex Gildo für immer verschwand.“ (Wohnung, S. 81 f.) Weigand zerstört den einzigen Beweis, dass er mit jenem verhassten Star, der ihm für Eventisierung und Massengeschmack steht, in einem Raum war. ${ }^{141}$ Es handelt sich um ein negatives basking in reflected glory ( $\Rightarrow$ I.3.3); der Abglanz einer nicht geschätzten Person soll sich tunlichst nicht auf Weigand spiegeln.

Handelt es sich meist um positive Konnotationen des Verschwindens, der Auflösung und der Unsichtbarkeit, finden sich dennoch auch negativ eingefärbte Evaluationen (vgl. Abschaffel, S. 42): „Die Leisigkeit, mit der ich neben Traudel sitzen bleibe und gleichzeitig verschwinde, wirkt auch auf mich unangenehm." (Glück, S. 23 f.) Vorausgegangen ist ein alltäglicher Streit, der Warlich - seiner Darstellung zufolge - keine andere Wahl lässt, als „stiller und stiller“ zu werden, um den Streit nicht eskalieren zu lassen (vgl. Glück, S. 23). Mit Aleida Assmann lässt sich hier die soziale Form des Schweigens aus Gründens des Taktgefühls anführen: „Takt ist das höfliche Schweigen. Es erlegt Zurückhaltung auf, die aus der Rücksichtnahme kommt und dem Schutz des Anderen dient." ${ }^{142}$ Allerdings passt Warlichs Empfindung so gar nicht zu dieser Manifestation des Schweigens, was die Vermutung nahelegt, dass seine Wortlosigkeit eher "[f]eige[] und hilflos[]" genannt zu werden verdient:

Es gibt viele Situationen, in denen Schweigen einfacher ist als Reden, weil das rechte Wort kostbar und nicht zur Hand ist. Mit dem feigen und unbeholfenen Schweigen hat jeder und jede vielfach Bekanntschaft gemacht. Schweigen kann zum Versäumnis und gar zur Schuld und Last werden, wo ein beherztes Wort helfen, trösten oder das Recht oder die Würde eines anderen Menschen hätte verteidigen können. ${ }^{143}$

\footnotetext{
140 Dass Beckmann zur Flucht, zum Versteck und zum Verschwinden biografisch noch ganz andere Bezüge aufzuweisen hat, ist evident.

141 Vgl. Zeillinger: Rex Gildo.

142 Assmann: Formen des Schweigens, S. 58.

143 Assmann: Formen des Schweigens, S. $56 \mathrm{f}$.
} 
Die enge Verbindung zwischen Schweigen $(\Rightarrow$ II.1.4) und Verschwinden lässt sich gut mit der bevorzugten Verwendung protektiven IMs parallelisieren, das neben habitueller Zurückhaltung auch den sprachlichen Generalverzicht kennt, um negativen Zuschreibungen zuvorzukommen ( $\Rightarrow$ I.3.3): „Der Rückzug macht mich leise und unscheinbar.“ (Glück, S. 55) Beide Begriffsbedeutungen werden im englischen „faint“ berücksichtigt, das Schütz in das Zentrum möglicher Konsequenzen bei der Nutzung protektiven IMs setzt (vgl. Lehnert 2015):

Using protective self-presentation, one may prevent negative evaluation but may risk not being viewed favorably either. Adopting this self-presentational style, one risks leaving only a faint impression, being considered uninteresting or unimportant, or even being totally overlooked. ${ }^{144}$

Da es nun häufig der erklärte Wunsch des Basistypus ist, ,übersehen` zu werden, um sich der Unsichtbarkeit und dem Verschwinden anzunähern, wird dieses ,Risiko‘ allzu gern in Kauf genommen. ${ }^{145}$

\section{GEMEINSAMKEITEN: SELBSTSCHUTZ(BARRIEREN)}

Es ist dies schon eine erste Gemeinsamkeit, die konkrete Fluchten, Ver- und Geborgenheit im Versteck und schließlich die eher metaphorische „Verschwindsucht“ (s.o.) gleichermaßen betrifft. Genazino fügt mit einer epitextuellen Ausführung der fiktionalen ,Theorie der Verborgenheit' eine Vergleichsgrundlage hinzu:

Es gibt einen wunderbaren Satz von Beckett: „Die Labsal der Fluchten“. Da steckt eigentlich alles drin, und das meint eben das äußerste einer privaten Utopie, die ich gelten lasse. Eine Befreiung ist nur individuell, punktuell möglich. Meine Texte beschrieben die negativen bis positiven Fluchten. ${ }^{146}$

Dem Wortgebrauch nach zielt diese „Utopie“ zwar eher auf die konkretere Form der Flucht, der Sache nach gilt sie aber auch für das Verschwindenwollen, denn nur der Unbeobachtete, besser noch: Unbeobachtbare ist ,frei': frei vom invasiven Blick, frei vom Rechtfertigungsdrang im Zwischenmenschlichen, frei von den ,Zumutungen' der Welt. Stets geht es Genazinos Figurenbasistypus darum, zusätzliche Barrieren um das eigene Selbst zu errichten, das laut Selbstaussage als „halb durchsichtig, im Kern weich, äußerlich nachgiebig und übertrieben anhänglich und außerdem schweigsam" (Regenschirm, S. 44) zu charakterisieren ist. Alle bereits erwähnten Überlegungen zur Besänftigung laufen letztlich darauf hinaus, „dass mich immer die Idee geleitet hat, dass aus meinem Leben eine Art Schonbezirk wird.“ (Regen, S. 154) Nicht nur konkrete Anforderungen von außen sollen damit eingedämmt werden, sondern auch das ungebetene ,Rauschen`

Schütz: Self-Presentation, S. 621.

Vgl. für ein Beispiel, bei dem sich die Figur diesen Wunsch kritisch vorhält, etwa: „Zum zweiten Mal verlasse ich an diesem Tag die Wohnung, weil ich den Narrheiten meines Kopfes anders nicht entkommen kann. Aber du kannst nicht immer ein Ablenkungsleben führen, sage ich halblaut zu mir selber. Es muß für dich auch noch eine andere Leidenschaft geben als immer nur die Verschwindsucht." (Regenschirm, S. 50) Vgl. für eine Lektüre des Verschwindens als Ausdruck der Poetik Genazinos schlechterdings Hirsch: Zwischen Lust und Angst. Hirsch/Genazino: Interview am 09. Februar 1998, S. 280. 
der Welt: „Eigentlich wollte er ununterbrochen sagen: Bitte nicht so laut, bitte nicht so schnell, bitte nicht zuviel. Es waren Bitten und Eindämmungen der ganzen Welt, wie sie gewöhnlich von älteren Personen geäußert werden." (Sorgen, S. 351; $\Rightarrow$ II.1.6)

Wilhelm Genazinos Romanfiguren sind in ihrer familienähnlichen Weichzeichnung als „,durch und durch neurotisches Subjekt "'147 zu bezeichnen, das sich zusätzlich durch mangelnde Sozialkompetenzen gehandicapt sieht und auf hundertfache Art und Weise die Außenwelt anfleht, in Ruhe gelassen zu werden. Das äußert sich etwa in banalsten Alltagsanforderungen: „Wenigstens hat das Telefon aufgehört zu klingeln. Es war mit Sicherheit Habedank. Nur er weiß, daß jedes leere Klingeln mich piesackt." (Regenschirm, S. 45) Der Protagonist wertet den Versuch, ihn telefonisch zu erreichen, als kalkulierte Quälerei, als Angriff auf seine Privatsphäre. Ins gleiche Horn stößt derjenige aus Leise singende Frauen, indem er sich entrüstet: „Die Übergriffe und Übertretungen begannen am frühen Morgen mit einem Klingeln an der Wohnungstür." (Frauen, S. 43)

Wenn man gelten lässt, dass es sich um gefühlte Überforderungen psychisch immens labiler Figuren handelt, ${ }^{148}$ sind die umfangreichen Schutzvorkehrungen gegen vermeintliche ,Angriffe‘ auf das eigene Selbst(wertgefühl) und die Kohärenz desselben letztlich fast einleuchtend:

\begin{abstract}
Augenblicksweise ist mir klar, warum ich mich nach einem Blätterzimmer gesehnt habe. Es sollte wenigstens einen Raum geben auf der Welt, in dem ich nicht erschreckt werden kann. Es sollte wenigstens einen Raum geben, in dem mir nichts zu nahe tritt, in dem keine Forderungen an mich erhoben werden können. Wenn ich zwischen den Blättern umhergehe, verläßt mich sogar das Gefühl, daß ich mit etwas abrechnen müßte. Zweifellos ist das Blätterzimmer eine Erfindung meiner vielleicht listigen Seele. (Regenschirm, S. 148)
\end{abstract}

Als Schlüsselmotiv geistert das besagte Blätterzimmer durch den Roman, wird aber erst an dieser Stelle durchschaut als ebenjener „Schonbezirk“, der von Ansprüchen, Verbindlichkeiten, Angriffen befreit. Es wäre der Gestalt gewordene locus amoenus, der den als allgegenwärtig empfundenen locus terribilis vertreiben und ersetzen könnte: „Man sitzt in einem Kasten, von außen wird dauernd geklopft, aber niemand weiß, wie man flüchten soll, und also verbringt man zitternd seine Tage." (Abschaffel, S. 137) Abschaffels Metapher ist einerseits sicherlich auf konkrete Missstände im System und sozialgeschichtlich lesbare Auswüchse des Angestelltendaseins hin zu deuten. ${ }^{149}$ Insbesondere die angesprochene Kollektivempfindung macht diese Aussage zu einer typisierten. Und doch steckt andererseits eine zutiefst klaustrophobische, individuelle Bildlichkeit darin: das Individuum im Käfig - eingesperrt, beobachtbar, schutzlos. „In den Au-

147 Hirsch/Genazino: Interview am 09. Februar 1998, S. 208.

148 Vgl. dazu etwa: „Danach hätte ich noch widerborstiger erklären müssen, dass ich kleine Teile meines Lebens wortlos für mich allein reserviert haben wollte, obgleich diesen reservierten Teilen nicht Verbotenes anhaftete. Ich war diesen sinnlosen Kompliziertheiten im Grunde nicht gewachsen. Schon spürte ich in meiner Brust den Knoten, den diese Verwicklungen hervorbrachten." (Tiere, S. 76)

149 Vgl. für eine solche systemkritische Lesart etwa: „Der Erschöpfte ist eine stigmatisierte Figur. Er bildet das System ab, das über uns herrscht, und die Lächerlichkeit seiner Versprechungen. Ich könnte (kann) den Erschöpften geeignete Ruheplätze zeigen, wo sie sich ungestört hinlagern können. Ich habe diese Plätze selbst ausprobiert, es sind Kleinode und Verstecke, absolute Geheimtips." (Liebesblödigkeit, S. 54 f.) 
genblicken des Besichtigtwerdens wandelte sich Pescheks Scham in eine Schande um. Er wollte sich die Arme vor das Gesicht halten, aber er genierte sich vor solchen Gesten." (Fremde Kämpfe, S. 251) Peschek griffe gerne zu basalsten, aber als kindlich disqualifizierten Abwehrmechanismen, um die ,Besichtigung' seiner/s s/Selbst zu vermeiden, wäre er sich nicht aufgrund seiner öffentlichen Selbstaufmerksamkeit des dadurch entstehenden, lächerlichen' Fremdbildes bewusst.

Aus diesem Dilemma des fragilen Selbst führt - wenn überhaupt - nur die übergeordnete Taktik protektiven IMs heraus, bevorzugt realisiert durch die Techniken Tarnen, Täuschen, Lügen.150 Eine Schattierung aus „dem großen Spektrum uns umgebender maskierter Unwahrheiten“151 ist die Funktionalisierung von Kleidung ( $\Rightarrow$ II.1.5): „Er hatte sich entschlossen, seinen schwarzen Anzug noch ein paar Tage zu tragen. Die Kollegen kondolierten ihm und vermieden allzu neugierige Erkundigungen, und das war ihm nur recht." (Ausschweifung, S. 265) Zwar exponiert sich Fuchs, ist doch die Aufmerksamkeit unumgänglich, hingegen ist die Schutzhülle gegen „allzu neugierige Erkundigungen" offensichtlich wirksam. ${ }^{152}$ Abschaffel ist es, der die diesbezüglichen Varianten kalkulierter Eindruckssteuerung über alle Teile der Trilogie ,durchdekliniert': „Durch ein übertrieben weiches, in sich gekehrtes Verhalten wollte er zum Ausdruck bringen, daß er nicht angesprochen werden wollte." (Falsche Jahre, S. 508) Erfolgversprechend scheint ihm insbesondere das Vorgaukeln von (fortwährender) Krankheit: „Die Grippe, die rasch nachließ, verhalf ihm zu einer Zurschaustellung eines kränklichen Fürsichseins; so wollte er es haben." ( $A b$ schaffel, S. 50) In Form des self-handicapping „bemerkte [er], daß eine undefinierbare Krankheit ein großer Schutz war. Die Kollegen gewöhnten sich ihm gegenüber eine Art Sanatoriumshaltung an." (Sorgen, S. 393) Eine vorgebliche Krankheit scheint ihn unangreifbar zu machen, die Täuschung verspricht derartiges Potenzial zu bergen, dass Fuchs an anderer Stelle „einige Minuten lang ernsthaft [überlegte], wer oder was ihn eigentlich daran hinderte, zu Hause, in der Firma und überall im Schatten eines Todesgerüchts hervorragend zu leben." (Ausschweifung, S. 246)

So plumpe Täuschungen können in Genazinos kunstvollen Verstrickungen nicht dauerhaft den Königsweg pflastern, wie Abschaffel schließlich einsehen muss:

Am besten wäre, dachte er, wenn ich den Eindruck einer leicht kränklichen Empfindlichkeit aufrechterhalten könnte. Davon versprach er sich am meisten Schutz. Aber dann erinnerte er sich an einen früheren Kollegen, [...] der [...] versucht hatte, mit der Zur-Schau-Stellung von Dünnhäutig-

150 Vgl. Klosinski (Hg.): Tarnen, Täuschen, Lügen.

151 Gunter Klosinski: Vorwort. In: ders. (Hg.): Tarnen, Täuschen Lügen (2011), S. 7 f., hier S. 7.

152 Vgl. auch: „Im Ausland war es einfacher, das Gefühl des Verstecktseins zu haben. Dort mußte ich nicht überlegen, welche Jacke und welche Hose mir dabei helfen könnte, Abstand zu wahren; seit ich wieder zu Hause bin, brauche ich Tricks zum Leben. Zum Beispiel den Koffer in der hinteren linken Ecke meines Zimmers. Er ist Tag und Nacht geöffnet; sobald mich das Gefühl überfällt, daß mir etwas zu nahe kommt, schaue ich in den geöffneten Koffer, und schon weiß ich: Du kannst verschwinden. Manchmal lege ich ein paar Schuhe oder ein Hemd dazu, dann ist es noch besser. Das sieht aus, als wäre ich schon nicht mehr da." (Fleck, S. 189) 
keit in Ruhe gelassen zu werden. Aber diese Rechnung ging leider nicht auf. Zeißbergs Zurückhaltung wurde von den Kollegen als Verachtung und Überheblichkeit aufgenommen (Falsche Jahre, S. 570).

Als Selbstreflexion von Intention und Wirkung Abschaffels ist dieses Zitat zu lesen, als Interpretation des damaligen Verhaltens Zeißbergs zugleich: Denn auf der Basis der vorliegenden Indizien spiegelt sich die Unzuverlässigkeit der intendierten Wirkung erneut - auch Abschaffel hält die Inszenierung seines Kollegen lediglich für die „Zur-Schau-Stellung von Dünnhäutigkeit“ mit dem Ziel, „in Ruhe gelassen zu werden.“ Und dennoch ziehen die Figuren weiterhin, um Selbstschutz(barrieren) aufzubauen, immer wieder die Lüge ${ }^{153}$ als Mittel der Unsichtbarkeit in Erwägung - nicht zuletzt deswegen, weil sie in der figuralen Causal History $(\Rightarrow I .3 .1)$ zum gewünschten Effekt geführt hat:

Als Kind hatte Abschaffel überhaupt nur durch Lügen weiterkommen können. Es war nichts zu kriegen, noch nicht einmal bloße Ruhe, wenn er nicht etwas vorzulügen in der Lage war. [...] So hatte er, nur um in Ruhe nach Hause kommen zu können etwas erfinden müssen. Da die Ereignisse nicht sprechen, die Menschen die Ereignisse aber als sprechende Ereignisse erleben wollen, muß man für sie eine Sprache erfinden, also lügen. (Abschaffel, S. 39 f.; $\Rightarrow$ II.2.3)

Aber jetzt kommt das große Aber: Entweder werden die strategischen Tarnungen früher oder später dekuvriert und mithin obsolet oder es bleibt bei der Überlegung, dem Plan, dem Wunsch (s.o.: Todesgerücht) ${ }^{154}$ - Genazinos Romane lesen sich mitunter wie Fallstudien des Nicht(s)tuns, ${ }^{155}$ der Basistypus ist die Grenze der Vorhandlungsphase selten überwindender $\Leftrightarrow$ ( $I$.3.1) Vermeidungs- und Verweigerungskünstler.

\subsection{Die innere Zensur}

Dieses Kapitel setzt recht nahtlos an den vorigen an, indem das Tertium comparationis die zuweilen verquer vermutete Perspektivübernahme ( $\Rightarrow$ II.2.3 u. $\Rightarrow$ II.2.4), die verquaste Konstruktion und Interpretation von Welt ist, die das Hauptfiguren-Handeln steuert bzw. Handlungen unterbindet und damit schließlich die Konsequenz aus den Flucht- und Vermeidungsstrategien $(\Leftrightarrow$ II.2.5) darstellt. Leonhard Fuest spürt in seiner Poetik des Nicht(s)tuns denjenigen - so der Untertitel - Verweigerungsstrategien in der Literatur seit 1800 nach und systematisiert in seiner Einleitung die durch die Klammer des Haupttitels angelegte Doppeldeutigkeit mit für die hier als innere Zensur konzeptualisierten Vorstellung durchaus relevanten Aspekten:

153 Vgl. für die ,horizontale' Figuren-Lügen-Achse ( $\Rightarrow$ II.1.2 u. $\Rightarrow$ II.3.5) sowie für die, vertikale', unzuverlässiges Erzählen meinende Erzähler-Leser-Achse ( $\Rightarrow$ I.2.2 u. $\Rightarrow$ I.2.3).

154 Wünsche und deren Unerfüllbarkeit - vgl. etwa: Abschaffel, S. 49; vgl. Sorgen, S. 163 u. S. 187; vgl. Ausschweifung, S. 64 u. S. 129; vgl. Fremde Kämpfe, S. 201 - sowie unverwirklichte Pläne und Vorhaben - vgl. etwa: Laslinstraße, S. 31 ( $\Rightarrow$ II.2.2); vgl. Einfalt, S. 58 f.; vgl. Sorgen, S. 206; vgl. Kein Geld, S. 51) - finden sich bei Genazino flächendeckend.

155 Vgl. Leonhard Fuest: Poetik des Nicht(s)tuns. Verweigerungsstrategien in der Literatur seit 1800. München 2008. 
Zunächst also NICHTSTUN als gleichsam passivischer Begriff, der auch übersetzbar und jedenfalls erläuterbar ist über den Begriff der PASSIVITÄT und in jedem Fall Schnittmengen mit dem Begriff der FAULHEIT oder auch der TRÄGHEIT aufweist. Es geht also hier buchstäblich um ein ÜberhauptNichts-Tun. Kein Tun, vor oder nach allem Tun passiv verharren und natürlich nicht arbeiten. Zudem überragt das Nichts das ganze Kompositum und deutet auf den Ort und Zustand, an und in dem definitiv nichts mehr getan und sich nicht mehr ereignen wird: den Tod.

Das NICHTTUN ist gewissermaßen der lebendigere, aktivischere, offenere und weniger extreme Begriff. Er erlaubt bzw. erfordert die jeweilige Spezifizierung eines Objekts der Negation durch das Nicht: Beim Nicht-tun wird irgendetwas nicht getan, das nicht immer nichts ist. Gut zu übersetzen oder doch zu verschränken ist dieser Begriff mit der VERWEIGERUNG. Der Sprechakt „Ich tue dieses oder jenes nicht“ dürfte den gleichen perlokutionären Effekt haben wir „Ich weigere mich, dieses oder jenes zu tun“. Spezifiziert man das Objekt dieser aktiven Verweigerung dahingehend, daß man nicht mehr nur von einem Tun spricht, sondern einem geregelten und vielleicht erforderten Tun, nämlich der Arbeit, dann hat man es eben mit der Arbeitsverweigerung zu tun, die in gewisser Weise auch als MÜSSIGGANG aufzufassen ist. Der Müßiggänger ist ein Nicht-Arbeiter, aber kein Nichtstuer, denn er tut ja noch etwas. Vielleicht ist es mehr als ein Wortwitz, wenn man sagt: Schließlich geht er (jedenfalls bleibt er beweglich). Wie präzise diese Begriffe auch immer auf einander abgestimmt werden mögen: Es geht hier zuerst um die Betonung einer Dynamik, die dem Nichttun und in Verlängerung auch dem Müßiggang in Abgrenzung zum Nichtstun und zur Faulheit innewohnt. ${ }^{156}$

Beide Dimensionen spielen für den Genazino'schen Basistypus eine entscheidende Rolle, ${ }^{157}$ so wie auch die MAJUSKELSCHRIFT schablonenhaft Stücke aus dem Figurenensemble auszustechen vermag: Nicht nur wurde Genazino zum Flaneurschriftsteller gestempelt, auch Passivität, Verweigerung, Trägheit und Müßiggang sind im wörtlichen oder übertragenen Sinn - und zwar zurecht - auf seine Figuren projiziert worden. ${ }^{158}$

Allerdings bestehen zwischen der Konzeption Fuests und der hier vertretenen Auffassung auch Unterschiede. Lässt sich Abschaffel noch als an der Arbeit krankende Figur auffassen, ${ }^{159}$ so ist doch spätestens für die Figuren der 1980er Jahre die Notwendigkeit von Lohn und Brot weit in den Hintergrund geraten $(\Leftrightarrow$ II.1.5 u. $\Rightarrow$ V.1).160 Allerdings lassen sich diese merkwürdig autarken Figuren über den Umweg der Flanerie wieder einfangen und auch Fuest führt den Protagonisten aus Ein Regenschirm für diesen Tag zumindest als Schwundstufe an. Laut Fuest weise dieser nur

noch motivische Verbindungen zur traditionellen Psychologie des Flaneurs auf: Einsamkeit, Melancholie, Absage an die Ideale der Arbeit und Zweckrationalität, und dann die Haltung des Zögerns und Zauderns. Einen sanften Nicht(s)tuer könnte man den Ich-Erzähler nennen. [...] Im urbanen Irgendwo ereignet sich somit nur noch ein angedeutetes Flanieren, das man als ironischen Abschied von der großen Tradition schon deshalb lesen kann, weil es schließlich mit der profanen Intention des Schuhtesters unternommen wird. 161

156 Fuest: Poetik des Nicht(s)tuns, S. 14.

157 Vgl. Otto A. Böhmer: Die Süße des Nichtstuns. Wilhelm Genazino feiert wieder die Lebensuntüchtigkeit. In: Die Zeit vom 23. April 2009.

158 So ist es auch nicht wirklich verwunderlich, dass bei Fuest Kracauers oder Robert Walsers Prosa im Kapitel zur „Flanerie“ (vgl. Fuest: Poetik des Nicht(s)tuns, S. 99-169) abgehandelt werden und der Name Benjamin sowohl in der Genazinosekundärliteratur wie bei Fuest an prominenter Stelle vertreten ist.

159 Vgl. etwa die qua Nullfokalisierung auch erzähltechnisch ins Unterbewusste entrückten Wortspiele rund um den Beruf: „Anstatt des Worts Betrieb dachte er einmal das Wort Betrüb, aber es fiel ihm nicht auf." (Falsche Jahre, S. 448)

160 Vgl. Öchsner: Subjekte der Arbeit in der Gegenwartsliteratur.

161 Fuest: Poetik des Nicht(s)tuns, S. 165. 
Mögen die Protagonisten nicht mustergültig in Fuests Konzeption der Flanerie passen; seine Untersuchung liefert eine hilfreiche Folie, vor der die innere Zensur des Genazino'schen Basistypus Gestalt gewinnt.

\section{DAS KONZEPT DER ,SCHERE IM KOPF"}

Lange schon gilt das Konzept der ,Schere im Kopf' (oder: der Schere als Kopf, wie es die weithin bekannte allegorische Karikatur im Leuchtturm von 1847 darstellt) als Sinnbild für unterlassenes (Sprach-)Handeln. Anders als die geschichtlich immer wieder auftretende externe Sanktionsinstanz (Religion, Politik etc.) lässt sich der individuelle Verzicht auf Äußerungen oder Handlungsweisen ,aus freien Stücken` - hier könnte man natürlich Instanzen wie Über-Ich oder anderes namhaft machen, aber es ließe sich zunächst formulieren: aus ,eher persönlichen Gründen` anführen, ein Verzicht, der quasi als internalisierter verstanden werden kann. Ein häufiges Movens ist es dabei, (unliebsame) Konsequenzen leicht verquer zu erahnen. Die Motivation dahinter könnte vielleicht damit angegeben werden, entgegen dem Wort von ,bad news is good news - Hauptsache: Aufmerksamkeit erregen und im Mittelpunkt stehen; solange man sich an einen erinnert, hat man alles richtig gemacht - alles daran zu setzen, durch protektives IM möglichst un(an)greifbar zu bleiben. Jedoch nicht in dem Sinne, sein ,Fähnlein in den Wind zu halten', opportunistisch zu allem und jedem ,ja und Amen' zu sagen - das nicht. Vielmehr aktiv das Verhalten und die möglichen Konsequenzen, das - ob zu Recht oder Unrecht - erwartbare Feedback und das eigene Handeln auf einander abzustimmen und dieses zu unterlassen, welches über ein Minimum hinausgehende Aufmerksamkeit auf den Handelnden richten würde. Dabei können natürlich nur solche Situationen interessieren, in denen das Abstehen von der Handlung auch thematisiert/gezeigt wird. Also starten alle induktiven ,Bottom-up'-Erwägungen bei - innert der Fiktion - realiter sich ereignenden Reflexionen, ob das Tun unterlassen werden solle oder nicht, bzw. bei Plänen, Dinge, die letztlich nicht getan werden, zu tun.

Um erneut die Unterscheidung von Hardcore und Familienähnlichkeit aufzurufen $(\Leftrightarrow I .2 .5)$ und zugleich mit den individuell-romanspezifischen Ausnahmen von der Regel zu beginnen, sei unverhohlen gesagt: Es gibt im Genazinotextuniversum Situationen, die mit innerer Zensur, mit Nicht(s)tun nichts zu tun haben. Aber es sind äußerst wenige und diese denken die Negativfolie zugleich immer mit. Wolf Peschek aus Genazinos Roman Fremde Kämpfe ist bspw. ein Kandidat, der auf den ersten Blick mit Attributen wie ,Tatkraft' und ,Entschlossenheit' belegt werden kann: „Am liebsten wäre Peschek ein bißchen auf der Straße herumgelaufen. Aber er durfte keine Stunde herschenken." (Fremde Kämpfe, S. 134) Im Konflikt zwischen Pflicht und Neigung versagt sich Peschek in der Tat das Nichtstun. Anders als der Basistypus gemeinhin, untersagt er sich das Angenehme und rückt die Pflicht in den Mittelpunkt, sodass die innere Zensur durchaus auch zu Fleiß und Gehorsam taugt. Allerdings reflektiert er an anderer Stelle, dass derjenige, der „bevor er etwas tat, allzu lange nachdachte, [...] am Ende nie etwas [tat].“ (Fremde Kämpfe, S. 69) 
Es handelt sich selbst bei den Ausnahmen nicht um ungebrochene Emsigkeit, da die Familienähnlichkeit des Nicht(s)tuns auch auf Peschek abfärbt und es der rechtfertigenden Reflexion bedarf, um das Tätigsein zu legitimieren.

Genazinotypisch wird dem Leser ohnehin selten das Nicht(s)tun im Sinne des showing unkommentiert vor Augen geführt, sondern nahezu immer von Elementen des telling flankiert $(\Rightarrow I .2 .4)$ :

Sofort spüre ich die Versuchung, meine Jacke hinunterzuwerfen. Ich weiß nicht, warum ich es nicht tue. Wenn ich die Jacke von oben betrachten könnte [...], wie sie den Fluß hinabtreibt und sich dabei ein wenig um sich selbst dreht, würde ich vielleicht die Sonderbarkeit verstehen können, daß ich soeben mit Hilfe eines lächerlichen Mißverständnisses und einer ebenso lächerlichen Plauderei zweihundert Mark verdient habe. [...] Ich weiß sogar, warum ich meine Jacke nicht in das Wasser geworfen habe: Trotz aller Merkwürdigkeit bin ich bisher nicht verrückt geworden. (Regenschirm, S. 159)

Ein ambivalentes Verhältnis kennzeichnet diese Szene, die das Unterlassen der Handlung mit dem Nicht-Vorliegen des Enabling Factors $(\Rightarrow$ I.3.1) ,hinreichende Verrücktheit' benennt. Anders gelagert sind diejenigen Belegstellen, in denen eindeutig nur die Lust am Gedankenspiel zentral ist - häufig handelt es sich um ,Nachahmungserwägungen' - und die Thematisierung vom Abstehen der Handlung aufgebauscht wirken: „Ich überlege, ob ich mir ebenfalls neue Socken kaufen und sie hier anziehen soll." (Einfalt, S. 34) Es ist von vornherein erwartbar, dass es sich nur um ein Gedankenexperiment handelt, wie es auch an anderer Stelle recht bald hinter den scheinbar in Erwägung gezogenen Plänen zur Sprache kommt: „Ich will das nicht wirklich, es ist nur ein Einfall während des Gehens." (Einfalt, S. 94) Expressis verbis gibt auch der Ich-Erzähler aus dem Regenschirm-Roman seinen inneren Monolog als galoppierenden Tagtraum aus: „Draußen, auf der Straße, fällt mir ein Mann mit zu weitem Hemdkragen auf. Ich möchte ihn gerne fragen, ob er die Lust verloren hat, sich passende Hemden zu kaufen. [...] Daraufhin könnten wir in ein Lokal gehen und, nein, das würde nicht passieren." (Regenschirm, S. 58)

Die Ursachen der ,echten' inneren Zensur hingegen lassen sich zumeist auf (teilweise ungeschriebene) gesellschaftliche Gesetzmäßigkeiten, genauer: Normen, Werte und Etikette der fiktionalen Gesellschaft zurückführen. Bei Genazinos Basistypus sind diese jedoch vollends internalisiert worden, sodass die häufig unerklärlich scheinenden Zwänge durchaus wieder im Figureninneren lokalisiert werden können. Laut Hirsch

ist zu beobachten, dass in der Prosa Genazinos die Ich-Erzähler selbst meistens ihre stärksten Kritiker sind: Die Trägheit ihrer Handlungen, ihre allgemeine Unentschlossenheit, hängt oftmals zusammen mit der Ausbildung eines starken Über-Ichs. Weniger die soziale Angst vor äußeren Autoritäten als die Gewissensangst prägt also Rede und Akte jener Reihe von Hauptfiguren [...].162

Dem ist einerseits uneingeschränkt beizupflichten, wenn es um ,gefühlte Verpflichtungen` handelt, die den Handelnden selbst Rätsel aufgeben und dem Rezipienten den unfreien Willen der Figuren vorführen: „Obwohl er sie nicht küssen wollte, küßte er sie auf die linke Wange, und

162 Hirsch: „Schwebeglück der Literatur“, S. 90 f. 
obwohl er nichts sagen wollte, sagte er: Ruf mal an, ja?“ (Ausschweifung, S. 280) ${ }^{163}$ Auch der Roman-Vorgänger, Abschaffel, handelt der höflichkeitsgebietenden Etikette konform. Erneut wird der Leser vor vollendete Tatsachen gestellt und der Drang des Über-Ichs bricht sich gar in der sprachlichen Hülle Bahn: „Abschaffel konnte es nicht verwinden, daß er die Treppen zu ihr hochwinken mußte." (Abschaffel, S. 75) Gewissermaßen handelt es sich um eine umgekehrte innere Zensur, indem er Dinge, die er nicht tun will, trotzdem tut bzw. tun muss - das Ich ist an dieser Stelle nicht Hausherr.

Andererseits ist die Einschätzung Hirschs dahingehend zu ergänzen, dass die Zahl an Fundstellen, die die „soziale Angst vor äußeren Autoritäten“ sehr wohl andeuten, nicht wegdiskutierbar ist. Zugegeben bleiben die besagten Autoritäten allerdings weitgehend namens- und gesichtslos, es sind die je vorherrschenden Über-Ich-Instanzen der konventionellen Umgangsformen, die mitunter auch überindividuell wirken. So ist es nicht Axel Degens alleinige „Gewissensangst", die ihn dazu anhält, seine Körpersprache respektive seinen Bewegungsdrang einem festlichen Anlass gemäß zu zensieren, sondern es handelt sich um einen sozialisierten Konsens der Festgesellschaft: „Und wir alle hatten anerzogene Hemmungen, auf dieser weißen Tischdecke unsere Hände zu bewegen, wir paßten auf, daß nichts von der Gabel fiel“ (Laslinstraße, S. 102). Diesem kategorischen Wir stehen allerdings viele individuelle Ichs zur Seite, die zwischen Furcht und Rücksichtnahme oszillieren (s.u.).

Der Furcht korrespondiert dabei häufig erneut das protektive Handlungsmuster, ungewünschte Fremdbilder ( $\Rightarrow$ II.2.1) erst gar nicht entstehen zu lassen: „Aber er traute sich nicht, weil er nicht übermäßig sonderbar erscheinen wollte." (Falsche Jahre, S. 465; vgl. Falsche Jahre, S. 551) Oder: „Nur meine Furcht, daß ich als Hausmeister gelten könnte, hält mich davon ab, die Mieter des obersten Stockwerks um eine Änderung ihrer Gewohnheiten zu bitten." (Glück, S. 15)

Rücksichtnahme ist janusköpfig. Sie meint zum einen tatsächlich, auf andere Rücksicht zu nehmen, um diese in ihrem Fühlen nicht zu verletzen: „Aber absagen konnte er nun auch nicht mehr; dazu hatte er sich bei der Annahme der Einladung zu eindeutig gefreut." (Ausschweifung, S. 87) Zum anderen ist es eine auf sich selbst gerichtete Rücksicht, qua innerer Zensur unerwünschte Reaktionen zu provozieren: „Peschek überlegte, ob er das Menu zurückgehen lassen sollte. Aber er fürchtete die Umstände“ (Fremde Kämpfe, S. 34 f.). ${ }^{164}$ Oder analog: „Aber ich genierte mich, nach den verbilligten Stücken zu fragen. Ich konnte nicht in den Laden gehen und sagen: Ich kaufe das und das und das - aber bitte alles von gestern.“ (Tiere, S. 103 f.)

Das Signalwort ,genieren' nötigt den Blick, sich der Scham zuzuwenden. Wie bereits dargelegt, bemüht sich diese Untersuchung, eingehende Schamanalysen zu vermeiden $(\Leftrightarrow I .5 .3)$. Allerdings stellt sie, die Scham, als entweder bereits im Moment vor der Handlungsausführung vorliegende

163 Vgl. auch: „[E]r war längst überfordert und wollte gehen, aber das durfte er nicht.“ (Ausschweifung, S. 37; vgl. Ausschweifung, S. 125)

164 Vgl. demgegenüber: „Ich lasse das Gemüse und die Bratkartoffeln zurückgehen.“ (Heimweh, S. 172) 
oder bezüglich ähnlicher Situationen in der Vergangenheit als unangenehm erinnerte einen veritablen Vermeidungsgrund dar: „Nein, die Geschichte von meinen Eltern, die Geschichte von Petra und Elke sollte dieser große Bankmann nicht erfahren“ (Laslinstraße, S. 123). Fischer spricht im Konnex von Scham und finanzieller Abhängigkeit davon, dass

sich zu vormals hauptsächlich auf dem Gebiet der Sexualität tabuisierten Themenstellungen bei Genazino eine ökonomisch sowie eine intersubjektiv begründete Scham [geselle]. Dabei werden, gemäß der soziologischen Umkehr von Fremd- in Selbstzwang, Außenursachen als Eigenschuld adaptiert. 165

An dieser Stelle interessiert hauptsächlich der bereits bei Hirsch angeklungene und für die innere Zensur elementare Befund, dass der Zwang von außen (Gesellschaft, Über-Ich etc.) nach innen gewandert ist - Genazinos Figuren sind sich selbst zum Zensor geworden. Zwei innere Zensuren lassen sich in Relation zu den Umgebungsvariablen begründet differenzieren: gesellschaftlich negativ vs. gesellschaftlich positiv behaftetes Nicht(s)tun.

\section{,NEGATIV' KONNOTIERTE AUSPRÄGUNGEN}

„Geh zu ihr, ein paar Schritte sind es nur bis zum Schlafzimmer, los, Junge - jetzt." (Laslinstraße, S. 5) Untypisch viel Suspense wird erzeugt, wenn man der Figur dabei zuhören darf, zu zögern und zu zaudern und sie zugleich drauf und dran zu sein scheint, sich selbst und mithin ihr Leben - immerhin geht es darum, dass Axel Degen auf Anraten seiner Gewissensstimme seiner offenkundig depressiven Mutter neues Leben einhauchend von deren Antriebslosigkeit befreien soll in eine ganz neue Richtung zu lenken.

Zur ästhetischen Faktur dieser Trilogie [Abschaffel-,Trilogie'; N. L.] und erst recht der folgenden Genazino-Romane gehört die Neigung, Dinge und Menschen in der Schwebe zu lassen, sie in einen zwischen Status Quo und radikaler Veränderung changierenden Möglichkeitsraum hineinzustellen, in dem noch nichts entschieden ist. 166

Im vorliegenden Beispiel allerdings wird dieser Möglichkeitsraum vordergründig einschneidend geschrumpft, indem die Möglichkeit zur radikalen Veränderung passé zu sein scheint: „Ich brachte es nicht fertig, dieser Stimme zu folgen, ich mußte im Wohnzimmer sitzen bleiben." (Laslinstraße, S. 5) Aber letztlich wird die Schwebe ja genau dadurch aufrecht erhalten:

Den Hauptgrund für die getroffene Wahl wird man darin sehen dürfen, dass genau diese und nur diese Entscheidung es dem Protagonisten ermöglicht, bis auf Weiteres keine Entscheidung fällen, keine Wahl treffen zu müssen. Es ist die Option für das Offenhalten der unentschiedenen Zweigleisigkeit, die den Zuschlag erhält. ${ }^{167}$

Man könnte es programmatische Unentschiedenheit nennen, die sich aus einer externen Perspektive zum poetologischen Prinzip ausbauen lässt: Die Figuren dürfen sich laut externer Analyseperspektive nicht entscheiden, weil dadurch erst mangelnde Selbstwirksamkeit $\Rightarrow$ II.1.3),

165 Fischer: „Schläft ein Lied in allen Dingen“, S. 16.

166 Honold: Doppelleben, halbbitter, S. 44.

167 Honold: Doppelleben, halbbitter, S. 47. 
Folgenlosigkeit, Stillstand, Lethargie etc. resultieren können, die für Genazinos Figurenzeichnung wichtige Funktionen übernehmen. „Was gab es denn daran zu überlegen? Warum konnte er nicht einfach baden?“ (Sorgen, S. 325) Diese und ähnliche Fragen stellen sich auch für den Rezipienten häufig, der zwar als Genazino-Leser mit der Grundstruktur vertraut, aber auch des Öfteren ratlos ist. Namentlich dann, wenn es um derart profane Dinge geht wie das Aufheben eines Geldstücks oder das Stutzen der Nasenhaare (vgl. Sorgen, S. 337), kann das Nicht(s)tun der Figuren auch den Leser strapazieren: „Noch nicht einmal solche kleinen Handlungen konnte er zu Ende bringen an diesem Morgen.“ (Sorgen, S. 337) Sowohl der Erzähler als auch der Leser wünschen sich nachgerade die sprichwörtliche ,Butter bei die Fische'; die Handlungsarmut wird sowohl vom Feuilleton gegen Genazino als auch von den Neben- gegen die Hauptfiguren als Vorwurf gewendet. Denn selbst dann, wenn die lang ersehnte Entscheidung gefallen ist, ist dies nicht gleichbedeutend mit einem Haken hinter der Angelegenheit: „Er bemerkte, daß er den Entschluß zum Besuch von Margot schon gefaßt hatte, weil er aber noch nicht wußte, wie er das praktische Aufeinandertreffen gestalten sollte, tat er eine Weile so, als hätte er sich noch nicht entschlossen." (Sorgen, S. 262) Vor diesem Hintergrund gewinnt Honolds Einschätzung zusätzliche Überzeugungskraft, insofern figurenseitig selbst bei gefällter Entscheidung noch immer auf Biegen und Brechen „für das Offenhalten der unentschiedenen Zweigleisigkeit“ optiert wird.

Wenn der Gegenstand der Handlungserwägung weitreichende Folgen nach sich zieht und das als desiderabel vorgestellte Handlungsziel noch nicht formuliert ist, leuchtet das letztlich im Nichttun verharrende Hin und Her eher ein: „Sollte er in die Küche gehen und Ruth betont munter begrüßen, als hätten sie sich gestern abend nicht gestritten? Aber er wollte auch nicht so tun, als beabsichtigte er, eine kritische Lage künstlich in Wohlgefallen aufzulösen." (Ausschweifung, S. 15) In dieser Erscheinungsform handelt es sich um einen Grenzfall zwischen nicht wirklich negativ konnotiertem Vergleichen zweier mit Vor- und Nachteilen behafteten Handlungsoptionen und ,echtem' Zögern im Sinne der inneren Zensur.

Deutlicher negativ belastet sind Settings, die unliebsame Eigenschaften der Figuren als Handlungsverhinderungsgrund herausstellen: „Denn natürlich war er zu müde dazu, noch einmal auf die Straße zu gehen und Baudreck zu besorgen (er war auch zu feige dazu, aber weil er glücklicherweise noch viel mehr müde als feige war, kam er um das Eingeständnis der Feigheit noch einmal herum).“ (Sorgen, S. 344) Erzähltechnisch wird gekonnt in der Schwebe gehalten, ob Abschaffel die geklammerte Parenthese im Wegdämmern mitdenkt oder ob der Erzähler Abschaffel qua direkter Charakterisierung das Etikett ,feige' aufklebt. Beide Lesarten teilen jedoch die Ansicht, dass Feigheit keine Auszeichnung sei. Denn Unsicherheit, mangelndes Selbstbewusstsein, mangelnder Mut und also Feigheit sind nach wie vor Charaktereigenschaften, die in den skizzierten Genazino-Gesellschaftspanoramen - und zu einem guten Teil in der westeuropäischen Leistungsgesellschaft ganz aktuell - alles andere als Hochwertworte sind. Diese Ansicht ist auch Genazinos Figuren wohl bekannt und so beklagen sie eher die Absenz der Antipoden (hier: Mut) in 
ihrer charakterlichen Ausstattung, als dass sie sich aktiv dagegen auflehnen würden. Ein wiedererkennbares reflexives Muster ist erneut im Bearbeitungsmechanismus der Rationalisierung sowie dem Hinzufügen einer weiteren Kognition zwecks Reduktion der Kognitiven Dissonanz zu erkennen ( $\Rightarrow$ II.2.1). Das Muster lautet in der Ich-Form etwa: ,Wäre ich [gewünschte Charaktereigenschaft], was ich aber nicht bin und wofür ich auch genaugenommen nichts kann, dann...': „Wenn ich mehr Mut hätte, würde ich wieder umkehren, aber ich habe keinen Mut, beziehungsweise ich spare ihn mir für die wirklich harten Situationen auf." (Liebesblödigkeit, S. 34) Analog dazu gibt Reinhard als Grund für unterlassenes Handeln an: „Wenn ich mich nicht geniert hätte, wäre ich auf das Flachdach geklettert und hätte den Amseln beim Umherrennen zugeschaut.“ (Regen, S. 62) Und auch der Ich-Erzähler aus Genazinos Wenn wir Tiere wären führt zum einen das negativ konnotierte Wesensmerkmal an, zum anderen rechtfertigt er es in der Grauzone zwischen Selbstbetrug und Selbsterkenntnis: „Aber ich war nicht kühn, ich fühlte mich schwächlich durch zu viele Erinnerungen." (Tiere, S. 14)

Was sich in diesen Zitaten zumindest auf die Selbst-Fremdbild-Passung gewendet ins Positive verkehren lässt, erhält dann einen nahezu tragisch zu nennenden desperat-faden Beigeschmack, sobald der Wunsch als Mangelwahrnehmung in die Vergangenheit verlagert wird: „Ich war damals weder schlagfertig noch frech." (Tiere, S. 73) Mit dieser Überzeugung ist ein kleiner Knotenpunkt berührt, da probabilistisch eigentlich nicht haltbare Mutmaßungen aus der erzählerischen Distanz des erzählenden Ichs gerne einmal vorgebracht werden, um das als defizitär wahrgenommene Jetzt-Selbst zu ,entschuldigen“: „Wenn er, als er so alt gewesen war wie diese Kinder, auch nur die Hälfte ihrer Frechheit gehabt hätte, dann würde er heute ein anderes Leben führen, überlegte er." (Falsche Jahre, S. 558) Der Wunsch nach Frechheit, also auch nach Durchsetzungsvermögen und der Fähigkeit, ,klare Kante‘ zu zeigen, entspringt immer wieder der in der Erzählgegenwart bzw. jüngeren -vergangenheit erlebten Unzulänglichkeit in dieser Hinsicht. Der Protagonist des Romans Außer uns spricht niemand über uns etwa ignoriert eine offenkundig derangierte Frau in einer U-Bahn, die fortwährend vor sich hin spuckt, mit der Angabe einer zivilcouragiert eher mangelhaft zu nennenden Entschuldigung: „Ich tat so, als würde mich nichts stören, ich wollte in nichts verwickelt werden. Den anderen Leuten in der Bahn schien es ähnlich zu gehen." (Außer uns, S. 47)

Es wäre erneut wohlfeil, die situativen Aspekte - im U-Bahn-Zitat etwa: Verantwortungsdiffusion; auch jemand anderes könnte ja eingreifen - der Kommunikationssituation außer Acht zu lassen. Für die negativ konnotierten Aspekte der inneren Zensur erweisen sich die jeweiligen Figurenverfasstheiten als wichtiger Prädiktor, was zum Beispiel von Abschaffel auch angedacht wird: „Aber es ist eine bestimmte Verfassung notwendig, damit man sich traut, so etwas zu erzählen. Schon wenig später konnte Abschaffel nichts mehr darüber sagen" (Abschaffel, S. 27). Mangelnder Mut liegt im weiteren Sinne immer noch vor, aber die ,Grundgestimmtheit' $(\Rightarrow$ II.4.2) und das - in der Literatur freilich nie wirklich abbildbare - Zufallsarrangement der Situation 
tragen maßgeblich zum (Miss-)Erfolg kommunikativer Anliegen bei; kurz: Ob die innere Zensur die Schere an die handlungsauslösenden Faktoren setzt oder nicht, ist ohne Berücksichtigung situativer Aspekte nicht einwandfrei zu beantworten.

In Laslinstraße braucht die Hauptfigur mehrere Anläufe, um sein Vorhaben, seine Eltern mit einer aus seiner Sicht aufrüttelnden Neuigkeit aus deren Phlegma zu reißen,168 in die Tat zu setzen. Vom ersten Scheitern ist weiter oben bereits die Rede gewesen. Ein späterer Anlauf misslingt ebenfalls: „Morgen früh werde ich - Schritte im Hausgang, es war meine Mutter. Ich will sie an der Tür erwarten, nahm ich mir vor, sonst machte ich das nicht, aber heute, ja, heute. [...] Ich traute mich nicht" (Laslinstraße, S. 31 f.). Die situative Komponente wird im epischen Präteritum geradezu überpointiert herausgestellt, es wimmelt von temporaler Deiktik und Käthe Hamburgers Überzeugung, dass gerade die Gemachtheit der Erzählung zugunsten der minimierten Mittelbarkeit in die wahrnehmbare Reichweite des Rezipienten rücke, muss an dieser Stelle verneint werden: der Modus ist dramatisch. Fünfundzwanzig Druckseiten nach diesem erneuten Eingreifen der Schere in Kopf und Körper ereignet sich etwas ziemlich Untypisches bzw. Romanspezifisch-Individuelles: Wenn Vorhaben überhaupt lange mit den Hauptfiguren spazierengehend herumgetragen werden, ist es umso unwahrscheinlicher, dass sie final in eine Tat überführt werden. Nicht so bei Axel Degen, der sich nun ,endlich' traut, der Gewissensstimme zu gehorchen und das Eis zu brechen sucht, indem er die ersten Worte an die Eltern adressiert: „,Morgens, wenn ich zur Schule gehe, treffe ich immer ein Mädchen.“" (Laslinstraße, S. 47)

Zwar gibt es dann und wann auch andernorts reflektiert bereute Zensurzurücknahmen, die Revision wird dann aber ,in einem Zug' erzählt: „Da ärgerte ich mich wieder, weil ich mich mit so einer fürsorglichen Schau hatte abfertigen lassen, [...] mit so viel Vernunft war ich davon abgehalten worden, meinem Leben eine Drehung zu geben“ (Laslinstraße, S. 125). Er bereut im Nachhinein - in der Nachhandlungsphase $(\Leftrightarrow I .3 .1)$-, nicht die Initiative ergriffen zu haben, was er aber entschlossen und geradlinig nachholt: „[I]ch ging in eine Telefonzelle, wählte die Nummer der Bank [...] und sagte gleich, fest und laut: ,Ich habe es mir überlegt, ich will bei Ihnen anfangen." (Laslinstraße, S. 126) Die wenigen solcher kleinen Erfolge über sich selbst werden anerkennend genossen: „Damit war Peschek frei. Wunderbar froh lief er [...]. Ahhh!“ (Fremde Kämpfe, S. 160) Kurz zuvor hat Peschek das Höflichkeitsgebot, einer bereits getätigten Zu- keine Absage folgen zu lassen, missachtet und Marga mit den Worten: „Ich habe keine Lust [...], wegen ein paar Muscheln eine Stunde lang in der Gegend herumzufahren“, den Laufpass (für diesen Abend) gegeben (Fremde Kämpfe, S. 160). Die unerhörte Empfindung einer Befreiung und die Überspitzung durch den exklamativen Ausruf mit Tripel-,h', der Adelung durch das „Wunderbar“ und Ausrufungszeichen verdeutlichen abermals die hohe psychische Anspannung, dem Gewissen bzw. den gesellschaftlichen Konventionen/dem Über-Ich Paroli zu bieten. Mit dieser Hyper- 
trophie der Genugtuung ob des Siegs der Sprach-Tat über die Zensur wird gleichsam deren unwahrscheinliche Seltenheit als Abweichung markiert. Usus ist die Haltung: ,I would prefer not to“ - aber eben nicht in radikalindividualistischer Deutung, sondern im Verweigerungsgestus.

Genauso in Verruf wie eine Absage an objektiv einsichtige Erfordernisse sowie Feigheit und/oder mangelndes Selbstbewusstsein ist im Auge des Betrachters unnötige Prokrastination. Denn Verstöße gegen die ,preußischen Tugenden' wiegen schwer im vermeintlich dem freien Willen unterworfenen Sektor der Notwendigkeiten. Damit geht auch eine bürgerliche Abneigung gegen das Lustprinzip einher: Wer sich sofort und auf dem Weg des geringsten Widerstands Befriedigung verschafft, ist faul, nutzlos und willensschwach.

Genazinos Figurenbasistypus, hier in der Person Abschaffels, „zögerte die Kontrollen hinaus, weil es schön war, morgens in der Halle herumzulaufen.“ (Sorgen, S. 227) Einfach, „weil es schön ist“. Die Protagonisten sind im Normalfall „dankbar für jede Ablenkung“ (Fremde Kämpfe, S. 175) und freuen sich beinahe darüber, wenn sie durch äußere Umstände von eigentlich anstehenden Tätigkeiten und/oder Entscheidungen entbunden werden: „Unversehens hatte sich eine Strategie der Verhinderungen ergeben, und genau das war es, was er heute brauchte." (Sorgen, S. 299) Im Hinblick auf das Reflexionsniveau der Prokrastination zeichnen sich vor allem die neueren Genazino-Figuren durch eine treffsichere reflexive Prädikatenzuweisung aus $(\Rightarrow I .4)$, wenngleich diese im Roman Wenn wir Tiere wären ironisch gebrochen das Selbstkonzept gegen die Diskrepanz von Selbst- und Idealbild ( $\Rightarrow$ II.2.1) in Schutz nimmt:

Im Kern bin ich ein Drückeberger, sagte ich; wenn es sein muss, zögere ich drei Stunden lang, um mit einer kleinen Arbeit endlich anzufangen. [...] Mein ganzer Individualismus ist nur ein kindisches Versteckspiel [...]. Ich zögere sogar das Scheißen hinaus, wenn ich nicht die richtige Klostimmung habe. Und wenn ich nicht telefonieren will, nehme ich den Hörer nicht ab. [...] Gleichgültigkeit, Überdruss, Ekel, Melancholie (Tiere, S. 91 f.).

Ins gleiche Horn wie der freie Architekt, der seine Charakterzüge regelmäßig immens gut einschätzen und auch verbalisieren kann, stößt der sich durch Initiativlosigkeit auszeichnende Reinhard aus Genazinos Bei Regen im Saal:

Ich litt an der zärtlichen Krankheit des Innehaltens, über die ich praktisch mit niemandem sprechen konnte, mit Sonja schon gar nicht. [...] Mein Innehalten bestand im Wesentlichen darin, dass ich irgendwo stehenblieb und etwas Nichtiges so lange betrachtete, bis es sich in meiner Betrachtung nahezu aufgelöst hatte. (Regen, S. 50; $\Rightarrow$ II.2.2)

Als „zärtlich“ klassifiziert er seine „Krankheit“, die ihn faktisch permanent im Alltag lähmt; auch ein entstehungsgeschichtlich junger Spross der Figuren bekennt: „Auf dem Weg zum Supermarkt litt ich unter meiner Angewohnheit, dass ich notwendige Erledigungen zu oft und zu lange hinausschob. Mit diesen Aufschiebungen hing es zusammen, dass aus meinem Leben mehr und mehr ein vertagtes Leben wurde." (Außer uns, S. 104) Bezeichnenderweise sind es Zitate aus zwei der neuesten Genazinoromane, die wörtlich akutes Leiden ausstellen: Das Nicht(s)tun überschreitet ohne viel Aufhebens die Grenze von der Faulheit zur pathologischen Antriebslo- 
sigkeit. Erneut ist es der namenlose männliche Rundfunksprecher des Romans Außer uns spricht niemand über uns, der metaphorisch im Bild der Inventur seine Lethargie eingesteht:

Es drängte mich danach, eine Art Inventur zu machen. Wenn ich es recht wusste, besteht eine Inventur aus zwei Schritten: 1. Eine Bestandsaufnahme dessen, was da ist. Und 2. Nach der Bestandsaufnahme eine Handlungsüberlegung: was zu tun sei mit den Beständen. Am liebsten war ich ein Betrachter der Bestände, alles andere war mir zu kompliziert und deswegen Angst hervorrufend. (Außer uns, S. 97)

Den erforderlichen zweiten Schritt zu gehen, hat schon Abschaffel umgetrieben:

Er hätte nur aufstehen und ein halbes Glas Wasser trinken müssen, und er hätte keine Gelegenheit mehr gehabt, sich schlecht zu fühlen. Aber er war liegengeblieben [...]. [...] Er hätte wenigstens die Balkontür öffnen und einen Schwarm von Nachtfaltern hereinfliegen lassen können [...]. Er tat nichts davon; er blieb liegen und suchte nach Tätigkeiten, die sich liegend ausführen ließen. ( $A b$ schaffel, S. $31 \mathrm{f}$.

Die galoppierende Antriebslosigkeit ist auch sein treuer Weggefährte, was im weiteren Textverlauf wörtlich fixiert wird: „Er hatte eigentlich drei schmutzige Hemden noch in die Reinigung bringen wollen [...]. Aber es fehlte ihm jeglicher Antrieb“ (Abschaffel, S. 147). Nun ließe sich begründet einwenden, dass Liegenbleiben oder das Abstehen von der Handlung ,Reinigungsbesuch' keine gewichtigen Argumente für krankhaftes Nicht(s)tun seien. Aber der Subtext des Discours legt es immer wieder nahe, größere Problemkomplexe im Hintergrund wirken zu wähnen und die marginal erscheinenden Symptome zutage zu fördern. Allein das Ausmaß des Gedankenraums, welchselben die zögerlichen Handlungsintentionen einnehmen, spricht dafür, von psychisch problematisch gestalteten Figuren zu sprechen $(\Leftrightarrow$ II.1.3):

Ich müsste es schaffen, einen Uhrenladen zu betreten und zu sagen: Ich möchte ein neues Armband für meine Armbanduhr. Dann müsste ich meine Uhr mit dem schadhaften Armband auf die Ladentheke legen. Statt dessen hatte ich angefangen, an dem abgerissenen Ende des Armbands Gefallen zu finden. (Tiere, S. 56)

Gleich zweimal ,winkt' der Konjunktiv mit dem ,lethargischen Zaunpfahl' nach dem Muster: ,Eigentlich müsste man ja mal, aaaber.... Der psychische Abwehrmechanismus, der die schmerzliche Wahrnehmung kognitiver Dissonanz ( $\Rightarrow$ II.2.1) auszublenden sucht, wählt den Weg: „Hinzufügen weiterer Kognitionen, um unser Verhalten zu rechtfertigen“.169 Noch eine Spur verzweifelter, da ohne Reparaturmechanismus, gestaltet sich die innere Zensur in Die Obdachlosigkeit der Fische:

Erst draußen bemerke ich, daß ich in der Eile meine Mütze vergessen habe. Ich blicke zurück und sehe sie drinnen an der Garderobe hängen. Ich sollte keine weitere Minute verstreichen lassen, aber es überfällt mich wieder ein Zögern, ich bleibe stehen und betrachte die Mütze, und dann habe ich das Gefühl, sie gehört mir nicht mehr. Es ist mir nicht möglich, in das Lokal zurückzukehren. (Obdachlosigkeit, S. 104)

Sowohl der melancholische Ton als auch die über weite Strecken des Romans verwendete Metapher einer Zitadelle, in der zu leben sich die Protagonistin bildlich eingerichtet hat, lassen es

169 Aronson/Wilson/Akert: Sozialpsychologie, S. 164. 
nicht übertrieben erscheinen, Grundzüge einer Depression in Betracht zu ziehen, die sich als Hand an der Schere der inneren Zensur zu schaffen macht: Kleinste Vorhaben können aus Energieverlustgründen nicht mehr ausgeführt werden. ${ }^{170}$ Im echten Leben ist der Ausweg aus der Depression für gewöhnlich ohne Impulse von außen kaum zu bewerkstelligen. Mögliche literarische Welten hingegen erlauben es - wenn auch im Kleinen - ihren Bewohnern sporadisch, sich selbst am Schopf aus dem Sumpf zu ziehen: „Erst jetzt bemerkte Abschaffel, welche enormen Energien an Nachdenklichkeit er an dieses sinnlose Problem verschleuderte. Er wurde wütend und überlegte überhaupt nicht mehr. Er riß beide alten Schnürsenkel heraus und zog die neuen ein" (Abschaffel, S. 114). Diese Entschlossenheit ist Mangelware bei Genazino und nicht eigentlich mehr im Dunstkreis innerer Zensur liegend. Allerdings bietet sie als gesellschaftlich positiv gesehene Eigenschaft eine gute Möglichkeit zur als ebenso ,gutartig' bewerteten Ausprägungen der inneren Zensur überzuleiten, denn nicht immer muss es unter dem Strich falsch oder gar ,krankhaft' gewesen sein, etwas nicht oder überhaupt nichts zu tun.

\section{,POSITIV' KONNOTIERTE AUSPRÄGUNGEN}

Obwohl sich nämlich das äußerlich beobachtbare Resultat nicht unterscheiden mag, ist die Motivationslage bei der Zuordnung zu negativ oder positiv konnotierter innerer Zensur alles andere als irrelevant:

Er war sogar kurz in Versuchung, ihr vorzuschwindeln, er sei in Winterurlaub gewesen: Skifahren im Ötztal (o weh), aber er schwieg und litt dabei. Er wollte ihr nicht sagen, dass er in Sattlach gewesen war, und er wollte sie auch nicht anschwindeln: Also mußte er schweigen. (Falsche Jahre, S. 556)

Dass Abschaffel, um sich protektiv nicht entblößen zu müssen ( $\Rightarrow$ I.3.3), seinen Klinikaufenthalt verschweigen möchte, ${ }^{171}$ würde an dieser Stelle gar eine Notlüge weitaus eher sozial akzeptiert scheinen lassen, als dies in vielen Situationen, in denen der Basistypus zur ,kleinen Lüge' greift $\Leftrightarrow$ II.1.2), der Fall ist. Dass er sich indes selbst diese versagt und ein peinigendes Schweigen $\Leftrightarrow$ II.1.4) in Kauf nimmt, um nicht schwindeln zu müssen, lässt ihn als aufrichtig und bemitleidenswert erscheinen. Spätestens hinsichtlich der harten und weichen Faktoren von Sympathielenkung ${ }^{172}$ sind die geschilderten inneren motivationalen Hintergrunddenkprozesse bedeutsam.

170 Zumal immer wieder einmal gesagt wird, dass es früher anders war: „irgendwann einmal, als er seine Absichten noch ausführte" (Sorgen, S. 347). Vgl. dazu auch Christian Heinrich: Volkskrankheit Depression. In: ZEIT ONLINE vom 10. November 2009. Online: <http://www.zeit.de/zeitwissen/2010/s1/Depression/komplettansicht>.

171 Vgl. für eine umgekehrte Situation des Taktgefühls: „Eigentlich wollte er ihn fragen, welche Krankheit er denn nun eigentlich habe, aber er traute sich nicht." (Falsche Jahre, S. 547)

172 Vgl. Schneider: Einführung in die Roman-Analyse, S. 23-26; vgl. Katharina Prinz/Simone Winko: Sympathielenkung und textinterne Wertungen. Überlegungen zu ihrer Untersuchung und exemplarische Analyse der Figur des ,unglücklichen Mordgehilfen' Olivier Brusson. In: Claudia Hillebrandt/Elisabeth Kampfmann (Hg.): Sympathie und Literatur. Zur Relevanz des Sympathiekonzeptes für die Literaturwissenschaft. Berlin 2014, S. 99-127, hier S. $108 \mathrm{ff}$. 
Zu positiv konnotierten Ausprägungen gehören fernerhin (unterlassene) Verhaltensweisen, die Affektkontrolle als Bestandteil Emotionaler Intelligenz ausweisen. Abschaffel „dachte: Wenn ich es noch einmal spüre, werfe ich sie aus dem Bett. Dann spürte er es wieder und sagte nichts." (Sorgen, S. 243) Der (überspitzte) kurzfristige Impuls wird einem längerfristigen Ziel untergeordnet, was freilich auf Basis „ganz allgemein und durchgängig anerkannte[r] Gesellschaftsnormen“173 eher begrüßens- als tadelnswert erscheint. Diese „Minimalforderungen der gesellschaftlichen Etikette“ ${ }^{\text {"174 }}$ akzentuieren auch Abschaffels ,Beherrschung' des folgenden Beispiels als gebotene Affektkontrolle und mithin positive innere Zensur: „Manchmal verspürte er Lust, jemandem zu sagen, daß dieser Tag sein letzter Tag sei, aber er beherrschte sich.“ (Sorgen, S. 308)175 Als ebenso positiv ist die Mutlosigkeit Rotmunds zu werten: „Immer mal wieder spiele ich mit dem Gedanken, die Tomate auf die Leute zu werfen, die laut und polternd auf der Straße reden. Aber ich finde den Mut nicht." (Heimweh, S. 12) ${ }^{176}$ Genazino (Figur) hingegen kratzt an der Grenze des Negativen, da er sich zwar zwingt, keine Passanten anzupöbeln, allerdings bereits die Möglichkeit eines späteren Ausbruchs mit reflektiert und die Kontrolle seiner Affekte nicht auf Dauer gewährleisten zu können glaubt: „Die Fähigkeit, in gefährlichen Augenblicken stumm zu bleiben, bewahrt mich zur Zeit davor, verrückt zu werden. Allerdings muß ich mir Sorgen machen, ob ich zukünftig immer werde schweigen können." (Einfalt, S. 9) Die Angst davor, die eigenen Affekte nicht mehr hinreichend kontrollieren zu können, kennt auch Abschaffel: „Abschaffel kämpfte schon eine ganze Weile gegen die Lust an, jemand aus dem Haus gegenüber anzurufen und ihm zu sagen, daß das Haus brannte. Dabei ließ er diese Lust nicht richtig nach vorne kommen." (Sorgen, S. 385)

Als ebenfalls nicht unverfängliche Variation lässt sich die innere Zensur als harmoniewahrende Instanz begreifen: „Er hatte Lust, hier im Wohnzimmer zu sagen: Wenn der Vater tot ist, reise ich mit dir drei Wochen nach Italien. Natürlich drang von allem, was er dachte und wünschte, nichts nach außen. Im Gegenteil, er machte ein freundliches Gesicht. Die Mutter war dafür dankbar und lachte ihn an." (Abschaffel, S. 70 f.) ${ }^{177}$ Den Vater im Beisein der Mutter herabzuwürdigen, wäre

173 Schneider: Einführung in die Roman-Analyse, S. 23.

174 Schneider: Einführung in die Roman-Analyse, S. 23.

175 Vgl. auch: „Mir fiel ein Spruch ein, den ich gerne gesagt hätte: Wer altert, hört auf zu planen. Aber diese Antwort hätte auch Carola nicht gefallen, also sagte ich nichts" (Außer uns, S. 26).

176 An der Grenze bewegt sich ein Beispiel aus dem Roman Außer uns spricht niemand über uns: „Es verlockte mich von Zeit zu Zeit, die Frau ein für allemal zurechtzuweisen, so dass sie für alle Zukunft genug haben würde, einen Schauspieler am Telefon abzuweisen. Ich wusste, natürlich würde ich diesen Mut nicht aufbringen. Es genügte mir die Vorstellung, dass sogar mir eines Tages der Kragen platzen würde." (Außer uns, S. 81) Aufgrund der erfahrenen Demütigung wäre es dem Gerechtigkeitsempfinden womöglich zuträglicher, diese Zurechtweisung mitbekommen zu dürfen. Glaubt man der Forschung, so erhöht allerdings das häufige Durchspielen der Vorhandlungsphase die Wahrscheinlichkeit für die Handlung selbst - und spätestens im vierten Schlaglicht kommt es schließlich auch zu (allerdings nur teilweise berechtigten) Wutausbrüchen ( $\Rightarrow$ II.4.3 u. $\Rightarrow$ II.4.4). Vgl. zum Gegenteil von Harmonie: „Ich unterdrückte meine Tendenz zur versöhnenden Leutseligkeit und grüßte ebenfalls nicht." (Kassiererinnen, S. 152 f.) Vgl. dazu, dass diese Figurenfacette relational zum Lebensstil positiv oder negativ ausgelegt werden kann $(\Rightarrow$ II.1.5). 
ihm zwar ein Anliegen - und vermutlich aus psychologischer Sicht eher ratsam ${ }^{178}$-, das gesamte familiäre Gefüge dafür aufs Spiel zu setzen, würde aber zumindest seiner Mutter den Tag verhageln. Die Überzeugung, insbesondere die Mutterfiguren „vor der Wahrnehmung seiner Schwierigkeiten schützen“ zu wollen, ist für den Basistypus allerdings strapaziös und „führte [...] am Ende nur zu einer Überreizung." (Ausschweifung, S. 104)179

Verschlagworten lässt sich diese Figurenfacette: einerseits der Etikette zu genügen, andererseits auch mit Verbiegungen des Selbst verflochten zu sein, mit ,Rücksichtnahme', „Diskretion bzw. Taktgefühl' sowie ,Mitleid ${ }^{180}$ bzw. Empathie‘. Ein wiederkehrendes Movens ist bspw. die Abwandlung des kategorischen Imperativs nach Kant: Genazinos Figurenbasistypus handelt häufig ,nur nach derjenigen Maxime, durch die er zugleich wollen kann, dass sie ein allgemeines Gesetz werde - und stiftet, da es sich nun einmal um höchst neurotische Figuren handelt, nolens volens emotionales Wirrwarr. Da der Basistypus Perspektivübernahmekompetenzen nur bedingt in einem ,normalen` Maß sein eigen nennen darf und die öffentliche Selbstaufmerksamkeit als Störvariable in der kategorischen Rechnung berücksichtigt werden muss, sind diejenigen Maximen des Handelns mitunter problematisch, wiewohl gesellschaftlich mehrheitlich begrüßenswert: Da er bspw. die Diskretion seitens anderer schätzt, erwartet er sie aus Fremdsicht auch von sich: „[E]r verhielt sich ganz still, weil er dem rülpsenden Mann die Idee, er sei allein, nicht zerstören wollte." (Falsche Jahre, S. 419) ${ }^{181}$ Nimmt man wie gesagt die Erwägung hinzu, dass ein Sich-zu-erkennen-Geben auf ihn selbst unangenehm zurückfallen könnte, wird die Vertracktheit deutlich: Als ethischer Grundsatz taugt öffentliches Rülpsen wohl kaum, wäre es dann nicht eventuell der negativen Konsequenzen ungeachtet eher angezeigt, den Mann darauf hinzuweisen?182 Ebenso fragwürdig erscheint die Diskretion William Genazinos: „Ich antwortete, daß ich nur verstehen wolle, warum sie jahrzehntelang denselben Scherz wiederholte. Nein, das sagte ich nicht, denn das traute ich mich nicht." (Einfalt, S. 62) Auf Besserung enervierender Verhaltensweisen seiner Mitmenschen darf letztlich nur hoffen, wer diesen Hilfe zur Selbsthilfe bei der

178 Genauso diskutabel ist die Sinnhaftigkeit des Verschweigens eigener Wünsche aus Gründen der triebunterdrückenden Scham bei Genazino. Vgl. etwa: „Er wollte sie um einen ihrer Schuhe bitten, damit er ihn zeichnen konnte. Aber er schaffte es, den Mund zu halten." (Fremde Kämpfe, S. 201) „Er hatte seine Eltern noch niemals überraschend verlassen; wenn er ging, dann ging er zu den passenden Stunden und Gelegenheiten; in allen Demütigungen wahrte er die Formen. In Wirklichkeit war es auch schon wieder zu spät, überraschend wegzugehen. Aus seinem Entschluß war ein langer Blick an die Zimmerdecke geworden, der immer noch anhielt." (Abschaffel, S. 74) Vgl. für ,problematisches Mitleid': „und ich werde ihm nie sagen können, daß ich ihn für einen Idioten halte, weil er immer kurz vorher mein Mitleid entzündet, so daß ich ihm nichts sagen kann." (Sorgen, S. 223) Vgl. für ähnliche Beispiele Ausschweifung, S. 68 u. S. 77. Vgl. für ein Gegenbeispiel Fremde Kämpfe, S. 75.

182 In Form der Handlungsmaximen: ,Störe nicht zwei sich gut unterhaltende Gesprächspartner` - „ich durfte jetzt nicht stören, sie sprechen sicher weiter, hoffte ich [...] am liebsten wäre ich in die Küche gestürzt“ (Laslinstraße, S. 63) - oder: ,Sei nicht indiskret zu sich allein wähnenden Personen, die nicht rülpsen“ - „Ich würde ihn mir gerne auf der Leiter liegend anschauen, aber ich möchte nicht, daß der Junge das Geheimnis, das er mit dem Fetisch teilt, verraten sieht" (Heimweh, S. 92) -, finden sich diskutable Ansatzpunkte für berechtigt erscheinende Zurückhaltung im Romanwerk. 
Selbsterkenntnis und mithin die Möglichkeit, an sich zu arbeiten, zuteilwerden lässt. Dass der Basistypus es mitunter in puncto Empathie übertreibt, reflektiert Warlich in vollem Zugriff auf sein Bewusstsein: „Ich würde Traudel das gerne einmal sagen, aber ich fürchte, sie würde mir nicht glauben. Es ärgert mich (auch jetzt wieder), daß ich nur aus Einfühlung in Traudels Mißtrauen nicht über ein Behagen spreche, das ich doch allein ihr verdanke." (Glück, S. 97)

Für die Annahme eines prinzipiell überzogenen bzw. sogar falsch verstandenen Taktgefühls finden sich zahllose Beispiele und nur eine aufschlussreiche Grundform soll hier noch angesprochen werden: diejenige, die Überlegenheitsgefühle hinsichtlich einer empfundenen kapitalstrukturellen Höherstellung in Rechnung stellt ( $\Rightarrow$ II.1.5). Wie Abschaffel den Bild-Zeitungs-lesenden Arbeiter aus der Befürchtung, „der Mann könne sich gedemütigt fühlen“ (Abschaffel, S. 63), nicht mit einer Insignie objektivierten kulturellen Kapitals (vulgo: Buch) behelligen möchte ( $\Rightarrow$ II.1.4) was sich übrigens auch als plumper Ausdruck von Überheblichkeit denken lässt: Vielleicht liest der Herr zuhause ja selbst Romane? -, so versagt sich Eckhard Fuchs es, die als „demütig[]“ erachtete „Arbeit des Zettelverteilers“ nicht dadurch weiterhin zu entwerten, „,indem er den Zettel in Sichtweise des Verteilers in den Papierkorb warf“ (Ausschweifung, S. 110), wie auch W. „auf das Aufschreiben“ besonderer, teils diese als sozial schwächer gestellte attribuierende, Merkmale seiner Nebenfiguren deswegen verzichtet, „weil es die wenigen Fahrgäste in der Bahn zu beunruhigen scheint." (Fleck, S. 71) Alle drei Beispiele eint die nonverbale Komponente, die prinzipiell nicht ehrenrührige Überzeugung, den anderen damit einen Gefallen zu tun, vor allem aber die Vorstellung, ,den anderen' derart überlegen zu sein, dass ihnen die (vermutete!) Diskrepanz zwischen den Lebensstilen unter allen Umständen verheimlicht werden müsse - und sei es unter Anwendung der inneren Zensur auf die Ausübung geläufiger und keinesfalls per se verletzender Handlungen.

Bevor nun abschließend ein Analysetool vorgestellt werden soll, das sich bei der inneren Zensur anbietet, sind zwei romanspezifische, nicht ohne Weiteres in die gewählte Kapitelstruktur einbettbare Auffälligkeiten hinsichtlich der inneren Zensur zu nennen: Zum einen handelt es sich um den erzähltheoretisch interessanten Aspekt, dass im Briefroman Das Licht brennt ein Loch in den Tag durch den Hinweis „(Nicht abgeschickt)“ (Licht, S. 86) ein gesamter Brief der inneren Zensur unterworfen wird, der beziehungstechnisch wichtige und mutige Aussagen getroffen hätte, womit das gesamte Konzept der inneren Zensur auf Discours-Level gespiegelt wird. Zum anderen fällt auf, dass in Der Fleck, die Jacke, die Zimmer, der Schmerz nur noch angerissen wird, was die Hauptfigur sich vornimmt - das inferierbare Nichtausführen wird nicht einmal mehr thematisiert (vgl. Fleck, S. 11 f.) und letztlich wird dem Leser überantwortet, diese Leerstelle mit den erwartbaren Werten zu füllen. 
Wohlgemerkt: Es handelt sich um eine gute, sicherlich jedoch nicht um die einzig seligmachende methodische Annäherung an den Komplex des Nicht(s)tuns bzw. der inneren Zensur ( $\Rightarrow$ I.5.2). Als miniaturisiertes Erkenntnisinteresse lässt sich die Fragestellung festhalten: Warum führen die Figuren bestimmte Handlungen nicht aus, obwohl sie (meist) als wünschenswert apostrophiert werden? Hauptsächlich am Roman Bei Regen im Saal soll dieser Frage - wie üblich sehr stark textbasiert - systematisiert nachgegangen werden.

Der 43-jährige Reinhard wird - nicht zuletzt durch seine Initiativ- und Antriebslosigkeit selbstverschuldet - von Sonja verlassen. Auf der Verlagshomepage wirbt der Hanser-Werbetext:

Erfahrungsgemäß ist schon das Leben eine schwierige Sache, aber noch deutlich schwieriger ist die Liebe. Hier hat man nicht nur mit den eigenen Ansprüchen zu tun, sondern auch noch mit denen einer Frau. Und wenn der Mann am liebsten unbeachtet im Abseits lebt - Sonja hat noch andere Wünsche. Und die erfüllt womöglich ein anderer Mann besser.

Die Einschätzung, dass Reinhard „am liebsten unbeachtet im Abseits lebt“, trifft den Nagel auf den Kopf und schlägt sich in dutzenden Momenten innerer Zensur nieder, sodass das folgende Motto, eine Selbstbeobachtung des Protagonisten, exemplarisch stehen kann: „Ich kann mich über mehrere Stunden hin einer Absicht nähern und führe sie dann doch nicht aus." (Regen, S. 110) ${ }^{183}$ Als Muster jedenfalls lässt sich für den Roman schnell ausmachen, dass dasjenige angedachte, imaginierte, erwünschte Verhalten, welches sich die Figur versagt, einen Angelpunkt darstellt, wenn es um das Verlassen-Werden geht. Denn das große ,Aber' steht unausweichlich am Ende stundenlanger Annäherungen der Vorhandlungsphase ( $\Rightarrow$ I.3.1). Argumentativ gestalten sich Situationen dieser Schlaglichtcouleur bei Genazino häufig nach einem bestimmten Schema:

Ich überlegte, ob ich ihr ein Geschenk mitbringen sollte, aber mir fiel nichts ein. Möglicherweise wäre sie verwirrt, wenn ich mit einem Geschenk ankäme. Ich müsste dann erklären, woher der Impuls der Dankbarkeit kam, und diese Erklärung würde mich überfordern. (Regen, S. 39)

Weil Handeln X (in diesem Fall: ,ein Geschenk mitbringen') mit Feedback Y (Verwirrung) quittiert werden könnte, das seitens des Protagonisten in Situation $\mathrm{Z}$ als unbequem, unangenehm o. Ä. empfunden wird oder werden würde (im Beispiel: ,überfordernde Erklärung abgeben'), wird ein alternatives Handeln oder aber die Unterlassung des Handelns vorgezogen. ${ }^{184}$ Eine derartige Annäherung über die Analyse der Argumentationsmuster lässt sich in Anlehnung an einen primär linguistisch eingefärbten Toposbegriff bewerkstelligen, der ,Topos' nicht ,literaturwissenschaftlich“ als „klischeehafte Denk- und Sprachbilder wie z. B. die Vorstellung vom ,Buch der Natur [ [...] oder die Idee des ,goldenen Zeitalters““185 und also als unspezifischen Verwandten des

183 Der gleiche Inhalt findet sich in der Form gespiegelt in folgendem Zitat: „Ich werde ... ich werde ... ach was ... ich werde gar nichts." (Kein Geld, S. 55; $\Rightarrow$ I.2.3)

184 Umwoben wird diese Grundform der inneren Zensur mit Diskussionen mit einer anderen Figur, mit innerem Monolog oder mit Handlungen anderer.

185 Schneider: Einführung in die Roman-Analyse, S. 31. 
Motivs $^{186}$ begreift, sondern mit ihm eine „Schlussregel [...], die von einem Argument auf eine Konklusion gezogen wird“", ${ }^{187}$ meint. ${ }^{188}$ In dieser für die vorliegende Analyse fruchtbringenden Bedeutung meint Topos einen „für den Argumentierenden bereitliegenden und von ihm dann sprachlich hergestellten Sachverhaltszusammenhang, der zur argumentativen Begründung konkreter, zur Diskussion stehender Positionen herangezogen wird."189 Für Genazinos Figurenbasistypus muss eingegrenzt werden, dass es sich bei diesen häufig nur implizit zu findenden Schlussregeln um höchst individuelle handelt: Die Nebenfiguren müssen nicht im Sinne einer im Diskurs vorliegenden Zugänglichkeit die gleichen Topoi kennen wie die Hauptfiguren. Daher sind die (vermeintlichen) Kausal- oder Analogieschlüsse, die die Hauptfiguren vornehmen, um ihre Entscheidungen zu plausibilisieren, nicht zwangsläufig ,logisch', ja nicht einmal intersubjektiv ohne größere Mühe vermittelbar: Der Topos: ,Man bringt besser keine Geschenke mit, weil man sich darüber möglicherweise erklären muss', ist ein für den Basistypus gültiger, keinesfalls aber in seiner um die Ecke gedachten Manier generell naheliegender.

Ergänzendes methodisches Analyserüstzeug für die innere Zensur sind freilich erneut die handlungsauslösenden Faktoren $(\Leftrightarrow$ I.3.1): Warum die Handlungsabsicht sich nicht zur Handlung auswächst, ist ja genau die hier interessierende Schnittstelle. Genaugenommen lässt sich mittels der zugrunde liegenden konkreten Schlussregel der handlungsvermeidende Faktor näher bestimmen: Im vorliegenden Beispiel ist die Überforderung zu veranschlagen. Als auslösender (besser gesagt: verhindernder) Faktor lässt sich im Gros der Fälle die Neigung zur öffentlichen Selbstaufmerksamkeit ( $\Rightarrow$ II.2.4) anführen. Sich selbst aus potenzieller Außenperspektive zu betrachten und die eigenen (potenziellen) Handlungen und deren (potenzielle) Rückmeldung durch andere zu antizipieren suchen, ist ein zweischneidiges Schwert: Zeugt es einerseits von der elaborierten Fähigkeit der Perspektivübernahme ( $\Rightarrow$ II.1.3; s.o.), ist es auf der Kehrseite eine herbe Einschränkung in der Handlungsfreiheit, da nur solche Handlungsweisen die innere Zensur ,unbeschnitten' durchlaufen können, die keine als unangenehm empfundene Konsequenz zeitigen würden. Dieses allgemeine Problem muss selbstverständlich kontextuell immer spezifiziert werden, da jeder Handelnde andere Konsequenzen als unangenehm imaginiert und mithin ein und dieselbe (erwartete) Reaktion des Publikums wünschenswert oder ablehnenswert gilt. Das methodische Besteck für die Analyse muss noch ergänzt werden um protektives Impression Management $(\Leftrightarrow I .3 .3)$, denn bereits im exemplarischen Beispiel schwingt mit, dass sich das Her-

\footnotetext{
186 Vgl. Schneider: Einführung in die Roman-Analyse, S. 31.

187 Nina Kalwa: Das Konzept „Islam“. Eine diskurslinguistische Untersuchung. Berlin/Boston 2013, S. 36.

188 Vgl. generell zur Struktur und Analyse von Argumentationen und Schlussregeln Stephen E. Toulmin: The Uses of Argument. Cambridge 1958.

189 Martin Wengeler: Argumentationsmuster im Bundestag. Ein diachroner Vergleich zweier Debatten zum Thema Asylrecht. In: Armin Burkhardt/Kornelia Pape (Hg.): Sprache des deutschen Parlamentarismus. Studien zu 150 Jahren parlamentarischer Kommunikation. Wiesbaden 2000, S. 221-240, hier, S. 222; zit. n. Kalwa: Das Konzept „Islam“, S. 36.
} 
auswagen aus der eigenen emotionalen ,Komfortzone' durch ,remaining silent' gut umgehen lässt.

Nach den bisherigen Ausführungen könnte man abstrahieren und meinen, Unsicherheit sei die Lösung für das Problem. Jemandem, der nicht auffallen mag, gebricht es womöglich am Rückgrat, eigentlich gewünschtes Handeln mit dem Preis der als unangenehm empfundenen Rückmeldung zu erkaufen. Jemandem, der sich permanent mit fremdem Blick beobachtet, mangelt es an Selbstsicherheit. Jemandem, der eher die leisen Saiten anschlägt, missfallen die Situationen, in denen er die ungeteilte Aufmerksamkeit auf sich zieht. Doch die Figuren bei Genazino sind häufig anders gestrickt. In nahezu histrionischer Manier wagen sie sich ins Scheinwerferlicht der Aufmerksamkeit, wenn sie bspw. Lügengebäude schier unüberblickbaren Ausmaßes errichten, sodass sie sich selbst in die missliche Lage bringen, über Minuten hinweg spontan extemporieren zu müssen - eine selbstgewählte Situation, die sich nicht mit Unsicherheit oder zögerlichem Zaudern in Einklang denken lässt $(\Leftrightarrow I I .3 .4)$. Auch die - wenngleich nicht im Branchenbuch verzeichneten, so doch ausgeübten - Berufsbilder, die den Protagonisten ihr Salär sichern, sind häufig solche, die mit Publikum und der Zurschaustellung sowie Angreifbarmachung eigener Intimitäten in Verbindung zu bringen sind. Was ist es aber dann, das die Figuren es unterlassen lässt, bestimmte Dinge zu tun, obwohl sie vorher als durchaus desiderabel vorgestellt worden sind? Zum einen ist es das Unbehagen Handlungsweisen gegenüber, die mit der als ,normal' etikettierten Üblichkeit brechen. Hier kommen die Gesellschaft und das Regel- und Wertekorsett der Figuren ins Spiel: „Aber weil es nicht möglich war, als einzelner gegen große Regeln anzugehen, verließ auch Abschaffel rasch den inneren Dorfkern und ging in Richtung Flußdamm." (Falsche Jahre, S. 525) Selbstverständlich sind diese Regeln je andere ( $\Rightarrow$ I.5.3): Mal geht es um eine Jugend in den Nachkriegsjahren, mal um eine Person jenseits der 60 in einem Abbild der Gegenwart. Dennoch ist die individuelle resultierende Schlussregel zumindest für den Basistypus generalisierbar: ,Wenn die Gesellschaft Regeln vorgibt, ist es ratsamer, diese nicht anzuzweifeln؛ Dazu ein Beispiel aus Bei Regen im Saal: „Ich überlegte kurz, ob ich mich trauen würde, zur Bedienung zu sagen: Ich will nichts, ich gehe gleich wieder. Aber dann sagte ich völlig unbehindert: Ich nehme ein Lachsfilet mit Spinat und Röstkartoffeln." (Regen, S. 41) Um keinen Preis möchte Reinhard sich der selbst entworfenen Mutprobe stellen; es wäre einfach zu ,mutig', mit einer solchen Aussage, die den Topos: ,Wenn man in ein Restaurant geht, so bestellt man etwas' sowie die Grice'schen Konversationsmaximen ${ }^{190}$ generell in Frage stellte, in den Blick zu geraten. Dass Genazinos Figuren die Verurteilung der Mitfiguren als Sonderling - sei es zu Recht oder zu Unrecht - scheuen, ist bereits bekannt. Als Topos nähme sich die argumentative Struktur etwa wie folgt aus: ,Vermeide Handlungen, die anderen Anlass dazu geben könnten, dich als merkwürdig wahrzunehmen':

190 Vgl. Herbert P. Grice: Logic and Conversation. In: Peter Cole/Jerry L. Morgan (Hg.): Syntax and Semantics. Vol. 3: Speech Acts. New York/San Francisco/London 1975, S. 41-58. 
Es rühren mich ein paar Grasbüschel, die zwischen den Pflastersteinen herauswachsen. Sie sind niedrig und kraftvoll und sehen doch aus wie Überlebende, die niemand kennt. Wenn ich Mut hätte, würde ich mich bücken und die wahrscheinlich feuchten Halme berühren. Wenn ich mehr Mut hätte, würde ich einen Grasbüschel in der Hand nach Hause tragen und während des ganzen Heimwegs die absolut himmlische Versunkenheit meiner Finger im Gras spüren. Aber ich bin feige und fürchte das Urteil der Leute: Schau, da trägt eine Verrückte einen Grasbüschel durch die Gegend. (Obdachlosigkeit, S. 82)

Nach einer Klimax, die das Begehren, die Grasbüschel mitzunehmen, als höchst wünschenswert markiert und steigert, folgt erneut das ,Aber'. Neben diesem weiterhin als Über-Ich-gedämpft beschreibbaren Topoi-Feld lassen sich allgemeine Vermeidungssituationen anführen. Immer dann, wenn es dem Protagonisten mit sich selbst zu viel wird, vermeidet er Konflikte und Entscheidungen, deren er sich in anderer Gemütslage ganz offensichtlich gewachsen zeigt: „Ich überlegte, ob ich zu Sonja oder in meine Wohnung zurückkehren sollte. Aus Ratlosigkeit betrachtete ich zwei Kinder, die sich hinter großen Mülltonnen versteckten." (Regen, S. 63) Beide Handlungsalternativen werden nicht in die Tat umgesetzt. Die Figur entzieht sich schlicht der Entscheidung durch eine temporäre ,Vogel-Strauß-Taktik‘ und den Topos: ,Begegne Ratlosigkeit mit Zerstreuung. Prokrastination (s.o.) lässt sich als dritte Variante ins Auge fassen, bei der der Handlungsaufschub selbst als Motivation betrachtet werden könnte: „Jede Beschäftigung, die den Arbeitsbeginn hinauszögerte, nahm er mit stiller Begeisterung hin." (Fremde Kämpfe, S. 132) Reinhard hingegen weiß durchaus um die ,krankhaften` Züge dieser Scheinlösungen in Form des Topos: ,Nutze Umwege, um nicht an das unliebsame Ziel zu gelangen': „Ich litt allenfalls an der innigen Erkrankung des beinahe endlosen Vor-sich-Hinschauens. Immerzu blieb ich irgendwo stehen oder sitzen und betrachtete Vorgänge, die mich nicht weiterbrachten." (Regen, S.60) Weiterbringen würden ihn verschiedene Entscheidungen und (unliebsame) Handlungen, aber bekanntlich war ,heute ja gestern schon morgen' und der Topos ein logischer Kurzschluss.

Schließlich ist es taktisches Kalkül, was als innerfiktionaler Grund für die innere Zensur der Figuren Genazinos vorgestellt wird. Um übergeordnete Ziele zu erreichen, werden Handlungen unterbunden, die diesen abträglich sein könnten. Kluges Taktieren nach dem Topos: ,Wenn langfristige (größere) Belohnungen durch die kurzfristige Unterdrückung bestimmter Handlungen die zu (kleineren) Belohnungen führen würden - erreicht werden können, ist es ratsam, sich für die langfristige - größere - Belohnung zu entscheiden', könnte man das nennen: „Ich war oft versucht, sie mit meinem Fall vertraut zu machen, das heißt, mit dem Bildungsschicksal eines Mannes, der trotz eines langen Studiums lediglich in der Rezeption eines Hotels gelandet war. Aber dann hielt ich doch den Mund und überließ sie ihrer Begeisterung." (Regen, S. 32 f.) Mit gewissen Vorzügen, die sich als ,social outcome' hinsichtlich der impression motivation $(\Rightarrow I .3 .3)$ angeben lassen und im konkreten Fall in Form von Oralsex ausdrücken. Ähnlich kalkuliert - es geht an dieser Stelle nicht darum, das vorige oder die kommenden Beispiele moralisch werten zu wollen, sondern um die Messung des Erfolgs am Plan - handeln die Figuren in puncto ,Selbstbildschönen` mit dem protektiven Mittel der inneren Zensur. Um ,self-esteem maintenance‘ zu 
erreichen, imaginieren sich die Figuren regelmäßig in heldenhafte Handlungskontexte (vgl. Glück, S. 123 f.), die realiter nie in Handlung überführt werden, nichtsdestotrotz momentweise das Selbstbild, das in den jeweiligen Situationen von kognitiver Dissonanz bedroht ist, ad hoc wieder instand setzen: „Diesen Satz, überlegte er, würde er gern am Montag, wenn er wieder im Büro war, allen Kollegen sagen, die hinter ihm saßen." (Falsche Jahre, S. 563) Besagter Satz „Wenn Sie nicht hinter mir sitzen würden, ginge es mir auch besser (Falsche Jahre, S. 563)“ -, den Abschaffel aus einer Tageszeitung auf seine Situation in einem Großraumbüro ummünzt, wird nie gesprochen werden, das ist unmittelbar klar. Aber er versetzt ihn in eine überlegene Stimmung, die den letzten hier skizzierten Topos als Erklärung für die Funktionalität der inneren Zensur zur Folge hat: ,Sofern die reine Imagination Befriedigung verschafft, die tatsächliche Äußerung zwar möglicherweise für den Moment über diese hinausginge, letztlich aber mit Ungemach einhergeht, verzichte darauf'. Mit dem Übergang zum dritten Schlaglicht weicht der kultivierte Verzicht aber der eindruckssteuernden Üppigkeit.

In Bezug zum hier vertretenen Schichtenmodell der Figuren Genazinos $(\Rightarrow I .2 .5)$ lässt sich festhalten, dass der Figurenkern zunächst hinsichtlich dieses Schlaglichts durch protektives IM grundiert ist. Auch der Beobachtungs- und Reflexionszwang ( $\Leftrightarrow$ II.2.2) mit der Neigung dazu, andere durchschauen zu wollen - etwa aus unbeobachteter oder unbeobachtbarer Perspektive heraus -, selbst aber undurchschaubar sein zu wollen, kennzeichnet fast ausnahmslos die Figuren. Einzige Ausnahme bleibt im Individuellen die unter sehr spezifischen situativen Rahmenbedingungen mögliche Aussöhnung mit dem Durchschautwerden ( $\Leftrightarrow$ II.2.4).

Ferner handelt es sich bei allen Figuren um Konstruktivisten mit Augenfixierung des gedehnten Blicks ( $\Rightarrow$ II.2.3), die neben diesen Blicken ,nach außen“ jedoch auch über den Weg der öffentlichen Selbstaufmerksamkeit ( $\Rightarrow$ II.2.4) die Blicke anderer auf ihr eigenes Verhalten mitdenken mit zwei Konsequenzen für den Gürtel des Familienähnlichen: Nicht-auffallen- und Anerkanntwerden-Wollen. Familienähnlich ist zudem die Diskrepanz zwischen Selbst- und Idealbild, die sich in Kognitiver Dissonanz mit den dazugehörigen Bearbeitungsmechanismen niederschlägt $(\Leftrightarrow$ II.2.1). Auch die teils problematische Einschätzung der Fremdbilder ( $\Rightarrow$ II.2.1) sowie von Zeichen und Welt per se $(\Rightarrow$ II.2.3) in Form von Mutmaßungen, Überinterpretationen etc. $(\Rightarrow$ II.2.3) umspannt zwar viele Romanfiguren, aber nicht alle. Analog dazu weisen zwar auch alle Figuren Besänftigungsstrategien sowie Ablenkungsmöglichkeiten $(\Leftrightarrow I$ I.2.2) gegen den Beobachtungsund Reflexionszwang auf, diese sind aber entweder ,nur' familienähnlich ausgeprägt (Meer) oder gar individuell (Sport). Auch die Strategien der Flucht, Verborgenheit etc. $(\Leftrightarrow I I .2 .5)$ sind in Graden individuell, wobei die Gemeinsamkeit der Selbstschutz(barrieren) durchaus allen Protagonisten eignet. Auch Voyeurismus und Stalking ( $\Rightarrow$ II.2.2) sind häufig wiederkehrende Elemente, die aber nicht in jedem Roman hochgeregelt werden. Das Sich-selbst-Versagen von als desidera- 
bel geschilderten Handlungen bzw. Kommunikationen in Form der inneren Zensur ( $\Rightarrow$ II.2.6) in negativer wie positiver Gestalt ist einerseits ubiquitär, andererseits ist die Etablierung individueller Schlussregeln, die mitunter den Bereich des Romanspezifisch-Individuellen vorwegnehmen, zu divers, um dieses Verhaltensmuster in den harten Kern zu verorten.

Idiosynkratische Ausnahmen finden sich weiterhin etwa in Form von zeitlich stabilem Tatendrang, der einer Poetik des Nicht(s)tuns entgegensteht ( $\Rightarrow$ II.2.6), oder im späteren Umsetzen lange gehegter Pläne in die Tat $(\Rightarrow$ II.2.1 u. $\Rightarrow$ II.2.6). 


\section{Strategien der Interessantheit bzw. Auffälligkeit}

„Wo steht eigentlich geschrieben, daß man andere Menschen unterhalten können muß?" (Heimweh, S. 95)

Nicht nur thematisch unterscheiden sich die Strategien der Interessantheit von denen des zweiten Schlaglichts $(\Rightarrow I I .2)$, sondern auch methodisch: Sind es dort unterlassende, vermeidende und tendenziell um Unauffälligkeit bemühte Handlungsroutinen und Darstellungsstrategien, die häufig aus der ,Trickkiste' protektiven IMs schöpfen, so lassen sich hier diejenigen sozialen Praxen ansiedeln, die erstens just die Bühne, die Kommunikationssituation, die Zur-Schau-Stellung suchen, dabei zweitens zugleich häufig auf assertive Techniken und Taktiken zurückgreifen. ${ }^{1}$

Dabei zoomt das Kapitel vom Allgemeinen auf das Spezielle ( $\Rightarrow$ II.3.1), indem die oberste Ebene zunächst das Konzept der Interessantheit fasst, es kulturgeschichtlich und psychologisch beschreibt und die Brücke zum Theoriesegment schlägt sowie die methodischen ,Plugins‘ vorstellt, bevor die zweite Ebene auf die Genazinofiguren abhebt, den Genazino'schen Basistypus mit einbezieht und an die vorigen Schlaglichtkapitel anknüpft. Die dritte Ebene ist dreigeteilt und typologisiert, in welcher Erscheinungsform Strategien der Interessantheit auftreten können: Handelt es sich um nur im Figurenbewusstsein verhandelte, imaginierte oder aber um in der Narration nach außen sicht- und hörbare Handlungen? Sind diese der analogen oder digitalen Kommunikation zuzuschlagen? Und: In welcher Konstellation manifestiert sich das Verhalten bezogen auf Vier-Augen- vs. Gruppengespräche bzw. in gleich- oder verschiedengeschlechtlichen Dyaden?

Die vierte Ebene $(\Leftrightarrow I I .3 .2)$ widmet sich Auffälligkeiten im erzähltheoretischen Milieu und spiegelt gleichsam die Interessantheit der Histoire-Ebene auf der Discours-Oberfläche. Und erst auf der fünften Ebene sind diejenigen ,Unterunterkapitel' anzusiedeln, welche konkrete Verhaltensmuster beschreiben. Es lassen sich drei Bereiche unterscheiden: das eher zögerliche, nur inszeniert spontane Verhalten - bspw. sammeln die Figuren gerne Stichworte für künftige Gespräche, die dann Impulse geben sollen $(\Leftrightarrow$ II.3.3) -; die tatsächlich originellen, extemporierten Auftritte $(\Leftrightarrow$ II.3.4) und die über das Ziel hinausschießenden Praktiken wie Diebstähle, Mythomanie etc. $(\Rightarrow$ II.3.5 u. $\Rightarrow$ II.1.2).

\subsection{Interessante Präliminarien}

Überraschenderweise ist das Konzept der Interessantheit lexikalisch nicht nur unterbelichtet, sondern scheint gar der konkreten Definition nicht bedürftig zu sein. Die schnelle Recherche legt einen Zirkelschluss nahe: Interessantheit sei gleichbedeutend mit ,Interesse erweckend'; Inte-

$1 \quad$ Dass dieses Schlaglicht das kürzeste ist, verdeutlicht die Unüblichkeit des Verhaltens - jedenfalls bemessen an der, Standardverteilung' des Basistypus. 
resse liege dann vor, wenn jemand seine Aufmerksamkeit auf etwas richte bzw. (geistige) Anteilnahme zeige - was er üblicherweise aufgrund der interessanten Beschaffenheit des Gegenstandes, Sachverhaltes oder Menschen zu tun pflege.

Scheinbar ist die Einfassung des Konzeptes obsolet, weil jeder das Gleiche darunter versteht, was selbstredend unsinnig ist, zeigt doch bereits ein kurzer Blick in das (mentale) Lexikon die Begriffsextension: Wenn sich jemand exemplarisch ,interessant macht', dann bemüht sich jemand entweder, einen nicht sofort durchschaubaren - „Tja, antwortete Eckhard gespielt vieldeutig, da kannte ich euch alle noch gar nicht" (Ausschweifung, S. 24) - oder just einen genauestens durchschaubaren, aber in der Konstellation interessanten Eindruck zu machen - „Wer sich nicht allzuoft blicken ließ, hatte damals die Möglichkeit, überschätzt zu werden“ (Fremde Kämp$f e$, S. 17) -- widersprüchlicher lässt sich ein Unterkonzept nicht denken. Mittlerweile ist übrigens die Begriffsverwendung auf den Kopf gestellt worden: Ist "Interesse' nach DUDEN in der ersten Begriffsbedeutung mit ,geistiger Anteilnahme' angegeben, hat das im Deutschen Wörterbuch der Grimms noch ganz anders ausgesehen: erst die fünfte und dezidiert die sechste Bedeutung zielt auf die heute erste: „6) endlich der reiz einer sache, der unsern antheil hervorruft: ists denn ein brief von interesse? Fr. Müller 3, 395; wie sie jedem alter seine reize abborgte, freimüthige unschuld von der kindheit, interesse von der jugend. Leisewitz Jul. v. Tarent 1, 1 s. 13.“2 Wie nun ist es dieser Bedeutungsverschiebung ungeachtet zu erklären, dass man einer Sache oder einer Person sein Interesse schenkt? Sicherlich spielen gewisse Vorlieben und Prädispositionen - im Sinne der vorderen Begriffsbedeutungen bei den Grimms - dafür eine Rolle, was die selektive Aufmerksamkeit erregt: Blickt der Eine interessiert auf stillende Frauen, so weckt evtl. die finanzielle Freigebigkeit das Interesse einer Anderen $(\Rightarrow$ II.5.3). In jedem Fall sind die Menschen als solche genauso wie Genazinos Romanfiguren, die durch den Grobfilter der Informationsflut diffundieren möchten, durchaus in der Lage, vermittels IM mit Kalkül die eigene Interessantheit aktiv mitzubestimmen. So äußert Axel Degen, die autodiegetische Figur aus Laslinstraße, in einer Selbstaussage: „[I]ch sprach von falschen Idealen, referierte Illustriertenpädagogik, ich gab Kreuzworträtselwissen zum besten [...]: Frau Bleidecker war von mir begeistert" (Laslinstraße, S. 81). Kalkuliert die erwarteten Erwartungen erfüllend, für sich selbst - durch assertives IM - mittelbar günstige Verhältnisse schaffend und dennoch auf Distanz zu sich selbst und seinem Idealbild gehend, reflektiert Degen Ursache und Wirkung von intentionaler Eindruckssteuerung. Auch der Protagonist aus Genazinos Außer uns spricht niemand über uns ist Virtuose auf der Klaviatur der gemanagten Eindrücke, erhöht allerdings die Komplexität der antizipierten Wirkung, indem er die Situationsadäquanz seinem Gesprächspartner gegenüber prinzipiell mit reflektiert:

2 [Interesse]. In: Deutsches Wörterbuch von Jacob Grimm und Wilhelm Grimm. Online: <http://woerterbuchnetz.de/DWB/?sigle=DWB\&mode=Vernetzung\&lemid=GI00627\#XGI00627>. 
Ich schätze komplizierte und schlichte Menschen gleichzeitig, sagte ich; die Schlichten denken, auch ich sei schlicht, tatsächlich bin ich oft, wenn ich mit Schlichten zusammen bin, von erschütternder Einfalt. Bin ich dagegen bei komplizierten Menschen, erschreckt mich schon der verschachtelte Bau meiner Sätze, so dass ich mich wieder nach mehr Einfalt sehne. Leider denken die Komplizierten sofort, ich sei einer von ihnen. (Außer uns, S. 78 f.)

Nicht nur die jeweilige Berücksichtigung des rhetorischen ,Aptums' stellt die Figur unter Beweis, sondern durch die Offenlegung der Verhaltensstrategie begünstigt sie die aktuellen Zuweisungen ,clever', ,sozial intelligent' und in der Folge ,interessant', was unter self-promotion als assertive, kurzfristige Technik fällt $(\Rightarrow I .3 .3)$.

(Evolutionärpsychologische) Begründungen dafür, interessant sein zu wollen, erklären sich letztlich von selbst, wenn man als evolutive Adaptationen anerkennt, was einen reproduktiven Vorteil der Spezies in der Entwicklungsgeschichte versprach: Sobald jemand von mehr Personen ,gesehen' wird (Interesse zuwenden), sind darunter auch potenziell mehr Personen, die ihn als Partner (für Handel, Bündnisse, aber auch Sex etc.) in Betracht ziehen und schließlich auch wählen können. ${ }^{3}$ Nun gibt es natürlich Dispositionen, die ein solches aufmerksamkeitsheischendes Verhalten begünstigen und solche, die es eher hemmen. Mögliche Trigger, um Interessantheit attribuieren zu können, sind: Alleinstellungsmerkmale, Besonderheiten oder gar Andersartigkeit, herausragende Eigenschaften, Auffälligkeit uvw. Jedes dieser Metamerkmale kann sich im Aussehen, in der Sprache, im Humor, im Habitus usf. manifestieren. Für diese unabgeschlossene Liste ist es der Blick über den disziplinären Tellerrand, der Aussicht bietet: Werbekontexte, Wirtschaftsbelange etc. liefern konkretere Schlagwortlisten (,USP` etc.) als der Blick in die geistes- und kulturwissenschaftliche Bibliothek. Bekanntlich lassen sich nur in der Abhebung von den Wegen der anderen Spuren hinterlassen. Obgleich es unterschiedliche Codes respektive Kanäle zu bespielen gibt, lassen sich diese Zustandszuweisungen üblicherweise durch assertives IM erreichen: die Vorzüge der eigenen Person zu betonen, sich über die Zugehörigkeit zu ,InGroups' aufwerten und dutzende andere Arten, Eigenwerbung zu betreiben, zeitigen in der Regel auch einen Aufstieg auf der Interessantheitsskala. Doch auch ein unangepasstes Verhalten popularisiert: der Vamp, der Bad Boy - kann kalkuliert interessant sein; man denke darüber hinaus an subkulturelle Abweichungen von der Norm usw.

Zur Analyse derartigen Verhaltens lassen sich neben der assertiven IM-Grundausrichtung methodologische Hilfswissenschaften aus der linguistischen Gesprächsanalyse anführen: Gesprächspläne, also zielgerichtete Sprachmuster, um bestimmte kommunikative Zwecke zu erreichen - etwa im Rahmen des Imponiergesprächs ${ }^{4}$-, können helfen, dieses Schlaglicht methodisch zu fundieren. Auch die genaue Untersuchung der „zehn kommunikativ-pragmatisch bedeutsamen Kategorien“ des Gesprächs liefert ein analytisches Instrumentarium, das die Untersu-

\footnotetext{
3 Die Auswüchse der Supertalent- und Modelshows, Influencer, Datingportale, letztlich die ,Zucht histrionischer Persönlichkeiten etc. sollen hier nicht eruiert werden.

$4 \quad$ Vgl. Klaus R. Wagner: Pragmatik der deutschen Sprache. Frankfurt am Main 2001, S. 413-417.
} 
chungsgegenstände gut fassbar werden lässt. ${ }^{5}$ Methodisch erfolgversprechend scheint weiterhin insbesondere das sogenannte ,Facework' - erneut ein Forschungsverdienst Goffmans, das sich insbesondere die linguistische Pragmatik anverwandelt hat, - zu sein. ${ }^{6}$ Vereinfachend gesprochen handelt es sich dabei um aus der Höflichkeitsforschung abgeleitete konträre, widerstreitende menschliche Kommunikationsbedürfnisse, die hier im Allgemeinen unter dem Label ,Individualität vs. Gesellschaft' $(\Leftrightarrow$ II.1.1) verhandelt worden sind, in der linguistischen und auf sprachliche Manifestationen im Speziellen ausgerichteten Pragmatikforschung mit den Termini technici ,positives‘ bzw. ,negatives Gesicht' bezeichnet werden:

Jeder von uns hat ein Gesicht. In diesem Zusammenhang ist mit dem Begriff aber das Image, die eigene öffentliche Identität, gemeint. Das Gesicht wird vom Gesprächspartner gegeben. Gesicht oder Image ist also das Bild, von dem man glaubt, dass der andere von einem hat. Man kann es zwar selbst definieren, aber solange es nicht als solches erkannt oder akzeptiert wird, hat man es auch nicht. Von daher ist es für jeden vom großen Interesse, sein Gesicht zu wahren. Das gegenseitige Wahren des Gesichts wird auch face-work genannt. Unter Höflichkeit versteh[t] man die linguistischen Mittel, mit denen face-work realisiert wird. In der Theorie wird davon ausgegangen, dass jeder ein sogenanntes positives und negatives Gesicht hat. Diese Begriffe haben allerdings keine Wertung. Es soll lediglich angedeutet werden, dass es sich um zwei gegensätzliche Konzepte handelt. Mit dem positive[n] Gesicht ist das Bedürfnis nach einem Gemeinschaftsgefühl gemeint. Man möchte von anderen anerkannt und akzeptiert werden. Das negative Gesicht bezeichnet den Wunsch nach Individualität und Handlungsfreiheit. In jeder Interaktion wird das Gesicht neu definiert. Die Gesprächspartner wollen ihr eigenes positives und negatives Gesicht wahren, müssen aber auch Sprechakte ausführen, die das positive oder negative Gesicht des anderen bedrohen könnten. Man lehnt beispielsweise Angebote ab, bittet um einen Gefallen oder entschuldigt sich für etwas. Höflichkeit hilft dann, diesen Konflikt zu lösen.7

Es wäre also erwartbar, dass Genazinos Figurenbasistypus für die im Folgenden zu diskutierenden Primärtextbeispiele entgegen seiner grundlegenden Figurenkonzeption vermehrt an der Etablierung des positiven Gesichts interessiert ist.

\section{BEZUG ZUM BASISTYPUS UND VERKNÜPFUNG MIT WEITEREN SCHLAGLICHTERN}

Genazinos Figuren lassen sich auf zwei Weisen an diese Vorüberlegungen knüpfen. Erstens: Im Einklang mit dem gegenwärtigen Gebrauch der Wendung ,sich für andere interessant machen', die bei einschlägigen Suchmaschinen nahezu ausschließlich sexuell konnotierte Treffer generiert, ist Interessantheit auch für Genazinos Basistypus vorwiegend mit inter- und intrasexuellem Wettbewerb und also der Schnittfläche zum fünften Schlaglicht $\left(\Leftrightarrow\right.$ II.5.2 u. $\Rightarrow$ II.5.4) ${ }^{8}$ anzutreffen:

Um Judith aufzuheitern, sage ich: Es ist die Dialektik des Deliriums, in der wir leben. Endlich lacht Judith ein bißchen und sagt: Von dieser Dialektik habe ich noch nie etwas gehört. Die Dialektik geht

\footnotetext{
$5 \quad$ Helmut Henne/Helmut Rehbock: Einführung in die Gesprächsanalyse. 4., durchges. u. bibl. erg. Aufl. Berlin/New York 2001, S. 27.

$6 \quad$ Vgl. Brinker/Sager: Linguistische Gesprächsanalyse, S. $88 \mathrm{ff}$.

7 [Höflichkeit]. In: TU Berlin - Institut für Sprache und Kommunikation. Online: <http://fak1alt.kgw.tu-berlin.de/call/linguistiktutorien/pragmatik/pragmatik\%20k7.html>.

8 Der Löwenanteil passender Beispiele findet sich dort.
} 
so: kaum einer tut etwas, kaum einer erreicht etwas, kaum einer verdient etwas, und trotzdem geht alles immerzu weiter. (Liebesblödigkeit, S. 50)

Es handelt sich um einen Imponier-Plan, der sich als „Imponieren-mit-exotischem-Sprachgebrauch“ klassifizieren lässt: „Der Sprecher beabsichtigt, durch gewählten/seltenen/exotischen Sprachgebrauch dem Hörer zu imponieren. Dieses Imponier-Muster ist in der Regel ein taktisches Mittel in dem strategischen Konzept der Prestigemehrung. ${ }^{{ }^{9}}$ Der Ich-Erzähler stellt späterhin im Roman auch dezidierte Überlegungen dazu an, wie man andere (hier: das andere Geschlecht) wirkungsvoll von der eigenen Interessantheit überzeugen kann:

Es ist seltsam, daß man sich erst mühsam ein paar nicht ganz saubere Tricks abgewöhnt hat (intellektuelle Angeberei), die man sich dann einer Frau zuliebe ebenso mühsam wieder angewöhnt. Natürlich habe ich einige Themen auf Lager. [...] Sandra hat nicht die geringste Möglichkeit, den Wahrheitsgehalt meines schnell sprudelnden Bildungswissens zu überprüfen. Sie möchte nur sicher sein (und es selber hören können), daß der Mann ihrer Wahl so phantastisch reden kann. Ich baue in meine Vorträge manchmal ein bißchen Blödsinn ein, den mir Sandra ahnungslos abnimmt, weswegen ich sie im stillen ein bißchen verspotte. Wer zuviel verlangt, muß betrogen werden, sage ich mir dann. (Liebesblödigkeit, S. 104; vgl. Heimweh, S. 96 f.; vgl. Regen, S. 90)

Allen andiskutierten Beispielen ist einerseits die assertive Technik der attractiveness gemeinsam ( $\Rightarrow I .3 .3),{ }^{10}$ andererseits der auf die Evokation des positiven Gesichts verwendete Kommunikationsaufwand - auch wenn mitunter asymmetrische, also von einem Machtungleichgewicht bestimmte Kommunikation genderproblematisch mitschwingt $\left(\Leftrightarrow\right.$ II.5.3). ${ }^{11}$

Genazinos Figuren sind ja nun aber hinsichtlich des Basistypus, also bezogen auf die Familienähnlichkeiten - zumal vor der Folie der bislang untersuchten Figurenfacetten -, anscheinend gerade nicht prädestiniert dafür, das zu verkörpern, was der klischierten Vorstellung dessen entspricht, was ,die Frau' an ,dem Mann' schätze. Dazu eine absichtlich subjektive ,Wunschliste‘ aus dem Diskussionsforum eines Datingportals: „+ souverän, selbstbewusst, über den Dingen stehend, die Situation im Griff habend + authentisch, keine Rolle spielend, ungekünstelt + natürlich, unkompliziert, umgänglich + humorvoll, eloquent, intelligent, gebildet + maskulin und ganz leicht dominant". ${ }^{12}$ Weder bezogen auf sexuelle Attraktion noch auf globaler Ebene lesen sich die Desiderate wie eine Umschreibung der Genazino-Figuren.

Durch die dispositiv stark ausgeprägte öffentliche Selbstaufmerksamkeit ( $\Rightarrow$ II.2.4), die den zweiten wichtigen Bezugspunkt bildet, der Genazinos Figuren in ihrer Interessantheit an andere Analyseteile dieser Untersuchung knüpft, entsteht vielmehr ein Zwiespalt zwischen zwei Polen: Wie es die öffentliche Selbstaufmerksamkeit und damit kombiniert die Dominanz des positiven Ge-

9 Wagner: Pragmatik der deutschen Sprache, S. $414 \mathrm{f}$.

10 Vgl. Mummendey: Selbstdarstellung, S. 53; vgl. Brunner: Portfolio-Werbung als Technik des Impression Management, S. $45 \mathrm{f}$.

11 Vgl. Watzlawick/Beavin/Jackson: Menschliche Kommunikation, S. 68 ff. u. S. 103 ff.; vgl. Henne/Rehbock: Einführung in die Gesprächsanalyse, S. 29.

12 [Forum ElitePartner.de]. Online: <https://www.elitepartner.de/forum/frage/wie-wird-man-n-beifrauen-interessant.15030/>. 
sichtes zunächst zu diktieren scheint, besteht bei Genazinos Figuren ein prinzipieller Argwohn gegen das Im-Mittelpunkt-Stehen ( $\Rightarrow$ II.1.2):

Ich wollte auch nicht, daß mich die anderen Menschen wegen der Neuheit meiner Kleidung extra anschauten. Genau dies geschah immer wieder. Einmal hatte ich einen Matrosenanzug [...] schon zurückgewiesen, da wurde Vater ärgerlich und befahl dem Verkäufer, er solle Lederhosen und Trachtenjacken herbeischaffen. [...] Vater sagte, ich solle die neuen Sachen auf dem Heimweg gleich anbehalten. Ich sah im Gesicht des Vaters die Zufriedenheit. Das war ein seltener Anblick, den ich mich nicht zu stören traute. [...] Schon auf dem Heimweg entdeckte ich, wie andere Menschen, Erwachsene und Kinder, heimlich ein bißchen über mich lachten, was Vater entweder nicht sah oder ignorierte. [...] Jetzt, in der Erinnerung, kam es mir so vor, als sei die Kindheit überhaupt der Ursprung aller Lächerlichkeit. (Wohnung, S. 108) ${ }^{13}$

Neben der legitimen Füllung der Kategorie ,Causal History‘ $(\Leftrightarrow I .3 .1)$, der Ursprung für den Unsichtbarkeitswunsch seit der Kindheit liege in solchen Ereignissen begründet, ${ }^{14}$ öffnet sich hier auch der Horizont, über dem die Kleidungskaufphobie dräut ( $\Rightarrow$ II.1.5). Dennoch ist im Kontrast zu dieser Herleitung der Wunsch nach Anerkennung prinzipiell durchaus vorhanden ( $\Rightarrow$ II.2.4): „Genau dieses Angeblicktwerden hatte ihm gefehlt, damit er sich selbst wieder ein wenig großartiger vorkam“, gesteht Eckhard Fuchs, der Innendienstleiter einer Reifengroßhandlung (Ausschweifung, S. 74), der permanent im unausgesprochenen, aber empfindbaren und empfindlichen Wettstreit mit seinem Kollegen steht (vgl. Ausschweifung, S. 127). Auch der „Kindertraum“ W.s, in welchem er hatte „Musiker oder Sänger werden wollen“, verhandelt das Spannungsfeld von Gesellschaft vs. Individuum ( $\Rightarrow$ II.1.1) - und mithin dasjenige von positivem und negativem Gesicht -: „Ich wollte vor ein Publikum treten und glücklich sein, indem ich fehlerlos Musik machte oder sang. Auch das Publikum sollte durch meine Makellosigkeit glücklich sein." (Fleck, S. 133) Nun ließe sich natürlich erneut einwenden, dass dort, wo die Willkür ,Küchenchef' ist, nach Gusto Stellen aus dem Korpus geschnitten würden, die natürlicherweise im Sinne einer der Maximen der Studie - dass es sich nämlich nicht um das ,Modell Einheitsbrei' handele ( $\Rightarrow$ I.2.5) entsprechend in anderen Romanen andere sein können oder gar müssen $(\Leftrightarrow I .5 .1)$. Doch auch die just erwähnte Figur mit Matrosenanzug aus Eine Frau, eine Wohnung, ein Roman legt im Erzählverlauf - dennoch noch immer im späteren Erzählen und in analeptischer Form - den Argwohn gegen das Im-Mittelpunkt-Stehen ab und exponiert sich - wenngleich über Artefakte und weniger über das, was man im omnipräsenten Selbstvermarktungsbusiness zuerst vermuten könnte (Körper, face to face), - selbst:

Zwei Zeitschriften, eine Tierschutz-Illustrierte und das Mitteilungsblatt des Apotheker-Verbandes, hatten kurze Texte von mir gedruckt und mir Belegexemplare geschickt. Ich setzte mich in die Küche, las meine Beiträge und freute mich. [...] Ich verstaute die beiden Belegexemplare und öffnete

13 Die Szene wird in Genazinos Roman Kein Geld, keine Uhr, keine Mütze variiert: „Dabei nahm er mich alle zwei oder drei Jahre an der Hand und kaufte mir eine Lederhose und einen Trachtenjanker. In dieser Kleidung schämte ich mich etwa zwei bis drei Wochen, dann hatte ich mich an den Spott der anderen Schulkinder gewöhnt." (Kein Geld, S. 136)

14 Ein weiterer möglicher Erklärungsansatz in der Causal History ließe sich etwa darin entdecken, dass die Vaterfigur selbst gelegentlich ein schlechtes Vorbild diesbezüglich gewesen ist (vgl. Falsche Jahre, S. 492). 
die anderen Briefumschläge. Es handelte sich um Rücksendungen von Manuskripten, die nicht angenommen worden waren. Ich las auch sie noch einmal durch und fragte mich, warum sie abgelehnt worden waren. Die noch Ansehnlichen unter den Manuskripten steckte ich in neue Briefumschläge und adressierte sie an die Redaktionen anderer Zeitschriften. [...] Ich ging zu dem Schalter ganz links und kaufte erneut zehn Sondermarken für den bestimmt nicht nachlassenden Versand meiner Manuskripte. (Wohnung, S. 9-11)

Nahezu ehrgeizig darum bemüht zu sein, Bestätigung zu akquirieren und zwar über Mechanismen, die dadurch gekennzeichnet sind, sich selbst interessant zu machen und sich also aus der Menge des Durchschnitts (über andere) zu erheben (self-enhancement; $\Rightarrow$ I.3.3), kennzeichnen diese Passage und den sie umgebenden Kontext. Dem negativen Gesicht des jeweils Ablehnenden setzt Weigand erneut sein positives, Anerkennung wünschendes entgegen - wenngleich anderen gegenüber; er schickt ja keine überarbeiteten Fassungen an die gleichen Magazine -, was für eine dem Basistypus unübliche psychische Widerstandsfähigkeit (Resilienz) spricht.

Allerdings fehlt dem Genazinobasistypus insbesondere in face-to-face-Kommunikation mitunter das ,Vokabular‘ assertiven IMs für „narrative Gespräche“,

die keine direkten außersprachlichen Handlungsimplikationen haben; in denen vielmehr ein Gespräch geführt wird, um überhaupt in einen sprachlichen Kontakt zu kommen, um etwas und damit sich mitzuteilen, um Zeit zu überbrücken. Dazu zählt das - in der Pragmatik inzwischen berühmte ,Gespräch über den Gartenzaun' ebenso wie ein den Kontakt ermöglichendes Partygespräch. ${ }^{15}$

Genazinos Figuren würden gerne ,Smalltalk‘ können: „Vielleicht hätte ich sprechen müssen wie Petra, aber das ging nicht, für die Dauer war ich untauglich, ich konnte nicht dauernd über nichts Worte machen, dauernd sprechen wie Frauen sprechen, Gespräche ohne Ziel." (Laslinstraße, S. 73 f.) Allein findet sich diese Fähigkeit nicht immer in Reichweite, womit die bereits weiter oben verhandelte Trias von tatsächlich existierendem Selbstbild, dem platzierten Fremdbild und Wunschdenken bzw. Idealbild aufgerufen wird ( $\Rightarrow$ II.2.1). Häufig kostet es die Haupthandelnden ernstzunehmende Überwindung, die Diskrepanzen zwischen diesen Instanzen zu akzeptieren, bzw. sie müssen die Sicht auf sich selbst strapazieren. In jedem Fall sind sie in denjenigen Momenten, in denen sie Strategien der Interessantheit respektive Auffälligkeit an den Tag legen sei es aus welchen Beweggründen oder aufgrund welcher handlungsauslösender Faktoren auch immer -, teils ungläubig angesichts dessen, was sich in ihnen verbirgt, ja es lässt sich mitunter nachgerade von einer ,Angst vor der eigenen Courage‘ sprechen: „Es war nicht ganz leicht für ihn, die eigene Kühnheit nachträglich zu begreifen.“ (Ausschweifung, S. 188) Oder auch: „Er kam sich raffiniert vor, sogar fast kühn. So etwas hatte er noch nie gemacht." (Sorgen, S. 208)

Diese überraschenden Selbstbeobachtungen bringen einen ganz neuen Blick auf die Quellen der Informationen für das eigene Selbst im Sinne einer reflexiven Prädikatenzuweisung mit sich $(\Leftrightarrow$ I.4): Wenn man sich nicht mehr auf sich selbst verlassen kann, man sich also selbst überrascht, ist das zwar für den Leser möglicherweise ganz apart, für die in Rede stehende Figur bzw. Person hingegen höchst erstaunlich bis verwirrend und Ausgangspunkt dafür, elementare, das

15 Henne/Rehbock: Einführung in die Gesprächsanalyse, S. 30. 
Selbst betreffende Ordnungsprinzipien infrage zu stellen: „Und jetzt Freizeitkapitän. Wie kamen nur diese Worte in ihn hinein? Und wie kam es, daß sie so rechtzeitig auftauchten, so passend zu den Gelegenheiten?“ (Sorgen, S. 299) Ganz ähnlich ergeht es dem Protagonisten aus Genazinos Eine Frau, eine Wohnung, ein Roman: „Ich wunderte mich, wie leicht mir eine erfundene Urlaubsgeschichte von den Lippen ging und wie problemlos sie mir geglaubt wurde." (Wohnung, S. 136) Weigand ist ob der eigenen Fähigkeit zur Interessantheit per Lüge überrascht; zudem beglaubigt das Zitat retrospektiv die tatsächlich erfolgte Äußerung.

Konterkariert werden diese Momente, in denen die Figuren nicht nur für andere, sondern zugleich auch für sich selbst interessante, überraschende, auffällige Register ziehen, von solchen, die ab ovo für andere gedacht sind und im inneren Bewusstseinsgefüge ,selbstbewusst' im doppelten Wortsinne genannt zu werden verdienen: „Bald hatte Eckhard den Wunsch, die anderen Spaziergänger sollten glauben, daß er ein Mann sei, der zwei Frauen liebte“ (Ausschweifung, S. 97). Neben der Bewusstheit im mentalen Verständnis lässt sich hier auch der alltagssprachliche Gestus beobachten: Sein Selbstbewusstsein in der Begriffsverwendung von ,(Selbst-)Sicherheit im Auftreten nach außen' wird nicht zuletzt durch die erzähltechnische Vorausdeutung auf die Promiskuität $(\Leftrightarrow$ II.5.2) im weiteren Erzählverlauf beglaubigt.

Auf diese Weise lässt sich erneut der Bogen zu den zwei obengenannten Polen ,Im-MittelpunktStehen' und ,Argwohn diesbezüglich'schlagen ( $\Rightarrow$ II.1.2): Die Figuren neigen zeitweilig eben auch dazu, die Bühne zu suchen - extremer: sich eine zu schaffen -, schaustellerisches Geschick an den Tag zu legen und als Sozialwesen mit der anderen Gesichtsausprägung, nämlich dem negativen, dem individuellen, herausstechenden Gesicht aufzutrumpfen. Das kann so weit gehen, dass sonst eher - an anderen sowie einem selbst - beargwöhnte Verhaltensweisen zelebriert werden. Ein bemerkenswertes Beispiel, das an der Grenze zur romanspezifisch-individuellen Ebene kratzt $(\Leftrightarrow I .2 .5)$, bietet William - wie sich die Figur selbst nennt - Genazino aus Die Liebe zur Einfalt, eine in puncto Reflexionsniveau von IM höchst elaboriert gezeichnete Figur:

Ich war begeistert über den Unterricht, aber leider hatte ich keine Lust, zu Hause die Griffe zu üben. [...] Viel mehr Vergnügen hatte ich daran, mich auf das Fahrrad zu setzen und mit der Gitarre unter dem Arm in die Stadt zu fahren und mich dort eine Weile als junger Mann mit Gitarre zu zeigen. (Einfalt, S. 129)

Genazino (Figur) ist eher dem Typus ,Blender' (s.u.) zuzurechnen: Der Wahrnehmungswunsch ist der als interessantes Gesamtpaket ,junger Mann mit Gitarre‘. Der Zuschauer soll sich bitte aufgrund der Tatsache, jemand fährt mit einer Gitarre unter dem Arm Rad, eine Fiktion ersinnen, die eben nicht mit ,Sohn bringt Vaters Gitarre zur Reparatur` o. Ä., sondern mit ,cooler Typ ist in der Lage, Gitarre zu spielen (Romantik etc.) sowie Fahrrad zu fahren (Ungebundenheit, Lässigkeit)‘ assoziiert werden möge. Denn das ist einfach ,interessanter‘. 
Auf drei relevanten Koordinatenachsen lassen sich so ,interessante' Verhaltensmuster mehrdimensional beschreiben und letztlich beliebig im vektoriellen Raum miteinander in Beziehung setzen: Es gibt erstens sowohl analog wie auch digital realisierte Interessantheit ( $\Rightarrow$ II.1.4), zweitens Imagination vs. ,echte‘ Handlung - „natürliches Gespräch“ vs. „fiktives Gespräch“16 - und schließlich drittens die Unterscheidung hinsichtlich der „Konstellation der Gesprächspartner“ also: Dyade vs. Gruppe. ${ }^{17}$

Bereits die Detailuntersuchungen zu den ersten beiden Schlaglichtern haben deutlich machen können, dass es zwar auch dann vornehmlich um verbale Handlungen gehen muss, wenn man die Strategien der Interessantheit bei Genazinos Figuren herauspräparieren möchte - lassen sie sich doch weder im spärlich beschriebenen Äußeren noch in fulminanten Aktionen flächendeckend finden. Aber immerhin häufig genug - vgl. neben dem Paradebeispiel des gerade fokussierten Genazinoprotagonisten aus Die Liebe zur Einfalt etwa denjenigen aus Der Fleck, die Jacke, die Zimmer, der Schmerz (etwa S. 85) -, um eine erste, dieses Unterkapitel durchwirkende Trennung der Erscheinungsformen interessanten und/oder auffälligen Verhaltens zu gewährleisten. Diese Unterscheidung liegt auf der X-Achse des gedachten Koordinatensystems in der spezifischen Manifestation des Verhaltens begründet: Handelt es sich um häufig anzutreffende digitale Interessantheitsbeglaubigungen verbaler Natur oder um solche markant der analogen Kommunikation ( $\Leftrightarrow$ II.1.4) zugehörige, wie sie etwa Abschaffel unter Beweis stellt: Abschaffel, gut gelaunt wie selten, entscheidet sich in einer spontanen Geste, zwei spielenden Kindern einen Tennisball zuzuwerfen, um ihnen eine Freude zu machen, was diese verdutzt: „Durch schnelles Weitergehen machte er deutlich, daß er die Rückgabe des Balls nicht erwartete. Er fühlte sich immer noch gut, und er begann sich vorzustellen, wie er bei diesen beiden Kindern nun als Ballverteiler galt." (Falsche Jahre, S. 443) Obgleich sich Abschaffel hier (womöglich) auf den schon bekannten, überspannten Pfaden der Mutmaßungen bewegt und (womöglich) etwas überambitioniert ein geschöntes Fremdbild zusammenfantasiert - damit wäre die weiter unten zu treffende Unterscheidung in Imagination vs. ,echte‘ Handlung zugunsten ersterer entschieden -, ist es keineswegs ausgeschlossen, dass sich eine Szene wie die folgende in der Diegese hätte abgespielt haben können:

Wenn die Kinder ihn wiedersahen, würden sie sich erinnern, und Abschaffel wäre eindeutig ein guter Mann. Er stellte sich sogar vor welche Unterhaltung der Vorfall in der Familie der Kinder hervorrief. Heute ist uns ein Ball geschenkt worden, sagten die Kinder, und die Mutter erschrak vermutlich. Ein Ball? Was für ein Ball? Ein Tennisball. Einfach so? Ja, einen Ball? hier ist er, sagten die Kinder. Wer hat euch diesen Ball geschenkt? Ein Mann. Ein Mann? Ja, ein Mann. Was für ein Mann? Wir kennen ihn nicht, wir haben ihn nie zuvor gesehen. Wie ging denn das vor sich? fragte die Mutter beunruhigt. Habt ihr gebettelt? Nein, nein, bestimmt nicht. Hat der Mann etwas dazu gesagt?

16 Henne/Rehbock: Einführung in die Gesprächsanalyse, S. 26. Vgl. dazu auch das zweite Unterkapitel im vierten Schlaglicht ( $\Rightarrow$ II.4.2).

17 Henne/Rehbock: Einführung in die Gesprächsanalyse, S. 26. 
362 - Teil II: Schlaglichter 3. Strategien der Interessantheit bzw. Auffälligkeit

Nein, nein, er lief einfach weiter. Wollte er etwas von euch? Nein, nichts, kein Wort hat er gesagt. (Falsche Jahre, S. 443 f.)

Mittels dieser ausschweifenden Imagination wird der eigene Selbstwert erhöht, ohne dass sich in der Fiktion irgendetwas zugetragen haben müsste. Jedenfalls wird das Ideal eines interessanten, verschwiegenen Alter Ego ,herbeispintisiert', das, ohne ein Wort zu sprechen, in der Lage ist, überraschend, unvorhergesehen zu agieren - ein prototypisches Beispiel für ,analoge Interessantheit'.18

Ferner ist es erforderlich, eine weitere Skala - um im Bild zu bleiben: die Y-Achse - auf den Plan zu rufen, die den Grad an Umsetzung des interessanten bzw. auffälligen Verhaltens der Figuren misst; denn es ist nicht notwendigerweise so, dass die Selbstaussagen der Figuren, die in die Zukunft weisen, probabilistisch in irgendeiner Weise vorab verifizierbar wären oder feststünden: „Abschaffel würde sie in Frankfurt auf dem Hauptbahnhof empfangen und ihnen dies und jenes zeigen." (Falsche Jahre, S. 449) Es bleibt offen, ob der Leser die Konjektur dahingehend entscheidet, dass Abschaffel das Vorhaben wohl umsetzen wird, oder ob er mit externem Blick der Figur/dem Erzähler die o.g. Unzuverlässigkeit attribuiert. Besonders raffiniert in der Schwebe gehalten mutet ein Statement des namenlosen Ich-Erzählers aus Wenn wir Tiere wären an, da es sich einerseits zweifelsfrei in die Möglichkeitsform verpackt findet - „Am liebsten hätte ich“; s.u. -, somit der ,Imagination', dem ,fiktiven Gespräch' zuzurechnen ist, zugleich aber ob seines elaborierten Eingebundenseins in die zukunftsgewisseren Vorausdeutungen - "ahnte, dass“; „hätte [...] beigetragen“; s.u. - mit der möglichen Übertragung in ,echte Handlungen', also ,natürliche Gespräche' liebäugelt:

Am liebsten hätte ich die beiden Frauen gefragt: Haben Sie sich wirklich so schick gemacht, um am Abend Gurkensalat zu essen? Vermutlich ahnten die Frauen meine innere Respektlosigkeit. [...] Leider ahnte ich, dass die Stunde meiner Nichtauthentizität bald anbrechen würde. Dann würde ich etwas halb Erfundenes erzählen, was ich noch während des Erzählens bereute. Aber die Erzählung würde schnell aus meinem Mund herauskommen und die Leute erstaunen und unterhalten. Dann hätte ich meinen Teil zum Gelingen des Abends beigetragen (Tiere, S. 71).

Die dritte Dimension (Z-Achse) nimmt personale und situative Aspekte zur Grundlage einer Typologie: Welchem biologischen Geschlecht - trans* gibt es bei Genazino nicht; nur kritisch oder ratlos beäugte Schwule $(\Leftrightarrow I I .1 .6$ u. $\Rightarrow$ II.5.3) - ist die sich interessant machende Figur zuzuordnen, welchem ihr Gegenüber? Diese Unterscheidung, die massive Auswirkungen auf den Handlungsspielraum innerhalb der Situation hat, lässt sich stets in zwei denkbaren Konstellationen realisieren: dyadisch oder in der Gruppe. Somit ist Interessantheit immer nur in Abhängigkeit von situativen Faktoren, milieuspezifischen Habitusformen $(\Leftrightarrow$ II.1.5) und dem dort üblichen Feedback zu bewerten. Und dieses ist immer nur Ausdruck von Erwartungen, Erwartungserwartungen (Luhmann) und Normen der Interaktionspartner. 
Was bei Genazino in privaten Gesprächen „,unter vier Augen““19 nur zwischen männlichen und weiblichen Akteuren an Interessantheit fruchtet, wäre in dieser Form in gleichgeschlechtlicher Besetzung nicht denkbar: „Ja, sagte er, ich lauf jetzt schon eine Stunde lang umher, um dich zu treffen. Sie lachte." (Sorgen, S. 321) Zwar sind gute, kurzweilige Gespräche, bei denen auch Interessantheit eine herausgehobene Bedeutung einnimmt, sehr wohl in männlich-männlichen Dyaden möglich - etwa im Gesprächsrahmen mit dem Privatdozenten in Die Kassiererinnen (S. 1114) -, doch der Grad an Höflichkeitsmarkern und Imponiersignalen ist dabei stark gedämpft. Dieser Unterscheidungsdimension zugehörig ist diejenige in ,privatere` Kommunikationssituationen, wie sie etwa in einer Dyade gegeben sind, und ,öffentlichere‘ Kommunikationssituationen, ${ }^{20}$ wie sie sich bspw. auf einer Party beobachten lassen. Allerdings verhält es sich nicht einfach nach Koch/Oesterreichers Nähe-Distanz-Modell, ${ }^{21}$ sondern gern auch mal umgekehrt und vor allem gerne auch anders als man denkt.

Denn trotz der natürlichen Nahkommunikation im interpersonalen dyadischen Gespräch, das privat und symmetrisch, narrativ und vertraut ist, ${ }^{22}$ also trotz des Schutzraums, kommt W. der folgende Satz nicht über die Lippen: „[Z]u Laura möchte ich sagen: Nur eine Frau kann die Welt als durchgehende Rundung darstellen. Aber dann kommt mir der Satz seltsam gespreizt und übertrieben vor; er paßt zu diesem Tag, und deswegen behalte ich ihn für mich.“ (Licht, S. 25) Bezieht man das Rubikon-Modell und die verhindernden, bzw. nicht-handlungsermöglichenden Enabling Factors mit ein ( $\Rightarrow$ I.3.1), dann gelingt erneut der Übertritt vom Motivationalen ins Volitionale nicht, dann spielt in actu das Moment „der Vorbereitetheit der Gesprächspartner“23 doch wieder hinein und verhindert die Aussage aus Gründen innerer Zensur ( $\Rightarrow$ II.2.6).

Standardwert in vertrauten, privaten männlich-weiblichen Dyaden ist symmetrische Schlagfertigkeit und Gewitztheit auf beiden Seiten: „Aber wenn man eine einzelne Beobachtung hervorhebt, klingt sie wie eine tolle Enthüllung, oder? Du bluffst ganz gut, sagte sie." (Fremde Kämpfe, S. 223) Dieser metakommunikativen Reflexion über Strategien der Interessantheit korrespondieren viele Beispiele, an denen das eben beschriebene Gesprächssetting - digital, natürliches Gespräch, Dyade mit allen benannten Spezifikationen - ablesbar ist:

Ich finde die Briketts frappierend und unverschämt, sagte ich.

Sie sind aber auch kindlich und unverletzbar, sagte Wanda.

Wir blieben vor dem Schaukasten stehen und betrachteten die Kohlen aus der Nähe.

Glaubst du, der Kohlenhändler weiß, dass ihm ein kleines intentionsloses Kunstwerk gelungen ist?, fragte ich. [...]

19 Henne/Rehbock: Einführung in die Gesprächsanalyse, S. 28.

20 Vgl. Ecker: Schiffbruch mit Zuschauer II, S. 126.

21 Vgl. Peter Koch/Wulf Oesterreicher: Sprache der Nähe - Sprache der Distanz. Mündlichkeit und Schriftlichkeit im Spannungsfeld von Sprachtheorie und Sprachgeschichte. In: Romanistisches Jahrbuch 36 (1986), S. 15-43.

22 Vgl. Henne/Rehbock: Einführung in die Gesprächsanalyse, S. 26.

23 Henne/Rehbock: Einführung in die Gesprächsanalyse, S. 27. 
Jetzt hab ich heute Nacht doch noch etwas gesehen, womit ich nicht gerechnet hatte, sagte sie. (Kassiererinnen, S. 34-36) ${ }^{24}$

Sehr verwunderlich ist es nicht, dass assertives IM zumal im Bereich der dyadisch-vertrauten Imponiergespräche auch mit Formen der Übertreibung bzw. Lüge arbeitet:

- Meine Familie arbeitet seit fünf Generationen im Zirkus, sage ich.

- Nein! sagt sie.

$[\cdots]$

- Als ich dreizehn war, sagt sie, hat das Haus meiner Eltern gebrannt.

$[\cdots]$

- Ich habe sofort gewußt, sagt sie, daß Ihre Zirkusgeschichte erfunden ist, aber ich wollte sie Wort für Wort hören.

- Auf einem Schiff bin ich ein anderer.

- Ist es die Beredsamkeit des Lichts und der Helligkeit? fragt sie.

- Vermutlich, sage ich; das Haus Ihrer Eltern hat doch auch nie gebrannt, oder?

- Es gab nicht einmal ein Haus, sagt sie. (Licht, S. 83-87)

In diesem Fall sind beide Gesprächspartner auf Augenhöhe mit allen kommunikativen Wassern gewaschen und wissen, wie das Interesse des Gegenübers geweckt und erhalten werden kann. Zwiefach asymmetrisch ${ }^{25}$ ist hingegen folgende Szene zu werten: „Jutta nennt mich plötzlich [...] einen Hochstapler und Aufschneider, einen Wichtigtuer und Faxenmacher. Wie habe ich dich im Schwimmbad bewundert! ruft sie aus. Und ich dumme Kuh bin auf dich hereingefallen!“ (Fleck, S. 217) Erstens werden die obengenannten Klischeevorstellungen, was sich ,die Frau' von ,dem Mann` erwartet - soll interessante Gespräche führen können - bzw. nicht erwartet: „+ Blender, Prahler, Protzer, Angeber + Schleimer und billige Komplimente + Selbstdarsteller und Labertaschen + Modeaffen, Männer mit Parfum + Klassenclown und Möchtegernhumoristen“, ${ }^{26}$ reproduziert. Dadurch werden dem männlichen Rollenbild en passant per Implikatur doch wieder aktive Züge zugewiesen. Zweitens aber werden die Stereotype durch die weibliche Figur reproduziert, was die Aufschneiderei zwar um keinen Deut besser macht, das Gesamtgefüge der Interessantheits-Eindruckssteuerung aber mit genderproblematisch doppeltem Beigeschmack zurücklässt ( $\Rightarrow$ II.5.3).

In Bezug auf die nicht öffentlichen Kleingruppengespräche mit Gesprächspartnern, die zwischen „vertraut" und „flüchtig bekannt" sich bewegen, stellt sich Interessantheit bei Genazino sowohl grundverschieden wie auch höchst ähnlich dar:

Vor einer halben Stunde habe ich das Wohnzimmer Margerita Mendozas Spezialitätenrestaurant genannt, worüber Susanne entzückt war. Weil nicht alle wußten, was es mit dem Namen Margerita Mendoza auf sich hat, habe ich hinterher die Theater-Episode aus Susannes Leben erzählt. Durch

$24 \quad$ Es ließe sich eine leichte Asymmetrie feststellen, die geschlechtsspezifisch markiert ist und im folgenden Beispiel auf den Punkt gebracht wird: „Es schien ihr zu gefallen, dass es jemanden gab, der sie mit verblüffenden Einzelheiten unterhielt." (Kassiererinnen, S. 51) Als Gegenbeispiel, in dem die weibliche Figur den interessanten Part innehat, vgl. etwa: „Seine Hast hat mich auf die Idee gebracht, daß er sich verachtet, sage ich. Allerdings kann er seine Verachtung schon lange nicht mehr ertragen; deswegen gibt er sie an andere weiter: Indem er sie betrügt, macht er sie ebenfalls verächtlich und damit sich selber ähnlich. Das klingt gut, sagt Helmuth." (Obdachlosigkeit, S. 99)

25 Vgl. Watzlawick/Beavin/Jackson: Menschliche Kommunikation, S. 68 ff. u. S. 103 ff.

26 [Forum ElitePartner.de]. 
die Erzählung ist mir die Geschichte peinlich geworden, aber es hat wohl niemand bemerkt. Susanne hat meine Darstellung offenbar gefallen, sie hat mich danach dankbar umarmt. Jetzt gilt sie wenigstens in diesem Zimmer und an diesem Abend und vor diesen Leuten als Künstlerin. (Regenschirm, S. 98 f.)

In dieser höchst unmittelbaren Erzählhaltung, die mit „vor einer halben Stunde“ eine QuasiGegenwärtigkeit heraufbeschwört, die sonst selten gegeben ist, und die das „Raum-Zeit-Verhältnis“ der Kommunikation als absolute „Nahkommunikation“ in einer Kleingruppe ausweist,27 konterkariert der lediglich in der Erwähnung des Gesprächs vorliegende Duktus auf das Äußerste die den Leser eigentlich brennend interessierenden Worte des Protagonisten. Das eigentlich Spannende wird im kurzgehaltenen Gesprächsbericht zugunsten der Schilderung von Susannes Reaktionen zurückgefahren. Dadurch mehren sich die Indizien dafür, dass es sich ,insgeheim‘ erzähltechnisch um die Vorbereitung auf eine dyadische Kommunikation handelt. Ist die Gruppe vielleicht gar nur Auditorium? So könnte man den unüblichen Mut des Protagonisten an dieser Stelle auch extern plausibilisieren. Kurz: ja! „Susannes Augen leuchten. Sie findet es wunderbar, daß an ihrem Wohnzimmertisch so gesprochen wird. Ich weiß nicht, ob sie merkt, daß ich nur wegen ihr so rede, ich glaube, eher nicht." (Regenschirm, S. 102)

Es handelt sich nicht nur um ein schlagendes Beispiel für ,ingratiation' (bei Susanne) und assertives IM überhaupt $(\Leftrightarrow I .3 .3)$. Weil der grundlegende Unterschied, der Gespräche zwischen zwei Personen und solchen in der Gruppe charakterisiert, nämlich das potenzielle Vorliegen der „Trennung von Adressat (als dem unmittelbar Angesprochenen) und Zuhörer“, ${ }^{28}$ nicht realisiert wird, so ließe sich argumentieren, vermag der Protagonist darüber hinaus mit seinen in der Dyade weitaus erfolgreicheren Interessantheitsevokationen aufzutrumpfen. Den feinen Unterschied macht vielmehr nur der extensive Gebrauch rhetorischer Mittel und die Form des gefälligen Bonmots: „Warten Sie ab, sage ich, eines Tages wehren Sie sich nicht mehr! Man liebt dann, wenn man vor dem anderen nicht mehr fliehen will, obwohl man ahnt, daß dieser andere unmögliche Forderungen stellen wird." (Regenschirm, S. 100) Wie intendiert, ist die öffentlichheimlich Angesprochene dann auch diejenige, die - an der Gruppe statt - die ersehnte Anerkennung zeigt: „Bravo! ruft Susanne.“ (Regenschirm, S. 100)

Nun wäre es eine nicht nur verkürzende, sondern auch verfälschende Darstellung, erwähnte man nicht auch die Überwindungsanstrengung des Ich-Erzählers - Dyade in der Gruppe hin oder her -, der auch im Folgenden das durchaus allen Regeln der Konversationskunst genügende, interessante Gespräch leitet: „Ich atme durch und trinke mein Glas leer.“ (Regenschirm, S. 101) In diese intern perspektivierten Interpretationszusammenhänge sollte sich immer wieder auch die externe Perspektive einmischen: Fällt es dem Protagonisten intern schwer, ohne Atemübung und Alkohol eine Kleingruppe zu interessieren, so wird es ihm extern zumal durch die ,flachen` Nebenfigurenskizzen ( $\Rightarrow$ I.2.4) leicht unterkomplexer Spießer äußerst leicht gemacht, zu glänzen.

27 Henne/Rehbock: Einführung in die Gesprächsanalyse, S. 26.

28 Henne/Rehbock: Einführung in die Gesprächsanalyse, S. 28. 
Nur deren Kopräsenz liefert eine hinreichende Erklärung dafür, dass sich der Erzähler im weiteren Party-Verlauf dazu hinreißen lässt, Fantasieberufsbezeichnungen loszulassen und anderswie zu extemporieren (vgl. Regenschirm, S. 105). Diese Figurantenfunktion, mittels derer sonst nicht allzu ,interessante' Protagonisten interessanter wirken, leitet über zum ebenfalls externen Milieu der Erzähltheorie.

\subsection{Auffälligkeit(en) im erzähltheoretischen Milieu}

Zumal im Umfeld der Passagen, die in diesem Schlaglicht versammelt sind, finden sich überzufällig häufig auch auf erzähltechnischer Ebene interessante, besondere, ungewöhnliche und also auffällige Strukturen im Sinne des ,literarischen Foregroundings' ( $\Rightarrow$ II.5.6),29 also einer Abwandlung der Figur-Grund-Wahrnehmung, denen nun exemplarisch-kursorisch nachgegangen wird. Allein der Gedanke, ,Erinnerungsaufträge‘ per Brief an Freunde zu verteilen, um sich dieser unter den Umständen eines möglicherweise dereinst versagenden eigenen Gedächtnisses zu bedienen, hebt sich als Alleinstellungsmerkmal vom Grundgesamt der Genazino'schen Romane auffällig ab. Einhundertfünfzehn sonst keiner äußeren kompositionsstrukturellen Segmentierung ( $\Rightarrow$ I.2.3) folgende Abschnitte, die zwischen adressierten Briefen und in Tagebucheintragsform abgefassten Passagen wechseln, lassen sich als erzählkompositorischer Fremdkörper und mithin einer externen Strategie der Interessantheit zugehörig werten, was W. auch reflektiert (vgl. Licht, S. 120). Aber auch intern begibt sich W. dabei in ein ungewöhnlich intimes Verhältnis mit seinem Freundes- und Bekanntenkreis, das seinesgleichen sucht, und nicht selten durch die ,Einbahnstraßenkommunikation` dem positiven Gesicht des Anerkennungswunsches schmeichelt. Allerdings handelt es sich dabei einwandfrei um romanspezifisch-individuelles Terrain.

Immer noch selten, aber zumindest am äußeren Rand der Familienähnlichkeit zu verorten sind die bereits angesprochenen, mitunter abrupten Wechsel der Erzählperspektive $(\Rightarrow$ I.2.3 u. $\Rightarrow$ I.4). Nicht nur in Laslinstraße ereignen sich solche, „den ungeschulten Leser stark irritierende[] Übergänge[]“,30 sondern bspw. auch im Roman Falsche Jahre:

Sie haben in der letzten Stunde erzählt, daß ihre Eltern so oft Streit miteinander hatten, sagte Dr. Buddenberg leise. Ja. Wann hatten sie denn Streit, bei welchen Gelegenheiten, meine ich. Über das Geld zum Beispiel, begann Abschaffel, stritten sie sich jede Woche, eigentlich fast jeden Tag, wenn sie nicht zu müde waren. [...] Für mich war das schwierig, erzählte Abschaffel, weil ich nie wußte, welche Partei ich ergreifen sollte. Eigentlich war ich immer Mutters Partei. Aber der Vater tat mir auch leid. Es war alles nicht zu verstehen, aber das habe ich damals nicht verstanden. (Falsche Jahre, S. 419 f.)

Durch die direkte autonome Rede Abschaffels ganz zu Beginn des Zitats („Ja.“) wird die „irritierende[]“ Wirkung zunächst gerade dadurch abgeschwächt, dass die verba dicendi radikal gestri-

29 Vgl. Nadine van Holt/Norbert Groeben: Das Konzept des Foregrounding in der modernen Textverarbeitungspsychologie. In: Journal für Psychologie 13 (2005), S. 311-332. 
chen werden. Der Übergang vollzieht sich dann, vorangekündigt', aber nichtsdestoweniger die interessanten, auf Selbstauskünften beruhenden und damit dem protektiven IM zuwiderlaufenden Erkenntnisse auf Histoire-Level im Discours spiegelnden Art und Weise. Nicht nur im Drama sind Monologe - und hier handelt es sich nicht um einen inneren - Momente der Offenbarung (interne Sicht), der plot points (externe Sicht). Auch wenn der Psychotherapeut nicht die richtige Adresse für ,interessante Stories‘ ist, kann der über eine Druckseite sich erstreckenden Erzählung nicht ein gewisses Maß an Leserinteresse abgesprochen werden.

Spannungsaufbau und Tempo sind zwei weitere Schlagworte, die hinsichtlich erzähltheoretischer Analyseperspektive $(\Leftrightarrow I .2 .3)$ für das Feld der Interessantheit ins Auge fallen. Bereits optisch einen stychomythischen Zeilenstil imitierend und zudem - bis auf die allererste Aussage Dagmars - durch autonome direkte (Wechsel-)Rede in äußerst unmittelbarer Form präsentiert, wird das folgende temporeiche Telefongespräch zum Aushängeschild für kommunikative ,Zielspannung:

Da klingelte das Telefon. Peschek stellte den Ton des Fernsehgeräts leise und nahm ab.

Was machst du? fragte Dagmar.

Ich esse Rigatoni und denke nach.

Seit wann bist du zu Hause?

Seit ungefähr einer Viertelstunde.

Wo warst du?

Unterwegs.

$[\ldots]$

Warst du mit Leuten zusammen?

Ja.

Kenne ich diese Leute?

Nein.

Ist irgend etwas passiert?

Nein.

Hast du etwas angestellt?

Nein.

Warst du mit einer Frau zusammen?

Mein Gott, nein.

[...]

Wie geht es dir?

Nicht besonders.

Habe ich etwas damit zu tun?

Nein.

Könnte ich dir helfen?

Kaum.

Kannst du mir sagen, warum es dir nicht besonders geht?

Kaum.

Und wenn ich es schon weiß?

Dann müßte ich es nicht sagen.

Kränkt es dich, daß ich es weiß?

Ein bißchen schon; ich wünschte, ich könnte es immer für mich behalten. (Fremde Kämpfe, S. 7274)

Fast könnte man meinen, einem Verhör beizuwohnen, das zunächst auf nichts Besonderes hinauszulaufen scheint, höchstens den Anruch leichter Eifersucht hat, an dessen Schluss dann aber das Bekenntnis zur Arbeitslosigkeit steht. Die Einsilbigkeit Pescheks in Kombination mit der 
grafischen Anordnung erhöht das (Lese-)Tempo ungemein und evoziert wie selten sonst interesseweckende Spannung.

Interessantheit und Spannung werden auch in den Analysesituationen Abschaffels in Falsche Jahre erzeugt, was sich letztlich gar in der Satzstilistik $(\Leftrightarrow I .2 .3)$, in den Satzbaustrukturen spiegelt: „Und warum habe ich die Schlittschuhe nicht bekommen? Weil dem Vater die fünfzig Pfennig Eintritt in das Eisstadion zuviel gewesen waren! Jawohl.“ (Falsche Jahre, S. 433) Mit dem Rückgriff auf eine rhetorische Frage, die notwendigerweise die Aufmerksamkeit auf die sie äußernde Person zieht, wird - analog zum Erzählen mit Pointe wie beim Witz - hier dyadischbekannt-nicht-öffentlich (Z-Achse) mit dem Vater abgerechnet - nicht ohne sich selbst dabei als Opfer zu stilisieren und damit hintergründig selbst positiv zu erscheinen. Die Abweichung vom erzählpraktischen Standard vollzieht sich allerdings noch auf einer anderen Ebene: nicht mehr ,unterwegs im inneren Monolog', sondern diegetisch-faktisch im natürlichen Gespräch geäußert $(\Rightarrow$ II.3.1), ist auf der Y-Achse die Imagination der in diesen intimen Momenten nachgerade sich aufdrängenden inneren Zensur ( $\Rightarrow$ II.2.6) entwachsen. Als weiteres interessantes Zeugnis dieser Tendenz ist das auf der X-Achse digital zu nennende kommunikative Handeln eines Wolf Peschek anzuführen: „Hochdramatisch sogar, sagte Wolf, ich hätte mich damals fast vom Eisernen Steg in die Tiefe gestürzt." (Fremde Kämpfe, S. 183) Dass dabei der Boden der fiktionalen Tatsachen verlassen wird, ist der Erwähnung nicht bedürftig. Dass der kurzfristige Effekt indessen auf Dagmar derartigen Eindruck macht, Peschek in die Position zu setzten, ihr in der Folge und ohne große Anbahnung „der Länge nach ihre Schamlippen in die Hand“ (Fremde Kämpfe, S. 184) zu nehmen und dergleichen mehr, spricht eine deutliche Sprache. Auf der X-Achse schlägt die nonverbale, selbstbeschreibende Verhaltensäußerung Degens, während der Erzähltechnik und öffentliche Selbstaufmerksamkeit $(\Leftrightarrow I I .2 .4)$ verschmelzen, eine andere IM-Saite an: „[J]etzt, Schritte von Axel, Schritte von mir." (Laslinstraße, S. 70) ,JETZT“ ist nicht erst seit Rainald Goetz ein Signalwort für erlebte Wirklichkeit und absolute Unmittelbarkeit, die Sekundenbruchteile später schon wieder der Vergangenheit angehört und somit die ungeteilte Aufmerksamkeit aller im Jetzt Anwesenden zu binden nötigt. ,Jetzt' ist auch schlicht ein temporal gebräuchliches Adverb, das eine Vorgeschichte von einem neuen Abschnitt trennt. In beiden Fällen ist der Parallelismus („Schritte von...”) bewusst gesetzt. Iterativ ist die Schilderung hingegen weniger zu nennen als vielmehr doppelt perspektiviert: Ist es zunächst diejenige externe, der öffentlichen Selbstaufmerksamkeit zuzuordnende, so wechselt mit dem zweiten Komma der Blickwinkel in die interne, der privaten Selbstaufmerksamkeit angehörige Perspektive.

Erzähltheoretisch sind es unterschiedliche Fokalisierungen, die konfligieren, was im Hinblick auf erzähltechnische Besonderheiten der Interessantheit auch andernorts an Gewicht gewinnt:

Weil es unmöglich war, das Leben eines anderen Menschen zu erfassen oder durchgängig zu begreifen (meinte er), wollte er in Zukunft nur noch Geschichten erzählen. Obwohl er gar nicht wußte, 
welche Geschichten er eigentlich erzählen wollte, aber in diesen Augenblicken spielte ihm sein Gemüt sich selbst als Geschichtenerzähler vor. (Falsche Jahre, S. 485)

Der Erzähler weiß mehr über die Motivationslage der Figur als diese selbst, wohingegen es der Figur so vorkommen muss, als trete ein unbewusstes Selbst die selbstbewusste Erzählung der ,Geschichten' an. Zumindest ein Unentschieden von Null- und interner Fokalisierung ist in Betracht zu ziehen, dem auch die Klammerkonstruktion Vorschub leistet. Allerdings steht wenigstens außerfrage, dass interessante Geschichten entstehen, wenn Abschaffel erzählt; wenn Abschaffels „Gemüt“ als Erzähler in Erscheinung tritt; wenn der Übersicht beanspruchende Erzähler erzählt, Abschaffels Gemüt erzähle Geschichten.

Zwei damit verbundene auffällige Aspekte - Planung und Spontaneität - sollen den Diskurs des Unterkapitels abschließend leiten. Von hinten nach vorne: Spontaneität findet sich als interessante ,Strategie‘ etwa in Form überaschender Orthografie und Satzstilistik wieder - „Weiter? Was? Weiter, weiter!! Weeiiter!“ (Laslinstraße, S. 174) -, manifestiert sich bspw. aber auch in der von nahezu kindlicher Entdeckerfreude beseelten Wort(neu)schöpfungskraft des Basistypus (vgl. Außer uns, S. 37). Mit Neologismen sprengen Wilhelm Genazinos Romanfiguren die Normgrenzen des alltagssprachlichen Lexikons ${ }^{31}$ und sammeln die Splitter dieser Wortzertrümmerung zunächst auf. In ihrer Reflexionsbeflissenheit verarbeiten sie diese dann zu neuen Sinnzusammenhängen, die als Auffälligkeit im erzähltechnischen Milieu insofern von Bedeutung sind, als sie den gedehnten Blick ( $\Rightarrow$ II.2.2 u. $\Rightarrow$ II.2.3), die Wiederverzauberung der Welt $(\Rightarrow$ II.2.3) und andere Aspekte berühren.

In puncto strategischer Gesprächsplanung sind hingegen Konversationsrouten, die sich beim assertiven IM bedienen, zu untersuchen, weil sie musterbildend wirksam sind, wenn sich die Figuren anschicken, sich, interessant zu machen':

Ich bereite mich, so gut es geht, auf das Bewerbungsgespräch bei der Wohnungsbaugesellschaft Kreditbau vor. Das heißt ich überlege, ob ich mich als bildungsverliebten Einzelgänger darstellen soll, der von Anfang an gewußt hat, daß das Philosophie-Studium gesellschaftlich wertlos ist. In Wahrheit bin ich ein durch und durch praktischer Mensch, werde ich sagen. Danach könnte ich ein bißchen die Universitäten und das Bildungssystem beschimpfen. Die Hochschulen bilden sowieso zu viele Leute aus, die hinterher niemand brauchen kann, werde ich sagen. Das kommt immer gut an. Aber wahrscheinlich werde ich mich ohnehin falsch benehmen, das ist jedenfalls meine momentane Furcht. (Glück, S. 118 f.)

Gerade Warlich, der das ,Verstellungstheaterspielen' wie kaum ein anderer (verab-)scheut, verwendet viel Aufwand darauf, kalkuliert zu interessieren - zumal er fürchtet, daran zu scheitern. Axel Degen investiert seinerseits sogar viele Stunden erzählter Lebenszeit, um lediglich „drei bestimmte Worte, die mich seit Tagen nun beschäftigten, Hackbeilworte, Endlichkeitsworte, der Worte, die nach Ende rochen, nach Abschluß, die Mut auffraßen, Vergangenes einkapselten und Neues in mich hineinbrechen ließen, drei Worte, vier Silben“, zu planen (Laslinstraße, S. 127). Es 
handelt sich offensichtlich nicht um ,Ich liebe Dich` - das bedeutet schon das umgebende Wortfeld. Dennoch erfordert es situative Schützenhilfe und persönliche Überwindung:

Für diese drei Worte, die ich heute zu sprechen mir gelobt hatte, brauchte ich eine Grundlage aus Gleichgültigkeit, aus Nebensächlichkeit [...]. [...] [H]erauspurzeln lassen müßte ich sie, überlegte ich, einfach herausfallen lassen, damit es nach Zufall aussähe, damit niemand den Entschluß riecht, auf dem diese drei Worte gewachsen sind, den Morast der Jahre, nein, den durfte niemand sehen, niemand. (Laslinstraße, S. 127 f.)

Degen will seine Eltern qua strategischer Gesprächsplanung über den eigenen Auszug in Kenntnis setzen: „Ich ziehe aus.“ (Laslinstraße, S. 127) Zwar ist dieser Sprechakt, da zunächst ,unverbindlich' bzw. revidierbar, weniger performativ und also wirklichkeitskonstituierend als eine Liebesbekundung, aber für die handelnde Hauptfigur stellt er eine ebenso hohe Hürde dar. Weiterhin ist die von mangelnder Selbstsicherheit getragene Angst vor der eigenen Courage ( $\Rightarrow$ II.3.1) dafür verantwortlich, dass die Gesprächsplanung fokussiert wird, um durch eine bestmögliche Vorhandlungsphase, also einen hohen „Grad der Vorbereitetheit“ zumindest eines „Gesprächspartner[s]“,32 mit der tatsächlichen Sprachhandlung erfolgreich zu sein. Die erstaunliche Regelmäßigkeit, mit der Genazinos Figurenbasistypus Zeit und Mühe in diese Vorstufe des ,Eigentlichen“ investiert, zeigt auch das Beispiel Dieter Rotmunds, der mit seiner Aussage: „Ich habe mir gerade die erste Strategieskizze für ein Gespräch mit Herrn Honke zurechtgelegt" (Heimweh, S. 108), die kalkulierte IM-Facette betont.

Namentlich diese letzten Zitate problematisieren ein spannungsreiches Verhältnis: strategische Planung vs. (gewünschte) Spontaneität. Auf den ersten Blick ein Widerspruch, ist man doch geneigt, diejenigen Personen interessant zu finden, die ehrlich wirkend ,aus dem Stegreif ${ }^{\prime}$ diese Eigenschaft unter Beweis zu stellen in der Lage sind $(\Leftrightarrow$ II.3.4). Einen Mittelweg fahren Genazinos Figuren, wenn sie sich strategisch interessant machen (wollen).

\subsection{Vorbereiten, Wappnen, inszenierte Spontaneität}

Es nimmt sich aus wie ein besonders sinnfälliger Anachronismus im an Anachronismen ohnehin reichen Roman-Werk Genazinos: Die Figuren orientieren sich an der Konversationskultur des achtzehnten Jahrhunderts, wenn sie sich - wie seinerzeit per Konversationslexika für Salongespräche - mit Vorlauf für mögliche oder erwartbar künftige Kommunikationssituationen rüsten. Diesen Wesenszug des Basistypus trägt bereits der Abschaffel der Vernichtung der Sorgen: „Er schämte sich, weil er so wenig zu sagen gewußt hatte, und er kam auf den Gedanken, sich für künftige, überraschende Anrufe von Margot ein Zettelchen mit zwei oder drei Stichworten vorzubereiten, von dem er jederzeit ein Gesprächsthema ablesen konnte." (Sorgen, S. 190) Zettel mit Gesprächsnotizen als Strategie gegen Wortlosigkeit allgemein, gegen den Eindruck mangelnder Interessantheit im Speziellen - ein offenkundig probates Mittel, das sich über die künfti-

32 Henne/Rehbock: Einführung in die Gesprächsanalyse, S. 27. 
gen Romane beharrlich hält. Noch gesteigert finden sich diese soufflierenden "Stichwortlisten“ etwa in Die Liebe zur Einfalt, wenn sie sich funktionell gar der ,Moderationskarte' anverwandeln und wieder näher an die oben bereits tangierte globale Gesprächsplanung anschmiegen:

Isolde durfte auf keinen Fall bemerken, daß ich zum Sprechen kleine Spickzettel benötigte. Denn ich wollte direkt und spontan und vor allem unerschöpflich sein. Außerdem hatte ich zu dieser Zeit die Vorstellung, daß eine Frau Anspruch darauf hatte, von einem Mann unterhalten zu werden. (Einfalt, S. 111$)^{33}$

Neben den Gender-Implikationen, die als auslösender Faktor namhaft gemacht werden können und gleichsam das Idealbild seiner selbst malen, „direkt und spontan und vor allem unerschöpflich“ zu sein (respektive wirken zu wollen), verdient das Moment der Heimlichkeit besondere Beachtung. Anlassgebunden und auf nähesprachliche, intime Gesprächssituationen zugeschnitten, bei denen ein Höchstmaß an Authentizität erwartet wird, muss es schreiend unpassend erscheinen, wenn der ,Leitfaden' durch das Gespräch durchschimmert wie ein Palimpsest.

Mit demselben Impetus beabsichtigt der Ich-Erzähler der Liebesblödigkeit, sich selbst eine ähnliche, ihm jedoch nicht in jeder Situation zu Gebote stehende Charaktereigenschaft zuzuschreiben: „Hätte sie sich beklagt, hätte ich geantwortet: Plötzlich hereinbrechende Grobheit gehört auch zu den unangenehmen Überraschungen des Alterns. Aber ich blieb auf meiner vorbereiteten Schlagfertigkeit sitzen." (Liebesblödigkeit, S. 60 f.) Wiewohl es hier nicht im Sinne der oben zum Schema erhobenen Auffächerung der tatsächlichen Verbalisation kommt, ist der Fakt der „vorbereiteten Schlagfertigkeit" in der Diegese real.

Obwohl es dem Genazino-Basistypus nicht ganz angenehm ist, sich ,herausragend' zu verhalten, nimmt er opportun hin, dass es in manchen Situationen - vorausgesetzt, bestimmte kommunikative Ziele sind anvisiert - geboten ist und plant und sammelt für diese Momente Material. Wolf Peschek bspw. überlegt sich nicht zuletzt aus handfesten Gründen - nachdem ihm als freischaffendem Werbegrafiker die Aufträge ausgehen -, wie er dereinst den Entscheidungsträger der Agentur, Münchmeyer, zu seinen Gunsten umstimmen könnte: „[E]r könnte sich den Greisenfilm ansehen, damit er [...] eine obskure Geschichte zu erzählen hätte [...]. Münchmeyer liebte es, sich inmitten eines Kreises von außergewöhnlichen Menschen zu vermuten“ (Fremde Kämpfe, S. 61). Je nach Vater des Gedankens - hier: Überzeugung anderer von eigener Interessantheit -, kann der Bogen auch unter Einbezug der kleinen Lüge ( $\Rightarrow$ II.1.2 u. $\Rightarrow$ II.3.5) weit gespannt werden, wie sich im weiteren Gedankengang Pescheks nachweisen lässt: „Dadurch kam Peschek auf eine Verzerrungsidee, die Münchmeyer beeindrucken könnte: er könnte behaupten, Vorfilm und Hauptfilm werden hier dreimal wiederholt, bis auch der letzte Schwerhörige und Halbblinde alles kapiert hatte." (Fremde Kämpfe, S. 61) Im Gewand einer interessanten Geschichte, die Pe-

33 Vgl. auch: „Und weil ich nicht wußte, wie ich meine sonderbare Verlegenheit noch länger rechtfertigen sollte, fertigte ich mir für die Abende mit Isolde winzige Spickzettel an, auf denen pro Heimweg fünf oder sechs Stichworte mit Gesprächsthemen standen, über die ich jederzeit und leicht sprechen konnte, wenn meine Redenot plötzlich auffallend war." (Einfalt, S. 111) 
scheks eigene Vorzüge unterstreichen soll, verbirgt er den Fake, um kalkuliert und strategisch im Vorfeld angebahnt etwas im geistigen Gepäck zu haben, das für konversative Herausforderungen gezückt werden kann: Peschek wappnet sich für alle Fälle mit einer falschen Geschichte, um seine Interessantheit zu inszenieren. ${ }^{34}$ Damit ist die ,Gemachtheit' von Gesprächen angesprochen und zwar in zwiefacher Wortbedeutung: einerseits mit Akzent darauf, dass sich - auch phraseologisch wie in ,Konversation machen` deutlich - Gespräche und Gesprächsbedeutung durchaus erst im performativen Akt konstituieren, andererseits mit Akzent darauf, dass Gesprächen immer auch etwas Unnatürliches anhaftet, sie mithin durchaus regelgeleitet planbar sind. Ein abschließendes Beispiel ergänzt diese bislang eher dyadischen, in m-w/m-m-Kontexten sich ereignenden (Z-Achse), geplant-fiktiven (Y-Achse), digitalen (X-Achse) Praxen der Interessantheit um eine realisierte analoge Kommunikation vor einer (Klein-)Gruppe, die sich jedoch über die vorwiegend assertive IM-Technik bestens verknüpfen lässt: „Eckhard tat, als würde er lange brauchen, um den richtigen Bildausschnitt zu wählen. Durch dieses Warten hatten die Japaner offenbar den Eindruck gewonnen, daß Eckhard ein besonders sorgfältiger und liebenswürdiger Fremder sei." (Ausschweifung, S. 198) Bemerkenswert an diesem Paradebeispiel für die Unterkategorie ,likable' der assertiven ingratiation $(\Rightarrow$ I.3.3) ist, dass Eckhard Fuchs - hier ist die externe Perspektive zwingend - durch diesen Akt inszenierter Interessantheit just ,diegetisch belohnt wird: Als ,Dank' für seine zögerliche, inszeniert spontane Redlichkeit lichten die Japaner nun ihrerseits Eckhard ab und nähren dadurch, dass sie sich seine Adresse nicht notieren - wie es erwartbar wäre, würden sie ihm das Foto zuschicken wollen -, die Vermutung, dass „Eckhards Foto in ein fremdes japanisches Familienalbum [wanderte], und diese Möglichkeit freute ihn.“ (Ausschweifung, S. 198)

Wie kapiteleingangs angemerkt, gibt es neben diesen Ausgestaltungen inszenierter Interessantheit bzw. Spontaneität die seltenen Schilderungen von Interessantheit ,im besten Sinne': Die Figuren verblüffen Leser und Mitfiguren (und gelegentlich auch sich selbst) durch originelle, überraschende Handlungen und Aussagen, wobei die Erzählinstanz sowohl die Lesererwartung, die diesen Möglichkeiten gegenüber eher zögerlich ist, als auch die Erwartung der Mitfiguren mitunter sogar thematisiert (vgl. Falsche Jahre, S. 478).

\subsection{Interessantheit ,im besten Sinne': Esprit sowie Extemporiergeschick}

Für diese Facetten der Interessantheit ist die oben getroffene Unterscheidung in Imagination vs. ,echte‘ Handlung oder besser mit Saussure (und anderen) als Differenz zwischen ,langue' und ,parole‘ von höchster Relevanz. Obwohl die strukturalistische Linguistik naturgemäß eher am dichotomischen Entweder-oder interessiert gewesen ist, lässt sich die Metapher des prinzipiell

$34 \quad$ Zu diesem Behuf schreckt er - zumindest im sicheren Metier der eigenen Kopfgeburt - auch nicht davor zurück, die „Verzerrungsidee“ vollends zur Räuberpistole weiterzuspinnen (vgl. Fremde Kämpfe, S. 62). 
sprachfähigen und im Besitz des mentalen Lexikons befindlichen Menschen, der die Kompetenz hat, ein Ansinnen zu verbalisieren - und damit sind alle Möglichkeiten des Ausdrucks inbegriffen -, gewinnbringend im Kopf behalten. ${ }^{35}$ Ist es dort der liminale Schwellenmoment, ${ }^{36}$ der aus der Kompetenz binnen eines Augenblickes die Realität durch eine Äußerung in Form eines performativen Akts in eine andere transformiert - was sich auch bestens mit dem Konzept der Enabling Factors und dem eigentlichen ,Output' deckt -, bietet sich für Genazinos Hauptfiguren eher die Vorstellung einer fließenden Kommunikationsperformanz an, die auf eine Skala zu applizieren ist. Wohingegen die bereits oben kurz analysierte Passage: „Aber die Erzählung würde schnell aus meinem Mund herauskommen und die Leute erstaunen und unterhalten. Dann hätte ich meinen Teil zum Gelingen des Abends beigetragen“ (Tiere, S. 71), als zwar nicht ausgesprochene, aber nicht nur potenziell im Repertoire des Ich-Erzählers, in seiner Kompetenz, in seiner langue liegende, sondern auch auf der Skala qua der konkreten Worttempovorauswahl und dem situativen Setting imaginierte als der Performanz nähere als der Kompetenz klassifiziert werden kann, finden sich Aussagen, die weiter am ,bloß imaginierten‘ anzusiedeln sind: „Ich könnte über ihre Schuhe einen kleinen Vortrag halten, der alle Gäste verblüffen würde; ich tue es nicht oder vielleicht später." (Regenschirm, S. 99) Die Planung des Vortrags ist hier noch nicht elaboriert, die Wirkung hingegen erneut sehr wohl: In der Gestalt eines unüblich selbstbewussten Selbstbilds ist sich der 46-jährige Namenlose seiner Wirkung, setzte er sein Vorhaben denn in die Tat um, sicher. Das Präsens bringt eine erzähltheoretische Besonderheit mit sich, die einerseits aufgrund der (vermeintlich) fehlenden zeitlichen Distanz ein Erleben ,als würde es sich jetzt ereignen' ermöglicht und mithin die (vermeintliche) Ergebnisoffenheit markiert („vielleicht später“), andererseits den Grad an Unmittelbarkeit potenziert - selten ist man aus interner Perspektive näher an einer Figur als in der abwägenden Planungsphase, à la: ,Soll ich's wirklich machen oder lass' ich's lieber sein'.

Dass hier auch lediglich Interessantheit suggerierende Gedanken, Pläne, Vorhaben diskutiert werden, die in der Diegese nicht in Interessantheit performativ umgemünzt werden, findet seine Begründung hingegen im externen Blick und im externen Kommunikationssystem: Für die Rezipienten wird neben des Eindrucks des Zauderns und Zögerns eben auch mittransportiert, dass die Hauptfigur es durchaus in der Hand gehabt hätte, so zu handeln. Denn auch in die Bereiche der Interessantheits-Performanz stoßen die Hauptfiguren Genazinos immer wieder vor, sodass sich die Vermutung, es in den eben zitierten Beispielen lediglich mit selbstwertdienlichen Fantasien zu tun zu haben, erübrigt: „In aufgeräumter Stimmung begebe ich mich eine halbe Stunde später nach unten und begrüße die Seminarteilnehmer mit einer kurzen launigen Rede. Hinter-

35 Vgl. Angelika Linke/Markus Nussbaumer/Paul R. Portmann: Studienbuch Linguistik ergänzt um ein Kapitel „Phonetik und Phonologie“ von Urs Wille. 4., unv. Aufl. Tübingen 2001, S. 176.

36 Vgl. Anja Hirsch: Zwischen Krise und Katastrophe. Warteschleifen im Schwellenraum deutschsprachiger Gegenwartsliteratur. In: Achim Geisenhanslüke/Georg Mein (Hg.): Grenzräume der Schrift. Bielefeld 2008, S. 269-288. 
her plaudere ich mit den Leuten auf eine Art, die ich sogar selbst als charmant empfinden muß.“ (Liebesblödigkeit, S. 72) Erzähltheoretisch interessant und auffällig an dieser Passage: Es handelt sich um einen Erzählerbericht, viele Leerstellen werden nicht gefüllt; wie etwa der Wortlaut der „launigen Rede“, Körpersprache, das Publikum oder Ähnliches. In dieser Raffung mit Ellipse wird vermittels des eigentlich ,negativen' Mittels des Understatement indirekt $(\Rightarrow I .3 .3)$ auf doppelter Ebene eine positive Wirkung hervorgerufen: im buchstäblichen Sinne in der positiven Selbstbeschreibung sowohl als auch auf einer auf der Erzähloberfläche sich spiegelnden Metaebene, die den externen Blick auf die Figur einfordert: Wenn eine geballte Portion positiver Attribute einer Figur just in Form eines Erzählberichts realisiert wird, zu dessen Definiens ,Auslassung' gehört, ist das eine Untertreibung ganz eigener kunstfertig-unaufdringlicher Art.

Genazinos Figuren steht also auch ein Arsenal an Verstandeswaffen zur Verfügung, das sich etymologisch um den ,Witz' formiert. Damit sind neben dem Witz in der Begriffsverwendung als ,auf Pointe zugespitzte Kurzerzählung, die Lachen oder Schmunzeln evozieren soll` (vgl. Falsche Jahre, S. 464; vgl. Liebesblödigkeit, S. 151 f.), namentlich auch die eher mit Gewitztheit, Originalität und Esprit zu bezeichnenden Fähigkeiten mit enthalten. So erlaubt sich etwa Abschaffel, um sich letztlich seiner selbst zu vergewissern - jedenfalls wenn man aus der Distanz auf die Handlung schaut, was bei Genazinos Figuren häufig zu einer Entstellung und/oder Verrätselung der Intention führen kann, - einen geistreichen Streich:

Und Abschaffel betrat das Büro und sagte, seine Frau sei Kindergärtnerin, und sie gehe mit den von ihr betreuten Kindern fast jeden Tag an den Schaufenstern der Bausparkasse vorbei, und die Kinder fragten sie jedesmal, ob ihnen die Tante nicht so ein Häuschen zum Spielen besorgen könnte. Und wirklich, das Gesicht des jungen Angestellten nahm einen teilnehmend-freundlichen Schimmer an. (Sorgen, S. 386)

Die hier evozierte Interessantheit ist - neben jener auf den „teilnehmend-freundlichen Schimmer" des Angestellten bezogene - hauptsächlich eine nur im Hinblick auf die Zielgruppe zu bestimmende: In Analogie zur bereits geläufigen Tatsache des IM auch vor sich selbst versucht die Hauptfigur ihr Selbst zu stabilisieren, das im Erzählverlauf durch eine psychische Erkrankung bedroht ist. Um, so könnte man also diese Passage ,selbstsichernd' interpretieren, die funktionierende Gewitztheit für sich unter Beweis zu stellen, setzt er den Plan in die Tat um. Als sich letztlich herausstellt, dass er misslingt, „glaubte er wieder, keine Grenzen mehr zu haben. Er zerlief und zerfloß und legte sich um die Häuser herum und wartete darauf, daß er sich wieder zusammensetzen konnte." (Sorgen, S. 387) Entkleidet man diese Szenen ihrer handlungsrelevanten Tragik, so bleibt die Fähigkeit der Figur zu konstatieren, verbal-digital originelle Kommunikationsakte hervorbringen zu können - subjektiv wie diegetisch-objektiv.

Hinsichtlich des Geistreichtums gibt es Spielarten, die eindeutiger auf ,Höhenflug' abonniert sind, wie im ,Künstlerroman' Der Fleck, die Jacke, die Zimmer, der Schmerz, und solche, die bodenständiger bürgerliche Bildungskommunikation bedienen: „Traudel ist entzückt über mein 
locker serviertes Bildungswissen. Sie hebt ihr Glas, wir prosten uns zu, Traudel lobt mich als Unterhalter und Literaturkenner." (Glück, S. 71)

Weisen, die auch im Sektor der ,Interessantheit im besseren Sinne' das gesprochene Wort um die Beteiligung anderer Codes transzendieren, lassen sich in Form überraschender Handlungen identifizieren, die zunächst durch die Realisation,vor kleinem Publikum' charakterisiert werden können:

Ich spanne das Bein ein wenig an, so daß sich, auch für mich zum erstenmal, das brüchige Gewebe über dem Knie öffnet. Giselas Gesicht wird von einem schönen Lachreiz bewegt. Die Mutter bemerkt unser Spiel nicht. Das ist Gisela und mir recht, dann kann ich die kleine Nummer wiederholen. (Fleck, S. 39)

W., der als verhältnismäßig selbstsicherer Protagonist gezeichnet wird, extemporiert in der Bahn eine Darbietung, die dem gegenübersitzenden Mädchen Gisela zur Freude gereicht und sich selbst dadurch in Form der Bewunderung ein positives Selbstbild sichert. Auch der ansonsten sehr blass bleibende Protagonist aus dem Roman Außer uns spricht niemand über uns brilliert in einer Szene, die Interessantheit in der Schattierung der Originalität versinnbildlicht: „Zeige mir eine beliebige Stelle meiner Regale, sagte ich, und verlange von mir, Titel und Verfasser des Buches zu nennen, das ich da oder dort unter das Regal gekickt habe." (Außer uns, S. 34) Ohne Ko- und Kontextwissen müsste man ihm von interner Warte aus den Sophismus-Vorwurf machen. Aber die Tatsache, dass es sich um ein spontanes Spiel handelt, das als prächtige Parade des Vorwurfs der Unordentlichkeit seiner Freundin Carola verstanden werden muss, und ihr aus dem Stegreif die tiefere Ordnung seines Chaos beweisen soll, legt die Originalität jedenfalls des Gedankens frei. Postwendend ereilt den Leser allerdings eine alte Plattitüde ( $\Rightarrow$ II.5.1): Sobald in einer Dyade von Frau und Mann Interessantheit unter Beweis gestellt wird, ist die vorhersagbare Reaktion der Frau eine wenigstens mit körperlichen, zumeist mit sexuellen Konnotationen garnierte: „Ich nehme alles zurück, sagte sie; sie öffnete mein Hemd und küsste mir wie einem Kind die Brust." (Außer uns, S. 35; vgl. Kein Geld, S. 29)

Über die Brücke der analogen Kommunikation schreitend müssen auch ,aggressiver` um Aufmerksamkeit buhlende Verhaltensweisen in den Blick genommen werden, die sich erstens durch das anvisierte Publikum (größer) und - damit zusammenhängend - zweitens durch die Sichtbarkeit der Aktionen (auffälliger) auszeichnen:

Ich nehme eine von ihnen [Wolldecke; N. L.] unter den Arm und verlasse das Hotel. Auf der Straße breite ich sie aus und lege sie mir in der Art eines Überwurfs über die Schultern. Mit den Fingern der linken Hand halte ich die beiden oberen Enden der Decke zusammen. [...] Ich sehe mich nicht um, ich gehe langsam die Grenzgasse entlang und spüre die Verwunderung der anderen. Die der jungen Leute geht, wenn ich mich nicht irre, nicht tief. Sie stellen nur knapp und resonanzlos fest, daß sie einen Mann mit Wolldecke nicht einordnen können. Ich bemühe mich, nicht den Eindruck von Ausgestoßenheit hervorzurufen. Eher möchte ich aussehen wie ein Wanderer. Ergiebiger sind die Reaktionen der Alten; sie sind verwundert und dadurch aufmerksam. (Fleck, S. 85) 
Das ist qualitativ etwas ganz anderes, als bspw. einem kleinen Kind in der S-Bahn seine fadenscheinig zu werden sich anschickende Kniebekleidung zu präsentieren. Insofern aber, als in beiden Fällen die öffentliche Selbstaufmerksamkeit ( $\Rightarrow$ II.2.4), die sonst häufig zensorische Funktion übernimmt $(\Leftrightarrow I I .2 .6)$, suspendiert ist, ja nachgerade lustvoll ausgekostet wird, sind beide Handlungen zu verbinden: „Immer wieder macht sich W. [...] selbst zum Objekt der Beobachtung. [...] Indem er verschiedene Rollen ausprobiert und die Reaktionen der anderen testet, stellt er Fragen nach Identität und Wahrnehmung in den Vordergrund.“" ${ }^{37}$ Mitunter ist nicht einwandfrei zu entscheiden, ob diese Rollenspiele um ihrer selbst willen ,aktiv' gespielt werden, oder ob es sich mehr oder weniger kontingent ereignet, dass das Verhalten der Figur ob seiner Merkwürdigkeit zum dezidierten Beobachtetwerden ( $\Rightarrow$ II.2.4) einlädt, ohne derart intendiert zu sein:

Ich bleibe in der Nähe kleiner Pfützen stehen, deren Ränder meine Schuhe berühren. Ich registriere die teils verwunderten, teils ratlosen und teils verbietenden Blicke um mich her. Manchmal bleibt jemand, meist eine Frau, länger in meiner Nähe und gibt zu erkennen, daß er oder sie an meinen Geheimnissen interessiert ist. (Frauen, S. 130 f.)

Für den eigenbrötlerischen Schriftsteller, der auf den ersten 100 Seiten keinerlei Kontakt zu Freunden oder Bekannten hat, ist die Frage danach für diese Momentaufnahme sicherlich eher mit ,Zufall' denn mit ,Absicht' zu beantworten, wogegen die folgende Szene ihn als denjenigen von Hirsch beschrieben ,Ausloter' porträtiert:

Aus meiner linken Jackentasche ziehe ich einen Brief hervor, den ich fast immer bei mir trage. Der Briefumschlag ist zwar frankiert und adressiert, aber leer. Ich [...] zeige ihn manchmal zum Schein, weil ich sehen möchte, wie die Phantasie von Menschen durch den Anblick eines Briefes in Gang kommt. [...] Ich zeige und schwenke den Brief vage umher, und es dauert nicht lange, dann treibt sich in meiner Nähe eine junge Frau herum, die sich ebenso vage für den Brief interessiert. [...] Für dieses Warten und Zögern, Lauern und Schauen angesichts eines fremden Briefes gibt es noch kein Wort. (Frauen, S. 21)

Wiewohl intrinsisch motiviert - er unternimmt dieses Spiel, weil er das Zentrum der teilnehmenden Beobachtung sein möchte -, ist es offensichtlich, dass sich der Protagonist mit dem Wecken fremden Interesses auch dezidiert der Beobachtung und den Mutmaßungen der anderen bereitwillig aussetzt. Selbst als interessant zu gelten, ist sicherlich eine der Triebfedern, aber eben auch die Generierung von Selbstidentität und Gewissheit in einer undurchsichtigen Welt: „Ich frage einen jüngeren Mann, ob im sechsten Stock eines Bürohauses Licht brennt oder nicht. Der Mann schaut das Haus an und sagt: Ja, es ist Licht dort. Dann ist es gut, vielen Dank, sage ich." (Fleck, S. 209) Kurz zuvor hatte W. seinerseits einer Passantin eine ähnliche Frage beantworten müssen und scheint von der Vergewisserung der die Figuren umgebenden Welt zu dieser rhetorischen Frage veranlasst worden zu sein. in der Poetologie Genazinos übernehme: „Die Intention des Autors wäre dann unter anderem die Preisgabe seines poetischen Verfahrens, der Text also grundlegend selbstreflexiv." 
Situativ müssen die jüngst diskutierten Beispiele von Interessantheit allesamt dem öffentlichen Bereich zugeschlagen werden. Nimmt man demgegenüber privatere Sphären in den Blick, fällt auf, dass die Fantasie, die Erfindungsgabe, das Extemporiergeschick hier zur vollen Blüte gereift sind. Schon der Abschaffel aus dem Roman Die Vernichtung der Sorgen, dessen unausgesprochenes Lebensmotto lautet: „Bitte nicht so laut, bitte nicht so schnell, bitte nicht zuviel“ (Sorgen, S. 351), zeigt sich ob seiner eigenen Wortwahl im belanglosen Gespräch mit seinem Arbeitskollegen überrascht $(\Leftrightarrow I I .3 .1)$ :

Er wunderte sich, daß er das Wort Freizeitkapitän verwendet hatte. Er war sicher, das Wort vorher nie ausgesprochen zu haben. (Gestern schon hatte er das Wort Urlaubsflamme gebraucht. Und jetzt Freizeitkapitän. Wie kamen nur diese Worte in ihn hinein? Und wie kam es, daß sie so rechtzeitig auftauchten, so passend zu den Gelegenheiten?) (Sorgen, S. 299)

Ohne die Komik zu übersehen, handelt es sich just um die Gabe des narrativen ,Schwätzchens', die ihm und Genazinos Basistypus in der Regel abgeht. Hier hilft die externe Figurenperspektive weiter: Um die bis zu dieser Stelle mühsam konstruierte Figur nicht unglaubwürdig werden zu lassen - ,Warum kann Abschaffel plötzlich Smalltalk?` -, greift Genazinos Erzähler auf den alten Trick der Verbalinspiration zurück und ergründet damit die Grenzen der Situationskomik: „Na, dann toi toi toi, sagte Abschaffel. Es war unglaublich, aber er hatte wirklich toi toi toi gesagt. Er hatte es selbst von sich gehört." (Sorgen, S. 299) Sind es in diesem Fall Impulse von außen, die Abschaffel befähigen, erfolgreich spontan phatisch zu kommunizieren und die Aufmerksamkeit auf sich zu lenken, ist es im auf die Abschaffel-Trilogie folgenden Roman die Hauptfigur Eckhard Fuchs selbst, welche sich - zumindest im Schutzraum der Imagination - dem Zwang zum Stegreif aussetzt: „Am liebsten hätte er Martha und Ruth zu sich gerufen und zu ihnen gesagt: Ihr glaubt nicht, was mir eben durch den Kopf gegangen ist! Und dann hätte er ihnen eine ganz andere Geschichte erzählt." (Ausschweifung, S. 98 f.) Bezeichnenderweise versagt sich Fuchs diese Einlage, die ihn für die zwei Frauen in einem günstigen Licht erscheinen ließe, weil er just zuvor eine sexuelle Fantasie mit der Freundin seiner Frau hatte - zusammengenommen und ohne, dass irgendetwas in die Tat umgesetzt worden ist, steht im positiven Sinne eines erzähltheoretischen Semper-aliquid-haeret: Übertreibe nur dreist, am (Selbst-)Bild werden Teile davon haften bleiben. Dass mit dem Titel Die Ausschweifung nicht nur diejenige sexuelle mit einer Bankangestellten gemeint ist, sondern durchaus auch die gedanklichen Verstrickungen Fuchs', zeigt die folgende Reflexion:

Oder geschah alles nur deswegen, weil er Lust hatte, etwas zu verheimlichen? Und das von ihm Verheimlichte durfte er selbst wiederum nicht verstehen, weil er sonst nicht das Gefühl haben konnte, überhaupt etwas verheimlicht zu haben. Mit diesem merkwürdigen Gedanken, den er selbst kaum verstand, lief er über die Hauptwache (Ausschweifung, S. 283 f.).

Bereits einige Beispiele sind in der Tendenz ,postfaktisch' gewesen, die nur durch Umsiedlungen innerhalb des Bedeutungsnetzes der Sprache von der Valeur ,Lüge‘ weg zum ,Flunkern` in diesem Kapitel ansässig sind, obwohl sie eher dem nächsten Unterkapitel zuzuordnen gewesen 
wären ( $\Rightarrow$ II.3.5). Die ersonnenen Fantasieberufe, die Genazinos Heldinnen und Helden regelmäßig aus der gedanklichen Taufe heben, sind Ausdruck dieser ,alternativen Fakten'. Für den Protagonisten aus Ein Regenschirm für diesen Tag ist es etwa das „INSTITUT FÜR MNEMOSYNE“, das er sich ausmalt und mit dem er Menschen in "Gedächtniskunst“ unterrichten möchte (Regenschirm, S. 47 f.). Dass die Hauptfigur im Handlungsverlauf tatsächlich eine erste zahlende Kundin für einen „Erfahrungsnachmittag“ (Regenschirm, S. 164) hat und eine weitere einen Termin wünscht, zeigt die durchlässige Grenze zwischen interessanter Kopfgeburt und in die Erzählwirklichkeit ausstrahlender Interessantheit.

Im Handlungsrepertoire des Basistypus finden sich gerade im Konnex mit den Fantasieberufen fulminante Momente, in denen die Figuren den Gedanken die Zügel schießen lassen, um auf den ersten Blick originell, schlagfertig oder überraschend zu erscheinen. Allerdings teilweise auch an der Grenze des ,moralisch Einwandfreien' und damit kurz vor Ende dieses Kapitels:

Plötzlich sagte ich zu Dr. Wolters, er könne sich auch als Sofortanalytiker bewerben ... ja! ... und als Enttäuschungspraktiker hätte er ebenfalls noch Chancen ... natürlich! Der Privatdozent stieß ein nicht sehr rätselhaftes Ach ja! aus, schwieg dann einige Sekunden und legte auf. Nach diesem Zwischenspiel am Telefon fühlte ich mich wohler. Ich wusste nicht, woher mir die Worte Sofortanalytiker und Enttäuschungspraktiker zugeflogen waren, ich hatte sie nie zuvor gehört oder gelesen, musste aber wenig später über sie lachen. Guter Gott! Nach meiner Einschätzung würde Dr. Wolters seine Kontakte zu mir jetzt mehr und mehr einschlafen lassen. Genau genommen hatte ich schon lange darauf gewartet, ihn einmal so sehr zu verwirren, dass er mich endgültig nicht mehr zu seinen Gartenfesten einlud. Als moralischer Mensch kam ich nicht sofort mit der Situation einer von mir ausgelösten Verhöhnung zurecht. (Kassiererinnen, S. 130)

Wie leicht ersichtlich wird, ist die Interessantheit hier nach außen hin verkleidet als Verwirrung und zeitigt durch eher offensiv zu nennendes IM kein positives Gesicht, sondern ein eindeutig negatives, indem der Wunsch danach, „dass er mich endgültig nicht mehr zu seinen Gartenfesten einlud“, stärker auf „Individualität und Handlungsfreiheit“ zielt als auf „das Bedürfnis nach einem Gemeinschaftsgefühl“ ( $\Rightarrow$ II.3.1). Für die Figur ist diese Unhöflichkeit des negativen Gesichts - nicht zuletzt aus Gründen der öffentlichen Selbstaufmerksamkeit - zunächst nicht mit dem Selbstbild in Einklang zu bringen: Das aus der geistreichen Geschmacklosigkeit resultierende Schamgefühl überwiegt zwischenzeitlich, wird aber sukzessive einerseits durch die Lust an der imposanten Wirkung an sich, andererseits durch die erfolgreiche Zielverfolgung der kommunikativen Absicht beerbt. Das Grenzgebiet zwischen Esprit sowie Extemporiergeschick und denjenigen Handlungsweisen, die ,über das Ziel hinausschießen', ist damit bereits betreten worden und spätestens im folgenden Beispiel wird diejenige Grenze, die man näherungsweise und in Ermangelung besserer Wendungen als diejenige des ,guten Geschmacks‘ bezeichnen könnte, überschritten:

Und jetzt stellen Sie sich mal vor, sagte er, da kommt so ein neunzehnjähriger Balkanlümmel hier an. Eine Eisenbahn wird er schon einmal gesehen haben, aber ob er zwei Züge zugleich schon gesehen hat, ist fraglich. [...] Frau Schönböck lachte, und Abschaffel schämte sich. Er hatte Spaß daran, mit einer diskriminierenden Rede ihr Vergnügen hervorzurufen. [...] Hätte er je eine Unterhaltung gehört wie die, die er nun selber führte, er hätte sich empört abgewendet. (Sorgen, S. 294 f.) 
Dass es durchaus möglich ist, auch (weit) jenseits dieser Grenze aufzufallen und sich dadurch ,interessant zu machen', zeigt das folgende Kapitel.

\section{5 Über das Ziel hinausgeschossen}

Kein Verhalten kann gänzlich ohne Bezug auf das Soziotop, innerhalb dessen es sich ereignet, als ,überzogen' stigmatisiert (geschweige denn in irgendeiner anderen Hinsicht adäquat beurteilt) werden. Howard S. Becker fasst es devianzsoziologisch auf den Außenseiter gemünzt in die prägnante Formel: „Der Mensch mit abweichendem Verhalten ist ein Mensch, auf den diese Bezeichnung erfolgreich angewandt worden ist; abweichendes Verhalten ist Verhalten, das Menschen als solches bezeichnen." ${ }^{38}$ Nichtsdestotrotz lassen sich Metakategorien heranziehen, welche die getroffene Einteilung plausibilisieren: So werden hier diejenigen Handlungsmuster zusammengefasst, die im Gegensatz zu denjenigen Randphänomenen ,im besseren Sinn` ( $\Rightarrow$ II.3.4) durch niedrigere Verträglichkeit bezüglich der Big Five - unfreundlich, selbstgefällig, berechnend, rücksichtslos, unsensibel, manipulativ etc. $(\Leftrightarrow$ II.1.3 u. $\Rightarrow$ II.4.1) - zu kategorisieren sind, im Gegensatz zu denjenigen des vierten Schlaglichts $(\Leftrightarrow I I .4)$ allerdings immer noch hauptsächlich im Zeichen des Interesseweckens stehen - eine für die westliche Welt des ,TurboIndividualismus' durchaus goutierte Motivation. So gehört es schon fast zum ,guten Ton', eigene Vorzüge noch ein wenig vorzüglicher zu präsentieren und hier und da noch ,eine Schippe obendrauf zu legen', wenn es um die Selbstpräsentation geht. Erscheinungsformen dieser Eindruckssteuerung sind dementsprechend: Lügen, Aufschneiderei, Überheblichkeit bis hin zum Größenwahn, aber auch sich bis zur Verrücktheit $(\Leftrightarrow \text { II.1.1 })^{39}$ ausdehnende Merkwürdigkeiten und deviantes Verhalten. ${ }^{40}$ Insbesondere das Feld der sich bisweilen in die Mythomanie versteigenden Lügen ${ }^{41}$ ist eines, das durch den Wunsch, interessant(er) zu sein (als tatsächlich), gedüngt wird:

Sicher, sagte Abschaffel überraschend, man sollte sich solche Wünsche erfüllen. Aber man ist ja schließlich nicht mehr der Jüngste und auch nicht mehr so aufnahmefähig, sagte er. Die beiden Frauen sahen ihn an. In ihr Schweigen hinein fuhr er fort: Auch ich habe mir einmal, es ist noch gar nicht so lange her, einen Wunsch erfüllen wollen. Und zwar wollte ich endlich Finnisch lernen. Ich kenne das Land gut, sehr gut sogar, und es wäre an der Zeit gewesen, daß ich die Sprache lerne. Von wegen! rief er aus. Ich meldete mich zu einem Finnisch-Kurs bei der Volkshochschule an, und schon in der ersten Stunde habe ich bemerkt, wie schwer mir das Lernen fiel. Und in der zweiten Stunde war ich überzeugt, daß ich das nie lerne. Es war zu schwer oder ich war zu alt oder sonstwas, sagte er und seufzte dazu. Er wischte sich noch einmal den Mund ab und ließ die Serviette auf den Tisch fallen. Dann stand er auf und ging vom Tisch. In seinem Zimmer zog er sich um für das Terraintraining. Einige Augenblicke lang war es ihm heiß im Kopf gewesen: Schon sehr lange hatte er nicht

38 Howard S. Becker: Außenseiter. Zur Soziologie abweichenden Verhaltens. 2. Aufl. Berlin 1963/2014.

39 Vgl. Marx: Erzählfiguren der Verrückung.

40 Vgl. Fischer: Wider das System.

$41 \quad$ Vgl. $(\Leftrightarrow$ II.1.2) für eine systematischere Untersuchung der ,kleinen Lüge` sowie $\Leftrightarrow \Rightarrow$ II.2.5) für die Indienstnahme der Lüge als Mittel der Unsichtbarkeit. Vgl. im Kontrast zu dieser horizontalen FigurenFiguren-Achse auch ( $\Rightarrow$ I.2.2) für die vertikale Erzähler-Leser-Ebene des unzuverlässigen Erzählens. 
derartig sinnlos erfundene Geschichten erzählt. Weder kannte er Finnland noch hatte er jemals den Wunsch verspürt, Finnisch lernen zu wollen. Es war einfach nur ein riesiger Kopfquatsch. Oder hatte er Lust gehabt, der Wuppertaler Sekretärin eins auszuwischen? Vielleicht war es auch nur eine Auswirkung seines ewigen Gefühls von Unvollständigkeit, das ihn manchmal dazu trieb, sich die Komplettheit teuer erlügen zu müssen. Denn natürlich klagte er sich nun an und jammerte sich voll: Wie kam er dazu, irgend etwas aus der Luft zu greifen und eine Weile darüber zu reden, als sei es etwas Wirkliches? (Falsche Jahre, S. 478)

Zuvörderst ist erneut auf die mittlerweile bereits geläufige Formel, dass Selbst-Identität, „Komplettheit" der ,inneren Mannschaftsaufstellung 42 und also die Harmonisierung der multiplen Ichs nur zu erlügen sei, hinzuweisen. Außerdem muss die kunstvolle Form des Auftritts gewürdigt werden: Auf einem Abstraktionsniveau ist dieser zweifelsfrei dazu angetan, seine eigene Interessantheit assertiv zu pushen. Konforme Ansichten - „man sollte sich solche Wünsche erfüllen“ - sind ein probates assertives Mittel, um einer Gruppe, hier: der Tischgesellschaft, zu demonstrieren, dass man als einer der ihren wahrgenommen werden möchte $(\Rightarrow$ I.3.3). In Ergänzung zum effektvollen Fallenlassen der Serviette ließe sich zwar beinahe an eine wirklich theatralische Szene denken, aber man darf nicht übersehen, dass ein wichtiger Teil der Strategie im Moderaten liegt: Nicht umsonst werden eigene Unzulänglichkeiten eingestreut, wird qua selfhandicapping der zu dominante Wettbewerbsgedanke, wie er Individuen von niedriger sozialer Verträglichkeit eignet, zurückgefahren. Weiterhin: Abschaffel befragt sich selbst zu seiner Motivation und gelangt über den ,niederen Beweggrund', „,der Wuppertaler Sekretärin eins auszuwischen“, und zwar lustvoll, in Übereinstimmung mit einer psychoanalytischen Einschätzung des Lügens per se:

Der passionierte Lügner versucht nun freilich, aus der Not einen zusätzlichen Lustgewinn zu ziehen [...]. Er verwendet das Lügen dazu, die Wahrheit an der Nase herumzuführen, die Realität so auszuschalten, dass ein möglichst hoher Gewinn an Triebbefriedigung dabei herauskommt. ${ }^{43}$

Angelika Ebrecht-Laermann setzt allerdings hinzu, beim Lügner werde sich - und erneut besteht eine (nur scheinbar) erstaunliche Passung von Abschaffels Selbstbefragung und psychoanalytischer Argumentation -, „sobald er versucht, sich gänzlich [...] seinen Lügen hinzugeben“, „das schlechte Gewissen bemerkbar machen und einen unbemerkten Irrtum erzeugen, der ihn verrät“.44 In der Tat wirft der personale Erzähler mit ,Jammern und Klagen` Schwergewichte in die Waagschale des aus der Balance gebrachten psychischen Gleichgewichts und beglaubigt damit die erste Stufe der Lügenreue in der Nach-Handlungsphase ( $\Rightarrow$ I.3.1). Zugleich weist der Erzählerkommentar aber die Äußerung Abschaffels vorsorglich bereits in der ersten Parenthese des Zitats („überraschend“) als für Abschaffel aus Fremdsicht (Mitfiguren sowie Leser) ungewöhnlich aus, was erzähltechnisch höchst bemerkenswert für die Figurenanlage ist: Die Filterfolie, durch die der Rezipient Abschaffel nach der vorsorglichen Entschuldigung sieht, relativiert die ,Schwere der Tat' immens. Nur scheinbar erstaunlich ist die Passung zwischen Theorie und Ge-

\footnotetext{
42 Vgl. [Inneres Team].

43 Ebrecht-Laermann: Lügen als Passion, S. $80 \mathrm{f}$.

44 Ebrecht-Laermann: Lügen als Passion, S. 81.
} 
nazino'scher Erzählpraxis übrigens zu nennen, da Genazinos Figuren über Umwege mit psychoanalytischem Wissen imprägniert sind $(\Leftrightarrow I .3 .2)$ und dementsprechend antizipieren, dass Lügen nun einmal auch psychoanalytisch nur kurze Beine haben, sich für diesen Fall aber auch sofort eine Entschuldigung parat legen, die ihrerseits den Wahrheitsbegriff dehnt:

[M]eine Demaskierung als Schwindler und Scharlatan wird noch einmal hinausgeschoben. Inzwischen übe ich im stillen die Sätze, die ich zu meiner Entschuldigung hervorbringen werde. Sehen Sie, es war nur eine Sektlaune. Mein Temperament geht manchmal mit mir durch. Was glauben Sie, wie oft ich schon Opfer meiner eigenen Redelust geworden bin. Das müßte genügen, so ungefähr. (Regenschirm, S. 155)

Die Psychoanalyse würde antworten: ,Früher oder später tritt die Fehlleistung schon ein.' Genazinos Figuren würden entgegnen: ,Seit Jahren sind wir geübte Lügner und die manipulative Verwendung einer nicht ganz der Wahrheit entsprechenden Geschichte ist lässliche Sünde, wenn das Ziel es rechtfertigt.' ${ }^{45}$ Die Psychoanalyse würde sagen:

Der passionierte Lügner befindet sich im Grunde auf der Suche nach Wahrheit. Er sucht seine eigene, innere Wahrheit, die unter einem großen Berg von Lügen verborgen ist, die sich oftmals bereits seit Generationen angehäuft haben und auf ihm abgeladen worden sind. ${ }^{46}$

Genazinos Figuren würden sagen: ,Das wissen wir.'

Dieser Tiefendimension zum Trotz wenden Genazinos Figuren die Lüge häufiger ausdrücklich als notwendiges Mittel zur Interessantheit an. So berichtet der Ich-Erzähler aus Wilhelm Genazinos Roman Kein Geld, keine Uhr, keine Mütze - wenn er „gut in Form war“ - „vor anderen Leuten: Als ich vor zwei Jahren in Odessa war, habe ich im Hafen der Stadt einen billigen Papagei gekauft und habe ihn wenig später einem armen Schulkind geschenkt." (Kein Geld, S. 18) ${ }^{47}$ Oder Gerhard Warlich, eine der kompliziertesten Psychen des Figurenensembles, das in den Basistypus strahlt, bekennt unverhohlen: „Wenn die Stille gar zu sehr drückt, fange ich plötzlich an, von privaten Erlebnissen zu erzählen, die mir niemals zugestoßen sind.“ (Glück, S. 33) Das lässt sich notfalls noch eher der mangelnden Fähigkeit zuschreiben, Stille ertragen zu können ( $\Rightarrow$ II.1.4), als es mit der Notwendigkeit zu kennzeichnen, unbedingt Eindruck machen zu wollen. Aber spätestens die Dichte an Fundstellen für genau diese Methode der Lügeninstrumentalisierung (vgl. Sorgen, S. 214 f.; vgl. Falsche Jahre, S. 460; vgl. Ausschweifung, S. 98 f.) ${ }^{48}$ lassen den (unbewussten) Zwang zu Tage treten:

45 Die Formulierung aus einem Standardfragebogens zur Erfassung von Verträglichkeit lautet: „Um zu bekommen, was ich will, bin ich notfalls bereit, Menschen zu manipulieren." (NEO-FFI-Kurzform) Vgl. dazu etwa Licht, S. 95 f., mit einer halbwahren Erzählung über Besuche in Nachtbars und die kalkulierte Verblüffung der Schulfreunde, die ihn ab dato in einem anderen Licht sehen.

46 Ebrecht-Laermann: Lügen als Passion, S. 81.

47 Als Besonderheit muss dazu angemerkt werden, dass der Erzähler im Begriff des Lügens von der Wahrheit überzeugt ist (vgl. Kein Geld, S. 18).

48 Vgl. weiterhin bspw.: „Haben Sie schon gehört, im Inneren der Berge werden zur Zeit Schächte gebohrt [...]?“ (Falsche Jahre, S. 412) Oder: „Später, zu Beginn der Stunde, war Abschaffel entschlossen, Dr. Buddenberg heute etwas vorzulügen." (Falsche Jahre, S. 460) Auch: „[I]ch wollte noch lustigere Sachen zusammenlügen, sie sollte mehr lachen, auch wenn sich Falten auf den Wangen bildeten“ (Laslinstraße, S. 73). 
Die drei Themen, über die ich erzählen konnte (ein bißchen Kindheit, ein paar Jahre Schule und dazwischen meine rätselhaften Eltern), kamen mir uninteressant vor. Ich hätte mich in ein Lügengespinst verstricken müssen, in dem ich mich bald selbst nicht mehr ausgekannt hätte. (Wohnung, S. 103)

Was sich erneut als Eindrucksschinderei auf männlich-weiblicher, dyadischer Ebene entpuppt ( $\Rightarrow$ II.3.1), wird andernorts noch massiv gesteigert. Sobald die potenzielle Angst der Mitmenschen zum eigenen wirtschaftlichen Nutzen heraufbeschworen wird, liegt genaugenommen Populismus unschönster Couleur vor: So ist die Lehrerin aus dem Text Die Obdachlosigkeit der Fische zumindest in der Erzählvergangenheit insofern über das Ziel hinausgeschossen, als sie als Teenager behauptet hat, „daß bald ein Krieg ausbrechen werde und daß es deswegen sinnvoll sei, sich vorher von mir porträtieren zu lassen." (Obdachlosigkeit, S. 54) Obwohl der Protagonistin die Arglist bewusst ist, heiligt der Erfolg für sie in diesem Fall die Mittel: „Meine Einschüchterung war erfolgreich. Das erste Porträt, das ich für zwanzig Pfennig verkaufte, zeigte die vierzehnjährige Ilse Schottländer, die begeistert war, gezeichnet zu werden." (Obdachlosigkeit, S. 55) Neben dem Aufmerksamkeits-bindenden Erfolg lässt sich zusätzlich thematisieren, dass es sich auch mit den Lügen im Dienste der Interessantheit ähnlich verhält wie mit Letzterer eo ipso: immer changierend zwischen Imagination und nach außen kommunizierter Erzählweltrealität (Y-Achse): „Ich bin über meine Lügengeschichte nicht einmal besonders irritiert. Ich bin es gewohnt, in meinem Inneren mit eigenartigen Gebilden umzugehen. Neu ist, daß diesmal etwas von diesen Gebilden nach außen gedrungen ist“ (Glück, S. 58).

Auch hinsichtlich der Untergliederung in analoge vs. digitale Kommunikation (X-Achse) und in Bezug auf das Publikum (Z-Achse) lässt sich die Lüge als ,Notwendigkeit zur Interessantheit‘ betrachten. Weigand, der Hauptakteur des Texts Eine Frau, eine Wohnung, ein Roman, schlägt Kapital in Form von Interesse an seiner Person daraus, dass er einer - teilweise bekifften - Partygemeinschaft in einer Mixtur aus verbalen sowie non- und paraverbalen Elementen seinen eigenen Drogenrausch vorgaukelt:

Ich fing an, die Straßenbahn zu schildern, und zwar verdoppelt, als Bild im Bild, als eine Straßenbahn, die gerade in eine andere Straßenbahn hineinfuhr und dann wieder aus ihr heraus. Mit der verdoppelten Straßenbahn hatte ich sofort Erfolg. Ein paar Gäste stellten sich neben mich und warteten auf meine nächsten Sätze. Gleichzeitig sahen sie ebenfalls auf die Straße hinunter. Sie erkannten, daß es immer nur eine Straßenbahn gab, obgleich ich fortfuhr, von zwei oder gar mehreren Straßenbahnen zu reden. Die Straßenbahn fuhr weiter, ich redete, die gespielte Halluzination machte mich zur Hauptfigur. Ich tat ein wenig benommen, es gab keinen Zweifel, die anderen glaubten, ich sei bekifft. Meine verdoppelte Straßenbahn verwandelte sich in den lang erwarteten Beweis, daß es eine bewußtseinsverändernde Wirkung der Drogen wirklich und tatsächlich gab. Meine Schilderungen ähnelten denen, die ich vor ein paar Wochen in den Rauschgiftbüchern von Borroughs, Ginsberg und Kerouac gelesen hatte. Es war das erste Mal, daß mir die Literatur unmittelbar aus der Patsche half. Ich war hier offenbar der einzige, der wirklich berauscht war, allerdings von der Literatur. Da kam schon die nächste Straßenbahn aus der Gegenrichtung. Diesmal hob ich in meiner Schilderung mehr auf die Farben ab. Das Gelb des Lichts ging über in das Orange des (nicht vorhandenen) Sonnenuntergangs, das Orange verfloß in das Tiefseegrün eines ebenfalls nicht vorhandenen Meeres und das Tiefseegrün wandelte sich in das Blaugelb eines vorüberflatternden Papageienschwarms. Siehst du auch Ringe und Spiralen? fragte jemand. Ich schaute vage 
umher und reagierte natürlich nicht mehr auf Fragen, schließlich befand ich mich in einem Rausch. (Wohnung, S. 61 f.)

Lügen, Rausch und Hochstapelei vertragen sich, wie gerade eindrucksvoll unter Beweis gestellt, gut, doch angeberisch, aufschneiderisch und prahlerisch sich zu verhalten, findet auch außerhalb dieser Verknüpfung statt:

Ich bin sogar ein bißchen froh, daß sie mir in den letzten Tagen nicht begegnet ist. Vermutlich hätte ich nicht der Versuchung widerstehen können, ein paar auftrumpfende Mitteilungen zu machen. [...] Ich hätte leicht merken können, wie verblüfft Lisa gewesen wäre, und ich hätte Lust gehabt, noch ein paar pompösere Verlautbarungen nachzuschieben. Meine Existenzlosigkeit geht zurück, findest du nicht auch? (Regenschirm, S. 165 f.)

Um sein Selbstbild zu pflegen (Wunschbild auszumalen), ereignen sich (häufig imaginierte) Gespräche oder Handlungen des Basistypus, die man der überschießenden Interessantheit zuordnen kann: „[I]ch bin überzeugt, eine neue, noch verborgene Wirklichkeit entdeckt zu haben, sagte er, soll ich es dir erklären? Ja, bitte, hörte Peschek Dagmar sagen. Seit langem fühle ich, sagte er, daß im kommenden, dem 21. Jahrhundert anders gelebt werden muß“ (Fremde Kämpfe, S. 65 f.).

Mit diesen großen Worten - obwohl es sich um ein fiktives, sogar in Teilen inszeniertes Gespräch handelt, ${ }^{49}$ wie die Abweichung von der Norm der typografischen Absetzung dem Leser diese Passage als Gedankenexperiment entdeckt - ist das Feld des ,erhabenen Duktus' betreten, ${ }^{50}$ der auch in den Romanen selbst thematisiert wird. ${ }^{51}$ Eckhard Fuchs gesteht sich etwa analeptisch ein: „Zu diesem Zeitpunkt wäre der Tod eines Elternteils etwas großartig Pathetisches gewesen, mit dem er vor seinen Freunden hätte angeben können." (Ausschweifung, S. 243) Ist es hier expressis verbis das rhetorisch-theatrale Pathos, das in der nur gedanklich-fiktiven Selbstkritik steht, ist es in Außer uns spricht niemand über uns ein realisiertes Gespräch, das vor Affekt überbordet: „Ich hatte zu affektiert geredet und war zu besorgt um meine Makellosigkeit. Ich hatte unter anderem über Kleists Zerbrochenen Krug geredet, und obwohl ich die Gestelztheit meiner Sätze sofort peinlich fand, konnte ich mich nicht bremsen." (Außer uns, S. 154) Auch wenn die Protagonisten das Auseinanderfallen von Selbst- und Fremdbild ( $\Rightarrow$ II.2.1) kritisch betrachten und das „Klug-Reden“ schlimmstenfalls „weniger an der Problemlösung als vielmehr an der eigenen Prestigemehrung" orientiert ist, ${ }^{52}$ scheint die Außenwirkung seiner Performances über jeden Zweifel erhaben: „Zum Glück sitzen meine Zuhörer in feinen Sesselchen, sonst würden sie mir jetzt zu Füßen liegen.“ (Liebesblödigkeit, S. 76)53

49 Vgl. Henne/Rehbock: Einführung in die Gesprächsanalyse, S. 26 u. S. 28.

50 Vgl. Klaus Herding/Bernhard Stumpfhaus (Hg.): Pathos, Affekt, Gefühl. Die Emotionen in den Künsten. Berlin/New York 2004.

51 Vgl. Pontzen: Banalität und Empfindsamkeit, für diejenigen Mechanismen, die das Pathetische abschwächen.

52 Wagner: Pragmatik der deutschen Sprache, S. 414.

53 Vgl. für eine ebenfalls mutmaßlich erfolgreiche und selbstbewusste Außenwirkung, die allerdings einem Missverständnis geschuldet ist: „Seit einigen Minuten gelte ich als risikofreudig, führungs- 
Größenwahn, Überheblichkeit und Überlegenheitsfantasien ( $\Rightarrow$ II.2.2) bilden also eine weitere Trias, die als Vehikel der überschießenden Interessantheit zumal dann relevant ist, wenn Genazinos Figuren nach gedachter oder vollzogener Handlung davon überzeugt sind, einmalig und unüberbietbar zu sein: „So sah es nämlich wirklich aus: wenn die Vögel allzu ermattet und hoffnungslos waren, kam der Fritten-Sämann und half ihnen auf die Beine." (Fremde Kämpfe, S. 33) Letztlich verfüttert Peschek nur alte Pommes Frites an „die Tauben, die rings um die Frittenbude herumzitterten“ - in seiner Deutung indes gelingt es ihm dadurch, „ein hoffnungsvolles Bild in die Welt setzen" zu können (Fremde Kämpfe, S. 33). Ähnlich überzogen wirkt Eckhards Resümee nach einer ad hoc erdachten Geschichte, die er im Kreise des familiären Essens seiner Frau und seiner Tochter auftischt, um seine Tochter vor der Aufdringlichkeit Ruths zu bewahren und das Thema zu wechseln, wofür er mit Gelächter bezahlt wird: „Die Verschwiegenheit seiner Motive gab Eckhard vorübergehend das Gefühl, der geheime, aber wirksame Mittelpunkt der Familie zu sein" (Ausschweifung, S. 30). In der faktischen Seltenheit, mit der Eckhard die Strippen als Familienoberhaupt zieht, ist sicherlich eine Ursache für das geschönte Selbstbild zu sehen. Aber auch der Wunsch nach Durchschauen bei gleichzeitig undurchsichtiger Motivation, mit der Folge „ein undurchschaubarer, das heißt sein eigener Mensch geblieben zu sein“ (Fremde Kämpfe, S. 124), spielt für seine Selbstsicherung, Individualität und gefühlte Selbstwirksamkeit eine wichtige Rolle ( $\Rightarrow$ II.2.2). Peschek, ein Grenzgänger, der durch den Kauf von Hehlerware - „Für vierhundert nehme ich sie, sagte Peschek“ (Fremde Kämpfe, S. 43) - ein ganz neues Kapitel von problematischer Auffälligkeit aufschlägt, knüpft nahtlos daran an:

Peschek fühlte sich von seiner Idee hochgehoben und deswegen vorübergehend ohne Boden unter den Füßen. [...] Er zweifelte nicht daran, daß er genügend Frauen für die Pelze interessieren konnte. [...] Wie er seinen Plan schätzte, hielt er sich schon für einen Intelligenztäter. Wunderbar samtig füllte die Idee sein Inneres aus. Wenn wenigstens ein paar Leute gekommen wären, um ihm zu gratulieren. (Fremde Kämpfe, S. 64)

Im Gegensatz zu anderen ist Pescheks ,Höhenflug' nicht situativ begrenzt, sondern romanspezifisch anhaltend angelegt. Zudem sind es nicht nur seine selbstwertdienlichen Zuschreibungen der vorangegangenen Zitate, die von Interessantheit zeugen, sondern auch die Tatsache, dass die Tat tatsächlich ausgeführt wird. Im Verlauf dieses handlungsreichsten Romans Genazinos zieht Peschek in Betracht, ob

er ein kleines Fest veranstalten und lauter pelzinteressierte Frauen einladen sollte. [...] Dann müßte ringsum der Neid aufblühen, und Pescheks Stunde wäre da. [...] Peschek geriet in eine kleine Nachmittagsverrücktheit hinein, die ihn glauben machte, sich schon fast alles herausnehmen zu können. (Fremde Kämpfe, S. 107)

Hauptsächlich werden die Überlegenheitsfantasie und der Reiz des Verbotenen zelebriert, aber die Imagination eines selbst ins Leben gerufenen Fests lässt Peschek wenigstens vor dem Leser

stark und durchsetzungsfähig. [...] Dr. Blischke lobt mich, ich werde verlegen, was mich vermutlich noch sympathischer macht." (Heimweh, S. 73) 
zu einer überraschend interessanten Figur werden. Aber nicht nur in Bezug auf die unübliche Bereitschaft zur Geselligkeit überraschen Genazinos Figuren: Auch durch Aufmüpfigkeit und Provokation treten sie mitunter in Erscheinung, wodurch quasi eine Gegenkategorie zur Unsichtbarkeit geschaffen wird. Geradezu begeistert erkunden die Figuren (selten) diese Grenzbereiche offensiver Eindruckssteuerung $(\Rightarrow I .3 .3) .54$ „Ich ziehe den Vorgang absichtlich in die Länge, denn ich habe inzwischen Spaß an der Beobachtung der verbietenden Frau gefunden. Es ist phantastisch, dabei zuzusehen, wie sich eine modische junge Frau in eine verrückte alte Aufpasserin verwandelt.“ (Einfalt, S. 21 f.) Menschen zu reizen, zu beeinflussen und aus ihrer eigenen Reserve zu locken, sind für den Basistypus insgesamt recht ungewöhnliche Strategien. Vor diesem Hintergrund ist das betretene Gebiet aus Selbstsicht mit dem Begriff „phantastisch“ nicht unpassend gewählt: es nimmt sich wie der Fantasie entlehnt aus und ist doch auch umgangssprachlich schlicht eine herausragende neue Erfahrung der eigenen Selbstwirksamkeit. Auch das absichtsvolle Nicht-Klarstellen eines missverständlichen Sachverhalts lässt sich diesem Bereich zuschlagen:

Vermutlich glauben sie, daß ich die Inhaberin der Schuhe kenne und daß ich eine unangenehme Auseinandersetzung mit ihr hatte, in deren Verlauf die Frau hat fliehen müssen. In ihren Augen bin ich einer der typischen unerträglichen Männer, die nur die Spuren ihrer Schandtaten beseitigen. Ich gebe zu, diese mich umflatternden Auslegungen machen mir Vergnügen. Ich schaue meinen Beobachtern mit einer schwer erträglichen Zwiespältigkeit in die Augen, die ihren schlimmsten Befürchtungen recht gibt. (Frauen, S. 35)

Ähnlich ,harmlos' offensiv ist auch der kalkulierte, mit Überheblichkeit gespickte Affront von W., einer durchaus selbstbewussten Figur:

Ein Mann schreibt mit einem breiten Filzstift einen Spruch an die Wand und verschwindet wieder, aber nicht vollständig. In einiger Entfernung bleibt er stehen und schaut zurück auf seine Tat. Ich gehe auf das kleine Graffito zu, und ich nehme an, der Schreiber beobachtet mich. Ich lese: Bube sticht, Futt ist Trumpf. Ich simuliere, so gut ich kann, eine Bestürzung. Mit dem Bleistift setze ich eine Bemerkung darunter. Danach verschwinde auch ich, allerdings auch nicht ganz. Es dauert nicht lang, dann sucht der Mann mit dem Filzstift meinen Text auf. Er muß mit den Augen nahe an die Wand, um lesen zu können: Wer erlöst uns von der Selbstbegeisterung der Dummheit? Rasch wendet sich der Mann ab. Ich nehme an, er kann mit der Bemerkung nichts anfangen. Oder doch? Wir laufen uns über den Weg und tauschen zwei oder drei Blicke. Feindlicher bin ich nie angesehen worden. (Licht, S. 43)

Erzähltechnisch bemerkenswert ist, dass diese Schilderung der Szene an anderer Stelle des Textes relativiert wird (vgl. Licht, S. 60 f.), indem eine zweite Fassung der Begebenheit dagegengestellt wird, die eine deutlich zögerliche Handlungsalternative vorstellt; der Leser wird die zweite Version für - am Genazino'schen Basistypus geschult - wahrscheinlicher erachten und die erste mutmaßlich nachträglich als Aufschneiderei zu entlarven trachten $(\Rightarrow I .2 .3)$.

54 Diejenigen Verhaltensweisen, die eindeutig im Zeichen stehen, dass andere sich unwohl fühlen sollen, werden weiter unten diskutiert ( $\Rightarrow$ II.4.4), hier überwiegt die ,spielerische' Erprobung offensiven IM. 
Ausdrücklich als „Spiel“ deklariert findet sich eine romanspezifische Dreistigkeit in Der Fleck, die Jacke, die Zimmer, der Schmerz: Gemeinsam mit seinem Bekannten Paul - insgesamt eine idiosynkratische Verbindung -, stellen W. und er "die Enge in modernen Selbstbedienungscafés dar“:

Obwohl wir sehen, daß kein Platz mehr frei ist, verschwinden wir nicht. Manche Gäste schauen uns fragend an [...]. Wir gehen zum Schein auf die Angebote ein, nähern uns also mit unseren Tabletts den mühsam frei gedrückten Plätzen, erwecken dann aber den Eindruck, daß wir doch erheblich mehr Bewegungsfreiheit benötigen, daß die anderen Gäste noch enger zusammenrücken müssen, wenn sie uns neben sich haben wollen. (Fleck, S. 29)

Im Grundduktus täuschend und manipulativ, ist dieses Ausloten der Grenzen von Höflichkeit indes genaugenommen nur ein längst überfälliges Aufbegehren gegen den Basistypus in seiner sonstigen Überangepasstheit und Über-Ich-Hörigkeit. W. und Paul verhalten sich auffällig und strapazieren damit den Begriff der Interessantheit bereits beträchtlich, was sich dann noch steigern lässt, sobald ,Verrücktheit' Einzug hält:

Ich kann ihre zwischen den Kuchenstücken und mir hin- und herflitzenden Blicke nur schwer ertragen. Ich muß aufpassen, es nähert sich mir ein Verrücktheitsgefühl, das sich für wahrer hält als alles andere. [...] Ich könnte die schreckliche Situation beenden, indem ich die größeren Kuchenstücke mit der Hand aufhebe und mir an der Rezeption eine Schaufel und einen Handbesen geben lasse, um die Reste aufzukehren. Aber es gibt einen Sog in mir, der eine Konfrontation will. Ich fühle den Drang, zeigen zu müssen, daß ich nicht alles tue, was von mir erwartet werden kann. Dann geschieht es. Ich rutsche von meinem Barhocker herunter und zertrete die heruntergefallenen Kuchenstücke. Ich sehe die entsetzten Gesichter der Rentner und einiger Hotel-Angestellten. Ein junger Mann verläßt die Rezeption und kommt auf mich zu. Entschuldigen Sie vielmals, sage ich, es tut mir leid, ich übernehme die Reinigungskosten. Beinahe hätte ich hinzugefügt: Ich komme von der Großwäscherei Eigendorff, die ist auf solche Fälle bestens vorbereitet. (Glück, S. 54 f.)

Diese zeitdeckend erzählte Szene strotzt vor analysierenswerten Einzelheiten: Einerseits ist Verrücktheit dem protektiven bzw. defensiven IM zuzuordnen, andererseits wird ausdrücklich gegen das Duckmäuserische opponiert, wenn Gerhard Warlich mit „Sog“ und „Drang“ eindeutig un(ter)bewusste (An-)Triebe in Anschlag bringt, die die Auffälligkeit forcieren. Die Vita Warlichs nimmt in dieser doch recht krassen Ausgestaltung leider ein ungutes Ende - am Romanschluss erfolgt die Einlieferung in eine Anstalt. Man könnte es dahingehend interpretieren, dass ständige Anpassung nicht allein erfüllend sein kann, zu verstörende Auffälligkeitsdemonstrationen hingegen ,zu weit über das Ziel hinausschießen', um von der gesellschaftlichen Ordnung noch verkraftet werden zu können. Zu fragen ist überdies, ob es sich tatsächlich um ,echte` Verrücktheit handelt, oder um Verrücktheit als längerfristige defensive/protektive Strategie, um nicht vollumfänglich für das eigene Verhalten verantwortlich sein zu müssen?55 Die Reflexionsbegabung würde eher die zweite Möglichkeit nahelegen und damit die hervorgerufene Aufmerksamkeit als un- oder unterbewussten Hilferuf interpretierbar machen.

Solange die Merkwürdigkeiten moderater ausfallen, wie die weiter oben diskutierten Beispiel mit Decken und Pfützen $(\Leftrightarrow I I .3 .4)$, gibt es offensichtlich seitens der Gesellschaft keinen Grund Vgl. $\quad$ Hans-Joachim
<http://psychonomie.de/sozialpsychologie/Impression_Management.htm>.

Online: 
zur Beanstandung; sobald eine unsichtbare Grenze überschritten ist, wohl doch. Spätestens bei deviantem Verhalten ist für gewöhnlich lediglich das Strafmaß geisterscheidend; die (moralische) Verurteilung der Tat Gesetz - sollte man jedenfalls denken. Aber das Gegenteil ist bei Genazino der Fall: Obwohl der Kauf von Hehlerware (s.o.) ,nur' durch einen Einbruch und eine blutige Nase sanktioniert wird, stellt sich aus unterschiedlichen Gründen leserseitig sogar eher Mitleid ein als die Empfindung poetischer Gerechtigkeit. Dass es Autoren seit Jahrhunderten gelingt, [s]ympathische Verbrecher und Mörder ${ }^{56}$ zu zeichnen, deren verurteilenswürdige Taten sich indessen nicht merklich auf die Sympathiewerte der Hauptfigur auswirken, lässt sich zumal für Genazinos Figuren gut belegen. Mit Katharina Bruch lassen sich

neben der Nutzung des ,primacy effects' [hier: zu Beginn positiv eingeführte Figuren erhalten einen ,Vertrauensvorschuss', der auch negative Taten graduell entkräftet; N. L.] sechs dominante Techniken feststellen: die Sympathielenkung durch den Erzähler, die Übertragung einer Mitschuld auf die Gesellschaft, verstärke Empathieerregung durch Präsentieren des Täters als Opfer [man denke an den verprügelten Peschek; N. L.], die Etablierung eines (besonders emotional) verständlichen Motivs und die (empathische) Darstellung der Tat an sich, die Entschuldigung und Parteinahme durch Autoritätsfiguren und eine Wiederherstellung des gemeinsamen ethischen Wertesystems von Schuldeingeständnis, Reue und Sühnebereitschaft der Figur. ${ }^{57}$

Für Genazino scheint es das Zusammenspiel von primacy effect, der Opfer-Charakterisierung und der nachvollziehbaren Motivationslage als Konglomerat zu sein, das über die Tat hinwegsehen lässt, sind doch etwa die häufiger thematisierten Diebstähle nur auf den ersten Blick ,mutwillige', auf den zweiten hingegen aus dem fragilen Selbst heraus hinreichend erklärliche:

Und weil sein Heimweg aus Fluchten bestand, fühlte er sich leer und fließend, es war, als würde sein Körper auslaufen, unten an den Füßen vielleicht, und er selbst würde dabei zuschauen. Er blieb sogar ein paar Augenblicke stehen, weil er die Hoffnung hatte, dadurch das Gefühl der Festigkeit wiederzuerlangen. Er erlangte nichts wieder, und da kam er auf die Idee, im Supermarkt, wo er ohnehin noch einkaufen wollte, etwas mitgehen zu lassen. Er klaute nur, wenn er sich selbst als nicht mehr richtig vorhanden fühlte, wenn nichts in ihm vorging und der den Anschluß an irgendein Gefühl erreichen wollte. In diesen Zuständen war das Stehlen eine Hilfe. Es war, als würde man mit einem Stock auf einen völlig verstaubten Teppich schlagen. Dann war wiederzuerkennen, daß es sich um einen Teppich handelte. Weil nichts geschah, ließ er einen kleinen Diebstahl geschehen, dann war alles nicht mehr so leer. Die Annehmlichkeit eines Diebstahls war nicht sofort zu spüren. Noch jedesmal, wenn er etwas eingesteckt hatte, begann er zu zittern, und dies sogar dann, wenn er vollkommen sicher war, daß er nicht beobachtet worden war. Dies war die Phase unmittelbar nach der Tat; sie lief nicht auf eine Stärkung, sondern, im Gegenteil, auf eine weitere Schwächung seiner Person hinaus. In diesen Minuten nach der Tat stellte er sich sowohl das sichere Entkommen als auch die ebenso sichere Entdeckung vor. Diese Spannung war kaum auszuhalten. Einmal mußte er sogar auf der Straße in ein Weinen ausbrechen, weil sich die Spannung nicht mehr anders lösen konnte. Die Spannung brachte es auch mit sich, daß er sich selbst, in seinem Verhalten, als Dieb kennzeichnete. Dieses nervöse Umherflackern des Blicks, die Neigung, in allen Leuten geheime Mitwisser zu vermuten, die nur den richtigen Augenblick zum Verrat abwarteten, und die reuige Lust, den gestohlenen Gegenstand wieder in das Regal zurückzustellen. Die Anstrengung, nicht als Dieb zu erscheinen, lief groteskerweise gerade auf eine Betonung der diebischen Erkennungszeichen hinaus. In diesem Durcheinander zwischen Verhalten und Sein war er schon so geschwächt worden, daß er vorübergehend überzeugt war, bei nächster Gelegenheit hinzufallen Aber am Grunde der Schwächung meldete sich dann der Genuß des Gefühls, sich selbst wiederzuhaben, sich selbst wieder als vorhanden zu fühlen. (Sorgen, S. 164 f.)

56 Vgl. Bruch: Sympathische Verbrecher und Mörder.

57 Bruch: Sympathische Verbrecher und Mörder, S. 117. 
Erneut drängt sich ein fiktionalisiertes Krankheitsbild auf: Borderline bzw. emotionale Instabilität. Insbesondere die unerträgliche Anspannung und der Verlust des Selbst-Empfindens lassen sich in diese Richtung deuten (vgl. Regenschirm, S. 19). Denn: „In angegriffenen Situationen hilft mir das Mitnehmen von kleinen oder nicht so kleinen Gegenständen, die inneren Übergriffe meiner Überforderung auszuhalten." (Liebesblödigkeit, S. 158) Mit Bezug auf Bruch lassen sich darüber hinaus Beinahe-Diebstähle listen, die jedoch aufgrund von Reue die Tat im Nachhinein entschuld(ig)en bzw. im Vorhinein unterbinden:

In einem dritten Kaufhaus fahre ich mit dem Fahrstuhl in den vierten Stock in die verloren erscheinende Mützenabteilung und habe dort einen befreienden und gleichzeitig bedrohlichen Einfall. Ich bin weit und breit der einzige Besucher der Mützenabteilung und vertausche meine alte Mütze gegen eine neue. [...] Ich mache mir noch eine Weile im Mützengebiet zu schaffen, bis ich ganz sicher bin, daß mein Coup unbeobachtet geblieben ist. Da keine Verkäuferin erscheint, nehme ich an, daß ich mich ungeschoren davonmachen kann. Aber mein zu langer Aufenthalt in der Mützenabteilung war (ist) ein Fehler. Er nützt nicht meiner Sicherheit, sondern, im Gegenteil, der Entstehung meiner Unsicherheit. Plötzlich fürchte ich, daß die Leute vom Überwachungs- oder Erkennungsdienst anhand meiner alten, hier zurückgelassenen Mütze meine Identität feststellen können. [...] Wahrscheinlich warten die Sicherheitsleute nur darauf, daß ich mit der neuen, unbezahlten Mütze den Fahrstuhl betrete. Dann werden sie mir folgen und mich im Fahrstuhl festnehmen, weil ich dort nicht fliehen und außerdem bequem niedergerungen werden kann. [...] Ich gehe tatsächlich zurück an den Ort der Vertauschung, vergewissere mich, ob mir niemand zuschaut, nehme meine alte Mütze wieder an mich und lege die neue Mütze zurück an die alte Stelle. (Glück, S. 84 f.) ${ }^{58}$

Es steht zu vermuten, dass die befürchtete ,Identitätsfeststellung‘ anhand der Mütze wörtlich intendiert ist, aber die Verbundenheit von Kleidungsstücken und Selbstergänzung schwingt mit $(\Leftrightarrow$ II.1.5). Aufgrund der langen Bedenkzeit sieht Warlich von der gänzlichen Umsetzung des Diebstahls ab - sein familienähnlicher Vorgänger W. ist seinerseits früher einmal bei einem Diebstahl ertappt worden (vgl. Licht, S. 107 f.), sein namenloser Nachfolger wird dereinst aufgrund seiner Trickbetrügereien und trotz seiner dunklen Vorahnungen (kurzzeitig) inhaftiert werden (vgl. Tiere, S. 114 ff.). Der sympathischen Verklärung zum Trotz ist damit der Schritt gegangen, der die positiven Merkmale ,Gewissenhaftigkeit' und ,Verträglichkeit' der Big Five $(\Leftrightarrow$ II.1.3) endgültig ins Gegenteil umschlagen lässt und mithin die vornehmlich assertive Eindruckssteuerung gegen die offensive tauscht - frei nach dem extern motivierten Motto: „unmerklich und absichtslos war er in den letzten Wochen seines Lebens bösartiger geworden.“ (Fremde Kämpfe, S. 167)

Zu guter Letzt das ausgefüllte ,Zwiebelmodell` $(\Rightarrow$ I.2.5). Zwei Grundtendenzen, die jeweils in zwei Ausprägungen zerfallen, sind hierbei im Hardcore zu finden: Zum einen lassen sich als Motivation zur Eindruckssteuerung ( $\Rightarrow$ I.3.3) Selbstbildschönen und/oder Selbstsicherung veranschlagen, zum anderen gründen alle Handlungsweisen und strategischen Überlegungen, die mit

58 Vgl. zur Analyse der hier verarbeiteten Komik Petersen: Zur Verwendung von Komik und Humor bei Wilhelm Genazino, S. 97 f. u. S. 99. 
,Interessantheit' verknüpft sind, auf assertiven IM-Techniken und -Taktiken $(\Rightarrow I I .3)$, diejenigen mit ,Auffälligkeit' verknüpften hingegen auf offensiven.

Für das dritte Schlaglicht steht familienähnlich das positive Gesicht im Vordergrund, obwohl auch das negative Pendant randläufig in Erscheinung tritt $(\Rightarrow$ II.3.1). Beide haben ihre Relevanz: Für die Interessantheit kommt hauptsächlich die Wahrung des positiven, kommunikativen, für die Auffälligkeit überwiegend das auf Individualität abzielende, negative in Anschlag. Obwohl die dem Basistypus zumeist eignende öffentliche Selbstaufmerksamkeit als Hemmnis dem assertiven IM und dem positiven Gesicht ( $\Rightarrow$ II.3.1) entgegensteht - und sich in der Tendenz zeigt, häufig die Interessantheit lediglich zu imaginieren ( $\Rightarrow$ II.3.1) - und obwohl es ihm eigentlich an den relevanten Voraussetzungen, um sich ,interessant zu machen' - Smalltalk, gerne im Mittelpunkt stehen etc. ( $\Rightarrow$ II.3.1) - mangelt, sind die assertiven Interessantheitsstrategien durchaus fruchtbar - zumindest, sofern es die kommunikativen Rahmenbedingungen hergeben, was etwa in gleichgeschlechtlich besetzten Dyaden seltener der Fall ist als in verschiedengeschlechtlichen ( $\Rightarrow$ II.3.1), obwohl beide Konstellationen als vertraut, privat und symmetrisch entworfen werden. Für verschiedengeschlechtliche Kommunikationen der Interessantheit sind die Verhaltensweisen des Basistypus zumeist auch mit sexueller ,Belohnung verbunden $(\Rightarrow$ II.3.4). Dieser , unglaubliche' Erfolg überrascht nicht nur immer wieder den Leser, sondern auch die Figuren selbst, was sich bis zur Angst vor der eigenen Courage steigern kann $(\Rightarrow$ II.3.1 u. $\Rightarrow$ II.3.4). Als unproblematischer Ausdruck von Interessantheit können die zahlreichen Neologismen und Wortspiele $(\Leftrightarrow$ II.3.2) sowie die originellen Fantasieberufsbezeichnungen $(\Leftrightarrow I I .3 .4)$ gelten. Der Grad an Vorbereitung auf interessantes Verhalten variiert: So wappnet sich der Basistypus einerseits, um interessant zu wirken, wobei die Gesprächsplanung im Vorfeld kalkuliertes IM widerspiegelt $(\Leftrightarrow$ II.3.3). Die Notwendigkeit von stichwortgebenden Gesprächsnotizzetteln lässt dabei gelegentlich die Inszenierung von Interessantheit erkennbar werden ( $\Rightarrow$ II.3.3). Andererseits ereignen sich auch sowohl digital wie analog erfolgreiche extemporierte Auftritte, die dem Basistypus Witz, Esprit und Spontaneität testieren ( $\Rightarrow$ II.3.4). Mitunter buhlen die Figuren auch aggressiver um Aufmerksamkeit ( $\Rightarrow$ II.3.4). Dabei werden mitunter assertive gegen offensive Techniken eingetauscht und das positive Gesicht wird dem negativen untergeordnet $(\Leftrightarrow I I .3 .4$ u. $\Rightarrow$ II.3.5). Dreistigkeit, Affront, Lust am Manipulieren etc. ( $\Rightarrow$ II.3.5) sind Manifestationen dieser Form; allerdings sind diese ,Auffälligkeiten' entschuldbar als Aufbegehren gegen die spießige Überangepasstheit und das übermächtige Über-Ich $(\Rightarrow$ II.3.5) Auch passioniertes Lügen sowie unterschiedlichen Motivationslagen entspringendes deviantes Verhalten wie Diebstähle fungieren als Möglichkeit, aufzufallen $(\Rightarrow$ II.3.5). So langsam ist damit der äußerste Streifen der Familienähnlichkeit betreten: Überheblichkeits- und Allmachtphantasien hinsichtlich der als exorbitant vorgestellten eigenen Wirkung sind zwar selten, aber zu häufig für den Außenkreis ( $\Rightarrow$ II.3.5) Ähnlich die zur Schau gestellte Verrücktheit, die jedoch vermutlich nicht so sehr zur Interessantheitsevokation 
390 - Teil II: Schlaglichter 3. Strategien der Interessantheit bzw. Auffälligkeit

intendiert ist, sondern protektiv bzw. defensiv dazu angewandt wird, um nicht die volle Verantwortung für das eigene Handeln übernehmen zu müssen $(\Leftrightarrow I I .3 .5)$.

Romanspezifika sind allesamt in der Hyperbel bereits genannter Merkmale des Familienbasistypus zu sehen: Ein Auftritt vor größerem Publikum lässt einmalig an eine nahezu histrionische Persönlichkeit denken; der An- und Verkauf von Hehlerware übersteigert die Tendenz zu deviantem Verhalten, das negative Gesicht wird in überbordender Weise ausgestellt. 


\title{
4. Das Ich, die anderen und das andere: Inszenierung - Beobachtung - Evaluation
}

\begin{abstract}
„Es blieb mir nichts anderes übrig, als ein paar Diffamierungen vor mich hinzumurmeln. Faulender Knöchel, lauf weiter! Verlorenes Auge du! Übrig gebliebener Pudding, kipp dich selber in die Toilette! Niemand hörte es, nur ich selber." (Außer uns, S. 88 f.)
\end{abstract}

Im Kontrast zum vorangegangenen, auf das Protagonistenhandeln scharfgestellten Schlaglicht wechselt nun die Warte: Es ist der (auch: ,gedehnte') Blick auf ,die anderen',1 ihre (vermuteten) Inszenierungen und die Evaluation durch die Hauptfiguren, die für IM bei Genazino eine ebenso wichtige Rolle spielen und ganz neue Figurenfacetten akzentuieren. Um die Mischpultmetapher $(\Leftrightarrow$ I.2.2) erneut zu bemühen: Hier werden provokante Verhaltensweisen hochgeregelt, hier werden Hohn, Spott und Häme großgeschrieben - für den tatsächlich in Kapitälchen realisierten „WUTSTEMPEL" vergleiche das Unterkapitel zur offenen Herabsetzung ( $\Rightarrow$ II.4.4) - und einige der ,Schattenseiten' der für gewöhnlich unter den Big Five unter Verträglichkeit hoch punktenden Protagonisten ins Licht gerückt. ${ }^{2}$ Viele der Verhaltensweisen, die das Figurenhandeln und damit auch die Figuren indirekt charakterisieren, lassen sich dem offensiven IM zuordnen. Wie oben $\Leftrightarrow$ I.3.3) breit dargelegt handelt es sich dabei um kritische oder gar herabwürdigende Praxen, die letztlich indirekt dafür sorgen, positiver wahrgenommen zu werden als die dritte Partei, die in die Kritik genommen, durch den Kakao gezogen oder unter Beschuss genommen worden ist.

Die ersten beiden Unterkapitel sind angelegt als Fundamentguss, bevor drei typische Verhaltensmuster jeweils genauer beobachtet werden. Der Blick geht dabei zunächst noch einmal vom Haupthandelnden aus. So werden unter Rückgriff auf methodische Plugins und per Rekurs auf bereits bekannte Figurenfacetten diejenigen Eigenschaften, die Genazinos Basistypus um dessen ,Schattenseiten` erweitern, beleuchtet ( $\Rightarrow$ II.4.1). Das zweite Unterkapitel ( $\Rightarrow$ II.4.2) abstrahiert Verlaufspläne von typischen Evaluationen, diskutiert die obwaltenden Kriterien und typologisiert die Beobachtungsobjekte; womit die Aufmerksamkeit auf die anderen, auf das andere überschwenkt. Drei wiederkehrende Verhaltensweisen können daraus folgend unterschieden werden: die Entlarvung der als brüchig wahrgenommenen Selbstentwürfe der anderen ( $\Rightarrow$ II.4.3), die mit Wut, Zorn und ,Pöbellaune` verbundenen Evaluationen, die auch davor, andere sich unwohl

1 Dass die anderen und das andere im Schlaglichttitel kleingeschrieben sind, erhellt auch daraus, dass sie, selbst wenn der Fokus auf sie gerichtet wird, hauptsächlich als Referenzobjekt für den Protagonisten bzw. die Protagonistin Wichtigkeit erhalten.

2 Es ist durchaus legitim bei diesem Licht-Schatten-Dualismus an C. G. Jungs Konzeptualisierung zu denken. Insbesondere die Projektion der ins Unterbewusste verbannten, dem Selbst- bzw. Idealbild widerstrebenden $\Leftrightarrow \Rightarrow$ II.2.1) Aspekte des Selbst auf andere - und die darüber mögliche ,moralisch einwandfreie' Aburteilung derselben - ist für Genazinos Figurenbasistypus nicht von der Hand zu weisen. 
392 - Teil II: Schlaglichter 4. Das Ich, die anderen und das andere: Inszenierung - Beobachtung Evaluation

fühlen zu lassen, nicht zurückschrecken ( $\Rightarrow$ II.4.4), und schließlich die aus unterschiedlichen Gründen erhellenden Situationen, in denen die Beobachteten bzw. ihr Handeln (überraschend) positiv evaluiert werden $(\Rightarrow I I .4 .5)$.

\section{1 (Prä-)Figuration zwischen schwarzer und gelber Galle}

Literarische Figuren Genazinos und lebende Menschen teilen sich die Eigenschaft, metaphorisch gesprochen, mehrere ,Seelen' in ihrer Brust zu beherbergen. ${ }^{3}$ Im Inneren des Figurenbasistypus von Genazino geht es diesbezüglich sogar recht lebhaft zu, wie die vorigen Kapitel haben zeigen können. Obzwar die Theoriebildung, die im Folgenden herangezogen werden wird, um bestimmte Figurenschattierungen zu veranschaulichen, seit geraumer Zeit bereits eher wissenschaftsgeschichtlichen Wert hat, ${ }^{4}$ als den Standards einer neueren Psychologie zu genügen, eignet sich die Humoralpathologie ${ }^{5}$ der Antike vortrefflich als Rahmen, um die stigmatisierten Grunddispositionen der Genazinofiguren einspannen zu können. ${ }^{6}$

Die vier Temperamente, denen sich der Vorstellung nach Menschen zuordnen lassen, werden durch die Dominanz eines ,Safts' bedingt: Je nachdem, ob Blut, Schleim, schwarze oder gelbe Galle die Vormachtstellung innehaben, ist das Temperament dementsprechend ausgeprägt und kristallisiert sich in einen der vier Grundtypen aus: Sanguiniker sind dabei die eher Unbeschwerten, Phlegmatiker die (körperlich wie geistig) Trägen. Die beiden Typen, die es auch im heutigen Sprachgebrauch noch zu einiger Bekanntheit bringen, sind der Choleriker (gelbe Galle) und der Melancholiker (schwarze Galle). Just diese beiden Ausprägungen einer Skala, auf der sich die Neurotiker wiederfinden (Choleriker: neurotisch und extravertiert; Melancholiker: neurotisch und introvertiert), treffen die hier in Rede stehenden Charakterzüge des Basistypus recht gut: Wo der Choleriker „einem alten dichterischen Gleichnis“ nach „einen Stein, der seinen Lauf hindert, wutentbrannt zur Seite schleudert",7 würde der Melancholiker vor dem Hindernis in Selbstzweifel ausbrechen, „seine Reise in Frage stellen und sich traurig auf den Stein setzen, um nachzudenken und sein Vorhaben zu reflektieren".8 Der Sanguiniker wäre einfach drüber hin-

3 Das liegt bezüglich der literarischen Figuren Genazinos an deren Konzeption als ,naturalistisch', ,inkohärent', ,ganz', ,literal', ,komplex', und ,transparent' ( $\Rightarrow$ I.2.4).

$4 \quad$ Frappierend ist die Tatsache, dass der immense Aufwand, mit dem man die Big Five herauspräpariert hat, nicht sehr weit von den vier Faktoren der Humoralpathologie entfernt liegt. Zumal in einigen „Schriften des Corpus Hippocraticum“ sogar „bis zu fünf“ angeführt werden ([Humoralpathologie]. In: Wikipedia. Die freie Enline: <https://de.wikipedia.org/wiki/Humoralpathologie>).

$5 \quad$ Womit sich erneut eine Parallele zu Jean Paul offenbart $(\Rightarrow I .2)$.

6 Vgl. für eine kritische Position, die diese Zuordnung in eine psychoanalytische Tradition einreiht und davor warnt, bei der bloßen Benennung stehen zu bleiben, Köhnen: Psychoanalytische Literaturwissenschaft, S. 304.

7 Alfred Adler: Temperamente und innere Sekretion. In: ders.: Menschenkenntnis. 1927. Online: $<$ http://www.textlog.de/adler-psychologie-temperamente-innere-sekretion.html>.

8 [Temperamentenlehre]. In: Wikipedia. Die freie Enzyklopädie. Online: <https://de.wikipedia.org/wiki/Temperamentenlehre>. 
weggesprungen - aber wie man weiß, sind Genazinos Figuren nun einmal neurotisch genug, um den Sprung auf die emotional stabile Skala selten bis nie zu schaffen. Weitaus häufiger lassen sich Textstellenbelege anführen, die dem Neurotizismus das Wort reden - sei es in der introvertierten Ausprägung und also in Gestalt des Melancholikers: „Wie sonderbar unser Innenleben organisiert ist, denke ich und seufze ein bißchen" (Heimweh, S. 40); sei es im extraversivcholerischen Phänotyp: „Er gestand sich ruhig ein, daß es vielleicht nur eine Frage der Zeit war, bis er wirklich Kinder anpöbelte. Er war grundsätzlich nicht dagegen gefeit, ein cholerischer alter Mann zu werden“ (Sorgen, S. 374). ${ }^{9}$ Hans Jürgen Eysenck ist der bekannteste Persönlichkeitspsychologe, der einerseits die Temperamentenlehre in die Big Five ,übersetzt' hat und zugleich in seinen Schriften ${ }^{10}$ insofern bei Hippokrates bleibt, als er die alte Nomenklatur übernimmt:

9 Die Relevanz der Kategorie ,Melancholie‘ und deren Verbindung zum ,Anderen` hat für das Romanwerk Genazinos Svenja Frank 2012 herausgearbeitet: Melancholy in Wilhelm Genazino's Novels and its Construction as Other.

10 Vgl. Hans J. Eysenck: The inequality of man. London 1973; vgl. ders.: Biological dimensions of personality. In: Oliver P. John/Richard W. Robins/Lawrence A. Pervin (Hg.): Handbook of Personality. Theory and Research. New York 1990, S. 244-276. 
394 - Teil II: Schlaglichter 4. Das Ich, die anderen und das andere: Inszenierung - Beobachtung Evaluation

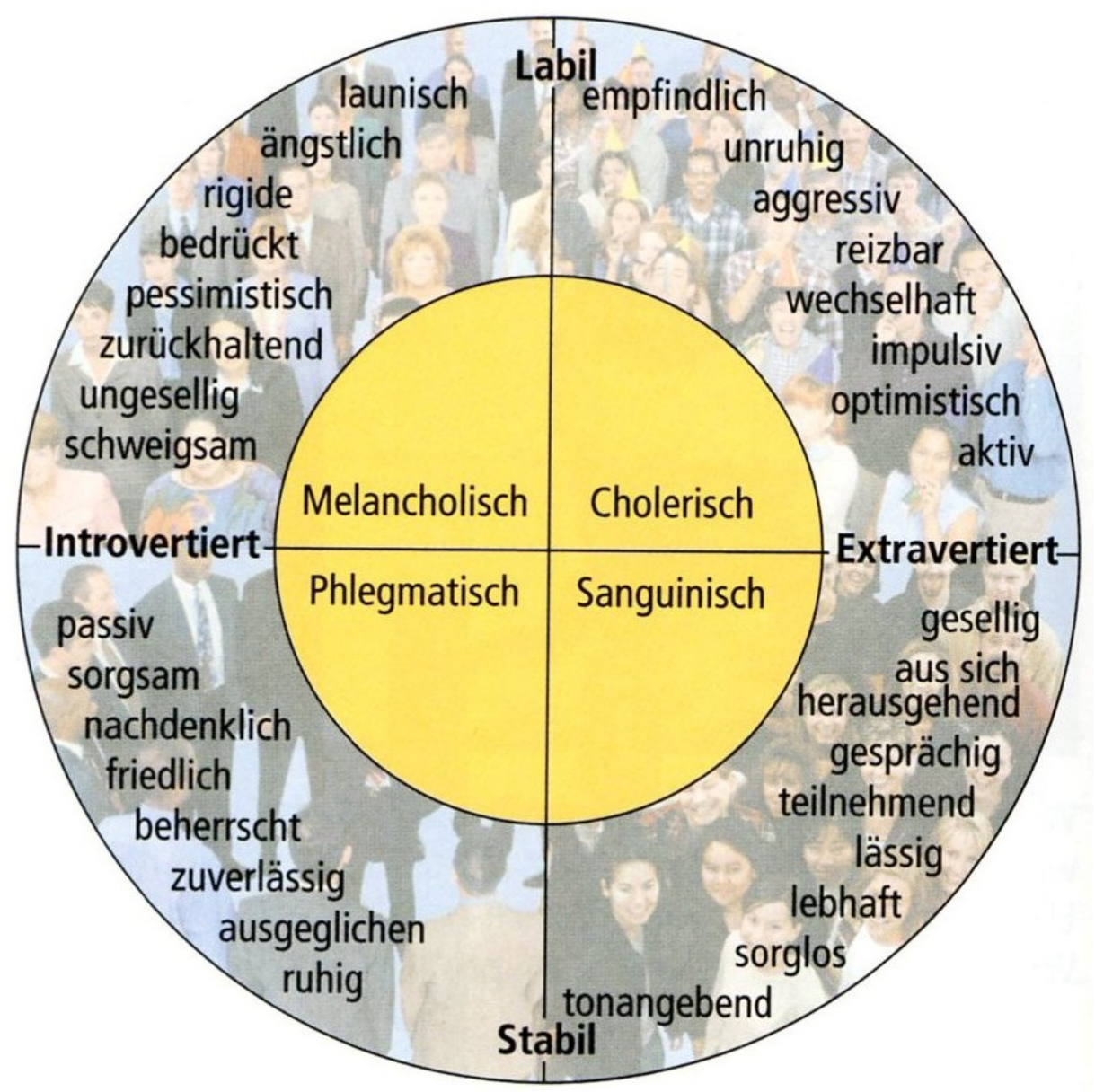

Abbildung 13: Eysencks Persönlichkeits-Kreis'11

Allerdings lässt sich eine Person nicht einfach nur einem der Quadranten zuordnen, sondern feiner verorten:12 Ein emotional sehr labiler Mensch, der nur leicht introvertiert ist, wird laut Eysenck eher als launisch denn als schweigsam in Erscheinung treten. Für Wilhelm Genazinos Figurenbasistypus, der erwiesenermaßen gleichermaßen labil und introvertiert genannt worden ist ( $\Rightarrow$ II.1.3), kommen hingegen alle Persönlichkeitsmerkmale in Frage. Zumal deshalb, weil die offensiven Techniken und Taktiken der Eindruckssteuerung in diesem Schlaglicht zum Vorschein kommen, ist auch die extravertierte Seite mit ins Repertoire aufzunehmen. Es handelt sich dabei - und das ist nicht oft genug zu erwähnen, um wertfreie Pole, zwischen denen ein breiter Horizont an Verhaltensweisen aufgespannt ist. Die Relevanz der Betonung der neurotischen Schnittstelle und der Thematisierung an dieser Stelle der Arbeit ergibt sich aus der Tatsache, dass „neurotische Menschen die Mimik anderer anders als gelassene Personen“ beobachten. ${ }^{13}$ Sowohl Genazino-Melancholiker als auch Genazino-Choleriker zeichnen sich in der Tat dadurch aus, eine „verzerrte Wahrnehmung“ an den Tag zu legen, indem sie zum ,Überinterpre-

11 Gerrig/Zimbardo: Psychologie, S. 508; nach Eysenck: The inequality of man u. ders.: Biological dimensions of personality.

12 Vgl. Gerrig/Zimbardo: Psychologie, S. 508.

13 Wüstenhagen: Ich-Bewusstsein. 
4.1 Das Ich, die anderen und das andere: Inszenierung - Beobachtung - Evaluation - 395

tieren“ neigen: „Neurotische Personen interpretieren selbst neutrale Gesichter vergleichsweise häufig als wütend oder ärgerlich“.14 Mit dem Hang, ,mehr zu sehen als ist', lässt sich tatsächlich ein Merkmal des Genazino-Hardcore-Protagonisten bezeichnen, wie es bereits angesprochen worden ist ( $\Rightarrow$ II.2.3). Auch im nächsten Unterkapitel $(\Rightarrow I I .4 .2)$ werden dazu einige Überlegungen angestellt werden - hier dezidiert unter der Vorgabe, es mit Menscheninszenierungen, beobachtungen und -evaluationen zu tun zu haben. Unentwegt beobachten Genazinos Figuren ihre Umgebung und - das ist die Besonderheit dieses Schlaglichts - haben für gewöhnlich an den ,Inszenierungen‘ der anderen irgendetwas auszusetzen: „Er saß nur da und betrachtete die anderen, nahm Anstoß an ihrer Bekleidung, an ihren Gesichtern und ihren Bewegungen. " Falsche Jahre, S. 408) Hier noch schweigsam, werden späterhin auch aggressivere Verhaltensweisen deutlich. Im Folgenden soll gezeigt werden, welche Wesenszüge - neben denjenigen neurotischen, die den Hang bzw. Zwang zur Beobachtung umfassen - diese Tatsache begünstigen. Dabei wird sich ein engmaschiges Netz an Querverweisen zu bereits getroffenen Charakterisierungsbemühungen auftun.

Einen wichtigen Punkt bildet die Überbetonung der Unterschiede von Ich und Welt $\Leftrightarrow \Rightarrow$ II.1.1 u. $\Rightarrow$ II.1.3). ,Seit Anbeginn' frönen Genazinos Figuren regelmäßig der Faszination, in den anderen, in dem anderen einen Gegensatz, Widerpart, Antipoden zu suchen und zu finden, der dem eigenen Selbstentwurf Kontur verleiht. Als komparative Prädikatenzuweisung ( $\Rightarrow$ I.4) handelt es sich dabei um eine allgemeinmenschliche Form, in der Differenz Einheit zu erlangen: „Und er ging gleich dazu über, sein Privatleben mit dem Privatleben Mörsts gegenüberzustellen. Ein Hundezüchter, hah! Die beiden Leben waren unvereinbar" (Abschaffel, S. 97). In der Literatur zum offensiven IM lässt sich die hier prototypisch vorgetragene Herabsetzung bei gleichzeitiger Selbsterhöhung nachlesen - bei Genazino handelt es sich um ein langjährig angelegtes Verhaltensmuster: „Abschaffel glaubte, von Hornung himmelweit entfernt zu sein und sich auf sicherem Boden zu bewegen. Er hielt Distanz zu Hornung“ (Sorgen, S. 179). Sowohl Hofmann als auch Moser zitieren Genazino mit seiner für die Romane als epitextuell zu klassifizierenden Aussage: „Individualität gewinnen wir nur in der Abweichung“ $(\Rightarrow$ II.1.1).15 In Form distinguierender Beobachtungen werden Grenzen nach außen gezogen, wird das eigene Selbst der Hauptfiguren somit definiert: „Es genügte, daß Abschaffel diesen Essern eine Weile zusah, um nicht mehr bei ihnen sein zu wollen." (Abschaffel, S. 117; vgl. Obdachlosigkeit, S. 89)

Diese feinen Unterschiede, die in der Feier der Individualität sichtbar werden, haben indes mehr als eine Kehrseite: Da bspw. Abschaffel mit Mauern im Kopf ausgestattet ist, die es seiner (selektiven) Wahrnehmung nicht gestatten, dass etwas, das nicht sein darf, dennoch sein könnte, sitzt er in der Falle der selffulfilling prophecy: „Natürlich kam kein Mensch, und das war allein Ab-

14 Wüstenhagen: Ich-Bewusstsein.

15 Hofmann: Beobachtete Beobachter in Wilhelm Genazinos Romanen, S. 59; Moser: Isola Insula, S. $42 \mathrm{f}$. 
396 - Teil II: Schlaglichter 4. Das Ich, die anderen und das andere: Inszenierung - Beobachtung Evaluation

schaffels Schuld. Er hielt sich alle anderen Personen vom Leibe, weil er glaubte, mit niemand etwas anfangen zu können." (Abschaffel, S. 38) Außerdem geht das Bedürfnis nach Distanz nicht selten mit einem ,klassistischen“ Impetus einher: „Heute waren sie die einzigen Menschen geworden, die ihm schon von weitem die Veröffentlichung seiner Distanz erlaubten: er wechselte die Straßenseite, ohne sich zu schämen." (Fremde Kämpfe, S. 127; $\Rightarrow$ II.1.6)

Wilhelm Amann leitet die Überheblichkeit anderen gegenüber aus der Schichtzugehörigkeit ab ( $\Rightarrow$ II.1.5), ${ }^{16}$ was insofern höchst plausibel scheint, als es Peschek nicht einmal Scham abringt, die Straßenseite zu wechseln. Und so wird an denjenigen gesellschaftlich als unverträglich abgestempelten Figurenfacetten gekratzt, die hier auf den Prüfstand kommen sollen: Hochmut, Arroganz, Dünkel. Eng verwandt mit dem Bedürfnis, aus Distinktionserwägungen bloß gleichwertig anders sein zu wollen als die anderen, manifestiert sich bei Genazinos Hauptfiguren also die Überzeugung, den Objekten der Beobachtung nicht nur unähnlich, sondern zugleich in irgendeiner Art und Weise überlegen zu sein ( $\Rightarrow$ II.2.2). Finden lassen sich sowohl hinsichtlich des in die Kritik genommenen Personenkreises als auch des Vorwurfs unbestimmtere Formen - „Das Klagen und Mahnen ist die Lieblingsbeschäftigung von fünfundneunzig Prozent der Menschheit, mit der mein Dünkel nichts zu tun haben will“ (Regenschirm, S. 93) -, aber auch klarer umrissene:

Er fühlte, daß es ihm in diesen Minuten gelang, sich über die Kollegen zu erheben. Er glaubte, viel klüger zu sein als alle seine Kollegen zusammen. In gekränktem Schweigen verhöhnte er das Gerede der anderen. [...] Abschaffels Überheblichkeit hielt den ganzen Vormittag [...] an. (Sorgen, S. 339 f.)

Erneut an der Grenze zur pathologischen Überlegenheitsfantasie $(\Leftrightarrow I I .2 .2)$ sich bewegend, ist der Distinktionswunsch offensichtlich bereits in eine geglückte Distinktion überführt worden ( $\Rightarrow$ II.1.1), wohingegen im folgenden Beispiel der aus Überheblichkeit entspringende Wunsch nach Abweichung erst parallel zur evaluativen Beobachtung entsteht:

Die Menschen, die ich noch kurz zuvor diskret, fast vornehm auf Rolltreppen durch die Etagen hatte schweben sehen, verwandelten sich jetzt in ein dumm-dusseliges Purzelvolk, das Schürzen, Schinken und Schuhe an sich riß und dabei eine Art Beglückung erlebte. Eine derartige Verwandlung hatte ich nicht für möglich gehalten. Warum war ich von diesen Menschen so sehr getrennt? (Wohnung, S. 93)

So holzschnittartig, wie es auf den ersten Blick zu sein scheint, ist es freilich nicht. Mitnichten lässt sich für den Hochmut eine schematische Vereinfachung treffen. Denn erstens folgt bei Genazino auf die Passagen des Spottes meist etwas Handfesteres (Reflexion, Verallgemeinerung, Selbstpreisgabe o. Ä.) und zweitens haftet bereits der erzähltechnischen Hülle ein bewusst plat-

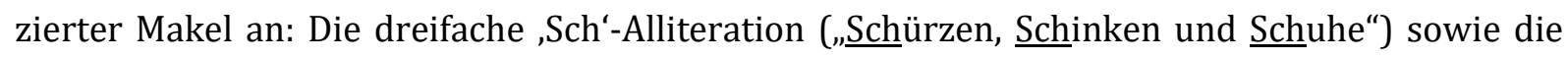

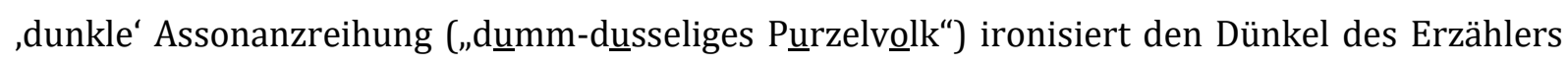
bzw. weist seinen eigenen Geltungsanspruch aus. Dazu sei noch ein Blick auf den Fortgang der Handlung gestattet: Denn der zunächst 17-, später 18-jährige Ich-Erzähler Weigand grenzt sich - 
4.1 Das Ich, die anderen und das andere: Inszenierung - Beobachtung - Evaluation - 397

durchaus unüblich für den Basistypus - in seiner ehrgeizigen und vor allem zielstrebigen Art mittels seines Dünkels nicht zwecklos von den anderen ab. Vielmehr weist er auf der Suche nach seinem Lebensmotto, das er schließlich in der titelgebenden Reihung von Frau, Wohnung und Roman auch findet, und seinem Werdegang zum Romancier einige Lebensentwürfe als für ihn persönlich ,gescheitert' aus und für ihn zurück, um seine Ziele nicht aus den Augen zu verlieren. Dass es sich dabei um „ein mit signifikanten Details ausgestattetes Sittenbild des Konsumzeitalters, dem Muff der ausgehenden Adenauer-Ära, in die ein Zipfel des ,Restkriegslebens' noch hineinragt“, 17 handelt, unterstreicht die Doppelbödigkeit der hier vorliegenden Dünkelverwendung zwischen individueller milieuspezifischer Abkehr und gesamtgesellschaftlicher Zeitgeistanalyse:

Die Massenbeglückung schlug sich bei mir als leise Beklemmung nieder. Ich versuchte, ein oder zwei richtige Gedanken zu denken: Nach dem Ende des Naziterrors sind die Deutschen in der Geschichtsstille eingetroffen. Jetzt dürfen sie entdecken, daß es einfache Seligkeiten gibt (Strohhüte, Süßigkeiten, Strandschuhe), die zum Leben völlig ausreichen. Und weil du den Naziterror nur aus Büchern kennst, verstehst du das Glück dieser Leute nicht. Aber beruhigende Gedanken dieser Art beruhigten mich nicht lange. Denn schon war die nächste Frage, die nächste Empörung da: Warum wurden die Menschen in diesem endlich erreichten Glück so läppisch, einfältig und töricht? Dabei kam mir mein Hochmut schon vertraut vor. Es war, als hätte das Gefühl der Herablassung schon seine eigene Dauer gefunden. (Wohnung, S. 93)

Neben einem Erklärungsansatz für die verhasste Spaß- und Erlebnisgesellschaft ( $\Rightarrow$ II.1.6) findet sich eine Manifestation des Wankelmuts hinsichtlich der Aburteilung von anderen Milieus ( $\Rightarrow$ II.1.5), die möglicherweise ja aus plausiblen Gründen Materialisten geworden sein mögen. Nach dem Herabsetzen jedenfalls reflektieren Genazinos Figuren regelmäßig ihre eigenen charakterlichen Grundlagen, die dazu geführt haben - und das sogar häufig unter Angabe eines elaborierten Beweggrundes. Besonders aufschlussreich sind die Reflexionspassagen. Für die Causa Weigand, welcher auf eine eigene dünkelhafte Bemerkung folgend Reue empfindet, muss aus externer Figurenanalyseperspektive der Griff zum Wörterbuch geradezu wie deplatziertes Understatement wirken: „Wieder beschuldigte ich mich der Überheblichkeit. Ich stand auf und schaute im Duden nach, was dort unter Hochmut zu finden war. Ich las: Hochmut, Eingebildetheit, Dünkel, Arroganz; ich dünke mich, ich habe eine hohe Meinung von mir, ich halte mich dafür." (Wohnung, S. 132 f.) Als Demutsgeste lässt sich diese Handlung intern nur als übersprungshaft, genussvoll narzisstisch motivieren - dass Weigand ernsthaft daran interessiert sein könnte, neue Erkenntnisse über die Begriffsbedeutung von, Überheblichkeit' zu erlangen, scheint eher ausgeschlossen. Über den Konnex von Individualstil und Figurencharakterisierung ist bereits gesprochen worden $(\Leftrightarrow I .2 .3)$. Dass es gerade für die Evaluation anderer von Wichtigkeit sein kann, ob das richtige Wort zur richtigen Zeit zur Hand ist oder nicht, zeigt auch der Blick auf William Genazino, der beginnend von einer Beobachtung ein kleines, aus seiner Sicht schlüssiges Psychogramm seiner Freundin entwirft: 
398 - Teil II: Schlaglichter 4. Das Ich, die anderen und das andere: Inszenierung - Beobachtung Evaluation

Sie glaubte, nicht genügend gebildet zu sein. Deswegen verwendete sie häufig Fremdwörter, die nicht recht in den Verlauf unserer Unterhaltung hineinpaßten. Ein solches Wort war zum Beispiel das Wort Fetischismus. Natürlich wußte Magda, was Fetischismus ist, aber sie wollte auch zeigen, daß sie es wußte. [...] Der Anblick der beiden Tuben veranlaßte Magda, aus dem Bad herauszurufen: Bist du ein Zahnpastatubenfetischist geworden? Ich gab keine Antwort; es war wieder einmal so weit, daß Magda ihr Teilwissen unbedingt hatte loswerden müssen, dieses ewig fragmentarische Konfettiwissen, das von Zeitungen und Zeitschriften jeden Tag neu und vollkommen wahllos über den Menschen ausgestreut wurde. (Einfalt, S. 69)

Genazinos (Figur) Schweigen kann entweder als Rücksichtnahme gewertet werden oder als zusätzlicher Distanzmarker. Diesen Umstand reflektiert auch der Ich-Erzähler aus Genazinos Roman Ein Regenschirm für diesen Tag:

Früher habe ich gegen die Auswirkungen des Dünkels gekämpft, heute nicht mehr. Natürlich muß ich mich, wenn ich mit Habedank zusammen bin, besonders anstrengen. Er soll von meinem Dünkel nichts bemerken. Er glaubt, elektrische Eisenbahnen seien auch mein Hobby [...]. Mein Dünkel besteht aus einem fast permanenten Zusammenstoß von Demut und Ekel. Beide Kräfte sind ungefähr gleich stark. Einerseits mahnt mich die Demut: Gerade die idiotischsten Geschichten deiner Mitmenschen sollst du dir anhören! Und gleichzeitig stichelt der Ekel gegen mich: Wenn du jetzt nicht fliehst, gehst du in den Ausdünstungen deiner Mitmenschen unter! (Regenschirm, S. 79 f.)

Beide Figuren handeln nach Doležel rational, in beiden Fällen sind die Nebenfiguren prädikative Charaktanten $(\Leftrightarrow I .2 .4)$, beidenfalls ist es zwar nicht willentliche Boshaftigkeit, aus der sich der Hochmut speist, aber eine latente reizbare Aggression, schreitet man den Eysenck'schen Typenkreis ab $(\Leftrightarrow I I .1 .5 / \Rightarrow$ Abb. 13), lässt sich nicht verleugnen. Für die generelle ,Veranlagung' zur Überheblichkeit lassen sich mannigfache Erklärungsansätze finden: selbst diagnostizierte, fremdgetätigte, solche, die das Zeug haben, als schwergewichtige Sentenz solitär stehen zu bleiben, solche, die bereits in sich den Widerspruch tragen etc. pp. Einige dieser Ansätze sollen im Folgenden genauer unter die Lupe genommen werden, und zwar weiterhin mit dem Ziel, den Rahmen möglichst genau festzustecken, innerhalb dessen sich die abschätzigen Bewertungen anderer abspielen.

W. aus Der Fleck, die Jacke, die Zimmer, der Schmerz, der immer wieder zwischen den Polen von elitärem Bei-sich-Sein (vgl. Fleck, S. 8 f.) und Zugehörigkeitswunsch (vgl. Fleck, S. 20) oszilliert, gibt als Genese seines Hochmuts einen Transformationsprozess unterschiedlicher Emotionen an: „In der Stunde der Selbstverengung, wenn mich die Empfindsamkeit in die Isolation und die Isolation in den Hochmut treibt" (Fleck, S. 40). Dabei handelt es sich weniger um die Angabe einer motivationalen Ursache als lediglich um die Benennung eines Ausgangspunkts, der laut Selbstanalyse letztlich vorprogrammiert und unwillentlich im Hochmut ende (s.u.).

Die Reflexionen, die das Bedeutungsfeld von Hochmut und Dünkel begleiten, münden auch immer wieder in die Selbstkritik. Als Figurenfacette steht das unter diesem Schlaglicht rubrizierte Verhalten nämlich zunächst quer zum oben skizzierten Basistypus. Als Charaktereigenschaft sind Hohn, Spott und Herabsetzung, die sich allesamt aus dem Handlungsrepertoire offensiven Impression Managements speisen, gesellschaftlich und christlich-kulturgeschichtlich im Großen 
4.1 Das Ich, die anderen und das andere: Inszenierung - Beobachtung - Evaluation - 399

und Ganzen geächtet oder zumindest ungern gesehen. Diese Tatsache ist Genazinos Figuren überdeutlich ins Figurenbewusstsein eingeschrieben:

Noch zwei Tage später [...] machte ich Monet herunter, was ich selbst ärgerlich fand. Es geschah nur deswegen, weil Karins verstorbener Mann den Maler geschätzt hatte. Es war ein sublimer Akt der Eifersucht, verschoben in ein Bildungserlebnis. Ich nannte Monet einen billigen Kaufhausmaler, der schon im 19. Jahrhundert den Massengeschmack des 20. und 21. Jahrhunderts erkannt hatte und Bilder malte, die heute in jedes Wartezimmer und in jedes Sekretariat hineinpassten. (Tiere, S. 109)

Gerne würde der Protagonist darauf verzichten, eine ,unschuldige' und - so lässt sich aus der Evaluation des eigenen Sprachhandelns schließen - prinzipiell sogar geschätzte Person zu diskreditieren. Den Stellvertreter anzugreifen, erregt sein Unbehagen und führt ihm die Diskrepanz zwischen Selbst- und Idealbild vor Augen $(\Rightarrow$ II.2.1).18 Doch ist der Kampf gegen den eigentlichen ,Gegner' nicht möglich - zum einen aufgrund seines Ablebens nicht mehr, zum anderen aufgrund der im harten Kern der Figuren festgelegten Fluchtpräferenz $(\Leftrightarrow I I .2 .5)$. In diesem Zitat schneiden sich sozialpsychologische Mechanismen offensiven IMs (Ironie, Herabsetzung; $\Rightarrow$ I.3.3) mit psychoanalytischen: Denn während der Satz: „Es war ein sublimer Akt der Eifersucht“ noch theoriefrei hätte durchgehen können, wird mit dem Kotext („verschoben“, „Bildungserlebnis“) das Konzept ,Sublimierung' aufgerufen. Dass es sich bei dieser laut Freud gesellschaftsfähigsten Triebabfuhr eigentlich selbst um kreative Akte handelt und nicht darum, Kreative zu verhöhnen, gibt diesem Bild eine komische Note, wobei man wiederum einwenden könnte, dass der unverhohlene Stolz auf die Formulierung der Anwürfe selbst als schöpferische Leistung gewertet werden kann. Um die Schieflage des Vergleichs zu verdeutlichen und erneut den metapsychologischen Charakter herauszustreichen, lässt sich hinzufügen, dass der Ich-Erzähler mit Karin, der Witwe seines Arbeitskollegen, längst freizügig sexuell verkehrt - wie auch mit einer zweiten Frau, Maria, sodass von libidinöser Ableitung recht eigentlich nicht die Rede sein müsste. ${ }^{19}$

Außer den bereits durch die Selbsterkenntnis der Protagonisten nahegelegten Erklärungsansätzen gibt es auch die Grundkonstellation, dass eine andere Figur als ,Analytiker auftaucht. In jedem Fall handelt es sich bei den Grunddispositionen für die Ablehnung anderer um neuralgische Punkte im Romanwerk. Eine erste musterhafte Ausgestaltung besteht in der absichtlichen Entfremdung bei gleichzeitiger Abwertung der anderen: „Du lehnst alles ab, und wenn du es nicht sofort ablehnen kannst, dann schaltest du es durch Fremdheit erst mal aus." (Falsche Jahre, S. 501) Dagmar trifft den Nagel auf den Kopf, was Abschaffel später selbst einsieht: „Um sich wirklich von ihr [nicht Dagmar; N. L.] distanzieren zu können, müßte er die Frau ausdrücklich

18 Vgl. auch Abschaffel, der sich dafür tadelt, andere zu verhöhnen: „Er kam sich dann selbst lächerlich vor." (Falsche Jahre, S. 435)

19 Vgl. zum Abwehrmechanismus ,Rationalisierung' etwa: „Es gab eine Form der Verachtung, die sich auswirkte wie eine Rationalisierung: dann arbeitete er fast doppelt so schnell." (Fremde Kämpfe, S. 135) Hier werden Überheblichkeit und Verachtung als Motor zur Arbeit selbstanalysiert. 
400 - Teil II: Schlaglichter 4. Das Ich, die anderen und das andere: Inszenierung - Beobachtung Evaluation

verhöhnen und entwerten, aber dazu hatte er keine Lust." (Falsche Jahre, S. 514) ${ }^{20}$ Vorgeblich handelt es sich um einen Selbstschutzmechanismus: Abschaffels Seelenheil (Distanzierung von Frau) sei nur dadurch zu erreichen, „die Frau“ zu verobjektivieren. Diese zuhöchst offensive Handlung ( $\Rightarrow$ II.4.4) unterbleibt lediglich aufgrund des handlungsvermeidenden Faktors „keine Lust" ( $\Rightarrow$ I.3.1). Abschaffel ist damit - eine andere verletzende Attitüde im besten Gewissen, nicht anders zu können - nicht allein:

Hohn ist die schnellste Art von Souveränität, die Menschen möglich ist. Der Grund für ihren plötzlichen Bedarf ist Notwehr. Ich verstand nicht mehr, was an diesen gockelartig aufgeputzten Männern und ihren Bonbons aufregend oder gar bewundernswert sein sollte. Weil ich ihnen aber noch Minuten zuvor gut gesonnen war, brauchte ich für meine überraschend eingetretene Distanz ein schnelles Ausdrucksmittel, den Hohn. Ich spürte, wie mich ein gleichmäßig fließender, innerer Spott rasch von diesen Männern entfernte. (Einfalt, S. 40 f.)

Aufgrund der Umdeutung von offensivem Hohn in protektive Selbstsicherung aus Gründen der Notwehr, kann das Figurenselbst in der Entfremdung aufrechterhalten werden. Damit ist bereits die Verbindung zur dritten Möglichkeit (s.u.) vorausgebahnt: Genazino (Figur) vermutet, „daß inmitten des dröhnenden Einerleis die persönliche Einsamkeit vielleicht die einzige Möglichkeit ist, unserer selbst wieder inne zu werden. Qualitativ wertvolle Einsamkeit ist nur die absichtsvoll herbeigeführte." (Einfalt, S. 147 f.)

Eine im Wesen verschiedene Grunddisposition zum Ablehnen besteht in Wilhelm Genazinos Romanen darin, ,berechtigte' Skepsis am Handeln der anderen anzubringen und somit ,aufgeklärt' die Maximen des eigenen Handelns denen der als moralisch zweifelhaft erachteten anderen vorzuziehen, wodurch diese der - subjektiv angebrachten und bezogen auf Eysenck $\Leftrightarrow$ II.1.5/ $\Rightarrow$ Abb. 13) ,aktiv' zu nennenden - Kritik ausgesetzt werden:

Kaum etwas von dem, was Eltern, Lehrer und Nachbarn vorlebten, stellte sich als nachahmenswert heraus. Deswegen mußte alles, was andere sagten oder forderten, erst auf verschwiegene, dann auf offene Weise bezweifelt werden. Am Untersuchungsverfahren gegen das bürgerliche Leben nehme ich bis heute teil (Einfalt, S. 76; vgl. Frauen, S. 30 f.; vgl. Heimweh, S. 142 f.).

Dass durch die Kritik des Falschen das Richtige zu suchen (und in Ansätzen auch zu finden) sei $(\Leftrightarrow$ II.1.6), motiviert die Figuren gelegentlich dazu, den Zweifel aus der Verschwiegenheit in die Öffentlichkeit zu transformieren. Ein dritter Erklärungsansatz, der noch vom „Untersuchungsverfahren gegen das bürgerliche Leben“ eingefärbt ist, verknüpft reflexiv den Abwertungswunsch mit ,drei Stufen der Einsamkeit' (s.o.):

Denn jetzt, in der dritten Stufe, wußte ich nicht mehr, was der Grund von Einsamkeit war und wer oder was bekämpft werden mußte. Mal griff ich die Menschen an (immer still, in Gedanken), mal die Verhältnisse, in denen sie lebten, mal bestimmte Eigenschaften der Menschen, die ich für verursachend hielt (Faulheit, Unlust, Infantilismus), mal das Bildungswesen, aber nach jedem der nur gedachten Angriffe spürte ich, daß sie ihr Ziel, die Erklärung von Einsamkeit, nicht leisteten. (Einfalt, S. 146)

20 Vgl. für den Fall, dass eine Figur dazu diese ,Lust' aufbringt: „In seiner Phantasie hatte er Margot schon oft so weit abgewertet, daß nichts mehr von ihr übriggeblieben war" (Sorgen, S. 163; $\Rightarrow$ II.5.3). 
4.2 Das Ich, die anderen und das andere: Inszenierung - Beobachtung - Evaluation - 401

Wie bereits festgestellt leistet dieser Erklärungsversuch weder eine befriedigende Darlegung des Ursprungs von Einsamkeit noch von Hochmut, sondern korreliert höchstens diese zwei für den Basistypus sich wechselseitig bedingenden Verfassungen.

Neben der Einsamkeit lassen sich weitere - teilweise bereits herausgeschälte, mitunter auch periphere - Figurencharakteristika benennen, die der offensiven Beobachtung und Evaluation Vorschub leisten, als da wären: die Tendenz zu ungehemmtem Frustabbau ( $\Rightarrow$ II.4.4), zum Beleidigtsein ( $\Rightarrow$ II.1.3), zu Eifersucht und Neid (vgl. Ausschweifung, S. 49 u. S. 130 f.), Enttäuschung, Verzweiflung und ,allgemeiner Unzufriedenheit' (vgl. Sorgen, S. 224), zur (häufig in Verbindung mit den eigenen Eltern vorkommenden) Fremdscham (vgl. Abschaffel, S. 50) sowie die Neigung zu ,Pöbellaune“ und „Spottlust“ (Abschaffel, S. 38; $\Rightarrow$ II.4.4), die in ,niederen Beweggründen` des Cholerikers wurzelt.

Es muss aber nicht immer das offensiv ,Grundböse' bzw. die auf Neurotizität zielende Einordnung in Choleriker oder Melancholiker als Erklärung für die Taxierung und Bewertung der anderen namhaft gemacht werden - ab und an ist es auch schlicht die Freude am Analysieren, Charakterisieren und „[K]lassifizieren“ (Fleck, S. 149), die den Impetus bildet ( $\Rightarrow$ II.2.2 u. $\Rightarrow$ II.2.3):21

Die Absicht der Geste ist offenkundig: Man muß ihn für den Besitzer des Koffers halten. [...] Wie der Mann durch die Art seines Umherschauens zeigt, daß er einen kleinen Diebstahl plant! [...] Es ist wunderbar: Im vollen Mittagslicht sehe ich einen Mann inmitten seiner Ratlosigkeit. (Liebesblödigkeit, S. 192)

Dieses Interesse an der Beobachtung, diese ungemeine Freude am Verstehen und Bewerten lässt sich für Genazinos Romanfiguren unabhängig von der Strenge des Urteils gut systematisieren, was zu leisten sich das folgende Unterkapitel anschickt.

\subsection{Evaluative Inaugenscheinnahmen}

Was genau letztlich den Ausschlag dafür gibt, den Prozess einer Beobachtungssituation in Gang zu setzen, lässt sich nicht pauschalisieren. Es kann die Reflexion über den ersten Eindruck sein (vgl. Abschaffel, S. 11 u. S. 126 f.),,22 ein körperliches Detail, eine bestimmte Stimmung, ein Zufall.

\section{FANTASIEREICHE VERLAUFSPLÄNE UND BEMERKENSWERTE BEWERTUNGSKRITERIEN}

Immer jedoch gilt die Vorliebe für (neurotisch motivierte; $\Rightarrow$ II.4.1) Mutmaßungen und Überinterpretationen, ${ }^{23}$ denn „der Ich-Erzähler gibt sich deutlich als jemand zu erkennen, der Spaß am

21 Vgl. für aufschlussreiche Beispiele etwa Ausschweifung, S. 132, Fremde Kämpfe, S. 96 ff., u. Regenschirm, S. 148.

22 Vgl. Sima Kappeler: First encounters in French and German prose fiction, 1830-1883. New York 1996. Vgl. für die Bedeutung der Frisur beim ersten Eindruck Reinhold Bergler/Tanja Hoff unter Mitarbeit von Barbara Schneider, Dietmar Haase, Meike Wemhoff: Psychologie des ersten Eindrucks. Die Sprache der Haare. Eine empirische Analyse zur Psychologie des Alltagsverhaltens in den baltischen Staaten, Deutschland, Rumänien, Russland, der Türkei und Ukraine. Köln 2001. 
402 - Teil II: Schlaglichter 4. Das Ich, die anderen und das andere: Inszenierung - Beobachtung Evaluation

Erfinden und Deuten hat." 24 Seit Genazinos Erstling ist dieser Grundzug fester Bestandteil des Basistypus und das Ausdrucksspektrum, mit dem es auf Discours-Ebene vorgetragen wird, ist mittlerweile immens: Manchmal wird der Leser in die Irre geführt mit vermeintlich sicheren Wahrnehmungen der Protagonisten, manchmal weisen die Figuren ihre Beobachtungen dezidiert als Mutmaßungen aus, manchmal erfordert es die sehr genaue Lektüre, um überhaupt Indizien zu erlesen, die den Verdacht erhärten, dass die Vermutungen, sollten sie sich bewahrheiten, nur um den Preis eines variabel intern fokalisierten Erzählers zu haben wären.

Meist treten die Markierungen des individuellen Vorbehalts allerdings deutlicher zu Tage. So ist Axel Degens Beobachtung: „dieser Mann ist vielleicht verheiratet [...] er sah gepflegt aus, wie sonst nie wahrscheinlich" (Laslinstraße, S. 57), gleich doppelt in gedankliche Fragezeichen gesetzt. Die Wahl der Präsentation von unsicherer sinnlicher Wahrnehmung ist schriftsprachlich mitunter auch mit ,echten' Fragezeichen verknüpft: „Oder hatte Sonja die Verfügung erfunden, um mir nicht mehr zu begegnen? Will sie nicht länger mit ihren Kollegen über meine prekären Verhältnisse sprechen wollte? Vorgänge dieser Art verführten mich zu der Vorstellung, dass Sonja mich allmählich loswerden wollte." (Regen, S. 27) 25

Ungeachtet der Bandbreite und Häufigkeit von derlei dezidierter Zweifelhaftigkeit ist der Trend dazu, die Einschätzung aufgrund von Mutmaßungen vorzunehmen, bereits bei den letzten Beispielen deutlich erkennbar. Rezipientenseitig dubios wird es, sobald die Reflexionsebene zurückgefahren wird und sich die Zweifel in der Wahrnehmung auf der Achse des äußeren Kommunikationssystems (Text-Leser) zu verschieben beginnen, wie es etwa im Anschluss an Axel Degens bereits Züge der Evaluation beinhaltende Beobachtung geschieht: „[U]nd der mit der Wildlederjacke ging immer auf und ab, langsam, damit seine wartende Funktion sichtbar wurde“ (Laslinstraße, S. 97). Degens Vermutung, es verberge sich eine Intention hinter dem beobachteten manifesten Verhalten, entbehrt an dieser Stelle zwar nicht jedweder Grundlage - scheint es sich doch um iteratives Erzählen zu handeln („immer“), was der Vermutung vordergründig eine höhere Glaubwürdigkeit sichert -, doch wäre eine alternative Erklärung auch schnell bei der Hand: Vielleicht geht der Wartende auch deswegen langsam, weil dann subjektiv die Zeit schneller vergeht. Noch deutlicher tritt die ,Überinterpretation', die der Leser zu recht vermutet, etwa zutage, wenn Abschaffel sich fragt, warum die Kundin, die beim Bäcker vor ihm an der Reihe ist, derart lange für den Bezahlvorgang benötigt: „War die Frau blind oder kannte sie die Münzen

23 Hier handelt es sich dezidiert um die Untersuchung personenbezogener Mutmaßungen. Das Kapitel zum Beobachtungszwang grundiert diesen familienähnlichen Charakterzug im Allgemeinen $(\Rightarrow$ II.2.2).

24 Hirsch: „Schwebeglück der Literatur“, S. 97.

25 Vgl. auch: „Wahrscheinlich, ich hatte ihn im Verdacht, wahrscheinlich hatte er das seiner Frau noch gar nicht gesagt, er wußte es, und das genügte ihm, vielleicht dachte er auch, das brauchte sie nicht zu wissen, dann würde sie eitel, aber das war nur eine Vermutung von mir" (Laslinstraße, S. 107). Oder: „Mein Vater saß in seinen Wünschen und Äußerungen rein und klar da, man konnte alles von ihm sehen, mit seinem Sprechen legte er sich selbst bloß, auch meine Mutter und Petra, aber der Mann von Petra, ich war mir nicht ganz klar." (Laslinstraße, S. 109) 
4.2 Das Ich, die anderen und das andere: Inszenierung - Beobachtung - Evaluation - 403

nicht? Oder war es möglich, daß sie nicht rechnen konnte?“ (Falsche Jahre, S. 414) Aufgrund der fast absurden Multioptionalität der Erklärungsansätze lässt sich in Betracht ziehen, ob nicht sogar die Komikevokation als externes Movens der Evaluation des Verhaltens der Bäuerin anzusetzen ist.

Erzähltheoretisch hervorhebenswürdig sind Evaluationen, die noch über die kontraintuitivsten Erklärungsversuche der Protagonisten hinausgehen: „Ich merkte, das hatte er gar nicht sagen wollen, es war ein schlechter Ausweg, er wollte gern etwas anderes sagen, war aber in letzter Sekunde wieder abgesprungen wie ein Spieler vor einem hohen Einsatz." (Laslinstraße, S. 172) Die Ebene der Kontraintuition - die beobachtbare Faktenlage ist solide, die Erklärung abstrus wird verlassen und durch eine höchst individuelle Intuition selbst auf der Ebene der Perzeption ersetzt: Indizien für die Einschätzung Degens stehen dem Leser nicht zur Verfügung, sodass die Erklärung zwar nicht per se widersinnig anmutet - aber eben bloß gemutmaßt. Ähnlich verhält es sich mit Abschaffels Befürchtung: „Dieser Ronselt bildete sich doch tatsächlich ein [...]. [...] Abschaffel spürte, daß Ronselt ihn für einen Mistkäfer hielt.“ (Sorgen, S. 204) Selbst von Intuition zu sprechen fällt hier schwer, da die semiotischen Mosaiksteinchen, die Abschaffel dazu bewegen, schon sehr in Form gedrückt werden müssten. Der Effekt, dem Leser die Neurotizität, dem Literaturwissenschaftler die Unzuverlässigkeit des Erzählens vor Augen zu führen, bleibt davon unbenommen eindrucksvoll bestehen.

Bildet bisher die fixierte interne Fokalisierung die Grundvoraussetzung für die Evaluationssituationen, entpuppen sich sporadisch Textbeispiele als solche der Multiperspektivität: „Ruth spürte, wie unbeholfen seine Unterhaltungsversuche waren, aber sie griff nicht ein." (Ausschweifung, S. 16) Anders als mit dem zeitweiligen Switch in die Innenperspektive von Eckhard Fuchs' Frau Ruth lässt sich diese Gewissheit nicht erklären. Damit aber liegt die Evaluationssituation nicht mehr im Auge des Protagonisten begründet und dementsprechend außerhalb dieses Kapitels. Herr Fuchs ist jedoch eine ,Vorzeigefigur', um die Freude am Analysieren/Charakterisieren und den Zug der Überinterpretation zu konturieren. Über ihn heißt es sogar dezidiert, er habe begonnen, „im stillen einen Lebenslauf des Kanarienweltmeisters zusammenzuphantasieren. [...] Zu gerne hätte Eckhard gewußt, ob sein Lebenslaufentwurf weitgehend richtig oder völlig falsch war." (Ausschweifung, S. 219 f.; Herv. N. L.) Fuchs zieht die Möglichkeit nicht nur in Betracht, dass seine folgende Einschätzung „völlig falsch“ sein könnte; sie ist vielmehr von vornherein gleichberechtigt (un-)wahrscheinlich. Mehr noch: Letztlich - nach getaner Analysearbeit - konstatiert Fuchs: „Es war unmöglich aus seinem Verhalten auf Enttäuschungen über den Verlauf seines Lebens zu schließen“ (Ausschweifung, S. 220), was aber gerade einen nicht unerheblichen Anteil seiner Einschätzung abgibt. Aufgrund einzelner Anhaltspunkte der Inszenierung Herrn Valentins (Kleidung, Habitus etc.; vgl. Ausschweifung, S. 218 ff.), spinnt sich Herr Fuchs dennoch vorab eine Vita zurecht, die er von den 50er über die 60er und 70er bis in die Erzählgegenwart der frühen 80er Jahre des zwanzigsten Jahrhunderts hin ausschmückt: 
404 - Teil II: Schlaglichter 4. Das Ich, die anderen und das andere: Inszenierung - Beobachtung Evaluation

In den fünfziger Jahren war Herr Valentin jung gewesen und war mit seinen Vögeln in Kabaretts und Varietés aufgetreten, überlegte er, war von Tingeltangel zu Tingeltangel gereist, und das Leben hatte ihm gut gefallen. Vielleicht war er sogar das eine oder andere Mal im Fernsehen zu sehen gewesen. (Ausschweifung, S. 219)

Dabei kleidet er die vorhandenen oder herbeigeirrlichterten Leerstellen mit eigenem Wissen aus und richtet die Aufmerksamkeit immer wieder vom Untersuchungssubjekt weg auf sich selbst, was in diesem Beispiel gleichbedeutend mit einer kleinen Fernsehgeschichte der Kleinkunst ist:

Eckhard erinnerte sich an die heute kaum noch zu verstehende Bescheidenheit des Fernsehens in den fünfziger Jahren. Damals gab es in der Kinderstunde noch nicht diese aufwendigen AbenteuerSerien oder jeden Tag einen anderen Zeichentrickfilm; damals traten solche Kleinkünstler wie Herr Valentin für eine Stunde ins Programm und führten vor, was sie konnten, und das war identisch mit dem, was allgemein für sehenswert gehalten wurde. [...] Dann aber, vermutete Eckhard, in den sechziger Jahren, brachen mit Macht die Zeichentrickserien in das Fernsehen ein, und Herr Valentin flog wie ein alter Papagei aus dem Programm hinaus. [...] Und dann, in den siebziger Jahren, kam seine schwierigste Zeit, weil er nur noch aufgrund von Mißverständnissen und Mitleid neue Engagements erhielt; er hatte wahrscheinlich schon viele Rentnerbetreuungsnachmittage aufgelockert und war Spitzenstar bei Betriebsfesten gewesen. Und nun, überlegte Eckhard, zu Beginn der achtziger Jahre war Herr Valentin unwiderruflich am allerletzten Endpunkt seiner Karriere angekommen: Er hatte sich und seine Papageien an eine Vogelfutterfirma verkauft und reiste von Zoohandlung zu Zoohandlung. [...] Herr Valentin (hieß er überhaupt so? Hieß er nicht einfach Heinz Meier oder Günter Müller?) [...]. Auch Eckhard hatte Lust, über Herrn Valentin zu lachen, aber er traute sich nicht, weil er so weit vorne saß. [...] Ob Herr Valentin bemerkte, daß in die Bewunderung der Kinder auch die Verächtlichkeit einiger Erwachsener gemischt war? (Ausschweifung, S. 219-221; Herv. N. L.)

Interessant ist nicht nur die mit Verve weiterverfolgte Inszenierungsanalyse bei gleichzeitig sehr dünner Faktenlage, sondern allzumal auch die Tatsache, dass einer nahezu mitleidig-empathischen Fantasie mehr und mehr kleine Spitzen eingeschrieben werden, die die Inszenierung der Lächerlichkeit preisgeben ( $\Rightarrow$ II.4.3).

Jedenfalls wähnen sich die Evaluierenden in der Mitte eines bedeutungsvollen Universums, das sich um sie und für sie bewegt. Diese Vorstellung hat nicht nur etwas mit Egozentrik zu tun, sondern auch mit der Notwendigkeit, nur von einer Ego-hic-nunc-Origo aus auf Personen deuten und (moralische) soziale Interpretationen der Umgebung vornehmen zu können. Allerdings ist dieser Sachverhalt bei Genazinos Figuren immer wieder dadurch gebrochen, dass es mangelnde Sozialkompetenzen (namentlich aus dem perzeptiv-kognitiven Bereich) sind ( $\Rightarrow$ II.1.3), die sich schlimmstenfalls in pathologische Überlegenheitsfantasien $(\Leftrightarrow I I .2 .2)$ als Kompensation von geringer Kontrollüberzeugung/Selbstwirksamkeit ( $\Rightarrow$ II.1.3) auswachsen, wie etwa bei Abschaffel: „Da nichts wirklich mit ihm [dem Alleinstehenden; N. L.] zu tun hat, glaubt er, alles müßte mit ihm etwas zu tun haben" (Abschaffel, S. 18). ${ }^{26}$ Zielt die Aussage hier noch auf Allgemeingültigkeit, verweisen die folgenden Beispiele bereits auf eine ins Bedenkliche übersteigerte Subjektivität: „Um so angestrengter mußte er darum kämpfen, daß die Ereignisse etwas mit ihm zu tun hatten, und dies gelang ihm jetzt nur noch, indem er über alles schimpfte." (Abschaffel, S. 55) Im zweiten

26 Vgl. dazu auch Jürgen Egyptien: Einführung in die deutschsprachige Literatur seit 1945. Darmstadt 2006, S. 54. 
4.2 Das Ich, die anderen und das andere: Inszenierung - Beobachtung - Evaluation - 405

Teil der Abschaffel-Trilogie etwa, wenn er glaubt, „die Hausordnung sei überhaupt nur seinetwegen angebracht worden“ (Sorgen, S. 346), gipfelt diese Ego-Perspektive.

Allerdings ist die Stoßrichtung auch umkehrbar: Nicht nur alles ,Äußere' scheint etwas mit ihm zu tun zu haben, sondern auch alles ,Innere' wird in das ihn Umgebende hineingelegt:

In der Gleichsetzung seines Lebens mit dem Leben von Dr. Buddenberg war er sogar so weit gegangen, dem Analytiker weitgehend dieselbe Wohn- und Lebensausrüstung anzuphantasieren, wie er sie selbst hatte. Wahrscheinlich besaß Dr. Buddenberg zwei Hosen, höchstens drei (Falsche Jahre, S. 456). ${ }^{27}$

Hauptsächlich im Grundlagenkapitel zur Verbindung von Literatur(wissenschaft) und Psychologie(sierung) ( $\Rightarrow$ I.3.2) ist ausladend dargelegt worden, dass zwischen Genazinos Romanfiguren, der Psychologie und den Lesern ein enges Beziehungsgeflecht besteht, weswegen es nicht erstaunen sollte, dass die problematische Einschätzung Abschaffels mit der psychologisch verbürgten Egozentrik d'accord geht:

Welche Persönlichkeit, Moralvorstellung oder politische Orientierung man anderen unterstellt, hängt stark von den eigenen Merkmalen ab. Wer selbst oft lügt oder gern Gedichte liest, überschätzt den Anteil jener Menschen in der Bevölkerung, die so etwas ebenfalls häufig tun. [...] Die egozentrische Projektion ist ein altbekanntes Phänomen in der Sozialpsychologie. Auch Joachim Krueger von der Brown University in Rhode Island erforscht sie. Er sagt: „Das Selbst ist eine wichtige Quelle, um andere einzuschätzen." Naturgemäß habe jeder mehr Informationen über sich selbst als über andere. „Da wir davon ausgehen können, dass Menschen einander grundsätzlich ähnlich sind, ist es nicht die schlechteste Strategie, von sich selbst auszugehen, wenn man wenig über andere weiß." Die Folgen sind allerdings kurios. Wir übertrügen mitunter ganze Persönlichkeitsprofile von uns auf andere, sagt Dunning. Seine These: Eigenschaften, die in der eigenen Persönlichkeit kombiniert sind, betrachten Menschen als zusammengehörig und legen diese Schablone auch bei anderen an. „Angenommen, ich bin introvertiert, nervös und lese außerdem nicht gern“, sagt Dunning, „dann werde ich, wenn ich jemanden treffe, der ebenfalls introvertiert ist, ihn womöglich auch für nervös halten und davon ausgehen, dass er keine Bücher mag. ${ }^{.28}$

Dreht man nun die Spirale ein wenig weiter, ist es nicht nur so, dass man in die Unbestimmtheitsstellen anderer bestimmte ,Eigenheiten' ,hineinliest', sondern auch eigene Ansprüche an die eigene Person bei anderen erwartet. Das schlägt sich nieder in teils explizierten, mitunter aber auch unausdrücklich formulierten Messlatten und Kriterien zur Evaluation anderer. So erwarten Genazinos Romanfiguren bspw. auch von anderen die von ihnen selbst wohl bekannte öffentliche Selbstaufmerksamkeit respektive Rücksichtnahme (vgl. Ausschweifung, S. 269; $\Rightarrow$ II.2.4) oder verurteilen mangelndes Empathievermögen (vgl. Frauen, S. 119 f.), wenn eine Mutter ihren behinderten Sohn (gegen dessen Willen?) in den Mittelpunkt rückt, was der Ich-Erzähler kritisiert und sich in den Jungen einfühlt.

Allerdings unterliegen diese Richtschnüre, nach denen die Evaluationen erfolgen, auch persönlichen und situativen Faktoren, was einer Vereinheitlichung entgegenwirkt: Grundgestimmtheiten und Stimmungsschwankungen $(\Rightarrow$ II.1.3) sind für Genazinos Figuren an der Tagesordnung

27 Erstens handelt es sich um eine unaufdringliche Selbstpreisgabe, zweitens muss Abschaffel später sein Urteil revidieren.

28 Wüstenhagen: Ich-Bewusstsein. 
406 - Teil II: Schlaglichter 4. Das Ich, die anderen und das andere: Inszenierung - Beobachtung Evaluation

und immer mit zu berücksichtigen, wenn die Analyse von Evaluationen ansteht: „Nach dem Verlust der Gewißheiten bleiben uns nur noch Wahrheitsstimmungen; mal scheint dieses plausibel, dann wieder jenes.“ ${ }^{29}$ Aber nicht nur die „Wahrheitsstimmungen“ schwanken, sondern auch die „Gemütszustände“ und zwar: „extrem“!30 Was sich - von Sill auf Pescheks Fremde Kämpfe bezogen - liest wie eine Diagnose: „zwischen Zuversicht und Angst, zwischen Euphorie und Verzweiflung“, weist in der Tat auf eine bipolare affektive Störung hin, die landläufig als manischdepressiv bekannt ist und deren Kriterienkataloge der jeweiligen Phasen genau zwischen diesen Extremen schwanken. Ob dem so sei und ob dem hinsichtlich literarischer Figuren überhaupt so sein könnte, ist vergleichsweise weniger wichtig als das unumstößliche Vorliegen der ,Stimmungsschwankungen', mit denen auch die Dynamik der Richtschnüre angerissen ist: Vom einen auf den anderen Moment „verstand er [Abschaffel; N. L.] selbst nicht, warum er das, was ihm eben noch gefallen hatte, so sehr ablehnte." (Sorgen, S. 192) Erneut ist dies keine idiosynkratische ,Diagnose' Abschaffels, ohne ersichtlichen Grund Margot in einem ganz anderen Licht zu sehen, sondern ein musterhafter Wesenszug des Genazino'schen Basistypus: „Aber plötzlich, ich weiß nicht wie, gehört Sandra nicht mehr zu den Problemfällen. Im Gegenteil, ich liebe Sandra jetzt sogar wegen ihrer treuherzigen Versuche, eine Künstlerin zu werden." (Liebesblödigkeit, S. 150 f.) Bis hinein in die sprachliche Verpackung, in die erzähltechnische Vermittlung des Innenlebens - obgleich es den Übergang vom Er- zum Ich-Erzähler gibt - doppelt dieses Beispiel das vorige: Die erlebte Rede mit bewusstseinsberichtendem Einschlag wird zwar ausgetauscht durch inneren Monolog, die Signale dafür, dass die Figuren jeweils keinen Zugriff auf die unterbewussten Mechanismen haben, bleibt hingegen bestehen. ${ }^{31}$

Einmal in einer Grundgestimmtheit begriffen, hat diese immense Auswirkung auf die Evaluation im Schwange. Es ließe sich sagen, dass die selektive Aufmerksamkeit nur für diejenigen Details, die dem stimmungsadäquaten Interpretationsmodus gelegen sind, empfänglich ist, was sich besonders eindrücklich an einer Episode der Laslinstraße demonstrieren lässt:

[V]ielleicht sprach er auch nur für sie, obwohl ich ihm den Vorwand dazu geliefert hatte, [...] ich beobachtete sie, wie sie sich plötzlich darin einig waren, mir ihre Geschichte vorzumachen mit allem Drum und Dran, mit Achselzucken, Augenbrauenhochziehen und bedeutenden Blicken [...]. [...] [S]ie wurgste an ihrer zweiten Portion herum, ungeschickt, immer darauf bedacht, den Mund voll zu haben [...]. [...] Ich weiß nicht, wie ich dazu kam, das Geld gleich zu zählen [...], vielleicht hätte ich danke sagen sollen [...], das Lächeln meines Vaters war wirklich nur Stoff und Fahne. Er [...] hißte auf seinem Gesicht Alltag, als hätte er an einer Schnur gezogen, die ihm Gesichter und Ausdrücke lieferte, ein Lächeln für die Überreichung von dreihundertfünfundzwanzig Mark, ein Schuß Feierlichkeit für die Worte Es ist nicht viel (Laslinstraße, S. 137-140).

29 Genazino: Aus dem Tagebuch der Verborgenheit, S. 9.

30 Sill: Moderne Zeiten, S. 30.

31 Dass sich die Stimmung bis in die Wortwahl hinein niederschlägt, zeigt das folgende Beispiel: „So nenne ich die beiden kleinen Zimmer heute noch, wenn ich gut gelaunt bin, das heißt, wenn ich genügend Spott in mir habe, der mir hilft, den Gegenstand [...] sowohl auszudrücken als auch mich über ihn zu erheben. Wenn ich nicht genügend Spott zur Verfügung habe, muß ich das Thema meiden oder lügen." (Einfalt, S. 38) 
4.2 Das Ich, die anderen und das andere: Inszenierung - Beobachtung - Evaluation - 407

Degen vermutet, dass seine Eltern ihm etwas vorspielen. Das verstimmt ihn. Also nimmt er eine Interpretationshaltung ein, die ,kein gutes Haar' an den Aussagen und Handlungen seiner Beobachtungsobjekte lässt: Tiefes Misstrauen im Rahmen der Causal History $(\Rightarrow I .3 .1)$ mag als Erklärung dienen, nichtsdestoweniger ist die Zuverlässigkeit der Wahrnehmung einerseits, die Zuverlässigkeit des Erzählens als ihr Abbild andererseits - und nur diese kann genaugenommen Grundlage einer literaturwissenschaftlichen Arbeit sein - höchst zweifelhaft. Ein besonders sinnschwangeres Exempel aus Genazinos erstem Roman kann die Abhängigkeit von Stimmung und Messlatte sowohl als auch die Dopplung von Wahrnehmung und Discours verdeutlichen: „[U]nd wenn sie kicherte, hatte ich das Gefühl, irgend etwas von dem, was sie sagte, sei nicht wahr, sei erlogen erfunden. Ihre Haare hingen feucht an ihr herunter wie ein nasses Hundefell“ (Laslinstraße, S. 195 f.). Die Stimmung interpretiert gewissermaßen an der Wahrnehmung mit: Momente vorher hingen die Haare noch nicht in dieser animalmetaphorischen Drastik! Aber wenn die Gewogenheit perdu ist, dann werden auch sinnliche Wahrnehmungen uminterpretiert, was sich im vorliegenden Beispiel zwar als Unterstellung selbst ausweist, die Empfindung und zugleich die herabwürdigende Interpretation des Aussehens hingegen sind für die Figur als ,echt' einzustufen. In diesen Fällen könnte man geneigt sein, Wilhelm Genazinos Figuren - ebenso wie erwiesenermaßen für den Bereich der Einschätzung von Ausländern und Minderheiten etc. - ein hohes Maß an ,evolvierter' Neigung zum (unbewussten) Schubladendenken anzudichten. Allein switcht die Einschätzung zu schnell und es finden sich zudem Selbstreflexionen und Aburteilungen zu starren Schubladendenkens:

Eine Minute lang will ich herausfinden, ob die Frau noch MITGLIED der Gesellschaft ist oder nicht mehr, welche Zeichen an ihr dafür sprechen und welche dagegen, ob sie als JENSEITIGE, als SCHWANKENDE oder ENDGÜLTIG ABGEGLITTENE zu betrachten ist. Eine Minute lang beurteile ich die Frau, wie man nur beurteilen kann, wenn man noch innerhalb eines bestimmten Urteilsschemas ist, erst dann bemerke ich, daß ich mich denkend an der Frau vergangen habe. (Fleck, S. 99)

Nicht nur die temporäre Unentschiedenheit der Etikettierung lässt den Protagonisten das Klischee des mental-ökonomischen Klischeewahrnehmenden brechen, sondern auch die selbstreflexive Schemakritik suspendiert - zumindest an dieser Stelle - die evaluative Rasterfahndung. Allerdings muss hinzugesetzt werden, dass eine Revision des Urteils ${ }^{32}$ bzw. des ersten Eindrucks nur in seltenen Fällen dazu führt, dass ein einmal bestehendes Image nachhaltig revidiert wird; vereinzelt sogar bis zur (ansatzweisen) Bewunderung $(\Leftrightarrow$ II.4.5). Diese Nachhaltigkeit eines Stimmungsumschwungs ist zwar nicht vorherzusagen und scheint keinem einfachen Verlaufsplan zu folgen, aber eine ,Faustformel' könnte lauten: Absolute Statisten der Romane können aus externer Perspektive der ästhetischen Motivierung nur einmalig mit einer Revision bedacht werden - „Er hatte sie unterschätzt, weil er sich von ihren Kopftüchern und Zipfelmützen vielleicht zu sehr hatte leiten lassen“ (Falsche Jahre, S. 412 f.) -, wohingegen Figuren mit zunehmen- 
408 - Teil II: Schlaglichter 4. Das Ich, die anderen und das andere: Inszenierung - Beobachtung Evaluation

der Wichtigkeit und höherer Frequenz im Auftreten potenziell der mehrmaligen Einstellungsänderung zugänglich sind. Über einen Arbeitskollegen Abschaffels sagt dieser aus: „Er schätzte Hornung seit einiger Zeit anders ein. Zu Anfang war Hornung für ihn ein armseliger Schwachkopf gewesen, ein Sozialkrüppel“ (Sorgen, S. 209). Das hindert ihn jedoch nicht daran, jenen nach einiger Zeit erneut zu verhöhnen und zu entwerten. ${ }^{33}$

Die Vielschichtigkeit der Evaluation anderer möge das folgende Beispiel illustrieren, das die Dimension der gesellschaftlichen Moralvorstellungen einbezieht:

Sie würden intelligenter handeln, wenn sie intelligenter handeln könnten. Sie können es nicht, man muß Mitleid mit ihnen haben. Mit dieser feinen Umschreibung vermeide ich die Feststellung, daß Wrede und Ehrlicher ein bißchen dumm sind, was man heutzutage nicht mehr sagen darf. (Glück, S. 44)

Einerseits sieht sich Warlich extrinsisch motiviert, zwei Personen neu zu labeln. Die alten Etiketten sind nicht mehr politisch korrekt, es müssen durch das Mittel einer „feinen Umschreibung“ neue gedruckt werden, die eine graduelle Uminterpretation zur Folge haben - wenngleich es im Umkehrschluss inferierbar ist, dass der Protagonist Wrede und Ehrlicher nach wie vor "dumm“ nennen würde, sofern die gesellschaftliche Konvention diese Möglichkeit unsanktioniert in ihrer Umgangsform festgelegt hätte. Es handelt sich mithin gleichzeitig um eine Persiflage des BeckerDiktums, wonach ein Mensch genau dann eine bestimmte Einschätzung erfährt, wenn andere Menschen sich darin einig sind, dass sie auf diesen zutreffe $(\Leftrightarrow I I .3 .5)$. Dummheit und die nicht vorhandene Möglichkeit, intelligenter zu handeln, sind nur zwei Begriffe für ein Konzept; die „Umschreibung“ wird zur Farce.

Genazinos Romanfiguren ist es aber, wie bereits vorher gezeigt werden konnte, nicht per se fremd, einen Irrtum in der Einschätzung anderer einzugestehen. Die Unentschiedenheit auszuhalten aber, eine Person nicht einsortieren zu können, ist eine Rarität, ihre (der Figuren) Sache nicht und muss demzufolge in den äußeren Bereich der familienähnlichen Figurenschichten $\Leftrightarrow$ I.2.5) sortiert werden:

Abschaffels Empfindungen für Hornung waren gespalten. [...] Weil Hornung zugab, daß er die schleppende Stille des Büros nicht so ohne weiteres Woche um Woche ertrug, verspürte Abschaffel eine ferne Neigung, Hornung zu bewundern. Aber Hornung verdarb sich Abschaffels mögliche Bewunderung wieder, weil er es zu sehr darauf anlegte, immer wieder im Interesse der anderen zu stehen, und das war auch für Abschaffel zu unseriös. (Sorgen, S. 172)

Solche Ambivalenzen fallen ebenfalls unter die gemutmaßte Faustregel (s.o.), nach der nur hinlänglich komplexe Nebenfiguren eine ihnen adäquate Einschätzung bzw. eine Revision generell hervorbringen können. Ein Sowohl-als-auch erfordert schließlich die Kenntnis (mindestens) zweier Seiten. So steht etwa auch Wolf Peschek zwischen den Stühlen:

33 Vgl. für doppelte Revisionen weiterhin bspw. Ausschweifung, S. 162, oder Die Kassiererinnen: „Wie war es möglich, dass ausgerechnet ich, der ich Wischinskis Hang zur Großschwätzerei gut kannte, nicht restlos ausgeschlossen hatte, es könne dem Kulturlokal vielleicht doch eine Spur Wirklichkeit anhaften?" (Kassiererinnen, S. 61) 
Die Art und Weise, wie Hirrlinger sein Leben schilderte, gefiel Peschek, obwohl er der Schilderung auch mißtraute. Das meiste von dem, was er mitteilte, hielt Peschek für unecht; es waren Teile einer gespielten Originalität, die er sich als Künstler zu jeder Stunde schuldig zu sein glaubte. Hirrlingers Verschrobenheit war in Pescheks Augen nur ein Zeichen ungehinderter Selbstliebe. (Fremde Kämpfe, S. 171)

Argwohn gegenüber verstellendem Verhalten bei anderen $(\Leftrightarrow$ II.1.2 u. $\Rightarrow$ II.4.3) und tendenzielle Bewunderung der Darstellung Hirrlingers ( $\Rightarrow$ II.4.5) konkurrieren um Pescheks Evaluation. Die unentschlossene Beurteilung, die nicht zu einer Seite hin tendiert (häufig in der dualistischen Form: Verachtung vs. Neid/Lob) ist nicht zuletzt deshalb verhältnismäßig selten, weil die Figuren nicht gut mit dieser Unentschiedenheit leben können, was sich in kleineren Signalformulierungen immer wieder begründet selbst offenlegt: „Leider konnte ich nicht klären, ob ich ihre Rücksichtslosigkeit bewunderte oder doch eher verabscheute." (Kassiererinnen, S. 14; Herv. N. L.) Nur so lassen sich die aufwändigen, weit über den ,bloßen` Beobachtungszwang hinausragenden Unterfangen intern motivieren - extern: den Voyeurismus des Lesers bedienen $(\Rightarrow$ II.2.2) -, einzelne Personen unbedingt in eine Schublade sortieren zu wollen. Neben der tragikomischen und bündigen Unterhaltsamkeit eines solchen Versuchs, wie es bei Herrn Valentin der Fall gewesen ist, finden sich auch über ganze Romane verteilte Anstrengungen, Personen in ihrer Wesensart fixieren zu wollen. Die Ich-Erzählerin aus Die Obdachlosigkeit der Fische bspw. teilt mit der Nebenfigur eines die Gäste anscheinend betrügenden Kellners mehrere Seiten Lebenszeit, die sich kurz gesagt im Beobachten erschöpft - genauer darin, ob ihr Blick auf diesen eher empathisch oder beargwöhnend ausfällt. Nach elliptischer Vorgeschichte und etlichen Augenblicken entschließt sie sich endlich, sich „den Kellner näher anzusehen." (Obdachlosigkeit, S. 93) Doch erneut muss das Urteil extern motiviert als retardierendes Moment vertagt werden: Eine genauere Prüfung ist erforderlich (vgl. Obdachlosigkeit, S. 99), die den Verdacht erhärtet, allerdings das experimentelle Setting - die Erzählerin ist nicht wie sonst alleine im Restaurant - verfälscht und eine erneute Überprüfung notwendig macht, die schließlich Klarheit schafft (vgl. Obdachlosigkeit, S. 107). Obwohl der Kellner ganz offensichtlich zumindest die Protagonistin regelmäßig prellt, bleibt deren moralische Wertung aus, was höchst resignative Züge annimmt und die Frage aufwirft, ob in einer extremen Form eine desolate Grundstimmung des Beobachters letztlich keine Gewissheit erzeugen kann, wie deutlich auch immer die Indizien sind, was sich gut mit der Deutbarkeit von Welt über Sinneseindrücke zu decken schiene $(\Rightarrow$ II.2.3). Auch in Mittelmäßiges Heimweh wird diese Korrelation thematisiert: „Sie macht einen verwirrt diffusen Eindruck auf mich, aber es ist auch möglich, daß mein Eindruck nicht mit Frau Schweitzer zu tun hat, sondern ausschließlich auf meine Phantasien zurückgeht." (Heimweh, S. 79) Diese Fraglichkeit der Einschätzung ist indessen in einem Roman, in dem der Protagonist zwei Körperteile verliert, ohnehin auf unsicherem Terrain getätigt.

Nach dem Blick darauf, wie die Hauptfiguren bezüglich ihrer beobachtenden Hauptbeschäftigung andere und anderes in den Blick nehmen, und wie eine Beobachtungssituation für gewöhn- 
410 - Teil II: Schlaglichter 4. Das Ich, die anderen und das andere: Inszenierung - Beobachtung Evaluation

lich abläuft, ist auch eine kurze Taxierung erhellend, die sondiert, wer überhaupt in den Fokus gerät (Gruppe vs. Individuen; Bekannte vs. Familie; Frau vs. Mann etc.), welche Aspekte des ,Gesamtpakets‘ zur Beurteilung herangezogen werden (Sprache, Kleidung, Körpersprache etc.) und natürlich, wie die erzähltechnische Realisierung (auch: stumm vs. verbalisiert etc.) geartet ist.

\section{KLASSIFIKATION DER BEOBACHTUNGSOBJEKTE: WER? AUF WELCHER GRUNDLAGE? WIE?}

In grober Analogie zum dreidimensionalen Koordinatensystem, das versuchsweise Ordnung in das Kapitel zur Interessantheit bringt $(\Leftrightarrow I I .3 .1)$, werden im Folgenden diese drei Raster separat angelegt.

Die bisherigen Ausführungen könnten den Eindruck nahegelegt haben, es handele sich bei den Beobachtungsobjekten hauptsächlich um solche, die auf den ersten Blick als Vertreter eines anderen Typus erkennbar sind, um dem beobachtenden Selbst ein maximalmögliches Maß an Individualität zu verleihen. In der Tat ist es dagegen nicht außergewöhnlich, dass es sich auch um Freunde und Eltern mit partiell übereinstimmenden Ansichten und Eigenschaften handelt - wobei die Differenz zu Letzteren den Wunsch nach Abnabelung und also Abgrenzung freilich überdeutlich bereits in sich trägt. Dementsprechend ist es in diesem Metier zumeist auch der Blick zurück, der dem erzählten Ich die Züge der Kindheit/Jugend verleiht und bspw. hart mit den Eltern ins Gericht geht bzw. erfreut ist, diese Strenge nunmehr aus der Sicht des erzählenden Ichs ablegen zu dürfen. Für die letztgenannte Option kann William Genazino Pate stehen, der sich im Roman Die Liebe zur Einfalt „in der Tradition von Peter Weiss' Abschied von den Eltern und Marguerite Duras' Der Liebhaber [...] den ,Gestalten' seiner Eltern erst nach deren Tod in Erinnerungsschüben vorsichtig annähert":34

Oh, wie herrlich ist es, sie verstehen zu können, ohne sie beobachten zu müssen! Sie atmen auf, weil ich endlich darauf verzichte, ihr Leben gegen das Licht zu halten, dabei den Kopf zu schütteln und zu seufzen: So sehen die beiden Wichte aus, die sich eingebildet haben, unter meiner schauenden Bestrafung Eltern sein zu können. (Einfalt, S. 57)

Trotz der versöhnlichen und heilsamen Distanz ist der Gedanke einer „schauenden Bestrafung“ noch immer gegenwärtig, der viele andere Hauptfiguren noch immer - selbst in der Retrospektive - leitet. Nachgerade investigativ stellt der namenlose Ich-Erzähler aus Wilhelm Genazinos Die Kassiererinnen den eigenen Vater bloß:

Denn auch ich nahm Anstoß an meinem Vater, und deswegen war ich zumindest momentweise damit einverstanden, wenn er ausgelacht wurde. [...] Ich verriet meinen Spielkameraden, dass die ohnehin lächerliche Aktentasche des Vaters so gut wie leer war und dass sie deshalb mit noch viel mehr Grund über ihn lachen konnten. [...] Tatsächlich gelang es mir mit diesen Details, das Vergnügen meiner Spielkameraden an der Erscheinung des Vaters zu verstärken und meinen eigenen Affekt in ihrem Gelächter zu verstecken. (Kassiererinnen, S. 89 f.) 
4.2 Das Ich, die anderen und das andere: Inszenierung - Beobachtung - Evaluation - 411

Es ist gewissermaßen ein ,Stellvertreterprozess' ganz anderer Art, der hier vonstattengeht: Andere sollen die Anklage übernehmen, die der Protagonist in der Jugend nicht zu übernehmen gewappnet ist, aber er steuert belastende Beweise bei und rechnet als Nebenkläger mit dem Vater ab. Auch Genazino (Figur) und seine Geschwister haben in der Vergangenheit dem Vater ,insgeheim' jedenfalls für sie in gegenseitiger Fraternisierung sichtbare Denkzettel verpasst: „Vater hatte sich eine Angewohnheit zugelegt, die ihn zugleich lächerlich machte. Er hielt Menschen, die im Fernsehen auftraten, für so bedeutsam, daß er ihren Sätzen bekräftigend nachnickte. [...] Wir lagen in unseren Betten und belustigten uns lautlos über den Vater." (Einfalt, S. 39) Aus verschiedenen Gründen ist die offene Konfrontation in der erzählten Anekdote nicht möglich gewesen, sodass Ersatzbefriedigungen gesucht und gefunden worden sind. Die Liste an zum Teil bitterbösen Evaluationen der Elternfiguren ${ }^{35}$ ist derart lang, dass nur wenige exemplarische Belege herausgegriffen werden können und sollen. Zunächst eine genauere Analyse des väterlichen Verhaltens, welche nicht in Bausch und Bogen aburteilt, sondern kenntnisreich Kleinigkeiten anprangert:

[A]ber manchmal konnte ich es genau sehen, mein Vater sprach und sprach, und der Mann von Petra war woanders, irgendwo. Seine Augen wanderten dann unruhig, Vater merkte das nicht, er erzählte von seiner Fabrik, und da der Mann von Petra schwieg, war das für Vater ein hinlänglicher Grund für die Annahme, Petras Mann höre zu (Laslinstraße, S. 109).

Eigenschaften, die nur dem Kenner und dem externen Beobachter vertraut sein können, stehen hier am Pranger. Und es sind genaugenommen möglicherweise unsensible Kleinigkeiten, die nichts darüber aussagen, wie ,störend“ „der Mann von Petra“, der Schwester des Protagonisten, dies wohl empfunden haben mag; geschweige denn darüber, ob jener überhaupt mit seiner ,unruhigen Augenwanderung' Desinteresse oder sonstiges hatte nonverbal signalisieren wollen, aber es sind Unverzeihlichkeiten zumal für die frühen Protagonisten Genazinos. Das entgeht auch dem sich tendenziell nullfokalisiert zu erkennen gebenden Erzähler aus Abschaffel nicht, wenn er kritisierend kommentiert: „Das Kind verhöhnte die Schwäche des Vaters; unfähig die Wirklichkeit des Lebens des Vaters zu begreifen, gelang dem Kind der Spott.“ (Abschaffel, S. 64) Dadurch eröffnet sich dem Leser sofort die Metakritik der Sitten: Nur die empathische Unfähigkeit des Kindes zur Perspektivübernahme - in diesem Sinne selbst eine Herabsetzung der kritisierenden Figur - erlaubt es, von einer schuldlosen Schuld zu sprechen, denn - so insinuiert der Kommentar - der angemessene Nachvollzug der Lebensweltrealität des Vaters hätte zu einem milderen Urteil im Sinne der Annahme des ,guten Grundes' gelangen müssen. Offensichtlich ist dazu die Distanz von Ich und Ich im Erzählen vonnöten: „Nun war er erstaunt, daß er kaum noch etwas Feindliches empfand. Nur ein grenzenloses Mitleid kam wie etwas Warmes über ihn; es war ein angenehmes Gefühl, weil es ein Gefühl des Überlegenseins war“ (Abschaffel, S. 74) Aber

35 Tatsächlich finden sich hier nur ,Abrechnungen' mit dem Vater. Aber auch mit der Mutter wird hart ins Gericht gegangen ( $\Rightarrow$ II.4.4 u. $\Rightarrow$ II.5.5). 
412 - Teil II: Schlaglichter 4. Das Ich, die anderen und das andere: Inszenierung - Beobachtung Evaluation

selbst dann sind es zwei Aspekte, die dieser Bewertung das Positive entziehen: Erstens ist er dem Vater gegenüber nur noch „kaum“ feindlich gesinnt, zweitens ist das „Gefühl des Überlegenseins" in diesem Kontext eine Contradictio per se: Mitleid aus Überlegenheit ist nicht nur im Sinne Lessings kontraproduktiv zu nennen. ${ }^{36}$

Im Gegensatz zur die kindliche oder jugendliche Machtlosigkeit kompensierenden Härte liegen ,gütigere' Einschätzungen dann vor, wenn es sich um aktuell emotional Nahestehende handelt, denen die Nachsicht gewisser ist, selbst dann, wenn die evaluierenden Protagonisten zunächst den ,strafenden“ Interpretationsmodus getriggert hatten: „[H] atte sie wirklich gelesen, fragte ich mich, oder hatte es nur so aussehen sollen, nur gut, dachte ich, daß es den unbedachten Verrat gibt" (Laslinstraße, S. 54). Liebevollere Wertmaßstäbe für genauso lässliche Sünden werden dann angelegt, wenn die Person durch Filterfolien der Freundschaft oder Liebe gesehen wird $(\Rightarrow$ II.4.5):

Gunhild könnte die beiden Wattestäbchen aufheben und sie der Mutter geben. Aber Gunhild kann weder in einen Zirkus gehen noch Wattestäbchen aufheben. In solchen Situationen kann Gunhild nur schnell aufbrechen. Im Grunde ist mir Gunhild deswegen sympathisch. Aber jedesmal ist sie verschwunden, ehe ich ihr meine Sympathie gestehen kann. Auch jetzt flüstert sie mir ein leises Tschüs! zu und löst sich aus der Situation. (Regenschirm, S. 13)

Gunhild verkörpert hier die gleichen mangelnden Sozialkompetenzen wie der Ich-Erzähler, was ihr in Kombination mit der grundsätzlichen Sympathie auch aus alten Zeiten einen Bonus in der Bewertung sichert. Doch auch Freunde und Bekannte sind nicht automatisch gefeit vor der analytischen Nagelprobe der Beobachterfiguren. So verspottet derselbe Erzähler wenige Seiten später einen alten Freund trotz der damit verbundenen Schmerzlichkeit allumfassend (vgl. Regenschirm, S. 20-23), obwohl keine innere Notwendigkeit dafür gegeben ist. Auch der Ich-Erzähler des Genazino-Romans Die Liebesblödigkeit verreißt nicht nur die „Laienkunst“ (s.u.) seiner Lebensgefährtin, sondern auch ihren Lebensentwurf als solchen:

Mir schwant nichts Gutes. Das Getue wegen einiger selbstgemalter Bilder deutet auf die Überspielung eines tief unbewußten Makels [...]. Es ist Hobbykunst, sehr farbig, sehr unbekümmert, sehr ahnungslos. Bilder dieser Art werden in den Foyers von Sparkassen und in den Fluren von Gesundheitsämtern ausgestellt. Es ist Provinzkunst, Laienkunst, Volkshochschulkunst. Ich nicke und gebe ein paar Ausrufe von mir, die selbst ich nicht deuten kann. In Wahrheit schmerzt es mich, von Sandra so fatale Bilder sehen zu müssen. [...] Wer altert, wird unbemerkt aus der Kurve getragen. Bei Sandra hat es die Geschmacksnerven getroffen. (Liebesblödigkeit, S. 109 f.)

Erneut „schmerzt" es den ,Herabwürdiger, was letztlich aber auch als Phrase der Entschuldigung lesbar ist. Die Fremdscham über Menschen, die „aus der Kurve getragen“ werden, ist größer als der emotionale Schutzstatus Nahestehender. Diese Beobachtung leitet über zur Differenz zwischen Evaluationen, die sich auf Individuen beziehen, und solchen, die auf Gruppen bzw. Ty-

36 Vgl. für ein Beispiel, in dem der erinnernde Erzähler trotz geringer zeitlicher Distanz auch seinen Vater milde evaluiert: „Ich hielt seine Arbeit schon deshalb für seriös, weil er kaum über sie sprach. Hätte er sich in langwierigen Selbstdarstellungen ergangen, hätte ich ihn für einen Angeber halten müssen." (Einfalt, S. 36) Und dennoch schwingt im Unterton ein dräuendes ,sonst' mit. Vgl. dazu auch Kein Geld, S. 44. 
4.2 Das Ich, die anderen und das andere: Inszenierung - Beobachtung - Evaluation - 413

pen zielen. Sandra ist im eben genannten Beispiel zwar Individuum, aber die reflexive Bewertung eigentlich eine Verallgemeinerung. Es geht um Allgemeinurteile, genauer: um analytische allgemeine nach Kant:

3. Allgemeine Regeln sind entweder analytisch oder synthetisch allgemein. Jene abstrahiren von den Verschiedenheiten; diese attendiren auf die Unterschiede und bestimmen folglich doch auch in Ansehung ihrer. - Je einfacher ein Object gedacht wird, desto eher ist analytische Allgemeinheit zufolge eines Begriffs möglich. ${ }^{37}$

Ohne die delikate Feststellung, dass weibliche Nebenfiguren bei Genazino in der Tat typisiert und mithin als ,einfache Objekte' gedacht und gestaltet werden, an dieser Stelle argumentativ auszukosten $(\Rightarrow$ II.5.3), ist es damit auf den Punkt gebracht: Es geht einmal mehr darum, die ableitbaren übergeordneten Urteile in Bezug zum Protagonisten zu setzen - weniger um andere Figuren in ihrer Eigenheit. Nichtsdestoweniger bleibt die oberflächliche Spaltung in Individuen vs. Gruppen/Typen bestehen. ${ }^{38}$ Logischerweise müssen analytische Aussagen über Typen allgemeiner ausfallen, da die Verschiedenheit der Elemente nur abstraktere Beschreibungen akzeptiert:

In diesen Personen erkannte Abschaffel die klein gebliebenen Angestellten, die nicht damit aufhören konnten, aus der Aufrechnung solcher kleiner Vorteile den Tagessinn ihres Lebens herauszuschlagen. [...] Die Arbeiter [...] bewegten sich linkisch [...]. Die Angestellten bewegten sich sichererer (Falsche Jahre, S. 415).

Beide Statusgruppen werden despektierlich begutachtet, ,die Arbeiter' ein wenig mehr als ,die Angestellten'. Für individuelle Unterschiede ist in diesem Kategoriensystem indessen kein Platz: „O Gott, was machte es ihnen einen Spaß, sich für nichts und wegen nichts aufzuplustern.“ (Sorgen, S. 301) Verallgemeinernde Evaluationen können dabei aber nicht nur deduktiv von einer konkreten Beobachtung ausgehen, sondern auch induktiv auf Basis mehrerer, die jedoch nicht benannt sein müssen:

In den Cafés saßen alte Leute oder tote Paare. Die Frauen schoben mit kleinen Gabeln die Krümel in die Mitte ihrer Kuchenteller, die Männer schauten heimlich zur Tür. Ich fühlte den Drang, ihre Erbarmungswürdigkeit sofort einzudämmen, obgleich mir dazu alle Mittel fehlten. (Wohnung, S. 53)

Gelegentlich lässt sich sogar fragen, ob es sich noch um konkrete Evaluationen handelt oder die Werturteile über Stereotype der Gesellschaft bereits als Vorurteile angelegt sind und durch einzelne Beobachtungen wieder wachgerufen werden: „Wieder frage ich mich, ob die Leute sich anders präsentieren würden, wenn sie wüßten, daß sie alle zu Karikaturen geworden sind. Oder ihre Lust besteht gerade darin, eine öffentlich wiedererkennbare Massenkarikatur geworden zu sein." (Liebesblödigkeit, S. 118 f.) Diejenigen Evaluationen, welche sich auf Typen beziehen, stehen nicht im leeren Raum, sondern ruhen einem Set an Überzeugungen (zur Gesellschaft, zum

37 Immanuel Kant: Von den Urtheilen. In: ders.: Logik, Physische Geographie, Pädagogik [AA 9] 1923, S. 101-113, hier S. 102 f. § 21.

38 Vgl. für den Sonderfall der Herabsetzung von Dingen, Städten und Unbelebtem per se exemplarisch: „und wieder über die Lächerlichkeit der Stadt seiner Herkunft herzuziehen.“ (Abschaffel, S. 76) 
414 - Teil II: Schlaglichter 4. Das Ich, die anderen und das andere: Inszenierung - Beobachtung Evaluation

Konsum, zur Religion etc.) auf, die in den Urteilen über andere Gruppen/Typen wieder aufgegriffen werden. Das äußert sich nirgends so deutlich (man könnte auch sagen: politisch unkorrekt) wie im Bereich der Alterität. ${ }^{39}$ Denn nicht nur von einem niemals explizierten Normalzustand abweichende Handlungen missfallen dem Basistypus; auch körperlich oder geistig behinderte Menschen, oder Menschen, die hinsichtlich Ethnie, sexueller Orientierung, oder Lebensstil von diesem abweichen, werden stigmatisiert. Andrea Bartl fasst diesen Umstand im Rahmen ihres Beitrags zum „Motiv der Fremdheit in ausgewählten Romanen Wilhelm Genazinos“ zunächst betont wertfrei, wenn sie festhält:

Diese selbstkritisch eingestandene Unmöglichkeit des Fremdverstehens und die daraus resultierenden Verstehens-Annäherungen werden wiederum in Genazinos Romanen variantenreich ins Bild gesetzt. In den zahllosen Szenen, in denen eine Figur einem italienischen Gastarbeiter, einem afrikanischen Asylbewerber, einem indischen Migranten etc. begegnet [...], tut sich ein Kaleidoskop des Fremderlebens auf. ${ }^{40}$

Kontrastiert man diese Aussage etwas reißerisch mit einschlägigen Primärtextstellen, fällt es schwer, ihr in dieser Form beizupflichten: „Peschek erblickte genau gegenüber dem neuen Schwulenladen ein ebenso neues Ausländerkino mit absolut fremdartigem Programm." (Fremde Kämpfe, S. 60) Wenige Anmerkungen einer minutiösen Analyse sind vonnöten. Erstens: Schwule und Ausländer sind indifferente Gruppen für den an dieser Stelle personalen Er-Erzähler. Zweitens: Bereits die Abhandlung beider in einem Satz schafft eine suggestive Nähe und rückt sie zugleich sowohl von Peschek selbst als auch dem Mittelmaß generell ab. Drittens wird nicht nur das „Ausländerkino“ als eines mit „absolut fremdartigem Programm“ attribuiert, sondern das Adjektiv ,fremdartig‘ brandmarkt rückbezüglich auch ,die Ausländer‘ selbst. Viertens: Durch die parallele Satzstruktur (vorwurfsvoll könnte man sagen: den rhetorischen Kniff) werden zudem der Schwulenladen und letztlich auch ,die Schwulen' rückbezüglich mit ,Fremdartigkeit' konnotiert: Wenn beide „neu“ sind: Warum sollten dann nicht beide auch fremdartig sein?

Bartl ist zuzustimmen, dass sich im Roman-Werk Genazinos facettenreiche Betrachtungen zum Fremderleben anstellen lassen. Von „Verstehens-Annäherungen“ hingegen kann im zitierten Beispiel keine Rede sein. Vielmehr handelt es sich mit Ortfried Schäffter, der auch Bartls Gewährsmann ist, um „Fremdheit als Gegenbild“:

Einem weitgehend anderen Zusammenhang entspringt Fremderleben, wenn es aus einer Ordnungsstruktur hervorgeht, die einerseits nach Eindeutigkeit sowie innerer Kohärenz und konsequenterweise andererseits nach Ausgrenzung des Andersartigen, des für sie ,Abartigen` und ,Artfremden` verlangt. In dem nun skizzierten Deutungsmuster erhält das Fremde daher den Charakter einer Negation der Eigenheit, und zwar im Sinne von gegenseitiger Unvereinbarkeit. Erlebbar ist hier nicht mehr das latente Verschränkungsverhältnis von Figur und Grund; statt dessen richtet sich die Aufmerksamkeit von Faszination und Bedrohtheitsgefühl auf eine feste und klar definierte Grenzlinie, mit der die Integrität der Eigenheit bewahrt und geschützt werden soll. Insofern gerät das Fremde zum Ausgegrenzten, das dem Eigenen, wesensmäßig' nicht zugehörig ist und als Fremdkörper die Integrität der eigenen Ordnung zu stören und in Frage zu stellen droht. Jenseits dieser Grenze je- 
4.2 Das Ich, die anderen und das andere: Inszenierung - Beobachtung - Evaluation - 415

doch erfüllt es die Funktion eines signifikanten Kontrasts, der als Gegenbild gerade die Identität des Eigenen verstärken kann. ${ }^{41}$

Bartl bezieht sich zwar auf Sartres Seh-Philosophie (vgl. gedehnter Blick), erwähnt die „latent xenophoben, ja an Fremdenhass grenzenden Reaktionen Abschaffels, die neuerlich in (an Sartre gemahnende) Degradierungen des Fremden durch Blicke münden“, allerdings nur in einer Fußnote. ${ }^{42}$ Dabei ist gerade diese Komponente von höchster Bedeutung: Mit der Grenzziehung wird anderes, werden andere in eine Out-Group abgeschoben, mit der Genazinos Figuren nichts mehr zu tun haben (wollen/müssen): „Aber die anderen, die Gastarbeiter, die Arbeitslosen und Umsiedler, die Türken und die Pakistani, gingen ins Woolworth." (Falsche Jahre, S. 425) Mitunter vollzieht sich im Lektüreakt selbst ein grenzwertiges Fremderleben, wenn der Rezipient von „diese[n] Südländer[n]“ (Sorgen, S. 282), einer „bärenartig tumb vorgetragene[n] Zufriedenheit“ eines Menschen mit Down-Syndrom (Regenschirm, S. 69), einer „Art Clownsnummer“ einer Frau im Rollstuhl (Außer uns, S. 38), „Klingel-Klangel-Musik“ (Außer uns, S. 125), Kugelschreiberklauenden Ausländerkindern (vgl. Fremde Kämpfe, S. 24) oder immer wieder auch von ,Negern` (vgl. Falsche Jahre, S. 550 u. Fremde Kämpfe, S. 93) lesen muss.

Nur auf den ersten Blick geben sich Beispiele weniger klischeebelastet, wenn andere vordergründig positiv evaluiert werden: „Hinter der Theke stand eine wunderschöne junge Japanerin. Ihr Gesicht war flach und weiß: wie aus Papier. [...] [A]ber sie schien nicht zu wissen, daß ihre Fremdartigkeit große Begehrlichkeiten hervorrief." (Falsche Jahre, S. 565 f.) Trotz der Schilderung als „wunderschöne junge“ Frau, die in der Lage ist, „große Begehrlichkeiten“ zu evozieren, bleibt der Ausgrenzungsmechanismus der gleiche: Nicht deshalb, weil sie diese Attribute zugeschrieben bekommt, sondern weil sie eine „Japanerin“ mit papierähnlichem Gesicht ist und sie der ,exotische Glanz‘ von „fernöstlich[er]“ (Kein Geld, S. 118) „Fremdartigkeit“ umgibt, ist sie begehrenswert. Der Schritt zur Vorstellung vom ,Edlen Wilden“ und zur eurozentristischen Weltsicht mancher Weltumsegler und Schriftsteller des achtzehnten Jahrhunderts (Ausnahme: Georg Forster!) ist nicht weit: „O Gott, machte Herr Fuchs noch einmal, wäre der Junge doch Schafhirte geblieben und hätte nie erfahren, was ein Skateboard ist." (Ausschweifung, S. 285)

Das eigene Leben, die eigene Sicht auf das Leben generell zur Messlatte zu erheben und andere und anderes kategorisch auszugrenzen, ist basistypisches Figurenmanko,43 was nur in romanspezifischer Häufigkeit nullfokalisiert oder insgesamt nachhaltig kritisiert wird: Abschaffel „kam

41 Ortfried Schäffter: Modi des Fremderlebens. Deutungsmuster im Umgang mit Fremdheit. In: ders. (Hg.): Das Fremde. Erfahrungsmöglichkeiten zwischen Faszination und Bedrohung. Opladen 1991, S. 11-42, hier S. 19.

42 Bartl: „The kindness of strangers", S. 83.

43 „Die Teilnahme an der Sehnsucht nach Veränderung und Wissen brachte einen starken Dünkel hervor. Ich hielt jeden, der Künstler nicht bewunderte, für bedauernswert und hoffnungslos." (Einfalt, S. 128) 
416 - Teil II: Schlaglichter 4. Das Ich, die anderen und das andere: Inszenierung - Beobachtung Evaluation

nicht auf den einfachen Gedanken, daß es unzulässig war, das eigene Leben als verbindliche allgemeine Form des Lebens anzusehen." (Falsche Jahre, S. 457) ${ }^{44}$

Viele der Kategorien, auf die die Evaluationen jeweils abgestützt werden, sind in den bisher diskutierten Situationen bereits implizit angeklungen und auch weiter oben abgehandelt worden und müssen daher nur abrissartig und auf das vorliegende Schlaglicht zugespitzt systematisiert werden. So fallen die Urteile häufig aufgrund von missliebiger Kleidung und habitueller Eigenheiten ( $\Rightarrow$ II.1.5) ungnädig aus. Abschaffel bemerkt an einer Person „eine graue, einfältige Weste, die Abschaffel sofort lächerlich fand." (Falsche Jahre, S. 407) Kleidung wird hier nicht nur als Charakterisierung verwendet, sondern in der Übertragung der nur auf Belebtes gebräuchlichen Zustandsbeschreibung „einfältig[]“ Persönlichkeit und Kleidung in eins gesetzt. Eine gesamte Gruppe wird etwa abgeurteilt, indem es über die Kleidung ,der Rentner' im Allgemeinen heißt:

Es ist unklar, worin das von den Rentnern verbreitete Unbehagen besteht. Vielleicht geht es von ihrer Einheitskleidung aus. Fast alle tragen helle Popelinejacken, helle Leinenhosen, hellbeige Hemden und sahnefarbene Schuhe beziehungsweise Sandalen. Vielleicht wird es auch von der zufriedenen Tumbheit ihrer Gesichter ausgelöst, von der schamlosen Selbstgewißheit derer, die sich von morgens bis abends für gesund halten müssen. (Liebesblödigkeit, S. 77)

Zur Kleidung im weitesten Sinne hält Abschaffel offensiv fest: „Es begegnete ihm ein lächerlicher Mann mit Perücke, der jeder entgegenkommenden Person ängstlich ansehen wollte, ob sie bemerkt hatte, daß er eine Perücke trug." (Sorgen, S. 323) ${ }^{45}$ Aufgrund kleinster Details wird das unerbittliche Geschmacksurteil gesamten Personen übergestülpt: „Der Mann war so alt wie häßlich, und die Frisur, die er sich machen ließ, steigerte seine Häßlichkeit in eine Unbarmherzigkeit hinein." (Falsche Jahre, S. 451) ${ }^{46}$ Nur vordergründig ,ausgeglichen` ( $\Rightarrow$ II.4.1/ $\Rightarrow$ Abb. 13), letztlich analog ,aggressiv‘ liest sich die Abgrenzung und Abwertung in puncto Kleidung in intratextueller Allusion auf die „UNTERSCHICHTEN-FARBENTHEORIE“ ( $\Rightarrow$ II.1.5):

Ich betrachtete sie gerne, obwohl sie fast immer in kitschiger Kleidung umherlief. Am liebsten trug sie ein enges Tigerfellhemdchen oder eine halb durchsichtige dunkelrote Seidenbluse mit Rüschen und kleinen Glöckchen am Kragen. Immer wieder glaubte ich, Menschen wie Jutta vor dem Kitsch warnen zu müssen, der ringsherum auf sie lauerte. In Wahrheit entsprachen die Menschen millimetergenau dem Kitsch, der extra für sie hergestellt wurde. Der Abstand zu den Verhältnissen existierte nur in mir selber, nicht bei den Leuten. Prompt fiel das Differenzgefühl kommentarlos auf mich zurück und beschämte mich. (Kassiererinnen, S. 54)

Doch auch die graduelle ,Abwesenheit' von Kleidung ist Anlass zur Kritik: „Er erinnerte sich an den Vater, der ganze Sonntagvormittage lang in Unterwäsche in der Wohnung herumgelaufen war. Als Kind hatte Abschaffel den Vater deswegen verachtet" (Sorgen, S. 248). Zwar handelt es sich eher um den Versuch, mit diesem Verhalten ganz andere, als unverzeihlich empfundene Verfehlungen des Vaters zu adressieren, aber in materialisierter Form ist die Verachtung leich-

44 Für ein Beispiel, das ,lediglich' einen anderen Lebensstil von der Warte vermeintlicher Überlegenheit aburteilt, vgl. Ausschweifung, S. 75.

45 Für die Ablehnung von Perücken per se sowie deren Relevanz für eine scheiternde Beziehung zu einer älteren Frau vgl. Kein Geld, S. 70 f.

46 Vgl. für die ungeheure Wirkmacht der Haare Bergler/Hoff: Psychologie des ersten Eindrucks. 
ter auszudrücken. Einer Frau mit sichtbarem Dekolleté unterstellt Abschaffel: „Wahrscheinlich gehörte sie zu den vielen Frauen, die aus Hoffnungslosigkeit langsam nachlässig wurden, weil sie sich von dieser körperlichen Frechheit einen letzten Vorteil versprachen." (Falsche Jahre, S. 442) Nicht nur die den Körper mehr oder weniger bedeckende Kleidung und der damit verbundene Habitus geraten ins Visier der bissigen Beobachter, sondern auch die Körpersprache bzw. analoge Kommunikation: Ein Beobachtungsobjekt „putzte sich die Nase und sah sich danach von allen Seiten den Rotz an, den er sich ins Taschentuch geschneuzt hatte. Abschaffel ekelte sich“ (Sorgen, S. 202). Abfällig auch das Urteil des Ich-Erzählers im folgenden Beispiel: „Ich erschrak, als ich sah, wie schüchtern sie sich bewegte. Linkisch bis zur Verhaltenslosigkeit achtete sie darauf, daß sie nicht von tanzenden Paaren angerempelt wurde." (Wohnung, S. 39) Wird hier von der Körpersprache ein Wesensmerkmal abgeleitet, sind es im folgenden Beispiel die aufgrund von Eifersucht negativ bewerteten Annäherungsversuche eines Nebenbuhlers:

Seine Berührungen von Margots Busen sehen so aus (sollen so aussehen), als geschähen sie aus Versehen. [...] Es ist nicht zu glauben! Der ungefähr zweiundvierzigjährige Himmelsbach nähert sich der kaum jüngeren Margot, indem er die schimmeligen Tricks der Pubertät wiederholt. In meinem Inneren mache ich ihn deswegen endgültig zu einer grotesken Figur. (Regenschirm, S. 132)

Auch äußerlich sichtbare Insignien bestimmter Lebensstile werden zum Ausgangspunkt der Beurteilung. Die Ressentiments gegen die Erlebnisgesellschaft sind bereits geläufig, im folgenden Beispiel werden sie anhand von Golfspielern durchexerziert:

Mit Frau Finkbeiner zusammen machte ich mich ein bißchen über die Freizeitmenschen lustig. Ich stieß mich an ihrem Drang, wie sie sich nach dem Vorbild von Großbürgern mit einem Golfschläger in der Hand [...] fotografieren ließen. Ich beobachtete ihre falsch gelernte Lässigkeit, mit der sie ihre Billigschuhe auf die Ränder der Golfbahnen stellten. Und ich lachte über das peinliche Getue, mit dem sie dann an der Bar für ein paar Pfennige eine Cola bestellten. Sie fanden es überwältigend, die Imitation von Vorbildern zu sein, die niemals in ihrer Nähe auftauchen würden. Schon während der Nachahmung vergaßen sie, daß sie Nachahmungen waren. (Wohnung, S. 151)

Im Milieu des (Freizeit-)Sports finden die Figuren immer wieder Nahrung für ihren Spott:

Da kamen von rechts drei ältere Freizeitsportler heran. Sie warfen sich während des Laufens einen kleinen Lederball zu und versuchten dabei zu lachen. Das Keuchen war nicht einmal das Auffälligste an ihnen. Noch beklemmender waren ihre schlotternden Gesichter, ihre mageren Schenkel und ihre trotz des Lachens gottverlassenen Blicke. (Kassiererinnen, S. 42)

Nicht selten versteigt sich die Überheblichkeit in elitäre Sphären. Bildungsferne bspw. wird häufiger zum Sakrileg erklärt und mit Verdikten geahndet: „Ich verurteilte im stillen die Leute ringsum, weil sie keine Bücher lasen, sondern nur Illustrierte.“ (Wohnung, S. 86) Die Dauerberieselung mit Unterhaltungsmassenware bereits junger Menschen ist genauso unerträglich für den Basistypus: „Es gab schon genug Kinder auf der Straße, die ein solches Ding immerzu mit sich führten und es sich sogar an das Ohr hielten, wenn ihnen die Umwelt entweder zu langweilig 
418 - Teil II: Schlaglichter 4. Das Ich, die anderen und das andere: Inszenierung - Beobachtung Evaluation

oder zu anspruchsvoll war." (Ausschweifung, S. 75) ${ }^{47}$ Auffällig sind die ausbleibenden ,Gegenvorschläge' in Form von konstruktiver Kritik, was sich auch in Fremde Kämpfe zeigt. Der Werbegrafiker Peschek geht hart ins Gericht mit seiner seit jüngstem der Malerei nachgehenden Freundin: „Die Linien waren nicht exakt beendet, Farbauftrag und Perspektivität stimmten nicht, von Stimmung und Komposition nicht zu reden. Selbst die Art, wie der Friseur seine Bilder präsentierte, verriet Untalent" (Fremde Kämpfe, S. 196). Anstelle eines ehrlichen Feedbacks zieht sich Peschek in die Wort- und also Kritiklosigkeit zurück. Hobbykunst ist in den Augen der Figuren verpönt und lediglich die Tatsache, dass der an anderer Stelle als zuhöchst demütigend empfundene Auftrag, einen Rentner, der aus Streichhölzern bekannte architektonische Sehenswürdigkeiten nachbaut, für die Lokalpresse zu interviewen (vgl. Wohnung, S. 128-132), erzähltechnisch mit Komik ,abgeschmeckt' wird, bewahrt die Situation vor rein offensivem Sarkasmus.

Als dritte Ebene der Klassifikation ist die erzähltechnische Realisierung zu nennen. In der Umkehrung der Analogie zur direkten und indirekten Charakterisierung von literarischen Figuren ( $\Rightarrow$ I.2.4) gibt es hinsichtlich der Evaluationen der Hauptfiguren zwar ebenfalls zwei Pole, die aber genau gegenläufig funktionieren. Ist es generell ein zumeist nullfokalisierter Erzähler, der explizit im Fiktionsvertrag Figureneigenschaften festschreibt, sind es die impliziten Äußerungen hauptsächlich der Figuren, die indirekt charakterisierend wirksam werden. Für den hier in Rede stehenden Bereich hingegen trifft man mit Pfister $(\Leftrightarrow I .2 .4)$ auf figural-explizite Äußerungen zum einen, auf auktorial-implizite zum anderen, sodass die Verallgemeinerung nicht gänzlich entkräftet werden kann, nach der die Figuren selbst schnell mit dem drastischen Urteil sind, wohingegen die erzählerische (Doppel-)Stimme, so sie deutlich zutage tritt, eher relativierende Funktion übernimmt und die Figurenwahrnehmung subtil erneut als subjektive ausstellt. Der Blick auf zwei kunstvolle Schattierungen dieser Erzählkonstruktion verdeutlicht dies:48 „In diesem Augenblick brachte Herr Fuchs den erbarmungswürdigen Anblick des Alkoholikers (Diese klebrigen Haare! Das lümmelnde Gehen! Diese hängenden, traurigen Schultern! Das labbrige Gesicht! O Gott!) in Zusammenhang mit den ordentlichen Gardinen“ (Ausschweifung, S. 13). Als Präsentationsform scheint es sich um erlebte (Gedanken-)Rede zu handeln, lassen sich doch die in Klammern vorgenommenen Evaluationen eindeutig als in einen ,neutraleren` Erzählerrahmen eingelassene, personal gefärbte Urteile lesen. Die Figur selbst spricht eine deutliche Sprache und

$47 \quad$ Hinsichtlich des Verlachens und Entwertens aufgrund von Gegenständen sei auf zwei Beispiele hingewiesen. Erstens: In Licht, S. 114, hat ein Manager lediglich Spielzeug in seinem Koffer, was die anderen amüsiert, diesem aber peinlich ist. Zweitens: „Aber dann, gerade noch rechtzeitig, schaute eines Morgens ein Otto-Katalog aus dem Briefkasten der Nachbarin heraus, und dann ahnte ich, dass die Geschichte wie das langsame Durchblättern eines Otto-Katalogs weitergehen würde." (Außer uns, S. 8)

48 Vgl. für eine Nebenform, bei der nicht die Hauptfiguren selbst die negative Evaluation vornehmen, sondern eine weitere anwesende Figur, sodass es sich letztlich um figural-explizite Äußerungen über eine gemeinsame Mitfigur handelt, etwa: „Was wollte die alles machen! Philosophie wollte sie studieren, weite Reisen wollte sie machen. Jetzt sitzt sie am Ufer eines stinkigen Baggersees und liest die Fernsehzeitschrift! Und Martina erst! Sie gibt ihr Geld für Klamotten und Kosmetik aus“ (Regenschirm, S. $71 \mathrm{f}$ ). 
sucht, um das Gesehene zu verarbeiten, sogar floskelhaft göttlichen Beistand. Das ist aber nur die halbe Wahrheit, denn bereits der Erzählerbericht als solcher gibt sich als höchst personal zu erkennen, indem er den „Anblick des Alkoholikers“ als „erbarmungswürdig[]“ klassifiziert (und dadurch indirekt auf die Gottesanrufung vorgreift). Halten sich also figuraler und ,auktorialer' Anteil bei vergleichbarer Indirektheit und der vorwiegenden Verwendung des tellings die Waage, kommt das zweite Anschauungsbeispiel gänzlich ohne figural-explizite Wertung aus:

Im Augenblick wurde über die sogenannte Badedas-Krankheit gesprochen, von der Herr Fuchs noch nie etwas gehört hatte. Es handelte sich um einen Hautausschlag, der entstand, wenn ein Körper allzu oft gewaschen wurde und die Haut dadurch vollkommen austrocknete. [...] Wohllebens Jugendfreund, Herr Karcher, war über diese neue Krankheit fast ein wenig begeistert, weil er sowieso immer der Meinung gewesen war, daß Dreck nichts schadet, im Gegenteil. Die Frauen lachten und stimmten ihm freundlich zu. Ist es nicht so? fragte Herr Karcher nach. (Ausschweifung, S. 132 f.)

Subtil und gänzlich ohne eine dezidierte Äußerung der Hauptfigur, Eckhard Fuchs, kann Karcher negativ evaluiert werden: Es ist nämlich nur scheinbar ein neutraler Erzähler, der bloß schildert, was in der Diegese ,sichtbar' ist. Zwei ineinandergreifende Rädchen der Erzähltechnik ermöglichen eine eindrückliche implizite Charakterisierung: einerseits die spärlichen, aber wirkungsvollen Erzählerkommentare, die Karcher als ,lustige Person“ charakterisieren, welche „fast ein wenig begeistert" auf eine Krankheit reagiert, die eine Anwesende am Tisch an sich selbst soeben demonstriert hat, indem sie, die lustige Person, sich die geschilderte Krankheit in Form der volkstümliche Plattitüde, nach der „Dreck nichts schadet“ banalisiert aneignet und letztlich, als Replik auf die ,freundliche Zustimmung', noch einmal effekthascherisch und bestätigungsheischend rhetorisch nachfragt, ob sie denn nicht recht habe. Und andererseits die eingängige Technik des showings, das dem Leser diese Deutungsmöglichkeit selbst überlässt und zudem unnachahmlich lakonisch nur über den mit Deutungssplittern durchzogenen Erzählerbericht durch eine Karikatur der (Tisch-)Gesellschaft Hohn generiert.

Diesen erzähltheoretischen Analyse-Kategorien, die bei den weiterhin zu untersuchenden (negativen) Evaluationen von Wichtigkeit sein werden, lässt sich eine stufige Unterscheidung zur Seite stellen, die für Genazino als Denkfigur und Figurenfacette gleichermaßen Relevanz hat $(\Leftrightarrow$ II.2.6 u. $\Rightarrow$ II.3.1): den Grad an Verbalisation.

Ausgehend von sprechakttheoretischen Positionen wie etwa John L. Austins einflussreicher Schrift How to do things with words ${ }^{49}$ lässt sich konstatieren: „Sagen und Tun sind kein Gegensatz, das Sagen kann selbst eine Form des Tuns sein.“"50 Dass diese Legion sprachwissenschaftlicher Forschung auch für sprachliche Gewalt gilt, ist ein vergleichsweise junger Spross eines Zweiges der linguistischen Pragmatik. ${ }^{51}$ Aber natürlich kann

49 Vgl. John L. Austin: How to Do Things with Words. Cambridge (MA) 1962.

50 Steffen K. Herrmann/Hannes Kuch: Verletzende Worte. Eine Einleitung. In: Steffen K. Herrmann/Sybille Krämer/Hannes Kuch (Hg.): Verletzende Worte. Die Grammatik sprachlicher Missachtung. Bielefeld 2007, S. 7-30, hier, S. 11.

51 Vgl. Herrmann/Kuch: Verletzende Worte, S. 9-11. 
420 - Teil II: Schlaglichter 4. Das Ich, die anderen und das andere: Inszenierung - Beobachtung Evaluation

Sprache selbst [...] Medium der Gewaltausübung sein: Von der leisen Ironie bis hin zum sarkastischen Spott, von der indiskreten Taktlosigkeit bis zum nackten Schimpfwort, von der herablassenden Demütigung bis hin zu diskriminierender hate speech kann Sprache als Gewalt wirken. ${ }^{52}$

Mit dieser Grundierung lassen sich nun freilich diejenigen diegetisch-verbalisierten oder nonverbal kommunizierten Mittel sprachlicher Gewalt bei Genazinos Figuren fassen und analysieren - aber was ist mit den ,stumm realisierten', was mit nur imaginierten Sprechakten?53 Dazu ist ein Umweg erforderlich: Per erneutem Rekurs auf die linguistische Höflichkeitsforschung $(\Rightarrow$ II.3.1) lassen sich gesichtsbedrohende Akte - also solche, die entweder das negative Gesicht (Handlungsfreiheit) oder das positive Gesicht (Anerkennung) des Gegenübers angreifen - als Brücke verwenden: „Da man davon ausgehen kann, dass Menschen ihr Gesicht verteidigen, wenn es bedroht ist, und sie das Gesicht von anderen bedrohen, wenn sie ihr eigenes Gesicht verteidigen, liegt es normalerweise im Interesse eines jeden, das Gesicht der anderen zu wahren.“54 Damit ist eine weitere plausible Antwort auf die Grundtendenz von Genazinos Figuren gefunden, die innere Zensur obwalten zu lassen. Insbesondere „FTAs [Face Threatening Acts/gesichtsbedrohende Akte; N. L.], die das positive Gesicht bedrohen“ und „anzeigen, dass dem Sprecher die Gefühle des Adressaten egal sind“ - also etwa: „Kritik, Gegenmeinungen, Beschwerden oder Beleidigungen“ -, bergen stets die Gefahr, auch ,das eigene Gesicht zu verlieren'.55 Als häufig stumm realisierte Sprechakte mischen Zusätze wie: „Natürlich kam der Spott nur in seinen Gedanken vor“ (Sorgen, S. 350), die prinzipielle Funktion von das positive Gesicht des Adressaten bedrohenden Sprechakten, und zwar, zu „signalisier[en], dass er ein oder mehrere von Hs Wünschen, Handlungen, Personenmerkmalen, Gütern, Glaubensüberzeugungen oder Werten nicht mag / nicht will“, 56 mit den Vorzügen der Nicht-Äußerung: Es steht nichts auf dem Spiel, niemand wird die Figur dafür tadeln, respektlos/unhöflich/beleidigend gewesen zu sein - das eigene Gesicht bleibt in jedem Fall gewahrt.

Angriffe auf das positive Gesicht des Gegenübers, die tatsächlich die Luft der Welt erblicken, sind demgegenüber - aus naheliegenden Gründen $(\Leftrightarrow I I .2 .6)$ - seltener:

Das würdest du niemals verstehen, du verstehst ja viel einfachere Vorgänge nicht! Wie willst du so vielschichtige Dinge begreifen, daß jemand ohne Absichten und ohne Wünsche vor den Schaufenstern von Zoogeschäften herumsteht, und zwar immer wieder! Dafür kann es hundert verschiedene Gründe geben, sage ich, aber eine derartige Vielfalt hat dein Mäusegehirn nicht vorgesehen! (Regenschirm, S. 31)

52 Herrmann/Kuch: Verletzende Worte, S. 7.

53 Vgl. dazu etwa: „Das junge Paar links von mir saugt jetzt so heftig an seinen Trinkröhrchen, daß ich überlege, zu den beiden zu sagen: Ich gebe Ihnen fünf Euro, wenn Sie mit Ihrem Geröchel sofort aufhören. Das Unangenehmste an meiner Ermüdung ist die Überempfindlichkeit. Ich bin noch nicht verrückt genug, dem jungen Paar das Angebot tatsächlich zu unterbreiten. Im Gegenteil, die Empfindung der öffentlichen Peinlichkeit macht mich noch schamhafter." (Glück, S. 8) Erzähltechnisch interessant dabei ist das sonst unüblich klare Foreshadowing. Oder: „Alles sehr schön, liebe Phil, dachte ich, aber laß mich bitte in Ruhe jetzt." (Laslinstraße, S. 149) Penelope Brown/Stephen C. Levinson: Gesichtsbedrohende Akte. In: Herrmann/Krämer/Kuch (Hg.): Verletzende Worte (2007), S. 59-88, hier S. 60. [Höflichkeit].

56 Brown/Levinson: Gesichtsbedrohende Akte, S. 66. 
4.2 Das Ich, die anderen und das andere: Inszenierung - Beobachtung - Evaluation - 421

Mit diesem gesichtsbedrohenden Akt gibt der Protagonist - zumindest in diesem Augenblick; ein Gespräch ist ja bekanntermaßen dynamisch - zu erkennen, dass a) ihm nichts an den Gefühlen seines Gegenübers gelegen ist, b) er eindeutig bestimmte Personenmerkmale nicht mag/will und er nicht davor scheut, c) diese „Respektlosigkeit“ in Form „heftiger (außer Kontrolle geratener) Emotionen“ an den Tag zu legen. ${ }^{57}$ Postwendend stellt sich jedoch eine Umwertung der kommunikativen Funktion ein und reflektiert zugleich das fragile und immer wieder neu auszuhandelnde Gesichtstaktieren: „Den letzten Satz möchte ich gleich wieder zurücknehmen. Andererseits konnte ich nicht auf ihn verzichten." (Regenschirm, S. 31) Man könnte also auch sagen, dass die Antizipation einer potenziellen eigenen Gesichtsbedrohung als Hemmnis der handlungsauslösenden Faktoren zu begreifen sei: Genazinos Basisfigur (ge-)braucht zwar für die Selbst(bild)konstitution unterschiedliche „Funktionen sozialer Diskriminierung“ - wie „Trennen“, „Distanzieren“, „Akzentuieren“, „Abwerten“ etc. ( $\Rightarrow$ II.4.4) - scheut indessen die kommunikativen Konsequenzen. ${ }^{58}$ Diese These lässt sich besonders gut anhand der etlichen ungehaltenen Reden respektive Vorträge illustrieren. Diese bilden nämlich einerseits einen Kulminationspunkt von sprachlich-sozialer Diskriminierung und zugleich Querverbindungen zur Interessantheit, verwoben mit innerer Zensur und letztlich geäußert als Körpersprache:

Junger Mann! Sie müssen noch viel viel toller schwindeln, damit die Menschen die Verzichtbarkeit von Lügen als ihr einziges Glück erkennen können! Haben Sie das verstanden?! Auch diesen Vorwurf spreche ich leise vor mich hin, und finde ihn, als Vorwurf an eine Lotterie, unüberbietbar. Es kostet mich Kraft, ihn für mich zu behalten. Wie immer kann ich mich beherrschen und belasse es dabei, den jungen Lügner zwiespältig anzuschauen. (Einfalt, S. 117)

Mit Wagner lässt sich dieser geplante Sprechplan als „Hochmut-Äußern“ deklarieren: „Der Sprecher empfindet ein[] Gefühl der Überheblichkeit, des (ungerechtfertigten) Stolzes und der Missachtung gegenüber einem Hörer/Dritten und drückt das in seinem Benehmen und Gehabe aus.“ ${ }^{\text {“9 }}$ Diese Zuordnung trifft auch auf Wolf Pesckeks Ansprache zu, wobei der Übergang zum „Verspotten“ fließend ist, da dabei „mehr der Sprecher als Spötter im Zentrum steht“ als der „der Lächerlichkeit Preisgegebene[]“:60 „Peschek konnte seinen Kaffee nur zu Ende trinken, indem er ein paar stille, verächtliche Sätze an die Jugendlichen richtete: Verehrte Glitzerbande! Eure Klamottenfolklore wird euch nicht weit bringen“" (Fremde Kämpfe, S. 228). Das lässt an Loriots genuschelte ,Morgen bringe ich sie um'-Frühstücksei-Szene denken und obgleich es dort vorwiegend die externe Funktion hat, den Leser im Sinne des Aparte-Sprechens über die Befindlichkeit der Figur zu informieren - diese Funktion ist natürlich auch bei Genazino allgegenwärtig -, ist die Parallele eindeutig in der internen Selbstsicherung qua negativen Gesichts zu sehen.

57 Brown/Levinson: Gesichtsbedrohende Akte, S. 66.

$58 \quad$ Carl F. Graumann/Margret Wintermantel: Diskriminierende Sprechakte. Ein funktionaler Ansatz. In: Herrmann/Krämer/Kuch (Hg.): Verletzende Worte (2007), S. 147-177, hier S. 149-151.

59 Wagner: Pragmatik der deutschen Sprache, S. 237.

60 Wagner: Pragmatik der deutschen Sprache, S. 290. 
422 - Teil II: Schlaglichter 4. Das Ich, die anderen und das andere: Inszenierung - Beobachtung Evaluation

Rund um diese Konstellation finden sich auch ,cholerischere‘ unausgesprochene Reden, wie diejenige Abschaffels an Frau Schönböck, die diese verachten und verletzen würde, aber aus Furcht vor Gesichtsverlust und kommunikativen Schwierigkeiten ungehalten bleibt ${ }^{61}$ - „Die Wahrheit ist, liebe Frau Schönböck, daß ich leider auch nicht weiß, warum ich mit Ihnen geschlafen habe. [...] Warum bieten Sie sich als mein Opfer an, Frau Schönböck? Macht Ihnen das Spaß?“ (Sorgen, S. 365 ff.) -, aber auch solche, die nahezu ohne sprachliche Gewalt auskommen und primär die Funktion des Selbstbildschönens übernehmen (vgl. Fremde Kämpfe, S. 65 f.) oder sogar als ,mutmachend' und damit als in der Tendenz zum eigenen Gesichtsverlust angetan bezeichnet werden müssen (vgl. Liebesblödigkeit, S. 39) und damit erst später verhandelt werden ( $\Rightarrow$ II.4.5). Um der oben ins Spiel gebrachten Humoralpathologie zu genügen, lässt sich die Achse der Neurotizität auch hinsichtlich der ungehaltenen Reden von der Extraversion hin zur Introversion abschreiten und ein melancholischer Duktus bescheinigen:

Peschek wollte den Hörer abnehmen und ein paar Sätze über den Schmerz der Menschen hineinsprechen. Er dachte an bewegende, nie gehörte Mitteilungen, die das ganze Kaufhaus zum Innehalten bringen sollten. Aber er fand nicht den Mut, den Hörer abzunehmen. Früher, als streunender Junge, mit dreizehn oder vierzehn, hätte er das gekonnt. Aber damals waren ihm alle Telefone gleichgültig und der Schmerz noch fern und unbekannt. (Fremde Kämpfe, S. 238; vgl. Regenschirm, S. 18; vgl. Obdachlosigkeit, S. 7; $\Rightarrow$ II.2.6)

„Schmerz“ und „Mutlosigkeit” paraphrasieren hier Eysencks Attribute „ängstlich“, „bedrückt“, „pessimistisch“, „zurückhaltend“ und „schweigsam“ ( $\Rightarrow$ II.4.1/ $\Rightarrow$ Abb. 13), die einem introvertierten und labilen Basistypus gut zu Gesicht stehen.

Nach dieser Vorarbeit, die sich des Phänomens der anderen, bzw. des anderen und auch des Fremden, angenommen hat, ist es an der Zeit, drei unterschiedliche Bereiche en détail zu untersuchen, die musterhaft aus den unzähligen Evaluationssituationen bei Genazino herausstechen: zunächst die brüchigen Selbstentwürfe der anderen ( $\Rightarrow$ II.4.3), deren Evaluation zwischen Melancholie und leichter Schadenfreude changiert, dann die gesichtsbedrohenden, ,bösen', cholerischen ( $\Rightarrow$ II.4.4), und schließlich die als scheinbare Ausnahme der Regel für gut befundenen $(\Leftrightarrow$ II.4.5), die aber nicht minder relevante Funktionen für die Protagonisten übernehmen.

\subsection{Brüchige Selbstentwürfe anderer und deren Entlarvung durch die Hauptfiguren}

Zur Vergleichsgrundlage für alle unter dieser Rubrik zusammengefassten Evaluationen lässt sich sagen, dass es samt und sonders um näher oder ferner in der Erzählvergangenheit liegende Selbstpräsentationen von Nebenfiguren geht, die entweder faktisch oder im Auge des Betrachters eine ,Macke' (bekommen) haben: Mal vermögen die idealisierten Entwürfe nicht mit der Erzählweltrealität Schritt zu halten, mal sind es weniger überhebliche Darstellungen der ande- 
ren Figuren als vielmehr die Unterstellung der Protagonisten, die bereits negative Evaluationen zeitigen und in Schein-Entlarvungen gipfeln.

Wie genau eine exemplarische Begutachtung einer anderen Figur aussehen kann, lässt sich an Himmelsbach demonstrieren,62 einer - zumindest in den Augen des Ich-Erzählers so gespiegelten - gescheiterten Existenz, über den es bereits zu Beginn des Romans heißt: „Er parfümiert sich kostenlos in Kaufhäusern und kommt sich wahrscheinlich noch raffiniert dabei vor." (Regenschirm, S. 22) Über den gesamten Roman hinweg begegnet der Leser ihm und seinem schrittweisen Verfall, was der Protagonist mit einer Mischung aus Mitleid und Schadenfreude verfolgt, bevor es schließlich zum evaluativen Showdown kommt:

Doch dann kann ich einem entsetzlichen Anblick nicht ausweichen. Ich sehe Himmelsbach, wie er mit einem mit Prospekten vollgeladenen Supermarkt-Wägelchen die Straße entlanggeht; vor jeder Haustür macht er halt und schiebt in jeden Briefkastenschlitz einen Prospekt ein. [...] Es kommt mir ein furchtbarer Gedanke: Himmelsbach scheitert an meiner Statt. Von Anfang an, seit ich ihn in Paris habe Schiffbruch erleiden sehen, war es seine Aufgabe gewesen, mir das Spiegelbild eines Scheiternden vorzuführen und mich vor mir selbst abzuschrecken. [...] Von Augenblick zu Augenblick wird klarer, daß meine Tränen nur am Anfang Himmelsbach galten; jetzt gelten sie nur noch mir. Auch ich würde, wenn ich nicht mehr anders könnte, idiotische Prospekte durch die Stadt fahren. Es war immer meine größte Furcht, eines Tages meine immense Beugbarkeit öffentlich zeigen zu müssen. Zum Glück geschehen auch wieder läppische Dinge. Es ist erneut Himmelsbach, der mich von meiner halb mir und halb ihm geltenden Erschütterung wieder befreit. Zum zweiten Mal bückt er sich zum Seitenspiegel eines Autos nieder und kämmt sich. Himmelsbach, schimpfe ich gutmütig mit ihm, du willst vor deinem Elend auch noch einen guten Eindruck machen. Diese Dummheit will mein Mitleid nicht mitmachen. Ich betrete ein staubtrockenes Modegeschäft und warte ab, daß die Klimaanlage auch mit der Eintrocknung meiner Tränen beginnt. (Regenschirm, S. 160 f.)

Dass Himmelsbach als Stellvertreter altere, ist zunächst aus externer Perspektive aufschlussreich. Die Vermutung, Himmelsbach sei als Charaktant deswegen in die Figurenkonstellation des Romans eingepflegt worden, um als Negativfolie die Makel, Marotten und Merkwürdigkeiten des Schuhtesters abzumildern, hat einiges für sich. Im Romanverlauf wird Himmelsbach mit unterschiedlichen Handlungsrollen versehen $(\Leftrightarrow$ I.3.1), wird er verschiedentlich funktionalisiert als Nebenbuhler (Opponent), fragwürdiger Mitbewohner (brüchiger Adjuvant) etc. Mit der Einnahme der internen Perspektive wird eine runde Einschätzung daraus. Dann nämlich tritt der Komplex der Egozentrik in zwei Ausprägungen in das Zentrum. Erstens: Die emotionale Anteilnahme, die durch die Tränen (die ja bekanntlich nicht zu lügen verstehen) immer wieder bezeugt wird, verlagert sich peu à peu vom Beobachtungsobjekt und dem ,Niedergang' Himmelsbachs auf das beobachtende Subjekt selbst. Mitleid wird zu Selbstmitleid, im leicht hinkenden Vergleich wird eleos („erleiden“; „Mitleid“; „Tränen“) zu phobos („ab[]schrecken“; „Erschütterung") aufgrund der ,Vanitas-Hamartia'. Zweitens: Mitleiden ist dem Protagonisten nur in dem Maß möglich, wie ihm die Gesellschaft bzw. andere für Himmelsbachs Scheitern verantwortlich

62 Vgl. für eine der in diesem Zusammenhang wohl am häufigsten interpretierten Szenen des Romanwerks den „Je[der]-ka[nn]-mi[tmachen]-Wettbewerb“ (Wohnung, S. 96-105), in dessen Rahmen sowohl Distinktion als auch Herabsetzung und Tragikomik durch die zusammenhaltende Klammer der Fremdscham präsentiert werden (vgl. Spreckelsen: Manche möchten lieber nicht, S. 86; vgl. Amann: „Doppelleben“, S. 94). 
424 - Teil II: Schlaglichter 4. Das Ich, die anderen und das andere: Inszenierung - Beobachtung Evaluation

scheinen - sobald sich dieser selbst etwas zu Schulden kommen lässt (hier: sich nach der Vorstellung des autodiegetischen Erzählers zu eitel zu zeigen), entzieht jener sein komplettes Mitleid und geht auf maximale Distanz zu diesem und seiner „Dummheit“. Himmelsbach ist dabei kein ,Einzelschicksal', sondern typisierte Ausformung der ,Gescheiterten'. Der ,Fall' Hirrlinger etwa weist eine immens hohe Parallelität auf: „Da ging er, Hirrlinger, der Frankfurter Stadtmeister im Ausgestoßenwerden, Übrigbleiben und Verlorensein, und Peschek hatte kein Mitleid mit ihm." (Fremde Kämpfe, S. 173) Auch Hirrlinger darf nicht auf verzeihende Einfühlung hoffen, da er, so Peschek, zu einer „hochfahrenden Empfindlichkeit“ (Fremde Kämpfe, S. 172) und „Starrsinn“ (Fremde Kämpfe, S. 173) neige - nach dem Motto ,selbst schuld“ legt Genazinos Figurenbasistypus anderen Figuren bestimmte Eigenschaften zur Last, die indes nicht wirklich auf deren freier Entscheidung beruhen.

Eine zweite Grundkonstellation negativer Bewertungen sticht hervor: die Identifizierung und Aburteilung eigener Schwächen an anderen: „Vermutlich fehlt dem Mann alles mögliche, aber eines fehlt im ganz besonders: die Betrachtung des Lebens von weit oben." (Frauen, S. 159) Analog zur Neigung, sich die Theory of Mind anderer immer ähnlich geartet der eigenen vorzustellen und also auch fehlerhaft eigene Bewusstseinsinhalte auf andere zu übertragen ( $\Rightarrow$ II.4.2), kann man in einigen Fällen allerdings davon ausgehen, dass Genazinos Figuren wissen, wovon sie sprechen. Sie kennen die verzweifelte Suche nach Gelassenheit vom eigenen harten Kern her und erkennen dieses Defizit an anderen treffsicher. Für eine andere Figurenfacette konstatiert Warlich diesen Sachverhalt:

Ich frage mich, warum ich an einen Bildungsangeber geraten bin. Ich möchte mich von ihm lösen, aber ich weiß nicht, wie ich das anstellen soll. Zwischendurch will ich zu Dr. Adrian immer wieder sagen: Suchen Sie sich einen anderen, ich bin zu alt für Ihre kleinstädtische Wichtigtuerei. Die Wahrheit ist: Ich bin selbst ein Bildungsangeber. Nur deswegen fallen mir andere Bildungsangeber sofort auf. (Glück, S. 144)

Zunächst als Kritik am „Bildungsangeber“ Dr. Adrian geäußert, schwenkt die Perspektive in eine Selbsterkenntnis: Die „kleinstädtische Wichtigtuerei“ ist Warlich genau deshalb suspekt, weil er erstens, um mit C.G. Jung zu sprechen, seinen zweifelsfrei vorhandenen Schatten an sich selbst und anderen verurteilen kann und zweitens darin seine eigenen Strategien wiederentdeckt ( $\Rightarrow$ II.3.3 u. $\Rightarrow$ I.3.4). Überhaupt liegt eine treibende Kraft in der Beobachtung generell und der Evaluation anderer konkret in der bereits hervorgehobenen Bedeutung des Durchschauenwollens ( $\Rightarrow$ II.2.2), was im folgenden Beispiel weniger gut funktioniert, mit der dezidierten Nennung der „Masken“ allerdings erneut an das Persona-Konzept Jungs erinnert:

Er drehte sich nach den Leuten um, weil er herausfinden wollte, ob sie sich verstellten oder nicht. Aber er sah nur Gesichter, die in jedem Augenblick von ihren Vertuschungsmöglichkeiten Gebrauch machten. Die Jungen mit ihren elastischen Erwartungsgesichtern, die alles Erwünschte noch herschwindeln konnten, enttäuschten ihn am meisten. Aber auch die Greise gaben nichts preis: sie lebten gut verborgen hinter den Masken ihres Alters. (Fremde Kämpfe, S. 145) 
Hingegen haben sowohl die Ich- als auch Er-Erzähler nicht nur nahezu unbegrenzte Deutungswut, sondern auch schlicht - zumindest erzählkompositorisch so verbürgte - Einsicht in die Lebensgeschichten der ,Originale', deren jeder Roman eines hat:

Dicht vor der Einmündung Dürerstraße kam uns Wolfgang entgegen, genannt Efze, ein ältlicher Gitarrenspieler. Ich mochte ihn nicht, weil er immer so tat, als würden wir alle in einer phantastischen Boheme leben. Aber jetzt war ich dankbar, dass er auf uns zukam und dabei ein paar seiner italienischen Erlebnisse erzählte. Er trug einen beigefarbenen, leicht zerknitterten Leinenanzug, dazu weiße Leinenschuhe mit braunen Kappen, ein weißes Hemd mit Schillerkragen und einen honigfarbenen Strohhut. Vermutlich wollte er ein wenig wie Nietzsche aussehen, von dem er auch gern erzählte. In Wahrheit trieb Efzes Leben langsam und zielstrebig in eine Katastrophe hinein, die nicht anzuerkennen er seine meiste Kraft brauchte. In seiner Jugend war er einmal Mitglied einer anspruchsvollen Jazzgruppe gewesen. Danach hatte er Musik studieren wollen, aber dazu hatte seine Energie dann doch nicht gereicht. So war er Amateur geblieben und spielte seit vielen Jahren abends in Kneipen oder bei privaten Festen. Er mochte dieses Herumvagabundieren schon lange nicht mehr, aber er sagte, auch jetzt wieder: Jeder sucht sich die Verhältnisse, die er dann bekämpfen kann. (Kassiererinnen, S. 110 f.)

Im Gegensatz zu Himmelsbach und Hirrlinger, denen jeweils die erzählerische Möglichkeit im Modus des showings gegeben worden ist, sich selbst lächerlich zu machen, treffen wir hier auf eine quasi-analytische Einschätzung durch eher statisches telling, die auf jahrelang gesammelte ,Insider-Informationen' gestützt wird und eine gemeinsame Vergangenheit verrät. Die Hauptkritikpunkte sind: mutmaßliche Nietzsche-Epigonalität, Nicht-Anerkenntnis der eigenen Misere, mangelnde Energie. Marit Hofmann hält dazu fest, es sei „nur konsequent, wenn Genazinos Einzelgänger sich zur Intellektuellen- und Künstlerszene [...] distanziert verhalten. Auch dieses Milieu ist vor Genazinos Sprachwitz, der jede überhöhte Selbstdarstellung entlarvt, nicht sicher."63 Allerdings liegt der zitierten Evaluation durchaus auch eine allgemeinere, der Milieuspezifik übergeordnete Deutungssystematik zu Grunde, welche sich bei den bereits angerissenen Strategien bedient: stellvertretendes Scheitern, Selbstverschuldetheit und Schattenverriss.

Häufig steht weniger das ,Produkt' (gescheitert) ${ }^{64}$ als der Prozess (scheitern) im Fokus der kritisch-optischen Anamnese der Nebenfiguren, was sich freilich auch extern-erzähllogisch daraus erklären lässt, dass es eine längere Periode braucht, um Selbstentwürfe skizzieren zu können, um sie durch die Protagonisten als brüchige Fassade dekuvrieren zu können:

[U]nd fast ebensolang plante sie ein ganz anderes Leben. Immer sollte es etwas Künstlerisches sein. Sie hatte getöpfert, gewebt und gebatikt und mit allem wieder aufgehört. [...] Das neue Ziel hieß: Abitur nachholen und studieren. In immer kürzeren Abständen folgten einander die Anfänge. (Fremde Kämpfe, S. 25)

Aber auch in der Miniaturform eines einzigen Abends lassen sich derartige Vorgeschichten verdichten:

63 Hofmann: Beobachtete Beobachter, S. 59.

64 Es sei denn, dass es sich um äußerst randständige Figuren handelt, wie in folgendem Beispiel einer erzählerischen Raffung: „Alkoholiker, die nicht mehr sprechen konnten, hielten aufrüttelnde Reden. Porträtisten, die nie hatten zeichnen können, malten für fünf Mark die Gesichter von Passanten ab. [...] Wolf sah ihn verächtlich an" (Fremde Kämpfe, S. 79). Allerdings ist dieses Beispiel aufgrund der dezidierten Verspottung potenziell dem nächsten Unterkapitel $(\Leftrightarrow$ II.4.4) genauso gut zuzuordnen. 
426 - Teil II: Schlaglichter 4. Das Ich, die anderen und das andere: Inszenierung - Beobachtung Evaluation

Im ersten Stock wohnte seit einem Jahr ein schönes junges, unverheiratetes Paar. Die Frau arbeitete als Verkäuferin in einer Boutique, und ihr Freund hielt sich für einen Filmregisseur. [...] Die Einladung bei ihnen wurde für Ruth und Eckhard dennoch eine Enttäuschung. Die Frau redete nur über Mode und Kleidung, und ihr Freund war mit seiner Zukunft als Filmregisseur beschäftigt, die er als unausweichlich darstellte. Tatsächlich war der ungefähr fünfunddreißig Jahre alte Mann ein Träumer, harmlos und anstrengend. [...] Als Eckhard einen Versuch machte, mit ihm über die Möglichkeit zu sprechen, daß sich sein Traum nicht verwirklichen könnte, schwieg er beleidigt. [...] Noch im Bett schimpfte Herr Fuchs damals über die Lebensahnungslosigkeit vieler Leute. (Ausschweifung, S. 32$)^{65}$

Unter der Chiffre „Lebensahnungslosigkeit" werden auch Lebensentwürfe ihrer pompösen Verpackung entkleidet, die das in gewissem Ausmaß selbstverschuldete Scheitern in Akademia ansiedeln:

Henschel hat vor mehr als zwanzig Jahren an einer Dissertation über das Anerkennungsproblem bei Hegel gearbeitet, mit der er bei Habermas promovieren wollte. Ich erinnere mich an seine Begeisterung, die fast immer so anfing: Ich muß meinen verehrten Vordenker Hegel kritisieren, weil er...Das klang eindrucksvoll und voller Zukunft, aber nach jahrelanger Arbeit verhedderte sich Henschel hoffnungslos in Hegels Metaphysik und Dialektik gleichzeitig. Er brach die Arbeit an der Dissertation ab und gab ein Jahr später sogar das Philosophiestudium auf. Aus der aufsteigenden Lebenslinie Hegel-Habermas-Henschel wurde das schlichte Eingeständnis Humanitas-HansaplatzHenschel, das mitzuteilen über seine Kräfte ging. Schon viel zu lange büßt er seine jugendlichen Höhenflüge hier in einem Erdgeschoß ab. Ich gedenke seines untergegangenen Übermuts und blicke dabei stumm und von hinten auf seinen reglosen Rücken. (Liebesblödigkeit, S. 154)

Als Modell ,Hegel-Hybris', das an den Begutachteten überdeutlich die IM-Variante ,basking in reflected glory' karikiert $\left(\Rightarrow\right.$ I.3.3), ${ }^{66}$ begegnen dem Leser häufiger Individuen, die sich selbst überschätzt haben in ihrem Vorhaben, eine universitäre Karriere einzuschlagen:

Vor neun Jahren wollte er über Hegel promovieren. Das Selbstverständnis des Subjekts in Hegels Phänomenologie. So sollte die Dissertation heißen. Er hatte es fast allen erzählt, den meisten öfter. Auf einmal wusste er nicht mehr weiter, er verlor die Lust oder er hatte Claudia kennen gelernt, so genau wusste das niemand. Dann fand er eine Stelle als Disponent bei der Rollladenfabrik Kipfler, bei der er noch heute arbeitete[]. (Kassiererinnen, S. 31)

Sprachlich bewegt sich die Drakonie des Gegensatzes von (philosophischer) Promotion und „Rolladenfabrik“ in ähnlichen Breitengraden wie ,Hegel-Humanitas“ - und gleichsam auch an der Grenze zur Lakonie, ist doch die Liste an möglichen Gründen für den Abbruch unsicher und heterogen wie banal zugleich.67

Ähnlich kurz und im doppelten Wortsinn treffend sind etliche ,Kurz-Diffamierungen', welche in Genazinos Romane eingelassen sind, und sich klassifizierende Merkmale teilen ( $\Rightarrow$ II.4.2): Sie richten sich gegen bekannte Einzelpersonen weiblichen Geschlechts und werden üblicherweise nicht laut ausgesprochen. Hinsichtlich der Grundlage, auf der die Verrisse aufgebaut werden,

65 Es muss nicht erneut erwähnt werden, dass der Basistypus sich mit dieser Kritik zugleich selbst im Visier hat. Vgl. zu ähnlichen Schilderungen überambitionierter, letztlich aber einer realistischen Grundlage entbehrender Selbstpräsentationen von Nebenfiguren, die sich in „ihrem kindischen IchGetue“ (Kein Geld, S. 86) bloßstellen, etwa auch Regenschirm, S. 75.

66 Vgl. dazu auch die kritische Evaluation bzw. den Vorwurf, „sein Leben mit einem fremden Glanz auszuzeichnen." (Einfalt, S. 39)

67 Dass der Titel der angedachten Dissertation auch losgelöst von Hegel nach dem „Selbstverständnis des Subjekts" fragt, letztlich aber nicht geschrieben wird, lässt sich auch als Kommentar zu der Unmöglichkeit werten. 
besteht hingegen eine größere Variabilität: Ein als pejorativ empfundener Lebensstil - „In ihrer Sehnsucht nach Kitsch, den sie so gerne für das Leben halten möchte, machte sie mit einem Neunzehnjährigen Bootsrundfahrten“ (Sorgen, S. 283) -, Selbstüberschätzung - „Offenbar hatte sie instinktiv erkannt, daß er alle ihre Selbstüberschätzungen, die einen großen Teil ihres Verhaltens ausmachten, nicht stützen konnte und daß er deshalb nicht in den Kreis derer gehörte, mit denen sie gerne redete" (Sorgen, S. 220) - und Diskrepanz zwischen Selbst- und Idealbild „Wie Marga pflegte auch Susanne das Selbstbild einer allzeit tätigen Frau und zahlte dafür hohe Verdrußkosten“ (Fremde Kämpfe, S. 198) - sind dabei häufig auftretende Ausgestaltungen.

Unterkapitelbeschließend sei der Blick noch auf eine zusätzliche Unterscheidungsdimension gerichtet: Zerbrochene Träume sind - allein ob der Überzahl derjenigen Romane, die späteres Erzählen verwenden ( $\Rightarrow$ I.2.3), - als retrospektiv und abgeschlossen oder zukunftsungewiss gegenwärtig zu bewerten: „Damals wollte sie eine zweite Lou Andreas-Salomé werden [...], eine Freundin bedeutender Männer. Die bedeutenden Männer tauchten nicht auf, und aus Andrea wurde eine Systemanalytikerin mit vermutlich zu wenig Lebensfreude." (Kassiererinnen, S. 30) Erneut ist es eine einzelne Frau, die den Untersuchungsgegenstand für die Hauptfigur abgibt, erneut ist es das Greifen nach den Sternen bzw. schwerlich erreichbaren Vorbildern, das zum Scheitern verurteilt bleibt und erneut ist es der Kalauer, der Andrea und Andreas(-Salomé) parallelisiert - so weit Bekanntes. Wichtiger ist die temporale Realisierung: Im zitierten Beispiel ist das Scheitern vergangen, unabwendbar und ,vollendet' (obwohl es im Imperfekt berichtet wird). Eine andere Form findet sich im komplexen gescheiterten Lebensentwurf von Susanne, einer Freundin der Hauptfigur aus dem Regenschirm für diesen Tag:

Eigentlich hält sich Susanne für eine Schauspielerin und möchte immer noch Margerita Mendoza genannt werden. Tatsächlich hatte sie, als sie jung war, eine Schauspielschule besucht und danach zwei oder drei Engagements an kleinen Theatern bekommen. Das liegt etwa fünfundzwanzig Jahre zurück. (Regenschirm, S. 16)

Susanne scheint das Scheitern ihrer Schauspielkarriere nicht verwunden zu haben, was nach „fünfundzwanzig Jahre[n]“ allerdings bedenklich ist. Erneut soll aber die temporale Komponente betont werden: Scheitern wird hier gedacht als unabgeschlossener Prozess, die Vorgeschichte strahlt in diesem ,Präsensbuch' noch immer insofern in die gleichzeitige Erzählgegenwart hinein, als „Susanne [...] immer noch Margerita Mendoza genannt werden [möchte]“.68 Ein vom Standpunkt der erzählten Szene aus gesehen in die Zukunft gerichtetes Wünschen eines Kollegen trachtet Abschaffel zumindest innerlich zu torpedieren: „Wenigstens einmal am Tag hatte Abschaffel Lust, ihm zu sagen: Hören Sie auf damit, Sie werden niemals Führungskraft. Aber er

68 Es handelt sich in mehrfacher Hinsicht um eine komplexe Evaluationssituation: „Ich selbst habe Susanne nie auf einer Bühne gesehen. Deswegen kann ich nicht beurteilen, ob sie eine gute, eine schlechte, eine mittelmäßige oder eine unglückliche Schauspielerin ist oder war. Ich darf sie nicht Margerita Mendoza nennen, weil dieser Name sie an ihre mißratene Karriere erinnert. Ich darf aber auch nicht Susanne Bleuler zu ihr sagen, weil ihr richtiger Name sie an das unbedarfte Wünschen ihrer Jugend erinnert." (Regenschirm, S. 16) 
428 - Teil II: Schlaglichter 4. Das Ich, die anderen und das andere: Inszenierung - Beobachtung Evaluation

sagte nichts zu ihm." (Abschaffel, S. 9) Sei es aus Rücksicht, Vorsicht oder sonstigen Gründen: Ein verbindendes Element ist und bleibt die innere Zensur ( $\Rightarrow$ II.2.6) auch bei der Entlarvung brüchiger Selbstentwürfe.

\section{4 ,[U]nter meiner schauenden Bestrafung“: Offensive Abwertung/Herabsetzung}

Eine Stufe radikaler, da sprachlich drastischer, gelegentlich in dieser Radikalität auch tatsächlich sprachlich realisiert und nicht nur im Stillen, geht es nun zu. Hier finden sich beispielhaft auf manifester Ebene diejenigen Handlungsweisen und Sprechpläne, die bereits weiter oben $\Leftrightarrow$ II.4.2) vorbereitet worden sind.

\section{(IMAGINIERTE) VERBALE GEWALT}

Bereits Wort- und Satzstilistik ( $\Rightarrow$ I.2.3) lassen sinnfällig werden, dass die hier analysierten Beobachtungen und Evaluationen wesensverschieden sind. So spart Degen nicht mit verbaler Gewalt, wenn er die Bedienung bloß auf Basis von Äußerlichkeiten verachtet, indem er sie wie folgt beschreibt als:

rotlippig, stumpfäugig, als hätte sie schon dreißig Jahre Ehe hinter sich, mit Puppenaugen, von künstlichen Wimpern drangsaliert, mit vergewaltigten Brauen, ausgezupft und den Rest gebürstet, weißgesichtig vor Puder, mit Bruststützen im Büstenhalter, die gegen die Jahre ankämpften und als Kanten auf ihrem engen Pullover sichtbar wurden, und jetzt, da sie sich zu uns herunterbeugte, machte sich an ihrem Hals das Alter bemerkbar, denn ihr Hals war puderfrei und daher echt, tiefe Falteneingrabungen zogen sich an ihrem Hals entlang, der sich gab wie ein unregelmäßiges Stück Schmirgelpapier. (Laslinstraße, S. 183)

Zieht man die generelle Skepsis der basistypischen Figuren Genazinos gegenüber Verstellungen jedweder Art als Bemessungsgrundlage zu Rate ( $\Rightarrow$ II.1.2), ließe sich die Schärfe abmildern und als Überspitzung aufgreifen, die eine wie auch immer geartete ,Natürlichkeit' bei Frauen höher achtet als deren Übertünchung durch Kosmetika. In der Folge könnte man darin einen genderkonstruktiv emanzipatorischen Akt hinsichtlich eines Schönheitsideals erkennen wollen ( $\Rightarrow$ II.5.3) - doch die Perfidie, im gleichen Atemzug - es ist tatsächlich nur der Teil eines einzigen Satzes - den ,echten', zugleich auch den entblößten und ungeschützten Hals als Altersausweis mit Spott zu überziehen, lässt dieses gedankliche Kartenhaus schnell zusammenfallen. Lediglich Hohn und Häme hat auch Abschaffel für einige weibliche Nebenfiguren übrig. Und obwohl er die Zynik selbst bemerkt, „ärgerte ihn ihre Naivität, die er für Dummheit hielt, und es ärgerte ihn noch mehr, daß sie nie merkte, daß er sie nicht ernst nahm." (Abschaffel, S. 13)

Obwohl beide Einschätzungen nicht verbalsprachlich an das Gegenüber herangetragen werden und damit vordergründig in das Metier verletzenden Nichtsprechens nach Hane ${ }^{69}(\Rightarrow$ II.1.4) zu 
fallen scheinen, ist der Bezug zu den [v]erletzende[n] Worte[n] $]^{70}$ gerade hinsichtlich ähnlicher Grundvoraussetzungen auch bereits für den Bereich der nicht-sprachlichen Äußerungen hilfreich - zumal der Rezipient als Adressat dieser „[d]iskriminierende[n] Sprechakte“, so der Aufsatztitel von Carl Friedrich Graumann und Margret Wintermantel, mitgedacht werden muss. In der hauptfigurenanalytischen Ausrichtung der vorliegenden Arbeit ist es wie bereits erwähnt erst von nachgeordneter Wichtigkeit, ob die Figuren durch Schweigen, Sprache, nonverbales Verhalten oder ambivalente Kommunikation verletzen und ob „die Voraussetzungen dafür, dass diskriminierendes Sprechen verstanden wird“,71 tatsächlich vorliegen: Alleine die abschätzige Bewertung anderer bzw. das dabei zu berücksichtigende problematische Fremderleben des Basistypus sind indizienreich genug für einen Abriss der Verhöhnung bzw. Herabsetzung und der damit einhergehenden emotionalen Grundbedingungen.

Um in gewisser Weise die Männerquote bei den Diffamierten nicht aus den Augen zu verlieren, sollen einige grundlegende Aspekte sprachlicher Missachtung anhand männlicher Beobachtungsobjekte veranschaulicht werden. Abschaffel, der diesbezüglich in Degens Fußstapfen tritt, teilt flächendeckend gegen seine Umgebung aus: „Der etwa fünfzigjährige Mann, der ihm in grünlich schimmerndem Anzug gegenübersaß, war einer der Lächerlichsten im ganzen Büro.“ (Abschaffel, S. 8) Ferner ist für ihn „Herr Mörst, der Betriebsratsvorsitzende, ein widerlicher, ewig stinkender Hundezüchter" (Abschaffel, S. 95). Subtiler geht bspw. der namenlose IchErzähler der Liebesblödigkeit zu Werk: „Das würde der Mann vermutlich nicht begreifen. Schon seinem fürchterlichen Pullover sehe ich an, daß er denkt, eine elektrische Eisenbahn ist nichts weiter als eine elektrische Eisenbahn." (Liebesblödigkeit, S. 160) Ein in seinen Augen geschmackloses Kleidungsstück wird zum Erkennungszeichen seiner geistigen Schlichtheit überstilisiert; dass der üblicherweise vom Basistypus geneidete Gedanke, dass ein Gegenstand kein Zeichen für etwas anderes, sondern in erster Linie einfach ein Gegenstand sei, in dieser Situation der Kritik unterzogen wird, bildet einmal mehr die postulierte Tendenz ab, die Messlatte der jeweiligen Evaluation an situativen Elementen und subjektiven Stimmungsschwankungen auszutarieren. Dieses Schwanken wird auch einigen älteren Menschen zum Verhängnis, die mit Peschek im Kino sitzen und die die zotigen Späße des dort gezeigten Films „,Ein Lied, ein Kuß, ein Mädel““ mit Gelächter honorieren:

Er fand auch nicht heraus, warum die Alten lachten. Amüsierte sie die Einfalt der Vorgänge oder die allgemeine Dummheit des Lebens, über die sie sich erst jetzt zu erheben wagten? [...] Der Geohrfeigte stieß das Wort DONNERWETTER aus, und dafür brüllte ihm wieder das ganze Kino entgegen. Im Gewieher der Alten erhob sich Peschek und suchte im Dunkeln den Ausgang. Zuerst hatte er für die Alten gedacht: weil sie alt geworden waren, hatten sie das Recht, das Veraltete zu verspotten. Dann hatte er bemerkt, daß die Alten das Alte gar nicht verhöhnten, sondern bewunderten: und wer so alt geworden und so schlicht geblieben war, mußte beargwöhnt werden. Deswegen dachte er jetzt gegen sie. [...] Auf die Rückseite ihrer Mäntel wollte er ihnen zwei Worte aufsprayen: VoRSICHT STARRE. (Fremde Kämpfe, S. 62)

70 Vgl. Herrmann/Krämer/Kuch (Hg.): Verletzende Worte.

71 Graumann/Wintermantel: Diskriminierende Sprechakte, S. 163. 
430 - Teil II: Schlaglichter 4. Das Ich, die anderen und das andere: Inszenierung - Beobachtung Evaluation

Zunächst handelt es sich nach Graumann/Wintermantel ,nur` um die Kategorie „Diskriminieren als Trennen“:72 Peschek unterscheidet bereits qua Wortwahl zwischen sich und der ,Outgroup“ und macht sich kategorisch mit ,den Alten' bereits dann nicht gemein, wenn er positiv über sie zu denken beabsichtigt. „Distanzieren“ als nächste Stufe der Diskriminierung73 liegt laut den Autoren und Autorinnen dann vor, wenn der Urteilende demonstrativ „[v]on einem sozialen Abstand aus auf jemanden“ zeigt - was hier „durch den Gebrauch abschätziger und verunglimpfender Worte“ („Gewieher“, „schlicht") realisiert wird und damit bereits in den Status „Abwerten“ übergeht. ${ }^{74}$ Besonders markant am diskutierten Beispiel ist allerdings der Plan, ,die anderen‘ nicht nur abzuwerten, sondern die überpointierten Unterschiede zu ihnen auch nach außen sichtbar festzuschreiben, sie mithin „zu stereotypisieren, d. h. zu entindividualisieren“. ${ }^{75}$ Obwohl man die an einen Kinderstreich erinnernde Praktik, einer Person durch einen ohne deren Wissen auf den Rücken geklebten Zettel mit einer Vorverurteilung lächerlich zu machen, vielleicht auf den ersten Blick harmlos nennen mag, ist die (freilich nur geplante) Stigmatisierung - gerade in Verbindung mit der Warnung "VoRSICHT“ in Kapitälchen - einer ganzen Gruppe definitiv gewaltsam und diskriminierend. Man kann zwar wertneutral von der Wortbedeutung her sagen:

Diskriminieren im weitesten Sinn ist eine der grundlegendsten und allgegenwärtigsten menschlichen Handlungen. [...] Aus einer kognitiven Perspektive bedeutet Diskriminieren das Wahrnehmen oder Kennzeichnen der besonderen Eigenschaften einer Person oder eines Gegenstands. ${ }^{76}$

Allerdings ist mit „sozialer Diskriminierung bzw. [...] Diskriminierung anderer" im engeren Sinn „die Ungleichbehandlung von Personen auf kategorialer Basis“ gemeint.77 Für Genazinos Figuren sind einige dieser Kategorien (Alter, Geschlecht, Ethnie, sexuelle Orientierung etc.) bereits verhandelt worden. Allerdings sind sie darüber hinaus in der Lage, auch völlig losgelöst von solchen Kategoriensystemen Diskriminierung zu betreiben - etwa dann, wenn sie sich - flapsig gesprochen - in ,Pöbellaune‘ befinden.

\section{,PÖBELLAUNE' UND WILLKÜRLICHE BELEIDIGUNGEN (ZUM STILLEN FRUSTABBAU)}

Dann nämlich gibt es gar keine Kategorie mit der Aufschrift ,richtig‘ mehr:

Blätterte er die Seiten zu schnell um, schrieb ich: Er ist unfähig, sich für ein Thema zu interessieren. Blätterte er die Seiten langsam um und beugte sich gar über ein Bild, lautete mein Urteil: Er interessiert sich für die Banalitäten einer Illustrierten. Ich bemerkte damals nicht, daß ich mir durch diese Art der Distanzierung selber eine verächtliche Art des Empfindens aneignete. (Einfalt, S. 96)

Die weiter oben referierte Forschungsmeinung, wonach ein und dasselbe Verhalten unter IMAspekten sowohl positiv als auch negativ beurteilt werden kann $(\leftrightharpoons I .3 .3)$, stellt also insofern

72 Graumann/Wintermantel: Diskriminierende Sprechakte, S. 149.

73 Graumann/Wintermantel: Diskriminierende Sprechakte, S. 158.

74 Graumann/Wintermantel: Diskriminierende Sprechakte, S. 158 f.

75 Graumann/Wintermantel: Diskriminierende Sprechakte, S. 160 f.

76 Graumann/Wintermantel: Diskriminierende Sprechakte, S. 147.

77 Graumann/Wintermantel: Diskriminierende Sprechakte, S. 147. 
4.4 Das Ich, die anderen und das andere: Inszenierung - Beobachtung - Evaluation - 431

eine unzulässige Vereinfachung dar, als auch zwei sich diametral gegenüberstellende Verhaltensweisen sowohl positiv als auch - im vorliegenden Beispiel - negativ ausgelegt werden können. Welche Deutungsintention den Zuschlag erhält, liegt im Auge des Betrachters, genauer: in dessen Vorurteilen begründet: Um sich vom Vater zu distanzieren, ist der Sohn geradezu auf der Suche nach dem sprichwörtlichen ,Haar in der Suppe', eine neutrale Beobachtung von Beginn an nicht möglich und auch nicht erwünscht. Auch Warlich ist diese „verächtliche Art des Empfindens“ nicht fremd: „Ich suche nach Einzelheiten, die mir an Herrn Wendt nicht gefallen. Zum Beispiel entdecke ich Mohnkörner zwischen seinen Zähnen. Wenn Herr Wendt den Kopf senkt, erscheint sein Doppelkinn.“ (Glück, S. 119 f.) Wenn man ,cholerisch'( $\Rightarrow$ II.4.1) in ,Pöbellaune‘ durch die Welt läuft, so könnte man es ,herunterbrechen', dann findet die selektive Aufmerksamkeit auch Verhaltensweisen, die sich (harsch) kritisieren lassen: „Er hätte ihn am liebsten angehalten und ihm gesagt, daß er so, wie er es getan hatte, nicht durch ein Kaufhaus gehen könne. Dann gefiel ihm die Jacke eines anderen Mannes nicht." (Abschaffel, S. 14) Abschaffel ist diesbezüglich zumindest sensibel genug, um den Zusammenhang zwischen Frust und Abwertung zu erkennen und (willkürliche) Beleidigungen zum Frustabbau als Triebfeder darzustellen:

Man muß sich immer davor hüten, aus lauter Verzweiflung nicht diese armen Beutel zu hassen, diese Kollegen, jeden Tag bin ich in Versuchung, meinen Haß einfach auf sie zu konzentrieren und gegen sie böse zu werden. Das machen auch einige, weil sie keinen anderen Ausweg mehr wissen. Und das geht schnell. Man braucht sich nur einige Details am Verhalten der anderen zu merken, die man nicht ausstehen kann (Abschaffel, S. 154).

Der Grund für den aus Verzweiflung erwachsenen Hass ist in diesem Beispiel - und häufiger die entfremdete Angestellten-Arbeit (vgl. Wohnung, S. 131), das Repertoire an Gründen für die Herabsetzung aus einer Laune heraus aber beträchtlich:

Aus Enttäuschung darüber, daß ich allein im Schnee übriggeblieben bin, möchte ich am liebsten einem beliebigen Passanten einen beliebigen Vorwurf machen. Zu einem Mann, der arglos über den Platz kommt, könnte ich sagen: Sie haben eine derart geschmacklose Jacke an, daß ich Sie bitten muß, diesen Platz ganz schnell zu verlassen. Ich spüre, wie ein verbotener Reiz zu meinen Lippen hindrängt und mich auffordert, den Mann anzuhalten und den Satz zu ihm zu sagen. Aber ich halte mich zurück. (Einfalt, S. 8 f.)

Wie am Mischpult $(\Leftrightarrow I .2 .2)$ finden sich bis ins kleinste Detail Regler für die gleichen Motive wie etwa: ,aufgrund eines Kleidungsstücks eine Person maßregeln'. Weitgehend grundlos scheint Pescheks ,Pöbellaune‘ zu sein, die nicht weiter motiviert wird als durch die Angabe: „Wenn er sich zu langweilen begann, ging er auf die Straße und suchte nach Menschen, die er wegen ihres veralteten Lebensstils verhöhnen konnte. Einmal beobachtete er in einem Supermarkt eine extrem rückständige Einzelperson" (Fremde Kämpfe, S. 104). An einer späteren Stelle des Romans taucht dafür sogar der treffende Begriff „Spottlust“ auf (Fremde Kämpfe, S. 194). Allerdings ist es nur der Grund, also der handlungsauslösende Faktor, der unmotiviert bleibt: der evaluative Trigger ,Lebensstil` ist explizit benannt und tatsächlich häufiger Anlass für diffamierende Einschätzungen $(\Rightarrow$ II.4.2): 
432 - Teil II: Schlaglichter 4. Das Ich, die anderen und das andere: Inszenierung - Beobachtung Evaluation

Als Abschaffel sie sah, wandelte sich seine Enttäuschung in Hohn um. Diese Fernsehkrüppel, diese elenden, diese Wohnbüffel, schimpfte er vor sich hin [...]. Sie sind kurz vorm Ersticken, aber sie nähen ihr Telefon ein und halten sich elektrische Zahnbürsten in den Mund. (Sorgen, S. 216; vgl. Ausschweifung, S. 130-132)

An einzelnen symboltragenden Gegenständen $(\Rightarrow$ II.1.5) hängen meist ganze Exkurse zu Lebensstilen, die sich mit der (gefühlten) Selbstverortung des Basistypus nicht vertragen:

Seit Jahren bin ich es gewohnt, sie im Innern still herabzusetzen. Wie leicht sie sich verachten lassen! Man braucht nur ihre Plastiktüten anzuschauen, die sie alle gleichmachen, und fertig ist der Hohn. Aber seit einiger Zeit gelingt mir die Überhebung nicht mehr. Im Gegenteil, ich empfinde Anerkennung, manchmal fast Dankbarkeit für die Ströme der Vorübereilenden, ohne die ich nicht wüßte, daß ich ein einzelner bin. [...] Und wie wichtig es ist, daß ich ihnen so fern bin wie ein Mond. (Licht, S. 28 f.)

Der Distinktionswunsch (unzufrieden damit, Teil der Gesellschaft zu sein) schlägt um in gelungene Distinktion ( $\Rightarrow$ II.1.1), ließe sich konstatieren. Die „Überhebung“, die als Leiter zu dieser neuen Bewertung vonnöten gewesen ist, wird damit überflüssig; die Erfordernis erkennbarer Kriterien, um sich selbst von den anderen zu distanzieren, bleibt bestehen:

Ich wußte nicht viel, aber ich wußte schon, daß ich mit Autos und Federball nicht viel zu tun haben wollte. Aber wo gab es eine andere Welt? Offenkundig gab es nur eine Welt, in der alle leben mußten. Wer sie nicht mochte, mußte sich etwas Eigenes aufbauen, egal wie. Ich las damals Gedichte von Rilke, Trakl, Heym, Benn. (Fleck, S. 215) ${ }^{78}$

In einer Welt der konsumkapitalistischen, erlebnissammelnden Grundorientierung ( $\Rightarrow$ II.1.6), in welcher sich einzurichten dem Basistypus schwerfällt, ist die Begeisterung für „Autos und Federball“ - zumindest in seinem Referenzsystem - mehrheitsfähig. Die Flucht kann nur in eine Nische führen - in diesem Fall in eine kapitalstrukturell-symbolische ( $\Rightarrow$ II.1.5) literarische. Mit dem Bezug auf die Plastiktüten schließt sich mit dem folgenden Zitat der kleine Kreis: „In ihr erkenne ich mich selbst, ihr Geigenkasten sind meine damaligen Gedichte. Vielleicht spielt sie nicht einmal Geige, vielleicht braucht sie den Kasten nur, um sicher zu sein, daß sie nicht plötzlich mit vier Plastiktüten behangen nach Hause geht.“ (Fleck, S. 217) Durch selbstdisziplinierte Exaltiertheit wollen die Protagonisten die belanglose Alltäglichkeit von sich fernhalten, wollen aber dennoch gleichartige Einzelindividuen erkennen, deren Verhalten und Einstellungen den ihren ähnlich sind: Wie Wüstenhagen treffend referiert ( $\Rightarrow$ II.4.2), neigt auch W. dazu, ganze Sets von Eigenschaften auf andere Figuren zu übertragen. So ist mit der Vergleichsgrundlage ,Gedichte und Geigenkasten` zwar eine belastbare ,musische` existent, das Sich-der-PlastiktütenSchämen indes ist als ein hinzu-übertragenes Element der Distinktion zu verstehen.

78 Der Benn-Bezug zum Motto-Zitat des vierten Schlaglichts soll wenigstens Erwähnung finden, lassen sich doch dessen absolutsetzende Übertragungen von abscheulichen Körperlichkeiten auf die beobachteten Personen à la „Nachtcafé“ (1912) - „Grüne Zähne, Pickel im Gesicht / winkt einer Lidrandentzündung. // Fett im Haar / spricht zu offenem Mund mit Rachenmandel / Glaube Liebe Hoffnung um den Hals // Junger Kropf ist Sattelnase gut. / Er bezahlt für sie drei Biere. // Bartflechte kauft Nelken, / Doppelkinn zu erweichen“- mühelos als stilbildender Prätext für Genazinos Worte ausmachen: „Faulender Knöchel, lauf weiter! Verlorenes Auge du! Übrig gebliebener Pudding, kipp dich selber in die Toilette!“ (Außer uns, S. 88 f.) Ein „[f]aulender Knöchel“ kann einem auch in Benns Leichenschauhaus begegnen. 
4.4 Das Ich, die anderen und das andere: Inszenierung - Beobachtung - Evaluation - 433

Anderen Figuren wird allenthalben die Möglichkeit abgesprochen, für diese dekadenten Verfeinerungen überhaupt ein Sensorium zu haben:

Für Menschen wie ihn ist das Verlangen nach Originalität nur eine wertlose kulturelle Erfindung; sie haben von Anfang an ihren Frieden damit gemacht, daß das Leben aus Gewohnheiten und Wiederholungen besteht. Und mein Versagen liegt darin, daß ich diese heroische Angemessenheit nicht begreifen will und deshalb nicht würdigen kann. (Einfalt, S. 65)

Die Selbstkritik zeugt einerseits von der Kenntnis der eigenen Hybris, findet andererseits nicht aus der Verfahrenheit der Dopplung von, glücklichem Schwein und unglücklichem Sokrates‘ ( $\Rightarrow$ II.2.2; vgl. Kassiererinnen, S. 119 f.) heraus: „Jetzt fahren sie wieder nach Hause, die armen kleinen Tiere, zu den Schlachtbänken der Einbildung, der Vergeblichkeit und der Hoffnung." (Obdachlosigkeit, S. 9)

In Analogie zu ( $\Rightarrow$ II.4.3) ist die Wort- bzw. Folgenlosigkeit zu gewärtigen, die den cholerischen Zügen allenthalben die Schärfe nimmt: ${ }^{79}$ „Auf der Straße hatte er Lust, in die Ereignisse hineinzupöbeln. Den massenhaft vorbeifahrenden Autos rief er zu: FAHRT WEITER, IHR SCHWEINE, nur Abschaffel hörte es, aber es machte ihn zufrieden." (Abschaffel, S. 98) Auch Pläne körperlicher Einschüchterung verpuffen auf diese Weise unausgesprochen: „[D]ann aber wollte er auf sie losgehen: Verdammt noch mal [...]. [...] [U]nd er stieß seine Beschimpfungen nicht aus." (Sorgen, S. 374) Bislang sind sich die ,Verurteilten“ selbst der „schauenden Bestrafung“ nicht gewahr geworden. Das ändert sich, wenn zumindest nonverbal die Herabsetzung als Affront sich zu erkennen gibt: „Dürfen wir dem jungen Herrn den Tag verschönern? Diese schleimige Anrede stieß mich ab und führte dazu, dass ich mich auf der Stelle umdrehte und das Modehaus verließ." (Außer uns, S. 54) Die Figuren geben anderen durchaus zu verstehen, dass diesen die Verachtung jener gewiss sein kann, wobei das geringste Ausmaß darin besteht, unwillkürliche böse Blicke oder das Lachen über andere - „Ein Faustschlag von Kafka! Ich drehe mein Gesicht weg, damit Bausback mein mühsam unterdrücktes Lachen nicht bemerkt“ (Liebesblödigkeit, S. 167) - verstecken zu wollen:

Es ist mir nicht recht, daß ich Herrn Schaller so heftig beobachte. Deswegen bin ich froh, daß er ein wenig überstürzt (hat er doch, vielleicht zum ersten Mal, etwas von seiner Wirkung bemerkt?) seinen Teller an der Theke zurückgibt und vor meinen Augen (nein, er hat doch nichts von seiner Wirkung bemerkt) sein jetzt benutztes Besteck einwickelt und wieder in seiner Anzugtasche verschwinden läßt. Himmel! Diese Anblicke sind fast zuviel für mich. (Heimweh, S. 77)

Und selbst dann, wenn Genazinos Figuren nonverbal die offene Konfrontation suchen, den Gesichtsverlust des Gegenübers trotz der drohenden Implikationen für das eigene Gesicht billigend in Kauf nehmen, bleibt es häufig folgenlos und führt - hier ist die externe Warte zwingend einzunehmen - vor Augen, dass die Selbstwirksamkeit der Figuren eine geringe ist, weswegen auch

79 Bereits hier sei darauf verwiesen, dass es auch (lautstark) geäußerte Herabsetzungen gibt: Wenn sich die Hauptfiguren ungerecht behandelt oder beleidigt fühlen, beleidigen sie hinwiederum andere (vgl. Ausschweifung, S. 70) oder werden mitunter sogar laut: „Aussprechen, rief Eckhard nun schon deutlich verärgert, beim Hausarzt?" (Ausschweifung, S. 101) 
434 - Teil II: Schlaglichter 4. Das Ich, die anderen und das andere: Inszenierung - Beobachtung Evaluation

der Rezipient den Figuren immer wieder Etiketten wie ,passiv', ,zurückhaltend“ aufdrückt: „Auf der anderen Seite der Bank saß ein dicker Mann [...] aber der Mann war versunken in sein Wippen und nahm ihn in seiner vorwurfsvollen Haltung nicht wahr.“ (Abschaffel, S. 125) Analog: „In der U-Bahn sah er sie schroff an, aber sie bemerkte es nicht." (Fremde Kämpf, S. 106) Was gibt es Zahnloseres, als den Versuch, ein aufwallendes Inneres in der archaischen Form des Nonverbalen ins kommunikative Abseits laufen zu lassen? Eine ähnlich gestrickte Situation findet sich: „Aus Verdruß sah er der Besitzerin eines Hundes, der gerade auf den Bürgersteig machte, so streng in die Augen, als sei sie es gewesen, die öffentlich gepinkelt hatte." (Falsche Jahre, S. 562) Zum einen ist damit der Komplex von gefühlter Bestrafung und Selbstwirksamkeit aufgerufen ( $\Rightarrow$ II.1.4), zum anderen derjenige offensive Gestus, andere sich unwohl fühlen zu lassen (s.u.). Beidenfalls motiviert die affektive Stimmung („Verdruß“) die Weltwahrnehmung wie die Messlatte, nach der die Hauptfiguren das Verhalten und die Inszenierungen anderer beurteilen. Für dieses Unterkapitel sind neben den bereits genannten Erklärungsansäten von Enttäuschung oder Verzweiflung entspringender genereller Unzufriedenheit insbesondere Zorn, Wut und Hass affektiv-emotionale Motoren für feindliche Einschätzungen. Peschek etwa

sehnte [...] sich danach, einen WUTSTEMPEL zu besitzen, ein klobiges, rundes Holzding [...], und mit diesem Wutstempel würde er alles abstempeln, was seine Wut hervorrief: zuallererst den Mann in seiner Brust, alle Alten, die Fernsehsendungen mit sich machen ließen, außerdem alle alten Schauspielerinnen, die nicht den Mund halten konnten, Münchmeyer natürlich, den würde er sogar mehrfach stempeln. (Fremde Kämpfe, S. 57)

Eng verquickt mit dem Eingeständnis, innerliche Empfindungen nur unzureichend ausdrücken zu können ( $\Rightarrow$ II.1.4), ergießt sich seine Wut metaphorisch ungerichtet auf Diverses. Wenig später ruft „Peschek eine LISTE DER GROSSEN ABSCHEULICHKEITEN ins Leben, auf die er alles eintrug, was ihm nicht paßte." (Fremde Kämpfe, S. 71) Wut und Zorn sind aber auch ad personam an der Tagesordnung. Axel Degen sagt über sich selbst in aggressiv-cholerischer Stimmung aus, „ich hätte ihn umbringen können, diesen schleimigen Kavalier, diesen blauen dienstmützenbeflissenen Treppenhauswandler.“ (Laslinstraße, S. 12 f.) ${ }^{80}$ Abschaffel, der ebenfalls „rasch wütend“ wird (Abschaffel, S. 67), „spürte den Zorn darüber so dicht hinter seinen Augen sitzen, daß er wirklich dachte: Wenn er es wagt, mir Ratschläge zum Brillenputzen zu geben, dann schlage ich ihm mit der Faust ins Gesicht" (Abschaffel, S. 75 f.). Am ,Umschlagplatz' von Wut und Hass zu verorten bezieht sich diese innere Drohung personenbezogen auf seinen Vater und trägt zudem eine erzähltechnisch interessante Prägung: Der Erzähler bekräftigt Abschaffels zwischen Gedankenzitat und autonomem inneren Monolog befindliche und damit in unüblich unmittelbare Form gegossene Absichtserklärung mit einem „wirklich“, womit die Grenze zwischen imaginierter und realisierter Form verwischt wird.

80 Dieser blinde Hass lässt sich mit einer Szene aus Kein Geld, keine Uhr, keine Mütze parallelisieren, welche regelmäßige Seitensprünge der Mutter, die auch Degen hier beschützen zu müssen meint, mit einem ,jungen Verkaufsleiter" nahelegt (Kein Geld, S. 72). 
4.4 Das Ich, die anderen und das andere: Inszenierung - Beobachtung - Evaluation - 435

\section{WUT, ZoRn, HASS: GEWALTFANTASIEN UND AUTORITÄRE PERSÖNLICHKEITEN}

Die Darstellung von Gewaltfantasien, die sich gegen andere richten, ${ }^{81}$ lohnen häufiger der narratologischen Detailanalyse. So besteht ein erzähltechnischer Kniff darin, interne und externe Perspektive gleichzeitig zu aktivieren:

Es fiel ihm Barbara ein, und in der verkürzten Art des Denkens, die dem geschmerzten Körper nur übrigbleibt, stellte er sich Barbara als Hauptschuldige vor. Wenn sie da gewesen wäre, hätte er sie vielleicht niedergeschlagen, zu einem blutigen Klumpen hätte er sie geschlagen und dann hinter die Bratwurstbude geworfen. (Sorgen, S. 274)

Abschaffel, der zuvor von Margot verlassen worden ist, empfindet zuerst Schmerz, dann Leere und schließlich, als das Zitat einsetzt, Hass auf die nur stellvertretend ,schuldige' Barbara, die eine Breitseite seiner Gewaltfantasie abbekommt. Dabei werden eine nullfokalisierte Wertung und der Figur unzugängliche Reflexion vorausgeschickt, die ihre Bewusstseinsinhalte fast verzeihlich geraten lassen. Außerdem geht damit eine forcierte Dopplung in der Figurencharakterisierung einher: Einerseits wird damit intern ein potenziell gewaltbereites Bild von Abschaffel evoziert - immerhin scheinen Gewaltfantasien Gewalttaten überzufällig häufig vorauszugehen. Andererseits schiebt sich der externe Filter davor, welcher dem Rezipienten signalisiert: ,Immerhin ist Barbara ja erzähllogisch absichtlich nicht zugegen, und würde Abschaffel denn wirklich...?' Damit bleibt es in der Schwebe, zu welcher Seite die Waagschale der Persönlichkeitsmerkmale sich neigt: zur cholerischen oder der introvertiert neurotischen.

Obzwar Degen und Abschaffel als Enfants terribles gelten müssen, die zu höchst drakonischen und auch konkreten Gewalt- und Tötungsfantasien neigen - „Noch immer hatte er Lust, auf diese unfaßbar abwesende Frau Hornung einzuschlagen und ihre Kinder aus einem Fenster zu werfen" (Sorgen, S. 218) -, ist es doch kein ,doppelter Einzelfall' im Sinne zweier romanspezifischer Ausnahmen: Auch Eckhard Fuchs „hatte Lust, Frau Hammerschmidt den Joghurtbecher aus der Hand zu schlagen“ (Ausschweifung, S. 269), nur weil sie seinem Dafürhalten nach mangelnde öffentliche Selbstaufmerksamkeit respektive Rücksichtnahme an den Tag legt.

Autoritäre Persönlichkeiten und die F-Skala sind bereits eingeführt worden ( $\Rightarrow$ II.2.2) und auch an dieser Stelle der Arbeit lohnenswerte Konstrukte, um Familienähnlichkeiten aufzutun. Abschaffels „Tendenz, nach Menschen Ausschau zu halten, die konventionelle Werte [im eben zitierten Beispiel: Rücksichtnahme; N. L.] missachten, um sie verurteilen, ablehnen und bestrafen zu können“,82 ist unübersehbares Indiz für die Subskala, die autoritäre Aggression misst. Insgesamt liest sich eine Zusammenschau der F-Skala -„Festhalten an Hergebrachtem“ $\Leftrightarrow$ II.1.5 u.

81 Vgl. zur Autoaggression ( $\Rightarrow$ II.1.3) sowie zum ,Runterschlucken` des Ärgers bspw. Stellen wie: „Abschaffel hatte diese Gespräche oft und oft angehört, und manchmal war seine Wut so groß geworden, daß er glaubte, er verwandle sich hier in einen hohen Turm, der dann von selbst umfällt." $(A b$ schaffel, S. 10)

82 [F-Skala]. 
436 - Teil II: Schlaglichter 4. Das Ich, die anderen und das andere: Inszenierung - Beobachtung Evaluation

$\Rightarrow$ II.1.6), „Allgemeine Feindseligkeit, Herabsetzung anderer Menschen“,83 „Machtdenken“84 nicht nur wie eine in diesem vierten Schlaglicht im Zentrum stehende Beschreibung der Figurenfacetten, sondern ist auch mit den Techniken offensiven IMs bestens vereinbar: Abwertung, Herabsetzung, Einschüchterung etc. ( $\Rightarrow$ I.3.3) sind immer wiederkehrende Eigenheiten der Figuren, die sich gebündelt in der Verhaltensstrategie, ,andere sich unwohl fühlen lassen', zu erkennen geben, worein sich auch sadistische Züge mischen, etwa in der Form, andere in Abhängigkeit zu halten etc. ${ }^{85}$ Viele der folgenden Beispiele sind tatsächlich (und mitunter lautstark) geäußert:

Mit elf fiel mir ein Trick ein, mit dem es mir gelang, meine Eltern wenigstens einmal zu düpieren. Ich verlangte damals nicht einzeln nach ihnen, sondern ich wollte sie beide gleichzeitig, ich rief: ,Eltern! Eltern!...!' Tatsächlich erschienen daraufhin beide zugleich in meinem Zimmer und schauten nach mir. Ich saß auf dem Boden und grinste sie an. Sie ahnten, daß sie in eine schwer durchschaubare Falle gegangen waren, und verließen schweigend das Zimmer. (Licht, S. 101)

Obwohl dieses Verhalten verhältnismäßig harmlos daherkommt, ist der Wunsch, die Eltern zum Narren halten zu wollen, ${ }^{86}$ gleichsam eine elementare Grundform der „Straflust“ des Basistypus:

Ich habe Lust, Frau Grünewald für ihre Anzüglichkeit zu bestrafen, aber ich weiß nicht wie. Da liefert mir meine Straflust einen passenden Einfall. Ich habe ein seltsames Gefühl, sage ich, als würde mir eine Fliege über das Kopfhaar laufen. Frau Grünewald verstummt sofort. [...] Ohne ein weiteres Wort verläßt Frau Grünewald den Fahrstuhl. (Heimweh, S. 164)

Im Gegensatz zu diesen Beispielen werden die Worte erzähltechnisch hingegen häufiger durch Gesprächsbericht realisiert als durch direkte oder indirekte Rede, sodass der Leser es womöglich einfacher hat, diese Verhaltensstrategien in das Bild des Basistypus zu integrieren: „Und Peschek machte es Vergnügen, Marga zu belehren und in die Belehrung immer mehr Rügen einzubauen." (Fremde Kämpfe, S. 154) Die Lust an der Bestrafung und der Erniedrigung wird hier verpackt in eine lediglich berichtende Präsentationsform des Gesprächs, die den Tenor festlegt, die Ausgestaltung aber dem Rezipienten freistellt. Als Machtdemonstration findet sich diese Erzähltechnik sogar noch weiter minimiert: „Frau Kaiser war ihm auch gleichgültig. Sie spürte, wie gelangweilt er war, und sie verstärkte ihre Nettigkeit." (Abschaffel, S. 29) Martínez/Scheffel sehen als Minimalform der Präsentation von gesprochener Rede hinsichtlich der Unmittelbarkeit unterhalb des Gesprächsberichts lediglich die „Erwähnung des sprachlichen Akts“ vor, ${ }^{87}$ wohingegen im zitierten Beispiel eher von einer Meta-Präsentation gesprochen werden müsste, da sie zwar keinerlei Rückschlüsse über den Inhalt, wohl aber über die Form und die kränkende Aussageabsicht des Gesprächs verstattet: „Er verkürzte ihr Reden, indem er in ihre Erklärungen hinein aufräumende und erledigende Sätze sagte, und er spürte, wie Frau Kaiser sich unsicher zu

83 [Autoritäre Persönlichkeit].

84 [F-Skala].

85 Vgl. für die ,kleinen Geschwister' dieser rabiaten Techniken wie Provokation, Dreistigkeit, Aufmüpfigkeit, Frechheit etc. das letzte Kapitel des dritten Schlaglichts $(\Leftrightarrow I I .3 .5)$.

86 Vgl. für eine abgeschmacktere Täuschung etwa: „Ich empfand sogar ein gewisses Vergnügen an seiner Haltlosigkeit. Ich lockte ihn mit ein paar Bemerkungen, die ihn dazu aufreizten, in der Manier eines bereits gesicherten Erfolgs weiterzureden." (Kassiererinnen, S. 97) 
4.4 Das Ich, die anderen und das andere: Inszenierung - Beobachtung - Evaluation - 437

fühlen begann, weil sie den Eindruck hatte, es nicht richtig und ausführlich genug erklärt zu haben." (Abschaffel, S. 30)

Sich der Unsicherheit anderer zu erfreuen, ist das Vergleichsmoment auch zum ,verletzenden Nichtsprechen“ (s.o.): „Ich antwortete nicht gleich, um ihm Gelegenheit zu geben, vor mir Respekt zu bekommen" (Laslinstraße, S. 136). Sadistisch-autoritäre Kommunikation ist gemessen am Grundgesamt relativ selten, dafür aber besonders eindrücklich:

Mit umherflackernden Blicken suchte sie nach einem Papierkorb, fand aber keinen. Ich sagte ihr nicht, dass sich ganz in der Nähe, hinter einem Kiosk, ein Papierkorb befand. Ich wollte Elisabeth noch eine Weile dabei zuschauen, wie sie mit einem Hundehaufen in der Hand suchend neben mir herging, zugleich aber weiter den Hund beobachtete, weil sie offenkundig Angst hatte, er könne vielleicht noch einen Haufen zurücklassen. (Kassiererinnen, S. 93 f.)

Der namenlose Ich-Erzähler weidet sich an der Unbeholfenheit Elisabeths und unterzieht sie dadurch einer wortlosen, „schauenden Bestrafung“. Dass daraus tatsächlich „[a]llgemeine Feindseligkeit“ (s.o.) sprechen kann, beglaubigen auch Aussagen Abschaffels wie diese: „Aus Bösartigkeit verlangte er Besteck“ (Abschaffel, S. 118), oder: „Manche sah er aufdringlich gierig oder verächtlich an." (Sorgen, S. 270) Dass es nicht nur feindselig und lautstark, sondern auch erzähltechnisch unmittelbar und wortreich sich ereignet, dass die autoritären Persönlichkeitsmerkmale der Figuren durchschlagen, soll abschließend anhand Abschaffels gezeigt werden:

Sie haben ihn also mit in das Hotel genommen, und dort ist es dann passiert, nicht wahr, und für ihn war es möglicherweise sogar das erste Mal? fragte er, und er hatte sich bemüht, soviel Spott und Zwiespältigkeit in seine Stimme zu legen, wie es ihm eben möglich war, damit sie ihm vielleicht das Mittagessen über das Hemd schüttete und vom Tisch wegging. Aber sie blieb sitzen und kicherte. (Sorgen, S. 283)

Mit der Motivation, Frau Schönböck zu demütigen, die ihm kurz zuvor von einer Urlaubsbekanntschaft mit einem weitaus jüngeren Mann berichtet hatte, beginnt Abschaffel diese ,Standpredigt'.88 Doch der gewünschte Effekt tritt (noch) nicht ein, und so legt Abschaffel verbal nach: „Nein, sagte er, das können Sie eben nicht; so wie Sie gebaut sind, lügen Sie immer weiter, auch wenn alles ziemlich unangenehm wird. Abschaffel lachte verächtlich, aber sie schien davon auszugehen, daß sie diese Predigt nun über sich ergehen lassen mußte." (Sorgen, S. 286 f.)

Resümieren lässt sich, dass der Genazino'sche Figurenbasistypus (zumeist) lange Zeit still bleibt und Beleidigungen und Bestrafungen lediglich imaginiert, in denjenigen Situationen hingegen, in denen sich die Worte ihre vernehmliche Bahn brechen, offensives IM verwendend die Entwertung und Herabsetzung anderer Figuren bis zum Äußersten treibt ${ }^{89}$ - und sei es im Flüsterton

88 Vgl. dazu auch: „O Gott, Frau Islinger! rief Peschek aus, Sie besuchen wieder einen Kurs der Volkshochschule, stimmts? Das ist nicht nur mit den Portugiesen so, sondern mit uns allen: einmal täglich ist fast jeder revolutionär, aber für den Rest des Tages sind wir wieder flau wie Postbeamte." (Fremde Kämpfe, S. 128)

89 Vgl. dazu den Unterschied zwischen „SCHIMPFEN“ - „Der Sprecher versucht, mit gesellschaftlich tabuierten, derben Ausdrücken [...] seinen negativen Gefühlen [...] Luft zu machen“ - und „BESCHIMPFEN“ - „gehört zur Klasse der Expressive, weil es sich an einen Hörer richtet, den es treffen will“ (Wagner: Pragmatik der deutschen Sprache, S. 263 u. S. 194). 
438 - Teil II: Schlaglichter 4. Das Ich, die anderen und das andere: Inszenierung - Beobachtung Evaluation

nach einer Therapiesitzung: „Diese Schlampe, diese elende, die sich jahrelang ins Bett legte und sich aushalten ließ, dieser stinkende, faule Fleischberg." (Falsche Jahre, S. 535) Spätestens jetzt ist die bloß gefühlte, schauende, zu einer sicht- und hörbaren Bestrafung geworden - die einerseits Ausdruck von Sadismus und Autoritarismus ist, andererseits auch gesunde Triebabfuhr „Er bemerkte, daß es ihm gutgetan hatte, Frau Schönböck Bescheid gesagt zu haben“ (Sorgen, S. 288) - symbolisieren kann.

Selbstredend gibt es auch Figuren, die eine wohlwollendere Einschätzung erfahren. Das liegt teils an der gerade verwendeten Messlatte, der aktuellen Stimmung, der analysierten Person; teils aber auch an der neidlos anerkannten Tatsache, dass andere das (nicht realisierbare?) Idealbild der Hauptfigur eher verkörpern, als sie dazu selbst jemals in der Lage wäre.

\section{5 (Anerkennendes und bewunderndes) Goutieren fremder Verhaltensweisen}

Direkt positiv dargestellte Bewunderung jenseits jedweder Ambivalenz ( $\Rightarrow$ II.4.2) findet sich ausschließlich auf dem schmalen Grat zwischen Romanspezifik und äußerster Familienähnlichkeit wieder ( $\Rightarrow$ I.2.5): „Phantastisch, wie sie sich selbst gefielen. Wo hatten sie das nur gelernt?“ (Falsche Jahre, S. 557) Die selbstsichere Selbstzufriedenheit der Kinder, die ohnehin meist positiv besetztes Inventar der Erzählwelten Genazinos sind, ruft Abschaffels Bewunderung hervor (vgl. Falsche Jahre, S. 402). Hinsichtlich einer nebensächlichen Beobachtung einer Nachbarin hält Fuchs fest: „Diese Frau kann wirklich wohnen, überlegte Eckhard anerkennend und seufzte.“ (Ausschweifung, S. 26) Fuchs kann das seinerseits nicht, könnte es aber gern. Soweit, dem anderen mit verbal geäußerter positiver Höflichkeit zu begegnen und ihn mithin in seinem Tun, Aussehen usw. zu bestärken, kommt es indessen selten:

Positive Höflichkeit basiert auf Kontaktaufnahme; sie ist Balsam für das Gesicht des Adressaten, indem sie signalisiert, dass $\mathrm{S}$ in bestimmter Hinsicht Hs Bedürfnis begehrt (z.B., indem man ihn als Mitglied einer Ingroup behandelt, als Freund, als Person, dessen Wünsche und persönliche Züge bekannt sind und gemocht werden)..$^{90}$

Das höchste der Gefühle ist in diesem Zusammenhang die Anerkennung über non- und paraverbale Kanäle: „Eckhard gefiel Marthas Widersprüchlichkeit, und er sah sie bewundernd an.“ (Ausschweifung, S. 94) Vergleichsweise selten sind die hier analysierten wohlwollenden Evaluationen ,ohne Hintergedanken' für das eigene Selbstkonzept: Zumeist schwingt - frei nach den Mechanismen des Wunsches nach dem eigenen positiven Gesicht und der damit einhergehenden Idealbildkosmetik - in der Lobhudelei der anderen auch ein gesteigertes Selbstwertgefühl mit: „Die Erzählung seines Erlebnisses machte ihn ein wenig unbeholfen, was mir gut gefiel. Verlegene Menschen waren mir ohnehin am liebsten." (Kassiererinnen, S. 12) Vordergründig fraternisiert sich die Hauptfigur mit der Unbeholfenheit eines anderen. In der Benennung und der Analyse 
des Figurenhandelns und der generösen Verallgemeinerung geht die Hervorkehrung der Gemeinsamkeit allerdings tendenziell unter und lässt die Vermutung zu, dass eigene basistypische Schwächen in einer ,unbeholfenen' Gesellschaft weniger Gewicht hätten. Diese Interpretation wird auch durch die Aussage des Protagonisten aus Genazinos Außer uns spricht niemand über uns gestützt: „Ich beobachtete einen Mann, der sich hilfesuchend hinter einer Frau versteckte und empfand sofort Sympathie mit ihm." (Außer uns, S. 107)

Viele dem ersten Vernehmen nach unumschränkt goutierte Verhaltensweisen geben sich unter dem analytischen Mikroskop als subtile Kritik zu erkennen: „Isolde überraschte mich mit Klugheit und Ehrlichkeit.“ (Licht, S. 19) Was Austin eine ,kostümierte Äußerung' nennt,91 ist nicht einwandfrei einer Anerkennung noch aber einer Abwertung in Reinform zuzuordnen: Ist Isolde in dieser Situation besonders intelligent? Oder generell weniger gescheit und unehrlich und der Ich-Erzähler ihr insgesamt überlegen?

Die Selbstbezüglichkeit, die in den positiven Evaluationen steckt, äußert sich auch dadurch, dass man sich anhand der evaluativen Kriterien immer wieder auf die Protagonisten zurückgeworfen sieht: Die Funktion ist weniger, Nebenfigur A, B oder C bewundernd zu würdigen, sondern vielmehr eine Spielart, die ,Figurenromanfiguren' auch figurenanalytisch extern zu profilieren. In den Evaluationssituationen lernt der Leser getreu des Wortes, nach dem ein Gutachten mehr über den Analytiker als über den Patienten aussage, mitunter weniger das beobachtete Subjekt/Objekt als vielmehr den Begutachter kennen. So existieren hinsichtlich der Evaluationen breite Überlappungen von Fremdscham und Verriss hinsichtlich Inszenierungen, die weit vom eigenen Idealbild abweichen (vgl. Ausschweifung, S. 35), wie andererseits diejenigen Figureninszenierungen gewogener ausfallen, die etwa (im kleinen Rahmen) private Selbstaufmerksamkeit als Idealbild-Desiderat an den Tag legen ( $\Rightarrow$ II.2.4 u. $\Rightarrow$ II.4.2): „Mir gefällt seine Unachtsamkeit, seine Selbstmaßstäblichkeit, seine öffentliche Schlamperei“ (Fleck, S. 13; vgl. Ausschweifung, S. 53 f.). Die Nebenfiguren übernehmen damit die Externalisation eigener Idealbildfacetten: „Ilona war mir sympathisch, weil sie manchmal zu vergessen schien, dass sie Kassiererin war und jederzeit von jedermann betrachtet werden konnte." (Kassiererinnen, S. 17) Eng damit zusammenhängend weiß dieses Verhalten zu gefallen, welches allem Anschein nach ,natürlich' selbstbewusst ist: „Ein junges Mädchen mit stark abstehenden Ohren und dennoch hochgestecktem Haar kam vorüber. Ein paar Augenblicke rührte mich der Anblick dieser Souveränität." (Außer uns, S. 77; $\Rightarrow$ II.2.1 u. $\Rightarrow$ II.5.3) Im ,dennoch“ wird markiert, dass es in den Augen des Erzählers wohl einem Widerspruch gegen den gesellschaftlichen Topos, nachdem man/frau die Haare über abstehende Ohren fallen lassen müsse, gleichkommt. ${ }^{92}$ Jedenfalls gefällt es den urteilenden

91 Vgl. Herrmann/Kuch: Verletzende Worte, S. 8.

92 An der Grenze von Lächerlichkeit und Neid auf private Selbstaufmerksamkeit bewegt sich etwa das folgende Beispiel: „Vor mir war ein Rentner an der Reihe [...]. Der Mann war zuversichtlicher Laune und wusste offenbar nicht, wie schräg das Bild war, das er abgab. Sogar die Verkäuferinnen kicherten über ihn, was ihn nicht irritierte." (Außer uns, S. 8) 
440 - Teil II: Schlaglichter 4. Das Ich, die anderen und das andere: Inszenierung - Beobachtung Evaluation

Figuren, wenn der Schein von Authentizität existiert und vermutlich kein überzogenes IM am Werk ist: „Obwohl sie nicht den geringsten Wert auf Äußerlichkeit legte, ging eine starke Ausstrahlung von ihr aus, die umso heftiger war, weil ihr keine Absicht zugrunde lag." (Außer uns, S. 123) Ein Beispiel, das noch im Zeichen des Neids auf private Selbstaufmerksamkeit steht, sich aber davon bereits entfernt, findet sich in der Liebe zur Einfalt:

Ich bewundere ihren Gleichmut, der ihnen erlaubt, inmitten des ordentlichen Lebens ringsum langsam zu verrotten. Ich bleibe stehen und staune über sie, wenn sie über andere Menschen höhnen und lachen. Und ich empfinde versteckten Neid, wenn sie in ihre Manteltaschen und Plastiktüten greifen, halbleere Flaschen herausziehen und sie ein wenig verächtlich und großspurig an den Mund setzen. So falsch und schlicht fühle ich, wenn ich der Verwirrtheit nahe und deswegen beschämt bin. Erst nach einer weiteren halben Stunde läßt die Erinnerung an die Eltern wirklich nach und mit ihr die Beschämung. Jetzt sehe ich, daß es sich mit den Stadtstreichern anders verhält; sie liegen auf der Straße, weil sie nichts mehr aushalten. (Einfalt, S. 32)

Wie sich herausstellt, ist die Bewunderung, die durch einen „versteckten Neid“ bereits früh eingetrübt wird, nur der temporären Verfassung des Wahrnehmenden geschuldet und kippt später in eine gänzlich andere Lesart. Somit muss immer abgeklärt werden, ob es womöglich die Grundstimmung des Protagonisten ist, die einem ,objektiven` Gutheißen widerspricht:

Es vergehen höchstens vier Minuten, dann kippt die Lockung. Jetzt gefallen mir die Männer nicht mehr, im Gegenteil. Auf der Stelle laufe ich weg, ich fürchte und beschimpfe die Musik dieser hergelaufenen Männer, ich nenne sie lächerlich, mehrmals. Kunstvoll flieht das immer noch lernunwillige Kind in mir die Erinnerung an sich selbst und verhöhnt sie zugleich. (Licht, S. 122 f.; vgl. Ausschweifung, S. 193)

Die Stimmung des Protagonisten wirkt sich massiv auch auf die Gesamtinterpretation seiner sonstigen Anschauungen und Bewertungen von Situationen aus (vgl. Regenschirm, S. 84 f.) und wohl gar auch auf eigenes Verhalten: „Weil ich mich durch die Wollknäuel-Therapie gestärkt fühle, agitiere ich in meinem Inneren nicht gegen die Anwesenheit von Herrn Schaller, sondern lade ihn mit ein paar freundlichen Blicken an meinen Stehtisch." (Heimweh, S. 76)

Neben der Stimmung ist es aber auch die Frage, wer das Beobachtungsobjekt ist, die beeinflusst, zu welcher Seite sich der Daumen der beobachtenden Protagonisten neigt:

Ein junger Bettler betritt die U-Bahn und spricht mit klarer, dramatisch ausgeformter Stimme über sein elendes Leben. Während er redet, streift er mit vorgehaltener Mütze durch die Bahn und schaut den Fahrgästen aus nächster Nähe ins Gesicht. Viele empfinden rasch Sympathien mit dem famosen Mann, der sein Schicksal so entschlossen in die Hand genommen hat, und greifen nach ihren Geldbörsen. So haben sie es gerne: Ein Bettler rattert seinen Text herunter wie ein modernes Theaterstück und bringt zum allgemeinen Entzücken einen neuartigen Kunsteffekt hervor. (Licht, S. 118; vgl. Kassiererinnen, S. 148-151)

Bei diesem Beispiel für eine vor anderen gut funktionierende Selbstdarstellung, die der Protagonist mit gemischten Gefühlen verfolgt, scheint es nicht unerheblich, dass der Bettler „jung[]“ ist, „mit klarer, dramatisch ausgeformter Stimme“ spricht und das Leben des „famosen Mann[s]“ ein „elendes“ genannt zu werden verdient. Es lässt sich nicht abschließend entscheiden, wo die eigene Anerkennung endet und diejenige der beobachteten Beobachter beginnt; aber dass die sonst so geschätzte Authentizität als Grundbedingung für Anerkennung und Mitleid über Bord 
geworfen wird, legt es nahe, dass das Subjekt der Beobachtung einen nicht geringen Anteil daran hat, selten auch brüchige Inszenierungen $(\Rightarrow$ II.4.3) als gelungen zu evaluieren. So wertet auch W. eine feinmaschige Inszenierungsstrategie des, falschen Inders' trotz ihrer Fadenscheinigkeit zumindest als weiterhin Interesse weckend und beeindruckend:

Aus dem Gewimmel der Menschen, die über den Rathenauplatz gehen, tritt der falsche Inder hervor. Zielstrebig und mit strengem Gesicht geht er vorüber, wie immer ohne Tasche, ohne Zeitung, ohne Plastiktüte. Er trägt die Hände frei, er hat niemals etwas zu besorgen. Wie oft habe ich ihn gesehen! Er ist mir ein fremder Bekannter geworden, wenn es das gibt. Immer noch gefällt mir seine enge grüne Hose und seine weiße, halblange Jacke, die vorne mit Messingknöpfen geschlossen ist. Auf dem Kopf trägt er einen weißen Turban mit einer rotgoldenen Brosche. Am auffälligsten sind seine grüngoldenen, mit Perlen besetzten, vorne spitz zulaufenden Schuhe. So geht er umher: wie ein dem Märchen entlaufener Maharadscha. Aber leicht ist zu sehen, daß alles an ihm künstlich ist, etwas mühsam Aufrechterhaltenes, eine peinliche Maskerade. Am liebsten möchte ich ihn anhalten und so lange fragen, bis ich genau weiß, was ihn einst so verstört hat, daß er sich nur noch getarnt zeigen will. Immer noch sind es die abweichenden Menschen, die uns daran erinnern, daß wir zuwenig wissen. Jahrelang hat mich sein Kostüm getäuscht; dann habe ich plötzlich entdeckt, daß in dem Kostüm nicht ein Inder, sondern ein Einheimischer steckt, ein auf stille Weise verrückt Gewordener, der sich mit Auffälligkeit schützt. Seit der Enttarnung interessiert er mich noch mehr. [...] Aber ich ahne natürlich, daß sein Kostüm die Aufgabe hat, die ganze Welt von ihm fernzuhalten. Früher war seine Hose tadellos, jetzt ist sie verschlissen und zerknittert. [...] Und doch beeindruckt mich der Hochmut, mit dem er am Fußgängerüberweg auf die vorüberfahrenden Autos herabschaut. Als wüßte er genau, was seine Abweichung wert ist! (Fleck, S. 22 f.)

Wenngleich der Protagonist in der Erzählvergangenheit die Inszenierung des Mannes durchschaut hat, nötigt sie ihm insofern Respekt ab, als er Sympathie für die (mutmaßlich) zugrundeliegende Motivation des ,falschen Inders“ hat: sich zu maskieren, zu tarnen, um „die ganze Welt von ihm fernzuhalten“, trifft bei W. wie dem Basistypus generell auf Verständnis. ${ }^{93}$

Ausnahmen, in denen sonst als negativ evaluierte Verhaltensweisen ad personam positiv konnotiert werden, finden sich also hauptsächlich immer dann, wenn die in Frage stehende Figur eine selbst geneidete Aufführung zeigt (vgl. Ausschweifung, S. 140 u. S. 210; s.o.), die Stimmung der gutachtenden Figur es hergibt und vor allem: wenn die Figur eine entweder durch längere Bekanntschaft oder ad hoc geschätzte ist. Besonders auffällig ist die ,Nachsicht' mit Angehörigen des weiblichen Geschlechts:

\begin{abstract}
Abschaffel rauchte und sah umher. Sie waren mit Essen fertig. Sie entzündete ein Streichholz und blies es wieder aus, spitzte ein Ende des Streichholzes mit dem Messer an und pulte sich damit Essensreste aus den Zähnen. Die herausgeholten Reste hingen als kleine Klumpen an dem Streichholz; sie entfernte sie mit den Fingern und streifte sie am Tellerrand ab. Sie schwieg. Abschaffel überlegte, ob er ihr sagen sollte, daß er zur Zeit, bis morgen, noch Läuse hatte. Er schämte sich [...]. Margot spitzte sich ein zweites Streichholz und reinigte sich die obere Zahnreihe. Abschaffel wollte nicht mit ihr schlafen, solange er Läuse hatte oder deren Ausrottung andauerte. (Abschaffel, S. 133)
\end{abstract}

Sofern man denjenigen alternativen Erklärungsansatz außer Acht lässt, demzufolge die Scham Abschaffel den Mund verschließt, welcher aber unmittelbar im Anschluss an das Zitat durch beiderseitiges Lachen und Unbeschwertheit entkräftet werden würde, bleibt festzuhalten, dass es sich um eine nahezu romanspezifische ,Milde' der Hauptfigur handelt. Ein derart indiskretes,

93 Gegen Ende des Romans wird das finale Scheitern des Mannes erzählt, sodass die Verachtung die Überhand gewinnt (vgl. Fleck, S. 220 f.). 
442 - Teil II: Schlaglichter 4. Das Ich, die anderen und das andere: Inszenierung - Beobachtung Evaluation

unmanierliches, in der Öffentlichkeit zur Schau gestelltes Verhalten wird in der Regel harsch kritisiert ( $\Rightarrow$ II.4.2), hier hingegen entweder schlicht nicht thematisiert oder - wahrscheinlicher als geduldet präsentiert, da es sich um eine sehr teure Person handelt, deren Gesichtswahrung auch Abschaffel selbst am Herzen liegt. Damit sind gleich mehrere Bereiche angeschnitten, die das fünfte, folgende Schlaglicht konturieren: auf der einen Seite der Trend, zumal in mit ,Sex' etikettierbaren Lebenssituationen, antiemotional zu erzählen ( $\Rightarrow$ II.5.6); auf der anderen Seite die Neigung, Frauen aufgrund geringster Petitessen zu verurteilen und generell zu objektivieren ( $\Rightarrow$ II.5.3) sowie die Suspendierung üblicher Einschätzungen aufgrund personaler Faktoren. Denn für den intersexuellen Wettbewerb werden die harschen Evaluationen gelegentlich außer Kraft gesetzt ( $\Rightarrow$ II.5.4 u. $\Rightarrow$ II.5.5): „Er zögerte. Er konnte Fastnacht und alles, was damit zusammenhing [...] nicht gut aushalten. Aber weil die Stimmung zwischen Dagmar und ihm gespannt und besserungsbedürftig war, entschloß er sich, mit ihr zu gehen." (Falsche Jahre, S. 502)

Hinsichtlich des vierten Schlaglichts verbindet Wilhelm Genazinos Romanfiguren im harten Kern des Schichtenmodells ( $\Rightarrow$ I.2.5) die Anwendung offensiven IMs ( $\Rightarrow$ II.4.1), hauptsächlich in Ausprägung verletzender Kommunikation ( $\Rightarrow$ II.4.4). Ein weiterer omnipräsenter Faktor ist ihre regelmäßig verzerrte Wahrnehmung ( $\Rightarrow$ II.4.1 u. $\Rightarrow$ II.4.2), die es ihnen auf Basis von Überinterpretationen ermöglicht, zu denken, dass alles mit ihnen in Zusammenhang stehe $(\Leftrightarrow I I .4 .2)$. Auch das Hineinlesen eigener Makel und Merkwürdigkeiten in andere ( $\Rightarrow$ II.4.2), die dann bei diesen als Stellvertreter für die eigene ,Schwäche' verurteilt werden können ( $\Rightarrow$ II.4.3), sowie der damit verbundene Versuch, durch komparative Prädikatenzuweisung im Gegensätzlichen das Eigene finden zu können $(\Rightarrow$ II.4.1), ist dem Hardcore zuzuschlagen.

Direkt oberhalb, also im Innersten der Familienähnlichkeit, ist die Neurotizität zu verorten, die in zwei Ausprägungen vorliegt: cholerisch und melancholisch ( $\Leftrightarrow$ II.4.1). Zwar reflektieren die Figuren allenthalben ihre Evaluationen und bedenken sich vereinzelt auch mit Selbstkritik am Verhöhnen, aber das ändert nichts an deren Unerbittlichkeit: Herabsetzung, Überheblichkeit (bis ins Pathologische), Hochmut, Arroganz und Dünkel $(\Leftrightarrow$ II.4.1) prägen sie. Dass die ,begutachteten` Figuren häufig prädikative Charaktanten sind $(\Leftrightarrow I I .4 .1)$, streicht zudem die Egozentrik der Hauptfiguren heraus. Gründe für die Ablehnung und den Hass geben die Figuren etwa mit einer notwendigen Triebabfuhr ( $\Leftrightarrow$ II.4.4) an, aber auch die Mutmaßung, andere und anderes deswegen abzulehnen, um in der bewusst herbeigeführten Einsamkeit zu sich selbst zu kommen $(\Leftrightarrow$ II.4.1). Ein Figurenmerkmal ist besonders markant: Stimmungsschwankungen $(\Rightarrow$ II.4.2) beeinflussen ganz erheblich die Messlatten für die Evaluationen ( $\Rightarrow$ II.4.2 u. $\Rightarrow$ II.4.4) und führen in der Konsequenz dazu, dass mit mindestens zweierlei Maß gemessen wird: Mit geliebten Personen und allzumal Frauen geht der Genazino'sche Basistypus weniger hart ins Gericht $(\Rightarrow$ II.4.2). Besonders harsch werden hingegen Personen(gruppen) abgekanzelt, denen unterschiedliche 
Stigmata (Ethnie, sexuelle Orientierung etc.) die Vorurteile der Protagonisten einhandeln, die nicht selten rassistisch, homophob etc. genannt zu werden verdienen ( $\Rightarrow$ II.4.2). Zwar besteht ein großer Unterschied zwischen ausgesprochenen (seltener) und nicht ausgesprochenen sprachlichen Gewaltakten (häufiger), aber das Vorliegen von auch körperliche Gewalt potenziell einbeziehenden Rache- und Tötungsfantasien lässt für den Basistypus begründet autoritäre Persönlichkeitszüge ( $\Rightarrow$ II.4.4) vermuten. Am äußeren Rand der mittleren Figurenschicht ist die folgende Facette zu verorten: Höchst selten bleiben ambivalente Einschätzungen bestehen ( $\Rightarrow$ II.4.2), was sich aus der Vorliebe für zumeist starres Schubladendenken und dem Hang zu Allgemeinurteilen erklären lässt $(\Rightarrow$ II.4.2).

Gehört das prinzipielle Goutieren von anderen hinsichtlich ihrer Lebensweisen und Inszenierungen (gerade) noch in die Sphäre des Basistypus, so ist die direkte und unumstößlich positive Evaluation dessen bereits ein Romanspezifikum ( $\Rightarrow$ II.4.5). Weiterhin als Alleinstellungsmerkmal kann die Milde gelten, die bei für gewöhnlich als Tabu empfundenen Verhaltensweisen wirksam wird ( $\Rightarrow$ II.4.5). 


\section{Liebe und Sexualität}

„Selbstverständlich hatte in meinem Leben der gute Beischlaf einen dreimal höheren Wert als das gute Gespräch." (Tiere, S. 116)

Das ,Balzverhalten' nimmt in Genazinos Romanen sehr unterschiedliche Ausformungen an. ${ }^{1}$ Von stürmischem Bedrängen über lange Entfaltungszeiten bis hin zu subtilem Taktieren reicht der Variantenreichtum. Dementsprechend handelt es sich hier - anders als bei den Schlaglichtern zwei bis vier, denen, in der Reihenfolge, protektives, assertives und offensives IM als Handlungsstrategien zu Grunde liegen - um gemischte Strategien. Das liegt bei einem derart diversen Themenkomplex freilich nahe: Es wäre schon hochgradig frappierend, wenn der Genazino'sche Figurenbasistypus , auf dem Schlachtfeld der Liebe' mit den immer gleichen Taktiken und Techniken nur einer Strategie zu reüssieren versuchte.

Sind die häufig vom Mann ausgehenden Beischlafversuche in den älteren Romanen stets von immenser Selbstsicherheit getragen und führen prompt zum Erfolg, problematisieren die neueren Texte zunehmend die Transitorik der Schwellenmomente von Gelingen oder Scheitern einer Annäherung. ( $\Rightarrow$ II.5.2) Auch dezidierte Abweisungen seitens der jeweiligen Frau werden ins Repertoire dieses Narrativs aufgenommen. ${ }^{2}$ Warum genau es nicht zum Geschlechtsverkehr kommt, wird unterschiedlich dargestellt: Manchmal werden die Gründe benannt, manchmal verschwiegen, in jedem Fall aber von der männlichen Hauptfigur als starker Affront gewertet, was nicht selten in wortlose (teils lediglich temporäre und lokale) Trennungen mündet.

Kaum sind es die Frauen, die die männlichen Hauptfiguren betrügen, sehr häufig ist es die männliche Hauptfigur, die entweder zwischen zwei oder mehreren Frauen steht, regelmäßig im engeren Sinn untreu und nur sehr selten zufrieden mit nur einer Frau ist ( $\Rightarrow$ II.5.2). Extraordinäre manifeste Liebeserklärungen oder -werbungen sucht man bei Genazino ebenso vergebens wie den offenen ,Kampf' mit dem früheren, gegenwärtigen oder potenziell künftigen Rivalen. Allerdings scheint sich diese Bestandsaufnahme dadurch erklären zu lassen, dass fulminantes Agieren in Liebesangelegenheiten weder im intra- noch intersexuellen Wettbewerb wirklich nötig erschiene ( $\Rightarrow$ II.5.4): Im intrasexuellen schneiden die Protagonisten in der Regel auch ohne offene Konfrontation ,besser' ab als die Kontrahenten - das tadelnswerte Attribut Nummer eins, das den gehörnten Nebenbuhlern seitens der Frauen zugeschrieben wird, ist ,langweilig' - und sind für gewöhnlich ohne Gegenwehr in der Lage, die Frauen für ihre Wünsche zu gewinnen. Sollte sich die Frau einen neuen Partner suchen, dann wird das für gewöhnlich heruntergespielt: „Es

$1 \quad$ Vgl. etwa den Kontrast von der Abschaffel-Trilogie hin zur Liebesblödigkeit.

2 Die Unlust der Frau wird etwa in der Ausschweifung, S. 250, allerdings geschickt umgewidmet: Plötzlich ist es Eckhard, der keine Lust mehr empfindet - wie er sagt -, um die Zurückweisung für sich zu verarbeiten. 
machte ihm nichts aus, Dagmar von einem anderen Patienten umarmt zu sehen. Wahrscheinlich kam dieser Patient besser mit den Fastnachtsumtrieben zurecht als Abschaffel." (Falsche Jahre, S. 515) Seltener wird im Zuge dessen auch mit dem Konzept der Eifersucht gearbeitet, etwa wenn der Ich-Erzähler im Regenschirm mutmaßt, ob Himmelsbach auch bei Margot war (vgl. Regenschirm, S. 89 f.) und ob diese der „Gelegenheitsprostitution“ (Regenschirm, S. 91) nachgeht. Im intersexuellen Wettbewerb fruchten wie gesagt selbst die halbherzigsten Annäherungsversuche zumeist. Häufig wird dabei prinzipiell davon ausgegangen, dass die Frauen ,verfügbar‘ und ,frei` seien, selten dieses Vorurteil reflektiert:

Daran hatte er keine Sekunde lang gedacht: daß Christine einen Freund haben könnte, der womöglich sogar in derselben Filiale arbeitete wie sie. Vielleicht waren sie sogar verheiratet. Sollte er nach Hause gehen und ganz schnell alles vergessen? Eckhard sah den beiden nach. Sie unterhielten sich aufmerksam, vermieden aber jede körperliche Berührung. Daraus schloß er vorläufig, daß sie vielleicht doch nur Kollegen waren, die lediglich denselben Weg vor sich hatten. (Ausschweifung, S. 181)

Damit ist das weite und nicht nur für Genazino wichtige Feld der Gender Studies umrissen, dem unter $(\Rightarrow I I .5 .3)$ nachgegangen werden wird.

Obwohl es mitunter zu relativ drastischen Schilderungen des Aktes kommt und in der Tendenz auch an der Schwelle zur Pornografie gekratzt wird ( $\Rightarrow$ II.5.5), ist die sprachliche Verpackung, das ,Sprachgewand der Liebe' bei Genazino ein regelmäßig unterkühltes, antiemotionales ( $\Rightarrow$ II.5.6). Diese Kontrastierung der Histoire-Ebene durch den Discours findet sich ganz deutlich auch hinsichtlich der Thematiken ,Prostitution' $(\Rightarrow I I .5 .5)$ sowie ,Alter(n) und Körper' $(\Rightarrow$ II.5.6).

Bevor dieses vielfältige Spektrum an Perspektiven je en détail untersucht werden kann, müssen in zwei Schritten zunächst die wichtigsten Rückbezüge zu den bereits geschürften Ergebnissen für dieses Schlaglicht fruchtbar gemacht werden ( $\Rightarrow$ II.5.1), um danach die bei Genazino verhandelten Liebeskonzepte und die mal mehr, mal weniger im Hintergrund wirksamen Grundannahmen der Figuren hinsichtlich Beziehungsmodellen etc. aufarbeiten zu können $(\Leftrightarrow$ II.5.2).3

\subsection{Rekurs: von Liebeslügen und „dem Paarungsdrang eines Maikäfers“}

Zumal das fünfte Schlaglicht dieser Arbeit ist eng an die vorangegangenen geknüpft. ${ }^{4}$ Diese intratextuellen Rückbezüge, die sowohl Figurenfacetten als auch Verhaltensstrategien betreffen,

3 Dieses Vorhaben wird in einigen Kapiteln $(\Rightarrow$ II.5.2, $\Rightarrow$ II.5.3 u. $\Rightarrow$ II.5.6) zunächst durch einen genaueren Blick auf Genazinos Die Liebesblödigkeit erfolgen, bevor die Betrachtung des Genazino'schen Basistypus jeweils wieder in den Fokus rückt.

$4 \quad$ Das betrifft neben Figurendispositionen und motivationalen Untersuchungsfeldern, welchbeide im Fließtext ausführlicher rekapituliert werden, auch bereits getätigte Unterscheidungen wie die nach ,Realitätsebenen' $\Leftrightarrow$ II.3.1 u. $\Rightarrow$ II.4.2). Auch für das Feld der Liebe muss nämlich unterschieden werden in ,lediglich' in der Fantasie bzw. der Erinnerung erfolgende und in der Diegese realiter in actu sich ereignende Handlungen: „Und er half ihr wirklich, er wusch ihr den Rücken und den Busen, und es gefiel ihr endlos." (Abschaffel, S. 101) Es handelt sich, im Gegensatz zum ersten Eindruck, lediglich um eine erotische Fantasie. Vgl. auch Sorgen, S. 326 ff. 
sollen im Folgenden kurz aufbereitet werden. So treten etwa die Parallelen, die hinsichtlich der Lüge bzw. Verstellung auftreten ( $\Rightarrow$ II.1.2 u. $\Rightarrow$ II.2.4), deutlich zu Tage:

Wenn Carola mich fragte, warum ich von den Orangen nicht lassen konnte, dann sagte ich, dass mich die Orangen an ihre schönen großen Brüste erinnerten, was nicht der Wahrheit entsprach, aber ich sagte es trotzdem, weil ich wusste, dass auch Carola übertriebene Komplimente schätzte. (Außer uns, S. 73) $)^{5}$

Ganz im Sinne der allgemeinen ,kleinen Lüge‘ ( $\Rightarrow$ II.1.2) wird deren Funktion hier auf das Feld der Liebe zugeschnitten. Verhältnismäßig unverfänglich - wenngleich genderproblematisch ( $\Rightarrow$ II.5.3) - nimmt sich dies aus, insofern keine verletzenden und/oder moralisch bedenklichen Hintergedanken den Impuls geben, wie es auch das folgende Beispiel aus Laslinstraße zeigt:

Elke deutete mit dem Zeigefinger auf irgendeinen Schirm, der in meinen Augen keine einzige Eigenschaft hatte, die ihn von den anderen Schirmen hätte abheben können, aber ich, Axel, konnte wieder das nicht sagen, was eigentlich hätte gesagt werden sollen, ich, Axel, ich sagte: „Er gefällt mir auch gut." (Laslinstraße, S. 164)

Indem Axel Degen aus Gründen der Opportunität seine tatsächliche Ansicht über den ,Schirm ohne Eigenschaften` zurückhält, begibt er sich sogar in den ,positiven' Bereich der inneren Zensur ( $\Rightarrow$ II.2.6): Um im ,vorauseilenden Gehorsam‘ mögliche - nota bene: lediglich antizipierte! Disharmonien bzw. Dissonanzen zu meiden, wird im weiteren Textverlauf auch mal ein ,Ja' zu einem ,Nein': „,Ja', antwortete ich, aber in diesem Augenblick wurde mir klar, wie schrecklich es sein würde, in Zukunft Ja zu sagen und Nein zu meinen." (Laslinstraße, S. 198) Es spricht einiges dafür, dass dieser vergewisserte ,Schrecken“ für Degen denjenigen Wendepunkt markiert, an welchem er den internen Entschluss zum Beziehungsende fasst, sich dadurch gleichsam frei macht vom Verstellzwang und die innere Zensur in Zukunft gerne selbst beschneiden möchte. Damit kann von der kleinen Lüge, die quasi als gesellschaftliches Schmiermittel funktionalisiert wird, nicht mehr die Rede sein. Und tatsächlich meldet sich die (Doppel-)Moral als innere Stimme: ${ }^{6}$, Ist was mit dir? Du bist so schweigsam?' ,Nein', sagte ich, ,nichts', und ich konnte diese beiden Worte so sagen, daß sie das mißtrauenlose Geschöpf Elke glauben konnte, ohne einen zweiflerischen Rest in ihr zurückzulassen." (Laslinstraße, S. 212)

Ganz ähnlich prangert sich der freie Architekt aus Genazinos Roman Wenn wir Tiere wären selbst an, was seinen sonstigen Fähigkeiten zur punktgenauen Selbsteinschätzung entspricht: „Maria konnte nicht erkennen und nicht fühlen, dass ich im Inneren ein Finsterling war, der sie eines Tages verlassen würde." (Tiere, S. 31) Eine entsprechende ,Schwere der Tat' - schließlich

5 Ähnlich gelagert: „ob es nicht vorteilhafter wäre, die Prokuristengeschichte vorerst für sich zu behalten. Und eines Tages, wenn Ruth ihn wieder einmal auf seine Liebesmüdigkeit ansprach, konnte er seine Enttäuschung über die Firma als den großen Grund hinstellen, der an allem schuld war." (Ausschweifung, S. 293)

6 Dass (nicht nur) Axel Degen prinzipiell gegen verstecktes Agieren eingenommen ist ( $\Rightarrow$ II.1.2), äußert er mit den Worten: „[A]ber ich konnte mich nicht dazu bringen zu zeigen, daß ich zu ihr wollte, es mußte einen zufälligen Anstrich erhalten, es durfte nicht gewollt erscheinen, ich fand dieses Versteckspiel überflüssig, aber es war nicht zu umgehen." (Laslinstraße, S. 83) 
,weiß' der Protagonist ja um seine moralisch ,finstere‘ Täuschung, leitet daraus aber keine Konsequenz ab - hat die Verstellung inne, wenn Abschaffel die abwertende Einschätzung einer momentanen Sexualpartnerin als „geschmacklose Angestellte“ vornimmt und hinzusetzt: „Noch wenn sie sich auszog und ihr Kleid auf einen Sessel legte, erklärte sie weitschweifig, was dieser und jener heute im Büro zu ihr gesagt hatte. Sie ließ sich gern von hinten beschlafen, und das war der Grund, warum Abschaffel über die Zeit mit ihr zusammenblieb." (Abschaffel, S. 40)7 Mit diesem häufiger variierten Motiv, lediglich aufgrund bestimmter sexueller ,Vorzüge', die den sexuellen Wünschen und Vorlieben $(\Leftrightarrow$ II.5.5) des Basistypus entgegenkommen, mit einer Partnerin zusammenzubleiben, ist einmal mehr das Untersuchungsfeld geschlechtsrollenstereotyper Figurenzeichnungen vorgezeichnet $(\Leftrightarrow$ II.5.3).

Die Lüge spielt für dieses Schlaglicht allerdings noch in zweierlei anderer Hinsicht eine Rolle. Und zwar erstens, wenn es um das Lügen anderer Figuren geht: „Abschaffel lachte und sagte: Das ist gelogen, Frau Schönböck, das glaube ich Ihnen nicht. [...] Sie konnte banale Ereignisse aus ihrem Leben nicht erzählen, ohne sie durch ein paar Lügen nicht erträglicher gemacht zu haben.“ (Abschaffel, S. 11) Dadurch, dass Abschaffel Frau Schönböck widerspricht, gibt diese letztlich zu: „Also gut, sagte sie, ich fand ihn nett, und warum sollte man dann nicht, das haben Sie selbst schon öfter gesagt, Herr Abschaffel.“ (Abschaffel, S. 12) Diese spielerische Variation der sonst tendenziell eher auf Tragik(omik) setzendenden Entlarvungen der brüchigen Selbstentwürfe anderer $(\Leftrightarrow I I .4 .3)$ übernimmt an dieser Stelle die narrative Funktion, dass Frau Schönböck im Gesprächsverlauf noch weitere Intimitäten preisgeben wird und ihre prinzipielle Empfänglichkeit für die Werbungen Abschaffels signalisiert: „(Sie mußte immer lachen, wenn er sie wieder einmal beim Lügen erwischt hatte.)“ (Abschaffel, S. 12) Zweitens findet die Lüge dann Anwendung, wenn der eigene Selbstentwurf des Schutzes bedarf ( $\Rightarrow$ II.2.4): Als Maria, der der namenlose Ich-Erzähler unterstellt, sie „wollte vermutlich schwanger werden und heiraten und sich verschlingen lassen von ihrer Rolle als liebevolles Hauswesen, welches Leben empfing und Leben zurückgab und neues Leben auf die Welt brachte, und zwar irgendwie unaufhörlich“, diesen einmal mehr „übertölpelt“, indem sie ihn sehr forsch zum Geschlechtsverkehr drängt,

griff ich zu einem Mittel, das in den Bereich der Notwehr fiel und das ich schon öfter angewandt hatte. Ich simulierte einen Samenabgang. [...] Nach einiger Zeit stöhnte ich ein bisschen herum und verlangsamte meine Bewegungen, so dass für Maria der Eindruck entstand, ich hätte kurz zuvor eine ausreichende Menge Samen abgegeben. (Tiere, S. 44 f.)

Die Neigung zu zwar durchaus originellen, aber nichtsdestoweniger etwas ,um die Ecke gedachten' Eindruckssteuerungsvarianten sind für Genazinos Figuren bereits thematisiert worden. Ist

7 Abschaffels Verschlagenheit gerät diesem selbst immer wieder in das Bewusstsein: „Wenn die wüßte, auf welch eine elende Weise ich zu meiner Zärtlichkeit komme! dachte er." (Abschaffel, S. 86) 
es hier die Selbstwirksamkeit ( $\Rightarrow$ II.1.3), die über eine Täuschung realisiert wird, ${ }^{8}$ ist das kommende Beispiel anders gelagert, aber im Ansatz, das eigene Selbst zu stützen und zu schützen, durchaus vergleichbar:

Alles hätte ein Ende nehmen können, wenn er ins Telefon gesagt hätte: Es ist gut, in einer halben Stunde bin ich da. Aber das tat er gerade nicht. [...] Abschaffel sprach eine ganze Anzahl undeutlicher, verwirrter Sätze in den Hörer, an deren Ende weder ein Ja noch ein Nein stand. Dennoch war es die Aufgabe der Frau am Telefon gewesen, seinen Sätzen ein Nein zu entnehmen und zu erraten, daß er müde und lustlos sei und nicht könne und alles und überhaupt. (Abschaffel, S. 32 f.)

Zwar versetzt Abschaffel ,die Frau', denn „[n]atürlich war am Telefon eine Frauengeschichte“ (Abschaffel, S. 33), zumindest der Intention nach in Unsicherheit und bedient sich damit offensiver IM-Techniken $(\Rightarrow$ I.3.3 u. $\Rightarrow$ II.4.4). Aber die überpointierte Zusammenfassung seiner mentalen Konstitution - „müde und lustlos [...] und alles und überhaupt“ - mag als Erklärungsansatz dafür herhalten, dass Abschaffel gerade nicht eine klare Aussage trifft, sondern den Weg der Vagheit geht, was an dieser Stelle erzähltechnisch trefflich durch eine „weniger reine Form der Raffung“ realisiert wird, „aber immer noch ein Fall von erzählter Figurenrede“ mit ihrer typischen Distanzwahrung im narrativen Modus ist. ${ }^{9}$

Bereits in den Beispielen weiter oben wurde die Nähe zwischen Lüge bzw. Verstellung und innerer Zensur behauptet. Die folgenden Beispiele zeigen, dass Letztere tatsächlich beträchtliche Teile auch des Beziehungs- und Liebeslebens der Figuren dominiert: „Aber Sonja schätzte es nicht, wenn sie wie meine Mutter nach etwa zwei Stunden aufwachte und dann allein war. Also blieb ich im Bett und sorgte mich, dass ich diese Duldsamkeit vielleicht nicht für alle Zeit aufbringen würde." (Regen, S. 13) ${ }^{10}$ Dem eigentlichen Wunsch des Protagonisten, die Wohnung für einen Spaziergang zu verlassen, kann nicht nachgegeben werden, was einen herben Einschnitt in dessen Handlungsfreiheit bedeutet. In anderen Beispielen ist die innere Zensur durchaus nicht so versagungsgesättigt, sondern eine kalkulierte Notwendigkeit, um negative Reaktionen abzuwiegeln: „Allerdings würde Elisa darauf bestehen, die ganze Geschichte zu erfahren, und ich wäre töricht genug, sie ihr auch noch zu erzählen. Daraufhin würde sie böse werden [...]. Ich schreibe ihr keinen Brief" (Licht, S. 60).

Gelegentlich erscheint die innere Zensur auch im Gewand einer quasi-didaktischen Erwägung. So etwa, wenn der Ich-Erzähler aus Genazinos Roman Außer uns spricht niemand über uns seiner Freundin zur Last legt, diese nehme seine Bedürfnisse nicht wahr: „Ich hoffte, Carola werde bald bemerken, dass ich auf sie wartete. Aber sie saß vor dem Fernsehapparat [...]. Meine Stimmung rutschte in einen nie gesehenen Keller." (Außer uns, S. 7; vgl. Kein Geld, S. 70) Der Erzähler stellt

$8 \quad$ Vgl. für eine Abwandlung dieser Taktik auch Peschek, der seinen Samen gern für sich behält, um „Dagmar in einer Stunde mit neuer Kraft zu überraschen. Dann wandelte sich sein Niederlagengefühl wollüstig um, und er kam sich als heimlicher Gewinner vor." (Fremde Kämpfe, S. 222)

$9 \quad$ Martínez/Scheffel: Einführung in die Erzähltheorie, S. 52.

10 „Ich hielt es für ein gutes Zeichen, dass mich Sonja an meine Mutter erinnerte, was ich ihr nicht sagte. Ich fürchtete, es würde ihr nicht gefallen, jetzt schon meiner üppigen Mutter zu ähneln." (Regen, S. 13; $\Rightarrow$ II.5.2) 
Carola (öffentliche Selbst-)Aufmerksamkeit in Rechnung, die diese innerhalb der von Schweigen, Sprachlosigkeit und Missverständnissen geprägten Beziehung allerdings nicht erübrigen kann oder will. Im zweiten Schlaglicht ist die öffentliche Selbstaufmerksamkeit $(\Leftrightarrow I$ I.2.4) als Grundvoraussetzung der inneren Zensur $(\Rightarrow$ II.2.6) beschrieben worden. In welchem Maß diese Figurendisposition auch in das fünfte Schlaglicht strahlt, zeigt neben dem vorangegangenen Zitat exemplarisch der Roman Das Licht brennt ein Loch in den Tag:

Sonntag für Sonntag verließen eine Menge hübscher Mädchen das Kino; warum mußte ich mich ausgerechnet mit der beschädigten Judith anfreunden? Ich konnte niemandem sagen, daß die Zahnspange mein Glück mit Judiths Brüsten nicht beeinträchtigte, und ich konnte noch weniger sagen, daß ich rasend darum besorgt war, es könnte dieses Glück auch von anderen entdeckt werden. Insofern war ich mit der Zahnspange zufrieden. Sie schreckte alle Konkurrenten ab. Allerdings brachte diese Beschwichtigung schon bald ein Zerwürfnis mit mir selber hervor. Ich begann, mich meiner Liebespolitik wegen zu verurteilen. Beziehungsweise ich war entsetzt über die Entdeckung, daß es Liebespolitik überhaupt gab und daß ich eine solche betrieb. (Licht, S. 83) ${ }^{11}$

Als verhaltensstrategischer Ableger der assertiven IM-Technik ,basking in reflected glory' ist den Figuren daran gelegen, dass nicht der unliebsame, ,schlechte‘ Ruf respektive das negative Bild, das die Gemiedenen in der Öffentlichkeit genießen, auf die Hauptfiguren abfärben möge $(\Rightarrow$ I.3.3).12 Mithin elaborieren die Figuren eine assertive Technik zu einer defensiven um: Positiver Eindruck soll über das Fehlen des negativen bewerkstelligt werden, und zwar in der Reformulierung von Schütz „by [not] associating oneself with others who are evaluated [negatively]“.13 Entfernt klingen damit Motive wie der ,standesbedingte Liebeskonflikt' an:14 Eine Figur erachtet eine andere aufgrund oberflächlicher Makel als ihrer nicht würdig bzw. knickt vor dem gesellschaftlichen Werturteil ein. Zwar handelt es sich bei Genazino freilich nicht um Standesdünkel, von Dünkel darf bezogen auf die Figurendisposition der Überheblichkeit aber durchaus gesprochen werden: „Alles, was nun ablief, war für Abschaffel von widerwärtiger Geläufigkeit und wurde deshalb von ihm abgelehnt." (Abschaffel, S. 84) Der Überdruss verleiht hier der Überheblichkeit Kontur: Nicht nur die Tatsache, dass Abschaffel Frau Schönböcks (sprechender Name!) Verhalten - „neu geschminkt, frisiert und eingeduftet“ (Abschaffel, S. 84) - selbstgefällig sofort als Einladung, die Nacht mit ihr verbringen zu dürfen, durchschaut, sondern allzumal der Kreis an Frauen, der dazu geführt haben muss, dieses Skript, das man als ,Frau bietet sich Abschaffel zur sexuellen Verfügung an' beschreiben könnte, zu verinnerlichen, zeugt von Überheblichkeit. Auch Ws Einstellung in Bezug auf Einzigartigkeit vs. „widerwärtiger Geläufigkeit“ ist aufschlussreich: „Erst zwei Tage später ist mir eingefallen, daß ich vor etwa zwei Jahrzenten ein paarmal mit Isolde geschlafen habe. Es war mir rätselhaft, beziehungsweise: Ich schämte mich,

11 Später im Romanverlauf, verrät' er Judith, da er dem Druck des Urteils der anderen nicht standhalten kann (vgl. Licht, S. 98 f.).

12 „Frau Hannemann galt als alte Frau, und es würde kein vorteilhaftes Licht auf ihn werfen, wenn er sich ausgerechnet mit ihr von den anderen trennte." (Sorgen, S. 354)

13 Schütz: Self-Presentation, S. 614. Diese Verfahren ex negativo - Gesundheit ist das Fehlen von Krankheit - sind zwar zutiefst menschlich, aber nicht wirklich nachhaltig. 
weil ich mich nicht sofort erinnert hatte." (Licht, S.9) Zwar muss sowohl eine potenzielle schlechte Erinnerungsgabe in Betracht gezogen werden als auch die Scham als, entschuld(ig)endes Korrektiv‘ in den Blick genommen werden, aber während des diesem Ausschnitt vorangegangenen persönlichen Treffens, sind Bedeutungsanteile der (ungewollten) Überheblichkeit zumindest in der Rezeptionsperspektive Isoldes vorhanden:

Isolde gehört zu den Frauen, die bemerken, ob ein Mann mit oder ohne Erinnerung zu ihnen spricht, und weil ich etwa fünfzehn Minuten lang ohne Erinnerung gesprochen beziehungsweise zugehört habe, war ich für die Dauer der Theaterpause ein erinnerungsloser und deswegen gespenstischer und lächerlicher Mensch gewesen. Isolde hatte vermutlich nicht einen Tag und nicht eine Einzelheit unserer Geschichte vergessen. (Licht, S. 9)

In anderen Romanen finden sich wörtliche Benennungen dieser Figurenfacette auch in Hinblick auf das hier untersuchte Schlaglicht: „Außerdem ist der periodisch auftauchende Gedanke an eine neue Frau ein entsetzliches Lebenslaufklischee, mit dem meine biografische Überheblichkeit nichts zu tun haben möchte.“ (Glück, S. 133) Im Grenzbereich zwischen Selbst- und Idealbild $\Leftrightarrow$ II.2.1) verfolgt Warlich auf seiner Suche nach ,einem anderen Leben' die Strategie, vermeintlich Banales vom Entwurf seines Idealbildes abzugrenzen. Das umfasst sowohl Anteile von Überheblichkeit als auch von Interessantheit, liegt es Warlich doch weitaus eher als früheren Figuren, Witz und Komik unter Beweis zu stellen (vgl. Glück, S. 58 f.). Strategien der Interessantheit bzw. Auffälligkeit ( $\Rightarrow$ II.3.1) haben generell bei der Partnersuche einen hohen Stellenwert:

Auf dem Sommerfest würden bestimmt ein paar in Frage kommende Frauen herumflirren und Nachtfalterblicke aussenden. Ich fürchtete mich vor meinen humoristisch gemeinten Reden, die sich bei solchen Anlässen unangenehm in den Vordergrund schoben. Ich hörte mich schon jetzt, wie ich zu einer alkoholisierten Frau sagte: Ich habe den seriösen Paarungsdrang eines Maikäfers und biete problemfreie Anhänglichkeit. Am liebsten wollte ich mich nach solchen Sätzen selber ohrfeigen, wenn derlei nicht noch peinlicher gewesen wäre. (Außer uns, S. 127)

Wenngleich es dem namenlosen Ich-Erzähler zur Peinlichkeit gereicht, dass sich seine „humoristisch gemeinten Reden“ Bahn brechen könnten, sind dessen an der Grenze zur Angeberei befindlichen Worte generell durchaus tauglich, um (auch nüchterne) Sexualpartnerinnen zu akquirieren: „Carola ließ mich spüren, dass sie von meinen Sätzen beeindruckt war. Sie atmete wie früher langsam ein und aus und wartete, dass ich weiterredete." (Außer uns, S. 16) Dass sich die Frauen gerne im Abglanz der männlichen Figuren aufgrund deren Wichtigkeit sonnen, zeigt auch ein Blick auf den Roman Ein Regenschirm für diesen Tag: „Susanne wird die Welt der Zeitung überschätzen und sich an meiner Seite endlich selber bedeutsam vorkommen." (Regenschirm, S. 123)

Dem Figurenbasistypus steht eine ganze Klaviatur der Interessantheit im Bereich der Liebe zur Verfügung; sie reicht von überraschend ehrlichen und dennoch interessanten Tönen (vgl. $A b$ schaffel, S. 140), über schlagfertige und witzige (vgl. Abschaffel, S. 12 f.) sowie tiefgründige Oktaven (vgl. Falsche Jahre, S. 498) bis hin zu kalkuliert-pompöser Überrumplung (vgl. Fremde Kämpfe, S. 101). Aber auch ganz unprätentiös-jugendlich funktionieren diese verbalen Bezirzungen, 
etwa dann, wenn Wolf Peschek eine Bekannte fragt, „ob sie früher auch so gern an Schulausflügen teilgenommen hätte. Bald nach diesem Anruf war sie seine Freundin." (Fremde Kämpfe, S. 14) Von erzähltheoretischer Warte aus ist natürlich die Ellipse bemerkenswert, die es dem Leser überlässt, den Kausalzusammenhang von dem lediglich in Form eines Gesprächsberichts erwähnten Telefonat und der Beziehungsinitiation herzustellen.

Wie hinsichtlich der Schnittfläche Interessantheit-Sex bereits einmal zusammengemixte Motive am Mischpult $(\Leftrightarrow I .2 .2)$ mit der Zeit umgewandelt werden, zeigt ein diachroner Blick auf die Romane Laslinstraße und Ausschweifung:

Plötzlich der Gedanke: Gefiel ich ihr vielleicht? Ich, Axel, der Tapetenliebhaber, der aus dem Wohnzimmer [...] morgen, überlegte ich, morgen werde ich aufpassen, meinen Kopf ein bißchen nach rechts drehen, damit ich gleich sehen würde, wenn sie mich, Axel, den Langsamen, überholte. Sicher wird sie es morgen wieder eilig haben, dachte ich, aber ich werde dann auch schneller gehen. Auffallen sollte es nicht. (Laslinstraße, S. 30)

Zwischen Minderwertigkeitsgefühlen, aufkeimendem Selbstbewusstsein und dem sprießenden Gefühl von Selbstwirksamkeit changierend wird dieses Muster im Falle von einem späteren Protagonisten bearbeitet: Eckhard Fuchs

grüßte freundlich und sprach von ihrer Geschwindigkeit. Ich gehe immer so schnell, sagte sie und verlangsamte ihr Gehen. Wenn Sie so schnell gehen, dann haben Sie doch sicher ein bißchen Zeit übrig, mit mir eine Tasse Kaffee zu trinken? Eckhard fand, daß er sein Anliegen geschickt, ja fast elegant vorgebracht hatte. (Ausschweifung, S. 183)

Wenn man so möchte, ist dies intratextuelle Umarbeitung von einem gemeinsamen Fundus an schilderbaren Erinnerungen aus einem produktionsästhetisch gedachten Zettelkasten bzw. Mischpult respektive ,Ich-Substanz-Garten` $(\Rightarrow$ I.1). Im zweiten Beispiel jedenfalls steht IM mit Kalkül und gelungener Interessantheit im Vordergrund.

Dass dabei in Liebesangelegenheiten die non- und paraverbale Kommunikation mindestens ebenso wichtig ist wie die verbale, ist offensichtlich. Bezeichnenderweise überlappen sich die Bereiche ,Sex' und ,Körpersprache‘ bemerkenswert breit. Während die Gehgeschwindigkeit in den vorangegangenen Passagen gleich mehrfach funktionalisiert und neben der strukturalistischen Engführung von Tempo und Charakterzug auch als ,Anmache‘ ausgewiesen wird, erhält es als Grundmotiv der folgenden Szene gleich mehrere weitere Aspekte von Körpersprachlichkeit und Paraverbalem zur Seite gestellt: „Manchmal sah ich während des Gehens zu ihr herüber und lächelte ihr zu, nein, ich kontrollierte ein bißchen, ob sie mir zuhörte oder ob ich sie langweilte." (Wohnung, S. 15) In der linguistischen Gesprächsanalyse sind Hörersignale ein wichtiger Garant für funktionierende Kommunikation. ${ }^{15}$ Hier wird durchaus strategisch unter dem Deckmantel zu lächeln das eigene Verhalten am nichtsprachlichen Feedback des Gegenübers austariert. Wie bereits verhandelt $(\Leftrightarrow$ II.1.4) scheint auch bei der mit Liebe in Beziehung stehenden Verhaltensweisen der außersprachlichen Sphäre ein hohes Maß an Verständigungspotenzial beigemessen 
zu werden: Der auf den ,aktiv-gebenden` Part des männlichen Sexualpartners bereitwillig hörende Frauenkörper ,versteht” dessen Wünsche und Drängen: „Frau Kiefers Körper verstand sofort. Die Beine öffneten sich wieder, und Frau Kiefer rutschte mit dem Hinterteil ein Stück nach vorne.“ (Wohnung, S. 69) Genauso unhinterfragt: „Mein Geschlecht ist vor mir wach, ich dränge mich an Sandra heran, sie versteht sofort. Eine halbe Minute später stecken wir ineinander." (Liebesblödigkeit, S. 15) Lässt man die späterhin auszulotende Problematik in dieser Typisierung zunächst außer Acht ( $\Rightarrow$ II.5.3), so kann man schlicht zwei sich wortlos verstehende Körper in Bewegungsharmonie am Werk sehen. Dass die nonverbale Kommunikation der verbalen mitunter überlegen ist, bestätigt auch die täuschende und zugleich kommunikativ-erfolgreiche Verwendung derselben: „Dann würde ich sie von hinten umarmen, so dass ihre Brüste in meinen Händen lagen und die Frage, was mir fehlte, geklärt wäre, jedenfalls für Carola. Ich war gemein, ich tat so, als wären meine Probleme lösbar." (Außer uns, S. 12) Der autodiegetische Erzähler setzt - im Glauben, wenn Worte versagen, helfe die analoge Kommunikation - gezielt körperlichen Ausdruck ein, um einen bestimmten Eindruck bei Carola hervorzurufen und reflektiert diese Täuschung als „gemein“.

Allerdings dringt die appellative ,Aussagefunktion' (v. Thun) nicht immer bis zum entsprechenden Ohr bzw. sind auch in puncto Körpersprache mögliche Missverständnisse bzw. die Vagheit des Ausdrucks zu bedenken: „Elke drängte sich enger an mich, ich glaube, es entstand in ihr ein ungewisses Angstgefühl vor einer Instanz, in diesem Augenblick aber auch ein stärkeres Zugehörigkeitsgefühl zu mir. Sie sagte nichts, ich spürte nur den festeren Griff ihrer Arme." (Laslinstraße, S. 167) Ob letztlich Angst oder Zugehörigkeitsbedürfnis Elkes Griff intensivieren, ist nicht einwandfrei zu entscheiden; Degen mutmaßt begründet auf der Basis seiner eigenen Einschätzung der Situation. Ein vergleichbares Beispiel: „Karin henkelte sich bei mir ein, worin ich eine deutliche Annäherung erkennen wollte." (Tiere, S. 27) Bereits auf erzähltechnischer Ebene ist der Zweifel im „wollte“ als Einsicht in die relative Gültigkeit der eigenen Wahrnehmung und immer auch als Allusion auf unzuverlässiges Erzählen ( $\Rightarrow$ I.2.3) geformt. Dennoch ist zumal auf die Liebe bezogen die Konsequenz, die Deutungsarbeit einzustellen, keine Option, da sich allenthalben zwangsläufig codierte und mehr oder minder decodierbare Zeichengebungsprozesse beobachten lassen $(\Rightarrow$ II.2.3), deren Interpretation ein ,notwendiges Übel' darstellt:

Linda ging auf die Toilette und kehrte mit leicht geschminkten Lippen zurück. Ich überlegte, ob die Schminke eine versteckte Aufforderung an mich sein sollte, mit ihr das Lokal zu verlassen. Ich wußte nicht, was ich mir einbilden durfte. [...] Ich wollte Linda küssen, heute abend noch. Aber ich wollte mich auf keinen Fall offenbaren und dann zurückgewiesen werden. (Wohnung, S. 102) ${ }^{16}$

Das, was sich für die Wichtigkeit der Körpersprache allgemein festhalten lässt, ist auch für das Metier von Gegenständen bzw. Wohnungseinrichtung, vor allem aber auch das der Kleidung

16 Degen ist sich diesbezüglich sicherer: „[I]ch betrachtete Elke, sie hatte sich zurechtgemacht für die zweite Hälfte des Abends, Lippenrot erneuert“ (Laslinstraße, S. 188). 
( $\Rightarrow$ II.1.5) gültig: „Im allgemeinen überschätzen Frauen die Wirkung ihrer Kleider, jedenfalls auf die Männer. Den meisten Männern ist es nicht wichtig, wie Frauen angezogen sind." (Regenschirm, S. 138) Zwar ist diese Apodiktik ein Fall für die Diskussion ( $\Rightarrow$ II.5.3), da mitnichten „die Männer" diese Einstellung an den Tag legen, aber der Wunsch, auf eine gelenkte Weise wahrgenommen zu werden, ein gewünschtes Bild in den Köpfen der fiktiven Mitmenschen verfestigen zu wollen, ist Genazinos männlichen wie weiblichen Figuren im Liebeswerben nicht fremd. Die Intention ist dabei teilweise vermutbar - Wirkung von Kleidung -, teilweise begründet inferierbar - ,Lippenröten` ist Teil des kulturell angeeigneten Habitus im Umfeld zum Skript ,Kennenlernen' und signalisiert Aufmerksamkeit, Zugewandtheit -, teilweise aber auch dezidiert angegeben: „Er zog sich viel langsamer aus, weil er glaubte, dadurch souveräner zu werden.“ ( $A b$ schaffel, S. 88) Woher diese Einschätzung stammt und ob Abschaffel dadurch tatsächlich „souveräner" auftritt, ist selbstredend mangels Textdaten nicht überprüfbar und damit eine literatur-, figuren- sowie fiktionalitätstheoretisch falsch gestellte Frage $(\Leftrightarrow I .2 .4)$ - der Einfluss von verführungstheoretischem Striptease gehört indes zum kollektiven Wissensbestand des Geschlechtswesens Mensch und über einen Autor vermittelt auch zu demjenigen literarischer Figuren. Ein anderer Aspekt des Zitats soll dagegen weiterverfolgt werden: Warum ist es ihm ein Anliegen, souveräner wirken zu wollen? Ist nicht der-/diejenige, der/die wirklich und von innen heraus Selbstsicherheit ausstrahlt, über derartige Finessen erhaben?

Die Skala von Selbstsicherheit vs. Unsicherheit $(\Rightarrow$ II.1.3 u. $\Rightarrow$ II.2.6) ist also eine weitere, die dieses Schlaglicht an die früheren knüpft, was in den Figurenpsychen auch gespiegelt wird: „Wir lachten künstlich und affektiert, vermutlich genierten wir uns unserer Schauspielerei. Wieso eigentlich? Erinnere mich, daß ich nie verstanden habe, warum die Geschlechter auf die Entstehung von Ironie mit Scham antworten." (Licht, S. 68) Kurz gesagt halten sich Passagen, in denen die Hauptfiguren sicher erscheinen, mit denen, in denen sie unsicher erscheinen, die Waage, sodass es zu einer kontradiktorischen Familienähnlichkeit kommt. Wenn Abschaffel auf die (ungewohnte) sanfte Abweisung einer Frau Beharrlichkeit an den Tag legt, spricht dies für sein Selbstvertrauen: „Das glaube ich nicht, sagte er lachend; ich habe mir eine Woche lang vorgenommen, zu Ihnen zu kommen, da werde ich mich doch jetzt nicht von Ihrem halben Schnupfen vertreiben lassen." (Falsche Jahre, S. 468) Genauso selbstsicher, allerdings um einen ,tadellosen“ Eindruck bemüht, zeigt ihn dieses Zitat: „Zur Mittagszeit war er wieder mit Margot verabredet. Er glaubte, daß sie heute mit ihm nach Hause ginge, wahrscheinlich schon bald nach dem Mittagessen. Er sah in seinem Zimmer umher und überlegte, ob er aufräumen und saubermachen sollte." (Abschaffel, S. 134 f.) Dass es sich um die romanspezifische Sphäre der Alleinstellungsmerkmale handelt, da Fuchs' Selbstsicherheit in seiner körperlichen Imposanz wurzelt, ist beachtlich: „Er war ein stattlicher, gutgebauter Mann, und er konnte es sich leisten, sein Interesse für Ruth zu zeigen." (Ausschweifung, S. 6) 
Dieselben Protagonisten, die in anderen Kontexten als interessant und sicher charakterisiert worden sind, zeigen ihre unsichere Seite ebenso offen; wie Axel Degen, der Bericht erstattet über sein ,erstes Mal':

[S]ie machte den Anfang, ich mußte für die Fortsetzung sorgen, immer wieder diese Angst vor der Wirtin, an vielen Stellen zugleich spürte ich Elkes weiche Haut, einmal der Wunsch: schnell aufstehen und weggehen, aber Elke hatte mich schon zu sehr in sich hineingelassen und half mir immer noch. (Laslinstraße, S. 86)

Nicht nur die zur literarischen und filmischen Topoi-Sammlung gehörende Überzeugung, der erste Sexualverkehr müsse zögerlich und gespickt mit Unsicherheiten geschildert werden kompositorische Motivierung ( $\Rightarrow$ I.3.1) -, sondern auch die situative Rahmung durch die allgegenwärtige Über-Ich-Instanz „der Wirtin“ lässt die Szene zur Gegenseite der Skala ausschlagen. Besonders markant nimmt sich Pescheks Unsicherheit in Liebesdingen aus: „Sein Verhalten war nichts als eine Folge von nicht ausgesprochenen, gestotterten Bitten." (Fremde Kämpfe, S. 185) Eine vor der Folie aktueller Debatten um die finale Selbstbestimmung der Frau (\#MeToo) auf ganz neue Weise virulent werdende Entscheidungsschwierigkeit beschäftigt den namenlosen Ich-Erzähler aus Die Kassiererinnen: „Ich war mir nicht sicher, ob ich ihr eine kurze Rückenmassage anbieten durfte." (Kassiererinnen, S. 50)

So schwer es ist, im Außerliterarischen eine definitorische Trennschärfe zwischen den Konzepten ,Unsicherheit' und ,Schüchternheit' herzustellen, so unsauber verlaufen die Grenzlinien im Literarischen und also auch bei Genazino: „Nur zweimal küßten wir uns an diesem Abend, nur zweimal, weil der Luftweg, den mein Mund zu ihrem Mund zurücklegen mußte, sich nur zweimal den Anschein eines Zufalls geben ließ." (Laslinstraße, S. 38) Allerdings handelt es sich, sofern hier Schüchternheit vorliegt, um eine beidseitige, die der evozierten Unschuld Vorschub leistet. Als Wortfeld begleitet diese Degen tatsächlich häufiger: „[I]ch schlüpfte in meine Schuhe, fuhr mit der rechten Hand durch meine Haare, wie sich ein Konfirmand durch die Haare fährt, wenn er einer Konfirmandin begegnet, komisch, dachte ich, und das bei Phil.“ (Laslinstraße, S. 193)

Alle diese Belegstellen lassen sich unter dem Erklärungsansatz der Introvertiertheit zusammenfassen, obwohl Schüchternheit und Introversion nicht zwangsläufig Hand in Hand gehen müssen $(\Leftrightarrow I I .4 .1 / \Rightarrow$ Abb. 13). Aber zumal in den Situationen, in denen Peinlichkeit und Scham im Liebesleben eine Rolle spielen, ist die Überforderung bezüglich des Erforderlichen auffallend: „Im Grunde weiß ich bis heute nicht, wie man mit einem vertrauten Menschen einen ganzen Abend verbringt." (Liebesblödigkeit, S. 12) Unsicherheit, Schüchternheit, Überforderung und ein Mangel an Sozialkompetenzen ( $\Rightarrow$ II.1.3) bilden hier eine implosive Mischung, wie sie von Abschaffel, S. 13, bis zu Außer uns, S. 27 f. u. S. 31, immer wieder auftaucht, und die auch mittelbar Saiten des basistypischen Minderwertigkeitskomplexes anschlägt ( $\Rightarrow$ II.1.3):

Selbstverständlich will ich eine Frau, aber mit jetzt sechsundvierzig Jahren fühle ich mich zu alt oder vielmehr zu verschlissen für die Rolle eines Mannes, der noch einmal den Liebhaber geben will. Ich kann nicht mehr sprechen wie ein solcher Mann, ich kann mich nicht mehr verhalten wie 
ein solcher Mann. [...] Erschwerend kommt hinzu, daß Susanne für mich eigentlich zu schön ist. Wirklich schöne Frauen bringen mich immer nur auf einen Gedanken: Für die bist du nicht gut genug. Nur bei weniger hübschen und weniger intelligenten Frauen denke ich, die sind wie du, die werden sich nicht wundern, wenn ich mich um sie kümmere. Trotzdem gehe ich jetzt wie ein Mann, der darauf achtet, daß Susanne entgegenkommenden Passanten nicht gar zu oft ausweichen muß. (Regenschirm, S. 74)

Außer der Altersthematik ( $\Rightarrow$ II.5.3 u. $\Rightarrow$ II.5.6) und der Überzeugung, als phallozentristische Phalanx für Susanne ein Spalier erkämpfen zu müssen, bleibt die Inferenz, dass Genazinos Romanfiguren nun einmal nur im Vergleich zu ihren Mitfiguren Innerlichkeit und Äußerlichkeit erhalten: „weniger hübsch[] und weniger intelligent[]“17 ( $\Rightarrow$ II.1.4) sind dann die relationalen Prädikatenzuweisungen, die sich auf den Protagonisten wenden lassen.

Schließlich muss ein das gesamte Romanwerk Genazinos durchwirkendes skalares Oppositionsverhältnis für das vorliegende Schlaglicht aufgegriffen werden: Die Protagonisten befinden sich häufig im Zwiespalt, ob Freiheit und Unabhängigkeit oder Sicherheit und Bindung gewünscht sind. Darüber wird eines der bereits diskutierten Grundprobleme der Figuren Genazinos thematisiert: das von Distinktion vs. Zugehörigkeit $(\Rightarrow$ II.1.1). Abschaffel resümiert diesbezüglich: „Wenn er Samstag und Sonntag mit ihr zusammen gewesen war, hatte er sich bis jetzt noch jedesmal überfordert gefühlt. Margot redete zuviel, und dann wußte er sich nicht mehr zu helfen.“ (Sorgen, S. 161) Bereits ein zweitägiges Zusammensein stellt ihn vor das Problem der ,Übernähe', das auch den Architekten aus Wilhelm Genazinos Roman Wenn wir Tiere wären umtreibt: „Ich suchte eine Frau, deren Anwesenheit ich ohne Fluchtgedanken ruhig ertrug. Diese Frau war Maria nicht." (Tiere, S. 18 f.) Bis in die Wortwahl hinein missfällt es dem Basistypus, sich zu binden: „Ich kann nicht mehr unangefochten darüber nachdenken, welcher Frau beziehungsweise welchem Leben ich mich ausliefern soll. Es ist das Gefühl der gebrochenen Souveränität, das ich nicht hinnehmen kann." (Liebesblödigkeit, S. 114)

Nähe und Distanz, Souveränität und Eingebundensein sind immer wiederkehrende Marker, ${ }^{18}$ die ankündigen, dass es in Genazinos Romanen in Liebesangelegenheiten um Aushandlungsprozesse unterschiedlicher Liebes(lebens)entwürfe geht.

\subsection{Genazinos Liebes(lebens)entwürfe}

Mit der Liebe ist das so eine Sache: ${ }^{19}$ Sie zerfällt nicht nur in verschiedene Gefühlsfacetten und wechselt ihr (sprachliches) In-Erscheinung-Treten im Laufe der Zeit, sondern sie lässt sich auch

17 [Wilhelm Genazino].

18 Vgl. für ein Beispiel, bei dem die prinzipielle Unentschiedenheit auch beim Gegenüber in Rechnung gestellt wird: „Die Gelegenheit ist günstig, ich könnte Gesa sagen, daß ich sie liebe. Ich sage es nicht, weil ich weiß, daß solche Geständnisse für sie Bedrohungen sind; sie wird dann unruhig und fürchtet, nicht mehr frei zu sein." (Fleck, S. 178; $\Rightarrow$ II.2.6)

19 Dieses Unterkapitel zitiert passagenweise in Form des Selbstzitats Nils Lehnert/Susanne Schul: Gefühlvoll oder voller Gefühl? Literarische Liebesentwürfe und deren Sprachgewand aus einer diachronen Perspektive. In: Langlotz/Lehnert/Schul/Weßel (Hg.): SprachGefühl (2014), S. 191-252, hier S. 193-198 u. S. 230-232. 
- in inner- wie außertextlichen Welten - auf unterschiedlichen ,universelleren' Ebenen ansiedeln. Unter dem ,umbrella term' der Liebe wimmelt es nämlich nur so von Heterogenität und obwohl sich Liebe in einer alltagssprachlichen Begriffsannäherung zunächst intensional als „starke, im Gefühl begründete Zuneigung zu einem [nahestehenden] Menschen“20 umschreiben oder als „innige Sympathie [...] mit einer Person, die Freude an der Gegenwart, Existenz, den Eigenschaften, dem Glücke dieser“21 definieren lässt, ist die extensionale Dimension weit gefächert.

Darstellungsmodi und Funktionen von Liebe in literarischen Texten zu analysieren, ist gleichbedeutend damit, ihre Codierung, Prozessualität und Kommunizierbarkeit in den Blick zu nehmen. ${ }^{22}$ Dazu bietet es sich an, zwei Liebes-Typologien zu fokussieren, die sich allerdings bereits gegenseitig überblenden: erstens diejenige, die sich an Liebesobjekten orientiert und als Segmentierung auf die Frage antwortet: „Wer oder was wird geliebt?“ Sie erlaubt es bspw., kategorisch zwischen Konzepten von familiärer Liebe, von Partner-, Objekt- oder Gottesliebe zu differenzieren. Zweitens lässt sich die ,Beschaffenheit” der Liebe („Wie wird geliebt?“) behelfsmäßig extensional in die Trias ,Agape (Fokus auf spirituell-religiöse Selbstlosigkeit der göttlichen Liebe), ,Eros' (Fokus auf menschliche Sinnlichkeit und Begehren), ,Philia' (Fokus auf gleichberechtigte Freundesliebe) gleichsam tranchieren; indes sind diese Schnitte aber nie wirklich trennscharf, wie sich im Folgenden zeigen wird.

All diesen emotionalen Spielarten und ihren Mischungsverhältnissen liegt der Versuch zugrunde, ,lebensweltliche‘ Gefühlserfahrungen zu ver(schrift)sprachlichen: Sie werden (bewusst) poetisiert und dabei verwenden literarische Liebesdiskurse häufig, wo die Gefühlssprache an ihre Grenzen stößt, Tropen, Metaphern oder Figurationen, um das ,Unsagbare` sagbar zu machen. Liebe zählt nach Wolfgang Iser zu den menschlichen „Evidenzerfahrungen“ und stellt deshalb

20 [Liebe]. In: Duden online. Online: <http://www.duden.de/rechtschreibung/Liebe>.

21 Rudolf Eisler: [Liebe]. In: Wörterbuch der philosophischen Begriffe. Berlin 1904. Online: <http://www.textlog.de/4356.html>.

22 Der Begriff der Codierung bezieht sich in der Emotionsforschung vor allem auf die Annahme, dass Emotionen ,grundsätzlich' als kulturell vermittelt angesehen werden. Als Herausforderung einer interdisziplinär ausgerichteten Emotionsforschung erweist sich somit die Suche nach analytischen Kategorien, die die untersuchten Phänomen auch im historischen Kontext zum einen adäquat beschreiben und zum anderen zugleich Anschlussstellen für unterschiedliche disziplinäre Zugänge eröffnen (vgl. Andrea Sieber: Medeas Rache: Liebesverrat und Geschlechterkonflikte in Romanen des Mittelalters. Köln 2008, S. 21). Demzufolge gilt es sich einem mehrdeutigen Forschungsgegenstand zuzuwenden, der über Bezeichnungen wie bspw. Emotion, Gefühl, Affekt, Leidenschaft, Begehren, Erfahrung oder Empfindung von vielseitigen Diskurs- und Wissenszusammenhängen bestimmt wird und dementsprechend differente Erwartungshaltungen und Vorstellungen eröffnet. Eine erste Annäherung verspricht auf diesem Gebiet die historische Semantik, die sich u. a. mit der Erfassung und dem Wandel von Emotionsausdrücken befasst (vgl. Ludwig Jäger (Hg.): Zur historischen Semantik des deutschen Gefühlswortschatzes. Aspekte, Probleme und Beispiele seiner lexikalischen Erfassung. Aachen 1988; vgl. Fritz Hermanns: Sprachgeschichte als Mentalitätsgeschichte. Überlegungen zu Sinn und Form und Gegenstand einer historischen Semantik. In: Andreas Gardt/Klaus J. Mattheier/Oskar Reichmann (Hg.): Sprachgeschichte des Neuhochdeutschen. Gegenstände, Methoden, Theorien. Tübingen 1995, S. 69-101; vgl. Klaus Grubmüller: Historische Semantik und Diskursgeschichte. zorn, nit und haz. In: Stephen C. Jaeger/Ingrid Kasten (Hg.): Codierungen von Emotionen/Emotions and Sensibilities in the Middle Ages. Berlin/New York 2003, S. 47-69). 
einen „zentralen Sachverhalt literarischer Inszenierung“ dar. ${ }^{23}$ Dabei ist von einem komplexen Zusammenspiel von (historischer) Lebenswelt und Fiktion auszugehen, das nicht als ein Abbildungsverhältnis missverstanden werden sollte, sondern nach produktions- und rezeptionsästhetischen Dimensionen, nach Handlungs- und Reflexionsebene zu differenzieren ist. ${ }^{24}$ Liebe schreibt sich demzufolge von Beginn der Literarhistorie an als Lebenslinie in Stoffe, Motive und Themen gattungs- und epochenübergreifend ein, emotionalisiert Leser und kann in ihren mannigfaltigen Ausformungen als das Movens der (Text-)Dramaturgie schlechthin gelten. Elisabeth Frenzel verschlagwortet in ihrem Lexikon dichtungsgeschichtlicher Längsschnitte (Untertitel) bspw. den „herkunftsbedingte[n] Liebeskonflikt“ und die „heimliche Liebesbeziehung“25 - und selbst nur eine einzige dieser beiden expressis verbis „Liebe“ im Titel tragenden literarischen Traditionslinien aufzuzeichnen (geschweige denn, die gefühlssprachliche ,Verpackung' des jeweiligen Inhalts genauer in Augenschein zu nehmen), hieße ins Unermessliche abzuschweifen. ${ }^{26}$ Auch in der neueren Literatur ist der ,Konzeptcontainer' mit dem Label ,Liebe‘ zum Bersten gefüllt mit Entwürfen, Unterkategorien, Spiel- und Abarten der Liebe. So zeigt auch das CEuvre Wilhelm Genazinos die Protagonisten immer wieder zwischen Freud und Leid in Liebesdingen. Insbesondere in seinem 2005 erschienenem Roman Die Liebesblödigkeit kommt der Liebe in ihren verschiedenen phänotypischen Ausprägungen eine herausgehobene Bedeutung zu; ja, bereits die Peritexte betreiben einigen Aufwand, um den Leser auf eine Lesart einzuschwören, nach der die Liebe das Textzentrum bildet: „Von den Mühen mit der Liebe und dem Leben: Ironisch und tiefsinnig erzählt Genazino von den heillosen Verwirrungen, wenn einer Ordnung bringen will in das, was von Natur aus die größte aller Verwirrungen ist: die Liebe." ${ }^{27}$ Freilich finden sich auch im ,eigentlichen' Haupttext, im literarischen Experimentierfeld verschiedentlich Reflexe der ,verwirrenden` Definitionsproblematik um das Konzept ,Liebe` - und zwar auf mehreren Ebenen:

Ich warte draußen und ergehe mich in Edelreflexionen. Wirkliche Liebe bedeutet Anerkennung der ganzen Person, denke ich; die Anerkennung betrifft nicht nur Teilaspekte des anderen (sein Aussehen, sein Körper, sein Geld, seine Intelligenz), sondern wirkliche Liebe ergreift die Totalität der ganzen Person. Ich kann meinen Edelsinn nicht lange ertragen und fliehe in den Spott. (Liebesblödigkeit, S. 108 f.)

So definiert der 52-jährige, namenlose Protagonist scheinbar universalistisch die ,wahre Liebe und perpetuiert damit das romantisch-romantisierende Klischee, um es dann im Handumdrehen in seinen eigenen „Edelreflexionen“ als alltagsuntauglichen Kitsch zu enttarnen. Das Zitat leistet

23 Wolfgang Iser: Das Fiktive und das Imaginäre. Perspektiven literarischer Anthropologie. Frankfurt am Main 1991, S. 509.

24 Vgl. Iser: Das Fiktive und das Imaginäre, S. 509; vgl. Sieber: Medeas Rache, S. 15.

25 Frenzel: Motive der Weltliteratur, S. 451-483.

26 Spätestens dann, wenn man darüber hinaus die Motive der Weltliteratur nach den im weiteren und weitesten Sinne mit Liebe verwobenen Motiven durchsähe - „Mann zwischen zwei Frauen“ (Frenzel: Motive der Weltliteratur, S. 499-510) oder „Verführer und Verführte“ (dies., S. 756-774) -, so wird die Ufer- und Aussichtslosigkeit dieses Unterfangens deutlich. 
aber noch mehr: Es benennt nahezu alle ,Teilaspekte', die eine Liebes-Typologie zumindest der Mensch-Mensch-Liebe umreißen können muss, um diesen Namen zu verdienen: Körper und Geist, Ideelles und Materielles, kapitalstrukturelle Varianz ( $\Rightarrow$ II.1.5). Auch die basale Unterscheidung nach Agape, Eros, Philia nimmt der „freischaffende Apokalypse-Spezialist“ ${ }^{28}$ selbst vor:

Die Liebe zu zwei Frauen ist weder obszön noch gemein noch besonders triebhaft oder lüstern. Sie ist im Gegenteil völlig normal (und normalisierend), sie ist eine bedeutsame Vertiefung aller Lebensbelange. Ich vergleiche sie oft mit der Elternliebe. Niemand hat je gefordert, daß wir nur die Mutter oder nur den Vater lieben dürfen. [...] Mir jedenfalls ist das Bewußtsein dafür, daß mein Sexualleben polygam genannt wird und nach den herrschenden Auffassungen niederträchtig ist, im Laufe der Jahre abhanden gekommen. (Liebesblödigkeit, S. 23)

Dabei mischt der Protagonist etwas leichtfertig die Spezifik der Sphären, liefert er sich doch (vor sich) selbst die Rechtfertigung seiner gesellschaftlich (vermeintlich) stigmatisierten Doppelliebesbeziehung (Partnerliebe), indem er sich des Argumentationsmusters für Elternliebe bedient. Seine darauf fußende Setzung, dass die „Liebe zu zwei Frauen [...] weder obszön noch gemein noch besonders triebhaft oder lüstern" sei, feilt an einer intern fokalisierten, für den Textverlauf nicht aufrechtzuerhaltenden Liebesdefinition des autodiegetischen Erzählers, die nicht nur die Grenzen der oben unternommenen Typologiebemühungen geflissentlich verwischt. Fundiert wird damit darüber hinaus eine als erzählerseitig porös-inkonsistent anzunehmende Sicht auf eine fiktionale Lebenswelt und den dortigen Liebesentwurf, da die Beobachtung zunächst von der nicht näher spezifizierten und also auch nicht auf Erotik verpflichteten Partnerliebe auf die asexuelle Elternliebe hinüberschweift, ${ }^{29}$ dann aber wieder blitzschnell in einen "Sex-Modus switcht, als plötzlich nur noch das „Sexualleben“ zum Prüfstein der gesellschaftlichen Bewertung namhaft gemacht wird. ${ }^{30}$ In Absehung davon, bereits hier Soziokulturelles und moralisch Maßgebliches der fiktionalen Welt thematisieren zu wollen, auf die der Leser nur durch die alles andere als wertneutrale Wahrnehmung des mitunter unzuverlässigen Erzählers zugreifen kann $(\Leftrightarrow I .2 .3)$, sei nur so viel festgestellt: Die Hauptfigur wirft in Liebesdingen mehrfach Unvergleichliches behände durcheinander. Um den in Aussicht gestellten Liebestypologien Rechnung zu tragen und um aus dem vielschichtigen Roman diejenige Liebestranche herauszuschneiden, die

29 Wortgeschichtlich steht hinter dem Begriff ,Erotik' bekanntlich der griechische Liebesgott Eros, Sohn der Aphrodite und des Ares. Eros wird zu einer Allegorie der Liebe: Er stiftet und entzündet sie und schießt bekanntlich mit Liebespfeilen, die zuweilen nur einen der beiden Liebespartner treffen, so das Liebesschmerz und Liebesklage folgen können. Diese liebesstiftende Funktion des Gottes Eros ist es dann wohl, die sich im Begriff Erotik semantisch niedergeschlagen hat: Dass ein Mensch auf einen anderen Menschen aufmerksam wird, hat demzufolge mit bestimmten Signalen zu tun, die ausgesendet, empfangen und gedeutet werden. Welche Signale zu welcher Zeit begehren- und/oder liebesstiftend wirken, ist abhängig vom ethnischen und kulturellen Kontext sowie von psychosozialen Prozessen, die einem historischen Wandel unterliegen. Vgl. Thomas Bein: Liebe und Erotik im Mittelalter. Darmstadt 2003.

30 Eine diesbezüglich literaturwissenschaftlich-psychoanalytische Lesart wird in dieser Arbeit zwar nicht systematisch verfolgt, verspräche aber aussichtsreich zu werden. Die Schnittmengen, die sich aus den Motivkreisen ,Kindheit/Eltern' und ,Sexualität' ergeben, sind großflächig. Vgl. dazu bspw. die Primärtextzitate weiter unten ( $\Rightarrow$ II.5.5). Vgl. auch Außer uns, S. 41. 
den analytischen Blick im Folgenden lenken soll, anempfiehlt sich ein chronologischkursorischer Blick in die einschlägigen Plotangaben: Helmut Böttiger, der den Roman veröffentlichungszeitnah im September 2005 in der ZEIT bespricht, sieht

[d]as Grundproblem des Protagonisten [...] darin, dass er gleichzeitig mit zwei Frauen liiert ist. Sie wissen davon nichts. Das geht schon seit etlichen Jahren so, und wegen der Selbstständigkeit der Frauen scheint es tatsächlich zu funktionieren. Der Held verbringt, wenn er nicht allein bleibt, die Nacht immer bei einer der beiden. ${ }^{31}$

Tanja van Hoorn konstatiert im Kindler: „Das letzte Aufbäumen eines noch sexuell aktiven, sich aber am Rande seiner Möglichkeiten wissenden alternden Mannes zeichnet der Roman Die Liebesblödigkeit (2005) nach“.32 Oliver Jahraus schließlich hält 2011 fest: „Schwerlich wird man wohl einen Roman finden, der schrecklichere und peinlichere Liebes- und Sexszenen enthält als Die Liebesblödigkeit.“33 Die Indizien mehren sich, es soll im Folgenden mithin um die verschiedengeschlechtliche Partnerliebe gehen, genauer um deren körperlich-sexuelle, sinnlicherotische Form, ${ }^{34}$ wiewohl auch der dafür namengebende und patenstehende Gott Eros viele Einträge in (Motiv-)Lexika vorzuweisen hat, und man sich in seinem Fahrwasser leicht in die Pornografie verfährt. 35

Die Untersuchung des Liebesentwurfs und dessen Versprachlichung in Bezug auf das partnerschaftlich-erotische Segment, das von der ersten Attraktion bis hin zum Liebesvollzug, dem ,Liebe-Machen', reicht, greift sich dabei einen eo ipso bereits aufgrund der Thematik schwierig in Gefühlssprache übersetzbaren Problemkomplex heraus: Durch wie auch immer geartete Handlungen ein vorgängiges Gefühl sukzessive in gewandelte Wirklichkeitsverhältnisse zu überführen und dem Begehren dabei (auch: biophysiologisch) zur Vollendung zu verhelfen, ist eine Paraphrase des mentalen Skripts ,Verliebtsein bis Sex' in der Lebenswelt. Im Literarischen ist das dafür zu Gebote stehende Gefühlssprachinventar zwar üppig, doch ein ,wirklichkeitsgetreues‘ Sprach-Abbild naturgemäß nicht zu erreichen, weswegen im literarischen Experimentierfeld seit jeher höchst diverse, mehr oder minder ,passend' anmutende Sprachkleider um die Gunst des Lesers buhlen.

31 Helmut Böttiger: Die Apokalypse trägt Stützstrümpfe. In: Die Zeit vom 24. Februar 2005.

Hoorn: [Genazino, Wilhelm].

Oliver Jahraus: Deemphase als Apokalypse. Genazinos Beitrag zur Subjektkritik. Am Beispiel des Romans Die Liebesblödigkeit. In: Bartl/Marx (Hg.): Verstehensanfänge (2011), S. 99-114, hier S. $101 \mathrm{f}$.

34 Unter dieser Liebestranche soll hier ganz allgemein all das gefasst werden, was sich als mentales Skript von einer ersten Attraktion bis hin zum( einvernehmlichen) Sex prototypisch ereignen kann. Auch wenn man gegenwärtig vielleicht noch nicht vom ,Hoffähig-Werden' erotischer Literatur sprechen darf, so doch mit einigem Recht von einer kleinen Renaissance der erotischen Liebeskomponente in den (nicht nur) ,belletristischen' Bestsellerlisten. Der manchmal recht schmale Grat zwischen Erotik und Pornografie soll hier nicht ausladender thematisiert werden. Nur so viel: Aus literarisch-emotionsanalytischer Sicht eint die Genres mehr als sie scheidet: Pornografische Literatur will genauso ,emotionalisieren' wie erotische oder auch die Sexualität nicht zum Thema machende. Allein in der Wahl der Mittel (Stichwort: Explizität) und den anvisierten Emotionen unterscheiden sie sich. 
Auf dieser konzeptuellen Basis, die auf Genazinos Liebesblödigkeit fußt, lässt sich anhand zweier skalarer Abstufungen: Liebes(lebens)entwürfe zwischen Heirat, Kindern, Familie vs. Ehebruch, Fremdgehen, Polyamorie, mehrere (Sex-)Partner, Untreue einerseits; Innigkeit, Zufriedenheit vs. Unzufriedenheit, Trennungen andererseits, genazinotypische und also über die Liebesblödigkeit hinausgehende Hintergründigkeit beschreiben.

\section{HEIRAT, KINDER UND FAMILIE?}

Überspitzt formuliert gibt es neben Enthaltsamkeit und Eremitentum, die allerdings für Genazinos Romanwerk nicht diskutiert werden müssen,36 lediglich die binären Optionen Kind vs. kein Kind; Heirat vs. keine Heirat; Monogamie vs. Polygamie. Genazino lotet dennoch die Welten zwischen diesen Polen aus. Insbesondere die Frage danach, ob die männlichen Protagonisten in eine Heirat einwilligen bzw. Bereitschaft signalisieren, eine Familie gründen zu wollen, sind wiederkehrende Elemente in Genazinos Romanen. Dass es bis auf in den Romanen Die Ausschweifung und Mittelmäßiges Heimweh keine eigenen Kinder der Frauenfiguren und Protagonisten zu geben scheint, lässt die Aussage zu, dass im breiten Gürtel der Familienähnlichkeit Genazinos Figuren tendenziell dem von den Partnerinnen vorgebrachten Kinderwunsch ablehnend - „Ich wollte auf keinen Fall, dass Sibylle schwanger wurde" (Kein Geld, S. 27) - oder zumindest ambivalent gegenüberstehen: ${ }^{37}$ „Vorstellungen, die ich ihren Augen ablesen konnte, wie man eine entzifferte Geheimschrift liest, Vorstellungen, die unsere Zukunft zu belegen schienen mit festen, unverrückbaren Ereignissen“ (Laslinstraße, S. 143) - kurz decodiert ( $\Leftrightarrow$ II.2.3): Elke würde sich über Kinder freuen. Diese Dechiffrierung gelingt nicht immer so hürdenlos: „Weil wir über diesen Punkt nicht redeten, wusste ich auch nicht, ob sich Carola vielleicht ein Kind wünschte, und wenn ja, wie heftig. Ihr Schweigen war für mich ein Symptom." (Außer uns, S. 24; $\Rightarrow$ II.1.4) Ungeachtet dieser Unwägbarkeit verlässt sich der Basistypus allerdings auf Vorurteile und verallgemeinert dementsprechend:

Nach meinen bescheidenen Kenntnissen über den Verlauf eines Frauenlebens war Sonja jetzt in einem Alter, in dem sie sich ein Kind wünschen konnte. Ich rechnete fast jede Woche einmal damit, dass sie es mir sagte. Ich fürchtete mich vor der Ratlosigkeit, die mich dann ergreifen würde. (Regen, S. 26)

Seine Position jedenfalls steht felsenfest: Furcht vor der Eröffnung, mutmaßliche „Ratlosigkeit“ im Fall des Falles. Ein anderer Protagonist bringt die dabei wirkende emotionale Ambivalenz auf den Punkt: „Am schlimmsten war im Augenblick, dass ich heute kein Kind mehr wollte. Die Familie als Lebensform hatte sich aus meiner Existenz entfernt. Momentweise fühlte ich die ge-

36 Vgl. als romanspezifische Ausnahme den namenlosen Ich-Erzähler des Textes Leise singende Frauen. Dieser tritt sexuell nicht in Erscheinung.

37 Dass dabei auch Lebensstilerwägungen eine Rolle spielen, verdeutlich etwa das folgende Beispiel, in dem „desto deutlicher wird, daß Bedürftigkeit immer stillos war und daß es deswegen keinen eleganten Schnuller und kein anmutiges Saugen und überhaupt niemals einen schönen Mangel geben kann." (Frauen, S. 47; $\Rightarrow$ II.2.5) 
wachsene Unklarheit meines Lebens, die ich kaum eine Minute lang aushalten konnte." (Tiere, S. 80) Einen aufgeklärteren Standpunkt nimmt Gerhard Warlich ein, der seinerseits die allzu simple Reduktion der Frau auf den Kinderwunsch kritisch hinterfragt:

Ich weiß, es gibt viele Männer, die ihre Frauen opfern, wenn diese ihren Kinderwunsch durchsetzen wollen. Das Geschlechtswesen Frau muß unter allen Umständen unverändert erhalten werden. Ich würde Traudel gerne sagen, daß ich nicht zu diesen harten geschlechtslastigen Männern gehöre. (Glück, S. 31)

Natürlich darf als Hemmnis hinsichtlich des Enabling Factors ,Kinder zeugen' die Causal History mit den Füllwerten ,negativ eingefärbte Kindheitserinnerungen' sowie die wenig vorteilhaft geschilderten Beziehungen der eigenen Eltern angeführt werden. Dass kaum ein Protagonist ohne gescheiterte Beziehungen bzw. Scheidung auskommt, mag im Zusammenschluss mit den Antibürgerlichkeitstendenzen, die hier auf die Kleinfamilie gemünzt werden, auch als Begründung des Votums gegen den als repressiv empfundenen ,Bund der Ehe' gelten. Insbesondere Axel Degen opponiert radikal gegen eine als überkommen wahrgenommene Bürgerpflicht: Seiner Aussage zufolge komme, „,so sicher wie der Winter kommt [...] auch irgendwann das Gespräch aufs Heiraten" (Laslinstraße, S. 197), was zeit- und sozialkritisch auf die soziokulturellen Rahmenbedingungen gewendet wird (vgl. Laslinstraße, S. 192) und in der eigene Kinder kategorisch ausschließenden Aussage gipfelt: „[I]ch dachte daran, in welcher Welt sie aufwuchsen." (Laslinstra$\beta e$, S. 193) Gesellschaftskritisch sind auch weitere Passagen zu bewerten, in denen Degen den als bigott und unzeitgemäß empfundenen Floskeln den Kampf ansagt: „verliebt aber noch nicht verheiratet, Schwätzer, furchtbarer Schwätzer“ (Laslinstraße, S. 210). Als Ausflucht legt sich etwa Gerhard Warlich mit einer IM-Strategie protektiven Einschlags per self-handicapping ( $\Rightarrow$ I.3.3) folgenden Plan zurecht: „Meine Abwehrstrategie war zunächst, daß ich mich als ungeeigneten Ehekandidaten dargestellt habe. Immer wieder habe ich gesagt, daß es mir rätselhaft ist, warum eine Frau ausgerechnet mit mir verheiratet sein wolle." (Glück, S. 21)

Mit all diesen ungewohnt deutlichen gesellschaftskritischen Worten ist die Antibürgerlichkeit auf den Plan gerufen ( $\Rightarrow$ II.1.6). Dem Modell der bürgerlich-modernen Kleinfamilie wird immer wieder ein Lebensentwurf zur Seite gestellt, der sich nicht auf die bürgerliche Wohlanständigkeit festnageln lässt. Ein Roman Genazinos, der diese Problematik wie kaum ein anderer auslotet, ist Die Liebesblödigkeit.

\section{EHEBRUCH, POLYAMORIE, UNTREUE!}

Was darin geschildert wird, muss man sich erst einmal auf der Zunge zergehen lassen: Bereits ziemlich zu Beginn wartet der Roman mit der „Brückenhaltung“ (Liebesblödigkeit, S. 14) auf, einer nicht gerade sexuelle Einfallslosigkeit verkörpernden Verrenkung. Mann und Frau(en) finden im Textverlauf zigmal körperlich zusammen. Überhaupt ist das Sexualleben des Protagonisten nicht sonderlich eingerostet: Neben den - so legt es die erzählte Welt nahe - exklusiven 
sexuellen Zugang zu zwei Frauen reihen sich Besuche in Nacktclubs und erotische Reminiszenzen, die sich an Begegnungen mit früheren Sexualpartnerinnen knüpfen. ${ }^{38}$

Insoweit man denn dem Erzähler trauen darf. Bei Genazino und bei ,diesem Genazino‘ ist diesbezüglich prinzipielle Vorsicht angebracht, weil man es häufig mit einer unzuverlässigen Erzählinstanz zu tun hat $(\Rightarrow I .2 .3),{ }^{39}$ wie Jonas Fansa ins Positive gewendet ausführt:

Die Flucht in die „verschiedenen Wahrheitsversionen“ [...] wird wohl auch in Zukunft dazu führen, dass wir einerseits immer neue Versionen der alten Geschichten zu lesen bekommen und andererseits stets den Leseeindruck haben werden, beim Schreiben dabei zu sein und die im Detail stattfindenden Entwicklungen dieses Autors unmittelbar mitzuerleben [...].40

Auch was die Liebe anbelangt, bleiben die Aussagen und Einstellungen des Ich-Erzählers stets relativierbar, „[d]enn alles, was ich im Augenblick über [...] Liebe denke, stimmt nicht ganz.“ (Liebesblödigkeit, S. 17) Zwar ist diese Relativität nicht unerheblich, im Auge zu behalten ist dessen ungeachtet auf der figuralen Ebene zuvörderst aber die Frage nach dem erotische Liebesentwurf bzw. -diskurs. Dieser Frage nähert sich Jahraus wie folgt auf tragfähigem Gerüst an und betont damit auch ein (vermeintliches) Alleinstellungsmerkmal des Romans im CEuvre Genazinos:

Die Liebesblödigkeit ragt aber dennoch insgesamt aus der Reihe der weiteren Romane heraus, weil der Ich-Erzähler gerade nicht an einem Mangel an emotionalen Bindungen leidet. Im Gegenteil, sein Problem besteht eher darin, dass er zu viele emotionale Bindungen hat, konkret gesprochen: sexuelle, emotionale und zum Teil auch intellektuelle Beziehungen zu gleich zwei Frauen, die unterschiedlich sind und daher in der narrativen Modellierung des Sujets so etwas wie eine Ausdifferenzierung von Beziehungsfunktionen ermöglichen. Auf der einen Seite steht die sinnliche Sandra, die Sex mit ihm sucht, auf der anderen Seite Judith, mit der er eher, jedoch nicht ausschließlich, intellektuell verkehrt. Beide Frauen wissen nichts voneinander, und so entfaltet sich eine klassische Dreieckskonstellation, mit einem Mann zwischen zwei Frauen; ein unhaltbarer Zustand, was wiederum dem Text seinen narrativen Spannungsbogen gibt. ${ }^{41}$

Der „unhaltbare[] Zustand“, der den dramatischen Textknoten erst zu schürzen vermag, ist ein von Jahraus hier kritiklos übernommener - vom Ich-Erzähler ins Spiel gebrachter, der Gesellschaft in die Schuhe geschobener, indem dieser unpersönlich in Richtung einer kritischen moralischen Masse moniert, „daß mein Sexualleben polygam genannt wird und nach den herrschenden Auffassungen niederträchtig ist“ (Liebesblödigkeit, S. 23). Dass ihm „im Laufe der Jahre“ „das Bewußtsein dafür“ „abhanden gekommen“ sei, dieser Stigmatisierung halber ein schlechtes Gewissen haben zu müssen, da er diesen Zustand als nicht deviant, sondern „im Gegenteil völlig normal (und normalisierend)“ erachte, lässt den in der Fiktion bestehenden Moralkodex durchscheinen (Liebesblödigkeit, S. 23). Aber: Was dem Erzähler selbst nicht zu Bewusstsein gelangt, ist, dass die weitgehend akzeptierte Vielfalt mehrheitsfähig geworden ist - „es ist doch längst normal, dass der Mensch zwei Frauen oder zwei Männer hat" (Kein Geld, S. 29) - und gesamtge-

38 Vgl. dazu generell Maria Kolberg: Polyamorie in Wilhelm Genazinos „Die Liebesblödigkeit“. Hamburg 2015.

39 Vgl. Fansa: Unterwegs im Monolog, S. 10-16.

$40 \quad$ Fansa: Unterwegs im Monolog, S. 147.

41 Jahraus: Deemphase als Apokalypse, S. 110. 
sellschaftlich in der modernen Wahlfreiheit gleichberechtigt nebeneinander existierender Partnerschaftsmodelle ,Polygamie' längst nicht mehr verteufelt, wohl aber aus tief-christlicher Verwurzelung die Lüge, das Geheimnis sanktioniert wird. Das ist der eigentliche Knackpunkt. Ein immer noch wirksames gesellschaftliches wie religiöses Moment ist bei der Notlage, eine Liebesund Lebensentscheidung herbeiführen zu müssen, nicht von der Hand zu weisen. Was im späten achtzehnten Jahrhundert Goethe veranlasst hat, sein ursprünglich als Polyamorie-Utopie entworfenes Schauspiel für Liebende, nämlich Stella, umzuarbeiten, wirkt als soziokulturelle Einflussgröße indirekt noch immer bis in die neueste deutsche Literatur nach:

Zerrissen zwischen der Leidenschaft, die ihn mit Stella verbindet, und der Seelenfreundschaft mit der reiferen Cezilie, wird er [Fernando; N. L.] von Letzterer der Entscheidung enthoben: Cezilie schlägt ihm und Stella eine Ehe zu dritt vor, und das Stück endet mit Fernandos Umarmung beider Frauen. Dieses Schlusses wegen löste Stella eine Woge moralischer Entrüstung aus. Goethe schrieb daher für die Aufführung in Weimar 1806 ein neues Ende, in dem Stella Gift nimmt und Fernando sich erschießt (erschienen 1816). ${ }^{42}$

Überraschenderweise löst in Goethes Erstfassung eine Frau das ternär-trianguläre Problem, was aus gendertheoretischer Lesart natürlich nicht darüber hinwegtäuschen kann, dass es (wie bei Frenzel schon erwähnt; s.o.) für gewöhnlich Männer zwischen Frauen, selten Frauen zwischen Männern sind, die sich im Dreieck positionieren. ${ }^{43}$ Genazinos Protagonist gönnt sich selbst zwar die Sichtweise, es sei ,normal' und ,gut', mit zwei Frauen zu verkehren - er „kann die dauerhafte Liebe zu zwei Frauen nur empfehlen“ (Liebesblödigkeit, S. 23) -; dass aber beide einer ,offenen Beziehung' zustimmen könnten, hält er für ebenso ausgeschlossen wie ihre prinzipielle Übereinstimmung mit seinem polyamorösen Beziehungsmodell:44

Vermutlich ist es sinnvoller, ich stelle Judith und Sandra endlich einander vor und mache sie mit einem künftigen Leben zu dritt vertraut, anstatt mich von der einen oder anderen zu trennen. Nein, das wäre die absolute und ultimative Apokalypse, die ich nicht überleben würde. (Liebesblödigkeit, S. 67)

42 Ulrike Landfester: [Goethe, Johann Wolfang von. Dramen]. In: Kindlers Literaturlexikon online. Online: $<\mathrm{http}: / / \mathrm{kll}-$ aktucell.cedion.de/nxt/gateway.dll/kll/g/k0241600.xml/k0241600_080.xml?f=templates $\$ \mathrm{fn}=$ indin.h tm $\$ \mathrm{q}=\% 5$ Brank,500\%3A\%5Bdomain\%3A\%5Band\%3A\%5Bfield,body\%3Astella\%5D\%5D\%5D\%5 Bsum\%3A\%5Bfield,lemmatitle\%3Astella\%5D\%5Bfield,body\%3Astella\%5D\%5D\%5D\$x=server\$3. 0\#LPHit1>.

43 Vgl. zu kulturellen Konfigurationen eines hierarchischen und heteronormativ angelegten Geschlechterverhältnisses Judith Butler: Das Unbehagen der Geschlechter. Aus dem Amerikanischen von Katharina Menke. Frankfurt am Main 1991, S. 60; vgl. für die Dreiecks-Konstellation bei Genazino Ulrich Rüdenauer: Ein falsches Timing von Heftigkeiten. Ein Spaziergang mit Wilhelm Genazino durch Frankfurt. In: literaturkritik.de vom 07. Juli $2005 . \quad$ Online: $<$ http://literaturkritik.de/id/8308>.

44 Auch er selbst ist nicht frei von Gewissensbissen: „Um ein großes Liebesunrecht (entweder an Sandra oder Judith) zu vermeiden, nehme ich laufende kleine Verstöße gegen die Ethik (die Untreue) stillschweigend in Kauf." (Liebesblödigkeit, S. 202) Allerdings wäre zu diskutieren, ob es sich nicht schlicht um eine selbstgerechte Rationalisierung handelt. 
Allerdings öffnet der Ich-Erzähler zumindest theoretisch im Sinne der Polyamorie - die wie gesagt aufgrund der Verheimlichung in seinem persönlichen Fall nicht gewährleistet ist - seinen Horizont auch für die entgegengesetzte Besetzung der Ménage-à-trois:

Ich wünsche allen Männern zwei Frauen und allen Frauen zwei Männer, wenigstens phasenweise, denn zwei Frauen oder zwei Männer sind die Mindestüppigkeit, mit der wir den Kampf gegen unser armseliges Leben antreten können, ohne uns gleich dem Gesetz der Kargheit auszuliefern. (Liebesblödigkeit, S. 45)

Jahraus' Einschätzung, die Liebesblödigkeit sei als Roman allein aufgrund der Tatsache einer Dreiecksbeziehung einzigartig (s.o.), darf angezweifelt werden. Denn schon Abschaffel erfüllt sich avant la lettre die „Mindestüppigkeit“: „Monatelang liebte er drei Mädchen, nein, er liebte sie nicht, sie waren nur um ihn herum. [...] Es ging nur, weil Abschaffel perfekt und umsichtig log.“ (Abschaffel, S. 38 f.) Als lakonische Erklärung gibt er an, er habe „nur ausprobieren wollen, wie sein Leben wäre, wenn er einmal das Gefühl nicht haben mußte, er komme immer und ewig zu kurz und alles." (Abschaffel, S. 38) ${ }^{45}$ Wie in der ersten Fassung der Stella macht es dabei einen gravierenden Unterschied für die empfundene poetische Gerechtigkeit, ob zwei Partnerinnen bzw. Partner ohne deren Wissen nebeneinander parallelgeführt werden, ob beide von den jeweils anderen wissen - und wie Fernando zeitweilig Cäcilie mit Stella betrügt, ohne dass beide etwas von der Existenz der je anderen ahnen, ${ }^{46}$ so ist auch Genazinos Basistypus kein Kind von Traurigkeit: „Mit Marga und Friederike hatte er sich, als er Dagmar schon kannte, sogar noch eine Weile getroffen. Dagmar hatte davon nichts erfahren dürfen; sie war so eifersüchtig wie ein Türke und ein Sizilianer zusammen." (Fremde Kämpfe, S. 96)

Insgesamt wirkt es mitunter so, als könnten sich die Hauptfiguren auch fortgeschritteneren Alters vor sexuellen Offerten gar nicht retten: „Schon überlege ich ängstlich, daß ich mir vor dem Ausbruch einer neuen Liebesbeziehung ein paar Wochen Zeit lassen wollte. Außerdem will ich kein Liebesnomade werden, dafür bin ich zu alt." (Heimweh, S. 186) Mindestens zwei zur Wahl stehende Partnerinnen sind jedenfalls ein derart markanter Standardwert im Romanwerk, dass man ihn direkt zwischen Familienähnlichkeit und Hardcore platzieren muss:

Eckhard versuchte zu überlegen, ob er Christine in der Bank besuchen sollte [...]. Natürlich kam er zu keinem Entschluß. Er bemerkte nicht, daß es ihm Schwierigkeiten machte, Christine und Ruth im Kopf eindeutig voneinander zu trennen. Er konnte über keine der beiden Frauen sinnvoll nachdenken, ohne daß in seinem Kopf die jeweils andere Frau dabei zuschaute: und das wollte er nicht. (Ausschweifung, S. 209)

Mit dieser widersprüchlichen Konstruktion - „Er bemerkte nicht“ vs. „das wollte er nicht“ - wird die potenzielle Triade von Beziehungen, in die drei Personen involviert sind, zu einer ,V-Form‘ verengt: Im Gegensatz zum Protagonisten der Liebesblödigkeit, der zumindest aus Gleichberech-

45 Ein ähnlicher Antrieb mag Eckhard Fuchs zu seinem damaligen Wunsch, „mit den Frauen von Kollegen zu schlafen" (Ausschweifung, S. 58), veranlasst haben.

46 Vgl. Lothar Pikulik: Goethes „Stella. Ein Schauspiel für Liebende“. In: Walter Hinderer (Hg.): Interpretationen. Goethes Dramen. Stuttgart 1992, S. 88-116, hier S. 89. 
tigungssorgen auch Frauen einen zweiten Mann zudenkt, sympathisiert Fuchs damit, der einzige Knotenpunkt zu sein und zu bleiben. Zusätzlich soll bei aller Simultaneität ein klares Nebeneinander eingehalten werden, auf dass keine gedankliche Vermischung sich ereigne. Analog die antiemotional erzählte ( $\Rightarrow$ II.5.6) Anbahnung eines (weiteren) Seitensprungs in Außer uns spricht niemand über uns:

Es lockte mich außerdem die Möglichkeit, mit einem Mannequin einen höchstens zweitägigen Sexualaustausch zu arrangieren, von dem beide Teilnehmer unausgesprochen wussten, dass es ein Nachspiel nicht geben würde, weil das Mannequin zu Hause genauso fest liiert wäre wie ich. (Außer uns, S. 63)

Auch in anderen Variationen und Konstellationen werden antibürgerliche Liebes- und Lebensentwürfe zu einem für Genazino häufig bearbeiteten Motiv, etwa in Mittelmäßiges Heimweh:

Dabei hat es von Edith genügend Warnungen gegeben. Kurz vor unserer Hochzeit erzählte sie mir, daß sie während der Hochzeitsfeier ihrer besten Freundin Susanne so heftig mit Susannes zukünftigem Ehemann geflirtet habe, bis dieser mit ihr, Edith, in ein nicht bewohntes Zimmer des Landgasthofes [...] ging und dort mit ihr kurz und heftig vögelte. (Heimweh, S. 109 f.)

Dieter Rotmund räsoniert im Nachhinein, ob er die Zeichen nicht richtig gedeutet hat und befragt sich selbst, warum er nun so erstaunt darüber ist, dass seine Frau Ehebruch ${ }^{47}$ begangen hat. Untreue Frauenfiguren sind indessen keine romanspezifischen Alleinstellungsmerkmale, aber immerhin vergleichsweise selten. Da im Regelfall eine interne Fokalisierung vorliegt, ${ }^{48}$ ist der Einblick in die weiblichen Figuren ohnehin begrenzt und weil die personengebundene Erzählperspektive nolens volens auch physisch an die Hauptfiguren gekoppelt ist, fallen alle Zeiten, die nicht beide Figuren gleichzeitig ,auf der Bühne' verbringen, in den Bereich der Mutmaßungen bzw. müssen erzähltechnisch dialogisch präsentiert werden: „Eckhard versuchte herauszufinden, ob Ruth aufgrund seiner Scheu auf seine Ausschweifung schloß. Dann überlegte er, ob nicht umgekehrt Ruths sicheres Verhalten ebenfalls eine Methode war, eine eigene Geschichte nicht zu verraten." (Ausschweifung, S. 252) Ebenfalls gemutmaßt, zusätzlich aber in der Präsentation ihrer Worte zwischen transponierter und zitierter Rede fundiert, ist die folgende emanzipierte Aussage Carolas: „Carola war, was Treue anging, nicht zuverlässig. [...] Besonders wenn wir mit Freunden zusammensaßen, nannte sie Treue die Selbstverödung von Hausfrauen, über die eine Frau wie sie nur lachen könne." (Außer uns, S. 45)

Ein Zitat, das den bisherigen insofern diametral entgegensteht, als es mit der Empfehlung bricht, mindestens zwei Partner oder Partnerinne parallel zu haben, lässt vordergründig das Bedürfnis nach traditionell-monogamen Verhältnissen durchscheinen, schönt selbstgerecht zugleich das eigene Selbstbild und verweist auf Genderfragen ( $\Rightarrow$ II.5.3):

$47 \quad$ Ehebruch und nicht Seitensprung deshalb, weil eine Heirat vorliegt, was tendenziell seltener der Fall ist. Auch der Ich-Erzähler des Romans Kein Geld, keine Uhr, keine Mütze bricht (mehrfach) die Ehe: „Dabei hatte ich, seit wir getrennt waren und auch schon vorher, gelegentlich mit anderen Frauen geschlafen." (Kein Geld, S. 26 f.) 
Eigentlich war es schon lange mein Wunsch gewesen, ein und dieselbe Frau für das Begehren und als einzige Adressatin meines Verlangens zu lieben. Bis heute war ich von diesem Ziel weit entfernt. Ich hatte in meinem Leben meistens zwei Frauen, eine für die häusliche Liebe und die andere für das eher wirre Querfeldeinbegehren. Dabei quälte es mich, dass ich die Differenzen zwischen meinen Bedürfnissen immer gleich Untreue nannte und die Untreue als Konstruktionsfehler meines Verlangens beklagte. (Regen, S. 89)

Damit gelangt man letztlich wieder bei Goethe und bei Jahraus an:

Will aber Fernando sich nicht eindeutig festlegen; erscheint ihm die Frau in beiderlei Gestalt, als Geliebte und als Gattin, und in beiderlei Gestalt gleichermaßen verlockend, so ist das, was Goethe mit seinem Stück gewissermaßen experimentell zu erkunden sucht, die Möglichkeit, inwiefern die Frau für den Mann nicht beides sein kann, Geliebte sowohl als Gattin, oder inwiefern, wenn die Rollen auf zwei verschiedene Frauen verteilt sind, sich nicht mit beiden zugleich ein Arrangement treffen ließe. ${ }^{49}$

Das ist die wortreichere Variante dessen, was Jahraus eine „Ausdifferenzierung von Beziehungsfunktionen“ nennt (s.o.), und was sich für die Liebesblödigkeit bis ins Detail auf die Dimension ,körperlich-geistig‘ abbilden lässt. Die Aussage des Ich-Erzählers: „Ich weiß, das Frauenvergleichen ist widerlich und sogar geschmacklos. Aber das Vergleichen ist unterhaltsam!“ (Liebesblödigkeit, S. 24), verlöre dann teilweise an Geschmacklosigkeit, wenn man davon ausgeht, dass es sich auch bei Genazino ,nur' um die metaphorische Aufspaltung zweier Rollenbilder und mithin um „die Wunschphantasie eines männlichen, seinem männlichen Selbstverständnis nachsinnenden Autors" handelte.50 Die intertextuellen Parallelen reichen sogar soweit, dass einerseits die nahezu niemals vorkommende Zusammenkunft aller drei involvierten Personen an einem Ort sowohl in Stella ${ }^{51}$ als auch in der Liebesblödigkeit evident ist, andererseits die Erfüllung zumindest momentweise mit beiden Hälften eines Idealbildes gewährleistet ist - und zwar unabhängig von monogamer Heirat oder Polyamorie.

Demnach gibt es trotz der als unstet zu klassifizierenden Eigenheit mancher Protagonisten mannigfaltige Situationen, in denen Zufriedenheit, Genügsamkeit (vgl. Kein Geld, S. 29 f.) und Innigkeit die Szenerie in ein romantisches Licht tauchen.

\section{ZUFRIEDENE INNIGKEIT - INNIGE ZUFRIEDENHEIT}

Diejenigen Passagen der Liebesblödigkeit, die sich sowohl inhaltlich als auch erzähltechnisch mit dem Etikett ,voller Gefühl' versehen lassen und gegenüber denjenigen ,ohne/mit wenig Gefühl in der Unterzahl sind, tragen meist die folgende Signatur: Sie entspringen entweder der Verlustangst der Liebesobjekte (Bsp. 1) und/oder sind im dramatischen Modus als Zwiegespräch konzipiert (Bsp. 2) und/oder in die Erzählvergangenheit verlegt (und dann entweder mit Judith und/oder der Kindheit verknüpft) (Bsp. 3):

49 Pikulik: Goethes „Stella. Ein Schauspiel für Liebende“, S. 102.

50 Pikulik: Goethes „Stella. Ein Schauspiel für Liebende“, S. 107.

51 Vgl. Pikulik: Goethes „Stella. Ein Schauspiel für Liebende“, S. 105. 
[Bsp. 1:] Schließlich sind es solche emotionalen Verstrickungen, sage ich mir, die den Menschen individuieren und seinem armseligen Dasein doch noch eine unverwechselbare Gestalt geben. Ich will jetzt keine Sekunde meiner Liebesverschlingungen missen, weder die mit Sandra noch die mit Judith. Sie sind es, die mir die Kraft geben, das Einerlei meines Lebens und meines Berufs auszuhalten. (Liebesblödigkeit, S. 72)

[Bsp. 2:] Judith [...] sagt: Man wird schön belohnt, wenn man dich liebt. Nach einer Pause sagt sie: So richtig verletzt haben wir uns noch nicht, oder?

Nein, sage ich; willst du, daß wir wegen irgend etwas aufeinander losgehen?

Natürlich nicht.

Aber es ist dir verdächtig, daß es zwischen uns keinen Hickhack gibt?

Ja, sagt Judith; ich denke häufig, daß sich im geheimen etwas ansammelt.

Das denke ich manchmal auch; aber warum sollten wir uns verletzen?

Ich möchte sehen, wie wir hinterher damit fertig werden, sagt Judith.

Wir lachen und kriechen unter der Hecke hervor. (Liebesblödigkeit, S. 45 f.)

[Bsp. 3:] Ich erinnere mich an die Zeit, als ich Judith kennenlernte. Sonntags fanden wir kaum aus den Kissen heraus. Um das Bett herum waren Zeitungen, Bücher, Wein, Gebäck, Gläser und Unterwäsche verstreut. [...] Nach zwei oder drei Stunden hatte ich das Gefühl, endlich in meinem Versteck am Wildbach angekommen zu sein. War die Liebe nicht überhaupt ein Nachspiel der Kindheit, eine Wiederholung des Wunsches, eine selbstgebaute Höhle niemals verlassen zu müssen? Ein paar Wochen lang wollte ich damals erreichen, daß wir unseren Orgasmus gleichzeitig hatten, aber ich hatte nicht viel Erfolg. Judith beruhigte mich. Sie sagte, der ungleichzeitige Orgasmus ist eine Fürsorge der Natur. Mann und Frau sollen lernen, sich furchtlos in der Abwesenheit der Lust zu betrachten. Die Erklärung erschütterte mich damals, gefällt mir heute aber sehr. (Liebesblödigkeit, S. 68)

Es sind allesamt intime Situationen, die Liebesglück verheißen und ebenso gefühlvoll in Sprache gekleidet sind: Liebe kann die Individualität stärken und „Kraft geben“, sie kann von solcher Gewissheit sein, dass man einen Streit in Erwägung ziehen kann, um dessen mutmaßliche Bewältigung als Intensivierung zu erleben, sie kann - mindestens im Stadium des Verliebtseins zum Ausblenden der Umgebung, dem Verzeihen von Schwächen und vor allem dem Gefühl, ,sich selbst zu leben', führen: „Mich übermannte das Gefühl einer unaussprechlichen Einigkeit mit Sibylle, ja einer nicht eigentlich verstehbaren Verschmelzung.“ (Kein Geld, S. 59) Dabei können die körperliche und die geistige Dimension auseinander- oder zusammenfallen, wobei Genazinos Romane mit zuverlässiger Konstanz die körperlich-erotische Facette nicht nur immer mitdenken, sondern zumeist exponieren: Die innigen und offenen Gespräche über ihre jeweiligen Macken gipfeln zwischen Abschaffel und Margot regelmäßig dann doch im Beischlaf (vgl. Abschaffel, S. 155 f.) und auch Axel Degens pathetische Feststellung: „Elke und ich waren unsere eigenen Hauptfiguren geworden, nichts galt mehr, nichts, nur Elke und ich“ (Laslinstraße, S. 177), hat ohne die körperliche Komponente keinen Bestand (vgl. Regenschirm, S. 138; vgl. Ausschweifung, S. 71). Gefühlsduselig-empfindsam wird es nicht nur deshalb bei Genazino selten, sondern auch aufgrund der Tatsache, dass erzähltechnische Distanzierungseffekte $(\Rightarrow$ I.5.6) die entstehende ,traute Zweisamkeit' bzw. die Schilderung per se konterkarieren: „Zwei Tage später kam Sonja. Sie war ein gütiger Mensch und verdiente außerdem gut. Wenn ich mich nicht täuschte (ich täuschte mich nicht), dann liebte sie mich, und wenn ich mich immer noch nicht täuschte (ich täuschte mich immer noch nicht), dann liebte ich sie ebenfalls.“ (Regen, S. 9) Warum, könnte man fragen, belässt es der Erzähler nicht beim Attribut ,gütig'? Warum verzichtet er nicht auf die 
,leseransprechenden' Klammern $(\Leftrightarrow I .2 .3)$ ? Und warum greifen andere Erzähler auf eine quasibiblische, pompöse Wortgestalt zurück: „Solange sie hier lebte, war das Nachhausekommen für mich das Wohlgefallen, das den Menschen auf Erden versprochen ist" (Regenschirm, S. 35)? Teilweise findet sich die Antwort mit externem Analyseblick im ,deemphatischen', antiemotionalen Distrikt ( $\Rightarrow$ II.5.6), teilweise ist es aber auch diegetisch so, dass sich in einige der exemplarisch untersuchten Liebes(lebens)entwürfe unversehens oder auch deutlich bereits ein leichter Schatten mischt, sodass die Situationen voller Gefühl nicht immer von Dauer sein müssen.

\section{UNZUFRIEDENHEIT UND TRENNUNGEN}

Dabei lebte ich jetzt in einem freundlichen sexuellen Klima, das ich mir schon lange gewünscht hatte. Durch die fast ununterbrochene Bereitschaft von Carola gab es kaum noch Spannungen zwischen uns; jedenfalls war das mein Eindruck. Mein früheres Verlangen, das stets auf einen Mangel zurückging, verschwand mehr und mehr. [...] Das war einerseits befriedigend, andererseits rätselhaft, fast verdächtig. (Außer uns, S. 69 f.)

Sobald der Zweifel Einzug in die Gedankenwelt der Protagonisten hält, ist die Blütezeit der Beziehung passé. Zumal dann, wenn Unausgesprochenes, Alltägliches oder die bereits erörterten Makel, Marotten und Merkwürdigkeiten ( $\Rightarrow$ II.1.3) die Beziehung belasten und der Unzufriedenheit einen Nährboden bereiten:

Zwischen Dagmar und Wolf türmte sich ein riesiges schmutziges Schweigen auf; sie spürten das Verquere und Unreine aller wirklichen Enttäuschungen, das sich niemals wieder aus den Gefühlen herausreinigen ließ. Jeder schob für sich allein irgendwelche Nachforschungen herum, die plötzlich nicht mehr auszusprechen waren. (Fremde Kämpfe, S. 234)

Obwohl im folgenden Beispiel der Unmut verbal artikuliert wird, ist das gezeitigte Resultat um keinen Deut befreiender. Vielmehr ist das verbale und körperliche Dimensionen verschmelzende Missverständnis ein nahezu fatales: „Du bist zu grob zu mir, sagte sie. Augenblicklich ließ er von ihr ab und legte sich zurück. Daß nicht nur er mit ihr, sondern auch sie mit ihm unzufrieden war, schuf eine riesige Entfernung zwischen ihm und ihr." (Sorgen, S. 244) In letzter Konsequenz sind diese ausgesprochenen Vorwürfe einerseits natürlich einem „schmutzige[n] Schweigen“ vorzuziehen; dennoch führen selbst offene Worte in Beziehungen mitunter zum Verlust der Sprache:

Er glaubte, zu jeder Frau, wenn er es nur wollte, zart sein zu können, und er war der Meinung, daß er zu Margot zart war. Verdutzt lag er da. Soll ich dir einmal sagen, wie du in letzter Zeit mit mir umgehst? fragte sie. Ja, sagte er. Du hast zum Beispiel drei Arten, mir an die Brust zu greifen. Die erste geht so, sagte sie, daß du eine Brust in deiner Hand liegen haben willst. Wenn du das möchtest, greifst du einfach hin und umschließt eine Brust mit deiner Hand und drückst daran herum. Die zweite Art geht so, daß du mit Zeigefinger und Daumen an meiner Brustwarze zupfst. Ich weiß nicht, ob das für dich schön ist, wahrscheinlich denkst du, es sei für mich schön. Es ist aber nicht schön für mich, es tut mir manchmal sogar ein bißchen weh, sagte sie. Und die dritte Art ist die blödsinnigste von allen; dann legst du deine Hand flach auf meine Brust und machst kreisförmige Bewegungen, immer im Kreis herum drehst du deine Hand mit meiner Brust darunter, ein richtiges Herumrühren ist das. Ich weiß nicht, wie das gekommen ist bei dir, sagte sie; vor einem halben Jahr war es nämlich noch ganz anders. Er war vollkommen stumm geworden. Er wußte überhaupt nicht, was er Margot sagen sollte. (Sorgen, S. 245) 
Selbst- und Fremdbild ( $\Rightarrow$ II.2.1) sind in der Handhabe des weiblichen Geschlechts für Abschaffel zwei verschiedene Sphären, die jedoch erst durch die mutige, offene und direkte Ansprache Margots zutage gefördert werden. Kritikfähigkeit ist des Basistypus Sache nicht - und so nimmt es nicht wunder, dass kein Dialog entspringt, sondern die Stummheit als Symptom von Überforderung eine konstruktive Problemlösung ab ovo unterläuft. Bedauerlicherweise führt das aus Kindheitserfahrungen resultierende „Beanstandungsverbot“ (Sorgen, S. 246) Abschaffels just zur Neuauflage der - dem Basistypus prinzipiell verhassten - Verhaltensweisen der Eltern:

Trotz aller Mühe, aus meiner Ehe etwas Besonderes zu machen, bin ich jetzt sicher, daß auch meine Ehe mittelmäßig war. Schon meine Eltern waren mittelmäßig, meine Kindheit war mittelmäßig [...], aber seit dem letzten Anruf steuere ich auf das Mittelmäßigste zu, was es überhaupt gibt: auf eine Scheidung. (Heimweh, S. 109)

Rotmund sieht sich als Wiedergänger seiner „mittelmäßig[en]“ Eltern, als vom Schicksal darauf verpflichtet, eine ebenso unglückliche Entzweiung erleben zu müssen. In der Beobachtung anderer Paare, die „das Mittelmäßigste [...]: [...] eine Scheidung“ zu umschiffen wissen, holt er ins Allgemeine aus:

Immer wieder wundere ich mich, wenn ich ältere Paare sehe, wie es ihnen gelingen konnte, so lange zusammenzubleiben. Dabei weiß ich längst, wie ihr Zusammenbleiben funktioniert: Man muß stillhalten. Die alten Paare erleiden alles, was alle erleiden, aber sie schreien nicht wie die Jungen, sie verhalten sich still. (Heimweh, S. 171)

Sofern Duldung als positiv konnotierte Handlungsalternative überhaupt diskutabel ist, geht den „Jungen“ die Fähigkeit ab, gleichsam überzureagieren und potenziellen Trennungssituationen fatalistische Züge anzudichten. In der Form häufig zukunftsgewisser Vorausdeutungen neigen bei Genazino jedenfalls namentlich ,die Jüngeren' zu übertriebenem und nicht hilfreichem Kalkül (vgl. Sorgen, S. 259), das das Beziehungsende lakonisch vorwegnimmt: „Zugleich fühlte er, daß es das letzte Mal war, daß sie zusammen weggewesen waren." (Falsche Jahre, S. 504) Unprätentiös schaut auch Weigand ohne die Fähigkeit des ,Stillhaltens' fast merkwürdig anteilnahmslos auf die sich erst konstituierende Trennung:

Als sie gegen 18.00 Uhr die Brotkrümel und den Sand von der Wolldecke herunterschüttelte, wußte ich, daß es mit uns beiden zu Ende war. Ich begleitete sie wie üblich nach Hause. Am Dienstag der folgenden Woche, in der Mittagspause, gingen wir gemeinsam zur Bank und lösten unser Sparbuch auf. Danach sahen wir uns nicht wieder. (Wohnung, S. 86)

Einem aus ca. zwanzigjähriger Verspätung heraus erstelltem Verlaufsprotokoll nicht unähnlich (konkrete Uhrzeiten und Ortsangaben) bei gleichzeitiger Zukunftsgewissheit spiegelt diese Passage wider, wie ohne größeren Eklat und lediglich aufgrund einer Lebensstilunverträglichkeit (Freibadbesuch) eine (nicht-eheliche) Beziehung in die Brüche gehen kann. Mit der Verwendung von ,wir` wird die Einvernehmlichkeit der Trennung markiert. Häufiger ist aber eine Einseitigkeit in der Entscheidung zu beobachten: 
Peschek war solange Margas Freund gewesen, solange er ihre Eigentümlichkeiten ertragen konnte. Wenn die Ticks von Menschen unterhalb der Zumutbarkeitsgrenze blieben, war es noch möglich, Vereinbarungen zu treffen, um auch in den Genuß der Vorzüge dieser Menschen zu gelangen. (Fremde Kämpfe, S. 97)

Bei näherem Besehen entpuppt sich Pescheks Entscheidung gegen Marga als Kosten-NutzenRechnung, die erzählseitig so aufgebaut ist, dass er vermeintlich ab dem Zeitpunkt, an dem „er ihre Eigentümlichkeiten“ nicht mehr „ertragen konnte“, alternativlos die Trennung forcieren muss. Nicht minder kalkuliert und an der Grenze zur Niederträchtigkeit schiebt der Protagonist aus Wenn wir Tiere wären bereits beschlossene Entzweiungen auf, um nicht ,ohne' dastehen zu müssen: „Aber ich konnte mich damals nur dann von einer Frau trennen, wenn die nächste Frau schon in Sicht war“ (Tiere, S. 84), denn „aus dem frauenlosen Leben dürfte kein Dauerzustand werden“ (Kassiererinnen, S. 18). Der „Genuß der Vorzüge dieser Menschen“ heiligt als Zweck die Mittel, sich Frauen ,warmzuhalten':

Er hätte einen Tag zu Hause bleiben können, um Frau Schönböck zu zeigen, daß er ihr aus dem Weg gehen wollte. Aber eine Störung dieser Art war ihm zu deutlich, obwohl er sich zugab, daß er nichts anderes wollte als die sofortige Distanzierung von Frau Schönböck. [...] Eine Weile spielte er sogar mit der Möglichkeit, Frau Schönböck als eine Art Betriebskonkubine zu behalten. (Sorgen, S. 297)

Weiblichen Nebenfiguren steht in Genazinos Romanen eine ebenso vielfältige Formsprache zur Verfügung, wenn sie sich von den Hauptfiguren trennen oder diese abweisen: „Er war verlassen worden und hatte es nur durch Zufall und beiläufig erfahren, weil Margot selbst auf die Mitteilung keinen Wert mehr legte." (Sorgen, S. 272) Abschaffel fühlt sich hintergangen und ist zusätzlich empört ob der nicht kommunizierten Beendigung der Beziehung. Sprichwörtlich am Beziehungsende ,zu schlucken' hat auch Eckhard Fuchs:

Christine hatte einen jungen Mann bei sich, den Eckhard nicht gleich bemerkt hatte. Fuchs du hast die Gans gestohlen, sagte sie kichernd. Ihr Begleiter stand eng neben ihr und tat ein wenig so, als müßte er für Christines Verhalten um freundschaftliche Nachsicht bitten. Christine wischte sich den Mund und die Hände ab. Das ist Stefan, sagte sie und stellte Eckhard den jungen Mann vor. Eckhard fühlte sich überrumpelt. Und das ist ein guter Kunde von uns, sagte sie zu Stefan und deutete auf Eckhard. Er schluckte und begann viel zu langsam, die Situation zu verstehen. (Ausschweifung, S. 234 f.)

Bevor Eckhard in einer inneren Gegenoffensive dazu übergehen wird, „Christine zu verhöhnen“ (Ausschweifung, S. 235), wird ihm zugesetzt: Mit dem seinen Nachnamen zitierenden Liedtext und dem Kichern wird er verniedlicht, mit der Vorstellung, er sei nur „ein guter Kunde“, vom Liebhaber zum Bekannten degradiert. Es fällt auf, dass die männlichen Hauptfiguren dabei wie Schmerzensmänner erscheinen, die schuldlos und hinterrücks verlassen werden. Außerdem wird die Situation der Trennung häufig als singuläres Datum im Lebenslauf herausgestrichen, wodurch die Überwältigung apostrophiert wird:

Der eigentliche Schlag traf mich zwei Tage später. Sonja sagte am Telefon, sie habe in ihrem Wohnzimmer meine Sachen [...] auf das Sofa gelegt, ich solle sie nächster Tage abholen. Am besten an einem Werktag vormittags oder nachmittags, wenn sie im Büro war. [...] Als ich ein paar Sekunden sprachlos blieb, sagte sie, dass sie bald heiraten und mit ihrem Mann in eine andere Stadt ziehen 
werde. Den Namen ihres Mannes und die zukünftige Adresse nannte sie nicht. [...] Noch nie war ich von einer Frau gebeten worden, aus ihrem Leben zu verschwinden. Sonja war bereit, ihre Körperlichkeit, ihren Drang nach Leben und ihre Freude im Bett einem anderen Mann zu schenken. Kurz darauf onanierte ich und dachte dabei an Sonja. Ich wiederholte im Kopf eine Szene, die sich oft zwischen uns ereignet hatte. Sie saß auf mir und vögelte mich, als sei ich die Frau und sie der Mann. Nach einer Weile sagte sie: Soll ich dich ... das folgende Wort sagte sie nicht. Ich nickte im Kissen und stöhnte tatsächlich wie eine Frau. (Regen, S. 63 f.)

Um die resolute und reulose Entscheidung Sonjas zu plausibilisieren, wird sie mit einer sexuellen Reminiszenz unterlegt, welche die ,üblichen' Geschlechterverhältnisse auf den Kopf stellt und die Frau auch im Bett als dem Mann überlegene Akteurin vorstellt ( $\Rightarrow$ II.5.3).

Offensichtliche Abweisung und Ablehnung ist in Genazinos Romanen Frauensache und wird von den Männern hinsichtlich der Interpunktion von Ereignisfolgen ${ }^{52}$ ursächlich bei jenen selbst gesehen. Diese Regel wird durch wenige Ausnahmen gebrochen, bei denen eine ,Teilschuld' zumindest in Erwägung gezogen wird: „Weil ich meinte, das alles nicht länger ertragen zu können, bedrängte ich Carola oft viel zu überraschend. Wahrscheinlich machte ich dabei keine gute Figur. Carola wich zurück oder wehrte mich sogar ab.“ (Außer uns, S. 28) In der unmissverständlichsten Sprache, der des Körpers $(\Leftrightarrow I I .1 .4$ u. $\Rightarrow$ II.5.1), findet Abweisung häufiger ihren Ausdruck: „Durch eine knappe Bewegung (sie stellt ihr Gesicht schräg und zeigt mir die abweisende Glätte ihrer linken Wange) teilt sie mir mit, daß sie nicht angehalten und nicht angesprochen werden möchte. Ich habe die Bitte verstanden und komme ihr nach." (Regenschirm, S. 124) Allerdings zumeist nicht ohne Groll: „Vor etwa zehn Jahren, noch bevor ich Edda kannte, hatte ich sie einmal umworben und war von ihr abgewiesen worden. Ich wusste nicht mehr, warum sie nichts von mir wissen wollte. Es fiel mir allerdings auch nicht mehr ein, warum ich sie damals begehrt hatte." (Kassiererinnen, S. 92) Es fällt auf, dass es sich um eine analeptische ,Retourkutsche' handelt: Anscheinend durch den Parallelismus als gleichrangige Erinnerungsteile eingeführt, überrascht es dennoch, dass sich der Ich-Erzähler angeblich nicht daran erinnern kann, was an Elisabeth begehrenswert gewesen ist, da er im gleichen Atemzug detailreich ihr damaliges Bild und Verhalten vor Augen zu führen imstande ist:

Im Stillen war ich ein wenig erschüttert, weil sie stark gealtert war. Über ihren Augenlidern hatte sich die Haut gefältelt. Elisabeth redete ein bisschen mehr und schneller als damals, auch ein wenig feuriger, und sie blickte mich beim Reden öfter an. Ich merkte, dass sie mir immer noch gefiel. (Kassiererinnen, S. 93)

Vor diesem Hintergrund ist das Schlussmuster: ,Sie hat mich damals abgewiesen, warum also sollte ich mich überhaupt daran erinnern, was mich damals für sie eingenommen hat?', wahrscheinlicher als die vorgebliche Amnesie. Es restituiert zugleich die Gendernorm, nach der der Mann der Erwählende ist, der auf weibliche Reize hin den Kontakt sucht. Sobald dieses Selbstverständnis in Zweifel gezogen wird, ist die Überraschung groß, wofür Dieter Rotmunds Erinnerung einstehen kann: 
Im Frühjahr, als Frau Bredemeyer ebenfalls eine ärmellose Bluse trug, habe ich mich zu einem Annäherungsversuch hinreißen lassen, den ich kurz darauf bereut habe. Ich wollte mich mit Frau Bredemeyer verabreden, aber sie sagte kühl, daß es für mich doch wohl besser sei, wenn ich meine Aufmerksamkeit meiner Frau und meinem Kind widme. Ich war über diese Abfuhr so verblüfft, daß ich mich entschuldigte und sofort an meinen Schreibtisch zurückkehrte. Ja, ich bin (noch) verheiratet, und ich habe leider den Fehler begangen, daß ich zwei- oder dreimal im Büro über meine Ehe gesprochen habe. Ich redete darüber, daß meine Ehe nur noch formal eine Ehe sei, und dies vermutlich nicht mehr lange. Ich gebe $\mathrm{zu}$, daß diese Mitteilung auch eine Botschaft an die zahlreichen allein lebenden Frauen in unserem Büro war, denen ich mich auf diese ungezwungene Weise als (wie soll ich sagen) Beziehungskanditat empfehlen wollte. (Heimweh, S. 16)

Über einen ,Korb` derart verblüfft zu sein, lässt verhältnismäßig tief blicken in die Geschlechterrollenstereotypien der Genazino'schen Figurenromane und Romanfiguren. Eine vertiefende Analyse unter gendertheoretischer Perspektive $(\Rightarrow$ II.5.3) ist nicht nur per se geboten, sondern geradezu ein bisher nicht eingelöstes Desiderat der Genazinoforschung, 53 taucht doch nahezu nie die Problematisierung der als ,normal' apostrophierten Heteronormativität, männlichen Dominanz und Vormachtstellung etc. auf. Eine eindrückliche Abweisung in Form einer Szene aus der Ehe der Rotmunds sei etwas ausführlicher zitiert:

Obwohl ich müde bin, wächst meine Unruhe. Erst eine halbe Stunde nach Mitternacht kommt Edith zurück. Sie öffnet nicht die Tür zum Wohnzimmer, wo ich immer noch liege und nicht schlafe, sondern sie geht ins Bad und duscht (ich kann es hören), was ich nach Mitternacht ein wenig sonderbar finde. Dann geht sie rasch ins Schlafzimmer und legt sich ins Bett, danach Stille. Wenig später erhebe ich mich, gehe zu ihr hinüber, schlüpfe in ihr Bett. Ich umfasse ihren Leib und drängle mich zwischen ihre Beine. Mein Drang ist heftig, weil er mit der Bitterkeit mehrerer Stunden vermischt ist. Ich werde mich nicht zurückweisen lassen. Aber dann geschieht etwas Sonderbares und eigentlich Unerhörtes. In den ersten Sekunden scheint Edith zugänglich. Dann umarmt sie mich, und ich merke sofort, daß ihre Hände naß und kalt auf meinem Rücken liegen. Ich erschrecke und zucke zusammen und löse mich von Edith. Es fällt kein Wort zwischen uns. Ohne einen weiteren Annäherungsversuch verlasse ich das Bett und gehe ins Bad, um mich abzutrocknen. Edith hat mich im Laufe unserer Ehejahre an häufige Versagungen gewöhnt. Oft, wenn ich mit ihr schlafen wollte, redete sie mir ein, daß der Austausch von Zärtlichkeiten schon ausreichend sei. Ich wollte schon auch zärtlich sein, aber nicht stundenlang und nicht ohne Kopulation am Ende. Edith hingegen stimmte mich mit Zärtlichkeiten so herab, daß ich mich nach einer halben Stunde einer inneren Verstimmung annäherte und meine Erektion nachließ, wenn sie nicht schon ganz verschwunden war. Ich kam immer weniger damit zurecht, daß Edith meinen Drang so oft verwandelte beziehungsweise auflöste. Mühsam mache ich mir klar, daß Edith an diesem Abend mit meinem nächtlichen Besuch gerechnet hatte und mich mit einer besonderen Abwehridee zur sofortigen Aufgabe zwingen wollte. (Heimweh, S. 69)

Der unmittelbare Präsentationsmodus (Präsens, Tempo) steht im krassen Gegensatz zur geistigen und körperlichen Distanz des Ehepaares. Bezogen auf den Liebesentwurf gendertheoretisch bedeutsamer ist allerdings, dass das unerhörte Ereignis die tückische Abwehrgeste der Frau sein soll - die im direkten Gegensatz übergriffige Umklammerung Rotmunds, der sich mit „Drang“ „zwischen ihre Beine“ begibt mit dem festen Vorsatz, sich „nicht zurückweisen“ zu lassen, was genaugenommen eine potenzielle Vergewaltigung paraphrasiert, ist das eigentlich Unsägliche. Nun arbeitet der Erzähler aber mit raffinierten Strategien, die mindestens bei einem Teil der Rezipienten dazu führen, Rotmund ihre Sympathie zuzudenken und dessen Verhalten als gerechtfertigt einzuschätzen. Ein strategischer Strang ist die Erzählung der Vorgeschichte, die von 
Entbehrungen, der sexuellen Unlust der Frau, die ihren ,ehelichen Pflichten' nicht nachkommen will, sowie der assertiven Vorbildlichkeit des Protagonisten - „Ich wollte schon auch zärtlich sein" - erzählt. Der zweite Strang flicht Fäden zusammen, die die moralische Integrität Ediths korrumpieren: Sie kommt erst „eine halbe Stunde nach Mitternacht“ nach Hause, wo der Mann auf das gemeinsame Kind aufpasst. Sie sieht weder nach diesem noch nach jenem, sondern beseitigt unter der Dusche mögliche Spuren einer außerehelichen Beziehung, wie dem Leser unmittelbar nach dem Zitat eröffnet wird (vgl. Heimweh, S. 69). Und sie sinnt darauf, die sexuelle Begierde ihres Ehemanns, die man dieser verqueren Logik zufolge ja phallozentristisch noch als Kompliment verstehen könnte, für immer zum Erliegen zu bringen, nachdem sie bereits in der Erzählvergangenheit alles Erdenkliche getan hat, um seinen „Drang“ zu „verwandel[n] beziehungsweise auf[zu]lös[en]“. Ist es dann nicht gerecht, wenn er sich holt, was ihm zusteht (Ironie!)?

Zugrunde liegt, wenn man diese Debatte auf das nächste Unterkapitel vertagt $(\Leftrightarrow$ II.5.3), die (auch, aber nicht nur) körperliche Entfremdung in einer Beziehung, die bei Genazino generell mit Lustlosigkeit und ,Verklemmung' verhandelt wird. Gerade die bereits kritisierte Form des ehelichen Zusammenlebens (s.o.) wird als Hort für den sexuellen Niedergang der Beziehungen präsentiert: Mit der Zeit, zumal mit der Geburt von Kindern, kann das Auseinanderleben und der damit einhergehende Libidoschwund prächtig gedeihen (vgl. Ausschweifung, S. 46 f.). In der Ausschweifung wird dies subtil-metaphorisch wie nachdrücklich-konkret am Beispiel des Kosenamens „Schwälbchen“ vorgeführt: Während dieser zunächst (vor der Ehe, vor dem Kind) das weibliche Genital bezeichnet hatte, wird er sukzessive ,entsexualisiert', bis er schließlich das Kind selbst meint und seine ursprüngliche Begriffsverwendung der Vergessenheit anheimfällt (vgl. Ausschweifung, S. 17 f.). Es handelt sich um eine im breiten Gürtel der Familienähnlichkeiten zu verortende Geläufigkeit, „dass meine Beziehung zu Carola lange nicht mehr so intensiv und freudig war wie in früheren Jahren. Jetzt überlegte ich auch noch, ob es ihre Schuld oder meine war, dass der Drang zwischen uns nachließ.“ (Außer uns, S. 14) $)^{54}$ Die aufgeworfene Schuldfrage ist in den wenigsten Fällen glasklar zu beantworten - wie bereits im Falle gelingender Sexualität gehören auch unter negativen Vorzeichen für gewöhnlich ,immer zwei dazu'. Dass der Überdruss zumeist seitens der männlichen Figuren geäußert wird, ist in letzter Konsequenz erneut nur gendertheoretisch erklärbar: „Aber wie sollte er sonst mit der Schwierigkeit fertig werden, daß er Ruth nicht mehr begehrte, obwohl er sie doch zweifelsfrei liebte?“ (Ausschweifung, S. 250) Eckhard verdreht die Tatsache, dass Ruth (ihn) ,nicht will', um sein Idealbild eines begehrten Partners nicht zu beschädigen. Seit Genazinos erstem Roman allerdings schwingt immer auch das Bedauern mit, dass es einst doch Zeiten der gegenseitigen Attraktion gegeben

$54 \quad$ Dass auch die ,unfruchtbare' Koinzidenz von Alter und Lustlosigkeit eine Rolle spielt, spiegelt das folgende Zitat ( $\Rightarrow$ II.5.6): „Das Verlangen nach Sexualität verschwand von Jahr zu Jahr ohne Angabe von Gründen [...]. Ich stand manchmal wie ein vergessenes Gestell herum, das nach einem Antrieb suchte." (Außer uns, S. 27) 
hat: „[I]ch betrachtete Elke jetzt nicht einmal so genau, wie ich es früher getan hatte, als es galt, Unentdecktes zu entdecken und Verborgenes zu lüften.“ (Laslinstraße, S. 201) Alltäglichkeit stellt sich ein, „ich stellte fest, ich spürte nichts, ich fragte mich, Axel fragte ich, ich rief mich, Aaaaxel rief ich, was ist denn los, hier ist doch Elkes Rücken, auf auf, Aaaaaxl, ich rief mich an und zurecht, aber es war, als hätte ich nichts gehört, und ich wußte doch, daß ich selbst rief." (Laslinstraße, S. 202) Die Lust ist abhandengekommen, erzähltheoretisch in stumme Selbstunterredung verpackt und mit dem Vorwurf gepaart, selbst Teil des Wahrnehmungsproblems zu sein: „[G]ewaltsam versuchte ich, in Elkes Augen das zu sehen, was ich sehen wollte, was ich von früher kannte." (Laslinstraße, S. 209) In Laslinstraße sind Gewöhnung, Trott, Stillstand und Alltag im Bild des schreckenden Gespensts der Langeweile vereint, sodass die sexuelle Unzufriedenheit nicht loslösbar von den anderen Formen der Gewöhnung ist. Aber der stets anwesende Überdruss ist als Vergleichsgrundlage deutlich erkennbar und auch Teil eines weiteren, mit Liebe, Sex und Zärtlichkeit verknüpften Problemkomplexes:

\title{
TRANSITORISCHE SCHWELLENMOMENTE: GELINGEN VS. MISSLINGEN
}

Gemeint sind diejenigen Situationen, in denen potenzielle Verabredungen oder sexuelle Vereinigungen ,auf der Kippe stehen' und durch geringste Kräfteverschiebungen sowohl zur einen als auch der anderen Seite nahezu gleichwahrscheinlich ausfallen könnten. Obwohl der Standardwert bei Genazino vorsieht, dass die Annäherungen relativ problemlos und zumeist aus dem Nichts heraus funktionieren - „An der Kasse küssen wir uns, genau wie beim letzten Mal vor etwa drei Wochen. [...] Es ist nicht das erste Mal, daß Margot und ich im Anschluß an das Haareschneiden miteinander schlafen“ (Regenschirm, S. 53) ${ }^{55}$-, werden doch immer wieder handlungsauslösende Faktoren (hier: Initiative und Zärtlichkeit) thematisiert:

\begin{abstract}
Wenn ich jetzt gestolpert und auf Elkes Bett gefallen wäre, hätte es zufällig ausgesehen, aber ich stand und konnte nicht stolpern; sollte ich anfangen zu gehen, um dann zu stolpern, nein, das würde läppisch aussehen, es ging mir immer so, sie setzte sich einfach auf ihr Bett und überließ alles andere mir, sie wartete und zeigte nicht, daß sie wartete, verflucht, es mußte wohl wieder sein heute abend. [...] [E]s wurde nichts gesprochen, das war der Übergang, der stumme Übergang, das mußte so sein, das war keine Vorbereitung, das waren die ekelhaften Minuten davor [...]. Ich küßte Elke, nicht lang und nicht feucht, auf die geschlossenen Lippen, Elke wollte zärtliche Küsse, das wußte ich, Zärtlichkeit mußte sein, kommt ein Mann betrunken nach Hause und bringt es fertig, zärtlich zu sein, dann ist alles wieder in Ordnung, seine Frau riecht das furchtbare Gesöff, aber wenn er zärtlich ist, ist er ein Mann, gleichgültig, was er sonst noch ist. (Laslinstraße, S. 83 f.)
\end{abstract}

Der Mann muss zumal in den früheren Texten Genazinos aktiv werden, obwohl zumeist als gesichert gelten kann, dass eine Frau, wenngleich sie es nicht zeigt, nur darauf wartet, dass der Mann die Initiative ergreift. Körpersprachliche und nonverbale Indizien finden sich - neben anderen ( $\Rightarrow$ II.5.3) - sonst etwa im Lachen oder Kichern der Frauen (vgl. Falsche Jahre, S. 470), aber gelegentlich handelt es sich auch um ergebnisoffene Schwellenmomente, in denen die Unsicherheit

55 Vgl. für die Thematisierung des Schwellenmoments beim Beischlaf mit, versöhnlichem‘ Ende etwa Kassiererinnen, S. 116-118. 
besteht, ob die Annäherung von Erfolg gekrönt sein wird: „Abschaffel stellte sich zum erstenmal vor, wie es wäre, wenn er mit ihr schliefe. Er stellte sich außerdem vor, daß sie nichts dagegen hatte. Vielleicht will sie es genauso stark wie ich, dachte er, aber vielleicht will sie es auch überhaupt nicht.“ (Falsche Jahre, S. 469) Axel Degen, der im Gegensatz zu Abschaffel das unsichere Moment, das einer nicht zuvor kommunizierten Annäherung naturgemäß inhärent ist, ausklammert, weil er Elkes überdrüssig ist, denkt hingegen: „[W]ahrscheinlich wartete sie darauf, daß ich etwas machen würde, zu ihr hinkommen, meiner Hand freien Lauf lassen, aber wenn ich das gemacht hätte, wäre es eine Lüge gewesen, Heuchelei, ich blieb stehen, es trieb mich nichts“ (Laslinstraße, S. 204) Auch wenn es deutlicher ist, dass die Frau Interesse am Beischlaf hat, kann es zur Zurückweisung kommen: „Er konnte zum Ausdruck bringen, ob er sie noch einmal wollte oder ob er sie nicht mehr wollte. Und weil Abschaffel die volle Länge ihres Schweigens mitschwieg, war die Sache entschieden." (Abschaffel, S. 145)

Wird hier das Nichtzustandekommen als bewusste, Rubikon-Entscheidung' $(\Rightarrow$ I.3.1) dargestellt, kann es auch durch Missverständnisse (vgl. Licht, S. 88; vgl. Fremde Kämpfe, S. 185 f.) sowie durch Zufall (intern) bzw. kompositorische Erwägungen (extern) motiviert werden:

Sie liest in einem Buch, ich lese in einem Buch. Sie hebt das Gesicht, ich hebe das Gesicht. Sie schaut mich an, ich schaue sie an. Sie senkt den Blick, ich senke den Blick. Sie kann nicht weiterlesen, ich kann nicht weiterlesen. Sie ist diskret, ich bin diskret. Sie hat Zeit, ich habe Zeit. Sie vermeidet weitere Blicke, ich vermeide weitere Blicke. Sie hebt ihr Buch, ich hebe mein Buch. Ihr wird klar, mir wird klar. Sie liest, ich lese. (Licht, S. 39)

Schließlich existieren - sowohl seitens der Frau als auch seitens des Mannes - personenbezogene Hindernisse, die ein Misslingen befördern. Diese werden häufig im (zu) jungen Alter der Akteure angesiedelt: „Sie war 17, ich 16. Wir wollten miteinander schlafen, aber unser Pech war, dass sowohl sie als auch ich absolut ahnungslos waren." (Kein Geld, S. 73) Der namenlose IchErzähler aus Genazinos Wenn wir Tiere wären bzw. dessen jüngeres erinnertes erzähltes Ich sieht sich ebenfalls aufgrund mangelnder Erfahrung (evtl. sogar mangelnder Aufklärung?) vor das folgende Problem gestellt:

Sie öffnete mir den Hosenladen und nahm mein erigiertes Glied in die Hand. Sie setzte sich auf einen halbhohen Karton, so dass ich leicht in sie hätte eindringen können, wenn ich gewusst hätte, wie das geht. Am meisten erschrak ich über die tiefen schwarzen Haarbüschel zwischen ihren Beinen. Inmitten des Schamhaars leuchteten die Schamlippen wie zwei kleine rosa Raupen hervor. Verärgert zog die Küchenhilfe ihren Schlüpfer wieder an und ließ mich kommentarlos stehen. (Tiere, S. 84)

Neben den Ekelassoziationen $(\Leftrightarrow$ II.5.6) wird der Protagonist durch die schlichte Unkenntnis der „Abfolge der Sequenzen“ (Tiere, S. 84) daran gehindert, den damals gewünschten Beischlaf zu vollziehen. Ein weiteres problematisches Hindernis wird im gleichen Roman erinnert:

Sie hatte eine entzückende kleine Kindermöse, lieblich umkräuselt von hellblonden Löckchen. Dieses begeisternde Paradieschen war voller Tücken. Erstens war es fast immer trocken und deswegen abgedichtet wie ein Frauenschließfach, wenn es so etwas gibt. Ich musste es lange liebkosen, damit es sich ein wenig öffnete und zutraulich wurde. Zweitens setzte dann, als ich endlich drin war, ein 
merkwürdiges Theater ein. Karin begann, mich wieder aus sich herauszuschieben, indem sie die Beine immer mehr zusammendrückte, bis ich tatsächlich wieder herausrutschte. Wir hatten nie über diesen fatalen Verlauf gesprochen, gewöhnten uns aber an ihn, als sei er zwischen Mann und Frau das Menschenmögliche. (Tiere, S. 111)

Der Akt misslingt - das ist sicher. Die Frage hingegen, warum, und auch die erzähltechnischen Umstände bis hin zur Wortwahl sind ergiebige Untersuchungsgegenstände einer gendertheoretischen Analyse. Im vorliegenden Beispiel ist es etwa der Diminutiv - wiewohl bei Kosenamen üblich -, der das weibliche Geschlecht unmittelbar verniedlicht und als „entzückende kleine Kindermöse“, als „Paradieschen“ bezeichnet. Subtextuell ist es die Pflicht des Mannes („Ich musste“), das „Frauenschließfach“ (vgl. derb: Dosen- bzw. Büchsen-Metaphern für Frauen; populär bspw. in der Bezeichnung des ,Büchsenöffners Alkohol') zu öffnen. Dieses ist „fast immer trocken“. Warum ist es das? Vaginaltrockenheit gibt es aus unterschiedlichen Gründen, doch die naheliegendste Lesart im Roman Wenn wir Tiere wären grenzt eine potenzielle Mitschuld des Mannes kategorisch aus - schließlich ist er es, der durch lange Liebkosungen das verdinglichte („zutraulich“) Genital ,zum Leben erwecken“ muss. Dass das Misslingen des Akts ferner durch das „merkwürdige[] Theater“, das die Frau inszeniert, indem sie den Mann „wieder aus sich herausschieben" möchte, untergraben wird, wird nicht unter einer problemorientierten Perspektive gedeutet, was zu tun sich das folgende Unterkapitel anschickt, sondern wird aus männlicher Situation für „fatal[]“ erklärt.

\subsection{Genderaspekte}

Anhand von Wilhelm Genazinos Figurenromanen und Romanfiguren lässt sich die moralisch mitunter hochproblematisch zu nennende Konstruktion von Geschlechterrollen ${ }^{56}$ bestens untersuchen und mit einer „dekonstruktive[n] Kritik von Geschlechtergegensätzen“ sowie einer „diskursanalytische[n] Kritk von sozialen Unterdrückungsmechanismen“ begegnen. ${ }^{57}$ Erneut soll zunächst Die Liebesblödigkeit herangezogen werden, um exemplarisch die Vielschichtigkeit dieses Untersuchungsfeldes unter Beweis zu stellen, mit der Fragestellung, „wie kulturelle Entwürfe von Weiblichkeit und Männlichkeit in der Literatur und ihrer Lektüre konstituiert, stabilisiert und revidiert werden".58 Zwei extreme Positionen stehen sich ziemlich unvermittelt in der Liebesblödigkeit gegenüber: eine häufig mit überraschender Selbstverständlichkeit vorgetragene, unterschwellig wirkende Sicht auf ,die Frau' als Objekt einerseits, eine von dieser geschlechts-

56 Vgl. grundlegend: Thomas Eckes: Geschlechterstereotype. Von Rollen, Identitäten und Vorurteilen. In: Ruth Becker/Beate Kortendiek (Hg.): Handbuch Frauen- und Geschlechterforschung. Theorie, Methoden, Empirie. 3. Aufl. Wiesbaden 2010, S. 178-189.

57 Achim Geisenhanslüke: Einführung in die Literaturtheorie. Von der Hermeneutik zur Medienwissenschaft. 4. Aufl. Darmstadt 2007, S. 113.

58 Dörte Bischoff: Gender-Theorien: Neuere deutsche Literatur. In: Claudia Benthien/Hans Rudolf Velten (Hg.): Germanistik als Kulturwissenschaft. Eine Einführung in neue Theoriekonzepte. Reinbek bei Hamburg 2002, S. 298-322, hier S 309. Dieses Unterkapitel zitiert passagenweise in Form des Selbstzitats Lehnert/Schul: Gefühlvoll oder voller Gefühl?, S. 233-235. 
stereotypisch im vorvergangenen Jahrhundert wurzelnden Folie sich positiv abhebende ,weibliche Selbstbestimmung' andererseits. ${ }^{59}$

Die späterhin $(\Leftrightarrow$ II.5.6) noch genauer zu untersuchende reflexive Rationalität, die erzählerseitig zwischen Figur und Leser steht, ist auch für die Geschlechterrollen und den Liebesentwurf von Bedeutung: Auf weiblicher Figurenseite empfundene Emotionen liest der Leser nur durch den männlich eingefärbten Ich-Erzähler-Bericht. Der ,männliche Blick` dominiert die ,Kameraführung' demnach auch in Liebesbelangen:60

Judith greift mir unters Hemd und flüstert: Kannst du kommen? [...] Aber dann hilft mir der Anblick von Judiths weißen Schenkeln inmitten einiger sanft wedelnder Gräser. Es ist ein unaussprechliches Glück, Judiths Hinternfalte zu öffnen, die Backen sanft hochzuziehen und dann die Stelle zu sehen, wo die Falte in die Geschlechtsritze übergeht. Judith läßt zwei, drei Seufzer hören, die von Nachtigallenseufzern kaum zu unterscheiden sind. [...] In den Augenblicken des Samenabgangs schwirrt ein Dutzend Sperlinge aus der Hecke. (Liebesblödigkeit, S. 44 f.)

In Filmsprache übersetzt müsste man hier vom Point-of-View-Shot ${ }^{61}$ sprechen - der mit einer wertneutralen Hier-Jetzt-Ich-Origo nur näherungsweise deckungsgleich ist -, also von der subjektiven Sicht des Handelnden auf das Geschehen, hier genaugenommen von oben auf den Hintern der Frau. Übertragen auf den Darstellungsmodus der Erotik zwischen Frau und Mann in der Korrektivlosigkeit ein erschreckendes Ungleichgewicht und eine Hierarchie der Blicke, zumal die Frauen sexuell immer, reibungslos funktionieren' und sich für gewöhnlich lediglich freudiger Laute entledigen ( $\Rightarrow$ II.5.5). Über Bettina, die ehemalige Frau des Protagonisten, heißt es in ähnlichem Duktus:

Sie war damals die Freundin eines Privatdozenten, der sie eines Abends etwas zu lange an einer Theke stehenließ, während er über Wittgensteins Privatsprachen-Argument redete. Ich stellte mich neben Bettina, unterhielt mich mit ihr und nahm sie dann mit nach Hause. (Liebesblödigkeit, S. 165; Herv. N. L.)

Auf ,den Mann' gewendet ist die klischierte Rollenvorstellung um keinen Deut ,moderner'. Der autodiegetische Erzähler wundert sich (an anderer Stelle) darüber, „daß Sandra über den mißratenen Beischlaf kein Wort verliert. Sie verhält sich, als hätte sie mit derlei Zwischenfällen schon länger gerechnet." (Liebesblödigkeit, S. 15) Subtextuell transportiert der Roman einen den Mann für die Sexualität verantwortlich machenden Liebesentwurf, der in Shades-of-Grey-,Sprech` ( $\Rightarrow$ II.5.6) etwa so klingen würde: „Allzeit bereit“.62 Einen Hauch von versuchsweise eingenom-

59 Im zeitlichen Nacheinander der veröffentlichten Genazino-Romane wird dem Thema ,Gleichberechtigung' zunehmend mehr Beachtung geschenkt.

60 Vgl. zu filmischen Blickstrategien, die vornehmlich männlich dominierte Machtkonzeptionen reproduzieren, Laura Mulvey: Visuelle Lust und narratives Kino. Aus dem Englischen von Karola Garmann. In: Liliane Weissberg (Hg.): Weiblichkeit als Maskerade. Frankfurt am Main 1975/1994, S. 48-65, hier S. $55 \mathrm{f}$

61 Womit erneut eine Parallele zur Pornografie gezogen werden könnte.

62 Erika L. James: Fifty Shades of Grey - Geheimes Verlangen. Roman. München 2012. Online: $<$ http://books.google.de/books?id=IcI-

N9bi3IIC\&pg=PT86\&dq=shades+of+grey+er+kommt+langsamen+schrittes\&hl=de\&sa=X\&ei=43uM 
mener Weiblichkeitsperspektive findet man dann doch im Text, aber noch immer den Mann als handelnden, aktiven Part akzentuierend:

Dieser Tage, als ich mit Sandra schlief, konnte ich zum ersten Mal meinen Samen nicht so lange zurückhalten, wie ich es von mir gewohnt bin (oder, vielleicht, war). [...] Beklagen sich nicht immer wieder Frauen darüber, daß die Männer zu schnell und lieblos mit ihnen fertig sind? Das ist der plötzlich zur Hauptsache gewordene Samenabgang! [...] Mir wird Himmelangst. Ein solcher Mann will ich nicht werden. (Liebesblödigkeit, S. 100 f.)

Mühelos lässt sich das Selbstbild des Protagonisten, das hinter dieser Angstvorstellung steckt, ergiebig untersuchen. Zunächst: Der Basistypus ,kann“ lange (vgl. Regenschirm, S. 56 f.): „Zum Glück gehöre ich nicht zu den Männern, denen der Same ohne innere Ankündigung entwischt. Mein Körpergefühl kann die Augenblicke ausmachen, wann sich ein Samenschub bildet und wenig später löst." (Regenschirm, S. 144) Wenn nicht, meint er, sich entschuldigen zu müssen, was manchmal als peinlich, seltener als nicht peinlich (vgl. Falsche Jahre, S. 471) wahrgenommen wird. Sowohl Libido als auch Mannbarkeit scheinen zumeist intakt zu sein: „Jetzt stand ich allein in der Wohnung, war ausgeschlafen und hellwach, aber ohne Frau, dabei reichte meine Kraft für drei Frauen." (Kein Geld, S. 85) Allerdings mischen sich immer wieder erste Indizien für die Vergänglichkeit beider in die Kotexte, denn wenig zuvor ist noch die Rede von seinen Altersflecken sowie seiner allgemeinen Erschöpfung gewesen, später werden seine Krampfadern ausführlich geschildert (vgl. Kein Geld, S. 153). Das Idealbild auch anderer Figuren beginnt irgendwann zu bröckeln:

Obwohl ich mich seit Tagen auf diese Stunde freue, werde ich wenig später das Opfer einer Beinahe-Impotenz. Es dauert, bis ich soweit bin, und ich bin ungeschickt, weil ich vor Ratlosigkeit halb gelähmt bin. Erst durch die Bewegung in Judiths Geschlecht gewinnt mein eigenes Geschlecht Fahrt und Stärke, aber das Warten darauf war enthüllend und demütigend. Auch das Überwältigungsgefühl beim Samenabgang ist nicht so stark wie früher. (Liebesblödigkeit, S. 163; vgl. Abschaffel, S. 79)

Potenzstrotzend, wie er sich selbst erinnert und/oder idealisiert, muss sich die Hauptfigur dem Alter(n) stellen ( $\Rightarrow$ II.5.6):63 „Doch nun schleicht sich das Alter an ihn heran, und er fühlt sich zunehmend überfordert. Auf einmal entdeckt er Krampfadern, das Zucken eines Augenlids, und auch beim Sex stellen sich Probleme ein. Mann und Männlichkeit zeigen sich alarmiert. Was, wenn die sexuelle Kraft versiegt [...]?“64 Der Erzähler (er)findet dafür in seiner Angst sogar ein eigenes ironisch-komisches Wortfeld: Neben der befürchteten „Wackelerektion“ „geistert bspw. das Wort ,Enderektion` (143) in unregelmäßigen Abständen durch den Text und jagt dem Ich-

U5baKMyO4gSJ5oGoAQ\&ved=0CDQQ6AEwAA\#v=onepage \&q=shades $\% 20$ of $\% 20$ grey $\% 20 \mathrm{er} \% 20 \mathrm{ko}$ $\mathrm{mmt} \% 20$ langsamen $\% 20$ schrittes\&f=false $>$.

63 Vgl. zu Krisenkonstellationen männlicher Subjektpositionen Toni Tholen: Subjektivität - Krise Utopie. Imaginationen von Männlichkeiten im zeitgenössischen Denken und Schreiben. In: Mechthild Bereswill/Anke Neuber (Hg.): In der Krise? Männlichkeiten im 21. Jahrhundert. Münster 2011, S. 170-192, hier S. 171. Vgl. auch Jürgen Martschukat/Olaf Stieglitz: „Es ist ein Junge!“ Einführung in die Geschichte der Männlichkeiten in der Neuzeit. Tübingen 2005, S. 85. 
Erzähler, der ohnehin um seine Existenz bangt, einen Schrecken ein. Es ist die Verdoppelung der Furcht vor dem eigenen Tod auf sexueller Ebene." 65

Selten, aber immerhin, wird das Rollenmodell des Liebesentwurfs teilweise aufgebrochen. Initiativ und selbstbestimmt handelt bspw. Sandra (wenn auch in einer durch den Erzähler so lancierten, kritiklos übernommenen Adaption des aus ihrer Sicht ,männlichen Verhaltens'), als sie fremdes Territorium besetzt: „Sandra besuchte mich schon am ersten Abend und forderte mich ohne Zögern zum Sofortbeischlaf auf. Später erzählte sie mir, daß sie damals weder Begierde noch Lust empfand, sie wollte nur ein Zeichen der Inbesitznahme der Wohnung setzen." (Liebesblödigkeit, S. 23) Kategorisch wird damit den involviert handelnden Frauen allerdings die Fähigkeit zur Kombination von sexueller Selbstbestimmung und Lustempfinden abgesprochen - jedenfalls auf der experimentellen Bühne des Liebesentwurfs der Textwelt.

Zusammenfassend lesen sich die Diskurslinien des weiblich-sexuellen Liebesentwurfs materialistisch-objekthaft und fremdbestimmt, wobei es just die fiktiven Frauenfiguren sind, die dem unverhohlen Vorschub leisten und wie im folgenden Beispiel durch ein Lächeln die Äußerungen jedweder Gender-Problematik vorderhand entkleiden:

Nach dem Vögeln schiebe ich Sandras Nachthemd wieder über ihren Hintern. Dieser Vorgang amüsiert Sandra jedesmal. Es ist, als wolltest du meinen Hintern wieder ordentlich in einer Schublade verstauen, sagt sie. Ein bißchen ist es auch so, sage ich, die guten Dinge muß man ordentlich verwahren. Sandra steigt lachend aus dem Bett und bereitet das Frühstück zu. (Liebesblödigkeit, S. 15)

Als Geschlechterrollen bedenklich festschreibend muss das männlich dominierte und qua männlichen Erzählerblicks bis ins Pornografische perpetuierte Wahrnehmungsmuster gelten. Wie weiter unten ausführlicher analysiert ( $\Rightarrow$ II.5.6), sind auch für das Liebessujet beide möglichen Ausprägungen des ,Gefühlsanteils' aus der Sicht des ,Was‘ durch die Darstellungsmittel häufig gebrochen. ${ }^{66}$ Eine erotisch-prickelnde Romantik ist allein durch die Gestaltungsform meist ,nicht drin', selbst wenn die Szenerie prinzipiell ,voller Gefühl` steckt.67 Ferner lässt sich die Abzieh-

65 Hirsch: Geheimgeschichten. Die (Ent)deckung der Scham, S. 66.

66 Vgl. zu stereotypen Reproduktionen von Geschlechterdifferenzen Walter Erhart, Walter/Britta Herrmann: Der erforschte Mann? In: dies. (Hg.): Wann ist der Mann ein Mann? Zur Geschichte der Männlichkeit. Stuttgart 1997, S. 3-34, hier S. 16.; vgl. Martschukat/Stieglitz: „Es ist ein Junge!“, S. 82. Lösungsvorschläge, wie dieses ,Wie' konzeptualisierbar und als Handwerkszeug für eine literaturwissenschaftliche Emotionsanalyse gebrauchsfertig zu machen sei, oszillieren zumeist zwischen Narratologie und linguistisch(-kognitionspsychologisch) affizierter Sprachanalyse. Lediglich drei Konzepte sollen angesprochen werden. Erstens: Monika Schwarz-Friesel setzt sich in Sprache und Emotion auf Wort-, Satz- und Textebene „mit dem Phänomen der Emotionen und ihrer sprachlichen Repräsentationen“ auseinander (Monika Schwarz-Friesel: Sprache und Emotion. Tübingen/Basel 2007, S. 3). Eine ihrer erkenntnisleitenden Untersuchungsfragen lautet daher: „Welche Ausdrucksmöglichkeiten für Gefühle bietet die Sprache lexikalisch, syntaktisch und textuell?" (SchwarzFriesen: Sprache und Emotion, S. 134) Zweitens: Unter dem Titel Das emotionale Wirkungspotenzial von Erzähltexten entwirft Claudia Hillebrandt „ein allgemeines Begriffs- und Analyseraster zur Beschreibung von Emotionslenkungsstrategien in Erzähltexten“ (Claudia Hillebrandt: Das emotionale Wirkungspotenzial von Erzähltexten. Mit Fallstudien zu Kafka, Perutz und Werfel. Berlin 2011, S. 136), das sich feiner untergliedern lässt ist in „[f]igurenbezogene“ und „[d]urch die Erzählkonstruktion ausgelöste Emotionen“ (Hillebrandt: Das emotionale Wirkungspotenzial von Erzähltexten, Kapitelüberschriften von 2.4.1 und 2.4.2). Drittens: Nach dem Konzept des „Foregrounding“ 
bildhaftigkeit der Geschlechterentwürfe auch dann anführen, wenn es darum geht, ungetrübte Fiktions-Emotionen $\left(\Leftrightarrow\right.$ II.5.6) ${ }^{68}$ veranschlagen zu wollen: Wo ein derart asymmetrisches Verhältnis entworfen wird, ist distanzarme ,Einfühlung' schwierig. Sollten sich Leser finden, die im ,Identifikationsmodus' all diesen artefakt- wie fiktions-emotionalen Fallstricken und Stolpersteinen ausgewichen sind, bringt sie spätestens der Motivkomplex des Alterns und der versiegenden Sexualität ,zur Strecke'. Aspekte, die das Interesse der Hauptfigur nicht zu wecken verstehen, bleiben kategorisch ausgeklammert: „Tatsächlich schaue ich mir den Film über Mischehen an, obwohl mich das Problem sowenig interessiert wie die Eifersucht schwuler Männer“ (Liebesblödigkeit, S. 12). Eine heteronormative Selbstentblößung. 69

\section{ROLLENBILDER À LA CLICHÉ}

Dass nicht nur Heteronormativität, sondern auch Phallozentrismus, Misogynie und Geschlechterrollenstereotypie obwalten, lässt sich etwa an den überbordenden Beispielen für Genderklischees belegen. Dabei bietet es sich an, bei den traditionellen Allgemeinplätzen und Vorurteilen über die vermeintlich ,typischen' Eigenschaften und Aufgaben der bipolaren Geschlechter anzufangen, die wohlgemerkt sowohl für Männer- als auch Frauenbilder in der Gedankenwelt der Protagonistinnen und Protagonisten als Schablone vorliegen. ${ }^{70}$

Bezüglich der Aufgabenverteilung, die sich etwa im Haushalt gut beobachten lässt, ist es selbstverständlich, dass die Frau für das Mittagessen verantwortlich zeichnet, wohingegen der Mann arbeiten geht (vgl. Ausschweifung, S. 16). Sollte dieses Vorrecht einmal auf die Frau ausgeweitet werden, heißt es: „Draußen die letzten Verrichtungen einer Frau, die arbeiten geht: Hausschuhe wegstellen, Schlafzimmertür schließen, Küchenlicht ausmachen: Strom sparen“ (Laslinstraße, S. 28). Zwar lassen im gleichen Roman Frauen tadelnswerterweise auch einmal Türen „offenste-

(vgl. dazu Holt/Groeben: Das Konzept des Foregrounding; vgl. dies.: Emotionales Erleben beim Lesen, S. 126-129), das hier in Nadine van Holts und Norbert Groebens Verständnis, welches sie in ihrem Sammelbandbeitrag „Emotionales Erleben beim Lesen und die Rolle text- sowie leserseitiger Faktoren“ darlegen, gebraucht wird, kann man pauschal sagen, „daß bei hohem Verfremdungsgehalt signifikant weniger fiktionsbezogene miterlebende Emotionen berichtet wurden als bei niedrigem Gehalt. Stattdessen wurden jedoch bei starker Verfremdung deutlich mehr Artefakt-Emotionen erlebt [...]." (Holt/Groeben: Emotionales Erleben beim Lesen, S. 129) Diese Ansätze nutzt die Studie im Folgenden als analytischen Kategorienpool von A wie „Ausdrucksvarianten von Emotionen“ auf lexikalischer Ebene (Schwarz-Friesel: Sprache und Emotion, S. 134-173) über „[e]mpathieermöglichende Textstrukturen“ (Hillebrandt: Das emotionale Wirkungspotenzial von Erzähltexten, S. 76-84) und "[t]extuelles Emotionspotenzial und kognitive Emotionalisierung" (Schwarz-Friesel: Sprache und Emotion, S. 210-218) hin zu Z wie „Zeitbezug: aktuelles vs. erinnerndes Erleben" (Holt/Groeben: Emotionales Erleben beim Lesen, S. 118).

68 Vgl. Holt/Groeben 2006: Emotionales Erleben beim Lesen.

69 Homosexualität findet überhaupt nur selten statt und wird entweder ausgeklammert - „Es ist das erste Mal, daß ein erwachsener Mann homosexuelle Kontakte zu mir sucht. Nur als Schüler, etwa mit dreizehn, hatte ich eine kurze gleichgeschlechtliche Phase, die sich nicht vermeiden ließ, weil Gruppenonanie in dieser Zeit eine Art Jugendbewegung war" (Glück, S. 155) -, als , abartig' abgetan ( $\Rightarrow$ II.1.6 u. $\Rightarrow$ II.4.2) oder als übergriffig und bedrohlich inszeniert (vgl. Kein Geld, S. 62; s.u.).

70 Vgl. dazu auch einen gendersensitiven Befund der IM-Forschung: Frauen, die self-promotion anwenden, „are often viewed as more competent but less socially attractive by observers of their actions" (Turnley/Bolino: Exploring the Role of Self-Monitoring in Impression Management, S. 352). 
hen, wie das Frauen oft tun" (Laslinstraße, S. 149), doch in der Tendenz sind Frauen ordentlich: „Keine Zigarettenasche auf den Teppichen“ (Laslinstraße, S. 148). Außerdem ist es deren Metier, die Hauswirtschaft zu besorgen, wobei dem Mann sogar die Termini technici dieser fremden Welten fremd sind: „Elke hatte heute Waschtag, oder wie Frauen das sonst nennen“ (Laslinstraße, S. 199). Eine zart komische Note ist im folgenden Beispiel des Wäschemachens nicht zu verkennen: „Eine Waschmaschine konnte von einem Kind nicht in Gang gesetzt werden. Es mußte eine Frau in der Wohnung sein." (Abschaffel, S. 129) Nicht nur im Haushalt sind die Aufgaben klar verteilt: „Sie hat zum Beispiel nie ein eigenes Konto gehabt, Führerschein und so ganz zu schweigen, ich glaube, sie weiß noch nicht einmal, was eine Zahlkarte ist. Alle diese Dinge haben die Männer für sie gemacht." (Sorgen, S. 293) Gemalt im Zeitkolorit ist diese Reminiszenz schon beinahe kritisch zu lesen, aber die schiere Masse an Gegenbeispielen lässt die innerfamiliäre Familienähnlichkeit eher die Gestalt auch eines reaktionären Männerbildes annehmen:

Ich hatte von Lisa die Erlaubnis, Geld von ihrem Konto abzuheben. Ich habe von dieser Erlaubnis nur ein einziges Mal Gebrauch gemacht und habe dabei sozusagen Schiffbruch erlitten. Das liegt etwa drei Jahre zurück. Ich konnte das Geld zwar in der Bank abheben, aber dann nicht ausgeben. Als ich zahlen wollte, überfiel mich eine fürchterliche Hemmung. Ich mußte die eingekauften Sachen zurückgeben und nach Hause gehen. Ich habe Lisa das Erlebnis seinerzeit nicht verheimlicht. Sie war gerührt und tröstete mich. Sie hat gesagt, ich würde das alles viel zu ernst nehmen. (Regenschirm, S. 42)

Es kommt einem Ehrverlust gleich, die Finanzen nicht selbst unter Kontrolle zu haben, wobei das möglicherweise abgegebene Bild, das andere haben könnten, einen genauso wichtigen Anteil daran hat, wie die inkorporierte Vorstellung: „Ich konnte doch jetzt nicht sagen, daß Elke schon manchmal für mich bezahlt hatte, das ging doch nicht" (Laslinstraße, S. 72; vgl. Kein Geld, S. 69). In den 1960er Jahren - setzte man denn die grobe Gleichzeitigkeit von Erscheinungs- und erzählter Zeit an - ist dies noch eher plausibel als 2003, wobei es sich hier um die Beobachtung älterer Menschen handelt: „Viele der alten Ehepaare hatten einen gemeinsamen Geldbeutel. Die Frau verwahrte die Börse, aber zahlen sollte der Mann." (Wohnung, S. 91) Wie aus männlicher Figurenperspektive sowohl Frauen wie Männer klar zuordenbaren Mustern gehorchen, ist auch aus femininer Sichtweise die Sache klar: „Ich stand dabei und hüpfte ein bißchen in die Höhe, als ich sah, wie der Schrotthändler Harald ausbezahlte. Denn ich war es, für die Harald sein Geld wieder ausgab." (Obdachlosigkeit, S. 64 f.) Artig freudig honoriert sie die männliche Freigebigkeit, was sich andernorts zum Topos der ,gierigen Frau' auszuwachsen droht: „Ob ich dauernd Geld kriegen will wie eine Mutter oder ob ich mir nicht lieber Geld abnehmen lassen möchte wie ein Vater." (Falsche Jahre, S. 424) Diejenigen patriarchalen Klischees im monetären Bereich lassen sich intersektionell ausweiten, doch finden sie sich grundlegend auch bestätigt: „Die Türkin bat ihren Mann um Erlaubnis, sich von ihm entfernen zu dürfen“ (Falsche Jahre, S. 564). Was sich selbst für das ,deutsche‘ Patriarchat nicht ,schickt', wird in andere Kulturkreise verlegt: „In den 
Gastarbeiterfamilien war der Mann der Dirigent der äußeren Ereignisse, und die Frau leitete die inneren, familiären Vorgänge." (Abschaffel, S. 116)

Was diese vorurteilsbelasteten Verallgemeinerungen mit den folgenden verbindet, ist die Tatsache, dass den Geschlechtern nicht nur qua ,göttlicher Ordnung' Rollen zugewiesen scheinen, sondern diese auf der Basis ,natürlich-biologischer' Wesenszüge legitimiert seien: ,Die Frau'...

- ...glaubt „alle Romane ihrer Männer“ (Laslinstraße, S. 58);

- ...zeichnet sich durch „weibische Lügsucht“ aus (Laslinstraße, S. 80);

- ...schläft nach dem Akt immer schnell und zufrieden ein (vgl. Sorgen, S. 296)71, wenn sie nicht währenddessen oder danach in Weinen ausbricht (vgl. Licht, S. 69 f.; vgl. Liebesblödigkeit, S. 128); 72

- ...will zuerst „ein Kind. Wenn das Kind da ist, will sie ein zweites, danach ein drittes. [...] Die Selbstmehrung einer Frau, die ihr Glück ausschließlich in der Familie sucht“ (Heimweh, S. 169);

- ...genießt es, „an der Seite von sicheren Männern zu Abend zu essen“ (Sorgen, S. 306 f.);

- ...unterdrückt „das Heulen; oft sah sie sich ein paar Tage später den Film noch einmal an, und zwar alleine, damit sie endlich ungestört heulen konnte" (Ausschweifung, S. 22).

Als ,typische‘ Wesenszüge ,der Frau' finden sich derartige Aussagen hardcoretypisch. Machohafte Selbstbilder - „Es war damals befreiend, wenn wenigstens der Punkt Beischlaf geklärt war. Ein auf diese Weise geordneter Mann tritt den anderen Frauen gegenüber gelassen auf, sie sehen sofort, dieser Mann wird wenigstens vorübergehend nicht von seinem Hauptanliegen gequält“ (Tiere, S. 135) - sind genauso wie verallgemeinernde genderspezifische Wesensvermutungen problematisch: „Meine Vermutung ist, daß Männer die größeren Melancholiker sind und körperliche Verschlechterungen leichter hinnehmen als Frauen, die viel zu heftig ihrer verschwundenen Jugendlichkeit nachtrauern, was Männer nicht tun." (Glück, S. 36) ,Was Männer tun', folgt scheinbar deren Genetik, wie es weiblicherseits gesetzt zu sein scheint, dass die Berufung zur ,Prinzessin' die emotionale Adelung krönen würde: „Als er weg war, setzte sich Frau Hildebrand mit der Zufriedenheit eines Kindes, das vor allen anderen Kindern Prinzessin genannt worden war, auf ihren Platz und arbeitete weiter." (Ausschweifung, S. 286) Es verwundert nicht, wenn eine komplexitätsreduzierte weibliche Figurenzeichnung auch auf die einzige weibliche Hauptfigur hinsichtlich der gendertheoretisch relevanten Funktionen als eifersüchtig abfärbt (vgl. $O b$ dachlosigkeit, S. 75). In Einzelfällen werden die abgegriffenen Merkmalssets auch durch Berufsbilder begünstigt: „Typisch Friseuse, dachte ich als typischer Mann und ging mit ihr. Sie hatte genau das in Aussicht gestellt, was ich schon immer einmal erleben wollte: Eine Frau ergreift die Gelegenheit und nimmt einen Mann mit in die Wohnung." (Regen, S. 81) Zwei Signale lassen aufhorchen und deuten bereits auf die (selteneren) Fälle einer Ironisierung oder Brechung der Vor-

71 Vgl. für ein Gegenbeispiel, bezeichnenderweise aus Sicht einer Protagonistin, Obdachlosigkeit.

72 Vgl. den Moment, in welchem Weigand bemerkt, wie schön Sex ist: „Die Überraschung wirkte so stark, daß mir ein paar Tränen hochschossen." (Wohnung, S. 70) 
urteile voraus: Erstens selbstkennzeichnet sich der Protagonist „als typischer Mann“ - wobei zu fragen wäre, ob damit nicht lediglich das Vorurteil plausibilisiert werden soll -, zweitens reproduziert die Frau das verdinglichte ,Mitnehmen‘ (s.o.). Häufiger werden Frauen per se als männliches Anhängsel, als Accessoire gezeichnet:

Besonders aufgeregt, fast wollüstig, hörte Frau Hildebrand [...] zu. Frau Hildebrand war die Geliebte von Wohlleben [...]. [...] Und Frau Hildebrand war eine kluge Geliebte; sie wußte, daß es keinen Sinn hatte, einen verheirateten Mann in dramatische Situationen zu bringen. (Ausschweifung, S. $49 \mathrm{f}$.)

Warum die als „kluge Geliebte“ Gelobte nun ausgerechnet „fast wollüstig“ zuhören (!) muss, geht auf die Rechnung einer externen Figurengestaltung, die einen Typus entwerfen will. Verobjektivierendes und entindividualisierendes Verhalten sexistischer Provenienz ist basistypisch eine männliche Domäne. Wie bei der Begutachtung auf dem Viehmarkt klassifiziert Degen seine eigene Schwester mit den Worten: „alles noch heil an Petra, Petras Mann konnte seine Frau noch verbrauchen, benützen“ (Laslinstraße, S. 76), wie er auch seine Freundin vor seinem Vater verniedlicht: ,,[E]igentlich ist sie noch ein Kind, vielleicht noch nicht einmal das, vielleicht ein Kindchen." (Laslinstraße, S. 174) Primär optisch funktioniert das Taxieren (und, bei Nichtgefallen: das Herabsetzen) von Frauen: „Ihre Hauptausstrahlungszeit als Frau hatte sie hinter sich, eine Ehe ebenfalls." (Tiere, S. 60) Die Reduktion einer Person auf ihre Körperlichkeit lässt sich dabei an den unterschiedlichsten Merkmalen festmachen: „Vermutlich wäre mein Interesse an Gunhild gering, wenn sie nicht diese Wimpern hätte." (Regenschirm, S. 12) Sekundäre Geschlechtsmerkmale sind dabei ein bevorzugtes Beobachtungsobjekt der Romanfiguren: „Eine Frau mit tiefem Ausschnitt und schönem Busen geht vorüber. Wenig später höre ich, welchen Unfug die Frau redet. Ihr Busen verliert dadurch an Attraktivität, worüber ich Erleichterung empfinde." (Heimweh, S. 188 f.) Wenngleich Körper und Geist, Äußerlichkeiten und Inneres in eine Hierarchie gestellt werden, die ein ambivalentes Gendermodell erlaubt - immerhin fällt der erzählte „Unfug" bei der Gesamtevaluation ins Gewicht -, wird doch durch die Hintertür das Vorurteil von aufreizend und blöd perpetuiert.

Peschek demgegenüber ist an menschlichen Tiefendimensionen von vornherein nicht sehr interessiert: „Hallenhandball interessierte ihn auch nicht, aber die wunderbar hüpfenden Brüste unter den Trikots der Spielerinnen gefielen ihm." (Fremde Kämpfe, S. 76) Erzähltechnisch besonders entmenschlichend ist eine Aussage über Abschaffel: „Statt dessen lief er Richtung Zoo, Nutten ansehen." (Sorgen, S. 272) Alleine der Plan, diese betrachten zu wollen, degradiert sie zum Lustobjekt - dass mit der doppeldeutigen Ortsbezeichnung ,(Bahnhof) Zoo‘ allerdings Gehege evoziert werden, setzt dem Ganzen die Krone auf. Der Protagonist des Romans Außer uns spricht niemand über uns hat wie auf einem Wunschzettel vermerkt, wie seine Zukünftige zu sein habe; auch das eine massive Form der verdinglichten Sicht auf das weibliche Geschlecht: „Die neue Frau, die ich suchte, wollte ich beiläufig kennenlernen; sie sollte nicht mehr ganz jung sein, 
sie sollte gebildet sein, wenn auch nicht durch Bildung anstrengend; sie sollte eigenes Geld verdienen, aber damit nicht angeben." (Außer uns, S. 118) Obwohl keine Wünsche über die konkrete Beschaffenheit ihres Aussehens geäußert werden, kann man dem Basistypus zumindest ex negativo ein ,Idealbild' einer Frau abtrotzen, indem man die als Makel empfundenen Äußerlichkeiten bündelt, wie es etwa Abschaffel tut, wenn er eine Frau normativ beschreibt als „zu dick, zu schwer, zu dumm, zu häßlich und zu ungeschickt. Gern wäre sie trotz allem geliebt worden, und sie bot sich den Angestellten an." (Abschaffel, S. 100) Viel potenziell Liebenswürdiges lässt diese Entwertung nicht übrig, wobei ,Body-Shaming‘ tatsächlich eine der niederträchtigsten Beleidigungsformen darstellt.

Bevor diejenigen kritischen, ironisierenden oder komischen Rollenbildkonzepte diskutiert werden (s.u.), soll kursorisch die Rede auf eine nur scheinbare Kritik gerichtet werden: auf die lediglich umgedrehte Verteilung der Klischees: „Ich stand vor dem Kleiderschrank und sagte wie eine Frau zu meinen Anzügen: Ich habe nichts anzuziehen." (Außer uns, S. 26; vgl. Außer uns, S. 41) Ergiebiger, da vielschichtig ist die folgende Passage:

\begin{abstract}
Dazu fiel mir ein, dass es Carola war, die im Bett zwischen uns die ,Führung' übernahm. Sie umarmte mich und sagte, dass sie nicht länger warten könne, [...] sie drückte mich an sich wie ein Kind, das seinen Vater allein haben wollte (obwohl sie keine Konkurrentin hatte), wir waren allein, sie schob mich ins Schlafzimmer und drückte mich ins Bett, ich war überrumpelt und ganz in ihrer Macht, was ich mir gern gefallen ließ, weil auch ich plötzlich nicht mehr denken konnte, und dieses endlich erreichte Nicht-mehr-denken war der Übergang und die Auflösung des Denkens, sie setzte sich auf mich, sie vögelte mich wie ein Mann und deckte mich hinterher doch wieder zu wie eine Mutter. Ihr Verhalten hatte mehr als eine männliche Note, was sie wahrscheinlich bemerkte. Hinterher und danach, wenn sie mich leckte und lutschte, war sie wieder die Mutter, die den Glücksbringer (das Kind) noch einmal überschwenglich herzte, bis es eingeschlafen war. Sie schlief nicht ein einziges Mal vor mir ein, sie wollte sehen, dass ich mit ihrem weiblichen Segen einschlief, dann war alles gut. (Außer uns, S. 83)
\end{abstract}

Ohne auf die überdeutlich angelegten Spuren zum Ödipus- (Sohn wird von Mutter zugedeckt) bzw. Elektrakomplex (Tochter möchte Vater für sich und konkurriert mit Mutter) sowie die Durchmischung von Eltern- und Partnerliebe näher einzugehen $(\Rightarrow$ II.5.2), gilt es das Hintergrundbild der Geschlechtervorstellungen zu betrachten. Egal, wer die Rolle letztlich ausfüllt - es ist männlich codiert, die „,Führung““ zu übernehmen, wobei ,drücken' und ,überrumpeln‘ durchaus im Handlungsrepertoire liegen. Die Rolle des Mannes wird mit „Macht“ assoziiert, mit Inbesitznahme des weiblichen Körpers durch oral eingefärbtes Lecken und Lutschen und schließlich mit dem hier nicht partnerschaftlich-gleichberechtigt, sondern aktivisch-dominant verwendeten Verb ,vögeln'. Die Rolle der Frau bleibt unterdeterminiert. Sie scheint sich auf passives Erdulden und späteres Einschlafen zu beschränken. Auch außerhalb der sexuellen Sphäre findet sich ein derartiger romanspezifischer Rollentausch:

Es war meine Aufgabe, tagsüber einzukaufen, damit ich abends - das gehörte ebenfalls zu meinen Aufgaben - ein tadelloses Abendbrot auftischen konnte. Wenn Sonja nach Hause kam und fand außer Salzstangen und mürben Keksen nichts Essbares, dann verlangte sie von mir, dass ich mich unverzüglich auf den Weg machte. Das war erst vorige Woche wieder passiert. Auch ich war erschöpft, aber ich nahm eine Tasche und zog los. [...] Im Supermarkt traf ich die immer noch locker gesonne- 
ne Jugendgefährtin Claudia M. [...]. Sie war (ist) eine von vier Frauen, die mich aufgefordert haben, mit ihr ins Bett zu gehen. Und deren Aufforderung ich nicht gefolgt war, ich wusste nicht mehr warum. (Regen, S. 19)

Beide Beispiele belegen, dass am Grundmuster der rollenspezifischen Verhaltensweisen keineswegs gerüttelt wird. Wie beim Cross-Dressing die Kleidung, bleibt hier das jeweilige Set - abhängig vs. autark; Beruf vs. Haushalt; Durchsetzung vs. Gehorsam etc. - grundlegend bestehen.73 Trotz der Aufmachung als Rollenbildverkehrung, wird übrigens das Machoimage durch zweierlei restituiert: durch die Selbstverkleinerung und das Arme-Männer-Gehabe einerseits, durch den Bruch, der entsteht, wenn er als wählender Mann das Sexangebot der bedürftigen Frau ausschlägt, andererseits.

\section{REFLEXION, IRONISIERUNG, KRITIK UND (SELTENE) DURCHBRECHUNG DER STEREOTYPE}

Sie sind gar nicht so selten: Stellen, an denen die herrschende Sexualmoral und Geschlechterstereotype zumindest in Ansätzen kritisch hinterfragt werden. Besonders hervorzuheben sind die weiblichen Selbstermächtigungen: „Wegen eines Kindes muß eine Frau heute nicht mehr ihr Leben ändern, sagt Traudel.“ (Glück, S. 72) Allerdings schlagen dann postwendend auch die Ressentiments durch: „Das ist, sage ich, die Propaganda der Frauenzeitschriften.“ (Glück, S. 72)74 Denn in der Tat scheint die fiktionalisierte Gesellschaft im Allgemeinen und der Figurenbasistypus im Besonderen in Genazinos CEuvre noch nicht wirklich reif für ein Umdenken:75 „Die meisten Ober sind immer noch unheimlich verblüfft, wenn Frauen zahlen, nicht wahr, sagte sie." (Abschaffel, S. 85) Selbst bereits über dieses Stadium hinaus gelangt, lässt sich die festgeschriebene Erwartung noch gut an der gesellschaftlichen Umgebung oder der eigenen Einstellung ablesen: „Ich habe bisher immer geglaubt, daß die Frauen von Männern gerettet werden. In meinem Fall ist es umgekehrt. Ich kann, wenn ich will, von einer Frau gerettet oder zumindest aufgefangen werden. Vermutlich ist es dieser Umsturz des Denkens, der mich nicht losläßt.“ (Liebesblödigkeit, S. 109) Wie das ungeschriebene Gesetz, dass Frauen nicht bezahlen, fällt es dem Protagonisten schwer, sich darauf einzulassen, dass auch Frauen als stützender Partner einer Beziehung in Erscheinung treten können. Mit der Akzentuierung gar als „Umsturz des Denkens“ ist ein den meisten Protagonisten eignendes Problem umschrieben: Sie wissen um die Überlebtheit, können

73 Ein gutes Gedankenexperiment, um diese Normen durchschauen zu können, ist die kritische Rezeption von Werbespots, indem man sich eine Umbesetzung der Darsteller durch Darstellerinnen und umgekehrt vorstellt.

74 Vgl. für eine treffsichere Einschätzung der männlich dominierten Gesellschaft aus weiblicher Perspektive: „Wir sind genommen worden, weil wir jung, hübsch, billig und demütig waren, sagte Martha, das war bei mir genau dasselbe." (Ausschweifung, S. 99)

75 Als romanspezifische Ausnahme ist die Hauptfigur des Romans Kein Geld, keine Uhr, keine Mütze zu nennen: „Früher, in meiner Kindheit, waren Väter und Ehemänner sogenannte Alleinverdiener. Wenn ich mich nicht täuschte, verschoben sich schon seit Jahren die Verhältnisse. Immer öfter drängten Frauen in die Spitzenpositionen; oft waren jetzt sie die Alleinverdiener, obwohl viele von ihnen gleichzeitig Mütter, Hausfrauen, Betriebsrätin oder sonst was waren." (Kein Geld, S. 57) Die mitzulesende negative Einschätzung der, verschobenen Verhältnisse` ist dabei deutlich. 
ihr Denken und Handeln aber nicht gänzlich frei machen von den alten Paragrafen der ungeschriebenen mentalen Sitten- und Anstandsbüchlein: „Dieses Bedürfnis mußte ein Rest der alten kindischen Idee sein, daß ein Mann jederzeit seine Frau beschützen mußte." (Ausschweifung, S. 21 f.) Ganz klar wird die „Idee“ als „alt[]“ und „kindisch[]“ verlacht, obwohl das „Bedürfnis“ offensichtlich noch auf deren Basis handlungsleitend ist. ${ }^{76}$

In ähnlicher Art und Weise existieren diese ,Ideen' gesellschaftlich fort und sind derart dominant, dass sie als innere Zensur wirken können ( $\Rightarrow$ II.2.6): „Ich selbst wollte eigentlich auch klagen, aber ich fand Klagen unmännlich und beherrschte mich mehr, als mir guttat." (Außer uns, S. 88) Ihr ,Über-Ich` verbietet es der Figur, das gesellschaftlich (vermeintlich) weiblich konnotierte „Klagen“ auszuleben, obwohl dies das Figurenselbst offenkundig verbiegt. Als gesellschaftlich akzeptierte, da nicht hörbare Auflehnung findet sich etwa die Persiflage von der stereotypen Geschlechterrollen: „Er sah sich die Fotos in den Schaukästen an, aber er sah nur die Gesichter von schmerzverzerrten Männern, die gerade andere Männer umbrachten oder selbst umgebracht wurden." (Falsche Jahre, S. 559) Wenn schon, so könnte man fragen, die platten Vorurteile und zugedachten Rollen dekuvriert worden sind, wenn diese auch mitunter problematisiert werden, warum wird dann der konsequente Schritt zumindest eines offenen Ohrs für Gleichberechtigungsbestreben nicht gegangen?

Beinahe jedes Wochenende redet Edith von ihrer nicht recht vorankommenden Emanzipation, aber wenn ich sie frage, wovon sie sich eigentlich emanzipieren will [...], findet sie keine Antwort, sondern wird wütend. Sie lebt inmitten ihrer Ansprüche (Kleidung, Kind, Urlaub, Wohlstand), aber es wird ihr nicht problematisch, daß sie als berufslose Hausfrau zu hundert Prozent von einem nicht einmal sehr gut verdienenden Ehemann abhängig ist. (Heimweh, S. 32)

Strategisch muss der Gesprächsplan perfide genannt werden: Trotz des Gesprächsgegenstands ,Emanzipationswunsch', argumentiert Dieter Rotmund just mit den ,weiblichen Pflichten' und den klischierten Vorurteilen einer (insbesondere materiell) anspruchsvollen Frau. Ob sie sich denn wirklich von ihrem materiellen Luxus ,emanzipieren' wolle, ist nicht nur starker Tobak, sondern auch in Form des ironic statements $(\Leftrightarrow I .3 .3)$ offensives IM par excellence. (Wobei die Sympathieverteilung aufgrund ihrer sonst zwischen dreist und gefühlskalt changierenden Wesenszüge selbst in dieser Situation eher auf Rotmunds Seite liegen dürfte.) Gelebte Emanzipation der Frau ist bei Genazino genaugenommen nur romanspezifisch zu haben. Die Protagonistin aus Genazinos Die Obdachlosigkeit der Fische verkörpert eine solche selbstständige, gleichberechtigte, unabhängige Frau, wobei gefragt werden müsste, ob es sich nicht um eine ,Superkompensation', also die Umkehr eines hierarchischen Beziehungsgefüges handele, wenn sie nachsinnt:

Der Mann, mit dem ich schon lange zusammen bin, heißt Helmuth und ist Rechtsanwalt bei einer Versicherungsgesellschaft. Helmuth ist ruhig, sachlich, vernünftig. Unser Anfang vor zwölf Jahren war schwierig. Helmuth hatte bis dahin nur Frauen gekannt, die auf Ehe und Familie hin lebten. Ich war für ihn die erste, die zwar bei ihm bleiben, aber nicht heiraten wollte. Bis heute leben wir in

76 Vgl. dazu auch die Ironisierung: „Der selbständige Grafiker Wolf Peschek suchte Schutz bei seiner Freundin." (Fremde Kämpfe, S. 58) 
zwei getrennten Wohnungen, und daran wird sich, denke ich, nichts ändern. Es hat lange gedauert, Helmuth davon zu überzeugen, daß mein Vorbehalt nicht ihm galt und nicht gilt. Ich fürchte die Dämonie des Alltags, und ein Paar, das eine Wohnung teilt und lange teilt, hat gegen diese Dämonie keine Chance. Helmuth wußte nichts von diesen versteckten Behinderungen und brachte sie doch, jedenfalls am Anfang schon hervor. Zum Beispiel wollte er gern mit mir einkaufen gehen, und es hat mich Wochen verdrießlichen Erklärens gekostet, ihm ein Gefühl dafür zu vermitteln, wie töricht und lähmend Kurzdialoge eines Paares über Zahnpasta oder tiefgefrorene Hühner sind. Meine stets die Einschnürung befürchtende Seele hätte nicht einen einzigen Einkauf dieser Art überlebt. Bis auf eine einzige Ausnahme habe ich bis jetzt keinen Mann kennengelernt, den ich nicht nach einiger Zeit wieder gern verlassen hätte. Helmuth könnte die zweite Ausnahme werden. Ich verkenne nicht, daß es unsere Geschichte nur deswegen noch gibt, weil sich Helmuth mir anpaßt. Sein Geschick wundert mich und flößt mir Respekt ein. Ich bemerke, daß ihn viele Probleme, mit denen er nur in Berührung kommt, weil er mich kennt, nicht zur Ruhe kommen lassen. Erst kürzlich hat er mich gefragt, wie ein Alltag aussehen muß, der nicht erbärmlich ist. Ich wunderte mich, weil ich diese Debatte für längst ausgestanden hielt. Ich hatte keine Lust, noch einmal von vorne anzufangen, und antwortete knapp: Es gibt keinen Alltag, der nicht erbärmlich ist. Wenig später wunderte ich mich selbst über meine Schroffheit. Meine Antwort stand zwischen uns und sorgte für ein Schweigen, das ich im stillen bedauerte. (Obdachlosigkeit, S. 13 f.)

Unmittelbar sinnfällig ist die Figurenzeichnung der Hauptfigur als basistypuskonform einzuordnen und mithin zumindest tendenziell ,nur' unter umgedrehter Rollentypologie zu verbuchen (s.o.): Die Bindungsangst, die sich im Freiheitswunsch inklusive des Beharrens auf separaten Wohnungen zu erkennen gibt, der Versuch, den Partner zu ,erziehen' etc. sind von den männlichen Hauptfiguren wohl bekannt, zumal Helmuth selbst stereotyp-männlich als „sachlich und vernünftig“ gebildet ist. Nimmt man die Tatsache, „daß es unsere Geschichte nur deswegen noch gibt, weil sich Helmuth mir anpaßt“, mit der offenbar längeren Liste an vormaligen Exfreunden zusammen, verdeutlicht dies, dass es für eine emanzipierte Frau - finanziell unabhängig, selbstbewusst, hier im Gegenentwurf zur auf Häuslichkeit und Kinder abgestellten Ausformung skizziert - in einer patriarchal organisierten Gesellschaft keine Selbstverständlichkeit ist, eine erfüllende Partnerschaft zu leben. Es mag dies ein weiterer Hinderungsgrund sein, um einer rundum starken Frauenfigur einen festen Platz im Genazinouniversum zuzudenken; in jedem Fall findet üblicherweise nur eine teilweise Emanzipation statt - etwa auf dem Gebiet beruflichen Erfolgs oder der Sexualität ( $\Rightarrow$ II.5.5).

Zwar ist Eckhard der dominierende Part in der Ausschweifung, wenn es um partnerschaftliche Belange und auch den Beischlaf geht, aber andererseits ist Christine es, die sich ihn als Notnagel und neuen Sexpartner ,beschafft' und diesem dann - nicht nur symbolisch - ihren Finger in den Hintern steckt:

Ich würde auch gern mal eine Frau sein, sagte Eckhard. [...] Und außerdem, sagte er, hat eine Frau, die darauf wartet, beschlafen zu werden, auch das größere Recht zu jammern und zu klagen, und das würde ich auch gerne tun. Am liebsten aber würde ich darauf warten, daß jemand kommt und mir unten etwas reinschiebt, sagte er. [...] Er war so beschäftigt mit den Wonnen von nicht nötigen Unterscheidungen, daß er nicht hörte, wie Christine mit dem linken Arm auf das Nachtschränkchen griff und dort eine Cremedose öffnete. Erst als der Deckel mit einem winzigen Geräusch auf die Glasplatte des Nachtschränkchens fiel, wurde er aufmerksam. Aber er konnte sich nicht denken, was das Geräusch bedeuten könnte. So zuckte er überrascht zusammen, als er spürte, wie Christine mit der sich kalt anfühlenden Creme seinen Anus zunächst eincremte und dann langsam ihren gestreckten Zeigefinger einschob. Ein paar Sekunden lang schreckte sein Körper zusammen und wollte sich vollständig verschließen und verwehren. Aber zum Glück bemerkte Eckhard, daß die neue 
Körpererfahrung zwar überraschend und befremdend, aber nicht verletzend und nicht schmerzhaft war, im Gegenteil, es stellte sich eine gleichmäßige Sanftheit von kleinen Bewegungen ein, die er allesamt Christine verdankte. Er bemerkte, daß es darauf ankam, sich hinzugeben, und so hörte er auf, im Kopf immer schon im voraus den Verlauf aller Ereignisse kennen zu wollen. (Ausschweifung, S. 205 f.)

Obzwar sich einwenden ließe, Christine erfülle nur Eckhards geäußerten Wunsch, „daß jemand kommt und mir unten etwas reinschiebt", und obwohl Eckhard die sexuelle Selbstbestimmung Christines mit den Worten einschränkt: „Eckhard hatte das Gefühl, daß Christine, obwohl er sie gar nicht kannte, sich heute mehr herausnahm und mehr erlaubte, als sie selbst von sich gewohnt war" (Ausschweifung, S. 204), ist nicht in Abrede zu stellen, dass Christine ein sexuell progressives Frauenbild verkörpert. In Bezug auf diesen Aspekt finden sich tatsächlich mehrere gleichberechtigte Frauenfiguren, die etwa der Plattitüde: „ein Mann muß öfter als eine Frau“, entschieden entgegensetzen: „[I]m Grunde bin ich genauso egoistisch wie jeder Mann“ (Abschaffel, S. 153). Auch frau ist also - auch bei Genazino - durchaus in der Lage, Sex selbstbestimmt abseits der als weiblich codierten Sphären einer Beziehung wertzuschätzen und aktiv herbeizuführen: „[A]ber viel später sagte mir Frau (...), dass sie den Geschlechtsverkehr nur gebraucht hätte, um wieder wach zu werden, was ihr meistens gelungen sei. Sie lachte darüber so grundehrlich und immer noch erfrischend, dass ich nicht den kleinsten Grund für eine Kränkung sah." (Außer uns, S. 137)

Diesen zumindest partiell starken Frauen kontrastiv zu Seite stellen sich einfühlsamere und selbstkritischere Männlichkeitsentwürfe, die durchaus auch komische Prägung tragen dürfen: „Ich fürchte mich ein wenig vor Frauen, die Gunhild, Gerhild, Mechthild oder Brunhild heißen.“ (Regenschirm, S. 8) Diese Figuren sind imstande, ihr sexuelles Handeln zu hinterfragen, der eigenen Triebnatur kritisch gegenüberzutreten - „Dann betrachtete er sein Geschlecht als gierigen und blöden Herrn, der das Niveau seiner übrigen Person leider nicht immer halten konnte" (Sorgen, S. 249 f.) - oder die negativ konnotierte Durchschnittlichkeit des eigenen Denkens aufzudecken: „Alle Sätze, die er dachte, machten aus ihm einen gewöhnlichen Mann, der gegen Geld eine genau abgemessene sexuelle Leistung eintauschte." (Sorgen, S. 335) Eher selten tritt diese Kritik allerdings aus der Gedankenwelt ans Tageslicht: „Ich hatte das Gefühl, dass ich zu grob zu dir war. Warst du auch. Aber deine Einsicht ist, äh, wie soll ich sagen, vorbildlich und macht dich sofort wieder sympathisch." (Außer uns, S. 79) Erneut wird die Entschuldigung aufgrund der Atypik gewichtiger inszeniert und es dem Mann sehr leicht gemacht, eigenes Fehlverhalten zu entschuldigen, zumal die Verwendung des für Genazinos externe Figurencharakterisierung verräterischen Füllworts, äh' die Zögerlichkeit und Unsicherheit der weiblichen Figur markiert. Dass dieses, äh' aber auch dazu verwendet werden kann, Stereotype aufzubrechen, zeigt ein Blick auf Die Vernichtung der Sorgen: „Ja sicher, sagte sie, diese Südländer sind doch bekannt für ihre, äh, Direktheit, nicht“ (Sorgen, S. 282). Mit dem erzähltechnisch entlarvenden Zögern, das paradigmatisch die Liste noch unpassenderer Worte, mit denen „diese Südländer“ bedacht hät- 
ten werden können, ins Gedächtnis ruft, wird die Herabsetzung der die Aussage treffenden Figur vollzogen. Zumindest innerlich protestieren einige Figuren gegen offensichtlich sexistische Äußerungen anderer. So ist es Axel Degen höchst peinlich, der folgenden Unterredung anderer, alkoholisierter Männer beizuwohnen: „,Ich habe meine feste Garage, ich brauch die Betty nicht.' ,Und dann ist's ja auch Wurst, es ist ja immer die gleiche Stelle, die haben sie alle“" (Laslinstraße, S. 188), und auch Abschaffel „seufzte [...] innerlich auf”, „weil soeben ein Lehrling Fräulein Schindler eine Büroklammer in den Ausschnitt geworfen hatte“ (Sorgen, S. 256). Allerdings ist das beides höchst couragearm sowie beidenfalls auch im Lichte indirekten IMs zu sehen: Positiver als jemand anderes - hier: die ungehobeltsten anderen - dastehen zu wollen, heißt ja nicht: ohne Relation positiv - hier: an einer nicht-sexistischen Sicht auf Frauen interessiert - zu sein. Diesbezüglich äußerst bedenklich nimmt sich das folgende Zitat aus: „Sie erinnert mich an die Männer, von denen es immer heißt, sie schlafen auch dann mit ihren Frauen, wenn diese gar nicht wollen." (Regenschirm, S. 54) Obwohl sich der Protagonist in Ein Regenschirm für diesen Tag von dieser Einstellung distanziert und der Vergleich auf der Handlungsweise einer Frau begründet ist, sind drei Anmerkungen vonnöten: Erstens präsupponiert die Aussage, dass es die Männer tatsächlich gibt, die „auch dann mit ihren Frauen“ „schlafen“, „wenn diese gar nicht wollen.“ Das ist 2001 ein starkes Stück. Zweitens wird relativiert, indem es „von denen“ lediglich „immer heißt“ - die Unschuldsvermutung gilt, wenn nicht gar die Existenz solcher Männer abgestritten werden soll. Drittens arbeiten Genazinos Romane einer flächendeckenderen Kritik an den Rollenstereotypen nicht nur insofern entgegen, als es, wie gezeigt werden konnte, häufig lediglich zur Umkehrung der Stereotypien kommt. Gerade auch die breit verhandelte und häufig kritiklos vorgetragene Unart der sexualisierten Gewalt ist höchst problematisch.

\section{ANZÜGLICHKEITEN, BELÄSTIGUNGEN, ÜBERGRIFFE}

Allerdings muss diesbezüglich im Sinne der Gleichberechtigung angebracht werden, dass es zwar einerseits eine ,08/15'-Variante der anzüglichen, belästigenden und übergriffigen Handlungsweisen gibt - Mann überwältigt Frau, Frau gefällt dies oder sie sagt nicht hinreichend laut und entschlossen genug ,nein' und ,erduldet' -, andererseits eine Umkehr des als Norm gesetzten Verhaltensmusters, indem die Frau sich anzüglich verhält, ,übermannt' etc., auch vorkommt:

Gleich drei alberne Frauen arbeiten zur Zeit in der Großbäckerei an der Paulskirche. Sie flirten und kichern fast ununterbrochen, besonders [...] natürlich mit Männern, und zwar rücksichtslos mit jedem, der vor ihrer Theke erscheint. [...] Die dritte, ältere Verkäuferin [...] bedient einen Mann, der ein Pfund milden Kaffees für den Handfilter verlangt. Sie führt die Bestellung aus, und als sie dem Kunden die Kaffeetüte und das Wechselgeld überreicht, flüstert sie leise zu ihm: Einmal mild mit der Hand für den Herrn. Der Mann erkennt die kleine, vielleicht nur für ihn erfundene Obszönität sofort und verläßt beglückt den Laden. (Obdachlosigkeit, S. 16)

Nicht minder stereotyp als sonst wird hier mit dem Klischee der lüstern-frivolen Frau und dem des nicht minder an Anzüglichkeiten interessierten Mannes gespielt. Bezeichnenderweise finden 
sich allerdings dann, wenn die belästigten oder zum Opfer übergriffigen Verhaltens gemachten Figuren aus der eigenen Perspektive berichten dürfen, auffällig viele Indizien dafür, dass dieses Verhalten zuhöchst problematisch, wenn nicht traumatisierend sein kann: „Ich komme mir eher geleckt als geküßt vor, was Frau Gschill nicht zu stören scheint." (Glück, S. 145) Ohne mit einem Sensorium dafür ausgestattet zu sein, das eine Feedbackschleife in die aktuellen Handlungen integriert, fährt Frau Gschill mit dem tendenziell übergriffigen Verhalten fort. Von ganz anderer und traumatischer Qualität sind diejenigen sexuellen Übergriffe von einer erwachsenen Frau auf einen sechzehnjährigen Jungen:

Die Verführung fand im Archiv, das heißt im Kellergeschoss der Firma statt und überforderte mich von Anfang an. Da wir beide kurz nacheinander das Archiv wieder verließen und mir dummerweise die Tränen kamen, wurde der Übergriff der Buchhalterin rasch publik. Die Kollegen lachten oder amüsierten sich über die Vorgänge im Archiv und redeten darüber, ob sich die Buchhalterin nicht schämen müsste, sich an einem ahnungslosen Lehrling zu vergehen. Mir entging nicht, dass meine lächerliche Person gehänselt und verspottet wurde. Die Buchhalterin konnte mir auch nicht beistehen, sie war selbst überfordert, weil sie nicht damit gerechnet hatte, dass ich nicht einmal wusste, was ich mit meinem überraschten Geschlecht anstellen sollte. Ich heulte und schloss mich in der Toilette ein. Der Abteilungsleiter sprach mir gut zu und schickte mich nach Hause. Ich sollte auch am nächsten Tag zu Hause bleiben, dann ist die Sache vergessen, sagte er. (Außer uns, S. 42 f.)

Dass es sich nicht um eine „Verführung“, sondern um einen „Übergriff“ handelt, muss herausgestrichen werden, da das Zitat eine Synonymität unterstellt. Auch die Reaktionen der Belegschaft (Amüsement) stehen in einem krassen Missverhältnis zur somatischen Reaktion (Tränen und Schutzsuche) des erinnerten Protagonisten-Ichs. Dass „die Sache" totgeschwiegen werden soll, spricht für eine unsensible fiktive Gesellschaft, die den Ernst der Lage völlig verkennt. Insbesondere im Discours lässt sich eine Tiefenschicht der psychischen Belastung ausmachen: So entschuldigt der Erzähler das Verhalten, indem er sie zu verstehen sucht - „sie war selbst überfordert, weil sie nicht damit gerechnet hatte, dass ich nicht einmal wusste, was ich mit meinem überraschten Geschlecht anstellen sollte“ - und nimmt damit Teile der eindeutig zuzuweisenden Schuld auf sich, was etwa dadurch ausgedrückt wird, dass ihm „dummerweise die Tränen kamen“. Kurz: Ein ,echter‘ Mann hätte das Liebeswerben der Buchhalterin durch gekonnten Einsatz des eigenen Geschlechts pariert und darüber selbstredend kein Wort verloren. Ein Spezifikum des Romans Außer uns spricht niemand über uns ist es, dass insgesamt drei unterschiedliche Übergriffe älterer Frauen auf den Protagonisten erzählt werden. Außer der drastischen Erfahrung in der Firma handelt es sich - in der Chronologie der Erzählung sowie der folgenden Zitate - um einen ebenso wenig platt-fröhlichen Übergriff der Mutter eines Nachhilfeschülers sowie die traumatisierende sexuelle Handlung einer Putzfrau:

Nach drei Wochen trat sie, als ich mich verabschieden wollte, nah an mich heran, nahm meine Hand und legte sie sich auf die rechte Brust. Dann umarmte sie mich und wollte mich küssen, was nicht gelang, weil ich zu ahnungslos war. Ich stellte fest, dass der Körper von Frau Weck rundum weich war, was ich von der Umarmung des Körpers meiner Mutter schon wusste. Danach fasste sie mir in die Hose, holte meinen arglosen Kinderpenis heraus, betrachtete auch ihn eine Weile und steckte ihn dann in die Hose zurück. Sie sagte etwas zu mir, was ich nicht verstand. (Außer uns, S. 61) 
Wenn man Frau Weck auch zugutehalten möchte, dass es der Hauptfigur im folgenden Verlauf nicht in den Sinn kommt, diesen quasi-pädosexuellen - die offensichtlich noch nicht eingetretene Pubertät lässt sie von weiteren sexuellen Handlungen absehen - Übergriff als negativ zu werten, bleibt doch unter dem Strich der zweite Straftatbestand des sexuellen Missbrauchs von Jugendlichen stehen. Die dritte Schilderung wird in Bezug ihrer Folgenschwere deutlicher problematisiert:

Als ich ungefähr sechzehn Jahre alt war, drängelte sich in dem Büro, in dem ich in den Schulferien arbeitete, eine ältere Putzfrau an mich heran. Meine Unbeholfenheit legte sie als Liebesbereitschaft aus. Etwa zwei Wochen lang beließ sie es dabei, mir mit der Hand unters Hemd zu fahren, worin ich keine Annäherung sehen wollte, weil ich nicht wusste, was eine Annäherung ist. Ich war nicht besonders überrascht, als mir die Putzfrau in einem Lagerraum ihre Brüste zeigte. Ich nahm nicht daran Anstoß, dass es sich um gealterte Brüste handelte. Ich hatte damals zwar schon eine Freundin, die mir ihre allerdings kleinen Brüste zeigte. Erst als ich dreißig Jahre alt war, hatte ich vorübergehend den Wunsch, mit einer älteren Frau zu verkehren. Aber ich hatte nicht geahnt, dass ich in diesem Alter die Scham empfand, die mir mit sechzehn unbekannt war. So kam es, dass mich, als wir zu Hause in ihrem Bett lagen, plötzlich eine so starke Hemmung überfiel, dass ich impotent blieb. Der riesige Busen der Putzfrau breitete sich fast über ihren ganzen Oberkörper aus, so dass ich nicht nur impotent, sondern auch sprachlos war, nach einiger Zeit wortlos das Bett der Frau verließ, mich anzog und voller Pein die Wohnungstür hinter mir zuzog. (Außer uns, S. 113 f.)

Ob es sich tatsächlich wieder um eine Putzfrau handelt oder sich das Bild der damaligen über das Erlebnis blendet, ob es damals wirklich so schamlos zuging oder die Zwischenzeit daran Erinnerungsarbeit geleistet hat ${ }^{77}$ und weitere Fragezeichen fallen weniger ins Gewicht als die verspätete Reaktion: „impotent“ und „sprachlos“ sind untrügliche Anzeichen dafür, dass die negativen Seiten der „Annäherung“ bei weitem überwiegen. ${ }^{78}$ In allen drei Beispielen unterbleibt eine wie auch immer geartete ,Anzeige‘ dieses Verhaltens konsequent, was sowohl vom Selbstverständnis der Figur (Schuld bei sich suchen) ${ }^{79}$ als auch der Gesellschaft (Verharmlosung) zeugt. ${ }^{80}$,Ahnungslos', , arglos' und ,unbeholfen' sind die einschlägigen Attribute der Selbstsicht tatsächlich Opfer zu sein, wird nicht in Erwägung gezogen und die Flucht (ins unaussprechliche Trauma) die einzige Richtung.

Nicht nur heterosexuelle Übergriffe auf minderjährige männliche Figuren ereignen sich, sondern auch romanspezifisch ein homosexueller, obwohl das eigene erinnerte Alter immerhin achtzehn beträgt (vgl. Regen, S. 139):

77 Vgl. dazu: „[I]n diesen Augenblicken fiel mir mein Pinkel-und-Foto-Erlebnis ein, jetzt allerdings in einer schon gedeuteten Fassung." (Kassiererinnen, S. 25)

78 Vgl. auch Kein Geld, S. 92 f., für eine „kurze Affäre“ - genaugenommen auch hier ein klarer Übergriff einer „nicht mehr jungen Frau“ auf einen „14 oder 15“ Jahre alten Jungen. Hinsichtlich des Alters der gravierendste Verstoß findet sich im gleichen Roman: Eine „Kindergärtnerin“ in einem „Kinderdorf“ "masturbierte" den an Heimweh leidenden Protagonisten (Kein Geld, S. 139 f.). Vgl. dazu auch Stefan Beyerle (Hg.): Schuld. Interdisziplinäre Versuche ein Phänomen zu verstehen. Leipzig 2009.

80 Romanspezifische Ausnahme einer ,Ahndung' bildet eine namenlos bleibende Nebenfigur aus der Erinnerung des Protagonisten aus Kein Geld, keine Uhr, keine Mütze: „Mit fünfzehn besuchte ich eine Tanzschule und lernte ein Mädchen kennen, das nur wenig älter war als ich. Als ihr ein Busen wuchs, bildete ich mir ein, dass der Busen nur wegen mir käme. Ich tanzte heftig mit dem Mädchen und griff ihr in einer Pause von oben in die Bluse. Sie stieß mich zurück und kündigte an, dass sie ihren Eltern ,alles' sagen würde." (Kein Geld, S. 75 f.) 
Da betrat ein männliches Mannequin die Garderobe und sah unser Gedränge in den Kleidern. Isolde verließ sofort den Raum, der Mann näherte sich mir und griff mir kurz darauf in die Hose. Jetzt hatte das Mannequin mein halb erigiertes Glied in der Hand. Ich war leider nicht schnell genug, um den Mann sofort abzuwehren. Schon bewegte er mein Geschlecht auf und ab, was mir zunächst gefiel und dann peinlich war, aber dann hatte ich erhebliche Mühe, den Mann von mir wegzudrängen, was mir erst gelang, als wir Schritte eines anderen Mannequins hörten [...]. Der Mann konnte sein Interesse an mir nicht so schnell aufgeben. Ich zog deswegen auch meine Hose in den Pausen nicht aus. Allerdings war meine Abwehr launenhaft und unentschieden, was das Mannequin ermunterte. Er versuchte immer wieder, mir den Hosenladen zu öffnen, was ich nicht heftig genug zurückwies. Mit der Zeit entstand daraus ein säuerliches Spiel, das für den Mann immer besser funktionierte, weil meine Zurückweisung immer öfter ausblieb. Es störte den Mann auch nicht, dass dann und wann ein anderes Mannequin die Garderobe betrat oder sogar eine Bemerkung über unser Treiben machte. Jetzt hast du ihn aber bald soweit, sagte einmal ein jüngerer Mann im Vorübergehen und lachte. Meine Willfährigkeit ging auch darauf zurück, dass mir das gegenseitige Onanieren aus der Schule vertraut war. Der Mann verlangte nicht, dass ich auch bei ihm Hand anlegte. Ich lehnte mich nur im Stuhl zurück und wartete ab, bis alles vorüber war. Von Zeit zu Zeit gab mir der Mann etwas Geld, meistens ein Fünf-Mark-Stück. Da ich von zu Hause kein Taschengeld bekam, begann mit den FünfMark-Stücken des Mannequins eine andere Art von Leben. Endlich konnte ich mir Comic-Hefte und Schokolade kaufen, sogar mehrmals in der Woche. (Regen, S. 140 f.)

Auch hier müssen die inkommensurablen Details aufmerken lassen: Schokolade kaufen als Wunsch eines Achtzehnjährigen, der kein Taschengeld erhält und zugleich Angestellter ist? Mag unzuverlässiges Erzählen oder ein fehlerhafter Aufbau des Romans dafür verantwortlich sein, ist es bezeichnend, dass sich kein Rezensent gefunden hat, dem diese Szene eine Bemerkung wert gewesen wäre.

Ist es hingegen ein Mann, der eine Frau belästigt, und berichtet die Frau über diese Vorkommnisse, so ist die Einschätzung der Übergriffe analog verteilt: Selten gefällt es, häufig stößt es ab und lässt tief in die Organisationsstruktur der Gesellschaft blicken. Auch in dieser Konstellation wird mit einer , positiven' Bewertung begonnen:

[D]a packte mich Albert von hinten mit beiden Armen und trug mich auf dem ein wenig nassen Pflaster zum LOLITA hinunter. Es war stockdunkel, ich schrie kurz auf, ich war beglückt, ich hing am Hals von Albert, der mir bis dahin nicht besonders nahe gekommen war, aber jetzt küßte ich ihn, so begeistert war ich. (Obdachlosigkeit, S. 17)

Insofern stereotyp, als die Reaktion der Frau die Erwartungshaltung der männlichen Figur tatsächlich spiegelt (s.u.), indem sie sich „beglückt“ und „begeistert“ zeigt ob der dominanten Gebärde, ist die Szene jedoch zusätzlich durch den intertextuellen Verweis auf Nabokovs Lolita in einen Problemhorizont gesetzt. Der Ich-Erzählerin fallen im Romanverlauf indessen viele weitere Beispiele männlich codierter sexueller Praktiken ein, die eine ganz andere Sprache sprechen; zwei sollen exemplarisch besprochen werden:

Harald begann, mir seine Hand unter den Pullover zu schieben, vorerst nur auf dem Rücken. Ich saß stocksteif im Gras. Ich hatte kein Verlangen. Warum hatte ich kein Verlangen? Ich erinnere mich nicht. Ich wußte von anderen Mädchen, daß es an der Zeit war, sich anfassen zu lassen. Es sah nicht vorteilhaft aus, wenn ein Mädchen vierzehn oder fünfzehn war und keinen Freund hatte. [...] Erst ungefähr fünfzehn Jahre später ist mir aufgefallen, daß ich damals drei Nebenbeschäftigungen brauchte, um Haralds Eroberungen auszuhalten. (Obdachlosigkeit, S. 51)

Wie auch die Erlebnisse männlicher Minderjähriger zeichnet sich die Situation durch eine Art Schockstarre aus; die Reaktionen der Protagonisten auf Gefahr sind also erneut auch im ,freeze 
or fright` zu sehen $(\Rightarrow$ II.2.5) und ähneln denjenigen berichteten bei Vergewaltigungen. Allerdings ist die hier durch die Peergroup vertretene gesellschaftliche Sichtweise ein weiterer handlungsverhindernder Faktor: Anstatt zu artikulieren, dass die Annäherung ungewollt ist, spielt sich im Figureninneren das Programm einer Selbstbezichtigung ab. Wenn es nun einmal so ist, „daß es an der Zeit war, sich anfassen zu lassen“, dann muss ein Mädchen dies nolens volens über sich ergehen lassen und die Schuld internalisieren. Dass es für diese Überwindung bzw. Duldung eines sexuellen Übergriffs erstens in actu verschiedener „Nebenbeschäftigungen“ bedarf und es zweitens „fünfzehn Jahre“ dauert, bis dieser Fakt erinnert werden kann, zeugt von einem durchaus traumatisierenden Setting. In der Erzählgegenwart des Romans hat sich allerdings wenig geändert. Obwohl es sich um denselben, als einfühlsam erzählten Helmuth handelt, der eine starke Frau an seiner Seite duldet (s.o.), entpuppt sich dessen sexuelles Handeln zunehmend als egoistisch und gewaltsam:

Vermutlich habe ich mich geirrt. Helmuth stellt sein Begehren keineswegs ein; er spezialisiert sich mehr und mehr auf eine Vorliebe. Wenn er mit mir schlafen möchte, dreht er mich neuerdings nur um und dringt von hinten in mich ein. Das wird jetzt die einzige Melodie, die von ihm kommt. Ich fühle mich ein bißchen wie in der Schule, wenn ich nicht weiß, was ich erlauben soll und was nicht. [...] Gegen meinen Willen schließe ich die Augen und überstehe Helmuths Überfall in einer Stimmung des Wartens. (Obdachlosigkeit, S. 103)

Es muss nicht eigens erwähnt werden, dass Aktivität und Passivität, Dominanz und Unterwürfigkeit den Schemata der Rollenklischees des neunzehnten Jahrhunderts entnommen sind. Unüblich klar werden jedoch in einem Satz die Signale sexueller Gewalt versammelt: „Gegen meinen Willen“ und „Überfall“ evozieren ein Wortfeld, das sich unschwer als Substitut einer Vergewaltigung interpretieren lässt. Und wiederholt ist das Aufbegehren suspendiert: „Sofort begreife ich, daß es zu meinen Aufgaben gehören wird, diese Schamlosigkeit nicht zu bemerken und nicht über sie zu sprechen." (Obdachlosigkeit, S. 109) Im Erscheinungsjahr 1994 hat man noch nicht mit Sicherheit prognostizieren können, dass in der Bundesrepublik just drei Jahre später die Vergewaltigung in der Ehe unter Strafe gestellt werden würde, aber dem für die damals geführte Debatte sensibilisierten zeitgenössischen Leser muss das Missverhältnis zwischen Selbstbestimmung und Selbstaufopferung der Protagonistin eklatant erschienen sein.

Festgehalten werden kann bereits jetzt, dass Anzüglichkeiten, Belästigungen und Übergriffe aus der Sicht der intern fokalisierten Erzähler weiblichen wie männlichen Geschlechts zumeist genauso empfunden werden, wie es der gesunde Menschenverstand und auch eine Theory of Mind nahelegen: demütigend, traumatisierend und abscheulich. Gleichzeitig ist das Selbstbewusstsein, diese Empfindungen zu äußern, zu gering, was sich vorwiegend auf eine gesellschaftlich marode Sexualmoral der Nachkriegszeit zurückführen lässt, die Genazino bis in seine neuesten Romane der Nuller- und Zehnerjahre des dritten Jahrtausends prolongiert. ${ }^{81}$

81 Eine mögliche Erklärung dafür lässt sich im Rückgriff auf Kämmerlings „Retro-Welt“ (Kämmerlings: Genazino gilt als bedeutender Autor. Warum nur?; $\Rightarrow$ I.5.3) finden: Genazinos Diegesen sollen mög- 
Im krassen Gegensatz gilt für all die angeführten Beispiele sexueller Gewalt, dass der Blickwinkel diese Feststellung verzerrt; denn aus Sicht der bedrängenden Männer ist es entweder von den Frauen genauso erwünscht oder - noch drastischer - dennoch geboten, auch gegen Widerstände sexuell aktiv zu werden. Eine kleine Zusammenschau exemplarischer Stellen gibt darüber Auskunft: „Frau Grünewald gratuliert mir schamhaft und gibt mir ein Küßchen auf die Wange. Ich ergreife ihren nackten Oberarm und gebe ihr einen Kuß hinters rechte Ohr. Frau Grünewald errötet stark, was bei ihrer weißen Haut besonders auffällt." (Heimweh, S. 81 f.) Rotmund erwidert ein „Küßchen auf die Wange“, das allenthalben kulturell auch als Begrüßungs- und/oder Abschiedsvariante ohne Anzüglichkeit gedacht werden kann, zumal es hier einer Gratulation geschuldet ist, mit einem „Kuß hinters rechte Ohr“, also auf eine in Nackennähe tendenziell erogene Zone. Dass Erröten nicht zwangsläufig als Aufforderung einer Fortsetzung gemeint sein oder von Gefallen schlechterdings zeugen muss, ignoriert Rotmund geflissentlich und setzt wenig später seine Annäherungsversuche fort, die vom folgenden inneren Monolog begleitet werden: „Ich nehme an, Frau Grünewald gehört zu den Frauen, die in der Verdutztheit einer plötzlichen Annäherung ihre größte Hingabe zustande bringen." (Heimweh, S. 87) Ähnlich fragwürdig sind die Umstände, die den Ich-Erzähler des Romans Bei Regen im Saal „plötzlich ermutigten, von oben in Isoldes Ausschnitt zu greifen. Isolde schien auf eine solche Annäherung gewartet zu haben, denn sie war weder überrascht noch erschrocken“ (Regen, S. 140). Wie bereits erwähnt worden ist, sind weder Überraschung noch Erschrockenheit wohl einwandfrei zu erkennen, zumal die männlichen Figuren selbst dazu neigen, starres Erdulden als sexuelle Zustimmung zu werten. Plötzliches, überfallartiges Erfassen der weiblichen Brust ist ein häufiger zu beobachtendes Phänomen, das seitens der Männer immer mit einer freudigen Empfindung der Frauen rezipiert wird (vgl. Fremde Kämpfe, S. 113 f.).

Wilhelm Genazinos Figurenbasistypus gesteht sich mitunter selbst ein, dass es keiner gesonderten Signale seitens der Damenwelt erfordert, um zu grenzwertigen Annäherungen verleitet zu werden, sondern auch die eigene Gemütsfassung ausreicht:

Aber seit ich mir als halbtoter Gebrauchtmann vorkam, der an einem Gebrauchtschreibtisch saß und von dort vielleicht nicht mehr wegkam, verlor ich eines Nachmittags die Fassung und drückte Frau Meinecke seitlich in die Jacken und Mäntel der Kollegen und küsste sie heftig und fasste ihr an die Brust und an den Popo. [...] Denn tatsächlich war Frau Meinecke über meinen Überfall erfreut und hoffte auf zivilere Fortsetzungen. (Tiere, S. 118)

Im Endergebnis bleibt das Muster bestehen: Ein Mann ,überfällt' eine Frau sexuell - hier: um sich aus Frust sexuell abzureagieren -, welchselbe darüber - in der männlichen Figurenwahr-

lichst viel vom ,Damals' in die Jetztzeit retten. Vgl. mit Bezug zur Kölner Silvesternacht 2016 die als „Spaß’ getarnten Übergriffe: „Und wenn die Gelegenheit gut, das Gedränge dicht und deckend war, griffen sie die Frauen von oben bis unten ab [...]. Es sah aus wie gut versteckte Gewalt, die unerkannt bleiben mußte, weil sie als Spaß eingeführt war. Nur in den Gesichtern der überraschten Frauen zeigten sich Spuren der Übergriffe; bleich und konsterniert stand die eine oder andere am Rande des Geschehens und ordnete sich die Kleider und die Haare." (Falsche Jahre, S. 515) 
nehmung - „erfreut“ zu sein scheint und sogar „zivilere Fortsetzungen“ wünscht, dabei aber nicht selbst zu Wort kommt. Und zwar weder in zitierter noch transponierter und recht eigentlich nicht einmal in erzählter Figurenrede $(\Rightarrow I .2 .3)$, sodass es nur eine (genderproblematischmännliche) Sicht auf die Dinge zu geben scheint. Namentlich die immens häufige problemlose Anbahnung des Geschlechtsverkehrs scheint den Basistypus in seiner Sichtweise zu bestärken, dass es ausnahmslos um einvernehmliche Vereinigungen ginge: „Christine redete weiter über Stefan, und Eckhard hinderte sie, die Träger ihres Kleides wieder hochzuschieben.“ (Ausschweifung, S. 202) Unmittelbar darauf schlafen beide miteinander. Analog dazu: „Ich war über Frau Kiefer gebeugt und küßte ihren magnolienartig aufgeblühten Busen. Ihre Körperlichkeit verwirrte mich, aber nicht sehr. Ich wunderte mich, daß die Annäherung an Frau Kiefer fast von selbst ablief." (Wohnung, S. 67)

Entsprechend dieser kritischen Bestandsaufnahme wurzeln viele sexuelle Annäherungen weiterhin im (Irr-)Glauben, die ,Empfänglichkeit' der Frauen einwandfrei an deren - als bewusst ausgesendeten und als Einladung interpretierbar imaginierten - Signalgebung ablesen zu können ( $\Rightarrow$ II.5.2): „Er glaubte, daß sie genau wußte, er konnte nun jeden Augenblick aufstehen, sie sofort ausziehen und sich noch am Tisch über sie hermachen." (Sorgen, S. 295) Dabei handelt es sich nicht nur um die Vermutung, dass sie einschlägige Signale ausgesendet habe, sondern sie auch seine ,drohende‘ Bereitschaft erkannt und - qua Schweigen - akzeptiert habe. Dezidiert um körpersprachliche Zeichengebung $(\Rightarrow$ II.1.4) geht es im folgenden Zitat:

Hier sitzt eine Frau vor dir, rede ich mir zu, die sich auf dich zutrinkt, beantworte ihre Signale, gewinne diese Frau für dich, es ist vermutlich nicht schwer. Du sieht die kaum noch verborgenen Vorleistungen dieser Frau (sie dehnt so stark ihren Oberkörper, daß ihr gleich zwei Blusenknöpfe aufspringen) [...]. Ich erhebe mich und schenke Frau Schweitzer ein weiteres Mal nach, und im Augenblick, als ich die leere Flasche auf dem Boden abstelle, drehe ich mich zu Frau Schweitzer und küsse sie. (Heimweh, S. 122 f.)

Es hieße, dieses Zitat in seinem Sinn zu entstellen, wenn die eindeutigen Zeichen des gegenseitigen Gefallens am folgenden Geschlechtsverkehr verschwiegen werden würden (vgl. Heimweh, S. 122 f.). Allerdings ist die häufig unzuverlässige Welt- wie Personenwahrnehmung der Protagonisten zumal in den vorigen Schlaglichtern und Beispielen evident gemacht worden, sodass zumindest die Möglichkeit immer in Erwägung gezogen werden muss, dass die Einvernehmlichkeit nur eine im ,Liebeswahn' befangen imaginierte ist. Wie angekündigt gibt es nämlich auch eindeutige Beispiele für die Ignoranz einwandfrei erkannten abwehrenden Verhaltens:

Ich bin nicht willens, auf meine Vorstellung von kinderloser Zukunft zu verzichten, und setze dafür auch meine Kraft ein, das heißt ich drücke mit den Händen Traudels geschlossene Beine auseinander. Es kommt zu einem Kampf der Wünsche, der uns mundtot und bitter macht. Fast wäre es mir gelungen, in Traudel einzudringen, aber sie greift in ihrer Bedrängnis zu der neben ihr liegenden Fernsehzeitschrift und haut sie mir nicht übertrieben hart, aber doch ernst und gezielt auf den Kopf. So etwas ist zwischen uns niemals zuvor geschehen. (Glück, S. 47) 
Vergisst man für einen Moment die ,mildernden Umstände` der Erzähltechnik - antiemotionaler Modus, euphemistische Umschreibung der Situation als „Kampf der Wünsche“ sowie Klassifizierung der Abwehr als „nicht übertrieben hart“ -, so liegt hier wie im weiter oben bereits berührten Beispiel $(\Leftrightarrow$ II.5.2) nichts anderes vor als eine durch beherztes Eingreifen der Frau verhinderte Vergewaltigung. ${ }^{82}$ Davon legt nicht zuletzt die eingesetzte „Kraft“ des erwachsenen Warlich Zeugnis ab, mit welcher er eindeutige Signale missachtend und um seinem künftigen Lebensentwurf zu entsprechen brachial tätlich sexualisierte Gewalt ausübt.

Viele Indizien legen hier wie andernorts das mentale Konzept ,Frauen erobern` nahe, sodass eine Untersuchung des allgemeinen Wettbewerbs in Liebesdingen lohnend erscheint.

\subsection{Inter- vs. intrasexueller Wettbewerb}

Es kann keinesfalls darum gehen, die vorigen Unterkapitel dieses fünften Schlaglichts zu entproblematisieren. Vielmehr soll durch die Offenlegung einiger evolutionspsychologisch motivierter Formulierungen und Vorstellungen versucht werden, die ,Denkweise' des Basistypus zu plausibilisieren - nicht zu entschuldigen.

So finden sich nämlich allenthalben mehr oder minder gezielt auf das Tierreich anspielende und auch die menschliche Sexualität in archaische Hirnregionen verlagernde Aussagen, die gendertheoretisch aufhorchen lassen:

Danach steigt sie erneut auf die Weinkisten und drückt ihren Hintern ein wenig in die Höhe, so daß ich leicht in sie eindringen kann. Ich denke an Judith. Sie würde den Eifer dieses Weibchens, das sich so zielgenau um das Gelingen eines Schnellbeischlafs vor Reisebeginn kümmert, weder verstehen noch billigen. (Liebesblödigkeit, S. 127)

Der Protagonist wähnt sich als ,Männchen' zwischen zwei ,Weibchen', welch eines das andere im intrasexuellen Wettbewerb dadurch auszustechen vermag, sich „zielgenau um das Gelingen eines Schnellbeischlafs vor Reisebeginn“ zu kümmern, wohingegen das andere ,Weibchen“ - die Verdinglichung spricht für sich - einer solchen Her- und Hingabe kritisch gegenüberstünde. ${ }^{83}$ Weder soll die prinzipielle Übertragbarkeit ,animalischer' Sexualität auf die menschliche gänzlich geleugnet noch eine der beiden Varianten gewertet, sondern einzig und allein die flächige evolutionsbiologi(sti)sche Diktion bei Genazino in Augenschein genommen werden: In Laslinstraße wird einer weiblichen Figur ein „produktives breites Becken“ (Laslinstraße, S. 144) attestiert, in Außer uns spricht niemand über uns ist von "Carolas Brünftigkeit" (Außer uns, S. 57) Carola ist schwanger und immer, willens' $(\Rightarrow$ II.5.3) - die Rede. Über den Oralverkehr heißt es im gleichen Roman: „Wie eine Hündin zitterte Margarete, wie ein Hund leckte ich ihr Geschlecht.“

82 Zwar nur vorgestellt, aber im weiteren Sinne als Vergewaltigungsfantasie zu werten ist auch die Überlegung Abschaffels, „ob es eines Tages möglich sei, diesen schimmernden Glitzerfrauen mitten in ihrer Ansage den Schwanz in den Mund zu stecken." (Sorgen, S. 268)

83 Vgl. für eine ähnliche Situation, in der eine Geliebte tatsächlich von der anderen weiß und deren sexuelle Freizügigkeit anprangert, Kein Geld, S. 147. 
(Außer uns, S. 136) Der Protagonist des Romans Kein Geld, keine Uhr, keine Mütze reagiert auf das Angebot seiner - mittlerweile Brustamputierten - Geliebten Christa, er „könne sie auch von hinten nehmen“, um ihren Hintern für die fehlende Brust zu halten, nicht ohne Vorbehalt gegenüber dem „Viehische[n]“, mit dem Gefühl, „dass ich mich in einen Hund oder in einen Ochsen verwandelt hätte, die das weibliche Tier stets von hinten bespringen." (Kein Geld, S. 134) Abschaffel zeigt sich affiziert davon, dass er „ihren Schweiß gerochen. Der Geruch war angenehm, und er hatte sich sofort vorgestellt, daß er diesen Geruch in seinem Zimmer haben würde, wenn er mit ihr schlief." (Falsche Jahre, S. 434) Immer wieder werden Haltungen und Handlungen mit Versatzstücken aus der evolutionären Psychologie unterfüttert, im letzten Beispiel etwa durch die Erkenntnis, dass das ,Sich-riechen-Können' ein adaptativ gewachsener Mechanismus ist, der dem Fortbestand der Spezies insofern zugutekommt, als unterschiedliche Immunsysteme als Ursache für das gegenseitige Wohlgefallen des Geruchs namhaft gemacht werden. Ebenso ,verwissenschaftlicht' lassen sich Passagen lesen, welche die intersexuelle Partnerwahl thematisieren: „[S]einen Samen behielt er für sich, denn der Same war allein für Dagmar bestimmt.“ (Fremde Kämpfe, S. 124) Peschek kehrt in diesem Fall der evolutionistischen Vorstellung davon, männliche Lebewesen wären in der Regel lediglich daran interessiert, ihr Erbgut möglichst weit zu streuen, den Rücken und wählt seine Partnerin, die tatsächlich damit in Kontakt kommen möge, gezielt aus. Sollte es einmal vorkommen, dass keine ideale Sexualpartnerin zur Verfügung steht, wird es hingegen als ,Naturgesetz' gewertet, dass sich der Basistypus „nun wieder an Frauen gewöhnen muß, die nicht zu mir passen, mit denen ich aber doch zusammen bin, weil es keine anderen Frauen gibt.“ (Regenschirm, S. 52) Eine bewusste (temporäre) Abstinenz scheint sich dem Geschlechtswesen ,Mann` nicht als Handlungsoption anzubieten:

Sie hätte leicht zu mir sagen können: Ein Mann, der vögeln will, sagt auch immer dasselbe, mit und ohne Worte. Eine solche Reaktion war von ihr nicht zu erwarten, was mir ein bisschen leid tat, aber auch recht war. Auch ich wollte nicht kritisiert werden, schon gar nicht wegen einer Normalität, die ich mit vielen anderen Menschen teilte. (Regen, S. 155)

Auf einer tieferen Ebene unterläuft diese Sichtweise alle subtileren Darstellungen zugunsten des klischeeüberfrachteten Bildes der „Normalität“ des immer sexbedürftigen Mannes. Obwohl die Annäherungen der männlichen Protagonisten an die weiblichen (Neben-)Figuren - zumindest aus deren Sicht $(\Leftrightarrow I I .5 .3)$ - problemlos zu funktionieren scheinen, ist das taktische Kalkül, das gelegentlich in der Anbahnung dieser Momente anzutreffen ist, nicht zu ignorieren. Variieren auch die Strategien - die männliche Initiative ist basistypisch verbürgt: Um eine Frau kennenzulernen, sie letztlich anzusprechen, verfolgt etwa Axel Degen wochenlang einen Plan, der letztlich aufgrund seiner Aktivität in die Tat gesetzt werden kann (vgl. Laslinstraße, S. 36 f.), Abschaffel plant ebenfalls von langer Hand, „eine jüngere Patientin, die ihm gefiel“, „kennenzulernen“ (Falsche Jahre, S. 434), und Eckhard Fuchs ,lauert' „,in einem Hauseingang gegenüber der Bank auf den Feierabend von Fräulein Heidenreich“ (Ausschweifung, S. 180). Der Übergang von Vorhand- 
lungs- in Handlungsphase $(\Rightarrow$ I.3.1) hinsichtlich des intersexuellen Wettbewerbs wird hingegen mehrfach brüchig gemacht: „Erst vor kurzem habe ich eine Frau kennenlernen wollen. Sie sitzt dann und wann mit mir morgens in der Straßenbahn und schaut mich empfänglich an. Aber wie spricht man eine fremde Frau an? Vielleicht habe ich es verlernt." (Heimweh, S. 12) Vorausdeutungshaft ließe sich hier eine Krise postulieren, die dem Mann bevorsteht; fehlen ihm doch im intrasexuellen Wettbewerb mitunter diejenigen Attribute, um uneingeschränkt agieren zu können:

Daß ich verliebt bin, merke ich in der Regel daran, daß ich eine Frau durch anteilnehmendes Reden vorerobern möchte. [...] Das beste wäre, ich könnte Frau Grünewald jetzt eine interessante und amüsante Anekdote erzählen. Im Vorübergehen, von Schreibtisch zu Schreibtisch. Leider kenne ich keine solchen Anekdoten, ich bin langweilig. (Heimweh, S. 94 f.)

Dem Vorhaben der Hauptfigur, „eine Frau durch anteilnehmendes Reden vorerobern“ zu wollen, sind gefühlte Grenzen gesetzt, da es Genazinos Figuren gelegentlich an Interessantheit $(\Rightarrow$ II.3) und mithin „amüsante[n] Anekdote[n]“ gebricht. Angesichts des Frauenüberschusses im Textuniversum Genazinos ist demgegenüber auch schlicht die IM-Technik der Untertreibung in Betracht zu ziehen, da der Kotext anzüglich-doppeldeutig das Gegenteil behauptet: „Solche Frauen stehen und sitzen überall in großer Zahl herum. Es sind Liebesruinen, die (wie ich) von fehlgeschlagenen Verausgabungen übriggeblieben sind. Man muß nur eine dieser Liebesruinen betreten, sie haben viele Eingänge." (Heimweh, S. 94) Mit der Wiederaufnahme der Eroberungsmetaphorik, die hier in eine Landnahme mündet, scheint die Flirt-Insuffizienz nicht gar so drastisch wie vordem bekrittelt. Gerade das Überangebot an einem bestimmten ,Schlag von Frau' ist immer wieder der Haken, an dem sich inter- und intrasexuelle Wettbewerbsgedanken festknüpfen lassen:

Es würde nicht lange dauern, dann würden aus den Verwaltungen und Büros zahlreiche Schreibtischdamen ausschwirren, sich ebenfalls drei Reibekuchen kaufen und sich zu mir an den Tisch setzen. Mit einer von ihnen würde ich eine Mittagsplauderei anfangen und sie am nächsten Markttag an derselben Stelle wiedersehen. So einfach ist es, eine Frau kennenzulernen, sagte ich zu mir. (Tiere, S. 156)

Was allerdings auf den ersten Blick wie eine aussichtsreiche Routine klingt, wird wenig später selbstironisch und humorvoll als zum Scheitern verurteilte revidiert (vgl. Tiere, S. 156). Der Wettbewerb in Liebesdingen wird mitnichten nur intersexuell auf Initiative des Mannes in Genazinos Romanen durchgespielt, sondern alle denkbaren Verbindungslinien, die sich aus den maßgeblichen Kategorien ,weiblich-männlich' und ,intra- vs. intersexuell' ergeben, tauchen auf. Dabei ist der intrasexuelle Wettbewerb auf Frauenseite geprägt von offensiv eindruckssteuernden Techniken: In der Anwesenheit eines von beiden Frauen für anziehend gehaltenen Mannes überführt Marga Elisabeth und ihre verbalen Annäherungsversuche der Lüge: „Neulich hast du aber gesagt, sagte Marga, daß du nur deshalb meditierst, weil du bei der anstrengenden Sitzweise endlich warme Füße kriegst. Elisabeth errötete und lachte." (Fremde Kämpfe, S. 115) Kontra- 
hentinnen schlechtzumachen, ist wiederum ein stereotyper Vorwurf an ,die intrigante Frau', die, um ein wenig reizvoller als ihres Gleichen erscheinen zu wollen, nicht davor zurückschreckt, andere herabzusetzen, was sich wie im eben diskutierten Beispiel raumzeitlich simultan oder unabhängig davon (vgl. Kassiererinnen, S. 118 f.) vollziehen und sich hinsichtlich unterschiedlichster Merkmale äußern kann. Neben körperlichen Attributen stehen etwa lebensstilbezogene auf dem Programm, etwa dann, wenn vor Eckhard Fuchs die Wohnungseinrichtung einer Wettbewerberin als „zu puppig und zu altmädchenhaft“ diskreditiert wird (Ausschweifung, S. 199).

Aus der unmittelbareren weiblichen Ich-Perspektive reflektiert die Protagonistin der Obdachlosigkeit der Fische: „Ich war meiner Sache sicher, obgleich ich bemerkt hatte, daß Dieter auch mit einem anderen Mädchen tanzte, mit einer etwas dickbackigen Blonden, die mir nicht als Konkurrenz erschien, weil ich sie als entschieden zu füllig empfand." (Obdachlosigkeit, S. 73) Aus der Sicht des Mannes zwischen zwei Frauen ist expressis verbis nicht nur von „Konkurrenz“, sondern gar von einem „Zweikampf[]“ die Rede:

Seit ich von Thea getrennt war, sah sich Maria als Siegerin eines Zweikampfs. Vor der Trennung von Thea hatte ich etliche Jahre lang Maria und Thea gleichzeitig geliebt, worüber Maria fast nervenkrank geworden war. Für die hochmütige Thea war Maria nur eine Büroliebe, die ihr nichts anhaben konnte. (Tiere, S. 31)

Intersexuell changiert die Beeinflussung auf Frauenseite - bei gleichbleibendem ,Auftakeln` zwischen dickem Auftrag - „Das ist gar nicht schwer, man braucht nur ein bißchen zu glitzern, dann kommen die Ehemänner“ (Abschaffel, S. 132 f.) - und gewinnender Ehrlichkeit: „Nein, ich will, sagte sie, daß du nachher mit mir weggehst in meine Wohnung, sonst war die ganze Anmalerei umsonst und das wäre entsetzlich. Ich habe meine Wohnung heute morgen extra aufgeräumt" (Abschaffel, S. 140).

Obgleich die schlaglichteingangs getroffene Verallgemeinerung, nach der im intrasexuellen Wettbewerb dem Basistypus das Glück ohne Mühe hold sei - etwa wenn der Figur seitens der Frau signalisiert wird, der ,bessere Liebhaber' im Wettbewerb zu sein (vgl. Regen, S. 97-101; vgl. Kein Geld, S. 85 f.) -, prinzipiell weiterhin Gültigkeit beanspruchen darf, gibt es also auch seitens der Männer intrasexuell Konstellationen von Rivalität, Eifersucht und Konkurrenz. Sonja, die den Protagonisten aus Bei Regen im Saal nicht zuletzt dessen Antriebslosigkeit halber verlassen hat, ist neu liiert: „[D]a stellte ich mir in quälender Ausführlichkeit vor, dass Sonja alles, was sie zuvor mit mir gemacht hatte, jetzt mit ihrem Bürokollegen machte [...]. Ich sah, wie Sonja vor dem neuen Mann ihre kurzen Beine weit spreizte und sich ihr Geschlecht dadurch von alleine öffnete." (Regen, S. 69) Das ist für die in dieser Hinsicht an Erfolg gewöhnten männlichen Figuren ein haltloser Zustand, der tatsächlich Katalysatorwirkung hat:

Im Grunde nahm ich die Stelle nur an, damit Sonja endlich bemerkte (ich war sicher, sie würde bald von meinem Job erfahren), dass ich ernsthaft angefangen hatte, die menschliche Ordnung zu begreifen. Mühsam gestand ich mir ein, dass mein Leben nach wie vor nahezu vollständig auf Sonja fixiert 
war. Durch die Heftigkeit meiner inneren Motive kam ich mir schwach vor und gleichzeitig verworren und aufrührerisch. (Regen, S. 83 f.)

Derjenigen Frau, die dem Protagonisten den Vorwurf der Weltfremdheit gemacht hat, soll nun kalkuliert bewiesen werden, nach bürgerlichem Maßstab lebenstauglich zu sein, um nicht von deren Bürokollegen dauerhaft verdrängt zu werden. Was dann nämlich passieren kann, erlebt der Ich-Erzähler des Romans Wenn wir Tiere wären schmerzhaft am eigenen Leib:

Obwohl ich keine Kinder wollte, wäre ich natürlich einverstanden gewesen, wenn Thea ein Kind gewollt hätte. Aber von dir wollte sie keines! Dafür musste ein anderer Mann kommen. Ich war voller Gram und ungeklärtem Heimweh. Der schwangere Bauch war nicht das, was er für mich hätte sein müssen: ein endgültiges Trennungszeichen. Im Gegenteil, der dicke Bauch holte Thea wieder nah an mich heran: als Versagen, als Versäumnis, als Schuld. [...] Dabei war längst klar, dass ich in diesem Fall der Verlierer war. (Tiere, S. 143) ${ }^{84}$

Inwieweit es sich um ein Schuldeingeständnis handelt, wenn post festum die Bereitschaft zum Vaterwerden ausgerufen wird, muss offen bleiben. In Sichtweite bleibt immer auch die Möglichkeit einer Umdeutung. In diesem Sinne geht der Ich-Erzähler aus Ein Regenschirm für diesen Tag selbstrechtfertigend mit der Eifersucht um:

Außerdem ärgert mich, daß sich ein leichtes Rivalitätsgefühl in mir ausbreitet. Es ist, glaube ich, für mich das erste Mal, daß mir eine Frau sozusagen bei schwebendem Verfahren sozusagen weggenommen wird oder entgleitet. Gut, ich habe mich nicht weiter um Margot gekümmert. Ich hätte ihr zeigen müssen, daß ich mich für sie auch außerhalb des Friseur-Salons interessiere. Die entsetzliche Wahrheit ist, daß ich mich für sie außerhalb des Friseur-Salons kaum interessiere. (Regenschirm, S. 131)

Hier wirkt die Eifersucht nicht als Ansporn, sondern sie wird dem mittlerweile geläufigen Topos, der besagt: ,Wirst du von jemandem hintergangen, tue so, als sei dir die Person gleichgültig', entkräftet, um die Ablehnung vor sich selbst zu rationalisieren. Genazinos Basistypus ist, das steht fest, auch zur Eifersucht begabt. In den bisherigen Beispielen taucht dabei kein offensiv agierender Nebenbuhler auf, vielmehr werden die männlichen Hauptfiguren von ihren Partnerinnen vor vollendete Tatsachen gestellt. Anders eine Szene aus Eine Frau, eine Wohnung, ein Roman: „Linda ist nicht da! Sie ist wieder bei ihrem Seemann! Kindsvogel schaute mir auf gleißende Art in die Augen. Vermutlich wollte er sehen, ob sich bei mir Spuren der Eifersucht zeigten. [...] Die Eifersucht war ein seltsam umherkriechender Schmerz." (Wohnung, S. 83-85) Obwohl es sich nicht einmal selbst um den größten Kontrahenten im Kampf um die umworbene Linda handelt, wird aktiv Eifersucht heraufbeschworen. Dabei benötigen Genazinos Romanfiguren weder einen aktiven männlichen Widerpart noch gesicherte Aussagen der Partnerinnen, um an der Treue ( $\Rightarrow$ II.5.2) der Frauen zu zweifeln oder in der Konsequenz eifersüchtig zu werden: „War Ruth eine Frau, die ein verschwiegenes Abenteuer wenn nicht suchte, so doch annahm, wenn es sich anbot?" (Ausschweifung, S. 149) Fragen wie diese treiben die Protagonisten immer

Für die entgegengesetzte Variation vgl.: „Sonjas Finanzbeamter wollte ein Kind, Sonja wollte keines, jedenfalls nicht von diesem Mann. Zur Sicherheit nahm sie die Pille und verschwieg es ihrem Mann. Ich fragte mich, ob sie, wenn sie von ihrem Mann befreit sein würde, nicht umso heftiger ein Kind von mir würde haben wollen und wie ich mich dann würde drücken können.“ (Regen, S. 85 f.) 
wieder um, wobei sich als Regel aufstellen lässt, dass es sich um eine zukunftsgewisse Vorausdeutung handelt, sprich: keine Zweifel geäußert werden, wenn nicht etwas ,dran' ist an der Vermutung:

Zum Beispiel beunruhigte es mich, dass sie manchmal erst lange nach Mitternacht vom Training zurückkehrte. Ich glaubte nicht, dass Carola eine feste Beziehung zu einem anderen Mann unterhielt. Eher neigte sie dazu, Gelegenheiten auszunutzen. Aus eigener Erfahrung wusste ich, dass Untreue in der Regel nicht geplant wird. Sie geschieht, wenn Erschöpfung, Gleichgültigkeit und eine plötzliche Chance überraschend ineinander greifen. (Außer uns, S. 24)

Es handelt sich um eine für den Basistypus erstaunlich gelassene Position und lakonische Schilderung zugleich, was im direkten Kontrast zu Fuchs besonders deutlich zu Tage tritt: „Endlich, als er seinen Todeswunsch für jeden seiner Konkurrenten gedacht hatte, fühlte er sich besser.“ (Ausschweifung, S. 150 f.) Wohin diese ,Cholerik' führen kann, zeigt sich in einem rachsüchtigen, intrasexuellen Plan Abschaffels, der den Konkurrenzkampf auf Männerseite ins Extreme steigert - und die Frau zum bloßen Mittel zum Zweck instrumentalisiert: Abschaffel zahlt Hornung dessen per offensivem IM getätigte Bloßstellung seiner selbst heim, indem er mit dessen Frau Sex zu haben plant: „Alle lachten, und aus blöder Verlegenheit stimmte Abschaffel lachend in seine eigene Verspottung mit ein. [...] Hornung hatte ihn blamieren und bloßstellen wollen." (Sorgen, S. 355) Der erste Schritt seines Rachefeldzuges ist ein Besuch bei Frau Hornung unter deren Mann wiederum diskreditierenden und deren Eifersucht mehrenden Umständen:

[W]eil ich ja weiß, äh, weil ich angenommen hatte, daß Ihr Mann wahrscheinlich nichts darüber gesagt hat. [...] [U]nd er ahnte, was sie hören und wissen wollte, und weil er einen Plan hatte, gab er ihr das Futter, nach dem ihre Angst verlangte. [...] Während Hornung glaubte, er versorge seinen Goldhamster, wollte er seiner Frau die Kleider vom Leib reißen, mit ihr schlafen und dabei das Gefühl haben, Hornung selbst zu schänden. (Sorgen, S. 357 f.)

Drei Gläser Cognac später „hatte er den kleinen Körper von Frau Hornung im Arm.“ (Sorgen, S. 361) Dass es als Machtdemonstration gängige Münze ist, die Ehre des Mannes durch die Degradierung der Frau zum Objekt zu kränken, ist literarhistorisch gut belegt. Das Beispiel zeigt zugleich, dass Eifersucht und intrasexueller Wettbewerb nicht nur als Empfindung, sondern auch als manipulatives Druckmittel in den Romanen Genazinos präsent sind. So gelingt es Eckhard Fuchs etwa, Christine für seine sexuellen Wünsche dadurch zu gewinnen, dass er mit der wohlerwogenen Abwertung einer Freundin Christines sie selbst sogleich in ein günstigeres Licht rückt:

Ihre Kollegin ist eine Übertreiberin, sagte Eckhard; aus dem einen Ventilator hat sie gleich ein halbes Dutzend gemacht, die beiden kranken Gummibäumchen in der Ecke hat sie in Palmen verwandelt, und das Problem der nicht vorhandenen Kokosnüsse wollen wir gar nicht erst behandeln. Christine lachte. (Ausschweifung, S. 187)

Mutmaßlich existiert kein anderes Feld als das des inter- und intrasexuellen Wettbewerbs, auf dem auch die Lexik so ausdrücklich von Ränkeschmieden und strategischen Intentionen durchwirkt ist: 
Ich war eine vorsichtige und gleichzeitig routinierte Garderobenmaus geworden, die bereit war, ein verlockendes Käsestück eine Weile zu beobachten, um dann sicher zu sein, dass außer ihr niemand das Käsestück im Auge hatte. Dabei schämte ich mich meines kleinlichen Kalküls (Außer uns, S. 64).

Der autodiegetische Ich-Erzähler umgeht metaphorisch wie konkret den offenen intrasexuellen Wettbewerb, indem er darauf achtet, dass er der einzige Interessierte ist - und gleichsam ,leichte Beute' machen kann. Dass er sich dabei selbst erneut als - wenngleich nicht prototypisch wehrhaftes - Tier vorstellt, das Werben um eine Frau mit einem Beutezug, die Frau mit einem Beuteobjekt (Käsestück) und sich selbst mit einem aus dem Verborgenen operierenden Jäger vergleicht, ist nicht nur wiederholter Ausweis der Geschlechterstereotypien, die Genazinos Romane fundieren, sondern allzumal auch Beweis für die der Tierwelt evolutionsbiologisch und -psychologisch entlehnte Sicht auf inner- wie zwischengeschlechtliches Taktieren. Für den Übergang zum nächsten Unterkapitel bietet sich eine letzte, nicht sehr bekannte Parallele von Menschheit und Tierreich an: jene wie dieses kennt Sex gegen Bezahlung.

\subsection{Sexuelle Wünsche, Vorlieben und Praktiken}

Die Erlebnisse in der halbseidenen Welt der Prostitution ließen sich in einem imaginierten Artikel unter dem Titel ,Unbefriedigende und unbefriedigte Lust: Genazinos Romane gegen den Strich gelesen' abhandeln. Trotz der permanenten Faszination von den Rotlichtbezirken im fiktionalisierten Frankfurt am Main (und Umgebung) und trotz des häufig variierten Wunsches, als Zuhälter sein Leben zu fristen, sind die Erfahrungen - gehäuft etwa bei Abschaffel - durchweg negativ konnotiert. Aber der Reihe nach.

In einem ersten Schritt gibt es zwei Wünsche zu unterscheiden: denjenigen danach, mit einer Prostituierten zu schlafen und daraus Befriedigung zu ziehen einerseits, denjenigen danach, eine Prostituierte entweder dem Rotlichtmilieu zu entreißen oder sie aber in genau diesem in Abhängigkeit als Zuhälter zu belassen andererseits. Zunächst zum zweiten Wunsch: Abschaffel „stellte sich vor, daß er sich eines Tages mit einer jungen hübschen Nutte anfreunden und ihr fester Zuhälter werden könnte." (Sorgen, S. 225) Dieser Wunsch wird mit der erzählten Zeit übermächtig und bspw. mit der Begründung unterlegt, dank des als entspannt vorgestellten Lebenswandels dann nicht mehr ins verhasste Büro gehen zu müssen (vgl. Sorgen, S. 303 f.). Für Fürsorge für die betreffende Frau ist dabei wenig Platz. Peu à peu stellen sich bei Abschaffel Unsicherheit und Ängstlichkeit während der Bordell-Besuche, die seine Zuhälterei begründen sollen, ein (vgl. Sorgen, S. 311 ff.). Nachdem auch ein zweiter und dritter Versuch scheitern, sich zum Essen zu verabreden (vgl. Sorgen, S. 334), lässt er den Plan fahren. Enttäuschung ist das verbindende Glied zum ersten Wunsch: dem nach sexueller Erfüllung im Bordell. Das beginnt schon bei den in großer Anzahl vorhandenen nicht zustandekommenden Besuchen in den Etablissements, die diejenigen Situationen eines tatsächlichen Beischlafs mit Prostituierten überwiegen: 
Ich werde leicht und leichtsinnig, ich schaue interessierter als zuvor in die Zimmer der Frauen. [...] Ich fühle mich aufgereizt vom Anblick einer kleinen und zierlichen Hure. [...] Ich gebe Edith die Schuld, daß ich in Gefahr bin. Wenn sie mich nicht so oft zurückgewiesen hätte, wäre ich jetzt nicht in diesem Zimmer. (Heimweh, S. 42)

Letztlich wird der Besuch allerdings durch einen ,Hund-ex-Machina', der unter dem Bett der Prostituierten herauskommt und aus ,externer Perspektive‘ bzw. kompositorischer Motivierung $\left(\Rightarrow\right.$ I.2.5) den Rückzieher besiegelt, abgebrochen. ${ }^{85}$ Eine andere (unbefriedigende) Variante ist das Aufsuchen der Nähe von Sexarbeiterinnen, um diese zu verhöhnen, also von vornherein ohne die volle Absicht, mit ihnen sexuell verkehren zu wollen: „Er beschloß, durch ein Bordellviertel hindurchzugehen, er hoffte, es täte ihm gut, von den Mädchen auf der Straße angesprochen zu werden und durch Schweigen und Weitergehen etwas ablehnen zu können. So geschah es auch, und es gefiel ihm wirklich." (Abschaffel, S. 15) Die Selbsterhöhung gelingt - der Preis, dafür andere per offensiven Impression Managements herabzusetzen, wird bereitwillig gezahlt. Dieser Abwertung - nicht zuletzt durch strafendes Schweigen $\Leftrightarrow$ II.4.4) - korrespondiert die despektierliche Sicht: „In der Regel sah eine Hure aus wie eine Hure“ (Sorgen, S. 307).86 Erzähltechnisch wird stark abstrahiert geschildert: Lediglich im gerafften Erzählerbericht wird wie in einem Ergebnisprotokoll die erhoffte Wirkung vermerkt. Unmittelbarer ist die ,wiederholte Variation“ dieses Musters in den folgenden Beispielen, wobei erneut das hohe Maß an Kalkül ersichtlich wird, das die Handlungen der Figuren bereits im Vorfeld flankieren. Abschaffel, der erneut durch einen Rotlichtbezirk ,flaniert', „,war einer der ganz wenigen, die allein auf- und abgingen. Er bemühte sich, nicht stehenzubleiben, denn Stehenbleiben wurde von den Frauen als ihnen geltendes Einzelinteresse ausgelegt.“ (Abschaffel, S. 77) Aber, obwohl er, wie erwartet, „animiert und angerufen“ wird, möchte er zunächst unnahbar erscheinen: „Alle sollten annehmen, daß er, Abschaffel, von niemand etwas wolle [...]. Und wenn er stehenblieb, dann sollte es aussehen, als wolle er sich erkundigen, ob auch bei den anderen alles in Ordnung sei.“ (Abschaffel, S. 78) Bezeichnenderweise wird es immer dann, wenn es bis zum Äußersten, dem eigentlichen Akt, kommt, enttäuschend:

Ihn wunderte der lächerliche Preis von zwanzig Mark. In Frankfurt fingen die Mädchen nicht unter sechzig Mark an. [...] Machen wir nackt? sagte sie, und Abschaffel sagte: Ja. Es dauerte wieder lange, bis Abschaffel ausgezogen war. Er sah jedes Kleidungsstück, bevor er es auf einen Stuhl legte, noch einmal an; am liebsten wäre er in ständiger Blickverbindung mit seinen Kleidern geblieben. Das kostet einen Zehner mehr, sagte sie, und Abschaffel legte ihr das Mehrgeld auf den Tisch. [...] Unter nackt verstand sie, daß er sich ganz auszog, sie ihren Pulli jedoch nur hochschob bis zur Büstenhaltergrenze. [...] Sie hatte die Hand an seinem Glied und bewegte es auf und ab, und Abschaffel sah in ihrem Zimmer umher. Sein Glied wurde nicht fest, und Abschaffel betrachtete seine Kleider. Sollen wir vorher etwas Französisch machen? fragte sie. Was kostet das mehr, fragte er. Du bei mir und ich bei dir sechzig Mark, sagte sie. Ich will nicht, sagte Abschaffel. Dann dreißig, sagte sie. Gut ja, sagte er. Leg dich hin, sagte sie. [...] Sie beugte sich herunter, da klopfte es an der Tür. Ich habe einen Gast,

85 Wobei die genderproblematische Begründung Rotmunds, überhaupt ins Bordell gegangen zu sein, für sich spricht ( $\Rightarrow$ II.5.3) Vgl. für eine alternative, psychoanalytische Erklärung dieser Vorliebe: „Die Entdeckung, daß er, wenn er ins Bordell ging, eigentlich seine Mutter hassen wollte, war etwas Unerhörtes für ihn. Er staunte, und es brach ihm der Schweiß aus." (Falsche Jahre, S. 534) 
rief sie laut, und das Klopfen hörte auf. Abschaffel schnaufte und wollte nach Hause. Sie tat so als leckte sie ihm das Glied [...]. Du tust überhaupt nichts, sagte Abschaffel, laß los. Du kommst nicht, sagte sie, du kommst nicht. Wir hören auf, sagte Abschaffel, laß los. Sie stand auf, und Abschaffel strengte sich an, durch schnelles Ankleiden sein Beleidigtsein auszudrücken. Er glaubte, er wollte ihr lediglich vorspielen, daß er böse sein, und er merkte nicht gleich, daß er es wirklich war. ( $A b$ schaffel, S. 78 f.)

Vier wiederkehrende Merkmale verketten sich hier: der Topos bzw. Typus der ,trickreichen Hure‘ (s.u.), das Nicht-bei-der-Sache-Sein mit der Folge (oder: als Folge?) der Unlust - „Ja, sagte er abwesend, mach irgend etwas“ (Sorgen, S. 322) -, die graduelle Impotenz - „Sie strengte sich an, und es gelang ihr tatsächlich, sein Glied aufzurichten“ (Abschaffel, S. 107) - sowie die antiemotionalen Erzählverfahren ( $\Rightarrow$ II.5.6), die sich etwa in der Flächigkeit des Wortfeldes ,Geld' ausdrücken. Besonders an diesem Beispiel ist die momentweise Nullfokalisierung auffällig („und merkte nicht gleich“), die als zusätzliche Distanzquelle funktionalisiert interpretierbar ist. Genazinos Basistypus erlebt während seiner Bordellbesuche, so sie denn wirklich zustandekommen, am eigenen Leib immer wieder Enttäuschungen. Allerdings kommt es romanspezifisch auch zu einer für beide Seiten negativen Erfahrung:

Ich rechne schnell nach und komme zu diesem Ergebnis: Das Vögelchen vögelt umsonst und bezahlt mich obendrein noch dafür. [...] Etwa zehn Sekunden lang habe ich ein schlechtes Gewissen und erwäge ernsthaft, das zuviel erhaltene Geld am Ende zurückzugeben. Aber dann wird klar, daß die Frau mich betrügen will. Sie beugt sich leicht nach vorne, greift sich zwischen die Beine und umschließt mit der Hand mein Geschlecht, führt es jedoch nicht ein. Sie gibt ihrer Hand eine langgezogene, schalenartige Form und drückt sich den Penis darin gegen ihr weiches Vaginalpolster. Wenn ich jetzt nicht wüßte, daß ich sie ebenfalls betrügen kann, würde ich vielleicht grob werden. Vermutlich glaubt die Frau, daß ich ihre Manipulation nicht bemerke. Sie faßt mit der anderen Hand meinen Hintern und bringt ihn in eine rhythmische Bewegung. Momentweise erinnert mich unsere eigenartige Sexualskulptur an die künstlichen Besamungen, die ich im Fernsehen schon öfter gesehen habe: Ein Stier wird mit Hilfe eines Duftlockstoffs auf eine Stierattrappe gelockt, über seinen Penis stülpt der Züchter ein Samenabfanggerät. Zehn Sekunden später ist das Ergebnis da. So ähnlich ist auch der Verlauf zwischen der kleinen Betrügerin und mir. (Heimweh, S. 53 f.)

Alle vier postulierten Prinzipien finden sich wieder, hier mit den Alleinstellungsmerkmalen garniert, dass Rotmund ob des Betrugs der Prostituierten erwägt, „grob“ zu werden - dass sexuelle Gewalt für ihn kein Einzelfall ist, ist bekannt ( $\Rightarrow$ II.5.3) -, sowie selbst zum Betrüger wird.

Neben der evidenten Hassliebe Prostituierten gegenüber respektive dem immer wiederkehrenden zweischrittigen Verlaufsplan, erstens ins Bordell zu gehen, um zweitens letztlich aber einen unbefriedigenden Besuch dort verlebt zu haben, nimmt die Problematisierung und Schilderung von Sexualpraktiken, sexuellen Wünschen und Vorlieben eine Menge Raum ein.

Als naheliegendste Handlung (an sich selbst) wird zwar die Autoerotik allenthalben thematisiert, bleibt aber im Vergleich zu den Schilderungen und Wünschen der Sexualität mit Partner(in) einerseits hinsichtlich des Einfallsreichtums erstaunlich ideenlos, andererseits bezogen auf den Detailgrad sehr blass: „Dauernd erinnerte er sich, wie er als Jugendlicher onaniert hatte [...]. Unter der Bettdecke" (Abschaffel, S. 88). Lediglich vereinzelt stolpert man über Aussagen, die die erotische Selbstliebe über die bloße Erwähnung der Handlung hinaus ausladender the- 
matisieren: „Onanieren ist wie einen Film anschauen, in dem man Regisseur, Hauptdarsteller und Kameramann zugleich ist.“ (Tiere, S. 123)

Im Gegensatz zur komfortablen Möglichkeit alle wichtigen Rollen des ,Kopfkinos‘ in Personalunion zu verkörpern, sind die zwischengeschlechtlichen Begegnungen nicht frei von Komplikationen - durchaus vergleichbar mit den Erlebnissen bei Prostituierten. Ein wichtiger Punkt in diesem Bereich ist die (gefühlte) Überforderung, die wie ein roter Faden das Sexualleben der Hauptfiguren zu durchziehen scheint: 87 „Sie öffnete ihm den Hosenladen, holte seinen Schlot heraus und lutschte ihn [...]. Er hatte nichts dagegen, aber er hatte das Gefühl, zum erstenmal in seinem Leben überwältigt zu werden." (Fremde Kämpfe, S. 19) Die Fellatio ist bei Genazino eine alte Bekannte und Vertraute (s.u.), aber hier interessiert vor allem die für Wolf verstörende Freizügigkeit - repräsentiert auf Histoire- wie Discours-Level -, die sich qua Wortwahl mit einem sexuell übergriffigen Verhalten identifizieren lässt ( $\Rightarrow$ II.5.3). Ganz ähnlich wie Wolf Peschek ,erleidet' Dieter Rotmund mit seiner Geliebten Sonja (alias Frau Schweitzer) Momente überfordernden Oralverkehrs, wobei freilich die intertextuelle Note sowie die schreiende Ironie nicht gänzlich außer Acht gelassen werden dürfen; ebenso wenig wie auch das Kokettieren mit der Ahnungslosigkeit als Szenenfilter ernst genommen werden muss:

Nachdem wir eine Weile herumgeschmust hatten, ging Sonja dazu über, mich zu fellationieren. Ich habe anfangs nicht gewußt, worauf Sonja hinauswollte, aber dann fielen mir die Comics von Robert Crumb ein [...]. In diesen Comics tauchen immer mal wieder kleine pummelige Frauen auf, die dürre hilflose Männer befriedigen. Diese Geräuschbeschreibungen fielen mir wieder ein, als ich Sonja über mein Geschlecht gebeugt sah, weil auch die Geräusche, die von Sonja kamen, Ähnlichkeit mit den Comicgeräuschen hatten: Org, Worg, Zorg, Schnorg - und andere, die ich nicht identifizieren kann. Ich hatte niemals für möglich gehalten, daß mein Geschlechtsleben einmal so drastische Formen annehmen würde. Ich hoffe inzwischen, daß der Erguß rasch eintritt, damit ich vom Augenblick des schnaubenden und würgenden Frauengesichts befreit werde. Es ist möglich, daß mich diese Art von Sexualität (wie soll ich sagen) eine Spur überfordert, aber vorerst lasse ich mir nichts anmerken. Auch damals, als ich mit der blutenden Edith schlief, kam ich mir ein wenig strapaziert vor. ${ }^{88}$ Und auch damals legte sich das Gefühl der Überforderung bald, beziehungsweise ich gewöhnte mich an die Stimmung unseres Über-die-Ufer-Tretens, die vielleicht das Wichtigste an der ganzen Sexualität ist. (Heimweh, S. 127)

Trotz des ,Gewöhnungseffekts` - und der über die ,Soundwords' antiemotional verpackten, zutiefst intimen Handlung - ist das gezeichnete Bild nicht ganz harmonisch: Zwar ist die Dünnhäutigkeit, die manische Selbstbeobachtung und auch die Hypochondrie der Hauptfiguren schon lang und breit verhandelt worden, doch ist nicht abzustreiten, dass Genazinos Figuren - möglicherweise wirklich an Crumb, dessen Portfolio sexuelle Übergriffe wie auch einige Wünsche des Basistypus umfasst - einiges abverlangt wird. Besonders eindringlich wird die Überforde-

87 Vgl. auch: „Abschaffel legte sich die Hand über das Gesicht wie immer, wenn ihm das Geschlechtsleben zu naheging. [...] Margot konnte mit dem männlichen Geschlecht fast besser umgehen als er selbst." (Sorgen, S. 199)

88 Die Dopplung von Zumutung und erfolgreich bestandener Prüfung verdeutlicht besonders schön: „Auch dann, wenn Edith ihre Tage hatte, steckten wir ineinander. Edith hatte stets eine Menge Papiertaschentücher auf dem Nachttisch, mit denen ich mir hinterher den blutigen Penis umwickelte und rasch ins Bad rannte. Ich betrachtete ihn lange im Badezimmer und schauderte voller Respekt. Wie lange ist das her!" (Heimweh, S. 72) 
rung im Roman Fremde Kämpfe vor Augen geführt. Dagmar Achatz, Wolf Pescheks Freundin, mit der er üblicherweise guten, beiderseitig einvernehmlichen und unverkrampften Sex zu haben pflegt (vgl. Fremde Kämpfe, S. 12 f., S. 53 f. u. S. 139), wünscht sich im Romanverlauf, Pescheks Urin in das Liebesspiel integriert zu wissen. Konkreter: Dagmar bittet Peschek, dass er „in sie hineinpinkelt“, was ihn hinwiederum befremdet und abneigend reagieren lässt: „Es geht nicht, ich will nicht, ich kann nicht, sagte er und löste sich von ihr." (Fremde Kämpfe, S. 141) Schließlich führt diese Störung der Sexualpräferenz zur Entzweiung beider:

Wolf dachte: Hoffentlich kann ich es nicht, wenn sie es wieder verlangt. In all seinen Bewegungen erkannte er ein kleines Lauern, das Dagmar entging. [...] Peschek fühlte, daß ihn seine Anspannung hinderte. In jeder Sekunde glaubte er, Dagmar könnte noch einmal von ihm verlangen, daß er in sie hineinpinkelte. Er sehnte sich danach, wieder arglos sein zu dürfen. Sein Verhalten war nichts als eine Folge von nicht ausgesprochenen, gestotterten Bitten. (Fremde Kämpfe, S. 185 f.)

Der Sachverhalt, dass Dagmars Fetischisierung des Urins zur finalen Trennung Pescheks von Achatz führt (vgl. Fremde Kämpfe, S. 223 f.), bildet den (gefühlten) Gipfel der Überforderung im sexuellen Metier, zumal er sich derart dezidiert im Unsagbaren ereignet.

Es offenbart sich hier gewissermaßen ein avant la lettre geführter Diskurs der Krise der Männlichkeit der Nullerjahre: ${ }^{99}$ Nicht mehr der ,Herr im eigenen Bett zu sein', ist eine Kränkung für das ,potente Subjekt', das sich zurücksehnt in die Zeit vor dem feministischen Sündenfall der ,dritten Welle': „Ich sehne mich nach Sandras Einfalt, von der ich mich nie bedroht gefühlt habe. Ich möchte Sandra von hinten nehmen und seitlich von oben dabei zuschauen, wie ihre Brüste beim Vögeln hin- und herschaukeln." (Liebesblödigkeit, S. 144) Aus männlicher Sicht ganz unbedrohlich, ist doch der Konnex von weiblicher Einfalt und gutem Sex ein uralter lebensweltlicher wie literarischer Topos.

Im Gegensatz zur als „bedrohlich“ wahrgenommenen, undomestizierten weiblichen Sexualität erneut eine Parallele zu Crumb! -, sind sexuelle Einfälle der Frauen tendenziell gerne gesehen, wiewohl nicht immer unumschränkt positiv evaluiert:

Wir lagen halb nebeneinander, halb übereinander, Carola hielt mein Geschlecht in der Hand, ich suchte mit dem Gesicht den Platz zwischen ihren Brüsten, war dabei etwas irritiert, weil ich plötzlich roch, dass Carola ihre Brüste eingeölt hatte, was ich von ihr nicht gewohnt war. Eine halbe Minute später wurde deutlich, was Carola im Sinn hatte. [...] Zwischendurch plagte mich der Argwohn der Eifersucht, weil ich [...] nicht der erste Mann sein konnte, mit dem Carola diesen Busenakt ausführte. (Außer uns, S. 22)

Sofort wird das prinzipielle Wohlgefallen ob der weiblichen Initiative wieder gebrochen: Ungehemmt Lust zu empfinden, klappt eben nicht ganz, wenn das weibliche Wesen als mit einem sexuellen Vorleben ausgestattetes imaginiert wird ( $\Rightarrow$ II.5.3 u. $\Rightarrow$ II.5.4). Allerdings wird die Grenze zwischen ,aktiv' und ,passiv', zwischen ,gebend' und ,nehmend'von Genazino auch immer

89 Vgl. Julia Kospach: Implodierende Männer in mittleren Jahren. In: Falter (Literaturbeilage) vom 13. März 2009. 
wieder aufs Neue ausgelotet. In Gestalt der Stellung 69 etwa, einer sozusagen Gleichberechtigung vorlebenden, versinnbildlicht der Erzähler die Ambivalenz:

So zuckte er überrascht zusammen, als er spürte, wie Christine mit der sich kalt anfühlenden Creme seinen Anus zunächst eincremte und dann langsam ihren gestreckten Zeigefinger einschob. Ein paar Sekunden lang schreckte sein Körper zusammen und wollte sich vollständig verschließen und verwehren. (Ausschweifung, S. 206)

Nach diesem Intro des oben bereits kurz analysierten Beispiels könnte man denken, ein Paradebeispiel für Übergriffigkeit ( $\Rightarrow$ II.5.3) entfaltet zu bekommen. Indes „bemerkte Eckhard, daß die neue Körpererfahrung zwar überraschend und befremdend, aber nicht verletzend und nicht schmerzhaft war, im Gegenteil, es stellte sich eine gleichmäßige Sanftheit von kleinen Bewegungen ein, die er allesamt Christine verdankte." (Ausschweifung, S. 206) Es handelt sich also ausgewiesenermaßen um eine derjenigen Praktiken, die ungeachtet ihres Innovationspotenzials in diesem Beispiel sogar der Umkehrung der ,klassischen' Rollenstereotypen $\Leftrightarrow \Leftrightarrow$ II.5.3) - beiden Partnern gefallen, für den Liebeskosmos bei Genazino allerdings peripher sind. Immerhin lassen sich auch die folgenden zwei Beispiele in dieses Kollektiv aufnehmen:

Bleib, solange du kannst, dann mach es mir auf den Bauch. Die Bitte erregt meine Vorstellungen, so daß ich den Beischlaf nicht mehr lange dehnen kann. [...] Wenig später beginnt sie, sich mit der Hand den Samen auf dem Bauch zu verstreichen. Ich schaue eine Weile zu und will etwas fragen, aber dann fällt mir ein, daß man eine still gewordene Frau besser nicht fragt, was sie gerade tut. (Regenschirm, S. 144 f.)

Dass es unerhört wichtig für den Genazino'schen Basistypus ist, ,den Beischlaf lange andauern zu lassen, ist nunmehr hinlänglich bekannt ( $\Rightarrow$ II.5.3). Dass sich allerdings durch autonome direkte Rede einer weiblichen ,Nebenfigur' dessen Vorstellungen in einer Weise beflügeln lassen, dass der ,Souverän' hinter seinen sonstigen Höchstleistungen zurückzubleiben genötigt ist, überrascht. Hingegen ist eine beiderseitige sexuelle Befriedigung zu konstatieren, wenn man einer geäußerten sexuellen Bitte und einer Gewährung dieser - obgleich nicht ausgeführt und also im Ungewissen belassen - nicht die Erfüllung absprechen möchte. Auch das intime (Liebes-)Spiel „IN IHR GEHEN“ (Fremde Kämpfe, S. 54) greift auf sexuell-praktischer Ebene die prinzipielle Innigkeit auf, wie sie auch auf Beziehungsebene grundsätzlich von den unbefriedigenden unterschieden werden kann ( $\Rightarrow$ II.5.2).

Ungeachtet dieser für beide erfüllenden und einvernehmlichen Vereinigungen sind - naturgemäß - bestimmte sexuelle Wünsche in bestimmten Konstellationen schwer verbalisierbar ${ }^{90}$ und firmieren daher - wenn sie nicht in das Cluster der Überforderung passen (s.o.) - als unausgesprochene Wünsche. Zumal in der Ausschweifung wird mit dem Mischpult-Regler sexueller Wünsche bei gleichzeitiger Nicht-Kommunikation gespielt: „Es war klar, daß er Ruth diese Phantasie niemals mitteilen durfte." (Ausschweifung, S. 59) ,Diese‘ ist im konkreten Fall als Platzhalter zu verstehen, da im Romanverlauf mehrere potenzielle sexuelle Wunschfantasien auftreten. Eine 
davon wird wie folgt charakterisiert: „Er leckte sie [...], und dann steckte er ihr eine schöne Schokopraline tief in den Körper und saugte sie anschließend wieder heraus." (Ausschweifung, S. 253) In einer unglückseligen Mischung aus innerer Zensur ( $\Rightarrow$ II.2.6) und tendenzieller Verklemmung, befürchtet Fuchs, dass, sollte er diesen oder andere Wünsche äußern, „Ruth entweder vor Überraschung oder vor Entsetzen kaum ein Wort sagen könnte." (Ausschweifung, S. 73) Die Probe aufs Exempel hingegen tritt nicht ein, weil „er sich so etwas“ nicht „trauen würde“ (Ausschweifung, S. 280). Wie deutlich wird, handelt es sich bei den sexuellen Wünschen, die den Kopf der Protagonisten - aus Scham, Kalkül und anderen Gründen - nicht verlassen dürfen, nicht um ,Störungen der Sexualpräferenz', da das Sexleben auch ohne diese besonderen Formen funktioniert und geschätzt wird. Allerding sind Genazinos Figuren dazu angetan, bestimmte Vorlieben doch bis zu veritablen Fixierungen zu inkorporieren.

Wie die männlichen Protagonisten sich häufig die gleichen Fixierungen und fixen Ideen in Liebesdingen teilen, so sind auch die Frauen hinsichtlich ihrer basalen sexuellen Vorlieben verhältnismäßig einfach und - wenig überraschend - genderproblematisch gestrickt. Der voyeuristisch und visuell-taktil dominierten männlichen steht dabei eine weibliche Sicht gegenüber, die einerseits durch Überwältigungsaffinität $(\Rightarrow$ II.5.3), andererseits durch Penisfixierung Kontur gewinnt. Um zum visuell organisierten Lustzentrum des Genazino-Mannes vorzudringen, kann als Wegmarke und Kontrast die weibliche ,Blindheit' auf diesem Auge dienen. Allzumal dann, wenn Frauen bei Genazino in Selbst- oder Fremdaussagen verlautbaren lassen, dass sie gerne überwältigt werden würden ( $\Rightarrow$ II.5.3), geschieht dies nicht durch Zufall (externe Perspektive) in Situationen, die lichtscheu, diffus und alles andere als klarsichtig sind: „Er wußte, daß Dagmar es mochte, morgens im Halbschlaf und im Halbdunkel von ihm gesucht und genommen zu werden; dann hatte sie das Gefühl, für ihn zu einem Schicksal zu werden, und dieses Gefühl ließ sie die Macht spüren, die sie über ihn schon gewonnen hatte." (Fremde Kämpfe, S. 12) Expressis verbis wird dem Halbschlaf 91 - man muss hier nicht auf die Marquise von O... eingehen - das Halbdunkel zur Seite gestellt: Frauen lieben nicht mit den Augen, sagen Genazinos Texte. Aber es geht noch einen Schritt weiter: Ist es in diesem Beispiel erzähltechnisch ,nur` die Überzeugung, zu wissen, was Dagmar mag, und damit das Vorgaukeln der Innenperspektive, ist es im folgenden Beispiel sogar die Beglaubigung durch iterativ erzählte Aussagen der Frau, was in der Form der transponierten indirekten Rede sogar verhältnismäßig unmittelbar daherkommt: „Sie hat mir schon öfter gesagt, daß sie nichts dagegen hat, wenn ich sie nachts überfalle. Früher habe ich mir sogar gewünscht, sagte sie einmal, daß du mich nachts überrumpelst, dann schäme ich mich kaum." (Glück, S. 26) Was sich außerhalb des Sichtbarkeitsfeldes der Augen abspielt, ist weniger sträflich, eher lässlich; was im quasi-unzurechnungsfähigen Zustand an sexuellen Handlungen

91 Vgl. für eine ,Erklärung' dieses Verhaltensmusters: „Am meisten perplex war Sibylle, dass dem Mann sogar nachts im Schlaf ohne Absicht und ohne Bewusstsein erneut das Glied steif werden konnte und der Mann (oft im Halbschlaf) abermals nach der Frau suchte oder griff" (Kein Geld, S. 56). 
abläuft, ist nicht mit ,überrumpeln', sondern mit ganz anderen Begriffen zu bedenken. Männliche Sexualität hingegen läuft bewusst, läuft rational und vor allem: läuft visuell fixiert ab:

Ich schaue mich um, offenbar sind wir hinreichend allein. Judith zieht ihren Schlüpfer aus und beugt sich nach vorne. Ich kämpfe mit meiner Schamhaftigkeit, die sich im Freien nicht leicht bändigen läßt. Aber dann hilft mir der Anblick von Judiths weißen Schenkeln inmitten einiger sanft wedelnder Gräser. [...] Judith weiß, daß ich den Beischlaf im Freien nicht lange dehnen kann. Obwohl wir allein sind, schaue ich mich doch verstohlen um und werde dabei nervös. (Liebesblödigkeit, S. 44 f.; Herv. N. L.); Jetzt sind die Augenblicke da: Sandra faßt sich mit einem Taschentuch zwischen die Schenkel und schaut dann mit rätselhaft mürrischen Blicken auf meinen Samen. Seit Jahren möchte ich wissen, woher diese plötzliche Liebesmürrischkeit kommt, aber ich wage nicht zu fragen. (Liebesblödigkeit, S. 128; Herv. N. L.); Traudel geht ins Bad, läßt wie üblich die Tür offen, so daß ich ihr beim Ausziehen zuschauen kann. Das geht auf einen Wunsch von mir zurück, der schon mindestens zehn Jahre alt ist. (Glück, S. 24; Herv. N. L.)

Das Grundmotiv des männlich codierten Voyeurismus (bei dem es sich tatsächlich laut Definition um eine Form der Paraphilie handeln kann; vgl. DSM-5) ist bereits angeklungen, wird aber nun variiert, indem eine als der Begründung nicht bedürftige Grunddisposition des Mannes unterstellt wird, nach der „ein Frauenbusen für einen Mann eine Art Grundorientierung war, ohne die er nicht auskam“ (Kein Geld, S. 120 f.), beziehungsweise „ein Mann das Geschlecht der ihm verbundenen Frau ohne Eile und intensiv und lange anschauen will.“ (Regen, S. 49 f.) Sonja, die dies „verstand“ (Regen, S. 49), ${ }^{92}$ wird somit zum einen zur Beglaubigung für den in Stein gemeißelten Wunsch, zum anderen zur Verbündeten, zu einer ,guten', ,verständnisvollen` Frau.

Prima vista eher unüblich - bezogen auf das Grundgesamt männlicher Sexualvorliebenstereotype im Literarischen - sind die flächig verstreuten Hinweise auf die besondere Bevorzugung olfaktorischer Reize aus Sicht des Mannes: ${ }^{93}$ „Nachts drücke ich mir Traudels Rock manchmal gegen das Gesicht, weil ich ihren Körpergeruch einatmen will, was Traudel nicht weiß." (Glück, S. 24) Auch weitere Protagonisten äußern sich zu ihren Vorlieben hinsichtlich des weiblichen Genitalgeruchs: „Von Susannes Geschlecht geht jetzt ein leicht säuerlicher Geruch aus, der Susanne wahrscheinlich nicht recht ist, mich aber anregt. Im Bett riecht es plötzlich nach der fast immer offenstehenden Brotschublade in der Kühe [!] ${ }^{94}$ meiner Mutter." (Regenschirm, S. 142) Nicht immer wird dabei die ,notwendige‘ Verheimlichung vor der jeweiligen Frau per telling thematisiert, sondern per showing vorgeführt $(\Leftrightarrow I .2 .4)$ : Der Protagonist aus Wilhelm Genazinos Außer uns spricht niemand über uns „ging kurz auf die Toilette, fasste mir in die Hose und tatsächlich, mein Geschlecht roch noch nach Carolas Mutter. Ich war beflügelt oder beschwingt

92 „Ich bitte Laura, Bluse und Büstenhalter abzulegen. Laura ist, wofür ich ihr sofort danken möchte, nicht irritiert. [...] Ich denke darüber nach, wie schwierig es normalerweise ist, eine Situation herbeizuführen, in der eine halbnackte Frau ohne Störung, ohne Eile und ohne Scham betrachtet werden darf.“ (Licht, S. 24) Vgl. auch: „Er hat begonnen, seine Lust an der Geschlechtlichkeit um die Lust an der Betrachtung der Geschlechtlichkeit zu erweitern" (Obdachlosigkeit, S. 109).

93 Vgl. für Schilderungen, denen eine Nähe zum Ekel nicht abgesprochen werden kann, Sex und emotionsloses Erzählen ( $\Rightarrow$ II.5.6). Die Richtschnur ist jeweils die Erzählerposition zum Geschehen.

$94 \quad$ Hier findet sich erneut die Verbindung von Sex und Mutter $\Leftrightarrow \Rightarrow$ II.5.1), was psychoanalytisch gedeutet werden könnte, zumal der zweiteinzige Druckfehler als Freud'scher Verschreiber in ein und demselben Satz steckt. 
oder drangvoll, Carolas Mutter so bald wie möglich wiederzusehen." (Außer uns, S. 153; vgl. Außer uns, S. 152) Aber auch Schweißgeruch wird mit sexueller Attraktion in Verbindung gebracht: „Wenn ich Frederikes Busen küsste, roch ich manchmal ihren Achselschweiß, was ich ihr nicht sagen durfte, weil sie nicht glauben mochte, dass Frauenschweiß manchmal genauso attraktiv (anziehend) war wie der Busen selbst." (Kein Geld, S. 162 f.)

Zur Sinnenwelt der Akustik gibt es vergleichsweise wenige positiv konnotierte Anmerkungen „Margot stößt ein paar Tierlaute aus, die ich gerne höre“ (Regenschirm, S. 56) -, wohingegen diejenigen zur Haptik eine schier überbordende Liste bilden, die allerdings auch häufig oral konnotiert sind: „Aber sobald ich mit Maria zusammen war, schlug die alte Beiß-, Greif- und Lutschgier wieder durch. Ich wollte dem Leben auf keinen Fall etwas schuldig bleiben." (Tiere, S. 35) Dass dabei die weibliche Brust eine herausgehobene Stellung einnimmt, lässt sich sowohl an musterhaft wiederkehrenden Situationen (Schielen auf den Busen stillender Mütter; $\Rightarrow$ II.2.2) als auch an der Brustfixierung beim Liebesspiel ablesen (vgl. Fremde Kämpfe, S. 40 f.; $\Rightarrow$ II.5.2). ${ }^{95}$ Nachdem die Haptik die Liste der umspannten Sinne bezüglich der sexuellen Fixierungen bereits vervollständigt hat, muss noch einmal auf die Penisfixierung in Form der Fellatio eingegangen werden, die als Analogieschluss gemutmaßt wird: „Wahrscheinlich hatte mein Geschlecht für Carola eine ähnliche Bedeutung wie ihre Brust für mich. Nur so konnte ich mir erklären, warum Carola so lange über mein Organ gebeugt war." (Außer uns, S. 123) Paradigmatisch sind die Frauenfiguren dabei typenhaft austauschbar, denn Carola könnte genauso gut Bettina heißen: „Wenn wir zusammen geschlafen hatten, lagerte sie sich zwischen meine Beine und nahm mein Geschlecht erneut in den Mund." (Liebesblödigkeit, S. 165) Oder Margot:

Fast jedesmal saugte sie lange an seinem Geschlecht. Das war nicht sehr ungewöhnlich, aber es war auch nicht selbstverständlich. [...] Wenn es so weiterging, konnte es passieren, daß der Mundverkehr der einzige Grund wurde, weshalb er weiter mit Margot zusammenblieb. (Sorgen, S. 162 f.)

Omnipräsent ist der weibliche Wunsch nach Oralsex. Dieser Befund lässt sich zum einen ,psychoanalytisch' als projizierter Wunsch auffassen, der den weiblichen (Neben-)Figuren gewissermaßen ,untergejubelt' wird; er lässt sich zum anderen aber auch erzähltextanalytisch betrachten. Dann klart sich die Machart auf, die zu dem Eindruck führen, es sei im Genazino'schen Textkosmos das Natürlichste der Welt, dass (alle) Frauen gerne (regelmäßig) Penes im Mund haben möchten, wie eine andere Margot beglaubigt: „Wieder, wie schon voriges Mal, setzt sie sich auf die Couch, zieht mich zu sich heran und lutscht mir das Geschlecht." (Regenschirm, S. 54) Das Bemerkenswerte an diesem Sachverhalt ist, dass der eigentliche Wunsch der Frauen ein der Leserimagination anheimgestellter Schritt ist. Durch zwei Faktoren wird der Eindruck hervorgerufen, dass es sich um die freie Wahl handelt: Einerseits treten die Frauen in den FellatioSituationen immer entschlossen und eigeninitiativ auf. Nach einem gängigen Schlussmuster ließe sich abstrahieren und feststellen: ,Was Menschen immer wieder freiwillig tun, scheint ihnen 
zu gefallen oder zumindest nicht deren Abscheu zu erregen'. Gewichtiger noch, wiewohl mit der ersten Feststellung verwoben, ist die Absenz der männlichen Bitte um den Oralverkehr: Kein einziges Mal taucht in einem Roman Genazinos expressis verbis ein von einer männlichen Figur vorgebrachtes Bittgesuch im Sexuellen auf! Da liegt der Hase im Pfeffer. Wenn nur das ,Ergebnis‘ beschrieben wird, schönt man das Bild der Protagonisten und tut so, als sei es der Wunsch der Damenwelt ( $\Rightarrow$ II.5.3).

Um dieses Kapitel zu einem befriedigenden Abschluss zu bringen, sei eine prominente Szene aus Genazinos Roman Fremde Kämpfe angeführt, in der die Oralverkehrschilderung aus der vermeintlichen Sicht der Frau präsentiert wird und einige erhellende abschließende Bemerkungen verstattet:

Ahhh! Ihre Hingabe hatte die schamlose Aggressivität eines Kindes. Sie setzte immer wieder kurz ab und sah sich an, was sie anzurichten in der Lage war. In ihre Heftigkeit war ein sanftes Irresein eingebaut, eine gestaltlose Übertriebenheit, die sie davon befreite, irgend etwas erklären zu müssen. Vollständig wollte sie ihn sich einverleiben. Und als sie bemerkte, daß das Verschlucken wieder nicht möglich war, kam etwas Hysterisches in ihr Lutschen und Beißen, eine zitternde Vergeblichkeit, die sich schmerzlich damit abfand, daß die Körper für immer getrennt waren. Für Sekunden glaubte Wolf, Teile seiner selbst seien ihm abhanden gekommen. Er sah in die Zimmer hinein, aber nirgendwo lagen Stücke seines Körpers herum. (Fremde Kämpfe, S. 53) ${ }^{96}$

Besonders aufschlussreich ist der Umstand, dass die Figurenmotivation Dagmar Achatz' dargelegt wird, indem die Fokalisierung auf Null schwenkt und eine Innensicht der Nebenfigur ermöglicht wird. Genaugenommen ist dabei aber weiterhin ein ,männlicher Blick' am Werk, ${ }^{97}$ der mit Kategorien wie ,Hysterie‘ und der damit verbundenen ,Lutschgier fragwürdige GenderZuschreibungen vornimmt. Zumal diese Passage letztlich dazu dient, Dagmars Urin-,Perversion‘ proleptisch vorzubereiten! Die Szene übernimmt genaugenommen aus externer Analyseperspektive die Funktion, die sexuelle Devianz Dagmars zu akzentuieren, wodurch sie als Figur in diesem Fall zum textverlaufsmotivierenden Element abgestempelt wird. Bereits auf der unmittelbaren Wortebene entgeht dem genauen Blick nicht, dass die zuhöchst intime Situations- und Emotionsbeschreibung, antiemotional' gebrochen wird: Vergeblichkeit, Schmerz und Trennung nehmen sich ebenso wie Fremdkörper im Gesamtgefüge aus wie die Befürchtung herumliegender ,Körperstücke؛.

\footnotetext{
96 Die Selbst-Zerfaserung einerseits, der Wunsch, sich etwas des Partners einzuverleiben, andererseits werden im Roman Kein Geld, keine Uhr, keine Mütze variiert: „Wenig später schluckte sie das Sperma, bis nichts mehr kam. [...] Ich war neidisch auf Sibylles Coup. Ich wollte mir auch gerne etwas aus Sibylles Körper einverleiben, was nur mir gehörte und was nur mir zustand. Aus dem gleichen Grund beneidete ich Säuglinge, die mit ihren Müttern in Cafés saßen beziehungsweise an deren Brust lagen." (Kein Geld, S. 59)

97 Vgl. dazu auch: „Wenn Dagmar keine Unterhose unter dem Rock trug, wollte sie sich verrucht und undurchschaubar vorkommen." (Fremde Kämpfe, S. 221)
} 


\subsection{Erotik vs. antiemotionales Erzählen (bis zum Ekel)}

Schilderungen von Liebe und Erotik stellen bei Genazino alles andere als eine betont sinnliche Bildsprache über eine glühende, nie verlöschende Liebe dar. ${ }^{98}$ Sie entsprechen dabei nicht den Darstellungsmodi literarischer Liebesdiskurse, dort, wo die Gefühlssprache an ihre Grenzen stößt, mithilfe von Tropen, Metaphern oder Figurationen das ,Unsagbare' sagbar machen zu wollen. Üblicherweise verfahren literarische Texte so $^{99}$ - Genazinos Roman(e) hingegen sperren sich dieser Erwartungshaltung und bedienen sich vielmehr einer rational-reflexiven, sachlichklaren mit bisweilen vulgär-derber Einfärbung versetzten Gefühlssprache, in welche die Liebesentwürfe eingefasst werden.

\section{,GEFÜHLLOSE' DARSTELLUNGSSTRATEGIEN EROTISCHER LIEBE AUF DISCOURS-EBENE}

Diese Versprachlichung begünstigt häufig eine emotional wirksame Textstrategie, gefühlloser Machart, 100 wie das folgende Beispiel auf dem schmalen Grat zwischen Erotik und Lustlosigkeit versinnbildlicht. Nachdem der Ich-Erzähler Judith, seine ältere Geliebte, „die eher für geistigen Zuspruch zuständig ist“,101 vom Flughafen abgeholt hat, werden beide Figuren intim:

Bei ihr in der Wohnung vertiefe ich mich in die kleinen, dennoch molligen Brüste von Judith und empfinde dabei genausoviel Glück wie Dankbarkeit. Obwohl ich mich seit Tagen dieser Stunde freue, werde ich wenig später das Opfer einer Beinahe-Impotenz. Es dauert, bis ich soweit bin, und ich bin ungeschickt, weil ich vor Ratlosigkeit halb gelähmt bin. Erst durch die Bewegung in Judiths Geschlecht gewinnt mein eigenes Geschlecht Fahrt und Stärke, aber das Warten darauf war enthüllend und demütigend. Auch das Überwältigungsgefühl beim Samenabgang ist nicht so stark wie früher. (Liebesblödigkeit, S. 163)

Obwohl der Text das „Glück“ und die „Dankbarkeit" des Protagonisten einwandfrei und explizit ,voller Gefühl' thematisiert, sodass die Leser es ,ablesen' können, ohne auch nur ansatzweise Inferenzen leisten zu müssen, ${ }^{102}$ lässt die Brechung sowie der damit einhergehende Umsturz in eine textweltliche Situation ,ohne Gefühl“ nicht lange auf sich warten („Ratlosigkeit“, „halb gelähmt“, „demütigend“). Gefühlssprachanalytisch sind es hier hauptsächlich - wie so oft bei Genazino - Lexik und Wortfeld, die bewirken, die Darstellung eher am ,gefühllosen' Pol zu tarieren. Mit dem im Textverlauf wiederholt thematisierten „Samenabgang“ raubt die Sprache dem literarisierten Moment höchster Ekstase - für gewöhnlich mit ,vögeln` bezeichnet - jeden (identifikatorischen) Reiz. Und was sogar noch schwerer wiegt: Selbst das „Überwältigungsgefühl“, das den Geschlechtsakt offensichtlich in der Erzählvergangenheit orgiastisch geadelt hat, schwindet dahin. Nimmt man nun noch das ,temporale` Wortfeld mit in den Blick - „seit Tagen“, „dauert [...]

98 Dieses Unterkapitel zitiert passagenweise in Form des Selbstzitats Lehnert/Schul: Gefühlvoll oder voller Gefühl?, S. 225-230.

99 Vgl. Schwarz-Friesel: Sprache und Emotion, S. 287-310.

100 Vgl. generell zur Codierung von Gefühlen Simone Winko: Kodierte Gefühle. Zu einer Poetik der Emotionen in lyrischen und poetologischen Texten um 1900. Berlin 2003.

101 Reschke: [Wilhelm Genazino].

102 Vgl. Schwarz-Friesel: Sprache und Emotion, S. 219. 
bis“, „Warten“ -, welches das Ich in ein erzählendes und erinnerndes spaltet, erklärt es sich, warum hier fernab des dramatischen Modus ( $\Rightarrow$ I.2.3) agiert wird und die Distanz zum Geschehen rund um die „Beinahe-Impotenz“ ein Höchstmaß an leserseitigen Artefakt-Emotionen zur Folge haben kann. Wie bei der Lektüre eines ,fehlerbehafteten' Texts schweift die Aufmerksamkeit vom (Gefühls-)Inhalt zur (Sprach-)Form ab.

Durch den intern auf das doppelte Ich eingeengten Blickwinkel wird die gefühlsnüchterne (weil einseitige) Berichterstattung vermutlich noch begünstigt: „Hinzu kommt, dass die [Genazino'schen; N. L.] Ich-Erzähler sich als hochgradig sprachbewusste Persönlichkeiten erweisen, denen durch ihr erhebliches Maß an Selbstreflexivität eine unbeschwerte Existenz unmöglich ist." ${ }^{103}$ Nicht nur ihre eigene Existenz wird dadurch allerdings erschwert, sondern erst recht diejenigen Emotionalisierungsangebote, die der Text für eine empathische bzw. sympathische Identifikation des Lesers bereitstellen könnte. Anja Hirsch führt dafür die folgenden Gründe an:

Es lassen sich im Werk Genazinos distanzierende Erzählverfahren beschreiben. Dazu gehören die Reflexionen, aber auch andere Techniken, die distanzierend wirken. So wird beispielsweise eine die Hauptfigur begleitende Erzählinstanz eingesetzt. Auch die Wahl eines erzählenden Ichs, das in mindestens ein erlebendes und darüber erzählendes, meist auch ein erinnerndes Ich zerfällt, wirkt distanzierend. Andere häufig verwendete distanzierende Erzählverfahren sind die Freisetzung von Komik, die Selbstbeobachtung (als spezielle Form der Reflexion) oder der bevorzugte Beobachterstandpunkt hinter Fenstern, aus verborgenen Blickwinkeln, erhöhten Perspektiven, die Überblick verschaffen, ohne dass die beobachtete Welt ihrerseits zu nah an den Beobachter heranrückt.104

In den seltenen Momenten, wenn der unmittelbar-dramatische den distanziert-narrativen Modus zur Seite drängt, wird die Darstellung zwar graduell ,gefühlvoller', die Gefühlssprache sogar näherungsweise eine ,blumige', weil das Wort nicht durch den artefakt-emotionalen ,Fokalisierungsschleier' zum Leser dringen muss (vgl. Liebesblödigkeit, S. 57). Allerdings bleiben diese raren Ausnahmen ausnahmslos z. B. durch die Inquit-Formeln zumindest lose an den distanzgebietenden, narrativen Discours festgebunden. Es sind der Stellen unzählige, auf die Hirschs Beobachtungen zutreffen - in der folgenden kulminieren allerdings alle benannten, sofern man das „Halbdunkel“ als „,bevorzugte[n] Beobachterstandpunkt“ gelten lässt:

Gegen halb zehn gehen wir ins Bett. Das Wiedersehen mit Sandras gemütlicher Unterwäsche amüsiert mich, was ich mir nicht anmerken lasse. Ich umarme sie und ziehe sie im Halbdunkel an mich heran und fremdle dabei ein bißchen. Die unendliche sexuelle Wiederholung treibt in mir eine gewisse Onkelhaftigkeit hervor, die ich nicht an mir mag und die ich trotzdem beobachten muß. (Liebesblödigkeit, S. 180)

Der Zugang zum erotischen Erlebnis bleibt durch die exponierte „Selbstbeobachtung“ nicht nur dem Leser, sondern auch dem Ich-Erzähler selbst verschlossen. Für die emotionsglättende Wirkung dieser Passage zeichnen aber hauptsächlich auch die Beschreibung der „Unterwäsche“, die „Wiederholung“ und die „Onkelhaftigkeit" verantwortlich: Nicht ohne Grund nennt der Volksmund „gemütliche[] Unterwäsche“ Liebestöter. Das Amüsement des Protagonisten legt darüber

103 Fansa: Unterwegs im Monolog, S. 7.

104 Hirsch: „Schwebeglück der Literatur“, S. 22. 
beredt Zeugnis ab: Wie ließe sich sexuelle Anziehung stärker entemotionalisieren? „Variatio delectat"105 - auch und gerade in Liebesangelegenheiten. Die sogar als „unendlich[]“ akzentuierte Wiederholung allerdings lässt das Singuläre, das der literarischen Beischlafschilderung die erotische Komponente konnotieren könnte, als Perle auf der Schnur immer gleicher Erlebnisse die Einzigartigkeit verlieren - besondere fiktions-emotionale Anteilhabe wird nicht ermöglicht. Schließlich sei die Sprache auf die damit verbundene „Onkelhaftigkeit“ gerichtet. Zwar korrespondiert „Onkelhaftigkeit" mit der allenthalben beschworenen „Sexualverlöschung“ irgendwie; eine Situation zu imaginieren, in der „Onkelhaftigkeit“ erotisch-emotionalisierend wirksam werden könnte, fällt hingegen schwer, zumal dem Begriff Bedeutungsanteile anhaften, die zwischen ,obszön' und ,pädophil' changieren. Hier liegt ein Paradebeispiel für eine auf Sujet-Ebene eher ,ohne' großes ,Gefühl' anzusetzende Mischform von Präsentation und Thematisierung in ,Gefühllos'-Form vor. Doch selbst dann, wenn im Kern eine Situation ,voller Gefühl' geschildert wird, die nicht thematisch in ihr Gegenteil umzukippen droht, entemotionalisiert die Darstellungsweise das vorhandene Emotionspotenzial:

Vergleichsweise häufig sind wir zusammen, um Sandras Ängstlichkeiten zu zerstreuen. Sie fürchtet, nicht mehr begehrenswert zu sein. Aus diesem Grund ist sie fast immer beischlafwillig. Mit zwei zärtlich überprüfenden Handgriffen überzeugt sich Sandra wenig später, daß ich geschlechtsbereit bin, und nimmt die Brückenhaltung ein. (Liebesblödigkeit, S. 14)

Der Ich-Erzähler berichtet Intimstes in Kombination mit einer selbstpreisgebenden Bewertung für die eigene Situation, die Verortung auf der Skala ,voller Gefühl - ,ohne Gefühl` müsste links erfolgen. Aber was spielt sich auf der ,Wie'-Ebene ab? Emotionalisierende Textsituationen ,gefühlvoll' zu entwerfen mit dem Wortmaterial: „beischlafwillig“, „Handgriffen“, „geschlechtsbereit", ist nun eben ein heikles Unterfangen: Das Perspektiv, durch das die paginale Bühne einzusehen ist, ist nicht rosarot, sondern eher kataraktbefallen.

Als zusätzlicher Eintrag auf der die Fiktions-Emotionen verhindernden Liste lässt sich darüber hinaus der Anteil an Rationalitätsmarkern vermerken: „Vergleichsweise häufig“ ist als sprachliches Entrée eindeutig zu wohlerwogen - für eine emotional aufgeladene Situation kaum der Lesererwartung ,angemessen“. „Aus diesem Grund“ interessiert bei reflektierten Handlungsmotivationen, untergräbt aber erneut eine Unmittelbarkeit, wie sie bei Erotik rezipientenseitig erwartbar wäre. Und eine ,Überprüfung', wenngleich eine „zärtlich[e]“, versinnbildlicht doch eher eine im vollen rationalen Bewusstsein sich ereignende Handlung.

Von den bisherigen Zitaten nicht nur aufgrund der vom, Üblichen' abweichenden Gefühlssprache grundverschieden, scheint das folgende Zitat meilenweit von einer durch Rationalität versperrten Erotik entfernt zu sein, äußert doch der Erzähler unumwunden:

105 Die Grobunterteilung der Herausgeberschrift Die Lust im Text: Eros in Sprache und Literatur untergliedert einen Schwung von Aufsätzen mit dieser Überschrift (vgl. Doris Moser/Kalina Kupczyńska (Hg.): Die Lust im Text. Eros in Sprache und Literatur. Wien 2009). 
Ich möchte Sandra von hinten nehmen und seitlich von oben dabei zuschauen, wie ihre Brüste beim Vögeln hin- und herschaukeln. Ich meine das nicht pornographisch, ich meine es mütterlich, warmherzig und ausweglos: Schaukelnde Brüste sind ein Ausdruck von Heimat und Freude. (Liebesblödigkeit, S. 144)

Das bereits unter Genderperspektive diskutierte $(\Leftrightarrow I$ I.5.5) Zitat beginnt zwar hart an der Grenze zum Pornografischen - (ver-)stößt den Leser allerdings erstens: mit der Selbstthematisierung (und Ableugnung!) dieses Eindrucks, zweitens: mit dem erneut dem Liebessegment der familiären Liebe entliehenen Empfindungsattribut („mütterlich“; $\Rightarrow$ II.5.2), drittens: mit dem nur in der prospektiven Vorstellung verbleibenden Wunsch auf den harten Boden der Artefakt-Emotionen, um dann unversehens sogar in eine Alpenidyllerotik ${ }^{106}$ abzudriften.

Methodisch bietet sich hier das Foregrounding-Konzept als emotionsanalytischer Schlüssel für die Gefühlssprache an: „Verstöße[] gegen innertextliche Normen, Verstöße[] gegen Text-WeltRelationen sowie gegen Wahrscheinlichkeiten“ listen Nadine van Holt und Norbert Groeben als weitere Manifestationen des die Artefakt-Emotionen überbetonenden Darstellungsmodus. ${ }^{107} \mathrm{Im}$ Zitat erfolgt der Verstoß gegen die sonst vorherrschende Gefühlssprache, der Verstoß gegen das Partner-/Elternliebe-Sphärencrossing sowie sogar ein Verstoß gegen die Wahrscheinlichkeit einer „Text-Welt-Relation[]“, man könne nach einem auf diese Art und Weise geäußerten ersten Satz ernsthaft den Wunsch nach „Heimat und Freude“ als Vater des Gedankens angeben.

Er kommt langsamen Schrittes auf mich zu, selbstbewusst und sexy. Ein Gefühl heißer Lust durchzuckt mich. Er steht vor mir, sieht mir in die Augen. Er ist so verdammt sexy.

„Wollen wir nicht die Jacke ausziehen?“, fragt er mit leiser Stimme, ergreift das Revers, schiebt mir vorsichtig den Blazer von den Schultern und legt ihn auf den Stuhl.

"Ahnst du eigentlich, wie sehr ich dich begehre, Ana Steele?"

Ich schnappe nach Luft.

Er lässt zärtlich seine Finger über meine Wange zu meinem Kinn gleiten. „Und ahnst du, was ich mit dir machen werde?", fügt er hinzu, während er mein Kinn streichelt.

Die Muskeln tief in meinem Innern ziehen sich aufs Köstlichste zusammen. Am liebsten würde ich die Augen schließen, aber sein Blick hypnotisiert mich.

[...] Ich werde rot. [...] Ich bin Wachs in seinen Händen.

[...] Ihn vor mir auf den Knien zu sehen und seinen Mund auf der Haut zu spüren ist unerwartet und erregt mich total.

[...] „Zieh die Knie an“, weist er mich an, und ich gehorche. „Ich werde Sie jetzt ficken, Miss Steele“, murmelt er, während er die Spitze seines Schwanzes vor meiner Vagina positioniert. „Hart.“

[...] Ich schließe die Augen, versuche, meine Atmung zu kontrollieren und mir über die chaotischen Empfindungen klar zu werden, die seine Berührungen in mir auslösen. Flammen durchzucken meinen Körper. ${ }^{108}$

Nun, abgesehen davon, dass der aus illustratorischen Zwecken hier präsentierte Textauszug nicht von Genazino stammt und das Tertium comparationis zur Liebesblödigkeit lediglich ein forciertes ist, kann man ihm eines nicht vorwerfen: den riesigen Gefühlssprachraum erotischer Liebe nicht auszuloten und abzuschreiten. Von die Grenzen des guten Geschmacks übertretender Explizität bis zu in heutiger Zeit höchst klischeeträchtig und abgegriffen anmutender Meta-

\footnotetext{
106 Vgl. dazu auch das Coverbild des Genazino-Romans Bei Regen im Saal.

107 Holt/Groeben: Emotionales Erleben beim Lesen, S. 127.

108 James: Fifty Shades of Grey.
} 
phorik weist er sprachlich alle Insignien dessen auf, was man von der literarischen Präsentation und Thematisierung sexueller Erotik erwarten könnte. „Wie das Lachen oder das Weinen können die Ausdrucksformen sexueller Erregung eine ansteckende Wirkung entfalten. Dem tragen die literarischen Techniken Rechnung." ${ }^{109}$ Die dafür notwendigen Ingredienzien tauchen bei Genazino, „obwohl es in der Darstellung der Sexualität keine Tabus gibt“,110 allerdings gerade nicht auf: „Stammeln, Stöhnen, Seufzen, Schreien, konvulsivisches Zucken, angeschwollene, gerötete und feuchte Körperteile gehören zum festen Repertoire einer [...] Rhetorik der Lust.“111 Nicht nur Präsenz oder Absenz dieser „Rhetorik der Lust“ markiert die gefühlssprachliche Grenze zwischen James und Genazino, sondern auch der narratologische Unterschied. So findet sich bei James ein ganzer Strauß spannungserzeugender und fiktions-emotionsbegünstigender Texttechniken: Parataxe, dramatischer Modus, autonomer innerer Monolog. Kommt die Liebe in James' Romanen in Reizwäsche daher, so trägt sie bei Genazino „Stützstrümpfe“.112 Damit ist die Eintrittskarte zum ,Was', und als nichts anderes muss man das ,Wie' wohl ansehen, nur teuer zu erkaufen: Mögliche gefühlvolle Fiktions-Emotionen bleiben dem Leser absichtlich vorenthalten.

\section{ZUSAMMENFÜHRENDES UND EMOTIONSANALYTISCH BILANZIERENDES}

In der Schwebe „zwischen Erzählzwang und Unsagbarkeit“113 ist Die Liebesblödigkeit ein Beispiel dafür, wie ein literarischer Liebesentwurf ein Sprachgewand verliehen bekommt, das unüblich geschneidert wirkt und dem Sujet prima facie nicht recht zu passen scheint. Jedwede textuelle Informationsvergabe lässt sich sprachlich unterschiedlich bewerkstelligen. Diese Erkenntnis ist schon sehr alt, doch ihre Brisanz für emotionale Anteile im literarischen Kommunikationsprozess noch immer ungebrochen:

Dass andere Varianten immerhin denkbar wären, hat damit zu tun, dass derselbe Inhalt stets auf verschiedene (nicht: beliebige) Arten ausgedrückt werden kann; dass innerhalb eines zugegebenermaßen beschränkten Sets (sprachlicher) Ausdrucksmöglichkeiten immer eine gewisse Wahlfreiheit besteht. Damit gewinnt die Wahl selbst an Bedeutung, gerade weil sie mit historischen und sozialen Gegebenheiten verwoben ist. ${ }^{114}$

Da die (literarische) Schriftsprache bspw. im Vergleich zur Filmsprache in manchen emotionalen Belangen defizitär erscheint, und per se deren „Lektüre [...] immer über das begriffliche Erfassen [geht]; sinnliche Wahrnehmung [...] zwar beschrieben werden, [...] aber [nur] durch die Imagination des Lesers gefüllt werden" kann, ${ }^{115}$ bleibt es Autoren von Texten, die die Liebe zum The-

\footnotetext{
109 Thomas Anz: Literatur und Lust. Glück und Unglück beim Lesen. München 1998, S. 226.

110 Reschke: [Wilhelm Genazino].

111 Anz: Literatur und Lust, S. 227.

112 Vgl. Böttiger: Die Apokalypse trägt Stützstrümpfe.

113 Fansa: Unterwegs im Monolog, S. 145.

114 Philipp Brunner: Unsägliche Gefühle: Die Liebeserklärung im Spielfilm. In: Matthias Brütsch/Vinzenz Hediger/Ursula von Keitz/Alexandra Schneider/Margrit Tröhler (Hg.): Kinogefühle. Emotionalität und Film. Marburg 2005, S. 243-263, hier S. 262 f. 
ma küren, freigestellt, möglichst unmittelbar ,anschaulich` emotionalisierend zu arbeiten - die „Imagination des Lesers“ lässt sich in Ansätzen vielleicht doch gar nicht so unpräzise abschätzen und lenken - und verkaufsträchtig-unmoralische Angebote zu machen (Shades of Grey). Oder aber, auch diese Variante bleibt ihnen unbenommen, entemotionalisierend-,gefühllos‘ zu Werke zu gehen und die Textwelt weniger fiktions-emotionalaffin zu verpacken (Die Liebesblödigkeit). Neben dem Sujet und dessen Aushandlung ist also das Sprachgewand für Emotionalisierungsstrategien und -angebote, mithin für Textstrukturen wie Leserreaktionen von höchster Relevanz. ${ }^{116}$ Mit der Liebesblödigkeit liegt ein exemplarischer Fall dafür vor, wie die Gefühlssprache der erotischen Liebe so gewählt worden ist, dass bereits produzentenseitig eine hohe Hemmschwelle für die Identifikation des Lesers mit den Figuren und der Textwelt an sich aufgebaut wird: Tendenziell ,explizite' Sex-Szenen werden mit auf allen Ebenen der Narratologie und der Linguistik beschreibbaren Darstellungsmitteln enterotisiert und dem Leser aufgrund der massiv eingesetzten ,gefühllosen' Filter die Artefakt-Emotionen überdeutlich ins Bewusstsein gerückt. Eine empathische Einfühlung, eine distanzlose Lesehaltung, unmittelbare Anteilhabe scheiden damit größtenteils aus ( $\Rightarrow$ I.2.3). Ganz in diesem Sinne votiert Jahraus dafür, eine „De-Emphase“ als Wirkmechanismus des Textes herauszukehren:

Genazinos Helden sind nicht dazu angetan, den Leser über das Angebot einer Identifikation in der Lektüre an ihr Schicksal zu binden. [...] Insgesamt aber geht es wohl eher darum, das Identifikationspotenzial für den Leser bewusst unattraktiv zu gestalten. [...] Nicht zuletzt die häufige Form der Ich-Erzählsituation wäre in besonderer Weise dazu angetan, Lesererwartungen im Hinblick auf Identifikationspotenziale zu wecken. Es geht nicht darum, diese Potenziale vollständig zu zerstören, sondern darum, sie unattraktiv zu machen. Auch dies ist kein erzählerisches Manko, sondern im Gegenteil ein narratives Programm [...]. Ja, man kann sogar so weit gehen, Genazinos Texten ein Programm der narrativen Enttäuschung des Lesers zu unterstellen. Wo Leser ebendies erwarten, wird ihre Enttäuschung geradezu als glücklich erfüllte Lesererwartung zu verbuchen sein. Dieses Spiel wird auf der Ebene der dargestellten Welt der Texte, auf der Ebene des Sujets nun selbst wiederum mit Geschichten enttäuschter Erwartungen gewährleistet. Man kann hier eine direkte Analogie zwischen beiden Ebenen, dem Was und dem Wie der Erzählung, feststellen. Dies gelingt Genazino, indem er emotional hochrangige Erfahrungs- und Erlebnisqualitäten in seinen Texten ,unter Wert verkauft' bzw. sie in einen Kontext stellt oder sie einer Kritik unterzieht, was ihren Wert drastisch reduziert, wenn nicht sogar ihre Wertigkeit ins andere Extrem umschlagen lässt. Dieses Verfahren wird besonders in jenen Passagen regelrecht spürbar, wo die Identifikation mit dem Protagonisten zwar zustande kommt, aber dann umso nachdrücklicher unterlaufen wird. Hierfür ist der Roman Die Liebesblödigkeit aus dem Jahre 2005 ein herausragendes Beispiel. Wenn man grundsätzlich davon ausgeht, dass eine Identifikation mit dem Helden durch Formen der geteilten Spannung des Handlungsbogens, vor allem aber durch eine emphatische Emotionalisierung des Lesers gewährleistet wird, dann zeigt dieser Roman, wie nachhaltig gerade auf diesem Gebiet Lesererwartungen enttäuscht werden können. Zu solchen Potenzialen der emphatischen Identifikation gehören seit dem 18. Jahrhundert vor allem erotische Erlebnisse, sexuelle Erfüllungen, Liebeserfahrungen und Glücksverheißungen, die zumindest als emphatischer Wert das Handeln des nicht nur männlichen Helden leiten und bestimmen. [...] Auf diesem Terrain treibt der Roman ein bemerkenswertes Spiel mit seinem Leser. Denn es ist keineswegs so, dass all das dem Helden versagt bliebe, jedoch vollzieht sich seine Erfüllung in einer Art, die den Charakter einer Verheißung, wie sie mit solch emphatischen Werten verbunden ist, umso radikaler desavouiert. Schwerlich wird man wohl einen Roman finden, der schrecklichere und peinlichere Liebes- und Sexszenen enthält als Die Liebesblödigkeit. Um die Inszenierung und ihr narratives, ästhetisches und ebenso rezepti-

116 Vgl. dazu Sarina Schnatwinkel: Das Nichts und der Schmerz. Erzählen bei Bret Easton Ellis. Bielefeld 2014. 
onssteuerndes Potenzial zu erkennen, ist es hilfreich, solche Szenen im Lichte der Diskussion über Pornographie seit dem 18. Jahrhundert zu betrachten. So kann deutlich werden, dass es jene berüchtigten ,Stellen' sind, an denen ein Höchstmaß an Identifikation, und zwar über Erregung - und das auf nicht kontrollierbare Weise -, erfolgen kann. Und umgekehrt kann man vor diesem Hintergrund ermessen, dass der ohnehin sehr mechanische Vollzug des Aktes aufgrund des Alters der Partner durch einen Krampf unterbrochen und dann auch noch fortgesetzt wird, was endgültig jeden erotischen Flair, jede erregende Identifikation mit dem Helden zerstört. Jedoch geht es nicht um einen erotischen Flair oder um sexuelle Empathie, sondern es geht ${ }^{117}$ -

Jahraus um etwas anderes. Wo er abbiegt, um Subjektkonzepte in den Blick zu nehmen, just da muss eine literarische Emotionsanalyse ,geradeaus fahren': Es geht genau um den absichtlich abgeschalteten „erotischen Flair“ und die unterdrückte „sexuelle Empathie“ - und zwar als produzentenseitige Emotionalisierungsstrategie, die im Text als Emotionalisierungspotenzial wirksam ist und Emotionalisierungsangebote an den Rezipienten macht (oder eben unterlässt).

Hier lässt sich ansetzen, um die beiden Stränge von Discours und Histoire gewinnbringend wieder zusammenführen und auch die Theorie mit der Analysepraxis zu verknüpfen. Eine potenziell ,gefühlvolle“ ,Wertigkeit” „,ins andere Extrem umschlagen“ zu lassen, ist exakt die Verbindungslinie, die beide Untersuchungsebenen integrativ zusammenrücken lässt: Die Emotionalisierungsstrategie Genazinos auf Produzentenebene sei es, „emotional hochrangige Erfahrungs- und Erlebnisqualitäten in seinen Texten ,unter Wert [zu] verkauf[en]““. Man kann diese Metapher umschreiben und das gefühlte Spannungsverhältnis, das sich durch den krassen Widerspruch zwischen der Darstellung sexueller Erotik und ,deemphatisch',enterotisierten' Textstrategien ergibt, als Defizit bewerten, als Versäumnis, nicht das komplette „emotionale Wirkungspotenzi$\mathrm{al}^{\prime}$, das im Sujet schlummert, ausgereizt, aufgeweckt zu haben. Diesem Wertmaßstab ist hingegen als kritisches Korrektiv zur Seite zu stellen, dass sich doch der emotionale ,Wert' eines Narrativs nur in Abhängigkeit vom gewünschten Emotionalisierungsziel angeben lässt. Ist es dasjenige, möglichst erotisierend-erregend wirksam zu sein, dann lässt sich von einem ,zu günstigen Kaufpreis' der narrativen ,Ware' sprechen - sonst nicht. Allenfalls sind forcierte ArtefaktEmotionen, die der Einfühlung widerstreben, als kalkulierte Verfremdungseffekte ernst zu nehmen. Auf der textuellen Fiktions-/Figurenebene lässt sich aufgrund Letzterer nämlich ohne Weiteres kein unmittelbarer emotionaler Kontakt zu Lieb und Leid der Figuren herstellen, womit nach den eingängigen Analysen von Gefühlssprache und Liebesentwurf Jahraus in einem zentralen Punkt entschieden widersprochen werden muss: Wo, wann und wie soll „die Identifikation mit dem Protagonisten [...] zustande komm[en]“, wenn sie doch spätestens in Zweizeilenreichweite, „aber dann umso nachdrücklicher unterlaufen wird“? Es bleibt dem Leser keine Zeit, diesen fiktions-emotionalen Verbrüderungsschritt zu gehen. Die Emotionalisierungsstrategie der ,Deemphase' sagt ja gerade aus, dass es ein produktionsseitiges Konzept gibt, das im Text wiederzufinden ist und schließlich den Leser im Blick hat, dem eine emphatisch-empathische Unmittelbarkeit verwehrt bleiben soll. Sujetseitig hätte Die Liebesblödigkeit tatsächlich das Poten- 
zial, fiktions-emotionalisierend tätig zu werden, doch die Wahl der Gefühlssprache ermöglicht frappierend wenig Gefühl durch Sprache. Nicht zuletzt deswegen, weil die körperliche Liebe - im Kontrast zum von Anz kompilierten „Repertoire einer [...] Rhetorik der Lust“ - nicht in aller möglichen Explizität präsentiert, sondern zumeist höchstens thematisiert wird. Was Anz mit der Unterscheidung von „intendierten und tatsächlichen“ Leseremotionen zu fassen versucht,118 dekliniert Jahraus mit der „Lesererwartung“ ironisch durch: Selbstredend ist der Erwartungshorizont des Lesers der Maßstab aller emotionalen Wirkungen. Doch das „Programm der narrativen Enttäuschung" von einem Text, der körperlich-erotische Liebe verhandelt, zu erwarten, ist höchstens einem die Romane Genazinos kennend überblickendem, also nicht dem ,Durchschnitts'-Leser zu unterstellen ( $\Rightarrow$ I.2.3, $\Rightarrow$ I.2.4 u. $\Rightarrow I .3 .3)$.

Genazino wollte keinen pornografischen und auch keinen ,reinrassig' erotischen Roman schreiben. Diese autorintentionale Behauptung lässt sich mit Blick auf sein Schaffen vertreten. Für emotionsanalytische Untersuchungen, die Texte auf ihre sinnlich-sexuellen Liebesentwürfe hin betrachten, kann man bei Genazino indes fündig werden und die erotischen Anteile „und ihr narratives, ästhetisches und ebenso rezeptionssteuerndes Potenzial“ beschreiben. Bei relativ tabuloser Darstellung der Sexualität - die allerdings den Vergleich mit ,echter` erotischer bzw. pornografischer Literatur in puncto Explizität nur momentweise gestattet (Point-of-View) könnte der Leser bei der Lektüre davon ausgehen, in erotischer Weise emotionalisiert zu werden. Dieses Anliegen teilen sich beide vorgenannten Genres und der Rezipient ist geneigt, diese Strategie bei Texten, die Anleihen bei ihnen machen, auch zu erwarten. Diese Erwartungen werden enttäuscht, der Leser wird artefakt-emotional auf Abstand gehalten.

Zusätzlich baut sich - so steht zu vermuten - neben der intendierten gefühlssprachlichen Distanz des ,Wie' eine weitere Trennwand zwischen Leseremotion und Textangebot auf: in Form einer anachronistischen Geschlechterrollenverteilung ( $\Rightarrow$ II.5.3). Vermutlich nicht als ArtefaktEmotion im Sinne eines Verstoßes gegen soziokulturelle Text-Welt-Relationen (ein-)kalkuliert, müssen Szenen wie die folgende mindestens ein gendertheoretisch ,halbwegs' sensibilisiertes Lesersegment stutzen lassen:119 „Sandra hingegen möchte immer und überall und ganz besonders auf der Straße geküßt werden. Sie will auch vor anderen Menschen eine geküßte Frau sein, weil sie im öffentlichen Kuß das Zeichen einer Wahl und einer Bevorzugung sieht." (Liebesblödigkeit, S. 24 f.) Selbst ohne erneut einen gar zu akribischen Blick durch die sozialgeschlechtliche Brille auf den Liebesentwurf der Liebesblödigkeit zu werfen - der vielleicht dem Erzähler hätte unterstellen können, mit dem naiv-dümmlich klingenden polysyndetischen „immer und überall und ganz besonders", Habitus und Duktus der Bezeichneten nachäffend nachahmen zu wollen -, ist die Zuschreibung, dass Sandra „im öffentlichen Kuß das Zeichen einer Wahl und einer Bevor-

\footnotetext{
118 Anz: Gefühl als Text?, S. 261.

119 Vgl. zu Geschlechtertypisierungen Renate Hof: Die Entwicklung der Gender Studies. In: Hadumod Bußmann/dies. (Hg.): Genus. Zur Geschlechterdifferenz in den Kulturwissenschaften. Stuttgart 1995, S. 3-33, hier S. 18 f.; vgl. Eckes: Geschlechterstereotype, S. 181.
} 
zugung" sehe, ungefähr auf dem Gleichberechtigungslevel anzusiedeln, das weiter oben für Genazinos Geschlechterrollen bereits postuliert worden ist offenbart ( $\Rightarrow$ II.5.3).

Zusammengenommen schreibt sich Genazinos Roman in die Ahnengalerie der die Liebe verhandelnden Gegenwartsliteratur ein, welche sich nach Stefan Neuhaus durch zwei konträre Trends charakterisieren lässt: Auf der einen Seite stehen Texte,

die Tabulosigkeit inszenieren, um das ,viktorianische‘ (Foucault) Dispositiv von Sexualität zu reetablieren. Ein Blick in populäre Zeitschriften oder Diskussionsforen bestätigt diesen konservativen Trend, der auch traditionelle Frauen- und Männerbilder aktualisiert. Dagegen stehen Texte [...], die mit dem sexuellen Dispositiv ein ironisches Spiel treiben und es so subvertieren. ${ }^{120}$

Die Liebesblödigkeit lässt sich in dieser bipolaren Einteilung, die die Untersuchungsebene des Liebesentwurfs akzentuiert, zwar nicht prototypisch unterbringen; auf den ersten Blick wäre man aber wohl geneigt, sie unter ,konservative Aktualisierung' zu verbuchen. Allerdings täuscht auch dieser erste Eindruck, ist doch Wilhelm Genazino - etwa als Preisträger des Kasseler Literaturpreises für grotesken Humor 2013 - als hochironisch und komisch schreibender Autor in den Ergebnissen der Gefühlssprach- und Liebesentwurf-Analyse bisher nicht ernst genommen worden. ${ }^{121}$ Dass nämlich Genazinos ,Mann von 52 Jahren‘ (Goethe!) beim Sex zu Krämpfen neigt, aber trotzdem noch mit zwei Frauen verkehrt und zusätzlich Nacktbars besucht, scheint - legte man die emotionsanalytische Brille kurz ab - eine hochironische Abrechnung mit gesellschaftlichen Normen, aktuellen Jugendlichkeitshypes und Altersmythen zu sein (s.u.). Wenn das so ist, wird der Histoire damit eine Vielschichtigkeit eingehaucht, die sich nun nicht mehr im Zweidimensionalen von ,Stereotyp' vs. ,Emanzipation' aufhängen lässt und die vordergründig wahrscheinlichen Fiktions-Emotionen subvertiert.

Auch hinsichtlich des Gefühlssprachkleids der Liebe muss die zeitgenössische Literatur noch kartografiert, muss Die Liebesblödigkeit dort eingezeichnet werden. Schwarz-Friesels Momentaufnahme konstatiert:

Der Sprachstil ist grob, es werden Lexeme der niederen Stilebene und stark konnotierte Lexeme eingesetzt. Es handelt sich um provokative oder resignierte Tabubrüche, die insbesondere den totalen Bruch mit den gängigen Liebesdiskurskonventionen widerspiegeln. ${ }^{122}$

Damit trifft sie den Nagel für Genazinos Gefühlssprache recht präzise auf den Kopf, wiewohl bei der ,Grobheit‘ literarisch noch einige ,Luft nach oben', bei der „Stilebene“ nach unten bleibt. Global lasse sich beobachten, dass „bei der Referenzialisierung der Emotionalität in modernen und

120 Stefan Neuhaus: „Ihre Möpse sind weich. Ungewöhnlich schön liegen sie in der Hand“: Zur Funktionalisierung von Erotik und Sexualität in der Gegenwartsliteratur. In: Moser/Kupczyńska (Hg.): Die Lust im Text (2009), S. 375-387, hier S. 387.

121 Weswegen man ihnen samt und sonders vorhalten kann, dass sie sowohl in puncto Machart als auch beim Sujet die Komik und die Ironie unterschlügen. Beide ästhetischen Kategorien nehmen in der literaturwissenschaftlichen Emotionsforschung wenig Platz ein, machen sie doch bei der Taxierung ,basalerer' Gefühle oder systematischer Aussagen zu Wirkungspotenzialen und Emotionalisierungsstrategien nur ,unnötigen Ärger'. 
postmodernen Werken [...] wenig emotionsbezeichnende Mittel benutzt werden, wenn es um die eigenen Gefühle der fiktiven Personen geht.“"123 Vielmehr fänden diese bei „Reflexionen auf der kognitiven Metaebene" Verwendung. ${ }^{124}$ Diesen Befund konnte die Analyse ebenfalls bestätigen, da der autodiegetische Erzähler seltener aktiv seine aktuellen Gefühle reflektiert, häufiger kontemplativ auf die Erzählvergangenheit gerichtet oder im Modus des Möglichen räsoniert. Bannt man beide zeitgenössischen Tendenzen zusammen in ein Bild, plausibilisiert sich die These, dass in der Liebesblödigkeit wie in der neuesten deutschsprachigen Literatur allgemein zwar noch die „Konzeptualisierungen der romantischen Liebe [...] implizit oder explizit immer vorhanden“ sind, sowohl gefühlssprachlich als auch qua Liebesentwurf indessen „bewusst [...] die Erwartungshaltung diesbezüglich [...] durchbrochen“ wird - und zwar in „schonungsloser, desillusionierender Manier“. ${ }^{125}$

„Sexualität, seit je ein wichtiges Thema in Genazinos Werken, ist in der Liebesblödigkeit zur radikalen Hirnfiktion aufgebläht, deren Ende mit allerletzter Kraft hinausgezögert wird (dafür muss die Frau verdoppelt werden)." ${ }^{126}$ Hier muss vehement widersprochen und entgegenhalten werden, dass diese ,Blähung` lediglich im ,Was‘ wiederzufinden ist; das ,Wie‘ wirkt wie ein Korrektiv, das aus dem Elefanten wieder eine Maus - oder mit den alten Indern gesprochen: eine Gazelle werden lässt. Zuvörderst durch den reflexiv wirkenden narrativen Modus, lexikalische und syntaktische Finessen und die Erzählerkonzeption des Romans treten nolens volens die ArtefaktEmotionen derart konturiert hervor, dass sie die Fiktions-Emotionen massiv überlagern. Insbesondere die nüchterne und ernüchternde Gefühlssprache mit Einsprengseln aus ,liebesfeindlichen' Lebensbelangen tut ihr Übriges, um romantisch-verklärten, liebestrunkenen BeischlafSchilderungen einen Riegel vorzuschieben.

Denn vielleicht ist es gerade in Zeiten, die diagnostisch unter der Signatur „Oversexed and underfucked“127 firmieren, in Zeiten des Alles-ausleben-Dürfens und der (vermeintlichen) Wahlfreiheit in jedweder Form, des Alles-sagen-und-schreiben-Dürfens, des Alles-schon-gelesen-underlebt-Habens eine heilsame Darstellungs-/Emotionalisierungsstrategie, ein Maximum an Artefaktdistanz zu schaffen, um die erotische Liebe literarisch wieder auf ein Normalmaß zusammenzuschrumpfen, um die Alltäglichkeit und Problematik (auch: tragikomisch und ironisch) wieder in ihr Recht zu setzen, ohne dabei ,Romantik' einerseits, Exorbitanz oder überbordenden Ekel (s.u.) andererseits zu benötigen. Per Foregrounding „sollen die bezeichneten Objekte wieder bewußt und neu erlebbar werden. " ${ }^{28}$ Evtl. könnte man sagen, dass der intendierte ArtefaktEmotions-Überschuss den Blick auf das fiktionale Liebespanorama weniger befangen macht,

\footnotetext{
123 Schwarz-Friesel: Sprache und Emotion, S. 309.

124 Schwarz-Friesel: Sprache und Emotion, S. 309.

125 Schwarz-Friesel: Sprache und Emotion, S. 309.

126 Hirsch: Geheimgeschichten. Die (Ent)deckung der Scham, S. 66.

127 Vgl. Iris Osswald-Rinner: Oversexed and underfucked. Über die gesellschaftliche Konstruktion der Lust. Wiesbaden 2011.

128 Holt/Groeben: Emotionales Erleben beim Lesen, S. 127.
} 
weniger emotional gefangen nimmt und also freier schweifen lässt - diese reflexive Einsicht ist vielleicht auf der Darstellungsebene nur durch ein ,gefühlloses‘ Sprachkleid bei der Thematisierung und Präsentation des tiefsten Gefühls zu erkaufen.

Dabei lassen sich für alle Instanzen: Autor - Text - Leser Annahmen zum Gesamtzusammenhang der über literarische Texte $d u r c h$ Sprache vermittelten Kommunikationskette zwischen Produzent und Rezipient anstellen, die sich - in Anlehnung an Anz - in bündige Regeln überführen lassen sollten, wie sie einer „Literaturwissenschaftliche[n] Text- und Emotionsanalyse (LTE)“ vorschweben. ${ }^{129}$ Beispielhaft könnte eine solche Regel für Genazinos Roman lauten: ,Wenn ein Autor in seinem Text die Darstellungsmittel zur Darstellung kontrastiv wählt, intendiert er eine Emotionalisierung (Verwunderung, Desorientierung o. Ä.) des Lesers.' In dieser abstrakten Form ist indes Einzeltexten nicht beizukommen. Mit den nötigen Zusatzelementen versehen, schwillt die Regel mit zunehmender Konkretisierung und Feinjustierung allerdings auf ein unhandliches Maß an: ,Ein Autor evoziert mit der durch unterschiedliche Textstrukturen begünstigten, sprachlich fiktions-emotionsstörenden Gefühlsverpackung fiktionalisierter körperlich-erotischer Partnerliebe heterosexueller Figuren ein Spannungsverhältnis, das den leserseitigen Emotionsapparat eher auf die Artefakt-Emotionen lenkt und damit die Identifikation mit der Hauptfigur und ihren Geschicken erschwert.' Schnell wird die (zweifellos reizvolle) Vorstellung davon, literarische Emotionskommunikation regelgeleitet beschreiben zu wollen, mit der Einzeltextrealität respektive -komplexität konfrontiert.

In jedem Fall müssen mögliche regelhafte Funktionsprinzipien literarisch-emotionaler Kommunikationsprozesse dringend sensibler auf das ,Wie' reagieren, sprich: an die narratologischlinguistische Gefühlssprachanalyse rückgebunden werden: ,Wenn ein Autor in seinem Text eine Hauptfigur erotisch-sexuelle Liebeserlebnisse (,voller/ohne Gefühl') sammeln lässt, intendiert er bei seinen Lesern emotionale Reaktionen, deren Art und Intensität maßgeblich dadurch bestimmt sind, aus welcher Gefühlssprache (,gefühlvoll/gefühllos') der Discours gemacht ist.' Emotionsanalytisch lässt sich immerhin festhalten, dass im Aufeinandertreffen von Textwelt und Darstellungsmitteln Genazinos Figurenromane durch ihre ,gefühllose` Verfertigung die emotionale Affizierung erschweren, stellenweise gar verwehren - sei es in Situationen ,voller Gefühl', sei es in solchen ,ohne‘. Wie im echten Leben können größte Lust und Lustlosigkeit so nahe beieinanderliegen wie zwei Liebende. Diese Tatsache versinnbildlichen Genazinos Texte par excellence, entwerfen sie doch eine, gefühllose' Sprache für erotische Liebesentwürfe und erzwingen dadurch ein leserseitiges ,deemphatisches' Gewahrwerden der Artefakt-Emotionen.130

129 Eine exemplarische Regel aus Anz: Kulturtechniken der Emotionalisierung, S. 232, lautet: „Wenn ein Autor in seinem Text einer Figur, die er zum Sympathieträger gemacht hat, ein Unglück erleiden lässt, intendiert er bei seinen Lesern emotionale Reaktionen des Mitleids und/oder der Traurigkeit und/oder zusätzlich der Empörung über diejenigen, die in seinem Text für das Unglück verantwortlich erscheinen."

130 Was hier pars pro toto an der Liebesblödigkeit hat gezeigt werden können, findet sich so oder so ähnlich in nahezu allen Romanen Genazinos wieder. Vgl. kursorisch in chronologischer Erstveröf- 


\section{EKEL: SEX, KÖRPER UND ALTER(N)}

Noch eine Spur weniger dazu einladend, erotisch zu wirken, ist das folgende Beispiel: „Wenn auf der vorderen Ausbuchtung einer der Wülste nicht eine Brustwarze erkennbar wäre, würde ich nicht wissen, daß es sich dabei um eine jetzt schräg liegende Frauenbrust handelt. Der Anblick stößt mich nicht ab." (Liebesblödigkeit, S. 129) Allerdings ist bereits die Schilderung von Wülsten mit Brustwarzen im Graubereich zum bis zum Ekel ${ }^{131}$ getriebenen antiemotionalen (und letztlich doch wieder emotionalisierenden) Erzählen anzusiedeln, welches bezeichnenderweise meist dann einsetzt, wenn die Passagen die Kategorien ,Körperlichkeit' und ,Alter(n) dezidiert ins Spiel bringen. Ein Rezept, nach dem diese Szenen zubereitet sind, lässt sich nicht ausmachen, denn sowohl eine Festlegung auf musterhafte stilistische als auch auf thematische Aspekte läuft ins Leere. Am ehesten könnte man für diesen Bereich sagen, dass jeder Text seinen eigenen Ausdruck dafür finde, Ekel über die Wege von Körperlichkeit und Alter(n) in die Erotik einzuschleusen (vgl. Fremde Kämpfe, S. 123; vgl. Glück, S. 126 f.; vgl. Abschaffel, S. 140 ff.).

$\mathrm{Zu}$ einem Zeitpunkt etwa, an welchem sich Gewöhnung und Lustlosigkeit in der Beziehung zwischen Axel und Elke eingestellt haben ( $\Rightarrow$ II.5.2), wird deren bis dato sehr geliebter Körper schlagartig zur „Porenhülle“ (Laslinstraße, S. 203) umdeklariert, im Roman Fremde Kämpfe derjenige Dagmars zu „bäurisch rund[]“ (Fremde Kämpfe, S. 65). Der üblicherweise geschätzte Genitalgeruch - „Es hat mir immer gut gefallen, daß Männer und Frauen bei der Ausübung der Liebe hinterher ein bißchen nach Fisch riechen“ (Liebesblödigkeit, S. 198; $\Rightarrow$ II.5.5) - wird stark intensiviert: „Frau Kiefer roch frisch nach Fischen und Pilzen. Der Duft war so stark, daß ich argwöhnte, er hätte uns schon verraten." (Wohnung, S. 68) Auch Krankheiten werden als Mittel eingesetzt, mit dem Zweck Ekel und Sexualität zu parallelisieren.132 So ist etwa Abschaffels Filzlausbefall ein einschneidendes Erlebnis für diesen wie für den Leser (vgl. Abschaffel, S. 110 ff.). Rund um die Thematisierung unterschiedlicher sexueller Praktiken ( $\Rightarrow$ II.5.5), die mit Ekel in Verbindung gebracht werden können, schildert Abschaffel auch das Scheidenekzem einer damaligen Geschlechtspartnerin sowie deren Vorliebe, dieses nicht als sexuellen Hinderungsgrund aufzufassen, „denn auch das Ekzem mache das Beischlafen für sie schöner.“ (Abschaffel, S. 41) Verbindet

fentlichungsreihenfolge etwa Abschaffel, S. 110 ff.; vgl. Sorgen, S. 361 u. S. 362; vgl. Kassiererinnen, S. 115; vgl. Regenschirm, S. 54 f. u. S. 141; vgl. Wohnung, S. 26 u. S. 68; vgl. Tiere, S. 84; vgl. Regen, S. 11; vgl. Außer uns, S. 21, S. 56, S. 63, S. 86 u. S. 150 ff.

131 Vgl. dazu generell bei Genazino Hirsch: Geheimgeschichten. Die (Ent)deckung der Scham, die Ekel wie auch Scham - quasi als ,Sekundäraffekt' begreift, also als Ersatzempfindung für ,Darunterliegendes'.

132 Vgl. für die Ausdeutung derjenigen Szene, in welcher der namenlose Ich-Erzähler aus Genazinos Liebesblödigkeit aufgrund seines dunkelfarbigen Urins die unmittelbar bevorstehende Apokalypse erwartet, Leonie Süwolto: Ereignis oder Kontinuum? Zur zeitlichen Codierung des Alter(n)s bei Wilhelm Genazino und Arno Geiger. In: Claudia Öhlschläger/Lucia Perrone Capano unter Mitarbeit von ders. (Hg.): Figurationen des Temporalen. Poetische, philosophische und mediale Reflexionen über Zeit. Göttingen 2013, S. 191-209, hier S. 194 f. 
die bisherigen Beispiele, dass sie letztlich erst im Kopf des Lesers zu Ekelassoziationen werden (können), so existieren ebenfalls solche, die aus Figurensicht bereits eingeordnet werden:

Unser Sexualleben ekelte mich. Es war so, daß Bettinas Geschlecht, während es auf seinen Höhepunkt hinzitterte, mehr und mehr Feuchtigkeit hervorbrachte, bis meine Lust in ihr Gegenteil umschlug, und zwar immer öfter, ehe Bettina ihren Orgasmus erreicht hatte. (Liebesblödigkeit, S. 132)

Weibliche Körperlichkeit wird häufiger an der Grenze zum ,Ekligen` konzeptualisiert: „Knapp unterhalb ihres linken Ohrs wächst ihr ein einzelnes, langes dunkles Haar, das Sandra nicht entfernt. Später, im Bett, wenn ich das Haar auf der weißen Bettwäsche werde liegen sehen, wird es mich beeinträchtigen." (Liebesblödigkeit, S. 11) An einem einzelnen Haar, das sich in Farbe, Länge (und Struktur) von den anderen unterscheidet und im Volksmund,Teufelshaar' genannt wird, ist freilich nichts besonders Ekelerregendes zu finden, ist es doch ein weitverbreitetes Phänomen. Dadurch indessen, dass es sich allerdings an eine üblicherweise weitgehend haarfreie Stelle verirrt hat, dort permanent zu bleiben genötigt ist und zudem ein bereits auf farbmetaphorischer Ebene funktionierender Kontrast zwischen dem Dunkel des Haares und der Helle des Bettzeugs wirksam ist; das Haar mithin schließlich den Protagonisten sogar „beeinträchtigen“ „wird“ - dadurch evoziert die Sprache die Ekelvorstellung.

Genazinos Romanfiguren haben generell ein gespaltenes Verhältnis zur (auch eigenen) Körperlichkeit. Einerseits halten sie „solche körperlichen Details, die uns erst richtig auffallen, wenn wir die Personen schon lange nicht mehr kennen“, sogar dafür geeigneter als gemeinsame „Erlebnisse“, um „andere Menschen unvergeßlich [zu] machen“ (Regenschirm, S.8), andererseits häufen sich Momente, in denen fremde oder der eigene Körper Anlass zur Beschwerde geben $(\Leftrightarrow I I .1 .4)$. Abschaffel gefällt weder sein Körper generell noch sein erigiertes Geschlecht und auch sämtliche Ausscheidungen und Absonderungen sind ihm zuwider (vgl. Abschaffel, S. 88, S. 202 u. S. 507 f.). Allerdings bringt auch die Körperpflege dem Basistypus keine Linderung:

Ich werde meinen Körper auch heute abend einer gründlichen Reinigung unterziehen, von der Edith nicht weiß, wie peinlich sie mir ist. [...] Zu Hause, in der Wohnung, verziehe ich mich sogleich ins Bad, reinige meinen Körper vorn hinten, oben und unten, vergesse auch die KÖRPERFALTEN nicht, auf deren Säuberung Edith stets besonderen Wert legt. (Heimweh, S. 58 f.)

Zwar könnte man einwenden, dass es im konkreten Beispiel der fremdbestimmte Zwang sei, der die Abneigung gegen die „gründliche[] Reinigung“ hervorrufe, aber sowohl die Tatsache, dass sie Rotmund trotz seiner gewahrten Intimsphäre zur Peinlichkeit gereicht, als auch die bei vielen anderen Figuren zu beobachtende Abscheu gegen Körperlichkeit und -reinigung (vgl. Abschaffel, S. 81-90) argumentiert gegen diesen Einwand. Dezidiert mit Alter(n) verquickt ist die Körperhygiene etwa in der Liebesblödigkeit:

Morgens und abends kann ich Sandra vom Bett aus dabei zusehen, wie sie sich wäscht. Immer wieder wundere ich mich, daß sie sich obenrum zart, untenrum jedoch mit heftigen, stoßartigen Bewegungen zu Leibe rückt. Durch die beiden Waschvorgänge fällt die Person für den Betrachter gewissermaßen auseinander. Ich kann sagen, obenrum wäscht sie sich wie eine junge, untenrum wie eine ältere Frau. (Liebesblödigkeit, S. 13) 
Leonie Süwolto interpretiert diese Passage in ihrem Aufsatz, der sich neben der Verknüpfung von Liebe und Alter(n) auch allgemein mit Körperkonzepten auseinandersetzt, wie folgt:

Es zeigt sich die körperliche Zäsur, welche die Trennung von Alter und Jugend besiegelt, nicht zufällig entlang des Hüftgürtels organisiert. Die Vorstellungen von Alter, Krankheit und erektiler Dysfunktion des Apokalyptikers werden alsbald indifferent. Ein durch einen (altersgemäßen) Krampfanfall unterbrochener koitus interruptus verwandelt flugs imaginär die „Geliebte[] in eine Krankenschwester" (Lb 14 f.). Immer wieder interferieren die Themen Liebe und Alter in ihrer temporalen Modellierung. Das drohende Scheitern des libidinösen Dreiecks als „die absolute und ultimative Apokalypse“ (Lb 67) erweist sich in Termen pathologischer Physiognomie (so etwa als „Liebesverstopfung", Lb 69) motivisch gekoppelt an die Darstellung des Alter(n)s im Roman. ${ }^{133}$

Obgleich, wie die Autorin späterhin konstatiert, der Ich-Erzähler letztlich „gängige temporale Repräsentationskodizes des Alter(n)s, welche Mechanismen der Ausgrenzung und Hierarchisierung zeitigen“, „unterminiert",134 sind hinsichtlich des Roman-CEuvres einerseits die dem Alter(n) geschuldeten Peinlichkeiten sowie Hässlichkeiten und deren Nähe zum antiemotionalen Erzählen in der Überzahl (vgl. Abschaffel, S. 12; vgl. Liebesblödigkeit, S. 14 f.), andererseits finden auch zunehmend düstere Farben bei der Ausgestaltung der Altersthematik Anwendung: Wo etwa im Roman Die Liebesblödigkeit noch wortspielerisch-komisch der Tod metaphorisch auf eine sexuelle Ebene verschoben worden ist ${ }^{135}$ - „Aus Versehen lese ich anstelle des Wortes Endredaktion das Wort Enderektion. Zwei Sekunden später landet ein schwarzer Vogel auf meinem Kopf und schaut an meiner Statt in die Welt" (Liebesblödigkeit, S. 143) -, sind die Verlöschungsfantasien und Todesahnungen in Kein Geld, keine Uhr, keine Mütze zwar auch weitgehend dem Dunstkreis des Ekels entrückt, zumeist aber bereits vollständig enterotisiert:

Wenn ich draußen umherging, dachte ich wenigstens nicht an meinen Tod. Nur zu Hause, in der Wohnung, überfielen mich Gedanken der plötzlichen Trennung und des Abschieds. Dabei drang ich nicht in das Innere der Probleme vor. Ich beschäftigte mich rasch mit der Frage, was mit meinen Schallplatten, CDs, Büchern und den Regalen geschehen sollte, wenn es mich nicht mehr gab. Und ob ich den Keller und den Speicher vorher aufräumen musste, weil ich als Halbtoter dafür nicht mehr die Kräfte hätte. Der Tod war dann plötzlich ein Haushaltsproblem, eine groteske Verschiebung, in deren Nähe ich mich wohlfühlte. (Kein Geld, S. 91)

Alter und Altern haben dem Sprichtwort nach ,nichts Schönes‘ und es scheint, als versteife sich Genazino beim Entwurf neuer Protagonisten zunehmend darauf, die Schattenseiten zu zeigen ob es sich bei den Wortwiederholungen (vgl. Außer uns, S. 154), inhaltlichen Redundanzen, unabgeschlossenen Erzählsträngen etc. um einen dem Alter(n) geschuldeten, poetisch nachgebildeten beginnenden Gedächtnisverlust (der Figuren) handelt oder schlicht um mangelnde Endredaktion, lässt sich (noch) nicht abschließend entscheiden, aber in der Tendenz weist alles auf ein Übergewicht der ,Demenz-Lesart' hin $(\Rightarrow$ V.1). Vielleicht spendiert der ,neueste Genazino‘ indes dem äußeren, romanspezifisch-individuellen Schichtenkreis $(\Rightarrow I .2 .5)$ überraschend eine Figur,

\footnotetext{
133 Süwolto: Ereignis oder Kontinuum?, S. 195.

134 Süwolto: Ereignis oder Kontinuum?, S. 200.

135 Vgl. dazu Dana Pfeiferová: Metaphern des sozialen Todes in Wilhelm Genazinos Roman Mittelmäßiges Heimweh.
} 
die mit dem fortgeschrittenen Alter(n) bereits zustimmend ,im Reinen' ist, vielleicht sogar an die versöhnlicheren Roman-Enden früherer Texte anschließt?

In den Hardcore der Figurenschichten $(\Leftrightarrow I .2 .5)$ müssen zweifelsfrei eingetragen werden: mehrere SexualpartnerInnen - damit einhergehend: Angst vor dauerhafter Partnerlosigkeit -, Untreue, Seitensprünge und Ehebrüche $(\Rightarrow$ II.5.2). Zudem sind die sexuell äußerst aktiven Figuren Genazinos allesamt heterosexuell, die romanspezifische Ausnahme gleichgeschlechtlichen Verkehrs ist als sexueller Übergriff zu werten ( $\Rightarrow$ II.5.3). Den Übergang zu den Familienähnlichkeiten machen die vorherrschenden, hauptsächlich antiquierten Geschlechterrollenstereotype der Haupt- und Nebenfiguren ( $\Rightarrow$ II.5.3), die nur romanspezifisch gänzlich gebrochen werden (s.u.). Diejenigen Präferenzen im Sexuellen gehören nur deswegen nicht in den innersten Kreis, weil zwischen Frauen (die Penis- und Fellatio-fixiert sind) und Männern (Brustfixierung) unterschieden werden muss.

Betreffs der Verhaltensmuster und Inszenierungsstrategien der Hauptfiguren für das fünfte Schlaglicht sind insbesondere die bereits in den vorangegangenen Schlaglichtern ausgiebig diskutierten Facetten erneut hervorzuheben: Liebeslügen, innerer Zensur, Überheblichkeit, Interessantheit und die Wichtigkeit analoger Kommunikation $\Leftrightarrow$ II.5.1). In der Tendenz haben die Hauptfiguren weder Ehepartner - wohingegen häufiger Expartner erwähnt werden - noch Kind(er) und leben in polyamorösen Verhältnissen $(\Leftrightarrow$ II.5.2), was sich teils aus ihrer Vorgeschichte erklären lässt und einen Rückbezug zur Antibürgerlichkeit umfasst. Bürgerliche Lebensentwürfe und insbesondere die Institution der Ehe führen zumeist zu Geläufigkeit und Lustlosigkeit, zumal dann, wenn Kinder ins Spiel kommen $(\Rightarrow$ II.5.2). Zudem existiert die Verwandtschaft zwischen den Protagonisten, dass Männer (nicht nur) in Trennungssituationen zu Opfern stilisiert werden, was auch dem männlichen Blick der Darstellung geschuldet ist ( $\Rightarrow$ II.5.2). Die bereits im Hardcore angemerkte Problematik des sozialen Geschlechts äußert sich sowohl in reaktionären Frauen- als auch Männerbildern, die klare Rollenverteilungen auf Basis der Zuordnungen des neunzehnten Jahrhunderts vorsehen und wenn überhaupt nur umgedreht werden $(\Leftrightarrow$ II.5.3). Als Zement dieser Zuordnungen dient hauptsächlich die (vermeintliche) Inakzeptanz der Gesellschaft für Neuerungen. Die männlichen Hauptfiguren sind durch die Bank gute und meistens potente Liebhaber, die Frauen ,erobern` - notfalls auch gegen deren Willen ( $\Rightarrow$ II.5.3). Dabei werden die Anzüglichkeiten, Belästigungen und Übergriffe einerseits insofern geschlechtsneutral dargestellt, als Frauen Männer, Männer Frauen und Männer Männer zum (LustJObjekt degradieren, andererseits auch samt und sonders entproblematisiert und lakonisiert ( $\Rightarrow$ II.5.3). Sowohl auf Histoire- als auch auf Discours-Ebene scheint das Tierreich als evolutionärpsychologische Blaupause für die zumeist zwar drastisch dargestellte, letztlich aber entemotionalisiert geschilderte ( $\Rightarrow$ II.5.6) Sexualität des Basistypus zu fungieren $(\Leftrightarrow$ II.5.4). Trotz der 
Leichtigkeit, mit welcher der Basistypus im intrasexuellen Wettbewerb Kontrahenten aussticht, existieren durchaus Eifersucht und Rivalitäten - auch zwischen Frauen im intrasexuellen sowie generell im intersexuellen Bereich ( $\Rightarrow$ II.5.4). Sexuelle Wünsche und Vorlieben stellen sich familienähnlich häufig als problembehaftet und/oder überfordernd heraus, worunter auch die Hassliebe zu Prostituierten zählt ( $\Rightarrow$ II.5.5). Eine innige und für beide Seiten zufriedenstellende Sexualität gibt es zwar auch, sie ist aber im Vergleich seltener $(\Leftrightarrow$ II.5.5). Nahezu romanspezifisch sind exakt zwei sexuell nicht aktiv in Erscheinung tretende Männerfiguren ( $\Rightarrow$ III).

Romanspezifikum bleibt eine nur fast vollumfänglich dem Mann gleichgestellte Frauenfigur und also gelebte Emanzipation - und selbst diese eine ist im Textverlauf mehreren phallo(go)zentristischen An- und Übergriffen ausgesetzt ( $\Rightarrow$ II.5.3). 

Teil III: Fazit 

Dieses Fazit eröffnet mit einer kurzen Zusammenfassung der fünf Analysekapitel (Schlaglichter). Allerdings werden wohlerwogen nur die groben Fluchtlinien und keine der unzähligen Einzelergebnisse aller 28 Analyseunterkapitel erneut präsentiert, um Redundanzen zu vermeiden. Außerdem wird auf ausgiebige Vergleiche zur maßgeblichen Sekundärliteratur sofern möglich verzichtet und stattdessen auf die jeweiligen Unterkapitel verwiesen. Ferner wird einer klaren, einfachen Sprache der Vorzug gegeben vor der in den eigentlichen Untersuchungsfeldern verwendeten Fachsprache. Auch die methodische Ausrichtung der jeweiligen Analysen findet nur randständig Erwähnung. Erst danach werden die textgattungsspezifischen Schlüsse hinsichtlich des gesamten Unterfangens gezogen.

\section{VERDÜNNTE QUINTESSENZ DER SCHLAGLICHTERGEBNISSE}

Im ersten Schlaglicht, das unter dem Titel „Innenwelten - Außenwirkungen“ Generelles für Genazinos Basistypus, der ,weichgezeichneten' Durchschnittsfigur, untersucht, wird der Fokus zunächst auf das höchst ambivalente Verhältnis der Figuren zur Gesellschaft und dem Gegenpol: der Individualität gerichtet $(\Leftrightarrow I I .1 .1)$. Die Frage, ob sich die Romanfiguren eher zur Gesellschaft zugehörig fühlen oder per Distinktionsstrategien dieser den Rücken kehren, um ihre Individualität zu betonen, und auch die Frage, inwieweit sie mit dem Status Quo zufrieden sind, stellen alle Figurenromane Genazinos mittel- oder unmittelbar. Schematisch und strukturalistisch geordnet lassen sie sich nicht beantworten, da Genazinos Romane diese ,Musterantworten' subversiv unterlaufen. So schließt dieses erste Unterkapitel mit einem - allerdings nur scheinbar - paradoxen Befund: Die meisten Protagonisten brauchen die Gesellschaft, lehnen diese indes in der vorliegenden Form ab, sodass sie auf bestimmte Verhaltensstrategien zurückgreifen müssen, um dieser Ambivalenz Herr zu werden.

Dass Selbstdarstellung und mithin Eindruckssteuerung einerseits unabkömmlich sind, andererseits immer im Spannungsfeld von Authentizität und Verstellung operieren, ist aus dem Theorieteil dieser Arbeit bereits genauso bekannt wie die Tatsache, dass Genazinos Erzähler es mit ,der Wahrheit' nicht immer ganz so genau nehmen. Im zweiten Unterkapitel des ersten Schlaglichts ( $\Rightarrow$ II.1.2) wird daher das generelle Verhältnis der Figuren zur Selbstdarstellung eruiert, wobei sowohl zu Tage gefördert wird, dass es Genazinos Basistypus zwar unlieb ist, sich selbstdarstellend zu verhalten, er es aber dennoch in mannigfachen Situationen, in denen er sozusagen ,nicht anders kann', gekonnt und kalkuliert zielgerichtet anwendet. Es gibt dabei keine verlässliche Richtschnur, die besagte, dass Genazinos Figuren gesellschaftliche Werte und Normen zur Maxime ihres eigenen Verhaltens erheben würden, sondern sie machen sich ihre eigenen Regeln und richten daran ihr Verhalten und ihre Handlungsstrategien aus. So greifen sie auch umfänglich auf die ,kleine Lüge‘ zurück, die hinwiederum als akzeptiertes gesellschaftliches Schmiermittel wie auch im Gewand der ,Mythomanie' in Erscheinung tritt. 
Was im Alltagsverständnis eine Figurenanalyse auszeichnet, unternimmt das folgende Unterkapitel ( $\Rightarrow$ II.1.3): Unter Zuhilfenahme unterschiedlicher sozial- und persönlichkeitspsychologischer Konzepte werden Genazinos Figurenbasistypus musterhafte Charaktereigenschaften zugewiesen, wobei basalere Merkmalszuschreibungen, die sich etwa mittels des Fünf-FaktorenModells (,Big Five'), eines weithin akzeptierten Konzepts der Persönlichkeitseigenschaften, erfassen lassen, von eher randständigen unterschieden werden müssen. Ein Hauptaugenmerk liegt auf denjenigen Makeln, Marotten und anderen Merkwürdigkeiten, die Genazinos Figuren einerseits höchst ,menschlich“ wirken lassen, andererseits zumal in den ,psychischen Problembezirken', die nicht zuletzt aus zahlreichen mangelnden Sozialkompetenzen resultieren, zu AntiHelden werden lassen.

Kommunikation erfolgt bekanntlich nicht nur sprachlich. Im vierten Unterkapitel des ersten Schlaglichts wird der nonverbalen Kommunikation im Allgemeinen, der Körpersprache im Speziellen die angemessene Aufmerksamkeit für Genazinos Romanfiguren zuteil ( $\Rightarrow$ II.1.4). Mit der Unterscheidung analoger (also nichtsprachlicher) Kommunikation in Kinesik, Haptik und Proxemik wird dabei ein taugliches Analyseraster für die oftmals ohne ein Wort operierenden Szenen bei Genazino etabliert. Dass die analoge Kommunikation zudem eine Antwort auf die bei Genazino immer wieder verhandelte Sprachkritik und den ,Unsagbarkeitstopos‘ gibt, gerät ebenso in den Blick wie die (zum Teil daraus resultierende) Stummheit und das (Ver-)Schweigen der Figuren. Mit einem exkursartigen Blick auf die Körper der Figuren, deren Aussehen generell bis auf die Kleidung, die sie umhüllt, sehr spärlich geschildert wird, erfolgt die Überleitung mittels der körperlichen, habituell-performativen Darstellungsstrategien zum nächsten Unterkapitel.

Dieses geht hauptsächlich durch soziologische Theoriebildung fundiert den ,feinen Unterschieden' auf den Grund, indem zunächst diskutiert wird, welche Erklärungsmodelle Genazino für soziale Ungleichheiten und Lebensstile heranzieht: Schichten, Milieus oder Lebensstile? Hilfreich für die Analyse konkreter Figuren und Handlungsmotivationen ist dabei die ,Kapitalstrukturanalyse'. Dadurch können bestimmte vorliegende Akkumulationen zunächst beschrieben werden, um daraus und auf Basis der plausibel vermutbaren Kapitalstrukturideale eine Handlungsmotivation zu generieren, die sich aus der Differenz des Status Quo und des gewünschten ,Idealzustands' ergibt. Eng damit verknüpft sind die Betrachtungen zu (symboltragenden und selbstergänzenden) Gegenständen sowie zur Kleidung, die allesamt bei Genazino herausragend wichtige Funktionen übernehmen.

Welche Einstellungen, Überzeugungen und Wertehaltungen in Form einer rudimentär wahrnehmbaren Weltanschauung Wilhelm Genazinos Protagonisten an den Tag legen, hinterfragt das sechste, letzte Unterkapitel $(\Leftrightarrow$ II.1.6). Neben den eindeutig als ,politisch inkorrekt' zu benennenden Zügen, die mitunter weniger als Ressentiments, sondern vielmehr als fehlgehende Bereitschaft von Fremderleben per se zu interpretieren sind, finden sich auch gesellschaftlich positiver konnotierte Auffassungen, die sich gegen (marode) bestehende Systeme richten. Sozialkritische 
Töne werden dabei sowohl in der Form als ,konservativer Aussteiger 'als auch als ,Frühvergreister' hörbar, was eine wichtige Grundlage dafür ist, etliche eindruckssteuernde Techniken und Taktiken des Figurenbasistypus besser verorten zu können.

Das zweite Schlaglicht trägt den Titel: „Im Auge des Betrachters“ und entwickelt auf der Vorarbeit des ersten peu à peu die in mannigfacher Form vorliegenden Blicke und Blickrichtungen, die im Rahmen von Selbst- und Fremdbeobachtungen etc. einen immensen Raum im Romankosmos Genazinos einnehmen. Als Grundierung dient dabei die notwendige Unterscheidung in SelbstFremd- und Idealbilder der Figuren $(\Leftrightarrow I I .2 .1)$. Da es in der echten wie in möglichen Welten die absolute Ausnahme ist, dass alle drei harmonisch-deckungsgleich vorliegen, treten zwei untersuchungswürdige Diskrepanzen in den Vordergrund des Problemhorizonts: erstens kognitive Dissonanzen, die entstehen, wenn Selbst- und Idealbild konfligieren, zweitens Ungereimtheiten zwischen Selbst- und (vermutetem) Fremdbild. Für beide Differenzen haben sich Genazinos Figuren ein breites Arsenal an psychischen Bearbeitungsstrategien angelegt, das ebenfalls diskutiert wird.

Genazinos Figuren sind auf dutzendfache Weise angespannt und überspannt. Insbesondere dann, wenn sich bestimmte Zwänge zu erkennen geben. Ein maßgeblicher ist dabei der ,Beobachtungszwang' $\Leftrightarrow$ II.2.2), welcher einen hohen Leidensdruck für den Basistypus bedeutet. Nur im von (vermeintlich bedeutungsvollen) Beobachtungen befreiten Raum wähnt er sich frei und glücklich, sodass die Anstrengungen, die Genazinos Figuren unternehmen, um sich selbst zu besänftigen, immens sind. Diese Strategien werden aufgefächert und genauer unter die Lupe genommen. Mitunter wird der Beobachtungszwang auch lustvoll erfahren, zumal dann, wenn es intellektuell etwas zu ,durchschauen' gibt. Allerdings wollen die Protagonisten dabei selbst um nichts auf der Welt von anderen durchschaut werden - ein schmaler Grat, der immer wieder durch einfallsreiche Handlungsstrategien gestützt werden muss. Dass die Beobachtungspositionen häufig unbeobachtbare, die Beobachter letztlich unbeobachtete sind, ist eine weitere Station, bevor Aspekte von Voyeurismus und Stalking dieses Kapitel beenden.

Bei Genazino wird viel und vor allem: wird fantasiereich beobachtet und geschaut. Dabei geben sich die Hauptfiguren als radikale Konstruktivisten zu erkennen, wofür sie aber selbst nicht immer sensibel sind. Die Konstruktion und Interpretation ,der Welt' jedenfalls ist sowohl auf Handlungs- als auch auf Darstellungsebene ein ergiebiges Untersuchungsfeld ( $\Rightarrow$ II.2.3). Eng damit zusammen hängen wahrnehmungstheoretische Reflexionen zu Zeichengebung und -verstehen: Was lässt sich überhaupt einwandfrei erkennen, was in einem zweiten Schritt gar verstehen? Da Genazinos Basistypus einerseits immerzu verstehen will, aber immer öfter feststellt, dass das graduelle Nicht-Verstehenkönnen ein unhintergehbarer Fakt ist, werden zwei miteinander verflochtene Strategien deutlich: die mit (fehlbaren) Mutmaßungen einhergehende Deutung der Zeichenwelt zum einen, die Überinterpretationen, die Kontraintuition, Kohärenzbestreben und Wiederverzauberung der Welt umfassen, zum anderen. 
Im Gegensatz zu diesen nach außen gerichteten Blicken, die im Inneren der Figuren die Welt konstruieren, existieren auch die (imaginierten) Blicke, die sie selbst treffen. Mit der Unterscheidung in öffentliche und private Selbstaufmerksamkeit $(\Rightarrow$ II.2.4) wird der Boden bereitet, um hauptsächlich die fremden Blicke zu systematisieren, wobei auf den ersten Blick nicht zu vereinheitlichende Aspekte wie etwa hypochondrische Selbstbespiegelungen aber auch ein nahezu reumütiger Rechtfertigungsdrang die Folge sein können. Einmal im Modus der öffentlichen Selbstaufmerksamkeit befangen, ist es zudem nicht unüblich, dass der Basistypus auch gefallen und dabei naturgemäß wahrgenommen werden möchte, um die gewünschte Anerkennung zu erhalten. Im krassen Kontrast dazu werden die als verletzend, bloßstellend und penetrant wahrgenommenen Beobachtungen durch andere eigens thematisiert.

Aus dem zuletzt Gesagten entwickeln sich im nächsten Unterkapitel des zweiten Schlaglichts $(\Rightarrow$ II.2.5) folgerichtig Verhaltensstrategien, mittels derer Wilhelm Genazinos Romanfiguren danach streben, aus dem Fokus fremder Blicke zu treten. Drei unterschiedliche Komplexe können dabei unterschieden werden. Zunächst ist erstens die mehr oder weniger konkrete Flucht gemeint, welche die Figuren zwar in den seltensten Fällen wirklich antreten, die sie aber immer umtreibt. Zweitens sind Verstecke(n) und Verborgenheit wichtige Faktoren in einer Gleichung, an deren Ende ein Minimum an Aufmerksamkeit stehen soll. Und drittens sind eher metaphorisch zu verstehende Kategorien wie das Verschwinden, die Auflösung und die Unsichtbarkeit als postulierte Wunschzustände Ausdruck des protektiven ,Nicht-geschaut-werden-Wollens'. Sie alle treffen sich in einem Fluchtpunkt: dem Selbstschutz.

So, wie der Basistypus den öffentlichen Blick scheut, so (ver-)meidet er es auch allenthalben, bestimmte Handlungen oder Kommunikationen in die Tat umzusetzen, obwohl diese mitunter durchaus als willkommen dargestellt werden. Dieser Wirkmechanismus, der hier ,innere Zensur genannt wird ( $\Rightarrow$ II.2.6), ist konzeptuell als ,Schere im Kopf ${ }^{\prime}$ zu begreifen, die aus unterschiedlichsten Gründen Handlungen beschneidet oder gänzlich unterbindet. Damit einhergehen können sowohl gesellschaftlich eher positiv als auch eher negativ konnotierte Auswirkungen und stets muss hinterfragt werden, ob es sich etwa um Takt oder Anstand handelt oder um eine Verstümmelung der eigenen Interessen aus übertriebener Rücksichtnahme. Das Kapitel schließt eine exemplarische Analyse ab, die sich zum Ziel setzt, die im Hintergrund wirksamen Schlüsse zu explizieren, die für das Einschreiten der Schere im Kopf verantwortlich zeichnen.

Im dritten Schlaglicht treten die Genazino'schen Protagonisten aus ihren Verstecken wieder bereitwillig ,ans Tageslicht': Im Gegensatz zur Verwendung protektiven IMs im zweiten Schlaglicht finden nun vermehrt assertive Techniken und Taktiken Verwendung, die soziale Kontakte und auch das Scheinwerferlicht der Aufmerksamkeit erfordern. Die „Strategien der Interessantheit bzw. Auffälligkeit" werden zunächst in den Präliminarien $(\Leftrightarrow I I .3 .1)$ durch den Bezug auf andere Facetten des Basistypus an die anderen Schlaglichter gebunden. Außerdem ist es erforderlich, eine Typologie zu skizzieren, die es ermöglicht, ,interessantes‘ bzw. ,auffälliges Verhal- 
ten' genauer fassen zu können, wobei auch die linguistische Höflichkeitsforschung und weitere für dieses Schlaglicht relevante Referenztheorien vorgestellt werden.

Als Grundanlage und als Teil der erkenntnisleitenden Forschungsfragen untersucht diese Studie immer auch den Bezug von Inhalt und Form. Das zweite Unterkapitel des dritten Schlaglichts $\Leftrightarrow$ II.3.2) tut dies dezidiert, indem es die erzähltechnischen Besonderheiten und Auffälligkeiten hervorkehrt und etwa plötzliche Perspektivwechsel der Erzähler, Spannungsaufbau und Tempo thematisiert, die sonst bei Genazino eher Mangelware sind. Dieses Kapitel fokussiert also sowohl die externe Analyseperspektive als auch die innere, wenn gesprächsanalytisch bspw. die strategische Gesprächsplanung in den Blick rücken.

Dieser ,Grad an Vorbereitetheit' ist allzumal für dasjenige Unterkapitel relevant, das inszenierte Spontaneität verhandelt ( $\Rightarrow$ II.3.3): Genazinos Figurenbasistypus selbst ist nicht immer in dem Maße originell und schlagfertig, wie er es sein müsste, um aus dem Stegreif interessant zu wirken (was sein Idealbild aber häufig vorsieht). Dementsprechend wappnet er sich im Vorfeld und glänzt dann in den Kommunikationssituationen mit vorbereiteten Gesprächsanteilen, die auch kleinere und größere Lügen umfassen, welche dazu dienen können, den Eindruck von Interessantheit etwa im Rahmen eines ,Imponiergesprächs' beim Gegenüber hervorzurufen.

Allerdings darf dadurch nicht der Eindruck entstehen, Esprit und Extemporiergeschick gingen Genazinos Figuren per se ab. Unter bestimmten kommunikativen Rahmenbedingungen sind sie sehr wohl in der Lage, auch ohne ,Spickzettel' Interesse ,im besten Sinne' zu wecken $(\Rightarrow$ II.3.4). Gewitzt unterhalten sie analog oder digital Dyaden oder auch - zumeist aber gegen eigenen inneren Widerstand - größere Publika, die ihnen immer wieder aufs Neue die Bestätigung geben, diese Fähigkeit tadellos zu beherrschen. Seltener sind diejenigen Momente, in denen der Basistypus absichtlich und freiwillig in eine Rolle schlüpft, um die Publikumsreaktionen auszutesten oder mitunter moralisch nicht ganz einwandfreie Reaktionen zu provozieren.

Allerdings schießt der Basistypus häufiger über das kommunikative Ziel hinaus, opfert er doch seine sonstige ,Verträglichkeit' der Aufschneiderei oder gar dem Größenwahn ( $\Rightarrow$ II.3.5). Als Vehikel dafür fungiert etwa die Mythomanie - der Zwang selbst gegen besseres Wissen die Finger nicht von der Lüge lassen zu können -, um Interessantheit heraufzubeschwören, wobei eher Auffälligkeit entsteht. Wilhelm Genazinos Romanfiguren ergehen sich dann angelegentlich in Überlegenheitsfantasien, die ein aufgeblasenes Selbstbild hervorbringen und sich letztlich in devianten Handlungsweisen verlieren. Zwar lassen sich die Diebstähle etc. figurenanalytisch sowohl intern - also auf psychologische Erklärungsmuster zurückgreifend - als auch extern etwa über die Darstellungskonventionen ,sympathischer Verbrecher - erklären, aber die offensiven, streitbaren Verhaltensweisen beerben sukzessive die selbstdienliche Eindruckssteuerung, die im restlichen dritten Schlaglicht vorgeherrscht hat.

Unter dem Titel „Das Ich, die anderen und das andere: Inszenierung - Beobachtung - Evaluation" nimmt das vierte Schlaglicht im Gegensatz zum dritten, auf die Hauptfiguren selbst gerichte- 
ten, nun gleichsam intern fokalisiert durch die Augen der Protagonisten die anderen Figuren in den Blick. Als Verbindung fungieren allerdings das gegen Ende des dritten Schlaglichts bereits aufkeimende offensive Handlungsrepertoire und der Hang zu Hochmut, Spott und Häme. Nicht nur als Metapher wird Genazinos Basistypus im ersten Unterkapitel $(\Rightarrow$ II.4.1) in die Tradition der Humoralpathologie gestellt, da sich die Figuren de facto melancholische wie cholerische Wesenszüge teilen. Das verbindende Glied ist die neurotische Eigenart im Sinne emotionaler Instabilität. Nicht zuletzt dadurch wird ihre mitunter ,verquere' Wahrnehmung und Einschätzung erklärbar, die auch im Feld der Beobachtung, Evaluation und häufigen Herabsetzung anderer wirksam ist.

Das zweite Unterkapitel des vierten Schlaglichts ( $\Rightarrow$ II.4.2) sucht Muster herauszustellen, nach denen die Beobachtungs- und Evaluationssituationen bei Genazino gestaltet sind. Als wiederkehrendes Kompositionsprinzip sind einerseits erneut Mutmaßungen und Überinterpretationen zu nennen, die es mitunter schwierig werden lassen, klar zwischen ,Faktenlage im jeweiligen Roman und bloßem Hirngespinst der Hauptfiguren zu unterscheiden. Auch die auffälligen Stimmungsschwankungen der Protagonisten sind dabei ein ernstzunehmender ,Stör-Faktor'. Klarer lassen sich die Beobachtungsobjekte klassifizieren: Wer häufiger in den Blick gerät, auf welcher Grundlage dies geschieht - sprich: welche Aspekte zur Begutachtung anderer herangezogen werden - und schließlich, wie dies erzähltechnisch realisiert wird, sind zu beantwortende Fragen. Diese notwendigen Vorarbeiten bilden die Basis für die drei folgenden Unterkapitel.

Ein zentrales Anliegen des Basistypus ist es, die brüchigen Selbstentwürfe anderer zu entlarven $(\Longrightarrow$ II.4.3). Dabei obwaltet für gewöhnlich auf den ersten Blick das folgende Schema: Durch die teilweise schadenfrohe Beobachtung, dass andere mit ihren selbst gesteckten Zielen nicht Schritt halten können oder gar an ihrer Überheblichkeit gescheitert sind, werten sich die Hauptfiguren selbst auf. Allerdings darf dabei nicht vergessen werden, dass es durchaus genau die eigenen ,Schwächen` sind, die der Basistypus in anderen erkennt und herabsetzt. Durchaus in Erwägung zu ziehen ist also immer, dass der Basistypus mit seinen Abgrenzungspraktiken Distanz auch zu an sich selbst nicht geschätzten Eigenarten gewinnen möchte und die anderen mitunter nur ,zur falschen Zeit am falschen Ort' - was fiktionstheoretisch freilich Nonsens ist - gewesen sind.

Wohingegen es im vorangegangenen Unterkapitel durchaus randläufig noch Mitleid oder Verständnis für die Lebensläufe anderer gegeben hat, fokussiert das vierte Unterkapitel drastischere Verhaltensweisen offensiver Abwertung ( $\Rightarrow$ II.4.4). Dabei werden weder verbale Gewalt noch der Hang zur ,Pöbellaune' gescheut, sodass (imaginierte) willkürliche Beleidigungen zum stillen Frustabbau ebenso an der Tagesordnung sind wie Wut, Zorn und Hass. Letztere Trias entlädt sich allerdings hauptsächlich in Gewaltfantasien. Dennoch ist der Vergleich zu autoritären Persönlichkeiten nicht von der Hand zu weisen, neigen doch die Romanhauptfiguren Genazinos bspw. immer wieder auch zu als rassistisch, misogyn und homophob zu nennenden Einstellun- 
gen, die den Wesenszug, das eigene Leben, die eigene Kultur etc. egozentrisch als Nonplusultra anderen Entwürfen entgegenzusetzen, betonen.

Ein harter Cut markiert den Wechsel zum letzten Unterkapitel des vierten Schlaglichts, welches die relativ seltenen positiven Evaluationen anderer untersucht $(\Leftrightarrow$ II.4.5). Dafür kann sowohl der Neid auf Lebensentwürfe, die für die Hauptfiguren zwar wünschenswert, aber nicht realisierbar erscheinen, den Ausschlag geben, als auch schlicht das Zusammenspiel von einer gewogenen Stimmung, einer damit einhergehenden ,niedrigen' Messlatte und einer bevorzugten zu evaluierenden Person. Doch sind nicht alle vordergründig goutierten Personen bzw. Inszenierungen ohne Eintrübungen derart bewertet; das Urteil gibt sich nicht selten im Nachhinein als negativer veranschlagtes zu erkennen.

Mit dem abschließenden, fünften Schlaglicht, das sich der Themenkomplexe „Liebe und Sexualität" zuwendet, werden die Karten der eindruckssteuernden Verhaltensweisen gänzlich neu gemischt. In Analogie zum ersten Schlaglicht lassen sich keine dominanten eindruckssteuernden Verhaltensstrategien auszumachen, sondern es liegt eine breite Palette unterschiedlicher Varianten vor. Mit der Thematisierung von ,Liebeslügen' oder dem gehäuften Vorkommen non- und paraverbaler Verhaltensmuster bindet das erste Unterkapitel das fünfte Schlaglicht an vorangehende zurück $(\Rightarrow$ II.5.1). Schlagworte wie ,Introvertiertheit', ,Bindungsangst' oder ,Interessewecken`erlangen unter sexuellen Vorzeichen ganz neue Wertigkeiten.

Genazinos Liebes(lebens)entwürfe sind das Hauptthema desjenigen Unterkapitels, das Genazinos Basistypus mehrdimensional in denkbaren Kontexten verortet $(\Rightarrow$ II.5.2): Die Ja-Nein-Frage, ob Heirat, Kinder und Familie das Maß aller Dinge darstelle, lässt sich mit Blick auf die Protagonisten abschlägig beantworten. Weitaus eher sind Ehebrüche, Polyamorie und Untreue als ,Standardwert' der diegetischen Gesellschaften anzusehen. Obwohl es auch in deren Rahmen innige Zufriedenheit gibt, sind - zumindest längerfristig betrachtet - die Trennungs- und Scheidungssituationen sowie die generelle Unzufriedenheit mit den bestehenden Verhältnissen weitaus in der Überzahl. Abschließend werden diejenigen Momente in Augenschein genommen, die hinsichtlich der sexuellen Anbahnungen und Vereinigungen ,auf der Kippe stehen', also durch das sprichwörtliche Zünglein an der Waage erst entschieden werden.

Dass gendertheoretische Literaturbetrachtung lohnenswert ist, muss mittlerweile glücklicherweise nicht mehr eigens begründet werden. Für Genazinos Romanwerk ist diese Betrachtungsweise, die das dritte Unterkapitel innerhalb des fünften Schlaglichts unternimmt $(\Rightarrow$ II.5.3), insbesondere deswegen nutzbringend, da es seine Gesellschafts- wie Figurenkomposition teils aus den geschlechtsstereotypen Rollenklischees des neunzehnten Jahrhunderts zusammensetzt. Wer den Haushalt ,schmeißt' ist ebenso wenig diskutabel wie die Frage nach dem Hauptverdienst - es sei denn, diese Vorurteile des gesellschaftlichen Geschlechts werden um $180^{\circ}$ ins Gegenteil verkehrt. Höchst selten sind veritablere Reflexionen, Ironisierungen oder kritische Durchbrechungen der Stereotypien anzutreffen und insbesondere die Betrachtungen zu Anzüg- 
lichkeiten, Belästigungen und Übergriffen sind für Genazinos Romanschaffen lange überfällig gewesen.

Weitergesponnen schneidet sich diese Bestandsaufnahme mit der Beobachtung, dass das ,Balzverhalten“ bei Genazino einer biologistischen Grundfaktur entspricht. Ausgehend vom Tierreich wird Sexualität evolutionärpsychologisch als intra- bzw. intersexueller Wettkampf aufgefasst $(\Leftrightarrow$ II.5.4), was sich nicht nur in den Sprachbildern, sondern auch in der Ausgestaltung der Konzepte von Eroberung, Eifersucht und Rivalität - inklusive aller möglichen perfiden Strategien widerspiegelt.

Ohne irgendwie geartete Wünsche, Vorlieben und Praktiken ließe sich Sexualität weder in der Realität noch in der Fiktion denken. Allerdings treten Genazinos Figuren innerhalb dieses Referenzrahmens, der innerhalb des fünften Unterkapitels beleuchtet wird ( $\Rightarrow$ II.5.5), häufig als $\mathrm{Ab}$ weichler in Erscheinung. Entweder sind es Passungsprobleme zwischen den Partnern, Überforderungsgefühle seitens des Basistypus, wenn sexuelle Wünsche ,spezielleren` Interesses an sie herangetragen werden, oder schlicht zu spezifische Fixierungen, die das Sexleben als Problembezirk brandmarken. Freilich strotzen die hier untersuchten Texte nachgerade vor sexuellen Vereinigungen, aber ganz ungebrochen erotisch ist die Angelegenheit selten bis nie.

Das liegt auch daran, dass erotische Liebesdiskurse bei Genazino hauptsächlich ,antiemotional dargestellt werden ( $\Rightarrow$ II.5.6). Ein Erzählen, das maximalen Aufwand betreibt, um gefühlssprachliche Blumigkeit und in der Folge vielleicht sogar lustinduzierende Effekte beim Leser zu unterbinden, muss genauer untersucht werden. Allgemein distanzierende Mechanismen kennzeichnen ebenso ,deemphatisch' die Erzähloberfläche wie es Brüche auf Histoire-Ebene gibt, die einem ungetrübten Gewahrwerden der Liebesdiskurse massiv entgegenstehen. Thesenhaft lässt sich dahinter ein heilsames Kalkül vermuten. Das Unterkapitel, das Schlaglicht und die Arbeit insgesamt schließt eine Randbemerkung zum Ekel ab: Sobald Sex, Körper und Alter(n) an Genazinos metaphorischem Mischpult zusammengeregelt werden, steigert sich das antiemotionale Wirkpotenzial in Sphären, die letztlich doch wieder emotionalisieren - nur eben umgekehrt.

\section{POINTIERTES RESÜMEE HINSICHTLICH DER ANLIEGEN UND FORSCHUNGSFRAGEN}

Wenn die Einleitung drei ,Begehren' ausgibt, darf ein bündiges Resümee nicht fehlen: Welchen Nutzen bringt die vorliegende Arbeit der Genazino(figuren)forschung? Welchen derjenigen ,Literaturpsychologie', die sich mit Handlungsmotivation und Eindruckssteuerung befasst? Welchen der Figurenforschung generell? Gemessen an den ,großen Würfen' der drei Forschungsreviere, in denen hier ,gewildert' worden ist, nehmen sich die diskursiven Bereicherungen auf den ersten Blick vergleichsweise marginal aus: Weder ist den bestehenden ,Pauschaldeutungen' zu Genazinos Roman-CEuvre - etwa Selbstreflexivität wie bei Hirsch ${ }^{1}$ oder Fansa ${ }^{2}$ - eine weitere 
hinzugefügt noch die Handlungsmotivationsanalyse literarischer Texte per se revolutioniert oder gar figurentheoretisch ein genuin neues Gesamtmodell, das über Genazino hinaus Gültigkeit beanspruchen würde, vorgestellt worden. Diesen drei mit ,understatement' arbeitenden Konzessionen stehen indessen drei gewichtige Argumente entgegen, die der rhetorischen Dispositio-Empfehlung: mittelstark - schwächer - stark nicht gehorchen können, da die ausgegebene Reihenfolge der Einleitung es verbietet.

Erstens: Die Genazino-Forschung wird durch ein Korrektiv sehr wohl ,nach vorne gebracht': Die nahezu ausschließliche Fokussierung auf Autor-Werk-Verhältnisse, eine starke Überbetonung von Selbstreflexivität und poetologischen Untersuchungen wird ergänzt um eine praxeologische Lesart. Zumal Genazinos Romane eindeutig als ,Figurenromane‘ klassifiziert werden können, ist der Zugang zu Genazinos Roman-Werk ohne eine profunde Figurenkenntnis nicht möglich. Umdesto verwunderlicher, dass die vorliegende Arbeit die erste ist, die tatsächlich in der Breite alle aktuell vorliegenden Figuren methodisch variabel in den Blick nimmt. Zumal das Schichtenmodell der Genazino-Figuren rückt den schiefen Blick auf den ,scheinhomogenisierten Einheitsbrei‘ zurecht; die erstmalige systematische Berücksichtigung des ungeliebten Erstlings Laslinstraße lässt sich zudem auf die Haben-Seite buchen.

Zweitens: Durch das hier herangezogene sozialpsychologische Konzept zur Erklärung von Verhalten werden die vorliegenden (literaturwissenschaftlichen) Motivationsmodelle in einen größeren Rahmen eingebettet. Sucht man nämlich die Frage nach dem ,Warum?' von Verhaltensweisen vor dem Hintergrund wünschenswerter Fremdbilder, der Aufrechterhaltung brüchiger Selbstbilder oder der Diskrepanzminimierung zwischen Selbst- und Idealbild zu beantworten, können Einzelhandlungen in größere Zusammenhänge gestellt und vor allem zunächst disparat erscheinende Figurenfacetten innerhalb eindruckssteuernder Strategien, Taktiken und Techniken als durchaus kohärent betrachtet werden. Genazinos Figuren können ferner hinsichtlich der Handlungsmotivationsanalyse im Allgemeinen, in Bezug auf ihre eindruckssteuernden Verhaltens- und Inszenierungsstrategien global als protektiver IM-Typ klassifiziert werden. Zwar ist es nicht möglich, einer Person eindeutig nur eine solche Präferenz zuzuweisen, „because people use different styles at different times",3 aber bestimmte ,habituelle' und mit Persönlichkeitsmerkmalen zusammenhängende ,Trends' lassen sich auch für Genazinos Basistypus sehr wohl beobachten. ${ }^{4}$ Im Sinne Mummendeys ${ }^{5}$ lassen sich diesbezüglich bestimmte Muster erkennen: Neben der nach außen getragenen Protektion findet im Inneren eine offensivere Gangart Anwendung: Hybris, Verhöhnung etc. bilden das Korrektiv.

Drittens: Bezüglich der Figurenanalyse in Theorie und Praxis konnte ein klares Votum für die rehabilitierende Ausweitung des internen Standpunkts in den Diskurs eingebracht werden. Etwa

2 Vgl. Fansa: Unterwegs im Monolog.

3 Schütz: Self-Presentation, S. 620.

$4 \quad$ Vgl. Schütz: Self-Presentation, S. 620.

5 Vgl. Mummendey: Selbstdarstellung. 
die Big Five und viele weitere hier angewandte Referenztheorien und Modelle können verdeutlichen, dass der interne Blick - gut operationalisiert - nicht naiv ist. Zumal dann, wenn man sich nicht (nur) auf Freud bzw. die Psychoanalyse verlässt, werden Figurenpsychologie und -soziologie etc. zu veritablen Bausteinen einer intern perspektivierten Figurenanalyse, die für alle mehr oder weniger realistisch gezeichneten Figuren analyseleitende Fragen bereitstellt. Aber auch die Kombination von interner und externer Warte bei einer literarischen Figurenanalyse konnte insofern verbessert werden, als durch die Verknüpfung von externen - erzähltheoretische Aspekten, Emotionalisierungsstrategien, Autor-Text-Leser-Bezügen etc. - mit internen wie Kapitalstrukturanalyse, Persönlichkeitsmerkmalen etc. - eine aussichtsreich scheinende Amalgamierung vorgenommen worden ist, die sich nicht zuletzt hinsichtlich der Handlungsmotivationsanalyse literarischer Figuren als musterbildend auch für die Applizierung auf andere Texte herausstellen könnte.

Auch bezüglich der Forschungsfragen ist Bilanz zu ziehen: ,Welche Muster sich generell im (intentionalen) Figurenhandeln bei Genazino ausmachen lassen', ist letztlich bereits im Vorfeld des hier lesbaren Substrats eruiert und gefiltert worden. Die fünf vorliegenden Schlaglichter können als hauptmotivationale Felder für Wilhelm Genazinos Romanfiguren gelten, die aufgrund ihrer mehrheitlich induktiven Gewinnung $(\Leftrightarrow I .5 .1)$ für sich beanspruchen können, nicht aus der Luft gegriffen zu sein. Die Frage: ,Was tun literarische Figuren Genazinos wie, wann, warum und mit welchem Erfolg, um andere oder sich selbst (bewusst oder unbewusst) zu einem bestimmten Verhalten bzw. einer bestimmten Sicht ihrer selbst zu veranlassen?', nach über fünfhundert Druckseiten bündig beantworten zu wollen, wäre vermessen. Eine Kurzfassung der Antworten findet sich zu Beginn des Fazits (s.o.), komprimierter ist die Beantwortung kaum möglich. Auch die Beschaffenheit der dritten Frage - ,Wie genau wird dies narratologisch ausgestaltet? - ist keine, die sich verschlagwortet befriedigend für immer aus der Welt schaffen ließe, indem von antiemotionaler, lakonischer, drastischer, parataktischer etc. Machart gesprochen werden würde. Wie im Theoriesegment deutlich gemacht werden konnte, ist narratologische Erzähltextanalyse ohnehin kein Selbstzweck, sondern immer nur in Verbindung zum ,Mehrwert' der interpretativen Aussagekraft zu begreifen. Dass die Gestalt der folgenden zwei (!) Sätze deren Aussagegehalt massiv einfärbt, ist aber vermutlich evident:

\footnotetext{
„Dreimal kräftig den Mund auftun, sagte ich mir, das genügt, ich muß es sagen wie: Der Ofen brennt, als wenn es nichts wäre, als wenn ich, Axel, nicht Degens Sohn, nur irgend jemand wäre, der irgendwann zu irgendwem sagt: Ich ziehe aus. Für diese drei Worte, die ich heute zu sprechen mir gelobt hatte, brauchte ich eine Grundlage aus Gleichgültigkeit, aus Nebensächlichkeit, jetzt noch, da ich nach Hause ging, da ich Elke abgeliefert hatte, jetzt noch sammelten meine Augen Gleichgültigkeit, um sie in mich hineinzubefördern, damit diese drei Worte aus einem Mund kommen würden, der Bedeutungslosigkeit vortäuschen konnte, Alltäglichkeit: Meine Augen grasten Häuserwände ab, ergriffen die Zerstreuung, die aus Glasscheiben flog, und führten sie der Gleichgültigkeit zu, meine Augen visitierten jeden Baum, vielleicht, dachte ich, können mir die Bäume etwas von ihrer Leichtigkeit geben, die ich brauchen würde, heute abend, bei uns zu Hause, beim Abendbrot, an Degens Tisch.“ (Laslinstraße, S. 127)
} 
Das Zitat bildet bereits auf der Histoire-Ebene ein Menge Mosaiksteinchen für Zuschreibungen an den Basistypus: die Thematisierung der Diskrepanz von Erzählweltrealität und Idealbild, die überbordende Reflexion über kalkuliertes Handeln, die (Selbst-)Zweifel, das Missverhältnis von Mut vs. innerer Zensur, die Elternproblematik, mangelnde Selbstwirksamkeit, die Neigung zu Empfindlichkeit und Schonung, das Schauen als Beruhigung, die Flanerie. Aber nur zusammengenommen mit der Discours-Perspektive, aus der eine Poetik der Langsamkeit und eine ausufernde Wiederholungsstruktur sichtbar werden, kann daraus interpretatorisch ein vollständiges Bild werden. ,Welche Selbstkonzepte dabei letztlich zur Disposition stehen', lässt sich kurz gefasst wie folgt darlegen: Genazino schreibt über das (post-)moderne Subjekt, das neurotisch, kaputt, fragil, zerrüttet, unrettbar oder anderswie geartet ,beschädigt' ist - obwohl er, auf diese Frage angesprochen, immer wieder betont, die ,Moderne-Frage' sei langweilig und hinlänglich beantwortet worden, lässt sich das nicht, wegdiskutieren'. Welchen Nutzen IM für ein solch gebeuteltes Selbst haben kann, wird nicht nur in einem eigenen Fokus aufgezeigt $(\Leftrightarrow I .4)$, sondern auch Unterkapitel für Unterkapitel mit den Analyseergebnissen eingelöst.

\section{SCHLUSSBETRACHTUNG}

Mit der Schrittfolge: (Figurenverhaltens-)Muster abduktiv erkennen, Muster induktiv clustern und kulturwissenschaftlich aufleiten, Muster mit adäquat ausgesuchtem Analysewerkzeug deduktiv-gliedernd eng am Text interpretieren, hat diese Arbeit in allen 28 Unterkapiteln für alle drei Anliegen und vier Fragestellungen forschungsrelevante Beiträge zum Diskurs des intentional-eindruckssteuernden Figurenverhaltens bei Wilhelm Genazino generiert. Allzumal ist die Fruchtbarkeit eines nicht Autor-zentrierten Vorgehens, das zudem ,moderat' methodenpluralistisch ausgerichtet ist und externe wie interne Analyseperspektiven berücksichtigt, auch für Genazino bewiesen worden.

Genazino arbeitet ,metapsychologisch'. Das heißt, dass er seine Texte im Sinne von Anz' ,Kategorie $\mathrm{IV}^{\prime}(\Rightarrow \mathrm{I} .3 .2)^{6}$ durch eigenes wissenschaftlich-psychologisches Wissen ,imprägniert' und damit zwar einerseits eine psychologisch-interne Analyseperspektive erzwingt, andererseits auch massiv erschwert. Denn darf etwa der psychoanalytische Interpret bei Herrmann Hesse hoffen, mit seiner ,wissenschaftlichen Psychologie‘ vom Autor nicht notwendigerweise beabsichtigte Zusammenhänge analytisch ,aufzudecken', sind diese und weitere Theorien von Genazino ab ovo bereits vorbedacht worden, um letztlich wortreich durch die Figuren selbst verhandelt zu werden. Diesbezüglich ist Richard Kämmerlings unumwunden zuzustimmen, dass sich Genazinos Prosa auch hinsichtlich der Psychologie treffender als „das Gegenteil von Literatur, nämlich Literaturinterpretation “ werten lasse. ${ }^{7}$

$6 \quad$ Vgl. Anz: Literatur und Psychologie, S. 223.

7 Kämmerlings: Genazino gilt als ein bedeutender Autor. Warum nur? 
Man muss demgemäß schon ,tief graben` - nicht in der Autorenpsyche, sondern der sozial- und persönlichkeitspsychologischen Forschungsschublade -, um bei Genazino proaktiv Neues zutage fördern zu können, was mittels des Impression-Management-Konzepts gelungen ist. Ausgehend von der ultimaten Begründung, dass Menschen und Figuren deshalb ihr immerzu im Entstehen befindliche Fremdbild steuern möchten, um eine der drei von Leary/Kowalski ausgegebenen Elemente der ,IM-Motivation“ zu erreichen: „Social and material outcomes“, „Self-esteem maintenance“, „Development of identity“ ( $\Rightarrow$ I.3.1), ${ }^{8}$ sind motivationale Anhaltspunkte gefunden worden, die für Genazinos Romanfiguren nicht nur jeweils bestätigt werden, sondern um die ,Defragmentierungsfunktion' $(\Rightarrow I$.4) ergänzt werden konnten. So gelesen ermöglicht es das Konzept ,IM` auch auf den ersten Blick singuläre bzw. zum üblichen Basistypus in Widerspruch stehende Einzelhandlungen in eine übergeordnete Motivationsanalyse einzupflegen (s.o.). Würde man etwa das Devianzverhalten der Figuren intuitiv zunächst mit krimineller Energie, Rebellion, mangelnder Sozialkontrolle o. Ä. in Verbindung bringen, werden die Diebstähle unter Einnahme der eindruckssteuernden Warte bei Genazino lesbar als ,Selbstsicherungsmechanismen durch Risikoverhalten': „Er klaute nur, wenn er sich selbst als nicht mehr richtig vorhanden fühlte“ (Sorgen, S. 164). In Genazinos Texte sind nämlich nicht nur psychologische Theorien, sondern auch ein wahres Potpourri psychischer Probleme eingeschrieben (vgl. Bartl 2011, S. $71 \mathrm{f}$;; $\Rightarrow$ I.3.2): Von Zwangshandlungen und Fixierungen (vgl. Falsche Jahre, S. 501) über mangelnde Sozialkompetenzen, Panikanfälle, Verfolgungswahn (vgl. Fremde Kämpfe, S. 211) und Klaustrophobie (vgl. Falsche Jahre, S. 503 f.) hin zu Depersonalisation, Dissoziation, Depression (vgl. Ausschweifung, S. 244; vgl. Liebesblödigkeit, S. 70) und bipolaren Persönlichkeitsstörungen inklusive manischer Phasen (vgl. Fremde Kämpfe, S. 201-204) tummeln sich Beschwerden. Abschaffel spricht dabei etwa einer depressiven Verstimmung die Drastik ab, da diese „für ihn im Rudel seiner Leiden nur im dritten Verfolgerdrittel eine Rolle spielte“ (Falsche Jahre, S. 510). Psychische Probleme und Krankheiten bilden also einen festinstallierten Regler auf Genazinos Mischpult ( $\Rightarrow$ I.2.2).

Jeder Roman greift auf die übergeordneten Melodien, Motive und Töne zurück, aber jeder setzt sie aufs Neue zusammen, blickt zurück, greift aus, moduliert, fügt Neues hinzu und verschiebt die einzelnen Fader: So lässt sich die innere Zensur bspw. entweder ,mischen' mit Rücksichtnahme bzw. Empathie - vgl. Ausschweifung, S. 109 f.; vgl. Einfalt, S. 35: „Zeitweilig verhielt ich mich besonders brav, weil ich wollte, daß sie wenigstens mich von morgens bis abends vollständig verstehen könnten" - oder mit der schieren Furcht vor gesellschaftlicher Ächtung oder übertriebener Aufmerksamkeit (vgl. Abschaffel, S. 9). Genauso sieht es mit anderen Elementen und Motiven aus, die immer das Gerüst für die handlungsarme - „es passierte nichts, nur meine Ge- 
danken bewegten sich" (Laslinstraße, S. 11) ${ }^{9}$ - Handlung10 geben, im Kleinen aber rekombiniert werden und so jedes Mal neu den Reiz hervorbringen, trotz des ,allzu Geläufigen' die Neukombination zu bewundern. Zwei Romane in Folge ,entsexualisieren` Genazinos CEuvre: Der Fleck, die Jacke, die Zimmer, der Schmerz sowie Die Liebe zur Einfalt, fallen aber aus dem Genazino'schen Kosmos deshalb nicht heraus, weil sie viele andere familienähnliche Verwandtschaftsbeziehungen und ,Bekanntheiten' mitbringen, und so das Vorliegen eines ,echten Genazino' testieren. Das allerdings ist nur für den Mittelkreis des hier vorgeschlagenen Figurenmodells gültig: Sowohl die Romanspezifik als auch der harte Kern sind im direkten Vergleich dünn besiedelt. Nur die ,Weichzeichnung', die entsteht, wenn man viele Genazinofiguren übereinander projiziert, ist für eine Untersuchung, die nach Musterhaftigkeiten fragt, relevant. Wie bei Galtons ,Kollektivfoto‘ $(\Leftrightarrow$ I.2.5) die herausragenden Eigenschaften abgeschliffen werden, so ist auch der hier gezeichnete Basistypus eine Art ,langweilig' gemachte Minimaldefinition der Vergleichbarkeiten. Setzt man hinzu, dass Genazinos Anti-Helden generell in jedweder Hinsicht als ,mittelmäßig' gelten, sollen ausgehend von diesbezüglichen Fragen - Warum eigentlich? Ist Genazino selbst so? Oder sind vielleicht die meisten so? - einige abschließende Überlegungen angestellt werden.

Genazino ist spätestens mit der Abschaffel-Trilogie angetreten, um das Porträt des Angestellten neben das des Arbeiters in die Literatur zu stellen. Denn der Angestellte läuft zu dieser Zeit dem Arbeiter den Rang des ,durchschnittlichen kleinen Mannes‘ ab. Diese Entscheidung zu einer ,Poetik der Mittelmäßigkeit' dauert fort, auch wenn einzelne Figuren hinsichtlich ihrer Kapitalstruktur ganz woanders in die Sinus-Milieus sortiert werden müssen ( $\Rightarrow$ II.1.5). Allerdings handelt es sich nicht um einen neu begonnenen literarischen Lebensfaden, sondern um eine Ahnenreihe der Literatur: Seit 1900 lässt sie sich verfolgen und findet mit Musils Mann ohne Eigenschaften (1930/1932) einen Höhepunkt: Wie der Basistypus Genazinos scheitert auch der Protagonist Musils

mehrfach an dem Versuch, „ein bedeutender Mann zu werden“, und nimmt „Urlaub von seinem Leben“. Er ist auf der Suche nach einem Grund zu leben, denn er bemerkt, dass ihm jede Ordnung in der technisierten Welt abhanden gekommen ist. Der rationalistische Geist und der Fortschrittsglaube der Moderne mit ihrem „Wirklichkeitssinn“ irritieren ihn, den Mann ohne Eigenschaften, für den diese Welt eine Welt der Eigenschaften ohne Mann, also ohne integrierendes Zentrum ist. Er entwirft einen „Möglichkeitssinn“, mit dem er die Wirklichkeit als Erfindung betrachtet. ${ }^{11}$

$9 \quad$ Vgl. für einen ähnlichen Befund auch Egyptien: Einführung in die deutschsprachige Literatur seit 1945, S. 54.

10 Ein schlagendes Gegenbeispiel für Spannung, Tempo, Überraschungen etc. gibt Fremde Kämpfe ab. 11 Christian Dawidowski: [Musil, Robert. Der Mann ohne Eigenschaften (letzte Aktualisierung in 2012)]. In: Kindlers Literatur Lexikon online. Online: <http://kllaktuell.cedion.de/nxt/gateway.dll/kll/m/k0490500.xml/k0490500_050.xml?f=templates\$fn=index.ht $\mathrm{m} \$ \mathrm{q}=\% 5$ Brank,500\%3A\%5Bdomain\%3A\%5Band\%3A\%5Bfield,body\%3Amann\%20ohne\%20eige nschaf-

ten $\% 5 \mathrm{D} \% 5 \mathrm{D} \% 5 \mathrm{D} \% 5 \mathrm{Bsum} \% 3 \mathrm{~A} \% 5 \mathrm{Bfield}$,lemmatitle $\% 3 \mathrm{Amann} \% 20$ ohne $\% 20$ eigenschaften $\% 5 \mathrm{D} \% 5$ Bfield,body\%3Amann\%20ohne\%20eigenschaften\%5D\%5D\%5D \$x=server\$3.0\#LPHit1>. 
Diese frappiernden Bezüge zu Genazinos Romanfiguren - Wahrheitsversionen, Selbstkrise, Fortschrittsverweigerung, Vermeidungshaltung, Scheitern, Mittelmaß - lassen sich über einen Umweg in die Gegenwart übertragen. Alexandra Pontzen titelt 2009: „Banalität und Empfindsamkeit. Wilhelm Genazinos Poetik alltäglicher Gefühle“, und beantwortet die Frage nach der Mittelmäßigkeit damit, dass es bei Genazino die „kleinen unspektakulären Regungen“ und das „klein-alltägliche Gefühl“ seien, die letztlich einerseits die „Kleinheit des Subjekts“ per se, andererseits „die Vergeblichkeit einer [...] Sehnsucht nach Kontrolle über die Unwägbarkeiten des Lebens“ ausdrücken: ${ }^{12}$ „So wird es [...] möglich, auf die Zurschaustellung emphatischer Gefühle von Liebe als Passion oder Arbeit als Selbstverwirklichung zu verzichten und sich in dieser Zurückhaltung als ästhetisch auf der Höhe eines Understatement-Kodex zu erweisen." ${ }^{13}$ Allerdings herrsche bei Genazino keinesfalls „Coolness und Gefühlskälte“, sondern ein „Paradigma von Empfindsamkeit“ vor: „Die Versprechungen von Empfindsamkeit [...] verkörpern ein psychoästhetisches Existenzmodell, dessen Fluchtpunkt in einer ,anderen Zeit' liegt."14

Was Pontzen positiv konnotiert, gerät bei Richard Kämmerlings zum Generalvorwurf. Unter der Schlagzeile: „Genazino gilt als bedeutender Autor. Warum nur?“, knüpft er an die Vorstellung einer ,,anderen Zeit““ an: „Genazinos Bücher breiten eine als Gegenwart kostümierte Retro-Welt aus, über die sich der Leser gemeinsam mit dem Autor erheben kann. Guten Gewissens, versteht sich - die Spießer sind immer die anderen. “15 Das ist aufzuschlüsseln: Wer erhebt sich über wen? Der Autor mitsamt dem Leser über die gesamte erzählte Welt inklusive ihrer ,Bewohner'? Eine diesbezügliche Fraternisierung übersähe den engen identifikatorischen Bund zwischen Leser und Figuren, sind letztere doch eindeutig als Sympathieträger konzipiert; obwohl diese Lesart der ,Überhebung' deshalb funktionieren könnte, weil Genazino Anti-Helden in die literarischen Möglichkeitsräume schickt, die selbst aufgrund ihrer ,Spießigkeit', Geschlechterrollenbilder etc. nicht dazu angetan sind, sich über die „längst verblichene Wirtschaftswunder-BRD von Anno Opa“16 zu erheben. Allerdings führt Kämmerlings wiederholt Genazino mit seinen eigenen Figuren eng und begreift diese zumindest teilweise als Sprachrohr des Autors, was spätestens am Anwurf: „Genazino hat keinen Stoff und keine Story, sondern nur den eigenen, stereotyp angeekelten Blick auf die Konsum- und Arbeitswelt, den er seinen Kopfgeburten unterschiebt" ${ }^{\prime 17}$ ablesbar ist. Die Lesart, nach der sich Autor, Figur und Leser gemeinsam über die geschilderte „Retro-Welt“ erheben, ist doppelt inkonsequent und mithin zu verwerfen.

Sowohl Pontzens als auch Kämmerlings Sicht mangelt es schließlich an Sensibilität dafür, dass obwohl viele der figürlichen Verhaltensmuster, Motivationslagen und IM-Strategien quasi ,all-

\begin{tabular}{ll}
\hline 12 & Pontzen: Banalität und Empfindsamkeit, S. 240 f. \\
13 & Pontzen: Banalität und Empfindsamkeit, S. 244. \\
14 & Pontzen: Banalität und Empfindsamkeit, S. 244. \\
15 & Kämmerlings: Genazino gilt als bedeutender Autor. Warum nur? \\
16 & Kämmerlings: Genazino gilt als bedeutender Autor. Warum nur? \\
17 & Kämmerlings: Genazino gilt als bedeutender Autor. Warum nur?
\end{tabular} 
gemeinmenschlich' sind - eine ganze Bandbreite an problematischen Figuren-Merkmalen akkumuliert wird, die keineswegs den Anspruch auf mittelmäßige ,banale Alltäglichkeit' (Pontzen) oder durchschnittliche ,Sprachrohre' für „Weltekelpakete"18 erheben können: Homophobie, Misogynie, Ausländerfeindlichkeit, teils massive psychische Probleme und neuerdings Demenz sind basistypische Makel, Marotten und Merkwürdigkeiten, die eher „unverständlich“ als „einleuchtend" genannt zu werden verdienen.

,Psychogramme' literarischer Figuren zu erstellen, war, ist und bleibt riskant und ist nur unter der Voraussetzung einer klaren diesbezüglichen Positionierung und eines definierten methodologischen Rahmens gewinnbringend. Denn Figuren bleiben aus Papier gemacht - letztlich kann man gleichsam nur deren ,verstreute Antworten' ex post mit ,Frage(böge)n` zudecken. Allerdings haben auch intern perspektiviert sehr wohl bestimmte Verfasstheiten, Eigenarten und Handlungsstrukturen beschrieben werden können, die (fast) allen Romanfiguren Genazinos eignen und einen ersten Schlüssel zum Verständnis dieser liefern. Zumal durch die ,Frontenglättende' Einbeziehung kognitionswissenschaftlicher Positionen, konnte eine Verständigung zwischen dem externen und internen ,Lager' erreicht werden. Da diese Studie den Ansatz über die Wittgenstein'schen Familienähnlichkeiten genommen hat, bleibt sie ,nur' eine - in Analogie zu den Verstehensanfängen - figurenbezogene ,Verstehensfortsetzung', die genaugenommen an den aktuell vorliegenden 21 Texten sowie allen hoffentlich noch folgenden Romanen Genazinos unter Berücksichtigung von deren individuellen Spezifika verifiziert bzw. weiterentwickelt werden muss. Aber immerhin: Das Feld ist bereitet.

Letztlich bleiben (glücklicherweise) nicht nur literarische Menschendarstellungen und echte Subjekte aus Fleisch und Blut per se, sondern auch speziell Genazinos Romanfiguren so vielschichtig und - es handelt sich, wenn man den Begriff in seinen latenten wie manifesten, instrumentalen musiktheoretischen Bedeutungen zumal für Johann Sebastians Solowerke verwendet, nicht um einen Bildbruch -: mehrstimmig „wie eine Cello-Sonate von Bach: Nirgendwo befestigt, vorüberschwebend, angeknittert, dunkel, im Kern unverständlich, obwohl jedem Menschen sofort einleuchtend" (Glück, S. 41).19

18 Kämmerlings: Genazino gilt als bedeutender Autor. Warum nur?

19 Vgl. in diesem Zusammenhang Genazinos Bewunderung für die Bach-Kantate „Ich habe genug“ (BMV 82[a]; vgl. Wolfgang Prosinger/Wilhelm Genazino: Schriftsteller Wilhelm Genazino. „Früher war ich ein Nachttiger". Interview. In: Tagesspiegel vom 20. Januar 2013. Online: <http://www.tagesspiegel.de/kultur/schriftsteller-wilhelm-genazino-frueher-war-ich-einnachttiger/7654686.html >), die zumindest den neueren und neuesten Genazino-Figuren den Text leihen könnte, sowie diejenige für die Bach-Kantate „Wo soll ich fliehen hin?“ (BWV 5) im Rahmen des Romans Kein Geld, keine Uhr, keine Mütze (vgl. Kein Geld, S. 93). 

Teil IV: Literaturverzeichnis 

Adler, Alfred: Temperamente und innere Sekretion. In: ders.: Menschenkenntnis. 1927. Online: <http://www.textlog.de/adler-psychologie-temperamente-innere-sekretion.html>.

Amann, Wilhelm: „Doppelleben“. Begründung von Autorschaft in Wilhelm Genazinos „Eine Frau, eine Wohnung, ein Roman“. In: Arnold (Hg.): Wilhelm Genazino (2004), S. 87-97.

Amthor, Wiebke/Hille, Almut/Scharnowski, Susanne (Hg.): Wilde Lektüren. Literatur und Leidenschaft. Festschrift für Hans Richard Brittnacher zum 60. Geburtstag. Bielefeld 2012.

Anz, Thomas: Literatur und Lust. Glück und Unglück beim Lesen. München 1998.

Anz, Thomas in Zusammenarbeit mit Christine Kanz (Hg.): Psychoanalyse in der modernen Literatur. Kooperation und Konkurrenz. Würzburg 1999.

Anz, Thomas: Literatur und Psychologie. Eine Typologie möglicher Beziehungen. In: Wiesinger (Hg.): Akten des X. Internationalen Germanistenkongresses (2003), S. 221-227.

Anz, Thomas: Emotional Turn? Beobachtungen zur Gefühlsforschung. In: literaturkritik.de vom 12. Dezember 2006. Online: <http://literaturkritik.de/public/rezension.php?rez_id=10267>.

Anz, Thomas: Kulturtechniken der Emotionalisierung. Beobachtungen, Reflexionen und Vorschläge zur literaturwissenschaftlichen Gefühlsforschung. In: Karl Eibl/Katja Mellmann/Rüdiger Zymner (Hg.): Im Rücken der Kulturen. Paderborn 2007, S. 207-239.

Anz, Thomas: Gefühl als Text? Möglichkeiten und Grenzen literaturwissenschaftlicher Emotionsforschung. Positionen der Neueren deutschen Literaturwissenschat. In: Langlotz/Lehnert/Schul/Weßel (Hg.): SprachGefühl (2014), S. 253-264.

Arnold, Heinz L.: Der Schuhtester. In: Schweizer Monatshefte 6 (2002), S. 46.

Arnold, Heinz L. (Hg.): Wilhelm Genazino. TEXT+KRITIK Heft 162. München 2004.

Aronson, Elliot/Wilson, Timothy D./Akert, Robin M.: Sozialpsychologie. 6., akt. Aufl. Mit über 540 Abb. München 2008.

Assmann, Aleida: Formen des Schweigens. In: dies./Jan Assmann (Hg.): Schweigen. Paderborn 2013, S. 51-68.

Augé, Marc: Orte und Nicht-Orte. Vorüberlegungen zu einer Ethnologie der Einsamkeit. Frankfurt am Main 1994.

Austin, John L.: How to Do Things with Words. Cambridge (MA) 1962.

[Autoritäre Persönlichkeit]. In: Wikipedia. Die freie Enzyklopädie. Online: <https://de.wikipedia.org/wiki/Autorit\%C3\%A4re_Pers\%C3\%B6nlichkeit>.

[Axiome Watzlawick]: Die Axiome von Paul Watzlawick. Online: <http://www.paulwatzlawick.de/axiome.html>.

Baasner, Rainer: Literaturpsychologie/Psychoanalytische Literaturwissenschaft. In: ders./Maria Zens: Methoden und Modelle der Literaturwissenschaft. Eine Einführung. 3., überarb. u. erw. Aufl. Berlin 2005, S. 147-158.

Bachorz, Stephanie: Zur Analyse der Figuren. In: Wenzel (Hg.): Einführung in die Erzähltextanalyse (2004), S. 51-67.

Ball, Melanie: Das Phänomen Scham bei Wilhelm Genazino. Magisterarbeit Universität Münster 2008. Online: <https://d-nb.info/1049611209/34>.

Bartels, Gerrit: Das Glück des Sisyphos. Vom beobachtenden Subjekt zum Objekt der Beobachtung. Eine Begegnung mit dem Schriftsteller Wilhelm Genazino. In: die tageszeitung vom 23./24. Oktober 2004.

Bartl, Andrea: „The kindness of strangers“. Das Motiv der Fremdheit in ausgewählten Romanen Wilhelm Genazinos. In: dies./Marx (Hg.): Verstehensanfänge (2011), S. 69-84.

Bartl, Andrea/Marx, Friedhelm: Wiederholte „Verstehensanfänge“. Das literarische Werk Wilhelm Genazinos. In: dies./ders. (Hg.): Verstehensanfänge (2011), S. 7-20.

Bartl, Andrea/Marx, Friedhelm (Hg.): Verstehensanfänge. Das literarische Werk Wilhelm Genazinos. Göttingen 2011.

Baßler, Moritz: Realismus - Serialität - Fantastik. Eine Standortbestimmung gegenwärtiger Epik. In: Horstkotte/Herrmann (Hg.): Poetiken der Gegenwart (2013), S. 31-46.

Bauer, Matthias: Romantheorie. Stuttgart/Weimar 1997.

Bauer, Matthias: Romantheorie und Erzählforschung. Eine Einführung. 2., akt. u. erw. Aufl. Stuttgart/Weimar 2005.

Bauer, Michael: Sehen, ohne gesehen zu werden. In: Süddeutsche Zeitung vom 08./09. April 1989. 
Beck, Ulrich: Risikogesellschaft. Auf dem Weg in eine andere Moderne. Berlin 1986/2016.

Becker, Howard S.: Außenseiter. Zur Soziologie abweichenden Verhaltens. 2. Aufl. Berlin $1963 / 2014$.

[Bei Regen im Saal]: Rezensionsübersicht auf perlentaucher.de - Das Kulturmagazin. Online: <https://www.perlentaucher.de/buch/wilhelm-genazino/bei-regen-im-saal.html>.

Bein, Thomas: Liebe und Erotik im Mittelalter. Darmstadt 2003.

Benthien, Claudia: Tribunal der Blicke. Kulturtheorien von Scham und Schuld und die Tragödie um 1800. Köln 2011.

Bergler, Reinhold/Hoff, Tanja unter Mitarbeit von Barbara Schneider, Dietmar Haase, Meike Wemhoff: Psychologie des ersten Eindrucks. Die Sprache der Haare. Eine empirische Analyse zur Psychologie des Alltagsverhaltens in den baltischen Staaten, Deutschland, Rumänien, Russland, der Türkei und Ukraine. Köln 2001.

Beyerle, Stefan (Hg.): Schuld. Interdisziplinäre Versuche ein Phänomen zu verstehen. Leipzig 2009.

Bielefeld, Claus-Ulrich: Der hessische Woody Allen im Finanzamt II. In: Welt.de vom 30. Juli 2014. Online: <https://www.welt.de/kultur/literarischewelt/article130705612/Derhessische-Woody-Allen-im-Finanzamt-II.html>.

Bischoff, Dörte: Gender-Theorien: Neuere deutsche Literatur. In: Claudia Benthien/Hans Rudolf Velten (Hg.): Germanistik als Kulturwissenschaft. Eine Einführung in neue Theoriekonzepte. Reinbek bei Hamburg 2002, S. 298-322.

Bischoff, Matthias: Der Lauf des Schuhtesters. Wilhelm Genazino im Pariser Hoftheater zu Wiesbaden. In: Frankfurter Allgemeine Zeitung vom 24. April 2002.

Bode, Christoph: Der Roman. Eine Einführung. Tübingen/Basel 2005.

Böhmer, Otto A.: Die Süße des Nichtstuns. Wilhelm Genazino feiert wieder die Lebensuntüchtigkeit. In: Die Zeit vom 23. April 2009.

Böttiger, Helmut: Anwalt kleinster Dinge. Eine Laudatio auf den Erzähler Wilhelm Genazino, der in Berlin mit dem Fontane-Preis 2003 ausgezeichnet wurde. In: Die Welt vom 26. April 2003. Online: <https://www.welt.de/print-welt/article690748/Anwalt-kleinster-Dinge.html>.

Böttiger, Helmut: Wilhelm Genazino und die Verborgenheit der Verkäuferinnen. In: ders. (Hg.): Nach den Utopien. Eine Geschichte der deutschsprachigen Gegenwartsliteratur. Wien 2004, S. 55-67.

Böttiger, Helmut: Die Apokalypse trägt Stützstrümpfe. In: Die Zeit vom 24. Februar 2005.

Bourdieu, Pierre: Die feinen Unterschiede. Kritik der gesellschaftlichen Urteilskraft. 30. Aufl. Frankfurt am Main 2003.

Breuer, Horst: Historische Literaturpsychologie. Von Shakespeare bis Beckett. Tübingen 1989.

Brinker, Klaus/Sager, Sven F.: Linguistische Gesprächsanalyse. Eine Einführung. 4., durchges. u. erg. Aufl. Berlin 2006.

Brown, Penelope/Levinson, Stephen C.: Gesichtsbedrohende Akte. In: Herrmann/Krämer/Kuch (Hg.): Verletzende Worte (2007), S. 59-88.

Bruch, Katharina: Sympathische Verbrecher und Mörder. Analytische und empirische Untersuchungen zu emotionalen Wirkungen von ausgewählten Erzähltexten. Marburg 2015.

Brunner, Christian B.: Portfolio-Werbung als Technik des Impression Management. Eine Untersuchung zur gegenseitigen Stärkung von Dachmarke und Produktmarken in komplexen Markenarchitekturen. Dissertation Universität Gießen 2010.

Brunner, Philipp: Unsägliche Gefühle: Die Liebeserklärung im Spielfilm. In: Matthias Brütsch/Vinzenz Hediger/Ursula von Keitz/Alexandra Schneider/Margrit Tröhler (Hg.): Kinogefühle. Emotionalität und Film. Marburg 2005, S. 243-263.

Bucheli, Roman: Die Begierde des Rettens. Wilhelm Genazinos Poetik des genauen Blicks. In: Arnold (Hg.): Wilhelm Genazino (2004), S. 46-54.

Bucheli, Roman: Partisanen des stillen Protests. In: Neue Zürcher Zeitung vom 29. Juli 2014.

Bude, Heinz 2012: Ein Mann verschwindet. Literarische und soziologische Evidenz an einem Fall sozialer Exklusion in Wilhelm Genazinos Roman Das Glück in glücksfernen Zeiten. In: Amthor/Hille/Scharnowski (Hg.): Wilde Lektüren (2012), S. 181-192.

Bühler, Kathleen (Hg.): Ego documents. Das Autobiographische in der Gegenwartskunst / The authobiographical in contemporary art. Anlässlich der Ausstellung Ego Documents. Das Au- 
tobiografische in der Gegenwartskunst, Kunstmuseum Bern, 14. November 2008-15. Februar 2009. Heidelberg 2008.

Bunia, Remigius/Dembeck, Till/Stanitzek, Georg: Elemente einer Literatur- und Kulturgeschichte des Philisters. Einleitung. In: dies. (Hg.): Philister. Problemgeschichte einer Sozialfigur der neueren deutschen Literatur. Berlin 2011, S. 13-51.

Butler, Judith: Das Unbehagen der Geschlechter. Aus dem Amerikanischen von Katharina Menke. Frankfurt am Main 1991.

Charms, Daniil: Das blaue Heft Nr. 10. In: ders.: Fälle. Szenen, Gedichte, Prosa, hg. u. übers. von Peter Urban. Zürich 1988, S. 207.

Culpeper, Jonathan: Language and characterisation. People in plays and other texts. Harlow 2001.

Currie, Mark: Postmodern Narrative Theory. 2. Aufl. Oxford 2010.

Daemmrich, Horst S./Daemmrich, Ingrid G.: Themen und Motive in der Literatur. Ein Handbuch. 2., überarb. u. erw. Aufl. Tübingen 1995.

Dawidowski, Christian: [Musil, Robert. Der Mann ohne Eigenschaften (letzte Aktualisierung in 2012)]. In: Kindlers Literatur Lexikon online. Online: <http://kllaktu-

ell.cedion.de/nxt/gateway.dll/kll/m/k0490500.xml/k0490500_050.xml?f=templates\$fn=ind ex.htm $\$ \mathrm{q}=\% 5$ Brank,500\%3A\%5Bdomain\%3A\%5Band\%3A\%5Bfield,body\%3Amann\%20oh ne\%20eigenschaften\%5D\%5D\%5D\%5Bsum\%3A\%5Bfield,lemmatitle\%3Amann $\% 20$ ohne\% 20eigensch

af-

ten\%5D\%5Bfield,body\%3Amann\%20ohne\%20eigenschaften\%5D\%5D\%5D\$x=server\$3.0\# LPHit1>.

Delius, Friedrich C.: Der Held und sein Wetter. Ein Kunstmittel und sein ideologischer Gebrauch im Roman des bürgerlichen Realismus. Dissertation T.U. Berlin 1970.

[Depersonalisation]. In: Wikipedia. Die freie Enzyklopädie. Online: $<$ https://de.wikipedia.org/wiki/Depersonalisation\#Diagnostische_Kriterien_nach_DSM5_.282013.29>.

Deschka-Hoeck, Katharina: Die Magie der Dinge: Wilhelm Genazinos erste Poetik-Vorlesung. In: Frankfurter Allgemeine Zeitung vom 12. Januar 2006.

[Die romantischen Jahre]. Rezensionsübersicht auf perlentaucher.de - Das Kulturmagazin. Online: <https://www.perlentaucher.de/buch/paul-ingendaay/die-romantischen-jahre.html>.

Diller, Franziska: Einheit in der Differenz - Die innere Struktur des Erzähler-Ichs. Hamburg 2015.

[Dissoziation]. In: Wikipedia. Die freie Enzyklopädie. Online: $<$ https://de.wikipedia.org/wiki/Dissoziation_(Psychologie)>.

Docherty, Thomas: Reading (Absent) Character. Towards A Theory of Characterization in Fiction. Oxford 1983.

Ebert, Helmut/Piwinger, Manfred: Impression Management: Die Notwendigkeit der Selbstdarstellung. In: Manfred Piwinger/Ansgar Zerfaß (Hg.): Handbuch Unternehmenskommunikation. Wiesbaden 2007, S. 205-225.

Ebrecht-Laermann, Angelika: Lügen als Passion. Über einige Möglichkeiten, die Wahrheit zu verwirren. In: Amthor/Hille/Scharnowski (Hg.): Wilde Lektüren (2012), S. 65-81.

Ecker, Hans-Peter: Schiffbruch mit Zuschauer II: „Fremdschämen“ bei Wilhelm Genazino. In: Bartl/Marx (Hg.): Verstehensanfänge (2011), S. 115-129.

Eckes, Thomas: Geschlechterstereotype. Von Rollen, Identitäten und Vorurteilen. In: Ruth Becker/Beate Kortendiek (Hg.): Handbuch Frauen- und Geschlechterforschung. Theorie, Methoden, Empirie. 3. Aufl. Wiesbaden 2010, S. 178-189.

Eder, Jens: Die Figur im Film. Grundlagen der Figurenanalyse. Marburg 2008.

Eder, Jens: Figuren in Film, Fernsehen, Literatur und anderen Medien. Eine interdisziplinäre Arbeitsbibliographie. In: Medienwissenschaft / Hamburg: Berichte und Papiere 90 (2008/2010): Figuren im Film und in anderen Medien. Online: <https://publikationen.ub.uni-frankfurt.de/files/13799/Medienwissenschaft_90.08.pdf>. 
Eder, Jens/Jannidis, Fotis/Schneider, Ralf: Characters in Fictional Worlds. An Introduction. In: dies. (Hg.): Characters in Fictional Worlds (2010), S. 3-64.

Eder, Jens/Jannidis, Fotis/Schneider, Ralf (Hg.): Characters in Fictional Worlds. Understanding Imaginary Beings in Literature, Film, and Other Media. Berlin/New York 2010.

Egyptien, Jürgen: Einführung in die deutschsprachige Literatur seit 1945. Darmstadt 2006.

Eickenrodt, Sabine: Ein Luftschiffer des Geistes. Eine Jubelrede auf Jean Paul, den größten Abschweifungsvirtuosen der deutschen Literatur - zum 250. Geburtstag des Dichters. Und ein Blick auf die Neuerscheinungen anlässlich des Jubiläums. In: Der Tagesspiegel vom 10. März 2013, S. 28. Online: <http://www.tagesspiegel.de/kultur/deutsche-literatur-ein-luftschifferdes-geistes/7903438-all.html>.

Eisler, Rudolf: [Liebe]. In: Wörterbuch der philosophischen Begriffe. Berlin 1904. Online: $<$ http://www.textlog.de/4356.html>.

Eke, Norbert O.: Epiphanische Augen-Blicke. Inszenierungen der Alltagswahrnehmung in der Prosa Wilhelm Genazinos und Angela Krauß'. In: Preusser/Visser (Hg.): Alltag als Genre (2009), S. 177-190.

Epple, Miriam: Soziale Kompetenz und Impression Management. Eine multimodale Validierung des Social Skills Inventory. Diplomarbeit Universität Bielefeld 2007.

Erhart, Walter/Herrmann, Britta: Der erforschte Mann? In: dies. (Hg.): Wann ist der Mann ein Mann? Zur Geschichte der Männlichkeit. Stuttgart 1997, S. 3-34.

Eysenck, Hans J.: The inequality of man. London 1973.

Eysenck, Hans J.: Biological dimensions of personality. In: Oliver P. John/Richard W. Robins/Lawrence A. Pervin (Hg.): Handbook of Personality. Theory and Research. New York 1990, S. 244-276.

[F-Skala]. In: Wikipedia. Die freie Enzyklopädie. Online: <https://de.wikipedia.org/wiki/FSkala_(Autorit\%C3\%A4re_Pers\%C3\%B6nlichkeit)>.

Fansa, Jonas: Unterwegs im Monolog. Poetologische Konzeptionen in der Prosa Wilhelm Genazinos. Würzburg 2008.

Fessmann, Meike: Vom stillen Zauber des Alltäglichen. In: Financial Times Deutschland vom 05. Oktober 2001.

Fink, Adolf: Der Name als Schreib- und Verstehensprogramm. Onomastische Beobachtungen zu Wilhelm Genazinos Abschaffel-Trilogie. In: Giesen (Hg.): Wilhelm Genazino (2006), S. 28-36.

Fischer, Alexander: Wider das System. Der gesellschaftliche Aussteiger in Genazinos Ein Regenschirm für diesen Tag und literarische Verwandte bei Kleist und Kafka. Bamberg 2012.

Fischer, Lorenz/Wiswede, Günter: Grundlagen der Sozialpsychologie. 3. Aufl. München 2009.

Fischer, Melanie: Ding-Diskurs - die Darstellung der Dingwelt bei Wilhelm Genazino, beispielhaft an „Ein Regenschirm für diesen Tag“ und „Eine Frau, eine Wohnung, ein Roman“. Magisterarbeit University of Waterloo 2004. Online: <https://uwspace. uwaterloo.ca/bitstream/handle/10012/752/m4fische2004.pdf?sequence=1\&isAllowed=y>.

Fischer, Melanie: „Schläft ein Lied in allen Dingen“ - Wilhelm Genazinos Prosa im Kontext des literarischen Ding-Diskurses. In: Giesen (Hg.): Wilhelm Genazino (2006), S. 9-18.

Fludernik, Monika: Unreliability vs. Discordance. Kritische Betrachtungen zum literaturwissenschaftlichen Konzept der erzählerischen Unzuverlässigkeit. In: Fabienne Liptay/Yvonne Wolf (Hg.): Was stimmt denn jetzt? Unzuverlässiges Erzählen in Literatur und Film. München 2005, S. 39-59.

Fludernik, Monika: Erzähltheorie. Eine Einführung. 2., durchges. Aufl. Darmstadt 2008.

[Forum ElitePartner.de]. Online: <https://www.elitepartner.de/forum/frage/wie-wird-man-nbei-frauen-interessant.15030/>.

Frank, Svenja: Melancholy in Wilhelm Genazino's Novels and Its Construction as Other. In: Mary Cosgrove/Anna Richards (Hg.): Edinburgh German Yearbook 6: Sadness and Melancholy in German-Language Literature and Culture. Rochester (NY) 2012, S. 151-172.

Franzetti, Dante A.: Die große Kunst des Understatements. In: Der Standard vom 12. Februar 2005.

Frenzel, Elisabeth: Motive der Weltliteratur. Ein Lexikon dichtungsgeschichtlicher Längsschnitte. 5., überarb. u. erg. Aufl. Stuttgart 1999. 
Friedman, Howard S./Schustack, Miriam W.: Persönlichkeitspsychologie und Differentielle Psychologie ergänzt um ein Kapitel zur Intelligenz von Heiner Rindermann. 2., akt. Aufl. München 2004.

Früchtl, Josef/Zimmermann, Jörg: Ästhetik der Inszenierung. Dimensionen eines gesellschaftlichen, individuellen und kulturellen Phänomens. In: dies. (Hg.): Ästhetik der Inszenierung. Dimensionen eines künstlerischen, kulturellen und gesellschaftlichen Phänomens. Frankfurt am Main 2001, S. 9-47.

Fuchs, Anne: Gendered Heimat discourse and the poetics of the ,gedehnter Blick' in Genazino's „Mittelmäßiges Heimweh“. In: German Life and Letters 64 (2011), S. 145-155.

Fuchs, Anne: Poetiken der Entschleunigung in Prosatexten Wilhelm Genazinos, Julia Schochs und Judith Zanders. In: Horstkotte/Herrmann (Hg.): Poetiken der Gegenwart (2013), S. 213-227.

Fues, Wolfram M.: Erinnerung, Entinnerung. Fiktionalität und Hyperfiktionalität. In: Peter U. Hohendahl/Rüdiger Steinlein (Hg.): Kulturwissenschaften - Cultural Studies. Berlin 2001, S. 263-271.

Fuest, Leonhard: Poetik des Nicht(s)tuns. Verweigerungsstrategien in der Literatur seit 1800. München 2008.

Fülleborn, Ulrich/Engel, Manfred (Hg.): Das neuzeitliche Ich in der Literatur des 18. und 20. Jahrhunderts. Zur Dialektik der Moderne - Ein internationales Symposion. München 1988.

Geisenhanslüke, Achim: Einführung in die Literaturtheorie. Von der Hermeneutik zur Medienwissenschaft. 4. Aufl. Darmstadt 2007.

Genazino, Wilhelm: ${ }^{1}$ Gott ja, die Angestellten! In: Faszination Psychologie. Glanzlichter aus drei Jahrzenten, hg. von der Redaktion Psychologie Heute. Weinheim/Basel 1981/2004, S. 70 f.

Genazino, Wilhelm: Aus dem Tagebuch der Verborgenheit. In: Arnold (Hg.): Wilhelm Genazino (2004), S. 3-10.

Genazino, Wilhelm: Der gedehnte Blick. In: ders.: Der gedehnte Blick. München/Wien 2004, S. 39-61.

Genazino, Wilhelm: Der Untrost und die Untröstlichkeit der Literatur. Dankesrede anlässlich der Verleihung des Georg-Büchner-Preises 2004.2 Online: <https://www.deutscheakademie.de/de/auszeichnungen/georg-buechner-preis/wilhelmgenazino/dankrede>.

Genazino, Wilhelm: Batterien des Poetischen. Erste Vorlesung. In: ders.: Die Belebung der toten Winkel. Frankfurter Poetikvorlesungen. München/Wien 2006, S. 5-23.

Genazino, Wilhelm: Metaphysische Westentaschen. Zweite Vorlesung. In: ders.: Die Belebung der toten Winkel. Frankfurter Poetikvorlesungen. München/Wien 2006, S. 25-43.

Genazino, Wilhelm: Von der Spielbarkeit der Angst. Vierte Vorlesung. In: ders.: Die Belebung der toten Winkel. Frankfurter Poetikvorlesungen. München/Wien: 2006, S. 65-86.

Genazino, Wilhelm/Kölsch, Jochen: Wilhelm Genazino im Gespräch mit Jochen Kölsch im Rahmen der Sendung alpha-forum vom 22. Oktober 2007. Online: $<$ https://www.br.de/fernsehen/ard-alpha/sendungen/alpha-forum/wilhelm-genazinogespraech100.pdf>.

Genazino, Wilhelm: Der Roman als Delirium. In: Bartl/Marx (Hg.): Verstehensanfänge (2011), S. 21-31.

Genazino, Wilhelm: Melancholische Renitenz. Bamberger Vorlesungen I. In: ders.: Idyllen in der Halbnatur. München 2009/2012, S. 31-44.

Genazino, Wilhelm: Ein Auftrittstreppchen fürs Ich. In: ders.: Idyllen in der Halbnatur. München 2009/2012, S. 185-189.

Gerrig, Richard J./Zimbardo, Philip G.: Psychologie. 18., aktual. Aufl. Aus dem Amerikanischen von Ralf Graf, Dagmar Mallett, Markus Nagler und Brigitte Ricker. Deutsche Bearbeitung von Ralf Graf. Mit über 430 Abb. München 2008.

1 Die verwendete Primärliteratur Genazinos, sprich: seine 21 Romane, wird separat inklusive Siglenangabe und der Verwendung der jeweiligen Ausgabe im Rahmen der Einzelfigurenliste im Anhang geführt $(\Rightarrow$ V.1). Ein Romanregister findet sich ebenfalls dort $(\Rightarrow$ V.4). 
Giesen, Winfried (Hg.): Wilhelm Genazino. Begleitheft zur Ausstellung 11. Januar-25. Februar 2006 mit Beiträgen von Adolf Fink, Melanie Fischer, Anja Hirsch, Susanne Mittag und Ulrich Rüdenauer sowie einer Erzählung von Wilhelm Genazino. Frankfurt am Main 2006.

Giesen, Winfried: Wilhelm Genazino - Sekundärliteratur. Neu zusammengestellt und aktual. v. dems. 2014.

Goeres, Ralf: [Familienähnlichkeit]. In: Online-Wörterbuch Philosophie: Das Philosophielexikon im Internet. Online: <http://www.philosophie-woerterbuch.de/onlinewoerter-

buch/?tx_gbwbphilosophie_main\%5Bentry\%5D=334\&tx_gbwbphilosophie_main\%5Baction \%5D=show\&tx_gbwbphilosophie_main\%5Bcontroller\%5D=Lexicon\&cHash=6323674fdb18 $1 \mathrm{fc} 888 \mathrm{f} 14 \mathrm{ce} 9118 \mathrm{c} 86 \mathrm{c} 4>$.

Goethals, Noortje: A dramaturgical perspective on Impression Management. The influence of audience characteristics. Masterarbeit Universität Maastricht 2008.

Goffman, Erving: Wir alle spielen Theater. Die Selbstdarstellung im Alltag. 9. Aufl. München 2011.

Graevenitz, Gerhart von: Das Ich am Rande. Zur Topik der Selbstdarstellung bei Dürer, Montaigne und Goethe. Konstanz 1989.

Graumann, Carl F./Wintermantel, Margret: Diskriminierende Sprechakte. Ein funktionaler Ansatz. In: Herrmann/Krämer/Kuch (Hg.): Verletzende Worte (2007), S. 147-177.

Grice, Herbert P.: Logic and Conversation. In: Peter Cole/Jerry L. Morgan (Hg.): Syntax and Semantics. Vol. 3: Speech Acts. New York/San Francisco/London 1975, S. 41-58.

Grimm, Gunter E./Schärf, Christian (Hg.): Schriftsteller-Inszenierungen. Bielefeld 2008.

Groeben, Norbert: Literaturpsychologie. Literaturwissenschaft zwischen Hermeneutik und Empirie. Stuttgart 1972.

Grubmüller, Klaus: Historische Semantik und Diskursgeschichte. zorn, nit und haz. In: Stephen C. Jaeger/Ingrid Kasten (Hg.): Codierungen von Emotionen/Emotions and Sensibilities in the Middle Ages. Berlin/New York 2003, S. 47-69.

Grundmann, Esther: Zur Konstruktion von Mikrowelten: Genazino und die Kunst des bedeutungsvollen Sehens. In: Psyche. Zeitschrift für Psychoanalyse und ihre Anwendungen 70 (2016), S. 337-350.

Haferland, Harald: Psychologie und Psychologisierung: Thesen zur Konstitution und Rezeption von Figuren. Mit einem Blick auf ihre historische Differenz. In: Florian Kragl/Christian Schneider (Hg.): Erzähllogiken in der Literatur des Mittelalters und der Frühen Neuzeit. Akten der Heidelberger Tagung vom 17. bis 19. Februar 2011. Heidelberg 2013, S. 91-117.

Hahn, Alois/Willems, Herbert: Zivilisation, Modernität, Theatralität: Identität und Identitätsdarstellung. In: Willems/Jurga (Hg.): Inszenierungsgesellschaft (1998), S. 193-213.

Hane, Reika: Gewalt des Schweigens. Verletzendes Nichtsprechen bei Thomas Bernhard, Kōbō Abe, Ingeborg Bachmann und Kanzaburō Ōe. Berlin/Boston 2014.

Hansen, Per K.: Karakterens rolle. Aspekter af en litterær karakterologi [Die Rolle des Charakters. Aspekte einer literarischen Charakterologie]. Holte 2000.

Hansen, Per K.: Figuren [Kap. IV.3.3]. In: Lahn/Meister: Einführung in die Erzähltextanalyse (2013), S. 232-247.

Hanuschek, Sven: „Das Sofa blieb und stank in abgeschwächter Form weiter“. Ekel und Erkennen im Werk Wilhelm Genazinos. In: Bartl/Marx (Hg.): Verstehensanfänge (2011), S. 131-147.

Heckhausen, Heinz/Gollwitzer, Peter M.: Thought Contents and Cognitive Functioning in Motivational versus Volitional States of Mind. In: Motivation and Emotion 11 (1987), S. 101-120.

Heinrich, Christian: Volkskrankheit Depression. In: ZEIT ONLINE vom 10. November 2009. Online: <http://www.zeit.de/zeit-wissen/2010/s1/Depression/komplettansicht>.

Henke, Silvia: „Fluktuierende Uneindeutigkeit“. Ironie, Witz und Komik bei und nach Wilhelm Genazino. In: Felix Christen/Thomas Forrer/Martin Stingelin/Hubert Thüring (Hg.): Der Witz der Philologie. Rhetorik - Poetik - Edition. Festschrift für Wolfram Groddeck zu 65. Geburtstag. Frankfurt am Main 2014, S. 70-80.

Henne, Helmut/Rehbock, Helmut: Einführung in die Gesprächsanalyse. 4., durchges. u. bibl. erg. Aufl. Berlin/New York 2001. 
Hennig, Hans M.: Zwischen den Stühlen. Poetisierung des Alltags. Wilhelm Genazinos Roman „Ein Regenschirm für diesen Tag“. In: Freitag vom 16. November 2001.

Herding, Klaus/Stumpfhaus, Bernhard (Hg.): Pathos, Affekt, Gefühl. Die Emotionen in den Künsten. Berlin/New York 2004.

Hermann, Iris: Elemente einer Sehphilosophie in Wilhelm Genazinos Essay Der gedehnte Blick. In: Bartl/Marx (Hg.): Verstehensanfänge (2011), S. 165-178.

Hermanns, Fritz: Sprachgeschichte als Mentalitätsgeschichte. Überlegungen zu Sinn und Form und Gegenstand einer historischen Semantik. In: Andreas Gardt/Klaus J. Mattheier/Oskar Reichmann (Hg.): Sprachgeschichte des Neuhochdeutschen. Gegenstände, Methoden, Theorien. Tübingen 1995, S. 69-101.

Herrmann, Leonhard: Andere Welten - fragliche Welten. Fantastisches Erzählen in der Gegenwartsliteratur. In: Horstkotte/ders. (Hg.): Poetiken der Gegenwart (2013), S. 47-65.

Herrmann, Steffen K./Kuch, Hannes: Verletzende Worte. Eine Einleitung. In: ders./Krämer/ders. (Hg.): Verletzende Worte (2007), S. 7-30.

Herrmann, Steffen K./Krämer, Sybille/Kuch, Hannes (Hg.): Verletzende Worte. Die Grammatik sprachlicher Missachtung. Bielefeld 2007.

Hiebel, Hans H.: Zur Kritik der Literaturpsychologie. In: John K. Noyes/Gunther Pakendorf/Wolfgang Pasche (Hg.): Kultur - Sprache - Macht. Festschrift für Peter Horn. Frankfurt am Main 2000, S. 41-67.

Hiebel, Hans H./Lange-Kirchheim, Astrid: Einleitung zu „Literatur und Psychologie“. In: Wiesinger (Hg.): Akten des X. Internationalen Germanistenkongresses (2003), S. 213-220.

Hillebrandt, Claudia: Das emotionale Wirkungspotenzial von Erzähltexten. Mit Fallstudien zu Kafka, Perutz und Werfel. Berlin 2011.

Hillgruber, Katrin: Beruf: Tagträumer. Genazino und Krechel im Literarischen Colloquium Berlin. In: Der Tagesspiegel vom 20. Februar 1999.

Hillgruber, Katrin: Das Quietschen des Kunstleders. Wilhelm Genazino erzählt von Geld- und Liebesproblemen eines freiberuflichen Schuhtesters. In: Literaturen 11 (2001), S. $79 \mathrm{f}$.

Hirsch, Anja: Zwischen Lust und Angst. Erzählen im Zeichen des Verschwindens. In: Arnold (Hg.): Wilhelm Genazino (2004), S. 70-78.

Hirsch, Anja: „Schwebeglück der Literatur“. Der Erzähler Wilhelm Genazino. Heidelberg 2006.

Hirsch, Anja: Geheimgeschichten. Die (Ent)deckung der Scham. In: Giesen (Hg.): Wilhelm Genazino (2006), S. 61-69.

Hirsch, Anja: Zwischen Krise und Katastrophe. Warteschleifen im Schwellenraum deutschsprachiger Gegenwartsliteratur. In: Achim Geisenhanslüke/Georg Mein (Hg.): Grenzräume der Schrift. Bielefeld 2008, S. 269-288.

Hirsch, Anja/Genazino, Wilhelm: Interview am 19. Januar 1998. In: Hirsch: „Schwebeglück der Literatur" (2006), S. 293-295.

Hirsch Anja/Genazino, Wilhelm: Interview am 09. Februar 1998. In: Hirsch: „Schwebeglück der Literatur" (2006), S. $280 \mathrm{f}$.

Hirsch, Anja/Genazino, Wilhelm: Die Lust an der komischen Empfindung - Interview am 3. Februar 2001. In: Giesen (Hg.): Wilhelm Genazino (2006), S. 19-27.

Hof, Renate: Die Entwicklung der Gender Studies. In: Hadumod Bußmann/dies. (Hg.): Genus. Zur Geschlechterdifferenz in den Kulturwissenschaften. Stuttgart 1995, S. 3-33.

Hoffmann, Christa: Die Bedeutung einer Romanfigur als unsichtbarer Begleiter einer psychoanalytischen Behandlung. In: Psyche. Zeitschrift für Psychoanalyse und ihre Anwendungen 63 (2009), S. 429-454.

Hoffmann, Matthias: Gesellschaftskritik in Wilhelm Genazinos Roman Das Glück in glücksfernen Zeiten. Frankfurt am Main 2015.

[Höflichkeit]. In: TU Berlin - Institut für Sprache und Kommunikation. Online: <http://fak1alt.kgw.tu-berlin.de/call/linguistiktutorien/pragmatik/pragmatik\%20k7.html>.

Hofmann, Marit: „Als könnte ich meinem eigenen Blick zuschauen“. Beobachtete Beobachter in Wilhelm Genazinos Romanen. In: Arnold (Hg.): Wilhelm Genazino (2004), S. 55-64.

Holler, Claudia/Klepper, Martin (Hg.): Rethinking Narrative Identity. Persona and perspective. Amsterdam/Philadelphia (PA) 2013. 
Holt, Nadine van/Groeben, Norbert: Das Konzept des Foregrounding in der modernen Textverarbeitungspsychologie. In: Journal für Psychologie 13 (2005), S. 311-332.

Holt, Nadine van/Groeben, Norbert: Emotionales Erleben beim Lesen und die Rolle text- sowie leserseitiger Faktoren. In: Uta Klein/Katja Mellmann/Steffanie Metzger (Hg.): Heuristiken der Literaturwissenschaft. Disziplinexterne Perspektiven auf Literatur. Paderborn 2006, S. 111-130.

Homann, Ursula: Zerbrechliches Glück und transzendentale Obdachlose. In: Der Literat. Fachzeitschrift für Literatur und Kunst 2 (2002), S. 11-15.

Honold, Alexander: Doppelleben, halbbitter. Unentschiedenheit als erzählte Lebensform bei Wilhelm Genazino. In: Bartl/Marx (Hg.): Verstehensanfänge (2011), S. 33-56.

Hoorn, Tanja van: [Genazino, Wilhelm. Das erzählerische Werk (letzte Aktualisierung in 2010)]. In: Kindlers Literatur Lexikon online. Online: <http://kllaktu-

ell.cedion.de/nxt/gateway.dll/kll/g/k0232700.xml/k0232700_020.xml?f=templates $\$ \mathrm{fn}=\mathrm{ind}$ ex.htm \$q=\%5Brank,500\%3A\%5Bdomain\%3A\%5Band\%3A\%5Bfield,body\%3Agenazino\%5 D\%5D\%5D\%5Bsum\%3A\%5Bfield,lemmatitle\%3Agenazino\%5D\%5Bfield,body\%3Agenazin o\%5D\%5D\%5D \$x=server\$3.0\#LPHit1>.

Horstkotte, Silke/Herrmann, Leonhard (Hg.): Poetiken der Gegenwart. Deutschsprachige Romane nach 2000. Berlin/Boston 2013.

Horváth, Márta: Unveröffentlichtes, unpaginiertes Manuskript zum Vortrag: „Arthur Schnitzlers Der Tote Gabriel aus Sicht der kognitionspsychologischen Figurenanalyse" am 16. Juni 2016 im Rahmen meines Seminars „Figur oder Person? Papier oder Psyche? Einführung in die Figurenanalyse" an der Universität Kassel im SoSe 2016.

Horváth, Márta/Mellmann, Katja: Ankündigungstext zur interdisziplinären Tagung „Die biologisch-kognitiven Grundlagen narrativer Motivierung" vom 3.-5. September 2014 in Göttingen. Online: <https://www.uni-goettingen.de/de/die-biologisch-kognitiven-grundlagennarrativer-motivierung/489234.html>.

[Humoralpathologie]. In: Wikipedia. Die freie Enzyklopädie. Online: $<$ https://de.wikipedia.org/wiki/Humoralpathologie>.

[Inneres Team]: Schulz von Thun Institut: das Innere Team. Online: <https://www.schulz-vonthun.de/die-modelle/das-innere-team>.

[Interesse]. In: Deutsches Wörterbuch von Jacob Grimm und Wilhelm Grimm. Online: <http://woerterbuchnetz.de/DWB/?sigle=DWB\&mode=Vernetzung\&lemid=GI00627\#XGI0 $0627>$.

Iser, Wolfgang: Das Fiktive und das Imaginäre. Perspektiven literarischer Anthropologie. Frankfurt am Main 1991.

Jäger, Ludwig (Hg.): Zur historischen Semantik des deutschen Gefühlswortschatzes. Aspekte, Probleme und Beispiele seiner lexikalischen Erfassung. Aachen 1988.

Jahraus, Oliver: Deemphase als Apokalypse. Genazinos Beitrag zur Subjektkritik. Am Beispiel des Romans Die Liebesblödigkeit. In: Bartl/Marx (Hg.): Verstehensanfänge (2011), S. 99-114.

Jakob, Hans-Joachim: Wilhelm Genazino - Auswahlbibliografie 1965-2004. In: Arnold (Hg.): Wilhelm Genazino (2004), S. 98-105.

Jakobs, Karl-Heinz: Tiefsitzendes Mißtrauen gegenüber den Dingen des Lebens. Interview. In: Neues Deutschland vom 04. November 1994.

James, Erika L.: Fifty Shades of Grey - Geheimes Verlangen. Roman. München 2012. Online: $<$ http://books.google.de/books?id=IcI-

N9bi3IIC\&pg=PT86\&dq=shades+of+grey+er+kommt+langsamen+schrittes\&hl=de\&sa=X\&ei

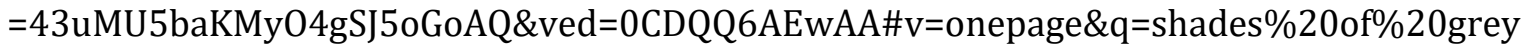
$\% 20 \mathrm{er} \% 20 \mathrm{kommt} \% 20$ langsamen\%20schrittes\&f=false>.

Jannidis, Fotis: Figur und Person. Beitrag zu einer historischen Narratologie. Berlin/New York 2004.

Jannidis, Fotis: [Character]. In: Peter Hühn/John Pier/Wolf Schmid/Jörg Schönert. (Hg.): the living handbook of narratology. Hamburg 2012/2018. Online: <http://www.lhn.unihamburg.de/article/character>. 
Jannidis, Fotis/Lauer, Gerhard/Martínez, Matías/Winko, Simone: Texte zur Theorie der Autorschaft. Stuttgart 2000.

Jappe, Lilith/Krämer, Olav/Lampart, Fabian (Hg.): Figurenwissen. Funktionen von Wissen bei der narrativen Figurendarstellung. Berlin 2012.

Jendrosch, Thomas: Impression Management. Professionelles Marketing in eigener Sache. Wiesbaden 2010.

Jones, Edward E./Pittman, Thane S.: Toward a General Theory of Strategic Self-Presentation. In: Jerry Suls (Hg.): Psychological perspectives on the self. Hillsdale (NJ) 1982, S. 231-262.

Jung, Werner: „Umhergehen und Zeitverschwenden“. Skizze zu einer literarischen Phänomenologie der Wahrnehmung. In: Arnold (Hg.): Wilhelm Genazino (2004), S. 65-69.

Jürgensen, Christoph/Kaiser, Gerhard: Schriftstellerische Inszenierungspraktiken - Heuristische Typologie und Genese. In: dies. (Hg.): Schriftstellerische Inszenierungspraktiken - Typologie und Geschichte. Heidelberg 2011, S. 9-30.

Jürgensen, Christoph/Kaiser, Gerhard: Abgrenzung, Re-Kombination, Neu-Positionierung. In: Sabine Kyora (Hg.): Subjektform Autor. Autorschaftsinszenierungen als Praktiken der Subjektivierung. Bielefeld 2014, S. 217-245.

Jurkowski, Susanne: Soziale Kompetenzen und Lernerfolg beim kooperativen Lernen. Kassel 2011.

Kalwa, Nina: Das Konzept „Islam“. Eine diskurslinguistische Untersuchung. Berlin/Boston 2013.

Kämmerlings, Richard: Genazino gilt als bedeutender Autor. Warum nur? In: Welt.de vom 26. Juli 2011. Online: <https://www.welt.de/kultur/literarischewelt/article13507983/Genazinogilt-als-bedeutender-Autor-Warum-nur.html>.

Kant, Immanuel: Von den Urtheilen. In: ders.: Logik, Physische Geographie, Pädagogik [AA 9] 1923, S. 101-113.

Kappeler, Sima: First encounters in French and German prose fiction, 1830-1883. New York 1996.

Käser, Rudolf: Die Schwierigkeit, ich zu sagen. Rhetorik der Selbstdarstellung in Texten des „Sturm und Drang“: Herder - Goethe - Lenz. Bern 1987.

Kaufmann, Vincent/Schmid, Ulrich/Thomä, Dieter: Einleitung. In: dies. (Hg.): Das öffentliche Ich. Selbstdarstellungen im literarischen und medialen Kontext. Bielefeld 2014, S. 7-9.

Kirschbaum, Marc/Schuster, Kai: Architektur und Lebensstil. Individuum, Gesellschaft und Raumpraxis. Dissertation Universität Kassel 2008. Online: <https://kobra.bibliothek.unikassel.de/bitstream/urn:nbn:de:hebis:342009021626305/3/DissertationKirschbaum\%2BSchuster.pdf>.

Klinge, Annika: Poetische Collagen. Einflüsse der bildenden Kunst auf ausgewählte Texte Wilhelm Genazinos. In: Bartl/Marx (Hg.): Verstehensanfänge (2011), S. 199-224.

Klosinski, Gunther: Vorwort. In: ders. (Hg.): Tarnen, Täuschen, Lügen (2011), S. 7 f.

Klosinski, Gunther (Hg.): Tarnen, Täuschen, Lügen. Zwischen Lust und Last. Tübingen 2011.

Koch, Alexandra: Das Bedeutungstheater des Epiphanikers. Zur Ver- und Entzauberung der Alltagswelt in der Prosa Wilhelm Genazinos. Hamburg 2012.

Koch, Peter/Oesterreicher, Wulf: Sprache der Nähe - Sprache der Distanz. Mündlichkeit und Schriftlichkeit im Spannungsfeld von Sprachtheorie und Sprachgeschichte. In: Romanistisches Jahrbuch 36 (1986), S. 15-43.

Koch, Thomas: Literarische Menschendarstellung. Studien zu ihrer Theorie und Praxis (Retz, La Bruyère, Balzac, Flaubert, Proust, Lainé). Tübingen 1991.

Köhnen, Ralph: Psychoanalytische Literaturwissenschaft. In: Benedikt Jeßing/ders.: Einführung in die Neuere deutsche Literaturwissenschaft. 2., aktual. u. erw. Aufl. Stuttgart/Weimar 2007, S. 302-306.

Köhnen, Ralph (Hg.): Selbstpoetik 1800-2000. Ich-Identität als literarisches Zeichenrecycling. Frankfurt am Main/New York 2001.

Kolberg, Maria: Polyamorie in Wilhelm Genazinos „Die Liebesblödigkeit“. Hamburg 2015.

Köppe, Tilmann/Kindt, Tom: Erzähltheorie. Eine Einführung. Stuttgart 2014.

Korte, Barbara: Körpersprache in der Literatur. Theorie und Geschichte am Beispiel englischer Erzählprosa. Tübingen/Basel 1993. 
Kospach, Julia: Implodierende Männer in mittleren Jahren. In: Falter (Literaturbeilage) vom 13. März 2009.

Kraume, Anne: Den Dingen lauschen. Ein Leben aus Wörtern. Wilhelm Genazino begibt sich für seinen neuen Roman „Eine Frau, eine Wohnung, ein Roman“ zurück in die Adenauerzeit. In: taz vom 01. April 2003.

Krause, Tilman: Er wollte nicht der Mensch sein, der er war. In: Die Welt vom 23. Juli 2011.

Krauss, Hannes: Menschen - Dinge - Situationen. Wilhelm Genazinos „Abschaffel“-Romane. In: Arnold (Hg.): Wilhelm Genazino (2004), S. 11-19.

Krepold, Christian: „,...als sei das Ende des Menschen die einzige ordentliche Verrichtung“. Altern, Melancholie und Komik bei Wilhelm Genazino und Italo Svevo. In: Andrea Bartl/Hanna V. Becker/Raoul Schrott (Hg.): Transitträume. Beiträge zur deutschsprachigen Gegenwartsliteratur: Interviews mit Raoul Schrott, Albert Ostermaier, Hanns-Josef Ortheil, Andrea Maria Schenkel, Kerstin Specht, Nora-Eugenie Gomringer, Olaf neopan Schwanke und Franzobel. Augsburg 2009, S. 55-102.

Krepold, Susanne/Krepold, Christian: Literarische Selbstreflexionen durch Lektüre. Wilhelm Genazino als Leser von Marguerite Duras. In: Steffen Buch/Álvaro Ceballos/Christian Gerth (Hg.): Selbstreflexivität. Beiträge zum 23. Nachwuchskolloquium der Romanistik (Göttingen, 30. Mai-02. Juni 2007). Bonn 2008, S. 107-124.

Krützen, Michaela: Dramaturgie des Films. Wie Hollywood erzählt. Frankfurt am Main 2004.

Kuhn, Christoph: Kein Plädoyer für Nabelschau. Aus der Solothurner Laudatio auf Wilhelm Genazino. In: Tages-Anzeiger vom 15. Juli 1995.

Kunckel, Susanne: „Ich bin ein humoristischer Leisetreter“. Besuch beim Büchner-Preisträger Wilhelm Genazino. In: Welt am Sonntag vom 17. Oktober 2004.

Kunckel, Susanne: Liebeswirrwarr eines Hypochonders. In: Welt am Sonntag vom 06. Februar 2005.

Kunisch, Hans-Peter: Sätze in Bewegung. Preise für Genazino und Schamoni in der Bayerischen Akademie. In: Süddeutsche Zeitung vom 28. Mai 1998.

Lahn, Silke: Wer erzählt die Geschichte? Parameter des Erzählers [Kap. IV.1]. In: dies./Meister: Einführung in die Erzähltextanalyse (2013), S. 61-100.

Lahn, Silke: Präsentation von Rede und mentalen Prozessen [Kap. IV.2.2]. In: dies./Meister: Einführung in die Erzähltextanalyse (2013), S. 116-133.

Lahn, Silke/Meister, Jan C.: Einführung in die Erzähltextanalyse. Mit Beiträgen von Matthias Aumüller, Benjamin Biebuyck, Anja Burghardt, Jens Eder, Per K. Hansen, Peter Hühn und Felix Sprang. 2., akt. Aufl. Mit Abbildungen und Grafiken. Stuttgart/Weimar 2013.

Landfester, Ulrike: [Goethe, Johann Wolfang von. Dramen]. In: Kindlers Literaturlexikon online. Online:

$<$ http://kll-

ak-

tucell.cedion.de/nxt/gateway.dll/kll/g/k0241600.xml/k0241600_080.xml?f=templates $\$ \mathrm{fn}=\mathrm{i}$ ndin.htm\$q=\%5Brank,500\%3A\%5Bdomain\%3A\%5Band\%3A\%5Bfield,body\%3Astella\%5D \%5D\%5D\%5Bsum\%3A\%5Bfield,lemmatitle\%3Astella\%5D\%5Bfield,body\%3Astella\%5D\%5 D\%5D\$x=server\$3.0\#LPHit1>.

Langlotz, Miriam/Lehnert, Nils/Schul, Susanne: SprachGefühl - eine Einleitung. In: Langlotz/Lehnert/Schul/Weßel (Hg.): SprachGefühl (2014), S. 9-25.

Langlotz, Miriam/Lehnert, Nils/Schul, Susanne/Weßel, Matthias (Hg.): SprachGefühl. Interdisziplinäre Perspektiven auf einen nur scheinbar altbekannten Begriff. Frankfurt am Main 2014.

Langner, Ralph (Hg.): Psychologie der Literatur. Theorien, Methoden, Ergebnisse. Weinheim/München 1986.

Lantermann, Ernst-Dieter: Selbstbehauptung in unübersichtlichen Zeiten. Unveröffentlichtes, unpaginiertes Skript zur Vorlesung am 07. Dezember 2009 im Rahmen der Vorlesung „Psychologie der Selbstinszenierung" im WiSe 2009/2010 an der Universität Kassel.

Lantermann, Ernst-Dieter/Döring-Seipel, Elke/Eierdanz, Frank/Gerhold, Lars: Selbstsorge in unsicheren Zeiten. Resignieren oder Gestalten. Weinheim 2007.

[Lateral]. In: Wikipedia. Die freie Enzyklopädie. Online: <https://de.wikipedia.org/wiki/Lateral_(R\%C3\%A4tsel)>. 
Laux, Lothar/Renner, Karl-Heinz: Theater als Modell für die Persönlichkeitspsychologie. In: Erika Fischer-Lichte (Hg.): Theatralität als Modell in den Kulturwissenschaften. Tübingen 2004, S. 83-110.

Leary, Mark R./Kowalski, Robin M.: Impression Management: A Literature Review and TwoComponent Model. In: Psychological Bulletin 107 (1990), S. 34-47.

Lehnert, Nils: Oberfläche - Hallraum - Referenzhölle. Postdramatische Diskurse um Text, Theater und zeitgenössische Ästhetik am Beispiel von Rainald Goetz' Jeff Koons. Hamburg 2012.

Lehnert, Nils: „Sehe ich nun gnädig aus?" - Eindruckssteuerndes Verhalten, Selbst- und Fremdbilder literarischer Figuren als mögliche transepochale ,Universalien' der Literatur. In: Endre Hárs/Márta Horváth/Erzsébet Szabó (Hg.): Universalien? Über die Natur der Literatur. Trier 2014, S. 179-199.

Lehnert, Nils: Refus aus Kalkül?! $\mathrm{Zu}$ Christian Krachts Fernsehauftritten. In: Stefan Greif/ders./Anna-Carina Meywirth (Hg.): Popkultur und Fernsehen. Historische und ästhetische Berührungspunkte. Bielefeld 2015, S. 133-166.

Lehnert, Nils: „So ermahnte man ihn, in Zukunft besser beim Niesen aufzupassen, und schickte ihn nach Hause." Paul Maars Pixi-Buch Vorsicht, Niesgefahr! zwischen Exklusion und (ReJIntegration, Über-Ich und Es, Philistertum und Selbstbestimmung, Sams und Sturmniesen. In: Andreas Wicke/Nikola Roßbach (Hg.): Paul Maar. Studien zum kinder- und jugendliterarischen Werk. Würzburg 2017, S. 139-158.

Lehnert, Nils/Schul, Susanne: Gefühlvoll oder voller Gefühl? Literarische Liebesentwürfe und deren Sprachgewand aus einer diachronen Perspektive. In: Langlotz/Lehnert/Schul/Weßel (Hg.): SprachGefühl (2014), S. 191-252.

Lehtonen, Jaakko: Imagepflege und ,Impression-Management'. Verfall der Sprecherziehung oder eine Neuorientierung? In: Siegrun Lemke/Susanne Thiel (Hg.): Sprechen - Reden - Mitteilen. Prozesse allgemeiner und spezifischer Sprechkultur. München 1996, S. 50-56.

Leithäuser, Thomas/Volmerg, Birgit: Anleitung zur empirischen Hermeneutik. Psychoanalytische Textinterpretation als sozialwissenschaftliches Verfahren. Frankfurt am Main 1979.

Lenz, Eva-Maria: Kleine Fluchten. In: epd/Kirche und Rundfunk vom 14. Februar 1981.

Leschke, Rainer: Einleitung: Zur transmedialen Logik der Figur. In: ders./Heidbrink (Hg.): Formen der Figur (2010), S. 11-26.

Leschke, Rainer/Heidbrink, Henriette (Hg.): Formen der Figur. Figurenkonzepte in Künsten und Medien. Konstanz 2010.

[Liebe]. In: Duden online. Online: <http://www.duden.de/rechtschreibung/Liebe>.

Linke, Angelika/Nussbaumer, Markus/Portmann, Paul R.: Studienbuch Linguistik ergänzt um ein Kapitel „Phonetik und Phonologie“ von Urs Wille. 4., unv. Aufl. Tübingen 2001.

Lukács, Georg: Die Theorie des Romans. Ein geschichtsphilosophischer Versuch über die Formen der großen Epik. Berlin 1916/1920.

Maidt-Zinke, Kristina: Die Schuhwurzel. Wilhelm Genazino spannt den Regenschirm auf. In Süddeutsche Zeitung vom 04./05. August 2001.

Maldonado Alemán, Manuel: „Das Bild schweigt. Aber es bringt mich zum Erzählen“. Intermediale Erinnerungen im Werk Wilhelm Genazinos. In: Bartl/Marx (Hg.): Verstehensanfänge (2011), S. 179-198.

Maldonado Alemán, Manuel: Intermedialität und Erinnerung. Zum Verhältnis von Bild und Text bei Wilhelm Genazino und Monika Maron. In: Olivia C. Pérez Díaz/Florian Gräfe/Rolf G. Renner (Hg.): Intermedialität und Alterität, Migration und Emigration. Tendenzen der deutschsprachigen Literatur. Tübingen 2014, S. 17-31.

Malle, Bertram F.: How People Explain Behavior: A New Theoretical Framework. In: Personality and Social Psychology Review 3 (1999), S. 23-48.

Mangold, Iljoma: Probelauf in neuen Schuhen. Wer genehmigt dem Helden das Leben? Wilhelm Genazinos Roman „Ein Regenschirm für diesen Tag“. In: Berliner Zeitung vom 08. September 2001.

Mangold, Iljoma: Du musst dein Frauenproblem lösen. In: Süddeutsche Zeitung vom 12./13. März 2005.

Martínez, Matías/Scheffel, Michael: Einführung in die Erzähltheorie. 7. Aufl. München 2007. 
Martschukat, Jürgen/Stieglitz, Olaf: „Es ist ein Junge!“ Einführung in die Geschichte der Männlichkeiten in der Neuzeit. Tübingen 2005.

Marx, Friedhelm: Erzählfiguren der Verrückung im Werk Wilhelm Genazinos. In: Bartl/ders. (Hg.): Verstehensanfänge (2011), S. 57-68.

Marx, Peter W.: Ein theatralisches Zeitalter. Bürgerliche Selbstinszenierungen um 1900. Tübingen/Basel 2008.

Matt, Peter von: Literaturwissenschaft und Psychoanalyse. Stuttgart 2001.

Meister, Jan C.: Handlung [Kap. IV.3.2]. In: Lahn/ders.: Einführung in die Erzähltextanalyse (2013), S. 210-231.

Michaelis, Beatrice: (Dis-)Artikulationen von Begehren. Schweigeeffekte in wissenschaftlichen und literarischen Werken. Berlin/New York 2011.

Mittag, Susanne: Im INSTITUT FÜR MNEMOSYNE oder Grundkurs in der Kunst des Erinnerns. Aspekte der Erinnerung in den Romanen Wilhelm Genazinos. In: Giesen (Hg.): Wilhelm Genazino (2006), S. 47-56.

Mohr, Peter: Flaneur mit Luxusschuhen. Wilhelm Genazinos Roman „Ein Regenschirm für diesen Tag“. In: literaturkritik.de vom 09. September 2001. Online: $<$ http://literaturkritik.de/id/4127>.

Moser, Doris/Kupczyńska, Kalina (Hg.): Die Lust im Text. Eros in Sprache und Literatur. Wien 2009.

Moser, Samuel: Isola Insula. Aspekte der Individuation bei Wilhelm Genazino. In: Arnold (Hg.): Wilhelm Genazino (2004), S. 36-45.

Moser, Tilmann: Tödliche Leere und schmerzliche Einsamkeit. Über zwei Romane von Wilhelm Genazino. In: ders.: Lektüren eines Psychoanalytikers. Romane als Krankengeschichten. Gießen 2013, S. 25-43.

Müller, Burkhard: Mut zum zarten Trost. „Bei Regen im Saal“: Wilhelm Genazino schreibt mal wieder den Roman eines versonnenen Außenseiters. In: ZEIT ONLINE vom 21. August 2014. Online: <http://www.zeit.de/2014/33/wilhelm-genazino-roman-bei-regen-im-saal>.

Müller, Jörn: Lüge und Wahrhaftigkeit. Eine philosophische Besichtigung vor dem Hintergrund der Sprechakttheorie. In: ders./Nissing (Hg.): Die Lüge (2007), S. 27-55.

Müller, Jörn/Nissing, Hanns-Gregor (Hg.): Die Lüge. Ein Alltagsphänomen aus wissenschaftlicher Sicht. Darmstadt 2007.

Mulvey, Laura: Visuelle Lust und narratives Kino. Aus dem Englischen von Karola Garmann. In: Liliane Weissberg (Hg.): Weiblichkeit als Maskerade. Frankfurt am Main 1975/1994, S. 4865.

Mummendey, Hans D.: Psychologie der Selbstdarstellung. Göttingen 1990.

Mummendey, Hans D.: Selbstdarstellung: Die Präsentation der eigenen Person. In: Hans-Werner Bierhoff/Dieter Frey (Hg.): Handbuch der Sozialpsychologie und Kommunikationspsychologie. Göttingen 2006, S. 49-56.

Neecke, Michael: Literarische Strategien narrativer Identitätsbildung. Eine Untersuchung der frühen Chroniken des Deutschen Ordens. Frankfurt am Main 2008.

Neuhaus, Stefan: Grundriss der Literaturwissenschaft. 2., überarb. Aufl. Tübingen/Basel 2005.

Neuhaus, Stefan: „Ihre Möpse sind weich. Ungewöhnlich schön liegen sie in der Hand“: Zur Funktionalisierung von Erotik und Sexualität in der Gegenwartsliteratur. In: Moser/Kupczyńska (Hg.): Die Lust im Text (2009), S. 375-387.

Neumann, Heiko: „Der letzte Strich des Flaneurs“. Schwierige Fußgänger in Wilhelm Genazinos Romanen Ein Regenschirm für diesen Tag und Die Liebesblödigkeit. In: Bartl/Marx (Hg.): Verstehensanfänge (2011), S. 149-164.

Neumann, Michael: Die fünf Ströme des Erzählens. Eine Anthropologie der Narration. Berlin/Boston 2013.

Nissing, Hanns-Gregor: Die Lüge. Ein Alltagsphänomen aus wissenschaftlicher Sicht. Zur Einleitung. In: Müller/ders. (Hg.): Die Lüge (2007), S. 7-25.

Nünning, Ansgar unter Mitwirkung von Carola Surkamp und Bruno Zerweck (Hg.): Unreliable Narration. Studien zur Theorie und Praxis unglaubwürdigen Erzählens in der englischsprachigen Erzählliteratur. Trier 2013. 
Nünning, Vera/Nünning, Ansgar (Hg.): Erzähltheorie transgenerisch, intermedial, interdisziplinär. Trier 2002.

Oberreither, Bernhard: Mit einer Spur von Wirklichkeit. Fotografie und literarische Detektion bei Wilhelm Genazino. In: Konstanze Fliedl/ders./Katharina Serles (Hg.): Gemälderedereien. Zur literarischen Diskursivierung von Bildern. Berlin 2013, S. 129-150.

Öchsner, Florian: Subjekte der Arbeit in der Gegenwartsliteratur. Enno Stahls Diese Seelen und Wilhelm Genazinos Das Glück in glücksfernen Zeiten. In: Susanna Brogi/Carolin Freier/Ulf Freier-Otten/Katja Hartosch (Hg.): Repräsentationen von Arbeit. Transdisziplinäre Analysen und künstlerische Produktionen. Bielefeld 2013, S. 347-364.

Osswald-Rinner, Iris: Oversexed and underfucked. Über die gesellschaftliche Konstruktion der Lust. Wiesbaden 2011.

Ott, Matthias: „Er hob die Hände und spreizte alle Finger“. Nonverbale Kommunikation in Franz Kafkas „Der Proceß“. Bachelorarbeit Universität Kassel 2013.

Papke, Kaja: Heinrich Manns Romane Die Jagd nach Liebe und Zwischen den Rassen. Mentalitäten, Habitusformen und ihre narrative Gestaltung. München 2007.

Paris, Bernard J.: Imagined human beings. A psychological approach to character and conflict in literature. New York 1997.

Pavel, Thomas G.: The Poetics of plot. The case of English renaissance drama. Minneapolis 1985.

Petersen, Philipp: Die Komik der Beiläufigkeit. Zur Verwendung von Komik und Humor bei Wilhelm Genazino. Magisterarbeit Universität Wien 2013. Online: <http://othes.univie.ac.at/25659/1/2013-01-30_0003406.pdf>.

Pethes, Nicolas: Helden, Hunde, Eigenschaften. Figurenkonzepte in der literarischen Narration. In: Leschke/Heidbrink (Hg.): Formen der Figur (2010), S. 87-107.

Pfeiferová, Dana: „Ich frage mich, ob aus dem simulierten ein wirklicher Tod werden kann, wenn er zu lange anhält". Metaphern des sozialen Todes in Wilhelm Genazinos Roman Mittelmäßiges Heimweh. In: Bartl/Marx (Hg.): Verstehensanfänge (2011), S. 85-97.

Pfeiffer, Joachim: Literaturpsychologie/Psychoanalytische Literaturwissenschaft. In: Jost Schneider unter redaktioneller Mitarbeit von Regina Grundmann (Hg.): Methodengeschichte der Germanistik. Berlin/New York 2009, S. 355-384.

Pflugmacher, Thorsten: [Vladimir Propp]. In: Einladung zur Literaturwissenschaft. Ein Internetvertiefungsprogramm zum Selbststudium. Online: <http://www.einladung-zurliteraturwissenschaft.de/index.php?option=com_content\&view=article\&id=245: personenpropp\&catid $=40$ :kapitel-5>.

Pikulik, Lothar: Goethes „Stella. Ein Schauspiel für Liebende“. In: Walter Hinderer (Hg.): Interpretationen. Goethes Dramen. Stuttgart 1992, S. 88-116.

Pollak, Anita: Müßiggang ist aller Tugend Anfang. Besprechung des Romans Ein Regenschirm für diesen Tag. In: Wiener Kurier vom 28. September 2001.

Pontzen, Alexandra: „Ziel der Scham ist das Verschwinden“. Wilhelm Genazino bei „Text und Kritik“. In: literaturkritik.de vom 11. November $2004 . \quad$ Online: $<$ http://literaturkritik.de/id/7590>.

Pontzen, Alexandra: Banalität und Empfindsamkeit. Wilhelm Genazinos Poetik alltäglicher Gefühle. In: Preusser/Visser (Hg.): Alltag als Genre (2009), S. 231-244.

Pontzen, Alexandra: Wilhelm Genazino: Poetik als romantische Psychopathographie des Alltagslebens. In: Alo Allkemper/Norbert O. Eke/Hartmut Steinecke (Hg.): Poetologisch-poetische Interventionen: Gegenwartsliteratur schreiben. München 2012, S. 219-234.

Poppe, Sandra: Emotionen in Literatur und Film. Würzburg 2011.

Preusser, Heinz-Peter/Visser, Anthonya (Hg.): Alltag als Genre. Heidelberg 2009.

Prinz, Katharina/Winko, Simone: Sympathielenkung und textinterne Wertungen. Überlegungen zu ihrer Untersuchung und exemplarische Analyse der Figur des, unglücklichen Mordgehilfen' Olivier Brusson. In: Claudia Hillebrandt/Elisabeth Kampfmann (Hg.): Sympathie und Literatur. Zur Relevanz des Sympathiekonzeptes für die Literaturwissenschaft. Berlin 2014, S. 99-127.

Propp, Wladimir J.: Morphologie des Märchens. München 1928/1972.

Prosinger, Wolfgang/Genazino, Wilhelm: Schriftsteller Wilhelm Genazino. „Früher war ich ein Nachttiger". Interview. In: Tagesspiegel vom 20. Januar 2013. Online: 
<http://www.tagesspiegel.de/kultur/schriftsteller-wilhelm-genazino-frueher-war-ich-einnachttiger/7654686.html>.

Quindeau, Ilka: Psychoanalyse. Paderborn 2008.

Randow, Gero von: Theodor W. Adorno. Der Trick mit der Gefühlsbefreiung. In: ZEIT ONLINE vom 01. Dezember 2016. Online: <http://www.zeit.de/2016/48/theodor-w-adornofaschismus-autoritarismus/komplettansicht>.

Reicher-Marek, Maria E.: Ontologie fiktiver Gegenstände. In: Tobias Klauk/Tilmann Köppe (Hg.): Fiktionalität. Ein interdisziplinäres Handbuch. Berlin/Boston 2014, S. 159-189.

Reschke, Thomas: [Wilhelm Genazino - Essay (letzte Aktualisierung 01.06.2008)]. In: Munziger Online/KLG - Kritisches Lexikon zur deutschsprachigen Gegenwartsliteratur. Online: <http://www.munzinger.de/search/klg/Wilhelm+Genazino/176.html>.

Reuvekamp, Silvia: Hölzerne Bilder - mentale Modelle? Mittelalterliche Figuren als Gegenstand einer historischen Narratologie. In: DIEGESIS. Interdisziplinäres E-Journal für Erzählfor$\begin{array}{llll}\text { schung } & 3 & \text { (2014). }\end{array}$ wuppertal.de/index.php/diegesis/article/view/168/221>.

Rimmon-Kenan, Shlomith: Narrative Fiction. Contemporary Poetics. 2. Aufl. London/New York $1983 / 2002$.

Rinke, Stefanie: „...und beauftragte jemanden mit meiner Observation.“ Angestelltenhabitus und Blickökonomie bei Wilhelm Genazino zwischen Moderne und Gegenwart. In: Gisela Ecker/Claudia Lillge (Hg.): Kulturen der Arbeit. München 2011, S. 33-50.

Rinsum, Annemarie van/Rinsum, Wolfgang van: Lexikon literarischer Gestalten. Deutschsprachige Literatur. Stuttgart 1988.

Rok, Cora: „Wir spüren nämlich nichts mehr, werte Dame“ - (Selbst-)Entfremdung bei Melle, Genazino, und Von Steinaecker. In: La prose allemande contemporaine: voix et voices de la generation postmoderne 55 (2014), S. 111-126.

Rüdenauer, Ulrich: Ein falsches Timing von Heftigkeiten. Ein Spaziergang mit Wilhelm Genazino durch Frankfurt. In: literaturkritik.de vom 07. Juli $2005 . \quad$ Online: <http://literaturkritik.de/id/8308>.

Rüdenauer, Ulrich/Genazino, Wilhelm: Der Reiz des Scheiterns. Interview (erstveröffentlicht im Börsenblatt vom 21. Oktober 2004). In: Giesen (Hg.): Wilhelm Genazino (2006), S. 57-60.

Rüdenauer, Ulrich: Weltekel mit Grundsicherung. „Bei Regen im Saal“ heißt die neueste Ausfaltung des Genazino-Mikrokosmos. In: Süddeutsche Zeitung vom 30. Juli 2014.

Rudolph, Udo unter Mitarbeit von Andreé Körner: Motivationspsychologie kompakt. 2., vollst. überarb. Aufl. Weinheim/Basel 2009.

Schäffter, Ortfried: Modi des Fremderlebens. Deutungsmuster im Umgang mit Fremdheit. In: ders. (Hg.): Das Fremde. Erfahrungsmöglichkeiten zwischen Faszination und Bedrohung. Opladen 1991, S. 11-42.

Schlenker, Barry R.: Impression management. The self-concept, social identity, and interpersonal relations. Monterey (CA) 1980.

Schmid, Wolf: Elemente der Narratologie. 3., erw. u. überarb. Aufl. Berlin/Boston 2014.

Schmuck, Anne: Poetische Doppelgänger. Bedeutung und Funktion von Kleidung in ausgewählten Romanen Wilhelm Genazinos. In: Bartl/Marx (Hg.): Verstehensanfänge (2011), S. 225238.

Schnatwinkel, Sarina: Das Nichts und der Schmerz. Erzählen bei Bret Easton Ellis. Bielefeld 2014.

Schneider, Jost: Einführung in die Roman-Analyse. 3., aktual. Aufl. Darmstadt 2010.

Schneider, Ralf: Grundriss zur kognitiven Theorie der Figurenrezeption am Beispiel des viktorianischen Romans. Tübingen 2000.

Schnitzler, Arthur: Fräulein Else. In: ders.: Gesammelte Werke in drei Bänden. Band I: Erzählungen, hg. von Hartmut Scheible. Düsseldorf 1924/2002, S. 557-620.

Schoeller, Wilfried F.: Die Dinge blicken zurück. In: Frankfurter Rundschau vom 07. Oktober 1998.

Scholz, Christian/Genazino, Wilhelm: „Ich bringe ja auch das Bild in Schwung“. Ein Gespräch mit dem Schriftsteller Wilhelm Genazino über Photographie. In: Neue Zürcher Zeitung vom 07 Mai 2001. 
Schulze, Gerhard: Erlebnisgesellschaft: Kultursoziologie der Gegenwart. Frankfurt am Main 1992.

Schütte, Wolfram: Im Gespinst verschiedener Aufmerksamkeiten. Wilhelm Genazinos ProsaMosaik „Leise singende Frauen“. In: Frankfurter Rundschau vom 18. Juli 1992.

Schütz, Astrid: Assertive, Offensive, Protective, and Defensive Styles of Self-Presentation: A Taxonomy. In: The Journal of Psychology 132 (1998), S. 611-628.

Schwarte, Johannes: Der werdende Mensch. Persönlichkeitsentwicklung und Gesellschaft heute. Wiesbaden 2002.

Schwarz-Friesel, Monika: Sprache und Emotion. Tübingen/Basel 2007.

[Selbstaufmerksamkeit]. In: Lexikon der Psychologie. Online: <http://www.spektrum.de/lexikon/psychologie/selbstaufmerksamkeit/13858>.

Sieber, Andrea: Medeas Rache: Liebesverrat und Geschlechterkonflikte in Romanen des Mittelalters. Köln 2008.

Sill, Oliver: Moderne Zeiten. Wolf Peschek als Held der achtziger Jahre. In: Arnold (Hg.): Wilhelm Genazino (2004), S. 29-35.

[Sinus-Milieus]: Die Sinus Milieus. Online: <https://www.sinusinstitut.de/fileadmin/user_data/sinus-institut/Bilder/sinus-mileus-2015/2015-0923_Sinus-Beitrag_b4p2015_slide.pdf>.

[Sinus-Milieus 2017]: Informationen zu den Sinus-Milieus 2017. Online: <http://www.sinusinstitut.de/fileadmin/user_data/sinusinstitut/Dokumente/downloadcenter/Sinus_Milieus/2017-0101_Informationen_zu_den_Sinus-Milieus.pdf >.

Skrzypczak, Sabrina: Psychologie in Prosa. Die Einflüsse der Analytischen Psychologie C.G. Jungs auf Hermann Hesses Erzählung Der Steppenwolf. Masterarbeit Universität Kassel 2016.

Solga, Marc: Defensives Impression Management in Einstellungsinterviews: Effekte verantwortlichkeitsbasierter Rechenschaftskommunikation auf Urteilsprozesse des Interviewers. Dissertation Universität Bonn 2007. Online: <https://d-nb.info/98646709X/34>.

Spiegel, Hubert/Genazino, Wilhelm: „Der Text ist sein eigenes Misstrauen“. Hubert Spiegel (F.A.Z.) im Gespräch mit Wilhelm Genazino (Transkription eines Podiumsgesprächs vom 17. Juli 2009). In: Bartl/Marx (Hg.): Verstehensanfänge (2011), S. 239-254.

Spreckelsen, Tilman: Manche möchten lieber nicht. Gesellschaftliche Teilhabe und Initiation in den Romanen Wilhelm Genazinos. In: Arnold (Hg.): Wilhelm Genazino (2004), S. 79-86.

Stangl, Werner: [Selbstaufmerksamkeit]. In: Lexikon für Psychologie und Pädagogik. Online: $<$ http://lexikon.stangl.eu/5150/selbstaufmerksamkeit/>.

Steiner, Hans-Joachim: [Impression-Management-Theorie]. Online: $<$ http://psychonomie.de/sozialpsychologie/Impression_Management.htm>.

Steinfath, Holmer: Orientierung am Guten. Praktisches Überlegen und die Konstitution von Personen. Frankfurt am Main 2001.

Steltz, Christian (2016): „Es ist nicht einfach, ein einzelner zu sein“ - Denormalisierungsangst und Normalisierungslust in Thomas Manns Tonio Kröger und Wilhelm Genazinos Mittelmäßiges Heimweh. In: Heribert Tommek/ders. (Hg.): Vom Ich erzählen (2016), S. 49-66.

Stemmler, Gerhard/Hagemann, Dirk/Amelang, Manfred/Bartussek, Dieter: Differentielle Psychologie und Persönlichkeitsforschung. 7., vollst. überarb. Aufl. Stuttgart 2011. Online: $<$ https://content-select.com/media/moz_viewer/517a52ea-10e4-413f-853c1b855dbbeaba/language:de>.

Stephenson, Roger H.: ,Man nimmt in der Welt jeden, wofür er sich gibt': The Presentation of Self in Goethe's Die Wahlverwandtschaften. In: German Life and Letters 47 (1994), S. 400-406.

Sternburg, Judith von: Elegie eines Provinz-Redakteurs. Wilhelm Genazino erzählt auch in seinem neuen Roman „Bei Regen im Saal“ fast von einer Existenzkrise. In: Frankfurter Rundschau vom 30. Juli 2014.

Stockinger, Claudia: Das Leben ein (Angestellten-)Roman. Wilhelm Genazinos Ästhetik der Wiederholung. In: Arnold (Hg.): Wilhelm Genazino (2004), S. 20-28.

Süwolto, Leonie: Ereignis oder Kontinuum? Zur zeitlichen Codierung des Alter(n)s bei Wilhelm Genazino und Arno Geiger. In: Claudia Öhlschläger/Lucia Perrone Capano unter Mitarbeit 
von ders. (Hg.): Figurationen des Temporalen. Poetische, philosophische und mediale Reflexionen über Zeit. Göttingen 2013, S. 191-209.

Taylor, Nathan: Am Nullpunkt des Realismus. Terézia Moras Poetik des hic et nunc. In: Horstkotte/Herrmann (Hg.): Poetiken der Gegenwart (2013), S. 13-30.

[Temperamentenlehre]. In: Wikipedia. Die freie Enzyklopädie. Online: $<$ https://de.wikipedia.org/wiki/Temperamentenlehre>.

Tedeschi, James T.: Impression management theory and social psychological research. New York 1981.

Ter-Nedden, Gisbert: Psychologie und Literatur. Unpaginiertes Manuskript, Hagen 1989 (Grundlage für eine Vorlesung: 1995 Die Seele und die Formen. Graz Sommersemester).

Ter-Nedden, Gisbert: Charakterprobleme. Philologische Psychologismus-Kritik der Jahrhundertwende - eine wissenschaftsgeschichtliche Erinnerung in systematischer Absicht. In: Wiesinger (Hg.): Akten des X. Internationalen Germanistenkongresses (2003), S. 235-243.

Tholen, Toni: Subjektivität - Krise - Utopie. Imaginationen von Männlichkeiten im zeitgenössischen Denken und Schreiben. In: Mechthild Bereswill/Anke Neuber (Hg.): In der Krise? Männlichkeiten im 21. Jahrhundert. Münster 2011, S. 170-192.

Tittel, Kathrin: „Die postmoderne Welt im Narrenkostüm“ - Genazinos Roman „Die Liebesblödigkeit" in der karnevalesken Romantradition. In: Tina Hoffmann/Marie-Christin Lercher/Annegret Middeke/dies. (Hg.): Humor. Grenzüberschreitende Spielarten eines kulturellen Phänomens. Göttingen 2008, S. 157-170.

Tommek, Heribert/Steltz, Christian: Vom Ich erzählen. Identitätsnarrative in der Literatur des 20. Jahrhunderts. Einleitung. In: dies. (Hg.): Vom Ich erzählen (2016), S. 7-25.

Tommek, Heribert/Steltz, Christian (Hg.): Vom Ich erzählen. Identitätsnarrative in der Literatur des 20. Jahrhunderts. Frankfurt am Main 2016.

Toulmin, Stephen E.: The Uses of Argument. Cambridge 1958.

Tseëlon, Efrat: Is the Presented Self Sincere? Goffman, Impression Management and the Postmodern Self. In: Theory, Culture \& Society 9 (1992), S. 115-128.

Turnley, William H./Bolino, Mark C.: Achieving Desired Images While Avoiding Undesired Images: Exploring the Role of Self-Monitoring in Impression Management. Research Report. In: Journal of Applied Psychology 86 (2001), S. 351-360.

Vellusig, Robert: Die Sinnenhaftigkeit der Poesie. Eine Literaturpsychologie ohne Freud. In: Wiesinger (Hg.): Akten des X. Internationalen Germanistenkongresses (2003), S. 245-250.

Vogt, Jochen: Aspekte erzählender Prosa. Eine Erzähltechnik und Romantheorie. 10. Aufl. Paderborn 2008.

Wagner, Klaus R.: Pragmatik der deutschen Sprache. Frankfurt am Main 2001.

Wallenhorst, Katja: Der Versager in der Literatur am Beispiel der Romane Wilhelm Genazinos. Magisterarbeit Universität Halle-Wittenberg 2012.

Wallmann, Hermann: Ein lesender Flaneur im Biotop Großstadt. Unsichtbar sein, um ganz Auge sein zu können: Wilhelm Genazinos Roman „Der Fleck, die Jacke, die Zimmer, der Schmerz". In: Basler Zeitung vom 14. Juli 1989.

Watzlawick, Paul/Beavin, Janet H./Jackson, Don D.: Menschliche Kommunikation. Formen, Störungen, Paradoxien. 11., unv. Aufl. Bern 2007.

Welle, Florian: Brüste sind schön. In: Süddeutsche Zeitung vom 07. August 2013.

Wengeler, Martin: Argumentationsmuster im Bundestag. Ein diachroner Vergleich zweier Debatten zum Thema Asylrecht. In: Armin Burkhardt/Kornelia Pape (Hg.): Sprache des deutschen Parlamentarismus. Studien zu 150 Jahren parlamentarischer Kommunikation. Wiesbaden 2000, S. 221-240.

Wenzel, Peter (Hg.): Einführung in die Erzähltextanalyse. Kategorien, Modelle, Probleme. Trier 2004.

Wiele, Jan: Der Überempfindliche hat keine Wahl. Der Künstler als empfindsamer Vorturner des Scheiterns. In Frankfurter Allgemeine Zeitung vom 12. Juni 2014.

Wiesinger, Peter unter Mitarbeit von Hans Derkits (Hg.): Akten des X. Internationalen Germanistenkongresses Wien 2000. Band 10: Geschlechterforschung und Literaturwissenschaft - Literatur und Psychologie - Medien und Literatur. Bern 2003. 
[Wilhelm Genazino]. In: Wikipedia. Die freie Enzyklopädie. Online: $<$ https://de.wikipedia.org/wiki/Wilhelm_Genazino>.

Willems, Herbert/Jurga, Martin (Hg.): Inszenierungsgesellschaft. Ein einführendes Handbuch. Opladen 1998.

Windemuth, Dirk: Die Selbstdarstellung in Alltagserzählungen als Technik des ImpressionManagements. In: Zeitschrift für Germanistik 2 (1992), S. 128-137.

Winkels, Hubert: Schauen, langsam. In: Die Zeit vom 13. Januar 2005.

Winko, Simone: Kodierte Gefühle. Zu einer Poetik der Emotionen in lyrischen und poetologischen Texten um 1900. Berlin 2003.

Wirthensohn, Andreas: Ein beschuhter Sisyphos oder die Wiederentdeckung des Flaneurs. „Ein Regenschirm für diesen Tag" und die von Wilhelm Genazino zur Perfektion getriebene Wahrnehmung des Unbeachteten. In: Aargauer Zeitung vom 22. August 2001.

Wittgenstein, Ludwig: Philosophische Untersuchungen. (Philosophical Investigations). DeutschEnglische Ausgabe. 3. Aufl. Übersetzt von G.E.M. Anscombe. Oxford/New York 1953/1967.

Woitkowski, Felix: Figurenwürfel. 36 mal 6 Seiten kreatives Schreiben. Norderstedt 2015.

Wollenhaupt, Annette: Ein Streuner, dessen Blick den kleinen Dingen gilt. In: Frankfurter Rundschau vom 20. September 2004.

Wollny, Karsten: Das Gehirn ist ein Genie. In: Titanic. Das endgültige Satiremagazin (01/2016). Online: <https://www.titanic-magazin.de/fachmann/2016/januar/\#c25148>.

Wolters, Dierk: Die Dinge zum Leuchten bringen. In: Frankfurter Neue Presse vom 09. Februar 2006.

Wüstenhagen, Claudia: Ich-Bewusstsein. Die Ich-Perspektive. In: ZEIT Wissen vom 10. April 2012. Online: <http://www.zeit.de/zeit-wissen/2012/03/Das-Ich-Serie-Teil2/komplettansicht>.

Yukl, Gary: Leadership in Organizations. 7. Aufl. Upper Saddle River (NJ) 2010.

Zarnegin, Kathy: Wilhelm Meisters Trauerjahre. Die Melancholie der Glückssuche in W. Genazinos Roman „Das Glück in glücksfernen Zeiten“. In: dies. (Hg.): Die Wissenschaft des Unbewussten. Würzburg 2010, S. 235-253.

Zeillinger, Gerhard: Rex Gildo oder: Vom Glück der kleinen Bürger. In: Die Presse vom 26. April 2003.

Zima, Peter V.: Theorie des Subjekts. Subjektivität und Identität zwischen Moderne und Postmoderne. 4., durchges. u. erw. Aufl. Tübingen 2017.

Zunshine, Lisa: Why we read fiction - theory of mind and the novel. Columbus (OH) 2006.

Zymner, Rüdiger/Fricke, Harald: Einübung in die Literaturwissenschaft. Parodieren geht über Studieren. 5., überab. u. erw. Aufl. Paderborn 2007. 

Teil V: Anhang 



\section{Kurzcharakterisierung der Hauptfiguren und Siglenliste}

\subsection{Laslinstraße. Roman (Köln: Middelhauve 1965) ${ }^{1}$}

Axel Degen, der autodiegetische Ich-Erzähler, verurteilt in den für ihn gar nicht goldenen Fünfzigerjahren des zwanzigsten Jahrhunderts den Konsumkapitalismus einerseits, andererseits seine Eltern nicht zuletzt wegen ihrer Wortlosigkeit und Erstarrung. Sein innerer Monolog löst sich mitunter in Bewusstseinsstrom auf, zudem schaltet sich zeitweilig eine zusätzliche ,Stimme des Bewusstseins' ein. Bereits Degen neigt zur öffentlichen Selbstaufmerksamkeit, die sich als innere Zensur manifestiert. Als gravierender Unterschied zu späteren Romanen sind seine häufigen Rechenschaftserklärungen, Begründungen und vermuteten Kausalzusammenhänge zu erwähnen, die dem Leser zumindest aus Degens Sicht fast immer vollen Einblick ins Innere gestatten. Zudem handelt es sich bei der Figur nicht um den Typus des späteren Zeitvertreibers und Flaneurs - Prokrastination und Lethargie generell sind im weitgehend fremd -, sondern um eine im weitesten Sinne zielstrebige Person. Interessantheitsstrategien sind Mangelware, genauso wie die Fähigkeit zur Unsichtbarkeit noch nicht ausgeprägt scheint. Axel Degen lässt sich häufiger zu Verhalten verleiten, das ihm selbst widerstrebt, was mit (gezwungenem) assertivem IM einhergeht und das Harmoniewahren umfasst. Später entdeckt er erste Züge der elterlichen Wortlosigkeit und des ,Alltagsgespensts' auch bei sich und Elke, seiner Freundin. Er fühlt sich zudem zurückgesetzt und eifersüchtig auf seine Schwester. Mit Elke vergisst bzw. verdrängt er vieles davon, zieht von zu Hause aus und verdient eigenes Geld. Die kleinen Lügen lernt er sukzessive, sodass ein Entwicklungsroman der Täuschung entsteht.

\subsection{Abschaffel. Roman (Reinbek bei Hamburg: Rowohlt 1977)²}

Abschaffel, der als (meist) intern fokalisierter Er-Erzähler häufig in erlebter Rede über sein Angestelltendasein in den frühen 1970er Jahren in der Nähe Frankfurts Bericht erstattet, ,schafft sich im Büro ab'. Laut Genazino nicht humorbegabt, gelingt es ihm aber sehr wohl, schlagfertig und witzig zu agieren. Manische Selbstbeobachtungen bis zur Nabelschau, die er zunehmend als störend empfindet, bestimmen seinen Tag. Auch Vorwürfe an die eigenen Eltern bzw. die Schuldzuweisung, dass diese mittelbar für seine Lage verantwortlich seien, finden sich als dauerhafter Bewusstseinsinhalt. Daher werden die Besänftigungsstrategien in Form des interesselosen Schauens, des Flanierens etc. eingeführt, die Beruhigung auch vor Selbstgesprächen und leichten Verrücktheitsanflügen bringen. Häufig ist Hass auf die Umwelt die Folge seiner als sinn-

$1 \quad$ Sigle: Laslinstraße. Sofern es keine Abweichung zwischen der jeweils zitierten und derjenigen in der Überschrift erwähnten Erstausgabe gibt, wird lediglich die Sigle angeführt.

2 Sigle: Abschaffel. Zit. n.: Wilhelm Genazino: Abschaffel. Roman-Trilogie. München: dtv 2002, S. 5156. 
los empfundenen Arbeit. Aber auch die Freizeit wird als langweilig und trostlos geschildert. Pessimismus und depressive Verstimmungen münden in Antriebslosigkeit, Überforderung und innere Zensur. Für Margot, die ihn auch die unangenehmen Seiten des Daseins ertragen lässt und Intimität, Interessantheit und Selbstzufriedenheit in sein Leben bringt, beendet er sein kurzes ,Techtelmechtel' mit Frau Schönböck, was allerdings nicht heißt, dass er vorher oder nachher nur eine Sexualpartnerin gehabt hätte.

\subsection{Die Vernichtung der Sorgen. Roman (Reinbek bei Hamburg: Rowohlt 1978) ${ }^{3}$}

Als abgebrochener Gymnasiast arbeitet Abschaffel bereits 13 Jahre in der Firma. Er ist 31 Jahre alt, wohnt in Frankfurt und wird äußerlich als blass, Brillenträger und am ,Hals geschwollen` beschrieben. Abschaffel, aus dessen Sicht zumeist intern fokalisiert erzählt wird, durchlebt nach der Trennung von Margot, die nach einigen Missverständnissen und beruflichen Entscheidungen die Stadt verlässt, eine Lebenskrise, die als Katalysator für seine generelle Unzufriedenheit gefühlte Benachteiligung, dauerhafte Enttäuschung -, seinen Hass auf das Bürogefängnis sowie das Gefühl, ohne Genehmigung leben zu müssen, wirkt. Er ist auf Selbstschonung und Selbstbesänftigung gepolt: Alles ist ihm zu viel, er ist schreckhaft, ängstlich und überempfindlich, dieweil sein Körper zusehends überstark und verfrüht altert, wofür durchaus auch psychosomatische Gründe ins Auge zu fassen sind. Abschaffel ist bieder und vernünftig, durchschaut sich aber nicht restlos, was immer wieder eingestreute Erzählerkommentare beglaubigen. Er leidet unter mangelnder Selbstwirksamkeit, insofern er nicht das Gefühl hat, relevante Lebensbelange selbstständig verändern zu können. Zudem hält er sein eigenes Leben für verpfuscht und würdelos, obwohl er nicht mit Sicherheit benennen kann, was sich ändern müsste, um diesen Eindruck zu revidieren. Dass sich etwas ändern müsse, ist Abschaffel hingegen deutlich. Viele für das Mischpult relevante Aspekte tauchen erstmals auf: das Tierseinwollen, die Körperteilfremdheit, der Selbstzerfall etc. Auch die eigentümliche Vermutung, alles auf der Welt stehe in Bezug zu ihm und gehe ihn etwas an, findet sich erstmals gehäuft. Eine bewilligte Kur sowie erste klare Hinweise auf eine beginnende Verrücktheit beschließen den Roman.

\subsection{Falsche Jahre. Roman (Reinbek bei Hamburg: Rowohlt 1979)4}

Eine sich abzeichnende allgemeine Desillusionierung mit depressivem Einschlag leitet den Klinikaufenthalt ein, der sowohl Linderung der körperlichen wie geistigen Beschwerden zur Folge hat: Überspanntheit, Beobachtungszwang und Verknöcherung des Skeletts gehen deutlich zu-

3 Sigle: Sorgen. Zit. n.: Wilhelm Genazino: Abschaffel. Roman-Trilogie. München: dtv 2002, S. 157398.

4 Sigle: Falsche Jahre. Zit. n.: Wilhelm Genazino: Abschaffel. Roman-Trilogie. München: dtv 2002, S. 399-572. 
rück. Dass Sport dabei eine Rolle spielt, ist bemerkenswert, insofern Genazinos Protagonisten sonst nur Spott für Sportler übrig haben. Insbesondere wird aber durch die erforderlichen Therapiesitzungen und Abschaffels Fähigkeit, sich reflektiert öffnen zu können, dem Leser ein ungezwungener Einblick ins Innere und zumal die Vorgeschichte ermöglicht. Sein ,Grundekel' entstamme der Verknüpfung von Scham, Eltern und Kindheit; da bspw. seine eigene Herkunft eher ärmlich und sein Vater gerne bedeutender gewesen wäre, leide Abschaffel noch immer unter dem Geiz bzw. anderen Eigenarten der Eltern (und Geschwister), deren Beziehung untereinander aber auch in Bezug auf Abschaffel aufgearbeitet wird. Die Kur scheint zu gelingen, Abschaffel lebt auf und auch die Affäre mit der selbstbewussten Dagmar scheint heilsam - immer wieder mischen sich allerdings erste Sterbefantasien, Indiskretionen Dagmars oder Rückschläge hinein, wenn er bspw. in der Analyse den Hass auf die eigene Mutter im Wunsch nach der Degradierung von Prostituierten erkennt. Auch sieht er den Grund zu permanentem IM in der Kindheit und im Verhältnis zu den Eltern. Das Fazit der Analyse bescheinigt Abschaffel: „Beeinträchtigungswahn“ sowie den „ewige[n] schmerzliche[n] Abstand zwischen sich und der Welt" als Kardinalprobleme, welche künftig durch unproblematische Erlebnisse besänftigt werden sollen. Buch und Held enden gestärkt, aber immer noch potenziell zerbrechlich und an der (Arbeits-)Welt krankend.

\subsection{Die Ausschweifung. Roman (Reinbek bei Hamburg: Rowohlt 1981) 5}

Eckhard Fuchs arbeitet als Innendienstleiter in der Reifengroßhandlung Norris in Frankfurt. Er macht seinen Job gut und ist damit nicht unzufrieden. Fuchs sah und sieht gut aus, hat in der Erzählgegenwart (frühe 1980er Jahre) Frau (Ruth) und Kind (Anna), er ist 42 Jahre alt. Fuchs ist dabei deutlich ,reifer' und gesetzter als die früheren Figuren Genazinos, verantwortungsbewusst und einfühlsam. Auch die Verhältnisse bzw. der Lebensstil weichen ab: regelmäßige (Strand-)Urlaube und eine geräumige Vierzimmer-Altbauwohnung sind Romanspezifika. Die Ehe beginnt allerdings einhergehend mit Fuchs' Midlifecrisis zu kriseln: die Probleme häufen sich, Aussprachen finden sich mehr statt, die Sexualität verliert den Reiz, die Schlafzimmer werden getrennt und Fuchs hegt insgeheim den Wunsch, seine Familie loszuwerden. Die Affäre mit einer jungen Frau während des alleinigen Urlaubs seiner eigenen gibt dem Buch den Titel und bringt Abwechslung, aber auch Verstörungen und gedankliche Wirrnis in Eckhards Leben. Der Tod seines Vaters und der Konkurrenzkampf am Arbeitsplatz sind Quellen von Enttäuschung und Unzufriedenheit. Letztlich söhnt er sich mit der Normalität ein wenig aus, wenngleich die Melancholie ein echtes Happy End unmöglich macht. Die Figur ist lebenserfahrener und eigenständiger als die früheren Figuren, auch bürgerlicher. Fuchs nutzt IM häufig erfolgreich zielgerichtet und weiß

5 Sigle: Ausschweifung. Zit. n.: Wilhelm Genazino: Die Ausschweifung. Roman. 2. Auflage. München: dtv 2005. 
sich auch in persönlich schwierigen Situationen angemessen und selbstsicher(nd) zu verhalten. Insgesamt werden die Alltags- und Beziehungsprobleme wichtiger als die Bürotristesse.

\subsection{Fremde Kämpfe. Roman (Reinbek bei Hamburg: Rowohlt 1984)6}

Wie Eckhard Fuchs ist auch Wolf Peschek von gutem Aussehen. Er ist freischaffender Werbegrafiker in Frankfurt, 34 Jahre alt und hat mit seiner Freundin Dagmar Achatz guten und unverkrampften Sex. Pescheks Eltern sind bereits tot, er pflegt eine lose Beziehung zum eigenen Bruder, dem er eine alte Geschichte nachträgt. Hauptsächlich mit seinem Vater rechnet er immer wieder ab, begehrt im eigenen Verhalten allerdings dagegen auf. Er ist mutig, macht sich interessant, kultiviert keine Schuldgefühle und agiert selbstwertdienlich, worein sich deutlicher als bislang Überheblichkeit mischt. Im Textverlauf trübt sich die Sicht: die Aufträge gehen ihm aus, insgesamt herrscht Rezession, Achatz wünscht sich von ihm überfordernde sexuelle Praktiken, was in den Entschluss zur Trennung mündet, und schließlich misslingt sein Plan, mit dem Anund Verkauf von Hehlerware Geld zu machen. Peschek empfindet zunehmend alles als Kampf. Den zweifelsfrei sorgenarmen Momenten und der starken Person mit zupackendem Charakter und guten Ideen zum Trotz zerfließt Peschek dem Ende entgegen in Angststörungen mit überzogener Lebensscham und Unsicherheit, sodass ein düsteres und hoffnungsloses Romanende weder beruflich-finanziell noch privat Gutes verheißt. Erzähltechnisch gibt es erste gravierende Hinweise auf unzuverlässiges Erzählen, das die Grenzen des Realismus berührt. Das Tempo und der Handlungsreichtum heben den Roman aus der Masse heraus.

1.7 Der Fleck, die Jacke, die Zimmer, der Schmerz. Roman (Reinbek bei Hamburg: Rowohlt 1989) ${ }^{7}$

Der erstmalige Verzicht auf einen konkreten Namen der Hauptfigur W. geht einher mit einer Erzählgegenwart, die im Präsens intern aus der Ich-Perspektive geschildert wird. Das Alter des Protagonisten lässt sich auf ca. 40 Jahre schätzen. Er scheint finanziell völlig abgesichert zu sein, ohne zu arbeiten, und unternimmt gerne mit seiner Freundin Gesa, die als eine der rundesten Nebenfiguren gelten kann, zusammen Reisen. Er (sowie Gesa und sein Bekanntenkreis) ist intellektuell und kunstbeflissen, dabei leicht kulturkonservativ - was sich in seinen philosophischen Reflexionen äußert -, selbstsicher bis zur Dreistheit und interessant. Zudem weiß er auch andere mit seiner Interessantheit zu beeindrucken und changiert dabei zwischen hochmütiger Weltabwendung mit Verborgenheitswunsch einerseits und Zugehörigkeitswünschen andererseits. Vom Basistypus weicht seine immense Spontaneität ab. Die tatsächlich ,handelnden', plotrele-

\footnotetext{
6 Sigle: Fremde Kämpfe. Zit. n.: Wilhelm Genazino: Fremde Kämpfe. Roman. Reinbek bei Hamburg: Rowohlt 1989.

7 Sigle: Fleck.
} 
vanten Parts wechseln sich mit Rückblenden, Erinnerungen, Beobachtungen ab und zeichnen das Bild eines gekonnt IM nutzenden und relativ selbstbewusst agierenden Mannes, welcher der privaten Selbstaufmerksamkeit von allen bisherigen Figuren am nächsten kommt. Hybris und eine elitäre Haltung, welche die Kunst generell bzw. die Künstler über andere bzw. die Gesellschaft stellt, lassen sich ausmachen. Trotz melancholischer Anklänge und der titelgebenden (Welt-),Schmerzen' führt W. ein recht unbekümmertes Dasein und auch der von erneuter Reiselust - die hingegen auch als (von der Mutter übernommener?) Wunsch nach prinzipieller Abwesenheit gedeutet werden kann - geprägte Romanschluss lässt einen Lichtblick zu.

\subsection{Die Liebe zur Einfalt. Roman (Reinbek bei Hamburg: Rowohlt 1990) ${ }^{8}$}

,William', wie sich die Figur selbst nennt, Genazino hat einen Bruder und eine ältere Schwester, seit Neuestem allerdings keine Mutter mehr, wohingegen der Vater bereits vor 15 Jahren das Zeitliche gesegnet hat. Beiden Elternteilen werden immer wieder ,schlechte Zeugnisse' ausgestellt: Der Vater sei eigenbrötlerisch, naiv und ungehobelt, die Mutter schamhaft und depressiv gewesen. Weitere Hauptvorwürfe sind die gesamtfamiliär gestörte Kommunikation, die Leidenschaftslosigkeit der Eltern sowie der versäumte gesellschaftliche Aufstieg. Auch die Geschwister kommen dabei nicht gut weg, sodass der Wunsch nach einer anderen Familie erwähnt, zugleich aber auch die Vermutung der eigenen Schuld an der familiären Misere deutlich wird. In Erinnerungsblöcken arbeitet der Ich-Erzähler analeptisch seine problematische Vergangenheit auf, wohingegen die im Präsens geschilderte Erzählgegenwart fast immer auf Pause gestellt ist - bis auf die Aussprache mit seiner Schwester. Mit autobiografischen Bezügen spielend erklärt sich Genazino (Figur) sein Leiden an der Welt, der Gesellschaft und den Eltern psychoanalytisch selbst und kommt zum Schluss, der einzige Ausweg, um die Tristesse, die Unerträglichkeiten des Elternhauses etc. hinter sich zu lassen, führe über den Beruf des Künstlers. Qua Alkohol, Freundinnen und Nebenjobs hat Genazino (Figur) früh bereits eine unüberwindbare Trennwand zu seiner Familie aufgebaut. Im doppelten Ich und der auch in anderen Romanen praktizierten Unzuverlässigkeit ist der erzählerische Raum dafür, sich bestimmter Empfindungen vermeintlich selbst nicht bewusst zu sein. Die Thematisierung und Reflexion von IM hat hier einen Höhepunkt: Einerseits ist das Niveau immens, auf dem die Hauptfigur Eindruckssteuerung reflektiert, andererseits ist die schamhafte Nicht-Selbstdarstellung des Vaters ein potenzieller Grund späterer Strategien (etwa der Unsichtbarkeit). 


\subsection{Leise singende Frauen. Roman (Reinbek bei Hamburg: Rowohlt 1992) ${ }^{9}$}

Der gerade durch die Handlungsarmut, seine poetische Selbstversunkenheit, die sich auch im Stil des Romans niederschlägt, und die mangelnden ,echten' sozialen Kontakte schwer greifbare männliche Protagonist, der in der Ich-Perspektive das interesselose Schauen erlernt zu haben scheint, hat keinerlei finanzielle Sorgen, sonstige Bindungen oder Verpflichtungen, ja nicht einmal Beschäftigungen und - romanspezifisch, bis auf ,William‘ Genazino -: auch keine einzige Freundin, Geliebte oder Frau. Die auftauchenden Kindheitserinnerungen sind außergewöhnlich unproblematische, die Beobachtungen sind erstmals dezidiert vom gedehnten Blick getragen und versteigen sich zu Mutmaßungen und Wiederverzauberungen der Welt. Die Figur scheint Schriftsteller zu sein, was sie auch mit der Selbstreflexion des Schriftstellerberufs etwa in Form der Notwendigkeit des Beobachtens des Alltäglichen für das Schreiben begleitet, und fortgeschrittenen Alters. Der Ich-Erzähler ist nicht mehr scheu oder übertrieben unsicher, sondern ein eigenbrötlerischer und hin und wieder seine Merkwürdigkeit auch für andere sichtbar zur Schau stellender Mann, der ab und an glaubt, heimlich wahnsinnig zu werden, was man aber eher als übersteigerte Empfindsamkeit umschreiben kann, die ihn seit der Kindheit begleitet und immer wieder in seine künstlich-erwachsene Abhärtung eindringt.

\subsection{Die Obdachlosigkeit der Fische (Reinbek bei Hamburg: Rowohlt 1994) ${ }^{10}$}

Die einzige weibliche Protagonistin ist Lehrerin, schätzt das Alleinsein, weil es sowohl ungerichtete Schuldgefühle als auch die öffentliche Selbstaufmerksamkeit in Schach hält, und bleibt konsequent namenlos. Als alternde und darunter leidende, mit ihrem Äußeren nicht zufriedene Mittvierzigerin hat sie einen Lebensgefährten namens Helmuth, seines Zeichens 52-jähriger Rechtsanwalt, den sie - wie alles andere auch - auf Distanz hält aus (mindestens) zwei Gründen: ihrer „Weltnichtzugehörigkeit“ als überzeugter Individualistin und der Furcht vor der Banalität des Alltags, die sie doch immer wieder einzuholen droht. In drei durch zahlreiche Rückerinnerungen unterbrochenen, von Beobachtungen, Wahrnehmungen, Reflexionen und Gedankenspielen durchzogenen Erzählblöcken verlebt sie die Schulferien. Die Figur wird selbstständig und emanzipiert gezeichnet, in ihrer kontrapunktischen melancholischen Zerrissenheit hat sie allerdings ihr inneres, ,eigentliches‘ Ich eingeschlossen und spricht in Form einer Zitadellenmetapher von ihrer ,Festung', von der aus sie die Welt aus der unbeobachteten Beobachterposition erlebt und mit ungerichteter Sehnsucht nur Nebenschauplätze des Lebens, aber nicht das gewünschte, originelle, einzigartige Leben findet. Hauptsächlich ihr Beruf führt zu lebensgesättigter Desillusionierung und deutlicher Kritik am Schulsystem, was schließlich die tadellose Fassade (Job, Partner, Geld) sprengt und eine grundlegend unzufriedene Frau erkennbar werden lässt. Dieses 
Bild wird hingegen durch den überraschend positiven Schluss, an welchem sie sich mit den Gegebenheiten weitgehend arrangiert, wiederum gebrochen. Die aufregende und sexuell aktive Vergangenheit wird zumeist positiv geschildert. Mit den titelgebenden Fischen teilt sie sich den Wunsch, sehnsuchtsvoll ,das Weite‘ suchen zu wollen. Hinsichtlich der Schlaglichter thematisiert der Text mittels der Figur insbesondere deutlich die innere Zensur, die Genderproblematik und die Unsichtbarkeitsstrategien.

\subsection{Das Licht brennt ein Loch in den Tag (Reinbek bei Hamburg: Rowohlt 1996) ${ }^{11}$}

Erzähltechnisch wird das Leben von W., der ein Kind der 1950er Jahre ist, anhand seiner mitunter beantworteten Briefe, Notate, Erinnerungen etc. geschildert. Er lebt mit einer 39-jährigen Laura zusammen, die seine Merkwürdigkeiten, Makel und Marotten gut aushält, und hatte früher eine mittlerweile verstorbene Ehefrau namens Elisa. Erneut liegen keine finanziellen Nöte vor, sodass äußerlich betrachtet ein ,unproblematisches' Leben gegeben schiene, was indessen durch die inneren Konflikte von Alter, Todesahnung, Erinnerungsverlust etc. eintrübt wird. W. erinnert Splitter seines Lebens - wobei die Investigation der Eltern eine absolut untergeordnete Rolle spielt - und verteidigt unzuverlässige, da weiter umgebaute (und somit seinem Selbstbild passendere?) Erinnerungen gegen die ,echten'. Briefe, Erzählgegenwart, Tagträume, Sehnsüchte und Erinnerungen verschmelzen dabei, sodass erstmals dezidiert Gedächtnisverlust und unzuverlässiges Erzählen parallelgeführt werden. W. scheint (wenn man den Briefen glaubt) sozial ungewöhnlich gut eingebunden, kontaktfreudig und selbstbewusst zu sein, was nicht heißt, dass er nicht zuhöchst eigenbrötlerisch wäre. Bemerkenswert ist generell, dass etliche ,Erzählschnipsel sowohl hinsichtlich der motivationalen Figurenhandlungen als auch -beobachtungen vor IM und dessen Reflexion strotzen. W. sucht seine Mitte und findet Beruhigung in der Nähe des Meeres; zwar wird der Haupterzählstrang offen gelassen, der letzte Brief ist allerdings versöhnlich.

\subsection{Die Kassiererinnen. Roman (Reinbek bei Hamburg: Rowohlt 1998) ${ }^{12}$}

Mit dem Roman werden die zuvor herrschende Experimentalität und auch die Verwendung des Präsens zurückgenommen, was sich in der Figur spiegelt: Sie distanziert sich von ,damaliger Empörung und freut sich ihrer nunmehrigen Gleichgültigkeit. Der namenlose Ich-Erzähler, dem an ,harten' biografischen Daten lediglich ein Alter von mindestens 41 Jahren und (vermutlich) der Beruf des Schriftstellers attribuiert werden kann, legt eine hochreflexive Selbstbeobachtung an den Tag: Keine andere Figur hat elaboriertere Beobachtungen über Selbst- und Fremdbilder,

\footnotetext{
11 Sigle: Licht.

12 Sigle: Kassiererinnen. Zit. n.: Wilhelm Genazino: Die Kassiererinnen. Roman. 4. Auflage. Reinbek bei Hamburg: Rowohlt 2009.
} 
öffentliche Selbstaufmerksamkeit und die Ausrichtung des eigenen Verhaltens an der Bewertung anderer, die sich wie ein roter Faden durch den Roman ziehen und sie zum Kronzeugen der IMReflexion werden lassen. Nach dem Tod seiner Frau Edda vor über zwei Jahren bahnt sich für den Erzähler erstmalig wieder geistiger und sexueller Kontakt zu einer Frau an (Wanda), der sich bis zum Romanende zur Beziehung auswächst. Die Figur entwickelt ein generöseres Verhältnis zum omnipräsenten Beobachtetwerden und übt sich erstmals erfolgreich in Gleichgültigkeit, die von einer Kraft getragen wird, die es ermöglicht, sogar andere sozial Inkompetente aufzurichten, sprich: Im Gegensatz zu den sonst eher hilfebedürftigen Protagonisten übernimmt dieser erstmals selbst die Rolle des Problemlösers bzw. ,Therapeuten' für andere. Der (nicht nur imaginierte) explizit fremde Blick wird erstmals greifbar und nicht nur im verquasten Inneren angesiedelt - doch anders als erwartbar bringt das den Ich-Erzähler nicht aus dem Konzept, sondern er wächst daran, anzuerkennen, dass alle mehr oder minder das Los teilen, hin und wieder beobachtet zu werden - eine bahnbrechende und nicht basistypische Erkenntnis, die sich auch im versöhnlichen Romanschluss ausdrückt.

\subsection{Ein Regenschirm für diesen Tag. Roman (München/Wien: Hanser 2001) ${ }^{13}$}

Als namenloser 46-jähriger steht der Ich-Erzähler zu Beginn des Romans vor den Trümmern eines Lebens: Von der Exfreundin Lisa - 42 Jahre alt, frühpensionierte Lehrerin - verlassen, ist sein Job als Schuhtester im Erzählverlauf bedroht, wodurch die existenziellen Sorgen erstmals seit vielen Romanen wieder Einzug halten. Er bewegt sich an der (gefühlten) Grenze zur Verrücktheit und das existenzialistische Gefühl des von ihm ,nicht genehmigten Lebens' treibt ihn um. Insbesondere der letzte Aspekt erinnert an Abschaffels Problem und mithin an das ,innere Visum' aus Ilse Aichingers Roman Die größere Hoffnung (1948), was sich in der hier verfolgten Lesart als Reflexion über die (mangelnde) Selbstwirksamkeit verstehen lässt. Ohne klare Wegmarken ausmachen zu können, macht der Erzähler eine - zumindest äußere - positive Entwicklung durch: Neue Frauen, an denen es dieser Figur nicht mangelt, mehrere neue Jobangebote, die Gewissheit, noch nicht verrückt geworden zu sein, und die Bereitschaft, sein Leben doch noch genehmigen zu können, lösen die Probleme zumindest scheinbar in Luft auf, obwohl etwa der vergebliche Kampf gegen die Spaß- bzw. Erlebnisgesellschaft nicht zu gewinnen ist. Hinsichtlich der mangelnden Sozialkompetenz und dem Hang zu massiver öffentlicher Selbstaufmerksamkeit bildet die Figur einen Gegenpart zur vorangehenden, in Bezug zur ,inneren Stärke - zwar immer gebrochen durch Minderwertigkeitsgefühle, Scham etc. - gelingt es ihr jedoch erneut, eine Therapeutenfunktion für andere einzunehmen und grenzt sich insgesamt von den als gescheitert gebrandmarkten Lebensentwürfen in seinem Umfeld ab. Erstaunlich ist die Tendenz, über die Kindheit nicht nachsinnen zu wollen, da dort peinliche Erlebnisse schlummern - man könnte 
fast von einer gezielten und ,bewussten Verdrängung' sprechen. Selbstreflexive Einlassungen zumal auch zur Eigenschaft des „bedeutungsvollen Sehens“ kennzeichnen eine Figur, deren Kapitalstruktur deutlich eine Kluft zwischen hoher Bildung und geringem materiellen Besitz akzentuiert. Die kalkulierte Außenwirkung nimmt für den Protagonisten, der sich gut auf Strategien der Interessantheit versteht, viel Raum ein. Den Vorwurf, Genazinos Erzähler würden publikumswirksam mit dem Leser kokettieren, kann man hier erstmals ausgeprägt am Werk sehen.

\subsection{Eine Frau, eine Wohnung, ein Roman (München/Wien: Hanser 2003) ${ }^{14}$}

Aus mindestens zwanzig Jahren Distanz schildert der Ich-Erzähler namens Weigand sein erinnertes Ich, das von größerer Wichtigkeit zu sein scheint, als das erzählende. Jenes ist mit 17 Jahren vom Gymnasium geflogen und wird unmittelbar darauf von seinen Eltern gedrängt, eine Lehrstelle zu suchen. Allerdings mausert sich der Erzähler, der weitaus eher an Literatur interessiert ist und proaktiv Texte an Verlage und Redaktionen schickt, im Textverlauf zum 18Jährigen, welcher gute Aussichten auf eine Schriftstellerexistenz und nebenbei zwei - sich letztlich ausschließende - Jobs als Journalist und Lehrling hat. Damit werden zugleich auch Arbeiter und Angestellte sozialkritisch einander gegenübergestellt. Dieser in Aussicht stehende Erfolg verdankt sich seiner unüblich zielstrebigen und ehrgeizigen Ausstattung und wird zudem bereichert um die Einführung in die Intellektuellenkreise Frankfurts. Der Erzähler wendet sich demzufolge in der Analepse von seiner früheren Freundin Gudrun ab, da sie seine Literaturbesessenheit nicht teilt, und wendet sich der Journalistin Linda zu. Eng damit verknüpft ist sein ,standessensitiver Dünkel' eine vordergründige Charaktereigenschaft, die sich hauptsächlich darin äußert, mit der Spaßgesellschaft und deren ,Einwohnern' nichts zu tun haben zu wollen und sein Selbstbild als Schriftsteller zu zelebrieren. Darüber vermittelt finden sich viele Milieu- und Lebensstilreflexe. Das im Zentrum stehende, damalige Ich verfolgt seinen vagen Lebensplan fokussiert und ist bis auf seine Schüchternheit für das junge Alter recht gewieft im Umgang mit anderen Menschen. Auch die Anspielungen auf eine damals depressive Mutter und der Selbstmord Lindas können ihn trotz einiger Schuldgefühle nicht bremsen; vielmehr nutzt er jene als Abrechnung mit den Eltern und diese als Anlass zu seiner ersten Reise überhaupt. So schlägt sich die Figur auch in ungewohnten Situationen erfolgreich, löst sich sukzessive von seinen Eltern, entdeckt die Sexualität (mehrfach) und findet ein Lebensmotto - das ist nicht nur die Paraphrase eines Entwicklungsromans, wobei das schnelle Erwachsenwerden den Erzähler um einige jugendliche Genüsse betrügt. 


\subsection{Die Liebesblödigkeit. Roman (München/Wien: Hanser 2005)}

Der namenlose, 52-jährige Ich-Erzähler vereint (in Ansätzen) Charaktereigenschaften auf sich, die basisuntypisch, wenngleich nicht neu sind: Zielstrebigkeit, Pflichtbewusstsein, Eigenwerbung für seinen Beruf, die auf gekonnte Werbeanzeigen und professionelle Vorträge vertrauen darf. Dabei ist die öffentliche Selbstaufmerksamkeit bei der Figur, die früher einmal mit Bettina verheiratet gewesen ist und ein Studium absolviert hat, weit zurückgefahren. Es ist der sexrelevanteste Roman bislang, der explizit zum Thema macht, was viele Protagonisten (und in ähnlicher Variante auch die einzige Protagonistin) bereits umgetrieben hat: Zwischen zwei antipodischen (Frauen-)Typen hinsichtlich Körper, Geist, und Eigenschaften stehend (Sandra vs. Judith), die er gleichzeitig polyamorös miteinander betrügt, muss er sich aus einem gefühlten moralischen Dilemma heraus für eine der beiden entscheiden, wobei das permanente Vergleichen so vergnüglich wie verwerflich ist. Sein Job als Apokalypsereferent gibt der im Präsens erzählenden Figur gutes Geld an die Hand und ist ihr fast nicht peinlich, ihre Interessantheitsstrategien, ihre lebenszugewandte Art - obwohl die mittlerweile obligatorischen Todesahnungen, Sterbefantasien und Hypochondrie omnipräsent sind - und der (relative) Handlungsreichtum machen das Figuren-Ich unüblich und lassen die Vermutung eines ,Angekommenseins' aufblitzen. Der hohe Grad an Selbstreflexion ermöglicht dem Erzähler detaillierte Einblicke in seine Probleme und Wünsche, die sich ums Altern, die Liebe und die Lust drehen, wobei am Ende zwar alles beim Alten bleibt, dies aber goutiert werden kann.

\subsection{Mittelmäßiges Heimweh. Roman (München: Hanser 2007) ${ }^{16}$}

Dieter Rotmund feiert im Erzählverlauf seinen 43. Geburtstag, erzählt aus der Ich-Perspektive im Präsens (mit Analepsen) von seinem Alltag und der Trennung von seiner Frau Edith, die ihn zwischen dreist, gefühlskalt und ehebrecherisch changierend - ,verstößt'. Rotmund erscheint im Text als Opfer einer selbstsüchtigen, faulen, und geldgierigen Frau, was durchaus im Einzelnen zu hinterfragen ist. Rotmunds Job als diplomierter Controller bei einem Pharmakonzern wird im Textverlauf aufgewertet zum Direktor, was zwar die Geldnöte mit einem Schlag vom Tisch wischt; die Distanz zu seiner Tochter Sabine sowie das allgemeine Alleinsein, das andere Romanfiguren ja dezidiert herbeisehnen, machen ihn hingegen ,fertig'. Im Alltag und im Beruf ist er ein selbstsicherer, melancholischer Charakter, der insgesamt zwei Körperteile verliert, was einerseits als Überschreitung realistischer Romankonventionen lesbar, vermutlicher indes als Symbol für den inneren Schmerz, den Selbstzerfall und die Ruhebedürftigkeit (Ohrverlust) interpretierbar ist. Die Affäre mit Sonja Schweitzer, der, wie sich herausstellt, eine Brust fehlt, und die, wie sich überraschenderweise herausstellt, Heiminsassin ist, zeichnet sich durch drastisch

15 Sigle: Liebesblödigkeit.

16 Sigle: Heimweh. 
geschilderte Sexpassagen aus, die jedoch aufgrund deren Gefängnisaufenthalts (Kreditkartenschwindel) versanden. Der ,Schmerzensmann' Rotmund möchte bemitleidet werden und hält eine bevorstehende Katastrophe für wahrscheinlich, die sich mit dem Körperteilverlust eines Kindes auch anzudeuten scheint. Auch das Kennenlernen einer neuen Frau, das dem Zufall geschuldet ist, kann das pessimistische, wenngleich offene Ende nicht kaschieren.

\subsection{Das Glück in glücksfernen Zeiten. Roman (München: Hanser 2009) ${ }^{17}$}

Gerhard Warlich, 41 Jahre alt, arbeitet als Organisationsleiter bei einer Großwäscherei. Nebenbei ist er Hobbykünstler: malt, schreibt und filmt. Warlich lebt seit zehn Jahren mit der 38jährigen Bankangestellten Traudel zusammen und verfällt - als komplizierter und schwieriger Charakter - in eine Depression, die mit zunächst kleineren, später größeren Verrücktheiten, die sich auch auf Darstellungsebene manifestieren, einhergeht und ihn nach einem Zusammenbruch auf Initiative Traudels (vermutlich mit einer ausgewachsenen Depression) in eine Klinik bringt. Offen bleibt am Schluss des Präsens-Romans, ob der Ich-Erzähler, der über Heidegger promoviert hat, es Traudel verzeihen kann, ihn eigeliefert zu haben. In den darauffolgenden Analysesituationen und unter medikamentösem Einfluss kann sich Warlich, der bereits vor der Einlieferung beginnt, äußerlich leicht zu verwahrlosen, messerscharf analysieren und gibt sehr viele Einsichten in sein Probleme, die sich um sein Selbst ranken, preis. Sein ungerechtfertigter Jobverlust und der Streit mit Traudel über potenzielle Heirat und Kinderkriegen, auch sein sexuell übergriffiges Verhalten, sind die äußeren Faktoren, die den ,Verfall' auslösen, aber im Kern geht es von Beginn an darum, dass Warlich ein anderes Leben sucht und nicht findet und die alltäglichen An- und Überforderungen an ihn - etwa ablesbar im Wunsch, nur halbtags leben zu wollen - ablehnen möchte. Insbesondere hinsichtlich der Diskrepanz zwischen Kapital-Ideal-Struktur und Status Quo scheint keine Vermittlung möglich: Warlich hat sich zwar in Ansätzen ,hochgearbeitet', seine Akkumulation bestimmter Kapitalformen ist letztlich aber nicht dazu geeignet, ihm Befriedigung zu verschaffen. IM-bezogen handelt es sich bei dieser Figur generell um durchdachte und gekonnte Ausübung von Selbstdarstellung, obwohl sie das tägliche Theaterspielen verabscheut. Warlich fühlt sich in der Klinik, wie seinerzeit Abschaffel, gut aufgehoben, findet (tablettengestützt) innere Ruhe, liebäugelt mit einem längeren Verbleib in der Klinik und/oder Frühverrentung und spricht gar vom dort gefundenen ,Glück'.

\subsection{Wenn wir Tiere wären. Roman (München: Hanser 2011) ${ }^{18}$}

Der namenlose Ich-Erzähler, dessen Eltern bereits längere Zeit tot sind, ist freier Architekt und leidet an akuter (Arbeits-)Unlust. Im prinzipiell im Präteritum präsentierten, mitunter ins Prä- 
sens umschlagenden Erzählverlauf tritt er dennoch eine feste Stelle an, was mit einem Einschnitt in seine geschätzte Unabhängigkeit einhergeht. Er neigt generell zum ,Einigeln' in seiner Zweizimmerwohnung und zur stillen Distanz, kann seine Wesenszüge gut einschätzen und verbalisieren, sodass Selbsterkenntnisse bzw. -charakterisierungen häufig sind. Diese schreiben ihm zu, vom Leben benachteiligt, langweilig, erstarrt und verwirrt zu sein. Der Protagonist ist augenscheinlich auf ,Selbst-Suche', von der Welt angewidert und vom Typ her Melancholiker. Er trauert seiner Exfrau Thea nach, hat, wie der Erzähler der Liebesblödigkeit, die ,Qual der Wahl' zwischen zwischenzeitlich zwei Geliebten - Maria: tatkräftig, Werbefachfrau, trinkt zu viel vs. Karin: Witwe des unlängst verstorbenen Kollegen Autz, dessen Beerdigung er teilnahmslos beigewohnt hat - mit temporären Trennungen, da Sexualität für ihn eine große Rolle spielt. Seine zelebrierte Überempfindlichkeit wächst sich bis hin zur Lebensfurcht und -vermeidung aus, Individualisierungsreflexionen und Individualismuswünsche sind wichtige Punkte auf seiner täglichen mentalen Agenda. Es handelt sich global besehen um einen im Ton und Leben mittelmäßigen und traurigen, von Alters- und Todesgedanken geplagten Protagonisten, der, wie Warlich, das Verstellen nicht mag, aber gekonnt IM betreiben kann. In Form des Betrugs sucht er qua Borderlineerfahrungen das Heil, welche ihn allerdings nur temporär ins Gefängnis befördern. Lebensangst und offenkundig ernstzunehmende Verwirrung, als er seinen toten Kollegen für verzogen statt tot hält, lassen das offene Ende merkwürdig ,unfertig' wirken.

\subsection{Bei Regen im Saal. Roman (München: Hanser 2014) ${ }^{19}$}

Der 43-jährige, promovierte, aber ,nur' zwischen Hotelbar und Lokalzeitschrift wechselnde Reinhard, dessen Namen der Leser erst kurz vor Ende des Romans erfährt, wird - nicht zuletzt durch seine Initiativlosigkeit selbstverschuldet - von seiner angehimmelten Freundin Sonja, die als Finanzbeamtin gut verdient, verlassen. Bereits vor diesem Ereignis hatte der Erzähler in der Vergangenheit (Erzähltempus: Präteritum) ein Verhältnis mit einer Sekretärin. Letztlich findet er, der ob seines nach überlangem Philosophiestudium gescheiterten Plans einer akademischen Karriere noch immer Scham empfindet, aber im Erzählverlauf über kurze Affären zu ihr zurück bzw. sie, die in der Zwischenzeit geheiratet hat, von ihrem Mann aber betrogen worden ist, zu ihm. Seine ehemals verachteten Eltern kann er nach deren Tod besser nachvollziehen, wobei trostlose Gedanken an die Kindheit seine frühere Biografie negativ einfärben. Auch seine aktuelle Lebenslage ist von Selbstzweifeln, Schamreflexionen, Resignation und Pessimismus überschattet. Starker Argwohn allem gegenüber gepaart mit Unsicherheit und Ansätzen zum ,Unterm-Pantoffel-Stehen' sowie einem äußerst starken Hang zur inneren Zensur kennzeichnen die Figur. Reinhard, der möglicherweise - seine Aussagen widersprechen sich - früher bereits einmal verheiratet gewesen ist, möchte einen „Schonbezirk“ für sein überempfindliches Leben er- 
richten, neigt zur Verwahrlosung und Frühvergreisung. Erneut wird die Figur, welche mitunter auch die Warenwelt verteufelt, auf Discours-Ebene gedoppelt als erinnerungsschwach bzw. nahezu dement dargestellt: Dopplungen und Redundanzen, widersprüchliche Aussagen sowie der Erzählchronologie widersprechende Einsprengsel erschweren die identifikatorische Lektüre. Er möchte alles ,überwinden' und hinter sich lassen, insbesondere sein schwieriges Verhältnis zu den Eltern (namentlich der Mutter). Daraus entsteht eine erstmals derart dezidiert vorgebrachte Gleichgültigkeit seiner Umgebung gegenüber. Seine eigene Biografie genügt nicht seinen Ansprüchen, da sein Selbstbild mitunter eklatant vom idealen abweicht. Alters- und Todesgedanken lassen sich für den Erzähler nur durch einen mittlerweile radikalisierten gedehnten Blick abmildern: Alles bis zur Selbstauflösung anzustarren ist Kern seiner ,Theorie der Überwindung‘. Unentschiedenheit, Unentschlossenheit und Nichtverstehen des Lebens lassen den unkomischen und unfertig wirkenden Roman, der zudem den Titelbezug fast völlig aufgibt, desperat enden. Kulminationspunkte hinsichtlich der Schlaglichter sind Sex und Gender sowie die Thematik der Individuation.

\subsection{Außer uns spricht niemand über uns. Roman (München: Hanser 2016) ${ }^{20}$}

Der namenlose, männliche Ich-Erzähler, der nach gescheiterter Theaterkarriere als Rundfunksprecher, Moderator von Modenschauen u. Ä. im Umkreis von Frankfurt arbeitet, bleibt im gesamten Text sehr blass und ,unausstaffiert'; durch Erinnerungs- und Formulierungsredundanzen auch unzuverlässig bzw. erneut ,dement'. Er hatte früher eine vor vielen Jahren an einer Hirnblutung verstorbene Exfrau Sybille sowie zahlreiche Affären, mittlerweile eine Freundin namens Carola, die einem ihr peinlichen Telefonistenjob in einer Spedition nachgeht, von der er allerdings zwischenzeitlich (mehrfach?) getrennt ist. Sie ist zwischen 35 und 40 Jahre alt, wird sensibel und einfühlsam genannt, hat einen Abort, der vom Erzähler möglicherweise hätte verhindert werden können, und begeht letztlich (vermutlich aufgrund von Alkoholismus und/oder einer Depression) Selbstmord, was den autodiegetischen Erzähler aus der Bahn wirft, obwohl er ohnehin bereits über die gesamte erzählte Zeit, die aufgrund etlicher Erinnerungskleinteile zäh und weitschweifig wirkt, unzufrieden - er würde gerne bedeutsamer leben -, melancholisch, depressiv und gelähmt ist. Schweigen, Sprachlosigkeit und Missverständnisse sowie die Einschätzung, dass sie nicht zusammenpassen, haben die Beziehung bereits vor dem Suizid belastet. Die permanente Furcht des Protagonisten, sozial abzurutschen oder verrückt zu werden, gepaart mit Selbst- vs. Idealbildinkongruenz, einem vagen Gefühl, aus der Zeit gefallen zu sein, Überforderung, Welt- und Sich-selbst-nicht-Verstehen sowie auf Körper und Geist bezogene Alterserscheinungen mit Todesanspielungen durchziehen sein Leben. Insbesondere die erneute Widersprüchlichkeit der Aussagen - finanziell abgesichert vs. kurz vor dem Bankrott; Erzähler 
wirft Carola Kulturlosigkeit vor vs. Carola ,nervt' Erzähler mit ,Bildungsgehabe‘ etc. - lässt nur ein schwindendes Erinnerungsvermögen plausibel erscheinen, das die Kohärenz einer erzählten Lebensgeschichte genauso aufweicht wie die Annahme, von einer fixen Position aus einer Erzählgegenwart heraus zu erzählen. Die nunmehr bekannten Tendenzen, dass alles an ihm abgleitet und sein Interesse nicht mehr davon erregt wird, was in der Welt passiert, sowie seine zunehmende Verwahrlosung bestärken diesen Eindruck noch. Einerseits handelt es sich um einen nahezu unerträglichen ,Schmerzensmann', andererseits finden sich die ebenfalls bereits geläufigen Leseransprachen, IM-Reflexionen und sogar die situationsadäquate Handhabe von Verhaltenskalkül. Letztere ist bis in seine Formulierungen hinein vorhanden. Eine große Rolle spielen Unsichtbarkeit und Flucht, Sex und Gender. Trotz vieler Selbsterkenntnisse entsteht keine ,tiefe oder ,runde' Figur.

\subsection{Kein Geld, keine Uhr, keine Mütze. Roman (München: Hanser 2018)}

Der namenlose, männliche Ich-Erzähler lässt sich nicht mehr einwandfrei als kohärente Figur bezeichnen, da (mindestens) die Zeitebenen zu verschwimmen beginnen, mithin Erzählgegenwart und Erinnerung nicht mehr eindeutig getrennt werden können. Zwar finden sich basistypische Angaben - wie die von zwei Geschwistern und toten Eltern, die Erwähnung von Altersflecken, die Nachkriegskindheit etc. -; die ,falschen', bzw. doppelten und sich widersprechenden Erinnerungen hingegen lassen kein klares Bild entstehen, sodass keine verlässliche Vita behauptet werden kann, genauso wenig wie ein fester Figurenkern. Über den Roman verteilt verliert der Protagonist seine Ex-Frau Sibylle, die ihm zuvor ein größeres Geldgeschenk macht, vermutlich aufgrund eines Selbstmords (evtl. Unfall); eine zweite langjährige Geliebte (Christa) verliert ihre Brüste aufgrund von Krebs, woraufhin beide sich aus den Augen verlieren; die dritte Frau, Frederike, und er hadern auch miteinander. Den drei unterschiedlichen Frauen, neben denen in der Vergangenheit dutzende (!) Affären gestanden haben, eignet die Funktion, abwechselnd als ,Ersatzmutter' gezeichnet zu werden, was die Investigation der Eltern zu nicht gekanntem Ausmaß steigert und - wie auch schon im vorangegangen Roman - ödipale Konstellationen aufruft, wobei der Verlustschmerz und das Verzeihen, auch erstmalig erwähnter antijudaistischer Tendenzen des Vaters, zunehmen. Nach dreimaligem Scheitern im Beruf (als Bibliothekar, Wertpapierhändler und Provinzredakteur) ist die Figur aktuell erneut arbeitslos, ohne am Hungertuch zu nagen; zum Ende taucht eine als erdrückend empfundene Jobaussicht auf. Es handelt sich um die radikalste Abkehr von Umwelt und Menschen: ,Echte‘ Langeweile, Todesgedanken, -vorbereitungen und -wünsche, Alterserscheinungen und Verwahrlosung deuten langsam aber sicher auf einen Abschied von der Welt hin, wofür auch die (trotz der mehrfach beteuerten NichtReligiosität) etlichen Bibelanspielungen Indizien abgeben. In diesem Sinne sind auch die Aussa- 
gen zu interpretieren, nach denen die Figur weder wisse noch wissen wolle, welche Jahreszeit, welcher Wochentag und welche Uhrzeit seien. Redundanzen in der Sache und der Formulierung fallen noch massiver als bisher ins Auge, genauso wie die etlichen ,Konstruktionsfehler ${ }^{\prime}$ - die Vergesslichkeit scheint final der Demenz gewichen. Der Protagonist hat die Peinlichkeiten und die öffentliche Selbstaufmerksamkeit mit innerer Zensur weitgehend abgelegt, was aber keine Versöhnung mit der Ratlosigkeit bedeutet, nicht zu wissen, was kommen wird oder soll, und den traurigen Schluss markiert. 


\section{Fragenpool für die Figurenanalyse}

Tabelle 2: Fragenpool für die Figurenanalyse

\begin{tabular}{|c|c|}
\hline Figur $=$ Person (Wie ist die Figur?) & Figur = Funktion (Wie ist die Figur gemacht?) \\
\hline \multicolumn{2}{|c|}{$\begin{array}{l}\text { Die im Folgenden kompilierten Aspekte bzw. Fragenkomplexe verstehen sich lediglich als mögli- } \\
\text { cher Pool einer prinzipiell unabschließbaren Liste. }\end{array}$} \\
\hline & $\begin{array}{l}\text { Grad der Profilierung: } \\
\text { Sind die Figuren - nach Forster - ,flach' oder } \\
\text {,rund'?1,2 }\end{array}$ \\
\hline & $\begin{array}{l}\text { Explizite vs. implizite Charakterisierung: } \\
\text { Wird die Figur in erster Linie von einem allwis- } \\
\text { senden Erzähler explizit beschrieben oder müs- } \\
\text { sen die Leser die Persönlichkeit der Figur aus } \\
\text { ihrem Handeln und ihren Äußerungen erschlie- } \\
\text { ßen?2, 3 }\end{array}$ \\
\hline & $\begin{array}{l}\text { Profilierung im Modus des Zeigens (sho- } \\
\text { wing): } \\
\text { Welche Mittel der Profilierung durch Figuren- } \\
\text { handeln, Figurenrede, äußere Merkmale oder } \\
\text { die Interaktion mit anderen Figuren (Charaktan- } \\
\text { ten-Beziehungen) werden eingesetzt?2 }\end{array}$ \\
\hline & $\begin{array}{l}\text { Prinzipien der Figurenwelt: } \\
\text { Stellt die fiktive Welt spezielle Regeln und Nor- } \\
\text { men auf, nach denen wir das Handeln und Äuße- } \\
\text { rungen der Figuren beurteilen müssen/sollen?2 }\end{array}$ \\
\hline & $\begin{array}{l}\text { Figurentypus: } \\
\text { Verkörpert die Figur einen sozialen, kulturellen } \\
\text { oder psychologischen Typus? Sind die Hauptfi- } \\
\text { guren einer bereits bekannten literarischen Fi- } \\
\text { gur, einer lebenden oder einer historischen Per- } \\
\text { son nachempfunden oder haben sie Ähnlichkeit } \\
\text { mit einer solchen?2 }\end{array}$ \\
\hline & $\begin{array}{l}\text { Genrespezifische Figurenrollen: } \\
\text { Wird die Anlage und Verteilung der Rollen unter } \\
\text { den Figuren von Genrekonventionen bestimmt?2 }\end{array}$ \\
\hline & $\begin{array}{l}\text { Figurenkonstellationen: } \\
\text { Gibt es systematische Beziehungen zwischen } \\
\text { den Figuren in der Erzählung wie z. B. Oppositi- } \\
\text { onen, Dualismen, Parallelismen, Ähnlichkeiten } \\
\text { oder Negationen? Erfasst werden soll die Positi- } \\
\text { on und der Stellenwert, die bzw. den einzelne } \\
\text { Figuren relativ zu anderen Figuren einnehmen, } \\
\text { sowie das gesamte System dieser Beziehungen. }\end{array}$ \\
\hline $\begin{array}{l}\text { Psychische Konstitution, Charakter: } \\
\text { Über welche Persönlichkeitsstruktur verfügt } \\
\text { die Person? Was sind ihre Bedürfnisse, Prin- } \\
\text { zipien, Verhaltensdispositionen? Ist ihr Cha- } \\
\text { rakter eher statisch oder entwickelt er sich? } \\
\text { usw. }\end{array}$ & \\
\hline
\end{tabular}




\begin{tabular}{|c|c|}
\hline $\begin{array}{l}\text { Äußeres, Verhalten: } \\
\text { Wie sieht die Person aus? Über welche physi- } \\
\text { schen Merkmale, welche Kleidung usw. ver- } \\
\text { fügt sie? Wie agiert sie habituell und situa- } \\
\text { tiv?4}\end{array}$ & \\
\hline $\begin{array}{l}\text { Mentales: } \\
\text { Was glaubt, denkt, fühlt, wünscht, plant, } \\
\text { fürchtet usw. die Person in Bezug auf sich } \\
\text { selbst und die Welt? Warum verfügt sie über } \\
\text { diese Einstellungen? Was hält sie für wichtig, } \\
\text { richtig, normal, geboten usw.? Wie ist das } \\
\text { Verhältnis von bewussten und unbewussten } \\
\text { Anteilen im Mentalen der Person? usw.4 }\end{array}$ & \\
\hline $\begin{array}{l}\text { Sozialer Status, Habitus, Rollenproblema- } \\
\text { tiken: } \\
\text { In welchen Umfeldern bewegt sich die Per- } \\
\text { son? Welchen sozialen Status hat sie inner- } \\
\text { halb ihres Umfelds? Welche Rollen füllt sie } \\
\text { aus und wie verhält sie sich zu Rollenangebo- } \\
\text { ten oder Rollenzwängen? usw. }{ }^{4}\end{array}$ & \\
\hline $\begin{array}{l}\text { Kultureller, gesellschaftlicher, histori- } \\
\text { scher Hintergrund: } \\
\text { In welchen gesellschaftlichen, kulturellen } \\
\text { und historischen Umfeldern bewegt sich die } \\
\text { Person? In welcher Weise prägen oder beein- } \\
\text { flussen diese Umfelder ihr Leben?4 }\end{array}$ & \\
\hline $\begin{array}{l}\text { Lebensgeschichtlicher Hintergrund: } \\
\text { Welche Selbst- und Fremdzuschreibungen } \\
\text { gibt es in Bezug auf die Vergangenheit, Ge- } \\
\text { genwart und Zukunft der Person? Gibt es } \\
\text { Entwicklungen?4 }\end{array}$ & \\
\hline & $\begin{array}{l}\text { Elementare (sprachliche) Mittel der Figurendar- } \\
\text { stellung: } 4\end{array}$ \\
\hline & $\begin{array}{l}\text { Die allgemeine Stilistik und Rhetorik } \\
\text { zählen zahlreiche Mittel auf, die beein- } \\
\text { flussen, wie wir einen sprachlich darge- } \\
\text { stellten Gegenstand auffassen: Neben } \\
\text { mikrostilistischen Mitteln (wie etwa } \\
\text { Wortwahl, Wortart, Tropen, Satzart, } \\
\text { Satzlänge, Lautqualitäten usw.) kommen } \\
\text { auch makrostilistische Einheiten in Fra- } \\
\text { ge (wie etwa Gruppen- oder Individual- } \\
\text { stile, Stilfärbungen usw.). }\end{array}$ \\
\hline & $-\quad$ Illustrationen \\
\hline & $\begin{array}{l}\text { - anthropologische, medienspezifische } \\
\text { u. a. Wissensbestände }\end{array}$ \\
\hline & $\begin{array}{l}\text { Übergreifende Strukturen der Figurendarstel- } \\
\text { lung: } 4\end{array}$ \\
\hline
\end{tabular}


- Grade der Direktheit:

Figuren können im Erzähltext direkt beschrieben werden („Peter war ein großer Mann von 35 Jahren, der regelmäßig zum Angeln zu gehen pflegte."). Figuren können auch indirekt charakterisiert werden (s.o.).

\section{- Ausführlichkeit:}

Figuren können mehr oder minder ausführlich charakterisiert werden. Aussparungen und Redundanzen sind wichtige Mittel der Charakterisierung.

- Verteilung/Dichte/Reihenfolge: Für die Konstitution fiktiver Personen kann die Verteilung der Charakterisierungen im Erzählverlauf von Bedeutung sein, also etwa, ob eine Figur gleich zu Beginn der Erzählung eingeführt wird und dann nicht mehr in Erscheinung tritt, oder ob sie bis zum Schluss präsent bleibt. Die Dichte der Charakterisierung betrifft die Frage, ob die fiktive Person ,geballt', d.h. gleichsam auf einmal, charakterisiert wird, oder ob wir uns aus vielen Mosaiksteinchen ein Bild zusammensetzen müssen. Die Reihenfolge bestimmt, wie die Beschreibungen der fiktiven Person angeordnet sind (vom Inneren zum Äußeren o. Ä.).

- Erzählebenen/Mittelbarkeit: Komplexe Erzählungen können über verschiedene Ebenen verfügen. Je nachdem, auf welcher Ebene etwas über eine fiktive Person ausgesagt wird, ändern sich der Grad der Mittelbarkeit und gegebenenfalls auch die Zuverlässigkeit und Perspektivierung des Mitgeteilten.

- Perspektivierung:

Die Charakterisierung einer Figur kann sich einer mehr oder weniger klar identifizierbaren Perspektive verdanken. Dabei kann es sich wie im Fall der internen Fokalisierung um eine identifizierbare Figur handeln.

- Zuverlässigkeit:

Die Figurencharakteristik kann im Kontext unzuverlässigen Erzählens stehen und insofern unterschiedliche Grade und Typen der Zuverlässigkeit bzw. Unzuverlässigkeit aufweisen.

\section{- Kontext:}

Auch der unmittelbare Kontext, in dem die Figurencharakteristik steht, kann diese beeinflussen (Schlüsselszenen etc.) 


\begin{tabular}{|c|c|}
\hline & $\begin{array}{l}\text { Komplexe Figurenkonzeptionen: Aus den ge- } \\
\text { nannten Mitteln und Strukturen der Charakteri- } \\
\text { sierung entstehen mehr oder weniger komplexe } \\
\text { Figurenkonzeptionen. }{ }^{4} \text { (Personifikation-Typ- } \\
\text { Individuum) }{ }^{1}\end{array}$ \\
\hline & $\begin{array}{l}\text { Komplexität: } \\
\text { Menge von Eigenschaften sowie deren } \\
\text { Beschaffenheit, die der Figur zuge- } \\
\text { schrieben werden (Kohärenz etc.). }\end{array}$ \\
\hline & $\begin{array}{ll}\text { - } & \text { Realismus: } \\
& \text { Figuren können mehr oder minder rea- } \\
& \text { listisch angelegt sein. } \\
\end{array}$ \\
\hline & - $\quad$ Typisierung/Individualisierung: s.o. \\
\hline & $\begin{array}{l}\text { Bewertung: } \\
\text { Teil der Figurenkonzeption kann eine } \\
\text { bestimmte Bewertung derselben sein, } \\
\text { d.h., eine Figur als ganze kann positiv } \\
\text { oder negativ bzw. sympathisch oder un- } \\
\text { sympathisch gezeichnet sein und ihren } \\
\text { Rezipienten entsprechende Urteile nahe- } \\
\text { legen. }\end{array}$ \\
\hline & $\begin{array}{l}\text { - } \quad \text { Relevanz für die Handlung: } \\
\text { Figuren können in ihrer Beziehung zur } \\
\text { Handlung untersucht werden (Haupt- } \\
\text { und Nebenfiguren; Aktantenfunktion } \\
\text { etc.; s.o.). }\end{array}$ \\
\hline & $\begin{array}{l}\text { Dynamik: } \\
\text { Figuren können eher dynamisch oder } \\
\text { eher statisch angelegt sein, d.h., die fikti- } \\
\text { ve Person kann sich im Laufe einer Er- } \\
\text { zählung entwickeln oder nicht. Zur Kon- } \\
\text { zeption mancher Figuren gehört, dass } \\
\text { sich das Bild der Leser von der Figur im } \\
\text { Laufe der Lektüre mehr oder minder ra- } \\
\text { dikal ändert. }\end{array}$ \\
\hline & $\begin{array}{l}\text { Offenheit/Opazität: } \\
\text { Mit diesen Kategorien soll erfasst wer- } \\
\text { den, ob das Innenleben der Figuren ge- } \\
\text { schildert ist oder nicht. }\end{array}$ \\
\hline & - Ganzheitlichkeit/Fragment-Charakter \\
\hline $\begin{array}{r}\text { Leerstellen und (Selbst-)Reflexion über Lese } \\
\text { der die notwendigen Leerstellen im Text komp } \\
\text { alen Herkunft, seiner Milieuzugehörigkeit, seir } \\
\text { tige Stellu }\end{array}$ & $\begin{array}{l}\text { rrollen: }{ }^{1,2} \text { Figuren sind Vorstellungen des Lesers, } \\
\text { lettiert, weshalb ,dem 'Leser, seiner eigenen sozi- } \\
\text { hen Einstellungen und Überzeugungen eine wich- } \\
\text { ng zukommt. }\end{array}$ \\
\hline & $\begin{array}{l}\text { Mehrdimensionalität und Dynamik vs. Ein- } \\
\text { dimensionalität und Statik }\end{array}$ \\
\hline
\end{tabular}




\begin{tabular}{|c|c|}
\hline & $\begin{array}{l}\text { Showing vs. telling: }{ }^{1} \text { (s.o.) } \\
\text { Wird die Figur in Aktion gezeigt oder wird zu- } \\
\text { sammenfassend gesagt/behauptet, sie sei so und } \\
\text { so? Es macht einen Unterschied, ob man auf- } \\
\text { grund einer Reihe von gezeigten Handlungen } \\
\text { selbst zu dem Schluss kommt, dass es sich bei } \\
\text { Mr. Scrooge um einen rechten Geizkragen han- } \\
\text { delt (meist: nachhaltiger und einprägsamer), } \\
\text { oder ob man ,dieselbe' Einschätzung dieser Fi- } \\
\text { gur vorgesetzt bekommt (effizienter). }\end{array}$ \\
\hline & $\begin{array}{l}\text { Figural vs. auktorial und explizit vs. implizit: }{ }^{1} \\
\text { Wer erzählt was über wen? Stammt die charak- } \\
\text { terisierende Information von einer Figur (figu- } \\
\text { ral) oder vom ,Autor' (gemeint ist: Erzähler) } \\
\text { (auktorial); wird sie explizit oder implizit verge- } \\
\text { ben? Die Folge sind vier Klassen von Techniken } \\
\text { der Charakterisierung: explizit-figurale, implizit- } \\
\text { figurale, explizit auktoriale und implizit- } \\
\text { auktoriale. }\end{array}$ \\
\hline & $\begin{array}{l}\text { Privilegierung und Gewichtung der Aussa- } \\
\text { gen: } \\
\text { Je nachdem, wer was über wen sagt, müssen die } \\
\text { (ggf. widersprüchlichen) Aussagen gegeneinan- } \\
\text { der abgewogen werden. }\end{array}$ \\
\hline & $\begin{array}{l}\text { Novel of character vs. novel of action:1,3 Es } \\
\text { scheint Romane/Erzählungen zu geben, die } \\
\text { prinzipiell den Fokus eher auf die Handlung, } \\
\text { andere, die den Fokus eher auf die Figuren (psy- } \\
\text { chologischer Roman, Entwicklungsroman etc.) } \\
\text { legen. }\end{array}$ \\
\hline \multirow[t]{2}{*}{$\begin{aligned} & \text {,Neun-Punkte-Plan' nach Cicero: }{ }^{3} \\
& \text { - } \text { Name, } \\
& \text { - } \text { natura (Geschlecht, Alter, Angebore- } \\
& \text { nes), } \\
& \text { - } \text { victus (Bildungsgang, Karriere), } \\
& \text { - } \text { fortuna (Stellung, Ansehen), } \\
& \text { - } \text { habitus (Tugenden, Fähigkeiten), } \\
& \text { - } \text { affectio (Gemütszustände), } \\
& \text { - } \text { studia (Interessen, Neigungen), } \\
& \text { - } \text { consilium (Projekte), } \\
& \text { - } \text { Einzeltaten } \\
&\end{aligned}$} & \\
\hline & $\begin{array}{l}\text { Aktantenfunktionsanalyse/Handlungsstruk- } \\
\text { turen nach Propp und Greimas:2, } \\
\quad \text { - Subjekt vs. Objekt, } \\
\quad \text { - Adressat vs. Adressant, } \\
\text { - Adjuvant vs. Opponent. } \\
\text { Eine konkrete Romanfigur lässt sich dabei meis- } \\
\text { tens (abhängig von der, Rundheit') nicht durch- } \\
\text { gängig nur einer dieser Aktanten-Funktionen } \\
\text { zuordnen. }\end{array}$ \\
\hline
\end{tabular}




\begin{tabular}{|c|c|}
\hline $\begin{array}{l}\text { Figurensoziologie: }{ }^{3} \\
\text { Die Figuren eines Romans bilden im Prinzip } \\
\text { einen eigenen sozialen Raum, d.h. eine er- } \\
\text { fundene kleine Gesellschaft mit ihren eige- } \\
\text { nen Normen und Konventionen des Zusam- } \\
\text { menlebens. In den allermeisten Fällen ist der } \\
\text { fiktive soziale Raum des Romans jedoch ganz } \\
\text { ähnlich strukturiert wie der reale soziale } \\
\text { Raum, in dem sich Autor und Leser bewegen. } \\
\text { Jedenfalls ist es sehr auffällig, dass selbst in } \\
\text { Urwelt-, Sciencefiction- oder phantastischen } \\
\text { Romanen so gut wie immer Gesellschafts- } \\
\text { strukturen auftauchen, die ein Pendant in } \\
\text { den eigenen Erfahrungen oder in den histori- } \\
\text { schen Kenntnissen des Lesers finden: Unter } \\
\text { Tieren gibt es dann einen Staat, unter Vor- } \\
\text { zeitmenschen Familien etc. }\end{array}$ & \\
\hline $\begin{array}{l}\text { Kapitalstrukturanalyse (nach Bourdieu): }{ }^{3} \\
\text { Die feinen Unterschiede, die ein Individuum } \\
\text { im sozialen Raum bestimmen und deren Ana- } \\
\text { lyse und (Um-)Verteilung wichtiger Ansatz } \\
\text { für die Figurenanalyse sein können, sind: }\end{array}$ & \\
\hline $\begin{array}{ll} & \text { materielles Kapital: } \\
& \text { Besitztümer (Geld, Immobilien etc.) }\end{array}$ & \\
\hline 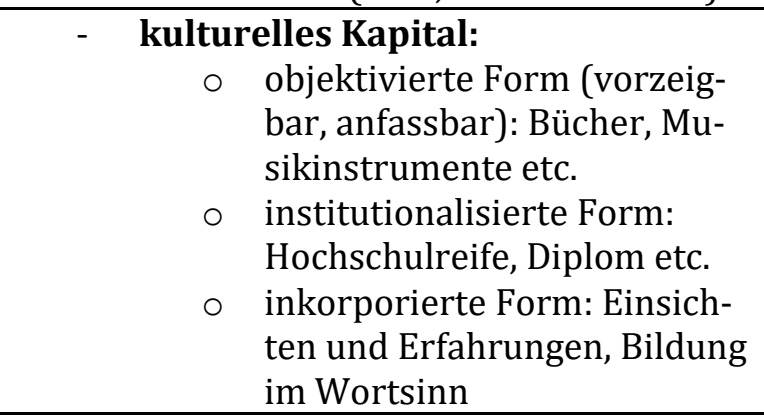 & \\
\hline $\begin{array}{ll}\text { soziales Kapital: } \\
\text { Beziehungen (Freundschaften, Kon- } \\
\text { takte) }\end{array}$ & \\
\hline $\begin{array}{l}\text { - } \text { symbolisches Kapital: } \\
\text { Ehre, Ansehen, gesellschaftliche Gel- } \\
\text { tung etc. }\end{array}$ & \\
\hline $\begin{array}{ll}\text { - } & \text { körperliches Kapital: } \\
\text { Schönheit, Gesundheit, Kraft etc. } \\
\end{array}$ & \\
\hline & $\begin{array}{l}\text { Sympathielenkung: }{ }^{3} \\
\text { Es lassen sich harte und weiche Faktoren unter- } \\
\text { scheiden: }\end{array}$ \\
\hline & $\begin{array}{l}\text { - } \text { harte Faktoren: in der Lebenssphäre der } \\
\text { voraussichtlichen Rezipienten ganz all- } \\
\text { gemein und durchgängig anerkannte Ge- } \\
\text { sellschaftsnormen. Dazu gehören bspw. } \\
\text { ethische Grundsätze, aber auch die Mi- } \\
\text { nimalanforderungen der gesellschaftli- } \\
\text { chen Etikette. Folterknechte und Kinder- } \\
\text { schänder, aber auch unzivilisierte Grobi- } \\
\text { ane verlieren demgemäß die Sympathie } \\
\text { vieler Leser. }\end{array}$ \\
\hline
\end{tabular}




\begin{tabular}{|c|c|}
\hline & $\begin{array}{l}\text { weiche Faktoren: machen sich das von } \\
\text { Affinität oder Distinktion geprägte Ver- } \\
\text { hältnis zwischen dem Habitus der litera- } \\
\text { rischen Figuren und demjenigen der } \\
\text { wahrscheinlichen Leserschaft zunutze. } \\
\text { Dass man ,bestimmte Typen nicht aus- } \\
\text { stehen kann', ist oft kein Effekt ganz per- } \\
\text { sönlicher, individueller Vorlieben, son- } \\
\text { dern der Ausdruck epochen- und schich- } \\
\text { tenspezifischer Dispositionen. }\end{array}$ \\
\hline & $\begin{array}{l}\text { Identifikation: } \\
\text { Mit welcher literarischen Figur ein Leser sich } \\
\text { identifiziert, hängt nicht von äußeren Faktoren } \\
\text { wie z.B. Alter, Geschlecht, Hautfarbe oder Beruf } \\
\text { ab. Entscheidend für das Zustandekommen der } \\
\text { Identifikation, die übrigens nicht mit Sympathie, } \\
\text { Mitleid oder Empathie verwechselt werden darf, } \\
\text { bleibt in jedem Fall der gemeinsame seelische } \\
\text { Konflikt. Lassen sich z.B. verdrängte aggressive } \\
\text { Impulse aufgrund des Handlungsverlaufes nicht } \\
\text { mehr länger an einer anfangs dazu benutzten } \\
\text { Figur festmachen, so kann der Rezipient, falls } \\
\text { der Text ein adäquates Ersatzangebot liefert, } \\
\text { kurzerhand das Identifikationsobjekt wechseln. }\end{array}$ \\
\hline \multicolumn{2}{|c|}{$\begin{array}{c}\text { Die Oberflächenstruktur des Modells nach Hansen (2000) unterscheidet vier Kategorien von } \\
\text { Beschreibungselementen, die zur Charakterisierung einer Figur beitragen: }{ }^{2}\end{array}$} \\
\hline $\begin{array}{l}\text { Figurenhandeln: } \\
\text { Diese Kategorie erfasst die aktiven und pas- } \\
\text { siven Taten der Figuren: } \\
\text { - } \quad \text { Ist das Handeln einer Figur mit einer } \\
\text { Veränderung der Figur verbunden } \\
\text { oder nicht? Ist die Figur in einer Ent- } \\
\text { wicklung begriffen oder werden fest- } \\
\text { stehende Charaktereigenschaften } \\
\text { deutlich? } \\
\text { - } \quad \text { Handelt eine Figur absichtlich oder } \\
\text { unabsichtlich? Kann sich die jeweilige } \\
\text { Figur ,beherrschen` oder nicht? } \\
\text { - Wird das Handeln einer Figur tat- } \\
\text { sächlich verwirklicht oder denkt die } \\
\text { Figur lediglich darüber nach, zu han- } \\
\text { deln - spielen sich die Aktionen also } \\
\text { primär im Kopf der Figur ab? } \\
\text { Werden die Aktionen ausgeführt oder } \\
\text { unterlassen? Liegt Handeln oder } \\
\text { Nicht-Handeln vor? } \\
\text { Ist die Ausführung bzw. die Unterlas- } \\
\text { sung des Handelns willensgesteuert } \\
\text { oder geschieht sie aufgrund eines } \\
\text { Drängens von außen her? }\end{array}$ & \\
\hline
\end{tabular}




\begin{tabular}{|c|} 
Sprache: \\
Diese Kategorie tritt auf zwei verschiedene Arten als Mittel der Figurencharakterisierung auf. \\
Zum einen werden stilistische Charakteristika (etwa: Dialekt) erfasst (Stil) (s.o.). Es geht aber \\
auch um die Inhalte (Botschaft) - durch die impliziten und expliziten Mitteilungen in ihrem \\
Sprechen und Denken wird die Figur zu einem Individuum in der erzählten Welt. \\
Äußere Erscheinung: \\
Attribute wie Physiognomie oder Kleidung, Körperhaltung und Aussehen. Auch: Namensgebung \\
(sprechende Namen): Schon der Klang des Namens Ebenezer Scrooge spiegelt die Feindseligkeit \\
und Grantigkeit der Figur wider. \\
Interpersonelle Charakterisierung: \\
In diese Kategorie fallen Beschreibungen einer Figur, die andere Figuren über sie geben. Diese \\
Art der Charakterisierung erfolgt also weder explizit durch den Erzähler noch durch das Han- \\
deln, die Sprache oder die äußere Erscheinung einer Figur. Konturiert eine Figur durch ihr Han- \\
deln oder eine Beschreibung den Charakter einer anderen Figur, wird sie damit ein Charaktant. \\
Wirkt der Charaktant aktiv oder passiv; d.h. wird die fragliche Figur aktiv durch das \\
Handeln und/oder die Sprache des Charaktanten konturiert oder passiv im Kontrast zu \\
ihm? \\
Wirkt der Charaktant dynamisch oder prädikativ; d.h. motiviert er eine Veränderung der \\
Figur oder bringt er bereits vorhandene, dem Leser bislang unbekannte Eigenschaften \\
der Figur ans Licht?
\end{tabular}

Basis der (teils wörtlich übernommenen und nicht eigens durch Anführungszeichen kenntlich gemachten!) Fragen und Kategorien liefern:

Bode (2005, S. 123-142) ${ }^{1}$, Hansen (2013, S. 232-247) ${ }^{2}$, Schneider (2010, S. 17-26) ${ }^{3}$, Köppe/Kindt (2014, S. 115-160) 4

Die grau hinterlegten Fragen/Aspekte können entscheiden helfen, ob eine Perspektive à la Figur $=$ Person eher angebracht ist oder der jeweiligen Figur eher ,Gewalt' antut.

Die rötlich hinterlegten Fragen/Aspekte erfordern (im Idealfall) psychologische und/oder soziologische Grundlagenkenntnisse. Außerdem lassen sich dort selbstverständlich ,Folgefragen' aus den jeweiligen Disziplinen anknüpfen: Psychoanalyse ist dabei nur ein prominentes (und nicht immer das beste) Beispiel. 


\section{Abbildungs- und Tabellenverzeichnis}

Abbildungen

Abbildung 1: Genazinos Mischpult-Verfahren

Abbildung 2: Drei-Schichten-Modell der Romanhauptfiguren bei Genazino.

.87

Abbildung 3: Alltagspsychologisches Modell zur Erklärung intentionalen Verhaltens (nach Malle)

. .98

Abbildung 4: Rubikonmodell der Handlungsphasen (nach Heckhausen/Gollwitzer)

Abbildung 5: Zwei-mal-zwei-Taxonomie des Impression Managements (nach Schütz)

Abbildung 6: IM-Techniken und -Taktiken

Abbildung 7: Schlaglichter

Abbildung 8: Pfaddiagramm Individuum vs. Gesellschaft.

Abbildung 9: Genazinos Figurenbasistypus und die Big Five

Abbildung 10: Wortwolke familienähnlicher Figurenmerkmale ...................................................... 193

Abbildung 11: Sinus-Milieus der 1980er Jahre ..................................................................................... 225

Abbildung 12: Sinus-Milieus in Deutschland 2017 ........................................................................... 226

Abbildung 13: Eysencks Persönlichkeits-Kreis..................................................................................... 394

Tabellen

Tabelle 1: Werkgruppen, Zäsuren und Besonderheiten .23

Tabelle 2: Fragenpool für die Figurenanalyse 


\section{Register der Romane}

Abschaffel.... 17, 18, 22, 24, 30, 35, 43, 44, 61, $86,132,157,176,179,180,184,185$, $198,204,208,209,210,211,213,216$, $217,218,219,220,221,231,233,234$, $236,241,242,243,266,268,279,283$, $287,288,290,293,295,296,306,307$, $310,311,312,314,316,318,322,324$, $326,328,330,331,332,336,339,342$, $343,344,345,346,395,396,401,404$, $411,413,428,429,431,433,434,435$, $436,437,441,445,447,448,449,450$, $453,454,464,467,475,478,481,482$, $484,485,488,499,503,504,523,524$, 525, 542, 569

Außer uns spricht niemand über uns $4,26,30$, $34,35,37,41,50,57,59,60,61,137,176$, $179,183,187,196,197,208,217,221$, $223,228,229,231,232,233,234,236$, $250,251,255,257,258,265,267,268$, $279,280,281,282,283,284,287,291$, $297,299,307,312,318,319,322,323$, $324,325,339,341,342,344,354,355$, $369,375,383,391,415,418,432,433$, $439,440,446,448,450,452,454,458$, $460,465,468,471,473,483,484,486$, $488,490,491,496,501,502,506,509$, $510,523,525,581$

Bei Regen im Saal.... 4, 26, 30, 44, 84, 85, 112, $141,168,172,173,183,184,185,188$, $194,195,198,199,205,220,233,234$, $249,253,260,274,275,293,296,297$, $308,320,325,328,329,339,341,347$, $349,350,357,402,448,460,466,467$, $471,482,485,491,492,494,497,499$, $500,507,509,515,523,580$

Das Glück in glücksfernen Zeiten 3, 14, 20, 26, $30,39,40,67,72,99,100,103,108,127$, $138,139,143,146,179,188,192,194$, $195,196,199,209,210,213,219,223$, $233,234,237,238,248,277,281,284$, $289,297,302,308,309,311,318,320$, $321,322,323,328,329,336,346,351$, $369,375,381,382,386,388,408,420$, $424,431,450,461,480,482,485,490$, $495,508,509,523,545,579$

Das Licht brennt ein Loch in den Tag ... 25, 30, $38,47,60,112,138,155,157,160,185$, $195,197,202,204,207,212,213,229$, $232,235,240,241,247,268,279,281$, $286,288,294,306,308,318,323,324$, $346,363,364,366,381,385,388,418$,
$432,436,439,440,448,449,450,453$, 475, 482, 503, 509, 575

Der Fleck, die Jacke, die Zimmer, der Schmerz ...... 21, 24, 34, 44, 166, 168, 190, 213, 214, $218,227,228,232,233,246,248,250$, $274,275,282,283,289,291,299,303$, $304,319,324,325,327,331,346,358$, $361,364,374,375,376,386,398,401$, 407, 432, 439, 441, 455, 543, 572

Die Ausschweifung.... 8, 24, 29, 30, 37, 41, 43, $44,45,46,58,82,89,96,146,157,159$, $169,176,180,184,186,192,193,197$, $201,206,208,209,211,213,215,219$, $220,228,230,232,236,243,245,246$, $254,258,259,260,268,269,273,277$, $279,282,286,287,290,291,298,302$, $307,312,314,326,331,332,336,338$, $345,346,354,358,359,360,372,377$, $381,383,384,401,403,404,405,408$, $415,416,418,419,426,432,433,435$, $438,439,440,441,444,445,446,451$, $453,460,464,465,467,470,473,480$, $482,483,485,486,487,488,495,497$, 499, 500, 501, 507, 508, 542, 571

Die Kassiererinnen ...... 25, 29, 61, 77, 97, 109, $112,120,146,158,168,171,184,193$, $194,195,200,205,206,213,238,242$, $246,251,252,272,282,283,286,303$, $313,315,316,317,322,325,344,363$, $364,378,408,409,410,416,417,425$, $426,427,433,436,437,438,439,440$, $454,470,471,474,491,499,523,575$

Die Liebe zur Einfalt. 4, 18, 19, 24, 27, 30, 37, $55,79,82,83,88,101,154,155,158,159$, $161,167,169,177,178,186,214,217$, $219,221,231,233,234,235,240,248$, $252,274,279,281,282,291,295,308$, $309,310,312,319,326,327,332,335$, $344,345,360,361,371,385,398,400$, $406,410,411,412,415,421,426,430$, $431,433,440,542,543,573$

Die Liebesblödigkeit.. 8, 25, 30, 34, 37, 48, 86, $88,108,110,124,139,140,144,156$, $169,172,180,184,188,190,194,195$, $196,197,202,203,204,213,219,231$, $232,251,252,253,254,258,259,260$, $266,268,272,276,281,282,283,289$, $301,302,304,309,311,312$, 骴 322, 330, $339,357,371,374,383,388,401,406$, $412,413,416,422,426,429,433,444$, $445,452,454,455,457,458,459,460$, $461,462,463,464,466,467,476,477$, 
$478,479,480,482,485,496,506,509$, $510,512,513,514,515,516,517,518$, $519,520,521,522,523,524,525,542$, 578,580

Die Obdachlosigkeit der Fische 25, 28, 37, 81, $88,156,170,173,199,201,211,212$, $216,241,244,251,252,283,284,289$, $291,302,317,327,328,342,350,364$, $382,395,409,422,433,481,482,486$, 487, 489, 492, 493, 499, 509, 574

Die Vernichtung der Sorgen 13, 18, 24, 29, 30, $36,112,128,130,157,159,166,168$, $169,173,179,184,187,192,204,205$, $213,214,217,219,229,232,233,234$, $240,246,250,260,266,271,272,286$, $287,289,294,296,298,299,307,308$, $309,310,311,312,314,317,322,324$, $327,330,331,332,338,341,343,344$, $345,359,360,363,370,374,377,378$, $381,387,393,395,396,400,401,403$, $405,406,408,413,415,416,417,420$, $422,427,432,433,435,437,438,445$, $449,455,468,469,470,481,482,483$, $488,489,495,496,501,502,503,504$, $505,510,523,542,570$

Ein Regenschirm für diesen Tag .4, 25, 29, 30, $34,36,39,40,42,44,47,51,52,53,54$, $55,56,57,58,59,91,97,98,108,128$, $133,138,139,141,155,156,168,170$, $171,187,194,196,197,198,199,200$, $202,204,206,212,214,215,217,218$, $219,222,231,232,235,236,239$, 骮 240 , $242,245,246,248,251,252,254,256$, $258,268,272,273,274,276,279,280$, 281, 282, 283, 284, 288, 296, 297, 298, $299,309,315,318,322,325,329,330$, $333,335,365,366,373,378,381,383$, $388,396,398,401,412,415,417,418$, $420,421,422,423,426,427,440,445$, $450,453,455,467,468,471,474,478$, $481,483,488,489,497,500,507,509$, $510,523,524,576$

Eine Frau, eine Wohnung, ein Roman. 4, 8, 25, $27,85,150,152,159,168,179,183,190$, $194,197,198,202,203,205,206,212$, $214,217,221,226,234,236,239,244$, $245,255,267,282,288,297,307,319$, $328,358,359,360,382,383,396,397$, $413,417,418,423,431,451,452,469$, $481,482,495,500,523,577$

Falsche Jahre....8, 9, 18, 24, 29, 36, 37, 43, 44, $45,51,58,112,114,142,143,159,176$, $181,185,187,197,198,202,204,205$, $210,212,213,221,240,241,244,249$, $251,254,258,259,260,267,269,270$,
$271,277,279,283,289,290,295,302$, $309,314,323,325$, 骴 331, 332, 333, 336, $339,343,345,349,351,358,361,362$, $366,368,369,372,374,380,381,395$, $399,400,403,405,407,413,415,416$, $417,434,438,442,445,450,453,469$, $474,475,478,481,486,494,497,503$, 542,570

Fremde Kämpfe 21, 24, 29, 30, 39, 41, 42, 46, $58,67,111,112,138,148,157,158,186$, $192,198,202,204,205,211,213,215$, $217,220,224,226,229,243,249,251$, $252,259,263,274,279,283,287,310$, $315,324,331,332,334,336,340,341$, $345,350,354,362,363,367,368,371$, $372,383,384,388,396,399,401,406$, $409,414,415,418,421,422,424,425$, $427,429,431,434,436,437,448,450$, $454,464,468,470,475,483,486,494$, $497,498,505,506,507,508,510,511$, $523,542,572$

Kein Geld, keine Uhr, keine Mütze......4, 18, 21, $27,30,75,105,135,138,157,159,179$, $186,188,196,197,221,223,227,232$, $233,234,235,243,246,259,260,279$, $282,283,287,290,296,307,320,324$, $325,332,347,358,375,381,412,415$, $416,426,434,448,460,462,465,466$, $467,475,478,480,481,485,491,496$, $497,499,508,509,510,511,525,545$, 582

Laslinstraße 6, 24, 27, 46, 47, 57, 60, 88, 143, $154,155,157,159,179,180,181,182$, $186,201,217,220,229,231,232,243$, $253,255,264,273,275,276,279,285$, $287,289,290,291,293,297,305,306$, $308,312,313,314,324,325,326,332$, $336,337,340,345$, 骴 $354,359,366,368$, $369,370,381,402,403,406,407,411$, $412,420,428,434,437,446,451,452$, $454,460,461,467,474,475,480,481$, $482,483,489,496,497,523,539,540$, 543,569

Leise singende Frauen 25, 30, 56, 74, 97, 129 , $151,158,159,166,169,170,174,194$, $198,201,203,206,210,215,232,242$, $244,259,265,266,284,288,290,300$, $301,302,310,315,319,323,330,376$, 385, 400, 405, 424, 460, 574

Mittelmäßiges Heimweh .4, 18, 26, 30, 48, 49, $56,75,97,108,138,156,165,172,175$, $187,195,196,197,198,199,202,205$, $210,232,233,235,236,241,242,249$, $253,254,256,267,272,280,281,290$, $294,308,315,317,318,321,323,324$, 
$326,327,336,344,345,353,357,370$, $384,393,400,409,433,436,440,460$, $464,465,469,472,473,482,483,486$, 494, 495, 498, 503, 504, 505, 524, 578

Wenn wir Tiere wären....... 21, 26, 35, 45, 144, $161,169,170,173,183,184,194,197$, $198,206,215,217,227,228,249,250$,
$258,260,274,281,284,288,290,293$, 296, 299, 306, 308, 309, 313, 317, 321, $330,336,339,341,342,362,373,388$, $399,444,446,447,452,455,461$, 骬此 470 , $475,476,482,483,494,498,499,500$, $505,510,523,579$ 


\section{Danksagung}

Texte haben Ko- und Kontexte - bei Menschen ist das ganz ähnlich. Im Entstehungsprozess (m)einer Dissertation sind hauptsächlich Menschen, Kommunikationen und ein paar Texte wichtig gewesen. Mein Dank gilt - kursorisch, aber nicht weniger herzlich und zunächst in chronologischer, dann in irgendeiner anderen Reihenfolge - (Pathos an):

Georg-Michael S.: dafür, dass du mir gezeigt hast, was es heißt, mit Liebe Wissenschaft zu betreiben - fernab von Geltungsdrang und anderen akademischen Sündenpfuhlen. Und wie man EMails schreibt.

Andreas W.: dafür, dass du unermüdlich beraten und vermittelt (nicht: gekungelt!) hast, um mir eine Promotionsstelle zu verschaffen; für Gespräche über die Diss., aber auch für bessere und andere.

Beiden Letztgenannten: dafür, dass ihr mich mit Genazino in Kontakt gebracht habt.

Stefan G.: für dein Verständnis, dass ich zu diesem Zeitpunkt Goetz nicht mehr sehen, geschweige denn nochmals ausrollen mochte und mithin die Möglichkeit, eine Dissertation, die zunächst so gar nix mit deinen Steckenpferden zu tun hatte, anfertigen zu dürfen; für viele, viele gute Gespräche und so weiter.

Endre H. und Márta H.: dafür, dass ihr mich auf meine erste internationale Tagung (zum Thema kognitive Literaturwissenschaft) eingeladen habt; und das, ohne dass ich wusste, was die kognitive Literaturwissenschaft überhaupt so denkt und macht, und ihr, was ich überhaupt so denke und mache.

Den FigurenforscherInnen: für die teilweise knackigen Entwürfe, an denen ich knabbern durfte.

Wilhelm G.: für seine herrlichen Figuren.

Ernst-Dieter L.: dafür, dass er mir die Psychologie im Allgemeinen und die Eindruckssteuerung im Besonderen in unvergleichlich vergnüglichen Vorlesungsstunden nähergebracht hat.

Nikola R. und Daniel G.: für die - neben dem herkömmlichen Wahnsinn - sensationelle Betreuung: Thx! Merci! Awesome! Formidable!

Dem GeKKo/den GeKKos: für Tagungsbesuche, Gedankenaustausch und den Weinkeller.

Dem Greifteam: für den regen Gedankenaustausch und das murrungslose Erdulden des 17. allegorisierten ,Hockers mit drei Standbeinen“ - der es dann doch nicht in die Endversion geschafft hat.

Den (ehemaligen) Kolleginnen und Kollegen: für Mensabesuche, Flurgespräche und Schoppenabende; alte: Nina und Bernd, Miriam und Sven, neue: Anna und Alf, Matze und Sven, Felix und Paul uvw. 
Meinen Freunden: dafür, dass ihr euch mit Fragen wie „Wann wirst du fertig?“ zurückgehalten und stattdessen zur (meist) richtigen Zeit für Ablenkung, Kontrollverlust und gute Laune gesorgt habt, wann immer es nötig war - oder auch nicht.

Meinen Eltern und Geschwistern: weil sie zwar nicht wussten, was ich so mache (bzw. immer wieder gefragt und es dann vergessen haben), aber es (immer wieder) gut fanden. Meinen Eltern zudem dafür, dass sie nicht einmal mit der Wimper gezuckt haben, dass ich eine der brotlosesten Künste überhaupt erlernen wollte. Was quatsch ist: Ich hatte immer was zu essen.

Apropos: Da diese Arbeit zu etwa zwei Dritteln nachts abgefasst worden ist, ${ }^{1}$ danke ich den beiden unmittelbar nebeneinander liegenden Läden in der Gottschalkstraße für die auch nächtens zuverlässige Versorgung mit erstklassigem Fladenbrot, Gemüse, Kalbfleisch sowie Getränken unterschiedlichster Couleur.

Zu guter Letzt: meiner Frau und meinen Kindern, weil sie auch für die extrinsische Motivation, irgendwann fertig promoviert zu sein, gesorgt haben. Aber auch (und eher) die vorher nie gekannte Perspektive in mein Leben gebracht haben, dass die Arbeit nur das zweitwichtigste der Welt ist. (Pathos aus)

$1 \quad$ Vgl. für die eindruckssteuernde Technik des ,self-handicapping‘ $(\Rightarrow$ I.3.3). 